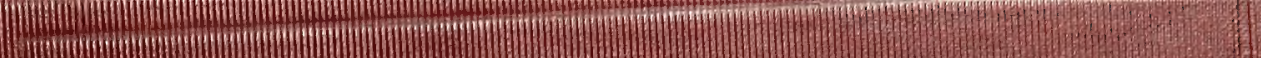




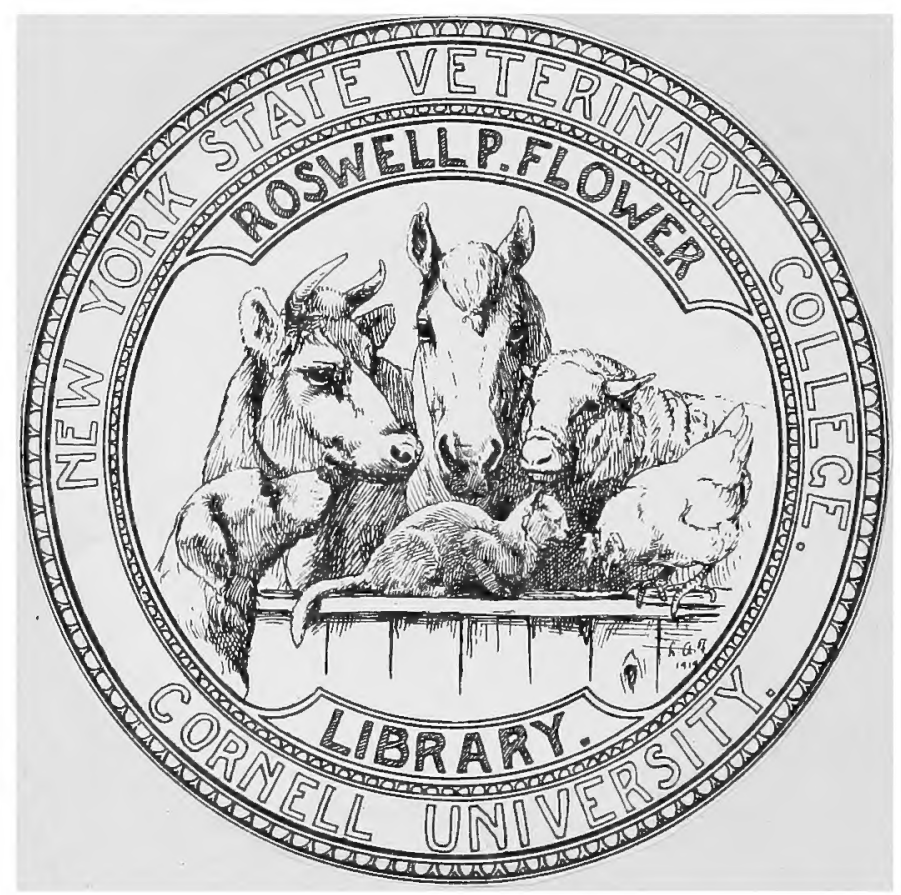




\section{SF $251 . \mathrm{H} 46$ \\ Cornell Universily Library}

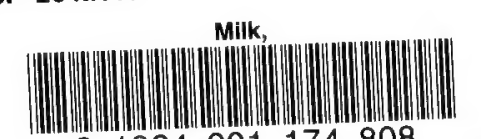

31924001174808 


\section{Cornell University Library}

The original of this book is in the Cornell University Library.

There are no known copyright restrictions in the United States on the use of the text. 




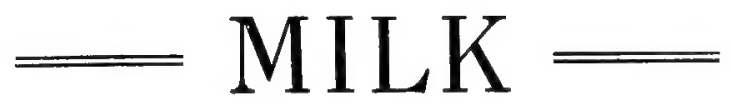

BY

PAUL G. HEINEMAN, Ph. D.

Director of the Laboratories of the United States Standard

Serum Company, Womlworth, Kenosha County, Wisconsin

\section{ILLUSTRATED}

PHILADELPHIA AND LONDON

W. B. SAUNDERS COMPANY

1919 


\section{No.5671}

Copyright, rgıg, by W. IB. Saunders Company

PRINTED IN AMERICA

PRESS OF

W. B. BAUNDERS COMPANY

PHILADELPHIA 
TO MY WIFE

THIS VOLUME IS AFFECTIONATELY DEDICATED 



\section{PREFACE}

DuRING a connection of thirteen years with the Department of Hygiene and Bacteriology of the University of Chicago, the author evolved a course entitled "The Sanitary Aspect of Milk Supplies." This course included laboratory work in which the student was made familiar with the most important methods for carrying out sanitary milk examinations. Parallel with this work a series of lectures was given covering the physical and chemical properties of milk; the biology of milk, including bacteriology; and methods of producing, handling, and distributing milk. The material for these lectures was gathered from books and a large number of original articles. Thus the foundation for the present book was laid.

The author does not claim that the subject has been exhaustively treated. It is quite probable that some of the many monographs have been overlooked, and suggestions from authors of the same will be received with gratitude. A book on milk which would cover the subject to the minutest detail would be in the nature of an encyclopedia and would suffer in interest for the reader. However, those interested in the milk problem, whether physicians, sanitarians, students, or producers, will find that nearly all the questions occurring to them have been touched upon, and for the benefit of those who wish to follow up any particular avenue in this vast subject a bibliography has been appended to each chapter. This bibliography is sufficiently complete to serve as a starting-point for further study.

I have been aided in the preparation of this' book by several of my friends whose kindness it is a pleasant duty to acknowledge. I am chiefly under obligations to Doctor Isaac A. Abt and Doctor A. Levinson, who are authors of the chapter on "Milk and its Relation to Infant Feeding." Doctor Henry L. Coit had kindly consented to critically read the chapter on "Certified Milk," but his lamented demise rendered the fulfilment of this promise impossible. Professor A. J. Carlson made some pertinent criticisms on the "Physiology of Lactation."

My thanks are due to Professors Edwin O. Jordan and Norman MacLeod Harris for valuable suggestions, and to Doctor Mary Hefferan for critically reading the first manuscript. 
I am under the deepest obligations to my wife, whose help and indefatigable enthusiasm have made the completion of the manuscript possible.

The illustrations were taken largely from books and monographs, to the authors of which I offer my gratitude. Due acknowledgment of the source is made in each instance. Illustrations of apparatus were kindly furnished by manufacturers or dealers in such articles. Finally I wish to thank the publishers for their interest and courtesy in all dealings.

P. G. Heineman.

WOODWORTH, WISCONSIN,

July, 1919. 


\section{CONTENTS}

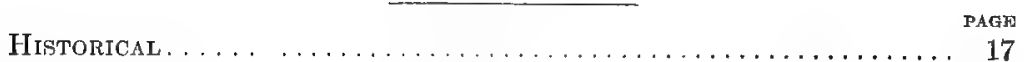

The Physiology of Lactation. . . . . . . . . . . . . . . .

Definition of milk, 32-Location of mammary glands, 33-Development of the mammary gland, 34-Formation of the secretion, 34Relation of colostrum to secretion, 36-Theories of lactation, 37The secretion of milk, 40-Duration of the lactation period, 43The total quantity of milk produecd during a lactation period, 44The cow's udder, 45-The quantity and quality of milk produced by cows, 49-Bibliography, 50 .

The Physical Properties of Milk.....................

Microscopic study of milk, 51-Creaming, 52-Cellular elements in milk, 57-The nature of the fat globules, 60 -Colostrum, 62-Properties of normal milk, 63-Odor and taste, 64-Viscu-ity and cohesion, 64-Specific gravity, 65-Freezing-point, 67-Electric conductivity, 67-Refractivity, 67-Specific heat, 68-Bibliography, 69.

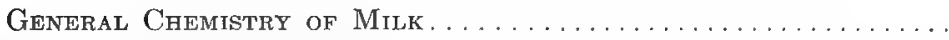

Composition of milk, 70-Composition of colostrum, cream, skimmed milk, whey, buttermilk, 73-The physiologic origin of milk constituents, 7.5-Origin of rasein, lactalbumin, and globulin, 75-Origin of butter-fat, 76-Origin of milk-sugar, 78 -Origin of mineral constituents, 78-The chemistry of butter-fat, 78-The decomposition of butter-fat, 81 -The chemistry of casein, 82-Properties of bovine casein, 86-Rennet coagulation, 90-Conditions governing rennet action, 93-Lactalbumin, 97-Lactoglobulin, 98-Mucoid protein or lactomucin, 98-Other proteins in milk, 98-Lecithir and cephalin, 99-Nitrogen-containing extractives, 99-Milk-sugar, 99-The mineral constituents of milk, 101-Gases in milk, 102--The reaction of milk, 10t-Variability in the composition of milk, 105-Difference in composition due to breed, 106-Difference due to individuality, 110 - Variation in composition during the lactation period, 114-Influence of food on milk, 123-Influence of weather and temperature on milk, 126-Exercise and nervous influences, 127-Influence due to the skill of the milker, 127 - Changes in composition of milk, 128 Spontaneous changes, 128 -Freezing of milk, $12 \mathrm{~s}$-Infiuener of heat on milk, 131--Centrifugation of milk, 132-Dilution of milk, 133Dialysis, 133-Electricity, 133-Bibliography, 134.

The Physical and Chemical Examination of Milk.......... 136

Sampling, 136-Composite samples, 140-The specific gravity, 141 - The determination of fat, 147-Fther extraction of fat, 147Refractometer method, 148-The Babcock method, 155-Modifications of the Babcock test, 164-Testing cream by the Babeock methorl, 167-Testing skimmed milk, buttermilk, and whey by the Babrnek method, 173-Determination of total solids and plasma solids, 175- 
Determination of ash, 179-Determination of proteins, 181-Volumetric methods of estimating casein, 185-Determination of milksugar, 191-Determination of acidity, 196-Milk sediment test, 200 - Test for viscosity, 207-Rennet tests, 207-Alcohol test, 208Albumin test for heated milk, 210-Tests to distinguish human and cow's milk, 210-Fermentation tests, 210-Bibliography, 211.

Adulteliations of Mili.

Kinds of adulterations, 213-Detection of watered and skimmed milk, 214-The lactoscope, 216-The immersion refractometer, 217 - Test for nitrates, 219-Detection of thickening agents, 219-Addition of foreign fat, 220-Coloring-matter in milk, 221-Addition of prescrvatives, 223-Detection of formaldehyd, 225-Detection of borax and boric acid, 227-Detection of benzoic acid, 228-Detection of salicylic acid, 229-Detection of sodium carbonate and bicarbonate, 229-Bibliography, 229.

EnzyMs in MiLK

Nature of enzyms and source of milk enzyms, 230-Proteolytic enzyms, 231-Carbohydrate-splitting enzyms, 233--Oxydases and reductases, 234-Tests for the presence of enzyms, 237-Bibliography, 239.

The Transmission of Toxins and Antibodies Through Milk........ Transmission of toxins, 240-Transmission of antitoxins, 241Transmission of other antibodies and hypersensitiveness, 243-The precipitin test, 244-The complement-fixation test, 245 -Tests for mistitis and colostrum milk, 246-Test for rennet inhibition, 248Bibliography; 248.

The Germididal Action of Fresh Cow's Mixk................ 249 Early observations, 249-Late work, 250-Present state of knowledge, 256-Bibliography, 256.

Micro-organisms in Milk

Sourees of micro-organisms, 258-Distribution of micro-organisms in milk, 258-Distribution of micro-organisms in cream, 259-Bacteria in market milk, 261-Souring of milk, 264-Contamination of milk in the udder, 267-Source of bacteria in the udder, 269-Number of bacteria in the udder, 269-Distribution of bacteria in the udder, 270-Growth of bacteria in the udder, 273- Kinds of bacteria in the udder, 274-Contamination during milking operations, $278-$ Dust from the stable air, 286-Influence of fodder on stable air, 290Bacteria in stable air, 293-Contamination from the hands and clothes of milksrs, 295-Wet and dry milking, 296-Milking pails, 297-Milking machines, 305-Contamination from utensils, 314Contamination of creamery and checse factory by-products, 323 Contamination during transportation, 327-Growth of bacteria at low temperature, 331-Contamination in the hands of dealers and consumers, 332-Aëration of milk, 335-Milk bottles, 335-Bibliography, 337.

The Kinds of Micro-organisms in Milk............... 340

Crouping of bacteria found in milk, 342-Lactic acid bacteria, 343Classification of lactic acid bacteria, 344-Distribution of lactic acic bacteria, 350-Products of lactic acid bacteria, 352-The kinds of lactic acid produced by lactic acid bacteria, 357-The kinds of curd formed by lactic acid bacteria, 360-Lactobacilli, 365-Acids pro- 
duced by lactobacilli, 370-Classification of lactobacilli, 371-Sporebearing bacteria in milk, 373-Chromogenic bacteria in milk, 376Blue milk, 377-Red milk, 379-Various colored milks, 379-Slimy, stringy, and ropy milk, 380-Bitter milk, 385-Sweet curdling of milk, 386-Soapy milk, 386-Abnormal tastes and odors in milk, 386-Molds, yeasts, and torulæ in milk, 388-Bibliography, 389.

Fermented Mrlks $\ldots \ldots \ldots \ldots \ldots \ldots \ldots \ldots \ldots \ldots \ldots$

Influence of fermented milk on bacterial flora of intestines, 393Therapeutic value of fermented milk, 395-Buttermilk, 398-Tätté Melk, 400-Fermented milks of pre-eminently acid fermentation, 401 - Yoghurt, 402-Fermented milks of pre-eminently alcoholic fermentation, 404-Kefir, 404-Koumiss, 406-Bibliography, 408.

The Bacteriologic Examination of Milk

The value of bacterial examination of milk, 409-Methods of bacterial examination, 413-The plate method, 413-F'rost's "little plates," 420-The direct method of enumerating bacteria, 421Other bacteriologic testis, 424-Test for Bacillus coli in milk, 425Test for anaërobes, 427-Sampling milk for bacteriologic examination, 428-Bibliography, 428.

Milik-Bonne Infećtions .

Diseases derived from human beings, 437-Typhoid fever, 437Dysentery and paratyphoid fever, 439-Diphtheria, 439-Septic sore throat, 440-Human tuberculosis, 443-Asiatic cholera, 443Scarlet fever, 443-Poisonous milk, 443-Diseases derived from cows, 444-Tuberculosis, 444-The tuberculin test, 450-Eradication of tuberculosis, 455-Immunization and vaccination against tuberculosis, 457-Transmission of tuberculosis, 458-Foot-and-mouth disease, 461-Mastitis, 462-Leukocytes and streptococci in milk, 463 -Anthrax, 473-Rabies, 473-Actinomycosis, 474-Botryomycosis, 474-Cowpox, 474-Milk-sickness, 474-Contagious abortion, 475Gastro-enteritis, 478-Malta fever, 478-Cholera infantum, 478Bibliography, 480.

Certified Milk.

Form of agreement, 483-Medical milk commission law, 488Efficiency score card, 492-Methods and standards of production, 497-Bacterial standards and methods, 501-Chemical standards and methods, 504-Methods and regulations for the medical examination of employees, 508-Bibliography, 510 .

\section{Pastedrization of Milk and Other Methods of Reddcing the}

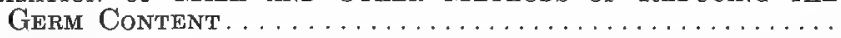

The flash or continuous process, 513-The holding process, 518Pasteurization in the final package, 522-Bottling hot pasteurized milk, 524-Pasteurization of milk and the public health, 529-Tests for pasteurized milk, 530-Objections to pasteurization, 530-Bacteria that survive pasteurization, 531-Home pasteurization, 538Buddeizing milk, 541-Formaldehyd milk, 541-Ultraviolet rays for reducing the germ content of milk, 541-Biorization of milk, 542 -Ozonization of milk, 542-Bibliography, 542.

The Control of Milk Supplies. .

Regulations of the New York City Health Department, 545-Dairy inspection, 550-Transportation of milk, 551-Score cards, 552Milk legislation, 556-A model ordinance, 565-Bibliography, 567. 
The Economlc Aspect of Milk Production.

Formation of the dairy herd, $572-$ Profitable dairy herds, $572-\mathrm{Se}-$ lection of productive cows, 574-Cow-testing associations, 577Co-operative bull associations, 579-Distribution of milk, 581Bibliography, 583.

Milk in its Relation to Infant Feeding, by Drs. Abt and Levinson. 584 Mother's milk and cow's milk, 584-Milk modification, 585-Alimentary disturbances, 590- Overfeeding, 592-Underfeeding, 592Disturbance of balance, 593-Dyspepsia, 593-Intoxication, 594Decomposition, 595-Infectious diarrhea, 596-Milk in its relation to infant welfare, 596-Bibliography, 598.

Butter

Systems of cream separation, 600-Centrifugal separators, 601Cream ripening, 603-Bacteria in butter, 606-Abnormal butter, 606-Whey butter, 608-Examination of butter, 609-Bibliography, 610 .

Cherese.

Varieties of cheese, 612-Food value of cheese, 612-Composition of cheese, 613-Cheese ripening, 613-Bacteria in eheese, 615Decomposition products in cheese, 617 - Cottage cheese, 619-Emmenthaler cheese, 620-Cheddar cheese, 621-Camembert cheese, 621-Roquefort cheese, 623-Abnormal cheese, 624-Examination of cheese, 627 -Bibliography, 628 .

ICE-CREAM AND ICES

Historical, 630-Varieties of ice-cream, 631-Stabilizers, 633-Icecream overrun, 634-Distribution of fat in ice-cream, 638-Fat test, 639-Bacteria in ice-cream, 642-Infectious material in ice-cream, 644-Scoring ice-cream, 646-Bibliography, 647.

Condensed and Desiccated Mrlks.

Composition of condensed milk and milk powder, 648-Methods of milk condensation, 649 - Millk powder, $650-$ Fat test for concentrated milk, 652-Bibliography, 653 .

Milk from Mammals Other than the Cow

Human milk, 654-Goat's milk, 655-Sheep's milk, 657-Buffalo's milk, 657-Ass's milk, 657-Mare's milk, 657-Camel's milk, 657Bibliography, 658.

Index of Names. . . . . . . . . . . . . . . . . . . . . . 659

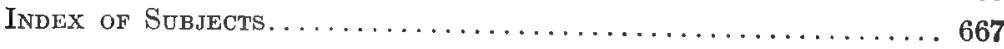




\section{ILK}

\section{HISTORICAL}

IF we take a survey of evolution in the animal kingdom we are impressed with the observation that the higher the stage attained, the more dependent are the newborn on their parents. Especially is this apparent in the inability to procure and assimilate food. Nature has provided for this deficiency by furnishing the maternal parent with the means of producing suitable nourishment during the necessary period, thus enabling the young to obtain the most fundamental necessity for maintaining life. This food is the fluid secretion of the mammary gland-milk.

In later discussions it will be shown that each mammal produces milk of a composition peculiarly suited to its offspring. However, all kinds of milk contain the essential elements necessary to support life, even though the relative proportions of these elements vary. Therefore milk from any mammal must have a high nutritive value for man. It seems natural enough today to use the milk of other mammals for our own food, but in all probability many ages passed before man learned to do so.

It seems impossible to ascertain at what period man began to utilize milk from other mammals. We have learned much of man's past history previous to the introduction of historic records by study of ancient tools and implements which have been discovered. Whether these tools and implements were used for peaceful occupations or for aggressive and defensive warfare is immaterial; in any case they have aided us in forming conceptions of the mode of life of prehistoric man. Among these implements the churn is pre-eminent. The churn has been a constant companion of man throughout his forward struggle, and its efficiency has been developed in answer to man's needs and progress. Its history has been compiled in a most interesting book by Benno Martiny, entitled "Kirne and Girbe." "Kirne" is derived from the Finnish word Kirnu, and means churn, chiefly the immovable churn. "Girbe" means the Arabian girba or kirba, which is a hose made of leather and used for containing milk, wine, and other liquids. The following brief historic outline is taken largely from this book. 
The churn for making butter was used by early tribes in Africa, America, Australia, the Southsea Islands, Asia, and Europe. It was not used by the Mongolian race, notably the Chinese and the Japanese, and the inhabitants of northern regions with climatic conditions unsuitable for cattle raising.

It is difficult to imagine by what accident it was discovered that the udder of wild animals might yield milk for human use. Hunting was a favorite occupation in former periods, and it is possible that a lactating deer trapped by a hunter was the first mammal from which man obtained the food intended for its own offspring. However that may be, the use of milk became general among ancient peoples. The primitive method of catching milk in the hollow of the hand soon gave way to the use of vessels made at first of clay, but later of wood and metal as well.

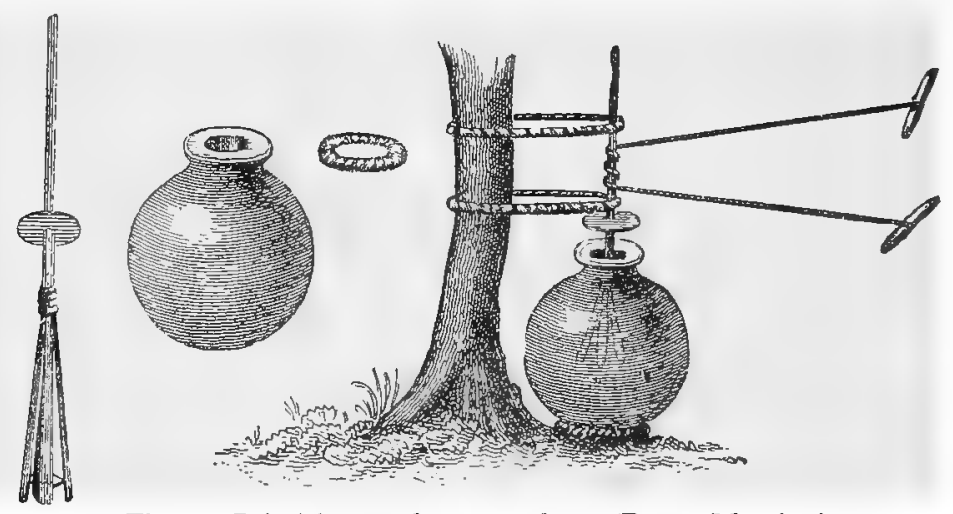

Fig. 1.-Primitive earthenware churn (Benno Martiny).

Milk products, also, were probably discovered by accident. Simple beating of milk that had turned sour by standing, separated butter, and this find led to the construction of simple devices for the regular production of butter.

The art of butter making originated in Asia and Europe and was communicated from there to other parts of the world. The tribes which were not in contact with Asiatic or European civilization never learned the use of butter and still live by hunting and gathering vegetables. We have no clear indication in what part of Asia or Europe butter making originated. Some records seem to point to Asia as the source of this art, while others seem to show that cattle and horses-the animals which are the chief sources of milk - were originally tamed by man in Europe. Perhaps we come nearest the truth by assuming that cattle raising and milk production started simultaneously in different localities, 
and that butter making developed independently in regions considerably removed from each other.

The object of the churn is the separation of the fat in milk from the other constituents. This is accomplished in one of two ways - either the churn itself is agitated and with it the contents, or the contents are agitated in a stationary vessel (Fig. 1). Which type of churning is the more ancient it is impossible to say. When the churn itself is movable, the agitation is caused by swinging back and forth or by complete rotation. Primitive people collected the milk in skin or leather bags and swung these bags to and fro. Later churns were built on rockers and rocked back and forth. Still later the churn was hung on central pivots and by means of a handle turned completely over. Churning in stationary vessels is now accomplished by some internal stirring device. There are also churns in which agitation is caused by introduction of air.

Records from East India show that butter was used at least as early as $2000 \mathrm{~B}$. C. The people estimated the value of their cows by the quantity of butter derived from them. Butter was held in high esteem and was used for their holiest sacrifices. The ancient Hebrews preserved milk in hose made of leather. Whether they used butter or not is uncertain. The word "chemah," which occurs often in the Scriptures, means "thick milk," and may stand for butter or cheese, or a mixture of both. In Arabia it was customary to take milk curd on journeys. The curd was prepared by pouring loppered milk into a bag, and as the whey passed out more loppered milk was poured in (Fig. 2). The curd was mixed with water, when wanted, and furnished an agreeable, cooling beverage.

Among the Scythians, the nomadic tribes in European and Asiatic Russia, mare's milk was gathered in wooden vessels and agitated, according to descriptions of Herodotus and Hippocrates. These authors seemed to believe that the Scythians used butter, but these tribes also prepared a fermented milk from mare's milk, known by the name kumiss, and probably the original descriptions confounded this with butter, since mare's milk is too poor in fat to permit of successful butter making.

The ancient Greeks did not use butter to any great extent at the time of the Christian era. However, butter was known to them, and investigators believe that the word "butter" is derived from the Greek "Boivivoov," although this word really means " $\beta \circ \tilde{v} \sigma "=o x$, and " $\tau v \rho \sigma \sigma "=$ cheese or curd. They made cheese from goat's and sheep's milk, and much later butter from cow's milk. Their butter contained a large proportion of curd, and the Greek "Bov́rvov" therefore meant in reality "coagulated 
milk." This corresponds to the Polish "tvarog," the Prussian "zwarg," the German "quarg," the Latin "lac concretum, compressum, or coactum," and the English "curd" or "green cheese." It also agrees with Pliny's definition of butter- "milk foam containing fat." It is not surprising that at those times butter and cheese were not clearly differentiated. As late as the middle of the eighteenth century it was thought that butter and cheese were fundamentally composed of the same substance. The assumed difference was that butter contained more oil than cheese dicl. It is quite probable, then, that the earliest butter made al-

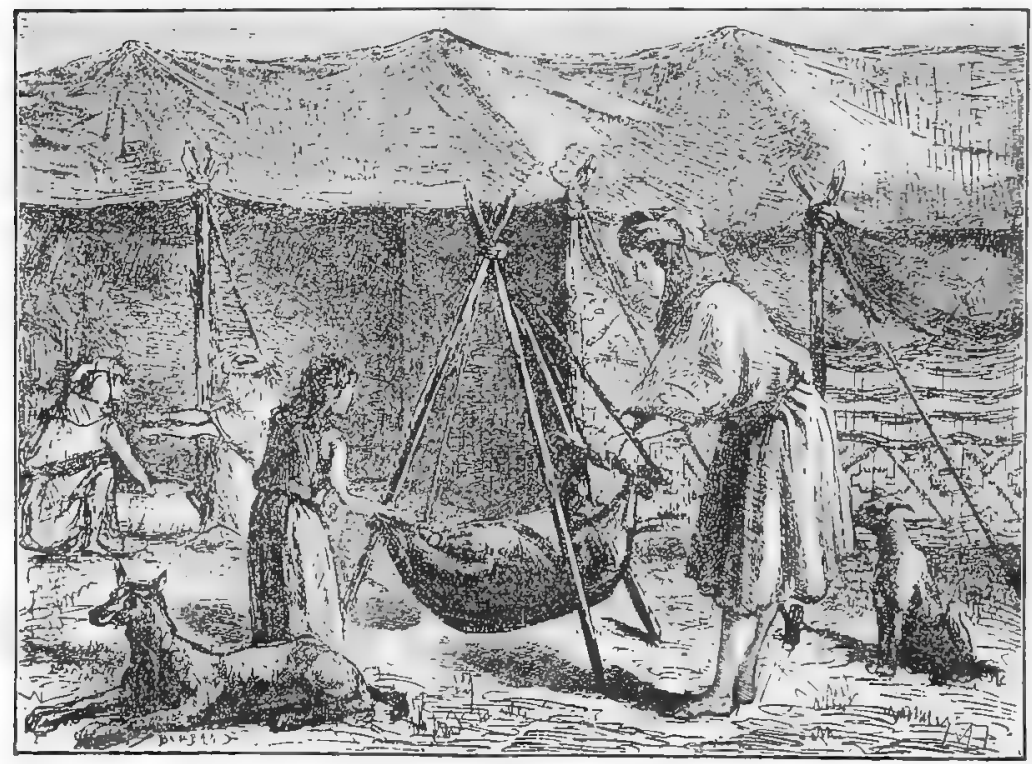

Fig. 2.-Leather churn (Benno Martiny).

ways contained much curd and was different from the refined product of modern times.

Since in ancient Greece cattle were used as draft animals and for meat production-not as milk producers-it seems likely that the true art of butter making was learned from other people, probably from the Thracians. The use of butter by the Thracians was reported by Anaxandrides nearly 400 years B. C.

In Lusitania, the modern Portugal, the use of butter dated back to $60 \mathrm{~B}$. C., as stated by Straban. Galen, in the second century A. D., described the making of butter, but recognized it only as a medical remedy. As a matter of fact, butter was used 
by ancient people more generally as a remedy than as food. It was a common excipient for ointments. In Spain in the seventeenth century butter was sold by apothecaries for external use only. Even at present fresh unsalted butter is applied as a relief for burns, and in England and Scotland large quantities are used for smearing sheep. This is done to combat skin diseases, destroy vermin, and give protection against dampness and cold.

Cæsar reported that the Germans used only milk, cheese, and meat for food, and Tacitus stated that their food consisted chiefly of fruit, fresh game, and loppered milk. Butter was not mentioned. At the same time the inhabitants of Britain used meat and milk, and in spite of a liberal supply of milk did not know how to make cheese. Pliny wrote of the Friesians as living on milk and stated that they knew little of cheese and butter making. Still, the Friesians later practised dairy methods which for a time were the most advanced in Europe. Such accounts, of course, do not exclude the possibility that butter and cheese were known, but their use was so limited as to escape observation.

In France, about $600 \mathrm{~A}$. D., butter was included in the dishes of the rich, but was rather difficult to obtain. In Norway that commodity was commonly included in the larder of outgoing vessels as early as the eighth century. Butter became an important article of commerce in Scandinavia in the twelfth century, and the Germans would travel to Bergen to exchange wine for butter and dried fish. In Norway the trade in butter was highly developed at the end of the thirteenth century, a fact that points to the assumption that butter must have been known in Norway in very ancient times. In the fourteenth century butter was extensively made in Prussia. In England the dairy industry began to develop about this time, but butter was used only exceptionally even in the sixteenth century.

Pallas, in 1776, described butter making by Mongolian Kalmucks, who used cow's or sheep's milk and boiled it before churning. The boiled milk was inoculated with sour milk and churned within twenty-four hours. It was thus preserved in leather bags, which were never washed. Their churns were made of leather. Thus we see that the method of making butter from heated milk, with the addition of a natural starter, is really an old process. The Tartars on West Siberia made a fermented milk and distilled an intoxicating beverage from it which resembled brandy. In Italy butter making was always of less importance than cheese making. In 1891 Italy produced $68,700,000$ kilograms of cheese, against $16,700,000$ kilograms of butter.

The earliest forms of churns consisted simply of vessels in which the cream was beaten with club-shaped sticks; or sticks 
which had perforated disks fastened at the ends were moved violently up and down. Such primitive churns were still employed in the nineteenth century, and probably can be found in use at the present time. In earlier periods the vessels were made of earthenware, but later wood was substituted. Mechanical means for increasing power were devised centuries ago. Levers were attached and worked by foot power. Dogs in treadmills and horses pulling large horizontal overhead wheels furnished power for larger dairies (Figs. 3-6). Gradually the modern forms of churns were evolved, among which the barrel churn is probably the most common. In this country the earliest patent on a churn was issued in 1848. The North American box churn has also been popular. Both the barrel and box churns are turned by handles;

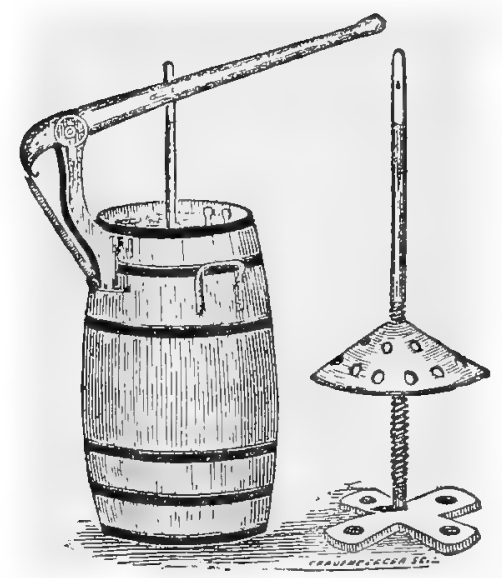

Fig. 3.-Wooden hand churn (Benno Martiny).

or, if they are stationary, the churning is accomplished by turning an internal stirring device. In modern times large creameries have steam or gasoline power, and churns which combine the making and working of butter are manufactured. Metal has taken the place of wood.

The dairy industry in England was highly developed toward the end of the eighteenth and the beginning of the nineteenth centuries. Benno Martiny considers England the leading dairy country during this period. In his book, "Vor Hunderd Jahren," he gives an account of dairy conditions in England which reveals many interesting features. It seems that at that time there were a number of agricultural societies in existence whose object it was to promote the farmer's interests, including dairy practices. A number of publications are mentioned in Martiny's book which 
show the great interest taken in dairy work. The problem of supplying milk to the city of London, with a population of $1,079,000$

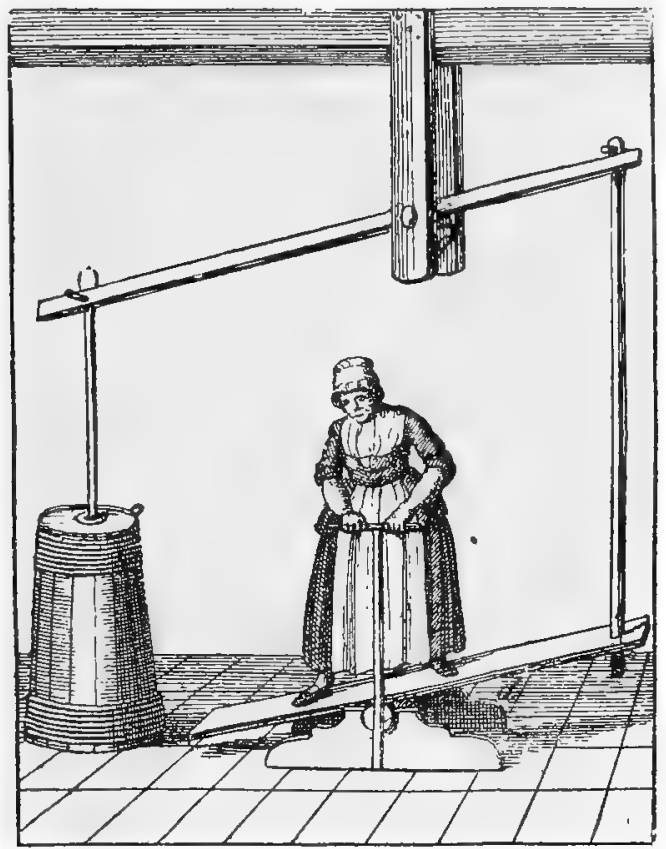

Fig. 4.-Churn operated by foot power (Benno Martiny).

in 1801, was solved by keeping a large number of cows within the city. Transportation in those times was too slow for the milk

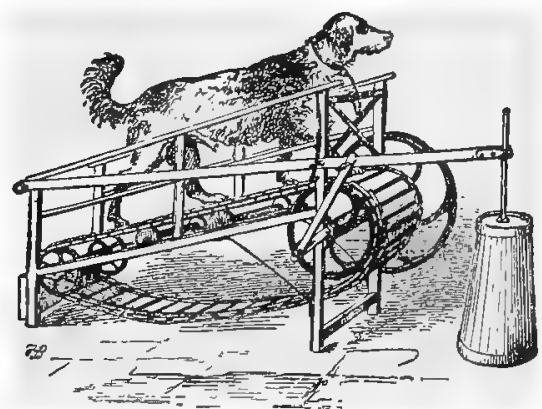

Fig. 5.-Churn operated by dog in treadmill (Benno Martiny).

business and the surrounding country could not furnish a satisfactory quantity of milk. About one-third of the total supply was derived from city cows. 
It is surprising to discover that methods which are advocated as innovations, in reality originated at earlier times. Competition among milkmaids was encouraged more than a hundred years ago by dairy farmers in England. The maid who drew the largest amount of milk from her cow was given extra pay. Attention was given to construction of dairy buildings with a view to cleanliness. It was not uncommon to find that a special room was. assigned to butter making, another to cheese making, a third to washing and cleaning utensils, etc. It was recognized that milk must be cooled, and when cold water was not available ice was used. The milk was cooled to between $50^{\circ}$ and $55^{\circ} \mathrm{F}$. Cow

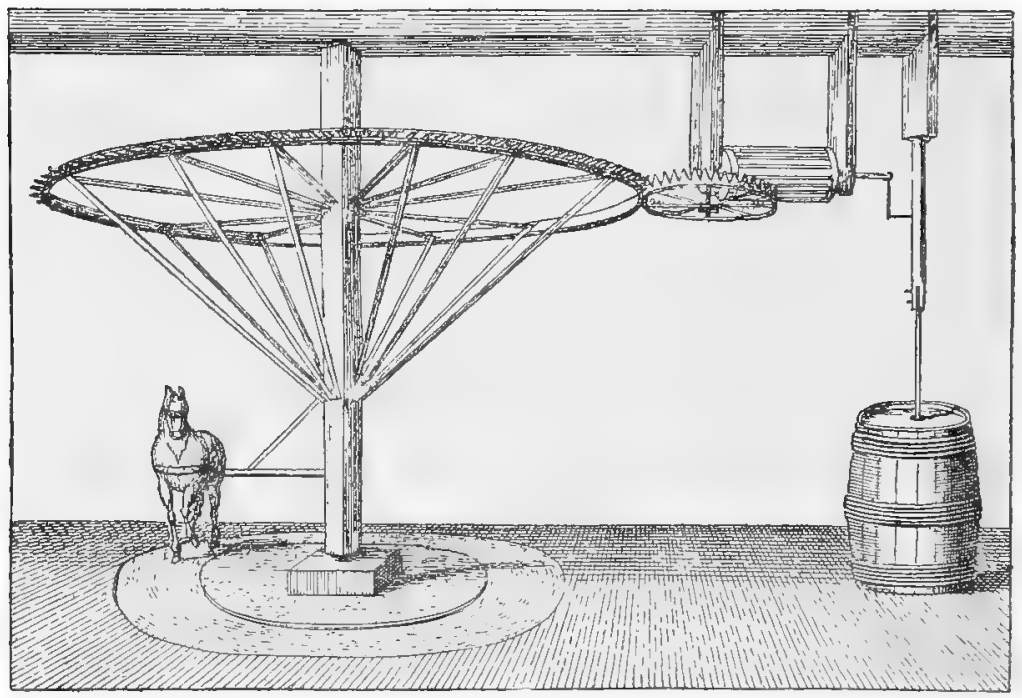

Fig. 6.-Churn operated by horse-power (Benno Martiny).

stables were built to give light and air to the animals and the milkers were instructed to treat the cows kindly. Most interesting is a description of a sanitary dairy, the Willow-bank dairy, in Glasgow, owned by William Harley. The object of this dairy was to furnish a perfect milk to the population of Glasgow, and re find that Harley recognized a number of points as important for his purpose, points which sanitarians are contending for to this very day. The stables were large, well aired, well lighted, and cleanly. The cows were kept well fed and clean. The best obtainable vessels were employed and the milkers had to be clean. Suitable food was selected and dry fodder was given only after milking. Accurate records of each cow were kept to ascertain her 
productiveness. The manure was promptly removed from the stables and spread on the farm as fertilizer.

However, after a number of years of prosperity, the enterprise failed due to the financial depression following the Napoleonic War, and it was not revived because of the apathy of the public. Milk was milk in those days as, unfortunately, it still is with many people today.

The quality of the supply sold by Harley was an exception. The majority of producers and dealers adulterated the milk in a shameless manner. In the salesroom of a dairy a pump- "the cow with the iron tail" of Dickens-was an almost universal necessity to aid the dealer in filling his cans with water. Not satisfied with diluting the milk, the dealer would remove some of the cream before selling the product. Prevention of these habits was difficult in those times, since reliable methods of testing milk were not known. It is true that a lactometer had been invented in the last decade of the eighteenth century, but its value was not appreciated. Milk commonly sold had a specific gravity of 1.0233 to 1.0267 , or if skimmed, only 1.0173 to 1.0213 . These abuses led to the enactment of a law in 1860 entitled: "An act for preventing the adulteration of articles of food."

Butter and cheese were made in large quantities in England during this period. Butter was made from sour cream and a variety of cheeses were made to which few have been added up to the present. Cream cheese, Gloucester, Chester, Cheddar, Stilton, Pineapple, Sago, Dunlop, and Wensleydale cheeses were marketed. The methods employed were empirical, of course, but protests against such methods appeared. Thus Henry Holland criticizes the utter lack of precision in manufacture. He suggested that a cheese experiment station be established under the control of the Board of Agriculture and under the management of a person well skilled in chemistry, "that something like scientific principles might be discovered on which to conduct the process." "Another utterance of a similar nature by William Aiton is this: "The dairy maids practice what they have seen done by others without the least attention to chemical experiment. The temperature of the weather, that of the milk house, or of the milk when coagulated, the quantity of rennet and of salt, etc., things of the first importance, which ought to be ascertained and executed exactly, on chemical principles, are conducted altogether at random."

It was recognized that clean milk will not sour as rapidly as dirty milk. The vessels should be rubbed with boiling water and then dried in pure air and in the sunshine. "A dairy maid should not sit down under a cow with a pail which a fine lady would scruple to cool her tea in." These suggestions were published in 
1756 in Complete Husbandry. In 1750 experiments were made in aëration to remove objectionable odors in milk. Furthermore, suitable temperatures for keeping milk $\left(50^{\circ} \mathrm{F}\right.$.), for churning $\left(60^{\circ}\right.$ to $70^{\circ} \mathrm{F}$.), and for coagulating milk for cheese making $\left(90^{\circ}\right.$ to $100^{\circ} \mathrm{F}$.) were given.

In $1790 \mathrm{~J}$. Anderson published rules for successful dairying, which may be briefly summed up as follows:

1. Difference of milk constituents of cows depends upon the race.

2. The amount of milk changes during lactation.

3. Milking three times daily yields a greater amount of milk than milking twice.

4. Careful, cleanly milking stimulates the milk glands; careless methods lead to smaller activity.

5. Fore-milk and strippings are distinguished by difference in cream content and quality of the skimmed milk.

6. After the cream has risen it loses in quantity and quality on standing.

7. Addition of water to milk facilitates the rising, but reduces the quality of the cream.

8. If milk is creamed after milking and while warm there is more and richer cream obtained than when the milk is transported and cooled.

9. Milk of old cows is salty only during the first half of milking.

10. For creaming, the temperature may be $40^{\circ}$ to $60^{\circ} \mathrm{F}$., but the best temperature is from $50^{\circ}$ to $55^{\circ} \mathrm{F}$.

11. The quieter the milk, the more complete is the cream separation.

12. Churning is best carried out by a phlegmatic person, who works quietly and steadily. No one else should be permitted to touch the churn, especially no young person.

13. Butter must be freed from buttermilk by working with a wooden spoon and without water.

14. The utensils used in creaming and churning sweet cream should be cleaned in the following manner: After churning the butter and buttermilk they should be filled with hot water and brushed with a wire brush or other stiff brush; then they should be washed with lukewarm water and wiped with a cloth. After that they should be turned upside down and wiped dry with a cloth and then exposed to the sun, or in wet weather to a fire to hasten drying.

After churning sour cream the vessels should be scrubbed with hot water containing potash or caustic lime and then stood for some time, filled with the cleaning solution. After that they 
should be filled with hot water, and after standing from ten to twelve hours, treated as after churning sweet cream.

15. For preserving butter conical vessels are best suited, because they prevent holes from forming when the butter settles.

16. Explicit directions are given for salting and treating butter.

17. Directions are set down for building a suitable dairy house with an ice-chest.

These directions show a profound knowledge of dairying, although some of the directions are based on faulty assumptions and do not hold in the light of modern knowledge.

This brief outline of the history of dairying shows that butter has assumed its present popularity as an article of food in relatively recent times. As a matter of fact, it is even now not as essential among inhabitants of tropical countries as among those in coole latitudes. No doubt its instability in a warm climate is a discouraging factor, detracting from its general usefulness. Moreover, in southern climates cow's milk is, usually, not as rich in butter-fat as in northern localities. In Cuba, for example, butter is served chiefly in the best hotels, especially in those that cater to American travelers, and the quality is not of the highest grade. This butter is imported, since the milk of native cows is not rich enough for butter making.

It has been proved that butter, whatever its quality and composition, was included in the diet of man in remote periods, and this fact is a safe indication that milk-other than human milkhas served as food for a long time. Dairy products-butter, cheese, buttermilk, fermented milks-probably were the result of accidental fermentations of left-over milks. A study of the kinds of cheese and the kinds of fermented milks most popular among different peoples shows that there is enough variety to lead to the assumption that they were developed independently. This fact confirms the hypothesis, previously advanced, that the dairy industry was initiated simultaneously in different parts of the world, or at least at the periods corresponding to definite stages of civilization. Perhaps the period when man changed from roaming habits to agricultural pursuits can be taken as the starting-point of dairying.

However this. may be, progress was necessarily slow. Rapid development of efficient methods in the dairy industry is of relatively recent origin. Even today dairy methods in general are not as highly developed as methods in other industries; and this in spite of the fact that the dairy furnishes the most valuable food known to mankind. Furthermore, the quantity of food derived from dairy products far outstrips that of any other food.

Sanitary precautions in milk production are of still more recent 
origin if we overlook a few sporadic cases of earlier times. "Kirne and Girbe" there are some interesting pictures of prevailing conditions, as, for example, butter making on the island of Guernsey in 1891. Churning is carried on in the open air, with no pretension to cleanliness or cleanly surroundings (Fig. 7). Another. picture shows a nude Hottentot milking a cow while another one is holding the tail of the cow to prevent its dropping into the open pail (Fig. 8). This picture might well serve as a model to some modern producers who do not take such precautions and calmly lift the tail out of the milk with their hands when it happens to switch into the pail. A later picture shows a modern, well-

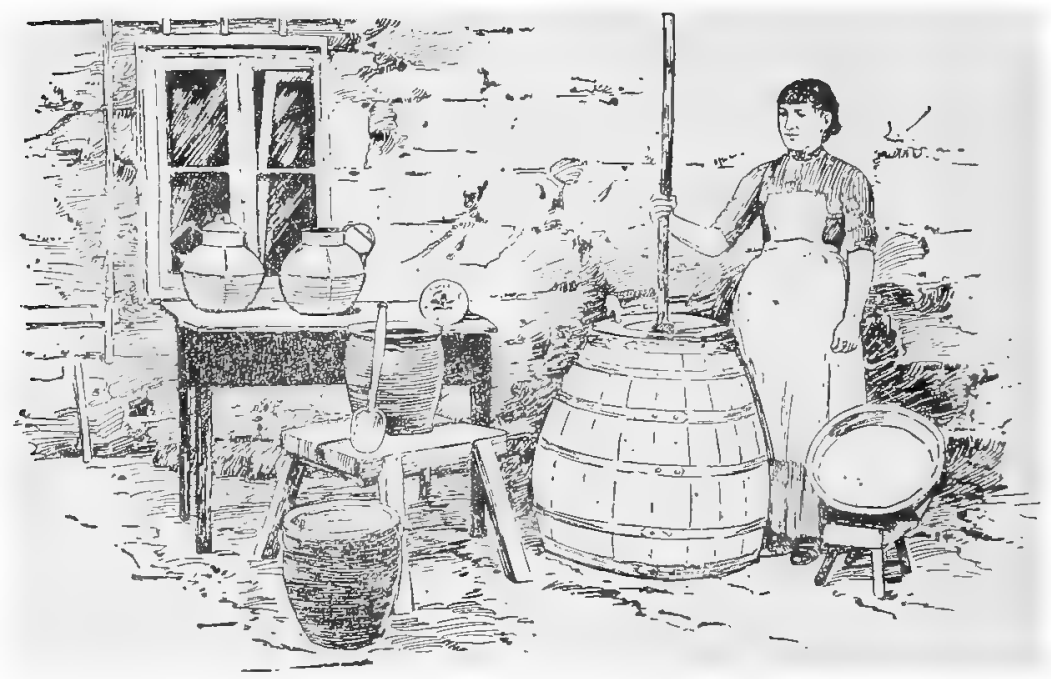

Fig. 7.-Butter making on the 1sland of Guernsey (Benno Martiny).

equipped creamery with up-to-date machinery, tile floor, tile walls, and cleanliness apparent everywhere (Fig. 9).

In this day of machinery and power progress in the dairy industry is more rapid than a few decades ago. In spite of ultraconservative methods a notable improvement is apparent when conditions of today are compared with those prevalent during the earlier part of the last century. Adulteration and dilution of milk, which was the rule a hundred years ago, is now the exception, and introduction of modern machinery has encouraged production on a large scale. Steam power in large plants and gasoline power on the farm do the work of man, horse, and dog of former times. The cream separator has facilitated butter making; clarifiers, coolers, bottling, and capping machines have made production 
and handling of large quantities of milk possible. Furthermore, transportation facilities bring the milk to our door from a distance of several hundred miles in better condition than was possible in times without the benefit of rapid train service.

Science has found means of recognizing adulterations and watering of milk. Bacteriology has shown that micro-organisms are inevitable in milk, but that the harmful ones can be eliminated or prevented from gaining access with reasonable certainty chiefly

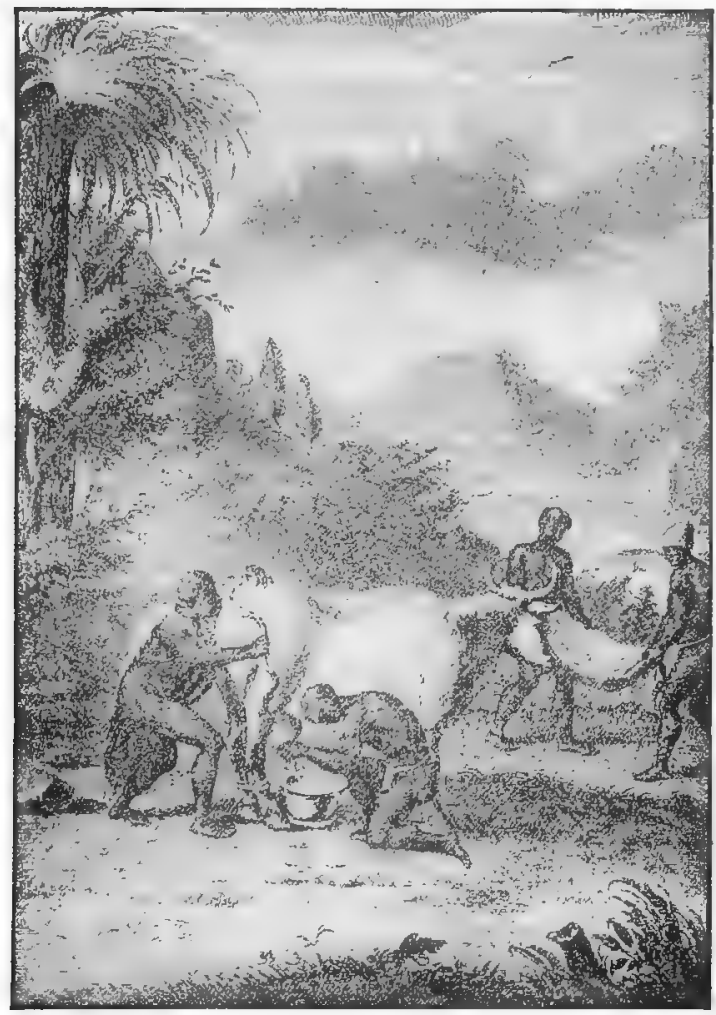

Fig. 8.-Hottentot milking a cow (Benno Martiny).

by boiling or pasteurizing the product. Bacteriology and mycology have enabled us to improve and control the quality of dairy products. This has aided in expansion of the industry and in obtaining reliable results. We have well-defined laboratory means at our disposal which further the industry and rid the market of unsatisfactory products. However, much is still obscure and more can be accomplished by scientific research, suitable legislation, and proper enforcement of regulations. 
But legislation is effective only when based on sound, scientific knowledge and judgment ripened by experience, and its greatest support is the education of milk producers, distributors, and last, but not least, consumers.

The past and the future of the dairy industry has been well described by Dr. Charles Cristadore in an article on "Certified and Pasteurized Milk," abstracted in the American Journal of Public Health, as follows:

"1. Neglect age (meaning anything and everything unsanitary): Filthy stables and as filthy cows; dust, flies, unclean cans and pails, and unclean milkers perhaps using unclean milking methods, and careless cooling and storing of the milk.

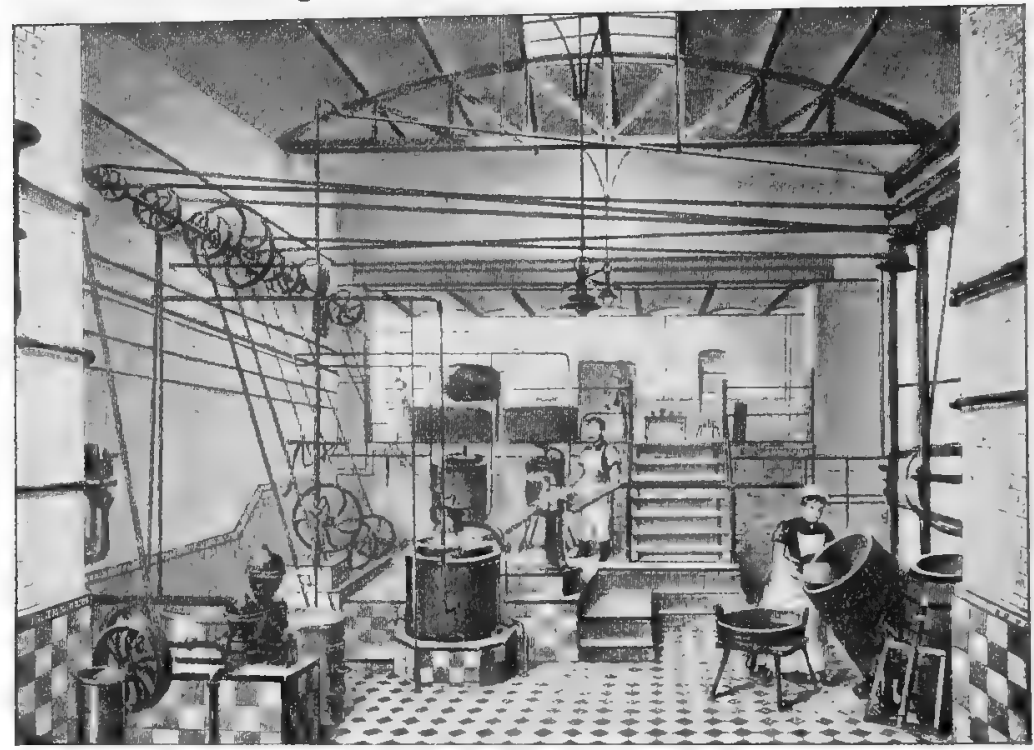

Fig. 9.-Modern creamery (Benno Martiny).

"2. Water age: When 25 to 50 per cent. of water was added to the milk to make it hold out.

"3. Skim age: When all or part of the cream was skimmed and kept at the farm, and the milk sent to town.

"4. Preservative age: When salicylic and boric acid were used, and then formaldehyd, to keep the milk chemically sweet.

"5. Tuberculosis age: When milk was found to be, through the bovine bacillus, a transmitter of the white plague.

"6. Pasteurization age: When all uncertain milk was made safe through application of heat, $145^{\circ} \mathrm{F}$. for thirty minutes, correctly, honestly, and thoroughly done. 
"7. Golden age: When all milk shall be 'certified' in the full and sanitary sense and meaning of the term as to environment and methods, machine clarification to take place immediately after the milking, when the milk is fresh from the $\mathrm{e}^{-}$, and before germ multiplication has commenced, either from the foreign matter or from the slimes already present in the milk; then cooling and bottling at the farm, pasteurization after bottling, to make assurance doubly sure."

\section{BIBLIOGRAPHY}

Cristadore: Abstracted from the December number, 1912, Dietetic and Hygienic Gazette in the Amer. Jour. of Public Health, 1913, vol. 3, p. 186.

Martiny, Benno: Kirne and Girbe, Leipzig, M. Heinsius Nachfolger, 1875. Vor Hundert Jahren, Leipzig, M. Heinsius Nachfolger, 1904. 


\section{THE PHYSIOLOGY OF LACTATION}

THE complex nature of milk has long aroused man's curiosity, and several speculations have been handed down to us by ancient philosophers. Empedocles, for instance, considered milk as "white pus," a view which recalls statements made by several modern authors, who have regarded milk secretion as the result of a pathologic process, evidenced by the presence of large numbers of leukocytes in the early product of the mammary glands. Aristotle thought that milk consisted of "parboiled substances from the blood." He reasoned that milk originated from the same food material that served to nourish the fetus, a view entertained today. Pfaundler - a modern investigator-defines milk as "the product of adaptation of the maternal system to the fetus." The fetus withdraws food in increasing quantity from the mother and the maternal system responds to this loss of substance by overproduction, a theory similar to the overproduction theory of Weigert. After birth the mother continues to produce these food substances, which are then transformed by the mammary glands into milkthe food for the newborn.

Milk is the characteristic production of mammals, but there are marked differences between the milks of various species. The fundamental substances - protein, milk-sugar, fat, and mineral matter-resemble each other, but their quantitative relation is not the same. The fat content especially is greater in some milks than in others, while protein, sugar, and mineral matter vary in lesser degree. The differences are both quantitative and qualitative. The mother furnishes the food to the young as the latter demands it, and we can understand, therefore, why the composition of milk should be particularly adapted to the nourishment of the young mammal. The milk of mammals which require large heat energy contains much fat; for example, in the milk of the whale and dolphin the fat makes up about one-half of the fluid. In any case, milk is a perfect food for early life, and since each mammal has characteristic requirements the substitution of milk from one species for milk of another may bring disappointing results unless special precautions are taken, such as cleanly production and suitable modification.

Pfaundler suggests the idea that milk may be regarded as an antibody elaborated by the maternal system in response to the introduction of a foreign body, meaning the spermatozoa. Ac- 
cording to this view milk would be an adaptation product of the mother to the growing embryo. It should be remembered in this connection that the digestive tract of the newborn has not yet entered upon its natural function. Hirth says that milk is a living substance, contains living protein, has the temperature of the living mother, and therefore is an aid to the young in assimilating food which the undeveloped digestive tract is unable to accomplish. This idea of "living millk" should not be confused with the "life of milk" of some authors, who regard the ferments in milk as the cause of this "life." According to Hirth's view, milk is not only a food, but furnishes the tools for assimilation in the young digestive tract. Whether these "tools" will remain in the domain of hypothesis or be really demonstrated is a matter for the future investigator to decide.

Mammary glands are the seat of milk formation and secretion and are characteristic of mammals. They occur in parallel rows and their location is determined by the habits of the young in taking food; in short, they offer the most convenient method of feeding. The number of glands is not the same in different species, and corresponds to the number of young usually born in one litter, varying from one to twenty-two pairs. Most quadrupeds have mammary glands on the abdomen; man and apes have them on the breast, while cattle carry them nearer the region of the genital organs. Usually the size of the glands is approximately the same in an individual. In the human, however, the left gland is frequently larger than the right, possibly because the baby is preferably held on the left arm so as to keep the right arm free.

Sometimes unusual conditions prevail and cause a unique location of the mammary glands. In some monkeys, for example, they are near the armpits; marsupialia have them in their pouches, while the hippopotamus and myopotamus have them on their backs, so that the young can obtain food while the mother is swimming.

Mammary glands are part of the anatomy of both sexes. In the male, however, they do not develop, as a rule, to the stage of actual milk secretion. There are some exceptions reported on good authority, although some reports may be legendary. There is the often cited example, reported by von Humboldt, who during a journey in South America spoke to a man forty-five years of age who told him that thirteen years previously he had nursed his son for five months. The mother was ill and the child accidentally sucked the father's breast. This stimulated a milk secretion which sufficed to feed the child for five months. More recently R. C. Creasy reported a case of lactation from the mammary gland of the male. A man of Russian descent, aged twenty-four, was 
in the habit of manipulating and massaging his left gland during his idle time, and this was the cause of milk secretion. Such cases are rare, of course, and the secretion, though resembling milk, is more watery.

The progressive stages in the development of the mammary gland are well summarized by Gaines in the following manner:

"Embryonic Stage.-The first signs of mammary organs, the milk line, appears at an early stage in embryonic life, and growth is continued until the gland reaches a considerable development at birth.

"Birth.-At birth a milky fluid may be expressed from the gland in either sex (the so-called witch's milk), indicating secretory activity, but this activity soon ceases and the gland remains quiescent until puberty.

"Puberty.-At puberty, under the influence of the ovaries, growth is resumed and carried to a greater or less development, varying with the individual and the occurrence of pregnancy.

"Pregnancy induces a great hypertrophy of the gland, and it reaches a high state of development, accompanied by the accumulation of colostrum.

"Delivery.-By the time of delivery milk secretion proceeds actively, and if the milk is removed at short intervals by nursing or artificially secretion continues for a period of days, months, or years. The rate of secretion, however, after a time gradually decreases to zero. This decrease is favored by a succeeding pregnancy.

"Pregnancy.-Further growth of the gland ensues, but not as marked as in the preceding gestation.

"Delivery.-At delivery milk secretion is again actively resumed. Whence the pregnancy delivery cycle is repeated."

The mammary gland of woman increases in size during pregnancy, especially during the second half of this period. This becomes manifest by an appearance of fulness and a feeling of tension in the breasts. During growth the breast sinks, owing to increased weight, and the veins become more prominent. In the first pregnancy this increase is more pronounced than during succeeding ones. After lactation the gland is reduced, but never returns to the original size.

\section{Formation of the Secretion}

The cells of the gland unload their contents into alveoli which take part in the formation of the secretion, milk-fat in particular. The fat is contained in the cells and the larger globules appear at that part of the cell which points toward the lumen. When the 
globules are released small particles of cell protoplasm frequently adhere, forming "caps" on the fat globules.

The rôle played by the cells of the alveoli may be one of the following:

1. The cells are converted into secretion.

2. Secretion is formed without alteration of the cells, so that secretion is not an essential part of the cell.

3. Part of the cell is converted into secretion, but the cell itself is regenerated.

The histologic condition of the normal milk-secreting gland changes up to the period of active secretion. The normally clear

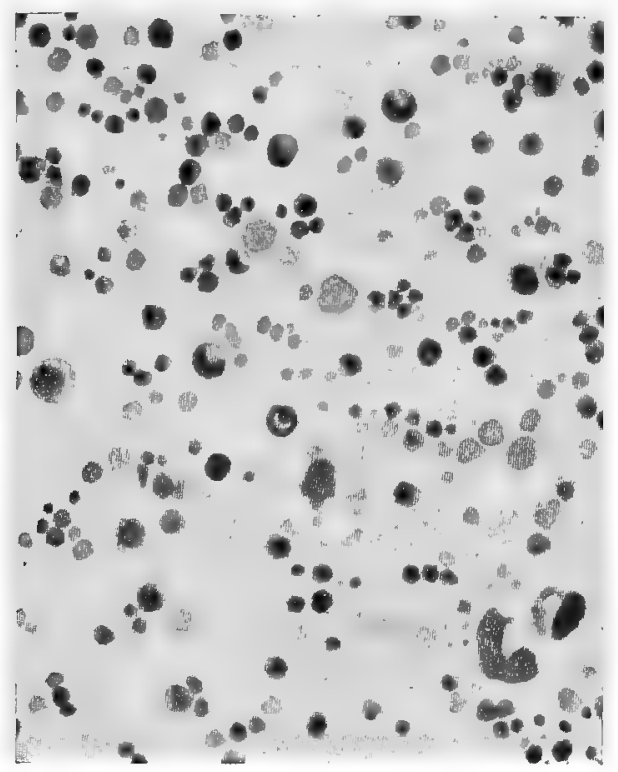

Fig. 10.-Corpuscles of Nissen (Ernst).

protoplasm becomes turbid, the cells appear not to be clearly separated, the nuclei enlarge, and mitoses are frequent. During the process small fat globules can be seen and several globules adhere, forming masses. Finally, the products of cell metamorphosis are discharged into the lumen of the milk-ducts. Leukocytes and other body cells assemble in large numbers near the milk-secreting glands and are discharged with the secretion. At the end of lactation a condition resembling the normal condition is restored.

The nuclei of epithelial cells undergo a transformation from which the "corpuscles of Nissen" (Fig. 10) appear. The chromatin assembles near the periphery of the nucleus and forms homogeneous, sickle-shaped bodies. A translucent ring is formed around 
the nucleus, and with this ring the nucleus moves toward that part of the cell which faces the lumen of the milk ducts and finally appears in it, leaving the cell behind. After the Nissen corpuscle has been discharged the cell regenerates and resumes activity. Some observers believe that the Nissen corpuscles are the origin of casein, while others argue that they are not formed in sufficient number to account for the amount of casein present in milk.

There is possibly some connection between leukocytes and milk secretion, and while this view is sometimes advanced it has not found much support. There is really a constant influx of leukocytes into the secretion, especially during the colostrum period and at the close of lactation. The significance of leukocytes is not understood, but has given rise to the idea, mentioned in another connection, that milk secretion is a pathologic process or at least comparable to one.

At the present state of our knowledge-which is very rudimentary-the most acceptable idea about milk secretion is that the cells of milk glands are not destroyed, but that since milk secretion is an intensive process the cells are unusually active, age rapidly, and therefore may degenerate (Ottolenghi).

\section{Relation of Colostrum to Secretion}

During the last days before and the first days after parturition the secretion is different from normal milk in chemical, physical, and biologic properties. This secretion is the colostrum milka yellowish, sticky fluid, rich in protein and containing extraordinarily large numbers of cellular elements-commonly called colostrum corpuscles. The function of these cells has been the subject of much speculation, but, as stated above, the view held at present is that they are not concerned in milk secretion. They are regarded rather as being actively engaged in reconstructing tissues to restore the condition preceding actual lactation. For this reason colostrum cells are present immediately before and after lactation has commenced and at its close. Corpuscles have actually been seen in sections of mammary glands after milk secretion has ceased. They probably act on the remnants of milk constituents and render them available as food for the maternal system (Czerny). This function is similar to the phagocytic action in pathologic processes, and the immigration of leukocytes during milk secretion has given rise to the comparison of milk to pus. Through their phagocytic action the ingested milk constituents are prepared for reabsorption by the system. The presence of these cells, therefore, indicates an incomplete condition accounting for their appearance both at the commencement and the close of lactation. 
There are evidently many links missing in the chain of our knowledge. Milk secretion is a complicated process, and the small positive knowledge we possess may be summed up in the following manner: Epithelial cells take up material from the circulation and transform it into milk constituents, then discharge the altered substances into the lumina of alveoli, and here the secretion is worked over into the finished product. The cells contribute from the chromatin and protoplasm part of their substance to the secretion and ultimately disappear. Part of the body - fluid enters the gland ducts, which become distended and attract leukocytes, which, in turn, aid in the regeneration of cells partly by furnishing food and partly by removing degenerated cell substance. With the progress of lactation the leukocytic infiltration increases again, and at the end of lactation cell products are reabsorbed.

\section{Theories of Lactation}

The appearance of milk in the mammary glands has been ascribed to two influences. The first of these is the increased amount of blood in the circulation available after the discharge of the fetus. The second is the presence in the blood of particular substances which favor milk formation.

The first influence is due to the fact that a large amount of blood is diverted into normal channels after the expulsion of the placenta. It is commonly assumed that increased blood-supply augments secretion from all glands, including the mammary glands. However, the importance of this influence is diminished when we remember that the blood diverted from large tumors after removal by operation has not been known to increase glandular secretions. Furthermore, milk has been actually secreted after premature birth when the fetus was not sufficiently developed to demand a large blood-supply, although in such cases the amount of milk secreted is smaller than under normal conditions.

The particular substances in the blood which favor milk formation may be of a stimulating nature or they may be converted by the mammary gland into milk. The theory is sometimes suggested that the mammary gland is endowed with the ability to secrete at all times. It has never been possible, however, to demonstrate a secretion in the rudimentary gland of a fetus. This gland is the so-called milk line. Gaines reported postmortem examinations of two kids whose mother died two weeks before term, and although he found the mammary tissue plainly developed, no milk could be detected. He adds, however, that chemical examination for milk-sugar was not made, and that this might have shown the presence of milk in an amount too small to be dis- 
covered by cutting the gland. We do know that a milky fluid is sometimes secreted from the glands of newborn infants, the socalled witch's milk. This, together with the above-mentioned cases of secretion from the gland of the male and occurrences of virgin lactation, seem to lend support to the hypothesis of permanent lactation ability of mammary glands. This idea is further borne out by Pfaundler, who has reported virgin lactation in a calf whose teats were sucked by its companions. A profuse secretion resulted, which ceased to flow when the animals were isolated. However, in all these cases the amount of secretion is small and contains more water than normal milk.

There is evidence of some particular influence stimulating the mammary glands of the mother at the time of birth when the gland enters on a period of full activity. It is the nature of this influence that must be made clear. Two hypotheses suggest themselves and have found ardent supporters, namely, the stimulating substances are either purely stimuli or their stimulating influence is due to actual food value.

Theories Depending on Purely Stimulating Substances.Advocates of this theory assume that hypothetic substanceshormones-are discharged from the fetus or placenta into the circulation. To the influence of these hormones they ascribe the enlargement of the gland during the period of gestation. As support for this theory it is stated that mammals instinctively know that the placenta contains hormones and sometimes eat the placenta after birth. Cattle raisers have believed that milk secretion is enhanced thereby and have encouraged cows in eating the placenta. Hormones are said to exert their influence until the gland is fully developed and enters upon active milk secretion. However, this theory is not entirely in harmony with the fact that in cases of premature birth milk appears before the gland is fully developed. Gaines examined the udder of the goat mentioned - the one that died before the birth of the kids. The udder was undergoing rapid hypertrophy and was increased in size, but part of this increase was due to accumulation of colostrum which exuded freely from the cut ducts of the gland. This shows that there is some secretion before birth, even though limited. Furthermore, in late births, milk secretion is delayed. We are forced to the conclusion, therefore, that there is an intimate connection between birth and profuse milk secretion. Only when the fetus has died has milk secretion been observed before actual expulsion.

During the period of pregnancy, when the gland enlarges, secretion is held in check, and consequently the assumption seems justified that, besides stimulating substances, inhibiting substances are also present, or the same hormone stimulates growth of the 
glands and at the same time prevents milk secretion. Lane-Claypon and Starling are of the opinion that a substance passes from the fetus into the maternal circulation. This substance stimulates growth of the mammary glands during pregnancy and at the same time inhibits milk secretion, although mammals sometimes lactate up to the next parturition. With expulsion of the fetus the stimulus disappears, growth of the gland ceases, there is no further inhibition of milk secretion, and flow commences. These authors produced enlargement of the mammary glands in a virgin rabbit by injecting extracts of rabbit fetus, but milk secretion was inhibited. The case of the Bohemian pygopagous twins is cited in support of this theory. One of the pair became pregnant, and during this period the mammary gland in both enlarged. Ribbert transplanted a mammary gland of a guinea-pig into the skin back of the ear of another female guinea-pig. Five months later living young were born and milk was promptly secreted from the transplanted gland. Gaines injected defibrinated blood into a lactating goat- 1 , from a pregnant goat near delivery; 2 , from a kid of the same goat two days after birth; 3 , from the same goat six days after delivery. In each case an inhibitory action was observed. Injection of a cow's placenta into a lactating goat also produced inhibition. Transfusion from a fresh, heavy milking goat to one giving a low yield seemed to cause a decrease in the milk of the injected goat. The author concluded from these transfusion experiments that the hormone is present in the blood in small quantity and that the gland of the pregnant female is more susceptible to its influence than the gland of the normal female; that lactation is not due to a hormone, because transfusion of blood from an actively lactating goat to a feebly lactating one does not increase secretion in the latter. Furthermore, one lactating gland may cease lactating before the other.

On the other hand, Lambroso and Bolaffio, working with parabiotic rats, found that pregnancy of one of the pair did not affect the mammary glands of the other. This might argue against the presence of a hormone, but the authors showed that food does not pass from one of the pair to the other, and consequently hormones are probably not carried from the circulation of one to the other.

Although there are some dissenting voices, the evidence of the presence of hormones in the blood is convincing, but whether the placenta or the embryo is the source of the hormone is a question that cannot be answered. A hormone originating in the embryo would have to pass through the placenta to reach the maternal circulation, and even this would leave us in doubt as to the true origin of the hormone. 
Hormones differ from food substances in not being assimilable. They are specific and consequently exert their stimulating influence on particular glands. They do not provoke antibody formation and are very stable, remaining uninjured by boiling, drying, or the addition of alcohol.

Theories Depending Upon the Presence of Food Substances in the Blood.-Rauber observed that leukocytes pass from the maternal circulation into the fetus, and since milk-especially colostrum-contains large numbers of leukocytes, he concluded that the food of the suckling is a direct continuation of the process of feeding the fetus. In other words, the food of the fetus after expulsion is diverted to the breast and there transformed into milk. Therefore, the author reasons that the food of fetus and suckling come from the same source. This theory explains in a measure the fact that milk flow commences with the birth of the child, that is to say, the food substances that were used by the fetus before birth become available after birth for milk secretion. There is a gradual adaptation of the mother to the needs of the infant, and this adaptation results in the formation of food substances. The mammary gland has the ability to produce milk even before birth, but lacks the necessary material. Schein holds that the hormones of other authors are really the substances the transformation of which results in secretion of the mammary glands. Furthermore, the quantity of food needed by the fetus is constantly increasing in proportion to its growth, and the mother has to furnish this increase. But after birth the direct influence of the productiveness of the mother ceases, and consequently there is no increase after the flow of milk has commenced.

This theory does not presume the presence of hormones. It is conceivable, however, that the food substances stimulate the gland to action by their presence, and on this assumption the two theories are not necessarily contradictory. The second theory does not explain the growth of the mammary gland previous to birth, and by combining both ideas the facts find a harmonious explanation.

\section{The Secretion of Milk}

Sucking of the infant is a downward movement of the lower jaw, followed by closing the jaws. Suction is thus produced and the milk is forced from the breast by negative pressure. The pressure caused by the first sucking movements is not sufficient to release much milk, but with each movement the pressure increases, until the milk flows more freely. Gaines has shown that in a dog the milk flow increased for the first three minutes, then declined, and was exhausted after six minutes. With bottle-fed 
infants the negative pressure produced by sucking is usually smaller than when breast fed. Artificial suction, by breast-pumps, for example, releases milk, but the method is not as favorable for continued milk production as the natural sucking of the baby.

The sucking of the infant or milking are the influences which stimulate glandular activity, although this is still an open question, and there are other factors to be taken into account. After the baby has commenced sucking there is a peculiar sensation of flowing milk in the breast. The flow seems to become spontaneous. Sudden removal of the baby does not stop the flow, but small drops or streams continue to be discharged for some time. Milk begins to flow sometimes even before the child has touched the breast, a phenomenon due to a nervous reflex action. When a lactating cow is temporarily removed from its calf the reappearance of the calf is sufficient to start the milk flow. Some experiments made by Gaines illustrate this point. The gland of a goat was milked dry by hand and then a kid placed at it. A considerable quantity of milk was obtained and the other gland filled under the same influence, so that the milk could be removed by hand milking. The stimulus of the kid's sucking exerted its influence on both glands. Hand milking of one gland also increased the flow in the other gland. Incidentally, it was noted that under the stimulus of nursing the fat content rose perceptibly. Gaines thinks that the flow of milk is caused not only by sucking but also by the pressure on the gland and by contraction of the muscles. That sucking is not the only cause of milk flow is borne out by the statement of Flower and Lydekker that a mother whale ejects milk from her mammary glands into the mouth of the young without active sucking on their part.

Gaines' experiments with injection of pituitrin are of value in this connection. Intravenous injection always caused a marked increase in milk flow after the udder was milked dry: The amount of milk flowing after injection of pituitrin was large when the previous hand milking yielded a small amount, and vice versa. Injection of pituitrin into a nursing dog gave no increase under natural conditions; but if the dog was placed under the influence of ether the natural flow was small until an injection of pituitrin brought the quantity back to normal. Pituitrin, therefore, does not act on $\operatorname{dog}$ and goat alike. Furthermore, pituitrin caused milk flow after injection into an excised guinea-pig gland filled with milk. Therefore, the stimulation of milk flow is caused by contraction of the small milk passages of the gland. It is not a secretory impulse, but simply an increase in flow. These experiments were made with single injections of pituitrin, but a second injection of pituitrin caused no additional milk flow. 
The modus operandi of milk secretion and milk flow is by no means perfectly clear in all its phases. We know that the sucking of the child is not the only and probably not the direct cause of flow. It stimulates nervous reflex action which is the direct influence. Gaines expresses the extent of our knowledge admirably in the following words: "During milking and nursing there is a reflex constriction of the gland; the removal of the milk from the gland is dependent upon the operation of this reflex; and the reflex is conditioned. The stimulus which naturally excites the reflex must be found in the friction and warmth of the sucking action of the young on the cutaneous sense organs of the teat; with possibly a further source in the passive dilation of the sphincter muscle of the nipple by passage of milk." Further: "Milking is a stronger excitant than an inserted canula; nursing is stronger than milking; and direct action of pituitrin is stronger than nursing. Removal of milk from the gland is dependent upon this (nursing, etc.) reflex and it may be completely inhibited by anesthesia. The psychic state of the mother modifies the strength of the reflex as shown by the flow of milk after absence of the young."

Milking machines have become a permanent factor in milk production, and their effect on cows is in perfect accordance with the above conclusions. Many cows do not give up as much milk when machines are used as they do when milked by hand. The strippings-the last and richest part of the milk-are frequently taken by hand after the machine has removed as much milk as the animal is willing to give up. Some dairymen claim that the duration of lactation is abbreviated by the use of machines. As one superintendent intimated to the writer, it is impossible to make a cow believe that a milking machine can take the place of sucking calves, and the maternal instinct, which is an important stimulus to milk production, is lacking.

The quantity of milk secreted by the mammary glands adjusts itself to the demand. Removal of milk encourages secretion, while accumulation of milk discourages secretion. Therefore milk should be removed at regular intervals and as completely as possible. The number of times milk should be removed daily to yield the maximum flow varies in different mammals. Cows are usually milked twice daily, sometimes three times. The quantity is increased somewhat by milking three times, but is not sufficient to pay for the additional work. Since cows have been milked by hand for many generations, it has been suggested that they have become adapted to this condition and that the milk thus obtained is equal in quantity to that obtained by sucking calves. However, there is no available evidence to prove this statement. It may be difficult to determine whether a cow will yield as much 
milk to a milker as to a calf, but the experiences with milking machines would indicate that artificial milking will never produce as much milk as a calf can obtain. Moreover, experience with nurses seems to show that milk secretion decreases rapidly when milk is removed by a breast-pump. The human breast should be emptied three or four times each day by the infant to insure continued secretion.

During the active lactating period milk is secreted constantly. Milk is accumulated in the udder in the intervals between milking and during the actual process of milking or sucking. It has been stated that during the time of milking or sucking the glands are stimulated to secrete an extraordinary quantity of milk. Fleischmann has estimated that the internal capacity of the cow's udder is too small to hold the quantity of milk that is frequently obtained by milking. He placed the total volume of a cow's udder at 6700 c.c., of which only 3015 c.c. represent hollow spaces capable of holding milk. If these measurements are correct, some explanation must be found for the large amount of milk that can be obtained. Stimulation of gland activity by milking may account for the phenomenon. Gaines estimated, however, that the actual capacity of the udder of a goat was in harmony with the quantity of milk obtained. In the absence of exact investigations on this point the question cannot be satisfactorily answered.

The first quantity of milk drawn from the udder is invariably poorer in fat content than the strippings. The difference is considerable and the fat globules of the strippings are usually larger than those of the fore-milk. This phenomenon has never been satisfactorily accounted for. Some scientists hold that the fat rises in the udder while the milk is slowly accumulating and that the fat adheres to the walls of the udder. The last streams of milk, if this theory is true, would then be richer in fat than the first streams, similar to top-milk in bottles. The quantity would be further increased by the fat adhering to the walls of the udder. Another explanation depends on the observation that during milking or sucking a richer milk is produced than during the intervening period. This latter view is supported by independent observations of Hammond and Gaines, who found that under the influence of a special stimulant (pituitrin) the last remnants of milk were squeezed out and contained an increased percentage of fat. If sucking or milking has a similar stimulating effect on secretion, either view might be accepted.

Duration of the Lactation Period.-If milk secretion were dependent exclusively upon continued demand, there would be no limit to the duration of lactation. As a matter of fact, lactation ceases after a lapse of time, the actual duration varying in different 
species and, in a measure, in different individuals. Lactation is a necessity among animals who depend for food-supply upon the mother for some time after birth. With development of the digestive tract other food becomes available, and the duration of lactation, therefore, is conditioned by the length of time required by the young mammal to become self-dependent. As the animal develops and begins to take increasing quantities of other food the demand upon the mother decreases and milk secretion gradually ceases.

It is not uncommon to find mothers who are able to produce milk for twenty to twenty-four months. Pfaundler, in Sommerfeld's Handbuch, mentions that some Indian tribes nurse for two to twelve years, and tribes of Eskimos for fourteen to fifteen years. These figures are probably extreme, while the actual duration of lactation is no doubt much shorter. It is possible, of course, that some tribes nurse their children for longer periods than others.

The total quantity of milk produced during a lactation period is dependent, as a rule, upon the number of infants nursed. If a mother nurses one child the quantity is less than if more are nursed. Pfaundler gives the following approximate figures: A woman nursing one child produces-

\footnotetext{
During a 6 month period about 1.25 to 150 hectoliters.

During a 7 -month period about 1.50 to 2

During an 8-month period about 2 to 2.5
}

Wet-nurses who nurse two or more babies produce-

During a 6-month period about 3.5 hectoliters.

During a 12-month period about 8

During a 24-month period about 15 or more heetoliters.

The statement is sometimes made that among civilized nations nursing is becoming less the rule than heretofore. Since comparative statements are difficult to obtain, it cannot be determined with accuracy whether the assumption is correct. It is true that more babies thrive on bottle feeding than formerly, but this does not prove that breast feeding is less common, since science has taught us how to raise children successfully by artificial feeding. On the other hand, it may be argued that modern social conditions compel many women to work for a livelihood, frequently under unsanitary conditions and at low wages, and that neglect or inability to nurse their offspring is a consequence. Furthermore, it is claimed that among certain classes there is a growing disinclination to nurse. It is difficult at present to form a decisive opinion on a subject which can be cleared up only by carefully compiled statistics covering a long period of time.

At the present time the cow is the chief milk producer for the 
civilized people of the West, and we are so completely accustomed to this fact that in our minds "milk" always means cow's milk. Cow's milk, therefore, commands our attention more than other milk, and it is mutually agreed that when "milk" is spoken of cow's milk is meant.

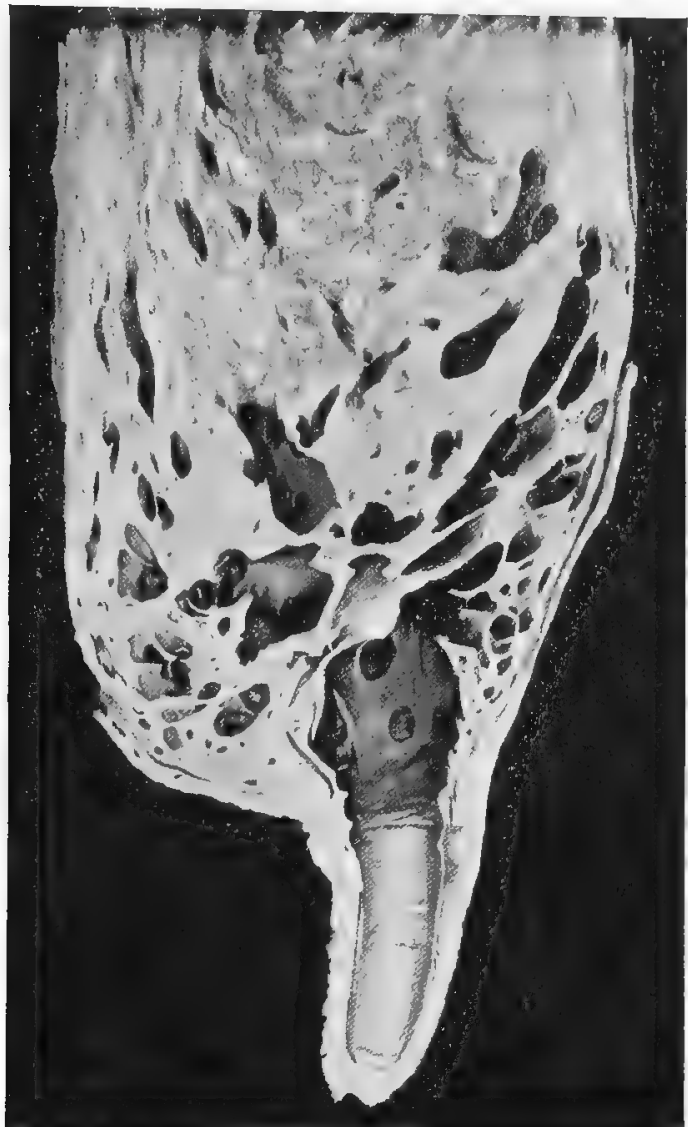

Fig. 11. - Showing a section through the teat and one quarter of the udder of a cow. (After Moore and Ward.)

The cow's udder is situated on the abdomen between the hind legs. It is separated into four quarters which are divided by layers of fibrous tissue. Each pair-the one on the right side and the one on the left-represents one gland, and while there is no connection between the glands, there is some connection between the two quarters of the same gland. It is possible, therefore, to obtain some milk from one quarter by milking the other one on 
the same side of the cow, but no milk can appear in a left quarter from a right quarter.

The udder is a spongy organ consisting of skin, muscle, nerves, veins, arteries, lymphatics, milk-ducts, secreting glands, and fibrous fatty and connective tissue (Fig. 11). The size of the fully developed udder is 24 to 54 by 16 to 32 by 10 to $20 \mathrm{~cm}$. The outer skin of the udder is soft and thin and is supported by fibrous tissue. It is covered with hair which is softer than the hair of the coat of the animal. The udder swells considerably when milk is accumulating and contracts while milk is removed.

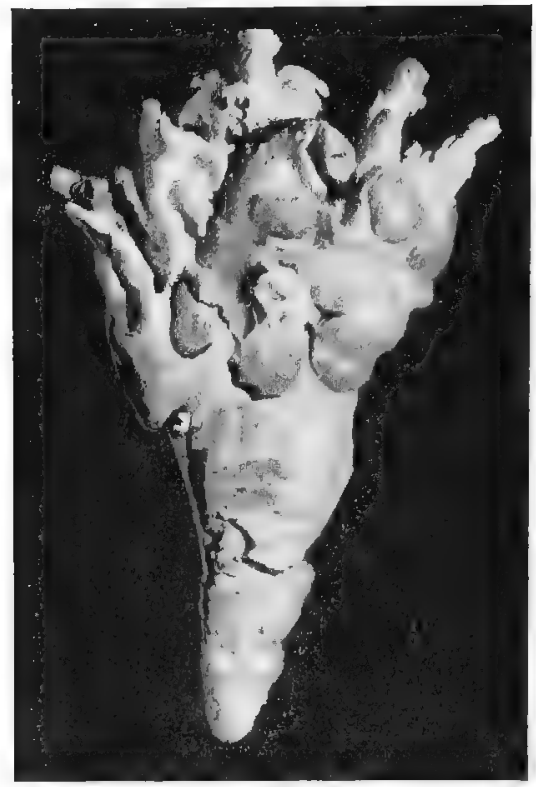

Fig. 12.-A plaster-of-Paris cast of the interior of the teat and milk cistern of one quarter of an udder (Moore and Ward).

The degree of contraction varies, and is particularly small when the udder contains much fatty tissue.

At the lower extremity of the udder are the teats, which are tube-like appendages, and are 6 to $10 \mathrm{~cm}$. long. There is one teat for each quarter of the udder (Fig. 12). A sphincter muscle, located at the end of the teat, keeps the milk from flowing from the udder until it is relaxed by sucking or milking. The cow has no voluntary control over this muscle. Sometimes, however, the muscle is weak and milk leaks from the udder under the pressure of the accumulating secretion. On the other hand, the muscle is occasionally so tight that a smooth, wooden wedge has to be 
placed in the aperture of the teat, thus opening it slightly and facilitating the release of milk. In other cases a surgical operation becomes necessary, by which the muscle is cut and weakened sufficiently to render milking less difficult. The skin of the teat has neither hair nor sweat-glands, and the mucous membrane which lines the teat duct expands in the cistern. The cistern, therefore, may be regarded as the expansion of the teat duct (Fig. 13). The cistern (sinus lactiferus) is a pouch which is separated from the teat by a circular muscle, over which the cow has little control. This cistern is of variable size and may contain from less than $\frac{1}{2}$ pint to 1 pint of milk. It is connected with other parts of the udder by a network of milk-ducts whose lumen is largest at the point where it opens into the cistern. These ducts

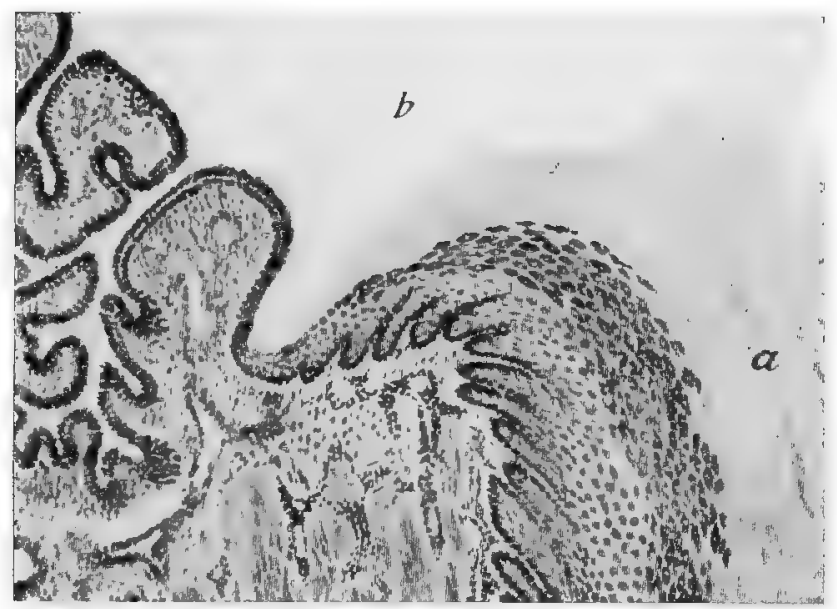

Fig. 13.- $a$, Upper end of teat duct; $b$, cistern. (Ernst.)

anastomose and end in the ultimate follicles or gland lobules. Anastomosis is more pronounced in the upper regions of the udder than near the cistern. The upper parts of the two quarters of the udder that belong to the same gland are connected by these milk-ducts, so that communication is established. At the juncture of the milk-ducts there are small cisterns and a system of sphincter muscles protects all junctures of the ducts. These sphincter muscles are under control of the cow and enable her to withhold milk at will, or perhaps by an involuntary reflex, so that, when she suffers from nervousness caused by disease, maltreatment, or dislike of the milker, she is able to hold up the greater part of the milk. Such conditions frequently interfere with the productiveness of a cow and are difficult to control. 
The ultimate follicles contain the secretory organs, the alveoli. Three to five ultimate follicles are grouped together, and have a common outlet into a milk-duct. They are about $\frac{1}{10}$ to $\frac{1}{12} \mathrm{~cm}$. in diameter, while the alveoli are of microscopic size (Fig. 14). The follicles develop during pregnancy and reach their maximum development during lactation. They shrink after milk secretion ceases, but develop again during succeeding periods of pregnancy. The follicles are lined with epithelial cells, which play-as we have seen-a most important rôle in milk secretion. They are supplied with blood by capillaries. Same follicles may degener-

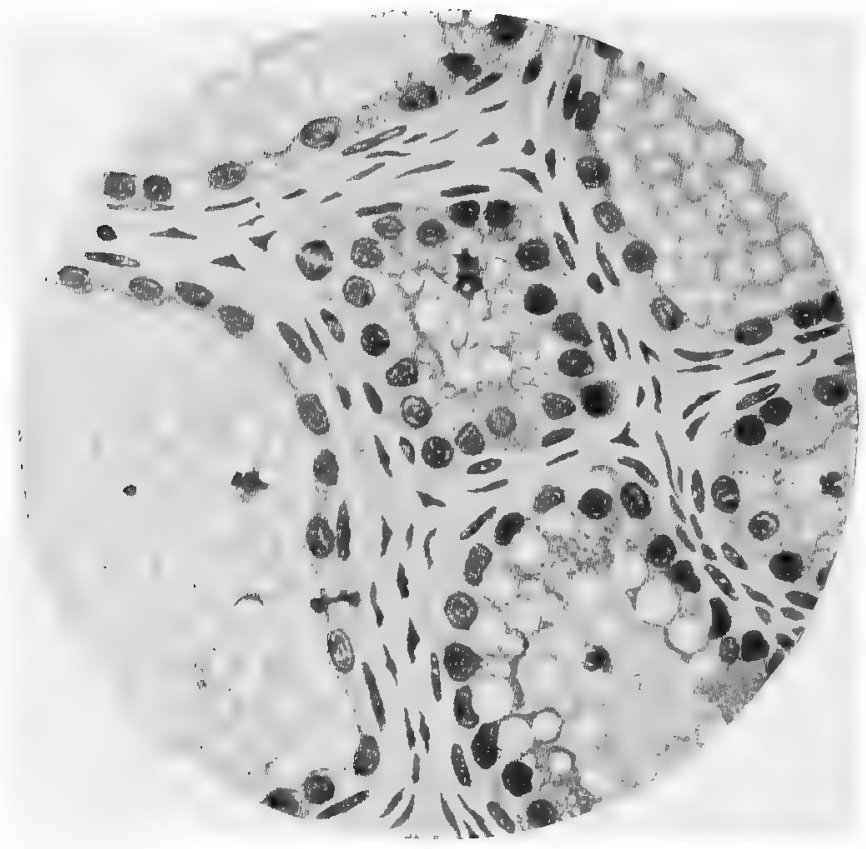

Fig. 14.-Gland during secretion of milk, magnified 800 (Ernst).

ate after a lactation period, and new ones are then formed during later periods, so that productiveness mav increase with each new period of lactation. This, however, rarely happens after the fifth or sixth year.

It may be inferred from our studies of the mechanism governing milk secretion and from the anatomic structure of the udder that milking is an art that requires practice, a suitable temperament on the part of the operator, and skill. It is not merely a manipulation of the teats. The milker must be able to influence the maternal instinct of the cow and thereby induce her to will- 
ingly relax the sphincter muscle which holds the milk in the udder. In practice it has proved profitable to permanently assign a certain set of cows to one milker so as to accustom them to his touch. This leads to greater milk production and facilitates work.

The quantity and quality of milk produced by cows varies within wide limits, differing with the breed and the individual. The fat content especially is subject to much variation. The following figures give some results obtained:

SUMMARY OF RESULTS OF TESTS OF DAIRY COWS AT THE WORLD'S COLUMBIAN EXPOSITION, CHICAGO, 1893 (ALVORD)

\begin{tabular}{|c|c|c|c|c|}
\hline & $\begin{array}{l}\text { Pounds of } \\
\text { milk. }\end{array}$ & $\begin{array}{l}\text { Fat in milk, } \\
\text { pounds. }\end{array}$ & $\begin{array}{l}\text { Cheese made, } \\
\text { pounds. }\end{array}$ & \\
\hline $\begin{array}{l}25 \text { Jerseys..... } \\
25 \text { Guernseys. } \\
25 \text { Shorthorns. }\end{array}$ & 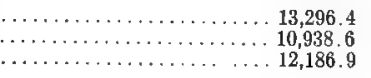 & $\begin{array}{l}601.91 \\
488.42 \\
436.60\end{array}$ & $\left.\begin{array}{l}1451.8 \\
1130.6 \\
1077.6\end{array}\right\}$ & 15 days in May. \\
\hline & $\begin{array}{c}\text { Pounds of } \\
\text { milk. }\end{array}$ & $\begin{array}{l}\text { Pounds of } \\
\text { fat. }\end{array}$ & $\begin{array}{l}\text { Pounds of } \\
\text { butter. }\end{array}$ & \\
\hline $\begin{array}{l}25 \text { Jerseys...... } \\
25 \text { Guernseys. } \\
24 \text { Shorthorns. }\end{array}$ & $\begin{array}{l}\ldots \ldots \ldots \ldots \ldots \ldots, \mathbf{7 3 , 4 8 8 . 8} \\
\ldots \ldots \ldots \ldots \ldots \ldots \ldots \mathbf{6 1 , 7 8 1 . 7} \\
\ldots \ldots \ldots \ldots \ldots \ldots, \mathbf{6 6 , 2 6 3 . 2}\end{array}$ & $\begin{array}{l}3516.08 \\
2784.56 \\
2409.97\end{array}$ & $\left.\begin{array}{l}4274.01 \\
3360.43 \\
2980.87\end{array}\right\}$ & $\begin{array}{l}\text { June, July, and } \\
\text { August. }\end{array}$ \\
\hline
\end{tabular}

Records of cows in California are given by Anderson as follows:

\begin{tabular}{|c|c|c|c|}
\hline Cows. & Year. & Pounds, milk. & Pounds, fat. \\
\hline $\begin{array}{l}\text { Black grade cow } \\
\text { Jersey .......... }\end{array}$ & $\left\{\begin{array}{l}1906 \\
1907 \\
1906 \\
1907\end{array}\right.$ & $\begin{array}{l}7,672.5 \\
6,120.4 \\
6,349.6 \\
6,586.9\end{array}$ & $\begin{array}{l}361.37 \\
286.27 \\
260.33 \\
270.06\end{array}$ \\
\hline
\end{tabular}

Hayden gives a large number of records from herds in Illinois. Guernsey cows gave between 5000 to over 12,000 pounds of milk, Holstein-Friesians from 10,000 to over 20,000 pounds, Brown Swiss from 6000 to over 11,000 pounds, and Jerseys 12,000 to over 17,000 pounds during one year. The same author gives the following highest records:

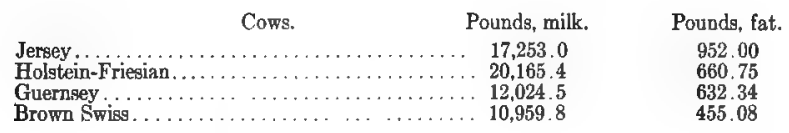

Alvord gives the following figures as estimates of milk yield by several breeds: Ayrshires average 5500 pounds a year, with maximum of 10,000 to 12,000 pounds; Guernseys average 5000 pounds, with maximum of 8000 to nearly 13,000 pounds; Holstein-Friesians are very productive, yielding frequently 100 pounds a day, with an annual production of 7500 to 8000 pounds, sometimes reaching the enormous figure of 20,000 to 30,000 pounds in a year; Jerseys yield an average of 6000 to 7000 pounds a year, while some produce $9000,10,000,12,000$, and nearly 17,000 pounds; Red Polls give an average of 5000 to 5500 pounds, and may give 
7000 pounds a year; Shorthorns give an average of 6500 to 7750 pounds, with occasional records of 10,000 to 12,000 pounds a year.

\section{BIBLIOGRAPHY}

Alvord: Farmer's Bull., U. S. Dept. of Agri., No. 106, 1899.

Anderson; Coll. of Agri. Exp. Sta., Berkeley, Cal., 1909.

Creasy: Jour., Amer. Med. Assoc., 1912, vol. 50, p. 747.

Fleischmann: Lehrbuch der Milchwirtschaft, 1908.

Gaines: The American Journal of Physiology, 1915, vol. 38, p. 285.

Hammond: Quart. Jour. Exper. Physiology, 1913, vol. 6, p. 311.

Hayden: Univ. of Ill. Agri. Exp. Sta., Bull. 160, July, 1912.

Journal of the American Medical Association, Editorial, The Physiology of Lactation, 1912, vol. 58, p. 638. Ibid., Virgin Lactation, 1912, vol. 58, p. 860.

Lane-Claypon and Starling: Proceedings of the Royal Society, 1906, vol. 72, p. 505.

McKay and Larsen: The Principles and Practice of Butter Making, John Wiley and Sons, 1911, New York.

Ottolenghi: Archivf. Mikroscopische Anatomie, 1901, vol. 58, p. 581. (Pfaundler, in Sommerfeld's Handbuch.)

Pfaundler: Zeitschr. f. Kinderheilk., 1911, vol. 3, p. 191; abstracted in the Jour. Amer. Med. Assoc., 1912, vol. 58, p. 72.

Pfaundler: Physiologie der Lactation, in Sommerfeld's Handbuch der Milchkunde.

Rauber: Uber den Ursprung der Milch und die Ernährung der Frucht im allgemeinen, Leipzig, 1879. (Pfaundler, in Sommerfeld's Handbuch.)

Schein: Theorie der Milchsekretion, Wien, 1908, Verlag Perles. (Pfaundler, in Sommerfeld's Handbuch.)

Wing: Milk and its Products, The Macmillan Company, 1909, New York. 


\section{THE PHYSICAL PROPERTIES OF MILK}

When milk is freshly obtained from the udder it is opaque, white in color, with more or less of a yellowish tint, and has a characteristic sweetish taste and odor. If a small amount of fresh milk is placed under the microscope the field is almost filled with homogeneous disks of strongly refractive power and greatly varying diameter. They appear structureless and without a membrane. Close observation of these disks shows that they frequently form clusters which consist of disks of varying size. In reality, the disks are spheres and consist of milk-fat. Besides these "fat globules," bacteria, cells, and particles of foreign matter may be seen. All these substances are suspended in a fluidthe milk plasma (Fig. 15).

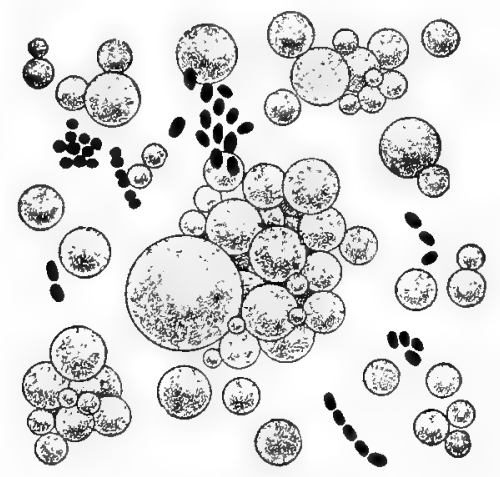

Fig. 15.-Fat globules and bacteria. Note the relative size of the fat globules of milk and the lactic acid bacteria (Russell and Hastings).

The fat globules in milk are in the form of an emulsion, which means that they are distributed throughout the fluid in small microscopic globules and held in suspension. Artificial emulsions can easily be made by mixing an oil with some substance like gum arabic, gum tragacanth, or extract of malt and some water, and by agitating the mixture violently in a mortar. An emulsion of this kind is white and opaque and under the microscope simulates the appearance of milk.

If milk is allowed to stand quietly the physical appearance changes rapidly. A yellowish layer gradually accumulates on the surface and increases in depth for some time, after which it dimin- 
ishes somewhat. If microscopic examinations are made of this yellowish layer, of the whiter portion below and of the very bottom, the three resulting slides represent a widely different appearance. They differ from each other and from the slide made of whole milk. The slide from the surface is fairly crowded with fat globules and may also contain many bacteria and body cells. The slide from the middle portion shows fewer fat globules and of smaller average size than the globules of the first slide. Bacteria and cells are relatively scarce. The third slide-from the bottom - contains few fat globules, but large numbers of bacteria, cells; and other substances, such as Nissen corpuscles, and frequently particles of dirt. These microscopic studies show that milk is not a homogeneous fluid and that by gravity alone it can be separated into three more or less distinct layers.

Further microscopic examination of the surface shows that the fat globules are larger nearer the surface than below. In the course of time they press against each other from below so that the layer becomes more compact. This is the cause of the diminished size of the surface layer after the maximum has been reached. The milk below this layer is white and retains its color and opacity indefinitely.

Lloyd poured Shorthorn milk into a vessel 15 inches high and after twelve hours measured the size of fat globules in different parts of the cream. The following table gives the results, namely, that the average size increases with approach to the surface:

THE SIZE OF FAT GLOBULES AT DIFFERENT PARTS OF THE CREAM IN A BOTTLE

\begin{tabular}{|c|c|c|c|c|}
\hline & \multicolumn{4}{|c|}{ Diameter of fat globules in microns. } \\
\hline & At bottom. & 5 in. up. & 10 in. up. & $10-15$ in. up. \\
\hline $\begin{array}{l}\text { Iargest: } \ldots \ldots \ldots \ldots \ldots \ldots \ldots \ldots \\
\text { Smallest. } \ldots \ldots \ldots \ldots \ldots \ldots \ldots \\
\end{array}$ & $\begin{array}{l}4 \\
1\end{array}$ & $\begin{array}{r}7-8 \\
2\end{array}$ & $\begin{array}{r}8-10 \\
2\end{array}$ & $\begin{array}{r}12 \\
2\end{array}$ \\
\hline
\end{tabular}

The surface layer is the cream layer; the process of its formation is called "creaming"; the milk below the cream is skimmed milk; while the fresh unchanged milk is the whole milk. When milk is obtained from more than one animal it is called mixed milk.

The milk-fat in cow's milk usually has a specific gravity of about 0.93 at $15^{\circ} \mathrm{C}$., but sometimes it is higher. Whole milk has a specific gravity of 1.027 to 1.034 . The smaller weight of the fat is the cause of its rising to form the cream layer. This is clearly a physical phenomenon and is influenced by a variety of factors. The most important of these factors are: 1, The origin of the milk; 2 , the age of the milk; 3 , the temperature of the milk; 
4 , the depth of the cream layer; 5 , the viscosity of the milk; 6 , the size of the fat globules; 7 , centrifugation.

1. The Origin of the Milk.-The milk from different animals has different creaming properties. Separation is rapid and nearly complete in human milk, for example, an opalescent, bluish-white fluid remaining under a layer of yellow fat. In cow's milk separation is slower and less complete. Below the characteristic yellow layer of cream there remains a white or bluish-white fluid which is nearly as opaque as the original milk. In goat's milk there is usually no spontaneous creaming unless the milk has been previously heated, while heating of cow's milk retards creaming.

The cause of these differences in creaming must be sought in the size of the fat globules and in the physical condition of the milk plasma. Milks with relatively large fat globules form a cream layer more rapidly than milks with small fat globules, other conditions being equal. Immediately after milking the casein is in a swollen condition and hinders the rising of the fat to a lesser degree than later, when it has contracted. Probably there is a similar difference between the milks from different animals. Furthermore, the quantity of casein in the different milks is not the same. Human milk, for example, contains much less casein than either cow's or goat's milk, and we may assume that the rising globules meet with less resistance. However, a full explanation is still lacking.

2. Age of the Milk.-It has been stated that the fat globules rise more rapidly in fresh milk than in old milk, because the casein gradually contracts and offers greater resistance to the upward movement of the fat. Moreover, when milk ages it becomes sour and the casein is precipitated. In this condition fat rises but slowly. Agitation of any kind, such as results from handling and transporting milk, retards creaming. The best results in creaming are obtained right after milking (Fig. 16).

3. Temperature.-Creaming is slower in cold milk than in warm milk, for two reasons. Milk increases in viscosity when the temperature is lowered and the fat congeals; the spheric shape is lost and the surface becomes wrinkled. Both these conditions retard the rising.

If the temperature of a can of milk is not uniform throughout, currents are created and these carry fat globules, especially the small ones, out of their upward path. Therefore cooling should commence from the bottom so as to prevent the formation of currents.

When milk is heated the fat clusters break up, small globules are isolated, and some coalesce (Fig. 17). Clusters of fat rise 
more rapidly than single globules, and consequently breaking up of clusters by heat retards creaming. In addition, the liberation of small globules decreases the volume of cream, since they remain in the skimmed milk. These processes are favored by stirring devices which are usually installed in milk-heating tanks. Heated

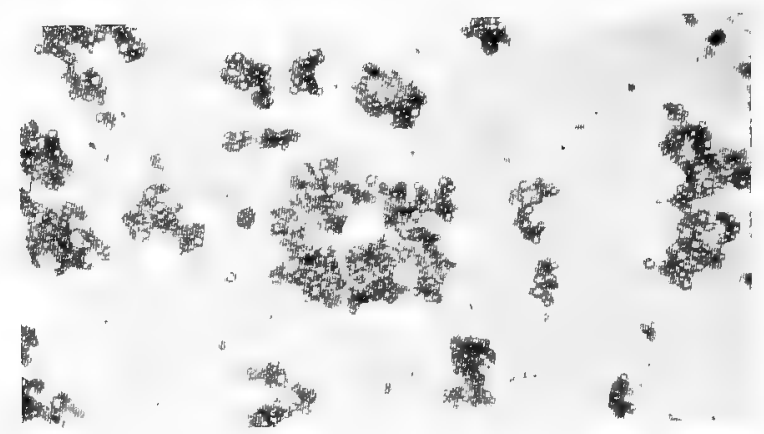

Fig. 16.-Fat globules in raw milk. In raw milk the fat globules are in masses of varying sizes. These rise to the surface quickly in gravity creaming (Russell and Hastings).

milk will, therefore, never cream as rapidly as raw milk and the quantity of cream obtained is less. The increased number of small globules in heated milk also renders the cream line less distinct, and this fact has given rise to the erroneous idea that there is less fat in the pasteurized product than in raw milk.

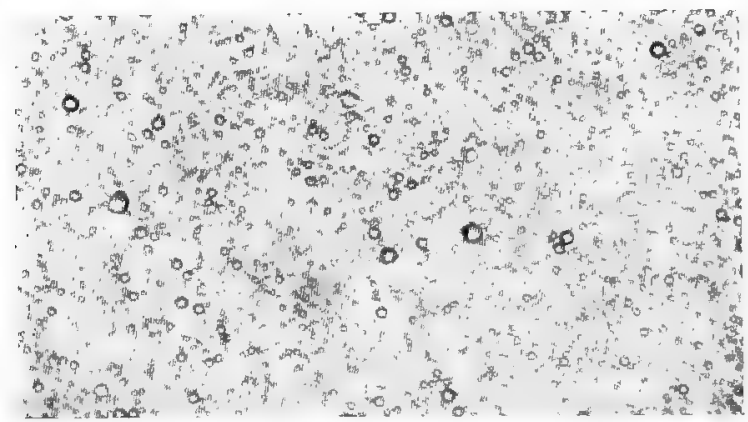

Fig. 17. - Fat globules in heated milk. When milk is heated the masses of globules are broken up and fat globules are uniformly distributed throughout the milk (Russell and Hastings).

4. The Depth of the Cream Layer.-In shallow layers the globules have less space to traverse than in deep ones and less weight to overcome, so that separation is more rapid and more complete than in deep layers. Therefore creaming is usually carried on in shallow pans, about 2 to 4 inches deep. 
However, in many localities, creaming is done by the "deepsetting system," which seems to overthrow the idea of creaming in shallow pans and at high temperature. In the deep-setting system the milk is stored in cans about 20 inches deep and kept at a temperature of $40^{\circ}$ to $55^{\circ} \mathrm{F}$. While in shallow pans of 2 to 4 inches deep the skimmed milk rarely contains less than 0.5 per cent. fat, the skimmed milk in the deep cans retains but 0.2 per cent. It is difficult to explain why milk at low temperature, with increased viscosity and with a greater volume for the fat globules to traverse, should yield a richer cream than milk kept in shallow pans at higher temperature. Possibly an explanation is found in the fact that the rising globules come in contact with a larger number of globules in deep layers than in shallow layers, thus facilitating the formation of clusters.

5. The Viscosity of Milk.-If two pipets of equal size and caliber are filled-the one with water and the other with milk-it turns out that it takes a greater length of time to discharge the milk than the water. This is due to the viscosity and adhesion of the milk. Viscosity depends upon the milk solids, especially the casein. The greater the quantity of solids and the lower the temperature, the more pronounced is the viscosity. The viscosity is an obstacle to the rising of fat. Dilution of milk reduces the viscosity and creaming proceeds more readily in diluted than in undiluted milk. Butter makers have discovered this fact and frequently take advantage of it.

6. The Size of the Fat Globules.-One of the most important factors which influence creaming is the size of the fat globules, since large globules naturally rise more rapidly than small ones. Large globules, therefore, rise first and crowd to the surface, while small ones rise more slowly and remain in the deeper layers of the cream. The smallest globules do not rise at all and reniain in the skimmed milk. Milk from some breeds of cows has globules of larger average size than milk from others. Jersey milk, for example, creams more readily than Holstein milk because of the difference in the size of the globules. Furthermore, the milk derived from a cow in carly stages of lactation creams better than that drawn during later stages, due to the gradually decreasing size of the globules as lactation progresses. Fat globules are relatively large in colostrum milk, but diminish when normal milk is secreted. This diminution goes on progressively to the close of the lactation period. At this time the fat globules are so small that creaming is slow and butter making becomes difficult.

It has been previously stated that the last milk from the udder-the strippings - contains more fat than other portions of the milk and that the fat globules are larger than during earlier 
parts of the milking. The relative size of fat globules in different portions of the milk is illustrated in the following chart (Fig. 18) prepared from figures by Bitting.

According to this chart the majority of globules in skimmed milk are 6 microns in diameter; in fore-milk, whole milk, and strippings, 8 microns; and in middle milk, 12 microns. However, the strippings contain the greatest number of large globules, measur-

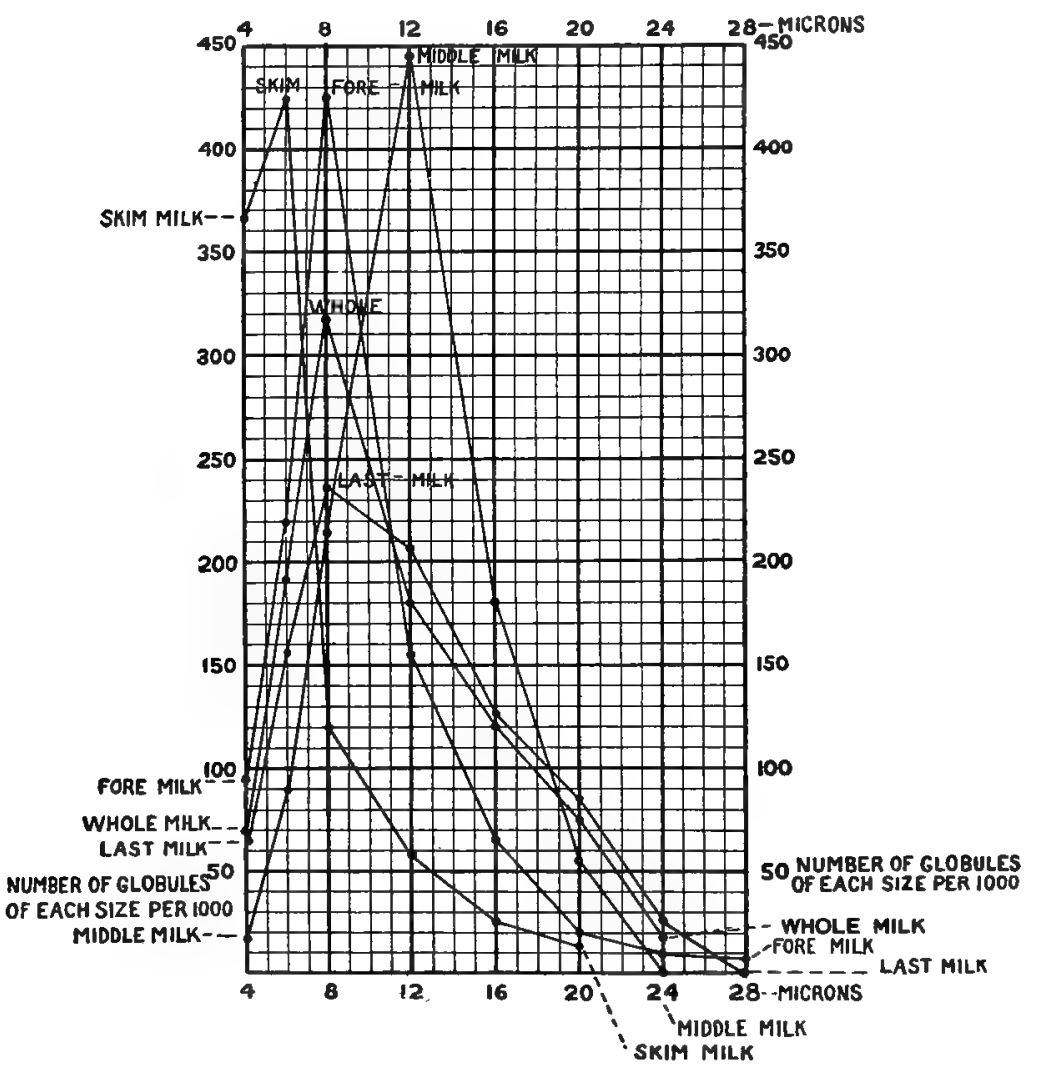

Fig. 18.-The number of globules of each size per 1000 globules.

ing from 20 to 24 microns in diameter. It is clear that strippings cream more rapidly than fore-milk and that the creaming of whole milk improves when the udder is milked dry.

7. Centrifugation of milk is used largely for two purposesthe separation of cream, and the removal of foreign substances. The violent motion in the machine breaks up the fat clusters, so that centrifugated milk does not cream as well as untreated milk. 
Some milk producers pass the milk through a cream separator in order to remove dirt and then mix the cream and skimmed milk again. However, the mixed product does not yield as much cream as the original milk.

\section{Cellular Elements in Milk}

The cellular elements in milk originate from several sources. They are derived from the circulation, from the secreting glands and from the membranes of the ducts, the cistern, and the teats (Fig. 19).

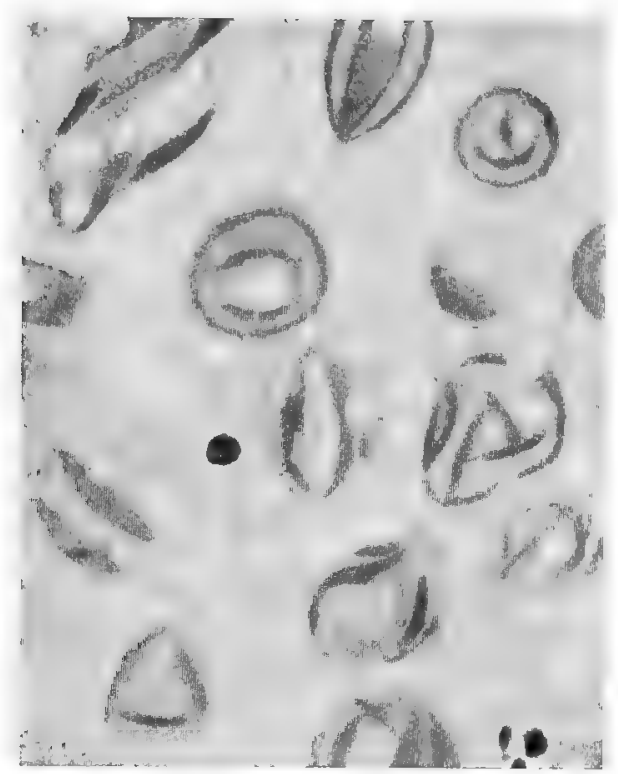

Fig. 19.-Smear from sediment of milk. Epithelial cells from teat duct (Ernst).

During the manipulation of milking epithelial cells are detached from the teat and the cistern. Those from the teat appear as folded platelets, as has been shown by Ernst, who saw the same formations in scrapings from the mucous membrane of the teat ducts. Cells from the mucous membrane of the cistern are oval or four cornered, are drawn out at the base, and have oval nuclei.

Cells from the secretary ducts and alveoli contain fat droplets whose size determines the size of the cells (Figs. 20, 21). Usually nuclei appear. These cells are the large colostrum corpuscles and are of epithelial origin, as shown by their structure and staining properties. They are present in large numbers at the commencement of lactation and reappear at its close. They also reappear 


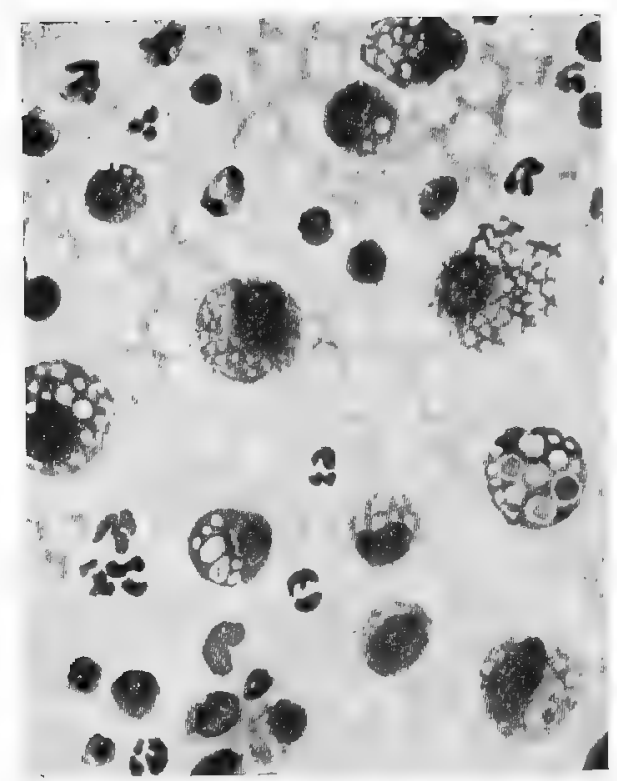

Fig. 20.-Detached epithelial cells and polynuclear leukocytes (Ernst).

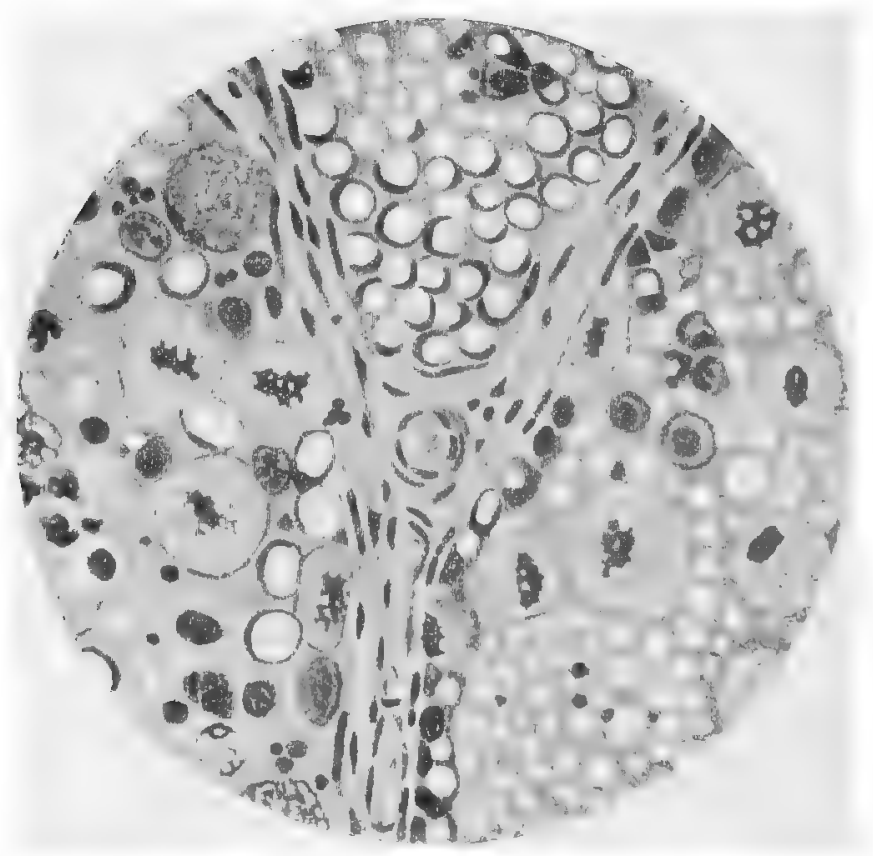

Fig. 21.-Formation of large colostrum corpuscles, magnified 800 (Ernst). 
under abnormal conditions, especially during chronic diseases of the udder. Their shape is conditioned largely by the fat, which is milk-fat and not the result of fatty degeneration. These cells are probably discharged from the milk glanils before the secretion is complete. Similar cells have been observed in the epithelial layers.

Epithelial cells that are attacked by phagocytes sometimes contain spheric bodies composed of protein and fat. These have been called albuminophores (Fig. 22).
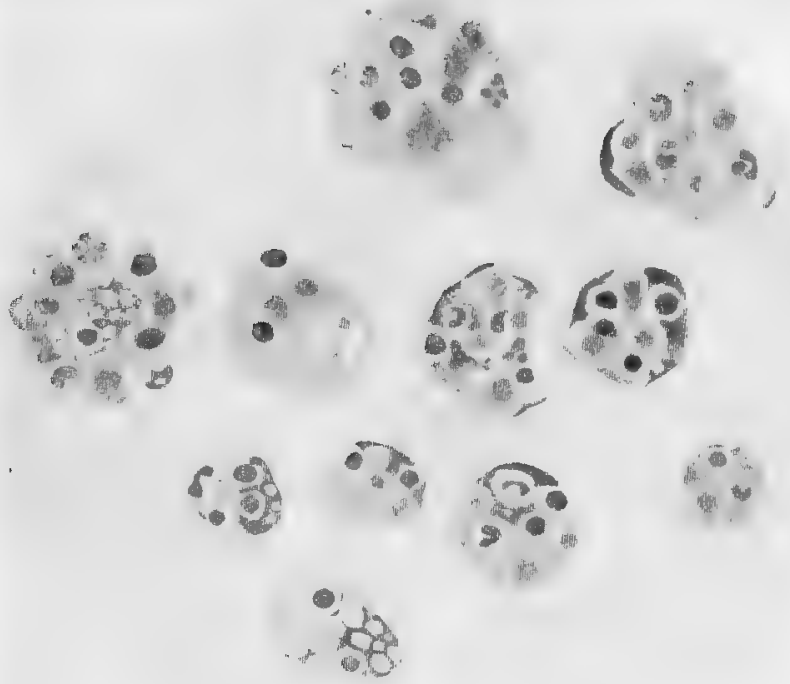

Fig. 22.-Epithelial cells in various stages of degeneration (albuminophores), magnified 1000 (Ernst).

Cells derived from the circulation are leukocytes of all kinds and red blood-corpuscles. The leukocytes may be mononuclear basophil and eosinophil, polynuclear basophil, acidophil, or finally cells with neutrophil and eosinophil granules. Lymphocytes never contain fat. The red corpuscles appear small, round, or with irregular outlines.

All these cells are subject to rapid degeneration and then appear in many odd forms. The nucleus breaks up and the chromatin mixes with the protoplasm, which then takes stain with intensity, leaving an unstained portion in place of the nucleus. 
This mixture of protoplasm and chromatin breaks up further into fragments (corpuscles of Nissen). These fragments may attach themselves to fat globules and then take the shape of helmets, caps, or sickles.

Besides organized cells, small structureless particles are frequently observed, which are readily stained with anilin dyes. These particles may form aggregations of considerable size, large enough to form emboli in the alveoli (Fig. 23). Later calcium and magnesium salts crystallize on these clusters and give a radiated appearance. These bodies are clearly degeneration forms

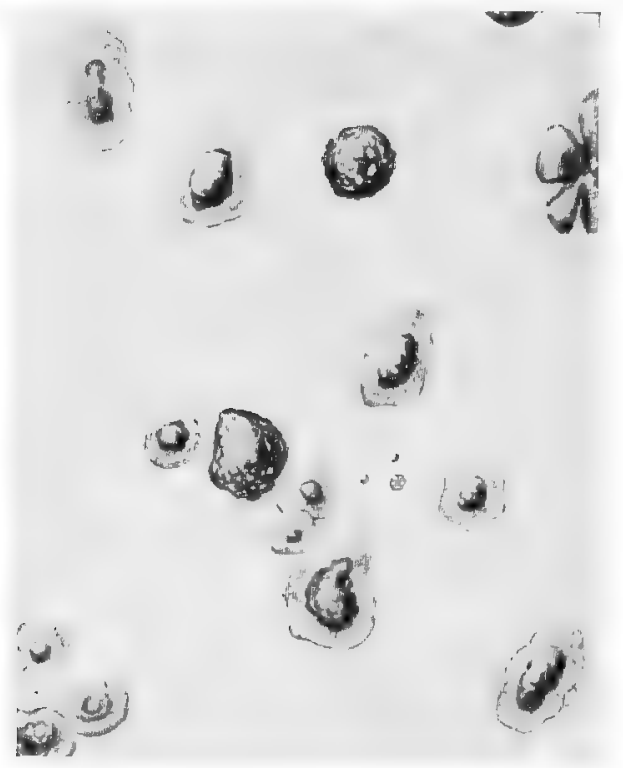

Fig. 23.-Calcium salt aggregations in cow's milk, magnified 1000 (Ernst).

and not-as has been supposed-antecedents of casein or fat. Leukocytes may digest them, but they may also resist the phagocytic action and increase in size.

\section{The Nature of Fat Globules}

Leewenhoeck in 1697 was the first to give a description of the microscopic appearance of fat in milk. He described the globules as disks, strongly refractive and without discernible structure. When milk is cooled the fat congeals and globules lose their disklike shape, become irregular, and assume a wrinkled surface.

The size of fat globules varies from less than 1 micron to 22 microns, and the number in one cubic centimeter of milk may be 
from $1,000,000$ to $11,000,000$. All kinds of milk contain fat globules of different size, but the extremes are farther apart in some milks than in others. In goat's milk, for example, the extremes lie between 3 and 4.5 microns; in sheep's milk, between 2.75 and 22.4 microns, and in Jersey milk, between 4 and 12 microns. It has been said that the chemical composition of the fat in the large globules differs from that in the small ones, that the small glotules contain more oleic and volatile acids than the large ones. Conclusive evidence on this point is still lacking.

The emulsion of fat in milk has been compared to an artificial emulsion of oil. In the latter the globules are kept in suspension and from coalescence by a thin covering of a gummy substance which is held in position by molecular attraction. Similarly, the fat globules in milk may be enveloped in casein, also held there by molecular attraction. Any condition, such as the addition of acid, alkali, or rennet, which affects the casein, would then release the fat globules and cause them to coalesce.

Another hypothesis, whose chief supporter is Béchamp, assumes that the globules are surrounded by an organized membrane. The supposition is that these membranes are destroyed by the violent agitation in butter making, so that fat separation becomes complete. Attempts to demonstrate the presence of a membrane have been made by dissolving the fat with some solvent in the expectation of finding the empty membranes. Some remnants have actually been found, but it has not been possible to show conclusively that they are membranes. Or the fat globules have been made to rise through a column of water in order to free them from adhering milk plasma. These washed globules have then been extracted with ether, and the substance left has been thought to constitute the membrane. Mathews states that these remnants give no biuret reaction and when hydrolyzed vield glycocoll which is not present either in casein or lactalbumin. According to this author the amount of nitrogen in these elements is 4.04 to 5.70 per cent., and he states: "It is clear that it is not a homogeneous substance nor is it composed of casein." Storch also believed in the existence of a membrane, but thought it was composed of a mucoid substance-mucoid protein. He isolated this substance from cream and butter and concluded that it must occur in milk. He treated milk with ammoniacal picrocarmin, and after cream had collected washed it with water until all milksugar had been removed. He then examined the globules under a microscope and found them surrounded by a stained halo. Furthermore, he was able to isolate a larger quantity of his mucoid protein from buttermilk than from sweet cream, which fact led him to believe that the churning had broken away the mucoid 
capsule, thus enriching the buttermilk. Richmond argues against Storch's theory, holding that if the latter's view were correct the ratio of plasma solids to water in cream would differ from the ratio in milk. He has shown, however, that this ratio is the same. In addition, the stained area around the globules may be only a condensed solution of solids due to surface attraction. This view is supported by the fact that the stain is the most intense near the surface of the globule and gradually fades away, while a real capsule would stain more distinctly.

Since it is obviously difficult to obtain globules which are completely free from adhering plasma, it is impossible to decide the question of the existence of a capsule or membrane with certainty in the present state of our knowledge. However, the homogenizing machine breaks up fat globules into very minute ones, and it is not possible to make butter from homogenized cream. The fine globules of homogenized cream do not rise, and it does not seem possible that membranes of any kind are formed in the homogenizing process. The homogenized globules remain suspended without noticeable change and, therefore, the assumption of a membrane is superfluous to explain the emulsion of fat in milk. Probably surface tension is an important factor in keeping the globules in suspension.

Fischer and Hooker, who have investigated the conditions governing the formation of emulsions, have stated that different factors work together in producing and stabilizing an emulsion. These factors are surface tension, viscosity of the dispersing medium, and an encircling film formed of a third substance between oil and dispersing medium. These factors may differ in different emulsions and in the same emulsion under different circumstances. The dispersing agent- the water-is all used up in the formation of a colloid hydration compound. An emulsion is not a subdivision of oil in water, but one of oil in a hydrated colloid. Casein is a stabilizing agent. It does not absorb much water in neutral solution, but if an alkali is added it develops marked hydrophilic properties and becomes one of the best stabilizing agents known for emulsions. Acid also converts neutral casein into a hydrophilic colloid which works as well as alkaline casein.

\section{Colostrum}

Colostrum is a viscous; sticky, yellow fluid, the secretion of the days immediately before and after parturition. The specific gravity of colostrum is more variable than that of normal milk. The following figures show the limits of variability: 


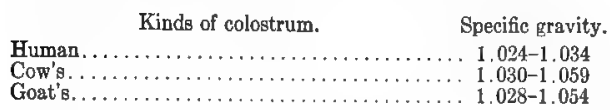

When colostrum stands, the cream often appears in two layers. The upper layer contains the large fat globules, characteristic of colostrum, and is yellow, while the lower layer is composed of true milk-fat.

Colostrum milk contains a large number of cellular elements, known as colostrum corpuscles, and which have been described before. They disappear five to eight days after parturition, but reappear after the close of lactation and during lactation if the milk is not promptly removed, a thing which may happen when the child is unable to use as much milk as the glands secrete. A large number of corpuscles in the colostrum milk has been considered an indication of profuse milk secretion.

Besides corpuscles there are mono- and polynuclear leukocytes and lymphocytes in colostrum.

\section{Properties of Normal Milk.}

Normal milk is an opaque fluid, ranging in color from yellowish-white to nearly white, the color due partly to a yellow pigment in the fat, partly to the reflection of light by the fat globules, and also to the colloidal casein.

The pigment, lactochrome, is associated with the fat and is different both qualitatively and quantitatively in the milk from different animals. It is yellow in cow's milk, for example, and red in human milk. The amount varies in the milk from the same animal, according to the season. In the spring there is more coloring-matter in the fat than later in the summer, and during the winter there is but little, so that butter is more highly colored during the spring than at any other time of the year. In the winter butter is nearly white. The kind of food is probably the cause of this variation.

According to Palmer and Eckles the pigment of bovine milkfat is composed of carotin and xanthophyls. Carotin is the more important one of the pigments and belongs to the hydrocarbon group. It is widely distributed in green plants and especially so in grass. Both pigments are contained in the food of cows and are transmitted through the mammary glands to the butter-fat. By giving food rich in carotin and xanthophyl the authors were able to intensify the color of the butter-fat. This work explains the heightened color of butter in early summer and the reduction of color in winter, when food poor in pigments is given.

The light is reflected by the globules in all directions, so that 
the fluid becomes opaque and white. The surface of small globules is larger in proportion to the size than that of large globules. Small globules, therefore, have a larger reflecting surface than large ones. It follows that the smaller are the globules, the whiter is the milk; the larger the globules, the more pronounced is the tendency toward yellow, other conditions being equal. The color of milk or cream is, therefore, not necessarily an indication of richness in fat.

The colloidal casein also contributes toward the opacity and whiteness of milk. Separator milk, containing but 0.1 per cent. fat, is still opaque and white, and a 3 per cent. solution of pure casein in lime-water resembles skimmed milk in appearance. Solutions of casein in alkalies are more translucent than solutions in alkaline earths. The cream separates almost completely in human milk, still the plasma is white and opalescent, showing that the casein is in part responsible for the color.

Boiled milk is more yellow than raw milk, due to protein decomposition. Addition of boiled milk to skimmed milk may, therefore, restore the yellow color and cause it to resemble whole milk.

Odor and Taste.-Fresh clean milk has little odor. The "cowey" odor usually given off by market milk is due to admixture of cow manure and absorption of odors from the air. Milk, especially when warm, absorbs odors rapidly and retains them tenaciously. When milk is heated the odors are quickly removed, a circumstance that accounts for the fact that pasteurized milk has a sweeter smell than raw milk. Part of the odor is due to volatile acids in the milk-fat. Cream, therefore, has a stronger odor than whole or skimmed milk.

The taste of clean milk is sweet and aromatic. The sweetness is due to the milk-sugar, while the aromatic taste comes from the fat. The "cowey" taste of market milk is due to manure and absorbed impurities.

Viscosity and Cohesion of Milk.-Cool milk has greater viscosity and cohesion than warm milk; therefore, cold milk will adhere to the walls of a vessel more closely and in larger quantity than warm milk. Cold cream holds foam better and is easier to whip than warm cream. Heating reduces the viscosity and ultimately destroys it if the temperature is high enough. Consequently, the pasteurized product is not as viscous as raw milk and more so than boiled milk. According to Bowen, the viscosity of milk at $30^{\circ} \mathrm{C}$. is about 1.7 times as great as that of water, and at $0 .{ }^{\circ} \mathrm{C}$. its viscosity is 2.6 times as great as that of water. At $0^{\circ} \mathrm{C}$. the viscosity of milk is about 2.6 times as great as at $30^{\circ} \mathrm{C}$. Fresh milk has less viscosity than milk that has been stand- 
ing for some time. The viscosity can be restored after milk has been heated by addition of "viscogen," first recommended by Babcock and Russell. Viscogen is prepared by mixing a concentrated solution of cane-sugar with freshly slaked lime. After the mixture has stood for some time the clear liquid is poured off. One part of viscogen in 100 to 150 parts of milk or cream will have the desired effect. Viscogen reunites the fat globules into clusters which were broken up by heat.

Under some conditions, such as the presence of slime-forming bacteria or pathologic conditions of the udder, accompanied by pus formation, the viscosity of milk may increase considerably. The "tätté melk" of the Norwegians is thick and slimy, due to microbial activity, and is eaten with a spoon. The "lange wei" of the Hollanders is also an example of slimy milk due to the action of a streptococcus.

Viscosity is measured by allowing the milk or cream to flow from a pipet and then comparing the time required for discharge with the time required to discharge an equal volume of water under the same conditions. Another method used is to let a few drops of milk flow down a smooth piece of glass inclined at an angle and then measure the line formed in a definite period of time.

Specific Gravity.-The specific gravity of milk from different animals is not the same, and since the solids-especially the fat -vary in different breeds of cows, we would naturally expect to find a corresponding variation in specific gravity. The specific gravity of mixed milk is more uniform than that from individual cows. The specific gravity of cow's milk is usually given as 1.027 to 1.034 at $15^{\circ} \mathrm{C}$. Human and goat's milk have about the same figure as cow's milk. The specific gravity of the total solids of cow's milk is 1.3 to 1.4 ; that of the plasma solids, 1.6 .

The specific gravity is conditioned by the presence of dissolved substances, casein and fat. While dissolved substances and casein increase the specific gravity, fat decreases it. Milk rich in fat, therefore, has a lower specific gravity than milk poor in fat. The specific gravity of skimmed or separated milk always exceeds that of whole milk, while cream has a lower specific gravity. There is a fairly definite relation between the specific gravity of milk, the percentage of fat, and the plasma solids, so that when two of these factors are known the third can be calculated. The values obtained by this method of calculation are useful for rapid determinations, but are only approximately accurate.

The table on page 66 shows the decrease of the specific gravity when the percentage of fat increases. The specific gravity was determined by Bowen at $20^{\circ} \mathrm{C}$, and is expressed in terms of water at the same temperature: 
SPECIFIC GRAVTTY OF MILK AND CREAM CORRESPONDING TO VARIOUS PERCENTAGES OF BUTTER-FAT AT $20^{\circ} \mathrm{C}$.

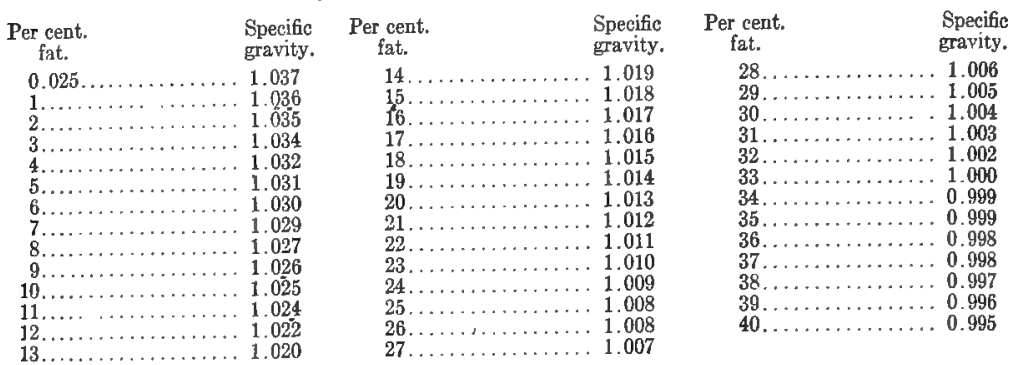

Milk expands when the temperature rises, and this involves a decrease of specific gravity. The expansion of milk of the specific gravity 1.032 at $15^{\circ} \mathrm{C}$. and 3.8 per cent. fat is given in the following table taken from Richmond's Dairy Chemistry:

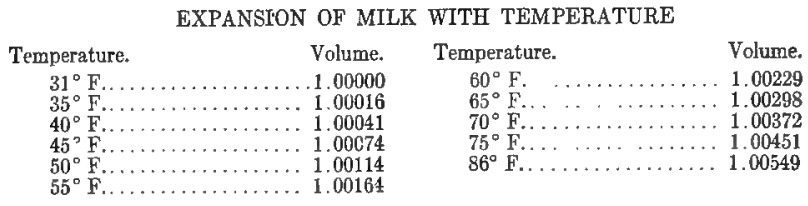

An extensive table of the coefficient of expansion on a basis of $20^{\circ} \mathrm{C}$. has been compiled by Bowen, and follows in condensed form:

VOLUME OF MILK AND CREAM AT VARIOUS-TEMPERATURES OCCUPIED BY A UNIT OH VOLUME AT $20^{\circ} \mathrm{C}$.

\begin{tabular}{|c|c|c|c|c|c|c|c|c|c|c|c|}
\hline \multirow{2}{*}{ Per cent. fat. } & \multicolumn{11}{|c|}{ Temperature in degrees $C$. } \\
\hline & 10 & 15 & 20 & 25 & 30 & 35 & 40 & 45 & 50 & 55 & 60 \\
\hline 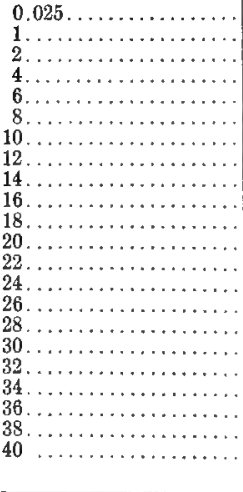 & $\begin{array}{l}0.9980 \\
0.9980 \\
0.9975 \\
0.9975 \\
0.9970 \\
0.9970 \\
0.9965 \\
0.9955 \\
0.9950 \\
0.9950 \\
0.9940 \\
0.9930 \\
0.9930 \\
0.9925 \\
0.9925 \\
0.9915 \\
0.9915 \\
0.9910 \\
0.9910 \\
0.9900 \\
0.9890 \\
0.9890\end{array}$ & $\begin{array}{l}0.9990 \\
0.9990 \\
0.9997 \\
0.9985 \\
0.9982 \\
0.9982 \\
0.9982 \\
0.9977 \\
0.9977 \\
0.9975 \\
0.9975 \\
0.9970 \\
0.9970 \\
0.9967 \\
0.9965 \\
0.9960 \\
0.9960 \\
0.9955 \\
0.9955 \\
0.9947 \\
0.9947 \\
0.9945\end{array}$ & $\begin{array}{l}1.000 \\
1.000 \\
1.000 \\
1.000 \\
1.000 \\
1.000 \\
1.000 \\
1.000 \\
1.000 \\
1.000 \\
1.000 \\
1.000 \\
1.000 \\
1.000 \\
1.000 \\
1.000 \\
1.000 \\
1.000 \\
1.000 \\
1.000 \\
1.000 \\
1.000\end{array}$ & $\begin{array}{l}1.0010 \\
1.0010 \\
1.0012 \\
1.0012 \\
1.0017 \\
1.0017 \\
1.0022 \\
1.0022 \\
1.0022 \\
1.0027 \\
1.0027 \\
1.0027 \\
1.0032 \\
1.0032 \\
1.0035 \\
1.0035 \\
1.0040 \\
1.0040 \\
1.0045 \\
1.0050 \\
1.0050 \\
1.0050\end{array}$ & $\begin{array}{l}1.0030 \\
1.0030 \\
1.0030 \\
1.0030 \\
1.0035 \\
1.0035 \\
1.0040 \\
1.0040 \\
1.0045 \\
1.0050 \\
1.0055 \\
1.0055 \\
1.0060 \\
1.0065 \\
1.0070 \\
1.0075 \\
1.0080 \\
1.0085 \\
1.0085 \\
1.0090 \\
1.0095 \\
1.0100 \\
1.00\end{array}$ & $\begin{array}{l}1.0047 \\
1.0047 \\
1.0047 \\
1.0052 \\
1.0057 \\
1.0057 \\
1.0062 \\
1.0067 \\
1.0072 \\
1.0077 \\
1.0082 \\
1.0087 \\
1.0092 \\
1.0097 \\
1.0105 \\
1.0110 \\
1.0115 \\
1.0120 \\
1.0125 \\
1.0130 \\
1.0135 \\
1.01 \div 7 \\
\end{array}$ & $\begin{array}{l}1.0070 \\
1.0070 \\
1.0070 \\
1.0070 \\
1.0075 \\
1.0080 \\
1.0085 \\
1.0090 \\
1.0095 \\
1.0100 \\
1.0105 \\
1.0110 \\
1.0120 \\
1.0125 \\
1.0135 \\
1.0140 \\
1.0145 \\
1.0150 \\
1.0160 \\
1.0165 \\
1.0170 \\
1.0175\end{array}$ & $\begin{array}{l}1.0092 \\
1.0092 \\
1.0092 \\
1.0092 \\
1.0092 \\
1.0102 \\
1.0102 \\
1.0112 \\
1.0117 \\
1.0122 \\
1.0132 \\
1.0137 \\
1.0145 \\
1.0152 \\
1.0162 \\
1.0170 \\
1.0172 \\
1.0182 \\
1.0187 \\
1.0197 \\
1.0205 \\
1.0212\end{array}$ & $\begin{array}{l}1.0120 \\
1.0120 \\
1.0120 \\
1.0120 \\
1.0125 \\
1.0125 \\
1.0130 \\
1.0135 \\
1.0140 \\
1.0145 \\
1.0155 \\
1.0160 \\
1.0170 \\
1.0180 \\
1.0190 \\
1.0200 \\
1.0200 \\
1.0210 \\
1.0215 \\
1.0225 \\
1.0230 \\
1.0240 \\
1.04\end{array}$ & $\begin{array}{l}1.0142 \\
1.0142 \\
1.0142 \\
1.0142 \\
1.0142 \\
1.0147 \\
1.0152 \\
1.0157 \\
1.0162 \\
1.0167 \\
1.0177 \\
1.0182 \\
1.0190 \\
1.0202 \\
1.0212 \\
1.0222 \\
1.0222 \\
1.0232 \\
1.0242 \\
1.0247 \\
1.0252 \\
1.0267\end{array}$ & $\begin{array}{l}1.0175 \\
1.0175 \\
1.0175 \\
1.0175 \\
1.0175 \\
1.0175 \\
1.0180 \\
1.0180 \\
1.0185 \\
1.0190 \\
1.0195 \\
1.0205 \\
1.0210 \\
1.0220 \\
1.0235 \\
1.0245 \\
1.0250 \\
1.0255 \\
1.0260 \\
1.0270 \\
1.0280 \\
1.0290\end{array}$ \\
\hline
\end{tabular}


The expansion of rich milk is greater than that of poor milk. Since temperature causes the specific gravity to vary, it should always be corrected accordingly. The usual temperature for the standard is $15^{\circ} \mathrm{C}$. or $60^{\circ} \mathrm{F}$.

The specific gravity increases immediately after milking for about twelve hours, due perhaps to the loss of air-bubbles, but also ascribed by Recknagel to the contraction of the casein. This phenomenon is spoken of as the Recknagel phenomenon. At low temperature this rise in specific gravity is greater than at high temperature. Richmond thinks the change is due to an increase in density caused by the contraction of the fat. Milk reaches the point of greatest density at a temperature slightly below the freezing-point of water and somewhat above the freezing-point of milk.

Freezing-point.-The freezing-point of milk is $0.54^{\circ}$ to $0.57^{\circ} \mathrm{C}$. lower than that of water. Variations from these figures due to difference in composition are slight. After acidity has developed the freezing-point is still lower.

It is possible to determine the addition of water to milk by finding out the freezing-point, although dilution with less than 10 per cent. cannot be detected with certainty. However, if salt solution (0.9 per cent.) is used for diluting, the freezing-point is not'affected, as salt solution of this strength has the same freezing-point as milk.

Sometimes variations in the freezing-point of milk from the same animal have been observed. Probably the food consumed contains a variable amount of mineral matter, which may have such an influence on the freezing-point. Boiled milk has a lower freezing-point than raw milk.

Electric Conductivity.-Milk, like other solutions containing salts, has electric conductivity showing the presence of ions. It has been thought that the degree of conductivity might serve as a measure of dilution with water, but this has been a disappointment because of the great variability of conductivity in different milks. No standard can be established in view of this variability. The conductivity varies in milk from different animals and changes with the progress of lactation. Creaming increases electric conductivity, while boiling reduces it. Udder diseases and souring of milk increase the conductivity.

Refractivity.--The refractive index of milk is usually determined in milk serum, prepared either by boiling the milk with acetic acid or precipitating the casein with a solution of calcium chlorid. The purpose of this is the detection of dilution with water. To obtain comparable results the serum must always be prepared according to the same method. Fluctuations of the re- 
fractive index in normal milk are small, but milk from diseased cows shows considerable variation. Usually the index of refraction of milk from diseased cows is smaller than that of normal milk.

Specific Heat.-The specific heat of milk, as determined by Fleischmann, is smaller than that of water-0.9457. Therefore, it takes less ice to cool milk or less heat to warm milk than to cool or heat an equal quantity of water. But since milk is a poorer conductor for heat than water, it takes a longer time to reach a certain temperature. The specific heat of cream is lower than that of milk.

The specific heat of milk has been exhaustively studied by Hammer and Johnson. These authors think that earlier observations were at fault in not paying attention to the temperature range over which the material is to be heated or cooled. They give the following average specific heats of whole milk and cream:

AVERAGE SPECIFIC HEATS

\begin{tabular}{|c|c|c|c|c|c|c|}
\hline & $0^{\circ}-15^{\circ}$ & $0^{\circ}-40^{\circ}$ & $0^{\circ}-60^{\circ}$ & $15^{\circ}-40^{\circ}$ & $40^{\circ}-60^{-}$ & $15^{\lrcorner}-$ưv \\
\hline Whole milk. & 0.929 & 0.940 & 0.935 & 0.947 & 0.923 & 0.937 \\
\hline 15 per cent. cream... & 0.837 & 0.900 & 0.889 & 0.940 & 0.899 & 0.925 \\
\hline 20 per cent. cream. . . . . . & 0.831 & 0.894 & 0.890 & 0.936 & 0.881 & 0.916 \\
\hline 30 per cent. cream. . & 0.830 & 0.883 & 0.875 & 0.925 & 0.854 & 0.899 \\
\hline 45 per cent. cream..... & 0.832 & 0.866 & 0.843 & 0.901 & 0.786 & 0.858 \\
\hline 60 per cent. cream . . . . . . . . . . . & 0.843 & 0.851 & 0.816 & 0.876 & 0.727 & 0.821 \\
\hline
\end{tabular}

Bowen has determined the specific heat of a sample of milk and of 20 and 40 per cent. cream. The composition of the samples was:

COMPOSITION OF MILK AND CREAM USED FOR DETERMINATION OF SPECIFIC HEAT

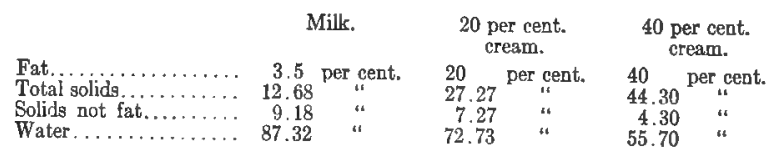

The specific heat of these samples is given in the following table and Fig. 24.

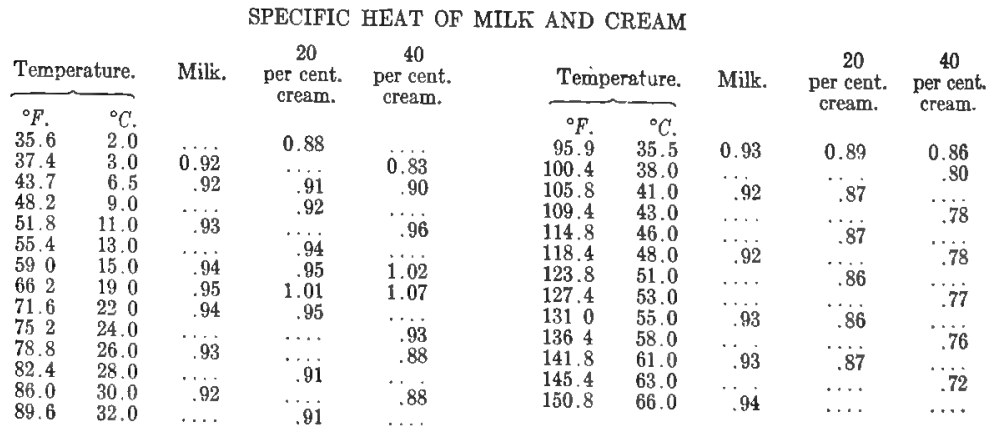




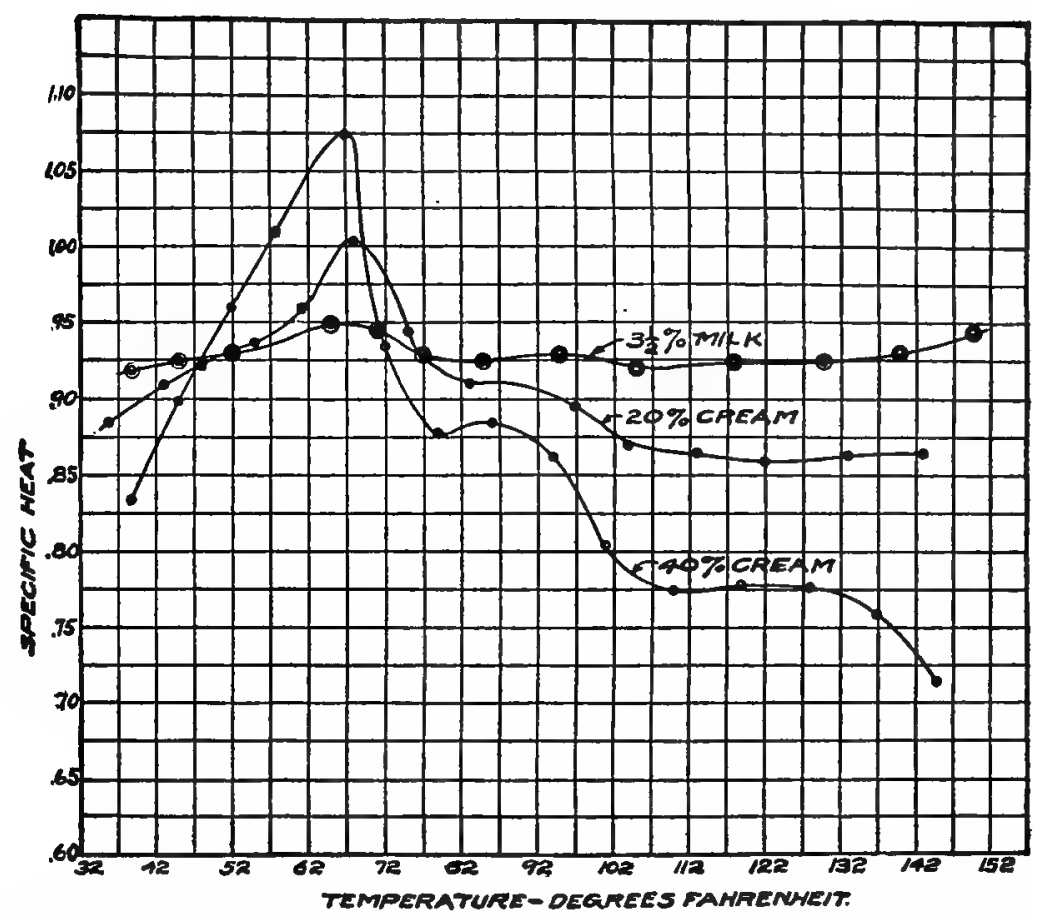

Fig. 24.-Curves showing the specific heat of milk and 20 and 40 per cent. cream at different temperatures.

\section{BIBLIOGRAPHY}

Babcock: Univ. of Wis. Agri. Exp. Sta., Bull. 18.

Bitting: U. S. Dept. of Agri., 19th Annual Report of the B. A. I., 1902.

Bowen: U. S. Dept. of Agri., Bull. 98, August 14, 1914.

Ernst: Milchhygiene für Thierärzte.

Fischer and Hooker: Science, 1916, vol. 43, p. 468.

Fleischmann: Jour. f. Landw., 1902, 50, 33, quoted from Hygienı Bull. 56.

Hammer and Johnson: Agri. Exp. Sta. Iowa State Coll. of Agri. and Mech. Arts, Research Bull. 14, October, 1913.

Koeppe: In Sommerfeld's Handbuch der Milchkunde.

Lloyd: Jour. of Bath and West of England Soc., 1902, vol. 12, p. 129. Quoted from Swithinbank and Newman, the Bacteriology of Milk, New York, E. P. Dutton and Co., 1903.

Mathews: Physiological Chemistry, New York, William Wood \& Co.

McKay and Larsen: Principles and Practices of Butter Making.

Palmer and Eckles: Univ. of Missouri Agri. Exp. Sta., Research Bull. 10.

Wing: Milk and its Products. 


\section{GENERAL CHEMISTRY OF MILK}

MiLK is composed of simple and complex substances which are so balanced as to meet the requirements of young mammals. The milk of different species of mammals varies greatly in composition, as shown in the following table (compiled from various sources):

\begin{tabular}{|c|c|c|c|c|c|c|c|c|c|}
\hline Animal. & $\begin{array}{l}\text { Specific } \\
\text { gravity. }\end{array}$ & Water. & Cascis. & Albumin. & $\begin{array}{c}\text { Total } \\
\text { proteins. }\end{array}$ & Fat. & Sugar. & Ash. & $\begin{array}{l}\text { Total } \\
\text { solids. }\end{array}$ \\
\hline Man. . & 1.0298 & 87.58 & 0.80 & $\begin{array}{l}1.21 \\
0.51\end{array}$ & $\begin{array}{l}2.01 \\
3.39\end{array}$ & $\begin{array}{l}3.74 \\
3.68\end{array}$ & $\begin{array}{l}6.37 \\
4.94\end{array}$ & $\begin{array}{l}0.30 \\
0.72\end{array}$ & $\begin{array}{l}12.42 \\
12.73\end{array}$ \\
\hline $\begin{array}{l}\text { Cow .......... } \\
\text { Cow colcstrum. }\end{array}$ & 1.0313 & $\begin{array}{l}87.27 \\
75.07\end{array}$ & $\begin{array}{l}2.88 \\
4.19\end{array}$ & $\begin{array}{r}0.51 \\
12.99\end{array}$ & $\begin{array}{r}5.59 \\
17.18\end{array}$ & $\begin{array}{l}0.00 \\
3.97\end{array}$ & 2.28 & 1.53 & 24.93 \\
\hline $\begin{array}{l}\text { Cow colcstrum }, \ldots \\
\text { Ass........... }\end{array}$ & $\begin{array}{l}1.042 \\
1.032\end{array}$ & 90.12 & 0.79 & 1.06 & 1.85 & 1.37 & 6.19 & .47 & 9.88 \\
\hline $\begin{array}{l}\text { Ass............................. } \\
\text { Sheep..... }\end{array}$ & $\begin{array}{l}1.032 \\
1.0355\end{array}$ & 83.57 & 4.17 & 0.98 & 5.15 & 6.1 & 4.17 & 0.93 & 16.43 \\
\hline Goat. . & 1.0305 & 86.88 & 2.87 & 0.89 & 3.76 & 4.0 & 4.64 & 0.85 & 13.12 \\
\hline & 1.0347 & 90. & 1.30 & 0.75 & 2.05 & 1.1 & 5.87 & 0.36 & 9.42 \\
\hline Reindeer. & & 67.00 & 8.30 & 1.50 & 9.80 & 17.0 & 2.80 & 1.50 & 33.00 \\
\hline Rabbit. & 1.047 & 69.5 & $\cdots$ & $\ldots$ & 12.00 & 13.5 & 2.00 & 2.50 & 30.50 \\
\hline Dolph & & 41.00 & $\ldots$ & $\ldots$ & 11.00 & 46.0 & 1.30 & 0.60 & 59.00 \\
\hline Sow. & 1.038 & 83.94 & 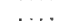 & $\ldots$ & 7.23 & 4.5 & 3.23 & 1.05 & 16.06 \\
\hline teh. & 1.035 & 75.44 & 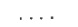 & $\ldots$ & 11.17 & 9.5 & 3.09 & 0.73 & 24.56 \\
\hline Elephant... & 1.0313 & 79.30 & $\ldots$ & $\ldots$ & 2.51 & 9.1 & 8.59 & 0.50 & 20.70 \\
\hline Came & 1.042 & 86.5 & & $\ldots$ & 4.00 & 3.0 & 5.59 & 0.77 & 13.43 \\
\hline Llame & 1.034 & 80 & & $\ldots$ & 3. & 3.1 & 5.60 & 0.80 & 13.45 \\
\hline Buffalo. & 1.035 & 82.25 & & $\ldots$ & 5.05 & 7.51 & 4.44 & 0.75 & 17.75 \\
\hline
\end{tabular}

There are distinct groups of compounds which are contained in all milks, although in different proportion. These groups are:

1. Fat.

2. Proteins.

3. Carbohydrate.

4. Salts.

5. Water.

In addition, there are other substances present in small amounts, namely: lecithin, nitrogen-containing extractives, cholesterin, lactosen (a carbohydrate), orotic acid, a pigment, citric acid, a mucin (lactomucin), gases, and besides these chemical compounds, enzyms, and antibodies. The milk enzyms are either products of the milk glands or of bacteria which are always present in the udder. The antibodies are transmitted from the maternal system to the young through milk.

Some chemical compounds have frequently been isolated from milk, such as amino-acids, ammonia, hydrogen sulphid, marshgas, and others, but it is doubtful whether these are normal constituents of milk, or whether they are formed by microbial action 
on the proteins and carbohydrates. Possibly amino-acids are also bacterial decomposition products. Milk direct from the glands - that is to say, milk which has not come in contact with microorganisms-is difficult to obtain in sufficient quantity for satisfactory chemical analyses. Consequently, such analyses have rarely been made, and it may never be known exactly just what the original mammary secretion is composed of.

Sometimes the mammary glands permit soluble chemicals or volatile substances, derived from odoriferous food, to pass. into the milk. Chemicals given for therapeutic purposes have been recovered in the milk and aromatic substances derived from the food have imparted their flavor and odor to the milk. The taste of silage is said to be communicated to milk when given shortly before milking. However, observations on these points are not always above criticism. Milk, especially fresh warm milk, rapidly absorbs odors from the air, and the presence of odoriferous food in the stable may impart its peculiar flavor to the milk. Furthermore, it has been shown that there are bacteria able to produce odors closely resembling those of aromatic foods. Therefore caution should be used in accepting statements in regard to the transmission of aromatic substances through the mammary glands.

Milk-fat, as has been stated, is in the form of an emulsion; some of the proteins-namely, casein, globulin, and mucin-are in colloidal solution; the other constituents are in true solution. When the fat is removed there remains a fluid containing the proteins, sugar, salts, and water. This fluid is known as milk plasma. When both fat and casein are removed a straw-colored fluid remains which contains all the soluble constituents. This is the milk-serum or whey.

The most important proteins are casein and lactalbumin. Besides these there is a globulin and traces of other proteins, which, however, may be decomposition products of the original milk proteins, or the results of reactions caused by reagents used for analysis. There is but one carbohydrate in milk, namely, milk-sugar or lactose. The statement is sometimes made that traces of dextrose are also present, but this is not reliable, as will be shown later. The fat is composed of a large number of nonvolatile and volatile fatty acids combined with glycerin. The mineral matter contains the elements of which the salts in milk are composed. The gases are $\mathrm{CO}_{2}, \mathrm{~N}$, and $\mathrm{O}$. The following analyses of cow's milk are given by Kastle in Bulletin 56 of the Hygienic Laboratory: 
ANALYSES OF COW'S MILK

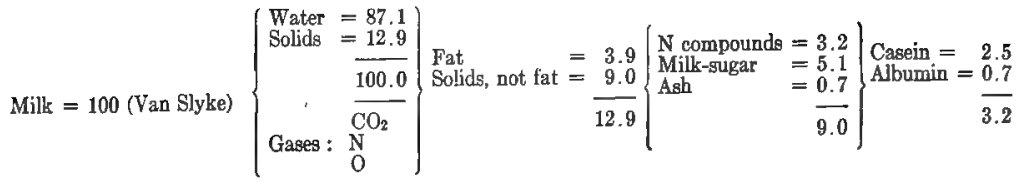

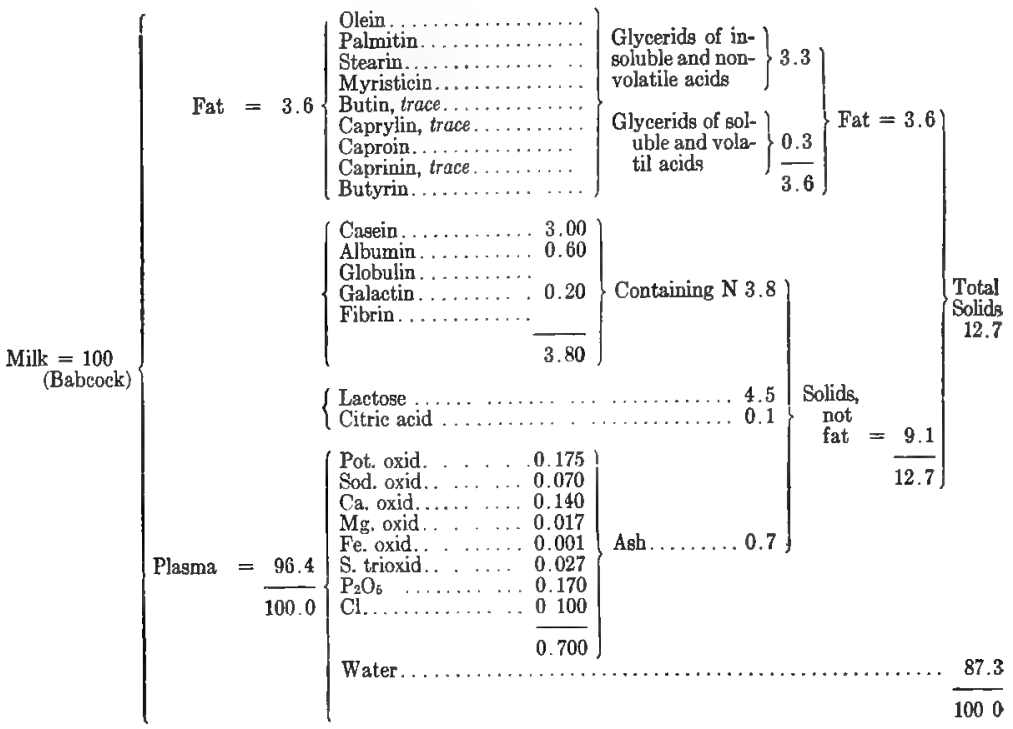

It is not possible, of course, to give an absolute standard composition of milk since the constituents vary in different breeds, at different periods of lactation, and in individual animals. Even the morning and evening milks are not always alike. The fat is the most variable factor, but the other solids vary also, although to a lesser degree. The following table gives analyses by several analysts:

ANALYSES OF COW'S MILK BY DIFFERENT ANALYSTS

\begin{tabular}{|c|c|c|c|c|c|c|c|}
\hline & Van Slyke & Babcock. & Richmond. & Oliver. & Fleischmann. & Willoughby. & $\begin{array}{c}\text { Van Slyke } \\
\text { (eheese } \\
\text { factory } \\
\text { mill). }\end{array}$ \\
\hline Water....... & 87.1 & 87.3 & 87.1 & 87.6 & 87.75 & 87.0 & 87.1 \\
\hline Fat....... & 3.9 & 3.6 & 3.9 & 3.25 & 3.40 & 3.8 & 3.75 \\
\hline Casein........ & 2.5 & 3.0 & 3.0 & 3.40 & 2.80 & 3.3 & 2.45 \\
\hline Albumin.... & 0.7 & 06 & 0.4 & 0.45 & 0.70 & 0.4 & 0.7 \\
\hline Total protein. & 3.2 & 38 & 3.4 & 3.85 & 3.50 & 3.7 & 3.15 \\
\hline Lactose....... & 5.1 & 4.5 & 4.75 & 4.55 & 4.60 & 48 & 50 \\
\hline Ash......... & 0.7 & 0.7 & 0.75 & 0.75 & 0.75 & 0.7 & 0.7 \\
\hline Total solids. & 12.9 & 12.7 & 12.9 & 12.4 & 12.25 & 13.0 & 12.6 \\
\hline
\end{tabular}

Colostrum differs materially from normal milk, especially in the percentage of albumin, which is greater than in normal milk, 
often more than 16 per cent. Perhaps the colostrum corpuscles are responsible in part for the large amount of albumin. The percentage of fat, casein, and milk-sugar are lower in colostrum, while that of ash is higher than in normal milk; the ash may be twice as high. The quantity of fat in colostrum is small, the normal emulsion is not properly developed, and the globules are large and irregular. The total solids of colostrum may be as high as 28 per cent. Colostrum has a strong odor, a bitter taste, and is more decidedly yellow than normal milk. It has an acid reaction and thickens when boiled because the albumin coagulates. The gradual transition of colostrum to normal milk is well illustrated in a table given by Leach:

THE COMPOSITION OF COLOSTRUM AND TRANSITION TO NORMAL MILK

\begin{tabular}{|c|c|c|c|c|c|c|c|}
\hline $\begin{array}{l}\text { Time after calving. } \\
\text { Immediately }\end{array}$ & $\begin{array}{l}\text { Specific } \\
\text { gravity. }\end{array}$ & Fat. & Casein. & Albumin. & Lactose. & Agh. & $\begin{array}{l}\text { Total } \\
\text { solida. }\end{array}$ \\
\hline Immediately.... & 1.068 & 3.54 & 2.65 & 16.56 & 3.00 & 1.18 & 26.93 \\
\hline After 10 hours. . . . . . . . . . & 1.046 & 4.66 & 4.28 & 9.32 & 1.42 & 1.55 & 21.23 \\
\hline After 24 hours. . . . . . . . . . & 1.043 & 4.75 & 4.50 & 6.25 & 2.85 & 1.02 & 19.37 \\
\hline After 48 hours..... $\ldots \ldots \ldots$. & 1.042 & 421 & 3.25 & 2.31 & 3.46 & 0.96 & 14.10 \\
\hline After 72 bours. . . . . . . . . . & 1.035 & 408 & 3.33 & 1.03 & 4.10 & 0.82 & 13.5 \\
\hline
\end{tabular}

Removal of cream disturbs the normal relation of milk constituents to a considerable degree. The total solids in cream are much greater; in skimmed milk smaller than in whole milk, owing to the increased fat content in cream and the diminished fat content in skimmed milk. The water is naturally present in greater percentage in skimmed milk than in whole milk, and greater in whole milk than in cream. The relation of the soluble substances is not greatly changed by skimming.

The composition of two samples of cream, one with a moderate amount of fat, the other rich in fat, is given by Richmond as follows:

\section{COMPOSITION OF CREAM}

\begin{tabular}{|c|c|c|}
\hline & $\begin{array}{l}\text { Thick cream. } \\
39.37 \text { per cent. }\end{array}$ & $\begin{array}{l}\text { Thin cream. } \\
63.94 \text { per cent. }\end{array}$ \\
\hline & 56.09 & 29.29 " \\
\hline Sug & 2.29 & 3.47 \\
\hline & 1.57 & 2.76 \\
\hline & 0.38 & 0.54 \\
\hline
\end{tabular}

Contrary to earlier beliefs are the results of the analyses made by Richmond, who has shown that the relation of plasma solids to water in cream is the same as in milk. Errors in analysis are liable to occur if the cream has lost water by evaporation. This occurs when gravity cream is exposed to the air for some time. The percentage of plasma solids to the volume of cream decreases in proportion to the increase in the percentage of fat. This is illustrated in the following table, given by Richmond: 


\begin{tabular}{|c|c|c|c|}
\hline \multicolumn{4}{|c|}{ COMPOSITION OF CREAM } \\
\hline No. & $\begin{array}{l}\text { Total } \\
\text { solids. }\end{array}$ & $\begin{array}{l}\text { Plasma } \\
\text { solids. }\end{array}$ & Fat. \\
\hline 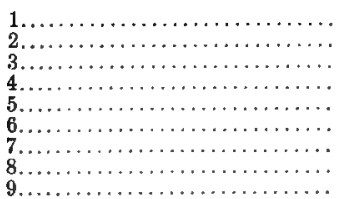 & $\begin{array}{l}32.50 \\
37.50 \\
50.92 \\
55.05 \\
55.18 \\
55.97 \\
56.37 \\
57.99 \\
68.18\end{array}$ & $\begin{array}{l}6.83 \\
6.14 \\
5.02 \\
4.65 \\
4.77 \\
4.47 \\
4.40 \\
4.17 \\
3.30\end{array}$ & $\begin{array}{l}25.67 \\
31.36 \\
45.90 \\
50.40 \\
50.41 \\
51.50 \\
51.97 \\
53.82 \\
64.88\end{array}$ \\
\hline
\end{tabular}

When casein is coagulated the curd encloses most of the fat mechanically. Only 1 per cent. fat, or less, remains in the whey. The solids of whey are, therefore, smaller than in whole or skimmed milk. The milk-sugar and the salts remain in the whey without material change, the milk-sugar suffering a small loss by acid formation.

The following tables show the composition of whey and the relation of milk, whey, and curd (after Richmond):

\begin{tabular}{|c|c|c|c|c|c|c|}
\hline & & & OSITION & WHEY & & \\
\hline $\begin{array}{l}\text { Water.... } \\
\text { Fat....... } \\
\text { Milk-gugar. } \\
\text { Protein... } \\
\text { Ash...... }\end{array}$ & 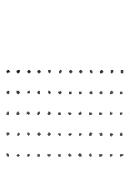 & $\begin{array}{c}\text { Fleischmann. } \\
\begin{array}{c}93.15 \\
0.35 \\
4.90 \\
1.00 \\
0.60\end{array}\end{array}$ & $\begin{array}{c}\text { König. } \\
93.38 \\
0.32 \\
4.79 \\
0.86 \\
0.65\end{array}$ & $\begin{array}{c}\text { Smetham. } \\
93.33 \\
0.24 \\
5.06 \\
0.88 \\
0.49\end{array}$ & $\begin{array}{r}\text { Vieth } \\
\text { skimm } \\
93 \\
0 \\
5 \\
0 \\
0\end{array}$ & ik). \\
\hline & & OMPOSITIOI & MILK, & IEY, AND & CURD & \\
\hline & $\begin{array}{l}\text { Water . . . . . } \\
\text { Fat....... } \\
\text { Milk-sugar. } \\
\text { Casein ..... } \\
\text { Albumin.... } \\
\text { Ash....... }\end{array}$ & 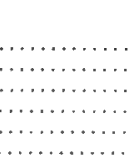 & 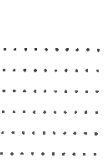 & $\begin{array}{r}\text { Milk. } \\
87.30 \\
3.75 \\
4.70 \\
3.00 \\
0.40 \\
0.75\end{array}$ & $\begin{array}{r}\text { Whey. } \\
80.80 \\
0.30 \\
4.40 \\
0.40 \\
0.40 \\
0.60\end{array}$ & $\begin{array}{l}\text { Curd. } \\
6.50 \\
3.45 \\
0.30 \\
2.60 \\
\text { trace } \\
0.15\end{array}$ \\
\hline
\end{tabular}

Buttermilk is usually made from skimmed milk and resembles it in composition. The most important difference is the presence of acid, chiefly lactic acid, in buttermilk. König gives the following analyses of milk, skimmed milk, cream, buttermilk, and whey:

THE COMPOSITION OF MILK, SKIMMED MILK, CREAM, BUTTERMILK, AND WHEY

\begin{tabular}{|c|c|c|c|c|c|}
\hline Constituents. & Milk. & $\begin{array}{l}\text { Skimmed } \\
\text { milk. }\end{array}$ & Cream. & $\begin{array}{l}\text { Butter- } \\
\text { milk. }\end{array}$ & Whey. \\
\hline $\begin{array}{l}\text { Water } \\
\text { Total solids. } \ldots \ldots \ldots \ldots \ldots \ldots \ldots \ldots \ldots \ldots \ldots \ldots\end{array}$ & & $\begin{array}{r}90.66 \\
9.34\end{array}$ & $\begin{array}{l}65.51 \\
34.49\end{array}$ & $\begin{array}{r}90.27 \\
9.37\end{array}$ & $\begin{array}{r}93.24 \\
6.76\end{array}$ \\
\hline 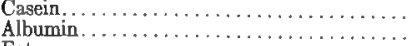 & $\left.\begin{array}{l}3.02 \\
0.53\end{array}\right\}$ & 3.11 & 3.61 & 4.06 & 0.85 \\
\hline 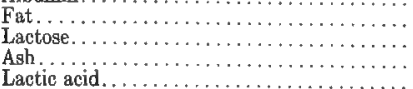 & $\begin{array}{l}0.007 \\
3.69 \\
4.88 \\
0.71\end{array}$ & $\begin{array}{l}0.74 \\
4.75 \\
0.74\end{array}$ & $\begin{array}{r}26.75 \\
3.52 \\
0.61\end{array}$ & $\begin{array}{l}0.93 \\
3.73 \\
0.67\end{array}$ & $\begin{array}{l}0.23 \\
4.77 \\
0.65\end{array}$ \\
\hline
\end{tabular}

The composition of buttermilk made from sour cream, sweet cream, milk, and separated milk averages about as follows (Richmond): 


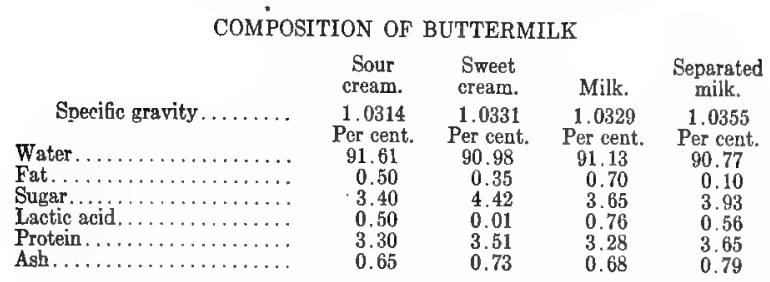

\section{The Physiologic Origin of Milk Constituents}

Casein, fat, and lactose are substances characteristic of milk, inasmuch as they do not occur in any other place. Their origin, therefore, must be sought in the tissue of the maternal system or in the mammary glands. Considerable study has been made of this subject, the results of which are briefly summarized in the following.

Casein, Lactalbumin, and Globulin.-Casein occurs exclusively in the mammary secretions of mammals. In small quantity it has been found in the tallow glands of animals and in some rump oil glands of birds. The body of the lactating mammal contains no casein except in the mammary glands. Two hypotheses have been developed to account for the appearance of casein in milk, namely, the enzymic theory, which assumes that blood proteins are transformed into casein by a special enzym, characteristic of the milk gland, and the pairing theory, according to. which blood proteins combine with substances derived from the milk glands.

Enzym Theory.-This theory originated before it was known that casein was a phosphoprotein. Without this knowledge it was not possible to arrive at conclusions which could stand the test of later experiments. Later Hammarsten (1894) ascribed the origin of both casein and milk-sugar to a protein "nucleoglycoprotein" which he isolated from milk glands. According to this idea, casein and milk-sugar are formed by breaking down of this complex protein which is then regenerated by the milk glands. Hildebrand in 1904 observed that even after autolysis of a cow's udder there was no casein formation from the substance of the milk glands. He thought that a ferment was active in the formation of casein from gland cells and blood albumin. The blood proteins are supposed to break down into simple compounds, building stones, which are then synthesized into casein.

Pairing Theory.-Basch in 1889 considered the nucleic acid of the milk glands to be the mother substance of casein. He thought that nucleic acid combined with serum albumin in the alvecli of the milk glands forming casein. However, chemists soon showed that casein does not yield the decomposition products which are 
characteristic of nucleic acid and that Basch's theory could not hold.

It is difficult to form an opinion of the correctness or fallaciousness of either of these hypotheses. The difficulties that are met with in investigations of this character are obvious, and for the present it is necessary to confess ignorance. The same difficulty holds in regard to knowing with certainty the origin of lactalbumin and lactoglobulins.

Milk-fat.-It was formerly believed that milk-fat was the result of fatty degeneration of proteins, and that upon standing the quantity of milk-fat would increase at the expense of casein, but many observations have shown clearly that the composition of milk-fat is influenced by the fat in food. This fact has led to the belief that fat from food passes directly into the milk. However, this is not a necessary conclusion, because fat may be assimilated as body fat and then reach the milk glands as such, or it may be broken down into building stones and then synthesized by the milk glands into milk-fat. In either case the resulting milk-fat would be dependent, in a measure at least, upon the original fat taken from the food and would have a similar composition. That such is the case is shown by comparison of the iodin number of body fat, colostrum fat-which is formed during a transition period-and genuine milk-fat. The following table given by Engel, and taken from Sommerfeld's Handbuch, illustrates the point:

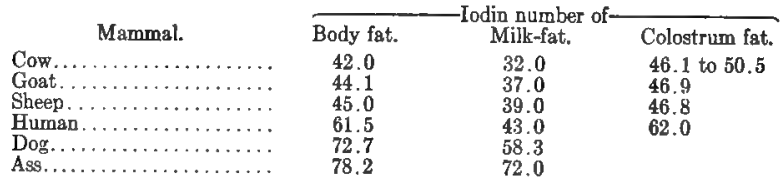

This table shows that while there is some difference between the iodin numbers of body fat and colostrum, which might be expected, there is a much greater difference between body fat and milk-fat. If the theory is correct that colostrum is a transition product between body fluids and milk, it would follow naturally that the fat of colostrum would also be a transition product. Extensive investigations by Engel (quoted from Pfaundler in Sommerfeld's Handbuch) have led to the conclusion that milk-fat is not identical with body fat, but that, since the iodin numbers of milk-fat and body fat are approximately proportionate, there must be a dominating influence of body fat upon milk-fat. Milkfat therefore is dependent upon body fat, but is not identical with it. Consequently, body fat is either not the exclusive source of milk-fat, or the milk glands transform the body fat into milk-fat. 
Colostrum fat, however, is nearly identical with body fat, so that in early milk secretion the formation of milk-fat depends upon body fat, while later fat formation is influenced also by the character of the food. The composition of milk-fat may fluctuate, therefore, according to which one of the two sources is predominant. However, the influence of the source of milk-fat is limited, since it is known that each species of mammal produces milk-fat of characteristic composition, so we must assume that there is a standard composition of fat derived from the milk of a certain species. This standard is variable only within narrow limits.

The source of mill-fat has been investigated by Jordan and Jenter in a carefully controlled experiment. Recognizing that many previous experiments did not cover a sufficiently long period of time, these authors fed a cow for ninety-five days on a ration from which the fat was nearly all extracted. The cow "continued to secrete milk similar to that produced when fed on the same kind of hay and grain in their normal condition. The yield of milk-fat during the ninety-five days was 62.9 pounds. The food fat eaten during this time was 11.6 pounds, only 5.7 pounds of which was digested. Consequently at least 57.2 pounds of milk-fat must have had some source other than the food fat. The milk-fat could not have come from previously stored hody fat, because, 1, The cow's body could have contained scarcely more than 60 pounds of fat at the beginning of the experiment; 2 , she gained 47 pounds in body weight during this period of time with no increase of body nitrogen, and was judged to be a much fatter cow at the end; 3 , the formation of this quantity of milkfat from the body fat would have caused a marked condition of emaciation which, because of an increase in the body weight, would have required the improbable increase in the body of 104 pounds of water and intestinal contents. During fifty-nine consecutive days 38.8 pounds of milk-fat were secreted and the urine nitrogen was equivalent to 33.3 pounds of protein. According to any accepted method of interpretation not over 17 pounds of fat could have been produced from this amount of metabolized protein. The quantity of milk solids secreted bore a definite relation neither to the digestible protein eaten nor to the extent of the protein metabolism. In view of these facts it is suggested that the well-known effect upon milk secretion of a narrow nutritive ratio is due in part to a stimulative, and not wholly to a constructive, function of the protein." The authors also state that "the composition of the milk bore no definite relation to the amount and kind of food," and that "the changes in the proportion of milk solids was due almost wholly to changes in the percentage of fat." 
The results of Jordan and Jenter's experiment appear to demonstrate that food fats bear no necessary relation to formation of milk-fat. Protein metabolism can account only for part of the fat secreted in the milk, and some of the fat must have been derived from carbohydrates.

The assumption appears to be justified that milk-fat is derived from four sources, namely, food-fat, body fat, protein, and carbohydrate. It is the function of the milk glands to transform these substances into milk-fat, and they produce a fat which varies but little from a standard suitable for the food of a certain species. It is true that the chemical composition of milk-fat in the same kind of milk varies within limits, according to the kind of fat contained in the food consumed. However, such variations are not permanent, and after a short period the normal constitution of the fat is restored, even when a particular fat is eaten with the food for a long time.

Milk-sugar occurs naturally only in milk and in the urine of mammals at the commencement and after the close of lactation. If the mammary gland is extirpated, milk-sugar disappears from the urine, which fact leads to the conclusion that the milk glands are the exclusive sources of milk-sugar.

At present the most generally accepted view is that milksugar is derived from dextrose in the circulation. Specific action of the milk glands transforms dextrose into lactose. When the mammary glands are extirpated dextrose appears in the urine, but if they are not completely removed lactose appears in the urine. Furthermore, injection of dextrose into lactating animals leads to the appearance of lactose in the urine. There can, therefore, be no doubt about the origin of lactose from dextrose, the latter being transformed into the former in the milk glands.

Mineral Constituents.-Fleischmann thinks that the origin of the salts in milk must be looked for in the mammary glands. The composition of milk ash differs from that of the blood and lymph of the cow, and therefore it cannot be assumed that mineral matter passes unaltered through the mammary gland. Feeding of phosphates has not been known to increase the phosphorus content of milk. The water in milk probably comes directly from the blood and lymph, and carries with it in solution some mineral matter and also some organic substances, such as urea and hypoxanthin.

\section{The Chemistry of Butter-fat}

Milk-fat is a compound of triglycerids, cholesterin, and a pigment. It is not a simple mixture of triglycerids; it is rather a chemical compound-a fact which can be proved by several 
observations. When butter is heated it melts almost uniformly, but if it were a simple mixture the glycerids of low melting-point would liquefy before the others. Tributyrin is contained in butter-fat in quantities of 1.5 to 5 per cent., averaging, according to Richmond, 3.85 per cent. Being soluble in water, tributyrin would impart its characteristic bitter taste to the milk and milkfat, while, as a matter of fact, there is normally no bitter taste in either. Furthermore, when tributyrin is mixed with butter it can be extracted with alcohol, while pure milk-fat does not yield butyrin to alcohol. Although milk-fat contains small amounts of glycerids of volatile acids, there is no distillate if it is heated to $275^{\circ} \mathrm{C}$. Volatile acids, therefore, must be present in combined form, so that they are not liberated by heating to $275^{\circ} \mathrm{C}$. Finally, an artificial mixture of the glycerids which have been isolated from milk-fat has a higher melting-point than the natural product. Butter cannot be reproduced by a mixture of its chemical compounds. Moreover, the molecular weight of such a mixture is 779.6 , against 760.3 of butter-fat.

It must be admitted, however, that the facts cited do not prove that milk-fat is necessarily a single compound. They prove only that the component parts are of complex nature. This possibility is supported by the fact that melted butter does not solidify uniformly, although this might also be explained by decomposition due to heating.

We frequently read of volatile and non-volatile fats as constituents of butter-fat. This is not strictly correct, of course. There are fats which are glycerids of volatile acids and fats which are glycerids of non-volatile acids. The volatile acids can be distilled with steam at normal atmospheric pressure and are more or less soluble in hot water. Acids with high molecular weight are less soluble in hot water than those with low molceular weight.

The glycerids of volatile fatty acids constitute 17.3 per cent. of milk-fat, according to Richmond; 8.5 per cent. according to Van Slyke, while the glycerids of non-volatile acids make up the balance of 82.7 or 91.5 per cent. The quantities of the different glycerids are given by Richmond as follows:

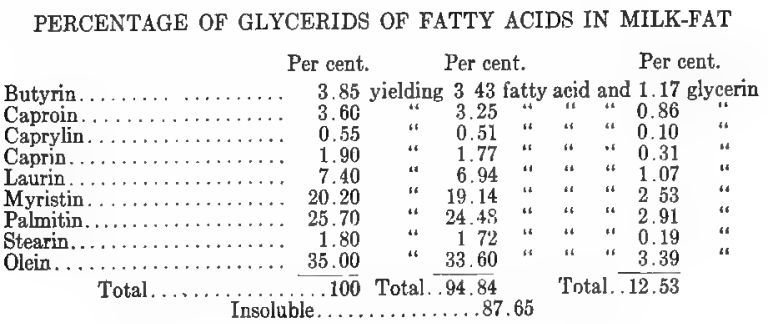


Of these compounds, butyrin, caproin, caprylin, caprin, and laurin are glycerids of volatile acids, while myristicin, palmitin, stearin, and olein are glycerids of non-volatile acids. Butyrin is present in larger amount than the glycerids and other volatile acids. It decomposes readily and forms butyric acid, which renders the fat rancid.

The volatile acids are largely responsible for the odor and flavor of milk and butter. They are present in milk-fat throughout the year in nearly the same quantity. The amount is somewhat greater in spring and summer, when cows feed on fresh fodder, than during the balance of the year, when the animals receive chiefly dry food. Volatile acids diminish during the progress of the lactation period.

The glycerids of non-volatile acids are chiefly oleic, palmitic, stearic, and myristic acids. The consistency of butter-fat depends largely upon the relative quantities of non-volatile acids. The melting-point of palmitin is $61^{\circ} \mathrm{C}$; of olein, $5^{\circ} \mathrm{C}$.; of myristicin, $54^{\circ} \mathrm{C}$; and of stearin, $65.5^{\circ} \mathrm{C}$. The largest amount of these is represented by olein, and consequently the variability of this compound has the greatest influence upon the consistency of milkfat. During the spring and early summer more olein is taken up from the green fodder than from the food consumed during the winter months, and consequently the fat is harder in winter than in spring and summer.

The chemical composition of large and small fat globules has been investigated by Klusemann, Gutzeit, and Lemus. The results of these authors are not in harmony, perhaps because it is difficult to separate globules of different sizes. Shaw and Eckles separated cream with a predominance of large globules from cream with a predominance of small ones by means of a hand separator, and further eliminated small globules from the first cream by allowing the fat to rise in a narrow, tall vessel. Chemical examination of the globules obtained showed differences so slight that they easily ranged within experimental error. Therefore it seems justifiable to assume that the composition of fat in globules is uniform, no matter what their size.

The melting-point of butter-fat is given by various authorities within the limits of $29.5^{\circ}$ and $36^{\circ} \mathrm{C}$. Butter-fat is liquid while the milk is in the cow's udder, therefore, since the body temperature of the cow is $38.5^{\circ}$ to $39^{\circ} \mathrm{C}$. While emulsified in milk, butterfat begins to solidify at about $25^{\circ} \mathrm{C}$; ; sometimes it is liquid at even lower temperature, depending upon its composition.

Milk-fat is insoluble in water, but it dissolves 0.2 per cent. water by heating to $100^{\circ} \mathrm{C}$. Milk-fat is soluble in ether, carbon disulphid, nitrobenzene, and acetone. It is slightly soluble in 
ethyl alcohol and amyl alcohol, but completely soluble in hot amyl Ellcohol.

Milk-fat is very susceptible to absorption of volatile substances. Undesirable flavors derived from fodder are, therefore, readily imparted to milk and butter. However, volatile substances are promptly carried off by the intestinal tract of the animal and do not appear in the milk if milking is done several hours after odoriferous food has been eaten. Therefore, if such food is given immediately before or after milking the milk is not liable to suffer. Even a strong flavor like that of onion will not be noticeable unless it is derived from wild onions or leeks on the pasture where cows graze for many hours during the day.

Desirable flavors may be communicated to milk in the same way. Clover hay, bran, and good pasture grass are known to improve the flavor of milk and butter.

The proportion of fatty acids in milk varies within limits according to the food taken, as has been pointed out. Sometimes fats are added to milk or butter with fraudulent intent. The separation of the different acids for detection of fraud is a difficult matter, and chemical tests for purity of butter-fat must, therefore, depend on reactions of butter-fat as a whole. With increasing quantities of low fatty acids the molecular weight and the melting-point decrease, while the saponification number, the Reichert-Meissl number, electric conductivity, and specific gravity increase. With increasing quantities of unsaturated fatty acids and cholesterin the iodin number and refraction number increase, while the melting-point decreases with increasing amount of oleic acid. The soluble and volatile acids are measured with Polenske's number and the non-volatile acids with Hehner's number.

\section{The Decomposition of Milk-fat}

Milk-fat is decomposed under the influence of light, oxygen, and some kinds of micro-organisms, and then acquires a disagreeable "rancid" taste and odor. The chemical processes which lead to a rancid condition of fat are hydrolysis and oxidation. Hydrolysis produces fatty acids and glycerin, and the glycerin is then further decomposed into water-soluble acids, aldehyds, and volatile fatty acids. Unsaturated fatty acids are oxidized to hydroxyacids which are not volatile.

Richmond gives the following reactions which result in the rancidity of butter-fat.

1. The glycerin is diminished on saponification.

2. Soluble and volatile acids are increased.

3. Free acids are greatly increased. 
4. Unsaturated acids are diminished by the formation of hydroxyacids.

The results of rancidity in milk are somewhat different from those in butter, inasmuch as the milk contains a larger amount of water than butter, and soluble products are dissolved. In contact with the air some volatile products escape.

The consistency of the fat changes when it becomes rancid. The texture is more like tallow and the taste is bitter.

The exact chemical processes which occur when fat becomes rancid are not thoroughly understood and probably are not always the same.

\section{The Chemistry of Casein}

Casein is not a clearly defined chemical substance, but probably consists of several compounds. It is a weak acid and occurs in milk in combination with calcium as calcium caseinate, and perhaps contains some calcium phosphate. Casein is an important constituent of all kinds of milk, but, although casein from different sources has important properties in common, there are also material differences. Therefore it would be more proper to speak of "caseins" rather than of "casein" as a substance of uniform composition. The complex constitution of casein is illustrated when milk is passing through a porous filter. Citrates and chlorids are removed by a filter and casein is split so that part of it passes into the filtrate as a soluble protein. The whey, therefore, contains more soluble protein than the milk. Furthermore, precipitation by salts used for protein precipitation gives results which are similar to those obtained when the proteins of blood-serum are precipitated. That is to say, the precipitated proteins vary according to the kind of salt employed and according to the concentration of the solution.

Casein obtained from the milk of one species has a fairly definite composition, but the caseins from different animals are not identical.

Casein occurs in milk in a colloidal condition. This is proved by the following facts: The colloidal particles have been clearly seen under the ultramicroscope. Furthermore, casein is thrown into the bowl sediment in centrifugal machines, so that after several hours of centrifugation nearly all the casein can be removed. Finally, casein is withheld by porcelain filters.

Halliburton suggested the name caseinogen for casein as it occurs in milk, and casein after it has been precipitated. The term "caseinogen" is not generally accepted; instead, casein is used to designate casein as it exists in milk, and paracasein the precipitate which is formed by rennet coagulation. 
Casein is precipitated by dilute acids. When small quantities of acid are used the precipitate is fine and flaky, while sufficiently large amounts of acid produce a more or less compact curd. Usually this phenomenon is explained by the combination of acid with the calcium which takes place, forming salts, thus rendering the casein insoluble. The process, however, is probably not so simple.

In the ordinary souring of milk the acid is chiefly lactic acid and is produced by bacterial action. This acid causes precipitation of the casein; a coagulum or curd is formed. The process takes place in two phases: the first phase is the liberation of casein after the calcium has combined with the acid; the second phase consists in actual combination of the acid with the casein. Thus, finally, the curd is formed. When milk is heated less acid is required for its precipitation than at low temperature.

Casein is prepared on a large scale commercially for various purposes. The commercial uses of casein are given by Allen as follows:

"1. Patent foods, such as Sanatogen.

"2. For administering medicinal agents, salicylates, alkaloids, lithium, mercury, silver, iron, bismuth, and others.

"3. Cheese.

"In the arts casein is used-

"1. In painting materials.

"2. Adhesives.

"3. Plaster materials, as substitutes for horn, bone, and in making rods, picture frames, etc.

"4. As a medium for mixing colors in textiles.

"5. For waterproofing colored papers, art papers, drawing papers, cartridge cases, cardboard, etc.

"6. Mixed with asbestos paper to form waterproof and fireproof materials.

"7. Miscellaneous uses, such as paint removers, shoe polishes, photographic plates, roofing pulp, glazing for inside of casks, preparation of artists' canvasses, solidifying mineral oils, billiard balls, etc."

The preparation of casein requires considerable care in order to precipitate all the casein and not lose part of it by an insufficient amount or excess of acid. It is advantageous to make a trial experiment before a large amount of milk is coagulated. A preliminary experiment is made as follows: Ten flasks are filled with 20 c.c. of skimmed milk each, and then $0.01 \mathrm{~N}$. acetic acid is added in rising quantity to each flask. The first flask may receive 100 c.c. of the acid; the second flask, 120 c.c., etc. The precipitate is filtered off, and the flask which leaves a water-clear filtrate 
is selected. If several flasks yield water-clear filtrates, the filtrates should be boiled, filtered again, and tested with potassium ferrocyanid and acetic acid. The flask which shows the smallest turbidity is selected, and the quantity of acetic acid necessary to precipitate the casein from the skimmed milk is calculated on the basis of the amount used in this flask. The casein is precipitated and allowed to settle, the supernatant fluid is decanted, and the precipitate washed with water. The precipitate is gathered on filters, pressed between cloth, and dissolved in $0.01 \mathrm{~N} . \mathrm{NaOH}$. After solution the casein is precipitated again with acetic acid and washed with water until $\mathrm{HCl}$-phosphotungstic acid produces but a slight turbidity. A small precipitate will always form with the addition of HCl-phosphotungstic acid, since water decomposes casein slowly and takes up part of it. The precipitate is then redissolved and reprecipitated twice. Finally, the gathered precipitate is washed with alcohol and ether to remove water and fat and then desiccated in vacuo.

Richmond gives the following method of preparing casein: "Milk is diluted with water to about five times its volume and sufficient acetic acid added to make 0.1 per cent. of the mixture. The fat is carried down with the casein. The precipitate is well washed by decantation some ten times, collected on a cloth filter, washed on the filter, and then dried, as far as possible, by pressure. The precipitate is dissolved in the least possible excess of ammonia, the solution allowed to stand for some time to allow the fat to rise, then siphoned off, and filtered. The filtrate is precipitated as before with acetic acid, the precipitate washed, and redissolved in ammonia. This treatment is repeated three or four times. The casein is now rubbed in a mortar with 80 per cent. alcohol and the alcohol poured off. It is then treated two or three times with ether which has been freshly distilled with some reagent which removes aldehyds, and then extracted for some hours in a Soxhlet extractor to remove the fat. The ether is evaporated at as low a temperature as possible. If a very pure product is required the casein is redissolved, reprecipitated, and treated again with alcohol and ether. Finally, the casein is dried at $100^{\circ}$ to $105^{\circ} \mathrm{C}$. If casein containing water is dried it forms a horny mass."

Hill has published a method of precipitating casein by the use of colloidal iron. The milk is boiled and then the colloidal iron is added. Holt, Courtney, and Fales, working with human milk, used colloidal iron as suggested by Hill, and added a few drops of a saturated solution of magnesium sulphate. By this method the filtrate is made clear and the casein precipitated entirely.

The casein of human milk is more difficult to precipitate 
than that of cow's milk, as it forms very fine flakes and usually leaves the serum opalescent.

Ash-free casein is prepared according to Van Slyke and Bosworth as follows: "Separator-skimmed millk is diluted with seven or eight times its volume of distilled water and diluted acetic acid (6 c.c. glacial acetic acid to 1000 c.c. distilled water) carefully added until the casein has completely separated. After the precipitate has settled the clear supernatant fluid is removed by siphon. Distilled water is then added, the mixture stirred vigorously, and the precipitate allowed to settle, after which the wash-water is siphoned off. Water is again added and the casein dissolved by adding for each liter of milk used 1 liter dilute $\mathrm{NH}_{4} \mathrm{OH}$ (6 c.c. strong reagent diluted to 1 liter). When the solution is complete, the whole is filtered through a thick layer of absorbent cotton. The casein is again precipitated with dilute acetic acid, the precipitate allowed to settle and then washed, redissolved in dilute $\mathrm{NH}_{4} \mathrm{OH}$, and filtered. This process of precipitation, washing, dissolving, etc., is repeated not less than four times. Finally, an excess of strong $\mathrm{NH}_{4} \mathrm{OH}$ (10 c.c.) is added, and then 20 c.c. of a saturated solution of ammonium oxalate. The mixture is allowed to stand for twelve hours or more. Calcium is precipitated as oxalate in a very finely divided condition, too fine to permit its satisfactory removal by ordinary methods of filtration. Better aggregation of the precipitate can be effected by means of centrifugal force. The centrifuged mixture is filtered through double thickness filter-paper. The filtered solution is next treated with dilute $\mathrm{HCl}$ (10 c.c. $\mathrm{HCl}$, specific gravity 1.20 , diluted to 1 liter) until the casein is precipitated. The precipitate is washed with distilled water free from chlorids and is then placed on hardened filter-paper in a Buchner funnel, as much water as possible being removed by suction. The mass is next transferred to a large mortar and thoroughly triturated with 95 per cent. alcohol. The alcohol is removed by suction in a Buchner funnel and the casein is again placed in a mortar and triturated with absolute alcohol. Most of the alcohol is removed and the casein treated twice with ether in a mortar by trituration, the ether being removed each time by means of suction on a Buchner funnel. The material is finally ground in a mortar until the particles pass a 40-mesh sieve and is dried for two days over $\mathrm{H}_{2} \mathrm{SO}_{4}$ in a desiccator under diminished pressure."

"Three lots prepared by this method contained the following amounts of ash: $0.10,0.09$, and 0.06 . The casein was insoluble in water and 50 per cent. alcohol. One of the lots was slightly soluble in 5 per cent. $\mathrm{NaCl}$ solution, the other lots were not. One gram of the casein treated with 10 c.c. N. $0.1, \mathrm{NH}_{4} \mathrm{OH}, \mathrm{NaOH}$, 
or $\mathrm{KOH}$ with 90 c.c. of water formed a clear solution, the casein dissolving completely. If a minute amount of a solution of a barium, strontiom, or calcium salt was added to the clear casein solution the characteristic opalescence of casein solutions developed. Elementary analysis gave the following result: Moisture 1.09 per cent.; in the dry substance, C. 53.50, H. 7.13, N. 15.80, P. 0.71, S. 0.72 , O. (by difference) 22.08 , and ash 0.06 per cent."

Ash-free paracasein is prepared according to Van Slyke and Bosworth according to the following method: "Separator-skimmed milk is warmed up to $37^{\circ} \mathrm{C}$. and rennet extract (Hansen's) added in the proportion of 0.12 c.c. for each liter of milk. The mixture is allowed to stand until the paracaseinate has separated as completely as possible. The resulting curd is stirred vigorously in order to break it into small pieces and hasten the separation of whey. After the curd has settled the whey is removed by siphon. The paracaseinate is washed with distilled water several times, and finally 5 liters of water are added for each liter of milk originally used. Dilute $\mathrm{NH}_{4} \mathrm{OH}$ (6 c.c. strong reagent diluted to 1000 c.c.) is then added and the mixture stirred until the paracaseinate is dissolved. The process of reprecipitation, washing, and dissolving is continued as in the preparation of casein. The remaining calcium is finally separated by addition of ammonium oxalate and centrifuging as described in the preparation of casein. The remaining calcium is finally separated by addition of ammonium oxalate and centrifuging as described in the preparation of casein. One preparation of paracasein contained 0.07 per cent. ash. One gram gave a clear solution when dissolved in 10 c.c. of $\mathrm{N}$. 0.1, $\mathrm{NH}_{4} \mathrm{OH}$, and 90 c.c. water. Another preparation with a high ash content gave the following analysis: Moisture 1.63 per cent.; in the dry substance, ash 0.61 , C. 53.50, H. 7.26, N. 15.80 , P. 0.83 , S. 0.87 , O. (by difference) 21.13 per cent. Another preparation with exceptionally low ash content gave: Ash 0.07 , P. 0.71, and S. 0.72 per cent."

\section{Properties of Bovine Casein}

Casein is an acid, forming mono-, di-, and tricaseinates, and replaces $\mathrm{CO}_{2}$ in carbonates. In milk it is a complex calcium salt containing phosphorus. Courant mixed casein, lime-water, and phosphoric acid and obtained a substance which closely resembled the casein of milk. It has not yet been determined whether casein is a complex chemical combination or whether it is merely a mixture of several compounds. However, we do know that all parts of it are necessary for rennet coagulation.

Pure casein is insoluble in water and alcohol, but dissolves readily in acids unless they are highly diluted. It dissolves in 
dilute alkalies and their carbonates and alkaline earths; such solution should not give the Mölisch reaction. Solutions in alkalies are slightly opalescent; in alkaline earths, milky. Casein replaces $\mathrm{CO}_{2}$ in carbonates, yields no ash on combustion, and has never been crystallized.

The following elementary analyses of caseins from different sources are given by Tangle:

\begin{tabular}{|c|c|c|c|c|c|c|}
\hline Animal. & C. & H. & $\mathrm{S}$. & P. & N. & 0. \\
\hline Cow $\ldots .$. & 52.69 & 6.81 & 0.832 & 0.877 & 15.65 & 23.141 \\
\hline Buffalo. & 52.88 & 7.81 & 0.833 & 0.773 & 15.78 & 21.925 \\
\hline Sheep. . & 52.92 & 7.05 & 0.717 & 0.809 & 15.71 & 22.794 \\
\hline Goat... & 52.90 & 6.86 & 0.700 & 0.760 & 15.48 & 23.300 \\
\hline Mare......... & 52.36 & 7.09 & 0.528 & 0.877 & 16.44 & 22.705 \\
\hline Ass.................. & 52.57 & 7.01 & 0.588 & 1.057 & 16.28 & 22.495 \\
\hline
\end{tabular}

Richmond gives the following formulæ and compositions of bovine casein: FORMUL \pm AND COMPOSITION OF CASEIN

\begin{tabular}{|c|c|c|}
\hline & $\mathrm{C}_{162} \mathrm{H}_{265} \mathrm{~N}_{41} \mathrm{SPO} \mathrm{O}_{52}$ & $\mathrm{C}_{170} \mathrm{H}_{268} \mathrm{~N}_{42} \mathrm{SPO} 5 \mathrm{~L}$ \\
\hline$\ldots \ldots \ldots \ldots \ldots \ldots$ & 52.96 per cent. & 54.04 per cent. \\
\hline${ }_{\ldots \ldots}$ & $\begin{array}{r}7.03 \\
15.64\end{array}$ & $\begin{array}{r}7.10 \\
15.56\end{array}$ \\
\hline$\cdots$ & 0.86 & 0.84 \\
\hline$\ldots$ & 0.84 & 0.82 \\
\hline 0 & 22.11 & 21.60 \\
\hline
\end{tabular}

Different properties of caseins are shown by the following facts:

1. The combining power of different caseins is not the same. The following values are given by Raudnitz, ccmpiled from various sources:

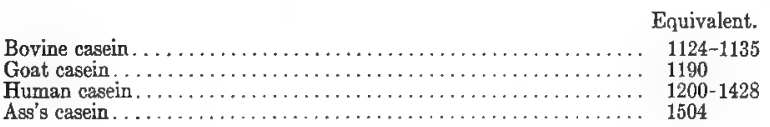

2. Electric conductivity and specific rotatory power differ in caseins from different animals.

3. Human casein and casein from the milk of solipeds is more readily soluble than caseins from ruminants. The precipitate of the former is in finer flakes than that of the latter. According to Richmond, the casein of ruminants is combined with phosphates and alkaline earths, while the casein of solipeds and human casein are combined with alkaline earths.

4. Caseins produce specific antibodies, precipitins, for example, so the fundamental differences can be demonstrated by immunity reactions.

On the other hand, there are some properties which are common to all caseins. They all contain phosphoric acid, but do not yield the decomposition products of nucleoproteins. Casein is, therefore, classified with the phosphoproteins. Furthermore, all caseins are precipitated from their calcium combinations by rennet.

Cow casein is a white, amorphous, hygroscopic powder, with- 
out taste or odor. Its specific gravity is 1.259. It does not melt under the application of heat, and gives the protein reactions, except Mölisch and Adamkiewicz. One gram of casein furnishes 5742 calories. The valency of the protein molecule in basic caseinates is 8 ; in basic paracaseinates, 4 . The molecular weight is given by different investigators from 6500 to 16,000 ; according to Van Slyke and Bosworth it is 8888 for casein and 4444 for paracasein.

Bovine casein is soluble in weak alkaline solutions and these solutions are levorotatory. When a small amount of alkaline solution is mixed with casein a jelly of acid reaction is formed. When more alkaline solution is added, an opalescent to milky fluid results which filters through paper. More alkaline solution renders the fluid clearer.

Casein in alkaline solution does not pass through parchment and is precipitated. Solutions in alkalies pass more readily through porcelain filters than solutions in alkaline earths. Solutions in alkaline earths are more milky than those in alkalies. When solutions of casein are heated to temperatures above $40^{\circ} \mathrm{C}$. opalescence increases, and a film, known as haptogen membrane, is formed which is similar to the film formed on heated milk. This film is insoluble in water, but dissolves in alkalies. When formed on milk it contains all the constituents of milk and may be the result of evaporation. Casein is precipitated from solutions by ammonium sulphate when the solutions are neutral or acid to litmus. Alcohol precipitates casein in alkaline earth solutions, but not in alkaline solutions.

Casein is precipitated by dilute acids and redissolved in excess of acid, forming acid caseins. When casein is shaken with dilute acids a jelly is formed which dissolves when more acid is added. From these solutions the casein is precipitated by alcohol, salts, and neutralization of the acid, the amount of acid required for casein precipitation varying according to the kind of acid and the temperature. For example, it requires more acetic than hydrochloric acid for precipitation, as shown by Hammarsten and Raudnitz. The following figures give the amount of acid required for complete precipitation of the casein in 1 liter containing 100 c.c. of milk and 900 c.c. of water:

THE AMOUNT OF HYDROCHLORIC ACID AND ACETIC ACID REQUIRED FOR PRECIPITATION OF CASFIN

\begin{tabular}{|c|c|c|}
\hline Kind of acid. & $\begin{array}{l}\text { Coagulation } \\
\text { commences. }\end{array}$ & $\begin{array}{l}\text { Congulation is } \\
\text { complete. }\end{array}$ \\
\hline $\begin{array}{l}\text { N. } 0.1 \mathrm{HCl} \\
\text { N. } 0.1 \mathrm{CH}_{3} \mathrm{COOH} \ldots\end{array}$ & $\begin{array}{l}435 \text { c.c. } \\
630\end{array}$ & $\begin{array}{r}600 \text { c.c. } \\
1000\end{array}$ \\
\hline
\end{tabular}

In boiling milk the following amounts of acids are required for coagulation according to Richmond: 
AMOUNTS OF ACIDS REQUIRED TO COLGULATE BOILING MILK

Kind of acid.

Amount requirề in normal cubic centi-

Hydrochloric acid. $\ldots \ldots \ldots \ldots \ldots \ldots \ldots \ldots \ldots \ldots \ldots \ldots \ldots, 8.6$

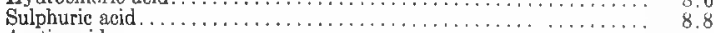

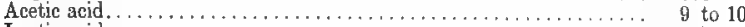

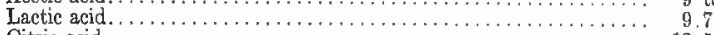

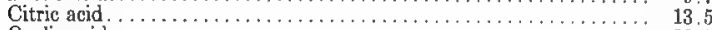

Oxalic acid...................................... 28.5

Phosphoric acid................................. 34 to 35

The quantity of acid required for complete coagulation of casein depends upon the amount necessary to transform diphosphates into monophosphates.

When casein is desiccated at a temperature above $90^{\circ} \mathrm{C}$. it splits into three bodies, namely, one which is soluble in dilute alkali-isocasein; one which forms a jelly in dilute alkali-caseid; and phosphoric acid. Isocasein is insoluble in water; neutral solutions in alkali are not opalescent and are not coagulated by rennet. Caseid is closely related to casein.

Freshly precipitated casein is decomposed by water, but the split products have not been studied. Neutral alkaline or alkali earth solutions of casein decompose rapidly at body temperature.

When a suspension of casein in water is boiled it splits into several products. One substance is formed which does not combine with alkalies as readily as casein; another one forms a soft mass which adheres to the walls of the vessel and is insoluble in alkalies. The filtrate from the boiled suspension of casein contains 2.27 per cent. of albumin and becomes opalescent when heated.

Heating casein in water under pressure decomposes it into products which are similar to those obtained by hydrolysis with acids or from digestion with proteolytic enzyms.

Hydrolysis of casein with pepsin yields different caseones. Hydrolysis with tryspin yields caseone, amino-acids, and ammonia. Frepsin also splits casein, although it does not attack native proteins. Trypsin produces more profound breaking up of casein than pepsin. The following products of trypsin digestion of casein and lactalbumin are given by Raudnitz:

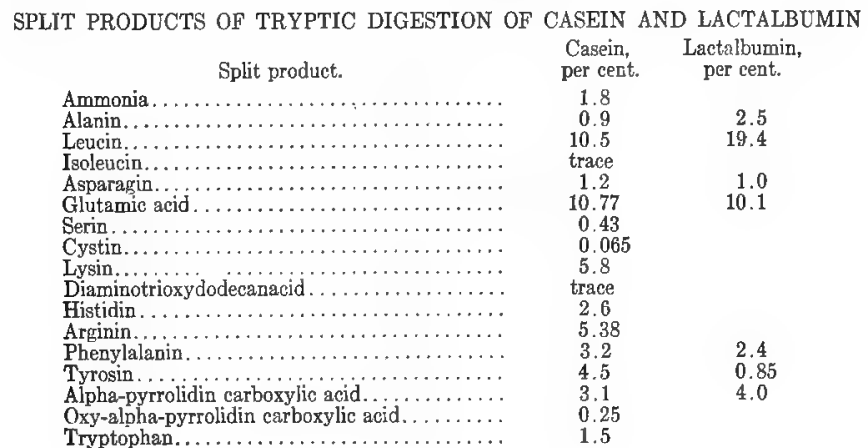


It is worthy of note that no carbohydrate radical was found. Glycocoll is also absent, while cystin is present in small quantity. On the other hand, tyrosin and mono-amino-acids are well represented. It is thought that these conditions render casein easy of digestion.

Casein is soluble in dilute solutions of salts, and according to Van Slyke and Hart more so in hot solutions than in cold ones. The solutions are opalescent and turn milky when boiled. The casein is precipitated from these salt solutions with ammonium or magnesium sulphate.

Casein is precipitated by saturation with $\mathrm{NaCl}, \mathrm{MgSO}_{4}$, $\mathrm{CuSO}_{4}$, and mercury salts.

Van Slyke and Hart found a salt-soluble substance in Cheddar cheese when it was extracted with a dilute solution of sodium chlorid. This body was present in large amount only when lactic acid was used. It occurs in fresh cheese, but the quantity diminishes as the cheese ages. When paracasein is treated with dilute lactic acid a substance is obtained which resembles this saltsoluble substance extracted from cheese both physically and chemically. Paracasein, which is the main component of green cheese, combines with acids in two different proportions: one is a monobasic salt, the other a dibasic salt. Lactic, hydrochloric, and sulphuric acids will form similar compounds with paracasein. Casein also combines with acids in a similar manner. The unsaturated salts formed by casein and paracasein with acids are soluble in dilute solutions of sodium chlorid and hot 50 per cent. alcohol, but they are insoluble in water. The unsaturated salts are practically insoluble in salt solution, hot alcohol, or water. In making Cheddar cheese the curd is tested with a hot iron, and when strings are formed from the hot iron the curd is ready for further treatment. These strings are due to unsaturated paracasein lactate. The ripening process of Cheddar cheese commences with paracasein lactate. The water-soluble nitrogen in cheese increases as the unsaturated paracasein salt decreases in quantity. Therefore, ripening commences with a peptic digestion of unsaturated paracasein lactate.

\section{Rennet Coagulation}

Rennet extract contains an enzym which coagulates casein and changes it into a non-coagulable substance. Rennet extract is prepared from the fourth stomach of a suckling calf, but similar enzyms are found elsewhere in nature, as, for example, in the stomach, the pancreas, in some plants, and as products of bacterial metabolism. Coagulating enzyms differ in some of their 
properties, such as optimum temperature, resistance to environmental conditions, etc. Enzyms have never been isolated in pure form. Differences in properties of coagulating enzyms may, therefore, be due to admixtures of other substances, and it is difficult to separate them.

Rennet extract for commercial purposes is made from the fourth stomach of a young calf. The calves are not fed for twelve hours before slaughtering, and the stomachs are then removed, washed, and cleaned. The clean stomachs are sprinkled with salt, inflated, and allowed to dry in the air. After three to twelve days they are extracted with 4 to 5 per cent. salt solution. It is thought that the potency of the stomachs increases up to twelve days after slaughtering. For scientific purposes the glandular part of the washed stomach is scraped off and the scrapings digested with ten to twenty times their volume of 0.2 per cent. hydrochloric acid. The acid is neutralized before the extract is used.

Rennet extracts deteriorate with age and if exposed to light or warmth. Therefore they should be kept in a cool, dark place. Rennin is a colloid and does not diffuse through animal membranes, but can pass through porcelain filters.

There are two changes produced in milk by rennet extract: one is coagulation of the casein, the other digestion of the coagulum. Whether these activities are due to one or two enzyms is not known. Some authors think that there is but one enzym which produces both reactions, others believe that there are two distinct enzyms, similar to pepsin in the stomach. The coagulative enzym is called rennin or chymosin, the proteolytic enzym is called pepsin. The latter enzym is of great importance in cheese ripening.

Rennin does not produce curds of the same character in all kinds of milk. Human milk, for example, is more alkaline than cow's milk, and rennin action is only possible in human milk after addition of acid, since rennin does not act in alkaline fluids. Mare's milk coagulates with rennet only after addition of a soluble calcium salt. As a rule, rennin acts more promptly and more completely on homologous milk than on heterologous milk. For example, rennin prepared from calves' stomachs acts better on cow's milk than on milk of any other animal.

The coagulation of casein by rennin is a complicated physical and chemical process. According to Van Slyke and Publow the reaction takes place in three phases, namely: 1 , the change of casein into paracasein; 2 , the change of insoluble calcium salts into soluble ones; 3 , the precipitation of uncoagulated paracasein by soluble calcium salts. 
The change of casein into paracasein is wholly dependent on the action of the enzym, and can be illustrated by the following experiment: Two solutions of acid casein alkali are prepared. To one of these solutions rennet extract is added and to the other rennet extract inactivated by boiling. After the solutions have been kept at body temperature for some time they are boiled so that rennin action ceases. At this stage no visible difference can be detected between the solutions, either in appearance or by testing the reaction with litmus or phenolphthalein. The solution to which raw rennet has been added has lost some of its viscosity, electric conductivity is increased, and the precipitation limit of ammonium sulphate is lowered. If an equal amount of a soluble calcium salt (a solution of calcium chlorid is usually used) is added to each solution there is a rapid change. The solution with raw rennet forms a curd which separates from the fluid portion, while the solution with inactivated rennet turns milky. If the reaction of the casein solution was neutral there is less difference in the precipitates formed, and if the solution was alkaline there is no difference. If a similar experiment is made with an acid solution of casein in an alkaline earth instead of an alkali, the difference between the two solutions is still more pronounced.

The experiment shows that rennin so alters the casein that it coagulates in the presence of soluble calcium salts after destruction of the enzym by boiling. Calcium salts do not coagulate casein unless it has been acted upon by rennin.

During the second phase the rennin acts upon the calcium salts which are in an insoluble condition in milk and renders them soluble. This phase requires more time than the first one. Action can be accelerated by addition of a soluble calcium salt.

As soon as the calcium salts have become soluble the reaction enters upon the third phase. The curd becomes visible and the fluid thickens. This change is brought about rapidly and does not depend upon rennet action, as in the first and second phases. The curd from milk always encloses insoluble calcium phosphates either mechanically or in actual combination with the paracasein. Milk-fat and colloidal substances are also enclosed in the curd.

The chemical reactions taking place in rennet coagulation of casein are not well understood, but the fact is established that without soluble calcium salts no coagulation occurs. It must be assumed that there is some difference in composition between casein and paracasein. Paracasein has lower precipitation limits than casein and is precipitated by soluble calcium salts, while casein is not. If after prolonged rennin action on casein-alkali 
solutions acetic acid is added, a precipitate is formed which consists of paracasein and paracasein-B. The latter is not precipitated by calcium salts and has been called whey-albumin, hemi-casein-albumin, and lacto-serum-protein by different authors. It is a protein of the nature of an albumose, and may be the result of partial digestion of the casein by a proteolytic enzym.

Loevenhart assumed that when casein changes to paracasein the molecules form large clusters and render paracasein more readily coagulable. Ultramicroscopic observation has shown that larger clusters are actually formed during the process. Whether this is a chemical or merely a physical phenomenon has not been determined. Van Slyke and Hart agree with Loevenhart, but Laqueur takes the opposite view and assumes that casein molecules are larger than paracasein molecules. However this may be, the following facts are not disputed:

1. Casein and calcium salts are the only substances acted upon.

2. Rennet action effects no change of reaction.

3. For rennin coagulation, rennin and soluble calcium salts are indispensable.

4. Casein does not coagulate before it is transformed into paracasein by rennin action.

Conditions Governing Rennet Action.-Rennet enzym or rennet activity is influenced by a number of factors which have received considerable study. The most important of these are:

1. The presence of calcium salts.

2. The presence of acids or alkalies.

3. The presence of salts and other chemical compounds.

4. Temperature.

5. Dilution of milk and relative quantity of rennet used.

6. The age and quality of the milk.

1. The Presence of Soluble Calcium Salts.-The necessity of their presence for rennet action has been discussed at some length previously.

2. The Presence of Acids or Alkalies.-Acids and acid salts in suitable dilutions favor rennet action. Up to a certain concentration rennet action is accelerated in proportion to increasing amounts of acids or acid salts. However, there is a limit beyond which the concentration cannot be carried without producing an inhibitory effect. For example, milk which has soured to the curdling point or buttermilk are not coagulated by rennet. A slight acidity is favorable. The following table given by Van Slyke and Publow demonstrates the influence of acid. The results were obtained by adding to 250 c.c. fresh milk at $29^{\circ} \mathrm{C}$. 1 c.c. of a rennet solution, prepared by dissolving a commercial 
rennet tablet in 150 c.c. of distilled water, and various amounts of acid:

\begin{tabular}{|c|c|c|c|c|c|c|}
\hline Kind of acid. & $\begin{array}{l}\text { Original } \\
\text { milk } \\
\text { coagulated } \\
\text { in seconds. }\end{array}$ & $\begin{array}{c}0.01 \\
\text { per cent. }\end{array}$ & $\begin{array}{c}0.02 \\
\text { per cent. } \\
\text { - Time }\end{array}$ & $\begin{array}{c}\text { Strength of acid. } \\
0.03 \\
\text { per cent, } \\
\text { f coagulation in }\end{array}$ & $\begin{array}{c}0.04 \\
\text { per cent. } \\
\text { seconds. }\end{array}$ & $\begin{array}{c}0.05 \\
\text { per cent. }\end{array}$ \\
\hline Acetic. & 110 & 70 & 45 & 35 & 25 & 20 \\
\hline Sulphuric . . ........... & 105 & 70 & 50 & 30 & 25 & 20 \\
\hline Citric . . . . . . . & 105 & 80 & 60 & 45 & 40 & 35 \\
\hline Lactic... & 110 & 80 & 65 & 45 & 35 & 30 \\
\hline Hydrochloric............ & 105 & 85 & 70 & 60 & 50 & 45 \\
\hline Phosphoric............... & 135 & 110 & 90 & 80 & 75 & 60 \\
\hline
\end{tabular}

This table shows clearly that with an increasing quantity of acid the time required for coagulation decreases. It also shows that the accelerating effect of different acids is not the same. Acetic acid is at the head of the list, while the following acids exert a smaller accelerating influence in the order given in the table.

The usual explanation of the accelerating action of acids is given as the formation of the solution of insoluble calcium salts, thus activating the enzym. Even a weak acid like $\mathrm{CO}_{2}$ favors rennet action. Alkalies and alkaline salts have an inhibitory effect on rennet action.

3. The Presence of Salts and Other Chemical Compounds.The effect of salts and other chemical compounds on rennet action may be favorable or otherwise. Acid salts are favorable, while alkaline salts retard and ultimately inhibit rennet action. Chlorids of alkalies inhibit in quantities of 0.5 per cent. and more. In smaller quantity there is slight acceleration. Sodium chlorid accelerates in quantities up to 0.9 per cent. Sodium chlorid and ammonium sulphate retard rennet action, while citrates and oxalates inhibit. The chlorids of calcium, strontium, and barium accelerate rennet action in quantities of one-tenth to one-thousandth normal solution.

The chlorids of zine and aluminum also accelerate rennet action, although in smaller amounts than other chlorids. Magnesium chlorid accelerates in quantities of one-fiftieth to onetenth normal solution, but retards below this amount. Salts of barium, calcium, strontium, beryllium, aluminium, and zinc have slightly accelerating action in minute amounts. Salicylic and benzoic acids also accelerate in small amounts (one-fiftieth normal). Alcohol, glycerin, thymol, and formaldehyd retard, while $\mathrm{H}_{2} \mathrm{O}_{2}$ accelerates rennet action. Ultraviolet rays act unfavorably on rennet coagulation.

The influence of calcium chlorid on rennet action when minute amounts of rennet are used is given by Hammarsten as follows ("Sommerfeld's Handbuch"): 


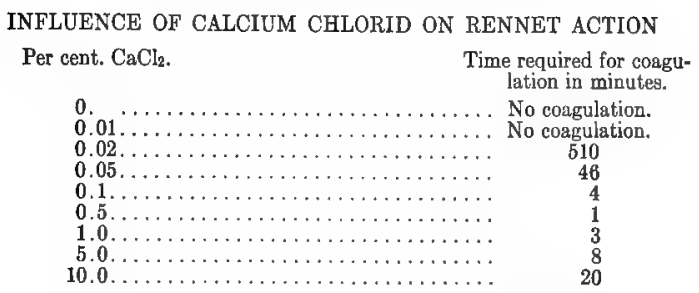

Milk which has been kept in metallic vessels does not coagulate with rennet as readily as normal milk, since some of the metal is dissolved. The effect of metal is very pronounced, and rusty cans have a retarding effect, since some iron combines with the lactic acid in milk. Platinum and tin have the least retarding effect (Olsen).

4. Temperature is of great importance in rennet coagulation, and influences the speed of reaction and the character of the coagulum. The lower the temperature, the longer the time required for coagulation; the longer the milk with rennin remains cold, the less rennin is necessary to coagulate milk when it is finally warmed. At $60^{\circ} \mathrm{C}$. there is no rennet action, but if rennet is added to milk in the cold it coagulates even when heated to $100^{\circ} \mathrm{C}$. At $60^{\circ} \mathrm{C}$., therefore, the transformation of casein into paracasein is inhibited, hut not the action of calcium salt. The following table (Fleischmann) shows the influence of temperature on rennet action:

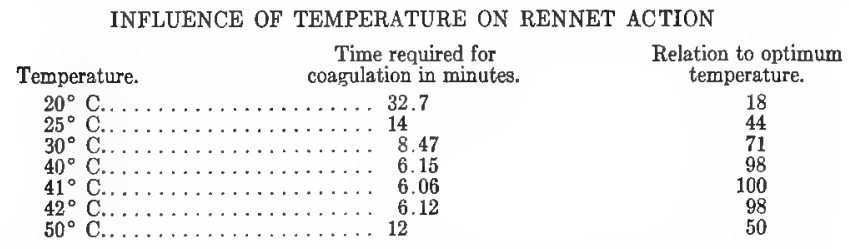

The table shows that the optimum temperature is $41^{\circ} \mathrm{C}$.

At $15.5^{\circ} \mathrm{C}$. the curd is flocculent, spongy, and soft; at $25^{\circ}$ to $45^{\circ} \mathrm{C}$. it is fine and solid; at $50^{\circ} \mathrm{C}$. it is soft and gelatinous.

Heating milk precipitates calcium salts; the greater the heat, the larger is the amount of calcium salt precipitated. Rennet action is consequently retarded in proportion to the degree of heat applied. According to Rupp, the time required for coagulation in milk heated up to $65^{\circ} \mathrm{C}$. is slightly less than that in raw milk. At $70^{\circ} \mathrm{C}$. there is slight retardation, and at $75^{\circ} \mathrm{C}$. the time is almost doubled. Van Slyke states that rennin normally fails to coagulate unless some soluble calcium salt or some acid is added. The coagulum of heated milk is flocculent and not as firm as that of raw milk. 
5. Dilution of Milk and the Relative Quantity of Rennet Used.Diluting milk retards rennet action by reducing the concentration of casein, calcium salts, rennet, and acidity. Coagulation is not complete, but this can be corrected by addition of soluble calcium salts or acids. The coagulum produced in diluted milk is flaky and not as compact as the one produced in undiluted milk.

The effect of diluting milk upon rennet action is shown in the following table (Van Slyke and Publow):

EFFECT OF DILUTING MILK ON RENNET ACTION

\begin{tabular}{|c|c|c|c|c|c|}
\hline C.c. of milk. & $\begin{array}{c}\text { C.c. of } \\
\text { water added. }\end{array}$ & $\begin{array}{l}\text { Per cent. of } \\
\text { water added. }\end{array}$ & $\begin{array}{c}\text { C.c. of } \\
\text { ronnet added. }\end{array}$ & \multicolumn{2}{|c|}{$\begin{array}{l}\text { Time of } \\
\text { coagulation. }\end{array}$} \\
\hline 175 & 175 & 50 & 0.5 & $5 \mathrm{~min}$ & $20 \mathrm{sec}$. \\
\hline 175 & 175 & 50 & 1.0 & 54 & 20 \\
\hline 280 & .70 & 20 & 1.0 & 2 & $00^{\prime \prime}$ \\
\hline 315 & 35 & 10 & 1.0 & 14 & 50 " \\
\hline 332.5 & 17.5 & 5 & 1.0 & $1 "$ & $45 \quad 1$ \\
\hline 350 & 0 & 0 & 1.0 & $1 " 4$ & 30 it \\
\hline
\end{tabular}

6. The Age and Quality of the Milk.-Freshly drawn milk coagulates more rapidly than cooled milk because of temperature reduction and the escape of $\mathrm{CO}_{2}$. Milk from different cows, different breeds, and different milkings varies in the time required for coagulation. No reason has been found to account for these phenomena except that, as Olsen states, the greater the solids, the longer is the time required for coagulation. A number of tests by Van Slyke give the extremes in the experiments from 40 seconds to 50 minutes, and in the same cow a variation of from 45 seconds to 50 minutes. At the beginning of lactation milk coagulates more readily than at later periods. Strippings, gargety milk, salty milk, and milk from sick and aged cows coagulates slowly with rennet.

Rennin is bound by casein in the process of coagulation. This is shown by the fact that after coagulation the whey contains much less rennin than was added.

Rennin is not injured at $180^{\circ} \mathrm{C}$. Dry rennin resists a temperature of $100^{\circ}$ to $140^{\circ} \mathrm{C}$., but liquid rennet is injured by prolonged heating at $50^{\circ}$ to $60^{\circ} \mathrm{C}$, and in a short time at higher temperature. Rennin is destroyed by alcohol.

Injection of rennin into animals produces antirennin; in fact, some animals, the horse, for example, have antirennin normally in their blood.

Raudnitz gives the following summary of the influences of various conditions on rennet action:

1. The chemical part of the process is accelerated by the distribution of the rennet extract and the quantitative relation to the casein. Perhaps the temperature also has an influence. Salts of alkaline earths and acids probably act by activation of the enzym. 
2. The chemical part of the process is retarded by gradual destruction of the rennet by temperatures above $41^{\circ}$ C., free hydroxyl ions, inactivation through antirennin, change of the casein by heating above $80^{\circ} \mathrm{C}$, and the presence of formalin.

3. The physical part of the process is accelerated by high temperature, free hydrogen ions and neutral salts up to a certain concentration, especially the salts of alkaline earths.

4. The physical part of the process is retarded by diminished concentration of the salts of alkaline earths, which are precipitated by heat, and the increased concentration of neutral salts. Possibly alkalies also act in this direction.

\section{LACTALBUMIN}

Lactalbumin is similar to serum albumin and can be prepared from milk by the following methods:

1. Milk is saturated with $\mathrm{MgSO}_{4}$ and filtered. To the filtrate are added a few drops of a 0.25 per cent. acetic acid. The precipitate is gathered and redissolved and the solution neutralized. By repeated precipitation with $\mathrm{MgSO}_{4}$ remnants of casein and globulin are removed and the solution is dialyzed until $\mathrm{MgSO}_{4}$ has disappeared. The albumin is then precipitated with alcohol. Finally the precipitate is dried at low temperature.

2. Milk is filtered through a porcelain filter and the albumin precipitated from the filtrate by saturation with ammonium sulphate. The precipitate is dialyzed, reprecipitated with alcohol and dried. Lactalbumin is crystallizable; if the solution of lactalbumin is saturated with $\mathrm{MgSO}_{4}$, this solution diluted with an equal volume of water, and then acetic acid added until a permanent turbidity appears, crystals will form on standing. Crystallization is aided by occasional gentle agitation. The form of the crystals is the same as that of egg-albumen and serum albumin, but its rotation is different (Mathews).

When prepared by one of the above methods, lactalbumin is a tasteless white powder, easily soluble in water. Lactalbumin contains no phosphorus, but twice as much sulphur as casein. Elementary. analysis gives the following composition (Sebelein):
C. $=52.10$,
H. $=7.18$,
N. $=15.77$,
S. $=1.73$,
O. $=23.13$

It is soluble in saturated solutions of $\mathrm{NaCl}$ and $\mathrm{MgSO}_{4}$, but is precipitated by a saturated solution of $\left(\mathrm{NH}_{4}\right)_{2} \mathrm{SO}_{4}$. It is precipitated from a saturated solution of $\mathrm{MgSO}_{4}$ by addition of acid, but is redissolved if the acid is neutralized. Rupp states that there is no albumin coagulated at $62.8^{\circ} \mathrm{C}$. if this temperature be maintained for thirty minutes. Under the same conditions at 
$65.6^{\circ} \mathrm{C} .5 .71$ per cent. are coagulated; at $68.3^{\circ} \mathrm{C} .12 .76$ per cent, are coagulated, and at $71.1^{\circ} \mathrm{C} .30 .87$ per cent, are coagulated. It is usually stated that lactalbumin coagulates at $70^{\circ} \mathrm{C}$., but that coagulation is not complete at this temperature.

\section{LACTOGLOBULIN}

Lactoglobulin is obtained from milk by the following methods:

1. Milk is saturated with $\mathrm{NaCl}$, filtered, and the filtrate warmed to $35^{\circ} \mathrm{C}$. to remove remnants of casein. The filtrate is then saturated with $\mathrm{MgSO}_{4}$, redissolved, precipitated with $\mathrm{NaCl}$, and finally dialyzed. Flakes of globulin are precipitated (Sebelein).

2. Colostrum is warmed to $40^{\circ} \mathrm{C}$. and saturated with alum. It is then filtered, the filtrate neutralized, and filtered again. The last filtrate is saturated with $\mathrm{MgSO}_{4}$ and $\mathrm{NaCl}$, the precipitate dissolved and dialyzed, and finally precipitated with nitric acid and alcohol (Tiemann).

Lactoglobulin is probably identical with serum globulin. It is soluble in $\mathrm{NaCl}$ solution, even when acidified, but is precipitated by $\mathrm{MgSO}_{4}$ and $\left(\mathrm{NH}_{4}\right)_{2} \mathrm{SO}_{4}$. It is also precipitated by tannin, but is not coagulated by rennet. It coagulates at $72^{\circ} \mathrm{C}$. Colostrum contains relatively large amounts of globulin, while normal milk contains only traces of it. It is believed to be the carrier of antibodies in milk.

\section{Mucoid Protein or Lactomucin}

Mucoid protein can be prepared from butter, sweet buttermilk, or cream by shaking with a mixture of 1 part alcohol and 2 parts ether. A gelatinous precipitate appears when the mixture has stood for some time. The precipitate is gathered and washed with alcohol and ether mixture, and finally dried at low temperature.

Mucoid protein is a bulky, grayish-white hygroscopic powder; it is insoluble in ammonia, acetic acid, and dilute mineral acids. It swells in weak alkalies, only a small amount of it being soluhle. Heated with $\mathrm{HCl}$ it yields a substance which reduces Fehling's solution.

\section{Other Proteins in Milk}

Minute amounts of the following proteins have been found in milk: Albumose, lactoprotein, galactozyme, and opalisin. The actual existence of these proteins is doubted by many investigators, and it must be admitted that there are sources of error possible. Colostrum contains a large amount of albumin 
and the leukocytes are constantly breaking down, and it is possible that protein decomposition products may be formed which are not found in normal milk. In the latter bacterial activity may be responsible for the presence of decomposition products in small quantity, since bacteria, chiefly liquefying micrococci, are practically always present in the udder. Furthermore, the isolation of proteins requires vigorous treatment, and consequently traces of by-products may be present, and these are perhaps the proteins referred to.

\section{LeCithin and Cephalin}

Both lecithin and cephalin are supposed to be present in milk, although only in traces. They are waxy substances which are soluble in alcohol and ether and contain P. and S. They are probably present in colloidal condition and are associated with the fat. Reliable quantitative determinations are not available.

\section{Nitrogen-Containing Extractives}

The presence of urea, creatin, creatinin, hypoxanthın, xanthin, and other similar substances in milk has been demonstrated. Uric acid and hippuric acid are absent.

Biscaro and Belloni have found an acid in milk which they named orotic acid. This acid has never been isolated from any other substance. The authors give the possibility of two formulæ:

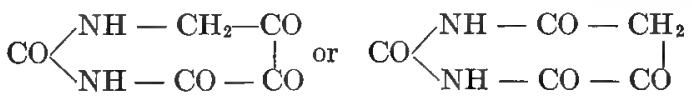

\section{MILK-SUGAR}

The chief carbohydrate in milk is milk-sugar or lactose. Its structural formula is as follows:

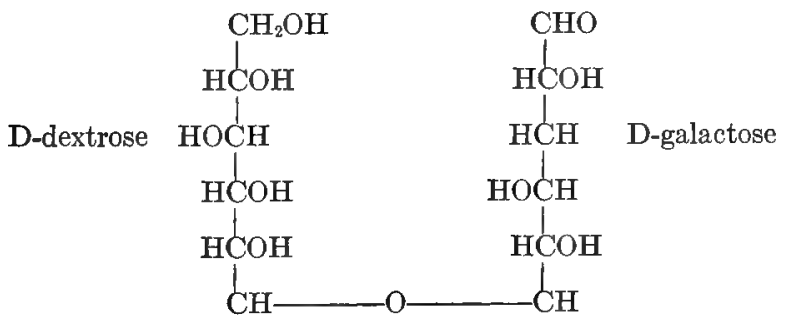

Raudnitz states that there is but one carbohydrate-lactose -in milk, and that the finding of other carbohydrates is due to faulty technic. He argues that the findings are based on dif- 
ferences in rotation, but that error is likely to occur because the rotation of lactose varies under different conditions. If, for example, lactose has been desiccated before dissolving, or if the solution stands for some time, the rotation may vary 100 per cent. either way. Furthermore, when a solution of lactose is heated to $120^{\circ}-130^{\circ} \mathrm{C}$. in the presence of alkali, sodium phosphate, or casein substances are formed which have lower rotation than lactose, but similar reducing power.

Theobald Smith concluded from observations of bacterial activity that milk contains 0.1 per cent. of a carbohydrate which is similar to dextrose. On the other hand, Leichmann has shown that Bacillus delbrücki, a bacillus of the group of lactobacilli, produces no fermentation in milk, although it decomposes dextrose, but not lactose.

These experiments were made in cow's milk. Richmond found a carbohydrate in the milk of the gamoose or Egyptian buffalo and named it "tewficose." This same author states that mare's milk easily undergoes alcoholic fermentation, a property not possessed by lactose. However, investigations by Hastings have shown that lactose-fermenting yeasts are widely distributed and, therefore, fermentation of milk can easily occur if conditions are favorable. Richmond also states that experiments made by Carter and himself seemed to show that the millk-sugar in human milk is not identical with that of cow's milk.

At the present time it is impossible to decide whether carbuhydrates-other than milk-sugar-really occur in milk. If they do, they are present in small quantity only and probably have no significance. Milk-sugar prepared from the milk of different animals has the same properties.

Milk-sugar is not as readily soluble in water as other sugars. Solutions of lactose are, therefore, not as sweet as solutions of cane-sugar or dextrose. Milk-sugar is soluble in about 6 parts of cold water and in $2 \frac{1}{2}$ parts of hot water. Milk-sugar crystallizes in rhombic prisms from a concentrated solution, leaving a mother liquor which contains 21 per cent. of sugar. The crystals contain one molecule of crystallization water. To prepare milksugar on a large scale whey is evaporated to a syrupy consistency and crystals are allowed to form. These are redissolved, the solution decolorized with animal charcoal, and recrystallized. It is usually sold in a white, slightly sweetish powder, and is used as a vehicle for drugs and for modifying milk for infant feeding.

Milk-sugar exists in several modifications. The hydrated $a$ milk-sugar crystallizes from water and has a high rotation which diminishes when the solution stands for some time. Anhydrous milk-sugar is obtained when $a$ sugar is heated to $130^{\circ} \mathrm{C}$. It is 
hygroscopic and dissolves in water with evolution of heat. By rapid evaporation of a solution of milk-sugar in metallic vessels the $\beta$ modification is obtained. It has a lower rotation than the $\alpha$ modification.

\section{The Mineral Constituents of Milk}

The mineral constituents of milk are usually given as ash, obtained by first evaporating milk to dryness and then incinerating the residue at low red heat. A white ash is thus obtained which has an alkaline reaction. Colostrum yields considerably more ash than normal milk. The ash varies in the milk from different animals, as the following figures given by Trunz, who quotes the work of several investigators, show: the ash of goat's milk is 0.7 per cent.; of sheep's milk, 0.8 per cent.; of mare's milk, 0.28 to 1.20 per cent.; of ass's milk, 0.30 to 0.40 per cent.; of human milk, 0.19 to 0.34 per cent.

The ash is composed of substances derived from organic and inorganic compounds. Carbon, sulphur, and phosphorus are derived in part from organic compounds. Therefore it is customary to speak of crude ash which contains all inorganic substances contained in milk and of pure ash which contains only those substances which are present in milk in inorganic form. Pure ash, therefore, is the crude ash from which the organic carbon, sulphur, and phosphorus have been deducted.

The ash does not represent all the elements which constitute the salts in milk, as some are lost by escaping during incineration.

Carbon appears in ash as $\mathrm{CO}_{2}$, sulphur as $\mathrm{SO}_{3}$, and phosphorus as $\mathrm{P}_{2} \mathrm{O}_{5}$.

The elements found in the ash of milk are potassium, sodium, calcium, magnesium, phosphorus, iron, sulphur, chlorin, hydrogen, oxygen, and traces of fluorin, iodin, and silicon. Söldner has given the following theoretic arrangement of these elements in salts:

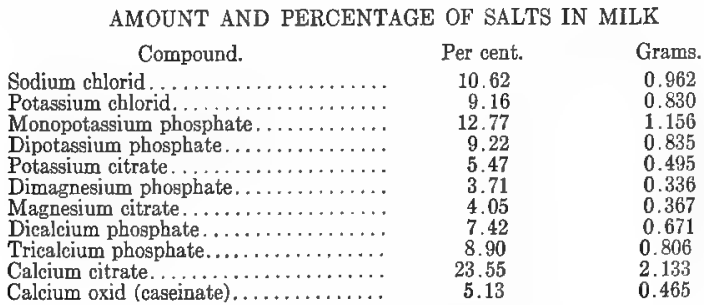

In solution are the salts of potassium, sodium, chlorin, citric acid, some phosphates, calcium salts, and magnesium salts: Biand triphosphates are in suspension and do not pass through a 
porcelain filter. Iron is present in cow's milk, according to Edelstein and Csonka, in amounts of 0.4 to $0.7 \mathrm{mgr}$. per liter, or an average of 0.5 .

The salts are essential for the food of the young. There is a balance between the salts and the other constituents of milk, and any cause which affects the one also affects the other. The condition of the salts is changed by loss of $\mathrm{CO}_{2}$, heating, formation of acid, diseases of the animals, food, lactation period, etc. Rennet action is influenced by the salts in milk. These changes will be discussed later. The salts sometimes produce almost an alkaline reaction in milk derived from aged or diseased cows, and rennet then fails to coagulate the casein.

The salts are indirectly derived from food and drinking-water. Some salts pass through the mammary gland and reappear in the milk. Sodium sulphate, if given in large quantity with the food, can be recovered from the milk, while sodium chlorid passes through only in small quantity.

Rich milk does not necessarily contain more mineral matter than poor milk; in fact, sometimes the reverse is true.

\section{Gases IN MILK}

The gases found normally in milk are oxygen, nitrogen, and carbon dioxid. The total amount of gas in fresh cow's milk is about 7 to 9 volume per cent.; in human milk much less-about one-tenth this amount. Since exposure causes milk to readily absorb gases from the air, it has long been the custom to remove gases by aëration. Animal odors and taints can be largely removed by aeration, but it is clear that milk obtained under cleanly conditions will not need aëration, since the source of taints is removed. Gases may originate from bacterial activity in milk, and this also can be prevented in a measure by cleanly methods of milking. It is obvious that presence of undesirable gases largely influences the quality not only of the milk but also of milk products, such as butter and cheese. As a matter of fact, cheese frequently suffers in quality through the action of undesirable gasforming bacteria.

Whether the methods of aëration in vogue are effective is a question which has been exhaustively investigated by Marshall, who also gives a complete review of the literature on the subject. $\mathrm{He}$ analyzed the gas formed by absorption of the carbon dioxid with potassium hydrate, the oxygen by alkaline pyrogallate, and the remnant was estimated as residual gas. This residual gas is usually considered to be nitrogen, but Marshall thinks that this assumption is not justified, since analyses have not been made. 
The following table has been compiled according to Marshall's results:

\begin{tabular}{|c|c|c|c|}
\hline Condition of milk. & $\begin{array}{l}\text { Carbon } \\
\text { dioxid, } \\
\text { per cent. }\end{array}$ & $\begin{array}{l}\text { Oxygen, } \\
\text { per cent. }\end{array}$ & $\begin{array}{c}\text { Residual gas } \\
\text { (nitrogen), } \\
\text { per cent. }\end{array}$ \\
\hline Unexposed milk....... & 81.496 & 2.42 & 16.535 \\
\hline After milking... & 59.636 & 13.176 & 27.17 \\
\hline After aëration over glass, $\ldots \ldots \ldots \ldots \ldots$ & 40.572 & 20.586 & 38.842 \\
\hline After aëration over tin $\ldots \ldots \ldots \ldots \ldots \ldots \ldots \ldots$ & 35.832 & 20.55 & 44.618 \\
\hline After aëration over copper........... & 42.328 & 17.256 & 40.416 \\
\hline After aëration through glass wool and copper sieves. . & 25.805 & 25.805 & 50.8775 \\
\hline
\end{tabular}

This table shows that there is gas before the milk leaves the udder, since Marshall's experiments were such as to exclude the air during milking. After the milk has left the udder there is a diminution of carbon dioxid, while there is an increase of oxygen.

Marshall thinks it possible that the carbon dioxid is actually present in loose combination, in part at least, and not altogether as free gas. This view is based on the fact that when the gas is removed from milk the last quantity is difficult to extract, and that the effect which the original carbon dioxid in milk has upon chemical indicators differs from the effect of impregnated carbon dioxid. However, carbon dioxid is easily soluble in water, and the last remnant is difficult to remove from distilled water, especially in the presence of salts, such as sodium carbonate, other carbonates, and acid sodium phosphate. This question must, therefore, remain undecided at present.

When sterilized milk was exposed to air Marshall found no evidence of absorption of gas after six weeks.

Since carbon dioxid decreases and oxygen increases when milk comes in contact with the air, there must be a rapid interchange of gases during milking, a process which may be considered a sort of aëration. .If oxygen is absorbed it is reasonable to assume that stable odors are also absorbed. By subsequent straining and aërating an equilibrium of gas content with the gases of the air is established, so that the gas content in milk is similar to the gas content of the air, whatever that may be. Tainted air will, therefore, impart its taint to the milk, while the milk will give up some of its normal gas to the air.

Lactic acid fermentation in milk is favored by the presence of oxygen, while absence of this gas favors anaërobic action on the protein and possibly the formation of toxic products.

Some of Marshall's most important conclusions from his investigations are these:

1. Milk drawn from the udder of a cow contains a high percentage of carbon dioxid and a low percentage of oxygen.

2. During the milking process the percentage of carbon dioxid contained in the gases pumped from milk dropped considerably. 
3. During aëration the carbon dioxid of the pumped gases dropped still farther by aëration over glass, tin, copper, and through glass wool. The oxygen increased at the same time.

4 . Below a certain percentage the elimination of carbon dioxid becomes very difficult.

5. Air confined over sterilized milk indicates no interchange of gases.

6. Most micro-organisms in milk generate carbon dioxid and absorb oxygen.

7. Milk fresh from the cow and confined in a flask consumes the oxygen and liberates carbon dioxid.

8. Free carbon dioxid in amounts of $100,96.5$, and 62.9 per cent. have a marked restraining action on bacteria, and in some cases an inhibitive action.

9. Free carbon dioxid has a direct influence upon the character and rate of milk fermentations induced by specific micro-organisms.

10. Confined milk does not ferment more readily than aërated milk. Aëration does not influence the amount of oxygen supply to the bacteria present.

11. Milk exposed freely to the air decreases in acidity for a. few hours after milking, then the acidity rises rapidly. Confined milk does not show a decrease in acidity after milking.

12. Carbon dioxid is one factor which keeps up the acidity of confined milk with phenolphthalein as indicator.

13. Closing milk-cans from the air reduces the amount of oxygen supply, therefore must change the conditions of germ life.

14. Aëration does not change the germicidal action of milk.

15. Aëration does influence the amount of oxygen supply to the bacteria present.

\section{The Reaction of Milk}

Fresh milk from most mammals reacts acid to rosolic acid and phenolphthalein, amphoteric to litmus, and alkaline to dimethylorange. Milk from carnivorous animals is usually more acid than milk from herbivorous animals. The acidity is due to acid phosphates, citrates, and casein; the alkalinity, to alkaline phosphates. Red litmus is turned blue; blue litmus, red. Carbon dioxid is partly responsible for the acid reaction and, since the carbon dioxid content decreases when milk is in contact with the air, there is a decrease in acidity for three to four hours after milking. After a lapse of about four hours the acidity increases rapidly, due to the activity of micro-organisms.

Raudnitz found that 1 liter of cow's milk required 17.5 c.c. of 
normal alkali for neutralization when phenolphthalein was the indicator, while human milk required but 2 c.c. per liter.

Acidity is higher at the beginning of lactation than at later periods. Milk from diseased cows is often more alkaline than normal milk.

\section{Variability in the Composition of Milk}

It has been mentioned that milks from different species of mammals contain practically the same constituents, but that the proportion of these substances varies within wide limits. Variation in composition is by no means confined to difference in species; in fact, there are conditions which cause considerable variability in the composition of milk within the same species. Furthermore, there are differences in composition of milk according to breed, individual character, and even in the milk from the same individual. The limits of variation in the composition of milk from different species may be seen from a table by Leach:

LIMITS OF VARIATION IN COMPOSITION OF MLLK FROM DIFFERENT MAMMALS

\begin{tabular}{|c|c|c|c|c|c|c|c|}
\hline Cow's milk: & $\begin{array}{l}\text { Specific } \\
\text { gravity. }\end{array}$ & Water. & Casein. & $\begin{array}{l}\text { Al- } \\
\text { bumin. }\end{array}$ & $\begin{array}{l}\text { Total } \\
\text { protein. }\end{array}$ & Fat. & $\begin{array}{l}\text { Lac- } \\
\text { tose. }\end{array}$ \\
\hline $\begin{array}{l}\text { Minimum...... } \\
\text { Maximum...... }\end{array}$ & $\begin{array}{l}1.0264 \\
1.0370\end{array}$ & $\begin{array}{l}80.32 \\
90.32\end{array}$ & $\begin{array}{l}1.79 \\
6.29\end{array}$ & $\begin{array}{l}0.25 \\
1.44\end{array}$ & $\begin{array}{l}2.07 \\
6.40\end{array}$ & $\begin{array}{l}1.67 \\
6.47\end{array}$ & $\begin{array}{l}2.11 \\
6.12\end{array}$ \\
\hline $\begin{array}{l}\text { Mean.......... } \\
\text { Human milk: }\end{array}$ & 1.0315 & 87.27 & 3.02 & 0.53 & 3.55 & 3.64 & 4.88 \\
\hline $\begin{array}{l}\text { Minimum...... } \\
\text { Maximum...... } \\
\text { Mean .......... }\end{array}$ & $\begin{array}{l}1.027 \\
1.032\end{array}$ & $\begin{array}{l}81.09 \\
91.40 \\
87.41\end{array}$ & $\begin{array}{l}0.18 \\
1.96 \\
1.03\end{array}$ & $\begin{array}{l}0.32 \\
2.36 \\
1.26\end{array}$ & $\begin{array}{l}0.69 \\
4.70 \\
2.29\end{array}$ & $\begin{array}{l}1.43 \\
6.83 \\
3.78\end{array}$ & $\begin{array}{l}3.88 \\
8.34 \\
6.21\end{array}$ \\
\hline Goat's milk & & & & & & & \\
\hline $\begin{array}{l}\text { Minimum...... } \\
\text { Maximum...... } \\
\text { Mean......... }\end{array}$ & $\begin{array}{l}1.0280 \\
1.0360 \\
1.0305\end{array}$ & $\begin{array}{l}82.02 \\
90.10 \\
85.71\end{array}$ & $\begin{array}{l}2.44 \\
3.94 \\
3.20\end{array}$ & $\begin{array}{l}0.79 \\
2.01 \\
1.09\end{array}$ & $\begin{array}{l}\cdots \\
4.29\end{array}$ & $\begin{array}{l}3.10 \\
7.55 \\
4.78\end{array}$ & $\begin{array}{l}3.26 \\
5.77 \\
4.46\end{array}$ \\
\hline Ewe's milk: & & & & & & & \\
\hline $\begin{array}{l}\text { Minimum...... } \\
\text { Maximum..... } \\
\text { Mean.......... }\end{array}$ & $\begin{array}{l}1.0298 \\
1.0385 \\
1.0341\end{array}$ & $\begin{array}{l}74.47 \\
87.02 \\
80.82\end{array}$ & $\begin{array}{l}3.59 \\
5.69 \\
4.97\end{array}$ & $\begin{array}{l}0.83 \\
1.77 \\
1.55\end{array}$ & $\begin{array}{l}\cdots \\
6.52\end{array}$ & $\begin{array}{l}2.81 \\
9.80 \\
6.80\end{array}$ & $\begin{array}{l}2.76 \\
7.95 \\
4.91\end{array}$ \\
\hline $\begin{array}{l}\text { Mare's milk: } \\
\text { Mean..... }\end{array}$ & 1.0347 & 90.78 & 1.24 & 0.75 & 1.99 & 1.21 & 5.67 \\
\hline $\begin{array}{l}\text { Ass's milk: } \\
\text { Mean....... }\end{array}$ & 1.036 & 89.64 & 0.67 & 1.55 & 2.22 & 1.64 & 5.99 \\
\hline
\end{tabular}

This table shows that the protein, fat, and sugar are subject to considerable variation, and that consequently the total solids and specific gravity also vary in proportion. It is obvious that the taste and food value must be different in the milks according to the prevalence of one or the other constituent.

Cow's milk has been studied more intensively than any other milk, and there are many observations referring to variations in the composition of cow's milk. As a general rule it can be stated that the fat is the most variable character; the protein follows next in importance, while the sugar is less variable, and the ash relatively constant.

It is clear that the variability in composition of milk is of economic importance. The food value of milk is proportionate 
to the amount of solids present; this is of special importance when the milk is destined for infant feeding. Furthermore, the digestibility of milk depends in a measure upon its composition, and finally butter and cheese makers are interested to know the quantity of products obtainable from a given milk. Not only the quantity but also the quality of milk products is influenced by the milk composition.

By far the majority of available data on the variability in the composition of milk refer to fat content. Relatively little attention has been given to other constituents of milk. Furthermore, samples for analysis have frequently been taken without consideration of such important factors as the kind and amount of food taken by the cow and the stage of lactation. There are, however, some apparently reliable data at hand and these will be discussed under the following heads:

1. Difference in composition due to breed.

2. Difference in composition due to individuality.

3. Difference in composition of milk from the same individual.

4. Difference in composition during the lactation period.

5. Difference in composition due to kind and quantity of food.

6. Difference in composition due to weather conditions and temperature.

7. Difference in composition due to exercise and other nervous influences.

8. Difference in composition due to the skill of the milker.

9. Difference in composition due to the health of the animal.

10. Difference in composition due to dilution of milk.

1. Difference in Composition Due to Breed.-It has been known for some time that reported analyses of milk from various countries show differences. Whether these are due in part to climatic conditions is not determined, but the theory has sometimes been advanced that the percentage of fat is lower in warm climates than in cold ones, since animals do not require as much heat energy in southern regions. However this may be, it is certain that the breeds which are most prevalent are responsible for marked differences in milk composition in various countries. That breeds differ widely in the composition of the milk they yield is shown by the following table taken from Swithinbank and Newman:

\begin{tabular}{|c|c|c|c|c|c|}
\hline Breed. & $\begin{array}{c}\text { Total } \\
\text { solids. }\end{array}$ & Fat. & $\begin{array}{l}\text { Lac- } \\
\text { tose. }\end{array}$ & $\begin{array}{l}\text { Pro- } \\
\text { tein. }\end{array}$ & Ash. \\
\hline American Grade Shorthorn... . . . . . . . & 13.17 & 401 & 4.36 & 4.06 & 0.74 \\
\hline 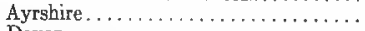 & 12.70 & 3.68 & 4.84 & 3.48 & 0.69 \\
\hline 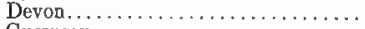 & 13.21 & 4.09 & 4.32 & 4.04 & 0.76 \\
\hline Guernsey . . . . . . . . . . . . . . . & 14.48 & 5.02 & 4.80 & 3.92 & 0.75 \\
\hline Holstein . . . . . . . . . . . . . . & 12.12 & 3.51 & 4.69 & 3.28 & 0.64 \\
\hline Jersey . . . . . . . . . & 14.34 & 4.78 & 4.85 & 3.06 & 0.75 \\
\hline 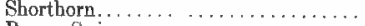 & 12.45 & 3.65 & 4.80 & 3. 27 & 0.73 \\
\hline Brown Swiss.................... & 13.06 & 4.00 & 4.30 & 4.00 & 0.76 \\
\hline
\end{tabular}


It can be seen here that the fat leads in variability, that the protein and total solids vary, and that the sugar and ash are the least variable.

Van Slyke and Publow give the following compositions of milk from different breeds of cows:

PERCENTAGE OF FAT AND CASEIN IN MILK FROM DIFFERENT BREEDS

\begin{tabular}{|c|c|c|c|}
\hline Breed. & $\begin{array}{l}\text { Per cent. } \\
\text { fat. }\end{array}$ & $\begin{array}{l}\text { Per cent. } \\
\text { casein. }\end{array}$ & $\begin{array}{l}\text { Relation of } \\
\text { fat to casein. }\end{array}$ \\
\hline 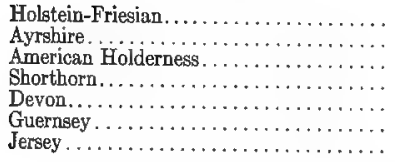 & $\begin{array}{l}3.26 \\
3.76 \\
4.01 \\
4.28 \\
4.89 \\
5.38 \\
5.78\end{array}$ & $\begin{array}{l}2.20 \\
2.46 \\
2.63 \\
2.79 \\
3.10 \\
2.91 \\
3.03\end{array}$ & $\begin{array}{l}1: 0.67 \\
1: 0.65 \\
1: 0.66 \\
1: 0.65 \\
1: 0.63 \\
1: 0.54 \\
1: 0.52\end{array}$ \\
\hline
\end{tabular}

These figures show clearly that with increased fat content the amount of protein also increases, although not in the same ratio. The fat increases at a greater ratio than the protein.

A careful and exhaustive study of the differences in the composition of milk from four important breeds was made by Eckles and Shaw. The authors examined samples of milk in four-week periods throughout the lactation period, thus eliminating one source of error resulting from the variation of fat during this period. The results are shown in the following table:

THE COMPOSITION OF MILK FROM DIFFERENT BREEDS OF COWS

\begin{tabular}{|c|c|c|c|c|c|c|c|c|c|c|}
\hline Breed. & $\begin{array}{l}\text { Total } \\
\text { solids. }\end{array}$ & Fat. & $\begin{array}{l}\text { Total } \\
\text { pro- } \\
\text { tein. }\end{array}$ & Casein. & Sugar. & $\begin{array}{l}\text { Size } \\
\text { of fat } \\
\text { glob- } \\
\text { ule. }\end{array}$ & $\begin{array}{l}\text { Reichert- } \\
\text { Meissl } \\
\text { number. }\end{array}$ & $\begin{array}{l}\text { Iodin } \\
\text { num- } \\
\text { ber. }\end{array}$ & $\begin{array}{l}\text { Koetts- } \\
\text { torfer } \\
\text { num- } \\
\text { ber. }\end{array}$ & $\begin{array}{l}\text { Melting- } \\
\text { point } \\
\text { of fat. }\end{array}$ \\
\hline 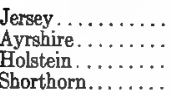 & $\begin{array}{l}14.00 \\
12.41 \\
11.38 \\
12.09\end{array}$ & $\begin{array}{l}4.95 \\
3.68 \\
3.09 \\
3.73\end{array}$ & $\begin{array}{l}3.64 \\
3.25 \\
2.93 \\
3.38\end{array}$ & $\begin{array}{l}2.93 \\
2.70 \\
2.36 \\
2.74\end{array}$ & $\begin{array}{l}4.87 \\
4.90 \\
4.51 \\
4.99\end{array}$ & $\begin{array}{l}328 \\
150 \\
142 \\
282\end{array}$ & $\begin{array}{l}26.73 \\
25.93 \\
25.46 \\
26.28\end{array}$ & $\begin{array}{l}30.52 \\
31.61 \\
34.20 \\
34.36\end{array}$ & $\begin{array}{l}228.9 \\
228.2 \\
229.1 \\
227.6\end{array}$ & $\begin{array}{l}32.95 \\
33.47 \\
32.88 \\
33.23\end{array}$ \\
\hline
\end{tabular}

The work of Eckles and Shaw brings out the following important facts in regard to the variability of milk constituents from the breeds examined:

Fat: The fat represents 28 to 35 per cent. of the total solids, and varies within these limits according to breed. While in Jersey and Guernsey milk an average of 34.9 per cent. of the solids is fat, it is but 28.1 per cent. in Holstein milk. According to Eckles and Shaw there seems to be no appreciable difference in the nature of the fat of different breeds, except in the size of the globules. In Jersey and Shorthorn milk large globules are predominant, while in Ayrshire and Holstein milk there are chiefly small globules. The relation of the size of globules is given in the following figures: Jersey milk, 328; Shorthorn milk, 282; Ayrshire, 150; Holstein, 142. This relation is graphically illustrated in circles in Fig. 25. 
The Reichert-Meissl number is lowest in Holstein fat, next higher in Ayrshire, and then follow Shorthorn and Jersey fat in the order named.

The variation in the iodin number is due to breed. In Shorthorn and Holstein fat it is higher than Ayrshire and Jersey fat. High iodin numbers are usually coincident with low ReichertMeissl numbers. The saponification number of Koettstorfer shows little variation, and the melting-point of fat is nearly the same.

Proteins: Jersey milk has a higher protein content than the other kinds. Holstein milk has the smallest amount. This shows that milk with high fat content has also a high protein percentage, but the two constituents do not increase in the same ratio.

The relation of the amount of casein to fat is about the same as the relation of the total protein to fat. Based on this fact,
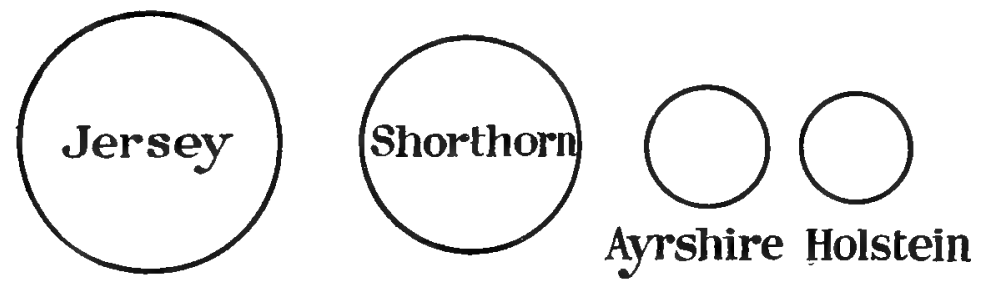

Fig. 25.-The relative size of fat globules (Eckles and Shaw).

Van Slyke has worked out a formula for determining the amount of casein in milk when the percentage of fat is known. If $F$. represents the percentage of fat in milk, the casein can be found by this formula:

$$
\text { (F. }-3) \text { by } 0.4+2.1=\text { percentage of casein in milk. }
$$

This formula gives the cheese maker a method for finding the amount of casein in milk after the fat content has been determined. It does not hold good when the milk is derived from cows in the last stages of lactation, since the protein is relatively high at this period. Of course, the formula is not applicable when refined results are desired.

Hart said that "the relation of casein to fat varies among animals of different herds and among animals of the same breed." Eckles and Shaw found similar relations. The following figures show the ratio between fat and casein: 
RATIO BETWEEN FAT AND CASEIN

\begin{tabular}{|c|c|c|c|c|}
\hline Breed. & Authority. & Fat & : & Casein. \\
\hline Guernsey ............. & Hart & 1.90 & : & 1 \\
\hline rthorn .... & Eckles and Shaw & 1.36 & : & 1 \\
\hline Jersey. & Hart & 1.72 & : & 1 \\
\hline Ayrshire. & Hart & $\begin{array}{l}1.69 \\
1.44\end{array}$ & $\vdots$ & $\begin{array}{l}1 \\
1\end{array}$ \\
\hline Ayrsmre. & Eckles and Shaw & 1.36 & : & 1 \\
\hline Holstein. & Hart & 1.49 & : & 1 \\
\hline & Eckles and Shaw & 1.31 & : & 1 \\
\hline
\end{tabular}

The figures show that breeds with high fat content usually have a wide ratio of fat to casein.

Van Slyke and Publow state that in milk with a high percentage of fat the albumin forms a smaller part of the total protein than in milk with low fat content, when the composition of different breeds is considered. Casein, on the other hand, forms a larger part of the total protein when the fat content is high. These statements are substantiated by Van Slyke and Publow by the following figures:

INFLUENCE OF BREED UPON RELATION OF CASEIN AND ALBUMIN

\begin{tabular}{|c|c|c|c|c|c|c|}
\hline Breed. & $\begin{array}{l}\text { Per cent. } \\
\text { fat. }\end{array}$ & $\begin{array}{l}\text { Per cent. } \\
\text { protein. }\end{array}$ & $\begin{array}{l}\text { Per cent. } \\
\text { casein. }\end{array}$ & $\begin{array}{l}\text { Per cent. } \\
\text { albumin. }\end{array}$ & $\begin{array}{l}\text { Relation } \\
\text { of casein } \\
\text { to al- } \\
\text { bumin. }\end{array}$ & $\begin{array}{l}\text { Per cent. } \\
\text { casein } \\
\text { of } \\
\text { protein. }\end{array}$ \\
\hline Holstein-Friesian. & 3.26 & 2.84 & 2.20 & 0.64 & $1: 3.4$ & .77 .5 \\
\hline Ayrshire. .......... & 3.76 & 3.07 & 2.46 & 0.61 & $1: 4.0$ & 80.1 \\
\hline American Holderness. . . . . . & 4.01 & 3.32 & 2.63 & 0.69 & $1: 38$ & 79.2 \\
\hline Shorthorn.............. & 4.28 & 3.43 & 2.79 & 0.64 & $1: 4.5$ & 81.3 \\
\hline Devon...................... & 4.89 & 3.93 & 3.10 & 0.83 & $1: 3.7$ & 78.9 \\
\hline Guernsey. & 5.38 & 3.56 & 2.91 & 0.65 & $1: 4.5$ & 81.7 \\
\hline Jersey...... & 5.78 & 368 & 303 & 065 & $1: 47$ & 82.3 \\
\hline
\end{tabular}

Jersey milk with a high percentage of fat has 82.3 per cent. of the total protein as casein and 17.7 per cent. albumin, while Holstein milk has only 77.5 per cent. of the total protein as casein and 22.5 per cent. albumin. This information is important to the cheese maker, who can obtain a higher yield of cheese from milk rich in casein.

White and Judkins show the variation in composition of milk from different breeds in the following figures:

VARIATION IN COMPOSITION OF MILK FROM DIFFERENT BREEDS

\begin{tabular}{|c|c|c|c|c|}
\hline \multirow{2}{*}{ Breed. } & \multicolumn{2}{|c|}{ Fat. } & \multicolumn{2}{|c|}{ Plasma solids. } \\
\hline & Average. & Limits. & Average. & Limits. \\
\hline 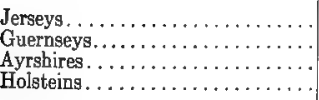 & $\begin{array}{l}5.32 \\
4.49 \\
4.10 \\
3.41\end{array}$ & $\begin{array}{l}4.25 \text { to } 6.49 \\
4.12 \text { to } 4.79 \\
3.85 \text { to } 4.42 \\
3.02 \text { to } 3.86\end{array}$ & $\begin{array}{l}9.07 \\
8.92 \\
8.82 \\
8.53\end{array}$ & $\begin{array}{l}8.52 \text { to } 9.56 \\
8.57 \text { to } 9.27 \\
8.62 \text { to } 9.24 \\
8.09 \text { to } 8.83\end{array}$ \\
\hline
\end{tabular}

Milk-sugar and ash: There is no appreciable variation in the percentage of sugar and ash in the milk of different breeds. 
The facts cited show clearly that milk from some breeds contains more nourishment than that from others. However, this is not an unqualified advantage, since fat consisting chiefly of large globules is not as readily digested as fat composed of small globules. Moreover, when milk is used for infant feeding the disadvantage of large globules of fat, coupled with the large number, is a decided disadvantage.

2. Difference in Composition of Milk Due to Individuality.Milk from individual cows may show considerable difference in composition. It occurs not infrequently that in a herd a cow will produce twice as much milk as another of the same breed, ancestry, age, and receiving the same feed and care. Eckles and Reed think that the difference in quantity produced is due to the amount of food consumed in excess of the quantity necessary for maintenance, and that the ratio between the food available for milk production and the milk produced is practically the same with each cow. A superior dairy cow, therefore, is one that is capable of using food in quantity above that required for maintenance and using the excess of food for milk production. The authors give figures on the quantity of milk and fat produced from two cows during two lactation periods as follows:

THE QUANTITY OF MILK AND FAT PRODUCED BY TWO JERSEY COWS

\begin{tabular}{|c|c|c|c|c|}
\hline & \multicolumn{2}{|c|}{ Cow 27.} & \multicolumn{2}{|c|}{ Cow 62.} \\
\hline & Lbs. milk. & Lbs. fat. & Lbs. milk. & Lbs. fat. \\
\hline 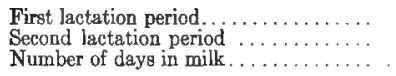 & $\begin{array}{l}4552 \\
7174\end{array}$ & $\begin{array}{l}238.8 \\
377.0\end{array}$ & $\begin{array}{r}878 \\
3189\end{array}$ & $\begin{array}{r}44.1 \\
114.8\end{array}$ \\
\hline
\end{tabular}

Reduced to the same number of days, Cow 27 during the first lactation period would have produced 2894 pounds of milk and 152 pounds fat; in the second lactation period she would have produced 4560 pounds of milk and 240 pounds fat. The productivity of cow 27 was, therefore, much greater than that of Cow 62. It is further worthy of note that during the second lactation period a larger quantity of milk was produced than during the first. That this is the usual experience has been referred to before.

Individual differences are made clear by a table given by Eckles and Reed, showing the records of daughters of the same sire: 
RECORDS OF THE DAUGHTERS OF THE SAME SIRE

\begin{tabular}{|c|c|c|c|c|}
\hline Cow. & $\begin{array}{c}\text { Number of } \\
\text { lactation periods. }\end{array}$ & Lbs. milk. & Lbs, fat. & Per cent. fat. \\
\hline 1 & 1 & 4910 & 205.5 & 4.18 \\
\hline 2 & 1 & 4728 & 267.0 & 506 \\
\hline 3 & 2 & 3450 & 193.7 & 5.60 \\
\hline 4 & 2 & 8807 & 462.1 & 5.25 \\
\hline 5 & 3 & 6750 & 365.8 & 5.40 \\
\hline 6 & 3 & 2225 & 109.4 & 4.90 \\
\hline 7 & 3 & 4723 & 227.0 & 4.81 \\
\hline 8 & 3 & 5336 & 273.7 & 5.10 \\
\hline 9 & $\mathbf{3}$ & 4960 & 223.8 & 4.50 \\
\hline 10 & 3 & 4909 & 287.9 & 5.86 \\
\hline 11 & 3 & 6582 & 355.9 & 5.40 \\
\hline 12 & 3 & 6844 & 331.0 & 4.84 \\
\hline 13 & 3 & 5271 & 238.5 & 4.50 \\
\hline 14 & 3 & 5776 & 320.6 & 5.55 \\
\hline 15 & 4 & 7746 & 405.6 & 5. 24 \\
\hline 16 & 4 & 5053 & 247.3 & 4.89 \\
\hline 17 & 4 & 4073 & 184.9 & 4.50 \\
\hline 18 & 5 & 6151 & 309.8 & 5.03 \\
\hline 19 & 5 & 6322 & 273.1 & 4.32 \\
\hline
\end{tabular}

If the total milk production of cows having the same number of lactation periods in the table is compared it will be seen that there is a great difference. The variation in fat is also considerable, a fact which is illustrated in the last column. All these cows were of the same sire, and the differences must be ascribed to individual differences in character.

In regard to the differences in quantity of milk constituents contained in the milk of individuals of the same breed, the general rule seems to be that the individual follows closely the average milk composition of her breed. Still there are variations even in this respect. The total solids, fat, and protein vary to some extent, while the milk-sugar-according to Eckles and Shawshows greater variation in milk from individual cows than the average of the breed. The ash, as might be expected, shows practically no variation. Usually the greater the fat and protein in the milk of a breed, the greater also is the individual variation. Therefore in Jersey milk individual variations are more marked than in the milk of other breeds.

3. Difference in Milk from the Same Individual.-A variation in the composition of milk from an individual cow exists: 1 , between milk from different milkings; 2 , between morning and evening milk; 3 , between fore-milk, middle milk, and strippings.

It is usually thought that the difference in composition under the three conditions mentioned is confined to the fat content. Fat unquestionably is the most variable factor, but other constituents vary also. In comparing analyses of morning and evening milk Eckles and Shaw give the extremes of fat variation in a series of tests as follows: 56 per cent. came within 0.3 per cent. of the average; 27.7 per cent. between 0.3 and 0.6 per cent.; 11.7 per cent. varied between 0.6 and 0.9 per cent. of the average, and 4.6 per cent. varied 0.9 per cent. from the average. 
The proteins varied less than 0.2 per cent., but the sugar not infrequently varied 0.5 per cent. from the average, although about 90 per cent. of the analyses showed a variation of less than 0.2 per cent.

Morning and evening milk differ chiefly in the greater fat content of the former. This, however, depends largely upon the period elapsing between milkings. When cows are milked twice daily, exactly twelve hours apart, the difference in fat content is slight. Eckles and Shaw state that there is no appreciable difference in the protein and melting-point of the fat and in the size of the fat globules. The Reichert-Meissl and the saponification numbers are lower in evening milk and the iodin number higher than in the morning milk. There is no noticeable variation in the amount of sugar.

There is then, on the whole, no great variation in the plasma solids between milkings when the intervals are of the same length, but the fat is slightly higher in morning milk than in evening milk.

Composition of Fore-milk, Middle Milk, and Strippings.-It is a well-known fact that the strippings contain more fat than either the middle milk or fore-milk. The reason for this phenomenon has been stated before. A few illustrations are given here:

DIFFERENCE IN FAT CONTENT OF DIFFERENT PORTIONS OF MILK (VAN SLYKE)

\begin{tabular}{|c|c|c|c|}
\hline & \multicolumn{3}{|c|}{ Percentage of fat in milk of- } \\
\hline & Cow 1. & Cow 2. & Cow 3. \\
\hline First portion drawn. & 0.90 & 1.60 & 1.60 \\
\hline Second portion drawn. . & 2.60 & 3.20 & 3.25 \\
\hline 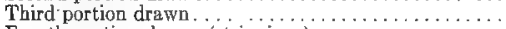 & 5.35 & 4.10 & 5.00 \\
\hline Fourth portion drawn (strippings) . ... . . . . . . . . & 9.80 & 8.10 & 8.30 \\
\hline
\end{tabular}
lows:

Leach gives figures comparing fore-milk and strippings as fol-

\begin{tabular}{|c|c|c|c|}
\hline & Water. & Solids. & Fat. \\
\hline Fore-milk. & & $\begin{array}{l}11.83 \\
11.27\end{array}$ & $\begin{array}{l}1.32 \\
1.07\end{array}$ \\
\hline Strippings. & $\left\{\begin{array}{l}80.32 \\
80.37\end{array}\right.$ & $\begin{array}{l}19.18 \\
19.63\end{array}$ & $\begin{array}{r}9.63 \\
10.36\end{array}$ \\
\hline
\end{tabular}

Richmond gives the following two tables, one showing the composition of morning and evening milk, the other the results of partial milking by analysis of six portions:

\begin{tabular}{|c|c|c|c|c|}
\hline \multicolumn{5}{|c|}{ COMPOSITION OF MORNING AND EVENING MILK } \\
\hline & $\begin{array}{l}\text { Specific } \\
\text { gravity. }\end{array}$ & $\begin{array}{l}\text { Total } \\
\text { solids. }\end{array}$ & $\begin{array}{l}\text { Plasma } \\
\text { solids. }\end{array}$ & Fat. \\
\hline 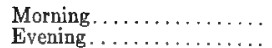 & $\begin{array}{l}1.0323 \\
1.0319\end{array}$ & $\begin{array}{l}12.47 \\
12.83\end{array}$ & $\begin{array}{l}8.91 \\
8.90\end{array}$ & $\begin{array}{l}3.56 \\
3.93\end{array}$ \\
\hline
\end{tabular}

These are averages for seventeen years throughout the year.

\begin{tabular}{|c|c|c|c|c|c|c|}
\hline \multicolumn{7}{|c|}{ PARTIAL MILKING } \\
\hline Portion. & 1 & 2 . & 3 & 4 & 5 & 6 \\
\hline 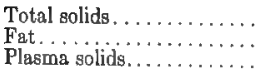 & $\begin{array}{r}10.47 \\
1.70 \\
8.77\end{array}$ & $\begin{array}{r}10.75 \\
1.76 \\
8.99\end{array}$ & $\begin{array}{r}10.85 \\
2.10 \\
8.75\end{array}$ & $\begin{array}{r}11.23 \\
2.54 \\
8.69\end{array}$ & $\begin{array}{r}11.63 \\
3.14 \\
8.49\end{array}$ & $\begin{array}{r}12.67 \\
4.08 \\
8.59\end{array}$ \\
\hline
\end{tabular}


An instructive series of tests, comparing the composition of fore-milk and strippings, not only in regard to fat but also as to other constituents, was published by Eckles and Shaw in the following complete table:

\section{ANALYSIS OF FORE-MILK AND STRIPPINGS}

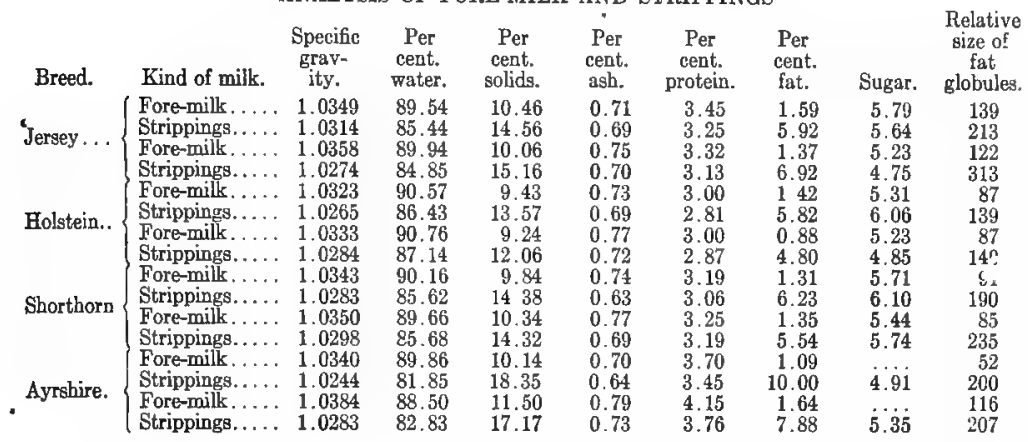

While sometimes the difference in the fat content of fore-milk and strippings is from less than 1 to 10 per cent., it should be remembered that these figures are more relative than they appear on the surface. That is to say, the smaller the quantity of foremilk and strippings examined, the greater will be the difference. The fat increases gradually from the first to the last streams, and it is known that the fat accumulates in the ducts by adhesion and perhaps by gravity, so that the last streams become the richest. The large globules remain tenaciously in the strippings until they are washed down by the last streams of milk, which require more energetic milking than the fore-milk.

The figures of Eckles and Shaw show that in fore-milk and strippings there is no appreciable difference in the plasma solias, protein, sugar, and ash. The only marked variation is in the fat content. While it is true that there is some variation in the specific gravity, this is in accord with the higher fat content.

The Reichert-Meissl, saponification, and iodin numbers are lower in the strippings than in the fore-milk, while the meltingpoint of the fat and the yellow color seem to be the same.

The marked difference in size of the fat globules is clearly indicated in the relative figures given in the last column.

A variation in composition of milk from the same cow has sometimes been observed to follow different calving periods, although this variation is probably not consistent and not marked. White and Judkins observed a decrease in fat from first calving to the mature condition, but state that the age factor was so small that other factors easily offset it. The same authors found that 
the physical condition of the cow seemed to have some influence on the quantity of plasma solids and fat. When the animals were in good condition the solids were relatively high in the beginning of the lactation period, but in a short time the normal was reached.

4. Variation in Composition of Milk During the Lactation Period. -The change in composition of milk during the lactation period has been determined by a number of investigators in this country and abroad. The variability of milk constituents during lactation naturally affects the food value and digestibility of milk. However, this is probably of consequence only when milk is derived from one or a few animals; usually market milk is obtained from a large herd of cows, and experience has shown that the composition of milk from a large herd is fairly well equalized.

The results of investigators are harmonious, on the whole, and may be summed up as follows: The quantity of milk diminishes as lactation advances, but the percentage of solids increases. This change is quite marked toward the close of lactation. Some observers have stated that during the first weeks there is a decline in the percentage of solids, and that after this period there is a small increase up to the eighth or ninth month, and all agree that during the last two or three months of the lactation period there is a marked increase in solids. The fat is usually considered the most variable factor, the proteins vary to a considerable extent, while the milk-sugar and ash remain nearly constant. The ReichertMeissl, iodin, and Koettstorfer numbers generally decrease with the progress of lactation. Hunziker's investigation led to the conclusion that after an initial rapid decrease during the colostral period and a few days afterward the protein decreases for two months, then remains constant for about three months, and finally increases up to the close of lactation.

The work carried on at the New York Experiment Station also showed conditions similar to those reported previously, namely: the quantity of milk diminished with progress of the lactation period; the fat content remained approximately stationary for about five months and then increased constantly. The number of small fat globules increased for the whole period, while the number of large ones decreased. The total solids declined slightly for one month and then increased to the close of lactation. The casein followed the decrease and increase of total solids, while the milk-sugar was relatively variable. The sugar at first decreased, then increased up to the tenth month, and finally decreased again. The percentage of ash remained practically constant.

The variability in composition during the lactation period has been extensively studied by Eckles and Shaw, whose results 
are, in general, in harmony with previous findings, and have added a great deal of valuable evidence to facts already known. With the exception of the ash content their work covers the quantitative change in milk constituents during the lactation period in a very thorough manner. The reports are given on milk examinations covering four-week periods during the whole length of lactation. The material was obtained from 11 cows belonging to four different breeds, namely, Jerseys, Holsteins, Ayrshires, and Shorthorns. The following table, condensed from the author's detailed reports, gives the total milk production and fat from the breeds whose milk was examined:

THE AMOUNT OF MILK AND FAT PRODUCED BY 3 JERSEYS, 3 HOLSTEINS, 2 AYRSHIRES, AND 3 SHORTHORNS DURING A LACTATION PERIOD IN FOUR-WEEK PERIODS

\begin{tabular}{|c|c|c|c|c|c|c|c|c|}
\hline \multirow{2}{*}{ Period. } & \multicolumn{2}{|c|}{ Jerseys. } & \multicolumn{2}{|c|}{ Holsteins. } & \multicolumn{2}{|c|}{ Ayrshires. } & \multicolumn{2}{|c|}{ Shorthorng. } \\
\hline & Lbs. milk. & Lbs. fat. & Lbs, milk. & Lbs, fat. & Lbs. milk. & Lbs, fat. & Lbs. milk. & Lbs, fat. \\
\hline 1 & 636.0 & 38.41 & 1058.2 & 32.69 & 725.1 & 28.48 & 745.9 & 29.95 \\
\hline 2 & 601.6 & 33.60 & 1071.5 & 30.62 & 727.2 & 26.59 & 699.6 & 26.74 \\
\hline 3 & 560.9 & 27.51 & 913.0 & 25.22 & 704.2 & 24.94 & 606.2 & 21.90 \\
\hline 4 & 553.3 & 26.31 & 813.8 & 25.24 & 674.5 & 23.95 & 596.2 & 20.76 \\
\hline 5 & 505.5 & 24.45 & 770.9 & 23.81 & 637.4 & 23.18 & 586.5 & 20.68 \\
\hline 6 & 487.4 & 23.97 & 729.6 & 21.72 & 666.0 & 23.27 & 550.2 & 19.47 \\
\hline 7 & 472.0 & 23.15 & 695.0 & 21.01 & 574,4 & 20.84 & 502.9 & 18.35 \\
\hline 8 & 451.5 & 21.60 & 686.3 & 21.12 & 483.5 & 18.16 & 462.7 & 17.17 \\
\hline 9 & 439.6 & 21.29 & 680.7 & 20.73 & 434.6 & 15.99 & 346.8 & 14.89 \\
\hline 10 & 456.6 & 22.22 & 560.1 & 18.46 & 355.6 & 13.30 & 196.0 & 8.12 \\
\hline 11 & 363.7 & 18.64 & 427.0 & 14.30 & 332.9 & 14.21 & 103.3 & 4.30 \\
\hline 12 & 270.0 & 14.71 & 359.3 & 13.10 & 235.0 & 9.30 & & \\
\hline 13 & 366.3 & 20.02 & 311.6 & 11.50 & 123.7 & 5.10 & $\ldots$ & $\ldots \ldots$ \\
\hline 14 & 150.9 & 9.74 & 139.7 & 5.20 & & $\ldots$ & $\ldots$ & $\ldots$ \\
\hline
\end{tabular}

The figures show that at the commencement of the second four-week period the quantity of milk from Holsteins and Ayrshires increased slightly, and from that time on decreased gradually for eight to ten periods, and rapidly toward the end of lactation. The apparent increase in Jersey milk production from the twelfth to the thirteenth period has no significance, as it is due to the dropping out of two of the animals which were less productive than the third one. This increased the figure, of course. The milk from the other two breeds diminished steadily, but in giving these figures in four-week periods an increase during the first period may be observed. The amount of fat produced was in proportion to the decrease of total milk-supply.

The detailed results of analyses of milk constituents during the period of lactation have been tabulated by the authors in a large number of elaborate tables from which the most important figures are incorporated in the following summary: 
THE VARIATION OF MILK CONSTITUENTS DURING THE LACTATION PERIOD IN FOURWEEK PERIODS

\begin{tabular}{|c|c|c|c|c|c|c|c|c|c|c|c|}
\hline Period. & $\begin{array}{l}\text { Total } \\
\text { pro- } \\
\text { tein. }\end{array}$ & $\begin{array}{l}\mathrm{Ca}= \\
\text { sein. }\end{array}$ & $\begin{array}{c}\text { Al- } \\
\text { bumin. }\end{array}$ & Fat. & Sugar. & $\begin{array}{l}\text { Total } \\
\text { solids. }\end{array}$ & $\begin{array}{l}\text { Size } \\
\text { of fat } \\
\text { glob- } \\
\text { ules. }\end{array}$ & $\begin{array}{c}\text { Reich- } \\
\text { ert- } \\
\text { Meissl } \\
\text { number. }\end{array}$ & $\begin{array}{l}\text { Iodin } \\
\text { num- } \\
\text { ber. }\end{array}$ & $\begin{array}{c}\text { Koetts- } \\
\text { torfer } \\
\text { num- } \\
\text { ber. }\end{array}$ & $\begin{array}{l}\text { Melt- } \\
\text { ing- } \\
\text { point } \\
\text { of fat. }\end{array}$ \\
\hline 1 & 3.25 & 2.68 & 0.300 & 4.00 & 4.87 & 12.74 & 357 & 29.13 & 33.28 & 233.7 & 31.73 \\
\hline 2 & 3.06 & 2.36 & 0.287 & 3.85 & 4.84 & 12.26 & 401 & 27.49 & 31.58 & 230.4 & 32.96 \\
\hline 3 & 3.06 & 2.49 & 0.255 & 3.79 & 4.94 & 12.29 & 249 & 27.06 & 32.22 & 231.0 & 32.82 \\
\hline 4 & 3.13 & 2.49 & 0.255 & 3.77 & 4.82 & 12.24 & 256 & 26.45 & 30.85 & 229.6 & 33.08 \\
\hline 5 & 3.25 & 2,62 & 0.262 & 3.82 & 4.80 & 12.35 & 200 & 26.58 & 31.36 & 229.2 & 33.28 \\
\hline 6 & 3.25 & 2.68 & 0.268 & 3.79 & 4.75 & 12.50 & 204 & 26.40 & 31.72 & 228.9 & 33.25 \\
\hline 7 & 3.32 & 2.68 & 0.274 & 3.83 & 4.88 & 12.61 & 201 & 25.52 & 32.06 & 225.7 & 33.32 \\
\hline 8 & 3.32 & 2.74 & 1. .268 & 3.85 & 4.83 & 12.70 & 192 & 25.20 & 33.26 & 226.7 & 33.41 \\
\hline 9 & 3.57 & 2.87 & 0.281 & 3.97 & 4.62 & 12.78 & 180 & 24.23 & 34.56 & 225.6 & 33,51 \\
\hline 10 & 3.83 & 3.06 & 0.306 & 4,11 & 4.55 & 13.16 & 152 & 22.48 & 35.41 & 223.4 & 33.94 \\
\hline 11 & 3.89 & 3.19 & 0.332 & 4.22 & 4.74 & 13.16 & 118 & 22.18 & 35.48 & 223.8 & 34.68 \\
\hline 12 & 4.08 & 3.38 & 0.357 & 4.54 & 4.91 & 14.04 & 166 & 20.29 & 35.17 & 220.6 & 33.85 \\
\hline 13 & 434 & 3.64 & 0.293 & 4.66 & 4.50 & 14.23 & 110 & 17.20 & 39.22 & 216.6 & 36.48 \\
\hline 14 & 4.08 & 3.70 & 0.287 & 5.08 & 5.01 & 15.29 & $\ldots$ & $\ldots$ & 39.03 & 20.0 & $\ldots \ldots$ \\
\hline
\end{tabular}

On the basis of these figures, the quantitative variation in milk constituents is, briefly, as follows:

Total Protein.-The total protein begins high right after the colostrum period, and diminishes for from four to six weeks. The lowest point is then maintained up to about the eighth month of the lactation period, and the percentage then rises. The rise is rapid toward the end of lactation.

There is a wide range of variation in the total protein during the lactation period; the variation on the basis of four-weekly figures is greater than that of fat. The daily fluctuations of fat, however, are always greater than those of protein.

In colostrum there is an abnormal amount of albumin and, therefore, the total protein is also great. The percentage then decreases rapidly up to a point when the decrease ceases. From this time on the increase is slight, but about two months before the close of lactation the increase is marked.

Eckles and Shaw think that the decline of protein after the colostrum period can be explained by assuming that the cow accumulates considerable of body substance during pregnancy and that part of this body fat is converted into milk protein, and "after calving she does not consume sufficient food to furnish maintenance and support milk production."

If the amount of protein in milk during the first four-weekly period of lactation is placed at 100 , the relation of the other periods becomes manifest. The successive figures are these: 100, 94, $94,96,100,100,102,102,110,118,120,125,133$. The initial decline, the constancy for four months, and the final increase are clearly expressed in these figures.

Casein.-The variation of casein is similar to that of total protein. If the amount of casein in the milk during the first period is placed at 100 , the relation of the amounts in the later periods compares as 100 to $88,93,93,100,100,102,107,114,119$, 
126, 136, and 138. The casein apparently declines for three periods, the next two periods are about equal to the original amount, and after these there is at first a slow, and later a rapid increase.

Albumin also varies according to the same rule as casein and total protein-up to the last month or two and during the final stage of lactation there is a rapid increase. Again, taking the amount of casein in the milk during the first period as 100 , the relation, as lactation progresses, is expressed in the following figures: 100 (first period), 95, 85, 85, 87, 89, 91, 89, 93, 102, 111, 119, 97, 96. The last two figures are from three cows whose lactation period exceeded that of the others, and, therefore, are likely to have no significance.

The relation of casein, albumin, and residual protein to total protein is expressed in the following table of Eckles and Shaw:

RELATION OF CASEIN, ALBUMIN, AND RESIDUAL NITROGEN TO TOTAL NITROGEN BY FOUR-WEEK PERIODS
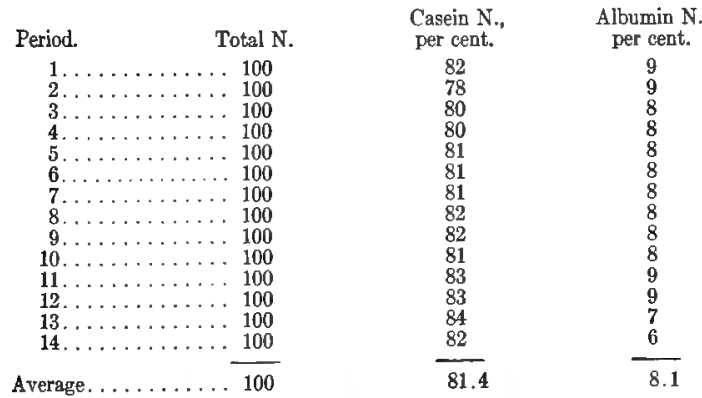

Residual N.

The relative quantities of casein, albumin, and total protein are consistent throughout the lactation period.

Van Slyke and Publow give a table on the relation casein and albumin bear to total protein, which shows also that the amount of these substances rises in nearly the same ratio during the lactation period. The figures of these authors follow:

INFLUENCE OF LACTATION UPON THE RELATION OF CASEIN TO ALBUMIN

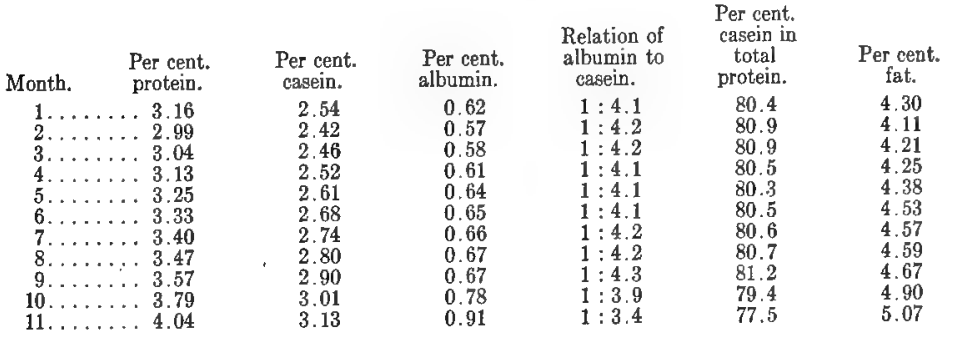


These figures show that the relation of casein to albumin remains constant up to the ninth month, after which the albumin increases more rapidly than the casein.

Fat.-The fat declines for about three months, to remain constant for the following four to five months, and finally to increase rapidly at the end of lactation. There is a parallelism between the increase or decrease of protein and fat, although the protein increase is somewhat greater than the fat increase. Therefore the protein is influenced in larger measure by the period of lactation than the fat. It should be remembered that other causes for variation in fat may be in operation at the same time that the change caused by progress of lactation is taking place. Among these causes are the differences in fat content between winter and summer milk; further, differences between changeable conditions of the animal, such as accumulation of body fat during pregnancy and other abnormal conditions. Any sudden decline in milk production is usually accompanied by a marked increase in solids, especially in fat.

The relation of fat to total protein, casein, and milk-sugar is demonstrated in the following table, compiled from the work of Eckles and Shaw. The fat is uniformly placed at 1 .

RELATION OF FAT TO TOTAL PROTEIN, CASEIN, AND MILK-SUGAR

$\begin{array}{cccc}\text { Period. } & \text { Fat : total protein. } & \text { Fat : casein. } & \text { Fat : milk-sugar. } \\ 1 & 1: 0.81 & 1: 0.67 & 1: 1.22 \\ 2 & 1: 0.79 & 1: 0.61 & 1: 1.30 \\ \mathbf{3} & 1: 0.81 & 1: 0.66 & 1: 1.36 \\ \mathbf{4} & 1: 0.83 & 1: 0.66 & 1: 1.31 \\ \mathbf{6} & 1: 0.85 & 1: 0.69 & 1: 1.29 \\ \mathbf{7} & 1: 0.86 & 1: 0.71 & 1: 1.30 \\ \mathbf{8} & 1: 087 & 1: 070 & 1: 1.28 \\ \mathbf{9} & 1: 0.86 & 1: 0.71 & 1: 1.20 \\ 10 & 1: 0.90 & 1: 072 & 1: 1.13 \\ 11 & 1: 0.93 & 1: 0.74 & 1: 1.16 \\ 12 & 1: 0.92 & 1: 0.76 & 1: 1.12 \\ 13 & 1: 0.93 & 1: 0.74 & 1: 1.05 \\ 14 & 1: 0.80 & 1: 0.78 & 1: 1.06\end{array}$

In total protein and casein the figures approach each other, which shows that, as the lactation period advances, protein and casein increase at a more rapid pace than does the fat. The figures giving the relation of milk-sugar and fat also approach each other, but this shows that the fat increases while the milk-sugar remains practically unaltered.

The ratio between fat and total protein is reduced constantly as shown in the above table. This is due, of course, to a greater increase of fat than of protein. The relation of fat to casein is shown in the following table of Van Slyke and Publow: 
RELATION OF FAT AND CASEIN DURING THE LACTATION PERIOD

$\begin{array}{cccc}\text { Month. } & \begin{array}{c}\text { Per cent. } \\ \text { fat. }\end{array} & \begin{array}{c}\text { Per cent. } \\ \text { casein. }\end{array} & \begin{array}{c}\text { Relation of fat } \\ \text { to caseiu. }\end{array} \\ 1 & \mathbf{4} .30 & 2.54 & 1: 0.59 \\ \mathbf{2} & 4.11 & 2.42 & 1: 0.59 \\ 3 & 4.21 & 2.46 & 1: 0.58 \\ 4 & 4.25 & 2.52 & 1: 0.59 \\ 5 & 4.38 & 2.61 & 1: 0.60 \\ 6 & 4.53 & 2.68 & 1: 0.59 \\ 7 & 4.57 & 2.74 & 1: 0.60 \\ 8 & 4.59 & 2.84 & 1: 0.61 \\ 9 & 4.67 & 2.90 & 1: 0.62 \\ 10 & 4.90 & 3.01 & 1: 0.62 \\ 11 & 5.07 & 3.13 & 1: 0.62\end{array}$

According to these figures, the casein decreases in somewhat greater proportion than the fat, and toward the end of lactation increases in greater proportion.

Milk-sugar is less variable than either proteins or fat. This is agreed to by all authorities. The amount of sugar is very constant throughout the whole lactation period with the exception of a slight decline toward the end.

Total Solids.-The total solids naturally follow the decrease and increase of proteins and fat, modified only by the relative constancy of the milk-sugar and ash. There is a decline during the first and sometimes during the second month, followed by little change up to the eighth or ninth month, and finally a marked increase.

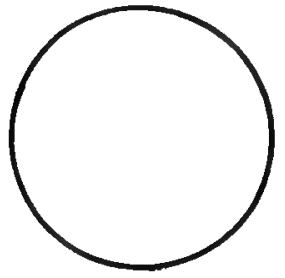

Fig. 26.-The decrease of the fat globules during the lactation period (Eckles and Shaw).

In the experiments of Eckles and Shaw the protein represented 27 per cent. of the total solids at the beginning of lactation, and increased so that at the end 3 per cent. were added. Casein increased slightly more than the total solids, while albumin increased slightly less. The fat constituted 31.3 per cent. of the total solids and increased 2 per cent. by the time the end of lactation was reached. The milk-sugar averaged 37 per cent. of the total solids. In the beginning it was 38.2 per cent. and at the end 32.8 per cent.

The relative increase of sugar as compared with that of fatin the beginning of the lactation period-is only apparent, and is due to the decrease of fat. The sugar remains nearly constant except for a decline toward the close of lactation.

The fat globules underwent a characteristic change during 
lactation. For the first six weeks there was a marked decline; then they remained fairly constant in size, and at the close of lactation decreased rapidly. The number of globules increased as the size diminished. Graphically the decrease in size is given in Fig. 26.

According to Eckles and Shaw the melting-point of the fat rose slightly as the size of the globules diminished. However, at the end of lactation there was sometimes a marked rise.

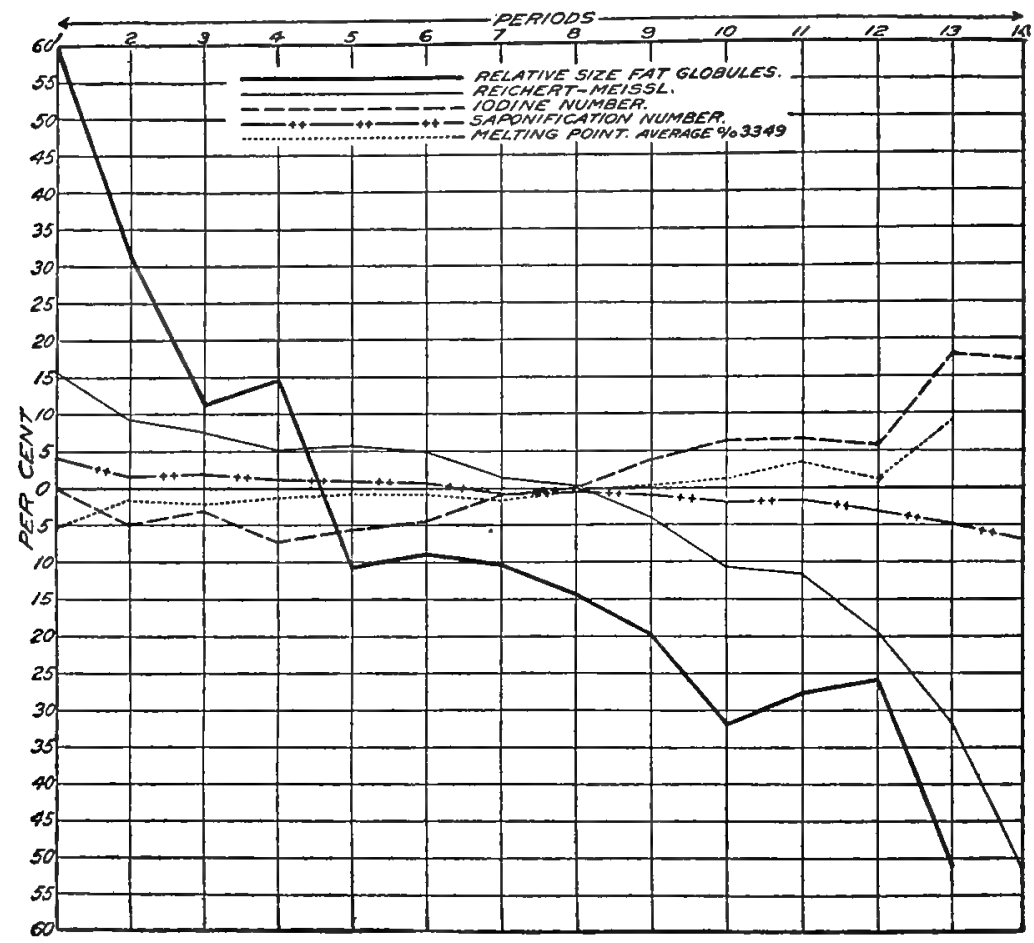

Fig. 27.-Chart showing the relative size of fat globules, the Reichert-Meissl number, the iodin number, the saponification number, and the melting-point (Eckles and Shaw).

The Reichert-Meissl number decreased gradually during the major part of the lactation period and declined more rapidly toward the end. There is a remote possibility that butter has a lower Reichert-Meissl number than 25 if obtained from the milk of a small herd with a number of cows in the last stages of lactation. Richmond suggests that butter with a lower number than 25 must be looked upon as suspicious, but such an assumption should be treated with caution. 
The iodin number was irregular in the beginning, then increased gradually to within two or three months of the end of lactation, with a rather sharp rise during the last weeks. The coincident increase of the melting-point is probably due, as Eckles and Shaw suggest, to a decrease in butyrin, which has a meltingpoint below that of olein.

The Koettstorfer saponification number declined with fair uniformity throughout the lactation period.

The chart (Fig. 27) plotted by Eckles and Shaw clearly shows the curves of the size of the fat globules, the Reichert-Meissl, iodin, and saponification numbers, and the melting-point of fat.

Eckles and Shaw observed an abnormal odor and taste in the milk of some cows near the close of lactation. This peculiarity was not noticeable in the freshly drawn milk, but appeared within twelve hours, even when the milk was kept at $10^{\circ} \mathrm{C}$.

The specific gravity of milk falls for a few weeks after the colostral period, and then rises constantly.

All authorities agree that the ash remains remarkably uniform throughout the lactation period. However, there are slight changes similar to those of the other milk constituents which indicate a slight decline during the first three months. This decline is followed by a slight rise for four months and a rather more rapid rise during the last three months. Trunz gives the following figures to illustrate this point:

THE VARIABILITY OF ASH IN MILK

\begin{tabular}{|c|c|c|}
\hline Period. & $\begin{array}{l}\text { Cow } 1 \text {, } \\
\text { per cent. }\end{array}$ & $\begin{array}{c}\text { Cow } 2 \text {, } \\
\text { per cent. }\end{array}$ \\
\hline 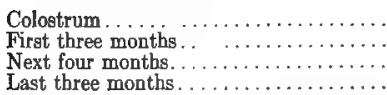 & $\begin{array}{l}0.774 \\
0.659 \\
0.663 \\
0.754\end{array}$ & $\begin{array}{l}0.758 \\
0.709 \\
0.764 \\
0.825\end{array}$ \\
\hline
\end{tabular}

These figures refer to crude ash. The pure ash gives the following results:

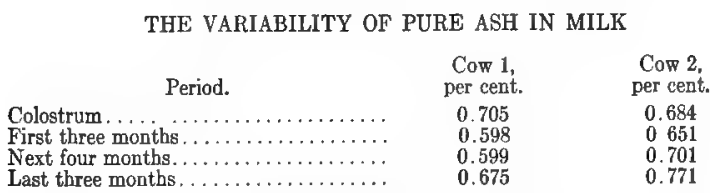

The initial decline of the ash is probably explained by the high ash content of colostrum, which gradually decreases as the lactation period advances. Trunz found 1.052 per cent. of ash in the first milking after the birth of the calf and only 0.687 per cent. on the sixth day. At the end of lactation he found 0.861 per cent. ash 
in the milk from one cow and 0.937 per cent. in that from the other cow.

The variation of the chief constituents of ash, according to Trunz, is, briefly, as follows:

Potassium is present in smaller quantity in colostrum than in later milk. It reaches a maximum in the second month, then declines slowly at first and rapidly during the last two months.

Sodium declines slightly during the first half of the lactation period and rises markedly during the second half. However, it is subject to considerable variation.

Calcium is higher in colostrum than in normal milk and remains about the same after the normal quantity has been reached up to the third month before the close of lactation, when it rises slowly. This rise is probably due to the increased amount of casein present at the end.

Chlorin is fairly constant throughout the lactation period. The quantity is somewhat smaller in colostrum than in normal milk and rises constantly to the end of lactation.

Phosphoric acid is higher in colostrum than in normal milk and declines slowly after the colostral period, at first gradually and then more rapidly. In pure ash there is a rise for three weeks and then a slow decline.

Iron and sulphuric acid are present in milk in such small amounts that no change can be observed.

If a summary is taken of the variations in milk during the lactation period the general aspect is shaped about as follows: During the first three to six weeks of lactation the proteins, fat, and ash decrease; the size of the fat globules declines rapidly; the melting-point of the fat is high and the iodin, Reichert-Meissl, and saponification numbers are variable. After this first period the compensation remains fairly constant for a period up to within about two months of the end of lactation. This period varies according to the whole length of the lactation period. The longer the whole period, the longer will the composition remain practically unchanged. The sugar remains constant; the size of the fat globules declines slowly, as do the Reichert-Meissl and saponification numbers. Within two months 'of the end of the lactation period there are marked changes. Proteins rise markedly, the fat also rises somewhat, the sugar may decline, and the ash rises. The fat globules become very small; the melting-point of the fat rises; the iodin number increases, while the Reichert-Meissl and saponification numbers decline.

Gestation does not influence the composition directly, but may do so indirectly by shortening the period of lactation. A variation of composition accompanying gestation is, therefore, only the 
normal variation usually observed during the lactation period. Such are the conclusions reached by Palmer and Eckles from a recent study of this question.

5. Influence of Food on Milk.-Authorities agree that the food given to the cows has an intimate connection with milk production, speaking both quantitatively and qualitatively. As a rule producers have the firm conviction that they can increase the yield of milk and fat by feeding certain foods rich in protein and fat. Scientific investigations which have been carried on in this country and abroad have not entirely confirmed this belief. The use of drugs for increasing the yield of milk and butter-fat has, according to McCandlish, also proved futile.

Studies on suitable rations for cows were commenced by German investigators about the middle of the last century and standards for food balances proposed. A comprehensive literature has accumulated since that time, and valuable contributions have originated in Germany, Denmark, France, and from experiment stations in this country. Prominent among these are the stations of Vermont, Wisconsin, New York, Illinois, Missouri, Minnesota, Pennsylvania, Ohio, Connecticut, Utah, Kentucky, Michigan, Massachusetts, Maine, Texas, and others.

Although there are some points on which there is still some difference of opinion, the main results of these studies are harmonious. Contradictory results have been harmonized by perfecting the nature of the experiments. Sometimes the period of observation has been too brief to warrant the conclusions drawn, as it is known that sudden changes in food and of other factors, for that matter, cause temporary changes in the quantity and quality of the milk produced. These changes gradually disappear and opinions based on short period observations have no lasting value. It is now generally agreed that feeding experiments should cover a sufficient length of time to get the animal accustomed to the new rations, and several months are therefore required to get results. The longer the animals remain under observation, the more valuable and trustworthy are the results.

Like other animals, the cow requires protein, fat, and carbohydrate in suitable ratio and quantity. Food is utilized for three purposes, namely: 1 , for the growth of young animals; 2 , for maintenance, that is to say, sufficient food of the right kind and quantity to maintain weight without gain or loss, and 3, for milk production. As a rule a good dairy cow is able to convert food in excess of her maintenance requirement into milk. However, when food is scant a cow will produce milk for a.considerable length of time by converting body substance into milk in order to care for her young and preserve the species. Under such condi- 
tions the quantity of milk gradually diminishes and the quality suffers.

As shown previously, each breed of cows produces milk of characteristic composition. Furthermore, some breeds are known to be large producers, others the reverse. It has also been noted that individual cows differ in the quantity and quality of milk produced. This shows that quantity and quality are determined by breed and individuality, and authorities are now of the opinion that it is impossible to materially and permanently alter the milk of a given breed or individual. The influence of food upon milk production becomes apparent when underfed cows are dealt with, or those that have received improperly balanced rations. This has been borne out by a large number of trustworthy observations. When a poorly or injudiciously fed herd is placed on a well-balanced ration milk production is increased and the quality improved. But this change cannot go beyond the limit which the breed or individual is capable of producing.

Wing and Foord cite an experience with a herd whose production was increased 50 per cent. The fat increased $\frac{1}{4}$ of 1 per cent. This was accomplished by feeding properly balanced rations in suitable quantity. Fraser has shown that on a balanced ration of a $1: 6$ ratio 6 cows produced as much milk as 9 on a $1: 11$ ration.

The "nutritive ratio" expresses the relation of protein to carbohydrate and fat. The sum of the weight of digestible carbohydrate plus two and one-fourth times the weight of digestible fat is divided by the weight of the digestible protein in the food. The result is the nutritive ratio. Investigations have shown that protein furthers milk flow and improves the quality. Woll therefore argues that a narrow ratio leads to higher milk production than a wide ratio. He suggests a standard of 2.15 pounds protein for 1000 pounds of body weight with sufficient fat and carbohydrate to make the nutritive ratio $1: 6.9$. Beach's experience leads him to advocate 2.5 pounds protein and a ratio of $1: 5.6$. Wheeler found that narrowing the ratio had a favorable effect upon milk production, while widening it tended toward the reverse.

The kind of food given is not a matter of indifference. Digestibility and the presence of water must be considered. Dry fodder does not further milk flow as well as succulent food, but moistening the food will not take the place of giving fresh, succulent fodder. It follows that a change from the stable to pasture in early spring increases the milk flow and the content of solids.

However, other conditions unquestionably aid in increasing the milk flow from cows that are turned into the pasture after having spent the winter in a stable. Exercise, fresh air, and sun- 
shine have a stimulating effect on their general health, and this tends to increase their milk production.

When cows feed throughout the year on nature's balanced ration in the open air a difference is observable between the milk production of the winter months and that of the spring and summer months. During the former food is scarce and not in as good a condition as in the latter months. In countries where climatic conditions make this possible the winter yield of milk is not as rich as that of the summer months.

Attempts at feeding fat into milk by mixing substances rich in fat with the food have not been successful. It is true that Caspari fed iodized fat and recovered iodin from the milk, although he was not able to find iodin in the milk when iodocasein or iodoalbumin was fed. But this proves only that fat in the food is in part the source of milk-fat, and it does not indicate an increase in milk-fat when fed in large quantities. Tallow has been fed with the same object in view, also without success. Furthermore, oils have been emulsified to render them easily digestible and have been mixed with the food. Such excessive rations of fat seem to increase the fat content of milk for a time, but as soon as the animal becomes accustomed to the change in food the normal composition of the milk reappears.

However, feeding oils and other fats has an influence upon the chemical composition of milk-fat. This has been proved conclusively. For example, when cottonseed oil is fed, the butter-fat gives cottonseed reaction, according to Woods. Cottonseed oil produces a hard butter; gluten, a soft butter. The firmness of the fat, the melting-point, the iodin number, the quantity of volatile acids, appearance, taste, and flavor are affected by the kind of fat given in the food.

Feeding foods rich in fat has been attempted in the expectation that they would increase the richness of the milk. Cottonseed meal, cocoanut cake, linseed cake meal, palm nut meal, peanut cake meal, malt sprouts, gluten feeds, brewers' grains, molasses feed, and others have increased the fat content for a short period, but the normal composition has gradually reappeared.

It must be admitted that the influence of the food given upon quantity of milk produced and on its composition is of far-reaching importance, inasmuch as careless feeding, underfeeding, or feeding unbalanced rations reduce the normal productivity of a cow. Judicious feeding, on the other hand, and any factor which preserves the health of the animal will cause her to produce the quantity and quality of milk which she is capable of producing. A careful milk producer will feed rational mixtures and vary them 
according to the demands of the individual cow and thus insure maximum production.

A cow producing rich milk requires a larger supply of good food with a larger proportion of protein than one producing a poor grade of milk. At the end of the lactation period, when the solids of milk are relatively high, still more food is required than at other times. Furthermore, young cows require more food than older ones, because the requirement for growth exists.

Woll and Humphrey have established the rule that each cow should receive as many pounds of grain per day as she produces pounds of butter-fat per week, or one-fourth to one-third as much grain as she gives pounds of milk daily. In addition, she should have as much roughage as she will eat up clean, preferably succulent food, as grass, silage crops, and roots.

The flavor of milk is influenced to a marked degree by the food. Grazing on pastures in spring and summer produces a desirable flavor and color of butter unless strongly flavored vegetation is present. Objectionable flavors are produced by a number of vegetables, such as cabbage, turnips, wild onions, spoiled silage, rape, etc.

The effect of water in the ration on the composition of milk has recently been studied by Turner, Shaw, Norton, and Wright. The authors sum up the results of their work in the statement "that the watery character of the ration has no effect upon the fat content of the milk," and they state further that there was no variation observable in the milk constituents, and that rations of varying water content have no effect upon the composition of the milk.

6. Influence of Weather and Temperature on Milk.-It has been mentioned that there are seasonal variations in the composition and quantity of milk produced. Van Slyke and Publow have stated that the greatest production of milk and fat commences about the middle of May and continues for several months. Eckles and Shaw, on the other hand, seem to think that milk produced in the fall and early winter has a higher percentage of fat than milk produced in early spring and summer. Van Slyke and Publow cite in support of their opinion not only their own analyses in New York State, but claim that reports of the Vermont and Wisconsin Experiment Stations are in harmony with their own. Possibly climatic conditions have some bearing on this point.

White and Judkins believe that fat and plasma solids are lower in summer than in winter and that the plasma solids decline at a greater rate than the fat. "The general direction of both the fat and solids-not-fat tests for the winter calving cows is up, down, 
and up; for the summer calving cows it is down and up; and for fall calving cows gradually up and down." They state further that "season and stage of lactation operate together in fall and winter and in opposite direction in the summer."

Lythgoe states that in Massachusetts the legal limit of 13 per cent. solids was reduced to 12 per cent. for May and June in 1886 on account of the lower solids in warm weather. In 1896 the fat standard of 3.7 per cent. was reduced to 3 per cent. for April, May, June, July, and August, and in 1899 September was added to these months. In 1908 a uniform standard of 12.15 per cent. solids and 3.35 per cent. fat was established for the entire year.

According to Trunz the ash content is smaller in spring and summer than in winter.

The fat increases slightly when the temperature is falling and declines when it is rising. The stable should be comfortable. If it is either too warm or too cold the fat decreases. Shelter from cold and inclement weather preserves the normal composition of milk, while exposure injures it. Warm drinking-water increases the flow of milk, probably because cows drink more of the warm water than of the cold.

Good or bad weather and storms seem to have no noticeable effect on the milk-supply.

7. Exercise and Nervous Influences.-Moderate exercise reduces the milk flow, but the milk is then richer in fat. A great deal of exercise, such as climbing hills, unfavorably influences the amount and kind of milk produced.

Any adverse nervous influence impairs the milk-supply. Illtreatment, sudden fright, shock, or rage materially reduce the quantity and quality of the milk.

8. Influence Due to the Skill of the Milker.-It is a usually accepted fact that a skilful milker can obtain a richer milk from a cow than an inexperienced milker. This is explained by the fact that a good milker empties the udder and adds the rich milk from the upper parts of the udder to the bulk. Furthermore, it is frequently claimed that a cow must become accustomed to the same milker in order to readily yield her whole supply. Carlyle doubts the accuracy of this statement. After a series of experiments he came to the conclusion that in so far as the amount of milk and total production of butter-fat is concerned the changing of milkers at every milking resulted in a direct gain with but two exceptions. The increase, however, was so slight that very little importance can be attached to it. The author concluded from his experiments that changing milkers has no appreciable effect upon the milk and butter produced when all the cows in a herd are kindly treated. 
9 and 10. Differences in composition of milk due to the health of the animal and to dilution of milk are discussed in other connections.

\section{Changes in Composition of Milk}

After milk has left the udder rapid physical changes occur and decomposition sets in due to the action of micro-organisms. While in the udder, the decomposition of milk proceeds slowly, as there are forces at work which restrain growth of bacteria. Furthermore, gases do not escape, and the rising of the fat is slow, since the milk is more or less in constant motion. As soon as the milk has left the udder conditions are materially changed. Microorganisms multiply rapidly, causing profound changes in composition; the gas escapes in large quantity and the fat rises. Besides these conditions milk may be exposed to freezing temperature, heating, centrifugation, etc. For convenience these causes may be grouped as follows:

1. Spontaneous changes.

2. Freezing.

3. Heating.

4. Centrifugation.

5. Dialysis.

6. Electricity.

7. Micro-organisms and enzyms.

Spontaneous Changes.-When milk stands in contact with the air an exchange of gases takes place, as has been stated before. By absorption of oxygen and nitrogen and release of carbon dioxid an equilibrium with the air is established. The loss of gases increases the specific gravity, while the loss of carbon dioxid reduces the acidity. This loss amounts to about $0.5 \mathrm{~N} . \mathrm{NaOH}$ per liter. Further, some soluble phosphates are rendered insoluble by the loss of carbon dioxid and are precipitated, but remain suspended. Milking machines depending upon suction remove the gases rapidly and more completely than mere intercourse with the air.

The rising of the fat globules is also a spontaneous change, but since this has been fully discussed previously it is only necessary to mention this phenomenon here for the sake of completeness.

Freezing of Milk.-Milk may freeze accidentally or may be frozen artificially to preserve it for transportation. Milk as it freezes undergoes profound physical changes which are more pronounced the longer it remains frozen. Under no conditions is thawed milk exactly the same in every respect as unfrozen milk.

The freezing-point of milk is slightly below that of water, as has been stated before. This is due to the presence of solids in solution. Milk freezes about $0.55^{\circ} \mathrm{C}$. below the freezing-point of 
water, but it does not freeze completely, according to Hastings, since the water freezes first and the solids form a more highly concentrated solution with depression of the freezing-point. The water freezes at first at the outside on the wall of the vessel; the solids are forced toward the center; a more concentrated solution is formed, and this freezes at lower temperature. The fat rises and is partially churned when the milk freezes. The natural emulsion of fat is never completely restored after thawing and the casein appears in flakes rather than in the original colloidal condition. The fat content of the upper layers may be three times as high as the original amount and much higher in the central portion of the milk than at the periphery. The emulsion of fat is destroyed more rapidly than the colloidal condition of the casein. Milk which has been frozen and then thawed is said to decompose more rapidly than normal milk.

Analyses of frozen milk are given by Mai, and the following table gives some of his figures. The degree of acidity is expressed in degrees or that amount of one-fourth normal alkali required to neutralize 100 c.c. of milk. For convenience the writer has calculated the acidity in lactic acid.

INFLUENCE OF FREEZING ON THE COMPOSITION OF MILK

\begin{tabular}{|c|c|c|c|c|c|c|}
\hline & $\begin{array}{l}\text { Specific } \\
\text { gravity. }\end{array}$ & $\begin{array}{c}\text { Refrac- } \\
\text { tion. }\end{array}$ & Fat. & $\begin{array}{l}\text { Solids, } \\
\text { not fat. }\end{array}$ & $\begin{array}{l}\text { Degrees, } \\
\text { acidity. }\end{array}$ & $\begin{array}{l}\text { in lactic } \\
\text { acid. }\end{array}$ \\
\hline $\begin{array}{l}\text { Sample 1: } \\
\text { Original milk. }\end{array}$ & 1.0317 & 38.5 & 3.4 & 8.87 & 6.5 & 0.146 \\
\hline Upper loose ice. & 1.0233 & 37.5 & 11.1 & 8.57 & $\ldots$ & ... \\
\hline Solid ice wall.......... & 1.0165 & 28.0 & 3.2 & 4.92 & $\ldots$ & $\ldots \ldots$ \\
\hline Liquid part. & 1.0534 & 52.2 & 2.0 & 1385 & & \\
\hline Reunited.... & 1.0321 & 38.5 & 3.3 & 895 & 7.3 & 0.164 \\
\hline \multicolumn{7}{|l|}{ Sample 2: } \\
\hline Original milk............ & 1.0312 & $\begin{array}{l}38.7 \\
35.3\end{array}$ & $\begin{array}{l}3.6 \\
3.0\end{array}$ & 8.78 & 7.1 & 0.16 \\
\hline $\begin{array}{l}\text { Crystals from sieve....... } \\
\text { Liquid part. . . } \ldots \ldots \ldots \ldots\end{array}$ & 1. 0352 & 41.3 & $\begin{array}{l}5.0 \\
2.9\end{array}$ & 965 & 8.0 & 0.18 \\
\hline Solid ice............. & 1.0172 & 30.4 & 5.8 & 5.75 & 3.8 & 0.085 \\
\hline Reunited.................. & 1.0320 & 38.7 & 3.5 & 8.96 & 7.4 & 0.167 \\
\hline \multicolumn{7}{|l|}{ Sample 3: } \\
\hline Original milk $\ldots \ldots \ldots \ldots$ & 1.0318 & 38.6 & 3.7 & 8.94 & 6.2 & 0.139 \\
\hline Upper loose ice. . . . . . . & 1.0256 & 40.2 & 11.6 & 9.30 & 8.2 & 0.185 \\
\hline Liquid part... & 1.0534 & 53.5 & 3.3 & 14.17 & 11.0 & 0.248 \\
\hline Hard ice...... & 1.0201 & 301 & 2.9 & 5.75 & 3.8 & 0.086 \\
\hline Reunited. & 1.0320 & 38.7 & 3.6 & 8.97 & 7.2 & 0.162 \\
\hline
\end{tabular}

The table shows that the upper layers have lower specific gravity than the original milk, but considerably more fat, while the solids have not changed materially. The central liquid portion has a much higher specific gravity than the original milk, much higher solids, and somewhat less fat. The thawed reunited milk differs from the original milk chiefly in having higher acidity. Since the mineral constituents of the milk go to the central part which remains liquid longer than the other parts of the milk, the acidity of this part is somewhat higher than that of the original milk.

The changes indicated by chemical analysis do not show the above-mentioned physical changes in the fat. Milk which has 
been frozen is not as readily digested as unfrozen milk, since the emulsion of the fat has been interfered with.

The following analyses given by Richmond show similar conditions in frozen milk:

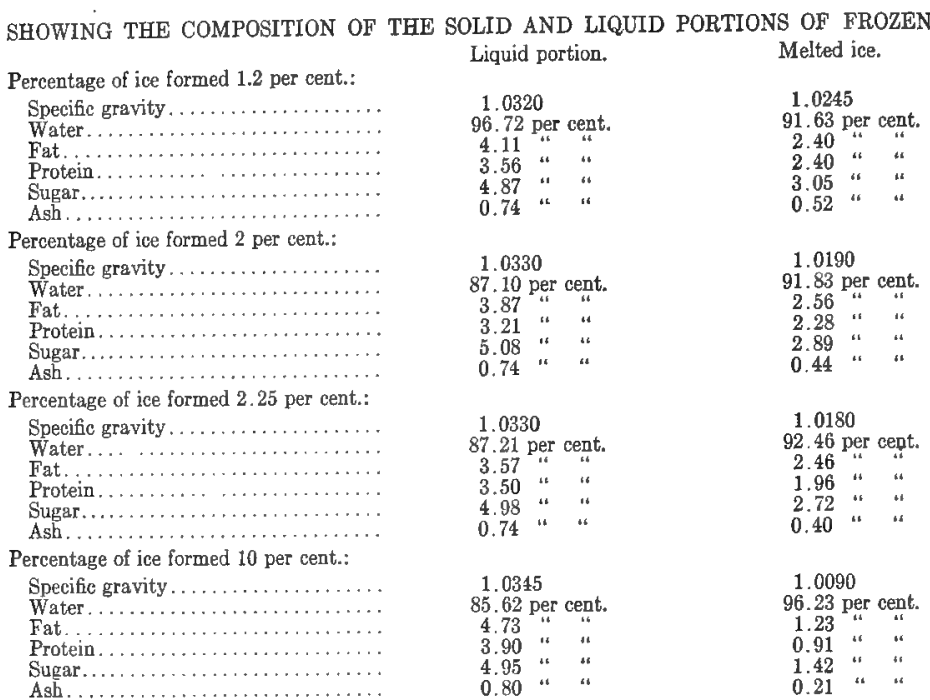

There is no appreciable difference between the ratio of the sugar to the protein and the ash in the two series of analyses, showing that no separation of any constituent except water takes place during freezing. The greater the percentage of ice separated, the more diluted is the melted ice.

When milk was frozen at $-10^{\circ} \mathrm{C}$. for three hours ice formed at the bottom and on the sides of the vessel, and a funnel-shaped cavity in the center was filled with liquid. The ice formed two layers, one of cream and the other of skimmed milk. These were poured off as completely as possible and analyzed:

COMPOSITION OF FROZEN MILK (VIETH, RICHMOND)

\begin{tabular}{|c|c|c|c|}
\hline & \multicolumn{2}{|c|}{ Ice. } & \multirow{2}{*}{$\begin{array}{l}\text { Liquid } \\
\text { portion. }\end{array}$} \\
\hline & Cream. & Stimmed milk. & \\
\hline 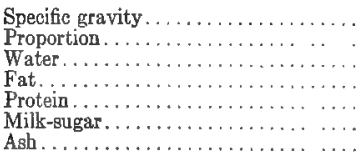 & $\begin{array}{l}1.0100 \\
8.8 \text { per cent. } \\
74.44 \text { " } \\
19.23 \text { " } \\
2.64 \text { " } " \\
3.33 \text { " " } \\
0.52 \text { " " }\end{array}$ & $\begin{array}{l}1.0275 \\
64.7 \text { per cent. } \\
92.10 \text { " } \\
0.68 \text { " " } \\
2.80 \text { " } \\
3.95 \text { " " } \\
0.60 \text { " }\end{array}$ & $\begin{array}{l}1.0525 \\
26.5 \text { per cent. } \\
80.54 \text { " } \\
5.17 \text { " } \\
5.38 \text { " } \\
7.77 \text { " } \\
1.18 \text { " }\end{array}$ \\
\hline
\end{tabular}

Milk cannot be frozen in blocks. 
The Influence of Heat on Milk.-Profound physical and chemical changes in milk are produced by heating it, and these changes become more intense the greater the heat applied and the longer milk is heated. This subject has been studied quite extensively, especially during recent years, because boiled and pasteurized milk have become popular.

All milk constituents are affected by heat--casein is altered, albumin is coagulated, fat globules coalesce, and some salts are precipitated. Furthermore, gases escape; the milk acquires a peculiar taste, usually called a "cooked taste," and the color deepens. In contact with the air a film forms which does not redissolve when the milk is cooled.

The film which forms on boiling milk is not soluble in limewater and consists largely of casein which has been transformed into the insoluble caseid. It also contains part of the other milk solids, including some fat. At lower temperature, between $40^{\circ}$ and $60^{\circ} \mathrm{C}$., a membrane is formed also, but this is soluble in limewater and can be coagulated from such a solution with rennet. The membrane does not form if the milk is diluted with at least twice its volume of water; if the surface is covered with a layer of oil; or if the air is excluded by other means.

Milk rich in albumin coagulates at the boiling-point. Colostrum contains an abnormally large percentage of albumin and coagulates when boiled, the coagulum enclosing some of the casein. When albumin is added to milk it also coagulates when boiled- 8 c.c. of egg-albumen or one-tenth this quantity of desiccated egg-albumen will produce a jelly in boiling milk.

When milk is heated to $80^{\circ} \mathrm{C}$. for fifteen minutes the casein is changed so that the time for rennet coagulation is prolonged. At $100^{\circ} \mathrm{C}$. the amount of protein which is precipitated by acetic acid is reduced and the reduction is still greater at higher temperature. Raudnitz gives the following figures:

THE AMOUNT OF PROTEIN PRECIPITATED BY ACETIC ACID AT DIFFERENT TEMPERATURES

Before heating.... $100^{\circ}{ }^{\circ} \ldots \ldots \ldots \ldots \ldots \ldots \ldots \ldots$

Temperature.

Fifteen minutes at $140^{\circ} \mathrm{C} \ldots \ldots \ldots \ldots \ldots \ldots \ldots \ldots \ldots$

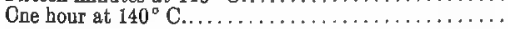

Per cent.
precipitated.
93.59
93.47
76.37
$\mathbf{7 4 . 3 9}$

Per cent, in golution.

6.41

6.53

23.63

25.61

Milk-sugar begins to decompose at $120^{\circ} \mathrm{C}$., and the change becomes more profound as the temperature rises. The sugar is caramelized and acids are formed.

Boiling removes a large part of nitrogen and oxygen gas and nearly all carbon dioxid. The loss of carbon dioxid renders boiled milk more alkaline than raw milk. 
The fat is not decomposed by heating to or even above the boiling-point. The physical condition, however, is easily disturbed. Commencing at about $70^{\circ} \mathrm{C}$, , or even lower, the clusters of fat globules break up, and then the cream rises slowly and incompletely. The amount of cream appearing at the surface of heated milk appears to be smaller than in the same milk raw. The higher the temperature, the more rapidly are the fat clusters broken up and the slower is the tendency to rise. The length of time at which milk is exposed to a certain temperature has a similar influence. The longer milk has been exposed, the more are the fat clusters broken up. Moreover, while the milk is hot agitation increases the tendency to break up clusters. Boiling causes the fat globules to coalesce.

In boiling milk soluble calcium phosphates are changed to insoluble salts and are precipitated. The loss of carbon dioxid by heating aids in the precipitation of salts. These salts dissolve again, in part at least, when boiled milk stands and absorbs carbon dioxid from the air.

The taste of milk is changed by boiling, due chiefly to decomposition of protein with evolution of hydrogen sulphid. When casein in boiled milk is coagulated by acid the flakes are smaller than when raw milk is coagulated. It is claimed, therefore, that the casein of boiled milk is more easily digested than the casein of raw milk.

A great deal has been written about the changes which occur in milk when it is pasteurized, but little experimental evidence on this point is available. Recently Rupp has made a careful investigation of this important problem and has obtained results which have aided much in overthrowing existing prejudices against the use of pasteurized milk. The author has shown that the chemical changes occurring in milk pasteurized at $62.2^{\circ} \mathrm{C}$. $\left(145^{\circ} \mathrm{F}\right.$.) for thirty minutes are so small as to range within experimental error. The albumin does not coagulate at this temperature, soluble phosphates of lime are not precipitated, and the acidity

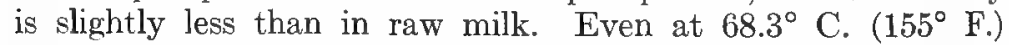
the quantity of phosphoric acid, lime, and magnesia is the same in the serum of both raw and heated milk. At $65.6^{\circ} \mathrm{C} .\left(150^{\circ} \mathrm{F}\right.$.) the albumin begins to coagulate, but the amount is only 5.75 per cent., while at $68.3^{\circ} \mathrm{C}$. $\left(155^{\circ} \mathrm{F}\right.$.) the amount of coagulated albumin is 12.75 per cent., and at $71.1^{\circ} \mathrm{C}$. $\left(160^{\circ} \mathrm{F}\right.$.) the amount rises to 30.55 per cent. Coagulation by rennet requires slightly less time in milk heated up to $65^{\circ} \mathrm{C}$. ( $149^{\circ} \mathrm{F}$.) than in raw milk, but at higher temperatures there is a retardation.

Centrifugation of Milk.- Since the introduction of centrifugal machines for cream separation and milk clarification it has become 
important to know in what respect milk is changed by the process: It may be expected that there is some separation of all suspended substances in milk, and this is actually true. The slime in the separator bowl contains 2 to 3 per cent. more ash than the milk and a considerable quantity of casein is thrown out. The longer centrifugation continues, the greater is the amount of casein thrown out, so that, according to Van Slyke, if centrifugation is continued for several hours practically all cascin can be removed. The increase in ash is due largely to the removal of suspended phosphates and to calcium and phosphoric acid from the casein. The centrifugal slime further contains insoluble dirt, bacteria, and body cells of great variety.

Dilutions of Milk.-When milk is diluted the reaction changes so that less N.NaOH is required for neutralization. The following figures adapted from Söldner show the change in reaction quite clearly (Sommerfeld's Handbuch):

\begin{tabular}{|c|c|c|}
\hline \multicolumn{3}{|c|}{ CHANGE IN REACTION OF MILK BY DILUTION } \\
\hline $\begin{array}{c}\text { Milk in } \\
\text { cubic centimeter. }\end{array}$ & $\begin{array}{c}\text { Water in } \\
\text { cubic centimeter. }\end{array}$ & $\begin{array}{l}\mathrm{N} . \mathrm{NaOH} \\
\text { required. }\end{array}$ \\
\hline $\begin{array}{l}100 \\
100\end{array}$ & 100 & $\begin{array}{l}1.50 \\
1.25\end{array}$ \\
\hline 100 & 200 & 1.10 \\
\hline $\begin{array}{l}100 \\
100\end{array}$ & $\begin{array}{r}500 \\
1000\end{array}$ & $\begin{array}{l}0.925 \\
0.625\end{array}$ \\
\hline
\end{tabular}

Dialysis.-By dialysis soluble calcium salts are removed and casein is precipitated.

Electricity.--There is a popular belief that during thunderstorms milk decomposes more rapidly than under ordinary conditions. Experiments with passing the electric current through milk have shown that acids are formed and that the casein undergoes some change. This change consists chiefly in separating the calcium from the casein, so that it is precipitated. It is questionable, however, whether these experiments have bearing on the influence of thunderstorms. It is claimed by some that the humidity in the atmosphere and the high temperature are responsible for rapid changes, and that if milk is kept cold these changes will not take place even when thunderstorms prevail. According to this view, the influence of thunderstorms consists merely in favoring bacterial growth. It is further, asserted that conditions at the dairy during thunderstorms are favorable to bacterial growth, and that subsequent rapid decomposition of milk may be due to this cause. If the utensils are not sterilized the atmospheric conditions during thunderstorms permit enormous multiplication of bacteria in the vessels between milkings, and the milkers may be careless due to the wearing effect of heat and humidity. Exact observations on these points are still lacking, and the effect of thunderstorms on milk must be considered an open question. 
Micro-organisms and Enzyms.-The changes caused by the activity of micro-organisms and enzyms in milk are of such magnitude that they will be considered in separate chapters.

\section{BIBLIOGRAPHY}

Allen: Commercial Organic Chemistry, 1913, vol. 8, p. 115.

Anderson: College of Agriculture Exper. Station, Berkeley, Cal., Bull. 204, December, 1909.

Basch and Raudnitz: Chemie and Physiologie der Milch, cited from Sommerfeld's Handbuch der Milchkunde.

Beach: Storrs' Agric. Experiment Sta., Bull. 34, January, 1905.

Biscaro and Belloni: Annal. Soc. Chim., Milano, 1905, vol. 11, cited from Sommerfeld's Handbuch.

Bowen: United States Dept. of Agri., Bu ll. 98, August, 14, 1914.

Carlyle: Univ. of Wis. Agri. Exper. Sta., 16th Annual Report, 1899.

Eckles: Univ, of Missouri Coll. of Agri. Exper. Sta., Research Bull. 4, October, 1911.

Eckles: Ibid., Research Bull. 5, October, 1911.

Eckles and Reed: Ibid., Research Bull. 2, April, 1910.

Eckles and Shaw: United States Dept. of Agri., Bull. 156, January, 1913.

Eckles and Shaw: Ibid., Bull. 157, January, 1913.

Eckles and Shaw: Ibid., Bull. 155, January, 1913.

Edelstein and Csonka: Biochem. Zeitschr., 1912, vol. 36, p. 14.

Fleischman: Lehrbuch der Milchwirthschaft, 1908.

Fraser and Hayden: Univ. of Ill. Agri. Exper. Sta., Bull. 159, July, 1912.

Gutzeit: Landwirthschaftliche Jahrbücher, Berlin, 1895, vol. 24, p. 539.

Halliburton: Jour. Physiol., 1890, vol. 11, p. 448.

Hammersten: Zeitschr. f. Physiol. Chemie, 1894, vol. 19, cited from Sommerfeld's Handbuch.

Hart: Jour. Amer. Chemic. Soc., 1908, vol. 30, p. 281.

Hayden: Univ, of I1l. Agri. Exper. Sta., Circular 152, August, 1911.

Hayden: Ohio Agri. Exper. Sta., Circular 128, June, 1912.

Hayden: Univ of Ill. Agri. Exper. Sta., Bull. 160, July, 1912.

Hildebrand: Hofmeister's Beiträge, Band. 5, p. 463. Cited from Sommerfeld's Handbuch.

Hill: Journal of Biol. Chem., 1915, vol. 20, p. 175.

Holt, Courtney, and Fales: Am. Jour. of Diseases of Children, 1915, vol. 10, p. 229.

Hygienic Laboratory Bulletin 56.

Jordan, W. H., and Jenter: New York Agri. Exper. Sta., Bull. 132, December, 1897.

Klusemann: Inaugural Dissertation, Leipzig, 1893. Cited from Bull. 111, United States Dept, of Agri., B. A. I.

Leach: Food Inspection and Analysis.

Leichmann: Centr, f. Bakt., Abt. 2, 1904, vol. 12, p. 328.

Lemus: Inaugural Dissertation, Leipzig, 1902. Cited from Bull. 111, United States Dept. of Agri., B. A. I.

Loevenhart: Zeitschr. f. Physiol. Chemie, 1914, vol. 41, p. 177.

Lythgoe: Sixth Annual Report of the International Association of Dairy and Milk Inspectors, Washington, D. C., 1917, p. 94.

Mai: Milchwirthsch. Zentralbi., 1913, vol. 42, p. 129.

Marshall: Mich. State Agri. Coll. Exper. Sta., Special Bull. 16, June, 1902.

Mathews: Physiological Chemistry, New York, William Wood \& Co., 1915

McCandlish: Jour. of Dairy Science, 1918, vol. 1, p. 475.

New York Agri, Exper. Sta., Geneva, N. Y., Annual Reports of 1890-94.

Olsen: Univ. of Wis. Agri. Exper. Sta., 24th Annual Report., 1907, p. 134.

Olsen: Ibid., Bull. 162, April, 1908.

Palmer and Eckles: Jour. of Dairy Science, 1917, vol. 1, p. 185.

Pfaundler: Physiologie der Laktation in Sommerfeld's Handbuch. 
Proceedings of the Sixth Annual Convention of the International Milk Dealers' Association, 1913.

Raudnitz: Allgemeine Chemie der Milch, Sommerfeld's Handbuch.

Richmond: Dairy Chemistry, London, 1914.

Rupp: United States Dept. of Agri., B. A. I., Bull. 166, April, 1913.

Savage: Cornell Univ. Agri. Exper. Sta. of the Coll. of Agri., Bull. 323, December, 1912.

Sebelien: Zeitschr. f. Physiol. Chemie, 1885, vol. 9, p. 445.

Shaw and Eckles: United States Dept. of Agri., B. A. I., Bull. 111, January, 1909.

Smith, Th.: Jour. Boston Soc. of Med. Sciences, 1898, vol. 2, p. 236.

Tangle: Pflüger's Archiv., 1908, vol. 121, p. 534. Cited from Sommerfeld's Handbuch.

Tiemann: Zeitschr. f. Physiol. Chemie, 1898, vol. 25, p. 363.

Trueman: Storrs' Agri. Exper. Sta., Bull. 73, June, 1912.

Trunz: Zeitsch. f. Physiol. Chemie, 1903-4, vol. 40, p. 263.

Turner, Shaw, Norton, and Wright: Jour. Agri. Research, 1916, vol. 6, p. 167.

United States Dept. of Agri., Farmer's Bull., 225, 1905.

Van Slyke and Bosworth: Jour. of Biol. Chem., 1913, vol. 14, pp. 203, 227.

Van Slyke and Hart: New York Agri. Exper. Sta., Bull. 214, July, 1902.

Van Slyke and Publow: The Science and Practice of Cheese Making, Orange Judd Company, 1910.

Wheeler: New York Agri. Exper. Sta., Bull. 210, December, 1901.

White and Judkins: Storrs' Agri. Exper. Sta., Bull. 94, January, 1918.

Woll: Univ. of Wis. Agri. Exper. Sta., Bull. 116, November, 1904.

Woll and Humphrey: Univ. of Wis. Agri. Exper. Sta., Bull. 200, January, 1911.

Woods and Bitting: United States Dept. of Agri., 19th Annual Report of the B. A. I., 1902, p. 233. 


\section{THE PHYSICAL AND CHEMICAL EXAMINATION OF MILK}

IN making routine examinations it is usually sufficient to examine milk for the following factors: Specific gravity, fat, total solids, and solids-not-fat-also called plasma solids. For more detailed analyses the quantity of ash, total protein, casein, albumin, and milk-sugar should be determined. It may also be desirable to estimate the acidity, sediment, viscosity, the speed of rennet coagulation, alcohol coagulation, and to determine if the milk has been heated. Sometimes it is necessary to distinguish between human and cow's milk. Furthermore, coloring-matter and gelatin are sometimes added to milk, the former to impart a yellowish color and the latter to increase the viscosity. Preservatives, too, are still sometimes added to milk, so their presence should be tested for. For special investigations detailed analyses of the ash may be made.

A correct sample of the milk to be examined must be obtained. As the fat rises within a relatively short time when the milk is quiescent, thorough mixing is necessary prior to the removal of samples. The longer the milk stands before sampling, the more difficult becomes the even distribution of the cream. This is especially true when the milk has been kept at the proper low temperature. The fat then solidifies and adheres to the walls of the vessel. Under these conditions the milk should be warmed to $40^{\circ}$ to $45^{\circ} \mathrm{C}$. to liquefy the fat.

Mixing is best accomplished by pouring the milk repeatedly from one vessel to another. When samples from large cans are to be taken the milk should be stirred with a large clean spoon or dipper. An instrument which is designed to stir the milk and take a sample at the same time is very useful. This consists of a stiff iron rod with a slightly concave disk attached to the lower end (Fig. 28). The milk is mixed by moving the stirrer up and down. Under no conditions should the milk be shaken violently, as the viscosity of milk prevents air-bubbles from rising, and therefore a sample taken after violent shaking would not represent the desired volume. Furthermore, violent agitation of milk has a tendency to churn it, with the result that even distribution of the fat becomes difficult. If milk is first diluted with water and then shaken, the result is not as detrimental as when undiluted milk is agitated. Therefore it is possible to obtain well mixed milk by the addition of a definite amount of water. 
When the container is large, as the common shipping can, for example, a fair sample can be obtained by the use of milk samplers. The "Scovell sampling tube" is an instrument designed for this purpose (Fig. 29). This sampler is made of copper or brass and consists of two cylinders which telescope together. The lower small cylinder has several oblong apertures and the upper long cylinder fits tightly into the small one. The sampler is lowered into the can until it reaches the bottom, and after it is filled with milk the upper cylinder is pushed down, thus closing

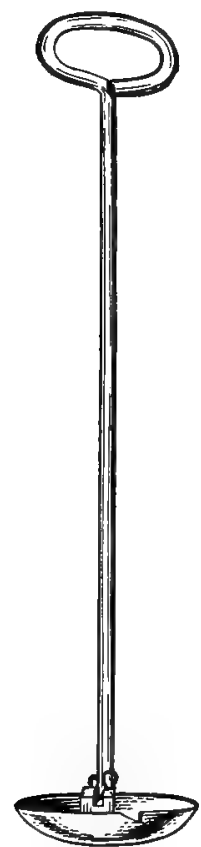

Fig. 28.-Combined cream stirrer and sampler (Van Slyke).

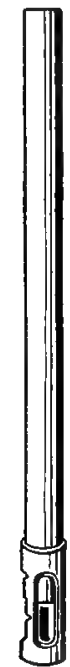

Fig. 29.-Scovell sampler.

the holes of the lower cylinder. The sample contains some milk from each layer of milk in the can and the contents fairly represent the whole amount of milk. The sample is poured into a small vessel and poured back and forth from this vessel to another until it is thoroughly mixed.

The McKay is another type of sampler. It consists of two tubes, each with a handle and one fitting inside the other. A turn of the handles opens or closes the sampler. Each tube has several slots on the side. The sample is taken after the sampler has been lowered to the bottom of the can and opened by a turn 
of the handles. The milk or cream fills the sampler through the slots and every layer of the can is then represented. After filling, the sampler is closed and removed. If cream is thick the sampler should be dipped into hot water. Cream samplers have larger slots than milk samplers (Fig. 30).

A sampling pipet designed especially for taking composite samples is described by Decker (Fig. 31). This pipet is a simple glass tube $\frac{1}{2}$ inch in diameter and about 12 inches long. The

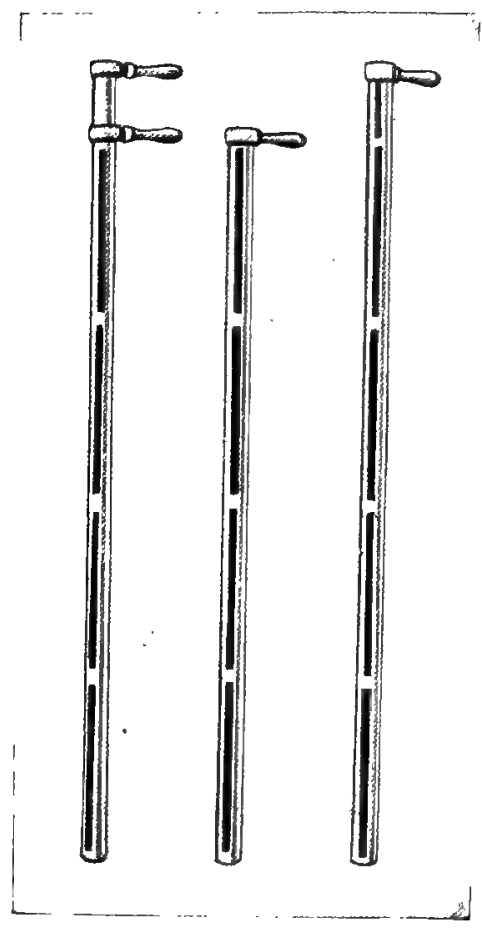

Fig. 30.-McKay sampler.

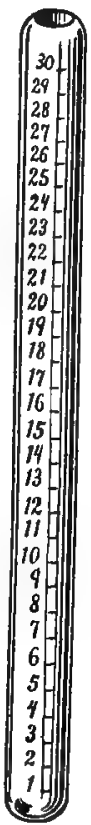

Fig. 31.-Composite milk sample pipet (Decker).

ends are drawn in abruptly, so that holes remain at the top and bottom. The hole at the bottom is large enough to admit and expel milk rapidly, while the hole at the top can be closed by the finger. The tube is graduated so that as many units of milk can be taken as there are pounds of milk in the pail. This pipet is used chiefly for composite samples taken in milking pails.

Other sampling devices are shown in Figs. 32-34.

When milk from a single cow is to be sampled the whole amount of milk should be drawn and mixed before a sample is 
taken. It is not infrequently desirable to take samples in the stable in order to find at what stage of handling the milk has been tampered with, or to locate the source of a particular abnormal milk. Sampling milk in the stable requires greater circumspection than sampling the milk from vendors. The samples should be taken from each cow after milking has been completed. The mixed milk from each cow may then be examined separately or an equal amount from each cow's milk mixed and the mixed sample examined. Which one of these procedures is to be selected depends upon the object of the examination. Sometimes samples

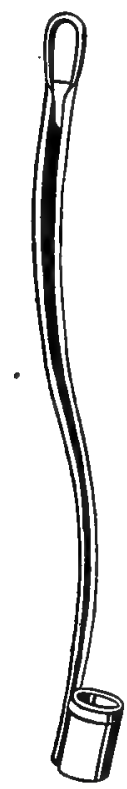

Fig. 32.-Tin sampler.

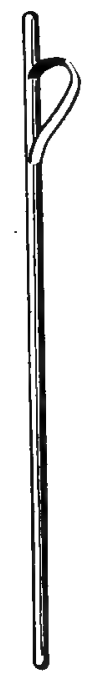

Fig. 33.-Milk thieves.

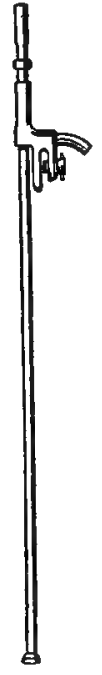

Fig. 34.-Equity milk sampler.

must be taken from each quarter of the udder. Small samples in such cases are usually sufficient.

Sampling cream is a difficult process and particular care is necessary to obtain a representative sample. When cream stands for some time the surface layer becomes tough from evaporation. Heating to $40^{\circ}$ to $45^{\circ} \mathrm{C}$. is necessary to overcome this difficulty. What has been said in regard to violent shaking of milk samples applies in even greater measure to sampling cream, as cream is more viscous than milk. Very rich cream should always be warmed to $30^{\circ}$ to $32^{\circ} \mathrm{C}$. before a sample is taken.

Samples from sour and loppered milk are always unreliable. 
When milk is coagulated the fat is not changed chemically, but it is unevenly distributed. The casein should then be dissolved by adding to the milk one-tenth to one-twentieth its volume of sodium or potassium hydrate solution or strong ammonia. Due allowance must be made for the increased volume caused by such addition when the results are calculated.

Frozen milk must be thawed completely and the mixed milk sampled. When either through freezing or churning the fat assumes a condition which renders it difficult to distribute, 5 per cent. ether may be added. This dissolves the fat and it can then be thoroughly mixed by a rotary motion.

Samples should be examined as early as possible after taking, since profound changes in physical condition, chemical composition, and bacterial content take place within a short time. If the milk cannot be examined promptly, it should be packed in ice. Even at this low temperature changes occur which influence the result, and consequently shipping samples for considerable distances renders analyses more or less unsatisfactory. Samples may be preserved by addition of 0.02 per cent. formalin or 0.1 per cent. potassium bichromate. Any such addition should always be clearly stated on a tag attached and, of course, for bacteriologic examination, addition of preservatives is not admissible.

Composite Samples.-The introduction of the Babcock method for fat determination has enabled creameries and milk dealers to rapidly test milk for fat content. Since fat is not readily decomposed it is not necessary to test the contents of each can upon delivery, but aliquot portions may be taken each day and kept for one or two weeks before the test is made. Such samples are known as "composite samples." A measured amount is taken from each can of the producer every time milk is delivered, and these samples placed in suitable vessels. A Mason jar, a glassstoppered wide-mouthed bottle, or any other style of bottle may be used, as long as air can be excluded to prevent evaporation. The amount of milk delivered is recorded and the average fat content determined by periodic examination. The producer is then paid according to the amount of butter-fat delivered and not according to the quantity of milk. The justice of this method is obvious, since watering milk brings no additional profit when the butter-fat made is the basis of payment. Furthermore, rich milk automatically brings better compensation than does poor milk.

Composite samples of milk must be properly cared for in order to yield reliable results. As has been mentioned before, the container must be closed air-tight to prevent evaporation and the contents guarded against decomposition. This is accomplished 
by addition of mercuric chlorid or potassium bichromate; both of these preservatives can be purchased in tablet form. Some prefer the use of formalin. Mercuric chlorid is the most popular chemical used for preserving composite samples, but it is poisonous, and therefore some coloring-matter should be added so that the milk has a strikingly different appearance from normal milk. Commercial tablets of bichlorid of mercury have a red coloringmatter incorporated.

Preservatives should be used in moderate quantity, since large amounts so alter the casein as to render it less soluble in sulphuric acid than normal casein. This is of importance in making the fat test by the Babcock method.

In order to obtain a fair determination from composite samples it is important to mix the contents of the bottle with the new sample which is added from day to day. By doing this the cream is prevented from forming a solid surface layer which always militates against accurate work. Furthermore, daily mixing is necessary to distribute the preservative thoroughly through the fresh sample. Mixing should be accomplished by a rotary motion, not by violent shaking.

Before taking the sample for the final test, which should be made at intervals of not more than two weeks, the contents of the bottle should be mixed by a rotary motion, and if the cream adheres to the walls of the vessel or appears to mix with difficulty the milk should be warmed to $40^{\circ}$ to $45^{\circ} \mathrm{C}$.

\section{The Specific Gravity}

The specific gravity was formerly thought to be clearly indicative of the quality of milk. At present it is considered of little importance in itself, but in connection with other tests it is of great aid in determining the composition of milk. The specific gravity of milk, as has been explained before, is greater than that of water, and the fat counteracts in a measure the effect of dissolved substances. Milk rich in fat has, therefore, a lower specific gravity than poor milk. The specific gravity of cream is below, and that of skimmed milk above, that of whole milk. It is obvious that the removal of fat causes the specific gravity of milk to rise, and that by the addition of water skimmed milk can again be brought to the normal specific gravity of whole milk.

It is clear that the specific gravity is not an accurate index of the quality of milk. It has, however, a definite relation to the percentage of fat and plasma solids. When two of these factors are known, the third one can be calculated. Therefore, if the specific gravity is taken and the fat content determined, the total 
solids and plasma solids need not be estimated unless very accurate results are desired.

Fresh milk contains considerable quantities of gas in solution, and therefore should be permitted to stand for at least ten hours from the time of milking before the specific gravity is taken. During this time excess of $\mathrm{CO}_{2}$ has escaped and the specific gravity is nearly constant. It is higher than immediately after milking and continues to rise for about two days, although slightly. This phenomenon is known as the Recknagel phenomenon. The rise of specific gravity during the first two days may also be due in part to a change in the volume of the proteins. The increase is within the limits of 0.0008 and 0.0015 .

The specific gravity may be determined by three methods, namely: 1 , a lactometer; 2 , a pycnometer, and 3 , by means of the Westphal balance. A lactometer is a hydrometer which has been constructed especially for use in milk work. The temperature of the milk should always be determined with the specific gravity, since increase of temperature reduces the specific gravity. The actual reading is reduced to a standard temperature, usually $60^{\circ} \mathrm{F}$. or $15.6^{\circ} \mathrm{C}$.

There are three styles of lactometer commonly in use: 1 , the Quevenne (Fig. 35); 2, the New York Board of Health (Fig. 36), and 3, Shaw and Eckles' lactometer (Fig. 37).

The Quevenne lactometer is probably used to a greater extent than either of the other two. The scale is divided into 25 parts, commencing with 15 and ending with 40 . These figures represent the second and third decimals. They are sufficiently below and above the normal specific gravity of milk to cover all cases. A thermometer is combined with the Quevenne lactometer, so that specific gravity and temperature can be read at the same time.

The New York Board of Health lactometer has an arbitrary scale, but since the subdivisions of degrees are smaller than on the Quevenne lactometer, accurate reading is facilitated. The scale is divided into 120 parts, 0 representing the mark to which the lactometer sinks when immersed in water. The 100 mark is equal to 29 on the Quevenne lactometer, which means a specific gravity of 1.029. The upper limit is 120 or 34.8 on the Quevenne lactometer. Milk with a specific gravity higher than 1.0348, such as skimmed milk may be, cannot be measured with the New York Board of Health lactometer. A separate thermometer may be used in connection with this lactometer, although a New York Board of Health lactometer provided with a thermometer can be purchased.

A lactometer of somewhat different construction has been 
devised by Shaw and Eckles. This instrument differs from the Quevenne in having a longer bulb and a finer stem. The spaces representing units are lengthened and the reading is therefore more accurate than on the Quevenne lactometer.

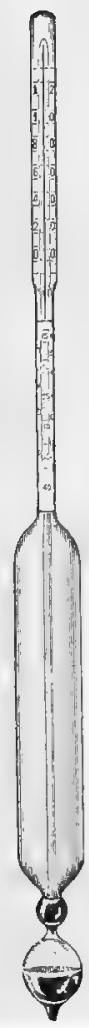

Fig. 35.-Quevienne's lactothermometer.

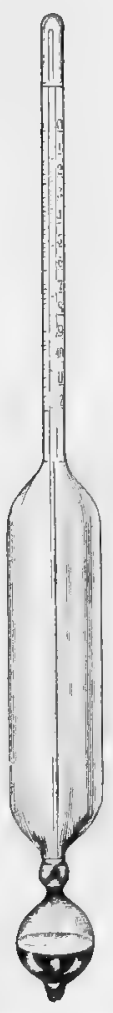

Fig. 36.-Spence's New York State lactothermometer.

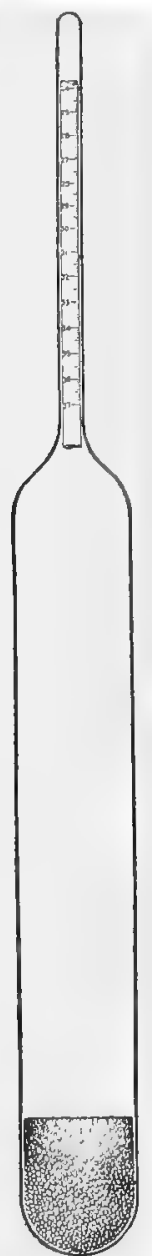

Fig. 37.-Lactometer designed for use in experimental work (Bull. 134, B. A. I.),

(A. H. Barber Creamery Supply Co.)

The following table gives the relation of the Quevenne, the New York Board of Health lactometers, and the specific gravity: 
RELATION OF QUEVENNE AND NEW YORK BOARD OF HEALTH LACTOMETERS TO SPECIFIC GRAVITY

\begin{tabular}{|c|c|c|c|c|c|}
\hline New York. & Quevenne. & $\begin{array}{l}\text { Specific } \\
\text { gravity. }\end{array}$ & New York. & Quevenne. & Specific \\
\hline 60 & 17.4 & 1.0174 & 91 & 26.4 & 1.0264 \\
\hline 61 & 17.7 & 1.0177 & 92 & 26.7 & 1.0267 \\
\hline 62 & 18.0 & 1.0180 & 93 & 27.0 & 1.0270 \\
\hline 63 & 18.3 & 1.0183 & 94 & 27.3 & 1.0273 \\
\hline 64 & 18.6 & 1.0186 & 95 & 27.6 & 1.0276 \\
\hline 65 & 18.8 & 1.0188 & 96 & 27.8 & 1. 0278 \\
\hline 66 & 19.1 & 1.0191 & 97 & 28.1 & 1.0281 \\
\hline 67 & 19.4 & 1.0194 & 98 & 28.4 & 1.0284 \\
\hline 68 & . 19.7 & 1.0197 & 99 & 28.7 & 1.0287 \\
\hline 69 & 20.0 & 1.0200 & 100 & 29.0 & 1.0290 \\
\hline 70 & 20.3 & 1.0203 & 101 & 29.3 & 1. 0293 \\
\hline 71 & 20.6 & 1.0206 & 102 & 29.6 & 1.0296 \\
\hline 72 & 20.9 & 1.0209 & 103 & 29.9 & 1.0299 \\
\hline 73 & 21.2 & 1.0212 & 104 & 30.2 & 1.0302 \\
\hline 74 & 21.5 & 1.0215 & 105 & 30.5 & 1.0305 \\
\hline 75 & 21.7 & 1.0217 & 106 & 30.7 & 1.0307 \\
\hline 76 & 22.0 & 1.0220 & 107 & 31.0 & 1.0310 \\
\hline 77 & 22.3 & 1.0223 & 108 & 31.3 & 1.0313 \\
\hline 78 & 22.6 & 1.0226 & 109 & 31.6 & 1.0316 \\
\hline 79 & 22.9 & 1.0229 & 110 & 31.9 & 1.0319 \\
\hline 80 & 23.2 & 1.0232 & 111 & 32.2 & 1.0322 \\
\hline 81 & 23.5 & 1.0235 & 112 & 32.5 & 1. 0325 \\
\hline 82 & 23.8 & 1.0238 & 113 & 32.8 & 1.0328 \\
\hline 83 & 24.1 & 1.0241 & 114 & 33.1 & 1.0331 \\
\hline 84 & 24.4 & 1.0244 & 115 & 33.4 & 1.0334 \\
\hline 85 & 24.6 & 1.0246 & 116 & 33.6 & 1. 0334 \\
\hline 86 & 24.9 & 1. 0249 & 117 & 33.9 & 1. 0339 \\
\hline 87 & 25.2 & 1.0252 & 118 & 34.2 & 1. 0342 \\
\hline 88 & 25.5 & 1.0255 & 119 & 34.5 & 1. 0345 \\
\hline 89 & 25.8 & 1.0258 & 120 & 34.8 & 1.0348 \\
\hline 90 & 26.1 & 1.0261 & & & \\
\hline
\end{tabular}

The correction necessary to bring the lactometer reading to the standard temperature of $60^{\circ} \mathrm{F}$. is given in the following table:

CORRECTION TABLE FOR SPECIFIC GRAVITY OF MILK (QUEVENNE LACTOMETER)

\begin{tabular}{|c|c|c|c|c|c|c|c|c|c|c|c|c|c|c|c|c|c|c|c|c|}
\hline & & & & & & & & Temp & eratur & Ire (in & degre & ees $\mathrm{F}$ & ahren & nheit). & & & & & & \\
\hline & 51 & 52 & 53 & 54 & 55 & 56 & 57 & 58 & 59 & 60 & 61 & 62 & 63 & 64 & 65 & 66 & 67 & $\begin{array}{ll}68 & 69\end{array}$ & 70 & \\
\hline & $\begin{array}{l}19.3 \\
20.3 \\
21.3 \\
22.3 \\
23.3 \\
24.2 \\
25.2 \\
26.2 \\
27.1 \\
28.1 \\
29.1 \\
30.0 \\
31.0 \\
31.9 \\
32.9 \\
33.8\end{array}$ & $\begin{array}{l}19.4 \\
20.3 \\
21.3 \\
22.3 \\
23.3 \\
24.3 \\
25.2 \\
26.2 \\
27.2 \\
28.2 \\
29.1 \\
30.1 \\
31.1 \\
32.0 \\
33.0\end{array}$ & $\begin{array}{l}19.4 \\
20.4 \\
21.4 \\
22.4 \\
23.4 \\
24.4 \\
25.3 \\
26.3 \\
27.3 \\
28.3 \\
29.2 \\
30.2 \\
31.2 \\
32.1 \\
33.1 \\
34.0\end{array}$ & $\begin{array}{l}19.5 \\
20.5 \\
21.5 \\
22.5 \\
23.5 \\
24.5 \\
25.4 \\
26.4 \\
27.4 \\
23.4 \\
29.3 \\
30.3 \\
31.3 \\
32.3 \\
33.2 \\
342 \\
\end{array}$ & $\begin{array}{l}19.6 \\
20.6 \\
21.6 \\
22.6 \\
23.6 \\
24.6 \\
25.5 \\
26.5 \\
27.5 \\
28.5 \\
29.4 \\
30.4 \\
31.4 \\
32.4 \\
33.3 \\
34.3\end{array}$ & 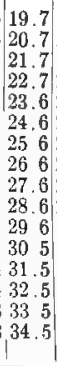 & $\begin{array}{l}19.8 \\
20.8 \\
21.8 \\
22.8 \\
23.7 \\
24.7 \\
25.7 \\
26.7 \\
27.7 \\
28.7 \\
29.7 \\
30.6 \\
31.6 \\
32.6 \\
33.6 \\
34.6\end{array}$ & $\begin{array}{l}19.9 \\
20.9 \\
21.9 \\
22.8 \\
23.8 \\
24.8 \\
25.8 \\
26.8 \\
27.8 \\
28.8 \\
29.8 \\
30.8 \\
31.7 \\
32.7 \\
33.7 \\
34.7\end{array}$ & 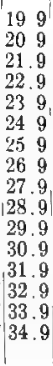 & $\begin{array}{l}20.0 \\
21.0 \\
22.0 \\
23.0 \\
24.0 \\
25.0 \\
26.0 \\
27.0 \\
28.0 \\
29.0 \\
30.0 \\
31.0 \\
32.0 \\
33.0 \\
34.0 \\
35.0\end{array}$ & $\begin{array}{l}20.1 \\
21.1 \\
22.1 \\
23.1 \\
24.1 \\
25.1 \\
26.1 \\
27.1 \\
28.1 \\
29.1 \\
20.1 \\
31.2 \\
32.2 \\
33.2 \\
34.2 \\
35.2\end{array}$ & $\begin{array}{l}20.2 \\
21.2 \\
22.2 \\
23.2 \\
24.2 \\
125.2 \\
126.2 \\
127.3 \\
128.3 \\
129.3 \\
130.3 \\
231.3 \\
232.3 \\
233.3 \\
234.3 \\
235.3 \\
35\end{array}$ & $\begin{array}{l}20.2 \\
21.3 \\
22.3 \\
23.3 \\
24.3 \\
25.3 \\
26.3 \\
27.4 \\
28.4 \\
329.4 \\
330.4 \\
331.4 \\
332.5 \\
333\end{array}$ & 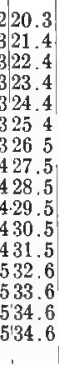 & $\begin{array}{l}20.4 \\
21.5 \\
22.5 \\
23.5 \\
24.5 \\
25.5 \\
26.6 \\
27.6 \\
28.6 \\
29.6 \\
30.7 \\
31.7 \\
32.7 \\
33.8 \\
334.8 \\
335.8 \\
\end{array}$ & $\begin{array}{l}4 \\
5 \\
5 \\
521.6 \\
522.6 \\
523.6 \\
524.6 \\
525.6 \\
626.7 \\
627.7 \\
628.7 \\
629.7 \\
730.8 \\
731.8 \\
732.9 \\
833.9 \\
834.9 \\
835.9\end{array}$ & $\begin{array}{l}20.6 \\
21.7 \\
22.7 \\
23.7 \\
24.7 \\
25.7 \\
26.8 \\
27.8 \\
28.8 \\
29.9 \\
30.9 \\
31.9 \\
33.0 \\
34.0 \\
35.0 \\
36.1\end{array}$ & \begin{tabular}{|l|l|}
20.7 & 20.9 \\
21.8 & 22.0 \\
22.8 & 23.0 \\
23.8 & 24.0 \\
24.9 & 25.0 \\
25.9 & 26.0 \\
27.0 & 27.1 \\
28.0 & 28.1 \\
29.0 & 29.1 \\
30.1 & 30 \\
31.1 & 31 \\
32.1 & 32.2 \\
33.2 & 33.3 \\
034.2 & 34.3 \\
035.2 & 35.3 \\
136.2 & 36.4
\end{tabular} & $\begin{array}{l}921.0 \\
22.1 \\
23.1 \\
24.1 \\
25.1 \\
26.1 \\
27.2 \\
27.2 \\
28.2 \\
29.2 \\
30.3 \\
31.3 \\
32.4 \\
33.4 \\
34.5 \\
335 \\
336.5\end{array}$ & 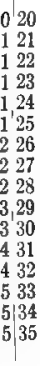 \\
\hline
\end{tabular}

Approximate correction can also be made by adding 0.1 to the lactometer reading for each degree above $60^{\circ} \mathrm{F}$. and deducting 0.1 for each degree below $60^{\circ} \mathrm{F}$. This method of correction is not quite as accurate, of course, as the corrections given in the table. 
The milk should be poured back and forth several times from one vessel to another before inserting a lactometer. A cylinder of sufficient width and height should be used. The lactometer is lowered into the central portion of the milk, care being taken that it does not come in contact with the wall of the cylinder. It should remain quiet for about one minute before reading is attempted. As fat rises rapidly, a longer time would vitiate the reading, while one minute is long enough to bring the instrument to perfect rest, and the thermometer then gives accurate temperature readings. There should be no foam on the surface of the milk and no bubbles
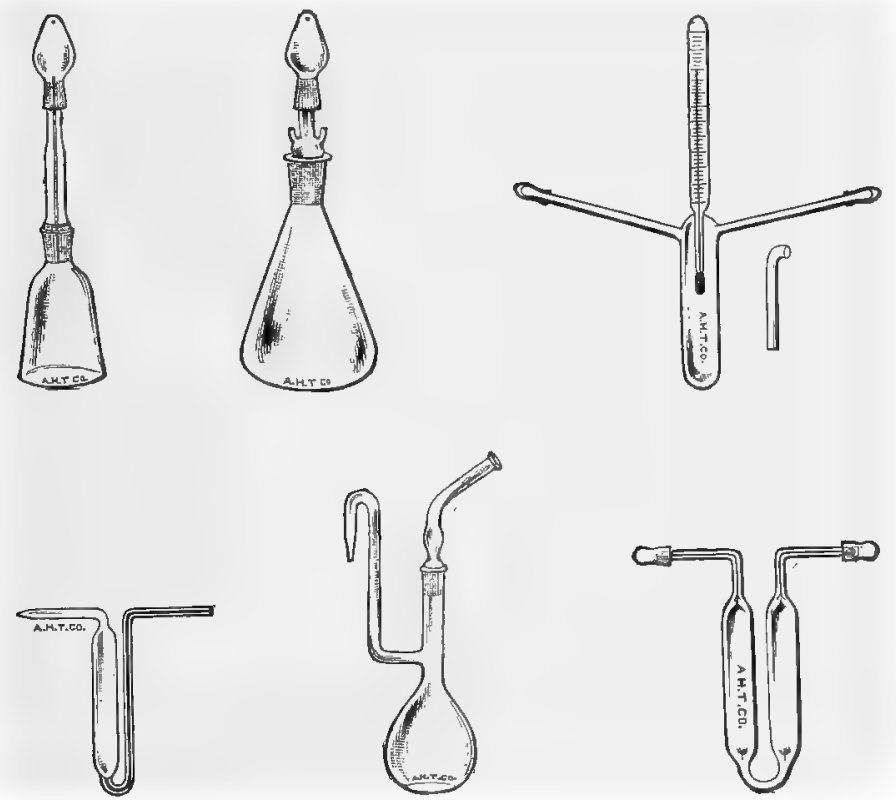

Fig. 38.-Various types of pycnometer (Arthur H. Thomas Co.).

should adhere to the lactometer. The line which is on a level with the surface of the milk is taken as giving the correct reading, not the higher part of the meniscus. Shaw and Eckles prefer to read the upper line of the meniscus and add 0.2 to the figure. After reading both specific gravity and temperature, the final correction should be made.

The pycnometer, several styles of which are shown in Fig. 38, is fundamentally a bottle with a glass stopper ground into the neck and a glass-stoppered side tube to discharge the overflow of expanding fluids. The bottle is first filled with water and the exact weight of the water noted; the bottle is then emptied and 
dried. It is then filled with milk and weighed again. From the difference in weight between the milk and water the specific gravity is calculated. The glass stopper may have a thermometer attached which reaches into the fluid to be tested and records the temperature. When milk is tested the temperature of both milk and water should be $60^{\circ} \mathrm{F}$.

Very accurate results are obtained by the use of a Westphal balance (Fig. 39). This instrument consists of a beam to the end of which a plummet is hung and a glass cylinder to hold the fluid to be tested. The beam is supported by a cylindric stand and fastened to a cylinder fitting closely inside the support. This inner cylinder carrying the

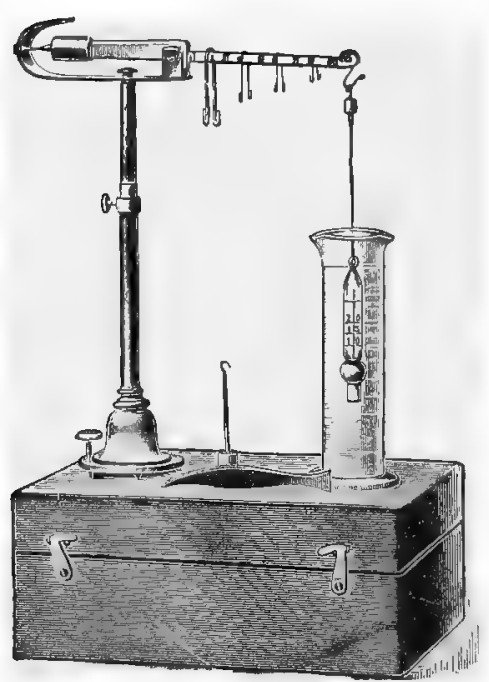

Fig. 39.-Westphal balance (Arthur H. Thomas Co.). beam is movable, so that the height of the beam can be adjusted. The absolute weight of the plummet (Reimann's plummet with thermometer) is 15 grams including the platinum wire, and it displaces 5 grams distilled water at $15^{\circ} \mathrm{C}$. The beam is divided into ten parts, each one of which is indicated by a notch. There are four weights (riders) which are hung on the beam. The largest rider represents 5 grams, the next size 0.5 , and the others 0.05 and 0.005 gram, respectively. To use the balance the procedure is as follows: The plummet is hung to the end of the beam and is immersed in distilled water contained in the cylinder. The largest rider is hung above the plummet. The balance is perfect when the plummet and twisted wire are covered with water and the metallic point at the further end of the beam is in opposition. The exact place where the surface of the water reaches the wire is to be noted. After this preliminary observation the water is discarded and the milk placed in the cylinder. The second largest rider is then placed on the beam and moved until perfect balance is established. This rider is then moved back into the nearest notch. The other riders are then placed one after the other on the beam and moved to the notch nearest the place where perfect balance is established. Finally the smallest rider will establish the correct weight. 
The following example will illustrate the method of reading:

The 5.0 rider is on notch 10 . Therefore this is 1 by $5=5.000$

The 0.5 rider is on notch 0.3 . Therefore this is 0.5 by $0.3=0.150$

The 0.05 rider is on notch 0.1 . Therefore this is 0.05 by $0.1=0.005$

The 0.005 rider is on notch 0.4 . Therefore this is 0.005 by $0.4=0.002$

Total, $\overline{5.157}$

As the plummet displaces 5 grams water and 5.157 grams milk, the specific gravity of the milk is 5.157 divided by 5 , which equals 1.0314. The specific gravity can also be read directly from the beam.

\section{The Determination of Fat}

The percentage of fat may be determined by three different methods, namely: 1, ether extraction; 2, centrifugation, and 3, refraction. The ether extraction and centrifugation methods are commonly employed, while the refraction method is used only exceptionally. By ether extraction more accurate results are obtained than by centrifugation, but this latter method, if carried out with care, gives sufficiently accurate results for practical purposes and takes much less time.

By ether extraction the fat is determined according to official and provisional methods of analysis as follows:

"Make rolls of thick filter paper, cut into strips of 6.25 by 62.5 cm., and thoroughly extract with ether and alcohol, or correct the weight of the final fat extract by a constant obtained for the paper. From a weighing bottle or weighing pipet transfer about 5 grams of milk to the coil, dry end down on a piece of glass, at the temperature of boiling water for one hour, or, better, in hydrogen at the temperature of boiling water; transfer to an extraction apparatus and extract with absolute ether or petroleum ether boiling at about $45^{\circ} \mathrm{C}$.; dry the extracted fat and weigh."

Leach gives the following method (Adams Method):

A fat-free strip of filter paper which can be purchased (Schleicher and Schüll) about $2 \frac{1}{2}$ inches wide and 22 inches long is rolled into a coil and held in place by a wire. About 5 c.c. of milk are placed in a beaker and the beaker and the milk weighed. The coil of filter paper is then brought in contact with the milk until as much of the milk as possible has been absorbed by the paper. The beaker is weighed again and the exact amount of milk absorbed by the paper coil calculated.

The milk on the coil is then dried, first in the air and then in an oven at a temperature not to exceed $100^{\circ} \mathrm{C}$. The coil is transferred to a Soxhlet ether extraction apparatus (Fig. 40) and extraction continued until the ether has siphoned over at least twenty times, which occupies about two hours. The ether is 
then evaporated from the flask, the exact weight of which is known, and the difference determined by weighing. From the weight of the fat in the flask the percentage is calculated. Traces of fat may remain in the paper coil even when extraction is continued for six to eight hours. In place of filter paper fat-free thimbles made of filter paper can be procured and used for fat extraction.

Another method of determining the fat content of milk by ether extraction is the one of Werner-Schmidt (Leach) as follows: Ten c.c. of milk are measured, or, better, 10 grams weighed, placed in a test-tube of 50 c.c. capacity and 10 c.c. of hydrochloric

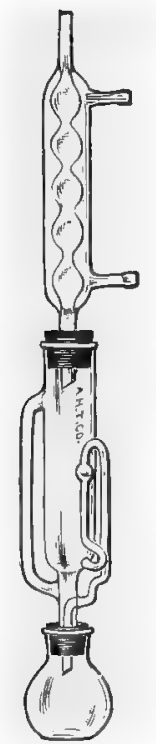

Fig. $40 \rightarrow$ Soxhlet ether extractor.

acid added. After shaking, the mixture is boiled over a flame for a few minutes or placed in boiling water for about ten minutes. The tube is then cooled and 30 c.c. washed ether added. A stopper with two glass tubes is used to close the tube. One of the glass tubes reaches just below the stopper, the other one reaches farther down and is bent up at the end. After thorough shaking of the acid-milk mixture the ether is allowed to form a layer on the surface. The bent glass tube is moved down into the ether until the opening of the curved end is just above the surface of the acid-milk mixture. The ether is then blown into a tared flask or beaker. The process is repeated twice, using 10 c.c. of ether 
each time. The ether is finally evaporated and the remaining fat weighed.

Wollny's Refractometer Method (after Leach).-The refractom-

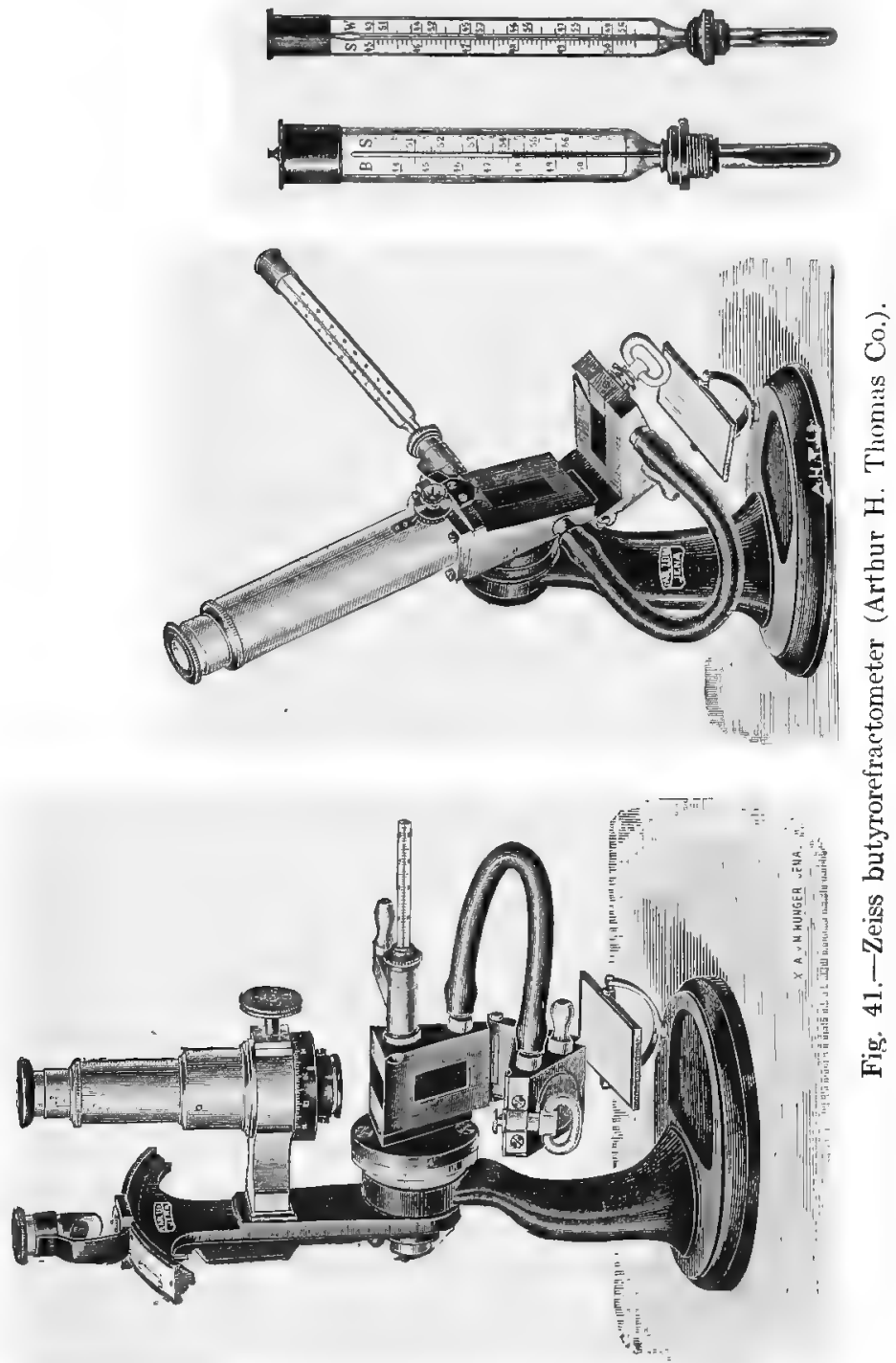

eter is based on the deviation of light through a solution of fat in ether at $17.5^{\circ} \mathrm{C}$., the solution to be prepared according to defi- 
nite directions. The instrument used is the Zeiss butyrorefractometer (Fig. 41). The apparatus used in this determination are shown in Fig. 42. Thirty c.c. of milk are measured into the stoppered flask by means of a 7.5 c.c. pipet. This pipet is so constructed that it can be placed in the sampling tube. To the 30 c.c. of milk 12 drops acetic acid are added to curdle the milk. The flask is then shaken in a mechanical shaker for one or two

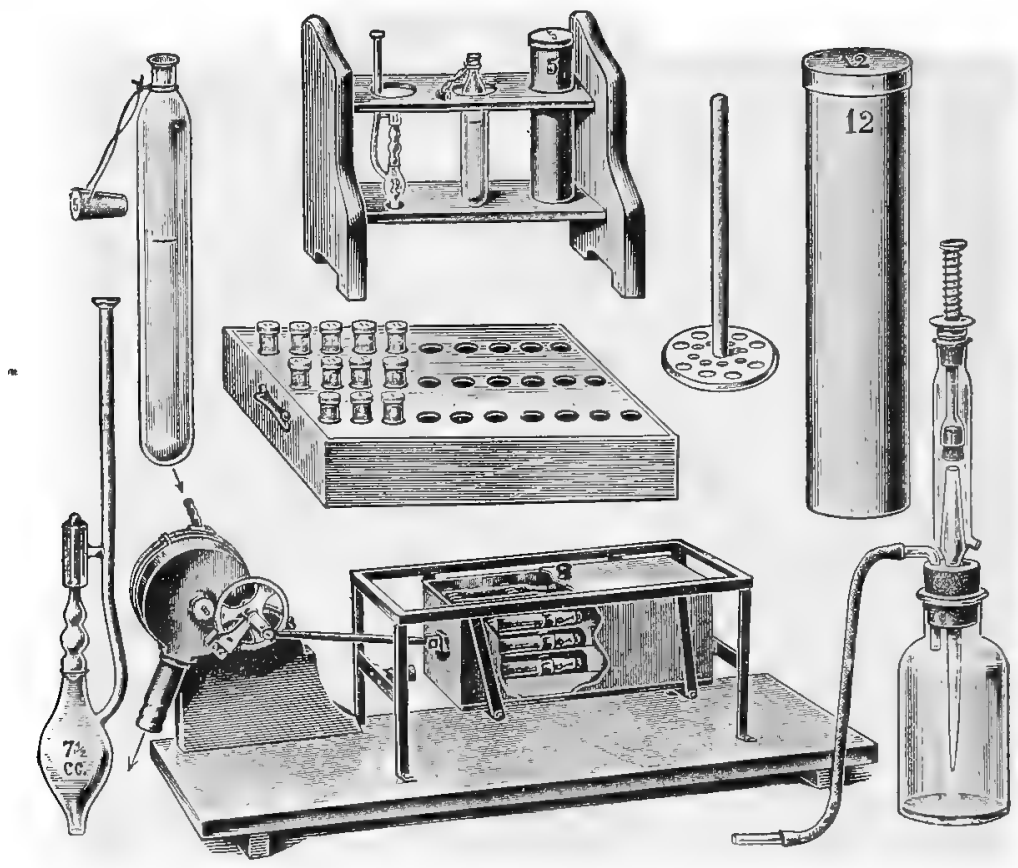

Fig. 42.-Apparatus used in Wollny's refractometer method.

minutes and then 3 c.c. standard alkali solution added. The flask is again placed in the mechanical shaker and shaken for ten minutes at a temperature of $17.5^{\circ} \mathrm{C}$. After this 6 c.c. watersaturated ether are added and the flisk shaken for fifteen minutes. Finally the flask is placed in a centrifuge and whirled for three minutes. Now a few drops of ether-fat solution are placed in the refractometer and theres ults read. The table on pages 151 and 152 gives the percentage of fat according to the reading (Leach). 
PERCENTAGES OF FAT CORRESPONDING TO SCALE READINGS ON THE WOLLNY REFRACTOMETER.

\begin{tabular}{|c|c|c|c|c|c|c|c|c|c|c|c|}
\hline $\begin{array}{c}\text { Scale } \\
\text { Read- } \\
\text { ing. }\end{array}$ & $\begin{array}{l}\text { Per } \\
\text { Cent } \\
\text { Fatt. }\end{array}$ & $\begin{array}{c}\text { Scale } \\
\text { Read- } \\
\text { ing. }\end{array}$ & $\begin{array}{c}\text { Per } \\
\text { Cent } \\
\text { Fat. }\end{array}$ & $\begin{array}{c}\text { Scale } \\
\text { Read- } \\
\text { ing. }\end{array}$ & $\begin{array}{l}\text { Per } \\
\text { Cent } \\
\text { Fat. }\end{array}$ & $\begin{array}{c}\text { Scale } \\
\text { Read- } \\
\text { ing. }\end{array}$ & $\begin{array}{l}\text { Per } \\
\text { Cent } \\
\text { Fat. }\end{array}$ & $\begin{array}{c}\text { Scale } \\
\text { Read- } \\
\text { ing. }\end{array}$ & $\begin{array}{l}\text { Per } \\
\text { Cent } \\
\text { Fat. }\end{array}$ & $\begin{array}{c}\text { Scale } \\
\text { Read- } \\
\text { ing. }\end{array}$ & $\begin{array}{l}\text { Per } \\
\text { Cent } \\
\text { Fat. }\end{array}$ \\
\hline 20.0 & $\ldots \ldots$ & $24 \cdot 5$ & $0.4 \mathrm{I}$ & 29.0 & 0.87 & $33-5$ & I. 34 & $3^{8.0}$ & 1.85 & 42.5 & $2.4 I$ \\
\hline I & $\ldots .$. & 6 & 0.42 & I & 0.88 & 6 & I. 35 & I & 1.87 & 6 & 2.43 \\
\hline 2 & $\ldots . .$. & 7 & 0.43 & 2 & 0.89 & 7 & I. 36 & 2 & 1.88 & 7 & 2.44 \\
\hline 3 & $\cdots$ & 8 & 0.44 & 3 & 0.90 & 8 & I. 37 & 3 & 1.89 & 8 & 2.46 \\
\hline 4 & $\ldots \ldots$ & 9 & 0.45 & 4 & 0.91 & 9 & I. $3^{8}$ & 4 & 1.90 & 9 & 2.47 \\
\hline 5 & $\ldots \ldots$ & 25.0 & 0.46 & 5 & 0.92 & 34.0 & 1.39 & 5 & $1.9 \mathrm{I}$ & 43.0 & 2.49 \\
\hline 6 & 0.00 & $I$ & 0.47 & 6 & 0.93 & I & 1.40 & 6 & 1.92 & I & 2.50 \\
\hline 7 & 0.01 & 2 & 0.48 & 7 & 0.94 & 2 & 1.42 & 7 & 1.93 & 2 & 2.51 \\
\hline 8 & 0.02 & 3 & 0.49 & 8 & 0.95 & 3 & 1.43 & 8 & I.94 & 3 & 2.52 \\
\hline 9 & 0.03 & 4 & 0.50 & 9 & 0.96 & 4 & I. 44 & 9 & 1.95 & 4 & 2.54 \\
\hline 21.0 & 0.04 & 5 & $0.5 \mathrm{I}$ & 30.0 & 0.97 & 5 & $I .45$ & 39.0 & 1.96 & 5 & 2.55 \\
\hline I & 0.05 & 6 & 0.52 & I & 0.98 & 6 & I. 46 & $I$ & I. 98 & 6 & 2.56 \\
\hline 2 & 0.06 & 7 & 0.53 & 2 & 0.99 & 7 & 1.47 & 2 & 1.99 & 7 & $2.5^{8}$ \\
\hline 3 & 0.08 & 8 & 0.54 & 3 & 1.00 & 8 & 1.48 & 3 & 2.00 & 8 & 2.60 \\
\hline 4 & 0.09 & 9 & 0.55 & 4 & I.OI & 9 & I. 49 & 4 & 2.02 & 9 & 2.61 \\
\hline 5 & 0.10 & 26.0 & 0.57 & 5 & 1.02 & 35.0 & $I .50$ & 5 & 2.03 & 44.0 & 2.63 \\
\hline 6 & O.II & I & $0.5^{8}$ & 6 & 1.03 & I & I. $5 \mathrm{I}$ & 6 & 2.04 & I & 2.64 \\
\hline 7 & 0.12 & 2 & 0.59 & 7 & I. .04 & 2 & 1.52 & 7 & 2.05 & 2 & 2.65 \\
\hline 8 & 0.13 & 3 & 0.60 & 8 & I. 05 & 3 & I. 54 & 8 & 2.07 & 3 & 2.67 \\
\hline 9 & 0.14 & 4 & $0.6 \mathrm{I}$ & 9 & 1.06 & 4 & I. 55 & 9 & 2.08 & 4 & 2.68 \\
\hline 22.0 & 0.15 & 5 & 0.62 & 31.0 & 1.07 & 5 & I. 56 & 40.0 & 2.09 & 5 & 2.70 \\
\hline I & 0.16 & 6 & 0.63 & I & 1.08 & 6 & I -57 & I & 2.10 & 6 & $2-7$ I \\
\hline 2 & 0.17 & 7 & 0.64 & 2 & 1.09 & 7 & I. $5^{8}$ & 2 & 2.12 & 7 & 2.72 \\
\hline 3 & 0.18 & 8 & 0.65 & 3 & I. IO & 8 & 1.59 & 3 & 2.13 & 8 & 2.74 \\
\hline 4 & 0.19 & 9 & 0.66 & 4 & I.II & 9 & 1.60 & 4 & 2.14 & 9 & 2.75 \\
\hline 5 & 0.20 & 27.0 & 0.67 & 5 & I. 12 & 36.0 & $1.6 \mathrm{I}$ & 5 & 2.15 & 45.0 & 2.77 \\
\hline 6 & 0.21 & I & 0.68 & 6 & I. 13 & I & 1.62 & 6 & 2.16 & I & 2.78 \\
\hline 7 & 0.22 & 2 & 0.69 & 7 & I. $x_{4}$ & 2 & 1.64 & 7 & 2.18 & 2 & 2.79 \\
\hline 8 & 0.23 & 3 & 0.70 & 8 & 1.15 & 3 & 1.65 & 8 & 2.20 & 3 & 2.80 \\
\hline 9 & 0.24 & 4 & 0.71 & 9 & 1.16 & 4 & 1.66 & 9 & $2.2 \mathrm{I}$ & 4 & 2.82 \\
\hline 33.0 & 0.25 & 5 & 0.72 & 32.0 & 1.17 & 5 & 1.67 & 41.0 & 2.23 & 5 & 2.84 \\
\hline I & 0.26 & 6 & 0.73 & I & I. 18 & 0 & 1.68 & I & 2.24 & 6 & 2.85 \\
\hline 2 & 0.27 & 7 & 0.74 & 2 & I. I9 & 7 & 1.69 & 2 & 2.25 & 7 & 2.87 \\
\hline 3 & 0.28 & 8 & 0.75 & 3 & 1.20 & 8 & 1.70 & 3 & 2.26 & 8 & 2.88 \\
\hline 4 & 0.29 & 9 & $0.7^{6}$ & 4 & 1.22 & 9 & 1.71 & 4 & 2.27 & 9 & 2.89 \\
\hline 5 & 0.30 & 28.0 & 0.77 & 5 & 1.23 & 37.0 & 1.72 & 5 & 2.28 & 40.0 & 2.90 \\
\hline 6 & 0.31 & $I$ & 0.78 & 6 & 1.24 & 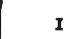 & & 6 & 2.30 & I & 2.92 \\
\hline 7 & 0.32 & 2 & 0.79 & 7 & 1.25 & 2 & 1.75 & 7 & 2.32 & 2 & 2.93 \\
\hline 8 & 0.33 & 3 & 0.80 & 8 & 1.26 & 3 & 1.76 & 8 & $2 \cdot 33$ & 3 & 2.94 \\
\hline 9 & 0.34 & 4 & $0.8 I$ & 9 & I. 27 & 4 & I. 78 & 9 & 2.34 & 4 & 2.96 \\
\hline 24.0 & 0.36 & 5 & 0.82 & 33.0 & I. 28 & 5 & 1.79 & 42.0 & $2 \cdot 35$ & 5 & 2.98 \\
\hline$I$ & 0.37 & 6 & $0.8_{3}^{\prime}$ & 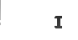 & 1.29 & 6 & I. 80 & I & 2.37 & 6 & 3.00 \\
\hline 2 & $0.3^{8}$ & 7 & 0.84 & 2 & 1.30 & 7 & I. $8 \mathrm{I}$ & 2 & $2.3^{8}$ & 7 & 3.01 \\
\hline 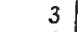 & 0.39 & 8 & 0.85 & 3 & $I \cdot 31$ & 8 & I. 82 & 3 & 2.39 & 8 & 3.02 \\
\hline 4 & 0.40 & 9 & 0.86 & 4 & $1 \cdot 32$ & 9 & I. 84 & 4 & 2.40 & 9 & 3.03 \\
\hline 5 & 0.41 & 29.0 & 0.87 & 5 & 1.34 & $3^{8.0}$ & I. 85 & 5 & $2.4 \mathrm{I}$ & 47.0 & 3.05 \\
\hline
\end{tabular}


PERCENTAGES OF FAT CORRESPONDING TO SCALE READINGS ON THE WOLLNY REFRACTOMETER-(Continued).

\begin{tabular}{|c|c|c|c|c|c|c|c|c|c|c|c|}
\hline $\begin{array}{c}\text { Scale } \\
\text { Read- } \\
\text { ing. }\end{array}$ & $\begin{array}{c}\text { Per } \\
\text { Cent } \\
\text { Fat. }\end{array}$ & $\begin{array}{c}\text { Seale } \\
\text { Read- } \\
\text { ing. }\end{array}$ & $\begin{array}{l}\text { Per } \\
\text { Cent } \\
\text { Fat. }\end{array}$ & $\begin{array}{c}\text { Scale } \\
\text { Read- } \\
\text { ing. }\end{array}$ & $\begin{array}{c}\text { Per } \\
\text { Cent } \\
\text { Fat. } \\
\end{array}$ & $\begin{array}{c}\text { Scale } \\
\text { Reagd- } \\
\text { ing. }\end{array}$ & $\begin{array}{c}\text { Per } \\
\text { Cent } \\
\text { Fat. }\end{array}$ & $\begin{array}{c}\text { Scale } \\
\text { Read- } \\
\text { ing. }\end{array}$ & $\begin{array}{c}\text { Per } \\
\text { Cent } \\
\text { Fat. }\end{array}$ & $\begin{array}{c}\text { Scale } \\
\text { Read- } \\
\text { ing. }\end{array}$ & $\begin{array}{c}\text { Per } \\
\text { Cent } \\
\text { Fat. }\end{array}$ \\
\hline 47.0 & 3.05 & 50.5 & 3.59 & 54.0 & 4.18 & $57 \cdot 5$ & $4 \cdot 78$ & 61.0 & 5.44 & 64.5 & 6.54 \\
\hline $\mathbf{I}$ & 3.06 & 6 & 3.60 & I & 4.20 & 6 & 4.80 & I & 5.46 & 6 & 6.16 \\
\hline 2 & 3.08 & 7 & $3.6 \mathrm{I}$ & 2 & 4.22 & 7 & 4.82 & 2 & $5 \cdot 48$ & 7 & 6.18 \\
\hline 3 & 3.10 & 8 & 3.63 & 3 & 4.23 & 8 & 4.84 & 3 & $5.5^{\circ}$ & 8 & 6.20 \\
\hline 4 & 3.12 & 9 & 3.64 & 4 & 4.25 & 9 & 4.86 & 4 & $5 \cdot 52$ & 9 & 6.22 \\
\hline 5 & 3.14 & 51.0 & 3.66 & 5 & 4.26 & $5^{8.0}$ & 4.88 & 5 & 5.54 & 65.0 & 6.24 \\
\hline 6 & 3.15 & I & 3.67 & 6 & 4.28 & I & 4.90 & 6 & $5 \cdot 56$ & I & 6.27 \\
\hline 7 & 3.16 & 2 & 3.68 & 7 & 4.29 & $2^{*}$ & 4.92 & 7 & $5 \cdot 5^{8}$ & 2 & 6.29 \\
\hline 8 & 3.17 & 3 & $3.7^{\circ}$ & 8 & $4.3 I$ & 3 & 4.94 & 8 & 5.60 & 3 & $6 \cdot 3 x$ \\
\hline 9 & 3.18 & 4 & $3 \cdot 7^{2}$ & 9 & 4.33 & 4 & 4.95 & 9 & 5.61 & 4 & 6.34 \\
\hline 48.0 & 3.20 & 5 & 3.74 & 55.0 & $4 \cdot 35$ & 5 & 4.97 & 62.0 & 5.63 & 5 & 6.36 \\
\hline I & $3.2 \mathrm{I}$ & 6 & $3 \cdot 76$ & $\mathbf{I}$ & 4.37 & 6 & 4.98 & $I$ & 5.65 & 6 & 6.38 \\
\hline 2 & 3.23 & 7 & 3.78 & 2 & $4 \cdot 3^{8}$ & 7 & 5.00 & 2 & 5.66 & 7 & 6.40 \\
\hline 3 & 3.25 & 8 & 3.80 & 3 & 4.40 & 8 & 5.02 & 3 & 5.68 & 8 & 6.42 \\
\hline 4 & 3.27 & 9 & 3.82 & 4 & 4.42 & 9 & 5.04 & 4 & 5.70 & 9 & 6.44 \\
\hline 5 & 3.28 & 52.0 & 3.84 & 5 & 4.43 & 59.0 & 5.06 & 5 & 5.72 & 66.0 & 6.46 \\
\hline 6 & 3.30 & I & 3.85 & 6 & 4.44 & I & 5.08 & 6 & 5.7 & & \\
\hline 7 & $3 \cdot 32$ & 2 & 3.8 & 7 & $4 \cdot 4$ & 2 & 5.10 & 7 & 5.76 & & \\
\hline 8 & 3.33 & 3 & 3.89 & 8 & 4.48 & 3 & 5.11 & 8 & $5.7^{8}$ & & \\
\hline 9 & 3.34 & 4 & 3.90 & 9 & 4.49 & 4 & 5.13 & 9 & 5.80 & & \\
\hline 49.0 & $3 \cdot 36$ & 5 & 3.92 & 56.0 & 4.51 & 5 & 5.15 & 63.0 & 5.82 & & \\
\hline I & $3 \cdot 3^{8}$ & 6 & 3.93 & $\mathrm{I}$ & 4.5 & 6 & 5.1 & I & 5.8 & & \\
\hline 2 & 3.4 & 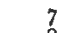 & 3.95 & 2 & 4.5 & 7 & 5.1 & 2 & 5. & & \\
\hline 3 & 3.42 & 8 & 3.97 & 3 & 4.5 & 8 & 5.20 & 3 & 5.8 & & \\
\hline 4 & $3 \cdot 43$ & 9 & 3-99 & 4 & 4.5 & 9 & 5.22 & 4 & 5.9 & & \\
\hline 5 & 3.44 & 53.0 & 4.01 & 5 & 4.60 & 60.0 & 5.24 & 5 & 5.92 & - & \\
\hline 6 & 3.45 & I & 4.0 & 6 & 4.6 & I & 5.26 & 6 & 5. & & \\
\hline & 3.2 & 2 & 4.0 & 7 & 4.6 & 2 & 5.28 & 7 & & & \\
\hline 8 & 3.48 & 3 & 4.06 & 8 & $4-6$ & 3 & 5.30 & 8 & 5. & & \\
\hline $50.0^{9}$ & $3.5^{\circ}$ & 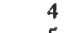 & 4.07 & 9 & 4.6 & 4 & $5 \cdot 3^{2}$ & 9 & 6. & & \\
\hline 50.0 & 3.51 & 5 & 4.09 & 57.0 & 4.69 & 5 & $5 \cdot 34$ & 64.0 & 6.02 & & \\
\hline I & 3.53 & 6 & $4 \cdot x$ & I & 4.7 & 6 & $5: 3$ & I & 6. & & \\
\hline 2 & $3-5$ & 7 & 4. & 2 & 4.7 & 7 & $5 \cdot 3^{8}$ & 2 & 6. & & \\
\hline 3 & $3 \cdot 56$ & 8 & 4. & 3 & $4 \cdot 7$ & 8 & $5 \cdot 40$ & 3 & 6. & & \\
\hline 4 & 3.57 & 9 & & 4 & 4.7 & 9 & $5 \cdot 42$ & 4 & 6.12 & & \\
\hline 5 & 3.59 & 54.0 & 4.18 & 5 & 4.78 & 61.0 & $5 \cdot 44$ & 5 & 6.14 & & \\
\hline
\end{tabular}


The following table gives the indices of refraction corresponding to the scale readings of the Wollny milk-fat refractometer:

INDICES OF REFRACTION $\left(n_{n}\right)$ CORRESPONDING TO SCALE READINGS OF THE WOLLNY MILK-FAT REFRACTOMETER.

\begin{tabular}{|c|c|c|c|c|c|c|c|c|c|c|}
\hline \multirow{2}{*}{$\begin{array}{l}\text { Refrac- } \\
\text { tive } \\
\text { Index. } \\
n_{D} .\end{array}$} & \multicolumn{10}{|c|}{ Fourth Decimal of $n_{D^{\circ}}$} \\
\hline & 0 & 1 & 2 & 3 & 4 & 5 & 8 & 7 & 8 & 9 \\
\hline & & & & & o Read & & & & & \\
\hline I. 333 & & & 0.0 & 0.1 & 0.2 & 0.3 & 0.4 & 0.5 & 0.5 & 0.6 \\
\hline$I=334$ & 0.7 & 0.8 & 0.9 & I.० & I.I & 1.2 & I. 3. & I. 4 & 1.5 & I. 6 \\
\hline I. 335 & 1.7 & I. 8 & I.9 & 2.0 & 2.1 & 2.1 & 2.2 & 2.3 & 2.4 & 2.5 \\
\hline I. $33^{6}$ & 2.8 & 2.7 & 2.8 & 2.9 & 3.0 & $3 \cdot 1$ & 3.2 & $3 \cdot 3$ & 3.4 & 3.5 \\
\hline I. 337 & 3.6 & 3.7 & $3 \cdot 7$ & 3.8 & 3.9 & 4.0 & 4.1 & 4.2 & $4 \cdot 3$ & 4.4 \\
\hline $1.33^{8}$ & 4.5 & 4.6 & 4.7 & 48 & 4.9 & 5.0 & 5.1 & 5.2 & $5 \cdot 3$ & 5.4 \\
\hline I. 339 & $5 \cdot 5$ & $5 \cdot 6$ & $5 \cdot 7$ & $5: 8$ & 5.9 & 6.0 & 6.1 & 6.2 & 6.3 & 6.4 \\
\hline I .340 & 6.5 & 6.6 & 6.7 & 6.8 . & 6.9 & 6.9 & 7.0 & 7.1 & 7.2 & $7 \cdot 3$ \\
\hline $\mathrm{I} .34 \mathrm{I}$ & $7 \cdot 4$ & 7.5 & 7.6 & 7.7 & 7.8 & 7.9 & 8.0 & 8.1 & 8.2 & 8.3 \\
\hline I. 342 & 8.4 & 8.5 & 8.6 & 8.7 & 8.8 & 8.9 & 9.0 & 9.1 & 9.2 & 9.3 \\
\hline I. 343 & $9 \cdot 4$ & 9.5 & 9.6 & 9.7 & 9.8 & 9.9 & 10.0 & I0. I & 10.2 & 10.3 \\
\hline I. 344 & 10.4 & 10.5 & 50.6 & 10.7 & 10.8 & 10.9 & II.O & II.I & 11.2 & 11.3 \\
\hline I. 345 & II. 4 & 11.5 & II. 5 & IF. 6 & II. 7 & II .8 & II.9 & 12.0 & $12 . I$ & 12.2 \\
\hline I. 346 & 12.3 & 12.4 & 12.5 & 12.6 & I 2.7 & 12.8 & I $2-9$ & 13.0 & I3.I & 13.2 \\
\hline I. 347 & $13-3$ & $13-4$ & 13.5 & I3.6 & 13.7 & 13.8 & 13.9 & I 4.0 & $14 . I$ & I 4.2 \\
\hline I. 348 & 14.3 & 14.4 & 14.5 & 14.6 & 14.7 & I4.8 & 14.9 & 15.0 & I5.I & 15.2 \\
\hline I. 349 & 15.3 & 15.4 & $15-5$ & 15.6 & $15 \cdot 7$ & I 5.8 & 15.9 & 16.0 & 16.1 & 16.2 \\
\hline 1.350 & 16.3 & 16.4 & 16.5 & I6.6 & 16.7 & I6.8 & 16.9 & 17.0 & I7.I & 37.2 \\
\hline 1. $35 \mathrm{I}$ & 17.3 & 17.4 & 17.5 & 17 & $17 \cdot 7$ & 17. & 17.9 & 18.0 & 18.1 & 18.2 \\
\hline I. $35^{2}$ & 18.3 & 18.4 & 18.5 & 18.6 & 18.7 & 18.8 & 8.9 & 19.0 & I9. I & 19.2 \\
\hline I. 353 & 19.3 & 19.4 & 19.5 & 19.6 & 19.7 & 19.8 & 19.9 & 20.0 & 20.1 & 20.2 \\
\hline 1.354 & 20.3 & 20.4 & 20 & 20.6 & 20.7 & 20.8 & 20.9 & 21.0 & 21.1 & 21.2 \\
\hline 1.355 & $21-3$ & 21.4 & 21.5 & 21.6 & $2 \mathrm{I}-7$ & 21.8 & 21.9 & 22.0 & 22.1 & 22.2 \\
\hline I. $35^{6}$ & 22.3 & 22.4 & 22.5 & 22.6 & 22.7 & 22.8 & 22.9 & 23.0 & 23.1 & 23.2 \\
\hline 1.357 & 23.3 & 23.4 & 23.5 & 23.6 & 23.7 & 23.8 & 23.9 & 24.0 & 24.1 & 24.2 \\
\hline I. $35^{8}$ & $24 \cdot 3$ & $24-4$ & 24.5 & 24.6 & 24.7 & 24.8 & 24.9 & 25.0 & $25-1$ & 25.2 \\
\hline 1.359 & $25 \cdot 3$ & 25.4 & 25.5 & 25.6 & 25.7 & 25.8 & $25 \cdot 9$ & 26.0 & 26.1 & 26.2 \\
\hline I. 360 & 26.3 & 26.4 & 26.5 & 26.6 & 26.7 & 26.8 & 26.9 & 27. & 27 & $27 \cdot 3$ \\
\hline I. $36 \mathrm{I}$ & $27-4$ & $27-5$ & 27.6 & & 27.8 & 27 & 28.0 & 28.1 & 28.2 & 28.3 \\
\hline I. 362 & 28.4 & 28.5 & 28.6 & 28.7 & 28.8 & 28.9 & 29.0 & 29.1 & 29.2 & 29.3 \\
\hline I. 363 & 29.4 & 29.5 & 29.6 & 29.7 & 29.8 & 29.9 & 30.0 & 30.1 & 30.2 & 30.3 \\
\hline I. 364 & 30.4 & 30.5 & 30.6 & 30.7 & 30.8 & $3 \mathrm{I}$. & $3 \mathrm{I} . \mathrm{I}$ & 3 I. 2 & $3 \mathrm{I} \cdot 3$ & $3^{\mathrm{I}} \cdot 4$ \\
\hline 1.365 & 3 I. 5 & 31.6 & $3^{\mathrm{I}}-7$ & 31.8 & $3^{1-9}$ & 32.0 & $32 . I$ & 32.2 & $3^{2} \cdot 3$ & $3^{2.4}$ \\
\hline 1.366 & 32.5 & 32.7 & 32.8 & 32.9 & 33.0 & 33. & 33.2 & $33-3$ & $33 \cdot 4$ & 33.5 \\
\hline I. 367 & 33.6 & 33.7 & 33.8 & 33.9 & 34.0 & & 34.3 & $34-4$ & $34 \cdot 5$ & 34.6 \\
\hline I 368 & $34: 7$ & 34.8 & $34-9$ & 35.0 & 35.1 & 35.2 & 35.3 & $35-4$ & $35 \cdot 5$ & 35.6 \\
\hline 1.369 & $35-7$ & 35.8 & 36.0 & 36.1 & 36.2 & $36 \cdot 3$ & 36.4 & 36.5 & 36.6 & 36.7 \\
\hline 1.370 & $3^{6.8}$ & 36.9 & 37 & & & & & 37.6 & 37.7 & 37.8 \\
\hline $1.37 \mathrm{I}$ & 37.9 & 38.0 . & & & & & 38.5 & $3^{8} .6$ & $3^{8.7}$ & 38.8 \\
\hline 1.372 & $3^{8} .9$ & $39.0^{\circ}$ & 39. & $39-3$ & 39.4 & 39.5 & 39.6 & $39-7$ & 39.8 & 39.9 \\
\hline 1.373 & 40.0 & 40.1 & 40. & & & & 40.7 & 40.8 & 40.9 & $4 \mathrm{I} .0$ \\
\hline I. 374 & $4 \mathrm{I} \cdot \mathrm{I}$ & $4 \pi-2$ & $4 \mathrm{I} \cdot 3$ & $4 \mathrm{I} .4$ & $4 \times-5$ & 41.6 & 41.8 & 41.9 & 42.0 & 42.1 \\
\hline $5 \cdot 375$ & 42.2 & 42.3 & 42.4 & 42. & 42.6 & 42.7 & 42.8 & 42.9 & 43.0 & $43 . I$ \\
\hline 1.376 & 43.2 & $43 \cdot 3$ & 43.4 & 43.6 & 43.7 & 43.8 & 43.9 & 44.0 & $44 \cdot I$ & 44.2 \\
\hline 1.377 & $44 \cdot 3$ & 44.4 & 44.6 & 44.7 & 44.8 & 44.9 & 45.0 & $45 . I$ & 45.2 & 45.3 \\
\hline 1.378 & 45.4 & 45.6 & $45-7$ & 45.8 & 45.9 & 46.0 & 46.1 & 46.2 & $4^{6} \cdot 3$ & 46.4 \\
\hline $1 \cdot 379$ & 46.6 & $4^{6.7}$ & 46.8 & $4^{6.9}$ & 47.0 & 47.1 & 47.2 & $47 \cdot 3$ & $47-4$ & 47.6 \\
\hline
\end{tabular}


INDICES OF REFRACTION $\left(n_{D}\right)$ CORRESPONDING TO SCAI.E READINGS OF THE WOLLNY MILK-FAT REFRACTOMETER-(Continued).

\begin{tabular}{|c|c|c|c|c|c|c|c|c|c|c|}
\hline \multirow{2}{*}{$\begin{array}{c}\text { Refrac- } \\
\text { tive } \\
\text { Index. } \\
n_{D .}\end{array}$} & \multicolumn{10}{|c|}{ Fourth Decimal of $n_{D}$. } \\
\hline & 0 & 1 & 2 & 3 & 4 & 5 & 6 & 7 & 8 & 9 \\
\hline & \multicolumn{10}{|c|}{ Scale Readings. } \\
\hline$I \cdot 3^{80}$ & $47 \cdot 7$ & 47.8 & 47.9 & 48.0 & $48 . x$ & $4^{8.2}$ & $48 \cdot 3$ & 48.4 & 48.6 & 48.7 \\
\hline I. $3^{81}$ & 48.8 & $4^{8.9}$ & 49.0 & $49 \cdot \tau$ & 49.2 & $49 \cdot 3$ & $49 \cdot 4$ & 49.6 & $49 \cdot 7$ & 49.8 \\
\hline 1.382 & $49 \cdot 9$ & 50.0 & $50 . I$ & 50.2 & $50 \cdot 3$ & 50.4 & 50.6 & 50.7 & 508 & 50.9 \\
\hline $\mathbf{r} \cdot 3^{8} 3$ & 51.0 & SI.I & 5 I -2 & $5 \mathrm{I} \cdot 3$ & $51 \cdot 4$ & 51.6 & 5 I. 7 & 51.8 & 51.9 & 52.0 \\
\hline $\mathbf{I}-384$ & $52 . I$ & 52.2 & $52 \cdot 3$ & $52 \cdot 4$ & 52.6 & 52.7 & 52.8 & 52.9 & 53.0 & $53 . \mathrm{I}$ \\
\hline I. 385 & 53.2 & $53 \cdot 3$ & $53-4$ & 53.6 & $53-7$ & 53.8 & $53-9$ & 54.0 & $54 \cdot I$ & 54.2 \\
\hline I. 386 & $54 \cdot 3$ & $54 \cdot 4$ & 54.6 & $54 \cdot 7$ & 54.8 & 54.9 & 55.0 & 55.1 & 55.2 & $55 \cdot 3$ \\
\hline 1. 387 & $55-4$ & 55.6 & 55.7 & 55.8 & 55.9 & 56.0 & 56.1 & $5^{6.2}$ & 56.3 & $5^{6} \cdot 5$ \\
\hline 1. 388 & $5^{6.6}$ & $5^{6} \cdot 7$ & 56.8 & $5^{6.9}$ & 57.1 & 57.2 & $57 \cdot 3$ & 57.4 & 57.6 & $57 \cdot 7$ \\
\hline 1.389 & 57.8 & 57.9 & 58.0 & 58.1 & 58.2 & $5^{8} \cdot 3$ & $5^{8} .4$ & $5^{8} .6$ & 58.7 & 58.8 \\
\hline I. 390 & $5^{8.9}$ & 59.0 & 59.1 & 59.2 & 59.4 & $59 \cdot 5$ & 59.6 & 59.8 & 59.9 & 60,0 \\
\hline I - 39 I & 60.1 & 60.2 & 60.3 & 60.4 & 60.6 & 60.7 & 60.8 & 60.9 & 6I.O & $6 \mathrm{r}: \mathrm{I}$ \\
\hline I. 392 & $61 \cdot 3$ & $6 \pi .4$ & $6 \mathrm{r} \cdot 5$ & 61.6 & $6 \mathrm{r}: 8$ & $6 \mathrm{I} .9$ & 62.0 & $62 . I$ & 62.2 & 62.3 \\
\hline I. 393 & 62.4 & 62.6 & 62.7 & 62.8 & 62.9 & 63.0 & $6_{3} \cdot 2$ & $63 \cdot 3$ & 63.4 & 63.5 \\
\hline I. 394 & 63.6 & 63.8 & 63.9 & 64.0 & $64 \cdot I$ & 64.2 & 64.4 & $64 \cdot 5$ & 64.6 & $64 \cdot 7$ \\
\hline I. 395 & 64.8 & 65.0 & 65.1 & 65.2 & 65.3 & 65.4 & 65.6 & $65 \cdot 7$ & 65.8 & 65.9 \\
\hline I. 396 & 66.0 & 66.2 & 66.3 & 66.4 & 66.5 & 66.6 & 66.8 & و.966 & 67.0 & $67 \cdot \mathbf{I}$ \\
\hline I. 397 & 67.2 & 67.4 & 67.5 & 67.6 & 67.7 & 67.8 & 67.9 & 68. I & 68.2 & 68.3 \\
\hline I .398 & 68.4 & 68.6 & 68.7 & 68.8 & 68.9 & 69.0 & 69.1 & $69 \cdot 3$ & 69.4 & 69.5 \\
\hline I - 399 & 69.6 & 69.8 & 69.9 & 70.0 & 70.1 & 70.2 & 70.4 & 70.5 & 70.6 & 70.8 \\
\hline I. 400 & 70.9 & 71.0 & 71.1 & 71.2 & 7 I. 4 & $7 \mathrm{I} \cdot 5$ & 71.6 & 71.8 & 71.9 & 72.0 \\
\hline I. 401 & $72 . I$ & 72.2 & $7^{2}-4$ & $72 \cdot 5$ & 72.6 & 72.8 & 72.9 & $73.0^{\circ}$ & $73 \cdot I$ & 73.2 \\
\hline I . 402 & 73.4 & $73-5$ & 73.6 & 73.8 & 73.9 & 74.0 & 74.1 & 74.2 & 74.4 & $74 \cdot 5$ \\
\hline I. 403 & 74.6 & $74-8$ & 74.9 & 75.0 & $75 \cdot I$ & 75.2 & $75-4$ & 75.5 & 75.6 & 75.8 \\
\hline I. 404 & 75.9 & 76.0 & 76.1 & $7^{6.2}$ & 76.4 & $7^{6.5}$ & 76.6 & 76.8 & 76.9 & 77.0 \\
\hline I. 405 & 77.1 & 77.2 & 77.4 & $77 \cdot 5$ & $77 \cdot 7$ & 77.8 & 77.9 & $7^{8} . \mathrm{I}$ & $7^{8.2}$ & 78.3 \\
\hline I. 406 & $7^{8} .5$ & 78.6 & $7^{8} \cdot 7$ & $7^{8.8}$ & 79.0 & $79 . \mathrm{I}$ & 79.2 & 79.4 & 79.5 & 79.6 \\
\hline 1.407 & 79.8 & 79.9 & 80.0 & 80.1 & 80.2 & 80.4 & 80.5 & 80.6 & 80.8 & 80.9 \\
\hline I. 408 & $8 \mathrm{I} .0$ & $8 \mathrm{I} . \mathrm{I}$ & 81.2 & $8 \mathrm{r}-4$ & $8 I .5$ & 81.6 & $81 \cdot 7$ & $8 \mathrm{I} .9$ & 82.0 & 82.1 \\
\hline 1.409 & 82.3 & 82.4 & 82.5 & 82.6 & 82.8 & 82.9 & 83.0 & 83.2 & $8_{3 \cdot 3}$ & 83.4 \\
\hline 1.410 & 83.6 & $83-7$ & 83.8 & 84.0 & $84 . I$ & 84.2 & 84.4 & $84 \cdot 5$ & 84.6 & 84.8 \\
\hline I. 4 I I & 84.9 & 85.0 & 85.2 & $85 \cdot 3$ & 85.4 & 85.5 & 85.6 & 85.7 & 85.9 & 86.1 \\
\hline I. 4 I 2 & 86.2 & 86.3 & 86.5 & 86.6 & 86.7 & 86.9 & 87.0 & 87.1 & $87 \cdot 3$ & 87.4 \\
\hline 1.413 & $87 \cdot 5$ & $87 \cdot 7$ & 87.8 & 87.9 & 88. I & 88.2 & 88.3 & 88.5 & 88.6 & 88.7 \\
\hline I. $4 \mathrm{I} 4$ & 88.9 & 89.0 & 89.1 & 89.3 & 89.4 & 89.6 & 89.7 & 89.9 & 90.0 & 90.1 \\
\hline I. 4 I 5 & 90.2 & 90.4 & 90.5 & 90.6 & 90.8 & 90.9 & 91.0 & 91.2 & $9 \mathrm{I} \cdot 3$ & $9 \mathrm{I} .5$ \\
\hline 1.416 & 91.6 & 91.7 & $9 \mathrm{r}-9$ & 92.0 & $92: I$ & 92.3 & $9^{2} \cdot 4$ & 92.5 & 92.7 & 92.8 \\
\hline 1. 4 I 7 & 92.9 & $93 \cdot \mathbf{I}$ & $93-2$ & $93 \cdot 3$ & $93 \cdot 5$ & 93.6 & 93.8 & 93.9 & 94.0 & 94.2 \\
\hline 1.418 & $94 \cdot 3$ & 94.4 & 94.6 & 94.7 & 94.8 & 95.0 & 95.1 & $95 \cdot 3$ & 95.4 & 95.6 \\
\hline I. 4 I9 & $95 \cdot 7$ & 95.8 & $96.0^{\circ}$ & 96.1 & 96.3 & 96.4 & 96.6 & 96.7 & 96.8 & 97.0 \\
\hline I. 420 & $97 . I$ & $97 \cdot 3$ & $97 \cdot 4$ & 97.6 & $97 \cdot 7$ & 97.8 & 98.0 & $98 . \mathbf{I}$ & 98.3 & $9^{8.4}$ \\
\hline $\mathrm{I}-42 \mathrm{I}$ & 98.5 & 98.7 & $9^{8.8}$ & 99.0 & $99 . I$ & 99.3 & 99.4 & $99 \cdot 5$ & 99.7 & 99.9 \\
\hline I. 422 & 100. & & & & & & & & & \\
\hline
\end{tabular}

The standard alkali solution used in the Wollny refractometer method is prepared as follows: 800 grams $\mathrm{KOH}$ are dissolved in 1000 c.c. of water, and after cooling 600 grams glycerin and 200 grams pulverized copper hydrate dissolved. The volume of the solution is made up to 3000 c.c. with water and allowed to stand 
for three to four days before using. During this time the solution should be shaken occasionally. It is ready for use when foaming has ceased.

If the sample of milk cannot be tested when fresh a preservative must be added. The preservative is prepared by dissolving 70 grams pure potassium bichromate in 312.5 c.c. of strong ammonia and 1000 c.c. of water.

Several methods are known by which the fat is determined volumetrically by use of strong chemicals and centrifugal force. The desirability of a rapid method for determining the fat content of milk became apparent with the rapid development of co-operative dairying. The producer was paid by weight or volume of milk delivered to the creamery, and the milk from herds producing rich milk was of the same pecuniary value as milk with low fat content, in spite of the fact that rich milk yields a higher percentage of butter-fat than does poor milk. Producers of rich milk felt justified in demanding a higher price.

This led to the working out of rapid methods of fat determination, which also rendered watering of milk unprofitable. Of the several methods designed to serve the purpose, the Babcock method is most generally employed in this country. It was introduced in 1890, and although other methods are used in some countries, they are modifications of Babcock's original method. In all these tests the casein is dissolved by the use of strong acid or alkali or alkali mixed with sodium sulphate, potassium-sodium tartrate, or salts of citric and salicylic acids.

The Babcock method is practically the only one of these used by practical dairymen in this country, and its detailed consideration is, therefore, of the utmost importance. An interesting account of its development is given in the Wisconsin Circular No. 32, entitled "The 'Coming of Age' of the Babcock Test." In this circular the Babcock test is called the "Founder of Modern Dairy Education." This simple test has done more than any other single factor to reduce the watering of milk; it has shown the producer how to learn the exact productivity of each individual animal, thus enabling him to weed our poor producers and replace them with good milk cows. It has shown sources of loss to butter and cheese makers; it has placed the pecuniary value of milk on a logical basis, and finally the dairyman can learn through this test whether his separator is working to best advantage by determination of the fat in the skimmed milk.

The principles involved in the Babcock test for butter-fat are: 1, The complete solution of colloids in milk by action of strong sulphuric acid; 2 , the production of sufficient heat by the mixture of acid and milk to completely liquefy the fat, and 3, 
the assembling of the fat in the graduated neck of a specially constructed bottle so that the percentage can be read off.

The sulphuric acid dissolves the casein and removes thereby the substance that holds the fat globules in suspension. The heat which is generated by mixing the acid and milk causes the released fat globules to coalesce and form a layer of melted fat on the surface. The sulphuric acid, furthermore, increases the specific gravity of the mixture, thus facilitating the complete separation of fat.

The apparatus required for the test are as follows:

A pipet measuring 17.6 c.c.

Specially constructed testing bottles.

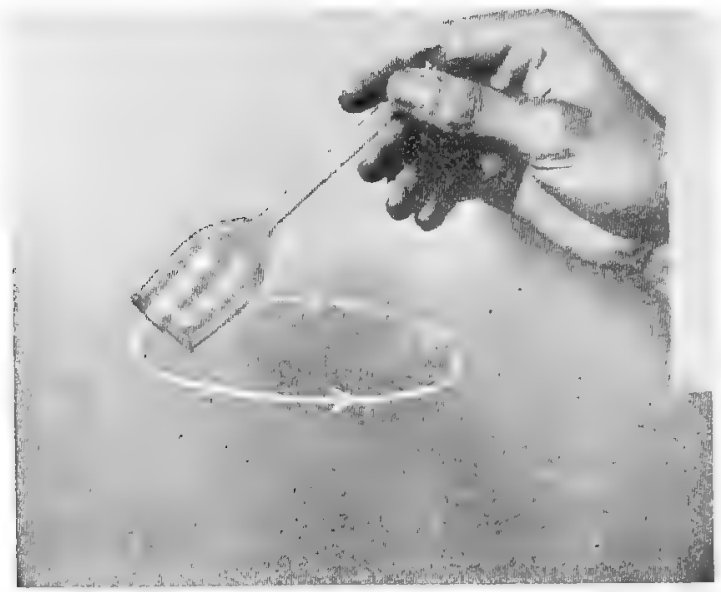

Fig. 43.-To mix the acid and milk shake the bottle until the contents are of a uniform brown color. (Circular of Information No. 27, July, 1916, Univ. of Wis. Agri. Exp. Sta.)

A glass cylinder to measure 17.5 c.c. sulphuric acid.

A pan for heating water.

A pipet or other instrument for adding the hot water.

A centrifuge.

An acidometer.

The following chemicals are needed:

Sulphuric acid of specific gravity of 1.82 to 1.83 .

A solution of glycerin consisting of 80 per cent. glycerin and 20 per cent. water.

Fat-saturated alcohol.

Fat-saturated alcohol is prepared by dissolving a teaspoonful of melted butter in warm alcohol. The fat from cream testing can be used to advantage. The bottle containing the alcohol and 
fat should remain warm and should be shaken frequently until the alcohol is saturated with butter.

In carrying out the Babcock test the procedure is as follows:

1. Mix the sample. If lumps of fat appear on the surface heat the milk to about $100^{\circ} \mathrm{F}$. to melt the fat.

2. Measure 17.6 c.c. of the sample in a Babcock pipet. The milk should flow into the bottle without loss. This is done by inclining the bottle and allowing the milk to flow down the side of the neck.

3. Measure in the graduate 17.5 c.c. sulphuric acid. Pour the acid slowly down the inside of the neck to avoid choking the opening.

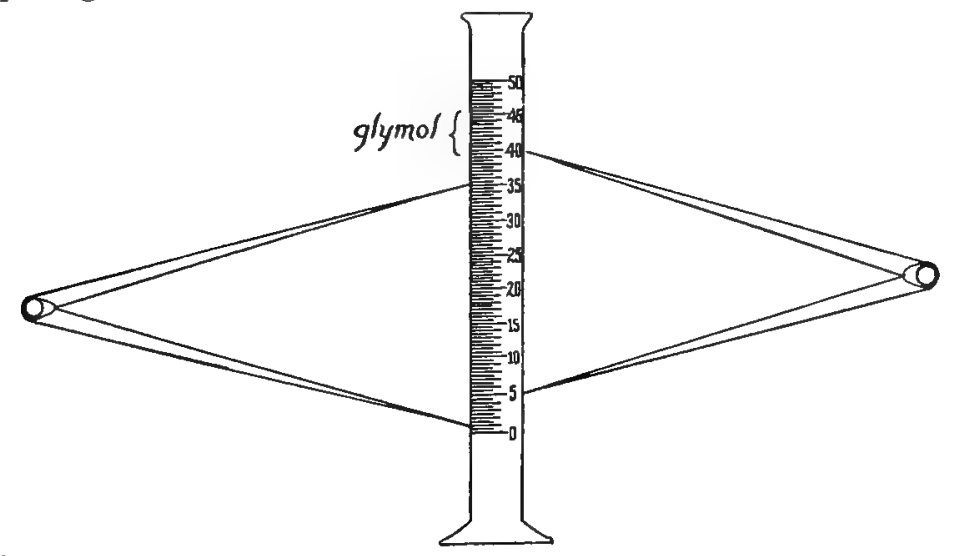

Fig. 44,-Reading of percentage of fat by using dividers. (Bull. No. 202, Nov., 1914, Agri. Exp. Sta. of Colorado Agri. College.)

4. Mix the acid with the milk by a rotary motion (Fig. 43). The fluid becomes yellow, turning darker until a dark brown has been reached. Allow to stand for a few minutes and then mix again.

5. Place the bottles in a centrifuge and whirl for four or five minutes.

6. After the centrifuge has ceased revolving, add enough hot water to bring the fat into the lower part of the neck and whirl again for two minutes.

7. Add more water to bring the fat column within the graduation of the neck and whirl again for one or two minutes.

8. Read the percentage of fat at a temperature of $120^{\circ}$ to $130^{\circ}$ $F$. by counting the dividing lines between the top and bottom of the fat column. The use of dividers facilitates correct reading. After the dividers have been spread to measure the distance from the top to the bottom of the fat column, place one point exactly on zero of the graduation and measure the length of the column (Fig. 44). 
A meniscus forms at both ends of the fat column. The reading should extend from the bottom of the lower meniscus to the top of the upper one. By doing this loss of fat in the bottle is compensated for.

After the test is finished the bottles should be cleaned immediately with hot water to prevent the fat from solidifying.

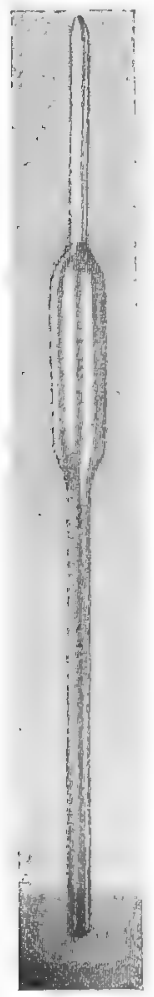

Fig. 45.-A pipet holding 17.6 c.c. of milk used in the Babcock test. (Circular of Information No. 27, July, 1911, Univ. of Wis. Agr. Exp. Sta.)
Otherwise thorough cleaning is rendered difficult.

Of course a representative sample is absolutely necessary. Methods of obtaining fair samples have been previously discussed. The pipets are calibrated to hold 17.6 c.c. of water (Fig. 45). As milk is a viscous fluid a small amount adheres to the inside of the pipet. Experience has shown that this loss amounts to 0.1 c.c., so that a 17.6-c.c. pipet discharges 17.5 c.c. of milk. If 17.5 is multiplied by 1.03 , the average specific gravity of milk, the actual weight is obtained, namely, 18.025 grams. Therefore, this is the basis for calculation.

The neck of one form of test bottle is graduated from 0 to 10 per cent. (Fig. 46). Each per cent. is again subdivided into 5 parts, each of the subdivisions representing 0.2 per cent. The volume between 0 and 10 is exactly 2 c.c. Therefore, if the graduated part of the neck is filled with fat, there are 2 c.c. of fat, or 1.8 grams, since the specific gravity of butter-fat is 0.9 . Since the amount of milk used was 18 grams, the milk would contain 10 per cent. of fat if the column between 0 and 10 were filled with fat. This is the basis for graduation of the neck of the test bottles.

There are different styles of test bottles in use, but the 10 per cent. bottle has been more used than any other. Recently an 8 per cent. bottle has been gaining favor, because the graduation between figures has increased from 5 to 10 , thus facilitating accurate reading of 0.1 per cent.

After the pipet has been filled with milk it is discharged into a test bottle. The aperture of the pipet should touch the glass inside the neck so that the milk runs down smoothly. This will 
prevent choking the opening (Figs. 47, 48). The acid should be poured into the bottle with the same care as the milk. The temperature of milk and the acid before mixing should be about $21^{\circ} \mathrm{C}$. If much higher the mixture is liable to boil and foam will escape.

The specific gravity of the acid should be 1.82 to 1.83 . Commercial sulphuric acid has a specific gravity of 1.84 . This is corrected by pouring the acid into a small volume of water and measuring the specific gravity after the mixture has cooled.

It is important that the acid should have a definite strength. If too strong, some of the milk solids char and black flakes collect

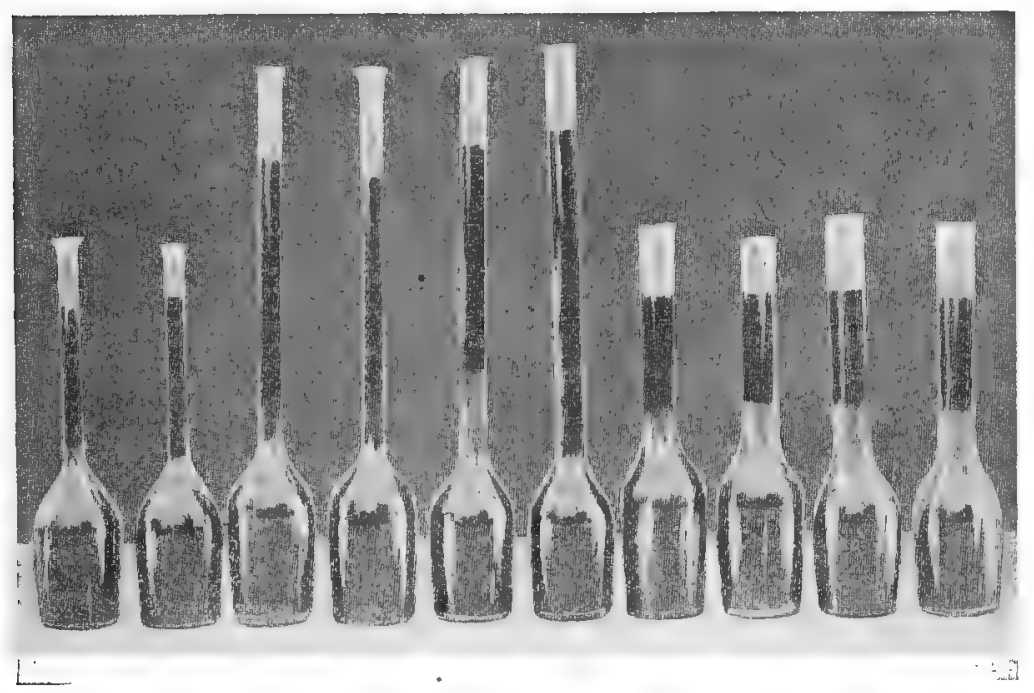

Fig. 46.-Types of cream and milk test bottles, showing fat columns, meniscuses, etc. (Bulletin No. 58, B. A. I.)

at the bottom of the fat column. If the acid is too weak, the casein may not dissolve completely and the fat is cloudy, or some undissolved casein gathers at the lower end of the fat column. Reading cannot be accurate when the column of fat is not clear and well defined. Charring can be prevented by using a smaller quantity of acid, but it is better still to add 2 c.c. of an 80 per cent. glycerin solution to the milk and mix before the acid is run in. When the acid is too weak a larger quantity than 17.5 c.c. will usually give satisfactory results. Sulphuric acid must be kept in wellclosed bottles, otherwise moisture from the air is absorbed and the acid becomes weaker. The specific gravity of the acid is tested with an acidometer. 
The graduations of test bottles are not always accurate and should be tested. This can be accomplished in various ways. A special plunger has been devised for this purpose, known as the Trowbridge calibrator, which can be procured for testing 10 per cent. milk test bottles and 30 per cent. cream test bottles (Fig. 49). This instrument consists of two parts, connected by wire. Each

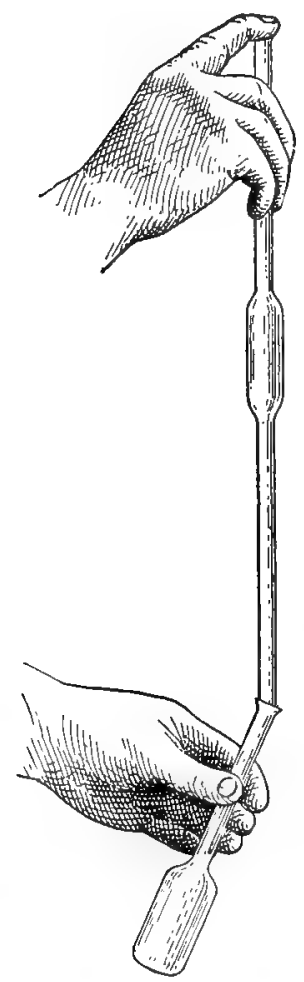

Fig. 47.-Correct way of holding pipet and bottle (Van Slyke).

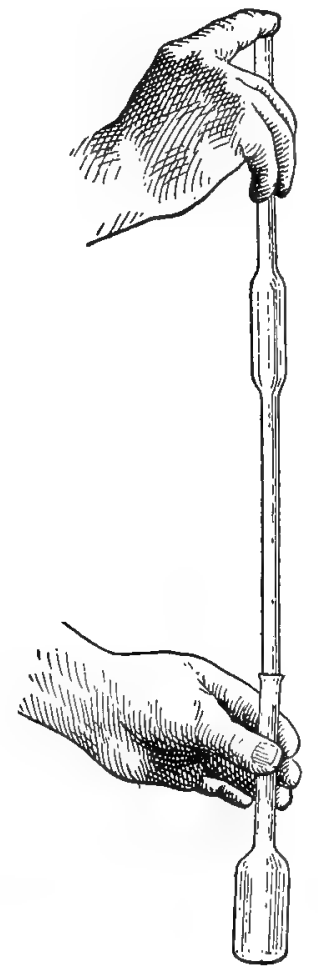

Fig. 48.-Wrong way of holding pipet and bottle (Van Slyke).

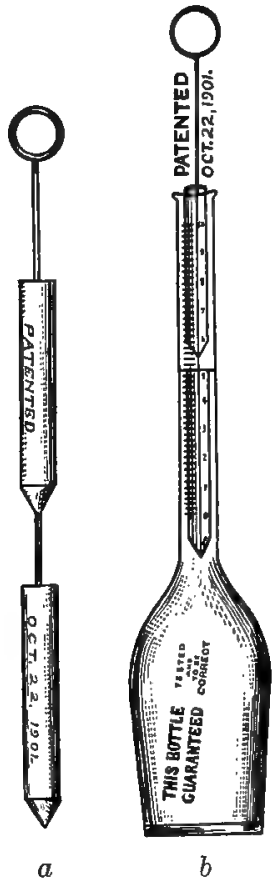

Fig. 49.- $a$, Milkbottle tester; $b$, testing accuracy of milk bottle (Van Slyke).

part displaces exactly 1 c.c. of water. The bottle is filled with water or some other fluid exactly to the 0 mark and the tester is inserted until the lower portion is submerged. One c.c. of the fluid is displaced, and therefore the surface line should reach to the 5 per cent. mark. The second portion of the plunger is now lowered and the fluid should reach to the 10 per cent. mark. It is assumed that when the 5 and 10 per cent. marks are correct 
the intermediate graduation is also correct. Care should be taken to remove all moisture from the neck of the bottle before the tester is inserted and the tester must be dry. The moisture

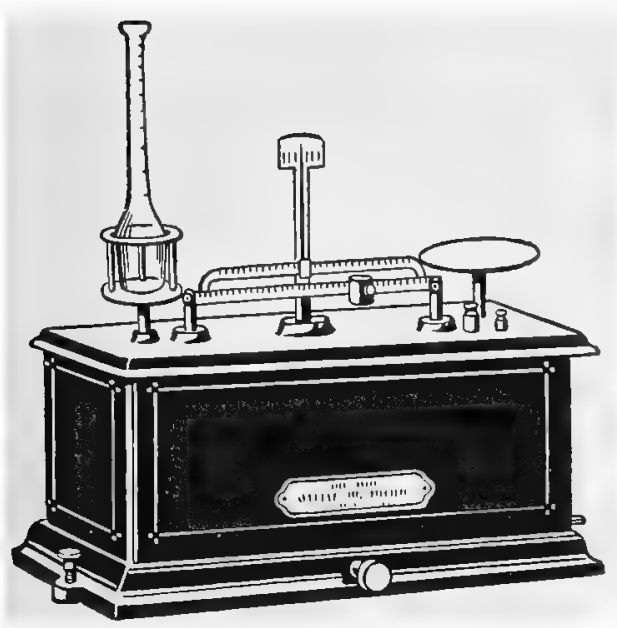

Fig. 50 .

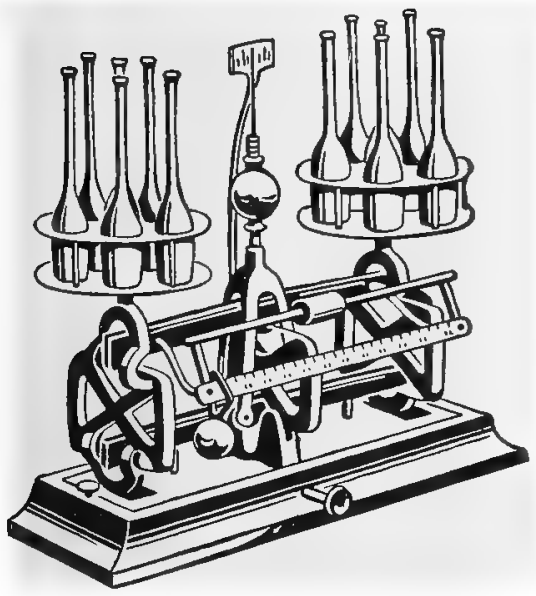

Fig. 52 .

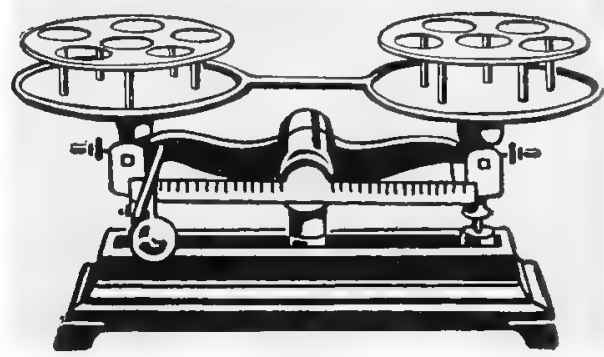

Fig. 51 .

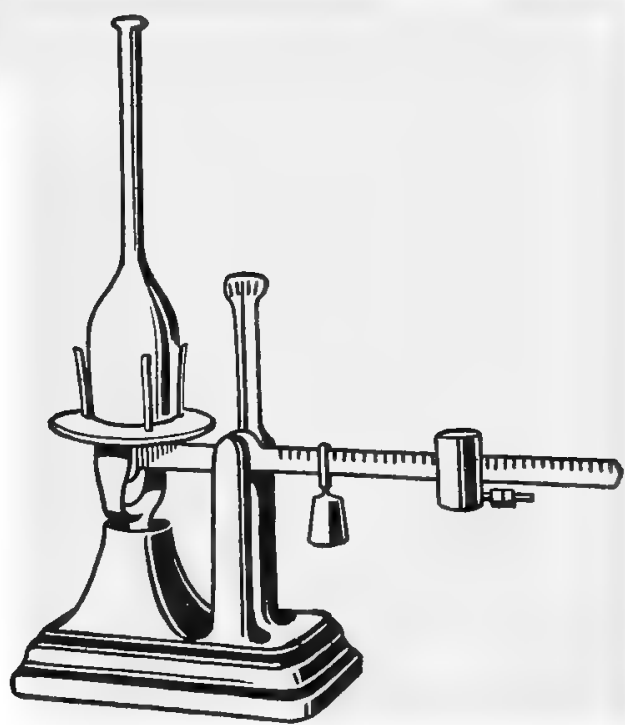

Fig. 53.

Figs. 50-53.--Scales for weighing samples of cream by the Babcock test. (Circular of Information No. 27, July, 1911, Univ. of Wis. Agri. Exp. Sta.)

can be removed with strips of filter paper. No air-bubbles should adhere to the plunger, and the temperature of the bottles, the liquid, and the test bottle should be the same.

Another method of testing the accuracy of the graduation is as 
follows: Water is filled into the bottle exactly to the 0 mark. To this is added from a reliable buret 1,5 c.c., etc., of water, or the amount of water may be added from accurate pipets. The mark on the neck of the bottle should correspond to the amount of water added. The same precautions as to the removal of moisture in the neck and the regulation of the temperature should be taken.

In both these methods accuracy is more easily attained if the fluid is colored with some dye, as this facilitates reading.

A third method consists in measuring exactly 2 c.c. of mercury or in weighing out accurately 27.18 grams into a test bottle and

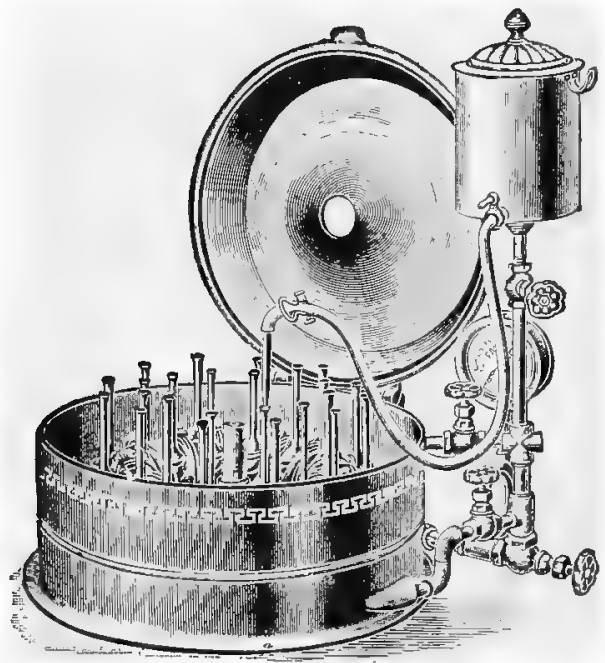

Fig. 54.

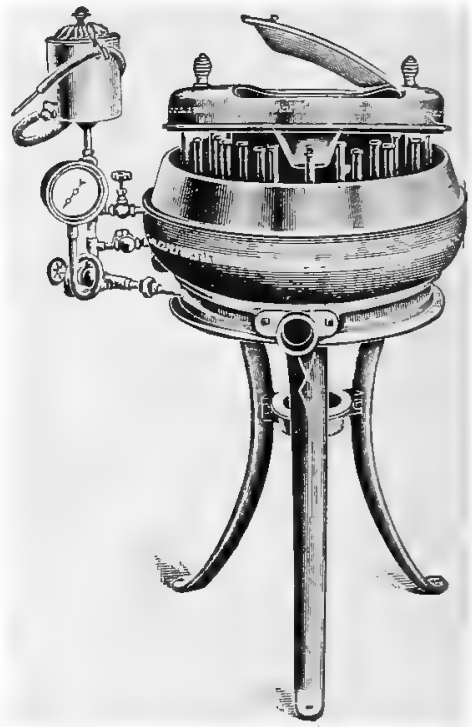

Fig. 55.

Figs. 54, 55.-Styles of centrifuges for the Babcock test. (A. H. Barber Creamery Supply Co.)

closing the mouth with a cork that has been cut so as to have a square end. The cork is pushed down to the 10 per cent. mark and the bottle inverted. The column of mercury should exactly reach the 0 mark.

The pipets used in the Babcock test can be tested by running 17.6 c.c. of water into them from an accurate buret.

After the sulphuric acid has been thoroughly mixed with the milk and the mixture has assumed a dark brown color, the bottles should be weighed (Figs. 50-53), as it is important to properly balance the centrifuge (Figs. 54-56). The number of revolutions required to give the best results depends upon the diameter of 
the wheel. The smaller the diamcter, the greater should be the number of revolutions per minute. The following figures give the

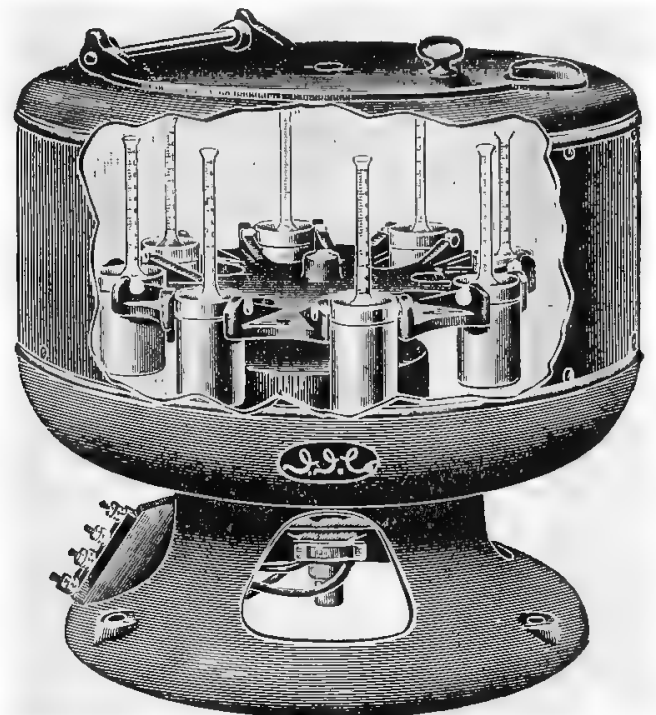

Fig. 56.-Electric centrifuge for the Babcock test. (A. H. Thomas Co.)

required number of revolutions per minute for çentrifuges of different diameter (Farrington and Woll):

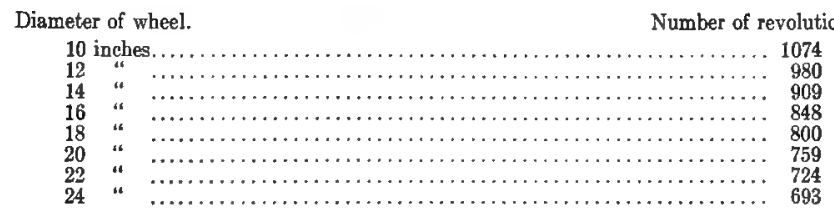

When a hand centrifuge is used the speed can be judged by counting the number of revolutions made by slowly turning the handle and then turning the handle as many times per minute as required.

The water which is used for filling the bottles so as to bring the fat column into the neck should be hot and soft. Hard water may contain carbonates and the acid then liberates carbon dioxid gas. Bubbles of this gas may then disturb the uniformity of the fat column and cause inaccurate reading. Hard water is made suitable by boiling.

The percentage of fat should be read at about $120^{\circ}$ to $140^{\circ} \mathrm{F}$. $\left(50^{\circ}-60^{\circ} \mathrm{C}\right.$. $)$. If the temperature should be higher than this, reading must be deferred until the right temperature has been reached. 
If the temperature is too low the bottles should be placed in a water-bath of $140^{\circ} \mathrm{F}$. for some minutes before reading is taken. Sammis states that reading between $110^{\circ}$ and $150^{\circ} \mathrm{F}$. gives practically the same results, the difference owing to expansion with increasing temperature being negligable. In cream testing the temperature must be controlled more accurately.

The mixture of milk and acid need not be centrifuged immediately after mixing, but will give accurate results if kept for some time. However, when not centrifuged immediately after mixing the fluid must be warmed in a water-bath at $71^{\circ} \mathrm{C} .\left(160^{\circ} \mathrm{F}\right.$.).

The test bottles must be washed after each test is finished before the fat solidifies. The contents, while still warm, may be emptied into a waste jar (Fig. 57). A solution

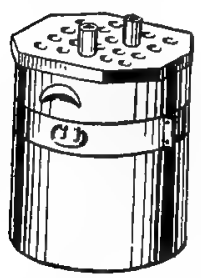

Fig. 57.-Waste jar for Babcock test bottles. (Bull. No. 202, Agri. Exp. Sta. of Colo. Agri. Coll.) of potassium bichromate 60 parts, in water 300 parts and concentrated sulphuric acid 460 parts or a strong alkali or soda solution can be used after the bottles have been rinsed in hot water. A little ether will facilitate the solution of lumps of fat adhering to the glass. A tube brush is often necessary to clean out the neck. Special bottle holders have been devised by means of which a number of bottles can be washed at the same time, and by inverting the holder the water can be drained out of the bottles. A bottle holder suitable for this work is illustrated in Fig. 58.

There are some devices which facilitate the work when a large number of tests are made. The acid can be run into the test bottles from a large container which has a buret attached (Fig. 59). Another style has a side tube attached which is just large enough to hold the requisite amount of acid when filled (Fig. 60). Finally, a dipper has been constructed which holds 17.5 c.c. of sulphuric acid (Fig. 61). Other devices aim to facilitate the adding of hot water. One style of centrifuge has a water container attached, from which hot water can be distributed to the bottles by means of a rubber hose. Or a special vessel containing hot water is kept near the centrifuge and the water distributed by means of a rubber hose. Automatic pipets have also been devised.

When a large number of samples are tested at the same time it is well to first place the milk in the bottles, arranged in a suitable rack (Fig. 62), then proceed to add the acid. Otherwise the first bottles will cool before centrifugation is possible. To avoid this it is advisable to place the bottles in a water-bath at $160^{\circ} \mathrm{F}$. and keep them there until all bottles are ready for the centrifuge.

Modifications of the Babcock Test.-The Russian Test.- 
This test differs from the Babcock test in mechanical devices, not in principle. A specially constructed pipet is intended to facilitate discharging the milk into the test bottle. The bottle also is specially constructed and the hot water is distributed to the bottles while the centrifuge is in motion.

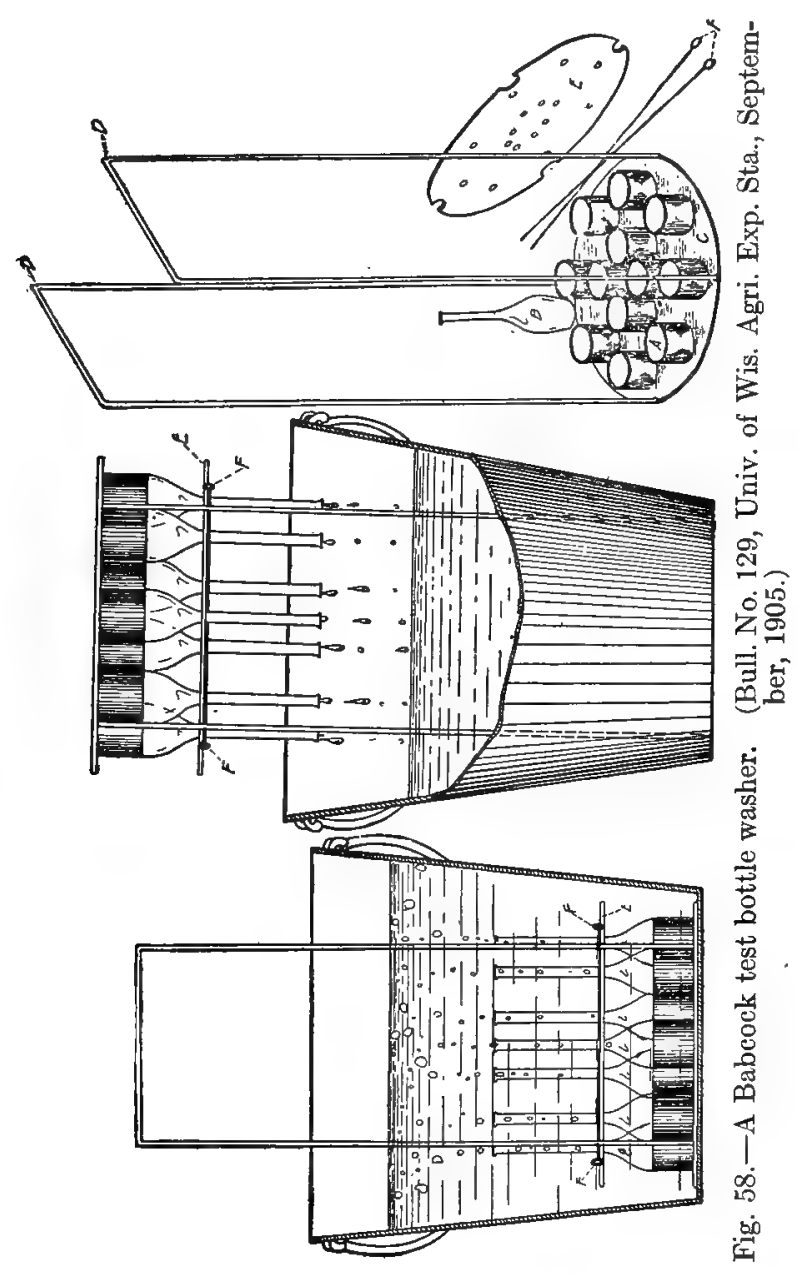

Gerber Butyrometer.-The principle involved in this test also is the same as in the Babcock test, but the bottles, pipets, etc., are of different pattern. Only 11 c.c. of milk are used with 10 c.c. of sulphuric acid mixed with 1 c.c. amyl alcohol. The separation of fat is said to be facilitated by the addition of amyl alcohol. 
There are several methods in which no acid is used. Instead, a solution of sodium hydrate, sodium sulphate, and potassium-

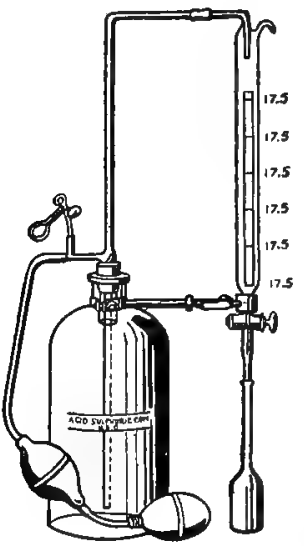

Fig. 59.-Automatic buret.

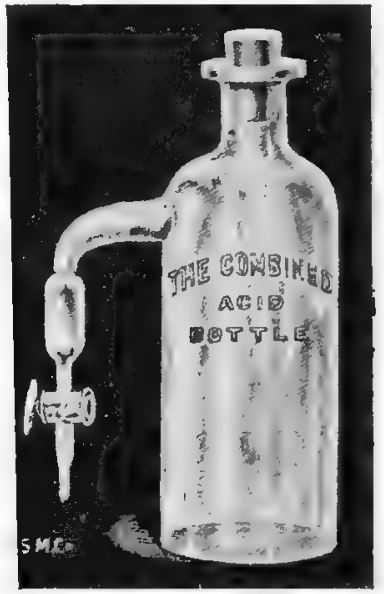

Fig. 60.-Swedish acid bottle.

sodium tartrate is the dissolving agent. As this mixture does not generate as much heat as the Babcock mixture it is necessary to heat the bottles to about $93^{\circ} \mathrm{C}$. before centrifuging.

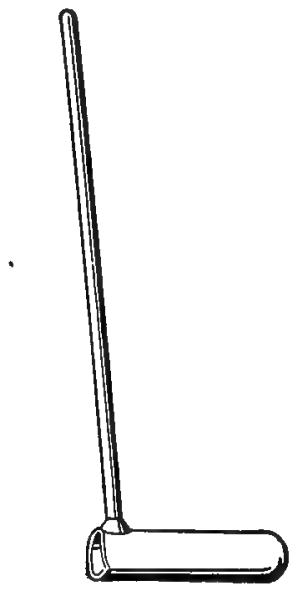

Fig. 61.-Acid dipper.

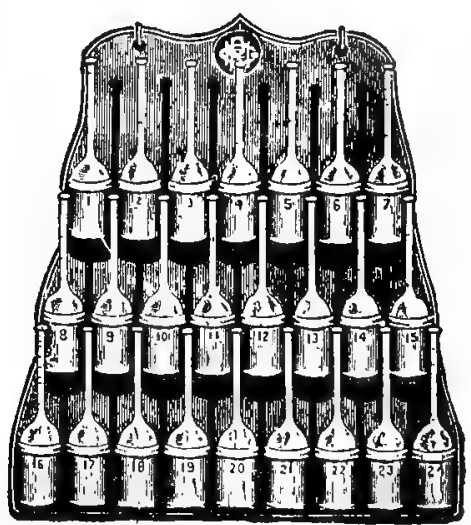

Fig. 62.-Rack for holding Babcock test bottles. (A. H. Barber Creamery Supply Co.)

None of these modifications give better results than the original Babcock method and are not likely to become popular. The 
Babcock test gives perfectly reliable results when it is executed with care.

Testing Cream by the Babcock Method.-The fat content of cream can be tested by the Babcock method, but special care is required to obtain reliable results. Since the specific gravity of cream is lower than that of milk, a 17.6-c.c. pipet will not deliver 18 grams of cream and the result will be too low. The determination is further complicated by the varying viseosity of cream. If cream has a high viscosity an appreciable amount will adhere to the glass of the pipet, and as air-bubbles are generally present in cream and tend to rise slowly, the real amount of cream falls short of the required 18 grams. Washing the adhering cream out of the pipet with water corrects the error in a measure, but a true charge can only be obtained by weighing.

Farrington and Woll have determined the weight of cream of different fat content delivered from a 17.6-c.c. pipet when the cream is fresh from a separator. The figures are given in the following table:

WEIGHT OF FRESH SEPARATOR CREAM DELIVERED FROM A 17.6-C.C. PIPET

\begin{tabular}{|c|c|c|c|c|c|}
\hline \multirow{2}{*}{$\begin{array}{l}\text { Per cent. } \\
\text { fat in } \\
\text { cream. }\end{array}$} & \multicolumn{2}{|c|}{$\begin{array}{l}\text { Specific gravity } \\
\text { at } 17.5^{\circ} \mathrm{C} .\end{array}$} & \multicolumn{2}{|c|}{$\begin{array}{c}\text { Weight of cream delivered } \\
\text { in grams. }\end{array}$} & \multirow{2}{*}{$\begin{array}{c}\text { Corrections } \\
\text { to be } \\
\text { added. }\end{array}$} \\
\hline & Weighed. & Calculated. & Weighed. & Calculated. & \\
\hline $\begin{array}{l}10 \\
15 \\
20 \\
25 \\
30 \\
35 \\
40 \\
45 \\
50\end{array}$ & $\begin{array}{l}1.023 \\
1.012 \\
1.008 \\
1.002 \\
0.996 \\
0.980 \\
0.966 \\
0.950 \\
0.947\end{array}$ & $\begin{array}{l}1.025 \\
1.020 \\
1.014 \\
1.000 \\
1.004 \\
0.998 \\
0.993 \\
0.988 \\
0.983\end{array}$ & $\begin{array}{l}17.9 \\
17.7 \\
17.3 \\
17.2 \\
17.0 \\
16.4 \\
16.3 \\
16.2 \\
15.8\end{array}$ & $\begin{array}{l}18.00 \\
17.95 \\
17.84 \\
17.75 \\
17.66 \\
17.56 \\
17.48 \\
17.39 \\
17.30\end{array}$ & $\begin{array}{ll}0 & 00 \\
0 & 04 \\
0.18 \\
0.35 \\
0.58 \\
0 & 88 \\
1.19 \\
1 & 59 \\
2 & 00\end{array}$ \\
\hline
\end{tabular}

When corrections are made according to these figures good results are obtained only when the cream is fresh from the separator. After it has stood for some time conditions change with the increasing acidity. Bacterial activity not only increases the acidity of the cream, but produces gas-bubbles, which are held in suspension and decrease the specific gravity of cream. Whenever possible cream samples should be weighed. Special balances can be procured for this purpose on which one or more bottles can be weighed and which remain sensitive if properly cared for. The bearings, if made of iron, must be kept free from rust. (See Figs. 52 and 53).

Cream Test Bottles.- Special test bottles have been designed for cream testing, since milk bottles record only 8 to 10 per cent. fat (Fig. 63). The necks of cream testing bottles are devised to hold more than 10 per cent. fat. Either a bulb is blown in the 
neck or the neck is made longer than the neck of a milk bottle, or, again, the diameter of the neck may be enlarged.

The earliest cream-testing bottle had a neck too long to fit in the majority of centrifuges. For this reason the type with a bulb was designed. The bulb type requires care when the water is added, otherwise the bottom or top of the fat column may be located in the bulb which has no graduations. The percentage of fat

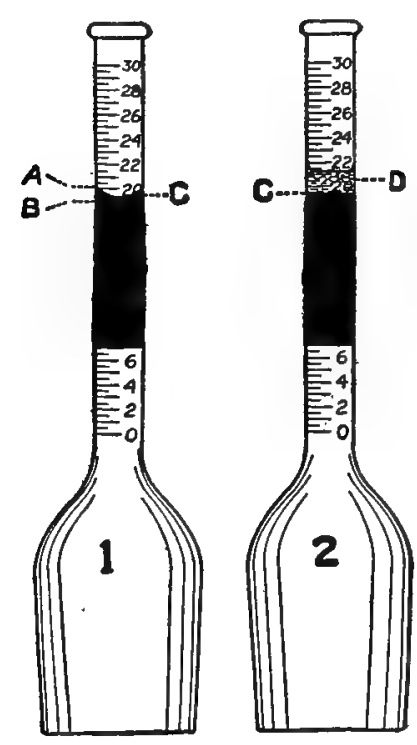

Fig. 63.-Cream testing bottles. The surface of the fat column is curved from $A$ to $B$ as shown in bottle No. 1 , with the medium point $C$ not clearly defined, while in bottle No. 2 the top of the fat column is made clear at $C$ by the fat-saturated alcohol D. (Bull. No. 195, 1910, Univ, of Wis. Agri. Exp. Station.) can be read in this style of bottle only when the top and bottom of the fat column falls in the graduated part of the neck. The Winton cream-testing bottle has a wide neck without a bulb and is graduated to measure 30 per cent. cream. By using a 9-gram charge instead of 18 , cream up to 60 per cent. fat content can be tested in this bottle. When a 9-gram charge is used the result must be doubled. The graduation records 0.5 per cent., but even 0.25 per cent. can be read with accuracy.

Cream-testing bottles which are graduated to read the percentage of fat directly when a 9-gram charge is used are also obtainable.

The smaller the diameter of a cream-testing bottle, the greater is the distance between divisions and the more accurate is the reading. Webster's experiments seem to show that 30 per cent. 9-inch bottles graduated to 0.2 per cent. are the most accurate. The results must be doubled when these bottles are used. The 50 per cent. 9-inch bottles graduated to 0.5 per cent. are next in accuracy. Bottles with 6 -inch necks are not accurate.

The Official Dairy Instructor's Association has recognized two types of cream-testing bottles, namely: 1 , a bottle with a 6 -inch neck, and 2, a bottle with a 9-inch neck. Both styles are graduated to 50 per cent. and are calculated on a 9-gram charge.

The standards for construction and graduation of Babcock glassware adopted by the Association of Official Agricultural Chemists in 1908 are these: 
"The following are the standard Babcock test bottles for milk and cream:

" 1 . Milk test bottles, 8 per cent., 18 grams, 6 inch.

"2. Cream test bottles, 50 per cent., 9 grams, 6 inch.

"3. Cream test bottles, 50 per cent., 9 grams, 9 inch.

"Standard milk test bottles, 8 per cent., 18 grams, 6 inch, 1 . Graduation: The total per cent. graduation shall be 8 . The graduated portion of the neck shall have a length of not less than 63.5 $\mathrm{mm}$. (2.5 inches). The graduation shall represent whole per cent., five-tenths per cent., and tenths per cent. The tenths per cent. graduations shall be no less than $3 \mathrm{~mm}$. in length; the five-tenths graduations shall be $1 \mathrm{~mm}$. longer than the tenths per cent. graduations, projecting $1 \mathrm{~mm}$. to the left; the whole per cent. graduations shall extend halfway around the neck to the right and projecting $2 \mathrm{~mm}$. to the left of the tenths per cent. graduations. Each per cent. graduation shall be numbered, the number being placed on the left of the scale. The error at any point of the scale shall not exceed one-tenth per cent.

" 2 . Neck: The neck shall be cylindric for at least $9 \mathrm{~mm}$. below the lowest and above the highest graduation mark. The top of the neck shall be flared to a diameter of not less than $10 \mathrm{~mm}$.

" 3 . Bulb: The capacity of the bulb up to the junction of the neck shall not be less than 45 c.c. The shape of the bulb may be either cylindric or conical, with the smallest diameter at the bottom. If cylindric, the outside diameter shall be between 34 and $36 \mathrm{~mm}$.; if conical, the outside diameter of the base shall be between 31 and $33 \mathrm{~mm}$., and the maximum diameter between 35 and $37 \mathrm{~mm}$.

" 4 . The charge of the bottle shall be 18 grams.

" 5 . The total height of the bottle shall be between 150 and $165 \mathrm{~mm}$. ( $5 \frac{7}{8}$ and $6 \frac{1}{2}$ inches). ber.

"6. Each bottle shall bear a permanent identification num-

"Standard cream test bottles, 50 per cent., 9 gram, so-called 6 inch and 9 inch: 1. Graduation: The total per cent. graduation shall be 50 . The graduated portion of the neck shall have a length of not less than $63.5 \mathrm{~mm}$. ( $2 \frac{1}{2}$ inches). The graduation shall represent 5 per cent., 1 per cent., and 0.5 per cent. The 0.5 per cent. graduations shall be at least $3 \mathrm{~mm}$. in length; the 1 per cent. graduations shall be $2 \mathrm{~mm}$. longer than the 0.5 per cent. graduations, projecting $2 \mathrm{~mm}$. to the left; the 5 per cent. graduations shall extend halfway around the neck to the right and project $4 \mathrm{~mm}$. to the left of the 0.5 per cent. graduations. Each 5 per cent. graduation shall be numbered, the number being 
placed on the left of the scale. The error at any point of the scale shall not exceed 0.5 per cent.

"2. Neck: (Same as standard milk test bottle.) The neck shall be cylindric for at least $9 \mathrm{~mm}$. below the lowest and above the highest graduation mark. The top of the neck shall be flared to a diameter of not less than $10 \mathrm{~mm}$.

"3. Bulb: (Same as standard milk test bottle.) The capacity of the bulb up to the junction of the neck shall not be less than $\mathbf{4 5}$ c.c. The shape of the bulb may be either cylindric or conical, with the smallest diameter at the bottom. If cylindric, the outside diameter shall be between 34 and $36 \mathrm{~mm}$.; if conical, the outside diameter of the base shall be between 31 and $33 \mathrm{~mm}$., and the maximum diameter between 35 and $39 \mathrm{~mm}$.

" 4 . The charge of the bottle shall be 9 grams.

" 5 . The total height of the 6 -inch bottle shall be between 150 and $165 \mathrm{~mm}$. ( $5 \frac{7}{8}$ and $6 \frac{1}{2}$ inches-same as standard milk test bottles); of 9-inch bottles, between 210 and $225 \mathrm{~mm}$. ( $8 \frac{1}{4}$ and $8 \frac{7}{8}$ inches).

"6. All bottles shall bear on top of the neck, above the graduations, in plainly legible characters, a mark defining the weight of the charge to be used ( 9 grams).

"Each bottle shall bear a permanent identification number.

"Standard pipet: Total length of pipet not more than 330

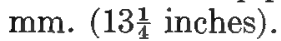

"Outside diameter of suction tube 6 to $8 \mathrm{~mm}$.

"Length of suction tube $130 \mathrm{~mm}$.

"Outside diameter of delivery tube 4.5 to $5.5 \mathrm{~mm}$.

"Length of delivery tube 100 to $120 \mathrm{~mm}$.

"Distance graduation mark above bulb 50 to $60 \mathrm{~mm}$.

"Nozzle straight.

"Delivery 17.6 c.c. of water at $20^{\circ} \mathrm{C}$. in five to eight seconds.

"Standard of Accuracy for Babcock Glassware and Rules for Testing.-Section 1: The unit of graduation for all Babcock glassware shall be the true cubic centimeter $(0.998877$ gram of water at $4^{\circ} \mathrm{C}$.).

"(a) With bottles the capacity of each per cent. on the scale shall be 0.2 c.c.

" $(b)$ With pipets and acid measure the delivery shall be the intent of the graduation, and the graduation shall be read with the bottom of the meniscus in line with the mark.

"Section 2: The official method for testing bottles shall be calibration with mercury (13.5471 grams of clean, dry mercury at $20^{\circ} \mathrm{C}$. carefully weighed on analytic balances, to equal 0.5 per cent. on the Babcock scale), the bottles being previously filled to zero with mercury. 
"Section 3: Optional methods: The mercury and cork, alcohol and buret, and alcohol and brass plunger methods may be employed for rapid testing of Babcock bottles, but the accuracy of all questionable bottles shall be determined by the official method.

"Section 4: The official method for testing pipets and acid measures shall be calibration by measuring in a buret the quantity of water (at $20^{\circ} \mathrm{C}$.) delivered.

"Section 5: The limits of error (a) for Babcock bottles shall be the smallest graduation on the scale, but in no case shall it exceed 0.5 per cent., or for skimmed milk bottles 0.01 per cent.

"(b) For full quantity pipets it shall not exceed 0.1 c.c., and for fractional pipets 0.05 c.c.

"(c) For acid measure it shall not exceed 0.2 c.c."

Milk-testing bottles can be used for cream testing by dividing the charge between two or more bottles. Enough water to bring the volume in each bottle to about 17.5 c.c. should be added. The readings of the bottles are then added to obtain the percentage of fat.

Sampling Cream for the Babcock Test.-As the sample should be representative of the true composition of the cream to be tested, it is important to mix the cream thoroughly before sampling. This is best accomplished by pouring the cream from one vessel to another. Ordinary milk cans are not suitable for this purpose, as cream is liable to be spilled on account of the small openings in such cans. Specially constructed cans with wide apertures should be used for this purpose.

After the cream has been mixed a sampler can be used to take a suitable amount, but care should be taken to prevent mixing the cream adhering to the outside of the sampler with the sample. If a sampling tube is used it should be lowered slowly into the can so that it fills as rapidly as it goes down. When several samples are taken from different cans the sampler must be thoroughly cleaned for each sample.

Frozen cream must be completely thawed. Frozen or partly churned cream should be rubbed through a sieve to break up the clumps of fat: Rich milk, as Jersey milk, for example, may be partly churned during transportation if the cans are not filled to the top. The small lumps of fat are difficult to distribute evenly through such cream.

It is probably safer to test the cream each time it is sampled rather than collect composite samples. However, when composite sampling is practised the cream must be preserved in tightly closed bottles to prevent evaporation. Unless this is provided for, a tough dry film forms on the surface and thorough mixing can be 
accomplished only after the cream has been heated to about $40^{\circ} \mathrm{C}$. The results will necessarily be too high, since water is lost through evaporation.

In order to avoid waste of cream small samples should be taken. Enough cream for a duplicate test is sufficient; if excessive quantities are taken for testing, there is a material loss. Cream samples should never be shaken, but mixed by a rotary motion.

The Amount of Acid Required for Cream Testing.-When 18 grams of cream are used for a test an equal amount of acid is added. When 9-gram charges are used the cream should be diluted with an equal amount of water and then the usual amount of acid added. Hunziker and Mills recommend the addition of enough acid to the cream to produce a color in the mixture similar to that of coffee to which cream has been added. The quantity of acid need not be measured, as the required amount varies with cream of different richness: For a 9-gram charge 4 to 8 c.c. of acid will be required, according to the per cent. of fat. A smaller amount of acid will answer for cream testing than for milk testing, because the acid reacts with the plasma solids, not with the fat, and consequently the larger the amount of fat, the less the quantity of acid necessary.

Reading the Results. - The reading should be taken at a temperature of about $49^{\circ} \mathrm{C}$. $\left(120^{\circ} \mathrm{F}\right.$.). If necessary the bottles must be warmed in a water-bath. The temperature in testers run by steam is liable to be too high and should be controlled so as to keep it evenly at $50^{\circ}$ to $55^{\circ} \mathrm{C}$. A thermometer inserted through a hole in the cover of the centrifuge will aid in regulating the temperature.

According to Webster, the readings should be taken in this manner: "Read from the bottom to the extreme top of the fat column. Read the depth of the meniscus and deduct four-fifths of it from the previous reading. When 9-gram bottles are used 0.2 per cent. should be added after the reading has been doubled."

Farrington and Woll state that the reading should extend from the bottom of the lower meniscus to the top of the upper meniscus.

Shaw says, "the important difference between reading the cream test and the milk test is that in the cream test the fat column included is from the bottom of the lower meniscus to the bottom, not the top, of the upper meniscus."

These differences of opinion have arisen since it has been found that all the fat is not brought within the graduated portion of the neck. A small amount adheres to the inside of the bulb of the bottle and small fat globules remain suspended in the acid milk mix- 
ture. It is advised by some to straighten the top meniscus by dropping a small amount of some liquid on the surface, but the liquid used must not dissolve any part of the fat. Fat-saturated alcohol can be used or glymol, which can be procured under the commercial name of white mineral oil. The reading is rendered more distinct if the oil is colored red by digesting some alkanet root in it. Amyl alcohol, colored red, can be used for the same purpose.

When the fat column is turbid and the acid-cream mixture milky, accurate reading is difficult. In such cases the bottles should be placed in hot water for about ten minutes, or, if this procedure does not clarify the fat, the bottles can be placed in cold water until the fat solidifies. After this the bottles may be placed in hot water and the fat melted.

Testing Skimmed Milk, Buttermilk, and Whey by the Babcock Method.-Testing skimmed milk, buttermilk, and whey for fat by the Babcock method is feasible, although some slight modifications are necessary owing to the small fat content in these products. In separated milk and buttermilk the percentage of fat is frequently less than 0.1 per cent., and, since it has been shown that as much as 0.2 per cent. of fat may be lost sight of in the Babcock test, greater accuracy is necessary in testing products containing but 0.1 or less per cent. fat. Furthermore, it is difficult to read accurately 0.1 per cent. or less in milk-testing bottles.

Attempts have been made to overcome these difficulties by doubling the reading when the test shows less than 0.1 per cent. This method obviously does not contribute to accuracy. The most approved method of correcting the error is by the use of special skimmed milk test bottles. These have necks of small diameter so that the graduations are far apart. However, since it is difficult to discharge the milk and acid through a narrow neck without choking it with consequent loss of material, a second neck has been provided in these bottles (Fig. 64). The fluids are poured into the bulb of the bottle through this side neck. The fat is forced into the narrow graduated neck, because the end of the side tube is below the surface of the acid-milk mixture. A tightly fitting cork may be placed in the mouth of the graduated neck and pushed down until the lower line of the fat column coincides with a mark so that reading is facilitated.

It has been stated previously that some fat remains in the acid mixture and that the smallest fat globules are difficult to separate from the liquid by centrifugal force. This difficulty is of greater importance when skimmed milk, buttermilk, or whey are tested than when milk or cream is tested, since the relative number of small globules is greatest in milk or milk products from which the bulk of the fat has been removed. As much as 0.05 to 0.1 
per cent. of the fat fails to appear in the column for this reason. Van Slyke gives the following method to separate the fat more completely from the mixture: "Use 20 c.c. sulphuric acid, whirl the bottles at full speed for three to five minutes longer than usually, and read the fat at a temperature of $130^{\circ}$ to $140^{\circ} \mathrm{F}$. Steam turbine testers which keep the bottles hot give the best results."

When carried out carefully the Babcock test gives results which differ but slightly from results obtained by the ether extraction method. The following figures given by Leach show the compar-

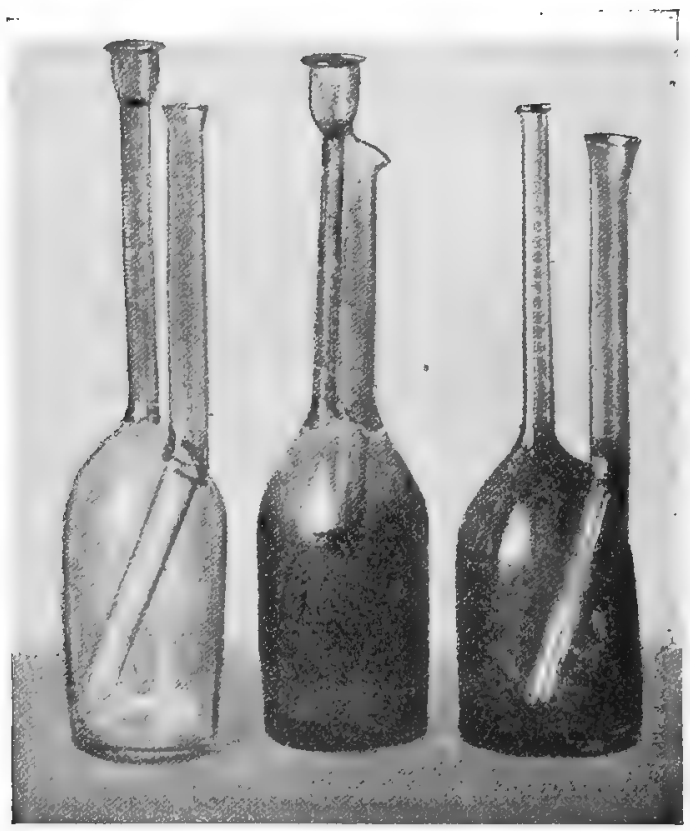

Fig. 64.-Test bottles used with skimmed milk and whey. Each division of the scale represents 0.05 per cent. on the neck of the bottle at the right. On the two bottles at the left each division represents 0.01 per cent. fat. (Circular of Information No. 27, July, 1911, Univ. of Wis. Agri. Exp. Sta.)

ative accuracy of fat determinations by the Babcock method with the results obtained by the Adams-Soxhlet method:

\begin{tabular}{|c|c|c|}
\hline FAT DETËRMINATIONS & $\begin{array}{l}\text { COMPARING THE BABCOCK } \\
\text { SOXHLET METHOD }\end{array}$ & METHOD WITH THE \\
\hline Kind of milk. & $\begin{array}{l}\text { Adams-Soxhlet method, } \\
\text { per cent. fat. }\end{array}$ & $\begin{array}{l}\text { Babeock method } \\
\text { per cent. fat. }\end{array}$ \\
\hline 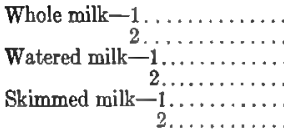 & $\begin{array}{l}\cdots \cdots \\
\cdots \cdots \\
\cdots \cdots \\
\cdots \cdots \\
\cdots \cdots\end{array}$ & $\begin{array}{l}4.30 \\
4.35 \\
2.70 \\
2.80 \\
0.15 \\
0.15\end{array}$ \\
\hline
\end{tabular}


The following table shows the results of Babcock tests of skimmed milk compared with those obtained by gravimetric analyses (Beach):

ANALYSES OF SKIMMED MILK BY THE BABCOCK METHOD, USING 17.6 AND 25 C.C. ACID, COMPARED WITH ANALYSES BY GRAVIMETRIC METHOD

\begin{tabular}{cccc} 
Sample No. & $\begin{array}{c}\text { Gravimetric } \\
\text { method. }\end{array}$ & \multicolumn{2}{c}{ Per cent. fat, steam turbine testa. } \\
\cline { 2 - 3 } 1 & $0.14 .6 \mathrm{c.c}$ acid. & 25 c.e. acid. \\
2 & 0.143 & 0.045 & 0.060 \\
3 & 0.149 & 0.055 & 0.055 \\
4 & 0.122 & 0.015 & 0.030 \\
5 & 0.121 & 0.025 & 0.055 \\
6 & 0.118 & 0.080 & 0.080 \\
7 & 0.147 & 0.060 & 0.090 \\
8 & 0.213 & 0.055 & 0.085 \\
9 & 0.135 & 0.065 & 0.090 \\
10 & 0.158 & 0.020 & 0.035 \\
& & 0.040 & 0.050
\end{tabular}

The Babcock readings were always lower than gravimetric analyses, although the steam turbine kept the fat at a high temperature and the bottles were whirled for six minutes at full speed.

\section{The Determination of Total Solids and Plasma Solids}

Total solids are determined by weighing 2 to 5 grams of milk in an evaporating dish, preferably a platinum dish, and evaporating the contents to dryness. Porcelain dishes, glass dishes, or those made of aluminum, nickel, or tin may be used, but a platinum dish is most suitable, especially when the ash is to be determined. The dish containing the milk is placed on a water-bath. After the water has been driven off, the outside of the dish is wiped and the dish placed in a desiccator to remove the last traces of moisture. By weighing the solids the percentage is finally calculated. A small amount of sand may be added to the milk before evaporation is begun.

Evaporation of milk for the determination of total solids is frequently carried on in specially constructed ovens. These ovens, of which several styles are used, are so constructed as to have a steam jacket surrounding the inner part of the oven. The temperature, therefore, is not above $100^{\circ} \mathrm{C}$. Higher temperatures cause decomposition of some of the constituents and must be avoided.

Two methods for determining total solids are given by the Association of Official Agricultural Chemists, as follows:

"Method 1.-Heat from 3 to 5 grams of milk at the temperature of boiling water until it ceases to lose weight, using a tared flat dish of not less than $5 \mathrm{~cm}$. diameter. If desired, from 15 to 20 grams pure dry sand may be previously placed in the dish. Cool in a desiccator and weigh rapidly to avoid absorption of hygroscopic moisture. 
"Method 2.-Babcock's Asbestos Method: Provide a hollow cylinder of perforated sheet metal, $60 \mathrm{~mm}$. long and $20 \mathrm{~mm}$. in diameter, closed $5 \mathrm{~mm}$. from one end by a disk of the same material. The perforations should be about $0.7 \mathrm{~mm}$. in diameter and about $0.7 \mathrm{~mm}$. apart. Fill loosely with from 1.5 to 2.5 grams of freshly ignited, woolly asbestos, free from fine and brittle material, cool in a desiccator, and weigh. Introduce a weighed quantity of milk (between 3 and 5 grams) and dry at the temperature of boiling water to constant weight."

Plasma solids or solids-not-fat are usually determined by subtracting the percentage of fat from the total solids.

Attention has been called to the fact that there is a definite relation between specific gravity and the percentage of fat and total solids. Based on this relation Babcock has worked out formulas by which the total solids and plasma solids can be calculated when specific gravity and fat percentage are known. The formula for plasma solids is as follows:

$\underset{\text { (solids-not-fat) }}{\text { Per cent. plasma solids }}=\left(\frac{100 \text { S. }- \text { F. S. }}{100-1.0753 \text { F. S. }}-1\right) \times(100-$ F.) 2.5.

S. stands for specific gravity and F. for the percentage of fat. A simplified formula giving approximate results is this:

$\underset{\text { Per cent. plasma solids }}{\text { (solids-not-fat) }}=0.25 \mathrm{~L} .+0.2 \mathrm{~F}$.

For calculating the total solids the following formula is given:

Per cent. total solids $=0.25 \mathrm{~L} .+1.2 \mathrm{~F}$.

In these formulas $\mathrm{L}$. is the Quevenne lactometer reading and F. the percentage of fat.

The table on pages 177 and 178, from Bulletin 134, Bureau of Animal Industry (Shaw and Eckles), gives the total solids when specific gravity and fat content are known. 
TABLE FOR DETERMINING TOTAL SOLIDS IN MILK FROM ANY GIVEN SPECIFIC GRAV. ITY AND PERCENTAGE OF FAT (SHAW AND ECKLES).

\begin{tabular}{|c|c|c|c|c|c|c|c|c|c|c|c|}
\hline \multirow{2}{*}{$\begin{array}{c}\text { Per- } \\
\text { cent- } \\
\text { age of } \\
\text { fat. }\end{array}$} & \multicolumn{11}{|c|}{ Lactometer reading at $60^{\circ} \mathrm{F}$. (Quevanne degrees). } \\
\hline & 26 & 27 & 28 & 29 & 30 & 31 & 32 & 33 & 34 & 35 & 36 \\
\hline $\begin{array}{l}2.00 \\
2.05 \\
2.10 \\
2.15 \\
2.20 \\
2.25 \\
2.30 \\
2.35 \\
2.40 \\
2.45\end{array}$ & 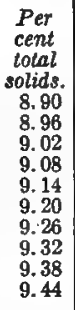 & 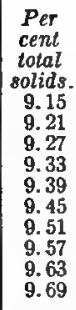 & $\begin{array}{c}\text { Per } \\
\text { cent } \\
\text { total } \\
\text { solids. } \\
9.40 \\
9.46 \\
9.52 \\
9.58 \\
9.64 \\
9.70 \\
9.76 \\
9.82 \\
9.88 \\
9.94\end{array}$ & $\begin{array}{c}P e r \\
\text { Pent } \\
\text { total } \\
\text { tolids. } \\
9.65 \\
9.71 \\
9.77 \\
9.83 \\
9.89 \\
9.95 \\
10.01 \\
10.07 \\
10.13 \\
10.19\end{array}$ & $\begin{array}{c}\text { Per } \\
\text { cent } \\
\text { total } \\
\text { solids. } \\
9.90 \\
9.96 \\
10.02 \\
10.08 \\
10.14 \\
10.20 \\
10.26 \\
10.32 \\
10.38 \\
10.44\end{array}$ & $\begin{array}{c}\text { Per } \\
\text { cent } \\
\text { tolal } \\
\text { solids. } \\
10.15 \\
10.21 \\
10.27 \\
10.33 \\
10.39 \\
10.45 \\
10.51 \\
10.57 \\
10.63 \\
10.69\end{array}$ & $\begin{array}{l}\text { Per } \\
\text { cent } \\
\text { total } \\
\text { solids. } \\
10.40 \\
10.46 \\
10.52 \\
10.58 \\
10.64 \\
10.70 \\
10.76 \\
10.82 \\
10.88 \\
10.94\end{array}$ & $\begin{array}{c}P e r \\
\text { cent } \\
\text { total } \\
\text { solids. } \\
10.66 \\
10.72 \\
10.78 \\
10.84 \\
10.90 \\
10.96 \\
11.02 \\
11.08 \\
11.14 \\
11.20\end{array}$ & 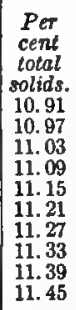 & \begin{tabular}{|l} 
Per \\
ceni \\
total \\
solids. \\
11.16 \\
11.22 \\
11.28 \\
11.34 \\
11.40 \\
11.46 \\
11.52 \\
11.58 \\
11.64 \\
11.70
\end{tabular} & $\begin{array}{l}\text { Per } \\
\text { cent } \\
\text { total } \\
\text { solids. } \\
11.41 \\
11.47 \\
11.53 \\
11.59 \\
11.65 \\
11.71 \\
11.77 \\
11.83 \\
11.89 \\
11.95\end{array}$ \\
\hline $\begin{array}{l}2.50 \\
2.55 \\
2.60 \\
2.65 \\
2.70 \\
2.75 \\
2.80 \\
2.85 \\
2.90 \\
2.85\end{array}$ & $\begin{array}{r}9.50 \\
9.56 \\
9.62 \\
9.68 \\
9.74 \\
9.80 \\
9.86 \\
9.92 \\
9.98 \\
10.04\end{array}$ & $\begin{array}{r}9.75 \\
9.81 \\
9.87 \\
9.93 \\
999 \\
10.05 \\
10.11 \\
10.17 \\
10.23 \\
10.29\end{array}$ & $\begin{array}{l}10.00 \\
10.06 \\
10.12 \\
10.18 \\
10.24 \\
10.30 \\
10.36 \\
10.42 \\
10.48 \\
10.54\end{array}$ & $\begin{array}{l}10.25 \\
10.31 \\
10.37 \\
10.43 \\
10.49 \\
10.55 \\
10.61 \\
10.67 \\
10.73 \\
10.79\end{array}$ & $\begin{array}{l}10.50 \\
10.56 \\
10.62 \\
10.68 \\
10.74 \\
10.80 \\
10.86 \\
10.92 \\
10.98 \\
11.04\end{array}$ & $\begin{array}{l}10.75 \\
10.81 \\
10.87 \\
10.93 \\
10.99 \\
11.05 \\
11.11 \\
11.17 \\
11.23 \\
11.30\end{array}$ & \begin{tabular}{|l|}
11.00 \\
11.08 \\
11.12 \\
11.18 \\
11.24 \\
11.31 \\
11.37 \\
11.43 \\
11.49 \\
11.55
\end{tabular} & \begin{tabular}{|r}
11.26 \\
11.32 \\
11.38 \\
11.44 \\
11.50 \\
11.56 \\
11.62 \\
11.68 \\
-11.74 \\
11.80
\end{tabular} & $\begin{array}{l}11.51 \\
11.57 \\
11.63 \\
11.69 \\
11.75 \\
11.81 \\
11.87 \\
11.93 \\
11.99 \\
12.05\end{array}$ & \begin{tabular}{|l|}
11.76 \\
11.82 \\
11.88 \\
11.94 \\
12.00 \\
12.06 \\
12.12 \\
12.18 \\
12.24 \\
12.30
\end{tabular} & $\begin{array}{l}12.01 \\
12.07 \\
12.13 \\
12.19 \\
12.25 \\
12.31 \\
12.37 \\
12.43 \\
12.49 \\
12.55\end{array}$ \\
\hline $\begin{array}{l}3.00 \\
3.05 \\
3.10 \\
3.15 \\
3.20 \\
3.25 \\
3.30 \\
3.35 \\
3.40 \\
3.45\end{array}$ & $\begin{array}{l}10.10 \\
10.16 \\
10.22 \\
10.28 \\
10.34 \\
10.40 \\
10.46 \\
10.52 \\
10.58 \\
10.64\end{array}$ & \begin{tabular}{|l}
10.35 \\
10.41 \\
10.47 \\
10.53 \\
10.59 \\
10.65 \\
10.71 \\
10.77 \\
10.83 \\
10.89
\end{tabular} & $\begin{array}{l}10.60 \\
10.66 \\
10.72 \\
10.78 \\
10.84 \\
10.90 \\
10.96 \\
11.03 \\
11.09 \\
11.15\end{array}$ & \begin{tabular}{|l}
10.85 \\
10.91 \\
10.97 \\
11.03 \\
11.09 \\
11.16 \\
11.22 \\
11.28 \\
11.34 \\
11.40
\end{tabular} & $\begin{array}{l}11.10 \\
11.17 \\
11.23 \\
11.29 \\
11.35 \\
11.41 \\
11.47 \\
11.53 \\
11.59 \\
11.65\end{array}$ & $\begin{array}{l}11.36 \\
11.42 \\
11.48 \\
11.54 \\
11.60 \\
11.66 \\
11.72 \\
11.78 \\
11.84 \\
11.90\end{array}$ & \begin{tabular}{|l}
11.61 \\
11.67 \\
11.73 \\
11.79 \\
11.85 \\
11.91 \\
11.97 \\
12.03 \\
12.09 \\
12.15
\end{tabular} & $\begin{array}{l}11.86 \\
11.92 \\
11.98 \\
12.04 \\
12.10 \\
12.16 \\
12.22 \\
12.28 \\
12.34 \\
12.40\end{array}$ & \begin{tabular}{|l}
12.11 \\
12.17 \\
12.23 \\
12.29 \\
12.35 \\
12.42 \\
12.48 \\
12.54 \\
12.60 \\
12.66
\end{tabular} & $\begin{array}{l}12.36 \\
12.42 \\
12.48 \\
12.55 \\
12.61 \\
12.67 \\
12.73 \\
12.79 \\
12.85 \\
12.91\end{array}$ & $\begin{array}{l}12.61 \\
12.68 \\
12.74 \\
12.80 \\
12.86 \\
12.92 \\
12.88 \\
13.04 \\
13.10 \\
13.16\end{array}$ \\
\hline $\begin{array}{l}3.50 \\
3.55 \\
3.60 \\
3.65 \\
3.70 \\
3.75 \\
3.80 \\
3.85 \\
3.90 \\
3.85\end{array}$ & $\begin{array}{l}10.70 \\
10.76 \\
10.82 \\
10.88 \\
10.94 \\
11.00 \\
11.06 \\
11.12 \\
11.18 \\
11.24\end{array}$ & $\begin{array}{l}10.95 \\
11.02 \\
11.08 \\
11.14 \\
11.20 \\
11.26 \\
11.32 \\
11.38 \\
11.44 \\
11.50\end{array}$ & \begin{tabular}{|l|}
11.21 \\
11.27 \\
11.33 \\
11.39 \\
11.15 \\
11.51 \\
11.57 \\
11.63 \\
11.69 \\
11.75
\end{tabular} & \begin{tabular}{|l}
1146 \\
11.52 \\
11.58 \\
11.64 \\
11.70 \\
11.76 \\
11.82 \\
11.88 \\
11.94 \\
12.00
\end{tabular} & \begin{tabular}{|l}
11.71 \\
11.77 \\
11.83 \\
11.89 \\
11.95 \\
12.01 \\
12.07 \\
12.13 \\
12.19 \\
12.25
\end{tabular} & $\begin{array}{l}71.96 \\
12.02 \\
12.08 \\
12.14 \\
12.20 \\
12.26 \\
12.32 \\
12.38 \\
12.44 \\
12.50\end{array}$ & \begin{tabular}{|l}
12.21 \\
12.27 \\
12.33 \\
12.39 \\
12.45 \\
12.51 \\
12.57 \\
12.63 \\
12.69 \\
12.75
\end{tabular} & $\begin{array}{l}12.46 \\
12.52 \\
12.58 \\
12.64 \\
12.70 \\
12.76 \\
12.82 \\
12.88 \\
12.94 \\
13.00\end{array}$ & \begin{tabular}{|l}
12.72 \\
12.78 \\
12.84 \\
12.90 \\
12.96 \\
13.02 \\
13.08 \\
13.14 \\
13.20 \\
13.26
\end{tabular} & $\begin{array}{l}12.97 \\
13.03 \\
13.09 \\
13.15 \\
13.21 \\
13.27 \\
13.33 \\
13.39 \\
13.45 \\
13.51\end{array}$ & $\begin{array}{l}13.22 \\
13.28 \\
13.34 \\
13.40 \\
13.46 \\
13.52 \\
13.58 \\
13.64 \\
13.70 \\
13.77\end{array}$ \\
\hline $\begin{array}{l}4.00 \\
4.05 \\
4.10 \\
4.15 \\
4.20 \\
4.25 \\
4.30 \\
4.35 \\
4.40 \\
4.45\end{array}$ & $\begin{array}{l}11.30 \\
11.36 \\
11.42 \\
11.48 \\
11.54 \\
11.60 \\
11.66 \\
11.72 \\
11.78 \\
11.84\end{array}$ & \begin{tabular}{|l|}
11.56 \\
11.62 \\
11.68 \\
11.74 \\
11.80 \\
11.86 \\
11.92 \\
11.98 \\
12.04 \\
12.10
\end{tabular} & $\begin{array}{l}11.81 \\
11.87 \\
11.93 \\
11.99 \\
12.05 \\
12.11 \\
12.17 \\
12.23 \\
12.29 \\
12.35\end{array}$ & $\begin{array}{l}12.06 \\
12.12 \\
12.18 \\
12.24 \\
12.30 \\
12.36 \\
12.42 \\
12.48 \\
12.54 \\
12.60\end{array}$ & $\begin{array}{l}12.31 \\
12.37 \\
12.43 \\
12.49 \\
12.55 \\
12.61 \\
12.67 \\
12.73 \\
12.79 \\
12.85\end{array}$ & $\begin{array}{l}12.56 \\
12.62 \\
12.68 \\
12.74 \\
12.80 \\
12.86 \\
12.92 \\
12.98 \\
13.04 \\
13.10\end{array}$ & $\begin{array}{l}12.81 \\
12.87 \\
12.93 \\
12.99 \\
13.05 \\
13.12 \\
13.18 \\
13.24 \\
13.30 \\
13.36\end{array}$ & $\begin{array}{l}13.06 \\
13.12 \\
13.18 \\
13.25 \\
13.31 \\
13.37 \\
13.43 \\
13.49 \\
13.55 \\
13.61\end{array}$ & \begin{tabular}{|l}
13.32 \\
13.38 \\
13.44 \\
13.50 \\
13.56 \\
13.62 \\
13.68 \\
13.74 \\
13.80 \\
1386
\end{tabular} & \begin{tabular}{|l}
13.57 \\
13.63 \\
13.69 \\
13.76 \\
13.82 \\
13.88 \\
13.94 \\
14.00 \\
14.06 \\
14.12
\end{tabular} & $\begin{array}{l}13.83 \\
13.89 \\
13.95 \\
14.01 \\
14.07 \\
14.13 \\
14.19 \\
14.25 \\
14.31 \\
14.37\end{array}$ \\
\hline $\begin{array}{l}4.50 \\
4.55 \\
4.60 \\
4.65 \\
4.70 \\
4.75 \\
4.80 \\
4.85 \\
4.90 \\
4.95\end{array}$ & $\begin{array}{l}11.90 \\
11.97 \\
12.03 \\
12.09 \\
12.15 \\
12.21 \\
12.27 \\
12.33 \\
12.39 \\
12.45\end{array}$ & \begin{tabular}{|l}
12.16 \\
12.22 \\
12.28 \\
12.34 \\
12.40 \\
12.45 \\
12.52 \\
12.58 \\
12.64 \\
12.70
\end{tabular} & $\begin{array}{l}12.41 \\
12.47 \\
12.53 \\
12.59 \\
12.65 \\
12.71 \\
12.77 \\
12.83 \\
12.89 \\
12.95\end{array}$ & $\begin{array}{l}12.66 \\
12.72 \\
12.78 \\
12.84 \\
12.90 \\
12.96 \\
13.02 \\
13.08 \\
13.14 \\
13.20\end{array}$ & \begin{tabular}{|l|}
12.91 \\
12.97 \\
13.03 \\
13.09 \\
13.15 \\
13.21 \\
13.27 \\
13.33 \\
13.39 \\
13.45
\end{tabular} & \begin{tabular}{|l}
13.16 \\
13.22 \\
13.28 \\
13.34 \\
13.40 \\
13.46 \\
13.52 \\
13.58 \\
13.64 \\
13.70
\end{tabular} & $\begin{array}{l}13.42 \\
13.48 \\
13.54 \\
13.60 \\
13.66 \\
13.72 \\
13.78 \\
13.84 \\
13.90 \\
13.96\end{array}$ & $\begin{array}{l}13.67 \\
13.73 \\
13.79 \\
13.85 \\
13.91 \\
13.97 \\
14.03 \\
14.09 \\
14.15 \\
14.21\end{array}$ & $\begin{array}{l}13.92 \\
13.98 \\
14.04 \\
14.10 \\
14.16 \\
14.22 \\
14.28 \\
14.34 \\
14.40 \\
14.46\end{array}$ & \begin{tabular}{|l}
14.18 \\
14.24 \\
14.30 \\
14.36 \\
14.42 \\
14.48 \\
14.54 \\
14.60 \\
14.66 \\
14.72
\end{tabular} & $\begin{array}{l}14.43 \\
14.49 \\
14.55 \\
14.61 \\
14.67 \\
14.73 \\
1.79 \\
14.85 \\
14.91 \\
14.97\end{array}$ \\
\hline
\end{tabular}


TABLE FOR DETERMINING TOTAL SOLIDS IN MILK FROM ANY GIVEN SPECIFIC GRAV. ITY AND PERCENTAGE OF FAT-CONTINUED (SHAW AND ECKLES)

\begin{tabular}{|c|c|c|c|c|c|c|c|c|c|c|c|}
\hline \multirow{2}{*}{$\begin{array}{l}\text { Per } \\
\text { cent- } \\
\text { age of } \\
\text { fat. }\end{array}$} & \multicolumn{11}{|c|}{ Lactometer reading at $60^{\circ} \mathbf{F}$. (Quevenne degreas). } \\
\hline & 26 & 27 & 28 & 29 & 30 & 31 & 32 & 33 & 34 & 35 & 36 \\
\hline $\begin{array}{l}5.00 \\
5.05 \\
5.10 \\
5.15 \\
5.20 \\
5.25 \\
5.30 \\
5.35 \\
5.40 \\
5.45\end{array}$ & $\begin{array}{c}\text { Per } \\
\text { cent } \\
\text { total } \\
\text { solids. } \\
12.51 \\
12.57 \\
12.63 \\
12.69 \\
12.75 \\
12.81 \\
12.87 \\
12.93 \\
12.99 \\
13.05\end{array}$ & $\begin{array}{c}\text { Per } \\
\text { cent } \\
\text { tolal } \\
\text { solids. } \\
12.76 \\
12.82 \\
12.88 \\
12.94 \\
13.00 \\
13.06 \\
13.12 \\
13.18 \\
13.24 \\
13.30\end{array}$ & $\begin{array}{c}\text { Per } \\
\text { cent } \\
\text { total } \\
\text { solids. } \\
13.01 \\
13.07 \\
13.13 \\
13.19 \\
13.25 \\
13.31 \\
13.37 \\
13.43 \\
13.49 \\
13.55\end{array}$ & $\begin{array}{c}\text { Pet } \\
\text { cent } \\
\text { total } \\
\text { solids. } \\
13.26 \\
13.32 \\
13.38 \\
13.44 \\
13.50 \\
13.56 \\
13.62 \\
13.68 \\
13.74 \\
13.80\end{array}$ & $\begin{array}{c}\text { Per } \\
\text { cent } \\
\text { total } \\
\text { solids. } \\
13.51 \\
13.57 \\
13.63 \\
13.69 \\
13.75 \\
13.81 \\
13.87 \\
13.93 \\
14.00 \\
14.06\end{array}$ & $\begin{array}{c}\text { Per } \\
\text { cent } \\
\text { total } \\
\text { solids. } \\
13.76 \\
13.83 \\
13.89 \\
13.95 \\
14.01 \\
14.07 \\
14.13 \\
14.19 \\
14.25 \\
14.31\end{array}$ & $\begin{array}{c}\text { Per } \\
\text { cent } \\
\text { total } \\
\text { solids. } \\
14.02 \\
14.08 \\
14.14 \\
14.20 \\
14.26 \\
14.32 \\
14.38 \\
14.44 \\
14.50 \\
14.56\end{array}$ & $\begin{array}{c}\text { Pet } \\
\text { cent } \\
\text { total } \\
\text { solids. } \\
14.27 \\
14.33 \\
14.39 \\
14.45 \\
14.51 \\
14.57 \\
14.63 \\
14.70 \\
14.76 \\
14.82\end{array}$ & $\begin{array}{c}\text { Per } \\
\text { cent } \\
\text { total } \\
\text { solids. } \\
14.52 \\
14.58 \\
14.64 \\
14.70 \\
14.76 \\
14,82 \\
14,88 \\
14,95 \\
15,01 \\
15.07\end{array}$ & $\begin{array}{c}\text { Per } \\
\text { cent } \\
\text { total } \\
\text { solids. } \\
14.78 \\
14.84 \\
14.90 \\
14.96 \\
15.02 \\
15.08 \\
15.14 \\
15.20 \\
15.26 \\
15.32\end{array}$ & $\begin{array}{c}\text { Per } \\
\text { cent } \\
\text { total } \\
\text { solids. } \\
15.03 \\
15.09 \\
15.15 \\
15.21 \\
15.27 \\
15.33 \\
15.39 \\
15.45 \\
15,51 \\
15.57\end{array}$ \\
\hline $\begin{array}{l}5.50 \\
5.55 \\
5.60 \\
5.65 \\
5.70 \\
5.75 \\
5.80 \\
5.85 \\
5.90 \\
5.95\end{array}$ & $\begin{array}{l}13.11 \\
13.17 \\
13.23 \\
13.29 \\
13.35 \\
13.41 \\
13.47 \\
13.53 \\
13.59 \\
13.65\end{array}$ & $\begin{array}{l}13.36 \\
13.42 \\
13.48 \\
13.54 \\
13.60 \\
13.66 \\
13.72 \\
13.78 \\
13.84 \\
13.90\end{array}$ & $\begin{array}{l}13.61 \\
13.67 \\
13.73 \\
13.79 \\
13.85 \\
13.91 \\
13.97 \\
14.04 \\
14.10 \\
14.16\end{array}$ & $\begin{array}{l}13.86 \\
13.93 \\
13.99 \\
14.05 \\
14.11 \\
14.17 \\
14.23 \\
14.29 \\
14.35 \\
14.41\end{array}$ & $\begin{array}{l}14.12 \\
14.18 \\
14.24 \\
14.30 \\
14.36 \\
14.42 \\
14.48 \\
14.54 \\
14.60 \\
14.66\end{array}$ & $\begin{array}{l}14.37 \\
14.43 \\
14.49 \\
14.55 \\
14.61 \\
14.68 \\
14.74 \\
14.80 \\
14.86 \\
14.92\end{array}$ & $\begin{array}{l}14.62 \\
14.69 \\
14.75 \\
14.81 \\
14.87 \\
14.93 \\
14.99 \\
15.05 \\
15.11 \\
15.17\end{array}$ & $\begin{array}{l}14.88 \\
14.94 \\
15.00 \\
15.06 \\
15.12 \\
15.18 \\
15.24 \\
15.30 \\
15.36 \\
15.42\end{array}$ & $\begin{array}{l}15.13 \\
15.10 \\
15.25 \\
15.31 \\
15.37 \\
15.43 \\
15.49 \\
15.55 \\
15.61 \\
15.67\end{array}$ & $\begin{array}{l}15.38 \\
15.44 \\
15.50 \\
15.56 \\
15.62 \\
15.68 \\
15.74 \\
15.80 \\
15.86 \\
15.92\end{array}$ & $\begin{array}{l}15.63 \\
15.69 \\
15.75 \\
15.81 \\
15.87 \\
15,93 \\
15.99 \\
16.06 \\
16.12 \\
16.18\end{array}$ \\
\hline $\begin{array}{l}6.00 \\
6.05 \\
6.10 \\
6.15 \\
6.20 \\
6.25 \\
6.30 \\
6.35 \\
6.40 \\
6.45\end{array}$ & $\begin{array}{l}13.71 \\
13.77 \\
13.83 \\
13.89 \\
13.95 \\
14.01 \\
14.07 \\
14.13 \\
14.19 \\
14.25\end{array}$ & $\begin{array}{l}13.96 \\
14.02 \\
14.08 \\
14.14 \\
14.20 \\
14.26 \\
14.32 \\
14.38 \\
14.44 \\
14.50\end{array}$ & $\begin{array}{l}14.22 \\
14.28 \\
14.34 \\
14.40 \\
14.46 \\
14.52 \\
14.58 \\
14.64 \\
14.70 \\
14.76\end{array}$ & $\begin{array}{l}14.47 \\
14.53 \\
14.59 \\
14.65 \\
14.71 \\
11.77 \\
14.83 \\
14.90 \\
14.96 \\
15.02\end{array}$ & $\begin{array}{l}14.72 \\
14.78 \\
14.84 \\
14.90 \\
14.96 \\
15.02 \\
15.08 \\
15.14 \\
15.20 \\
15.26\end{array}$ & $\begin{array}{l}14.98 \\
15.04 \\
15.10 \\
15.16 \\
15.22 \\
15.28 \\
15.34 \\
15.40 \\
15.46 \\
15.52\end{array}$ & $\begin{array}{l}15.23 \\
15.29 \\
15.35 \\
15.41 \\
15.47 \\
15.53 \\
15.59 \\
15.65 \\
15.71 \\
15.77\end{array}$ & $\begin{array}{l}15.48 \\
15.54 \\
15.60 \\
15.66 \\
15.72 \\
15.78 \\
15.84 \\
15.90 \\
15.96 \\
16.02\end{array}$ & $\begin{array}{l}15.73 \\
15.79 \\
15.85 \\
15.91 \\
16.97 \\
16.03 \\
16.09 \\
16.15 \\
16.21 \\
16.27\end{array}$ & $\begin{array}{l}15.98 \\
16.04 \\
16.10 \\
16.16 \\
16.23 \\
16.28 \\
16.34 \\
16.40 \\
16.46 \\
16.52\end{array}$ & $\begin{array}{l}16.24 \\
16.30 \\
16.35 \\
16.42 \\
16.48 \\
16.54 \\
16.60 \\
16.66 \\
16.72 \\
16.78\end{array}$ \\
\hline $\begin{array}{l}6.50 \\
6.55 \\
6.60 \\
6.65 \\
6.70 \\
6.75 \\
6.80 \\
6.85 \\
6.90 \\
6.95\end{array}$ & $\begin{array}{l}14.31 \\
14.37 \\
14.43 \\
14.49 \\
14.55 \\
14.61 \\
14.67 \\
14.73 \\
14.79 \\
14.85\end{array}$ & $\begin{array}{l}14.56 \\
14.62 \\
14.68 \\
14.74 \\
14.80 \\
14.86 \\
14.92 \\
14.98 \\
15.04 \\
15.10\end{array}$ & $\begin{array}{l}14.82 \\
14.88 \\
14.94 \\
15.00 \\
15.06 \\
15.12 \\
15.18 \\
15.24 \\
15.30 \\
15.36\end{array}$ & $\begin{array}{l}15.08 \\
15.14 \\
15.20 \\
15.26 \\
15.32 \\
15.38 \\
15.44 \\
15.50 \\
15.56 \\
15.62\end{array}$ & $\begin{array}{l}15.32 \\
15.38 \\
15.44 \\
15.50 \\
15.56 \\
15.62 \\
15.68 \\
15.74 \\
15.80 \\
15.86\end{array}$ & $\begin{array}{l}15.58 \\
15.64 \\
15.70 \\
15.76 \\
15.82 \\
15.88 \\
15.94 \\
16.00 \\
16.06 \\
16.12\end{array}$ & $\begin{array}{l}15.83 \\
15.89 \\
15.95 \\
16.01 \\
16.07 \\
16.13 \\
16.19 \\
16.25 \\
16.31 \\
16.37\end{array}$ & $\begin{array}{l}16.08 \\
16.14 \\
16.20 \\
16.26 \\
16.32 \\
16.38 \\
16.44 \\
16.50 \\
16.56 \\
16.62\end{array}$ & $\begin{array}{l}16.33 \\
16.39 \\
16.45 \\
16.51 \\
16.57 \\
16.63 \\
16.69 \\
16.75 \\
16.81 \\
16.87\end{array}$ & $\begin{array}{l}16.58 \\
16.64 \\
16.70 \\
16.76 \\
16.82 \\
10.88 \\
16.94 \\
17.00 \\
17.06 \\
17.12\end{array}$ & $\begin{array}{l}16.84 \\
16.90 \\
16.96 \\
17.02 \\
17.08 \\
17.14 \\
17.20 \\
17.26 \\
17.32 \\
17.38\end{array}$ \\
\hline
\end{tabular}

PROPORTIONAL PARTS.

\begin{tabular}{|c|c||c|c||c|c|}
\hline $\begin{array}{c}\text { Lactometer } \\
\text { fraction. }\end{array}$ & $\begin{array}{c}\text { Fraction to } \\
\text { be added } \\
\text { to total } \\
\text { solids. }\end{array}$ & $\begin{array}{c}\text { Lactorneter } \\
\text { fraction. }\end{array}$ & $\begin{array}{c}\text { Fraction to } \\
\text { be added } \\
\text { to totel } \\
\text { solids. }\end{array}$ & $\begin{array}{c}\text { Lactometer } \\
\text { fraction. }\end{array}$ & $\begin{array}{c}\text { Fraction to } \\
\text { be added } \\
\text { to total } \\
\text { solids. }\end{array}$ \\
\hline 0.1 & 0.03 & 0.4 & 0.10 & 0.7 & 0.18 \\
.2 & .05 & .5 & .13 & .8 \\
.08 & .6 & .9 & .20 \\
.3 & .08 & \\
\hline
\end{tabular}

The table giving Proportional Parts shows the amount to be added when lactometer readings are in whole numbers and decimals. 
In England Hehner and Richmond have worked out a formula for calculating solids as follows:

Per cent. total solids $=0.25 \mathrm{~S} .+1.2 \mathrm{~F} .+0.14$.

$\mathrm{S}$. is the lactometer reading and $\mathrm{F}$. the percentage of fat.

Richmond has also designed a sliding rule for the rapid calculation of results (Fig. 65).

Shaw and Eckles, who have investigated the accuracy of results obtained by the use of formulas, have concluded that when exact percentages of total solids are demanded the use of any formula will not fulfil the requirements. The authors found that the Babcock formula gave results close to those obtained gravimetrically, and these results can be used when only close approximations are desired. They further stated that the ordinary lactometers are not sufficiently sensitive for estimation of total solids, but that the lactometer devised by them (see p. 143) gave results as accurate as those obtained with a Westphal balance.

Fleischmann's formula for calculating total solids is as follows:

Per cent. total solids $=1.2 \mathrm{~F} .+2.665 \frac{100 \mathrm{~S} .-100}{\mathrm{~S} .}$

in which $\mathrm{F}$. stands for percentage of fat and $\mathrm{S}$. for specific gravity.

\section{The Determination of Ash}

The platinum dish containing the total solids is ignited over a Bunsen flame at dull red heat until a white residue is obtained. This is cooled and weighed and the percentage of ash calculated.

The following method is given by the Association of Official Agricultural Chemists:

"Weigh about 20 grams of milk in a weighed dish, add 6 c.c. of nitric acid, evaporate to dryness, and ignite at a temperature just below redness until the ash is free from carbon."

When the ash is to be further analyzed for its elements the following method can be employed (Richmond):

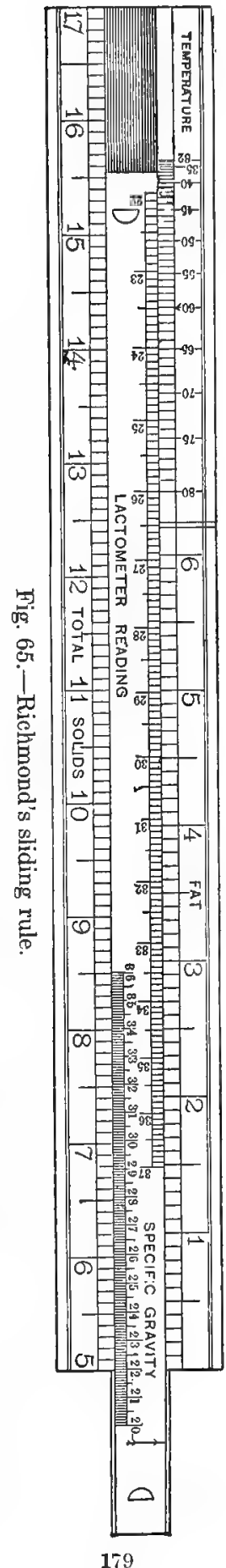

179 
" 25 to 50 grams of milk are evaporated and the solids ignited over barely perceptible red heat until thoroughly charred, otherwise alkaline chlorids are lost. The ash is extracted with hot water and filtered. The residue on the filter is ignited at red heat until white. This gives the insoluble ash. The filtrate is evaporated and cautiously ignited at low temperature and the soluble ash obtained. This method gives 0.02 per cent. higher results than ignition of the total residue. To examine the ash further two parts are kept separate. One part is titrated with N. 0.1 acid with methyl orange as indicator for alkalinity and with standard silver nitrate solution for chlorin, with potassium chromate as indicator.

"The insoluble part is dissolved in a slight excess of hydrochloric acid, the solution nearly neutralized with ammonia, and heated to boiling. A cold saturated solution of ammonium oxalate is dropped in slowly until no more precipitate forms. This should stand for at least two hours. Then the precipitate is filtered off, washed, and ignited at low temperature. The ignited precipitate may be moistened with ammonium carbonate solution and re-ignited at low temperature. After weighing, the residue is dissolved in dilute hydrochloric acid, keeping the bulk small; ammonia is added to an alkaline reaction. The small precipitate of calcium phosphate is collected, ignited, and weighed. The weight is subtracted from the previous weight and the difference gives calcium carbonate, which, multiplied by 0.4 , gives the calcium, or by 0.56 , the lime. The weight of the calcium phosphate multiplied by 0.3871 gives the calcium; by 0.5419 , the lime. The total calcium or lime is the sum of the two.

"The filtrate is made strongly ammoniacal with 0.880 ammonia and allowed to stand for twenty-four hours. The precipitated magnesium-ammonium phosphate is filtered off, washed with dilute ammonia, ignited, and the magnesium pyrophosphate weighed. The weight multiplied by 0.21622 gives the magnesium, and by 0.36036 , the magnesia obtained. To the filtrate from this magnesia mixture is added. The precipitated magnesium-ammonium phosphate is filtered off after twenty-four hours and treated as above. From the total weight of the two quantities of magnesium pyrophosphate the phosphoric anhydrid is calculated by multiplying by 0.63964 . To this is added the phosphoric anhydrid in the calcium phosphate, calculated by multiplying the weight by 0.4581 .

"No account of traces of iron is taken in this method. The iron is precipitated with the calcium phosphate and the magnesiumammonium phosphate. If the iron is to be estimated the precipitate of calcium phosphate and the first magnesium-ammonium 
phosphate are dissolved in dilute hydrochloric acid and the iron determined colorimetrically as sulphid, ferrocyanid, or thiocyanate.

"To estimate the alkalies, another portion of the milk is ignited and the ash dissolved in dilute hydrochloric acid and boiled. A few drops of barium chlorid solution are added to make 0.1 gram per 100 grams of milk and boiling continued for some minutes. After some hours the precipitate of barium sulphate is filtered off, ignited, and weighed. The weight multiplied by 0.34335 gives the sulphuric anhydrid in milk. Ferric chlorid solution is added to color the solution brown and the filtrate made alkaline with ammonia. The precipitate is well washed and the filtrate evaporated and cautiously ignited. The weight gives the alkaline chlorids. The residue is redissolved in water, and if the solution is not quite clear, ammonium carbonate is added, the liquid evaporated to dryness, and the residue cautiously ignited. The residue is again taken up with water, filtered; and evaporated; the residue is cautiously ignited and weighed.

"Chlorin is titrated with standard silver nitrate solution. with potassium chromate as indicator. The potassium and sodium are calculated as follows:

"W. = weight of alkaline chlorids.

"C. = weight of chlorin therein.

"Weight of sodium $=2.997 \mathrm{C} .-1.4254 \mathrm{~W}$.

"Weight of potassium $=2.4254 \mathrm{~W}$. $-3.997 \mathrm{C}$.

"Potassium is directly estimated by evaporating the solution of alkaline chlorids with excess of platinum tetrachlorid solution almost to dryness. The pasty residue is treated with 80 per cent. alcohol containing 5 per cent. ether and washed repeatedly with this mixture. The alcohol is passed through a weighed filter or a Gooch crucible, and the precipitate finally transferred to this and washed with ether. It is then dried at $100^{\circ} \mathrm{C}$. and weighed. The weight multiplied by 0.3056 gives potassium chlorid; this subtracted from the weight of the alkaline chlorids gives sodium chlorid.

"Potassium chlorid multiplied by 0.5244 gives potassium, and by 0.6314 , potash. Sodium chlorid multiplied by 0.3932 gives sodium, and by 0.5299 , soda.

"Magnesia Mixture.-100 grams magnesium chlorid are dissolved in water and ammonia added until the solution smells strongly of ammonia. Then enough ammonium chlorid is added to dissolve the precipitate and the volume made up to 1 liter."

\section{Determination of Proteins}

Determination of Total Nitrogen.-The total nitrogen is best determined by the Gunning method, which is carried out as fol- 
lows, according to the Association of Official Agricultural Chemists: "About 5 grams of milk are placed in a Kjeldahl digestion flask, 10 grams powdered potassium sulphate and 15 to 25 c.c. (average 20 c.c.) sulphuric acid added. The digestion is started with a temperature below the boiling-point and the heat gradually increased until frothing ceases. The mixture is digested for some time after it has become colorless or until oxidation is complete. A small piece of paraffin is added to prevent bumping. After cooling the mixture is diluted with about 200 c.c. water, a few pieces of granulated zinc or pumice stone added, and enough soda solution to make the fluid strongly alkaline. The soda solution must be poured down the side of the flask so that it does not mix at once with the acid solution. The flask is then connected with a condenser, the contents mixed by shaking, and heated until all ammonia has passed over. The ammonia is received in a definite amount of standard acid. This operation usually requires from forty minutes to one hour and a half. The distillate is then titrated with standard alkali. The percentage of nitrogen obtained is multiplied by 6.38 to obtain the percentage of total protein. This method is not applicable when nitrates are present. This, however, occurs rarely with milk.

"The Reagents Used.-Potassium sulphate should be pulverized before using.

"Standard sulphuric acid for receiving the ammonia should be half normal or one-tenth normal when very small amounts of nitrogen are present.

"Standard alkali solution should be one-tenth normal.

"Concentrated sulphuric acid.

"Sodium hydrate solution should be saturated.

"Cochineal is used as indicator."

Determination of Total Nitrogen by the Ritthausen Method.Ten grams of milk are measured into a beaker and diluted with water to about 100 c.c. Richmond modifies the process by neutralizing the milk to phenolphthalein before proceeding. To the diluted milk are added 5 c.c. copper sulphate solution prepared by dissolving 34.64 grams copper sulphate in 500 c.c. water and the mixture stirred. Then a solution of sodium hydroxid (2.5 per cent.) is slowly added till the mixture is nearly neutral. Excess of alkali is to be avoided, since this prevents complete precipitation of the proteins. After the precipitate has settled the supernatant fluid is poured through a weighed and dried filter. The precipitate is washed several times by decantation and then transferred to the filter. It is washed with water, drained, and washed with strong alcohol, dried, extracted with ether in a Soxhlet extraction apparatus, and then transferred on the filter to an 
oven, dried at $130^{\circ} \mathrm{C}$., and weighed. The precipitate with filter are incinerated in a porcelain crucible and the weight of the residue deducted from the first weight. The result gives the weight of the protein.

Determination of Casein and Albumin.-Method of the Association of Official Agricultural Chemists: "The milk should be kept fresh, or if this is not possible, 1 part formaldehyd is added to 2500 parts milk and the milk kept on ice. About 10 grams of the milk are placed in a beaker with about 90 c.c. of water at $40^{\circ}$ to $42^{\circ} \mathrm{C}$. and 1.5 c.c. of a 10 per cent. acetic acid solution added. The mixture is stirred with a glass rod and allowed to stand for three to five minutes or longer. The supernatant fluid is decanted on a filter, the precipitate washed with cold water two or three times by decantation, and the precipitate transferred completely to the filter. The precipitate is then washed once or twice on the filter. The filtrate should be clear or nearly so. If it does not run clear, the filtrate is poured back and this process repeated two or three times, after which the washing of the precipitate can be completed. The nitrogen is determined in the washed precipitate by the Gunning method. The nitrogen is multiplied by 6.38 to obtain the amount of casein.

"The filtrate obtained is neutralized exactly with alkali and 0.3 c.c. of a 10 per cent. acetic acid added. The liquid is heated to the boiling temperature until the albumin is completely precipitated. The precipitate is collected on a filter, washed, and the nitrogen determined by the Gunning method. The result is multiplied by 6.38 .

"Optional Method of Determining Casein and Albumin.-To 10 c.c. of milk 50 c.c. of distilled water at $40^{\circ}$ C. are added, and then 2 c.c. of alum solution saturated at $40^{\circ} \mathrm{C}$. or higher. The precipitate is allowed to settle, transferred to a filter, and washed. Nitrogen is determined by the Gunning method.

"To the filtrate 0.3 c.c. of a 10 per cent. acetic acid solution are added and the mixture boiled until the albumin has been completely precipitated and the nitrogen determined as before.

"Leffman and Beam's Method for Determining Casein and Albumin.-Twenty c.c. of milk are mixed with saturated solution of magnesium sulphate and the mixture saturated with the powdered salt. The whole is then washed into a graduate with a little saturated solution and the precipitate allowed to settle. The volume of the mixture in the graduate is noted and as much as possible of the clear supernatant fluid removed with a pipet and filtered.

"An aliquot portion of the filtrate is taken and the albumin 
precipitated from it by a solution of tannin. The precipitate is washed and the amount of nitrogen determined.

"The casein is calculated by difference between the total protein and the albumin."

Casein may also be determined by precipitation with acetic acid in the following manner: 20 c.c. of milk are diluted with water to 200 c.c. and enough dilute acetic acid (10 per cent.) added to complete precipitation. This is indicated when the filtrate is perfectly clear. The amount of acetic acid necessary for complete precipitation of the casein varies somewhat in different milks. It is therefore necessary to add the acid cautiously so as to leave no excess of acid which would redissolve the casein. It is advisable to prepare several samples of the milk and place these in different flasks. To each flask is then added a different amount of acid, and that flask selected for operation which shows a clear filtrate with the smallest amount of acetic acid. Introtroduction of $\mathrm{CO}_{2}$ aids in completing precipitation. The precipitate is allowed to settle, is washed repeatedly by decantation, and gathered on nitrogen-free filters. The nitrogen is then determined by the Gunning method.

Instead of estimating the nitrogen by the Gunning method the acetic acid precipitate may be washed until free from lactose and albumin and the fat extracted with ether. The precipitate is then gathered on a weighed filter, desiccated, and weighed.

To determine the albumin the filtrate from the casein determination is boiled, the precipitate washed, and gathered on a weighed filter. After desiccation the filter is weighed again and the weight of the albumin calculated.

Determination of Nitrogen as Caseoses, Amido-compounds, Peptons, and Ammonia (Van Slyke's Method). - The filtrate obtained after the albumin has been removed is heated to $70^{\circ} \mathrm{C}$.; 1 c.c. 50 per cent. sulphuric acid is added, and then chemically pure zinc sulphate to saturation. The mixture is allowed to stand at $70^{\circ} \mathrm{C}$. until the caseoses have separated and settled. The precipitate is then cooled and washed with saturated zinc sulphate solution slightly acidified with sulphuric acid and the nitrogen in the precipitate determined.

Amido-compounds and ammonia are determined as follows: 50 grams of milk are placed in a 250-c.c. graduated flask with 1 gram sodium chlorid and a 12 per cent. solution of tannin added drop by drop until no more precipitate is formed. The mixture is then diluted to the 250 c.c. mark, shaken, and filtered. The nitrogen in 50 c.c. of the filtrate is determined and represents the nitrogen of the amido-compounds and ammonia.

The ammonia nitrogen is determined by distilling with mag- 
nesium oxid 100 c.c. of the filtrate from the tannin and salt solution. The distillate is received in standard acid and the ammonia determined as before. The peptones are calculated by subtraction of the ammonia nitrogen from the combined nitrogen from all other nitrogen compounds.

Volumetric Methods of Estimating Casein in Milk.- Since the Babcock test for fat has been eminently successful in showing the butter maker the value of milk and cream for butter making, it has seemed desirable to work out a test which gives the cheese maker equally reliable information as to the content of casein in milk. It has been shown that the fat content of milk does not always bear a definite relation to the casein, so a test for fat is not a reliable guide for cheese makers. Although the casein content rises when the fat content rises the proportion of increase is not the same, and cheese makers have observed that a milk rich in fat may yield less cheese than poor milk, other conditions being equal. It is true that mixed milk rich in fat yields a cheese of better quality than does poor milk; therefore a test for fat is of considerable value in estimating the suitability of a certain milk for cheese making. On the other hand, the variability in the relation of fat to cheese makes a rapid test highly desirable.

Furthermore, by means of the Babcock test for fat the producer can raise the average fat production of his herd by elimination of poor milk cows, and it is possible that a similar increase in casein content can be obtained if a simple quantitative test for casein be used.

Several tests have been devised for this purpose. In the following two methods one given by Hart and one by Van Slyke and Bosworth are described.

The Hart Centrifugal Test.-The principles involved in the test are these:

"1. Construction of a tube whereon percentages of casein in milk are read directly. These tubes can be purchased (Figs. 66, $67)$.

"2. Establishment of a proper volume of milk to be used that will conform to the tube and scale adopted, allowing percentage of casein to be read directly. 
"3. The precipitation of the casein by dilute acetic acid. the fat.

"4. The agitation of the precipitate with chloroform to remove

" 5 . The application of a definite centrifugal force in order to mass the casein into the pellet.

"6. Reading the percentage of casein."

The test is carried out in the following manner: A suitable rack is provided to hold the tubes and 2 c.c. of pure chloroform poured into each tube from a buret. On top of the chloroform are poured 20 c.c. of a 0.25 per cent. acetic acid solution. For convenience a 10 per cent. solution of 99.5 per cent. acetic acid is kept in stock. Previous to making the test 25 c.c. of this stock solution are diluted to 1 liter with water. The temperature of the

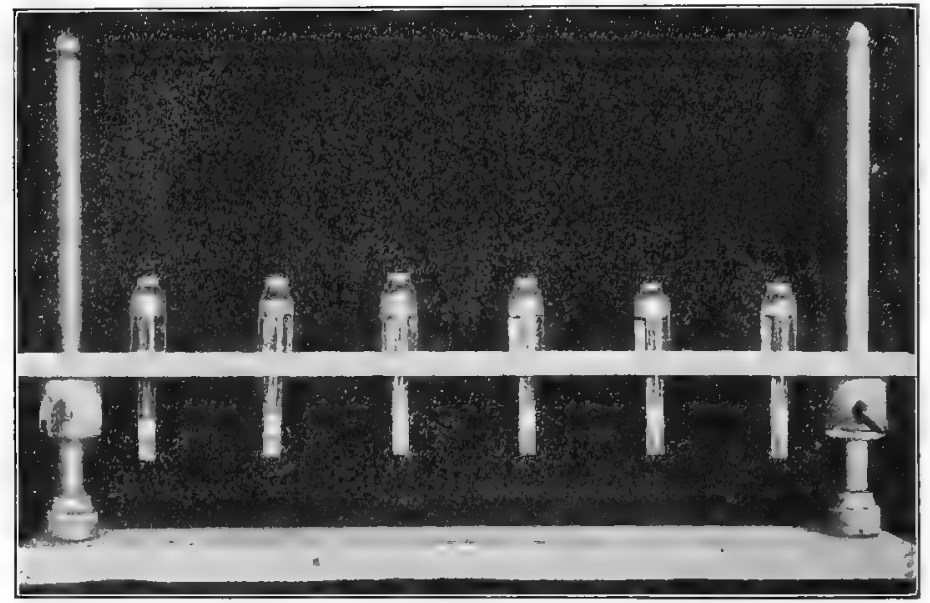

Fig. 67.-A convenient rack for supporting the tubes. (Bull. 156, November, 1907, Univ. of Wis. Agri. Exp. Sta.)

acetic acid should be $21^{\circ} \mathrm{C} .\left(70^{\circ} \mathrm{F}\right.$.), hut a variation of 5 degrees on either side is not material. The next step is to measure into a pipet exactly 5 c.c. of the milk sample. After this is placed in the tube the mouth of the tube is closed with the thumb and the chloroform brought down into the barrel by rotation. The tube is then shaken vigorously for fifteen to twenty seconds. The chloroform is broken up and comes in contact with the fat, which is dissolved. After shaking, the tubes should not be allowed to stand for more than fifteen to thirty minutes. If a large series of tests is to be made, the chloroform and acetic acid should be placed in all tubes before the milk sample is added. The tubes are then placed in a centrifuge and whirled for seven and a half to eight minutes, counting from the time when a speed of 2000 revolutions 
per minute has been attained. A range of 50 revolutions per minute on either side will not introduce serious error. After a lapse of eight minutes the power is turned off, and when the centrifuge has stopped rotating the tubes are removed and placed in the rack. They should rest there for at least ten minutes before readings are taken. The casein will form a well-defined mass above the chloroform and the percentage can be read from the scale. Sometimes a film forms below the layer of casein, but this should not be included in the reading, as it is usually the result of violent shaking.

In order to obtain accurate results with this test several conditions should be carefully considered. These conditions are: 1, The acidity of the milk; 2, the influence of prolonged shaking; 3 , the temperature of the ingredients; 4 , the influence of preservatives.

The Acidity of the Milk.-The accuracy of the test is not materially altered by acidity up to 0.36 per cent. This is shown by the following figures given by Hart:

SUCCESSIVE DETERMINATIONS OF CASEIN IN MILKS OF VARYING ACIDITY

\begin{tabular}{|c|c|c|c|c|c|c|}
\hline \multirow[b]{2}{*}{ No. } & \multicolumn{2}{|c|}{1} & \multicolumn{2}{|c|}{2.} & \multicolumn{2}{|c|}{3.} \\
\hline & Acidity. & $\begin{array}{c}\text { Per cent. } \\
\text { casein. }\end{array}$ & Acidity. & $\begin{array}{l}\text { Per cent. } \\
\text { casein. }\end{array}$ & Acidity. & $\begin{array}{c}\text { Per cent. } \\
\text { casein. }\end{array}$ \\
\hline $\begin{array}{l}1 \\
\cdot 2 \\
3 \\
4 \\
5 \\
6\end{array}$ & $\begin{array}{l}0.15 \\
0.17 \\
0.12 \\
0.14 \\
0.15 \\
0.16\end{array}$ & $\begin{array}{l}3.10 \\
3.05 \\
2.20 \\
2.10 \\
2.60 \\
2.50\end{array}$ & $\begin{array}{l}0.25 \\
0.27 \\
0.22 \\
0.24 \\
0.25 \\
0.26\end{array}$ & $\begin{array}{l}3.10 \\
2.95 \\
2.15 \\
2.10 \\
2.55 \\
2.45\end{array}$ & $\begin{array}{l}0.35 \\
0.37 \\
0.32 \\
0.34 \\
0.35 \\
0.36\end{array}$ & $\begin{array}{l}3.05 \\
3.00 \\
2.20 \\
2.10 \\
2.59 \\
2.50\end{array}$ \\
\hline
\end{tabular}

When milk is curdled the test cannot be made.

The Influence of Prolonged Shaking.-When the shaking takes more than 20 seconds a ragged line forms at the juncture of the casein and chloroform, and readings become inaccurate.

Influence of the Temperature of the Ingredients.-The proper temperature of the ingredients is $21^{\circ} \mathrm{C}$. $\left(70^{\circ} \mathrm{F}\right.$.). If it varies 5 degrees $\mathrm{F}$. on either side, the influence is negligable, but greater variation vitiates the test. When the temperature falls below $70^{\circ} \mathrm{F}$. the reading will be too high; when above $70^{\circ} \mathrm{F}$. the reading will be too low. This is illustrated by experiments made by Hart and given in the following table:

INFLUENCE OF TEMPERATURE ON THE DETERMINATION OF PERCENTAGE OF CASEIN IN MILK

$\begin{array}{ccccccc}\text { No. } & 68^{\circ}-70^{\circ} \mathrm{F} . & 58^{\circ}-60^{\circ} \mathrm{F} . & 65^{\circ}-66^{\circ} \mathrm{F} . & 74^{\circ}-75^{\circ} \mathrm{F} . & 80^{\circ} \mathrm{F} . & 95^{\circ} \mathrm{F} . \\ \text { per cent. } & \text { per cent. } & \text { per cent. } & \text { per cent. } & \text { per cent. } & \begin{array}{c}\text { per cent. } \\ 1\end{array} \\ 2 & 2.80 & 3.20 & 2.90 & 2.88 & 2.65 & 2.20 \\ 2 & 3.10 & 3.58 & 3.10 & 3.00 & 2.85 & 2.30 \\ 3 & 2.00 & 2.25 & 2.00 & 2.10 & 1.80 & 1.70 \\ 4 & 2.05 & 2.20 & 2.10 & 2.00 & 1.90 & 1.50 \\ 5 & 2.75 & 2.80 & 2.75 & 2.70 & 2.45 & 1.90 \\ 6 & 2.40 & 2.60 & 2.45 & 2.30 & 2.25 & 1.80\end{array}$


The Influence of Preservatives.-After a series of tests Hart concludes that potassium bichromate is the only preservative commonly used for preserving composite samples that permits an accurate test to be made. In these tests formaldehyd, mercuric chlorid, toluol, chloroform, and potassium bichromate were used. The readings were always too high except when potassium bichromate was used. After the samples had stood for more than three days and a half with potassium bichromate the reading line was ragged.

The speed of the centrifuge should be 2000 revolutions per minute when the revolving wheel is 15 inches in diameter. When a hand centrifuge is used the author advises regulation of speed by means of a metronome.

When carefully executed the Hart centrifugal test for casein gives results which closely approximate those obtained by the Association of Official Agricultural Chemists in their test for determining casein. The comparison is shown by the following figures:

COMPARATIVE DETERMINATIONS OF CASEIN BY THE OFFICIAL METHOD AND BY THE NEW METHOD

\begin{tabular}{|c|c|c|}
\hline \multirow{2}{*}{ Breed of cow. } & Official method. & New method. \\
\hline & 2.45 & 2.50 \\
\hline \multirow{3}{*}{ Jersey. } & 3.31 & 3.20 \\
\hline & 3.65 & 3.70 \\
\hline & 2.47 & 2.60 \\
\hline \multirow{2}{*}{ Guernsey. . } & 2.91 & 3.10 \\
\hline & 3.50 & 3.70 \\
\hline \multirow{2}{*}{ Holstein. } & $\begin{array}{l}1.00 \\
2.10\end{array}$ & 2.08 \\
\hline & 2.13 & 2.13 \\
\hline \multirow{2}{*}{ Brown Swiss } & 2.66 & 2.65 \\
\hline & $\begin{array}{l}270 \\
256\end{array}$ & $\begin{array}{l}2.70 \\
2.50\end{array}$ \\
\hline \multirow[t]{2}{*}{ Ayrshire..... } & 261 & 2.55 \\
\hline & 314 & 3.18 \\
\hline
\end{tabular}

Hart's Titration Method for Determining Casein.-Another method for rapidly estimating the casein content of milk has been described by Hart. The test is based on the following principle: When casein is precipitated by acid and the acid removed by prolonged washing, a substance remains which has acid properties and displaces $\mathrm{CO}_{2}$ from calcium carbonate to form an opalescent solution. Lime-water or a fixed alkali dissolves the casein precipitate with production of a slightly milky solution. When the excess of alkali in such a solution is titrated with acid and phenolphthalein as indicator, some alkali remains unaccounted for. This fact shows that the casein precipitate neutralizes a definite amount of alkali. By a series of tests it was ascertained that 0.1 c.c. of $\mathrm{N}$. one-tenth $\mathrm{NaOH}$ bound on the average 0.0108 gram casein precipitate. Therefore, 10.8 grams of milk are re- 
quired for casein estimation in order that the percentage may be read directly from the buret. As milk has an average specific gravity of 1.03 , a volume of 10.5 c.c. will weigh 10.8 grams. The volume of 10.5 c.c. is the basis for this method.

The test is carried out as follows: "In a 200-c.c. Erlenmeyer flask are placed 10.5 c.c. of the milk sample, 75 c.c. of clistilled water at room temperature, and 1 to 1.5 c.c. of a 10 per cent. solution of acetic acid. The flask is given a vigorous rotary motion. Usually 1.5 c.c. of acetic acid gives a clear and fast filtering separation, but occasionally, with milks low in casein, a better separation is effected if a little less acetic acid is used. The separated precipitate is now filtered through a 9-11 cm. filter. As the casein accumulates on the filter there is a marked retardation of the filtering process. This can be made rapid again by conducting a fine stream of cold water against the upper point of contact of filter paper and casein. This loosens the casein mass and accumulates it at the apex of the filter. This is all essential to proper working of the process."

The acid must be removed by cold water for the success of the test. When this is done, the casein is in a loose, easily soluble form. The temperature should not be above $20^{\circ} \mathrm{C}$. Any casein particles that adhere to the glass of the flask need not be removed, but the acid must be washed out of them. Washing of the precipitate should be continued until 250 to 300 c.c. of the filtrate have accumulated and the filter has become perfectly clear.

The precipitate, together with the filter paper, is now returned to the flask in which precipitation was made; 75 to 80 c.c. of neutral $\mathrm{CO}_{2}$-free water added, and then a few drops of phenolphthalein and 10 c.c. of $\mathrm{N}$. one-tenth potassium hydrate solution. The flask is stoppered with a rubber stopper and vigorously shaken either by hand or in a machine until solution is effected. Complete solution is easily indicated, even in the presence of the filter paper, by the disappearance of the white casein particles, which otherwise would settle to the bottom. After solution the stopper is rinsed off with neutral, $\mathrm{CO}_{2}$-free water and immediately titrated with $\mathrm{N}$. one-tenth acid until the red color disappears. It is imperative that a blank should be run parallel with the entire determination. The blank usually runs 0.2 to 0.3 acid. The correction for the blank is made by addition to the number of cubic centimeters of acid used for titration. The difference between this corrected acid reading and the 10 c.c. alkali used gives directly the percentage of casein in the milk.

"Example.-Suppose it took 6.7 c.c. of N. one-tenth $\mathrm{H}_{2} \mathrm{SO}_{4}$ in the titration and the blank was 0.2 c.c., then the per cent. of casein would become $10-6.9=3.1$ per cent." 
The accuracy of the method is shown by the following table: COMPARISON OF RESULTS OF OFFICIAL METHOD AND HART'S VOLUMETRIC METHOD

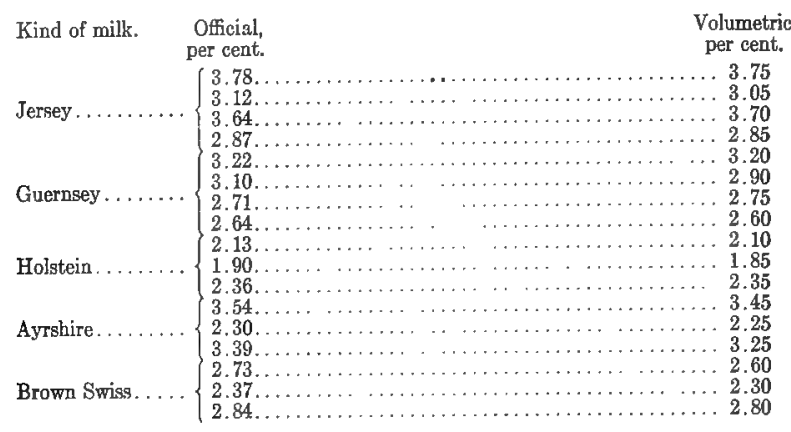

The volumetric method of Van Slyke and Bosworth is given by Van Slyke as follows: "Into a 200-c.c. flask measure 17.5 c.c. (18 grams) of milk, add about 80 c.c. of water, and 1 c.c. of phenolphthalein solution; after which run in a solution of sodium hydroxid until the mixture is neutral. Standardized acetic acid is then added until the casein is completely precipitated, the volume of the mixture is made up to 200 c.c. by addition of water, and the whole is filtered. Into 100 c.c. of the clear filtrate standardized sodium hydroxid solution is run until neutral. The solutions are so standardized that 1 c.c. is equivalent to 1 per cent. of casein in the milk examined. Therefore, the number of cubic centimeters of standard acid used divided by 2 , less the amount of standard alkali used in the final titration, gives the percentage of casein in milk. The operation usually requires twelve to fifteen minutes when apparatus and solutions are at hand in convenient form for ready use; several determinations can be carried on at the same time to advantage.

"The reagents needed in this test are: Sodium hydroxid solution: 10 c.c. standard normal solution are diluted to 1260 c.c. with distilled water. Alkali tablets cannot be used for the test.

"Acetic acid: The acetic acid solution is diluted so that 1 c.c. will neutralize 1 c.c. of the sodium hydrate solution."

The apparatus used for the test of Van Slyke and Bosworth are shown in Fig. 68.

The milk to be tested should not be more than twenty-four hours old and must have been kept cold. Sour milk cannot be used. If the milk cannot be tested fresh, mercuric chlorid must be added in the proportion of $1: 1000$ to 1500 . Commercial mercuric chlorid tablets containing coloring-matter cannot be used. 
The milk sample must be neutralized exactly and excess of alkali avoided. The temperature of the diluted and neutralized milk should be $60^{\circ}$ to $80^{\circ} \mathrm{F}$. ( $\left(15^{\circ}\right.$ to $25^{\circ} \mathrm{C}$.). Enough acid must be added to promptly separate the casein into large flakes, leaving
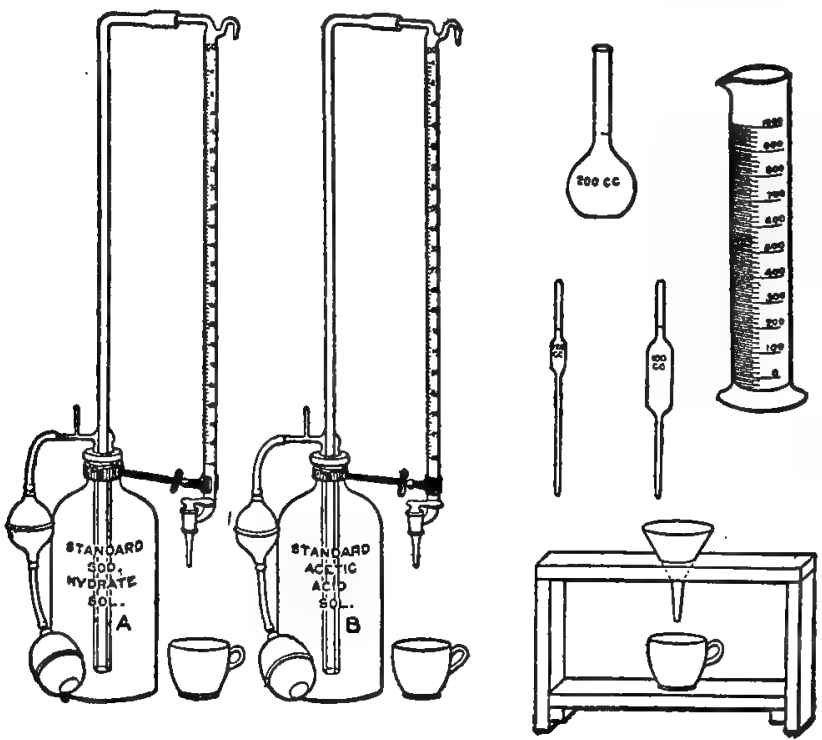

Fig. 68.-Apparatus and reagents required in the New York State station volumetric casein test (Van Slyke).

the supernatant fluid clear. The authors advise the use of a color standard by which to judge the phenolphthalein end-point, as this will insure consistent results.

\section{The Determination of MilK-sugar}

Milk-sugar may be determined by means of the polariscope or by its reducing power on copper salts. The reduction of copper salts is measured either gravimetrically or volumetrically. The methods given by the Association of Official Agricultural Chemists are as follows:

Optical Method (Official).- "Preparation of Reagents.-1. Acid mercuric nitrate. Dissolve mercury in double its weight of nitric acid, specific gravity 1.42 , and dilute with an equal volume of water. One c.c. of this reagent is sufficient for the quantities of milk mentioned below. Larger quantities may be used without affecting the results of polarization. 2. Mercuric iodid with acetic acid. Mix 33.2 grams of potassium iodid, 13.5 grams mercuric chlorid, 20 c.c. glacial acetic acid, and 640 c.c. of water. 
"Determination.-The milk should be at constant temperature and its specific gravity determined with a delicate hydrometer. When greater accuracy is required, a pycnometer is used.

"The quantities of the milk measured for polarization vary with the specific gravity of the milk as well as with the polariscope used. The quantity to be measured in any case will be found in the following table:

\begin{tabular}{|c|c|c|c|c|}
\hline \multirow{2}{*}{$\begin{array}{c}\text { Specific } \\
\text { gravity. } \\
1.024 \\
1.026 \\
1.028 \\
1.030 \\
1.032 \\
1.034 \\
1.035\end{array}$} & \multicolumn{2}{|c|}{$\begin{array}{l}\text { For polariscope of which } \\
\text { the sucrose normal weight } \\
\text { is } 16.19 \text { grams. }\end{array}$} & \multicolumn{2}{|c|}{$\begin{array}{l}\text { For polariscope of which } \\
\text { the sucrose normal weight } \\
\text { is } 26.048 \text { grams. }\end{array}$} \\
\hline & $\begin{array}{l}60.0 \\
59.9 \\
59.8 \\
59.7 \\
59.6 \\
59.5 \\
\quad 59.35\end{array}$ & $\begin{array}{l}\text { c.c. } \\
" ، \\
" ، \\
" . \\
" .\end{array}$ & $\begin{array}{l}64.4 \\
64.3 \\
64.15 \\
64.0 \\
63.9 \\
63.8 \\
63.7\end{array}$ & $\begin{array}{l}\text { c.c. } \\
" . \\
" 4 \\
" ، \\
" ،\end{array}$ \\
\hline
\end{tabular}

"Place the quantity of milk indicated in the table in a flask graduated at 102.4 c.c. for a Laurent, or 102.6 c.c. for a Ventzke polariscope (Mohr cubic centimeter). Add 1 c.c. of mercuric nitrate solution or 30 c.c. of mercuric iodid solution (an excess of these reagents does no harm), fill to the mark, agitate, filter through a dry filter, and polarize.' It is not necessary to heat before polarizing. In case a $200-\mathrm{mm}$. tube is used, divide the polariscope reading by 3 , when the sucrose normal weight for the instrument is 16.19 grams; or by 2 , when the normal weight for the instrument is 26.048. When a $400-\mathrm{mm}$. tube is used these divisors become 6 and 4 respectively. For the calculation of the above table the specific rotary power of lactose is taken as $52.53^{\circ}$, and the corresponding number for sucrose $66.5^{\circ}$. The lactose normal weight to read $100^{\circ}$ on the sugar scale for Laurent instruments is 20.496 grams, and for Ventzke instruments 32.975 grams. In case metric flasks are used the weights here mentioned must be reduced to 16.160 and 26.000 grams respectively."

Gravimetric Method.-Preparation of the Milk Solution.Dilute 25 c.c. of the milk with 400 c.c. of water and add 10 c.c. of a copper sulphate solution prepared as follows: Dissolve 34.639 grams of $\mathrm{CuSO}_{4}, 5 \mathrm{H}_{2} \mathrm{O}$ in water and make up to 500 c.c. Add to the mixture about 7.5 c.c. of a solution of $\mathrm{KOH}$ of such strength that one volume of it is just sufficient to completely precipitate the copper as hydroxid from one volume of the solution of copper sulphate. Instead of a solution of $\mathrm{KOH}$ of this strength, 8.8 c.c. of a half-normal solution of $\mathrm{NaOH}$ may be used. After the addition of the alkali solution the mixture must still have an acid reaction and contain copper in solution. Fill the flask to the 500 c.c. mark, mix, and filter through a dry filter. 


\section{SOXHLET'S TABLE FOR THE DETERMINATION OF LACTOSE.*}

\begin{tabular}{|c|c|c|c|c|c|c|c|c|c|}
\hline $\begin{array}{c}\text { Milli- } \\
\text { grams } \\
\text { of Cop- } \\
\text { per }\end{array}$ & $\begin{array}{l}\text { Milli- } \\
\text { grams } \\
\text { of Lac- } \\
\text { tose. }\end{array}$ & $\begin{array}{l}\text { Mill. } \\
\text { gram: } \\
\text { of Cop- } \\
\text { per }\end{array}$ & $\begin{array}{l}\text { Millı. } \\
\text { grams } \\
\text { of Lac- } \\
\text { lose }\end{array}$ & $\begin{array}{l}\text { Mills- } \\
\text { grams } \\
\text { ol Cop- } \\
\text { per. }\end{array}$ & $\begin{array}{l}\text { Mtlli- } \\
\text { grams } \\
\text { of Lac- } \\
\text { tose. }\end{array}$ & $\begin{array}{l}\text { Milli- } \\
\text { gram: } \\
\text { of Cop. } \\
\text { per. }\end{array}$ & $\begin{array}{c}\text { Mill. - } \\
\text { grams } \\
\text { of Lac- } \\
\text { lose. }\end{array}$ & $\begin{array}{l}\text { Milli. } \\
\text { grams } \\
\text { of Cop- } \\
\text { per. }\end{array}$ & $\begin{array}{l}\text { Milli- } \\
\text { grams } \\
\text { of Lac- } \\
\text { tose. }\end{array}$ \\
\hline 100 & 71.6 & 161 & 117.1 & 221 & 162.7 & 281 & $209 . I$ & $34 !$ & 256.5 \\
\hline IOI & 72.4 & 162 & 117.9 & 222 & I $63-4$ & 282 & 209.9 & - 342 & $257 \cdot 4$ \\
\hline 102 & 73.1 & 163 & I 18.6 & 223 & $16+-2$ & 283 & 210.7 & 343 & 258.2 \\
\hline 103 & 73.8 & 164 & 119.4 & 224 & 164.9 & $28+$ & 211.5 & $3+4$ & 259.0 \\
\hline 104 & 74.6 & 165 & I 20.2 & 225 & 55.7 & 285 & 212.3 & $3+5$ & 259.8 \\
\hline 105 & $75-3$ & I 66 & 120.9 & 226 & 166.4 & 286 & 213.1 & 346 & 260.6 \\
\hline 106 & 76.1 & 167 & 121.7 & 227 & $167 \cdot 2$ & 287 & 213.9 & 347 & $26 I \cdot 4$ \\
\hline 107 & 76.8 & 168 & 122.4 & 228 & $167 \cdot 9$ & 288 & $21+.7$ & 348 & $262 \cdot 3$ \\
\hline 108 & 77.6 & 169 & 123.2 & 229 & 165.6 & 259 & $215 \cdot 5$ & $3+9$ & $263 . \mathrm{I}$ \\
\hline 109 & 78.3 & 170 & I 23.9 & 230 & $169 \cdot 4$ & 290 & 256.3 & $35^{\circ}$ & 263.9 \\
\hline I10 & 79.0 & 171 & $124 \cdot 7$ & $23 I$ & 170.1 & 291 & 217.1 & 351 & $264 \cdot 7$ \\
\hline I I I & 79.8 & 172 & 125.5 & 232 & I 70.9 & 292 & 217.9 & $35^{2}$ & 265.5 \\
\hline I I 2 & 80.5 & 173 & 126.2 & 233 & 171.6 & 293 & 218.7 & 353 & 266.3 \\
\hline I I 3 & 8 I. 3 & 174 & 127.0 & 234 & I72. 4 & 294 & 219.5 & 354 & $267 \cdot 2$ \\
\hline I 14 & 82.0 & 175 & I 27.8 & 235 & I $73 \cdot \mathbf{I}$ & 295 & 220.3 & 355 & 268.0 \\
\hline I I 5 & 82.7 & 176 & I 28.5 & $23^{6}$ & I73.9 & 296 & 221.1 & 356 & 268.8 \\
\hline 116 & $83 \cdot 5$ & I77 & I 29.3 & 237 & 174.6 & 297 & 221.9 & 357 & 269.6 \\
\hline 117 & 84.2 & 178 & 130.1 & 238 & $175 \cdot 4$ & 298 & $222 \cdot 7$ & $35^{8}$ & 270.4 \\
\hline 118 & 85.0 & I 79 & 130.8 & 239 & 176.2 & 299 & 223.5 & 359 & 27 I. 2 \\
\hline I I 9 & 85.7 & 180 & 131.6 & 240 & 176.9 & 300 & $22+.4$ & 360 & 272.1 \\
\hline 120 & 86.4 & $18 \mathrm{I}$ & I 32.4 & 245 & เ 77.7 & 301 & 225.2 & $36 \mathrm{r}$ & 272.9 \\
\hline I 2 I & 87.2 & 182 & 133.1 & 242 & 178.5 & 302 & 225.9 & 362 & $273 \cdot 7$ \\
\hline 122 & 87.9 & 183 & $133-9$ & 243 & 179.3 & 303 & 226.7 & 363 & 2745 \\
\hline 123 & 88.7 & 184 & I 34.7 & 244 & I80. 1 & 304 & $227 \cdot 5$ & 364 & 275.3 \\
\hline 124 & 89.4 & 185 & I $35 \cdot 4$ & 245 & 180.8 & 305 & 228.3 & 365 & 276.2 \\
\hline 125 & 90.1 & 186 & 136.2 & 246 & 181.6 & 306 & $229-I$ & 366 & 277 I \\
\hline I 26 & 90.9 & 187 & 137.0 & 247 & I $82-4$ & 307 & 229.8 & 367 & 2779 \\
\hline I 27 & $95: 6$ & 188 & I $37 \cdot 7$ & 248 & I83.2 & 308 & 230.6 & 368 & 2788 \\
\hline I 28 & $92 \cdot 4$ & 189 & 138.5 & 249 & $184-0$ & 309 & 231.4 & 369 & 2796 \\
\hline I 29 & $93 \cdot I$ & 190 & 139.3 & 250 & 184.8 & 310 & 232.2 & 370 & 280.5 \\
\hline I 30 & 93.8 & 191 & 140.0 & $25 \mathrm{I}$ & I 85.5 & 3 II & 232.9 & 371 & 281.4 \\
\hline $13 I$ & 94.6 & 192 & 140.8 & 252 & I $86-3$ & 312 & 233.7 & 372 & 282.2 \\
\hline 132 & $95: 3$ & 193 & 141.6 & 253 & 187.1 & 313 & $234 \cdot 5$ & 373 & 283.1 \\
\hline$\$ 33$ & 96.1 & 194 & $142 \cdot 3$ & 254 & 187.9 & 314 & $235 \cdot 3$ & 374 & 283.9 \\
\hline I 34 & 96.9 & 195 & I $43 . I$ & 255 & 188.7 & 315 & 236.5 & 375 & $28+.8$ \\
\hline 135 & 97.6 & 196 & $343 \cdot 9$ & 256 & 180.4 & 316 & 236.8 & 376 & 2857 \\
\hline 136 & 98.3 & 197 & 1 44.6 & 257 & 190.2 & 317 & 237.6 & 377 & 2865 \\
\hline 137 & $99 \cdot I$ & 198 & I $45-4$ & 258 & J9I.0 & 318 & 238.4 & 378 & $287 \cdot 4$ \\
\hline 138 & 99.8 & 199 & 146.2 & 259 & 191.8 & 319 & 239.2 & 379 & 288.2 \\
\hline 139 & 100.5 & 200 & 546.9 & 260 & 192.5 & 320 & 240.0 & 380 & 2891 \\
\hline 140 & $101 \cdot 3$ & 201 & I $47 \cdot 7$ & $26 \mathrm{I}$ & 193.3 & 321 & 240.7 & 381 & 2899 \\
\hline 141 & 102.0 & 202 & 148.5 & 262 & 194.1 & 322 & $241 \cdot 5$ & 382 & 290.8 \\
\hline 142 & 102.8 & 203 & 149.2 & 263 & 104.9 & 323 & $242 \cdot 3$ & 383 & 291.7 \\
\hline 143 & 103.5 & 204 & 150.0 & $26+$ & 195.7 & $3^{24}$ & $243 . I$ & 384 & 292.5 \\
\hline 144 & $104 \cdot 3$ & 205 & I $5^{\circ} .7$ & 265 & 1964 & $3^{25}$ & $243 \cdot 9$ & 385 & 293.4 \\
\hline I 45 & 105 - I & 206 & 15 I. 5 & 266 & 197.2 & 326 & 244.6 & 386 & 2042 \\
\hline 146 & 105.8 & 207 & 152.2 & 267 & 198.0 & 327 & $245 \cdot 4$ & 387 & $205 \cdot 1$ \\
\hline 147 & 106.6 & 208 & 153.0 & 268 & I98.8 & 328 & 246.2 & 388 & 206.0 \\
\hline 148 & 107.3 & 209 & 153.7 & 269 & I99. 5 & 329 & 247.0 & 380 & 296.8 \\
\hline I 49 & 108.1 & 210 & $154 \cdot 5$ & 270 & $200 \cdot 3$ & $33^{\circ}$ & $247 \cdot 7$ & 300 & $297 \cdot 7$ \\
\hline 150 & 108.8 & 211 & 155.2 & $27 \mathrm{I}$ & 201.1 & $33 r$ & 248.5 & 391 & 298.5 \\
\hline I 5 I & 109.6 & 212 & 156.0 & 272 & 201.9 & $33^{2}$ & 249.2 & 392 & $290 \cdot 4$ \\
\hline 152 & 110.3 & 213 & I 56.7 & 273 & $202-7$ & 333 & 250.0 & 393 & $300 \cdot 3$ \\
\hline I 53 & I I I I I & 214 & I $57 \cdot 5$ & 274 & $203 \cdot 5$ & 334 & 250.8 & 394 & 301.1 \\
\hline I 54 & 1 I I .9 & 2 IS & 158.2 & 275 & $204-3$ & 335 & 251.6 & 395 & 302.0 \\
\hline 155 & 112.6 & 216 & 159.0 & 276 & $205 . I$ & $33^{6}$ & 252.5 & 396 & 302.8 \\
\hline $15^{6}$ & I I $3 \cdot 4$ & 217 & J $59 \cdot 7$ & 277 & 205.9 & 337 & $253 \cdot 3$ & 397 & 303.7 \\
\hline 157 & I I $4, \mathrm{I}$ & 218 & 160.4 & 278 & 206.7 & $33^{8}$ & $254 . I$ & 398 & 304.6 \\
\hline $15^{8}$ & 114.9 & 219 & 161.2 & 279 & $207 \cdot 5$ & 339 & 254.9 & 399 & 305.4 \\
\hline $\begin{array}{l}159 \\
160\end{array}$ & $\begin{array}{l}\text { I I } 5.6 \\
\text { I } 16.4\end{array}$ & 220 & 161.9 & 280 & 208.3 & $34^{\circ}$ & $255 \cdot 7$ & 400 & $306 \cdot 3$ \\
\hline
\end{tabular}


DEFREN'S TABLE FOR THE DETERMINATION OF LACTOSE

\begin{tabular}{|c|c|c|c|c|c|c|c|c|c|c|c|}
\hline $\begin{array}{l}\text { Milli- } \\
\text { grams } \\
\text { of cu- } \\
\text { pric } \\
\text { oxid. }\end{array}$ & $\begin{array}{c}\text { Milli- } \\
\text { grams } \\
\text { of lac- } \\
\text { tose. }\end{array}$ & $\begin{array}{l}\text { Milli- } \\
\text { grams } \\
\text { of cu- } \\
\text { pric } \\
\text { oxid. }\end{array}$ & $\begin{array}{l}\text { Milli- } \\
\text { grams } \\
\text { of lac- } \\
\text { tose. }\end{array}$ & $\begin{array}{l}\text { Milli- } \\
\text { grams } \\
\text { of cu- } \\
\text { pric } \\
\text { oxid. }\end{array}$ & $\begin{array}{c}\text { Milli- } \\
\text { grams } \\
\text { of lac- } \\
\text { tose. }\end{array}$ & $\begin{array}{l}\text { Milli- } \\
\text { grams } \\
\text { of cu- } \\
\text { pric } \\
\text { oxid. }\end{array}$ & $\begin{array}{c}\text { Milli- } \\
\text { grams } \\
\text { of lac- } \\
\text { tose. }\end{array}$ & $\begin{array}{l}\text { Milli- } \\
\text { grams } \\
\text { of cu- } \\
\text { pric } \\
\text { oxid. }\end{array}$ & $\begin{array}{c}\text { Milli- } \\
\text { grams } \\
\text { of lac- } \\
\text { tose. }\end{array}$ & $\begin{array}{l}\text { Milli- } \\
\text { gromes } \\
\text { of cu- } \\
\text { pris } \\
\text { oxid. }\end{array}$ & $\begin{array}{c}\text { Milli- } \\
\text { grams } \\
\text { of lac- } \\
\text { tose. }\end{array}$ \\
\hline $\begin{array}{l}30 \\
31 \\
32 \\
33 \\
34\end{array}$ & $\begin{array}{l}18.8 \\
19.5 \\
20.1 \\
20.7 \\
21.4\end{array}$ & $\begin{array}{l}80 \\
81 \\
82 \\
83 \\
84\end{array}$ & $\begin{array}{l}50.5 \\
51.1 \\
51.7 \\
52.4 \\
53.0\end{array}$ & $\begin{array}{l}130 \\
131 \\
132 \\
133 \\
134\end{array}$ & $\begin{array}{l}82.4 \\
83.0 \\
83.6 \\
84.2 \\
84.9\end{array}$ & $\begin{array}{l}180 \\
181 \\
182 \\
183 \\
184\end{array}$ & $\begin{array}{l}114.6 \\
115.2 \\
115.8 \\
116.5 \\
117.1\end{array}$ & $\begin{array}{l}230 \\
231 \\
232 \\
233 \\
234\end{array}$ & $\begin{array}{l}147.0 \\
147.7 \\
148.3 \\
149.0 \\
149.6\end{array}$ & $\begin{array}{l}280 \\
281 \\
282 \\
283 \\
284\end{array}$ & $\begin{array}{l}179.6 \\
180.2 \\
180.9 \\
181.5 \\
182.2\end{array}$ \\
\hline $\begin{array}{l}35 \\
36 \\
37 \\
38 \\
39\end{array}$ & $\begin{array}{l}22.0 \\
22.6 \\
23.3 \\
23.9 \\
24.5\end{array}$ & $\begin{array}{l}85 \\
86 \\
87 \\
88 \\
89\end{array}$ & $\begin{array}{l}53.6 \\
54.3 \\
54.9 \\
55.5 \\
56.2\end{array}$ & $\begin{array}{l}135 \\
136 \\
137 \\
138 \\
139\end{array}$ & $\begin{array}{l}85.5 \\
86.1 \\
86.8 \\
87.4 \\
88.1\end{array}$ & $\begin{array}{l}185 \\
186 \\
187 \\
188 \\
189\end{array}$ & $\begin{array}{l}117.8 \\
118.4 \\
119.1 \\
119.7 \\
120.4\end{array}$ & $\begin{array}{l}235 \\
236 \\
237 \\
238 \\
239\end{array}$ & $\begin{array}{l}150.3 \\
150.9 \\
151.6 \\
152.2 \\
152.9\end{array}$ & $\begin{array}{l}285 \\
286 \\
287 \\
288 \\
289\end{array}$ & $\begin{array}{l}182.9 \\
183.6 \\
184.2 \\
184.9 \\
185.6\end{array}$ \\
\hline $\begin{array}{l}40 \\
41 \\
42 \\
43 \\
44\end{array}$ & $\begin{array}{l}25.2 \\
25.8 \\
26.4 \\
27.1 \\
27.7\end{array}$ & $\begin{array}{l}90 \\
91 \\
92 \\
93 \\
94\end{array}$ & $\begin{array}{l}56.8 \\
57.4 \\
58.1 \\
58.7 \\
59.3\end{array}$ & $\begin{array}{l}140 \\
141 \\
142 \\
143 \\
144\end{array}$ & $\begin{array}{l}88.7 \\
89.3 \\
90.0 \\
90.6 \\
91.3\end{array}$ & $\begin{array}{l}190 \\
191 \\
192 \\
193 \\
194\end{array}$ & $\begin{array}{l}121.0 \\
121.7 \\
122.3 \\
123.0 \\
123.6\end{array}$ & $\begin{array}{l}240 \\
241 \\
242 \\
243 \\
244\end{array}$ & $\begin{array}{l}153.5 \\
154.2 \\
154.8 \\
155.5 \\
156.1\end{array}$ & $\begin{array}{l}290 \\
291 \\
292 \\
293 \\
294\end{array}$ & $\begin{array}{l}186.2 \\
186.9 \\
187.6 \\
188.2 \\
188.9\end{array}$ \\
\hline $\begin{array}{l}45 \\
46 \\
47 \\
48 \\
49\end{array}$ & $\begin{array}{l}28.3 \\
29.0 \\
29.6 \\
30.2 \\
30.8\end{array}$ & $\begin{array}{l}95 \\
96 \\
97 \\
98 \\
99\end{array}$ & $\begin{array}{l}60.0 \\
60.6 \\
61.2 \\
61.9 \\
62.5\end{array}$ & $\begin{array}{l}145 \\
146 \\
147 \\
148 \\
149\end{array}$ & $\begin{array}{l}919 \\
92.6 \\
93.2 \\
93.9 \\
94.5\end{array}$ & $\begin{array}{l}195 \\
196 \\
197 \\
198 \\
199\end{array}$ & $\begin{array}{l}124.3 \\
124.9 \\
125.6 \\
126.2 \\
126.9\end{array}$ & $\begin{array}{l}245 \\
246 \\
247 \\
248 \\
249\end{array}$ & $\begin{array}{l}156.8 \\
157.4 \\
158.1 \\
158.7 \\
1594\end{array}$ & $\begin{array}{l}295 \\
296 \\
297 \\
298 \\
299\end{array}$ & $\begin{array}{l}189.5 \\
190.2 \\
190.8 \\
191.5 \\
192.1\end{array}$ \\
\hline $\begin{array}{l}50 \\
51 \\
52 \\
53 \\
54\end{array}$ & $\begin{array}{ll}31 & 5 \\
32 & 1 \\
32.7 \\
33.3 \\
34.0\end{array}$ & $\begin{array}{l}100 \\
101 \\
102 \\
103 \\
104\end{array}$ & $\begin{array}{l}63.2 \\
63.8 \\
64.4 \\
65.1 \\
65.7\end{array}$ & $\begin{array}{l}150 \\
151 \\
152 \\
153 \\
154\end{array}$ & $\begin{array}{l}95.2 \\
95.8 \\
96.5 \\
97.1 \\
97.8\end{array}$ & $\begin{array}{l}200 \\
201 \\
202 \\
203 \\
204\end{array}$ & $\begin{array}{l}127.5 \\
128.2 \\
128.8 \\
129.5 \\
130.1\end{array}$ & $\begin{array}{l}250 \\
251 \\
252 \\
253 \\
254\end{array}$ & $\begin{array}{l}160.0 \\
106.7 \\
161.3 \\
162.0 \\
162.6\end{array}$ & $\begin{array}{l}300 \\
301 \\
302 \\
303 \\
304\end{array}$ & $\begin{array}{l}192.8 \\
193.4 \\
194.1 \\
194.7 \\
195.3\end{array}$ \\
\hline $\begin{array}{l}55 \\
56 \\
57 \\
58 \\
59\end{array}$ & $\begin{array}{l}34.6 \\
35.2 \\
35.9 \\
36.5 \\
37.1\end{array}$ & $\begin{array}{l}105 \\
106 \\
107 \\
108 \\
109\end{array}$ & $\begin{array}{l}66.3 \\
67.0 \\
67.6 \\
68.2 \\
68.9\end{array}$ & $\begin{array}{l}155 \\
156 \\
157 \\
158 \\
159\end{array}$ & $\begin{array}{r}98.4 \\
99.1 \\
99.7 \\
100.4 \\
101.0\end{array}$ & $\begin{array}{l}205 \\
206 \\
207 \\
208 \\
209\end{array}$ & $\begin{array}{l}130.8 \\
131.5 \\
132.1 \\
132.8 \\
133.4\end{array}$ & $\begin{array}{l}255 \\
256 \\
257 \\
258 \\
259\end{array}$ & $\begin{array}{l}163.3 \\
163.9 \\
164.6 \\
165.2 \\
165.9\end{array}$ & $\begin{array}{l}305 \\
306 \\
307 \\
308 \\
309\end{array}$ & $\begin{array}{l}196.0 \\
196.6 \\
197.3 \\
197.9 \\
198.6\end{array}$ \\
\hline $\begin{array}{l}60 \\
61 \\
62 \\
63 \\
64\end{array}$ & $\begin{array}{l}37.8 \\
38.4 \\
39.0 \\
39.7 \\
40.3\end{array}$ & $\begin{array}{l}110 \\
111 \\
112 \\
113 \\
114\end{array}$ & $\begin{array}{l}69.5 \\
70.1 \\
70.8 \\
71.4 \\
72.0\end{array}$ & $\begin{array}{l}160 \\
161 \\
162 \\
163 \\
164\end{array}$ & $\begin{array}{l}101.7 \\
102.3 \\
103.0 \\
103.6 \\
104.3\end{array}$ & $\begin{array}{l}210 \\
211 \\
212 \\
213 \\
214\end{array}$ & $\begin{array}{l}134.1 \\
134.7 \\
135.4 \\
136.0 \\
136.7\end{array}$ & $\begin{array}{l}260 \\
261 \\
262 \\
263 \\
264\end{array}$ & $\begin{array}{l}166.5 \\
167.2 \\
167.8 \\
168.1 \\
169.5\end{array}$ & $\begin{array}{l}310 \\
311 \\
312 \\
313 \\
314\end{array}$ & $\begin{array}{l}199.3 \\
199.9 \\
200.6 \\
201.3 \\
202.0\end{array}$ \\
\hline $\begin{array}{l}65 \\
66 \\
67 \\
68 \\
69\end{array}$ & $\begin{array}{l}40.9 \\
41.6 \\
42.2 \\
42.8 \\
43.5\end{array}$ & $\begin{array}{l}115 \\
116 \\
117 \\
118 \\
119\end{array}$ & $\begin{array}{l}72.7 \\
73.3 \\
74.0 \\
74.6 \\
75.2\end{array}$ & $\begin{array}{l}165 \\
166 \\
167 \\
168 \\
169\end{array}$ & $\begin{array}{l}104.9 \\
105.6 \\
106.2 \\
106.9 \\
107.5\end{array}$ & $\begin{array}{l}215 \\
216 \\
217 \\
218 \\
219\end{array}$ & $\begin{array}{l}137.3 \\
138.0 \\
138.6 \\
139.3 \\
139.9\end{array}$ & $\begin{array}{l}265 \\
266 \\
267 \\
268 \\
269\end{array}$ & $\begin{array}{l}169.8 \\
170.4 \\
171.1 \\
171.7 \\
172.4\end{array}$ & $\begin{array}{l}315 \\
316 \\
317 \\
318 \\
319\end{array}$ & $\begin{array}{l}202.6 \\
203.3 \\
203.9 \\
204.6 \\
205.3\end{array}$ \\
\hline $\begin{array}{l}70 \\
71 \\
72 \\
73 \\
74\end{array}$ & $\begin{array}{l}44.1 \\
44.7 \\
45.4 \\
46.0 \\
46.6\end{array}$ & $\begin{array}{l}120 \\
121 \\
122 \\
123 \\
124\end{array}$ & $\begin{array}{l}75.9 \\
76.6 \\
77.2 \\
77.9 \\
78.5\end{array}$ & $\begin{array}{l}170 \\
171 \\
172 \\
173 \\
174\end{array}$ & $\begin{array}{l}108.2 \\
108.8 \\
109.5 \\
110.1 \\
110.8\end{array}$ & $\begin{array}{l}220 \\
221 \\
222 \\
223 \\
224\end{array}$ & $\begin{array}{l}140.6 \\
141.2 \\
141.9 \\
142.5 \\
143.2\end{array}$ & $\begin{array}{l}270 \\
271 \\
272 \\
273 \\
274\end{array}$ & $\begin{array}{l}173.0 \\
173.7 \\
174.4 \\
175.0 \\
175.7\end{array}$ & $\begin{array}{l}320 \\
\ldots \\
\ldots \\
\ldots \\
\ldots\end{array}$ & $\begin{array}{c}205.9 \\
\ldots \ldots \\
\ldots \ldots \\
\ldots \ldots \\
\ldots \ldots\end{array}$ \\
\hline $\begin{array}{l}75 \\
76 \\
77 \\
78 \\
79\end{array}$ & $\begin{array}{l}47.3 \\
47.9 \\
48.5 \\
49.2 \\
49.8\end{array}$ & $\begin{array}{l}125 \\
126 \\
127 \\
128 \\
129\end{array}$ & $\begin{array}{l}79.1 \\
79.8 \\
80.4 \\
81.1 \\
81.7\end{array}$ & $\begin{array}{l}175 \\
176 \\
177 \\
178 \\
179\end{array}$ & $\begin{array}{l}111.4 \\
112.0 \\
112.6 \\
113.3 \\
113.9\end{array}$ & $\begin{array}{l}225 \\
226 \\
227 \\
228 \\
229\end{array}$ & $\begin{array}{l}143.8 \\
144.5 \\
145.1 \\
145.8 \\
146.4\end{array}$ & $\begin{array}{l}275 \\
276 \\
277 \\
278 \\
279\end{array}$ & $\begin{array}{l}176.3 \\
177.0 \\
177.6 \\
178.3 \\
179.9\end{array}$ & $\begin{array}{l}\cdots \\
\cdots \\
\cdots\end{array}$ & $\ddot{*}$ \\
\hline
\end{tabular}

Preparation of Soxhlet's Modification of Fchling's Solution.-1. Dissolve 34.639 grams of $\mathrm{CuSO}_{4}, 5 \mathrm{H}_{2} \mathrm{O}$ in water and make up to 500 c.c.

${ }^{1}$ Adapted from Leach. 
2. Dissolve 178 grams of Rochelle salts and 50 grams of $\mathrm{NaOH}$ in water and make up to 500 c.c.

3. Mix equal volumes of Nos. 1 and 2 immediately before use.

Determination.-Mix 50 c.c. of the mixed copper reagent in a beaker and heat to the boiling-point. While boiling add 100 c.e. of the mill solution and boil for six minutes. Filter immediately through asbestos and determine the amount of copper reduced by hydrogen or by an electrolytic process. Obtain the weight of lactose equivalent to the weight of copper found from the table on page 193 .

Leach prefers the method of O'Sullivan and Defren for the gravimetric determination of lactose, and gives the following directions: "25 grams of the milk sample $(24.2$ c.c.) are transferred to a 250-c.c. flask, 0.5 c.c. of a 30 per cent. solution of acetic acid are added, and the contents well shaken. After standing för a few minutes about 100 c.c. of boiling water are run in, the contents again shaken, 25 c.c. of alumina cream are next added, the flask shaken once more, and set aside for at least ten minutes. The supernatant liquid is then poured upon a previously moistened ribbed filter, and finally the whole contents of the flask are brought thereon, and the filtrate and washings made up to 250 c.c. The filtrate must be perfectly clear. The milk-sugar in a solution thus prepared would ordinarily not exceed 0.5 to 1 per cent.

"Twenty-five c.c. of the milk-sugar solution are added to a hot mixture of 15 c.c. each of Fehling's copper and alkali solution and 50 c.c. of water. The cupric oxid is filtered off and weighed. By multiplying the weight with 0.6024 the amount of anhydrous milksugar is obtained." For more accurate results the table on page 194 should be used.

Volumetric Method.-" Twenty c.c. of raw milk are diluted with water to a volume of 400 c.c. and a few drops of a 10 per cent. solution of acetic acid added. The amount of acetic acid may vary between 8 and 16 drops. After the precipitate has settled, it is filtered off and washed with cold water. The filtrate is boiled in a flask and the albumin precipitated. This is filtered off also and the precipitate washed with cold water. The filtrates and wash water are mixed and measured accurately. A portion of the filtrate is placed in a buret, and this run into a boiling mixture of 20 c.c. Fehling's solution and 80 c.c. water. After the copper has been completely precipitated the number of cubic centimeters used is read. Twenty c.c. Fehling's solution correspond to 0.135 gram milk-sugar.

The milk-sugar solution prepared for the O'Sullivan and Defren method, or the solution from the casein and albumin determination given on p. 184 can be used for titration. To facili- 
tate recognition of the end-point a solution of potassium ferrocyanid and acetic acid can be used or a piece of filter paper moistened with this solution.

A somewhat simpler method of determining the milk-sugar by reduction of a copper solution is Pavy's method, as modified by Long. The solution used in this test is made up as follows:

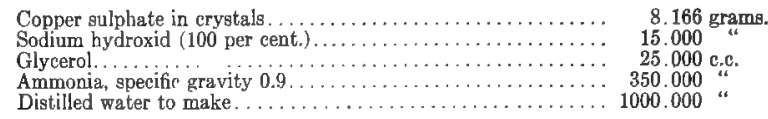

One cubic centimeter of this solution oxidizes $1 \mathrm{mg}$. dextrose or 1.9 $\mathrm{mg}$. lactose in 0.2 per cent. solution.

The technic is as follows: "Measure 50 c.c. of the solution into a flask and dilute to 100 c.c. with water. Add enough pure white paraffin to form a layer 3 to $4 \mathrm{~mm}$. thick when melted. This is to prevent escape of ammonia. Add a few pieces of porous plate to prevent bumping. The tip of the buret is made long enough to pass below the layer of paraffin. By boiling gently and adding the weak saccharine solution slowly until the blue color disappears very close and constant results can be obtained. If the sugar solution is very strong, the reduced copper will not be held in solution unless an inconveniently large volume of ammonia is used. Some practice is necessary to show just how fast the saccharine solution may be safely added. If added too rapidly the end-point may be overlooked and the sugar content appear too low.

"Instead of allowing the tip of the buret to extend below a layer of paraffin, the following method may be employed: Fit a 500c.c. Kjeldahl flask with rubber stopper with two holes. Into one hole insert the tip of the buret and into the other one a Bunsen valve, and proceed as before."

Lactose Determination by a Refractometer.-The apparatus needed for the use of Wollny's refractometer is shown in Fig. 42. Five c.c. of the milk are placed in the sample bottle and 5 drops of a 4 per cent. calcium chlorid solution added. The stopper is then tied on with a string and the bottle placed in a water-bath for ten minutes. After cooling, a small part of the serum is taken up with a pipet and filtered. It is then examined in the refractometer at $17.5^{\circ} \mathrm{C}$.

\section{Determination of Acidity in Milk}

Milk freshly drawn from the udder contains no free acid, but gives an acid reaction when phenolphthalein is used as an indicator. This is due to the presence of acid phosphates and per- 
haps to dissolved carbon dioxid gas. The amount of bound acid thus found is usually from 0.07 to 0.1 per cent., expressed in lactic acid. To litmus paper fresh milk reacts amphoteric by turning blue paper red and red paper slightly blue.

Within a short time after milking the acidity increases perceptibly, due to bacterial activity. The increase during the first few hours is usually slow, but soon becomes more marked. The degree of bacterial contamination and the temperature at which the milk is kept are the chief factors influencing acid formation. Therefore the amount of acid depends in a measure on the cleanliness of production and the temperature at which milk is kept. For this reason the determination of acid in milk is often an important factor in judging the quality of milk.

Furthermore, tests for acidity are of value to the butter and cheese makers, whose products are largely influenced by the amount of acid present in cream and milk. According to the richness of cream an acidity of 0.5 to 0.7 per cent. is most conductive to yield butter of good quality.

Acidity in milk can be measured by several methods which depend upon neutralizing the acid with solutions of sodium hydrate, the neutral point being indicated by the use of phenolphthalein. Soxhlet mixed 2 c.c. of a 2 per cent. alcoholic solution of phenolphthalein with 50 c.c. of milk and titrated this mixture with one-fourth normal sodium hydrate solution. The number of cubic centimeters of the one-fourth normal sodium hydrate solution necessary to cause the first permanent pink color to appear, multiplied by 2 , were recorded as degrees of acidity. In this country the most popular tests are those of Manns, Van Norman, Publow, Marshall, and Farrington.

Manns' Test.-The "neutralizer" used in Manns' test is a 0.1 normal sodium hydrate solution and the indicator is prepared by dissolving 10 grams phenolphthalein in 300 c.c. 90 per cent. alcohol. The milk is measured in a 50-c.c. pipet. The neutralizer is slowly discharged from a buret into the milk containing a few drops of the indicator. The result is expressed in per cent. lactic acid and is obtained by multiplying the number of cubic centimeters of the neutralizer used by 0.009 , dividing the result by the number of cubic centimeters of the sample, and then multiplying this result by 100 . When 50 c.c. milk are used the number of cubic centimeters of neutralizer used is multiplied by 0.018 (Fig. 69).

Van Norman's Test.-The milk is measured in a 17.6-c.c. pipet, placed in a cup, a few drops of phenolphthalein solution added, and the mixture titrated with 0.02 normal sodium hydrate solution. Each cubic centimeter of the sodium hydrate solution corresponds to 0.01 per cent. acid. 
Publow's Method.-9 grams of milk with addition of a few drops phenolphthalein solution are titrated with 0.1 normal sodium hydrate solution. Each cubic centimeter of the sodium hydrate solution neutralizes 0.1 per cent. acid.

Marshall's Test.-According to this method 9 grams of milk are titrated with 0.1 normal sodium hydrate solution, the same as in the previous test. The alkaline solution is contained in a bottle with a buret and pressure bulb attached (Fig. 70). The buret has graduations of 0.2 , and the alkali is furnished in dry form so that

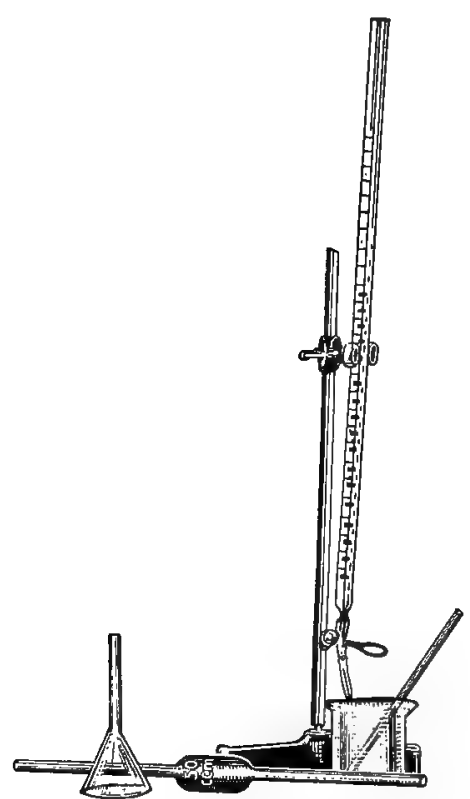

Fig. 69.-Apparatus used in Manns' test (Farrington and Woll).

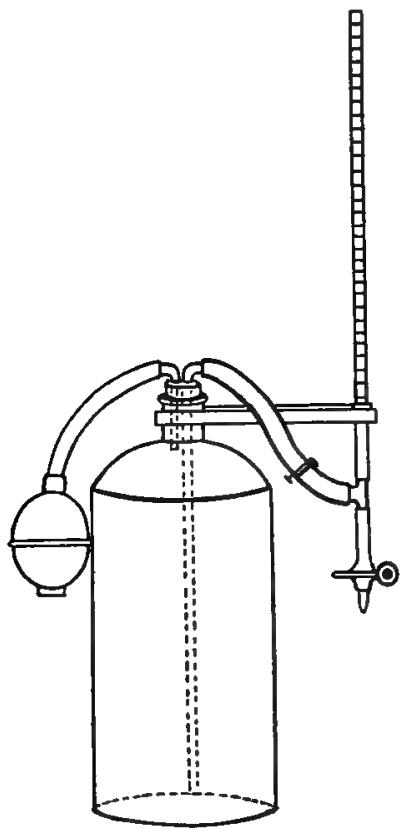

Fig. 70.-Convenient apparatus for acidity testing (Van Slyke).

the contents of one package by addition of water make 1000 c.c. 0.1 normal sodium hydrate solution.

Farrington's Alkali Tablet Method.-This method has found great favor because of its simplicity, enabling those inexperienced in chemical work to make the test accurately. Each tablet contains enough alkali to neutralize 0.035 gram lactic acid, and a small amount of phenolphthalein is incorporated. If five tablets are dissolved in enough water to make the solution measure 85 c.c. each cubic centimeter of the solution used in neutralization represents 0.01 per cent. acid when 20 c.c. of milk are used. When 
17.5 c.c. of milk are used the solution is made up by dissolving five tablets in 97 c.c. of water. This is equal to a 0.02 normal alkali solution, and each cubic centimeter of the solution represents 0.01 per cent. of acid when 17.5 c.c. of milk are used (Fig. 71).

Spillman's Modification of Farrington's Test.-Five tablets are dissolved in "Spillman's acid test cylinder" (Fig. 72) filled with water to the 8 mark. The solution is placed in a well-closed container (fruit jar). In a cup is placed 17.6 c.c. of the milk to be tested and the tablet solution added until the pink color is perma-

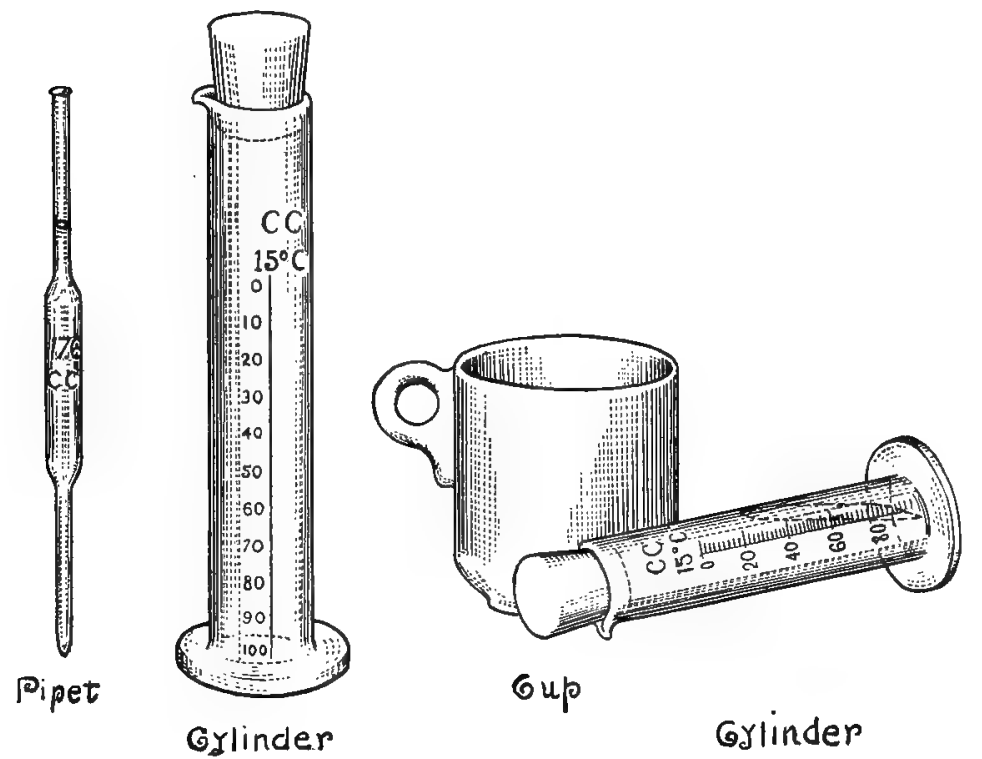

Fig. 71.-Apparatus used for determining the acidity of cream or milk (Farrington and Woll).

nent. The contents of the cup are then poured into the Spillman cylinder and the mark at the surface noted. The figure expresses the acid in tenths per cent.

The acidity of milk is frequently expressed in degrees. Unfortunately, there is no general agreement as to a standard degree. Soxhlet's degrees represent the number of cubic centimeters of one-fourth normal sodium hydrate solution necessary to neutralize 100 c.c. of milk. Others take the number of cubic centimeters of one-tenth normal solution required to neutralize 25 or 50 c.c. of milk. Uniformity of expression is best accomplished, perhaps, by using lactic acid as a basis. This is obtained by multiplying the 
number of cubic centimeters of normal alkali used for neutralization of 100 c.c. of milk by 0.009 .

Titration of milk for acid content by means of accurate chemical methods is accompanied by some sources of error. Some chemists recommend diluting the milk with water to facilitate recognition of the end-point. However, an error is introduced by the addition of water, because alkaline phos-

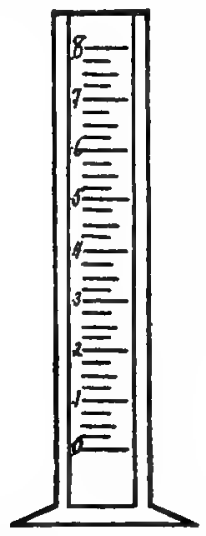

Fig. 72.-Spillman's acid-test cylinder (Van Slyke). phates are more easily soluble in diluted than in normal milk. On the other hand, if milk is titrated undiluted, the end-point of phenolphthalein is not as sharp as in diluted milk and the acid may be overestimated. By heating milk some of the acid phosphates are precipitated and the carbon dioxid gas is lost, with the result that lower figures are obtained than when raw milk is titrated.

\section{The Milk Sediment Test}

A test for visible dirt or sediment in milk is valuable in giving a general idea of the methods practised in the production of the milk. Dirt is a carrier of bacteria and, therefore, should be kept out of milk as far as possible. Aside from the possibility of introducing disease germs with dirt, the flavor of milk and milk products is materially depreciated by its presence.

The insoluble matter which settles to the bottom in bottles or which is shown to be present by filtration of milk does not represent the whole amount of dirt actually present, to be sure. A portion of the dirt goes into solution and escapes detection. Therefore any test for visible dirt has no claim to scientific accuracy. This is further emphasized by the variability in the amount of soluble material contained in the polluting material. Cow manure is unquestionably the most important factor in furnishing the dirt that enters milk, although cow hairs and particles from food and bedding are liable to be present. Consequently there will be relatively more insoluble dirt in the milk when cows are stabled and live largely on stored fodder than in spring and summer, when succulent fodder is abundant. The feces, as a rule, are softer in summer than in winter and contain more soluble material.

Any quantitative determination of insoluble dirt in milk is not absolute, but only relative. However, practice has shown that much can be accomplished by a regular test for milk sediment. - Dealers and butter and cheese makers have used a sediment test 
with advantage to improve the product of their patrons. In the opinion of some practical men the sediment test has done more for cleanly milk production than any other single factor. The dealer makes the test and records the results on a pledget of cotton fastened to a card (Fig. 73). This is given to the patron,

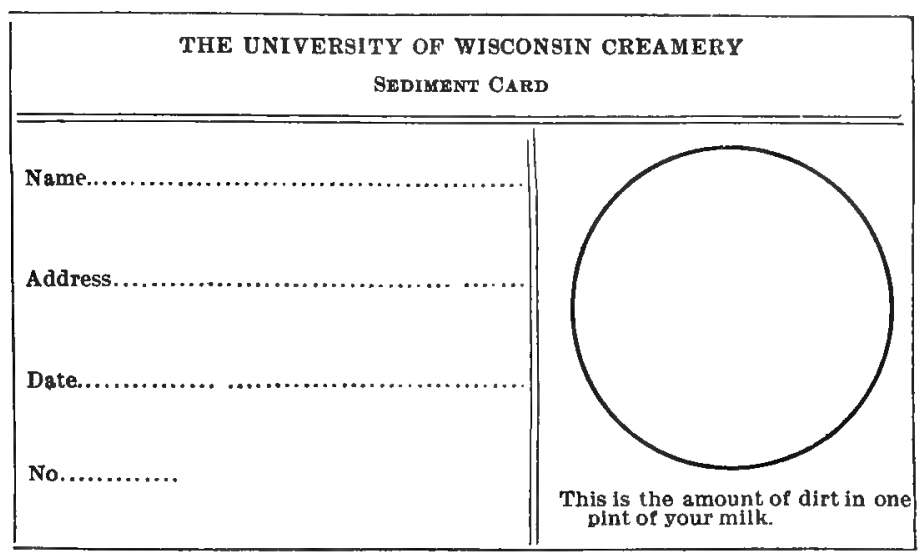

Fig. 73.-Sediment card. (Circular of Information No. 41, September, 1912, (Tniv. of Wis. Agri. Exp. Sta.)

who then actually sees the dirt which has been filtered out of his milk, and a rivalry among producers is started which ultimately leads to a greatly improved milk-supply.

Reiss and Sommerfeld give the following average amounts of visible dirt found in the milk-supplies of some European cities:

AMOUNT OF DIRT IN MILK IN SOME EUROPEAN CITIES,

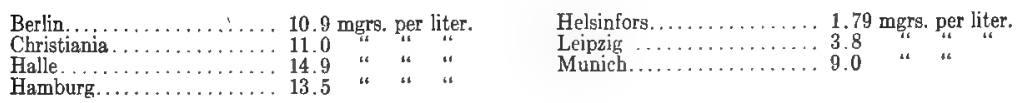

The writer, in an investigation of Chicago milk, found that the average amount of dirt in 108 samples of raw milk was 2.2 mgrs. per liter, and in 107 samples of pasteurized milk, 1.4 mgrs. per liter. The amount in raw milk never exceeded 9 mgrs., and in pasteurized milk 6 mgrs., per liter.

It should be remembered in this connection that the introduction of centrifugal clarifiers has in large measure reduced the amount of visible dirt in market milk.

Rough tests of the quantity of milk sediment can be made by allowing the milk to stand for several hours in a conical glass vessel so that the dirt accumulates in the apex; or by centrifuging a small amount of the milk in a tube with a conical bottom. 
Several methods which permit the quantity of dirt to be measured with some degree of accuracy have been introduced. Renk's

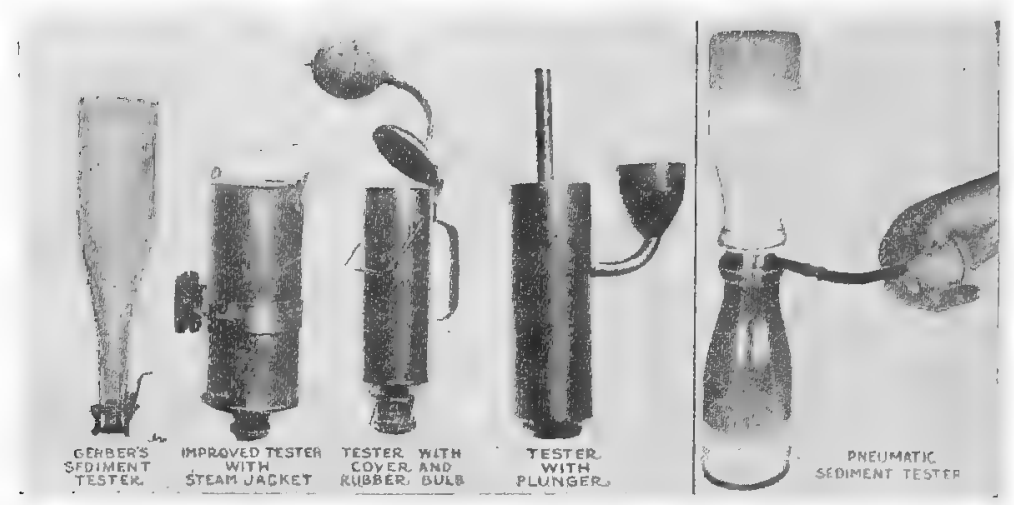

Fig. 74.-Milk sediment test. (Circular of Information No. 41, Univ. of Wis. Agri. Exp. Sta.)

method is this: Allow the dirt of 1 liter of milk to settle, decant the milk; wash the sediment by decantation, and collect it on a

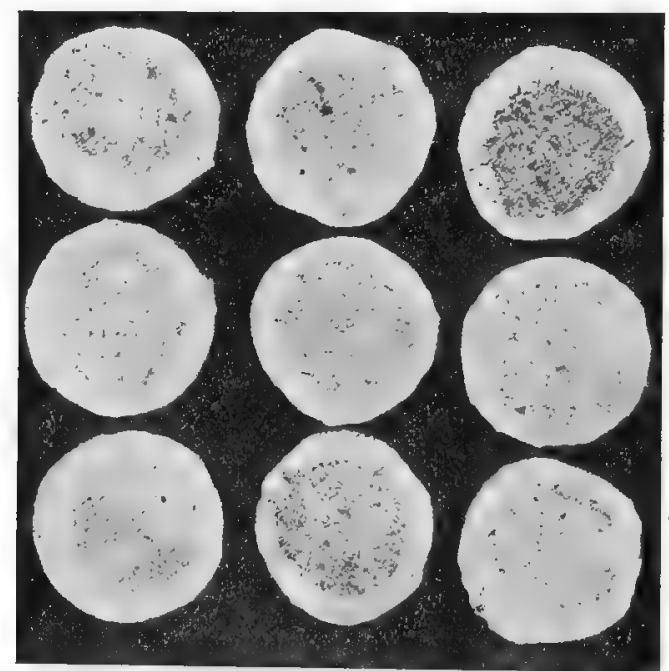

Fig. 75.-Sediment in 1 pint of market milk. (Circular of Information No. 41, Univ. of Wis. Agri. Exp. Sta.)

filter. Then wash the residue on the filter with alcohol and ether, desiccate, and weigh.

The method of Renk was modified by Stutzer in the following manner: A liter of milk is filled in a bottle which is connected 
with a strong test-tube by means of a rubber hose. The bottle is inverted and kept in this position for several hours. The dirt collects in the tube, which can be removed after closing the rubber hose with a pinch-cock. The dirt in the tube is then treated as described above.

Gerber used a 500-c.c. flask without a bottom, and connected the neck by means of a rubber hose with a glass tube having a narrow graduated end. By this process the dirt collects in the graduated portion of the glass tube and can be measured.

Fliegel introduced a new test based on principles different from those of previous ones. The apparatus consists of a cylindric

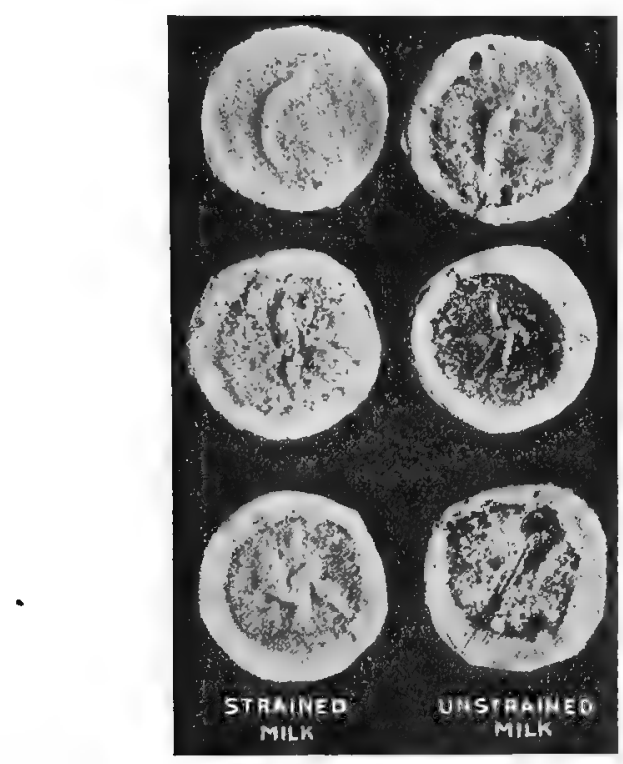

Fig. 76.- Sediment in 1 pint of milk at the farm. (Wisconsin Circular No. 41.)

vessel which rests on a piece of wire gauze covered with a layer of absorberit cotton: the wire gauze, in turn, rests on a beaker or similar vessel. The milk is poured into the cylinder and filtered through the cotton, leaving the insoluble dirt on the cotton in spots below the holes of the cylinder. Comparative estimations of the quantity of insoluble dirt can be made by this method and the results preserved for future reference.

A practical apparatus for estimating suspended dirt in milk, the Lorenz sediment tester, has been devised by Babcock and Farrington (Fig. 74). The milk is filtered through a small pledget of absorbent cotton and the cotton pasted on a clean piece of 
white paper for comparison with standards. The efficiency of the tester depends largely upon the temperature of the milk, as hot milk filters more rapidly than cold milk. The Lorenz sediment tester is provided with a jacket to hold hot water so as to keep the milk hot. The pledget of cotton is supported by a piece

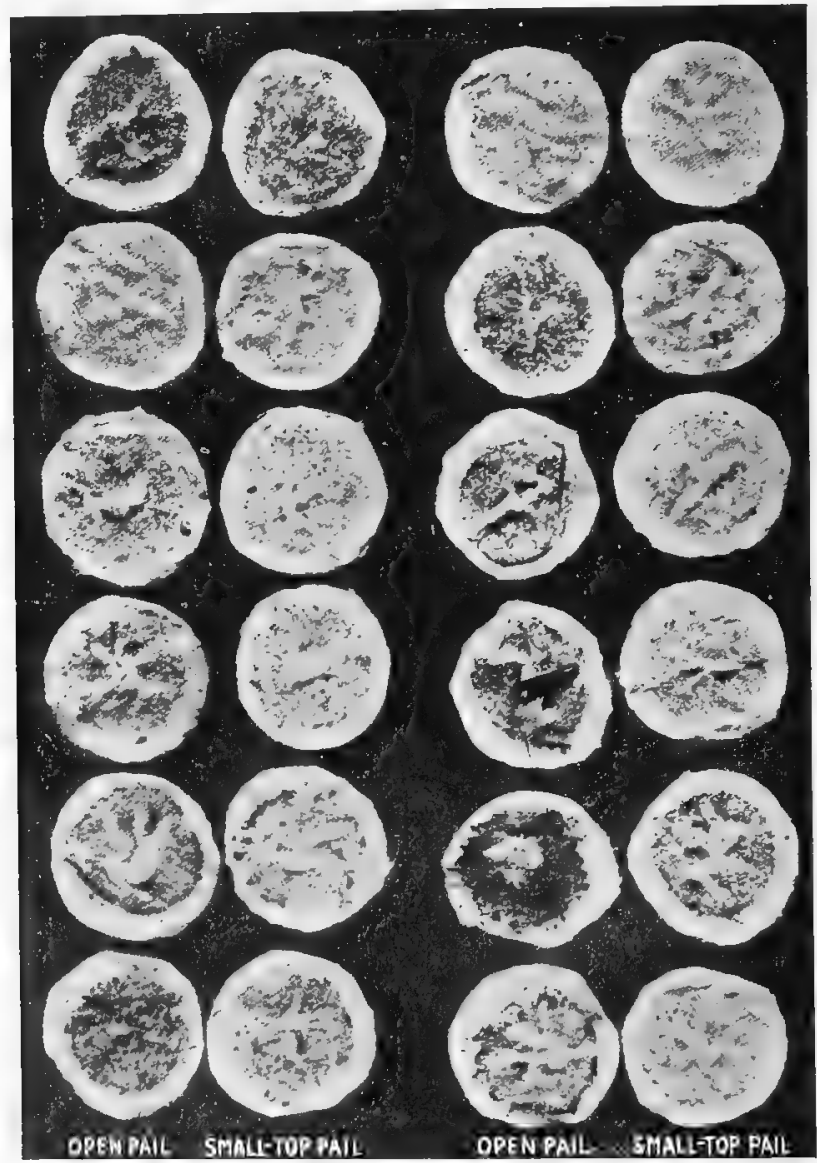

Fig. 77.-Sediment from open and small-top pails. (Wisconsin Circular No. 41.)

of wire gauze and must be of the best quality, free from fat and other substances which might interfere with rapid filtration of the milk. The appearance of pledgets of cotton with the accumulated dirt from milk obtained under a variety of conditions is illustrated in Figs. 75-79. The pledgets are pasted on clean white paper and compared with standards for quantitative estimation. The 
standards are prepared as follows: One gram of pulverized cow manure is suspended in a liter of filtered or distilled water and

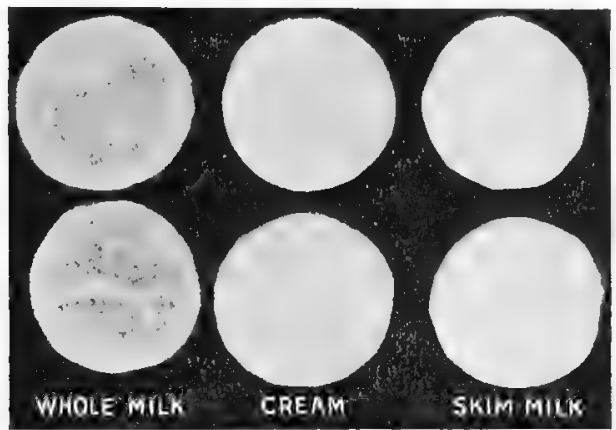

Fig. 78. - Sediment in milk before and after separating. The left column shows sediment from a pint sample of whole milk. The center shows that there is no sediment in newly separated cream from the same milk, and the right shows the test for the skimmed milk. This test was made at the factory. (Wisconsin Cireular No. 41.)

definite quantities of this suspension passed through the cotton pledgets so as to leave the following amounts of cow manure: $\frac{1}{2}$ milligram, 1 mgr., 2 mgrs., and so on to $10 \mathrm{mgrs}$.

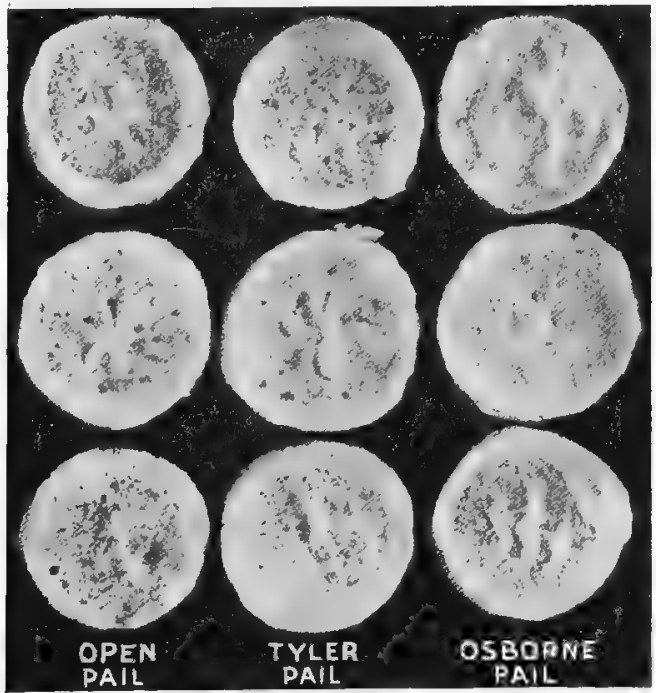

Fig. 79.-Open-top pails catch dirt. The larger the open top, the more dirt it catches. (Wisconsin Circular No. 41.)

A simple apparatus for testing the sediment in milk has been devised by Tonney. A Gooch crucible is fastened in the mouth 


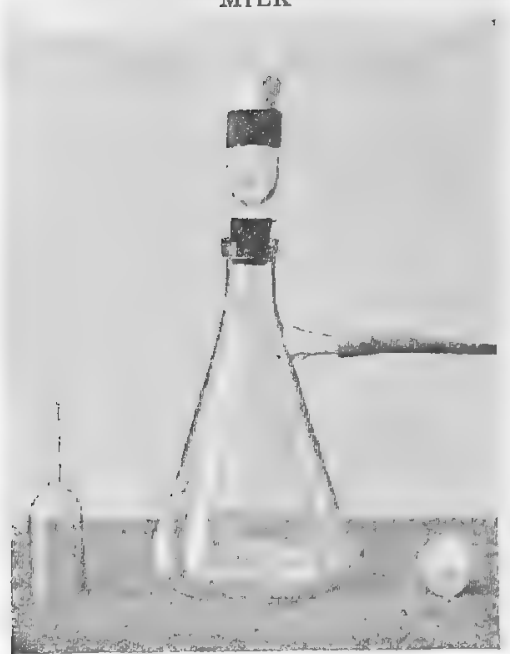

Fig. 80-Gooch filtering apparatus, showing also unassembled parts, e.g., porcelain Gooch crucible, with perforated sieve bottom, glass Gooch funnel, and pressure tubing leading to Chapman pump. (Tonney, Amer. Jour. of Public Health, 1912, vol. 2, p. 280.)

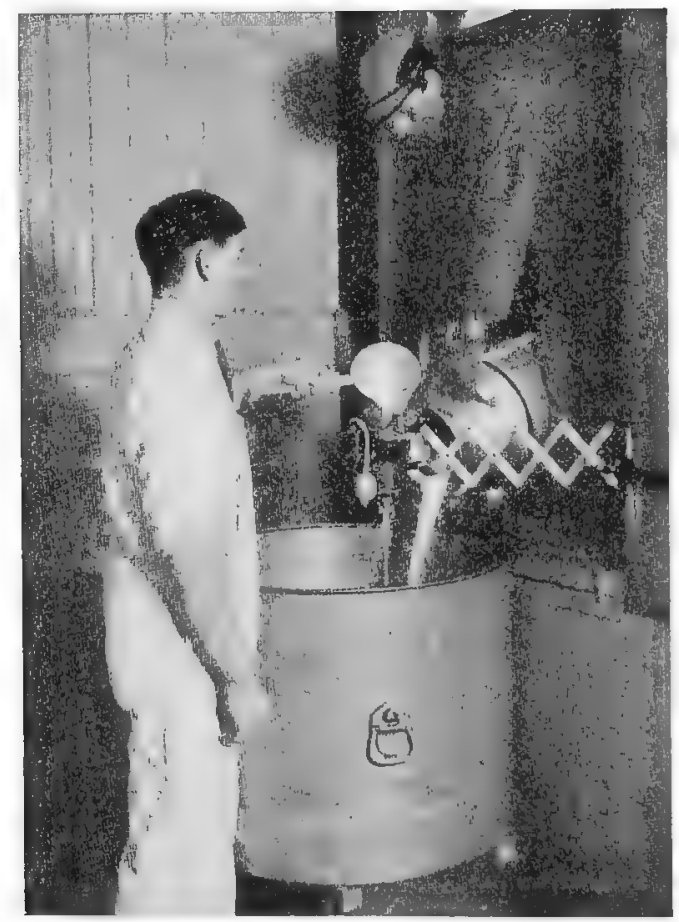

Fig. 81.-A simple aid to sediment testing. This convenient method of fastening the sediment tester by means of a telephone bracket is a handy time saver. (Bull. 241, July, 1914, Univ. of Wis. Agri. Exp. Sta.) 
of a flask provided with a side tube in such manner that there can be no air suction through the neck of the bottle. The pledget of cotton is placed on the bottom of the crucible and moistened with a few drops of water or milk to prevent slipping of the cotton. The milk is then poured into the crucible and filtered through the cotton. As the cotton soon clogs with fat, filtration is aided by suction through the side arm of the flask (Fig. 80).

A convenient arrangement for making sediment tests is illustrated in Fig. 81. The apparatus is held by a telephone bracket, and can be moved back and forth as desired.

\section{TEST FOR VISCOSITY}

The viscosity of milk can be measured by two simple methods. One of these consists in allowing a definite amount of water to run from a pipet, and noting the time required to completely discharge the amount. Then the same amount of milk is discharged from the same pipet, and the time required for complete discharge compared with the time required by the water. The second method consists in allowing a few drops of the milk or cream to run down an inclined piece of glass, and measuring the distance covered in a definite length of time. The following table, which gives the variation of viscosity according to temperature, may serve as standard:

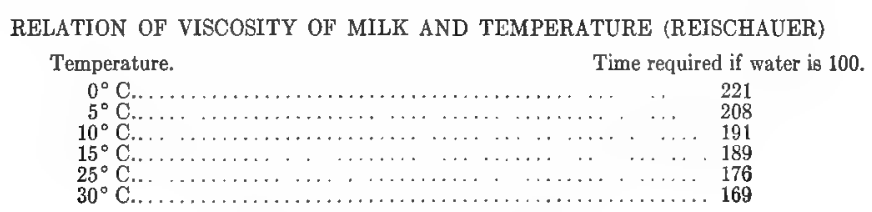

\section{Testing Milik by Rennet}

The cheese maker is interested to know the exact degree of ripeness at which to add rennet extract to the milk. The tests designed to serve this purpose are based on the speed of rennet action. Two tests are in practice, namely, the Monrad and the Marschall tests.

The Monrad Test.-Five c.c. of rennet extract of known strength are placed in a 50-c.c. flask and the remains of the rennet in the pipet washed with water into the same flask. The rennet is then diluted with water to 50 c.c. and the contents mixed by shaking. A graduated cylinder is filled to the 160 c.c. mark with the milk to be tested and this is then emptied into an open vessel. The temperature of the milk should be $30^{\circ} \mathrm{C}$. $\left(80^{\circ}\right.$ to $86^{\circ} \mathrm{F}$.). To the milk are then added 5 c.c. of the diluted rennet extract 
and the mixture is stirred with a thermometer. The time elapsing between addition of the rennet extract and coagulation of the milk is noted accurately. By floating a few dark particles on the surface of the milk and setting the milk in motion with the thermometer, the exact moment when coagulation takes place can be sharply noted by the arrested motion of the particles. For Cheddar cheese making coagulation should be complete in thirty to sixty seconds.

The Marschall Test.-One c.c. of rennet extract is measured into an ounce bottle, previously half filled with water. The pipet is rinsed by drawing up the water two or three times. The milk is placed in a cup of pint capacity which has graduated spaces from 0 at the top to 7 at the bottom. In the bottom is fastened a metal tube of small bore. The milk will flow through the tube, and as soon as the surface has reached the 0 mark the rennet will quickly mix with it. As long as the milk is liquid it will continue to flow through the tube. When coagulated the amount of milk that has escaped will be indicated by the graduated scale. When two and one-half spaces are uncovered the milk will be in suitable condition for cheese making.

Hastings and Evans think that the rennet test is superior to the acid test for determining the ripeness for Cheddar cheese making.

The age of milk can also be determined in a rough manner by a rennet test, because milk coagulates more rapidly in proportion to the increase in the amount of acid present.

Commercial pepsin is used to some extent in place of rennet extract. This can be used for the tests described if 5 grams of socalled $1: 3000$ pepsin are dissolved in 120 c.c. of water. This solution can be used like rennet extract.

\section{The Alcohol Test}

The alcohol test for acidity is used to some extent abroad, but has not found much favor in this country. Normal fresh milk should not coagulate when mixed with an equal amount of 68 per cent. alcohol. If curdling takes place with this amount of alcohol, the acidity is assumed to be about 0.25 per cent. expressed as lactic acid. Ayers and Johnson have found that the test is not as reliable as has been believed. Milk may curdle when mixed with alcohol even when the acidity is low, as other conditions may produce coagulation of the casein. A positive test with an equal volume of 68 per cent. alcohol means something abnormal in the milk, and the cow producing such milk should be examined. The test may also be positive when rennet-producing bacteria are present. The coagulation may, therefore, be the result of the 
presence of acid, rennet, or both. Ayers and Johnson could find no relation between a positive alcohol test and any of the following conditions:

1. Large numbers of bacteria.

2. Large numbers of streptococci.

3. Large numbers of cellular elements. bined.

4. Large numbers of cellular elements and streptococci com-

They suggest that the alizarin test may give more valuable information. This test is made as follows: 1.2 grams of fresh alizarin, or 0.4 gram dry alizarin, are dissolved in 1000 c.c. of 68 per cent. alcohol. Two. c.c. of this solution are mixed with 2 c.c. of the milk to be tested. The condition of the milk is judged by the color developed, as alizarin is very sensitive to acids. Ayers and Johnson give the following table as a result of their tests with alizarin-alcohol solutions:

REACTION OF MILK WITH ALCOHOLIC SOLUTION OF ALIZARIN

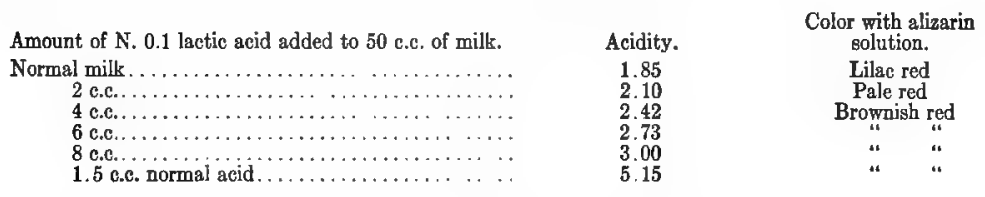

Van Slyke states that when equal parts of fresh normal milk and alcohol (spec. grav. 0.89) are mixed, there is no change, but that when old milk or milk from diseased udders is used, there is more or less coagulation of casein. The author states further that there is no close relation between the alcohol test and real acidity of milk, though milk containing more than 0.21 per cent. of acid commonly gives a marked precipitation.

In regard to the alizarol test, Van Slyke adds that when 2 c.c. of the alizarol solution are mixed with an equal volume of milk, an intense reddish color develops similar to that of lilac or red clover blossoms. Morres gives the following color reactions according to the amount of acid in milk:

COLOR REACTIONS IN MILK WITH ALIZAROL SOLUTION

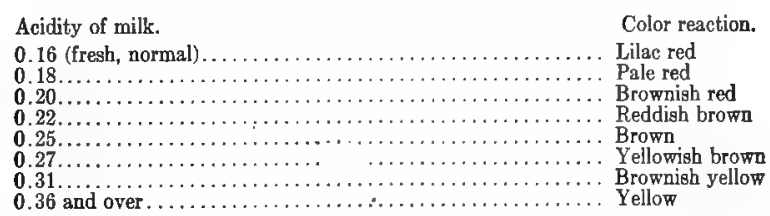

On the whole, it would seem that neither the alcohol test nor the alizarin modification are of much practical value. 


\section{Albumin Test for Heated Milk}

When milk is heated to $65.6^{\circ} \mathrm{C}$. albumin begins to be coagulated. At this temperature the amount is small, but at higher temperature the amount of coagulated albumin is considerable. If the casein is precipitated by acetic acid and the clear filtrate boiled, albumin is precipitated. In the boiled filtrate from milk heated above $65.6^{\circ} \mathrm{C}$. the amount of precipitated albumin is less than in that from raw milk. If the milk has been heated to much higher temperatures the albumin is completely coagulated, and therefore the filtrate from the acetic acid precipitate yields no precipitate after boiling.

\section{Chemical Tests to Distinguish Human Milk from Cow's Milk}

1. Human milk mixed with ammonia and kept at room temperature turns reddish violet; the larger the amount of ammonia added, the more intense the color. Cow's milk produces no such color with ammonia.

2. When equal amounts of human milk and a 1 per cent. solution of silver nitrate are heated to boiling a brown color develops which has a touch of violet in it. Cow's milk with silver nitrate solution develops no color or, at best, a very faint one.

3. A 1 per cent. solution of neutral red in physiologic salt solution produces a red color in cow's milk and a yellow color in human milk. A few drops of the solution added to several cubic centimeters of milk will produce this reaction.

\section{Fermentation Tests}

Fermentation tests are designed to enable the cheese maker to judge the condition of the milk that is to be used for cheese making. Undesirable bacteria sometimes are present in large numbers, and their early detection may prevent financial loss. When the curd is abnormal it becomes expedient to trace the trouble to its origin. It may be that a single cow in the herd is responsible for a contaminated milk. By testing the milk from each cow the real source of the abnormal milk can be found, and the milk can be excluded until it appears to be normal again.

In countries where cheese is made on a large scale, Switzerland for example, tests for the purpose of detecting abnormal curds have been practised for some time. These tests consist in curdling a small portion of milk and examining the curds. The test known as the Wisconsin curd test was worked out in the Wisconsin Agricultural Experiment Station, and is carried out as follows: Pint jars provided with covers are sterilized in live steam and filled to two-thirds their capacity with the milk samples to be tested. 
They are then immersed in water at a temperature of $38^{\circ}$ to $39^{\circ} \mathrm{C}$. $\left(100^{\circ}\right.$ to $102^{\circ} \mathrm{F}$.). By giving the jars an occasional rotary motion the temperature soon rises, and when the thermometer shows that the milk has reached $37^{\circ} \mathrm{C}$. $\left(98^{\circ} \mathrm{F}\right.$.) 10 drops of rennet extract are added to each jar. The thermometer used to determine the temperature of the milk must be scalded for each jar so as to avoid infecting one sample of milk from another. After the milk has coagulated it is allowed to stand for about twenty minutes. The curd is now firm, and is cut with a knife, which must be sterilized for each jar. The whey is liberated and the curd settles rapidly. The sample is then tested with the senses and the whey poured off. Additional whey that separates within the succeeding six to twelve hours is poured off at intervals. Finally, after the last whey has been removed, the curd is tested. It is cut into pieces and, if normal, should be firm and free from holes. A spongy consistency indicates activity of gas-producing organisms, chiefly of the Bacillus coli and B. aërogenes type. When gas is formed the curd is filled with small holes, "pin-holes," and forms the so-called "floating" or "gassy" curd. The odor of the curd may betray the presence of undesirable organisms which, while they do not produce gas, may impart an unpleasant flavor to the cheese.

Gerber's fermentation test was designed for a purpose similar to that of the Wisconsin curd test. For making this test the milk is placed in tubes, heated for six hours at $40^{\circ}$ to $41^{\circ} \mathrm{C}$. $\left(104^{\circ}-\right.$ $106^{\circ} \mathrm{F}$.), and then the taste, odor, and general appearance obobserved. The milk is again heated for six hours at the same temperature. If it coagulates during the second heating period, it is considered abnormal.

\section{BIBLIOGRAPHY}

Ayers and Johnson: United States Dept. of Agri., Bull. 202, May, 1915.

Babcock: Univ. of Wis. Agri. Exp. Sta., Bull. 24, July, 1890.

Babcock and Farrington: Univ. of Wis. Agri. Exper. Sta., Bull. 195, February, 1910.

Baer: Univ. of Wis. Agri. Exper. Sta., Circular of Information 41, September, 1912.

Baer: Univ. of Wis. Agri. Exper. Sta., Bull. 241, July, 1914.

Benkendorf, Bruhn, Baer, and Sammis: Univ. of Wis. Agri. Exper. Sta., Bull. 241, July, 1914.

Decker: Univ. of Wis. Agri. Exp. Sta., 16th Annual Report, 1899, p. 155.

Farrington: Univ. of Wis. Agri. Exper. Sta., Bull. 129, September, 1905.

Farrington and Woll: Testing Milk and Milk Products.

Fleischmann: Lehrbuch der Milchwirtschaft.

Hart: Univ. of Wis. Agri. Exper. Sta., Bull. 156, November, 1907.

Hart, Suzuki, and Sammis: Univ. of Wis. Agri. Exper. Sta,, Research Bull. 10, May, 1910.

Hastings and Evans: United States Dept. of Agri., B. A. I., Circular 210, April 10, 1913.

Heinemann: Reprint from the Transactions of the 15th international Congress of Hygiene and Dermography. 
Leach: Food Inspection and Analysis.

Long: Physiological Chemistry,

McCann: Agri. Exper. Sta, of the Colorado Agri. College, Bull. 202, November, 1914.

Official and Provisional Methods of Analysis: Association of Official Agricultural Chemists, United States Dept. of Agri., Bull 107.

Reiss and Sommerfeld: Sommerfeld, Handbuch der Milchkunde.

Richmond: Dairy Chemistry.

Rinkle: Univ. of Missouri, College of Agri. Exp. Sta., Circular 64, July, 1913.

Russell: Univ. of Wis. Agri. Exper. Sta., Circular of Information 32, March, 1912.

Russell and Hastings: Outlines of Dairy Bacteriology.

Sammis: Univ. of Wis. Agri. Exper. Sta., Circular of Information 27, July, 1911.

Sammis: Univ. of Wis. Agri. Exper. Sta., Bull. 195, 1910.

Shaw: Chemical Tests of Milk and Cream, United States Dept. of Agri., B. A. I., February, 1916.

Shaw and Eckles: United States Dept. of Agri., Bull. 134, 1911.

Tonney: Amer. Jour. of Public Health, 1912, vol. 2, p. 280.

Van Slyke: Modern Methods of Testing Milk and Milk Products, Orange Judd. Co., 1915.

Webster: United States Dept. of Agri., B. A. I., Bull. 58, 1904. 


\section{ADULTERATIONS OF MILK}

Although adulterations and preservatives are no longer commonly used, they are still a source of temptation to some. Fraudulent intent and the pressure of legislation sometimes induce producers to take refuge in adulterating their product and in using preservatives so as to prolong the salable character of the milk. The addition of chalk, calves' brains, starch, glycerin, and similar substances, for the purpose of restoring solids and viscosity when the milk has been tampered with, need no consideration. Their application has never been common and is largely mythical, but skimming of milk is probably still practised and the addition of water or skimmed milk not uncommon. Tests for such adulterations are, therefore, imperative. However, there is some difficulty experienced in determining fair and reliable standards which give a clear definition of what normal milk ought to be. The fat content, as has been shown, is variable according to the breed of cows from which the milk is obtained and according to a number of other conditions which have been discussed in detail in a former chapter. Furthermore, the milk of some breeds naturally contains less fat than 3 per cent., which is the lowest legal limit usually permitted in this country. On the other hand, the milk of some breeds contains more fat than legally required, and there is the temptation to remove some of the cream from such rich milk, as long as the remaining product averages well within legal limits.

After the milk has been skimmed or watered, thickening agents and coloring-matter are sometimes added in an attempt to restore at least the appearance and consistency of the milk. However, the composition is permanently altered by this addition.

The adulterations of milk which have been detected may be treated under the following heads:

1. Reduction of fat by

(a) Addition of water.

(b) Skimming of milk.

(c) Both watering and skimming.

2. Addition of thickening agents to restore consistency, viscosity, and solids.

3. Addition of coloring-matter to restore color lost by skimming or diluting, or to make naturally poor milk appear rich.

4. Addition of preservatives. 


\section{Detection of Watered Milk, Skimmed Milk, or Both Watered aNd SKIMMed MilK}

The addition of water involves dilution of the product and the danger of introducing germs with polluted water. It is conceivable, and actually has happened, that water containing pathogenic bacteria has been added to the milk or has been used for washing utensils which held milk. The addition of skimmed milk is of relatively small sanitary importance, but it cheapens the product.

When skimmed, milk has a higher specific gravity, and when diluted with water the normal specific gravity is restored. The solids, however, are reduced, and by determining the solids the condition of tampered milk is revealed. The specific gravity increases about 0.001 for each per cent. of fat removed, and decreases 0.003 for each 10 per cent. of water added. Each 10 per cent. of water reduces the solids about 1.2 per cent., as shown in the following table (Sommerfeld):

THE REDUCTION OF TOTAL SOLIDS WITH ADDITION OF WATER

\begin{tabular}{|c|c|c|c|c|c|c|}
\hline $\begin{array}{l}\text { Per cent. water added } \\
\text { Per cent. solids, . . . } \ldots \ldots \ldots \ldots \ldots \ldots \ldots \ldots \ldots \ldots \ldots \ldots\end{array}$ & $\begin{array}{c}0 \\
12.0 \\
88.0\end{array}$ & $\begin{array}{l}10 \\
10.8 \\
89.2\end{array}$ & $\begin{array}{r}20 \\
9.6 \\
90.4\end{array}$ & $\begin{array}{r}30 \\
8.4 \\
91.6\end{array}$ & $\begin{array}{c}40 \\
7.2 \\
92.8\end{array}$ & $\begin{array}{r}50 \\
6.0 \\
94.0\end{array}$ \\
\hline
\end{tabular}

The addition of water also raises the freezing-point, lowers the index of refraction, and reduces the viscosity.

Skimmed milk is sometimes added to whole milk to increase the producer's profits. The chief difference between milk that has been watered and milk that has been skimmed or milk to which skimmed milk has been added is that in the first instance the relation of milk constituents remains the same, while in the other cases the proportion of the constituents is seriously disturbed. But while skimmed milk or milk diluted with skimmed milk retains the solids in approximately their natural proportion with the exception of the fat, watered milk contains the solids in reduced quantity. Van Slyke gives the following formula for calculating the amount of fat in milk mixed with skimmed milk:

$$
\text { Per cent. of fat removed }=100-\frac{F \cdot \times 100}{3}
$$

F. represents the percentage of fat determined in the suspected milk and the divisor 3 means that the original milk contained 3 per cent. fat. Since whole milk usually contains a greater amount of fat than 3 per cent., the above formula gives results more or less below the real amount of fat removed.

Watering of milk can be detected by various methods. If but small amounts of water are added, its presence may escape discovery, and any quantity of water below 10 per cent. may be 
added without serious danger of detection. If larger amounts of water are added, comparison of the specific gravity, total solids, and plasma solids of the suspected milk with the same factors in normal milk will usually lead to detection. The specific gravity of the solids also aids in revealing the shortage in cream, inasmuch as the solids of whole milk have a lower specific gravity than the solids of skimmed milk, owing to the smaller amount of fat in the latter. Milk has been watered when the specific gravity is below the normal, when the percentage of plasma solids is low, and the specific gravity of the milk solids 1.25 to 1.35 . Milk has been skimmed when the specific gravity of both the milk and the total solids is high, the percentage of fat low, and the percentage of plasma solids high. Milk has been both watered and skimmed when the percentage of fat is low, the specific gravity of the total solids normal or above normal, and the specific gravity of the milk either normal or not.

The lowest percentage of plasma solids permissible has been legally determined in many states and cities. On the basis of such limits, Van Slyke has given formulas for estimating the quantity of water added. However, it should be observed that, since legal standards represent the minimum, the results obtained by these formulas are usually too low. The formulas depend upon the well-known relation of specific gravity, fat, and solids. After the percentage of fat and the specific gravity of the suspected milk have been determined, the plasma solids are calculated and the amount of water estimated according to the formula:

$$
\text { Per cent. of added water }=100-\frac{\text { Per cent. of plasma solids } \times 100}{\text { Legal standard for plasma solids }}
$$

The following formula may also be used:

Per cent. of added water $=100-\frac{\text { Lactometer reading }+ \text { per cent. fat }}{36} \times 100$

Herz gives the following formulas for estimating the amount of water added, the amount of fat removed by skimming, or both, if both conditions exist:

\section{Addition of Water}

The amount of added water contained in 100 parts
of watered milk

The amount of water added to the undiluted milk $=\frac{100\left(r_{1}-r_{2}\right)}{r_{2}}$

Skimmed Milk

The amount of fat removed from the milk $=f_{1}-f_{2}+\frac{f_{2}\left(f_{1}-f_{2}\right)}{100}$ 
Both Skimmed and Watered

The amount of fat removed from the milk =

$$
\mathrm{f}_{1}-\left[100-\left(\frac{\mathrm{Mf}_{1}-100 \mathrm{f}_{2}}{\mathrm{M}}\right)\right] \times\left[\mathrm{f}_{1}-\left(\frac{\mathrm{Mf}-100 \mathrm{f}_{2}}{\mathrm{M}}\right)\right]
$$

In these formulas the letters stand for:

$\mathrm{r}=$ plasma solids.

$\mathrm{f}=$ fat content.

$\mathrm{M}=$ the amount of whole milk contained in 100 parts watered milk.

$f_{1}=$ the per cent. of the normal (barn) milk.

$\mathrm{f}_{2}=$ the per cent. of fat in the suspected milk.

$\mathrm{r}_{1}=$ the per cent. plasma solids in the normal (barn) milk.

$\mathrm{r}_{2}=$ the per cent. plasma solids in the suspected milk.

The index of oxidation of milk has been recommended by Commanducci as a check upon watering milk. A one-tenth normal potassium permanganate solution in acid is placed in a buret and discharged into 1 c.c. of milk. The number of cubic centimeters required to complete the reaction is the index of oxidation, which is uniform for milk from the same species. The index decreases when the milk has been watered, skimmed, or both watered and skimmed. The normal figures as given by the author are these: Cow, 50-52; goat, 44-46; sheep, 43-48; ass, 55-58; human, 53-60.

The lactoscope (Fig. 82) is an instrument designed to estimate the amount of fat in milk, although the values obtained are only approximate. A white glass cylinder with black lines is fitted by means of a stopper into a larger glass of cylindric shape, constricted below and having an aperture at the top. Four c.c. of the milk are measured accurately and placed in the large glass cylinder. Enough water is added to permit the black lines. of the small cylinder to appear clearly. The line on a level with the surface of the liquid indicates the amount of fat. This instrument gives only the amount of fat without taking into account the amount of other solids. Therefore a rich milk might be diluted and still show a reasonable amount of fat, but in connection with the specific gravity watered or skimmed milk can usually be detected by the lactoscope.

Since the fat is the most variable constituent of milk, the milk serum containing all the other solids has been used for determining whether water has been added to the milk. The specific gravity of the serum is fairly constant and, when below normal, indicates watering. Milk serum can be prepared by the use of calcium chlorid or by coagulation with acetic acid. 
Added water in milk can also be determined with an immersion refractometer. The tables on pages 218 and 219 give the refractometer reading and the specific gravity of milk serum according to the amount of water added to the milk.

Determination of added water either by the use of the refractometer or by determining the specific gravity of the serum requires considerable experience to yield reliable results. Experts with these methods claim that 5 per cent. of added water can be detected by these methods.
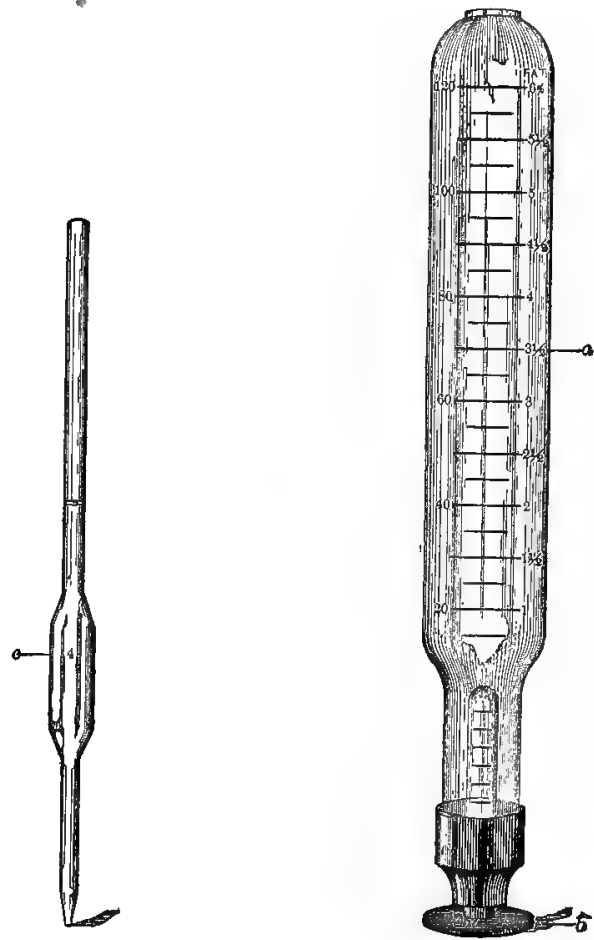

Fig. 82.-Feser's lactoscope (Leach).

The Association of Official Agricultural Chemists gives the following method for determining added water by the use of the Zeiss immersion refractometer:

"To 100 c.c. of milk at a temperature of about $20^{\circ} \mathrm{C}$. add 2 c.c. of a 25 per cent. acetic acid (spec. grav. 1.035) in a beaker, and heat the beaker, covered with a watch-glass, in a water-bath for twenty minutes at a temperature of $70^{\circ} \mathrm{C}$. Place the beaker in ice water for ten minutes and separate the curd from the serum by filtering through a $12.5-\mathrm{cm}$. folded filter. Transfer about. 
I. CONSTANTS OF MILK AND MILK SERUM. LABORATORY SAMPLES (LEACH)

\begin{tabular}{|c|c|c|c|c|c|c|c|}
\hline \multicolumn{6}{|c|}{ Determinations on Milk. } & \multicolumn{2}{|c|}{ On Milk Serum. } \\
\hline $\begin{array}{l}\text { Total Solids. } \\
\text { Per Cont. }\end{array}$ & $\begin{array}{l}\text { Water, } \\
\text { Per Cent. }\end{array}$ & $\begin{array}{c}\text { Fat, } \\
\text { Per Cent. }\end{array}$ & $\begin{array}{c}\text { Solids } \\
\text { not Fat, } \\
\text { Per Cent. }\end{array}$ & $\begin{array}{c}\text { Ash, } \\
\text { Per Cent. }\end{array}$ & $\begin{array}{l}\text { Specific } \\
\text { Gravity } \\
\text { at } 25^{\circ} \mathrm{C} .\end{array}$ & $\begin{array}{l}\text { Specific } \\
\text { Cravity } \\
\text { at } 15^{\circ} \mathrm{C} .\end{array}$ & $\begin{array}{l}\text { Immersion } \\
\text { Refractom- } \\
\text { eter Read- } \\
\text { ing at } 20^{\circ} \mathrm{C}\end{array}$ \\
\hline 1645 & 83.55 & 8.20 & 825 & $\ldots \ldots$ & I 0255 & 1.0274 & 40.95 \\
\hline 15.90 & 8410 & 700 & 890 & 069 & 10277 & I. 0285 & 42.00 \\
\hline $14 \cdot 37$ & 85.63 & - 550 & 8.88 & $0.5^{8}$ & 1.0282 & $1: 0280$ & 42.40 \\
\hline 14.17 & 85.83 & $4 \cdot 85$ & $9 \cdot 32$ & 0.62 & 1.0313 & I. $028 \mathrm{I}$ & 44.20 \\
\hline $1+.04$ & 85.96 & 4.95 & 909 & 0.60 & 1.0303 & 1.0274 & $42 \cdot 70$ \\
\hline 1380 & 86.20 & 5.00 & 880 & 0.65 & 1.0302 & 1.0289 & $42 \cdot 75$ \\
\hline 13.59 & $86.4 \mathrm{r}$ & $4 \cdot 30$ & 929 & 0.64 & $1.032 \mathrm{I}$ & $\mathbf{1 . 0 2 8 5}$ & $44 \cdot 5^{\circ}$ \\
\hline 13.39 & $86.6 \mathrm{r}$ & $4 \cdot 40$ & 809 & $0.5^{\circ}$ & I. .0324 & I. .0285 & $43 \cdot 70$ \\
\hline 13.28 & 86.72 & $4 \cdot 40$ & 8.88 & 0.60 & I. 0299 & 1.0289 & 42.65 \\
\hline 13.12 & 86.88 & .4 .00 & 912 & 0.59 & 1.0317 & I. 0280 & $43 \cdot 75$ \\
\hline 1300 & 87.00 & $4 \cdot 30$ & 870 & $0.5^{6}$ & 1.0310 & 1.0266 & 42.60 \\
\hline 1290 & 87.10 & 3.85 & 905 & $0.6 \mathrm{r}$ & 1.0318 & - I 0280 & $43 \cdot 40$ \\
\hline 1280 & 87.20 & 430 & 8.50 & 0.46 & 1.0304 & 10277 & 42.70 \\
\hline 12.70 & $87 \cdot 30$ & 3.80 & 8.90 & 0.53 & 1.0314 & I 0280 & 43.10 \\
\hline 12.63 & $87 \cdot 37$ & 3.50 & 913 & 0.65 & 1.0323 & I. $C=77$ & 43.65 \\
\hline 12.62 & 87.38 & $4 \cdot 10$ & $85^{2}$ & 0.52 & I. $0<98$ & 1.0272 & $42 \cdot 40$ \\
\hline 12.57 & 87.43 & 3.70 & 8.87 & 0.68 & 1.0317 & 1.0278 & 43.45 \\
\hline 12.47 & 87.53 & 3.60 & 887 & 0.65 & I. 0303 & 1.0282 & 43.15 \\
\hline 12.36 & 87.64 & 3.20 & 916 & 0.55 & 1.0327 & 1. 0282 & 43.25 \\
\hline 12.30 & 87.70 & 3.20 & 9.10 & 0.62 & 1.0327 & 1. 028$\}$ & 44.00 \\
\hline 12.16 & 8784 & $4 \cdot 35$ & 781 & 0.49 & 1.0275 & I. 0265 & 41.10 \\
\hline 12.00 & 88.00 & 3.40 & 860 & 0.62 & 1.0275 & I. 0280 & 41.75 \\
\hline I1. 86 & $88 . \mathrm{I} 4$ & 360 & 826 & 0.49 & 1.0306 & I. .0266 & 42.40 \\
\hline II. 67 & 88.33 & 3.95 & $7 \cdot 72$ & 0.48 & 1.0265 & I. 0240 & $39 \cdot 30$ \\
\hline II. 60 & 88.40 & 2.75 & 8.85 & 0.65 & 1.0320 & I. 0282 & 43.55 \\
\hline II. 50 & $88.5^{\circ}$ & 3.45 & 8.05 & $05 I$ & I 0200 & 1.0260 & 41.40 \\
\hline II. 40 & 8860 & 310 & 8.30 & 0.60 & 10297 & 1.0278 & $42 . \infty$ \\
\hline II. 25 & 8875 & 2.80 & 845 & $0.5^{8}$ & I. 0280 & 1.0274 & 40.90 \\
\hline It .07 & 88.93 & 300 & 807 & 0.62 & I 0200 & I. $0.77^{\circ}$ & 40.75 \\
\hline 10.69 & 8931 & 12.95 & $7 \cdot 74$ & $\ldots \ldots$ & 1.0288 & 1.0262 & 39.85 \\
\hline 10 25 & 8975 & 320 & 695 & 0.55 & I. 0230 & 1.0223 & 36.40 \\
\hline $8 \cdot 34$ & $9 \mathrm{I} .66$ & 12.20 & 6.14 & $0.3^{8}$ & 1,0224 & 1.0207 & 34.70 \\
\hline
\end{tabular}

II. CONSTANTS OF MILK AND MILK SERUM. A WHOLE MILK SYSTEMATICALLY WATERED (LEACH)

\begin{tabular}{|c|c|c|c|c|c|c|c|c|}
\hline \multicolumn{7}{|c|}{ Determinations on $M_{1} 1 \mathrm{k}$. } & \multicolumn{2}{|c|}{ On Milk Serum. } \\
\hline $\begin{array}{l}\text { Added } \\
\text { Water } \\
\text { Per Cent. }\end{array}$ & $\begin{array}{c}\text { Total } \\
\text { Sulids, } \\
\text { Pet Cert. }\end{array}$ & $\begin{array}{l}\text { Water, } \\
\text { Per Cent }\end{array}$ & $\begin{array}{c}\text { Fat, } \\
\text { Per Cent. }\end{array}$ & $\begin{array}{l}\text { Solids } \\
\text { not Fat } \\
\text { Per Cent. }\end{array}$ & $\begin{array}{c}\text { Ash, } \\
\text { Per Cent }\end{array}$ & $\begin{array}{l}\text { Specific } \\
\text { Gravity } \\
\text { at } 15^{\circ} \mathrm{C} \text {. }\end{array}$ & $\begin{array}{l}\text { Specific } \\
\text { Gravity } \\
\text { at } 15^{\circ} \mathrm{C} .\end{array}$ & $\begin{array}{l}\text { Immersion } \\
\text { Refrac- } \\
\text { tometer } \\
\text { Reading } \\
\text { at } 20^{\circ} \mathrm{C}\end{array}$ \\
\hline$\circ$ & 12.65 & $87 \cdot 35$ & 40 & 865 & $\therefore 65$ & 1.0315 & I. 0287 & 42.40 \\
\hline 10 & II. 33 & 88.67 & 350 & $78_{3}$ & 060 & I. 0278 & I. .0260 & 39.75 \\
\hline 20 & I0. 10 & 89.90 & 3.10 & 7.00 & 0.53 & I. 0252 & 1.0230 & 36.90 \\
\hline $3^{\circ}$ & 8.95 & 91.05 & 2.80 & 6.15 & 0.48 & $1.02 \mathrm{II}$ & 1.0200 & 34.10 \\
\hline 40 & 7.67 & $92 \cdot 33$ & 2.40 & $5 \quad 27$ & 0.40 & 1.0192 & s.0167 & 31.10 \\
\hline 50 & 6.43 & 93.57 & 2.00 & $4 \cdot 43$ & 0.38 & 1.0154 & I.OI 40 & 28.45 \\
\hline
\end{tabular}


III. CONSTANTS OF MILK AND MILK SERUM. A WHOLE MILK SYSTEMATICALLY WATERED (LEACH)

\begin{tabular}{|c|c|c|c|c|c|c|c|c|}
\hline \multicolumn{7}{|c|}{ Determinations on Milk. } & \multicolumn{2}{|c|}{ On Milk Serum. } \\
\hline $\begin{array}{l}\text { Auded } \\
\text { Water, } \\
\text { Per Cent. }\end{array}$ & $\begin{array}{c}\text { Total } \\
\text { Solids, } \\
\text { Per Cent. }\end{array}$ & $\begin{array}{l}\text { Water, } \\
\text { Per Cent. }\end{array}$ & $\begin{array}{l}\text { Fat, } \\
\text { Per Cent. }\end{array}$ & $\begin{array}{l}\text { Solids } \\
\text { not Fat, } \\
\text { Per Cent. }\end{array}$ & $\begin{array}{c}\text { Ash, } \\
\text { Per Cent. }\end{array}$ & $\begin{array}{l}\text { Spècific } \\
\text { Gravity } \\
\text { at } 15^{\circ} \mathrm{C} \text {. }\end{array}$ & $\begin{array}{l}\text { Specific } \\
\text { Gravity } \\
\text { at } 15^{\circ} \mathrm{C} .\end{array}$ & $\begin{array}{l}\text { Immersion } \\
\text { Refrac- } \\
\text { tometer } \\
\text { Reading } \\
\text { at } 20^{\circ} \mathrm{C} \text {. }\end{array}$ \\
\hline o & 9.05 & 9095 & 0.03 & 902 & 0.64 & I. 0350 & I. .0296 & 42.85 \\
\hline Io & 8.14 & 91.85 & 0.03 & 8. I I & 0.60 & 1.0317 & 1.0260 & 39.60 \\
\hline 20 & 7.27 & 92.73 & 0.02 & $7.25^{\circ}$ & 0.56 & I. 0278 & 1.0230 & 36.85 \\
\hline 30 & $6.4 \mathrm{r}$ & 93.59 & 0.02 & 6.39 & $0.4 \delta$ & I. .0247 & I. 0200 & 34.00 \\
\hline 40 & 5.50 & 94.50 & 0.01 & $5.49^{\circ}$ & 0.44 & 1.0200 & I. 0170 & 31.20 \\
\hline 50 & 4.61 & $95 \cdot 39$ & 0.01 & 4.60 & 0.39 & 1.0172 & 1.0140 & 28.50 \\
\hline
\end{tabular}

35 c.c. of the serum to one of the beakers that accompanies the control-temperature bath used in connection with the Zeiss immersion refractometer, and take the refractometer reading at exactly $20^{\circ} \mathrm{C}$., using a thermometer graduated to tenths of a degree. A reading below 39 indicates added water; between 39 and 40 the sample is suspicious."

A test for nitrates in milk has been recommended for detecting addition of water. Usually the water used on farms is derived from deep wells, and these commonly contain nitrates. In pure milk there are no nitrates, even, as has been shown by experiments, if saltpeter is added to the cow's food in moderate quantity. A simple test can be made in this manner: 2 c.c. pure sulphuric acid are placed in a white evaporating dish and a few crystals of diphenylamin dusted on the acid. Then a small amount of milk serum, prepared with calcium chlorid, is poured down the side of the dish. As the serum mixes with the acid bluish streaks indicate the presence of nitrates.

\section{Detection of Thickening Agents}

When milk is watered, skimmed, or both watered and skimmed, or even when it is naturally of low fat content, it is usually whiter than milk with normal fat content and may be deficient in viscosity. Consistency or viscosity may be restored by addition of sucrate of lime or gelatin, the latter being not infrequently used to thicken buttermilk in imitation of Bulgarian milk. Canesugar is also added sometimes to increase the solids and conceal acidity.

To detect cane-sugar in milk the following method can be used: Mix 25 c.c. of milk or cream with 10 c.c. of a 5 per cent. solution of uranium acetate, and filter after five minutes through a folded filter. To the clear filtrate add 2 c.c. of a cold saturated 
solution of ammonium molybdate and 8 c.c. hydrochloric acid (1 part 25 per cent. $\mathrm{HCl}$ and 7 parts water). After shaking, heat in a water-bath at $80^{\circ} \mathrm{C}$. for five minutes. A blue color develops when saccharose is present, and becomes more intense with prolonged heating. Normal milk develops a faint green color unless the temperature is raised to boiling, when a blue color appears.

Cane-sugar can also be detected by boiling 5 to 10 c.c. of the milk with 0.1 gram resorcin and a few drops of hydrochloric acid for a few minutes. A rose-red color develops in the presence of cane-sugar.

Richmond's method for detecting cane-sugar consists in determining the polarization of the suspected milk as for milk-sugar. The amount of milk-sugar is then determined by using Fehling's solution. The difference hetween the amount of anhydrous milksugar found and that resulting from dividing the polarization by 1.217 gives the percentage of cane-sugar present.

The presence of gelatin is determined according to the following method given by the Association of Official Agricultural Chemists:

"Prepare an acid solution of mercuric nitrate in twice its weight of nitric acid of 1.42 specific gravity, and dilute this solution to twenty-five times its bulk with water. To 10 c.c. of the milk (or cream) to be examined add an equal volume of the acid mercuric nitrate solution, shake the mixture, add 20 c.c. of water and shake again, allow to stand five minutes, and filter. If much gelatin is present the filtrate will be opalescent and cannot be obtained quite clear. To a portion of the filtrate contained in a test-tube add an equal volume of a saturated aqueous solution of picric acid. A yellow precipitate will be produced in presence of any considerable amount of gelatin, while smaller amounts will be indicated by cloudiness. In the absence of gelatin the filtrate obtained will remain perfectly clear."

There is no sanitary objection to the use of sucrate of lime or gelatin, but their presence is a confession of some deficiency in the quality of the milk unless the sucrate of lime is added to restore the viscosity lost through pasteurization. In this case the addition should be stated on the bottle. But when such addition is made to conceal the effects of tampering with the milk, its detection is of importance.

Addition of Foreign Fat to Milk.-If milk has been skimmed, some foreign fat may be added to replace the amount of milkfat removed. By the use of homogenizing machines the fat may be incorporated in the form of an emulsion, simulating the natural emulsion of butter-fat. However, the globules formed by a homo- 
genizing machine are exceedingly small, and microscopic examination readily reveals this condition. Furthermore, the small globules resulting from the homogenizing process do not rise readily, and the absence of a cream line indicates that the milk has been tampered with.

Foreign fats may be discovered by chemical methods, but these are laborious, time consuming, and not always reliable.

\section{Coloring-Matter in Milk}

Coloring-matter is sometimes added to milk to impart a rich appearance, especially after it has been either skimmed or watered. Then, too, when milk is derived from animals producing milk poor in fat, artificial color is added to increase its attractiveness. Annatto, caramel, and anilin dyes are chiefly used for this purpose. While annatto and caramel are harmless, the azo-dyes may be poisonous, as arsenic, copper, tin, lead, and zine may be introduced during manufacture. A general indication of the presence of caramel or azo-dyes can be had by coagulating the casein with rennet extract or acid. In pure milk the pigment (carotin, xanthophyll) is contained in the fat, and therefore the curd of pure milk is white, while the curd of milk colored with caramel or some azo-dye has the characteristic color of the dye used. Annatto is taken up by the fat and the curd remains white.

Another indication of the presence of caramel or some azodye is the color of the skimmed milk after the cream has risen.

The use of caramel or annatto does not injure the wholesomeness of the milk, but there is no advantage in their use unless the milk has been tampered with or is of poor quality.

Artificial coloring of milk can be detected by the following tests (Leach's method): Warm about 150 c.c. of the milk to be tested in a casserole over the flame and add about 5 c.c. of acetic acid, after which slowly continue the heating nearly to the boiling-point, stirring all the while. Gather the curd, when possible, into one mass by the use of the stirring rod, and pour off the whey. If the curd breaks up into small flakes, separate from the whey by straining through a sieve or colander. Press the curd free from adhering liquid, transfer to a small flask, and macerate for several hours (preferably over night) in about 50 c.c. of ether, the flask being tightly corked and shaken at intervals.

Detection of Annatto.-Decant the ether extract as obtained above into an evaporating dish, place on the water-bath, and evaporate the ether. Make the fatty residue alkaline with sodium hydroxid, and pour upon a very small wet filter while still warm. After the solution has passed through, wash the fat 
from the filter with a stream of water and dry the paper. If, after drying, the paper is colored orange, the presence of annatto is indicated. Confirm by applying a drop of stannoús chlorid solution, which in presence of annatto produces a characteristic pink on the orange-colored paper.

Annatto can also be detected in milk if 10 c.c. are mixed with ether and then shaken. After the ether has separated it becomes yellow if annatto was present.

Detection of Anilin Orange (Leach).--If the extracted fatfree curd (see above) is distinctly dyed an orange or yellowish color, anilin orange is indicated. To confirm the presence of this color treat a lump of fat-free curd in a test-tube with a little strong hydrochloric acid. If the curd turns pink immediately, the presence of anilin orange is assured.

Anilin dyes in milk can be detected by mixing 10 c.c. of milk with 10 c.c. of strong hydrochloric acid. A pink color appears in their presence.

Detection of Caramel (Leach).--If the fat-free curd is colored dull brown, caramel is to be suspected. As in the test for anilin orange, shake a lump of the curd with strong hydrochloric acid in a test-tube and heat gently. In the presence of caramel, the acid solution will gradually turn a deep blue, as will also the white fat-free curd of an uncolored milk, while the curd itself will not change color. It is only when this blue coloration of the acid occurs in connection with a brown colored curd, which itself does not change color, that the presence of caramel is to be suspected, as distinguished from the pink coloration produced at once under similar conditions by anilin orange.

The following summary of the scheme for color analysis is given by Leach:

"Curdle 150 c.c. of milk in a casserole with heat and acetic acid. Gather the curd in one mass. Pour off whey, or strain, if curd is finely divided. Macerate curd with ether in corked flask. Pour off ether.

Ether Extract.

Evaporate off ether, treat residue with $\mathrm{NaOH}$, and pour on wetted filter. After the solution has passed through, wash off fat and dry filter, which, if colored orange, indicates presence of annatto. (Confirm by $\mathrm{SnCl}_{2}$.)

\section{Extracted Curd.}

1. If colorless-indicates presence of no foreign color other than in ether extract.

2 . If orange or brownish-indicates presence of anilin orange or caramel. Shake curd in test-tube with concentrated $\mathrm{HCl}$.

If solution gradually turns blue, indicative of caramel. (Confirm by testing for caramel in whey of original milk.)
If orange curd immediately turns pink, indicative of anilin orange." 


\section{Addition of Preservatives to Mrlk}

In adding preservatives to milk, one of three objects is sought, namely: 1, Prolongation of the period of sweetness; 2, the destruction of pathogenic bacteria together with saprophytes; 3, the neutralization of acid formed by bacteria.

Since decomposition of milk depends upon the presence of micro-organisms, the chief purpose of adding a preservative is to destroy micro-organisms, in whole or in part. If preservatives are added in relatively small quantities, multiplication of bacteria is restrained and decomposition is deferred. The question comes up whether substances which destroy bacterial cells do not also injure the cells of the digestive tract, a question of special importance when milk is intended for consumption by infants and invalids. In relatively small quantities the action of preservatives on bacteria is selective. It is necessary, in order to accomplish the desired end, to use preservatives in sufficient amount to really destroy at least all pathogenic bacteria. To destroy spore-bearing organisms larger amounts of preservatives are required than for vegetative forms. On the other hand, there is danger of too much preservative being used. This may result from ignorance or from repeated addition of preservatives at different stages of the milk's journey from producer to consumer. A preservative may be added by the producer, again by someone at the collecting station, and finally by the dealer. Furthermore, in the warm season a larger amount of preservative is required than during the cold months.

The preservatives that have been used in milk are chiefly the following: formaldehyd, either as formalin, or under some trade name, as Preservaline, Iceline, or Freezine; and borax and boric acid, sold under the trade name Aseptine. Less commonly used are salicylic acid, benzoic acid, hydrogen peroxid, fluorids, potassium bichromate, sodium carbonate or bicarbonate.

Formaldehyd is used to a greater extent than any other preservative, and while the other substances mentioned are not used as frequently as formaldehyd, they are found frequently enough, and methods for determining their presence must be applied. Salicylic acid is dissolved with difficulty unless the milk is first heated, and the quantity necessary to produce the desired effect is so great that its presence can be recognized by the taste.

Chester and Brown have shown that formaldehyd in milk in the proportion of $1: 2000$ to $1: 800$ causes a rapid decrease of bacteria during the first twenty-four hours, and that only a few resistant spores remain at the end of five days. In the proportion 
of $1: 5000$ there is a rapid decline of bacteria for four to six hours, a continued slow reduction up to twenty-four hours, and after that multiplication begins. When formaldehyd is present in a dilution of $1: 10,000$ to $1: 20,000$ there is evident a marked restraining influence which in a dilution of $1: 40,000$ is less distinct. The authors think that 1 part formaldehyd in 40,000 parts of milk, as advised by von Behring, improves the sanitary quality of the milk if it is kept at $60^{\circ}$ to $70^{\circ} \mathrm{F}$. by preventing objectionable fermentations. They further state that there is no reason to believe that in this proportion any marked injury could result to the person consuming it.

Whether formaldehyd is injurious to the health of the consumer is a question that cannot be satisfactorily answered, and which is largely dependent upon the quantity consumed and the period for which its consumption is continued. Exact experiments are difficult to conduct, and the experiments actually made by a number of investigators were those with animals. Such results as were obtained are not necessarily applicable to human beings. However, some observations on the effect of this preservative upon children are available. It should be further taken into account that in some experiments formaldehyd and other preservatives have been made with unnecessarily large amounts of these substances. Formaldehyd in a concentration of $1: 20$,000 preserves the milk for several days, and it has never been shown that this amount is actually injurious. Von Behring even advocated the use of formaldehyd in a concentration of $1: 40,000$ in milk destined for infant feeding.

On the other hand, it should be remembered that, as previously stated, a preservative may be present in excessive quantity, either through ignorance or repeated addition. Under such conditions it is conceivable that the effect of formaldehyd on casein-that is, rendering it less digestible - is appreciable and that the irritating effect in the digestive tract is not negligible.

Furthermore, it does not seem unjustifiable to assume that, while occasional consumption of a small amount of formaldehyd may be without untoward effect, the habitual ingestion of even small amounts may be detrimental. It is well known that formaldehyd has an inhibiting influence on the digestive enzyms and on enzyms in general if the concentration is $1: 500$ or greater.

In regard to borax and boric acid, the same holds good as for formaldehyd. Borax and boric acid in relatively large quantity (1 to 2 per cent.) seem to produce a slightly deleterious effect on the digestive system, but in smaller amount the question still awaits solution. Indeed, it should be remembered that borax and boric acid are easily eliminated through the urinary tract, 
so that permanent effects are realized only when these substances are taken continuously. Tunnicliffe and Rosenheim go so far as to assert that children increased in weight when the food contained borax and boric acid.

Boric acid in a concentration of $1: 2000$ is sufficient to preserve milk in good condition for twenty-four hours.

Salicylic acid and benzoic acid are used only in rare instances. Their effect on the system has not been definitely determined, as opinions on the subject are divided. Hydrogen peroxid has been recommended for preserving milk, and the "Buddeizing" of milk as proposed by Budde has been shown to be very effective in destroying micro-organisms. Buddeized milk is milk to which hydrogen peroxid has been added at a temperature of $52^{\circ} \mathrm{C}$. The process has never become popular because there are several serious drawbacks to the product. Excess of hydrogen peroxid imparts a bitter taste to the milk and, furthermore, commercial preparations of hydrogen peroxid deteriorate and, therefore, are not reliable. They may also contain poisonous substances, such as arsenic, barium salts, etc.

The use of fluorids and potassium bichromate is so exceptional that consideration of these substances as preservatives is hardly profitable. Fluorids are poisonous, and potassium bichromate, while not a violent poison, is by no means harmless.

In summarizing the knowledge concerning the physiologic effect of preservatives in milk, it may be said that in minimal quantities most of the preservatives used in milk are probably not harmful when taken occasionally. When taken continuously they may not be entirely safe, but since the quantity added is an uncertain factor their use should be discouraged. Moreover, there is no excuse for their use, since pasteurization furnishes the means of removal of possible dangers in milk. Preservatives can only be designed to disguise imperfect milk or altered milk, and their presence is, therefore, not defensible in the light of present knowledge.

Detection of Formaldehyd.-1. Hehner's Sulphuric Acid Test. -Place 5 c.c. of the milk in a test-tube and pour about 3 c.c. of commercial concentrated sulphuric acid slowly down the side of the tube, so the liquids do not mix. At the junction of the liquids a violet zone appears in the presence of formaldehyd. If pure sulphuric acid is used a few crystals of ferrous sulphate should be added to the acid, as iron is a necessary ingredient for this test.

When milk containing formaldehyd is tested by the Babcock method for fat, a violet ring will form at the junction of the acid and milk. 
2. Leach's Hydrochloric Acid Test.-."Commercial hydrochloric acid (spec. grav. 1.2) containing 2 c.c. of 10 per cent. ferric chlorid per liter is used as reagent. Add 10 c.c. of the acid reagent to an equal volume of milk in a porcelain casserole, and heat slowly over a free flame nearly to boiling, holding the casserole by the handle and giving it a rotary motion while heating to break the curd. The presence of formaldehyd is indicated by a violet coloration, varying in depth with the amount present. In the absence of formaldehyd the solution slowly turns brown. By this test 1 part of formaldehyd in 250,000 parts of milk is readily detected before the milk sours. After souring the limit of delicacy proves to be about 1 part in 50,000."

3. Confirmatory Tests with Distilled Milk (Leach).-Distil 100 to 200 c.c. of the milk and use the first 20 c.c. of the distillate for testing. The following tests can be applied:

(a) To a few drops of the distillate in a test-tube add 1 drop of Schiff's reagent. A pink coloration appears in the presence of an aldehyd.

Preparation of Schiff's reagent: One gram of fuchsin is dissolved in water and a mixture of 20 c.c. of a saturated solution of sodium bisulphate and 10 c.c. of pure hydrochloric added, and the volume made up to 1000 c.c.

(b) Add to 5 c.c. of the milk distillate a few drops of a 1 per cent. aqueous solution of resorcin or phenol, mix, and pour down the side of a tube containing sulphuric acid. A rose-red zone is formed at the junction of the liquids. Formaldehyd can be detected 1 part to 200,000 . If present in larger quantity than 1 part to 100,000 a white turbidity or precipitate is formed above the colored zone.

(c) Use 1 or 2 c.c. of the milk distillate in a test-tube. Add to this 2 to 4 drops of the following reagent: One gram of phenylhydrazin hydrochlorid and 1.5 grams sodium acetate dissolved. in 10 c.c. of water. A green coloration appears when formaldehyd is present.

(d) To a distillate from milk which has been acidified before distillation to bind ammonia a few drops of Nessler's reagent are added. A yellow color appears in presence of formaldehyd. If much formaldehyd is present the color is dark and a grayish precipitate may form upon standing.

The following methods for detecting formadehyd in milk are given by the Association of Official Agricultural Chemists:

1. To 3 to 5 c.c. of milk add a lump of phenylhydrazin hydrochlorid about the size of a pea, from 2 to 4 drops (not more) of a 5 to 10 per cent. solution of potassium ferrocyanid, and from 8 to 12 drops of an approximately 12 per cent. solution of sodium 
hydroxid. A distinct bluish-green or green reaction is obtained if formaldehyd is present in quantities of $1: 70,000$ or more.

2. Treat 15 c.c. of the milk or the distillate thereof with 1 c.c. of a dilute solution of phenylhydrazin hydrochlorid, then a few drops of dilute ferric chlorid solution, and, finally, with concentrated hydrochloric acid. A red color changing to orange yellow indicates presence of formaldehyd (Rimini's method).

3. Prepare the reagent by dissolving 1 gram phloroglucol and 20 grams sodium hydroxid in sufficient water to make 100 c.c. To 10 c.c. of milk add, by means of a pipet, 2 c.c. of this reagent, placing the end of the pipet on the bottom of the tube in such a manner that the reagent will form a separate layer. A bright red color is formed at the zone of contact if formaldehyd is present.

Formaldehyd can be detected by heating a few cubic centimeters of the milk with an equal volume of hydrochloric acid and adding 1 or 2 drops of a 1 per cent. ferric chlorid solution. A violet color appears when formaldehyd is present.

Determination of Formaldehyd in Milk (Leach).—“ To 100 c.c. of milk add 1 c.c. of $1: 3$ sulphuric acid and subject to distillation in a 500-c.c. Kjeldahl nitrogen flask, using a low circular evaporating burner to avoid frothing. Collect 20 c.c. of the distillate and determine the formaldehyd as follows: Treat 10 c.c. of tenthnormal silver nitrate with 6 drops of 50 per cent. nitric acid in a 50-c.c. flask, add 10 c.c. of a solution of potassium cyanid containing 3.1 grams $\mathrm{KCN}$ in 500 c.c. of water, and make up to the 50 c.c. mark. Shake, filter, and titrate 25 c.c. of the filtrate with tenth-normal ammonium sulphocyanate, using ferric chlorid as an indicator.

"Acidify" another portion of 10 c.c. of tenth-normal silver nitrate with nitric acid, add 10 c.c. of the potassium cyanid solution to which the above 20 c.c. of the formaldehyd distillate has been added. Make up the whole to 50 c.c., filter and titrate as before 25 c.c. of the filtrate with tenth-normal ammonium sulphocyanate for excess of silver.

"The amount of potassium cyanid used up by the formaldehyd, in terms of tenth-normal ammonium sulphocyanate, is found by multiplying by 2 the difference between the two results, and the total formaldehyd is calculated by multiplying by 3 the amount found in the 20 c.c. of the distillate."

Detection of Borax and Boric Acid.-Method of the Association of Official Agricultural Chemists: "Render decidedly alkaline with lime-water about 25 grams of the milk and evaporate to dryness on a water-bath. Ignite the residue to destroy organic matter. Digest with about 15 c.c. of water, add hydrochloric acid, drop by drop, until all is dissolved, and add 1 c.c. in excess. 
Moisten a piece of delicate turmeric paper with the solution; if borax or boric acid is present, the paper on drying will acquire a peculiar red color, which is changed by ammonium hydroxid to a dark blue green, but is restored by acid."

A preliminary test may be made by immersing a strip of turmeric paper in about 100 c.c. of the milk, to which about 7 c.c. of concentrated hydrochloric acid has been added.

Boric acid or borax can be detected by evaporating 10 c.c. of the milk to dryness after addition of a small amount of hydrochloric acid, mixing the residue with alcohol, and lighting the alcohol. A greenish color in the flame indicates the presence of either boric acid or borax.

The following test for the detection of borax and boric acid is given by Shaw: "Ten c.c. of the milk is mixed with 5 c.c. of hydrochloric acid in a white cup. A strip of turmeric paper about 3 inches long is suspended in the mixture, so that at least 2 inches of the dry strip remain out of the liquid. The dry portion of the paper will gradually become moist by capillarity, and if borax or boric acid is present the paper will take on a reddish-brown tint. If only a trace of the preservative is present, several hours may be required for this color to develop. A drop of ammonia-water on the red portion will produce an olive-green color, which becomes lighter, and finally disappears as the ammonia evaporates."

Quantitative estimation: "Render 100 grams of the sample decidedly alkaline with sodium hydroxid and evaporate to dryness in a platinum dish. Ignite the residue thoroughly, heat with about 20 c.c. of water, and add hydrochloric acid, drop by drop, until all is dissolved. Transfer to a 100 -c.c. flask, the volume not being allowed to exceed 50 to 60 c.c. Add 0.5 gram of calcium chlorid and a few drops of phenolphthalein, then a 10 per cent. solution of caustic soda until a permanent slightly pink color is produced, and finally add 25 c.c. of lime-water. Make the volume up to 100 c.c. Mix and filter through a dry filter. To 50 c.c. of the filtrate add normal sulphuric acid until the pink color disappears, then methyl orange, and continue the addition of the acid until the yellow is just changed to pink. Boil to expel carbon dioxid. Add fifth-normal caustic soda until the liquid assumes the yellow tinge, excess of soda being avoided. Cool the solution, add a little phenolphthalein, and an equal volume of glycerin. Titrate with standardized sodium hydroxid until a permanent pink color is produced.

"One cubic centimeter of fifth-normal soda solution is equal to 0.0124 gram of crystallized boric acid."

Detection of Benzoic Acid.-Method of the Association of Official Agricultural Chemists: "Add 5 c.c. of dilute hydrochloric 
acid to 50 c.c. of the milk in a flask and shake to curdle. Then add 150 c.c. of ether, cork the flask, and shake well. Break up the emulsion which forms by aid of a centrifuge, or if the latter is not available, extract the curdled milk by gently shaking with successive portions of ether, avoiding the formation of an emulsion. Transfer the ether extract (evaporated to small volume if large in bulk) to a separator funnel and separate the benzoic acid from the fat by shaking out with dilute ammonium hydroxid, which takes out the former as ammonium benzoate. Evaporate the ammoniacal solution in a dish over the water-bath till all free ammonia has disappeared, but before dryness is reached add a few drops of ferric chlorid reagent. The characteristic fleshcolored precipitate indicates benzoic acid. Care should be taken not to add the ferric chlorid until all the ammonia has been driven off, otherwise a precipitate of ferric hydrate is formed."

Detection of Salicylic Acid.-Method of the Association of Official Agricultural Chemists: "Proceed exactly as directed for benzoic acid in the preceding section. On applying the ferric chlorid to the solution after evaporation of the ammonia the wellknown violet color indicates salicylic acid.

"Salicylic acid can also be detected by evaporating 10 c.c. of the milk to dryness on a water-bath, pulverizing the residue, and adding a few drops of ferric chlorid solution. The characteristic purple color will appear if salicylic acid is present."

Detection of Sodium Carbonate and Bicarbonate.-Mix 10 c.c. of the milk with 10 c.c. of alcohol and a few drops of a 1 per cent. solution of rosolic acid. Carbonate present gives a rose red color, while pure milk gives a brownish-yellow color.

Roughly, the presence of sodium carbonate or bicarbonate can be detected by evaporating about 10 c.c. of the milk to dryness on a water-bath; a yellow color will appear if sodium carbonate was present. Addition of an acid to the residue will cause effervescence.

\section{BIBLIOGRAPHY}

v. Behring: Hygienische Zeitschr., 1907, vol. 3, p. 632.

Budde: Milchzeitung, 1903, vol. 44, p. 690.

Chester and Brown: Delaware College Agri. Exper. Sta., Bull. 71, August, 1905.

Heinemann: Jour. Amer. Med. Assoc., 1913, vol. 40, p. 1603.

Herz: Quoted from Sommerfeld's Handbuch der Milchkunde.

Leach: Food Inspection and Analysis.

Official and Provisional Methods of Analysis: Association of Official Agricultural Chemists.

Reiss: Sommerfeld's Handbuch der Milchkunde.

Reiss and Sommerfeld: Sommerfeld's Handbuch der Milchkunde.

Richmond: Dairy Chemistry.

Shaw: Chemical Testing of Milk and Cream, United States Dept. of Agri., B. A. I., February 17, 1916.

Tunnicliffe and Rosenheim: Jour. of Hygiene, 1901, vol. 1, p. 168.

Van Slyke: Modern Methods of Testing Milk and Milk Products. 


\section{ENZYMS IN MILK}

ENzYMs or ferments are substances of unknown composition produced by living cells. They accelerate chemical processes and act in relatively small amounts as compared to the substances on which they react; nor are they destroyed by their activity. They are specific; that is to say, each enzym reacts only with one substance. By their action an equilibrium is established and this reaction is reversible. Usually a distinction is made between intracellular or endo-enzyms, or those which react only inside of the living cells, and extracellular or exo-enzyms, those which are able to penetrate the cell wall and react in the surrounding medium. The distinction between organized or living ferments, and unorganized or ferments acting independently from the cell, is not held by most investigators, since Buchner has shown that so-called organized ferments really act by means of unorganized ferments contained in the living cell. By separating ferments from living cells by means of pressure Buchner was able to reproduce fermentations similar to those brought about by the living cell.

Enzyms are sensitive to acids, alkalies, salts, and temperature. Some enzyms act best in slightly acid media, as rennin and pepsin for example; others prefer slightly alkaline media, as trypsin. Excess of acid, alkali, or salt is inhibitory. Some enzyms require the presence of small amounts of certain salts without which they are unable to produce chemical changes. Rennin and the fibrin ferment exert their coagulative influence only when calcium salts are present. Each enzym has an optimum, minimum, and maximum temperature, and is destroyed at a certain temperature, which varies with different enzyms. Some enzyms are destroyed at $60^{\circ} \mathrm{C}$., or even below, others are destroyed at higher temperature.

Enzyms are always present in raw milk, and when we read of "life in milk" they are usually referred to. The distinction between inherent milk enzyms and enzyms produced by microbial activity is sometimes made. However, it is difficult to exclude beyond criticism the activity of micro-organisms, since only a small portion of the milk in the udder is really free from bacteria. There is reason to believe that milk is secreted by the mammary gland in sterile condition, but it becomes contaminated with bacteria before it leaves the finest ducts. The so-called strippings 
are rarely free from bacteria, and therefore it is difficult to obtain sterile milk in sufficient quantity to make successful experiments. The usual procedure, when studying milk enzyms, is to add an antiseptic, such as chloroform, toluol, etc., which restrains bacterial activity, but does not materially retard enzym action. It is true that in this manner bacterial activity can be prevented and the production of enzyms inhibited, but enzyms that have been produced previous to the addition of the antiseptic are not excluded.

Milk enzyms may originate in the circulation and pass through the mammary glands uninjured; they may originate in the mammary gland or they may be liberated from disintegrating leukocytes. Finally, they may be the result of bacterial metabolism before the milk is drawn from the udder. It must be confessed that our knowledge of the origin of milk enzyms has not reached the point where it can be positively stated that certain enzyms originate from one source or another. There is little doubt that some enzyms which have been found in milk are really of bacterial origin, but the existence of inherent milk enzyms still awaits positive proof.

It has been assumed that some enzyms in milk are an aid in digestion, and special stress has been laid upon this point in reference to the use of cow's milk for infant feeding. It is doubtful, however, whether enzyms in cow's milk are of real importance to the human infant, for it is natural to assume that, if inherent digestive enzyms actually exist in cow's milk, they would be of little value for another species of mammal.

A variety of enzyms obtained from milk have been reported in the literature. These include proteolytic, carbohydrate-splitting, oxidizing, and reducing enzyms.

Proteolytic Enzyms.--Duclaux found a proteolytic enzym associated with rennet and which he considered of importance in cheese ripening. This "casease" can be obtained by precipitating with alcohol a broth culture of Tyrothrix tenuis, a bacterium of the hay bacillus group. Duclaux's casease is a trypsin-like ferment.

A great deal of attention has been given to a ferment discovered in milk by Babcock and Russell and named galactase. This enzym was found in milk of the cow, sheep, goat, pig, horse, halfbreed buffalo, and in human milk. Cow's milk in which the enzym was studied was drawn under aseptic precautions and preserved with an antiseptic. The antiseptics used were chloroform, ether, benzol, and toluol, but preference was given to chloroform as being the most effective. These antiseptics prevent bacterial growth, but do not inhibit enzym activity. 
Harding and Van Slyke, in a study of the quantity of chloroform required to restrain bacterial growth without materially affecting enzym action, have observed that some of the chloroform is absorbed by the fat and then becomes useless as a restraining agent. The greater the percentage of fat in the milk, the larger the amount of chloroform lost. It settles to the bottom with the dissolved fat. Skimmed milk containing 3 per cent. protein required 0.2 per cent. by volume of chloroform to destroy vegetative forms of bacteria gradually and 0.4 per cent. to destroy them within twenty-four hours. In whole milk of 5 per cent. fat content 1 per cent. chloroform destroyed the vegetative forms gradually, 1.5 per cent. within twenty-four hours, and 2 per cent. in four hours. Spores were not immediately destroyed even with excessive amounts of chloroform. In chloroformed cheese a uniform destruction of vegetative forms was not obtained with less than 10 per cent. chloroform by weight. In skimmed milk digestion progressed at a uniform rate in the presence of 0.2 to 0.7 per cent. chloroform by volume. With greater quantity of chloroform the rate of digestion decreased. The decrease when 2.5 per cent. chloroform was present was 12 per cent. of that occurring in the presence of 0.7 per cent. Beyond 2.5 per cent. an increase to 30 per cent. chloroform did not retard the rate of digestion more than did 2.5 per cent. The authors conclude that chloroform is a fairly satisfactory agent for repressing germ life in connection with the study of milk enzyms, and that quantitative studies of enzym action should receive a correction of 10 per cent. where 2.5 per cent. chloroform or more is used.

Babcock and Russell studied the increase of soluble protein in milk obtained under aseptic precautions and after addition of chloroform. As the soluble protein increased the protein precipitable with acetic acid decreased. The progressive proteolysis is shown by the following figures:

\section{PROGRESSIVE PROTEOLYSIS IN MILK WITH ANTISEPTIC}

Kind and age of milk.

Soluble protein.

Average of analyses of whole milk, fresh.

Average analyses of whole milk, twenty-five days old.

21.07 per cent.

Average analyses of centrifugal skimmed milk, fresh.

Average analyses of centrifugal skimmed milk, eight to twelve month

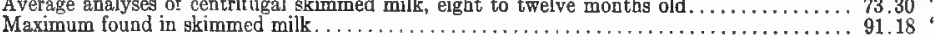

Galactase was also obtained from centrifugal slime of milk that had been continuously kept in contact with an antiseptic. Aqueous extracts had proteolytic properties, curdled fresh milk, and rapidly decomposed hydrogen peroxid. The aqueous extract probably contained a mixture of enzyms.

Galactase was at first thought by Babcock and Russell to be a tryptic ferment, because its action is increased in neutral or 
slightly alkaline media. Subsequent study by Babcock, Russell, Vivian, and Hastings, however, showed that it could be sharply differentiated from trypsin by its decomposition products. As the authors state: "The digestion products approach more nearly those produced by the liquefying or peptonizing bacteria than they do any of the ferments of animal origin." Ammonia is formed during early stages of digestion when galactase is used, but it is absent in tryptic and pancreatic digestion. Galactase differs further from trypsin in being inhibited by formalin.

Galactase is different from pepsin, inasmuch as the latter does not act on boiled milk unless free acid is added. The authors think that galactase is the main causal agent in the proteolytic changes that occur in Cheddar cheese.

Babcock, Russell, and Vivian have also studied the influence of galactase in the ripening of cottage cheese. Their studies have led to the conclusion that the digestion of casein in cottage cheese is due to the effect of inherent milk enzyms, chiefly galactase, but not so much to the action of vital ferments. They showed that when casein is precipitated by acid instead of rennet it undergoes a proteolytic change comparable to that occurring in normal milk.

Galactase acts best in neutral or slightly alkaline media and is destroyed by heating at $76^{\circ} \mathrm{C}$. for ten minutes. Babcock and Russell think that galactase is a true milk enzym and not a bacterial product, but it is questioned by some whether their milk was really sterile and whether the antiseptics used were in sufficient quantity to prevent all bacterial growth. It is further questioned whether galactase is a single enzym or a mixture of several different ones. Furthermore, there is some similarity between galactase and Duclaux's casease, which is clearly a bacterial product.

Pepsin and trypsin-like ferments have been found in milk by Spolverini, who demonstrated the formation of protein decomposition products which gave the biuret reaction.

Carbohydrate-splitting Ferment.-An amylase has been demonstrated in milk and can be shown to exist by the following method (Koning): Place 10 c.c. of milk in each of a series of test-tubes. Add to the first tube 1 drop of a 1 per cent. solution of starch, to the second tube 2 drops, and so on. Mix and add after thirty minutes 1 c.c. of an iodin solution prepared by dissolving 1 gram iodin and 2 grams potassium iodid in 300 c.c. of water. If all the starch has been digested a yellow color appears after addition of the iodin solution, while if part of the starch only has been digested, the characteristic blue color of the iodin-starch reaction appears. 
Fat-splitting Ferment.-A fat-splitting ferment has been found in milk. This is destroyed at $65^{\circ} \mathrm{C}$. Recently Rogers has found a similar ferment in butter.

Miscellaneous Ferments.-A salolase and an enterokinase have been reported, but their actual existence in common market milk is doubted.

Oxydases and Reductases.-Oxidizing and reducing ferments have been constantly found in milk and are of special interest, since they produce reactions by which recently heated milk can be distinguished from raw milk.

The question whether these enzyms are inherent milk enzyms or bacterial products has not been satisfactorily settled. However, the majority of investigators hold that they are of bacterial origin. This opinion is supported strongly by the fact that milk, when heated to a degree which is destructive to the enzyms, upon standing, again contains these ferments.

Four classes of oxidizing ferments may be distinguished, namely:

1. Superoxydases, splitting hydrogen peroxid into water and free oxygen. These are also known as catalases.

2. Oxydases, oxidizing by using the oxygen of the air.

3. Peroxydases, or indirect oxydases, acting similarly to the true oxydases, but utilizing oxygen liberated from hydrogen peroxid.

4. Reductases, reducing colored substances and changing sulphur to hydrogen sulphid.

Superoxydases differ from peroxydases, inasmuch as they utilize the $\mathrm{O}_{2}$ resulting from decomposition of two molecules as hydrogen peroxid, while peroxydases utilize $O$ from one molecule of hydrogen peroxid, as shown in the following formulas:

$$
\begin{array}{ll}
\text { Superoxydases (catalases): } & 2 \mathrm{H}_{2} \mathrm{O}_{2}=2 \mathrm{H}_{2} \mathrm{O}+\mathrm{O}_{2} \\
\text { Peroxydases: } & 1 \mathrm{H}_{2} \mathrm{O}_{2}=\mathrm{H}_{2} \mathrm{O}+\mathrm{O}
\end{array}
$$

Superoxydases act best at a temperature of $37^{\circ} \mathrm{C}$; they are destroyed at $68^{\circ} \mathrm{C}$.; are weakened by prolonged heating at $60^{\circ} \mathrm{C}$., and may be destroyed by heating at $62^{\circ} \mathrm{C}$. for one hour. Heating to $56^{\circ} \mathrm{C}$. for three hours partially destroys them. Their action is not inhibited by presence of lactic acid, in which respect they differ from the peroxydases. Superoxydases go into the coagulum when casein is precipitated, and into the cream when cream rises or is obtained by centrifugation. They can be extracted from cream by using water or physiologic sodium chlorid solution.

Superoxydases are present in large quantity in human milk, especially in the colostrum. In cow's milk they are also constantly present, and in excessive quantity when the udder is 
diseased. A test for catalase has, therefore, been used to indicate mastitis. Seligmann thinks that the large amount of catalase in colostrum is derived from the leukocytes, since these are present in large numbers. In milk from diseased udders their presence also suggests leukocytes as the origin. The catalases of normal milk are probably the product of saprophytic bacteria.

There is the possibility of superoxydases being inherent milk enzyms, but convincing proof of this is lacking. We know that there are bacteria, chiefly cocci, that are capable of producing superoxydases. According to Seligmann addition of an antiseptic to milk in sufficient quantity to prevent bacterial growth also decreases the amount of superoxydase, but when the antiseptic is removed the quantity of enzym increases. This fact points clearly to the bacterial origin of superoxydases.

Catalase action is inhibited by $\mathrm{HCN}$, cyanids of potassium and mercury, barium nitrate, hydrochloric acid, nitric acid, hydrogen sulphid, acetic and oxalic acids, and potassium nitrate.

Peroxydases or indirect oxydases have the property of producing colored compounds from easily oxidizable substances. When fresh tincture of guaiac and hydrogen peroxid are added to milk, a blue color appears. When old tincture of guaiac is used the addition of hydrogen peroxid is not necessary, since a peroxid is formed in the tincture. Similar color reactions are produced with guaiacol, paraphenylendiamin, ursol D, dimethyl- and tetramethylphenylendiamin, paramidophenol, creasote, and other substances. Hydrogen peroxid must be present in these reactions.

The reactions of peroxydases have been studied by Kastle and Porch. The authors found that the power of milk to induce oxidation of leuko- compounds is intensified by certain substances of the phenol type. Phenolphthalein, guaiacum, and paraphenylendiamin accelerate the reaction, and these substances can be used with certainty as peroxydase reagents. Fresh milk from different cows shows different peroxydase activity. They have further shown that by means of the peroxydase reaction, modified by addition of phenol accelerators, raw milk can be distinguished from cooked milk, and raw milk from milk heated to $70^{\circ} \mathrm{C}$. or somewhat higher for short intervals. Milk heated to $60^{\circ} \mathrm{C}$. for twenty minutes increases the intensity of the reaction slightly, while milk heated to $70^{\circ} \mathrm{C}$. for one hour or to $75^{\circ} \mathrm{C}$. for twenty minutes no longer gives a peroxydase reaction. Peroxydase intensifiers are trikresol, phenol, and beta-naphthol. Most of the experiments were carried out with trikresol. One c.c. of a 1 per cent. solution of trikresol was added to 5 c.c. of milk.

The optimum temperature of peroxydases is $25^{\circ} \mathrm{C}$., and they are destroyed at $72^{\circ}$ to $75^{\circ} \mathrm{C}$. Prolonged heating at $70^{\circ} \mathrm{C}$. is 
not detrimental, but heating for ten to fifteen minutes at $72^{\circ} \mathrm{C}$. and instantaneous heating at $76^{\circ} \mathrm{C}$. are destructive.

Peroxydases act best in neutral or slightly acid media; they are not precipitated with the casein, but remain in the filtrate. Excess of hydrogen peroxid is detrimental, but formaldehyd intensifies the reaction and protects the enzym to some extent against heat destruction. Milk that has been heated and has become inactivated is reactivated by addition of formaldehyd. The guaiac reaction is not influenced by formaldehyd.

Reductases.-Fresh milk reduces sulphur to hydrogen sulphid and decolorizes pigments, such as indigo, litmus, methylene-blue, etc. This property is due to the presence of reductases. The reducing property is lost when milk is heated above a certain temperature. Three kinds of reductases have been distinguished, namely:

1. Hydrogenase, which reduces sulphur to hydrogen sulphid.

2. Reductase, which reduces methylene-blue.

3. Aldehyd-catalase, which reduces methylene-blue with formaldehyd.

It is probable that all these reactions are due to the presence. of but one enzym.

Reductases are present in cream in greater quantity than in milk; they are precipitated with the casein and do not pass through a porcelain filter. They cannot be recovered from cream by water or sodium chlorid solution. They act best in slightly alkaline media. Reductases are constantly present in cow's milk, but have not been found in human and goat's milk.

Reductases are probably bacterial products, since sterile raw milk does not reduce sulphur to hydrogen sulphid. Furthermore, the reducing power increases when milk stands for some time, and finally, boiled milk is reactivated by inoculation with raw milk.

Schardinger's reductase, which acts on methylene-blue and formaldehyd, has been also called indirect reductase and aldehyd reductase. Seligmann assumes that formaldehyd plays a rôle with the reductases similar to that played by hydrogen peroxid with the indirect oxydases. Excess of formalin injures the enzym.

It is clear that up to the present it has not been possible to show with certainty that there are any true milk enzyms. It is possible that bacteria are able to produce all the enzyms that so far have been found in milk, and it is difficult to exclude bacterial action from milk. To prove the presence of inherent milk enzyms it is necessary to obtain milk directly from the mammary glands in sufficient quantity to carry on experiments. This is evidently a difficult problem. 
Based on the presence of some enzyms found in milk several tests have been devised for the purpose of detecting whether milk has been heated to a certain temperature to control pasteurization, or to simulate raw milk. Some of these tests depend upon color production from colorless compounds by oxidation by a peroxydase or superoxydase in presence of hydrogen peroxid. Other tests depend upon the reduction of colored compounds by reductases. When the temperature applied has been high enough to destroy the enzyms there is no reaction, but the temperature required by different enzyms is not the same, and therefore it was expected that the tests would be of considerable value.

However, no reliable test depending upon destruction of enzyms has been devised that can be applied to milk pasteurized at low temperature. Whether such a test is possible can only be determined by patient research among the enzyms usually found in milk.

The reducing power of milk has also been used for a rough estimation of bacterial pollution, since bacteria have the property of decolorizing methylene-blue. The following method is practised for this purpose: A methylene-blue solution is prepared by dissolving 2 grams methylene-blue in 100 c.c. 50 per cent. alcohol. The test is then carried out in this manner: Place in test-tubes falling amounts of milk from 1 to 0.05 c.c., add to each tube 3 drops of the methylene-blue solution, and fill with boiled milk to a volume of 10 c.c. As control fill a tube with 10 c.c. of the same boiled milk and 3 drops of methylene-blue solution. Then cover the surface of the mixtures of milk and methylene-blue with melted paraffin or paraffin oil and incubate all tubes at $37^{\circ} \mathrm{C}$. One c.c. of fresh raw milk will be decolorized in one to two hours. old milk or heavily contaminated milk is decolorized in a shorter time. Heated milk is decolorized slowly. If heated to $60^{\circ} \mathrm{C}$. for twenty minutes the milk is decolorized after about six hours, while boiled milk takes a much longer time for decolorization.

The following test for catalase according to Koning is used to detect the presence of milk from diseased udders: Place in a graduated fermentation tube 5 c.c. of a 1 per cent. solution of hydrogen peroxid and 15 c.c. of the milk to be tested. The amount of oxygen liberated after two hours' incubation at room temperature should not exceed 2.5 c.c. Abnormal milk produces more oxygen. Van Slyke states that if milk is more than six hours old and more than 4 c.c. oxygen are in the closed arm, the milk has been derived from a diseased udder.

The catalase test is also indicative of heated milk. The test may be carried out as follows: 25 c.c. of the milk and 0.5 c.c. of Merck's perhydrol are placed in a fermentation tube, which is 
incubated at $37^{\circ} \mathrm{C}$. for one hour. If the milk was heated to $62^{\circ} \mathrm{C}$. for one minute or more a small amount of oxygen will collect in the closed arm, but if heated to $62^{\circ} \mathrm{C}$. for one hour, or to $66^{\circ} \mathrm{C}$. for thirty minutes, or to $68^{\circ} \mathrm{C}$. for one minute, no oxygen is liberated. The test is vitiated if heated milk is inoculated with bacteria or if a small amount of raw milk has been added.

The following tests also are designed to indicate heated milk:

Storch's Test.-20 c.c. of milk are placed in a container and 10 drops 3 per cent. hydrogen peroxid and 1 c.c. paraphenylendiamin-chlorid solution ( 2 per cent. aqueous) added. The reaction is negative if milk has been heated to $80^{\circ} \mathrm{C}$. or above for a short time. Below this temperature a blue color develops unless the milk has been heated for five minutes at $75^{\circ} \mathrm{C}$., or for fifty minutes at $70^{\circ} \mathrm{C}$. Preservatives in milk vitiate the reaction.

Arnold's Reaction.-Guaiac resin is dissolved in alcohol or acetone to make a 5 or 10 per cent. solution, and 0.5 c.c. of the solution mixed with 5 c.c. of the milk to be tested. If the milk has been heated to $72^{\circ} \mathrm{C}$. for fifteen minutes the reaction is negative. Heated to $75^{\circ} \mathrm{C}$. for five minutes and at $76^{\circ} \mathrm{C}$. for one minute the reaction is also negative. A positive reaction is indicated by formation of a blue color.

Instead of a solution of guaiac resin an aqueous solution of crystallized guaiacol (1 per cent.) can be used.

Rothenfusser Reaction.-One gram paraphenylendiamin-chlorid is dissolved in 15 c.c. of water. Two grams guaiacol are dissolved in 135 c.c. of alcohol. The two solutions should be preserved separately and mixed immediately before using. To 100 c.c. of milk are added 6 c.c. of a solution of subacetate of lead, and the mixture shaken and filtered. To the filtrate are added 2 drops hydrogen peroxid ( 3 per cent.) and 2 drops of the reagent. Raw milk turns violet, but if heated above $80^{\circ} \mathrm{C}$. remains white. The color should appear in one to two minutes. This test is more delicate than Storch's test and is not influenced by formalin, boric acid, and salicylic acid when one of these preservatives has been used. If boiled milk has been contaminated the reaction remains negative.

Benzidin Test.-In presence of hydrogen peroxid benzidin is changed by peroxydase action into an azo-compound and a blue color is produced. Execution of the test: Prepare an alcoholic solution of benzidin, 4 parts benzidin in 100 parts alcohol; add 2 c.c: of this solution to 10 c.c. of the milk, and then 2 to 3 drops of 30 per cent. acetic acid. Then add carefully without shaking a few drops hydrogen peroxid. If the milk was heated above $79^{\circ} \mathrm{C}$. no color appears. 
All the above tests depend on the presence of peroxydases in milk.

Schardinger's Test.-This test depends upon the decolorizing action of a reductase in milk. The original test devised by Schardinger was made with methylene-blue, but later a small amount of formalin was added which rendered the test more sensitive. The reagent is composed of 5 c.c. of a saturated alcoholic solution of methylene-blue, 5 c.c. of formalin, and 190 c.c. of water. To 1 c.c. of this reagent 20 c.c. of the milk are added. The mixture is immediately covered with a layer of melted paraffin or paraffin oil to exclude the oxygen of the air. The tube is placed in a waterbath at $45^{\circ} \mathrm{C}$. If the milk was heated above $72^{\circ} \mathrm{C}$. the color disappears. The reductase is destroyed at somewhat lower temperature than the peroxydase, and this test, therefore, has a larger range of temperature than tests depending on peroxydase reactions. If the tube is kept at $37^{\circ} \mathrm{C}$. instead of $45^{\circ} \mathrm{C}$. a negative result is obtained if the milk was heated for five minutes at $65^{\circ} \mathrm{C}$. Below $65^{\circ} \mathrm{C}$. the reaction is doubtful. Decolorization may be partial, but whether such partial decolorization can be used as an indication of heating has not been definitely determined.

\section{BIBLIOGRAPHY}

Babcock and Russell: Univ. of Wis. Agri. Exper. Sta., 14th Annual Report, 1897, p. 161 .

Babcock, Russell, and Vivian: Univ. of Wis. Agri. Exper. Sta., 16th Annual Report, 1899, p. 175.

Babcock, Russell, Vivian, and Hastings: Univ. of Wis. Agri. Exper. Sta., 16th Annual Report, 1899, p. 157.

Bauer: Die Methodik der Biologischen Milch Untersuchung, Stuttgart, Ferdinand Enke, 1913.

Harding and Van Slyke: New York Agri. Exper. Sta., Technical Bull. 6, December, 1907.

Kastle and Porch: Jour. of Biol. Chem., 1908, vol. 4, p. 301.

Rogers: Cent. f. Bakt., Abt. 2, 1904, vol. 12, pp. 388, 597.

Seligmann: In Sommerfeld's Handbuch der Milchkunde.

Spolverini: In Sommerfeld's Handbuch der Milchkunde.

Van Slyke: Modern Methods of Testing Milk and Milk Products, New York, Orange Judd Company, 1915. 


\section{THE TRANSMISSION OF TOXINS AND ANTIBODIES THROUGH MILK}

DURING the process of milk secretion, proteins, carbohydrates, and fats of the body are so altered as to form the normal constituents of milk. Since casein, lactalbumin, butter-fat, and milk-sugar occur in milk and in no other place in nature, it is assumed that they are transformation products of proteins, fats, and carbohydrates contained in the system of the milk-producing mammal, and that these substances do not pass through the mammary gland unaltered. On the other hand, it has been shown that some substances can pass into the secretion without undergoing material alteration. Such substances as potassium iodid, sodium salicylate, mercury and arsenic compounds, bromids, carbolic acid, aspirin, ether, chloroform, turpentine, and asafetida have been given to cows and then have been recovered from the milk. It is conceivable, therefore, that vegetable poisons may reach the mammary secretion if the animal, while grazing, should eat poisonous plants. As a matter of fact, essential oils occasionally appear in the milk when aromatic food is taken. These oils are not necessarily poisonous, but they impart unpleasant flavors to milk and may prove injurious if fed to infants.

However, all such substances that may appear in the milk are present in highly diluted form, and the probability of injurious consequences after the consumption of such tainted milk is not great.

Similarly, it is conceivable that toxins may appear in the milk either through the food of the mother or from her circulation if the mother is suffering from a bacterial infection.

The term "toxin" is now commonly used to mean substances which may be related to proteins, but which do not possess the general properties of proteins. The chemical composition of toxins and their structure are not known. Introduced in the animal body they induce the formation of immune bodies similar to the antibodies produced in living animals and man when foreign colloidal substances invade them. There are many kinds of these antibodies, but the discussion of these does not come within the scope of this work. The reader is referred to any good treatise on immunity, hygiene, bacteriology, or pathology. The antibodies formed after the introduction of toxins in the body are known as antitoxins. 
Toxins are produced by some animals (snake venom, spider poison), plants (abrin, ricin, crotin), and by some bacteria. Bacterial and animal poisons are usually harmless to adults when taken through the alimentary tract, but may not be harmless in the infant's digestive tract. Most toxins, when introduced into the digestive tract, are decomposed by digestive ferments and rendered harmless. The poison produced by the bacillus of botulism is a notable exception to this rule. In the digestive tract of infants there is no such digestion of toxins, and their introduction may therefore be followed by grave consequences. However, the toxins - if present at all in the milk-are there in relatively small quantities, and, furthermore, the mother is not able to nurse her infant if she is suffering from a serious toxemia.

Vegetable poisons exert their poisonous influence from the alimentary tract, but probably rarely occur in milk, since the plants from which they are derived are not common in pastures. It has not been conclusively shown that vegetable poisons pass through the normal mammary gland into the secretion.

The transmission of antibodies with milk from the mother to the young is of much interest and perhaps of value in regard to the health of the infant. There is a popular impression that during the first year of life infants are not highly susceptible to diseases, such as scarlet fever, measles, whooping-cough, and typhoid fever. This impression has been entertained chiefly in regard to breast-fed infants. Whether the idea is in accord with facts has not been proved, and it must be admitted that other factors may cause this seeming immunity. For example, a young baby, as a rule, is not exposed to infection to the same extent as older children, as it does not come in as close contact with other children.

The transmission of immune bodies to the young was thoroughly studied by Ehrlich. Previous to his experiments some observations were recorded which showed that immunity was present in the young, but whether it was communicated before birth or afterward with the milk was not clear. By an ingenious experiment Ehrlich was able to show that antitoxins actually pass with the milk into the system of the suckling. He took young mice born of a normal mother and had them fed by a mother that had been actively immunized. The immunity of the foster mother was transmitted to the young. When the mother was passively immunized antitoxins were also transmitted through the milk to the young.

Ehrlich was able to show by experiment that-

1. Immunity is not conferred from father to child.

2. Immunity may be transferred before birth from mother to child. 
3. Immunity may be transmitted through the milk from actively immune and passively immunized mothers.

Antibodies, as a rule, are united with the pseudoglobulin fraction of the blood protein. The amount of globulin in normal milk is exceedingly small, and consequently antibodies can exist only in relatively small quantity. The amount of antitoxin found in milk is from one-fifteenth to one-thirtieth the amount contained in the blood. In colostrum the globulin content is much greater than in normal milk, and this fact may account for the relatively large quantity of antibodies in colostrum milk. The globulin content diminishes as lactation progresses and, with this decrease, antibodies also decrease.

Römer and Much showed that when the mother was injected with tetanus antitoxin during the first seven days after birth the intestinal mucosa of calves allowed ten times as much antitoxin to pass into the circulation as during the fifth to twelfth days. They showed further that when tetanus antitoxin was mixed with milk and fed to calves from bottles the relative amount that passed through the intestinal mucosa was similar to the above results, but the absolute amount was only about one-tenth. This shows that antitoxin mixed with milk does not pass from the digestive tract as readily as when it is injected into the mother and then fed from the breast, or as when the mother has acquired the antitoxic immunity. The authors assume that the horse-serum undergoes a material alteration when passing through the circulation of the mother into the milk, and that by this alteration it becomes more readily absorbable by the intestinal mucosa.

It is clear from these experiments that antitoxin passes into the circulation of the young from the milk whether the mother has been actively or passively immunized. But the amount of antitoxin that actually passes is substantial only during the first few days after birth. This is due to two causes, namely: 1 , To the presence of large quantities of antitoxin-globulin in the early secretion, but the quantity diminishes as lactation progresses; 2 , to a condition of the intestinal mucosa which permits passage of the globulins and which rapidly disappears.

The amount of antitoxin in the system of the young is further influenced by the length of the lactation period. In mammals with a lactation period of short duration the amount of antitoxin transmitted through the milk is smaller than in mammals with a long period of lactation.

It is not definitely known whether antitoxin introduced with milk from a different species of mammal enters the circulation in sufficient quantity to be of real value to the young. There can be little doubt, however, that limited amounts actually pass 
through the intestinal mucosa of the young mammal into the circulation.

Most of the studies on transmission of antibodies through milk have been carried on with antitoxins. However, some evidence is at hand which seems to indicate that other immune bodies may be transmitted through milk directly to the suckling. Transmission of agglutinins, bactericidal substances, hemolysins, and opsonins (Woodhead and Mitchell) have been observed, and even hypersensitiveness seems to be transmissible through milk.

Agglutinins have been observed in the circulation of the fetus and in the milk of immunized mothers. Typhoid fever agglutinins especially have been shown to exist in the milk of women suffering or recovering from typhoid fever.

Experiments as to the transmission of agglutinins through milk to the young have not always led to concordant results. While some observers claim that this is possible, even though the quantity transmitted is small, others were unable to detect the presence of agglutinins in the circulation of the young.

Precipitins have been found in the blood of sucklings, and their presence is due to the passage of proteins through the intestinal wall. Whole milk and the different milk proteins separately can act as antigens. Injection of milk into animals produces specific antibodies and a serum containing these antibodies is called lacto-serum. In infancy, when milk proteins pass through the intestinal wall, or in cases where the intestinal mucosa is injured so that proteins can pass through, precipitins are formed in the blood. The presence of precipitins is demonstrated by adding some of the serum to a solution of the particular protein which has induced antibody formation. For example, an animal treated with cow's milk will produce precipitins which react only with cow's milk; or if bovine casein is injected, the blood-serum of the animal will develop precipitins to bovine casein and not to casein of another kind of milk. It is possible by means of the precipitin reaction to detect adulteration of one kind of milk with that of another mammal. If, for example, goat's milk has been mixed with cow's milk, this can easily be detected. Milk from one mammal, if heated to the boiling-point, can still be distinguished from milk of another species by this biologic test. Even if de'composed, as in ripened cheese, the kind of milk used can be determined. However, the specificity of the reaction is not strictly confined to the milk of the same species, as milk from closely related species will react, although in lesser degree.

Precipitins, like agglutinins, belong to the second order of immunity, according to Ehrlich's hypothesis.

Hemolysins and bactericidal substances belong to the third 
order of antibodies in Ehrlich's theory of immunity. Antibodies of the third order require the presence of two substances before they can react, namely, the amboceptor, which is the true immune body, and the complement, which is a substance present in normal blood. When either of these substances is lacking the presence of the other cannot be detected. The failure to find bactericidal substances in milk may be due, therefore, to the absence of complement, although amboceptor may be present. When milk is taken by the young mammal the amboceptor, if present, may pass into the circulation, where it is activated by the complement of the blood. It is possible then that antibodies of Ehrlich's third order are present in milk, but escape detection in absence of the complement. But the amboceptor passes into the blood of the young and its presence can then be demonstrated, since complement is normally present in blood.

Some investigators have found hemolysins and bactericidal substances in milk, while others have failed to find them. Since complement is frequently absent in normal milk or present in small quantity, it seems probable that the amboceptor is commonly present, but remains inactivated because of lack of complement.

In abnormal milk derived from diseased animals complement is more abundant than in normal milk, and bactericidal substances and hemolysins are readily detected.

Applying the principles of immune body formation, several interesting biologic tests have been devised by means of which adulteration of the milk of one mammal with milk from another can be detected. Bauer claimed that he was able to find cow's milk in human milk in the proportion of $1: 1000$. By similar tests mastitis milk or colostrum milk, if mixed with normal milk, can be detected. However, these methods have not been practised to a great extent, and it is unwise at this time to consider them entirely satisfactory. As a rule, biologic tests take much time and expensive material, and, furthermore, they require such skill and experience that competent operators are necessary to conduct them. On the other hand, their usefulness cannot be questioned, since early discovery of pathologic conditions of an animal makes it possible to eliminate it from the herd before clinical symptoms are sufficiently obvious. It is highly probable that with more experience and research biologic tests will develop which may become highly useful. Descriptions of certain biologic tests are here given:

The Precipitin Test.-A rabbit is injected intraperitoneally or intravenously with a few cubic centimeters of a certain milk suspected of having been used as an adulterant. The injection is 
repeated every four or five days for three weeks or at close intervals. The blood-serum of this rabbit will then produce a precipitate with highly diluted milk of the same species, but no precipitate with other kinds of milk. However, there are two complicating factors in this test, namely: 1 , the milk must be diluted highly enough to be fairly clear, otherwise a slight precipitate cannot be observed; and 2, when milk is highly diluted relatively small amounts of the adulterant escape detection. Furthermore, it should be remembered that the precipitin reaction is not strictly specific and a precipitate will be formed with milk from mammals closely related to each other.

The precipitin test is carried out by placing 1 c.c. of the milk diluted $1: 1000$ in physiologic salt solution in a test-tube and allowing a few drops of the immune rabbit serum to flow down the inside wall of the tube. The reaction is positive when a white disk forms at the juncture of the two fluids. The fat should be removed from the milk before dilutions are prepared.

The Complement-fixation Test (Bauer).-This test is more complicated than the previous one, but can be used with milk in relatively low dilutions, and it is strictly specific. For this test the following material has to be prepared:

1. Amboceptor Serum.-In each of a series of ten to twelve tubes place 1 c.c. of a 5 per cent. suspension of washed sheep corpuscles and 0.1 c.c. of guinea-pig serum (complement). To the mixture add in falling amounts from 0.01 to 0.0001 c.c. of inactivated amboceptor serum. This is prepared from rabbits injected several times with the 5 per cent. suspension of sheep corpuscles. It is inactivated by heating to $56^{\circ} \mathrm{C}$. for thirty minutes. One tube is left without amboceptor serum as control. The amboceptor serum must be suitably diluted with physiologic salt solution in order to obtain the proper quantities.

After all the tubes have been filled, enough salt solution is added to each one to bring the volumes up to a definite amount. Then all tubes are placed in an incubator at $37^{\circ} \mathrm{C}$. and left for two hours. After this time one of the tubes will show which amount of amboceptor serum produces complete hemolysis. Twice this amount is taken as the titer of the serum. It may be kept in a frozen condition for a long time. As a minimum titer for practical use 0.001 to 0.0005 c.c. should be sufficient to produce complete hemolysis with 1 c.c. sheep corpuscles and 0.1 c.c. guineapig serum.

2. Complement.-Place in each of a series of about eight tubes one dose of the amboceptor serum, 1 c.c. suspension of washed sheep corpuscles, and falling amounts of suitably diluted complement serum in quantities of from 1 c.c. to 0 . Then add enough 
salt solution to bring the mixtures to a uniform volume and incubate the series at $37^{\circ} \mathrm{C}$. The titer is twice the smallest amount of complement which produces complete hemolysis.

3. Lactoserum. - This is a serum from a rabbit repeatedly injected with the milk. Place in each of two series of eight tubes falling amounts of lactoserum, suitably diluted with physiologic salt solution, in quantities of from 1 to 0 c.c. To each tube of the first series add 0.1 c.c. of milk in a dilution of $1: 100$. No milk is added to the second series. Then add to each tube of both series the amount of complement determined under No. 2. Place both series for one hour in an incubator at $37^{\circ} \mathrm{C}$. Then add to all tubes 1 c.c. of the 5 per cent. suspension of washed sheep corpuscles and the amount of amboceptor serum determined under No. 2. After mixing, incubate at $37^{\circ} \mathrm{C}$. for two hours.

The second series without milk (antigen) should show hemolysis in all tubes. The first series should show hemolysis according to the relative potency of the lactoserum. For the real test that amount of lactoserum is chosen which is slightly in excess of the smallest amount producing complete hemolysis.

The Test.-Place into each of a series of six tubes-

1. Falling amounts of the milk to be tested, suitably diluted (0.1 to 0.00001 c.c.). No milk is placed in the last tube.

2. The amount of lactoserum determined under No. 3 .

3 . The amount of complement determined under No. 2 .

After one hour's incubation at $37^{\circ} \mathrm{C}$. add to each tube 1 c.c. of the 5 per cent. suspension of washed sheep corpuscles and the amount of amboceptor serum determined under No. 1. As control, fill another series of tubes with the same mixture, omitting the lactoserum. Incubate all tubes for two hours at $37^{\circ} \mathrm{C}$. At the end of this period all tubes of the second series should show complete hemolysis. The tubes of the first series will show more or less inhibition of hemolysis if a foreign milk is present.

Anaphylactic Method.-If a guinea-pig is injected with a dose of a certain milk and the injection repeated after about twelve days, it will show serious symptoms of poisoning and may die. If a different protein is injected the second time, no symptoms appear. If there is reason to suspect that goat's milk has been mixed with cow's milk a guinea-pig is injected with pure cow's milk and after twelve days with the suspected goat's milk. If cow's milk was actually present in the goat's milk, anaphylactic symptoms will appear. If the goat's milk was pure, no symptoms will appear.

Tests for Mastitis and Colostrum Milk.-Milk from cows suffering from mastitis and colostrum milk contain complement in appreciable quantity, while normal milk contains only traces or 
none. Therefore, if a test shows that complement is present, the conclusion is justified that the milk contains either mastitis milk or colostrum. Mastitis milk can be distinguished from colostrum milk by microscopic examination. The complement appears in the milk when mastitis is in an early stage of development, so the disease can be diagnosed by this method before clinical symptoms are pronounced. The test after Bauer and Sassenhagen is made as follows: Three series of seven tubes each are filled in this manner: The first series contains amounts of the milk to be tested from 1 down to 0.1 c.c. and a tube without any. To the milk is added enough physiologic salt solution to bring the volume in each tube to 1 c.c. Then 0.2 c.c. inactivated sheep serum and 1 c.c. 1 per cent. suspension of washed rabbit corpuscles are added to each tube. The contents are mixed and the tubes placed in an incubator at $37^{\circ} \mathrm{C}$. for two hours. The second series of tubes is filled with the same material except that the milk is previously heated to $56^{\circ} \mathrm{C}$. for thirty minutes. The third series also contains the same material except that, in place of the test milk, milk from a healthy cow is used. The cream should always be removed from milks used for these tests. All tubes are incubated for two hours at $37^{\circ} \mathrm{C}$.

Interpretation of Results.- If the corpuscles have not laked, they settle to the bottom of the tubes and the milk remains white. If the milk is colored, some of the corpuscles have laked and hemoglobin has gone into solution. Therefore, whenever a tube shows that the milk is colored, complement was present. The quantity of complement can be judged by the number of tubes showing hemolysis. If much complement is present, tubes 1 to 6 are colored; if complement is present in small amounts, only one or two are colored. The seventh tube, which contains no milk, should never be colored, otherwise the sheep serum is useless. The second series, which contains heated milk, never shows hemolysis because the complement, if present, has been destroyed by heat. This series, therefore, serves as a guide for the first.

Sometimes normal milk contains small amounts of complement. The amount is usually so small that no hemolysis appears, but in some cases slight laking may take place. For this reason the third series of tubes has been prepared. This series contains normal milk, and if hemolysis develops in this series it shows that the suspension of sheep corpuscles is not in good condition. It is well, therefore, to make preliminary tests of the sheep corpuscles that are to be used, and find a suspension which shows no hemolysis with normal cow's milk.

If there are colored tubes in the first series the proof is at hand 
that the milk actually contained complement, indicating colostrum or mastitis milk.

Test for Rennin Inhibition (Schern).--Milk from sick cows or colostrum milk requires more rennin for coagulation than normal milk. For this test the milk must be fresh and contain no free acid. The chemical reaction should be the same as normal milk. Rennet of known potency is diluted with physiologic salt solution $1: 10,1: 20,1: 30$, etc. Of each of these dilutions, 0.5 c.c. are mixed with 4.5 c.c. milk. The relative dilution must be judged according to the potency of the rennet. The tubes containing the mixtures are placed in an ice-chest for an hour and then in a water-bath at $37^{\circ} \mathrm{C}$. Normal milk will be found coagulated after this time, while abnormal milk will not. Small differences are negligible.

\section{BIBLIOGRAPHY}

Bauer: Die Methodik der Biologischen Milchuntersuchung, Stuttgart, 1913, Ferdinand Enke.

Ehrlich: Zeitschr. f. Hygiene, 1892, vol. 12, p. 183.

Ernst: Grundriss der Milchhygiene für Tierärzte, Stuttgart, 1913, Ferdinand Enke.

Römer: Sommerfeld's Handbuch der Milchkunde.

Römer and Much; Quoted from Sommerfeld's Handbuch.

Woodhead and Mitchell: Jour. of Pathology and Bacteriology, 1906-7, vol. 11, p. 408. 


\section{THE GERMICIDAL ACTION OF FRESH COW'S MILK}

IN the preceding chapter it has been shown that antibodies of various kinds may be transmitted to the milk from the circulation. Therefore it is not surprising that many investigators believe they have demonstrated an actual germicidal property in fresh cow's milk.

It has been noted that there is no increase of bacteria in the milk while in the udder. On the contrary, when cultures of bacteria have been injected into the udder, it has been difficult to recover them after the lapse of some time. Furthermore, it is generally assumed that bacteria actually present in the udder have gained access from the outside. If this is true, it is natural to expect to find a variety of species in the milk while in the udder; as a matter of fact, however, micrococci are predominant, while other species are exceedingly scarce, indicating that there is some restraining influence at work in the udder which perhaps persists for some time after the milk has been drawn. This influence may affect different kinds of bacteria to a greater or lesser degree, and this assumption would explain the dying off of most species, while micrococci are but slightly restrained. But even micrococci are present in relatively small numbers, considering the fact that a good food substance and a favorable temperature furnish good conditions for growth in the udder.

It has been assumed by some that the leukocytes are responsible for the disappearance of bacteria in the udder. This view has been advocated chiefly by Rullmann and Trommsdorff, who have stated that there is a definite relation between the germicidal property of fresh milk and its cellular content. Rosenau and McCoy do not agree with this view, but believe they have demonstrated that the germicidal property of milk is independent of the number of cells present. However, Luckhardt and others have shown clearly that phagocytes actually occur in milk not uncommonly, although it has not been shown whether the number of bacteria disposed of by phagocytosis is sufficiently great to cause a decided decrease.

Fokker was the first to suggest the presence of bactericidal substances in fresh milk. He drew goat's milk under aseptic precautions and boiled one portion of it. After inoculating both the boiled and raw milk with lactic acid bacteria he found that the boiled milk turned sour before the raw milk did. $\mathrm{He}$ con- 
cluded from this observation that the bacteria multiplied at a greater rate in boiled milk than in raw milk. Fokker's work stimulated a number of other investigators to take up the problem.

The results are not concordant, and while there are those who firmly believe in the existence of a germicidal property in fresh cow's milk, even though a feeble one, others maintain that bactericidal substances do not exist in milk.

Ehrlich and Brieger in 1893 demonstrated that antitoxins and bactericidal substances may be transmitted through milk. Uffelmann, Park, Hunziker, Koning, Kolle and his co-workers, and Hippius are among those who believe in the presence of bactericidal substances in milk.

Park does not think that the germicidal effect is of sufficient intensity to be of practical value. Kolle and his collaborators carried on extensive experiments which indicate that milk has a bactericidal property which affects cholera spirilla, but does not affect Bacillus typhosus, B. dysenteriæ, B. coli, and B. enteritidis. However, according to these authors, fresh milk has a restraining property for dysentery bacilli, but in small measure only and in negligible quantity for Bacillus typhosus, B. paratyphosus, B. coli, and B. enteritidis.

Marshall found that the number of bacteria in fresh milk may be reduced to one-fortieth, Hunziker to one-tenth the original number, while Klimmer noted a less marked reduction, and concluded that bacteria are merely restrained, not destroyed.

Hunziker's work not only confirmed the presence of a germicidal property in fresh milk, but showed that it was more marked -although of short duration-at $37^{\circ} \mathrm{C}$. than at lower temperature.

While Hesse recorded the destruction of cholera spirilla in fresh milk, Basenau took the opposite view, claiming that cholera spirilla multiply readily in fresh milk.

More recently v. Behring has claimed that milk possesses a bactericidal property similar to that of blood, and that this property is enfeebled by heating the milk to $60^{\circ} \mathrm{C}$. for thirty minutes. He thinks that heated milk, having had its immune bodies destroyed or diminished, is not suitable for infant feeding.

St. John and Pennington found that heating to $79^{\circ} \mathrm{C}$. destroyed the restraining property of fresh milk, and concluded that pasteurized milk permits greater multiplication of bacteria than does raw milk. Ayers and Johnson hold a different view and have stated that when the initial number of bacteria in pasteurized and raw milk is approximately alike the rate of multiplication is also similar. It should be remembered, however, that if there is any difference in the rate of growth of bacteria in raw and pasteurized milk, this phenomenon would be manifest only when 
the raw milk is quite fresh. When a few hours old the germicidal property rapidly disappears.

According to Evans and Cope the bactericidal property of fresh milk is destroyed at $68^{\circ} \mathrm{C}$. and injured at $55^{\circ} \mathrm{C}$. The authors further claim that the germicidal property exerts its influence only on some types of bacteria, while others are merely restrained. The property also varies in milk from different animals.

Rosenau and McCoy think that the presence of agglutinins is an important factor in bringing about the apparent reduction of bacteria in fresh milk. They have shown that when milk is violently shaken the number of colonies does not decrease, and this observation leads the authors to conclude that the milk, after standing, causes the bacteria to clump, and that, therefore, fewer colonies appear on the plates, although the actual number of cells may not have been reduced. This view seems to be supported by the fact that in centrifugalized milk the colony count is greater than in the same milk before centrifugation.

Brudny, working with Bacillus coli, observed that this organism is restrained in fresh milk, or even injured to such a degree as to acquire altered properties.

Heinemann and Glenn found a distinct relation between the decrease of numbers of a certain type of bacteria inoculated into milk and the agglutinative property toward the same type of the serum prepared from the same milk. The higher the agglutinative property of the milk-serum, the more marked was the reduction in the number of colonies counted.

Stocking takes the position that among the large number of bacteria which gain access to milk, many find themselves in an unfavorable environment and die. This phenomenon, the author thinks, explains the so-called germicidal property of fresh milk. In agreement with this view is an observation of Coplans, who assumes that bacteria, when dropping into a new medium, remain dormant for a time before beginning to multiply. It seems difficult, however, to harmonize this hypothesis with all the facts observed.

The majority of investigators agree on the point that in fresh milk there is not a marked multiplication, but that, as a rule, there is a limited decrease. The following figures may illustrate the degree to which bacteria actually seem to diminish in fresh milk if the colony count is taken as index (Heinemann and Glenn):

\begin{tabular}{|c|c|c|c|c|c|c|c|c|}
\hline NUMBER OF BACT & IA & FR & MILK & $\mathrm{TT}$ & $\mathrm{HO}$ & NT & $\mathrm{LS}$ & \\
\hline Original number. & 500 & 1100 & 1400 & 500 & 1000 & 600 & 300 & 500 \\
\hline After two hours. . & 400 & 200 & 500 & 1300 & 1000 & 200 & 0 & 1400 \\
\hline After four hours. . . . . . & 300 & 0 & 400 & 1800 & 400 & 100 & 800 & 3400 \\
\hline six hours......... & 600 & 300 & 300 & 2300 & 200 & 200 & 1000 & 5600 \\
\hline eight hours. . . . . . & 1000 & 4300 & 900 & 3200 & 1000 & 200 & 1100 & 6300 \\
\hline
\end{tabular}


These figures show that the decrease, when it really exists, is relatively small and hardly comparable to the germicidal action of fresh blood. In some instances there is no decrease, but rather the reverse. When there is an actual decrease, this may continue for four to six hours at $37^{\circ} \mathrm{C}$, after the lapse of which time there is usually a consistent increase.

The estimation of numbers of bacteria in practically all the work reported was made by counting the colonies formed. It is clear that this method has its limitations, as it is not possible to determine whether each colony originated from one or more cells. The method takes no account of the possible clumping of bacteria, with an apparent instead of a real reduction in numbers.

Furthermore, bactericidal substances would destroy bacteria in large numbers, while the figures show merely a limited reduction. Agglutinins, on the other hand, would cause a smaller colony count, without diminution of bacteria as a necessary consequence.

Rosenau and McCoy, Heinemann and Glenn, and others have shown that the restraining property of fresh milk does not act alike on all kinds of bacteria. In fact, some types do not seem to suffer, but hold their own or even increase. This fact may account for some variations in results obtained by different investigators since the bacterial flora of milk is a variable one. When those bacteria that are sensitive to the germicidal action predominate in a given sample of milk a marked reduction of numbers will be noticeable; and when the bacteria that are unaffected predominate the count will remain the same or increase. This is graphically illustrated in Fig. 83, which shows the relative effect of heating milk to $56^{\circ}$ and $75^{\circ} \mathrm{C}$.

The milk used in these experiments was drawn fresh from the cow under aseptic precautions and contained small numbers of bacteria. The chart shows that even in the first two hours raw milk shows a slight bacterial increase if the average number of fifteen samples is taken. After four hours there is a decided increase. When the milk is inoculated with large numbers of bacteria growth is restrained for two hours, and then there is an increase which becomes more marked after four hours. If the milk is heated to $56^{\circ} \mathrm{C}$. bacteria apparently multiply from the start, and if heated to $75^{\circ} \mathrm{C}$. this seeming increase is more pronounced. After a lapse of two hours the increase in heated milk is quite rapid.

Rosenau and McCoy have shown that the degree of vigor employed in shaking the sample of milk has some influence on the number of colonies appearing. With vigorous shaking the number is, as a rule, larger than with moderate shaking. This 
phenomenon argues in favor of the presence of agglutinins, and it must be assumed that agglutination is at least one of the factors that produce the results ascribed to a germicidal property in fresh milk.

The possible presence of other antibodies is not excluded, however. Bactericidal substances do not react unless complement is present, and it is believed by some investigators, as stated before, that milk contains complement in but small quantity, if

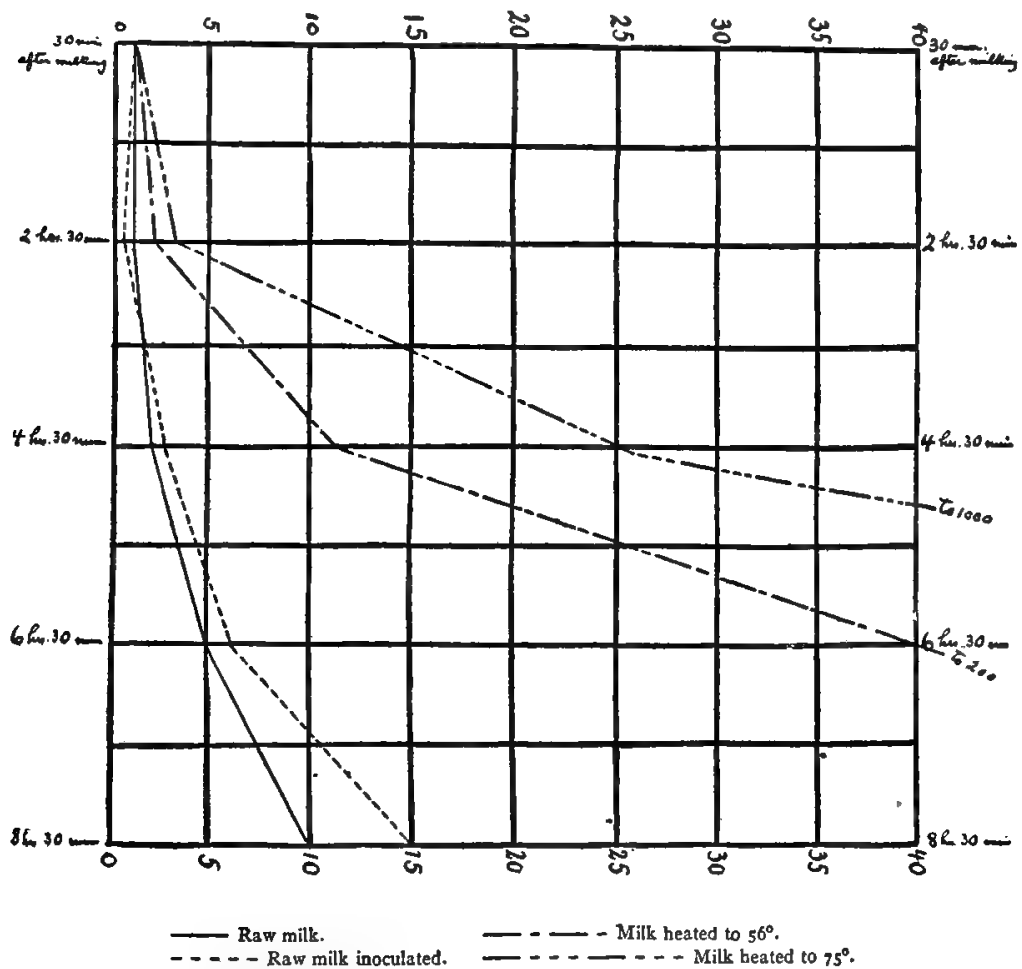

Fig. 83.-Relative growth of bacteria in raw milk, raw milk inoculated, and inoculated milk previously heated to $56^{\circ}$ and $75^{\circ} \mathrm{C}$.

at all. In the absence of complement, bactericidal substances cannot be instrumental in reducing numbers of bacteria. In colostrum milk, however, complement is usually present, and this fact and the presence of relatively large numbers of leukocytes may explain the marked reduction of bacteria in the early secretion. This phenomenon has been observed by several investigators, notably Koning and Rullmann and Trommsdorff.

The actual facts in regard to the so-called germicidal property 


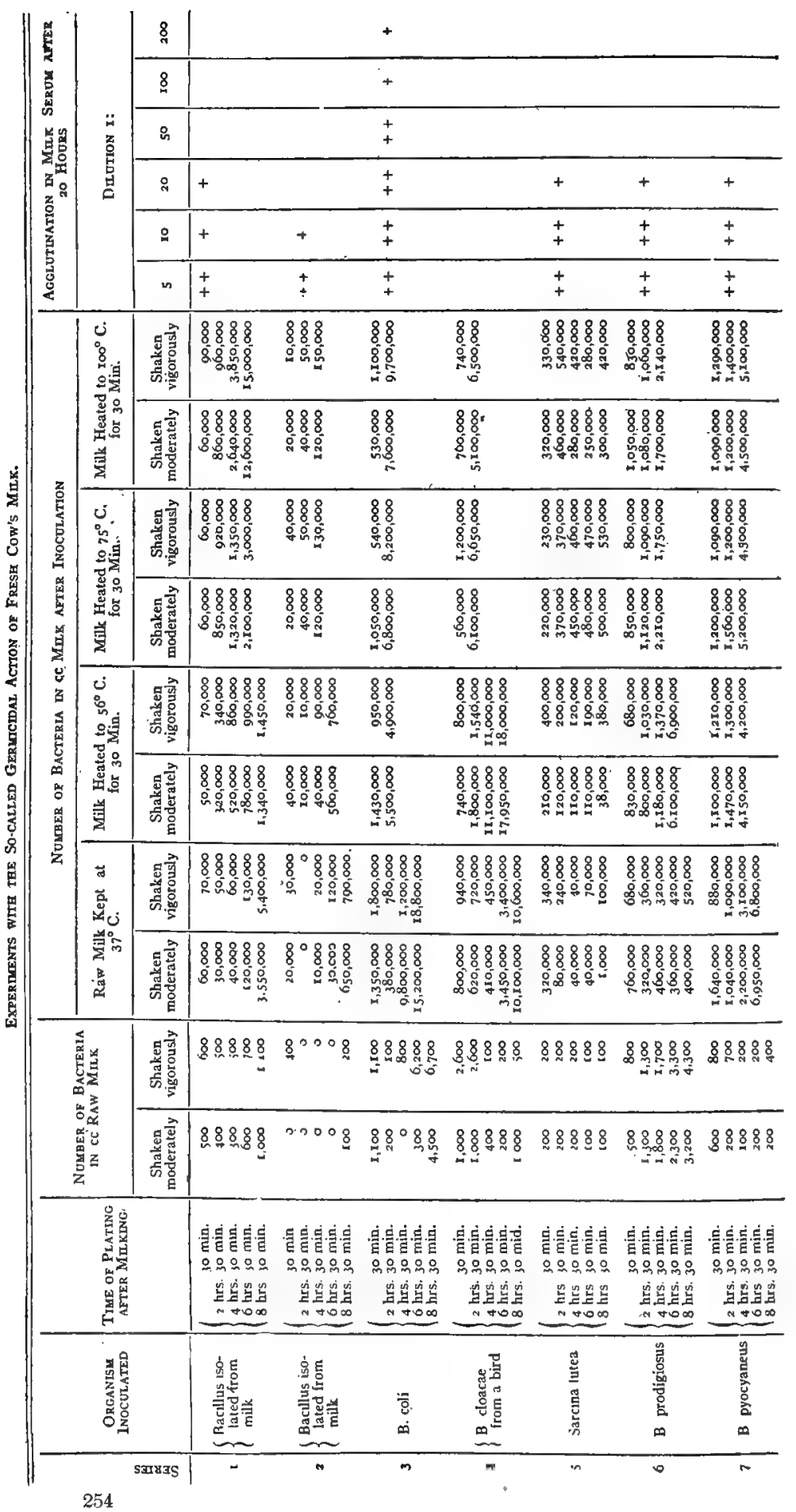




\begin{tabular}{|c|c|c|c|c|c|c|c|}
\hline & & & & & $\begin{array}{l}+ \\
+ \\
+\end{array}$ & & $\stackrel{+}{+}$ \\
\hline & & & + & & $\begin{array}{l}+ \\
+ \\
+\end{array}$ & + & $\begin{array}{l}+ \\
+ \\
+\end{array}$ \\
\hline \pm & & + & + & + & $\begin{array}{l}+ \\
+ \\
+\end{array}$ & + & $\begin{array}{l}+8 \\
+ \\
+\end{array}$ \\
\hline $\begin{array}{l}+ \\
+ \\
+ \\
\end{array}$ & + & \pm & $\begin{array}{l}+ \\
+ \\
+\end{array}$ & + & $\begin{array}{l}+ \\
+ \\
+\end{array}$ & $\begin{array}{l}+ \\
\pm \\
+\end{array}$ & $\begin{array}{l}+ \\
\pm+1 \\
+\quad+ \\
\end{array}$ \\
\hline $\begin{array}{l}+ \\
+ \\
+\end{array}$ & + & $\begin{array}{l}+ \\
+ \\
+\end{array}$ & $\begin{array}{l}+ \\
+ \\
+\end{array}$ & + & $\begin{array}{l}+ \\
+ \\
+\end{array}$ & $\begin{array}{l}+ \\
+\end{array}$ & $\begin{array}{l}+ \\
+ \\
+\end{array}$ \\
\hline $\begin{array}{l}+ \\
+ \\
+\end{array}$ & + & $\begin{array}{l}+ \\
+ \\
+ \\
\end{array}$ & $\begin{array}{l}+ \\
+ \\
+ \\
\end{array}$ & + & $\begin{array}{l}+ \\
+ \\
+ \\
\end{array}$ & $\begin{array}{l}+ \\
+ \\
+\end{array}$ & $\begin{array}{l}+ \\
+ \\
+ \\
+\end{array}$ \\
\hline $\begin{array}{l}88.8 \\
880 \\
388 \\
58 \\
40\end{array}$ & 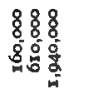 & 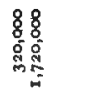 & 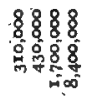 & $\begin{array}{l}888 \\
88.8 \\
500 \\
70 \\
\infty\end{array}$ & 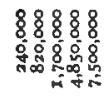 & 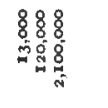 & 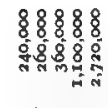 \\
\hline 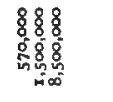 & 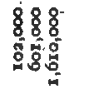 & 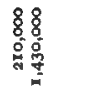 & 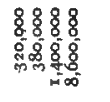 & 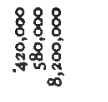 & 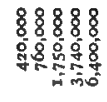 & 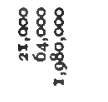 & 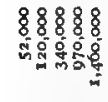 \\
\hline 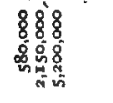 & 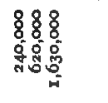 & 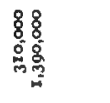 & 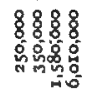 & 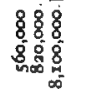 & 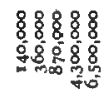 & 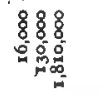 & 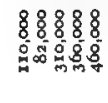 \\
\hline 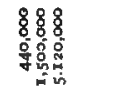 & 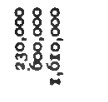 & 88 & 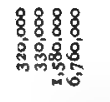 & 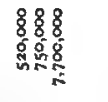 & 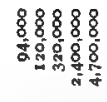 & 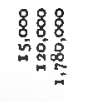 & 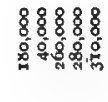 \\
\hline 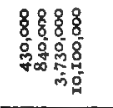 & 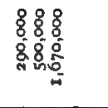 & 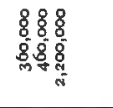 & 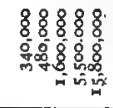 & 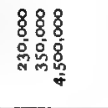 & 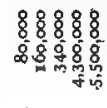 & $\begin{array}{r}8888 \\
888 \\
=480 \\
40\end{array}$ & 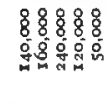 \\
\hline 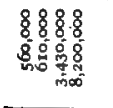 & 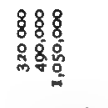 & 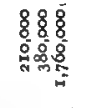 & 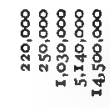 & 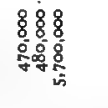 & 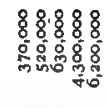 & 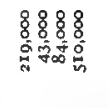 & 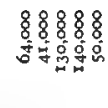 \\
\hline 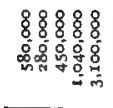 & $\begin{array}{l}88888 \\
8888 \\
58 \\
08 \\
08\end{array}$ & 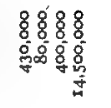 & 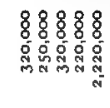 & 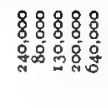 & 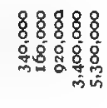 & 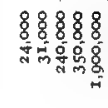 & $\begin{array}{l}88^{\circ} 00 \\
80^{\circ} \\
0 \% \\
0 \%\end{array}$ \\
\hline 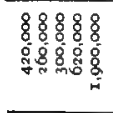 & 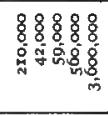 & 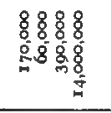 & 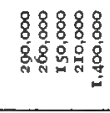 & 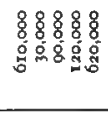 & 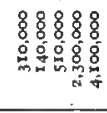 & 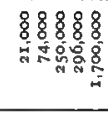 & $\begin{array}{l}888^{\circ} 8 \\
880^{\circ} \\
800 \\
8\end{array}$ \\
\hline $8888 \%$ & 88888 & 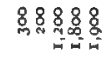 & \& 8088 & 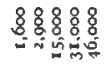 & 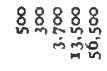 & $8888 \%$ & 88888 \\
\hline 8\%용ㅇㅁㅇㅛ & 878 & $8^{\circ} 8888$ & 88888 & 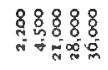 & 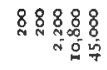 & 88888 & $88 \%$ \\
\hline 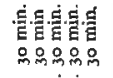 & 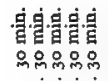 & 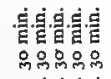 & 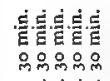 & 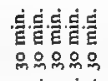 & 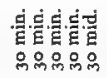 & 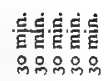 & 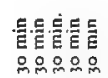 \\
\hline 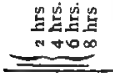 & 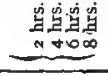 & 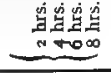 & 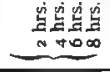 & 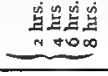 & 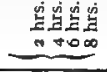 & 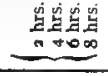 & 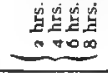 \\
\hline 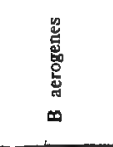 & 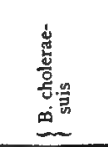 & 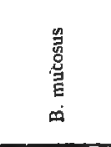 & 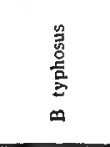 & 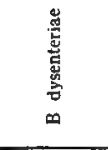 & 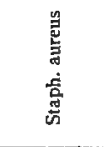 & 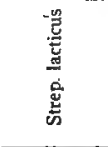 & 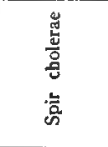 \\
\hline to & $=$ & \& & $=$ & $\cong$ & 9 & \pm & $\approx$ \\
\hline
\end{tabular}


of fresh milk are these: A moderate decrease of bacteria, when estimated by the colony count, is frequently observed in fresh milk. The reduction is marked at $37^{\circ} \mathrm{C}$., but of short duration, lasting from four to six hours. At lower temperature the reduction is less definite, but is observable for a period of twelve or even twenty-four hours. At $56^{\circ} \mathrm{C}$. the reduction becomes less apparent, and when the milk is heated to $68^{\circ} \mathrm{C}$. or above no reduction is noticeable. The decrease in numbers varies with the predominant kind of bacteria present and with the source of the milk. Typical lactic acid bacteria seem to be but slightly affected by the restraining property of fresh milk and multiply substantially from the moment the milk is drawn.

Freezing seems to have no destructive influence upon the germicidal property unless the time factor enters, and dilution of milk renders it less apparent.

The cause of the phenomenon usually called the germicidal property of fresh cow's milk is probably the influence of several factors, of which the following are perhaps the most important:

1. The presence of antibodies; these are chiefly agglutinins and bactericidal substances.

2. The phagocytic action of leukocytes which operates chiefly during the colostral period.

3. The disappearance of micro-organisms that find in milk an unsuitable environment.

4. The fact that some bacteria do not seem to multiply from the moment they enter a new environment, but hesitate for a brief period.

5. The presence of lecithin, which has a restraining action on bacteria.

Whatever the true cause or causes of the so-called germicidal property of fresh milk may be, it seems certain that it is too feeble to be of practical value. It cannot be used successfully as an argument against the practice of heating milk for the purpose of destroying pathogenic bacteria, even though antibodies are partly destroyed at the temperature required for pasteurization. As a matter of fact, the germicidal action disappears, as a rule, after a lapse of twelve hours, so the keeping quality of milk is not materially prolonged.

\section{BIBLIOGRAPHY}

Ayers and Johnson: United States Dept. of Agri., B. A. I., Bull. 126, November, 1910 .

Basenau: Arch. f. Hyg., 1895, vol. 23, p. 170.

v. Behring: Therapie der Gegenwart, 1904 , vol. 4, p. 1.

Brudny: Cent. f. Bakt., Abt. 2, 1908, vol. 22, p. 193.

Coplans: Lancet, 1907 , vol. 2, p. 1074.

Ehrlich and Brieger: Ztschr. f. Hyg., 1893, vol. 13, p. 336. 
Evans and Cope: Univ. of Penna. Med. Bull., 1908, vol. 21, p. 264.

Fokker: Ztschr. f. Hyg., 1890, vol. 9, p. 41; Fortschr. d. Med., 1890, vol. 8, p. 7.

Heinemann and Glenn: Jour. of Inf. Dis., 1908, vol. 5, p. 534.

Hesse: Zeitsch. f. Hyg., 1894, vol. 17, p. 238.

Hippius: Jahrb. f. Kinderheilk., 1905, vol. 61, p. 372.

Hunziker: Cornell Univ. Agri. Exper. Sta., Bull. 197, 1901.

Klimmer: Zeitsch. f. Tiermed., 1902, vol. 6, p. 206; Arch. f. Kinderheilk., 1903 , vol. 36 , p. 1 .

Kolle: Milchhygienische Untersuchungen, Jena, 1904, G. Fischer; Kilin. Jahrbuch, 1905 , vol. 13 , p. 328 .

Koning: Milchwirthsch. Centr., 1905, vol. 1, pp. 49, 60, 99.

Luckhardt: Jour. Inf. Dis., 1910, vol. 7, p. 57.

Marshall: Cent. f. Bakt., Abt. 2, 1902, vol. 9, p. 496.

Park: New York Univ. Bull. of Med. Sci., 1901, vol. 1, pp. 2, 71.

Rosenau and McCoy: Jour. Exper. Med., 1908, vol. 18, p. 165; Bull. 56, Public Health and Marine Hospital Service, p. 457.

Rullmann and Trommsdorff; Arch. f. Hyg., 1906, vol. 59, p. 229.

St. John and Pennington: Jour. Inf. Dis., 1907, vol. 4, p. 647.

Stocking: Storrs' Agri. Exper. šta., Bull, 28, 1904, p. 89.

Uffelmann: Berl. Klin. Wchschr., 1892, vol. 29, p. 1209. 


\section{MICRO-ORGANISMS IN MILK}

IT is now generally conceded that milk is secreted from the mammary glands in sterile condition. This assumption is borne out by experimental evidence, which has shown that at least the majority of bacteria do not pass from the circulation into the secretion. It has been possible furthermore to obtain sterile milk occasionally by inserting a sterile tube into the udder and, finally, we know that other body secretions are commonly sterile.

The milk in the udder, however, contains, as a rule, microorganisms, although, as we have seen in the previous chapter, multiplication is limited and the actual number present in the udder relatively small. When milk is taken from the udder by sucking there is small chance for contamination, but when it is drawn for supplying the market the operations necessary between removal from the udder and consumption are numerous, and with each step of the journey from cow to consumer an opportunity is offered for the entrance of micro-organisms.

The dust from the air, filth attached to the udder or coat of the animal, foreign matter from the hands of the milker, all these sources of bacteria serve to contaminate the milk in the stable. The utensils may contribute their share of bacterial pollutionstrainers, coolers, bottles, cans, pasteurizing machinery, bottle caps, and other appurtenances require great care in order to avoid heavy pollution. And at best some bacterial contribution is added to the milk from all these sources. By careful attention to details, however, the number of bacteria in market milk can be reduced to a marked degree.

The entrance of micro-organisms is not the only cause of the great pollution of milk. Milk contains all the food substances required for enormous multiplication of many types that gain access to milk, and the only reliable method of preventing this multiplication is keeping milk at low temperature. Provision should be made to cool milk as soon as possible after milking. During transportation on the producer's cart, in the railroad car, or in the delivery wagon cooling facilities must be provided for, to reduce bacterial multiplication to a minimum. Equal care is necessary in the home, where cooling facilities are only too frequently poor or wholly absent.

The distribution of micro-organisms in milk is not a homogeneous one, as might be expected. Examination of several sam- 
ples from the same bottle of milk, even though well shaken, will almost invariably give different results, sometimes varying within wide limits. This is due in part to the fact that bacteria occur largely in clumps, and these clumps are not always easily broken up. Furthermore, bacteria cling to suspended matter and, when milk stands, many bacteria settle with suspended particles, while large numbers adhere to the fat globules and rise to the surface. Gravity cream, therefore, contains more bacteria than the skimmed milk below the cream line.

The distribution of bacteria in fresh cream depends in a measure upon the method by which the cream is separated. Since bacteria cling to the fat globules it is to be expected that a large number of the bacteria in the milk rise with the cream. Furthermore, bacteria multiply rapidly during the time required for the cream to rise, and the temperature best adapted to the process is also favorable for bacterial growth. In centrifugal cream conditions are somewhat different. The cream is separated from the milk immediately after milking, when the temperature is still relatively high, or the cream is separated within a short time, if the milk is delivered at a creamery. There is, therefore, no appreciable chance for bacterial growth, although clumps of bacteria are broken up during centrifugation.

The germ content of cream has received the attention of some investigators. Russell and Hastings state that gravity cream is usually richer in bacteria than separator cream, but that both gravity and separator cream have a larger germ content than the milk from which they were obtained. This is not surprising in gravity cream, since some time must elapse before the cream is gathered, but in separator cream the only explanation that is offered is the fact that bacteria cling to the fat globules and thus escape from the skimmed milk. This view is held by some authorities. Scheurler, working with 20 per cent. cream, agrees that both gravity and centrifugal cream contain more bacteria than the milk before centrifugation, and Niederstadt goes so far as to state that the cream contains 75 per cent. and the separator milk 25 per cent. of the germ content of the milk. Rolet, after centrifugating five samples of milk, found a slightly higher number of bacteria in the cream than in the milk. Anderson and also Wilkens substantially agree with this view.

Other workers have obtained wholly different results. Backhaus and Cronheim's experiments indicate that by centrifugation the majority of bacteria go into the skimmed milk. Eckles and Barnes state that 47 per cent. of the bacteria are thrown into the bowl sediment; 29 per cent. are in the skimmed milk, and 24 per cent. in the cream. Swithinbank and Newman state that 
"roughly, 60 per cent. of the organisms will be found in the bowl sediment (separator slime); 25 per cent. in the separated milk, and 15 per cent. in the separated cream."

The writer, together with Luckhardt and Hicks, working with 40 per cent. cream, found that the skimmed milk running from the separator contained an average of 2130 bacteria per cubic centimeter, while the cream contained 132 bacteria per cubic centimeter and the original milk 738 . The cream contained 17 per cent. of the germ content of the milk, not taking into account the number thrown into the separator slime. The total germ content per cubic centimeter of the final product after the milk and cream were reunited was, therefore, considerably greater than that of the original milk. This result is in agreement with the work of Severin, who explains the phenomenon on the ground that clumps of bacteria are broken up by the centrifugal force, and that then the colony count increases, although the actual number of cells is diminished by the loss in the bowl sediment.

The writer and Class attempted later to harmonize the contradictory results reported by various authorities. The work was carried out by regulating a hand separator in such a manner as to obtain cream of varying richness. The 99 tests made covered cream of different' fat content from 16 to above 55 per cent. The experiments demonstrated that-1, cream fresh from the separator, as a rule, contains less bacteria than the original milk; 2 , the number of bacteria in separator cream decreases proportionately as the fat content increases; 3 , the number of bacteria in separator milk is larger than the number in the milk from which it was obtained if the cream contains up to about 35 per cent. of fat. Above this percentage the number is smaller; 4, the number of bacteria in separator milk decreases proportionately with the increase of fat in the separator cream. The results are graphically illustrated in Fig. 84 .

Similar results were obtained by Lamson, who states that "there is a slight indication that an increase in butter-fat results in a decrease in percentage count of bacteria."

The decrease of bacteria coincident with the increase of fat in centrifugal cream is readily explained by the following reasoning: Bacteria cling to the fat globules and move toward the center of the separator, but during this time the centrifugal force gradually releases them from the fat and they are thrown into the skimmed milk and to some extent into the slime. The longer the centrifugal force exerts this influence, the larger is the number of bacteria that are released from the fat. The richness of the cream in the separator used for these experiments is regulated by 
a screw which operates so as to hold the cream for a longer or shorter period in the separator. The cream becomes more compact and richer in fat the longer it is held subject to the centrifugal force, so that with increasing richness more bacteria are removed.

The reason for the progressive decrease of bacteria in the skimmed milk as the cream becomes richer is not clear. Wilkens thinks that a large number of bacteria are destroyed by the violent rotation of the centrifuge, but this does not explain the facts. While the period during which the cream is held in the separator increases, it decreases for the skimmed milk, so that fewer bacteria

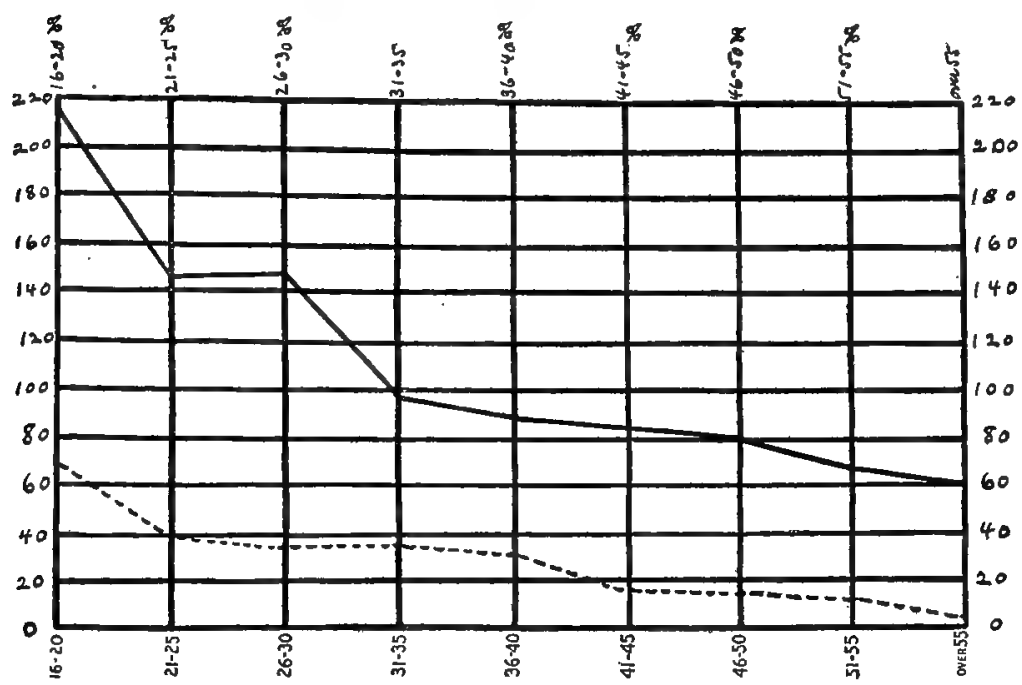

Fig. 84. - Showing relative number of colonies in separator cream and milk. Ordinates represent relative numbers of colonies, abscissæ represent percentage of fat in cream. Solid line = skimmed milk; broken line $=$ cream. The 100 line represents the relative number of bacteria in the original milk.

are thrown into the slime. Since, however, the skimmed milk is held for progressively shorter periods, as the cream is held longer, the clumps of bacteria are probably broken up in smaller degree, and thus the progressive decrease of the germ content in separator milk is partially explained.

Market milk, it is readily understood, may contain large numbers of bacteria, enormously greater than the number contained in the udder. As a matter of fact, unless great precautions are taken by producers, shippers, and distributors alike, heavy bacterial pollution of milk. cannot be avoided. In most cases the entrance of bacteria to milk is due to filth which drops into the 
milk and to insufficient washing of utensils, but not infrequently it is due to faulty transportation facilities. It is fortunate for the milk-consuming public that, as a rule, the micro-organisms in milk are harmless. If this were not true the consequences of drinking milk would be far more serious than they actually are. When we consider that the average daily consumption of milk by each individual in the United States is about two-thirds of a pint, without counting the enormous amount of butter, cheese, and other dairy products consumed, it is amazing that disease is not more frequently spread through the milk-supply than actually seems to be the case.

According to Alvord there were about 17,000,000 dairy cattle in the United States at the close of the year 1895. Of these $17,000,000$, about $11,000,000$ cows were primarily butter producers, $1,000,000$ cheese producers, and the milk of 5,000,000 was consumed by the families of their owners, or on the farms where produced, or was sold to be consumed as milk, either fresh or condensed. These estimates are tabulated by Alvord as follows:

\begin{tabular}{|c|c|c|c|c|c|}
\hline $\begin{array}{c}\text { Number of } \\
\text { cows. }\end{array}$ & Product. & $\begin{array}{l}\text { Rate of } \\
\text { product. }\end{array}$ & $\begin{array}{c}\text { Total } \\
\text { product. }\end{array}$ & $\begin{array}{c}\text { Rate of } \\
\text { value. }\end{array}$ & Total value. \\
\hline $\begin{array}{r}11,000,000 \\
1,000,000 \\
5,000,000\end{array}$ & $\begin{array}{l}\text { Butter } \\
\text { Cheese } \\
\text { Milk }\end{array}$ & $\begin{array}{l}125 \text { pounds } \\
280 \text { " } \\
350 \text { gallons }\end{array}$ & $\begin{array}{r}1,375,000,000 \mathrm{lbs} . \\
280,000,000 \mathrm{l} \\
1,750,000,000 \text { gals. }\end{array}$ & $\begin{array}{l}20 \mathrm{c} . \\
8 \mathrm{c.} \\
9 \mathrm{c.}\end{array}$ & $\begin{array}{r}\$ 275,000,000 \\
22,400,000 \\
157,500,000\end{array}$ \\
\hline
\end{tabular}

These figures give an idea of the amount of milk and dairy products consumed by the population. The actual amount at the present time is, of course, much greater, and the rate of consumption has probably increased. The consumption of cheese especially is larger in proportion to the population today than it was heretofore.

There are many figures available as to the number of bacteria present in market milk. Rosenau found in Washington, D. C., in the general milk-supply $11,270,000$ bacteria per cubic centimeter in the summer of 1907 , and $22,134,000$ in the summer of 1906. Park counted from 300,000 to $5,000,000$ in the milk of New York City, and Sedgwick and Batchelder determined the average number of bacteria per cubic centimeter in the milk of Boston 4,500,000. Jordan and the writer examined market milk in Chicago, with the following results:

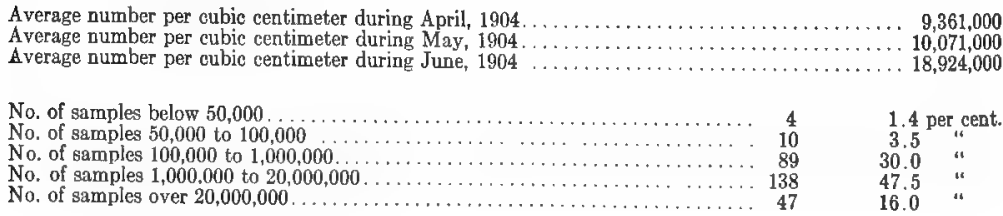


The writer found in Chicago in 108 samples of raw milk 4,804,300 bacteria per cubic centimeter, and 1,772,100 in 107 samples of pasteurized milk.

If milk were a transparent fluid like water these enormous numbers would render it turbid, and we would hesitate to consume as food a substance of such appearance.

These figures do not, however, adequately represent conditions as they exist at the present time. Pasteurization of milk has greatly increased, especially in large communities, and the number of bacteria is materially reduced by this process. Furthermore, the methods of production have improved, and milk with relatively small numbers of bacteria is not as uncommon today as formerly. It should also be remembered that numbers of bacteria in milk as published are not obtained by uniform methods, so that the results are by no means comparable. However, the fact remains that in communities where chiefly raw milk is consumed the bacterial pollution is relatively heavy.

As stated before, the great majority of micro-organisms detected in milk are harmless, but not infrequently the germs of infectious diseases gain access. Epidemics of typhoid fever, diphtheria, scarlet fever, sore throat, and other diseases have been traced to infected milk-supplies. It has been shown further that milk infected with bovine tubercle bacilli is not infrequently the cause of tuberculosis in children, and such milk is only too common. Probably in all municipalities where raw milk is sold some of it is infected with tubercle bacilli.

The virus of the diseases mentioned gains access to milk through human carriers or infected animals. And we know furthermore that some disease germs are able to multiply in milk at an enormous rate when the temperature of the milk is favorable. Even at $15^{\circ} \mathrm{C}$, a temperature not at all uncommon in market milk, there may be multiplication of some disease germs.

On the other hand, germs may be useful by their action on the constituents of milk. Buttermilk, for example, may contain. $500,000,000$ to $1,000,000,000$ bacteria per cubic centimeter; the flavor of butter is largely dependent upon the kinds of bacteria active in the ripening of cream; and the aroma and digestibility of cheese are the result of the action of bacteria and molds. None of these dairy products can be successfully produced from sterile milk, or even from milk containing a relatively small number of bacteria, unless the necessary organisms are inoculated, but as our knowledge of the bacteria that produce desirable flavors in dairy products grows, it becomes more feasible and more desirable to use only clean and pasteurized milk for manufacture of cheese, butter, and other dairy products. This is the more important, 
since diseases have also been spread by milk products, and by preventing infectious material from entering milk, or destroying disease germs by application of heat, the menace from dairy products is reduced.

Micro-organisms in milk produce profound changes in its constituents, and these changes become manifest. shortly after milking; the larger the number of organisms present, the sooner, as a rule, does decomposition commence. Milk proteins are broken down by proteolytic bacteria and by molds, the products being similar to the proteolytic changes of other proteins. Caseoses, caseones, amino-acids, ammonia, hydrogen sulphid, phosphoric acid, and gases are some of the bacterial products. Lactalbumin is broken down by bacteria into albumoses, peptones, amino-acids, etc. Milk-sugar yields lactic acid, volatile acids, alcohol, gases, etc. Milk-fat is not readily decomposed, but a few types of bacteria that have the ability to decompose fat occur quite commonly in milk. However, these fat-splitting organisms are usually held in check by other ones, chiefly the lacticacid-producing bacteria, so that decomposition of milk-fat is a slow process, and does not become noticeable, as a rule, for many days.

The nature of decomposition of milk depends largely upon the predominant kinds of organisms present and the temperature at which the milk is kept. At low temperature a different result obtains from room temperature, and at $37^{\circ} \mathrm{C}$, or higher still, other products appear. At room temperature milk undergoes changes which are fairly uniform, although exceptions are not wanting. These changes are sometimes called "spontaneous" or "normal." Both these terms are not strictly correct and are apt to give misleading impressions. The term "spontaneous" is not correct, because milk will not decompose unless micro-organisms are present. It is true that market milk without microorganisms does not exist, but in its true meaning "spontaneous" suggests decomposition without the presence of a foreign agency. The term "normal" is perhaps more appropriate, since the bacterial flora of milk almost invariably includes lactic acid bacteria, and these multiply in milk at such a rate as to outstrip other organisms in the large majority of instances.

The "normal" changes taking place in milk when it stands at room temperature take a fairly definite course and represent periods which can be observed with regularity. These periods are, of course, not distinctly separated from each other, but for convenience may be divided into five phases.

The first phase is the so-called incubation period of milk. The changes in milk during this period are relatively insignificant. 
The period is of short duration, lasting usually not beyond twelve hours. The cleaner the milk, the longer is the duration of this period, because in clean milk the number of bacteria is relatively small, and multiplication, therefore, does not become evident for some time. During the incubation period all those bacteria that are able to grow in milk increase slowly in numbers and their products neutralize each other to some extent. Some types are restrained by the so-called germicidal property of fresh milk, while others - among them the lactic acid bacteria-are not influenced. However, in spite of growth of lactic acid bacteria, the acidity apparently does not increase for several hours after milking. This phenomenon may be due to at least four causes, namely:

1. Carbon dioxid escapes, so that acid formation in small quantity is obscured.

2. Some of the acid produced by lactic acid bacteria combines with calcium and phosphates, so that these are precipitated, and the increase in acidity is not recorded by the usual chemical indicators.

3. The increase in acid is slow at best, so that titration figures may be within the limits of experimental error.

4. Proteolytic bacteria produce small amounts of alkaline protein decomposition products which may partially neutralize the acid formed.

During the second phase the increase of acid is distinct, due to greater multiplication of lactic acid bacteria. Proteins have been partly broken down by proteolytic bacteria and more suitable food conditions are created thereby for lactic acid bacteria. As acid increases proteolysers are restrained, while Bacillus coli, B. aërogenes, and Streptococcus lacticus multiply readily. More or less gas is formed, the amount depending upon the relative number of bacteria of the Bacillus coli group present and upon the temperature. When the temperature is above $30^{\circ} \mathrm{C}$. and approaches $37^{\circ} \mathrm{C}$. gas formation is marked.

The third phase finds enough acid produced to restrain proteolytic bacteria entirely, and bacteria of the Bacillus coli group grow less and less rapidly up to a point where they cease multiplying entirely. Streptococcus lacticus, however, continues to multiply, as it is able to resist a larger amount of acid than the Bacillus coli group. But soon the acid accumulates to a degree which inhibits further growth of Streptococcus lacticus, and the maximum of acid has been reached.

Now the fourth phase commences. Molds and yeasts which prefer an acid medium begin to multiply. The former attack chiefly the proteins, while the latter ferment the milk-sugar which 
is rarely completely used up by the lactic acid bacteria. By protein decomposition ammonia is formed and the acid is gradually neutralized. The amount of acid is further decreased by molds, since some are able to utilize it for food.

Gradually the acid has completely disappeared, and proteolytic bacteria, having survived chiefly as spores, begin to multiply, producing protein cleavage products, and an ill-smelling fluid results. This is the fifth phase.

It should be emphasized that these periods are not distinctly defined and that frequent deviations may occur. After part of the acid has been neutralized in the fourth phase, it is quite probable that some lactic acid bacteria again multiply and the acid again increases. There may be a temporary reduction of acid, followed by a temporary increase, and this process may be repeated, so that the acidity goes back and forth several times. However, in the course of time the milk-sugar becomes nearly exhausted and, as this forms the chief food for lactic acid bacteria, acid formation becomes difficult. Variations from the general scheme outlined may also be the result of differences in the numeric strength of the groups of bacteria present.

Furthermore, the temperature at which the milk is kept naturally influences the results. Bacteria of the Bacillus coli group, as stated before, multiply at $30^{\circ}$ to $37^{\circ} \mathrm{C}$. more rapidly than at room temperature, while Streptococcus lacticus seems to grow at room temperature at least as well as at higher temperature. At room temperature, therefore, we have a relatively greater multiplication of Streptococcus lacticus and less growth of the Bacillus coli group, so that the desirable products of the streptococcus are more prevalent at the lower temperature. At $30^{\circ}$ to $37^{\circ} \mathrm{C}$., on the other hand, the products of the Bacillus coli group may be prevalent, so that gas and undesirable flavors develop.

When the temperature is above $37^{\circ} \mathrm{C}$. and up to $50^{\circ} \mathrm{C}$. lactobacilli enter the field, and by the large amount of acid produced may suppress molds and yeasts. Under these conditions proteolytic bacteria cannot grow, and the milk remains in a state of intense acidity.

Sometimes the number of lactic acid bacteria in fresh milk is exceedingly low, and peptonizing bacteria may obtain an early foothold. In such cases the milk putrefies before enough acid is formed to check the putrefactive bacteria. Rennet-forming bacteria also sometimes are present in great numbers and the milk coagulates without souring. This condition is known as sweet curdling.

It is evident from what has been said that there are many 
sources of bacterial pollution during the journey of milk from the cow to the consumer. A more detailed discussion of these sources will be taken up under the following heads:

1. Contamination in the udder.

2. Contamination during milking operations.

3. Contamination from utensils, machinery, bottles, etc.

4. Contamination during transportation.

5. Contamination in the hands of dealers and consumers.

\section{Contamination in the UdDeR}

Based on observations of Roberts, Lister, Hüppe, and others the belief was for some time prevalent that milk in the healthy udder contained no micro-organisms. By using a sterile cannula connected with a sterile flask milk has been obtained by these observers that seemed to remain unchanged for long periods unless exposed to the influence of the air. Lister in 1877 declared that "unboiled milk, as coming from the healthy cow, really has no ferment in it capable of leading to lactic fermentation or any other fermentation or any organic development whatever." This statement was based on an experience with two samples of milk. Trommsdorff claimed that he could easily obtain milk "absolutely free from germs" in any quantity desired by introduction through the teat duct of a catheter $10 \mathrm{~cm}$. long and $1.5 \mathrm{~mm}$. in diameter. And Evans and Cope also worked with milk obtained by introduction into the udder of a cannula that was supposedly sterile. Swithinbank and Newman obtained sterile milk by a simple apparatus, description of which is given in their book "The Bacteriology of Milk." They think that "no great difficulty need be experienced in obtaining sterile milk direct from the udder of the normally healthy cow." With the simple apparatus designed by them "the authors have for some years past found no difficulty in holding ready to hand a constant supply of sterile milk in its natural condition."

Later work, however, has shown that milk in the udder usually contains micro-organisms, and that even the strippings are not always sterile, although, as far as present knowledge goes, milk is secreted in a sterile condition by healthy mammary glands.

Schulz in 1892 examined milk at different stages of the milking process, and found that the first streams are richest in bacteria and that the number decreases as milking progresses. Moore, agreeing with Schulz, states that it is an exception to find milk directly from the udder free from micro-organisms, unless taken during the latter part of the milking process from a single quarter of the udder. 
The number of bacteria in milk while in the udder is usually small, and probably earlier examinations have failed to detect their presence, because but small amounts of milk were actually examined. When large amounts are used, as in experiments of Bolley and Hall, absence of bacteria is a rare occurrence; in fact, Moore was never able to obtain even a small amount of milk that was germ free. Boekhout and de Vries took 320 samples of milk, each one 15 c.c., without finding a single one sterile.

It is true that sometimes with rigid aseptic precautions milk that seems to contain no bacteria can be obtained from the udder. Bergey obtained such milk in about one-third of the samples examined. A similar result was obtained by the writer. In examining 45 samples of strippings, 15 plates remained sterile. However, since but 0.2 c.c. of milk was plated from each sample, it is quite likely that the presence of bacteria would have been detected if larger quantities had been used.

- Approaching the problem from a different direction, Simon found no bacteria in the glands of 9 udders from freshly slaughtered cows, while in the udders of 3 other cows streptococci were present. These latter ones, however, came from diseased cows. Ward, on the other hand, found bacteria in all parts of udders from freshly slaughtered cows. Barthel obtained results similar to those of Ward, but after investigation of the kinds of bacteria present he doubted the accuracy of his results, because the same types of bacteria occurred in the stable air and in the milk from the slaughtered animal. ${ }^{\prime \prime}$ It does not seem, however, that these findings militate against the interpretation that bacteria were actually present in the udder, since the view held by modern investigators holds that micro-organisms gain access to the udder from without.

The question of the origin of bacteria in the udder has occupied the attention of investigators to a considerable degree. It is now generally accepted that bacteria do not enter the milk from the mammary gland unless it is in an abnormal condition. Basenau's observation that Bacillus morbificans when injected into a cow can be recovered from the milk does not prove that bacteria pass through healthy mammary glands. According to Basch and Weleminsky, only those bacteria can pass through the mammary glands that cause hemorrhagic lesions or other abnormal conditions that alter the normal state of the udder. Mixing cultures with food, as Ward did, using Bacillus prodigiosus, produced negative results. Whether ultramicroscopic organisms, as the organism of foot-and-mouth disease, can be communicated to milk through the secreting glands is a problem that has not yet been solved.

When all the evidence pro and con of the existence of bacteria 
in the udder is weighed, the conclusion becomes inevitable that bacteria are constantly present in the udders of normal animals. The number of bacteria may vary, of course, within wide limits, and when relatively few are present it is perhaps possible to obtain milk that contains very few bacteria from the higher parts of the udder and that sometimes may be germ free.

Since bacteria probably do not pass through healthy mammary glands, the source of micro-organisms in the udder must be sought elsewhere. The most obvious portal of entry is the teat canal. The small portion of milk remaining in the teat duct, the favorable temperature, and the protecting folds of the membrane afford ample opportunity for bacteria to multiply in the duct. The aperture of the teat comes in contact with substances that carry bacteria, such as bedding, fodder, and dust, for example. These then multiply in the intervals between milking and some types reach into the cistern, where they persist and from whence they gradually invade upper parts of the udder. It may be objected that the sphincter muscle at the teat is an obstacle to the entrance of bacteria, but the folds of the muscle probably leave openings of sufficient size to permit micro-organisms to pass.

Whether this is the only source of bacteria in the udder remains problematic. Harding and Wilson have observed that during the first few days of the lactation period, the colostrum period, germs were distinctly more abundant than later, and that toward the end of lactation the numbers tended to decrease. The authors suggest that perhaps the inflamed condition of the udder during the early lactation period is responsible for the large numbers of bacteria present, and that later, while the normal udder is in full flow, it is daily subjected to complete distention, which is the first stage of inflammation. And finally, when the flow begins to fall off rapidly, the udder is no longer fully distended, and this inflammatory condition ceases. The relation of the germ content of milk in the udder during inflammatory conditions is a problem that has not been fully investigated, and that may throw additional light on the presence of bacteria in the udder.

The number of bacteria in milk, when drawn aseptically from the udder, varies in different animals and may also vary in the quarters of the udder of the same animal. Hastings and Hoffmann have studied the bacterial content in milk directly from the udder of 3 cows, and found that the averages were 31,$000 ; 191,000$; and 810 respectively. The authors think that the milk in the udder of some cows contains consistently greater numbers of bacteria than in others, and that this fact should be taken into account when low bacterial numbers are specially desirable, as in 
certified milk. The variation in the milk from each one of the 3 cows was also material. The maximum count from one cow was 305,000 , the minimum 1700 ; from the second cow the figures were $3,500,000$ and 2500; and from the third one, 4250 and 50 . It is clear that the variation in numbers of bacteria in the udder at different periods may be considerable.

This fact is emphasized by the work of Harding and Wilson, who made the following counts in milk derived from the different quarters of the same udder: the average content of the samples from the front quarters was 191 and 249 per cubic centimeter respectively, while those from the back quarters gave averages of 625 and 635 per cubic centimeter. The authors state further that this is not an accidental relationship, because in each of the three herds studied the average germ content of the back quarters was from two to four times that of the corresponding front quarters. This study showed furthermore that the maximum number of bacteria found in the front quarters was 4632 per cubic centimeter, while in the back quarters more than 16,000 were found. In some cases the reverse was found, namely, a higher number in the milk from the front quarters than from the back quarters. However, the authors state that in these cases the milk was obtained largely from cows during the early part of the lactation period, or in cases where the front quarters contained large numbers of a particular type which was absent from the corresponding back quarters. No explanation is offered for the cause or significance of this phenomenon.

The distribution of bacteria in the udder is not uniform, as has been pointed out before. The first streams of milk are invariably richer in bacteria than succeeding portions. Schulz found the following numbers of bacteria in the first and last milk:

\begin{tabular}{ccc}
\multicolumn{3}{c}{ BACTERIA IN FIRST AND LAST MILK } \\
First milk. & Last milk. & Average of whole product. \\
55,566 & 0 & 2070 \\
97,240 & 500 & 2590 \\
74,088 & 0 & 9261
\end{tabular}

In this work but 0.1 c.c. of the milk sample was plated, so that the absence of bacteria in the last milk does not necessarily imply that none were present in larger amounts.

Russell counted 2800 bacteria per cubic centimeter in foremilk, against 330 as an average for the whole product.

There is no difference of opinion about the germ content of fore-milk compared to that of later portions, it being generally agreed that the first streams usually contain many more bacteria than later ones. But whether bacterial numbers gradually diminish, or whether there are fluctuations, or whether finally there is 
a more or less abrupt falling off after the fore-milk has been discharged, is not definitely known. The germ content of the strippings is lower than that of the middle milk according to some authorities, while others maintain that it is higher, as a rule. The figures given by Schulz, quoted above, seem to indicate that the strippings contain fewer bacteria than the middle or whole milk. Lux, in an extensive investigation, found the following figures:

\begin{tabular}{|c|c|c|c|c|c|c|c|}
\hline Kind of food. & $\begin{array}{c}\text { No. of } \\
\text { samples. }\end{array}$ & 1 & $\begin{array}{l}\text {-Stream. } \\
\quad 2\end{array}$ & $\sqrt{3}$ & Middle. & $\begin{array}{l}\text { Strip- } \\
\text { pings. }\end{array}$ & Average. \\
\hline $\begin{array}{l}\text { y mixed with straw, mea, } \\
\text { bran, etc............... }\end{array}$ & 60 & 753 & 49 & 1428 & 1556 & 367 & 919 \\
\hline ay and malt. .............. & 100 & 1396 & $163 \overline{7}$ & 2066 & 839 & 1020 & 1391 \\
\hline $\begin{array}{l}\text { From right back quarter... } \\
\text { From right front quarter... }\end{array}$ & 60 & $\left\{\begin{array}{l}1809 \\
1002\end{array}\right.$ & $\begin{array}{l}2326 \\
1900\end{array}$ & $\begin{array}{l}1872 \\
1530\end{array}$ & $\begin{array}{r}1357 \\
743\end{array}$ & $\left.\begin{array}{r}3950 \\
220\end{array}\right\}$ & 1671 \\
\hline
\end{tabular}

This table shows that the germ content of the first three streams fluctuates and does not decrease gradually. The germ content of the middle milk is sometimes greater than that of the fore-milk and that of the strippings is in two cases greater than that of the previous milk, while in other instances it is smaller. The author thinks that milk accumulates in the ducts and that but little reaches the cistern before milking operations begin. In the different ducts the milk may contain widely varying numbers of bacteria which do not mix with the milk of other ducts until the udder is being emptied. When the milk from ducts that are richer in germ content reach the cistern the counts are higher than when the milk from other ducts is discharged, so that a variable germ content of the product results.

Similar results have been reported by other authors. Unfortunately, the precautions for excluding external contamination during the milking process have sometimes not been adequate, so that the results are not always trustworthy.

Backhaus and Appel, working with great caution, have obtained the following results:

BACTERIAL CONTENT OF DIFFERENT PORTIONS OF MILI FROM THE SAME MILKING

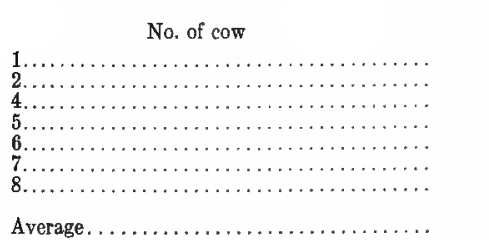

\begin{tabular}{|c|c|c|c|}
\hline 1 & 2 & 3 & 4 \\
\hline 685 & 230 & 70 & 30 \\
\hline 935 & 145 & 20 & 0 \\
\hline 950 & 60 & 10 & 0 \\
\hline 950 & 110 & 60 & 25 \\
\hline 375 & 125 & 20 & 45 \\
\hline 175 & 90 & 60 & 0 \\
\hline 345 & 255 & 55 & 0 \\
\hline 631 & 145 & 42 & 14 \\
\hline
\end{tabular}

According to these figures there is a very consistent falling off in germ content as the milking process advances, and the strippings contain the smallest number of bacteria per cubic centimeter. 
v. Freudenreich arrived at similar conclusions, as the following figures show:

GERM CONTENT OF FORE-MILK, MIDDLE MILK, AND STRIPPINGS

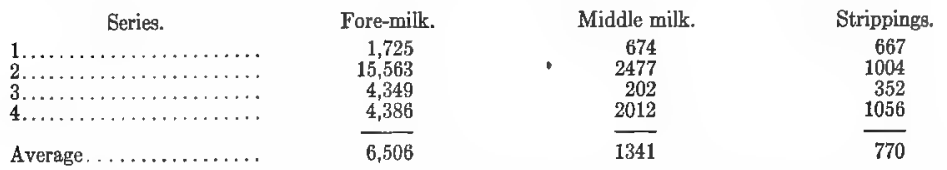

Stocking, on the other hand, has found that the strippings have a richer germ content than previously drawn milk. In a series of 9 experiments he found an average of 272 bacteria per cubic centimeter of strippings against 187 in earlier milk. In each case the earlier milk contained fewer bacteria than the last milk. Harding and Wilson made an extensive study of this question and arrived at results similar to those of Stocking. The average of 360 samples gave the following figures: First milking 458 bacteria per cubic centimeter; middle milk, 187; and the last milk, 274. The grand average was 306 bacteria per cubic centimeter. The germ content of the strippings was closer to the average of the mixed milk than either fore-milk or middle milk.

Comparing the relation of bacterial content of the entire yield of milk with the strippings, Harding and Wilson found the following average figures for the four quarters:

RELATION OF BACTERIAL CONTENT OF ENTIRE YIELD OF MILK AND OF STRIPPINGS

\begin{tabular}{|c|c|c|}
\hline 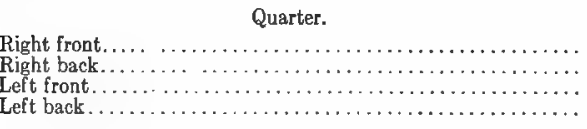 & $\begin{array}{l}\text { Whole milk. } \\
126 \\
606 \\
262 \\
226\end{array}$ & $\begin{array}{l}\text { Strippings. } \\
263 \\
845 \\
97 \\
257\end{array}$ \\
\hline 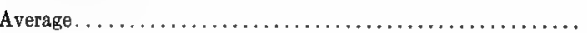 & $\overline{305}$ & $\overline{365}$ \\
\hline
\end{tabular}

In these figures we find the strippings with a higher germ content than the whole milk in three quarters, while they contain fewer bacteria in one quarter. The average is, of course, higher in the strippings.

It seems that there is some evidence in favor of a higher germ content of strippings than in the earlier milk and also some evidence in favor of a lower content. It is difficult to decide which condition is the more common one. As a matter of fact, there are probably some cows whose milk seems to be richer in germs when the last streams are drawn than when the earlier portions are taken, but the reverse is also frequently true. If the very last streams of milk are actually richer in bacteria than the previous ones, the results obtained would depend in a measure upon the amount of milk which the operator considers strippings or the last streams. The larger the quantity taken as a sample, the 
smaller in proportion would be the germ content. One fact, however, is established by the work accomplished so far, and that is the constancy with which bacteria are present in all parts of the udder, except possibly only in the secreting glands.

Some figures are available to show whether bacteria multiply in the udder. Stocking has found that when the udder is not milked dry the milk from the next milking contains a greater number of bacteria than when the udder is milked dry. In a series of experiments bearing upon this point he found that when the udder was milked dry the germ content of the product of the next milking was 6542 bacteria per cubic centimeter against 11,324 , when the udder was not milked dry. Lux approached the subject from another direction. He milked the udder dry and then commenced taking samples two hours later at regular intervals, and determined the bacterial content, with the following results:

BACTERIAL CONTENT OF MILK LEFT IN THE UDDER

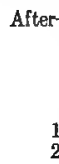

$\begin{array}{cc}\text { Right front quarter. } & \text { Left front quarter } \\ 22 & 65 \\ 365 & 221 \\ 400 & 230 \\ 112 & 217 \\ 897 & 1897 \\ 1217 & 2933\end{array}$

The experiments of both Lux and Stocking show clearly that there is a limited degree of multiplication in the udder, and milking the udder dry is advantageous from this point of view.

The distribution of bacteria in the milk while in the udder appears to be subject to considerable variability. It seems established, however, that the first streams always contain more germs than later milking, but how many streams must be discharged before the number approaches the average germ content of the mixed milk has not been thoroughly investigated. It is thought that by discarding the first few streams the bacterial content of the whole product can be materially lowered. Experiments made by Stocking throw some light on this question. By determining the bacterial content of the first fourteen streams and comparing this with the number of bacteria in the strippings Stocking found the following figures: The first two streams in four experiments averaged 10,143 bacteria per cubic centimeter; streams five and six averaged 2347; streams nine and ten, 272; streams thirteen and fourteen, 382; and the strippings, 204 . To judge by these figures the first six streams discharge the greatest number of bacteria and later milk contains materially smaller numbers.

However, the quantity of milk represented by the first six streams is small as compared with the whole product, and when the 
germs of these streams are distributed throughout the mixed milk the increase per cubic centimeter of the whole product is relatively small. In a series of experiments carried on by Stocking the average germ content of the milk, when the fore-milk was not rejected, was 522 per cubic centimeter, while when the fore-milk was rejected the average number was 499 , a difference of 23 bacteria per cubic centimeter in favor of rejecting the fore-milk. The advantage of keeping the first streams separate from the final product is apparently very small and hardly compensates for the additional work.

From all the figures quoted it may be inferred that the actual number of bacteria usually present in the udder is not great. Probably 500 germs per cubic centimeter represent ordinarily the maximum. There are, however, frequent exceptions, and these seem to occur most commonly when some particular variety of micro-organism is numerous, and in such cases the kind of bacteria present persists often for a long time. This may occur without causing any detectable pathologic condition of the udder. Harding and Wilson have averaged the number of bacteria in milk obtained directly from the udder with precautions to avoid external contamination, and give the following results:

Average germ content per c.c. in 316 samples from a herd, 518
Average germ content per c.c. in 730 samples from a herd, 420
Average germ content per c.c. in 184 samples from a herd, 320
Average germ content per c.c. in 1230 samples from 78 cows, 428

The grand average of all samples, then, was 428 bacteria per cubic centimeter, which probably represents the number of germs that can be assumed to be present normally in the udder.

The same authors have attempted to trace some relation of germ content to the period of lactation. They conclude that there is no evidence of any well-marked connection between the germ content of milk in the udder and the period of lactation. However, there is a distinctly greater number of bacteria in the milk during the colostral period than later, and there is a suggestion that toward the close of lactation there is a slight tendency for the germ content of the udder to fall.

The age of the cow was also found to exert no appreciable effect upon the germ content of the udder.

Studies of the kinds of bacteria commonly present in the udder have led to fairly harmonious results. As a rule, micrococci seem to be the predominant group. Lux found 90 to 95 per cent. of all organisms studied to be micrococci, and only 5 to 10 per cent. bacilli. Von Freudenreich and Thöni's work led to similar results; they found both liquefying and non-liquefying cocci, but 
suggest that the non-liquefying cocci, in reality, may be slowly liquefying ones. The colonies were grown on gelatin plates and the property to liquefy judged from liquefied areas forming at the seat of the colony.

The lactic acid bacteria that cause normal souring of milk were never found in the udder by Burr, and v. Freudenreich could not detect the presence of Bacterium lactis acidi (Streptococcus lacticus) in the milk from the majority of cows, but sometimes isolated colonies of this organism appeared on the plate. Its presence, therefore, is indicated in at least some cases, and perhaps if enriching media had been used it would have been found in a considerable number of samples. v. Freudenreich also made the interesting observation that the flora in different quarters of the same udder may vary widely. In two quarters he found very few bacteria and these were micrococci, while in the other two quarters Bacterium lactis acidi (Streptococcus lacticus) was present in large numbers.

The presence of Streptococcus lacticus in the udder has heen observed by other investigators. Russell and also Conn report finding it in considerable numbers, but adhere to the appellation of Bacterium lactis acidi. Avirulent streptococci which probably were identical with Streptococcus lacticus were found by Bergey, Reed and Ward, Savage, and others. Lammeris and Harrevelt observed an avirulent streptococcus to persist in the udder of a cow that had recovered from an attack of mastitis.

Sherman and Hastings found streptococci in the mixed milk from all but two out of twelve herds and in 38.6 per cent. of samples from 88 cows. The authors recorded the presence of streptococci only when chains of twelve cells or more were present in abundance, and determined this by microscopic examination. Miss Evans made a study of the flora of the udder, and states that the majority of udder bacteria are of the same type as those common on the skin and mucous membranes of man and animals. In 16.1 per cent. of the samples examined bacteria did not seem to multiply to any great extent in the udder. Streptococcus lacticus was not found in any of the samples. Isolation of bacteria was made by transferring colonies from the plated milk. Longchained streptococci which failed to reduce the litmus in litmusmilk, reduction of litmus being a characteristic of Streptococcus lacticus, were isolated from 15.1 per cent. of the samples. In one case as many as 264,000 streptococci per cubic centimeter were present. Micrococci were present in 58.8 per cent. of the samples. The highest number of micrococci was 80,000 per cubic centimeter. The majority of these were avirulent, but two strains killed rabbits in sixteen hours. The author also found Bacillus 
abortus in 23.4 per cent. of the samples, the highest number being 50,000 per cubic centimeter.

Probably many reports of finding streptococci or Streptococcus pyogenes in milk from apparently healthy udders in reality mean the presence of Streptococcus lacticus (Bacterium lactis acidi).

In the milk of a cow examined by Hastings and Hoffmann 90 per cent. or over of the total germ content consisted of a streptococcus very similar to Streptococcus pyogenes in morphology and in its biochemical reactions. Since no udder disease could be observed, it is probable that this also was Streptococcus lacticus.

Streptococei have been known to occur in market milk quite frequently. There are many reports of such findings in the literature, but there is no evidence in the majority of these reports that the streptococci were derived from the udder, and they may have been external contaminations.

Bacilli of the Bacillus coli group were isolated from milk obtained directly from the udder by v. Freudenreich, although not frequently. He also found an organism similar to Bacillus coli in some properties, but it failed to ferment lactose.

Bacillus subtilis, B. radiciformis, proteus, sarcinæ, yeasts, and molds were occasionally met with in milk directly from the udder.

Esten and Mason describe the following organisms which they found in milk directly from the udder:

VARIETIES OF UDDER ORGANISMS FOUND IN COLLEGE HERD AT STORRS

\begin{tabular}{|c|c|c|c|c|}
\hline Name. & Frequency. & Liquefaction. & Acidity. & Color. \\
\hline Micrococcus lactis acidi. & 22 & 一 & + & White \\
\hline Micrococcus lactis albidus. & 9 & + & + & White \\
\hline ococcus lactis albidus, variety B........ & 8 & 1 & 1 & White \\
\hline 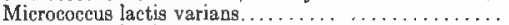 & 7 & + & + & Yellow \\
\hline ococcus lactis aureus . . . . . . . . . . . . . . . . & 3 & - & + & Yellow \\
\hline illus subtilis, variety B. . . . . . . . . . . . . & 3 & + & 1 & White \\
\hline Bacillus subtilis.......................... & 2 & + & - & White \\
\hline
\end{tabular}

The authors state that Micrococcus lactis acidi which was found twenty-two times is the most common of the milk cocci, and is almost constantly found in fresh milk. It "is classified very near Streptococcus lacticus, which is the same as Bacterium lactis acidi. It is even considered a variety of Streptococcus lacticus III." The nomenclature is that of Conn's Classification of Dairy Bacteria.

Harding and Wilson in an extensive study of the udder flora separated 71 distinct groups of organisms from over 900 samples of milk. Of these, 75 per cent. were micrococci. Streptococcus lacticus was found occasionally. The authors suggest that streptococci would be more frequently discovered if special media, favorable to their growth, were employed. Two non-sporing yeasts were also isolated. Spore-forming bacteria were wholly 
absent, a fact which is not surprising, since the majority of forms were cocci which are not known to form spores. Motile rods were not discovered.

Gelatin was liquefied by 55 per cent. of all the bacteria studied, although the reaction usually proceeded slowly. Nitrates were reduced by 59 per cent. of the forms. Starch was not digested by 80 per cent. of the cultures, while 16 per cent. dissolved starch feebly and 4 per cent. almost completely.

The Gram stain was positive in 96 per cent. of all cultures. This is in accordance with the fact that the majority of organisms were cocci most of which are Gram-positive.

It is an interesting fact that the bacterial flora of the udder represents relatively few types with a marked predominance of micrococci. The bacteria that enter the teat duct are of a manifold variety and multiply readily in the duct. But these are apparently poorly represented in the udder, although most of them multiply readily in milk, especially at the temperature of the body. Both food and temperature conditions are favorable in the udder, and still the majority of bacteria fail to grow. Russell and Hastings have introduced cultures of Bacillus prodigiosus into the udder and have shown that they gradually disappear. A complete explanation of this pnenomenon is still lacking. Unquestionably the germicidal property of milk and animal tissue is one of the factors producing this result, and it must be assumed that micrococci are more resistant to this action than other bacteria. Whether this is a full explanation of the facts or not cannot be decided at the present time. It must be borne in mind, as has been pointed out, that sometimes other organisms are the predominating kind in the udder. Whether such occurrences are due to lack of germicidal power in the udder, or increased resistance of the organism, is not known. The fact remains established that among the many species that gain access to the teat duct and multiply there, but few, even if they invade the udder, are able to persist there.

Furthermore, it should be taken into account that the possibility of hematogenous origin of bacteria in the udder is not wholly excluded. v. Freudenreich found that the spleen and kidney of cows are not free from bacteria. This is in agreement with work done by Ford, which seems to indicate that internal organs are not always germ free. Russell and Hastings comment on this view as follows: "It is interesting to note that the bacteria found in the udder are similar to those that seem to be most abundant in such glandular tissues as the liver and the spleen. This fact increases the probability that these comparatively inert coccus forms of the udder may originate directly from the blood- 
stream." Barthel, on the other hand, found that the microorganisms which he observed in the udder of a freshly slaughtered cow were the same as those existing in the air of the stable. This work has been referred to before.

The unsuitability of the interior of the udder for bacterial growth is further proved by the fact that cultures introduced into the udder gradually disappear unless injected in large quantity, in which case an inflammation usually results. The udder flora apparently cannot be deliberately altered by experiment, but remains characteristic. But a relatively small number of microorganisms are able to thrive there.

\section{Contamination During Milking Operations}

We have seen that milk when drawn from the udder contains some germ life, but the number of micro-organisms in such milk is relatively small. When the calf sucks the milk this number of germs is not greatly increased, the only possible source of increased germ content being the dirt which adheres to the teats. The milk which is drawn by human hands and which is destined for human consumption is subjected to a variety of operations, and at each step a new source of contamination exists. During the milking process micro-organisms may enter the milk from 1 , dirt dropping from the outside of the udder and the coat of the animal; 2 , from dust in the air, and 3 , from the hands and clothes of the milker.

1. Dirt from the Outside of the Udder and the Coat of the Animal.-The dirt which may drop into the milk from the coat of the animal is chiefly cow manure, although particles of fodder and bedding, hairs, chips of wood, soil particles, and other foreign material are occasionally found in milk. Very ordinary cleanliness can protect the milk from gross substances, but the fine dust which is shaken from the animal at every move, by switching the tail, or by the movement of the udder during the milking process, is not so readily kept out of the milk. Solid material falling into the milk breaks up and the bacteria are distributed throughout the bulk of the milk. It is a strange testimony of ignorance that a farmer pays more attention to the cleanliness of his horses than to that of cows, although horses are used for work only, while cows produce the most valuable food product for man and upon which the very lives of many babies depend.

The dirt which mixes with the milk is a carrier of micro-organisms and it might be supposed that there is a definite relation between the amount of dirt and the germ content of milk. This, however, is only approximately true. It is, of course, not an easy 
matter to determine the exact amount of foreign matter that is actually present in milk, and modern methods take account only of the insoluble portion of dirt (Fig. 85). Esten and Mason state that three-quarters of cow manure is soluble, but this varies with

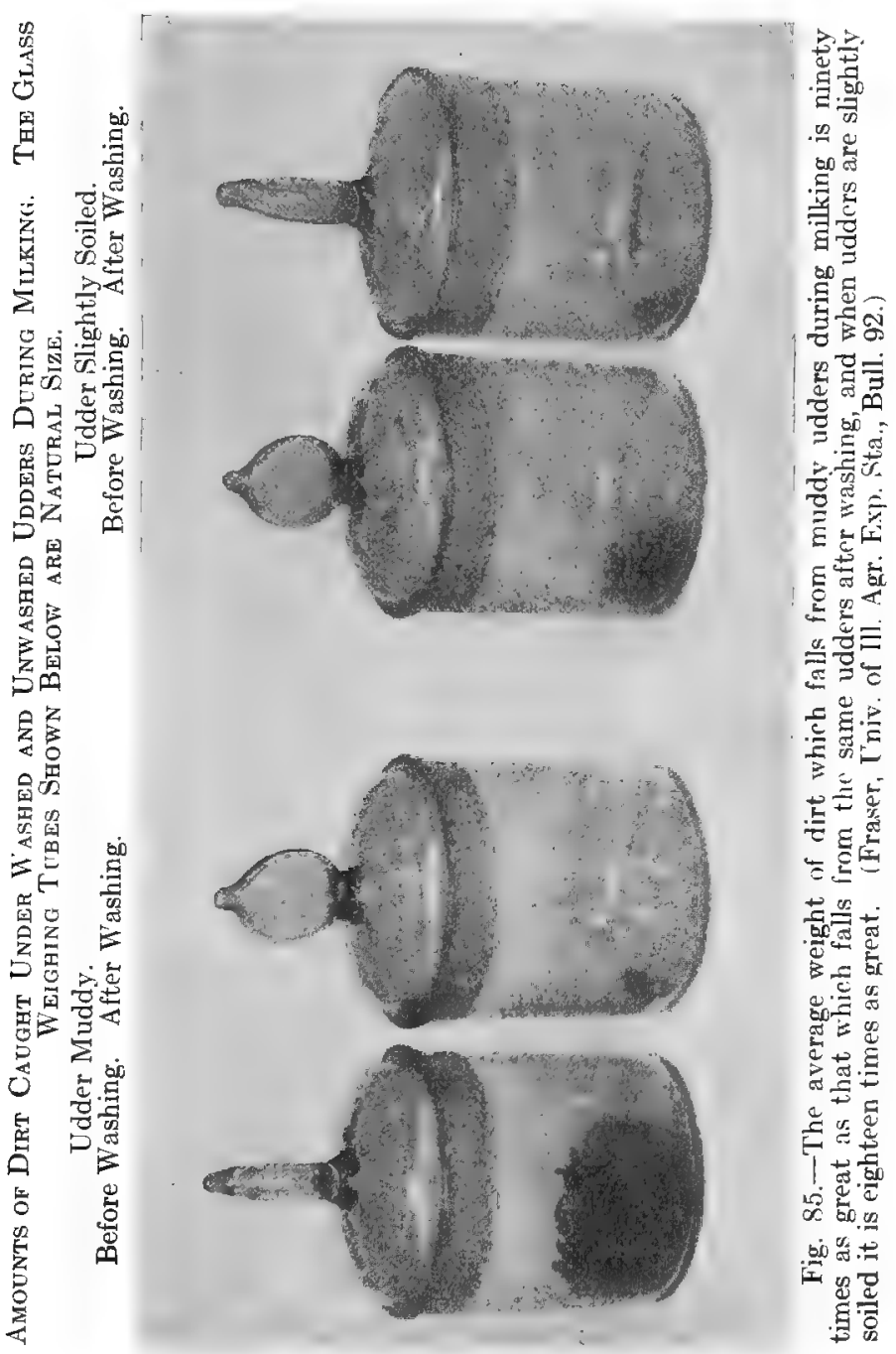

the consistency of the feces. However, a considerable portion of cow manure is insoluble, and consequently unclean milk, as a rule, contains more or less of this disgusting material. Even though the insoluble dirt is removed by modern centrifugal clari- 


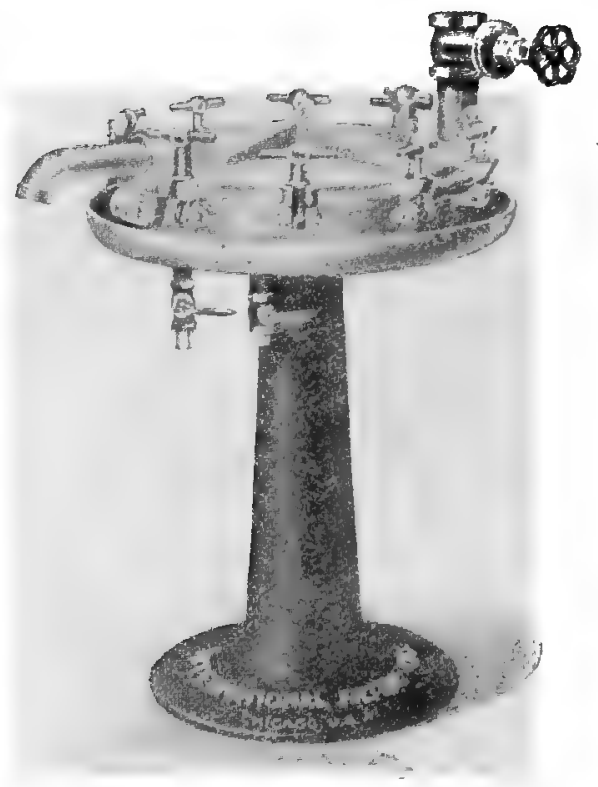

Fig. 86.-International filter.

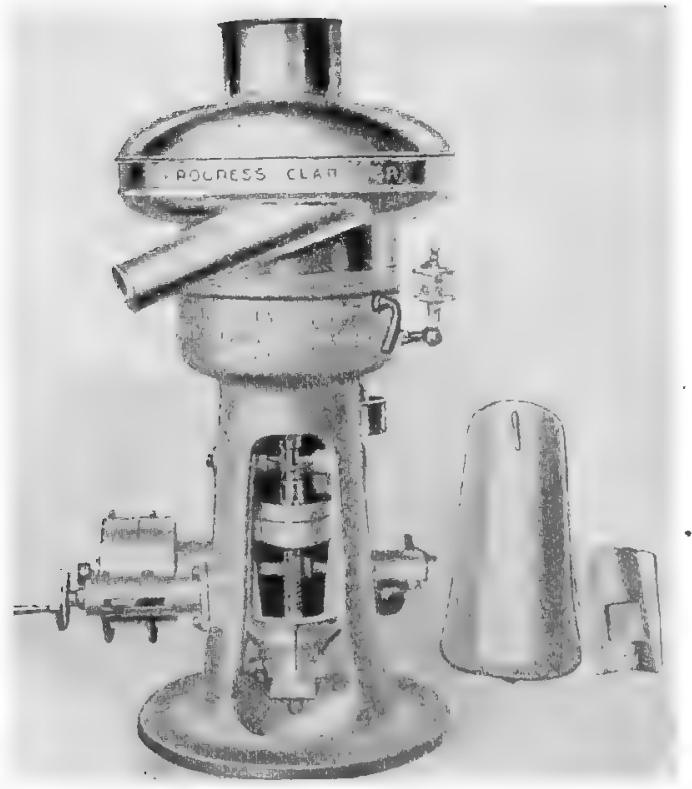

Fig. 87.-Progress clarifier. 
fiers (Figs. 86-88), the soluble portion remains. Aside from the addition of bacteria chiefly of the fecal type, including gas formers, from this source, the very presence of fecal matter is highly objectionable from an esthetic point of view.

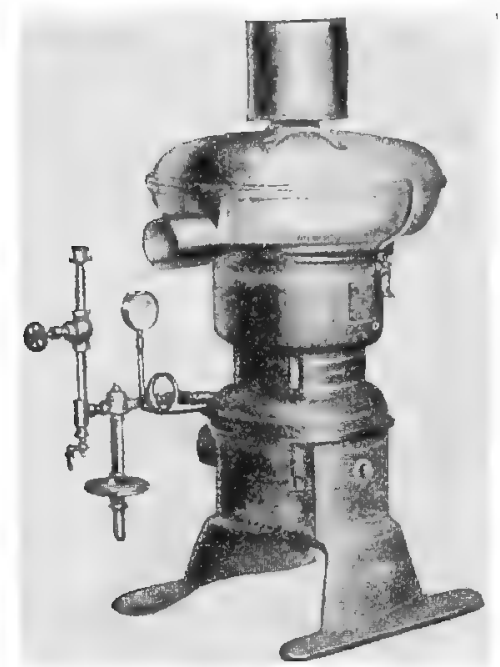

Fig. 88.-Simplex centrifugal milk clarifier.

The absence of a definite relation of insoluble dirt to the germ content of milk is shown by the following work of Uhl:

RELATION OF INSOLUBLE DIRT TO GERM CONTENT OF MILK

Number.

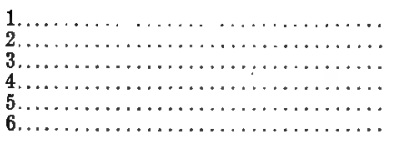

Mgrs. dirt per liter.

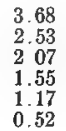

Number of bact
$12,897,000$
$36,690,606$ $36,690,606$ $55,365,800$ $3,831,460$ $3,338,775$
Each number average of five samples.

The writer in an examination of Chicago market milk also could detect no definite relation between insoluble dirt and bacterial numbers, while Ayers, Cook, and Clemmens found that the sediment test bears a "somewhat close relation to the number of bacteria in fresh, unstrained milk handled in sterilized utensils."

It should be considered, however, that all kinds of dirt do not carry the same number of bacteria. One kind contains much greater germ life than another, so that the source of the dirt has a substantial influence on the number of germs that are carried with it into the milk. Furthermore, many bacteria are not taken into account because they do not grow on ordinary culture-media. If the dirt, for example, 
is largely soil, the count will be much smaller in proportion to the actual number present than if manure is the chief contaminating substance. The extensive use of clarifiers also tends to reduce the amount of dirt present without materially decreasing the germ content.

It has been shown by Esten and Mason that the dust which accumulates on poorly cared for cows is very rich in bacteria. One gram of curry powder from a cow contained 207,000,000 bacteria, while one gram of curry powder from a horse had 18,000,000. The dust drops from the animal at every move and contaminates the stable air. Whether bacteria multiply on the skin of the

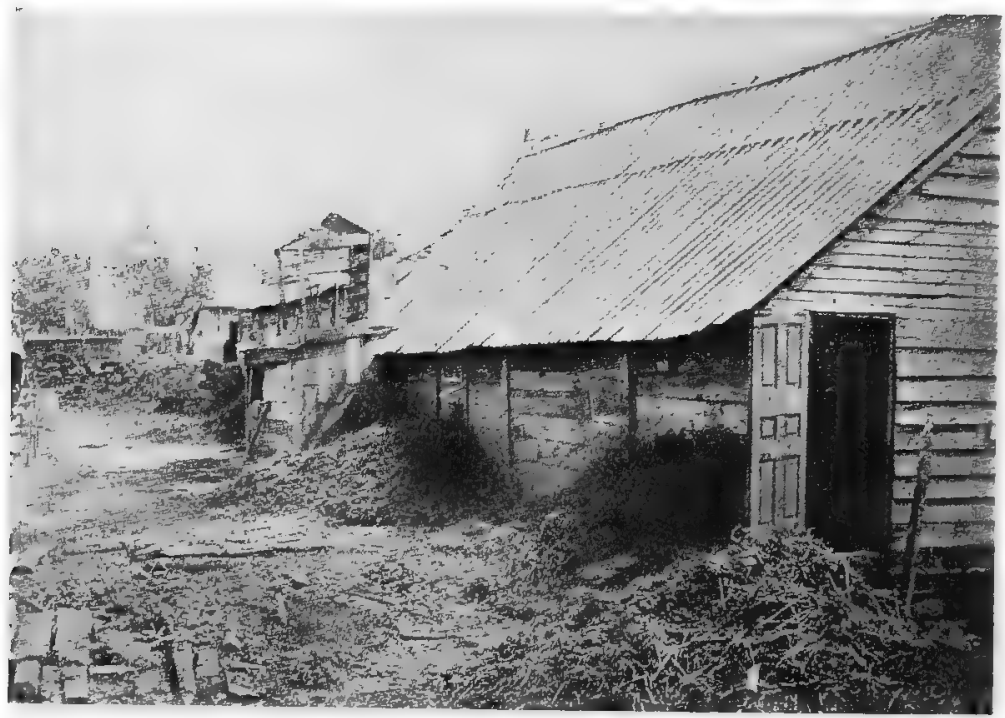

Fig. s9.-A barn with filthy surroundings. (Webster, Bull. No. 56, Hygienic Labnratory.)

cow is not definitely known, but it does not seem unlikely that some kinds may do so. Food for bacteria is present in the form of organic matter, chiefly manure, and sometimes sufficient moisture may be present, although the cow's skin does not perspire (Figs. 89-91).

Esten and Mason think that the cow is the most prolific source of bacteria in milk, and state that the udder furnishes 4 per cent. and the surface of the animal 70 per cent. of all bacteria in milk, and that the balance of 26 per cent. comes from all other sources combined. Some investigators, as we shall see, do not agree with this estimate, but there can be no doubt that in the last analysis the surface of the cow harbors the bacteria that later 


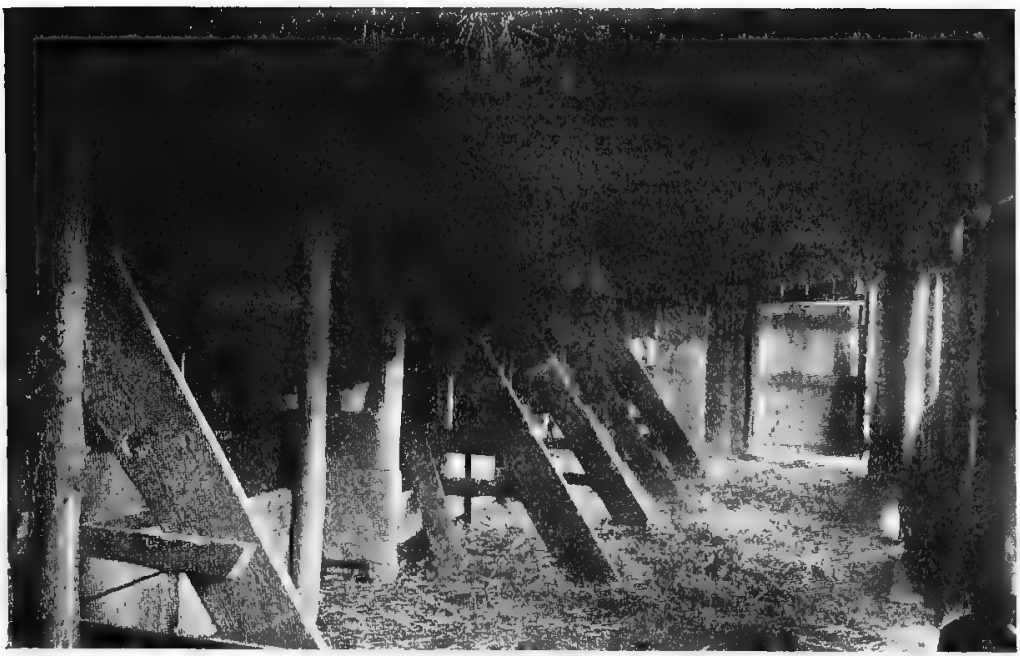

Fig. 90-Barns of this character are entirely too numerous. (Fraser, Bull. No. 92, Univ. of Ill. Agri. Exp. Sta.)

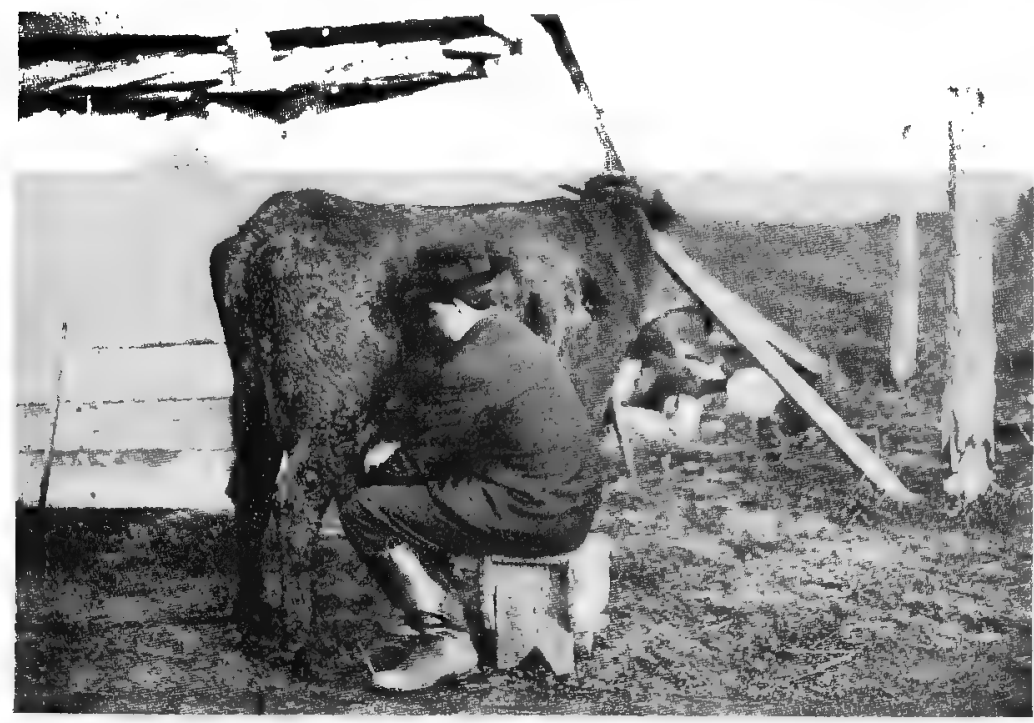

Fig. 91.-Dirty flanks. A common condition in winter. Flanks become caked with manure, which there is often no thought of removing. This is the source of most of the dirt found in winter milk. (Webster. Bull. No. 56, Hygienic Laboratory.)

may multiply in vessels, or in the milk, and thus greatly increase the germ content. 
That movement of the cow during the milking process may increase the germ content of the milk is shown in a statement made by Löhnis. The milk under investigation contained 23,800 bacteria per cubic centimeter, but when the milker touched the animal and caused her to move the number rose to 900,000 . The same cow, when thoroughly curried, gave milk with but 7000 bacteria per cubic centimeter.

By cleaning the udder Schulz was able to reduce the bacterial content of milk from $1,500,000-1,900,000$ to $22,000-33,000$ per cubic centimeter. Russell obtained from a clean, moist udder milk with 115 bacteria per cubic centimeter, while from the same udder not cleaned the germ content of the milk was 3250 per cubic centimeter. Similarly, Harrison counted 640 to 2350 bacteria per cubic centimeter of milk from a clean udder, against 9845 to 17,155 from a dirty udder. In a series of thirteen tests Stocking enumerated an average of 716 bacteria per cubic centimeter when the udder was wiped with a damp cloth, and 6342 bacteria per cubic centimeter when the udder was not wiped. Löhnis recommends cleaning the udder by rubbing it dry and then smearing it with grease or vaselin, so as to cause the dust particles to adhere. In the best dairies in this country the udder is washed previous to milking with a damp cloth and allowed to remain moist. Care must be taken, however, not to permit enough water to remain on the udder to cause drops to fall into the milk.

A method to protect the milk from droppings from the udder was devised by Backhaus, and is known as the "Nutricia" method. -A bag of water-proof material is tied on the udder and filled with boric acid solution. The antiseptic solution is brought in intimate contact with the skin by pressure against the bag. After a few minutes the solution is drained off through a cock and the bag filled with boiled water. Milking is then commenced, the teats protruding through holes in the bag provided for this purpose. The results have not proved that this method is advantageous as far as bacterial numbers go and the manipulation is rather cumbersome. Löbnis obtained the following counts by the use of the Backhaus bag and by ordinary washing of the udder: With the bag 800 to 49,500 bacteria per cubic centimeter; with ordinary washing, 4500 to 29,380 per cubic centimeter.

The evidence in favor of thorough cleaning of the udder before milking is strong, and as this manipulation requires but little time and labor it should be practised in all dairies.

It is usually thought that clipping the hair on the udders and flanks is a necessary procedure for producing milk with a low germ content. This practice is assuredly a help in keeping the udder clean, but whether it reduces the germ content is questioned 
by Harding, Ruehle, Wilson, and Smith. These authors found in a series of experiments that the germ content in milk from clean udders the hair of which was clipped was greater than in milk from unclipped udders. The difference was not great, but the authors think that clipping offers no distinct advantage. They explain this rather surprising result by the assumption that after clipping there is small protection against dirt, and bits of dead skin that are constantly breaking loose fall with their share of germs into the milk.

Periodic grooming of cows will remove much dirt and loose hair. Hairs are not infrequently found in milk and may carry many bacteria. This is illustrated in Fig. 92, taken from Russell and Hastings' Dairy Bacteriology, which shows the colonies grown from a hair placed on an agar plate.

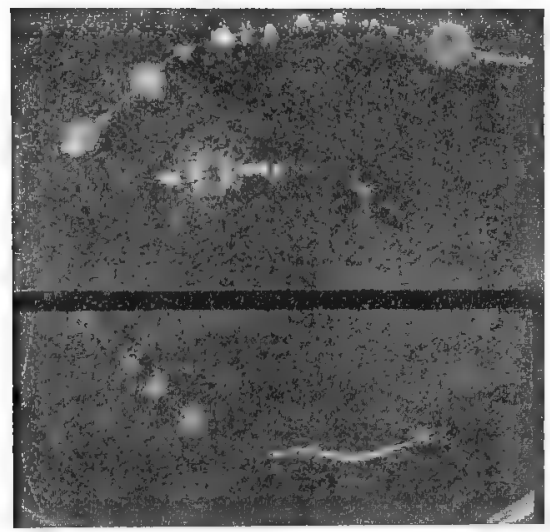

Fig. 92.-Bacteria on hairs. Each colony on the hair represents one or more bacteria that were adherent to the hair when it was placed on the surface of the solid culture-medium (Russell and Hastings).

During the winter, when cows spend most of the time in a stable, the accumulation of dirt on the animal is usually greater than during the summer. The same condition obtains during the night, when cows are stabled. The morning's milk, therefore, as a rule, has a greater germ content than the evening's milk. On the other hand; the fecal discharges are usually softer in summer than in winter. Soft feces are more apt to splatter into the milk than hard ones and adhere more readily to the skin and hairs of the animal. Fodder rich in nitrogenous material is also conducive to the formation of soft feces.

In some dairies vacuum cleaners are used for currying cows. Theoretically this is an ideal method, since the dirt is removed from the stable without vitiating the air. However, experiments 
on the effect of vacuum cleaning of cows so far have not shown a distinct advantage. Harding, Ruehle, Wilson, and Smith have made a number of tests which seem to show that when the vacuum is relatively high, machine cleaning is as effective as hand cleaning, but at low pressure hand cleaning gives better results than machine cleaning.

Whatever means of cleaning animals are employed, the germ content in the milk will always be lower when cows are kept clean than when they are poorly cared for, other things being equal.

2. Dust from the Stable Air.-The air of the stable usually contains dust in amounts proportionate to the care devoted to keeping the stable clean. The construction of the stable is of importance, inasmuch as the practicability of keeping it clean and

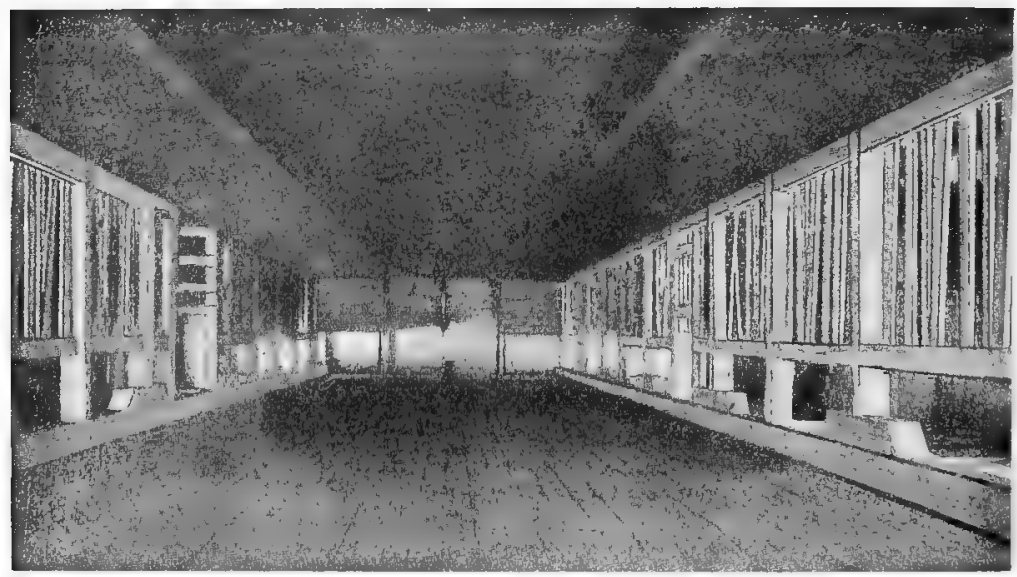

Fig. 93.-A sanitary barn, clean and whitewashed. (Fraser, Bull. No. 92, Univ. of Ill. Agri. Exp. Sta.)

the amount of work required to accomplish this object depend in large measure on suitable construction. Ledges, exposed rafters, sharp corners, braces, and rough supports should be avoided as much as possible, since they give opportunity for dirt and cobwebs to gather. Location of the stable on elevated land is to be highly recommended, since drainage is facilitated thereby.

The floor of the stable should be made of non-absorbent material, . concrete being the most suitable. Concrete is not only advantageous because of its lack of permeability to liquids that are usually heavily contaminated, but because it can be moistened with water in order to prevent dust from rising (Figs. 93-95).

The walls and ceiling must also be tight so as to avoid crevices. in which dust can accumulate. The surface of the walls and ceil- 
ing is most easily kept clean when it is smooth. Rafters should be covered with matched lumber or plaster, so as to leave no open places. Plastering the walls seems to be of no advantage, accord-

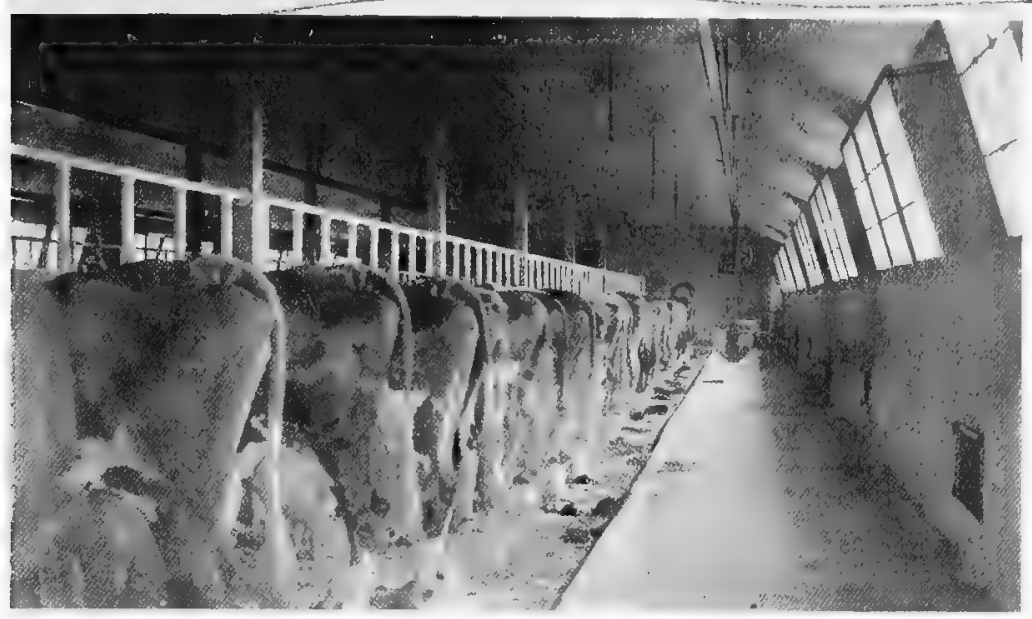

Fig. 94.-Clean stables.

ing to Harding, Ruehle, Wilson, and Smith, who have made bacterial counts to ascertain this point. The work of these authors

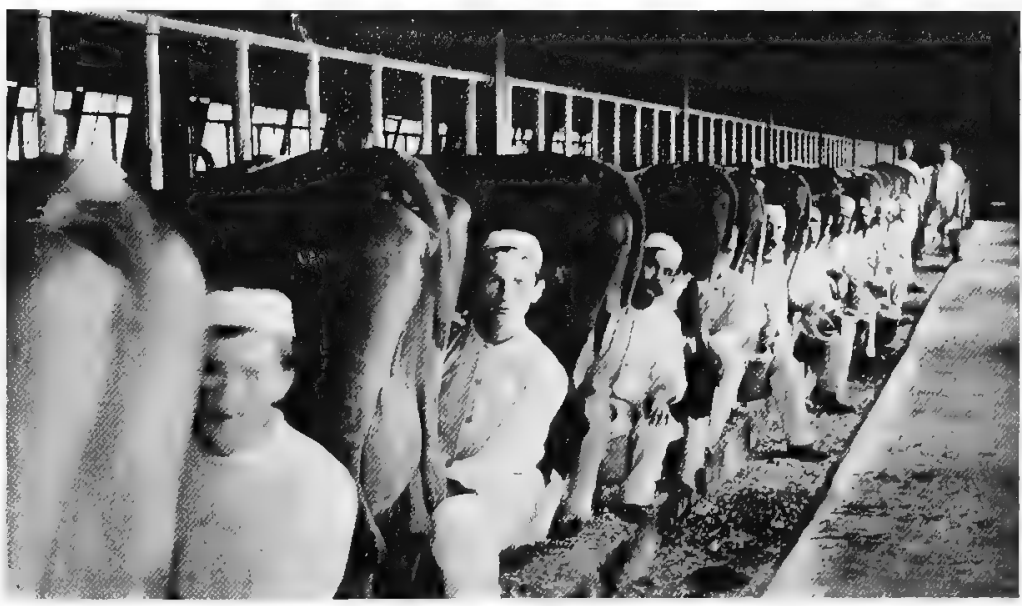

Fig. 95.-Clean cans in clean stables.

indicates that in freshly plastered stables the germ content of the milk is higher than under the usual conditions. In a special case the germ content before plastering was 44 per cent. lower than 
after. Even whitewashing the walls, according to the experiments of the same authors, does not decrease the germ content of

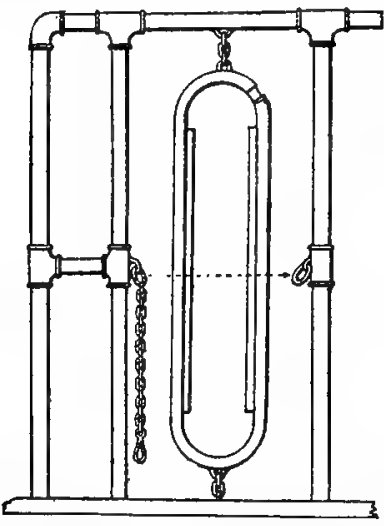

Fig. 96.-Chain on stanchion frame (or stanchion) to pass under the neck when desired to keep cows standing after being cleaned and before being milked. (Pearson, U. S. Dept. of Agric., Farmer's Bull. 63.)

\section{with a minimum chance of contaminating the bedding and} floors.

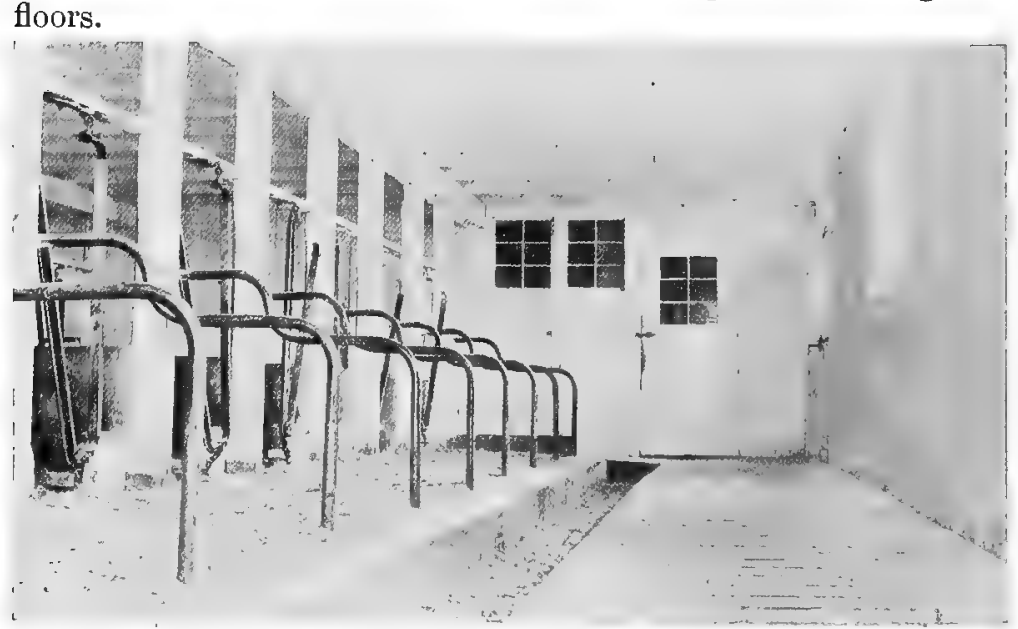

Fig. 97.-Side aisle of certified milk dairy transformed from old barn at small expense.

Food should be carried into the stable on carriers suspended from the ceiling, and manure should be removed in similar man- 
ner (Fig. 99). Fodder should not be lowered into the stable by openings in the ceiling.

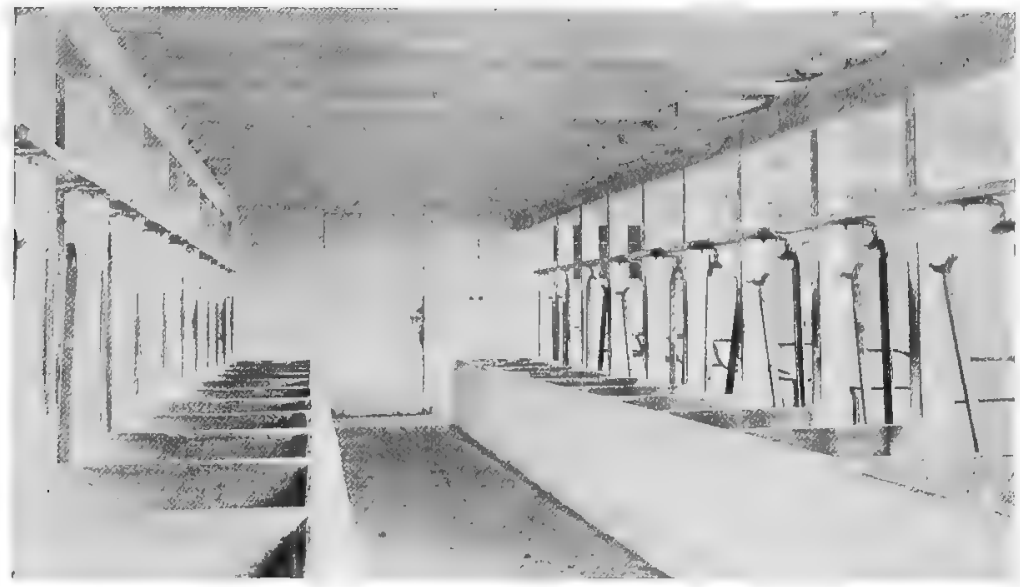

Fig. 98.-Center aisle of certified milk dairy transformed from old barn at small expense.

Good drainage of the stable is an important consideration. As milk rapidly absorbs odors, all manure and liquid excretions should be removed frequently, and should be taken to a place at

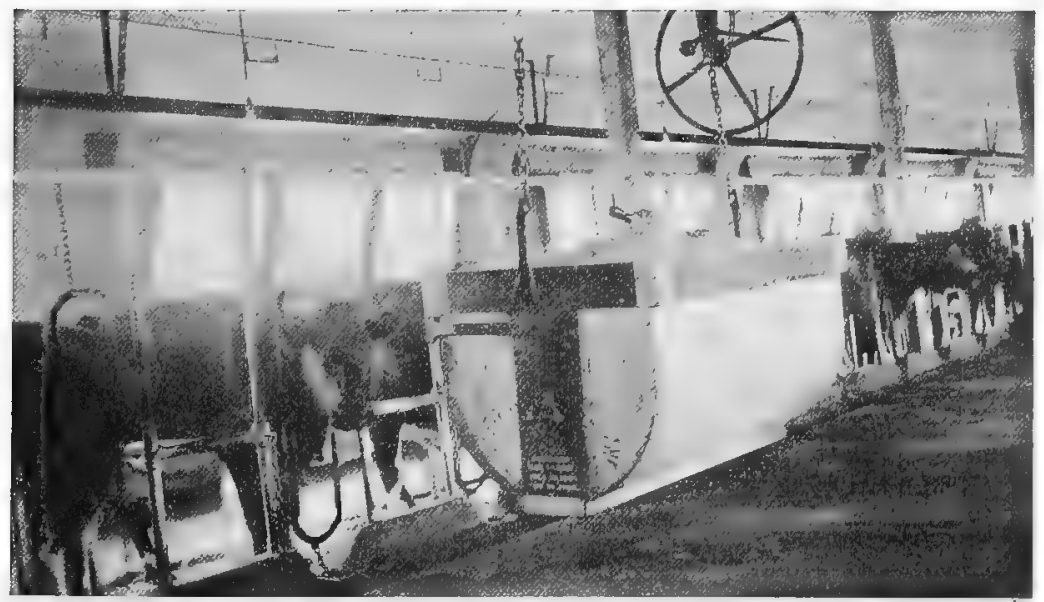

Fig. 99.-Method of carrying food into stable or manure out of stable.

such distance as to render it impossible for dust from manure heaps to be carried back into the stable. Manure should not be permitted to remain in the stable long enough to dry out. The 
barnyard, therefore, should not serve as a place for accumulating manure and other filth, but should always be in reasonably cleanly condition.

Stables for other farm animals should be at a distance sufficiently great to avoid contaminations from this source, and farm animals should never be permitted in the cow barn.

Dust in stable air is derived chiefly from the cow, manure, fodder, the bedding, and perhaps from flies. A further source of dust is that blown through open windows, but this is probably the least important contribution.

It has already been pointed out that dust from the coat of the cow is shaken off by each movement. Larger particles drop on the floor, but finer particles may remain suspended in the air for some time. Currying the cows should, therefore, be done at a sufficient length of time before milking to permit the dust from this operation to settle. When this is properly done, however, the germ content of the milk is reduced, and the time consumed in currying cows is not great. Trueman states that a cow çan be thoroughly curried in twelve to fifteen minutes. In a series of 14 experiments Stocking showed that the germ content of milk drawn before brushing the cows was 1207 , while in milk drawn from cows after brushing contained 2286 per cubic centimeter. These figures show how necessary it is to allow the dust to settle before milking is commenced.

That manure, when it remains in the stable or in close environment long enough to dry out, is a source of dust needs hardly he mentioned. Prompt removal of manure is, therefore, not only a sanitary measure, but aids in reducing the clust of the stable air. In the hest dairies manure is removed every day and, when not immediately spread on the field, is placed in a pit at least 100 feet from the stable. Manure is a valuable fertilizer and farm economy requires that it be well cared for.

Much has been said and written about the influence of fodder on the dust content of stable air. Carrying food into the stable and distributing it should, therefore, be done with care, and it is of further importance not to give the cows dry fodder for at least one hour before milking. Stocking obtained the following results by examining milk for its germ content before and after feeding; Before feeding corn stover the germ content was 1233 bacteria per cubic centimeter, while after feeding it was 3656 . Feeding hay and grain gave 2096 germs per cubic centimeter before and 3506 after. These figures are the averages of five estimations; they show clearly that the dust from dry fodder, when given shortly before milking, adds a considerable number of bacteria to the milk. 
The bacterial content of some foods has been investigated by Esten and Mason. According to these authorities curing and sweating of hay is a bacterial fermentation, accompanied by formation of a layer of mold on the surface. The average number of bacteria per gram of hay was found to be $16,800,000$, and a mixture of grass and rye contained 15,000,000 bacteria per gram. In hay two-thirds of the moisture is lost during storage, so that 1 gram of hay equals in bacterial content about 3 grams of grass. During storage of hay the number of bacteria diminishes due to the disappearance of many varieties, but a few kinds increase. Liquefying bacteria decrease. The authors found Bacterium lactis acidi (Streptococcus lacticus) in but one out of a total of 28 samples examined. The following table shows the distribution of groups of bacteria in hay (Esten and Mason):

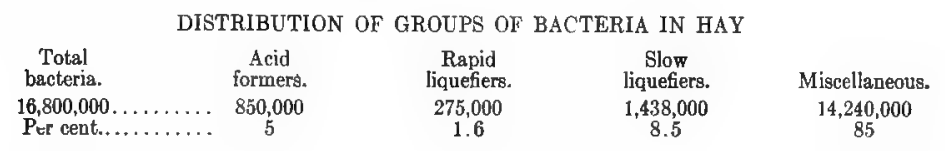

Distribution of hay in the stable evidently contributes its quota of germ-laden dust to the air. This fact emphasizes the necessity, mentioned before, of constructing the ceiling of tight, dust-proof material and, if hay is stored in a loft above the stable, to carry it into the stable from the outside, instead of lowering it through a hole in the ceiling or through a chute. The contamination of the air from hay is decreased somewhat if it is cured in the field before storage and if moistened hefore it is carried into the stable.

The relation of the predominant groups of bacteria in grass is given by Esten and Mason as follows:

\begin{tabular}{|c|c|c|c|}
\hline & TION OF & F BACTERIA IN & \\
\hline $\begin{array}{c}\text { Total bacteria. } \\
1,5,000,000 \ldots \\
\text { Per cent.... }\end{array}$ & $\begin{array}{c}\text { Acid formers. } \\
\quad 42,000 \\
3\end{array}$ & $\begin{array}{c}\text { Liquefying bacteria. } \\
232,000 \\
155\end{array}$ & $\begin{array}{c}\text { Miscellaneoup. } \\
14.700,000 \\
815\end{array}$ \\
\hline
\end{tabular}

Swamp grass contains more bacteria than grass from meadows that are located on elevated ground. Esten and Mason found Bacterium lactis acidi in but 1 out of 9 samples examined. The average number of liquefying bacteria was 50 per cent. greater than on stored hay. Soil bacteria are well represented on grass, but are not included in the estimations made from milk, as they do not multiply on the media that are commonly used for determining the germ content of milk.

Esten and Mason give the following number of bacteria on grain food, sawdust which is sometimes used for bedding, and dried blood: 
NUMBER AND KINDS OF BACTERIA IN GRAIN FEEDS, SAWDUST, AND DRIED BLOOD

\begin{tabular}{|c|c|c|c|c|c|}
\hline Sample. & $\begin{array}{l}\text { Kind of } \\
\text { material. }\end{array}$ & $\begin{array}{c}\text { Total } \\
\text { number. }\end{array}$ & $\begin{array}{c}\text { Acid } \\
\text { bacteria. }\end{array}$ & Liquefiers. & $\begin{array}{l}\text { Miscel- } \\
\text { laneous. }\end{array}$ \\
\hline 1. & . Cottonseed meal & $2,458,000$ & $\ldots$ & 45,000 & $2,410,000$ \\
\hline 2 & Cottonseed meal & 310,000 & $\cdots$ & $\cdots$ & $\cdots$ \\
\hline$\cdots$ & Cottonseed meal & 30,500 & $\cdots \cdot$ & $\cdots$ & .. \\
\hline . $\cdots$ & $\begin{array}{l}\text { Gluten } \\
\text { Gluten }\end{array}$ & $\begin{array}{l}70,500 \\
38,000\end{array}$ & 7,000 & 1,800 & 29,500 \\
\hline & Gluten & 41,500 & $\ldots$ & $\ldots$ & $\ldots$ \\
\hline & $\begin{array}{l}\text { Corameal } \\
\text { Bran }\end{array}$ & $\begin{array}{r}3,200,000 \\
2,000,000\end{array}$ & 590,000 & 200,000 & $1,210,000$ \\
\hline $\begin{array}{r}9 \\
10\end{array}$ & $\begin{array}{l}\text { Dried blood } \\
\text { Moist sawdust }\end{array}$ & $\begin{array}{r}169,500,000 \\
384,000\end{array}$ & $\ldots$ & 1,300 & 382,700 \\
\hline
\end{tabular}

On grain the percentage of acid-forming bacteria is twice as great as on hay, while liquefiers are present in only half the numbers. Bacterium lactis acidi was found in cornmeal only.

Flies are almost constantly present in cow stables during the warm season. No matter how efficiently windows and doors

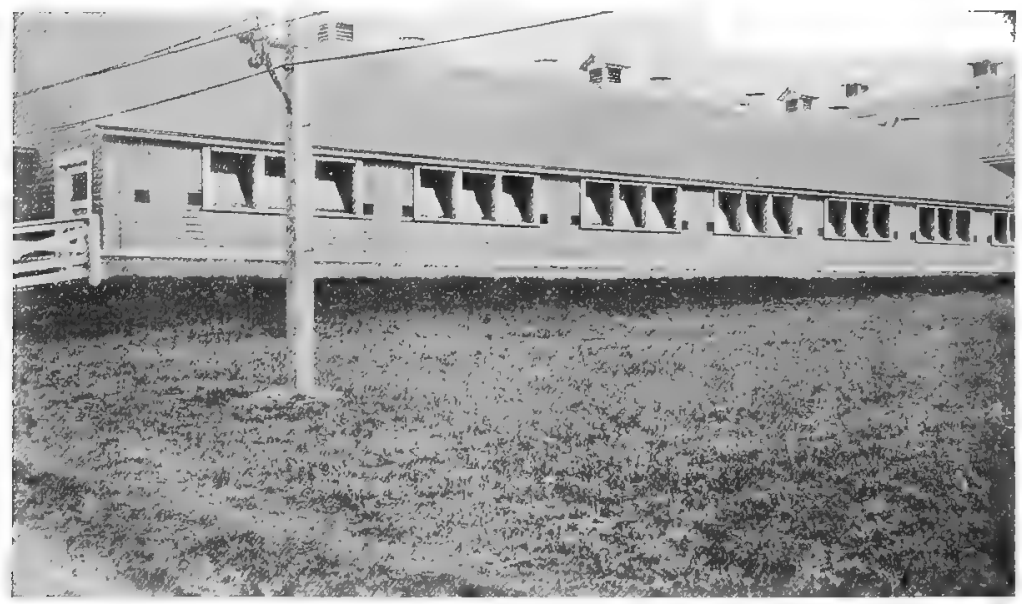

Fig. 100.- Showing construction of windows to facilitate screening and ventilating.

are screened, it seems practically impossible to exclude the pests completely. When cows leave the stable or return, the time during which the doors have to remain open is long enough to admit flies which follow the animals. Furthermore, flies are always attracted to cattle, and large numbers enter the stable with them (Fig. 100).

Whether flies contribute to dust in the stable air is not certain, although it seems reasonable to assume that they do in a measure. However, flies frequently drop into the milk and then the bacteria and the dust which they carry contribute to the germ content of the milk. The fly constitutes a particular menace, since it visits everywhere where filth is present. Flies may 
carry the germs of intestinal diseases of man by visiting privies and urinals; or the germs of throat and lung diseases by feeding on sputum; or, finally, the germs of skin diseases by alighting on human beings suffering from such troubles.

Esten and Mason estimated the number of bacteria on 414 flies, and recovered from 550 to $6,600,000$ from individual insects. The average for the 414 flies was $1,250,000$.

The material used for the bedding of cows may be an important source of dust. Wood shavings are usually recommended as the most cleanly, as they do not contain much dust and soon absorb enough moisture to hold the dust. Straw and hay, however, may emit clouds of dust when stirred by movements of the animal, and are not as absorbent as wood shavings. When straw or hay are used for bedding it should be frequently renewed, and even then operations are liable to create dust. Wood shavings are cheap and can be readily obtained, so that there can be no serious objection to their use.

It would appear from what has been said that the stable air is in a condition of greater or lesser saturation with dust and that it must be a formidable factor in contributing bacteria to the milk. Unfortunately, there are not many exact investigations available that throw light on this question. In most cases the number of bacteria in stable air has been estimated by exposing culture-media in Petri dishes in different parts of the stable. This obviously is a crude method and, while it may show the presence of large numbers of micro-organisms in the air, it does not show the number by which the germ content of the milk is increased thereby. It is true that it has been sought to attain this object by milking the same set of cows alternately in dust-laden air and in a relatively pure one, and then enumerating the germs of the milk. This method, however, does not differentiate between the - dirt that drops into the milk from the animal during milking from the dust that is blown into it. Therefore, a more refined method is necessary to inform us as to the increase of the germ content due exclusively to the stable air. This subject has been exhaustively investigated by Ruehle and Kulp by means of an ingenious apparatus which the authors call their "tin cow." The "tin cow" is an artificial udder made of tin; two "teats" are attached to the udder and are made of rubber tubing with pieces of glass tubing, flattened at the end. The "tin udder" is supported so as to give it the same protection from the air as the body of the cow, and is placed at such height from the pail as to give the same distance that obtains in actual milking. After the "tin udder" is covered with two thicknesses of closely woven cheesecloth and sterilized, it is filled with sterile water. The 
tests that were made with this apparatus consisted in enumerating the number of bacteria in the air by use of a specially designed aëroscope. Sterile water was "milked" from the udder into a narrow-top pail for the same length of time as was required to aspirate 7 liters of air through the aëroscope. As a check some of the sterile water from the "tin udder" was "milked" into sterile test-tubes. Another parallel test consisted in placing 500 to 1000 c.c. of sterilized tap-water in a pail having an opening of $266 \mathrm{sq} . \mathrm{cm}$. This pail was kept covered until the other tests were commenced. The cover was then removed and not replaced before the other tests were finished. Pails were also placed on the floor beside the apparatus to receive dust dropping from the air. The results of these exhaustive tests were these: During such barn operations as milking, feeding hay, grain, and the like the number of bacteria per liter of air would run from 50 to 200 . The extremes were much lower and up to 825 per liter. When sterile water was "milked" from the "tin udder" the germ content of the "milked" water averaged 12 bacteria per cubic centimeter, with a maximum of 73 . In similar tests made in the stable loft, where dust was raised by sweeping the floor, the air contained 1000 to 2000 bacteria per liter, with a minimum of 329 and a maximum of 5200 . When the dust was raised continuously throughout the test period the average was 2500 to 10,000 bacteria per liter.

Sterile water "milked" under extremely dusty conditions averaged 47.6 bacteria per cubic centimeter, and when the dust was maintained throughout the test period it averaged 604. The authors further enumerated the number of bacteria that would develop from the dust dropping into milk contained in an open 12-inch pail during one hour. The maximum was 199 bacteria per cubic centimeter.

The conclusion drawn by the authors from these experiments is that "occasionally under exceptionally dusty conditions the number of bacteria getting into the milk from the air may be approximately as high as the number derived from the udder, but the number so derived under ordinary conditions does not increase the germ content of the milk to any important extent."

The work published by Ruehle and Kulp is a great aid in the study of sources of the bacterial content of milk, but it should not be interpreted as an encouragement to uncleanliness of barns. On the contrary, as it shows exactly how the germ content of milk is increased from dust in the air, it also shows by how much the germ content can be kept down by avoiding dustraising operations immediately before or during the process of milking. 
3. Contamination from the Hands and Clothes of the Milker. - The milker may become a source of bacterial contamination of milk, and this factor is one of considerable importance. Cleanly personal habits (Fig. 101) will aid in keeping the germ content low, while filthy habits serve to increase it. Russell has shown that by careful milking the milk may contain 120 to 300 bacteria per cubic centimeter, against 7680 to 15,000 by ordinary milking. Esten and Mason found that after a milker had washed his hands in a quart of sterile water $45,000,000$ bacteria had been removed from the hands. After the milker had washed his hands with soap and warm water but 900,000 could be removed with sterile water - a reduction of 98 per cent. This experiment shows that a large number of bacteria may drop into the milk from dirty

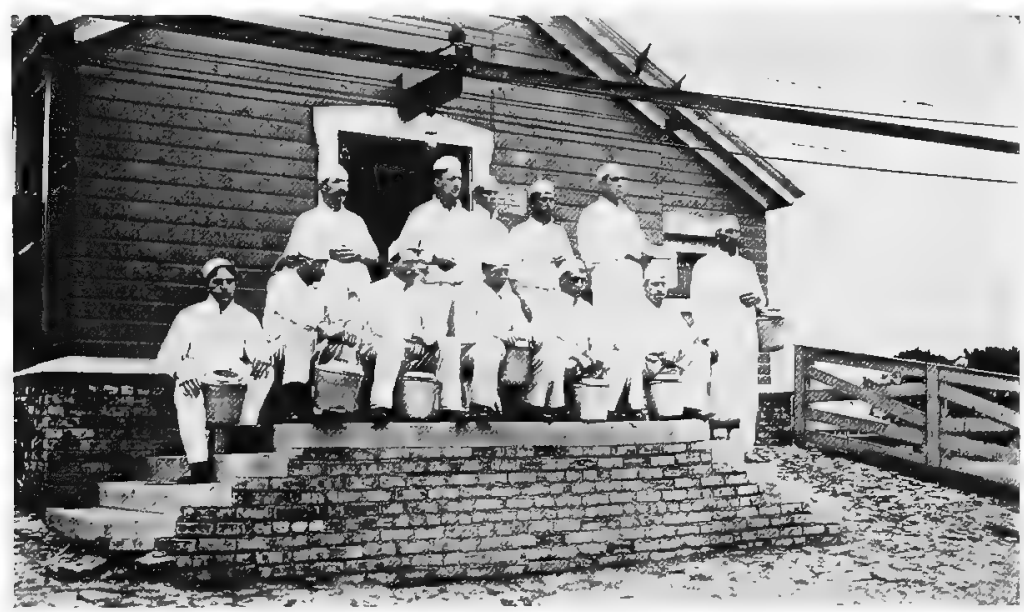

Fig. 101.-Clean milkers in clean suits.

hands. It is obvious that dust-laden clothing of the milker may also add a contribution of germ life to the milk.

That the bacterial content of milk may vary when different milkers milk the same cow has been clearly shown by Stocking. By comparing the germ content of milk drawn by regular men with that of milk drawn by students who had received college training in cleanly milking, it was found that the milk drawn by regular men contained an average of 2846 bacteria per cubic centimeter, against 914 in the milk drawn by students. These results were substantiated by another series of tests with 19 lots of milk. While the milk drawn by regular men averaged 17,105 bacteria per cubic centimeter, the milk drawn by students contained 2455 .

The reduction of germ content by milkers trained in habits of cleanliness is not the only reason why attention should be given 
to personal hygiene of operators. There may be carriers of disease germs among the milkers, and in that case a real menace is added to the milk. Perhaps the communication of pathogenic bacteria from milkers who are carriers, or who are in the incubation period of a communicable disease, or who are actually suffering from light attacks, as walking typhoid fever, for example, cannot be entirely avoided by cleanly habits, but the menace from a cleanly person is surely not as great as from a careless one. Periodic medical examination of dairy employees is desirable if communication of infectious diseases is to be avoided, and even then the result is not absolutely certain.

The method of milking has its influence on the germ content of milk. The method commonly known as "wet milking" is carried out by closing the thumb and forefinger around the upper end of the teat and then gliding down to the aperture. The air is squeezed out of the teat duct and suction created so that the milk flows from the udder.

The gliding causes considerable friction on the skin of the teat and on the fingers of the milker. To remedy this trouble it is customary to lubricate the hands. This is done by moistening with some of the first milk or by the use of vaselin. Even saliva has been used as a lubricant, but this filthy and dangerous habit is becoming obsolete.

When the hands are moistened with milk the dirt from the teat is rapidly loosened and mixed with the milk. This naturally increases the germ content. When the teats are smeared with vaselin the number of germs removed during milking operations is probably not great. Vaselin holds the dirt and with it the micro-organisms on the skin so that they are not easily detached. The use of vaselin or some other grease has been advocated by some as a protection of the teat against undue friction, thereby avoiding local inflammatory conditions.

A more sanitary method of milking is becoming more popular, although it requires more strength on the part of the milker and consequently more practice and perseverance. This method of "dry milking" is the only one permitted in the best dairies. The thumb and forefinger are closed around the upper end of the teat, and then, instead of gliding down, the other fingers are closed on the teat in succession. The vacuum is created in this manner. No lubricant is required in this method and the disadvantages of wet milking are largely avoided.

Still it does not seem that the average germ content of milk is greatly increased by wet milking. Backhaus, for example, found 7833 to 9000 bacteria after wet milking and 5600 to 7400 after dry milking. The difference between these numbers is not great, 
but in carelessly managed dairies there would undoubtedly be a greater difference. Clean cows with clean udders and teats produce a milk with small germ content even with wet milking. However, any condition that tends to increase the number of bacteria should be liminated as much as possible.

Not of least importance is the sort of pail used to receive the milk. Wooden pails are being rapidly replaced by metal ones, because the latter are cheaper, more durable, and easier to clean. Aside from the bacteria that are present in improperly cleaned pails, the wide opening of the usual style admits much of the dirt that drops from the cow during milking and dust from the air. This fact was first recognized by the introduction of the so-called "strainer pail." This is an ordinary metal pail of which onehalf or less is covered to protect the milk from dust falling into
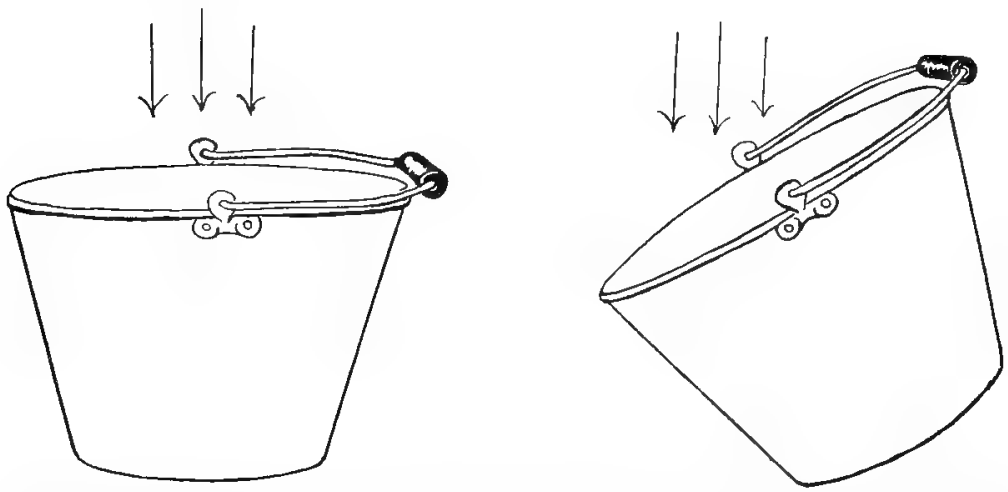

Fig. 102.-Showing how a pail set on the level offers a larger space for dust to enter than one held at an angle.

it. The milk is strained by pouring it out of the pail through a section of closely woven wire-cloth soldered into one side of the can. This pail never was popular and is now practically abandoned.

It is not difficult to realize that a great deal of dirt ordinarily drops into the milk during the milking process, since much of it is held by the foam that forms on the surface. As milking progresses the foam becomes darker with dirt particles. The germ content of the foam, however, does not appear to be excessive, according to Harding, Ruehle, Wilson, and Smith, who found in a series of 36 samples that the foam had a germ content of 13,511 bacteria per cubic centimeter, while in the center of the milk there were 14,876 bacteria per cubic centimeter, and in the stirred milk 18,089. These figures suggest that the dirt particles in the foam 
were not broken up, but as soon as they were broken up by stirring with the milk the bacterial content increased.
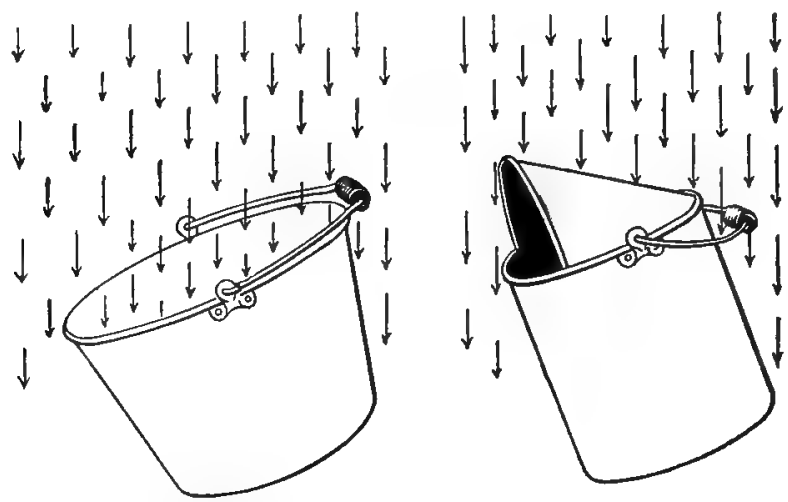

Fig. 103.-Use of sanitary milk-pails. The open pail is fully exposed to the falling dust, while the hooded pail excludes much of the dust and dirt coming from the animal. (Lane, U. S. Dept. of Agric., B. A. I., Circular 158.)

The amount of dust dropping into milk may be somewhat reduced by holding the pail at an angle as illustrated in Fig. 102.

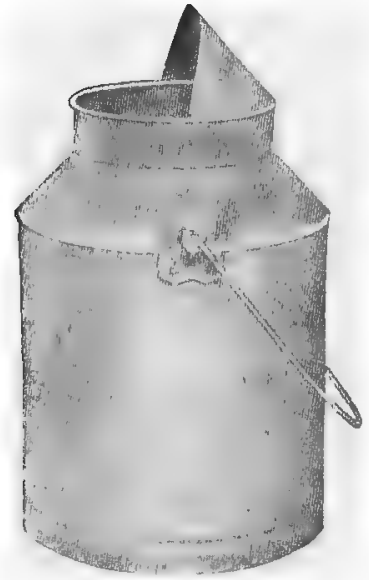

Fig. 104.-Good style of Freeman milk-pail.

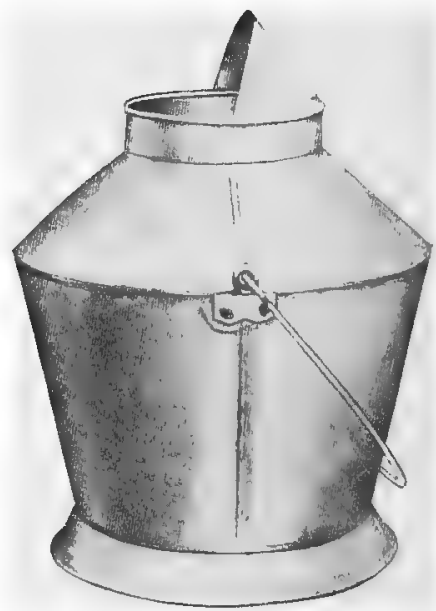

Fig. 105.-Poor style of Freeman milk-pail.

(Harding, Wilson, and Smith, New York Agric. Exp. Sta., Bull. No. 326.)

A more efficient protection is obtained by using some device to reduce the size of the opening (Fig. 103). Freeman designed a pail (Figs. 104, 105) with a hood attached, by means of which a 

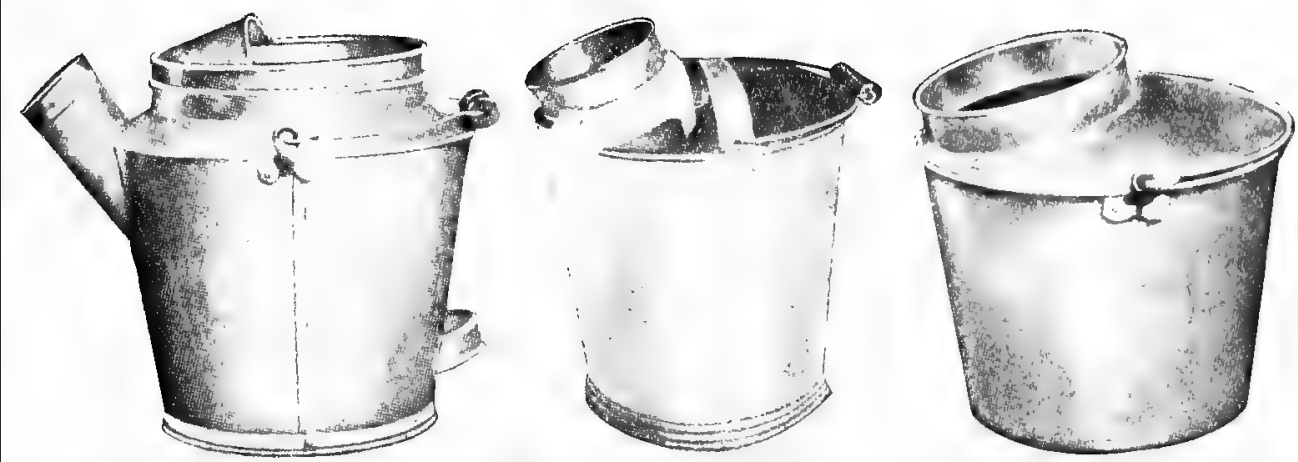

Fig. 106.-Gurler pail.

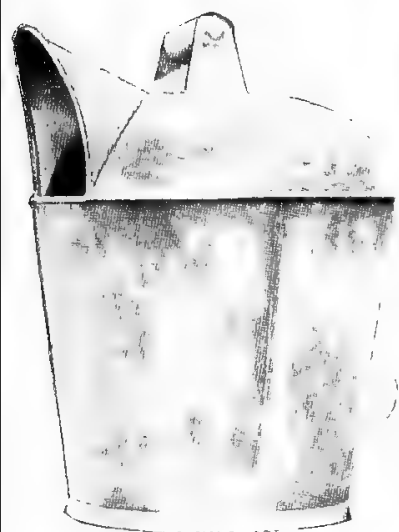

Fig. 109.-Atlantic pail.

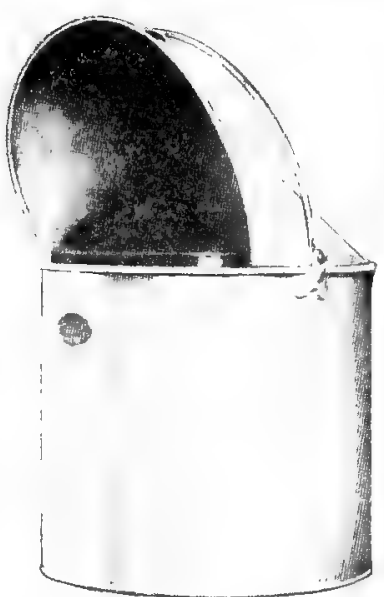

Fig. 110.-Champion pail.

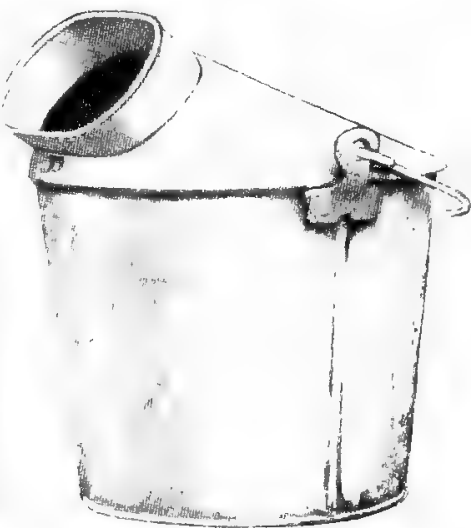

Fig. 111--Francisco pail.

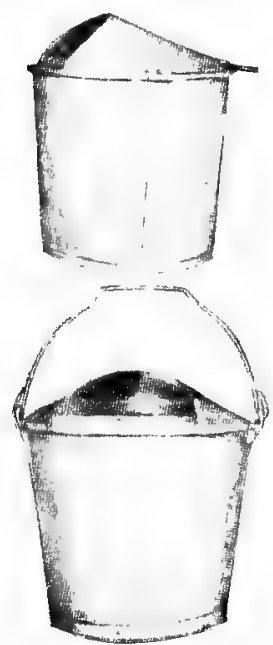

Fig. 112.-Storrs' pail.

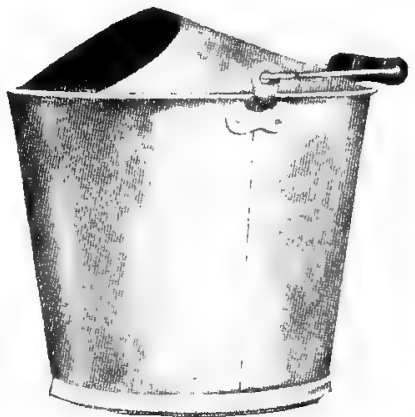

Fig. 113.-Loy pail.

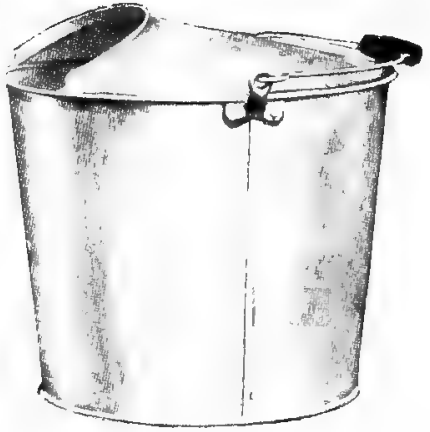

Fig. 114.-Modified Loy pail. 299 
considerable portion of the dirt was diverted from the milk. However, this hood rendered it difficult to clean the pail and the actual milking process required more time than with an ordinary pail. Subsequently pails were designed whose tops were partially covered, leaving but a small opening of a few inches in diameter. It has been objected to these devices that milking is rendered more difficult, but it has been shown that this objection can easily be overcome by some practice. Pails of such construction are now widely used, especially in certified milk dairies.

One of the earliest types of "small-top" pails was designed by Mr. H. B. Gurler, of DeKalb, Ill. (Fig. 106), and was used in

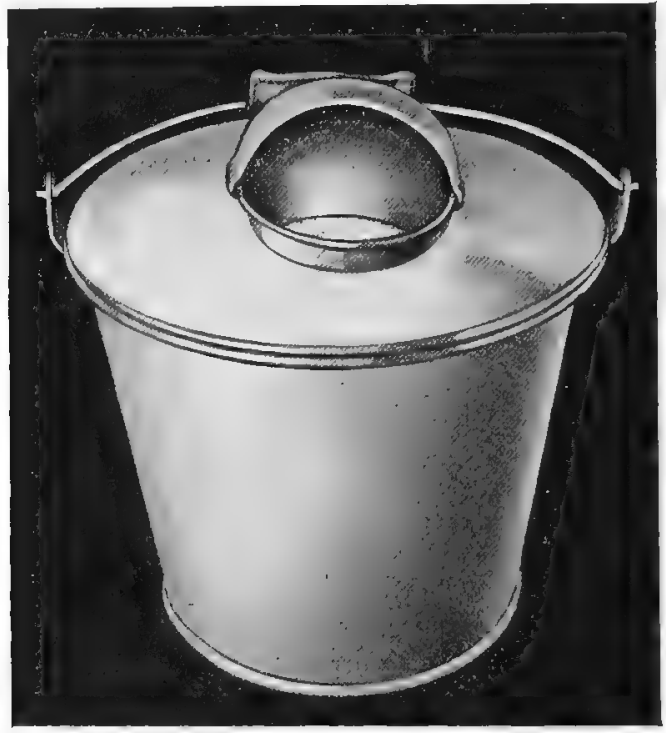

Fig. 115.-Haymaker pail. (Stocking, Storrs' Agric. Exp. Sta., Bull. No. 48, May, 1907.)

his dairy as early as 1895 . The opening is covered with a layer of absorbent cotton held in place by two pieces of cheesecloth. The pail with the cheesecloth and cotton cover is sterilized before using. A side spout with a cover enables the milker to remove the milk from the pail without disturbing the strainer.

Another style of small-top pail is known as the Stadtmueller pail and used first in 1897 (Fig. 107). The opening is $3 \frac{5}{8}$ inches wide and the milk enters the pail through a metal and cloth strainer. The Newburgh pail is similar to the Stadtmueller, the chief difference being the absence of the strainer (Fig. 108). 


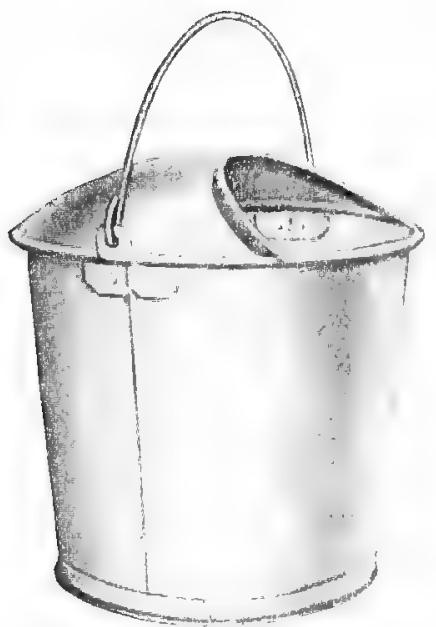

Fig. 116.-Lisk sanitary milk-pail.

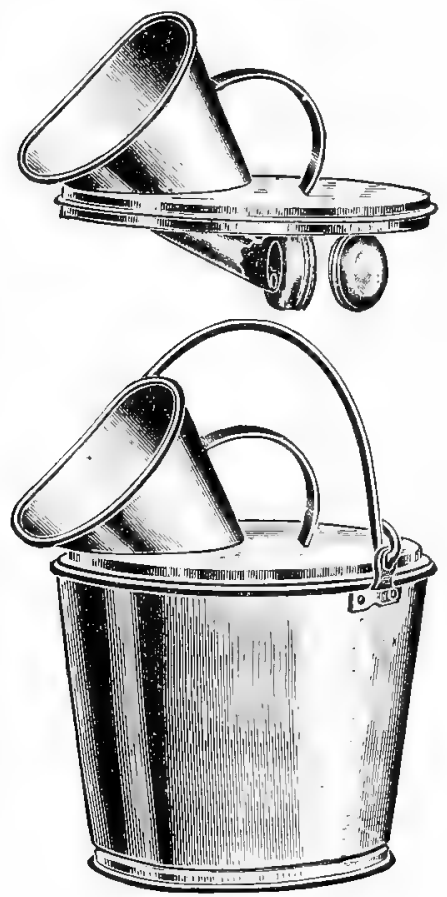

Fig. 118.-Bostwick's sanitary milkpail and cover.

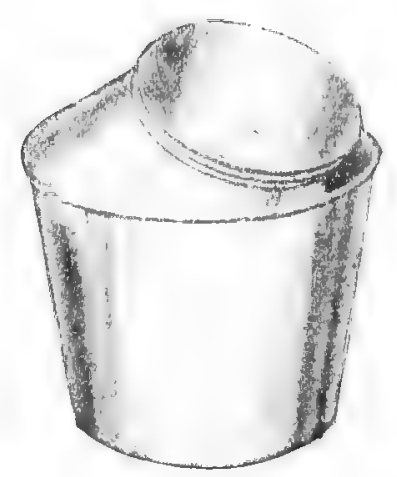

Fig. 117.-Siterilae sanitary milk-pal.

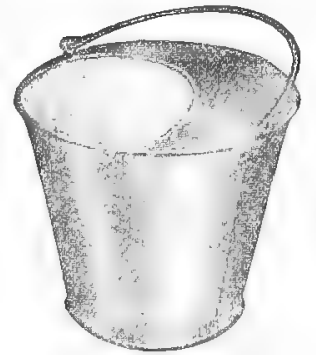

Fjg. 119.-The Elgin sanitary milkpail.

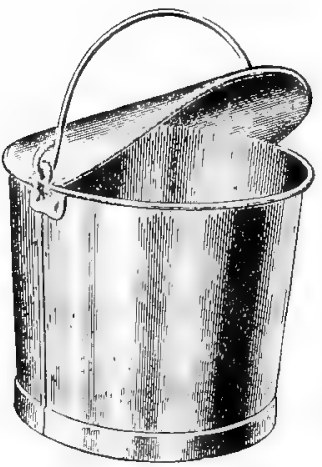

Fig. 120.-Fishmouth sanitary milkpail. 
There are three objections to strainers, namely: 1 , the filth that gathers on the strainer is exposed to the force of succeeding streams of milk, so that part of it is broken up and passes through the strainer; 2, cotton can be used but once, and the expense of pro-

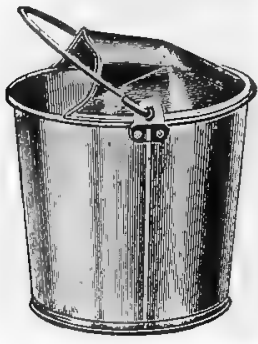

Fig. 121.-Nesco sanitary milking pail.

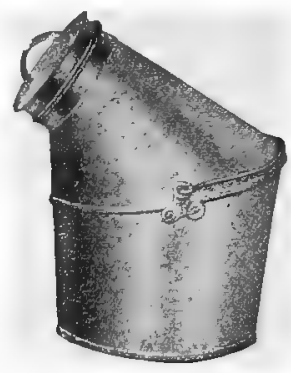

Fig. 122.-The North milking hod.

(A. H. Barber Creamery Supply Co.)

duction is increased thereby; 3 , the cloth requires much care if used repeatedly, and any carelessness in cleaning the cloth increases the germ content of the milk.

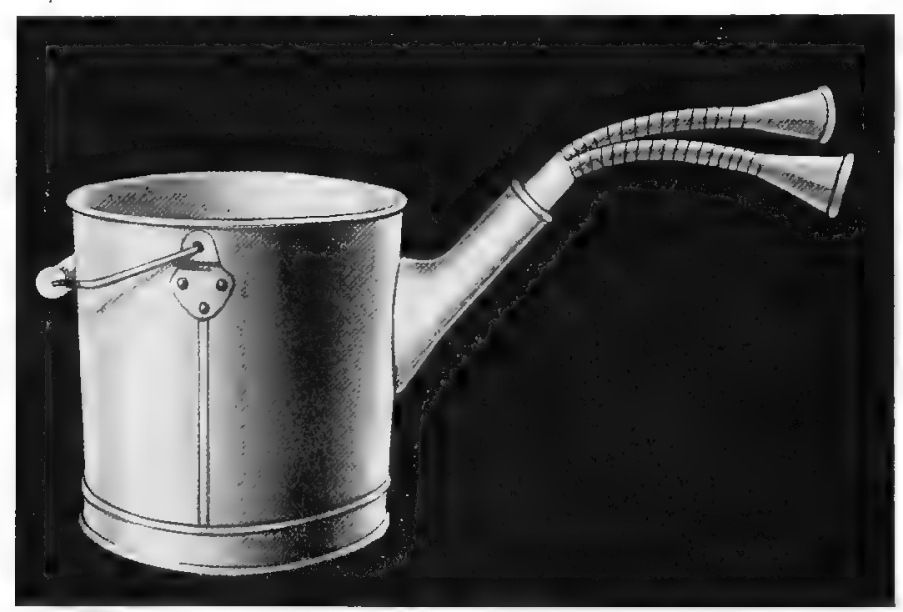

Fig. 123.-The latest development in covered milk-pails. (Stocking, Storrs' Agric. Exp. Sta., Bull. No. 4s, May, 1907.)

Other pails that have gained considerable favor are the Trueman, Loy, Haymaker, North, Storrs, Atlantic, Champion, Francisco, Lisk, Sterilac, Bostwick, Elgin, Fishmouth, Nesco (Figs. 109122), and others. Dirt is excluded most effectively by using a pail described by Stocking (Fig. 123). The pail itself serves as a stool 
for the milker. It has a spout attached to one side, and to the top of the spout two rubber tubes are attached. Each rubber tube has a funnel of about $1 \frac{1}{2}$ by 2 inches around the top. The funnels are attached to the hands of the milker by elastic bands, so that each funnel is held directly under the end of the teat from which the milk is being drawn. Very good results in reducing the germ content have been obtained, but the pail is inconvenient, not easy to clean, and probably not practicable for use when large herds are milked.

The benefits derived from the use of narrow-top pails are illustrated by the work of several investigators. Stocking has given the subject considerable attention, and has published figures of the germ content of milk drawn into ordinary pails and small-top pails. In a stable where considerable care is exercised the following results were obtained:

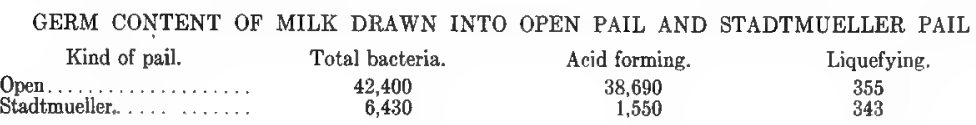

In a stable above the average the results were these: GERM CONTENT OF MILK DRAWN INTO OPEN PAIL AND STADTMUELLER PAIL IN A

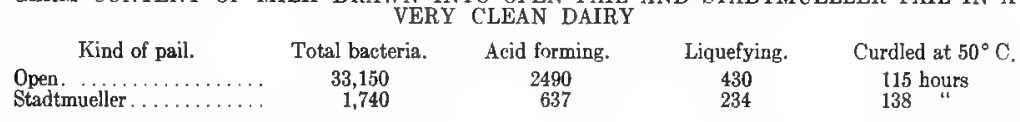

In a dirty stable the difference between the two styles of pails was considerable, as shown by the following figures:

GERM CONTENT OF MILK DRAWN INTO OPEN PAIL AND STADTMUELLER PAIL IN A

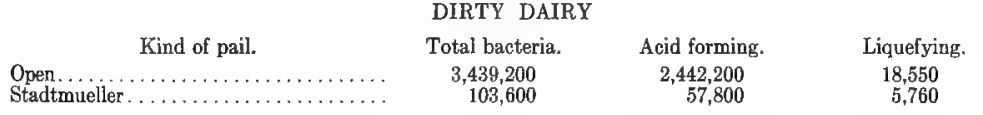

These experiments show clearly the effect of a small-top pail in reducing the germ content of milk, and show further that the reduction is more marked in proportion to increasing carelessness of methods.

Extensive studies as to the benefits derived from using smalltop pails were made by Harding, Wilson, and Smith. When using the Freeman pail 740 bacteria per cubic centimeter of milk were enumerated, while in an open pail there were 1435, a reduction in favor of the small-top pail of 48.4 per cent. The Loy pail gave even better results, the reduction of germ content being 56 per cent. The Atlantic pail reduced the germ content by 50.7 per cent.; the Champion pail, by 66.1 per cent.; the Newburgh pail, by 70.1 per cent.; the Gurler pail, by 55.6 per cent.; and a 
modified Loy pail, by 66 per cent. This modified Loy pail in another series of experiments gave a reduction of 70 per cent. The modification consisted in reducing the size of the opening to 5 by 7 inches and making the cover flush with the top of the pail, so that entrance of foreign matter, when emptying the milk, was prevented.

The evidence is convincing that the use of covered pails reduces the germ content of milk to a marked degree. It is stated by Harding, Wilson, and Smith that an elliptic opening is more satisfactory than a round one, as the former facilitates milking without waste. The cover of a small-top pail should be sufficiently convex so that the entire inside of the pail can be seen and easily reached for cleaning. The cover should be flush with the top of the pail so as to avoid a groove in which dirt collects.

Some small-top pails are higher than ordinary pails, thus causing difficulty in milking short-legged cows. A height of 12 inches is the best adapted for all purposes. Covers that can be removed and that are fitted to the tops of ordinary milk-pails answer the purpose very well when well made, and are inexpensive.

The influence of strainers in small-top pails on the germ content of milk has also been investigated by Stocking. When using the Stadtmueller or Haymaker pail he found that the milk had a smaller number of bacteria when the strainer was omitted than otherwise. This is shown by the following figures:

GERM CONTENT OF MILK DRAWN INTO A STADTMUELLER PAIL WITH STRAINER AND ONE WITHOUT STRAINER

\begin{tabular}{|c|c|c|c|}
\hline & Total bacteria. & Acid forming. & Liquefying. \\
\hline $\begin{array}{l}\text { Without strainer. . . . . . . . . . . . . } \\
\text { With strainer }\end{array}$ & $\begin{array}{r}890 \\
1210\end{array}$ & $\begin{array}{l}204 \\
240\end{array}$ & $\begin{array}{l}36 \\
52\end{array}$ \\
\hline
\end{tabular}

The strainer in these experiments consisted of wire gauze with two thicknesses of fine cheesecloth.

Opposite results were obtained when using the North and Gurler pails. This is shown in the following table:

GERM CONTENT OF MILK DRAWN INTO NORTH AND GURLER PAILS WITH STRAINERS AND WITHOUT STRAINERS

\begin{tabular}{|c|c|c|c|c|}
\hline Kind of pail. & Strainer. & Total bacteria. & Acid forming. & Liquefying. \\
\hline ... & Without strainer & 1160 & 200 & 150 \\
\hline & $\begin{array}{l}\text { With strainer } \\
\text { Without strainer }\end{array}$ & $\begin{array}{r}890 \\
2775\end{array}$ & $\begin{array}{r}180 \\
1830\end{array}$ & 87 \\
\hline & With strainer & $\begin{array}{r}2715 \\
824\end{array}$ & $\begin{array}{r}1830 \\
242\end{array}$ & $\begin{array}{l}87 \\
22\end{array}$ \\
\hline
\end{tabular}

The Haymaker pail again gave higher results with the strainer:

GERM CONTENT OF MILK DRAWN INTO STADTMUELLER AND HAYMAKER PAILS WITH AND WTHOUT STRAINERS

\begin{tabular}{|c|c|c|c|c|}
\hline Kind of pail. & Strainer. & Total bacteria. & Acid forming. & Liquefying. \\
\hline Stadtmueller & Without strainer & 890 & 204 & 36 \\
\hline & Without strainer & 1829 & 767 & 37 \\
\hline & With strainer & 1237 & 827 & 27 \\
\hline
\end{tabular}


In an investigation of several dairy problems the writer, with Luckhardt and Hicks, studied the effect of a brass strainer in a small-top pail similar to the Stadtmueller type. The bacteria were enumerated in 108 lots of milk drawn into the pail with the strainer inserted, and the same number of lots from the same cows on alternate days into the pail without the strainer. The average was 674 bacteria per cubic centimeter without the strainer and 620 with the strainer. The figures are too close to draw conclusions in favor of either method. Since the strainer increases the work of cleaning the pail and unless properly sterilized would tend to increase the number of bacteria, it seems profitable to omit it in some styles of small-top pails.

In some pails, as Stocking has shown, the presence of a strainer reduced the germ content, while in others the germ content was increased. The increase of bacteria can be explained only on the hypothesis that the accumulating dirt is broken up and carried into the milk by succeeding streams of milk. If the strainer is constructed in a manner which causes the dirt to be washed aside, better results can be obtained with a strainer. If the strainer were of a conical shape the dirt would be washed away from the place where the fresh streams of milk strike. Theoretically a properly constructed conical strainer would seem to be useful. Such a strainer was placed on the market, but has apparently not met with much favor.

The narrow-top pail is clearly a decided improvement over the old-fashioned open pail, inasmuch as the germ content is materially reduced by its use. Cotton strainers seem to be of some benefit if the dirt remains in a place where it is not struck by streams of milk, but if the streams do strike the dirt it is broken up and a portion of it will eventually reach the milk and increase the germ content.

On the foregoing pages it has been shown that there are important sources of contamination by which the germ content of milk is increased during milking operations. With the introduction of milking machines it was hoped that, by conducting the milk from the udder into the pail without exposure to contaminating conditions, such as dust, filth, and stable odors, these sources of bacterial pollution could be eliminated. Expectations have been realized in a measure, but the machine has introduced factors which need special attention.

It is obvious that the simpler the construction of machines and utensils, the more easily can they be kept in sanitary condition. The milking machine is rather complicated, and the different parts, unless properly cleaned, offer harboring places for 
bacteria which multiply in remnants of milk and then increase the germ content of the product.

Besides reduction of germ content of the milk, other advantages may be derived from the use of milking machines. One of these is the reduction of help necessary to carry on milk production. Farm help is notoriously difficult to obtain, and through scarcity of help the dairy industry has not developed to a desirable degree. Another advantage lies in the fact that the chances of contaminating milk with pathogenic bacteria from the milker are materially reduced by the aid of milking machines, since the direct contact of human beings is largely excluded.

The idea of substituting machines for milkers is not by any means of recent origin. Perhaps the earliest attempt to facilitate milking was by introducing straws through the teats into the cistern, thus opening the sphincter muscle and allowing the milk to flow from the udder. This method, however, is objectionable because of the contamination from the straw and the possibility of irritating or injuring the tissues. Inventors first occupied themselves with designing milking machines in the decade commencing with 1870. Martiny, quoted by Lane, knew of 29 different machines that had been patented or mentioned in the literature between 1877 to 1899 . In the United States 127 patents on milking machines or separate parts thereof were applied for during the period from 1872-1905. But few machines survived actual tests, and it is only within very recent years that the milking machine has become an efficient factor in milk production.

Three principles have been applied in designing milking machines, namely: 1 , introduction of a milk tube into the cistern; 2 , pressure applied to the base of the teat where it is attached to the udder; 3 , suction. The third principle has proved the only successful one, as by its means the natural sucking of the calf can be imitated. In machines constructed on this principle the teat is placed in a cup from which the air can be exhausted by means of a pump - either a hand-pump, a foot-pump, or a vacuum created by machinery. The best modern machines alternate sucking and pressure by inflowing air, thus creating pulsations in imitation of the sucking of calves.

Several difficulties presented themselves when machines were first put into practical use. The difficulties have been successfully overcome, in a measurc at least, so that milking machines of modern type actually do the work demanded of them. One of the difficulties was found in proper cleaning of the machine after use. Some parts of the machine are made of rubber, and this is notoriously difficult to sterilize without injuring the material. 
Next to this the greatest difficulty experienced has been proper construction of the teat cups. The size of teats varies greatly not only in different animals but also in the same animal according to the stage of the lactation period. To meet this condition it was formerly required to have a number of cups available. As a consequence changes frequently had to be made after the cups had been sterilized, thus exposing tbem to renewed contamination. By accident or carelessness cups might drop and become contaminated with filth from the floor.

A third, by no means unimportant, difficulty was the necessity of accustoming the cows to the use of the machine. The suction power must be properly regulated, otherwise injury to the teat may result, and the animal must get used to the clicking of the machine caused by the alternation of sucking and pressure.

Finally, the problem arose whether the machine would exert an influence on milk secretion and decrease the amount of the product and perhaps abbreviate the lactation period.

These problems have been investigated by a number of authorities, and it can be stated that the milking machine has emerged from the experimental period and that means have been found for overcoming many difficulties in large measure. Improvements have been made rapidly since scientific investigation has shown where the machine was at fault, and it is expected that within a short time further improvements will be made, so that the milking machine will be useful even in the hands of untrained men.

The results of using milking machines in earlier periods were rather discouraging. Harrison in 1899, working with the "Thistle" machine, found that the machine-drawn milk had 141,616 bacteria per cubic centimeter in the morning's product and 165,033 in the evening milk. Hand-drawn milk had but 10,619 in the morning's product and 12,890 in the evening milk. The hand-drawn milk had, therefore, about one-fourteenth the number of bacteria that machine-drawn milk contained.

Later investigations, however, have given more encouraging results. Hastings and Hoffmann found that machine-drawn milk contained no more bacteria than hand-drawn, and this result was obtained when operations were carried on in a barn which was kept in good condition, but not in a scrupulously clean condition, such as prevails in certified milk barns. Under more ordinary conditions the outcome of the experiments would probably have been decidedly in favor of the machine.

An exhaustive study was made by Stocking and Mason in 1907. The authors found that the method of cleaning the machine was of paramount importance in producing results. Ma- 
chine-drawn milk had a higher germ content than hand-drawn milk when the following methods of cleaning were employed: Cleaning the machine by pumping water through it; placing the cups after cleaning the machine in a solution of Gold Dust $1: 300$; and by using borax in the cleaning fluid. When the parts of the machine were sterilized in steam the germ content of machinedrawn milk was still somewhat higher than in hand-drawn milk. And even when the rubber parts were placed in a.10 per cent. sodium chlorid solution after the machine had been washed the bacteria were more numerous in machine-dramn milk than in hand-drawn milk. Good results were obtained when $2 \frac{1}{2}$ per cent. of formalin were used for cleaning, and still better results with 3.5 per cent. formalin. In the latter case the parts were practically sterile.

Strong brine has been recommended by manufacturers of milking machines as a suitable antiseptic for keeping the rubber parts of the machine between milking periods. Stocking and Mason, however, found that when the salt solution was three days old it contained 1000 to 2000 bacteria per cubic centimeter.

An important factor came to light in the experiments of Stocking and Mason. It has been stated before that milking machines operate by alternating suction and admission of air for relief of the vacuum. This air, of course, comes from the stable and from the immediate environment of the cow. It therefore contains many bacteria. By filtering the relief air through absorbent cotton impurities were eliminated and satisfactory results obtained. This is illustrated in the following table given by the authors:

INFLUENCE OF COTTON RELIEF FILTERS ON THE GERM CONTENT OF MACHINE-DRAWN MILTi

Total bacteria.

With cotton filters ........ $\left\{\begin{array}{l}\text { Machine } \\ \text { Hand } \\ \text { Wachine }\end{array}\right.$

1,578
4,560
11,541
7,467

Acid formi
662
662
1142
5209
3226

\begin{tabular}{cc}
\multicolumn{2}{c}{ Liquefiers. } \\
Rapid. & Slow. \\
14 & 80 \\
18 & 280 \\
22 & 238 \\
40 & 181
\end{tabular}

The effect of cotton filters is clearly shown not only in regard to total numbers of bacteria but also in regard to groups. Acidforming bacteria and liquefiers were less numerous, as were total numbers.

Results obtained by Haecker and Little showed also that low bacterial counts can be obtained by machine milking, but only when all parts are thoroughly cleaned.

Meek again found that machine-drawn milk contained about twice as many bacteria as hand-drawn, but Hastings and Hoffmann after a series of tests concluded that machine-drawn milk and hand-drawn milk contained about the same number, possibly 
slightly less in machine-drawn milk. The parts were kept in lime-water during the intervals between milkings.

Harding, Wilson, and Smith made extensive studies of the germ content of machine-drawn and hand-drawn milk. The teat cups remained in 10 per cent. salt solution after the machine had been carefully cleaned. Comparative counts of milk obtained after the teat cup had been kept in brine with those of milk not so treated gave the following results: Average of 11 samples after immersion of the cups in brine, 17,086 bacteria per culic centimeter, and 9 samples with the cups not immersed in brine gave an average of 188,580 bacteria per cubic centimeter.

The authors call attention to the importance of removing the air from the tubes of the machine while they are immersed in brine. Tests showed that when air was present the average of 11 samples was 4740 bacteria per cubic centimeter, while without air in the tubes the average of 12 samples was 1999 bacteria per cubic centimeter.

These authors confirmed Stocking and Mason's work on the efficiency of relief filters, and determined that absorbent cotton is more efficient than common cotton. An improvement in the construction of the teat cups made possible a further reduction of germ content by allowing a larger filter to be inserted. Milk drawn by a machine of the old type contained 8340 bacteria per cubic centimeter in an average of 24 samples, while milk drawn with the new machine had 3210 bacteria per cubic centimeter in an average of 24 samples.

Changing of teat cups before milking increased the germ content from 4150 to 6410 bacteria per cubic centimeter. The importance of proper handling of the machine is further emphasized by tests made of milk that had been milked in a pail the cover of which had been removed and replaced before milking. The bacterial content was 5850 , against 4220 in a pail the cover from which had not been removed.

The influence of machine milking on milk secretion has been studied by Lane, Woll and Humphrey, Beach, Price, Alexander, Smith and Harding, and others. The difference in quantity produced by machine and hand milking, if there is any, is too small to be measured.

The investigations recorded show that milking by machine is not only feasible, but has some advantages. The expense of running a machine is small, amounting to 4 cents per hour, 6 cents per milking, and $\$ 3.60$ per month (Woll and Humphrey). The expense for repairs is relatively small and the saving in help considerable.

In order to obtain favorable results, however, intelligent care 
is necessary, probably more than in hand milking. The vacuum should not be higher than 15 to 15.5 , otherwise injury to the cow may result, and the yield is not greater with a higher vacuum. Cows have to become accustomed to the machine, and this is more difficult with some animals than with others. It has been observed that when hand milking is replaced by machine milking there is a temporary shrinkage in yield. This, however, is also true when milkers are changed, and is, therefore, no objection to the use of a machine. The cost of a machine and the cost of installing amounts to nearly $\$ 400$. It is, therefore, not advantageous for herds smaller than 15 cows.

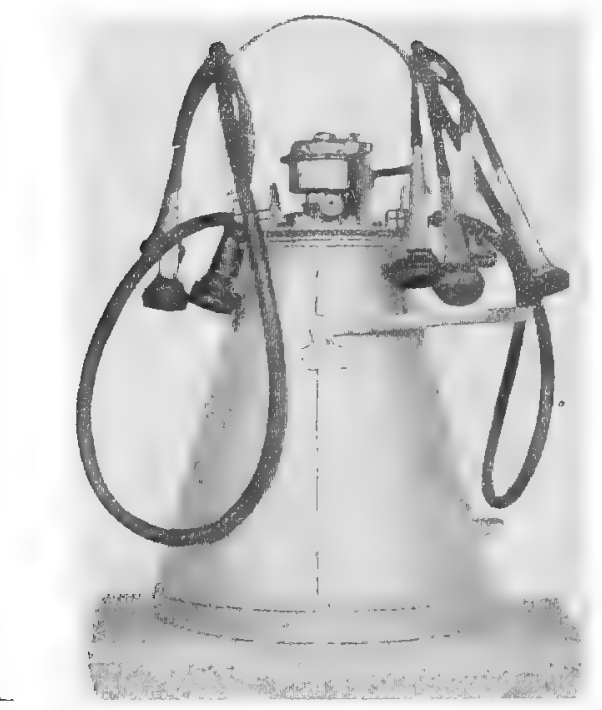

Fig. 124.-Milking machine used in experiments by Lane and Stocking. (Bull. No. 92, B. A. I.)

The machine must be properly cleaned and the parts kept in brine or an equally efficient antiseptic solution between milkings. Cleaning the machine before use is estimated to occupy ten to twenty minutes, and attention after milking about twenty minutes. This extra time is, of course, more than compensated for by the time saved in milking, as each milker can handle two machines or even three at the same time, and each machine milks two cows simultaneously. In the usual form of machine the milk runs into one pail from two cows. This is a disadvantage when it is desired to learn the productivity of individual animals. Recently 


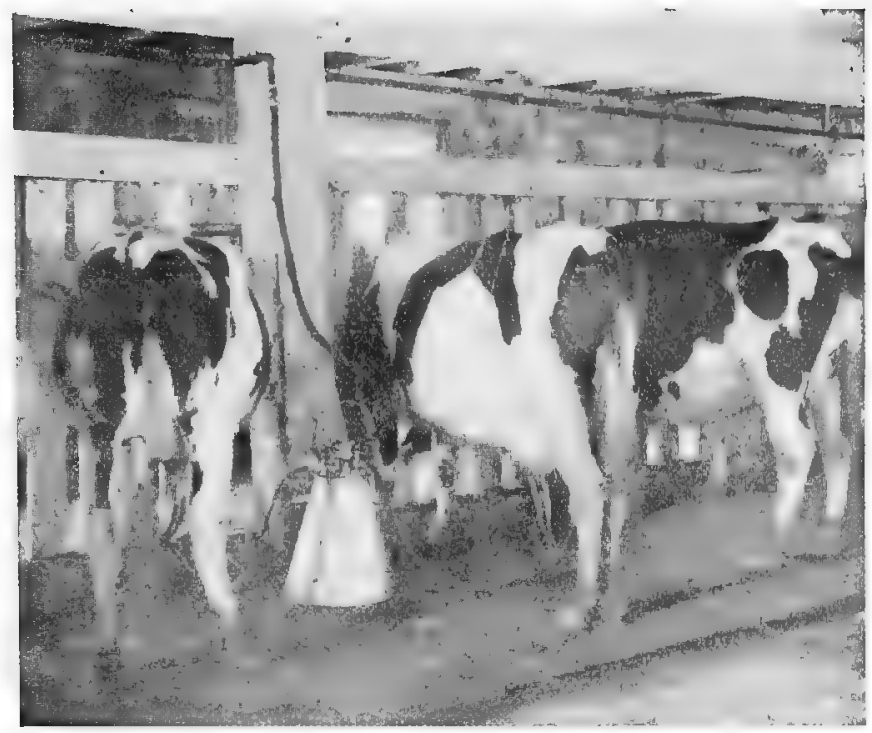

Fig. 125.-The same machine in operation. (Bull. No. 92, B. A. I.)

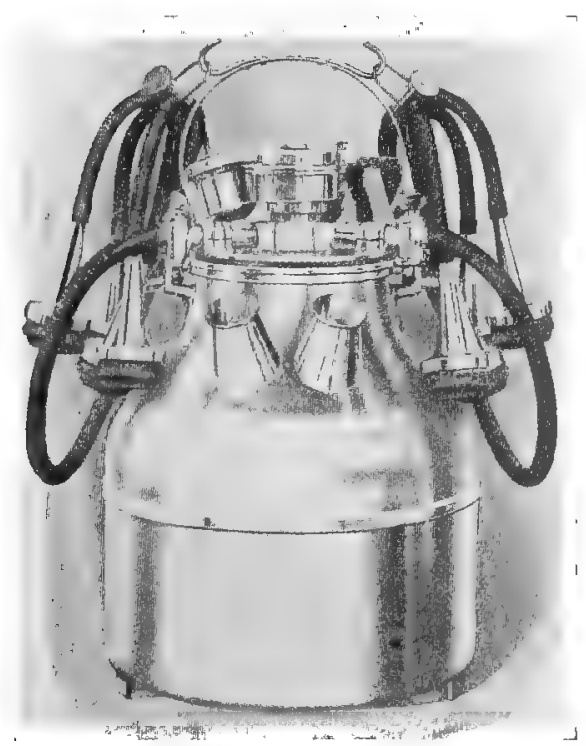

Fig. 126.-Burrell-Lawrence-Kennedy milking machine. Used in station experiments. (Smith and Harding, New York Agric. Exp. Sta., Bull. No. 353.)

designed machines receive the milk from each cow separately (Figs. 124-131). 
When carefully used the machine has no injurious effect on the teats or the udder. Some cows are difficult to milk by machine, as, for example, old cows, those advanced in the lactation

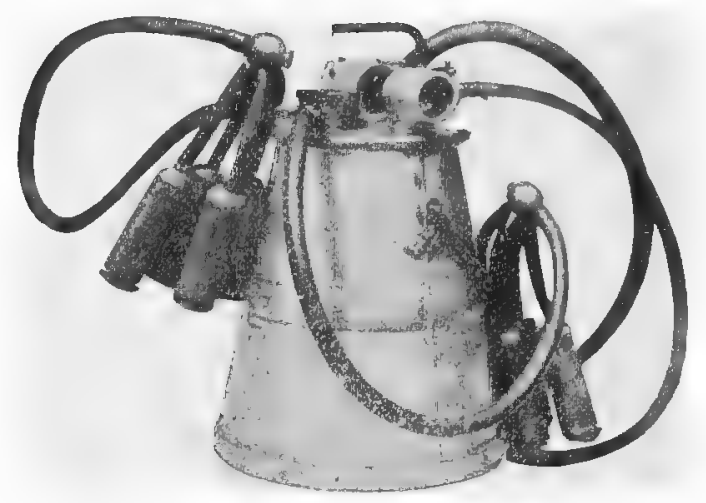

Fig. 127.-Globe milking machine. (Harding, Wilson, and Smith, Bull. No. 317, New York Agric. Exp. Sta.)

period, those having abnormal teats or udders, and those with nervous temperament. These must either be milked by hand or removed from the herd.

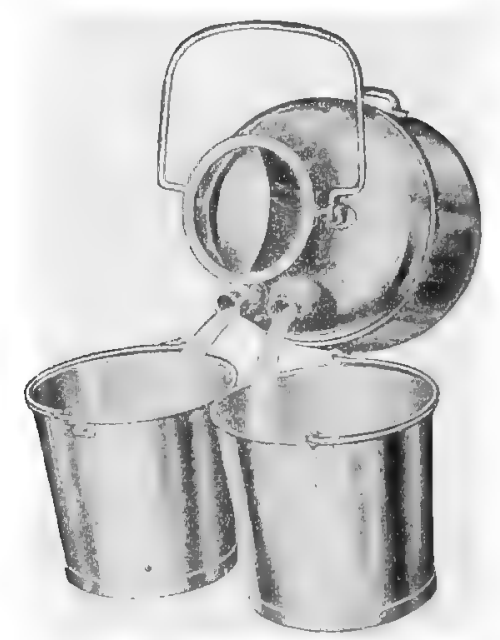

Fig. 128,-Method of delivery of milk by Burrell-Iawrence-Kennedy machine. Harding, Wilson, and Smith, Bull. No. 317, New York Agric. Fxp. Sta.)

The teat cups must always fit well to the teats, otherwise the latter may be injured, or air may be sucked in and the milk become contaminated. Most of the work on milking machines 
that has been published has been done with the Burrell-LawrenceKennedy machine. In this machine the vacuum is produced at the end of the teat, where a cup is provided to support the teat. The air is prevented from entering the cup by a lubber curtain.

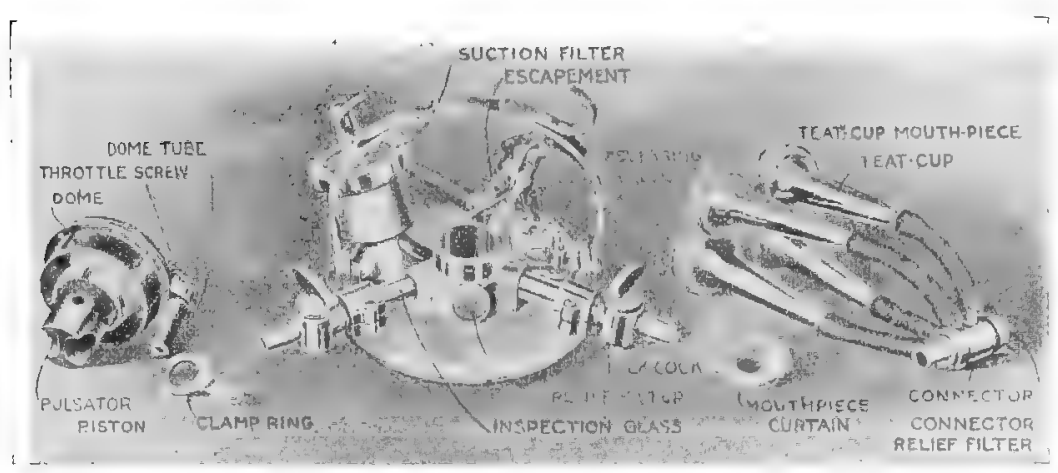

Fig. 129.-Details of construction of Burrell-Lawrence-Kennedy machine.

(Harding, Wilson, and Smith, Bull. No.317, New York Agric. Lixp. Sta.)

The four cups are connected by means of tubes to the teat cup connector, and from here a large rubber tube connects with the pail. A piece of glass tubing is inserted so that the passage of milk can be observed. The vacuum is intermittent and pulsations occur about once a second. The rate of pulsation is adjust-
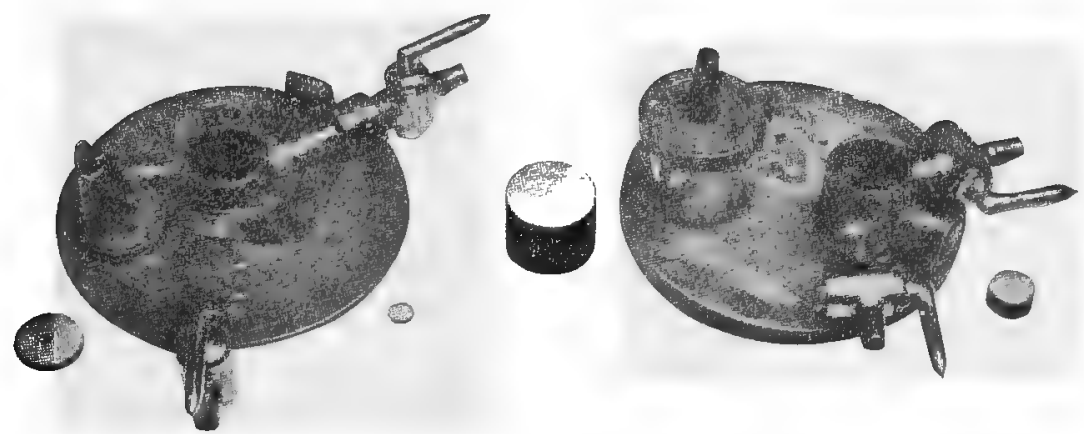

Fig. 130.-Two styles of pulsator head of Burrell-Lawrence-Kennedy machine. Blocks show sizes of filters. (Harding, Wilson, and Smith, Bull. No. 317, New York Agric. Exp. Sta.)

able. The air that is admitted between pulsations is filtered through a cotton filter.

The milking machine has proved to be helpful in milk production and a better grade of milk can be produced than by hand milking. However, good results clearly depend upon 
intelligent usage, but when this is exercised there is a saving in time and money and dairying as a source of profit is encouraged.

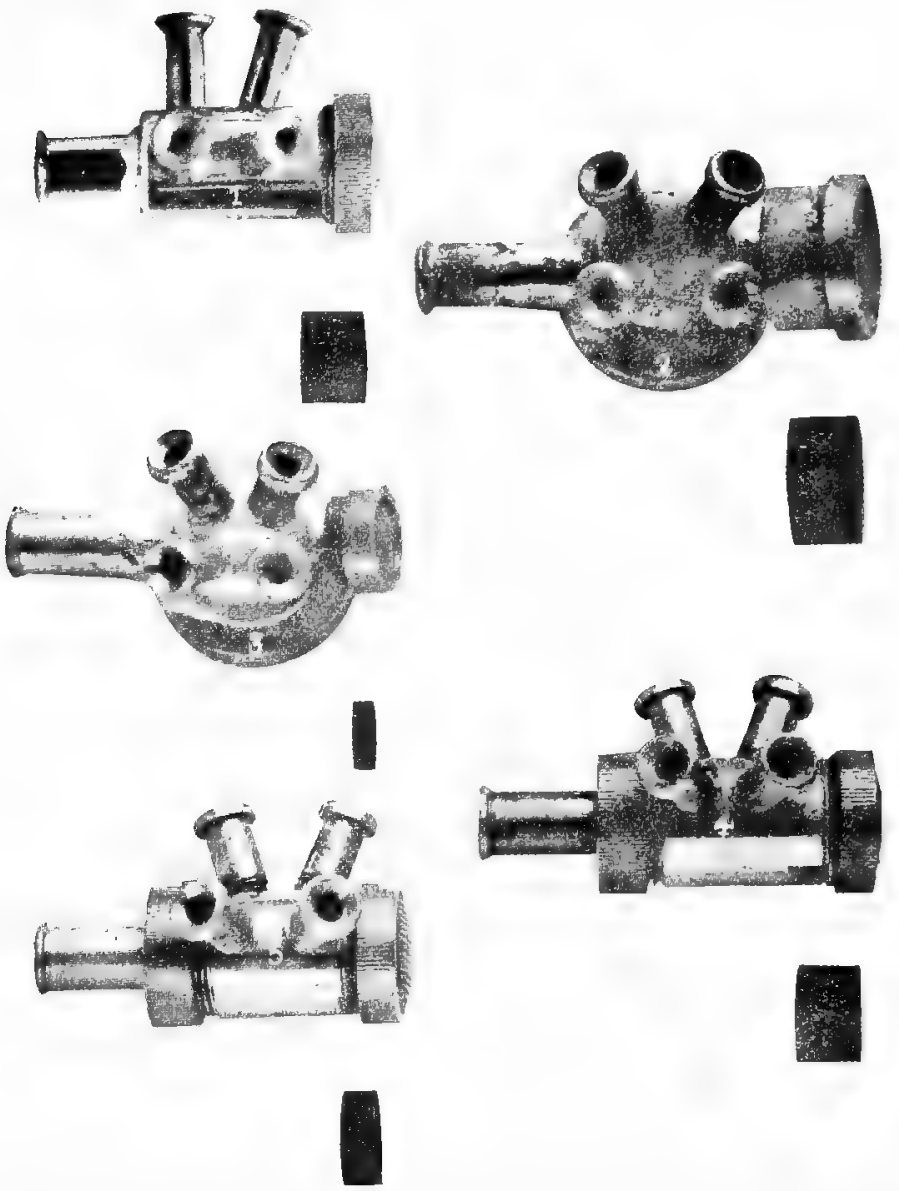

Fig. 131.-Various styles of teat cup connectors of Burrell-Lawrence-Kennedy machine. Blocks show sizes of filters. (Harding, Wilson, and Smith, Bull. No. 317, New York Agrie. Exp. Sta.)

From a sanitary point of view the reduction of the germ content and the small chance of infection reaching the milk are the chief advantages.

\section{Contamination from Utensils}

Utensils may contribute largely to the germ content of milk. It is very probable that under ordinary farm conditions the utensils are, in reality, the most prolific source of bacteria, a greater source perhaps than the cow. In both cases cleanliness and 
care aid in reducing the germ content of the product. In cans, seams and sharp corners, dents and rusty spots are difficult to
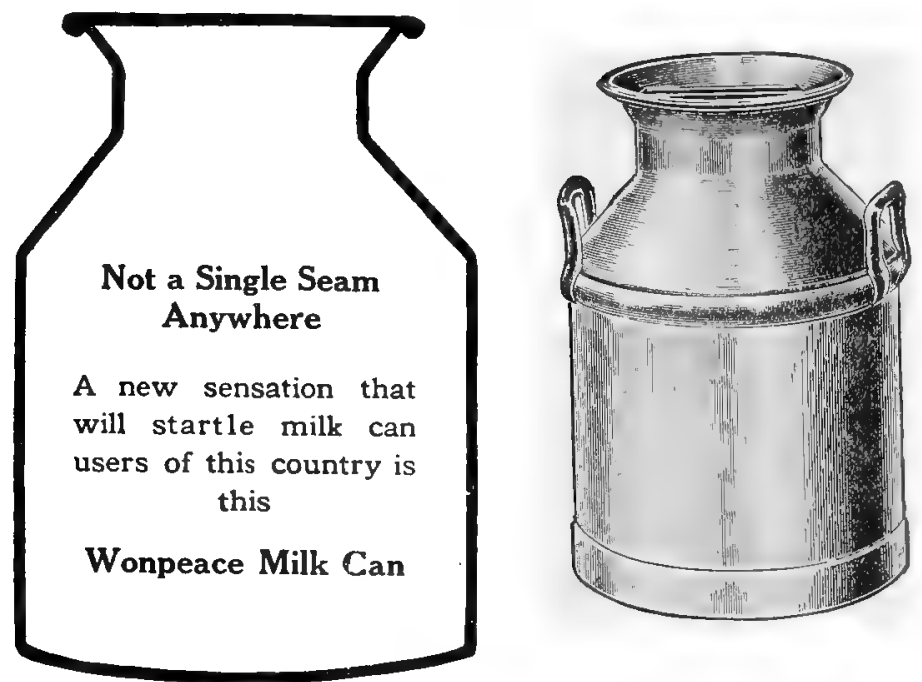

Fig. 132.-Wonpeace milk-can. (A. H. Barber Creamery Supply Co.)

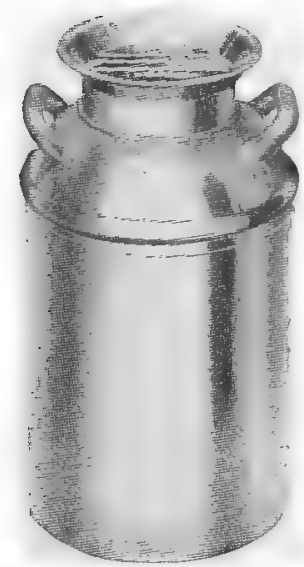

Fig. 133.-The Wisconsin pattern milk-can.

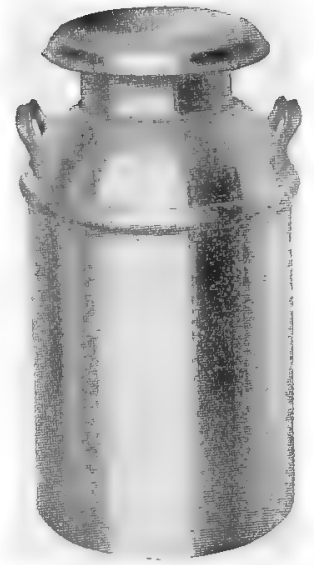

Fig. 134.-The Hudson pattern milk-can.

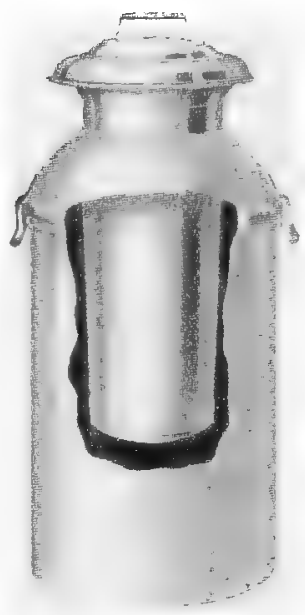

Fig. 135.-The Virginia pattern milk-can.

(A. H. Barber Creamery Supply Co.)

clean thoroughly, and the diluted milk that may remain there for the time elapsing between milkings furnishes food for bacterial growth. This condition is intensified in summer when favorable 
temperature encourages germ growth. Furthermore, the handling and repeated sterilizing of cans subject them to rough usage, so that dents are formed which offer hiding places for bacteria. The inside wall of cans and other utensils should be smooth and

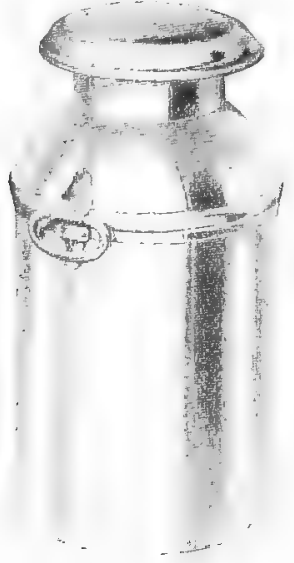

Fig. 136. -The "New York Special" milk-ean. (A. H. Barber Creamery Supply Co.)

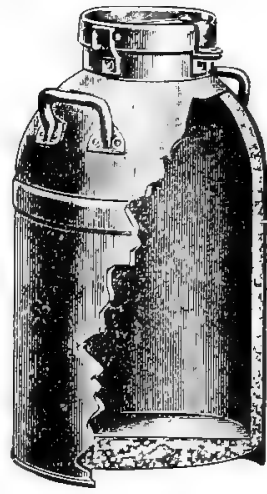

Fig. 137.-Sanitary cold-hold can.

the corners rounded off. Seams should be filled with solder, and after washing no moisture should remain (Figs. 132-137).

Similarly, the strainers (Figs. 138-140), the coolers (Figs. 141143), and the bottling machines (Figs. 144-147) require care in order to clean out hiding places of bacteria. Strainers should
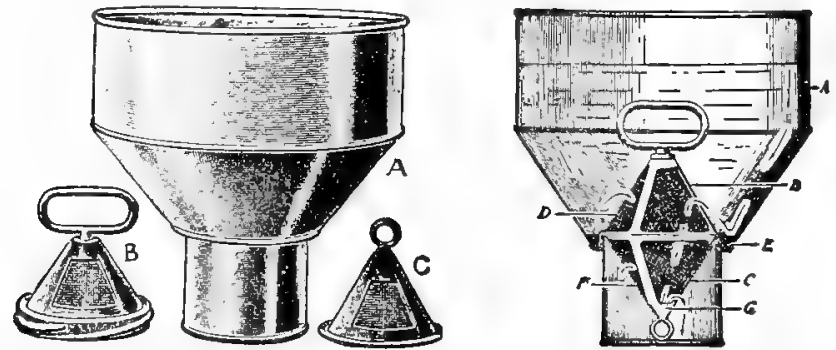

Fig. 138.-Ekvall Duplex milk strainer. (A. H. Barber Creamery supply Co.)

be constructed so as to have a higher center than periphery, so as to facilitate washing down dirt particles without exposing them to the new streams of milk that tend to break them up. Talves, bearings, and other intricate parts of machinery need special 
attention, since.they are difficult to reach. In all such places bacteria may multiply at a great rate if remnants of milk remain.
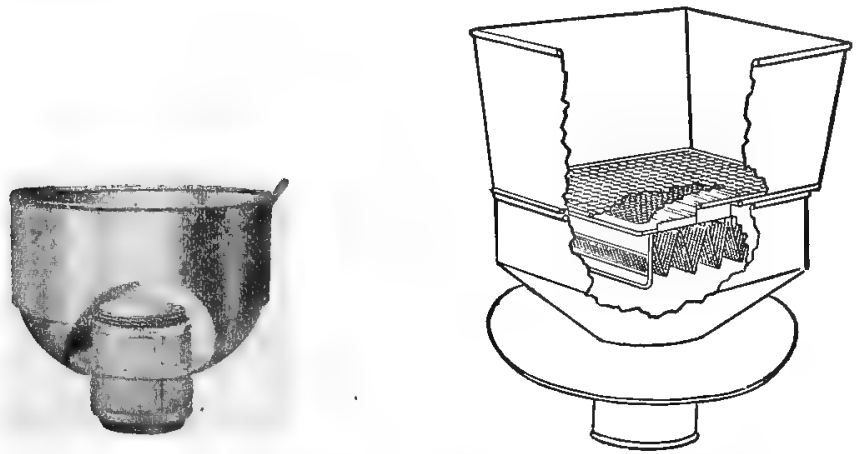

Fig. 139.-The Beverly double strainer. ' Fig. 140,-Cuppel sanitary strainer. (A. H. Barber Creamery Supply Co.)
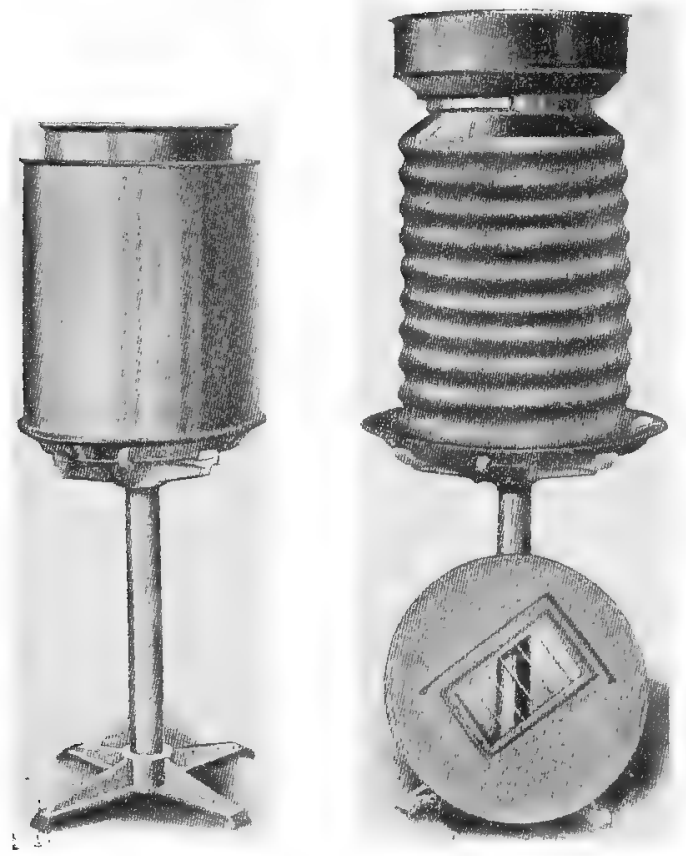

Fig. 141.-Davis' milk and cream cooler.

Russell found that when a pail was sterilized the germ content of the milk was 165 per cubic centimeter, while in a pail not sterilized the number was 4265 . Löhnis and Kuntze counted in 

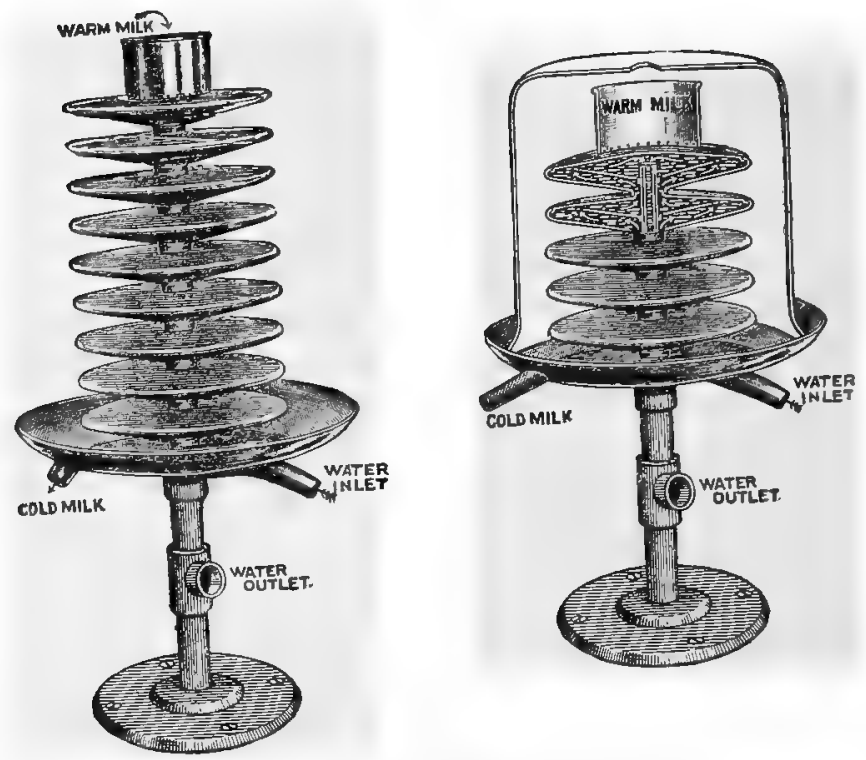

Fig. 142.--Circular milk cooler.

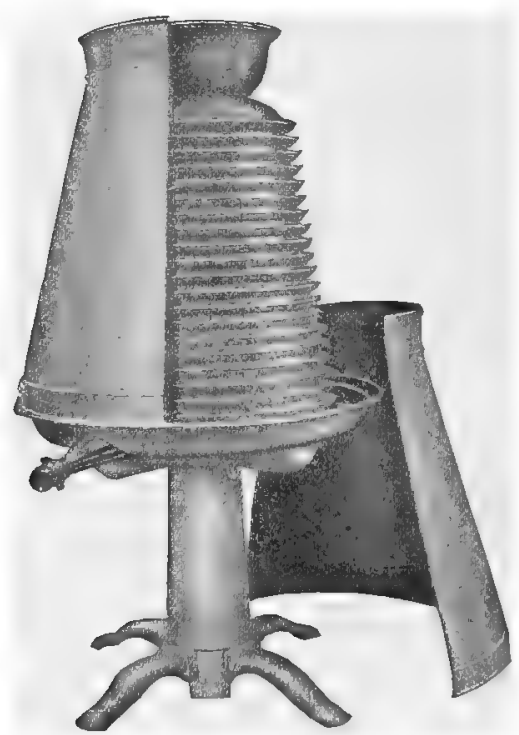

Fig. 143.-Chilly King cooler. (A. H. Barber Creamery Supply Co.)

unsterilized pails ten to one hundred times as many bacteria as in sterilized ones. In cans cleaned in ordinary fashion Harrison 
found 442,000 bacteria per cubic centimeter in 100 c.c. of washwater, but in cans that were washed with tepid water and then

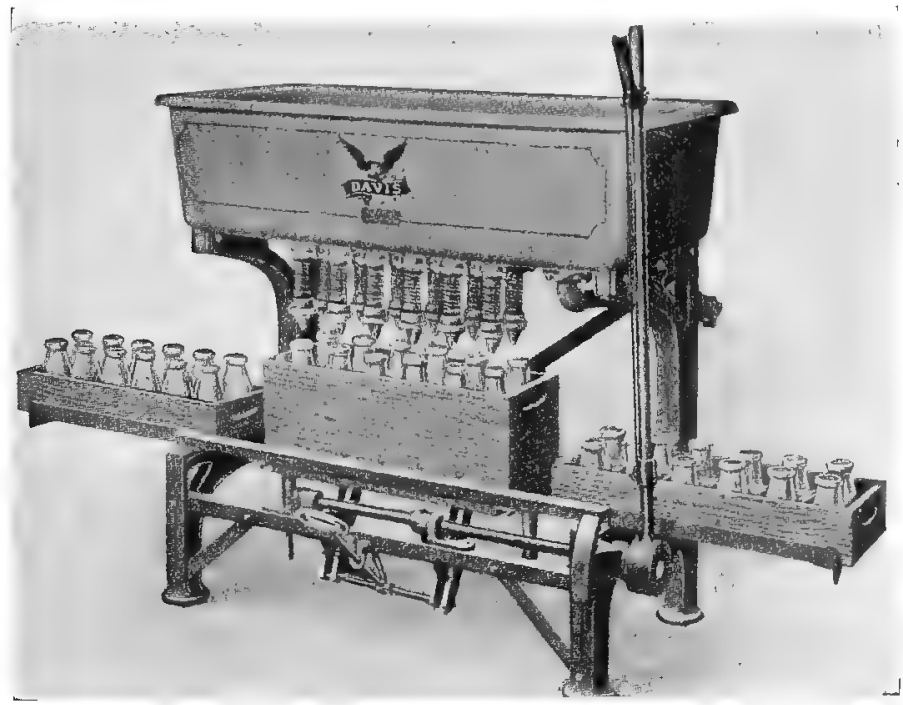

Fig. 144.-Standard twelve-bottle filter.

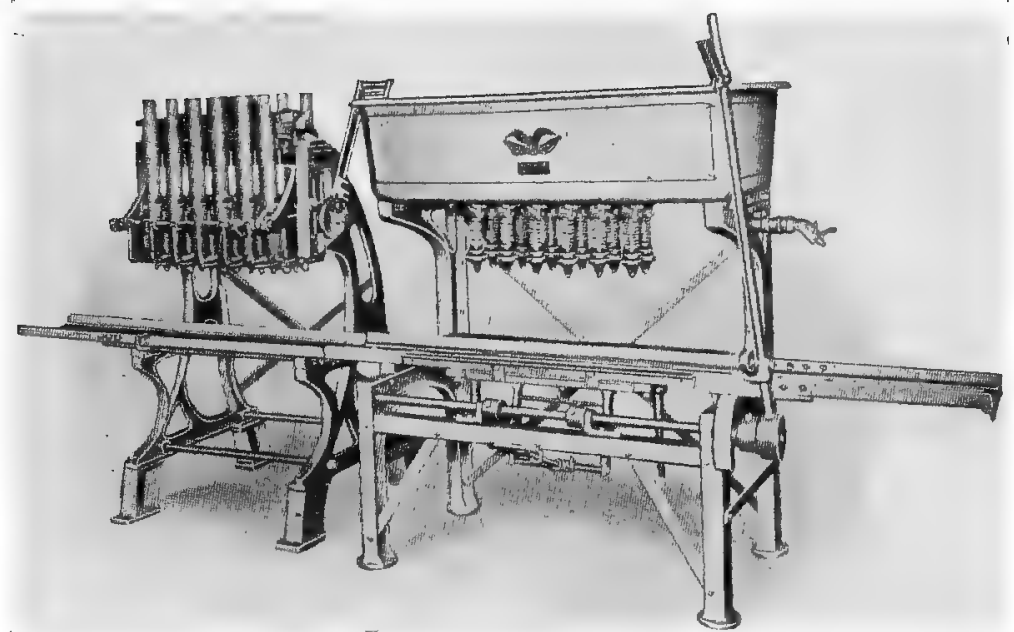

Fig. 145.-Davis' standard combined filler and capper.

scalded the number was reduced to 54,000. Careful washing and subsequent steaming for five minutes caused a further reduction in germ content to 880 per cubic centimeter. 


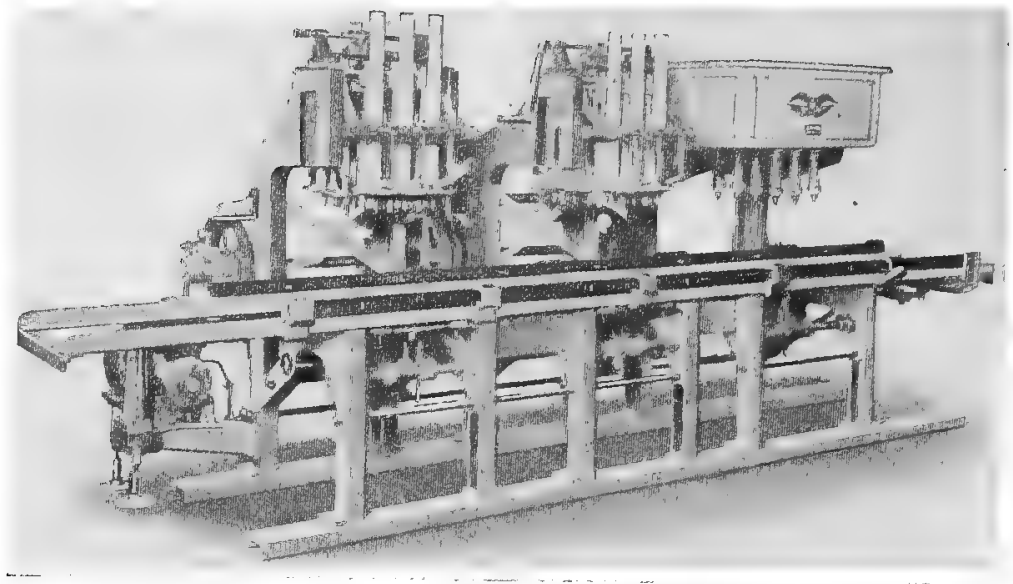

Fig 146 -Davis' automatic power combined filler and capper.

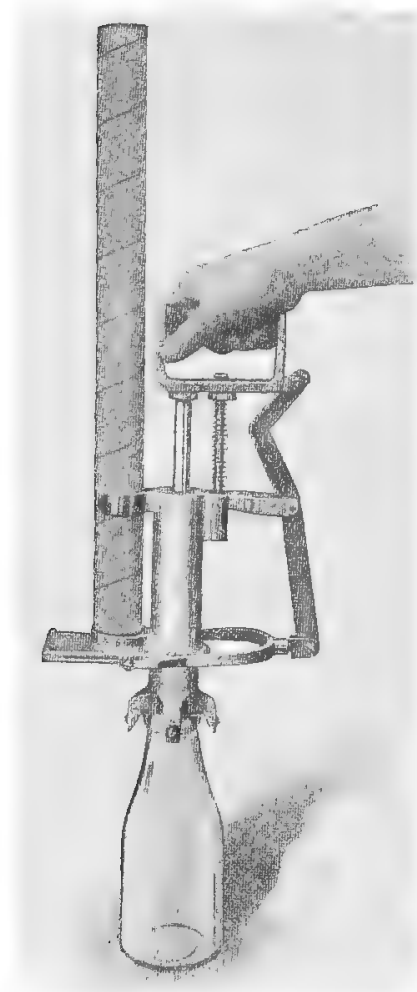

Fig. 147.-Davis' single bottle capper.

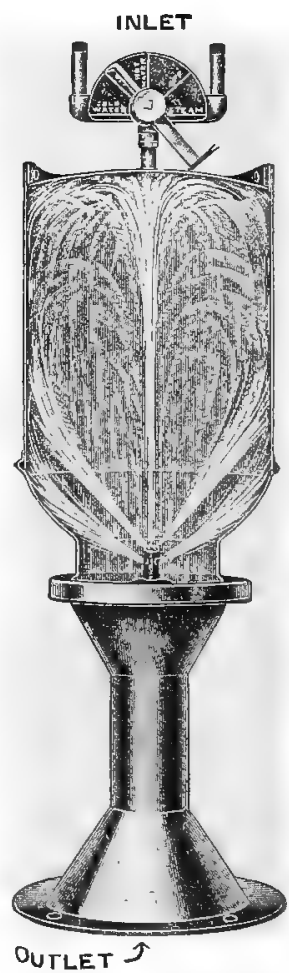

Fig. 148,-Can rinser. 
Prucha, Harding, and Weeter determined in a series of experiments that the germ content of the milk was increased by 57,077 bacteria per cubic centimeter when the pails were merely washed, but not sterilized.

Thorough cleaning and washing of pails seems to be indispensable if the germ content of milk is to be kept low. Care expended on stables, animals, and milking pails may produce milk with small numbers of bacteria, but good results from these practices are largely vitiated unless equal care is given to cans, coolers, and bottles. The remnants of milk adhering to utensils should be rinsed with cold or lukewarm water, then the utensils should

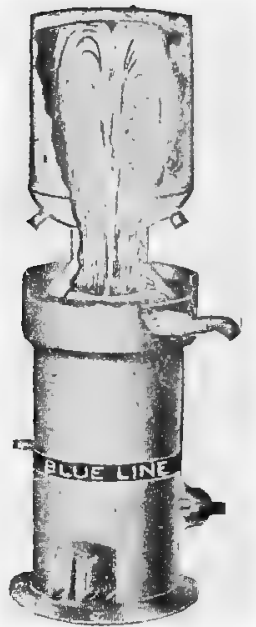

Fig. 149.-Can rinser.

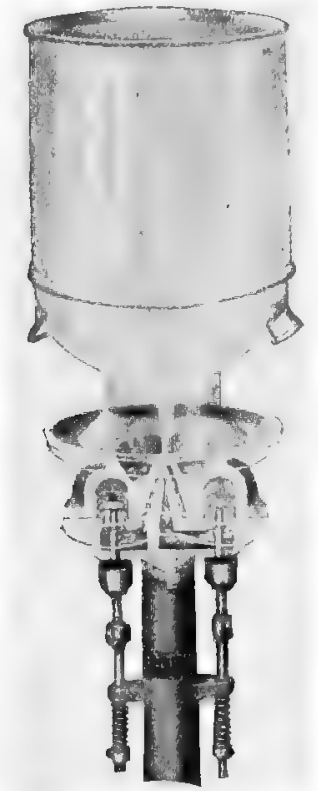

Fig. 150.-Sterilizer and cleanser.

be scrubbed with some alkaline solution, wash powder, soap powder, or some similar preparation. Finally, steam should be applied (Figs. 148-151). Steam under pressure is most effective, and large autoclaves have been constructed to serve this purpose. Cans and pails may be treated with a jet of pressure steam, or may be held tightly by a special device while subjected to the action of steam. Good results may be obtained by exposing utensils to steam in a closed chamber for a considerable time, and even boiling water destroys nearly all micro-organisms. A simple and inexpensive steam sterilizer for small dairies has been devised by Ayers \& Taylor and is described in Farmer's Bulletin No. 748. 
Under practical conditions none of these methods of "sterilization" sterilize in the bacteriologic sense. A few bacteria, mostly spores, remain, and, therefore, all utensils must be thoroughly dried in order to prevent growth of these germs. By inverting cans and pails in a warm place or in the sunshine this is readily accomplished, but the air must be free from dust and other contaminating influences (Fig. 152).

The possible sources of bacteria in utensils are chiefly remnants of milk, air, and water. A supply of pure water must be

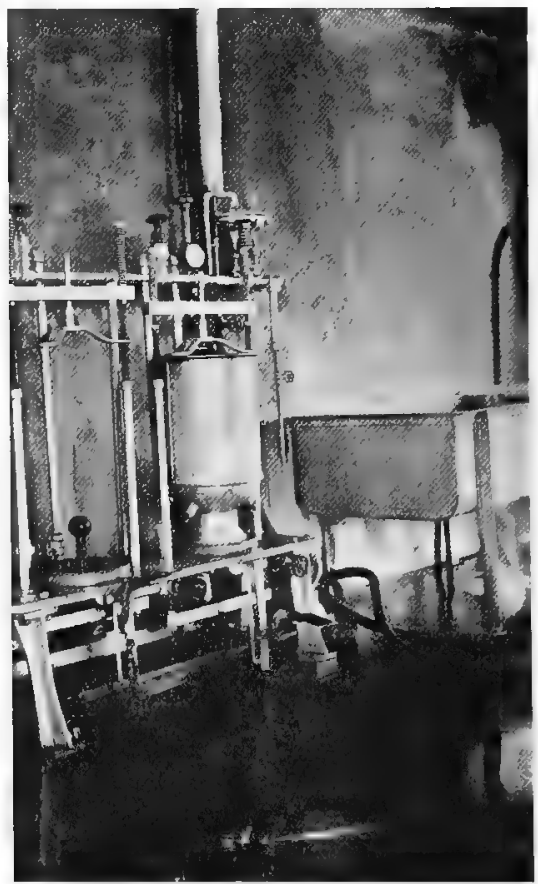

Fig. 151.-Steam sterilizer for cans.

available to avoid pollution of utensils from this source, and by inverting cans the amount of dust that enters is largely reduced. The milking pails should be covered with cloth after cleaning, according to Harding, Ruehle, Wilson, and Smith. The authors tested milk from improved Loy pails which had been cleaned in the same manner and steamed for fifteen minutes, but two were protected by cloths tied over the tops, while two were not so treated. The pails were brought to the milkers immediately before milking and the cloths removed at this time. The milk in the protected pails contained 922 bacteria per cubic centimeter, 
while in the unprotected pails there were 2391 bacteria per cubic centimeter.

By-products of creameries and cheese factories are usually returned to producers in the containers that the cream or milk was delivered in. The skimmed milk and whey sometimes stand for days in the cans or barrels before called for by their owners. During this time fermentation and putrefaction sets in and flies have free access to the products. It is obvious that under such conditions cans and barrels are difficult to clean, and one careless producer may thus infect the utensils of other patrons. This condition needs particular attention, since it may become the means

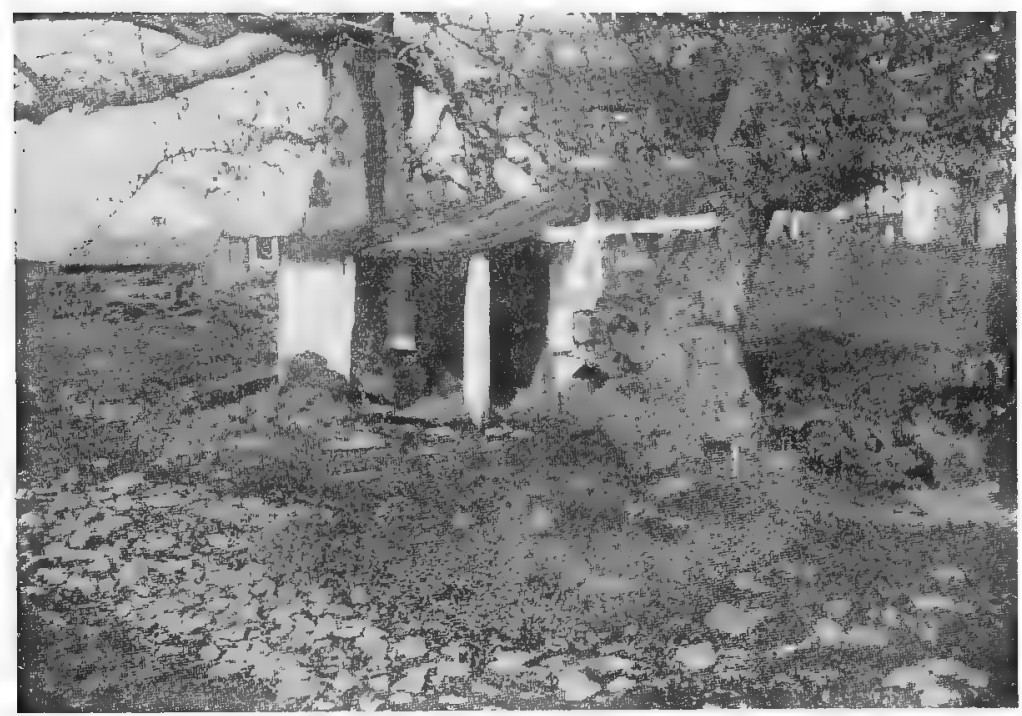

Fig. 152.-A mere pretense of a milk-house. Turkeys roosting around the milk utensils. (Webster, Bull. No. 56, Hygienic Laboratory.)

of spreading disease germs, especially the germs of bovine tuberculosis. It is, therefore, customary in the best creameries and cheese factories to wash and steam the cans before returning them to their owners. The same practice is carried out by many dairies, since it is realized that steam is not available at many farms. All by-products of creameries and cheese factories should be pasteurized as soon as possible, so as to prevent decomposition and the spread of disease germs. A pasteurized by-product has the additional virtue of being more suitable as food for farm animals than a fermented or putrefied product.

The evidence shows clearly that the bacterial content of milk may be considerably increased if utensils are not properly cared 
for. Harding, Ruehle, Wilson, and Smith made a series of 17 tests to determine at what point bacterial pollution was of greatest influence. The following figures were obtained:

The strippings contained

Milk from the pail contained 161

Milk from the cooler contained 426

Milk from the can contained 443

Milk from the strainer contained 473

57 bacteria per cubic centimeter

$\begin{array}{lll}" \prime & \text { " } & \text { " } \\ " & \text { " } & \text { " }\end{array}$

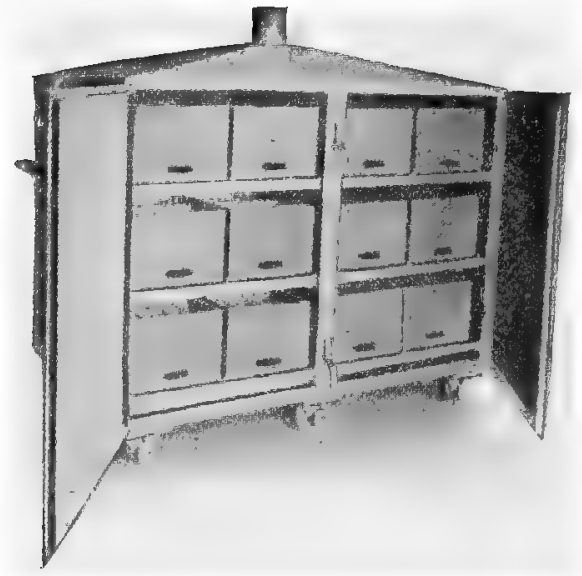

Fig. 153.-Combined sterilizing oven and truck. (A. H. Barber Creamery Supply Co.)

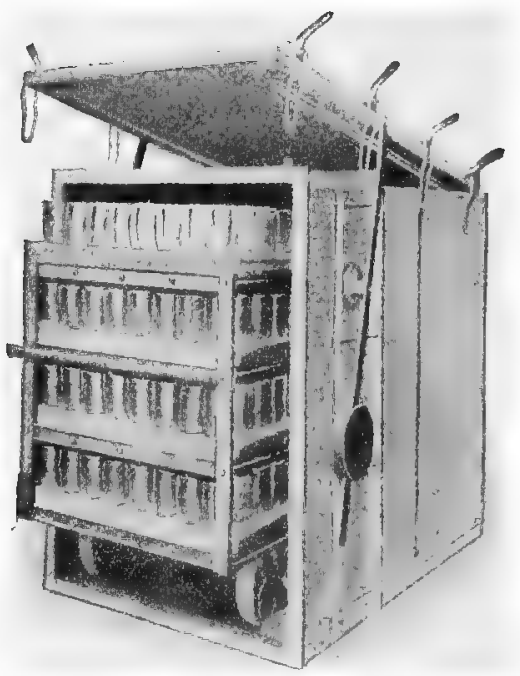

Fig. 154.-Sterilizing oven. (A. H. Barber Creamery Supply Co.) 
These figures show that even when great care is taken to clean utensils there is a constant increase of bacteria, although the actual

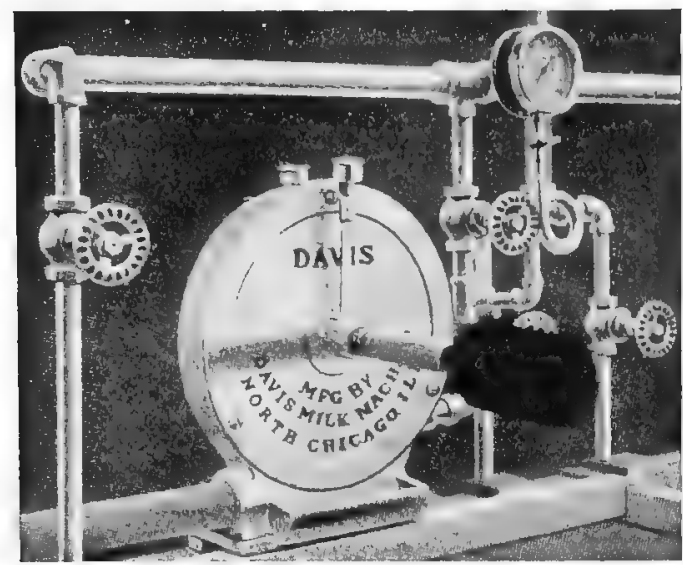

Fig. 155.-Steam turbine washer.

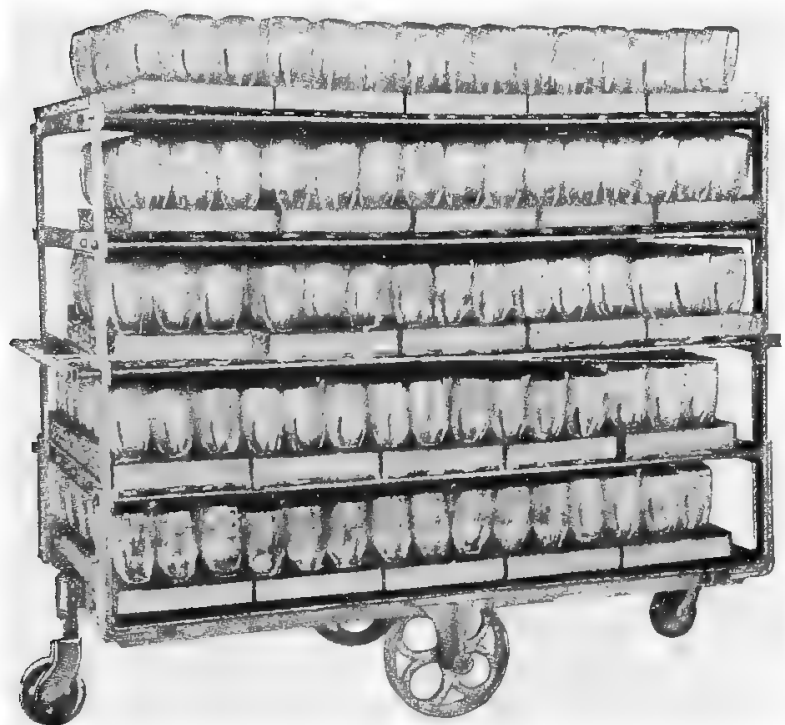

Fig. 156.--Special steel frame bottle truck.

germ content of the milk may be surprisingly low. The sudden bacterial increase in the sample from the cooler was due to two exceptionally high counts, which raised the average, and shows that in 
spite of all possible care sometimes the utensils contribute largely to the germ content. The utensils were cleaned with hot water

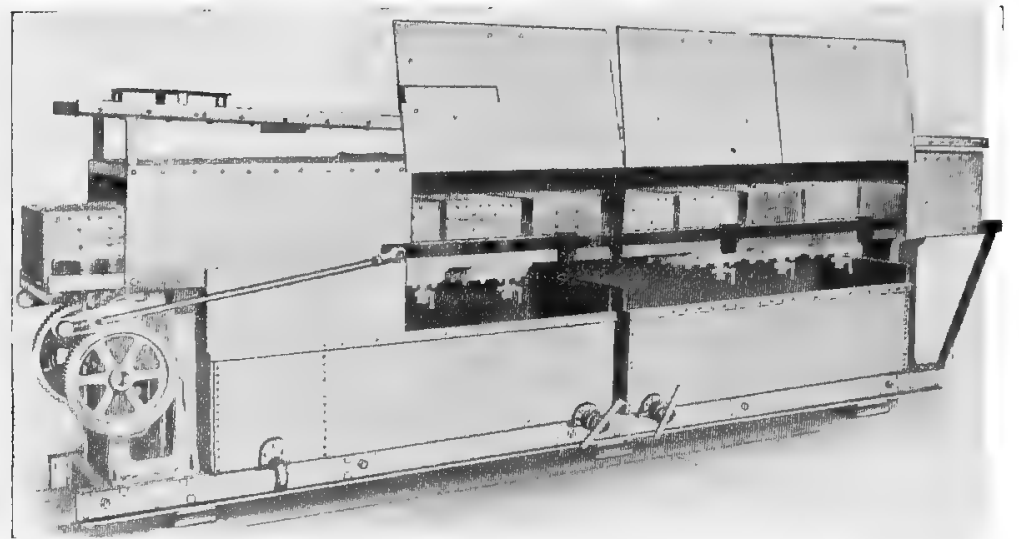

Fig. 157.-Davis' automatic power high-pressure washer.

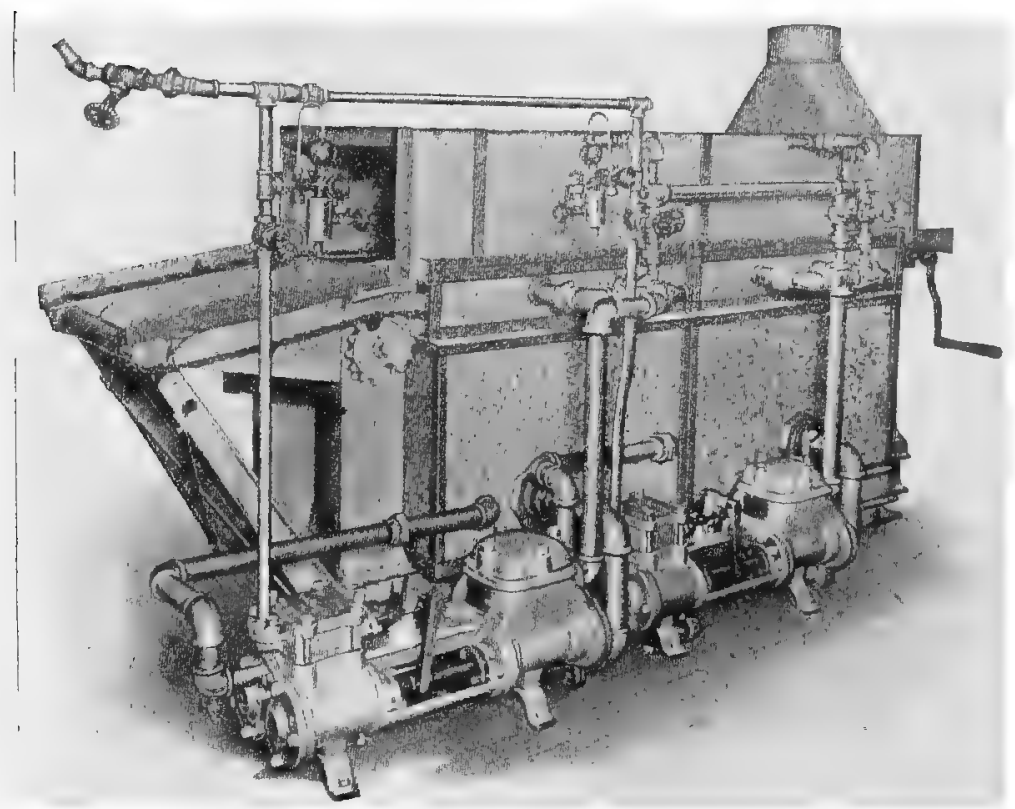

Fig. 158.-Davis' combined rinser and sterilizer.

and sal soda and then treated for ten to fifteen minutes in a steam box. 
The bottles in which milk is sold require special care to avoid undue pollution. Here also the number of bacteria may be increased, and there is the further menace of communicable diseases being carried in bottles. Milk is frequently delivered at houses early in the morning and is left outside without ice, exposed to the rays of the sun, and sometimes a prey to animals.

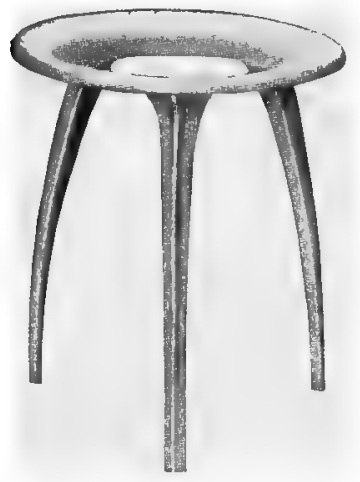

Fig. 159.-Sanitary hygienic milking stool.

Domestic animals have been known to be carriers of diphtheria and other infectious diseases and may communicate the germs of these diseases to the milk by licking the caps of exposed bottles. Even after bottles have been cleaned and sterilized at the dairy there is possible danger of reinfection by handling (Figs. 153-158).

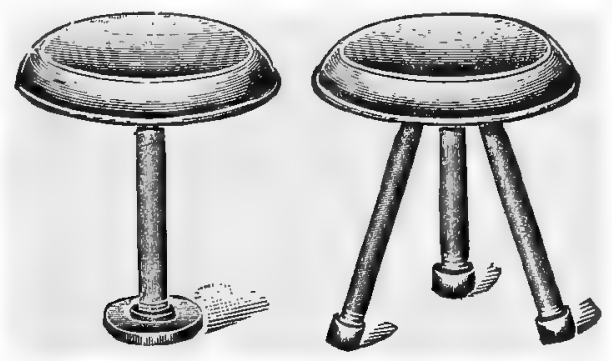

Fig. 160.-Sanitary milking stool.

As a matter of fact, the germ content of milk in bottles is usually higher than in the milk as it leaves the cooler, whether the milk is pasteurized or not (Figs. 159, 160).

\section{Contamination During Transportation}

During transportation several causes may operate to increase the germ content of milk. The most important factor is probably 
the temperature. Cooling facilities are not as efficient, as a rule, as is desirable. The rate of multiplication of bacteria in milk, according to Hunziker, is as follows:

\begin{tabular}{|c|c|c|c|c|}
\hline Original number of bacteria in the milk. & 5,000 & per & bic & imeter \\
\hline After twenty-four hours at $42^{\circ} \mathrm{F} \ldots .$. & 2,400 & & " & 16 \\
\hline After twenty-four hours at $50^{\circ} \mathrm{F} .$. . & 7,000 & “‘ & 4 & “ \\
\hline After twenty-four hours at $65^{\circ} \mathrm{F}$.. & 280,000 & “ & "4 & “6 \\
\hline After twenty-four hours at $95^{\circ} \mathrm{F}$... & $12,500,000$ & “ & "4 & " \\
\hline
\end{tabular}

The decrease at $5^{\circ} \mathrm{C}$. may be explained by the so-called germicidal property of fresh milk, which also may account for the relatively small increase at $10^{\circ} \mathrm{C}$. At higher temperature the influence of this property is of such short duration that the results are not materially affected.

Conn gives the following figures illustrating the multiplication of bacteria according to temperature:

NUMBER OF BACTERIA PER CUBIC CENTIMETER IN MILK KEPT AT DIFFERENT TEM* PERATURES

\begin{tabular}{|c|c|c|c|c|c|c|}
\hline $\begin{array}{l}\text { No. at } \\
\text { outset. }\end{array}$ & $\begin{array}{l}\text { In } 12 \text { hours } \\
\text { at } 50^{\circ} \mathrm{C} \text {. }\end{array}$ & $\begin{array}{l}\text { In } 12 \text { hours } \\
\text { at } 70^{\circ} \mathrm{C} \text {. }\end{array}$ & $\begin{array}{l}\text { In } 50 \text { hours } \\
\text { at } 50^{\circ} \mathrm{C} \text {. }\end{array}$ & $\begin{array}{l}\text { In } 50 \text { hours } \\
\text { or at time } \\
\text { of curdling } \\
\text { at } 70^{\circ} \mathrm{C} \text {. }\end{array}$ & $\begin{array}{l}\text { No. of hours } \\
\text { to curdling } \\
\text { at } 50^{\circ} \mathrm{C} \text {. }\end{array}$ & $\begin{array}{l}\text { No. of hours } \\
\text { to curdling } \\
\text { at } 70^{\circ} \mathrm{C} \text {. }\end{array}$ \\
\hline $\begin{array}{l}46,000 \\
47,000\end{array}$ & $\begin{array}{l}39,000 \\
44,800\end{array}$ & $\begin{array}{l}249,500 \\
360,000\end{array}$ & $\begin{array}{r}1,500,000 \\
127,500\end{array}$ & $\begin{array}{l}542,000,000 \\
792,000,000\end{array}$ & $\begin{array}{l}190 \\
289\end{array}$ & $\begin{array}{l}56 \\
36\end{array}$ \\
\hline 50,000 & 35,000 & 800,000 & 160.000 & $\begin{array}{c}2.560 .000,000 \\
42 \text { hours }\end{array}$ & 172 & 42 \\
\hline
\end{tabular}

Conn further estimated that the initial number increased fivefold at $10^{\circ} \mathrm{C}$. during twenty-four hours and 750 -fold at $21^{\circ} \mathrm{C}$. (Fig. 161).

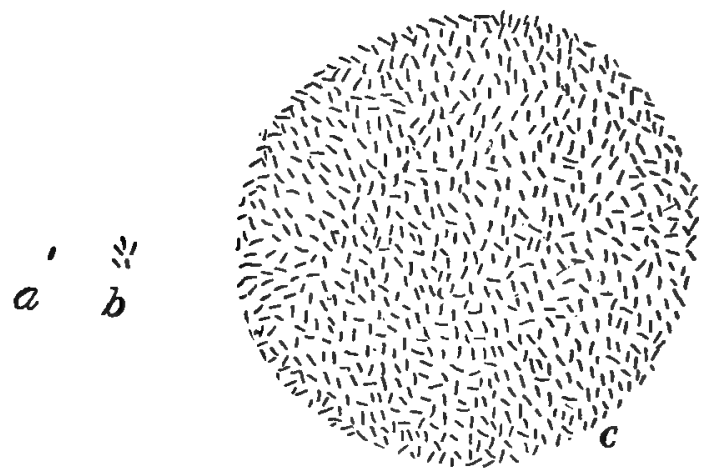

Fig. 161.-a, Single cell. $b$, Progeny of one cell, milk kept at $50^{\circ} \mathrm{F}$. for twenty-four hours. $c$, Progeny of one cell, milk kept at $70^{\circ} \mathrm{F}$. for twentyfour hours. (Conn, Storrs' Agric. Exp. Sta., Bull. No. 26, October, 1903.)

The author concludes that "keeping of milk is more a matter of temperature than of cleanliness," and Harding says that "in practically all cases when more than twelve hours elapse between 
milking and sampling, growth accounts for the larger part of the germs found. Accordingly, temperature control is the largest factor in controlling germ life in city milk."

After testing nearly 300 samples of Chicago market milk Jordan and the writer found that the number of bacteria increases steadily as the seasonal temperature rises. During April the average number of bacteria in all samples was $9,361,000$ per cubic centimeter, during May, which was relatively cool, 10,071,000, and during June, 18,924,000.

Lewis and Wright investigated the bacterial content of cream and found that cream of 3.3 days' age delivered in summer contained $462,600,000$ bacteria per cubic centimeter, while in winter after five days the number of bacteria was $134,800,000$ per cubic centimeter.

These figures suffice to show the importance of keeping milk cool during transportation. Prompt cooling immediately after

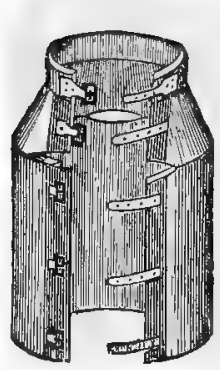

Fig. 162.-Milk-can jackets.

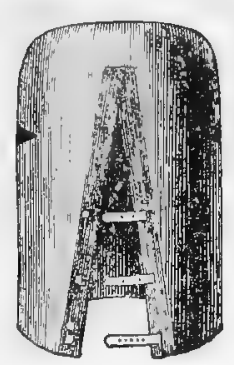

Fig. 163.-Standard shipping jacket.

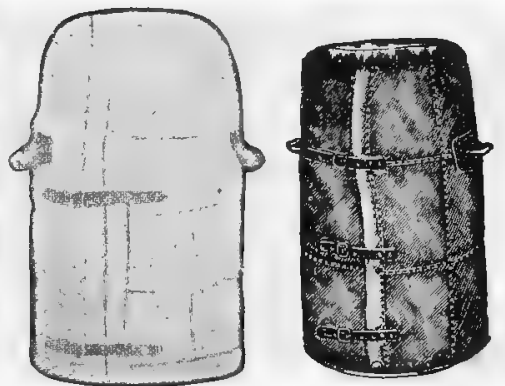

Fig. 164.-Milkcan jacket.

(A. H. Barber Creamery Supply Co.)

production is not the only factor, but during subsequent transportation means must be provided for keeping the temperature low up to the time of consumption. This involves proper carrying to the railroad station, suitable refrigerator cars, cooling facilities on the delivery wagons, and, last but not least, keeping cool in the home.

During transportation to the railway station the cans can be kept cool by covering them with moist jackets (Figs. 162-164), the evaporating water reducing the temperature. At the station the platforms should be enclosed, which is, unfortunately, not common (Fig. 165). On ordinary railway platforms the milk cans are exposed to the heating influence of sun and air, and if the covers are not tight dust may gain access to the inside. An inexpensive shed would obviate these troubles in large measure.

For supplies of large communities some of the milk may have 
to be shipped for a considerable distance by railway. Special refrigerator cars are provided by some railway companies for transportation of milk, and in these milk is preserved in good condition for many hours. Frequently, however, milk cars are not suitably constructed, and the bacterial content increases markedly during transportation. This is especially true in summer.

James $\mathrm{O}$. Jordan, in reporting an investigation of the distribution of ice for keeping milk cool, says that of 48 cases, 10 had no ice; 26 were inadequately iced; 3 had the ice improperly distributed, and only 9 were good. The author states, furthermore, that health authorities do not or are not permitted to inspect railway milk cars, and that proper control is therefore lacking.

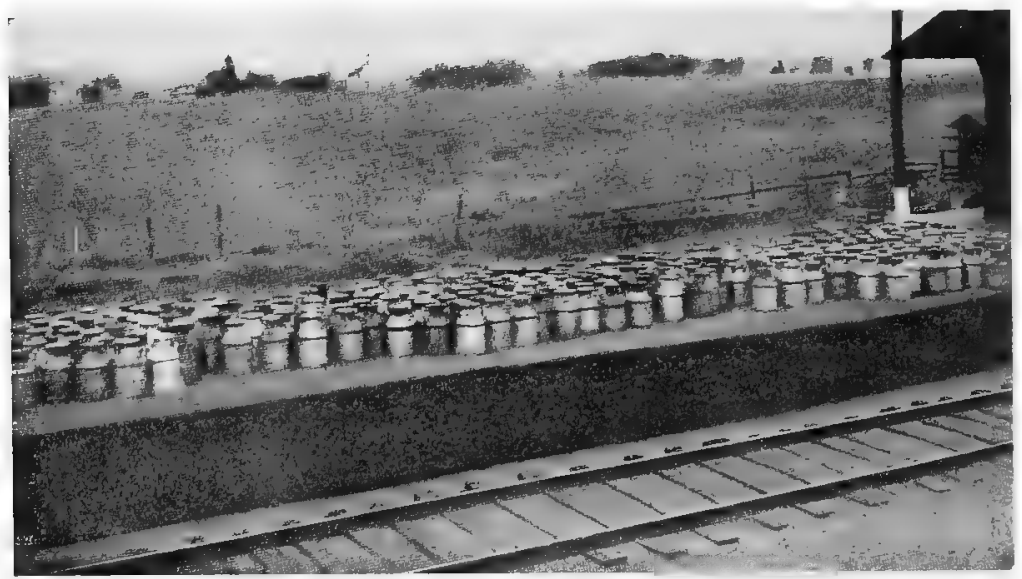

Fig. 165.-Milk-cans at the railway station. (Fraser, Bull. No. 92, Univ. of Ill. Agric. Exp. Sta.) .

The time schedule of milk trains leaves much to be desired, as it prolongs the period that milk has to travel and, consequently, there is the chance of increased bacterial growth. When milk is shipped in bottles they are usually packed in boxes and the boxes filled with chipped ice. The temperature is kept low for twentyfour to thirty-six hours by this means. Ordinances have been enacted that provide for the delivery of milk at low temperature, the highest permissible limit being usually $60^{\circ} \mathrm{F}$. However, even at this temperature there is considerable germ growth, and the requirements should be lowered to $50^{\circ} \mathrm{F}$. At this temperature growth is slow for a few days at least. Near the freezing-point there is usually an actual reduction of bacteria for a limited period which is long enough to keep the germ content low up to a reasonable time of consumption. But since some bacteria possess considerable tolerance toward low temperature, a decided increase 
seems to take place after the lapse of a few days. This at least is the opinion of some investigators. The importance of prompt cooling immediately after milking is emphasized by this fact, so as to prevent initial multiplication.

Conn and Esten observed that when milk was kept at $1^{\circ} \mathrm{C}$. there was no increase of germ life for six to eight days; after that time there was decided growth, but no lactic acid bacteria seemed to multiply. The authors think, therefore, that when milk is kept at low temperature for some time it becomes unfit for food, especially for infant feeding, as the organisms multiplying at this temperature do not change the milk in such manner as to render the altered condition easily detectable. The milk, according to this reasoning, may become a menace. However, it has not been conclusively shown that the products of these bacteria are really injurious.

Pennington found in milk kept at $29^{\circ}$ to $32^{\circ} \mathrm{F}$. that both acidforming and proteolytic bacteria multiply. Ravenel, Hastings, and Hammer held milk at $-9^{\circ} \mathrm{C}$. and observed no increase in bacteria that grow on agar and gelatin; they further found that the acidity decreased, while the amount of soluble nitrogen increased. In milk kept at $0^{\circ} \mathrm{C}$. there was a marked increase in bacterial content, also an increase in acidity and soluble nitrogen. The period of observation was 203 days. According to the work of these authors increase in soluble nitrogen is not necessarily due to multiplication of bacteria, but possibly to enzyms produced by them.

Bischoff observed that in milk kept at $0^{\circ}$ to $1.5^{\circ} \mathrm{C}$. there was a decrease of bacteria for four to seven days, after which period there was an increase in number and in acidity.

There seems to be sufficient agreement in the work of a number of investigators to assume that at a temperature $0^{\circ} \mathrm{C}$. or somewhat higher there is an initial decrease of germ content, followed by a marked increase. It is probable that many bacteria cease multiplying at such low temperature and gradually die, similar to conditions observed in ice. But some types are tolerant, in a measure at least, toward low temperatures, and finding suitable food conditions in milk, multiply, at first slowly and later with greater rapidity. The study of the types that are able to multiply in cold milk is still incomplete.

In this connection Rullmann's investigations are interesting. The following table gives the author's results of bacterial enumerations in raw and pasteurized milk kept at $4.5^{\circ}$ to $5.5^{\circ} \mathrm{C}$.:

NUMBER OF BACTERIA IN RAW AND PASTEURIZED MILK AT $4.5^{\circ}$ TO $5.5^{\circ} \mathrm{C}$.

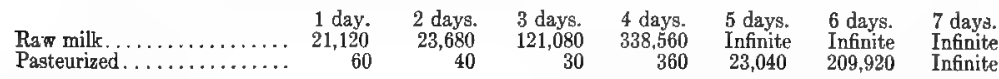


At this temperature there was an increase of bacteria in raw milk from the first day, insignificant for two days, but more pronounced later. In pasteurized milk the decrease lasted for three days before an increase commenced.

Investigations seem to show that prompt cooling and keeping the milk below $50^{\circ} \mathrm{F}$. are of substantial help in keeping the germ content low. The nearer the freezing-point milk is kept, the more marked is the keeping quality. Freezing milk would probably enhance its keeping quality further, but the physical changes caused by freezing render it inadvisable to resort to actual freezing.

It is desirable that extensive investigations be carried on in regard to the kinds of bacteria that are able to multiply at low temperature in milk. Milk for infant feeding is frequently taken on lengthy trips and protected from decomposition by keeping it cold. It is important to learn whether the products of bacterial growth at low temperature may constitute a danger in milk. Taste, odor, and physical appearance do not seem to be visibly changed in milk kept at low temperature for a number of days. Milk with low germ content will probably keep in perfectly wholesome condition for a longer period at low temperature than milk with high germ content. This has been illustrated repeatedly when milk was shipped for great distances and kept sweet and low in bacterial content for weeks.

What has been said about country receiving stations holds also for railway platforms at the point of delivery. Sufficient protection should be afforded to prevent warming of the milk and access of dust.

\section{Contamination in the Hands of Dealers and Consumers}

The delivery wagon must be provided with facilities for keeping the milk cool during its journey from the railway platform to the house of the consumer. This is not a difficult matter when milk is sold in bottles. When sold from cans it is not as simple. Selling milk from cans by dipping is a custom that should be condemned, since it not only makes it difficult to keep milk cool, but exposes it to contamination from the air and from the milker.

In stores conditions are as unfavorable for handling milk from cans as on a wagon. As a matter of fact, in stores milk is liable to become tainted from odors and contaminated from flies. Only bottled milk should be sold from stores. The bottles should be sealed in such fashion that tampering with them, or filling bottles "to order," becomes impossible. The latter custom which still prevails to some extent exposes the milk to dangerous contamination from the caps which are placed on the bottles by hand. 
Milk should be taken into the house as soon as possible after delivery and placed immediately on ice. It should not be permitted to stand on tables or any place where its temperature may rise. As mentioned in another connection, when left outside the milk is exposed to the sun, the temperature of the air, and also to sampling by domestic animals. The expansion caused by heat or freezing may push the cap out of place, and the danger of exposure becomes more imminent. The menace is increased in summer by the presence of flies and other insects.

In the house the bottles should always be covered. Practical inexpensive devices for removing the cap can be purchased, and the same devices serve as covers. Good covers protect not only against bacterial invasion but also against absorption of odors. The refrigerator, of course, must be kept clean, and spoiled food should not be permitted to accumulate.

Before opening a bottle of milk the neck and covering should be wiped with a clean cloth. After emptying, bottles should be washed first in cold or lukewarm water and then in soapsuds. This will largely prevent bacterial multiplication in empty bottles and render cleaning easier for the producer.

Milk bottles should be kept out of sick rooms. The consumer can do much to encourage production of clean milk by visiting dairies. He can judge of the conditions prevailing at the dairy and will incidentally see some of the abuses that milk bottles are exposed to. In many dairies milk bottles have accumulated that have been used as containers for various foods, paints, varnishes, etc. Such abuse renders them practically useless for further delivery.

It has been shown on the previous pages that micro-organisms may gain access to milk at different stages during its journey from cow to consumer. The original contamination from the udder is not great, but pollution from the cow and from utensils may be considerable. The amount of pollution depends primarily upon the quantity of dirt that falls into the milk. Subsequently, lack of cleanliness of utensils and machinery may increase the germ content materially, and finally failure to cool milk promptly and to keep it cool encourages multiplication of the micro-organisms that originally gained access.

As it seems impossible to keep all foreign matter out of milk, the attempt is made to reduce the amount to a minimum. This is accomplished in large measure by producers of certified milk, but considerable expense is involved in the process, and it cannot be applied under present conditions to the bulk of milk consumed.

But clean milk can be produced without as great expense as is 
demanded for production of certified milk, and even certified milk can be produced at lower cost than was thought possible a few years ago. Experience and experimental work carried on chiefly at Agricultural Experiment Stations has shown that an expensive equipment is not necessary to produce clean milk, but that the methods of production are of paramount importance. We have reported work that seems to show that stable air, expensive construction of stables, and costly machinery are of relatively small influence in reducing the germ content of milk. On the other hand, cleanliness of cows, the small-top milking pail, cleaning and steaming utensils, prompt cooling, and keeping the milk cool are important factors in producing milk with low germ content. Cement floors are to be preferred to wooden floors, iron-pipe stanchions to wooden stanchions, and painted walls to rough walls; but in some dairies milk is produced that is fully equal to certified milk as far as bacterial counts are concerned, in spite of inferiority of construction and equipment. Clean methods are more highly responsible for improved milk-supplies than expensive buildings and complicated machinery. These latter, furthermore, increase the cost of production and bring the product beyond the reach of the poorer classes of the population.

With introduction of the cream separator it was learned that insoluble substances were thrown out of milk by the centrifugal force. The bowl sediment contains cells, bacteria, casein, and insoluble dirt. Dairymen resorted to the scheme of centrifugalizing the milk in order to remove foreign matter and then of reuniting the cream and the skimmed milk. Recently centrifugal clarifiers which do not separate the cream from the milk have come into use and are rapidly gaining favor. It is true that insoluble dirt is easily removed by these machines, but the soluble material remains and the count of bacteria increases on account of the clumps being broken up. It seems, however, according to Hammer's work that the increase of the colony count from milk after clarification is, on the average, not as great as after separation of cream and reuniting cream and skimmed milk, and Sherman states that the average number of bacteria in 24 tests of milk before clarification was 4720 , while the same samples after clarification contained an average of 7120 .

Although the clarifier removes many bacteria, it is obvious that infected milk cannot be made harmless by the process, because only a limited number of bacteria is removed, while the balance remain in the milk. Sherman has shown that streptococci are present practically in as great numbers in the clarified milk as in the milk before clarification.

Filtration of milk through sand has been practised in some 
countries, chiefly in Denmark, for the removal of insoluble dirt. Dirt particles are, of course, removed by filtration, but the bacterial content is not decreased, if the colony count is taken as index. A filter which is capable of retaining bacteria would also retain fat globules, as these on the average are larger than bacteria.

Aëration has been resorted to in order to eliminate disagreeable odors. The milk is brought in contact with the air by pouring it in thin layers from one can to another, or by using open coolers. Odors are largely removed by this process, but there is danger of additional contamination from the air, and clean milk does not need aëration.

In some dairies the milk is strained several times before it is ready for shipment. It may be strained into the milking pail, then into a large can, and finally again before it passes to the cooler. This frequent straining tends to increase the colony count because the dirt that is retained on the strainer is broken up by succeeding amounts of milk poured on it, and finally in part passes through the strainer. The strained milk, therefore, contains more single bacteria than the unstrained milk. In a series of experiments carried out by the writer with Luckhardt and Hicks it was found that the average of 80 samples contained 2060 bacteria per cubic centimeter before straining and 2790 after straining. Milk squeezed from the cotton strainer contained 3912 bacteria per cubic centimeter. These figures show that although an appreciable number of bacteria were retained in the cotton, the colony count of the strained milk was higher than that of the unstrained milk. These tests were carried on in a highclass dairy and the conclusion is obvious that in an ordinary dairy the difference would be greater. It follows that frequent straining is not conducive to reduction of the germ content.

These methods of making milk attractive have some advantages. The consumer does not see the dirt collect at the bottom of the bottle and the milk has a sweet taste and odor unless the pollution has been so heavy that soluble substances are present in excessively large quantity.

The modern milk bottle is designed more with convenience in view than sanitation. The wide mouth of the bottle facilitates washing, but the shoulder on which the pulp cap rests may retain dirt that falls on the bottles during transportation. Bottles with small necks can be thoroughly cleaned with appropriate machines and would do away with some of the disadvantages of the wide mouth bottle now generally in use. It is true that a change from the present style of bottle to a narrow neck bottle would meet with some practical difficulties which, however, time will have to 
overcome. Filling machines, cleaning machines, and caps are designed for wide mouth bottles, and much expense will be involved in making the change, which must be effected by degrees.

It has been pointed out before that too much stress has been laid in the past on expensive equipment, and that the true road to clean milk production lies in the application of proper methods. With reasonable care of the cows; with the use of the small-top pail; with the use of well cleaned and steamed utensils and machinery; and by keeping the cooled milk cold up to the point of delivery the bacterial content, as a rule, can be kept low, and instead of having to remove dirt from the milk by special treatment the dirt will not be permitted to gain access.

Ayers, Cook, and Clemmens have made practical experiments to determine the important factors which affect the bacterial content of milk. The authors found that three factors. are chiefly influential in reducing the germ content, namely:

1. Sterilized utensils.

2. Clean cows with clean udders and teats.

3. The small-top pail. A fourth factor, the temperature at which the milk is kept, prevents multiplication and serves to keep the bacterial content low. The temperature should be near $10^{\circ} \mathrm{C}$. $\left(50^{\circ} \mathrm{F}\right.$.) or lower. The authors believe, furthermore, that a high bacterial content of market milk is generally due to bacterial growth.

The same authors state that "undue emphasis has been given to factors and methods of minor importance, while those which directly affect the bacterial content have not been sufficiently emphasized," and that "milk of low bacterial content and practically free from visible dirt, when fresh, was produced in an experimental barn under conditions similiar to those on the average low-grade farm."

There is much to be learned as to the most important points at which milk may become contaminated. When research shall have pointed out clearly which operations are responsible for large germ content and which are of less importance, clean milk will be produced without greatly increased financial outlay, but will require intelligent care in regard to methods of production. Old slovenly habits are slowly giving way to modern improved methods. It should be borne in mind that the crucial point is the prevention of disease germs from gaining access to milk. A few disease germs will prove dangerous, where large numbers of harmless bacteria will have no significance, as in buttermilk, for example. The gospel of milk with small numbers of bacteria which is preached in many places should have the moral effect of 
introducing cleanliness, care, and circumspection in all branches of the dairy industry. With increasing care the chances of introducing disease germs into milk diminish. Medical examination of employees for germ carriers and veterinary inspection of the cattle should be practised to a greater extent than is customary at present.

\section{BIBLIOGRAPHY}

Alexander: Univ. of Wis. Agri. Exper. Sta., Research Bull. 3, June, 1909, p. 109.

Alvord: United States Dept. of Agri., B. A. I., Bull. 11, 1896.

Anderson: Jour. Inf. Dis., 1909, vol. 6, p. 392.

Ayers and Johnson: United States Dept. of Agri., Farmer's Bull. 608.

Ayers and Taylor: United States Dept. of Agri., Farmer's Bull. 748.

Ayers, Cook, and Clemens: United States Dept. of Agri., B. A. I., Bull, 642, April, 1918.

Backhaus: Milchzeit, 1906, vol. 35, p. 169.

Backhaus and Appel: Quoted from v. Freudenreich, Cent. f. Bakt., 1904, Abt. 2, vol. 13, pp. 287, 407.

Backhaus and Cronheim: Koch's Jahresberichte, 1897, vol. 8, p. 151.

Barthel: Milchzeit, 1903, vol. 32, p. 659.

Basch and Weleminsky: Arch. f. Hyg., 1899, vol. 35, p. 205.

Basenau: Arch. f. Hyg., 1895, vol. 23, pp. 44, 170.

Beach: Storrs' Agri. Exper. Sta., Bull. 47, May, 1907, p. 131.

Bergey: Univ. of Penna. Med. Bull., July-August, 1904, vol. 17, 187.

Bischoff: Arch.f. Hyg., 1903, vol. 47, p. 68.

Boekhout and DeVries: Cent. f. Bakt., Abt. 2, 1901, vol. 7, p. 826.

Bolley and Hall: Cent. f. Bakt., 1895, Abt. 2, vol. 1, p. 794.

Conn: Storrs' Agri. Exper. Sta., 15th Annual Report, 1903, Bull. 26.

Conn and Esten: Storrs' Agri. Exper. Sta., 16th Annual Report, 1904, p. 27.

Eckles and Barnes: Iowa Agri. Exper. Sta., Bull. 59, 1901, p. 55.

Erf: Kansas Agri. College, Bull. 140, October, 1906.

Esten and Mason: Storrs' Agri. Exper. Sta., Bull. 51, April, 1908, p. 65.

Evans: Jour. Inf. Dis., 1916, vol. 18, p. 437.

Evans and Cope: Univ. of Penna. Med. Bull., 1908, vol. 21, p. 264.

Ford: Trans. of Assoc. of Amer. Phys., 1900, vol. 15, p. 389.

Fraser: Univ. of Ill. Agri. Exper. Sta., Bull. 92, December, 1903.

v. Freudenreich: Cent. f. Bakt., 1904, Abt. 2, vol. 13, pp. 287, 407.

v. Freudenreich and Thöni: Cent. f. Bakt., 1902, Abt. 2, vol. 10, p. 305.

Haecker and Little: Univ. of Neb. Agri. Exper. Sta., Bull. 108, December 7, 1908.

Hammer: Agri. Exper. Sta., Iowa State Coll. of Agri. and Mechan. Arts, Research Bull. 28, January, 1916.

Harding: Amer. Jour. of Pub. Health, 1916, vol. 6, p. 562.

Harding and Wilson: New York Agri. Exper. Sta., Technical Bull. 27, March, 1913.

Harding, Ruehle, Wilson, and Smith: New York Agri. Exper. Sta., Bull. 365, August, 1913, p. 197.

Harding, Wilson, and Smith: New York Agri. Exper. Sta., Bull. 326, December, 1910 , p. 249.

Harding, Wilson, and Smith: New York Agri. Exper. Sta., Bull. 317, September, 1909.

Harrison: Cent. f. Bakt., Abt. 2, 1899, vol. 5, p. 183.

Hastings and Hoffmann: Univ. of Wis. Agri. Exper. Sta., 24th Annual Report, 1907, p. 213.

Hastings and Hoffmann: Univ. of Wis. Agri. Exper. Sta., Research Bull. 6, June, 1909, p. 189.

Hastings and Hoffmann: Univ, of Wis. Agri. Exper. Sta., Research Bull. 3, June, 1909 , p. 98.

Heinemann: Trans. 15th International Congress on Hygiene and Demography. 
Heinemann: Trans. Second Annual Meeting of the Amer. Assoc. for Study and Prevention of Infant Mortality, 1911.

Heinemann and Class: Jour. Amer. Pub. Health Assoc., 1911, vol. 1, p. 209.

Heinemann, Luckhardt, and Hicks: Jour. Inf. Dis., 1910, vol. 7, p. 47.

Hunziker: Cornell Univ. Agri. Exper. Sta., Bull. 197, 1901.

Hüppe: Mitthl. d. Kaiserl. Ges. Amt., 1884, vol. 2, p. 325.

Jordan, James O.: Sixth Annual Report of International Association of Dairymen and Milk Inspectors, held at Washington, D. C., 1917, p. 114.

Jordan, E. O., and Heinemann: Report of the Civic Federation, Chicago, 1904.

Lamson: Jour. of Dairy Science, 1918, vol. 1, p. 498.

Lane: United States Dept. of Agri., B. A. I., Bull. 92, January, 1907, p. 9.

Lane: United States Dept. of Agri., B. A. I., Circular 158, 1908.

Lewis and Wright: Oklahoma Agri. Exper. Sta., Bull. 75, June, 1907.

Lister: Quarterly Jour. of Microsc. Sc., 1878, vol. 18, p. 189.

Löhnis: Handbuch der Landwirthschaftlichen Bakteriologie, Borntraeger, Berlin, 1910.

Löhnis: Vorlesungen über Landwirthschaftliche Bakteriologie, 1913, Borntraeger, Berlin.

Löhnis and Kuntze: Quoted from Löhnis' Handbuch.

Lux: Cent. f. Bakt., 1903-4, Abt. 2, vol. 11, p. 267.

Mairs: Penna. State Coll. Agri. Exper. Sta., Bull. 85, January, 1908.

Marshall: Mich. State Coll. of Agri., Special Bull. 16, June, 1902.

Meek: Penna. State Coll. of Agri., 1907, p. 146.

Moore and Ward: Cornell Univ. Agri. Exper. Sta., Bull. 158, 1899.

Niederstadt: Koch's Jahrb., 1893, vol. 4, p. 205.

Park: Jour. Hygiene, 1901, vol. 1, p. 391.

Pearson: United States Dept. of Agri., B. A. I., 17th Annual Report, 1900.

Pearson: United States Dept. of Agri., Farmer's Bull. 63, 1906.

Pennington: Jour. Biol. Chem., 1908, vol. 4, p. 353.

Price: Tenn. Agri. Exper. Sta., Bull. 80, June, 1908.

Prucha, Harding, and Weeter: Science, 1915, vol. 42, p. 353.

Ravenel, Hastings, and Hammer: Jour. Inf. Dis., 1910, vol. 7, p. 38.

Reed and Ward: Am. Med., 1903, vol. 5, p. 256.

Roberts: Philos. Trans. Royal Soc., 1874, vol. 164, p. 468.

Rogers and Dahlberg: Jour. Agri. Research, 1914, vol. 1, p. 491.

Rolet: Koch's Jahrb., 1901, vol. 12, p. 340.

Rosenau: Hygienic Bull. 56, p. 429.

Ruehle and Kulp: New York Agri. Exper. Sta., Bull. 409, August, 1915, p. 419 .

Rullmann: Cent. f. Bakt., Abt. 2, 1902, vol. 9, p. 658.

Russell: Univ. of Wis. Agri. Exper. Sta., 11th Annual Report, 1894, p. 150.

Russell and Hastings: Experimental Dairy Bacteriology, 1909, Ginn \& Co.

Russell and Hastings: Outlines of Dairy Bacteriology, Madison, H. L. Russell, 1914.

Russell and Hastings: Univ. of Wis. Agri. Exper. Sta., 21st Annual Report, 1904, p. 164.

Russell and Hoffmann: Univ. of Wis. Agri. Exper. Sta., 22d Annual Report, 1905, p. 227.

Savage: Milk and the Public Health, McMillan Co., 1912.

Scheurler: Arb. a. d. Kaiserl. Ges. Amt., 1891, vol. 7, p. 269.

Schulz: Arch. f. Hyg., 1892, vol. 14, p. 260.

Sedgwick and Batchelder: Boston Med. and Surg. Jour., 1892, vol. 126, p. 25.

Sherman: Jour. of Dairy Science, 1917, vol. 1, p. 272.

Sherman and Hastings: Creamery and Milk Plant Monthly, 1915, vol. 3, No. 6, p. 11.

Simon: Ueber Bakterien am und im Kuheuter, Dissertation, Erlangen, 1898, quoted from Löhnis' Handbuch.

Smith and Harding: New York Agri. Exper. Sta., Bull. 353, November, 1912.

Sommerfeld: Handbuch der Milchkunde, Wiesbaden, Bergmann, 1909.

Stocking: Storrs' Agri, Exper. Sta., Bull. 42, June, 1906, p. 66.

Stocking: United States Dept. of Agri., B. A. I., Bull. 92, January, 1907, p. 33.

Stocking: Storrs' Agri. Exper. Sta., Bull. 48, May, 1907, p. 77. 
Stocking and Mason: Storrs' Agri. Exper. Sta., Bull. 47, 1907, p. 105.

Swithinbank and Newman: Bacteriology of Milk, Dutton and Co., New York. Trommsdorf: Cent. f. Bakt., 1909, vol. 49, p. 295.

Trueman: Storrs' Agri. Exper. Sta., Bull. 53, June, 1908.

Uhl: Zeitschr. f. Hyg., 1892, vol. 12, p. 475.

Ward: Cornell Agri. Exper. Sta., Bull. 178, 1900.

Ward: Pure Milk and the Public Health, Taylor and Carpenter, Ithaca, New York, 1909.

Wilkens: Cent. f. Bakt., Ref. 1894, vol. 16, p. 969.

Winslow: The Production and Handling of Milk, Jenkins, New York.

Woll and Humphrey: Univ. of Wis, Agri. Exper. Sta., Research Bull. 3, June, 1909, p. 61 . 


\section{THE KINDS OF MICRO-ORGANISMS IN MILK}

IN the previous chapter the important sources of bacteria commonly found in milk have been discussed. It is clear that most of these bacteria are saprophytes, and since the bacterial pollution of milk originates from external conditions surrounding the dairy it is not surprising that there are certain predominant types that are almost universally present in milk. As a rule, therefore, milk undergoes a fermentative process usually termed the "normal" souring of milk, and this process is similar in milks from widely different sources. However, in different localities and different dairies the kinds of bacteria are not necessarily the same, but since milk is an excellent culture-medium for many bacteria we find that after the lapse of some time distinct phases of fermentation are observable. These phases of fermentation are very similar in milks derived from various localities, although occasionally there are abnormal products so that the milk is changed in appearance, taste, and odor, and differs materially from the normal product.

The fact that certain kinds of micro-organisms are found with astonishing persistence in milk has given rise to the term "milk bacteria," a term still adhered to by some authors. However, it is generally conceded that milk is secreted by the mammary glands' in a sterile condition and, therefore, the term "milk bacteria" is misleading and should be abandoned.

Considerable meritorious work has been carried on in regard to the kinds of bacteria that occur in milk. Conn, Esten, and Stocking have studied about 160 types, and have carefully described and grouped them. This number includes bacteria isolated by the authors from milk in Connecticut. In addition to these forms, cultures were studied that came from different parts of this country and also some from European sources. Besides, descriptions when sufficiently complete were taken from the literature and incorporated in the list. The authors think, therefore, that "while by no means complete, the cultures represent fairly the dairy forms in the parts of the civilized world where bacteria are studied."

It should be borne in mind in this connection that the term "species" is wholly unsuitable in speaking of bacteria. It is recognized that among high forms of life variations occur, and this is true in even larger measure in regard to bacteria. More promis- 
ing is the tendency among bacteriologists today to arrange bacteria in groups, since they are extremely sensitive to environmental conditions and respond promptly by varying in one or more of their properties. Owing to their great range in variability, we find the same organism described under different names in some instances. For example, Bacillus aërogenes has been recognized to be identical with Bacillus acidi lactici. Several names have been given to Streptococcus lacticus, as Bacterium lactis acidi, B. güntheri, Streptococcus hollandicus, etc. The same principle applies to that group of bacilli now frequently called the Bacillus bulgaricus group. The Bacillus bulgaricus of the Bulgarians is known to be a member of a group of organisms which have the most important properties in common, and differ only in minor points which probably have developed under special environmental conditions. To this group belong the Bacillus lebenis, the bacillus of Boas-Oppler, and others. It is not surprising, therefore, that bacteriologists are inclined to reduce the number of "species" rather than to increase it by giving new names to organisms that do not differ materially from well-known types.

Classification of bacteria in groups is gaining in favor, although it must be confessed that it is sometimes difficult to find suitable fundamental properties for this purpose. Morphology, motility, biochemic properties, carbohydrate fermentation, hemolysis, and other characteristics have been studied, and authors frequently find that none of these properties are entirely permanent, but vary sometimes with ease and sometimes with considerable difficulty.

The foregoing discussion applies to the bacteria found in mill with as much force as to bacteria found elsewhere. A systematic arrangement of bacteria found in milk cannot be considered as governing conditions in all cases, but, aside from occasional predominance of some rare type, we find that certain bacteria differ somewhat in their activity and in the quality of their product. For example, butter made in some localities has a better aroma than butter made in other regions. Still, if the bacterial flora from milks from two such localities were studied the result would show the presence of similar types in both milks. The aroma of butter is largely due to products of streptococci, and it is a recognized fact that one type of Streptococcus lacticus will produce a superior aroma in butter, while another type-bacteriologically indistinguishable from the first type-will not produce the same aroma.

Grouping bacteria in milk can manifestly be only tentative, and any attempt at classification must be incomplete and subject to future revision. However, there are some groups that 
can be found in most milks, and these groups must form the subject of our study.

According to their ability to grow best at different temperatures bacteria in milk are sometimes classified as follows: 1, Cryoflora, those multiplying at $5^{\circ}$ to $20^{\circ} \mathrm{C} . ; 2$, Mesoflora, those multiplying at $20^{\circ}$ to $37^{\circ} \mathrm{C}$; 3 , Thermoflora, those growing above $37^{\circ} \mathrm{C}$. This classification is, in reality, of little value, because the limits of temperature at which bacteria grow overlap considerably, and different strains of the same type may have different optimum temperatures. The majority of bacteria in milk belong to the mesoflora, although the other two groups have not yet been sufficiently studied. Especially is this true of the cryoflora. These may constitute a very important group, since possibly the bacterial flora of ice-cream belongs to this group. Furthermore, it is claimed by some authors that milk kept near the freezingpoint will soon teem with bacteria that are able to grow at this temperature, and that these are not desirable. In view of the importance of keeping milk cold for preservation, the cryoflora should receive attention. The above-mentioned Bacillus bulgaricus group contains some members that multiply at temperatures considerably above $37^{\circ} \mathrm{C}$. The function of this group of bacteria has not been well understood. They are active in the formation of some fermented milks and probably in the ripening of some cheeses.

Aside from the large number of saprophytic types that commonly occur in milk, pathogenic organisms may be present under unusual conditions. Epidemics due to milk-supplies have been noted, although it must be admitted that disease is actually disseminated through milk in surprisingly small proportion when we consider the enormous amount of milk and milk products that are consumed. Disease germs gain access to milk chiefly from two sources, namely: 1, from the cow, as, for example, bovine tuberculosis, foot-and-mouth disease, and others; and 2 , from the milkers and others concerned in the handling of milk. Among infections of the second group are typhoid fever, diphtheria, scarlet fever, sore throat, and others. The important subject of transmission of disease through milk will be dealt with in a separate chapter.

For the present we are concerned with the saprophytic organisms in milk, and these will be discussed for convenience under the following grouping:

1. Lactic acid bacteria.

2. Spore-bearing bacteria.

3. Bacteria causing abnormal conditions in milk.

4. Molds, yeasts, and torulæ. 
To these groups soil bacteria might be added. That soil bacteria may be present in milk and, in fact, probably are always present, can hardly be questioned. They may be carried into the stable with soil adhering to the cows after pasturing or wading in water. However, they have so far received but little attention at the hands of investigators, and probably are of small importance as inhabitants of milk. It should, furthermore, be remembered that soil bacteria probably do not multiply in milk, and would be numerically negligible after the milk has been standing for some time.

Ayers and Johnson have grouped saprophytic bacteria in milk as follows:

1. Acid-coagulating-those bacteria that produce enough acid to coagulate the casein promptly.

2. Acid-non-coagulating-those that produce acid, but do not coagulate the milk.

3. Inert bacteria-those that produce no visible change in litmus milk in two weeks.

4. Alkali-forming bacteria-those that produce an alkaline reaction in milk. milk.

5. Peptonizing bacteria-those that liquefy the proteins of

This grouping was not designed to cover all types found, but was the result of the authors' comparative study of the bacterial flora in raw and pasteurized milk. Bacteria not forming colonies on agar under aërobic conditions, molds, and yeasts were purposely omitted from this classification.

\section{Lactic Acid Bacteria}

There are different conceptions of the meaning of the term "lactic acid bacteria," inasmuch as some investigators include all bacteria which are able to produce lactic acid from milk-sugar, while others include only those which are responsible for the socalled "normal" souring of milk, and some less common acid fermentations. Still another group of investigators confine the term "lactic acid bacteria" strictly to those kinds which are usually active in producing the "normal" souring of milk.

There is really not much justification in grouping all bacteria that produce lactic acid from milk-sugar as "lactic acid bacteria." This term has become so closely associated with the souring of milk that we cannot logically include all organisms that produce lactic acid from milk-sugar. Furthermore, the "normal" souring of milk is not due to the formation of lactic acid alone. Other acids are formed by certain bacteria that are almost invariably associated with the "normal" souring of milk. 
Kruse and, somewhat later independently, the writer proposed a classification in two groups, namely: 1, those bacteria belonging to the Bacillus coli group, and 2, those belonging to the Streptococcus lacticus group. These two groups are always present in raw milk, and also most generally in milk pasteurized by the holding process at relatively low temperature. In this grouping cognizance is taken only of acid-producing bacteria that actually cause the "normal" souring.

Jensen has classified lactic acid bacteria into three groups as follows:

1. Those that grow at $25^{\circ}$ to $50^{\circ} \mathrm{C}$. To this group belong the long bacilli, which form usually levorotatory lactic acid, although some produce racemic acid.

2. Those that grow at a wide range of temperature, namely, from $5^{\circ}-7^{\circ} \mathrm{C}$. to $45^{\circ}-50^{\circ} \mathrm{C}$. These are all streptococci.

3. The genuine lactic acid bacteria that grow well at $10^{\circ}$ to $40^{\circ} \mathrm{C}$. This group does not include the coli-aërogenes group.

Rogers and Davis, in a bulletin entitled "Methods of Classifying the Lactic Acid Bacteria," say: "The bacteria taking part in the souring of milk may be readily divided into four general groups.

"Group 1 includes those bacteria which sour milk without peptonization or gas formation; they grow poorly on artificial media and fail to liquefy gelatin. Morphologically, they show some variation, usually appearing as a coccus or very short bacillus in pairs or in chains of varying lengths. The bacteria of this group are the ones ordinarily designated as the lactic-acid bacteria and have been described under various names. They have a very general distribution, and their presence in milk is so constant that they may be considered as normal inhabitants of this medium.

"Group 2 includes the bacteria forming an acid curd with evolution of gas. This embraces varieties of Bacillus coli and Bacterium aërogenes or the Bacillus acidi lactici of Hüppe. The members of this group are readily distinguished from those of Group 1 by their abundant growth on artificial media, the vigorous evolution of gas, and the marked difference in their morphology. An examination of milk usually reveals their presence in small numbers, but their number is increased by the influence of high temperatures or unsanitary conditions under which the milk has been collected or held.

"Group 3 includes those bacteria forming an acid curd which is subsequently partially peptonized. The bacteria of this group have been little studied in their relation to milk. It will be shown that this description applies to varicties only distantly 
related to our Group 1, as well as to some closely connected with this type.

"Group 4 includes the high acid-forming bacteria, of which the Bacillus bulgaricus is the type. This organism is distinguishable from those of the preceding groups by its slender rod-like form, its characteristic colonies on agar, its inability to grow in ordinary artificial media, and its growth in the presence of free acid. Bacillus bulgaricus has been studied in its relation to the fermented milks extensively used in Turkey and the neighboring countries. It has recently been shown that it is very widely distributed and may be isolated from almost any sample of mixed milk. Its growth at normal temperatures is so slow that it is improbable that it is a factor in the ordinary souring of milk."

The authors state that these groups are connected only by their ability to ferment lactose to acid, and the consequent precipitation of the casein. They attempt a scientific classification of lactic acid bacteria by grouping them according to their ability to ferment raffinose and glycerin and by the liquefaction of gelatin.

A more elaborate and comprehensive classification of lactic acid bacteria has been proposed by Löhnis. This author distinguishes four groups of lactic acid bacteria, namely:

1. Bacterium pneumoniæ (Friedländer): The members of this group are plump rods, Gram-negative, gas formers; they grow luxuriantly on laboratory media and do not liquefy gelatin. Representatives are Bacillus acidi lactici (Hüppe) and other members of the coli-aërogenes group.

2. Streptococcus pyogenes (Rosenbach): This group is composed of oval, spheric, lancet-shaped, or flat cocci, inclined to chain formation and anaërobiosis; they are Gram-positive; grow scantily on laboratory media, better when carbohydrates are present. Representatives of this group are Streptococcus lacticus, the streptococci from kefir, and other fermented milks, Bacillus acidi lactici 1 and 2 of Conn and Esten, Streptococcus acidi paralactici non-liquefaciens Halensis of Hashimoto, some streptococci isolated from cheese, Bacterium lactis acidi of Leichmann, and many other bacteria with the morphology and properties of streptococcus.

3. Bacterium caucasicum (Kern): The members of this group are long, more or less slender rods, inclined to filament formation and anaërobiosis; they are Gram-positive in young cultures, Gram-negative in old cultures; and some produce large amounts of acid in milk. Some produce gas, but these are exceptions. They grow poorly on laboratory media; generally coagulate milk, although some do not; some have an extraordinarily high optimum temperature. Representatives of this group are: Bacillus 
bulgaricus, B. caucasicum, and B. casei of Freudenreich, B. delbrücki of Leichmann, and others.

4. Micrococcus pyogenes (Rosenbach): The members of this group are staphylococci; they are Gram-positive, aërobic, liquefy gelatin; some coagulate milk, some do not; some have a tendency to slime formation. Representatives of this group are: Micrococcus lactis acidi of Marpmann, M. acidi paralactici liquefaciens, Halensis of Kozai, M. varians lactis of Conn, the acid-coagulating micrococci of Gorini, and others.

The third group of Löhnis' classification is in no manner concerned in the "normal" souring of milk, but includes bacteria that are chief agents in producing a variety of fermented milk products, such as are prepared in different parts of the world and form important articles of food among a variety of peoples.

The fourth group, in all probabliity, is also not concerned in the "normal" souring of milk. However, they may not be entirely indifferent in this fermentative process, since the liquefying micrococci break up the proteins of milk and render them more suitable for absorption by the Streptococcus lacticus group. Incidentally, members of this group produce some acid from lactose, and may, therefore, contribute to a limited extent to the "normal" souring of milk.

On the whole, we must consider the first two groups of lactic acid bacteria of Löhnis' classification as the common agents in the fermentative process, usually called the "normal" souring of milk. They are, therefore, the most important "lactic acid" bacteria.

Pasteur in 1858 was the first to describe an organism which would simulate the souring process normally occurring in milk under ordinary conditions. His "levure lactique," according to his description, is a variety of Bacillus aërogenes. He observed "small globules or very short particles resembling certain kinds of amorphous precipitates. They are constricted in the middle, occur isolated or in irregular clusters. They ferment lactose with acid and gas formation, and cultures are often viscid." In a later publication Pasteur described the lactic acid bacteria as short bacilli, sometimes joined in short chains, thus giving additional evidence of their identity with Bacillus aërogenes. Lister's Bacterium lactis (1788) is now usually identified with Streptococcus lacticus, although the description is too meager to permit proper classification. An exhaustive study of a lactic acid bacterium was published by Hüppe in 1884. He found it in large numbers in all samples of milk examined, and it was considered the lactic acid organism par excellence for some time. There is little doubt that this Bacillus acidi lactici is a variety of B. aerrog- 
enes. From this time on many varieties of lactic acid bacteria have been described, but inasmuch as bacteriologic technic was not sufficiently developed, it is sometimes difficult to realize to which group of organisms the lactic acid bacteria reported by some authors belong. Those described by Clauss, Grotenfelt, Schardinger, Kozai, and Utz probably are identical with Hüppe's Bacillus acidi lactici or B. aërogenes. In this country Conn also found an organism that he identified as Hüppe's Bacillus acidi lactici, but stated that it was present only exceptionally in sour milk. They all grow luxuriantly on laboratory media; dextrose and lactose are fermented, with the formation of acid and gas; milk is coagulated more or less rapidly and the curd contracts with the liberation of whey. The colonies on agar or gelatin are large, moist, and frequently viscid. These organisms are found chiefly in surface layers of milk.

Lactic acid bacteria have also been described by Leichmann, Günther and Thierfelder, Kozai, Utz, Esten, Schierbeck, and others. These were not distinctly separated from the type described by Hüppe, although Leichmann insisted that his organism was not the same. Later he became convinced that he had discovered an organism wholly different from Hüppe's bacillus, and gave it the appellation Bacterium lactis acidi. While Hüppe's organism was the bacillus of lactic acid, Leichmann's was the bacterium of sour milk. The appellations are so similar that much confusion has resulted, and even in modern publications the two organisms are sometimes hopelessly confused. Günther and Thierfelder went so far as to clearly identify their organism with Hüppe's, although some properties, according to their own description, were so entirely different that the identification was wholly unjustified.

Some sort of system was brought out of the confusion by Kruse in 1903. This author studied the literature and, without experimental evidence, separated the lactic acid bacteria previously described into two groups, namely, the Bacillus aërogenes group with Hüppe's B. acidi lactici as chief representative, and the Streptococcus lacticus group, with Bacterium lactis acidi of Leichmann as the chief representative organism. Kruse proposed to substitute the name Streptococcus lacticus for this group in order to avoid confusion with the previous one, and because he thought that earlier descriptions warranted the assumption that Bacterium lactis acidi was really a streptococcus and not a bacillus. Experimental evidence for the correctness of Kruse's view was brought by his pupil Hölling and the writer.

It was shown that the lactic acid bacteria of the Bacillus acidi lactici (Hüppe) type when inoculated into sterile milk pro- 
duced a coagulum that was granular and broken up by gasbubbles. When sterile milk was inoculated with a mixture of B. aërogenes and Streptococcus lacticus, less gas was produced, and the gas evolution ceased after a short period. Sterile milk inoculated with Str. lacticus alone was coagulated promptly, and in

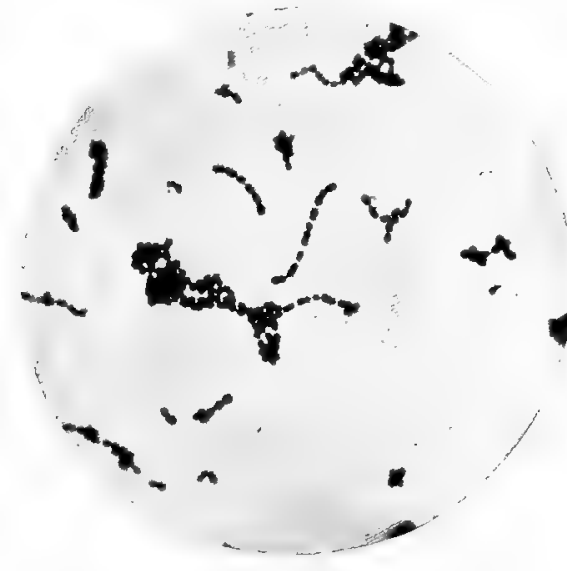

Fig. 166, a.-Streptococcus pyogenes from serum broth.

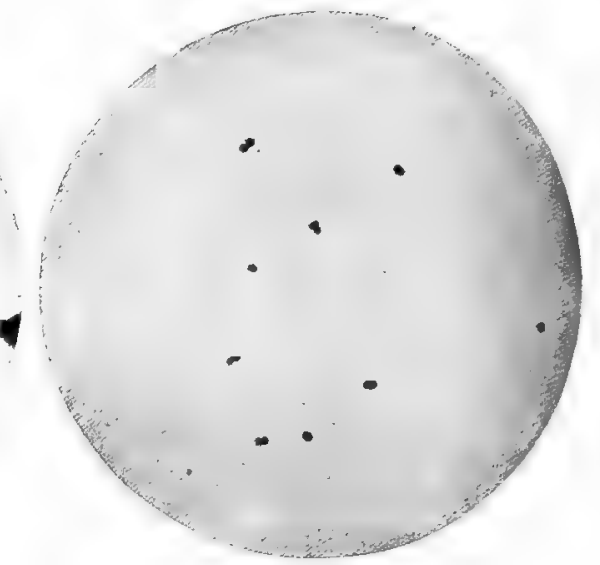

Fig. 166, b.-Streptococcus pyogenes from litmus milk.
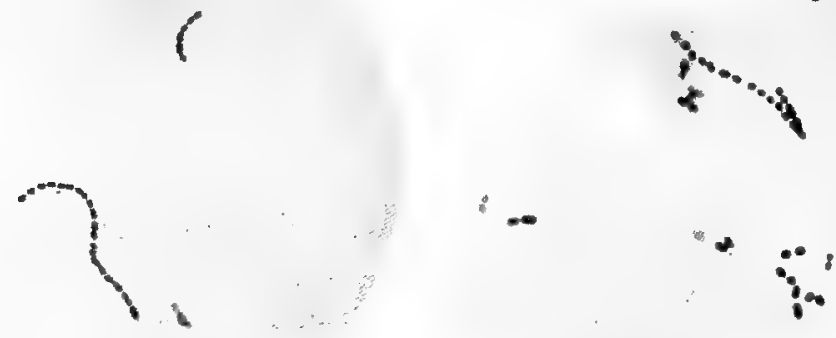

Fig. 166, c.-Streptococcus lacticus from serum broth. (Strain I.)

Fig. 166, d.-Streptococcus lacticus from serum broth. (Strain II.)

this case the coagulum was smooth and without evidence of gas evolution. Hüppe's organism is most frequent in surface portions of milk, while Leichmann's is more common in deep portions, owing to the inclination of the streptococcus to anaërobic conditions. Both types are practically always present in market 
milk, and the souring is produced by the activity of both. Hüppe's Bacillus acidi lactici, therefore, is, in reality, B. aërogenes, and Leichmann's Bacterium lactis acidi is Streptococcus lacticus.

Streptococcus lacticus is now almost universally recognized as the lactic acid bacterium par excellence. We have learned that

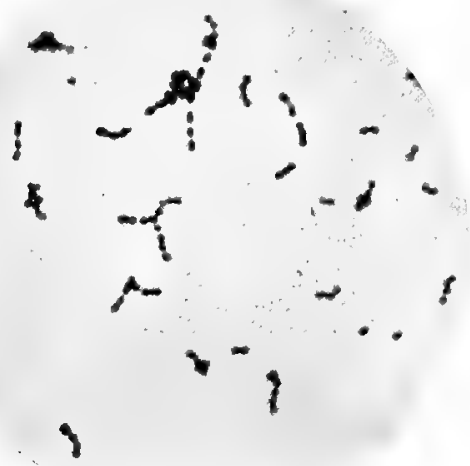

Fig. 166, e.-Streptococcus lacticus from lactose broth. (Strain I.)

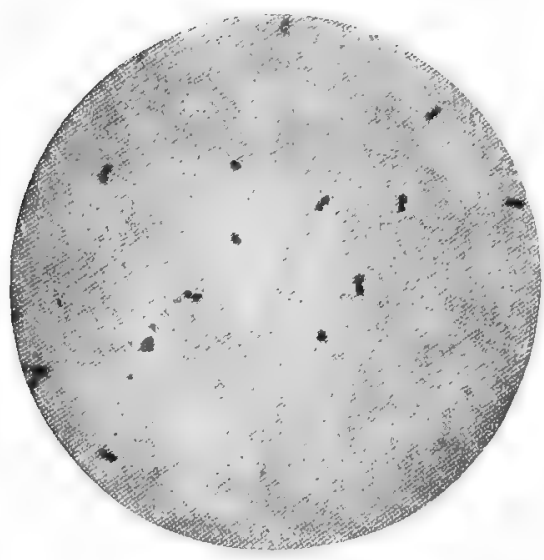

Fig. 166, g.-Streptococcus lacticus from litmus milk. (Strain I.)

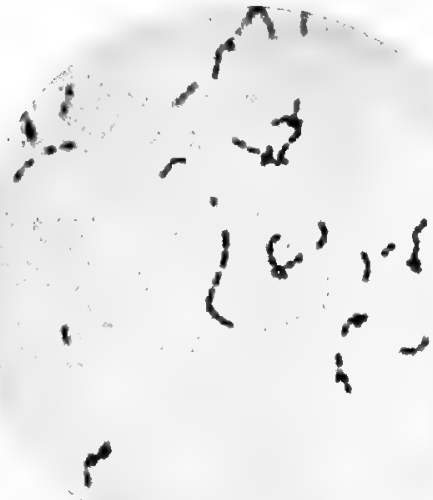

Fig. 166, f.-Streptococeus lacticus from lactose broth. (Strain II.)

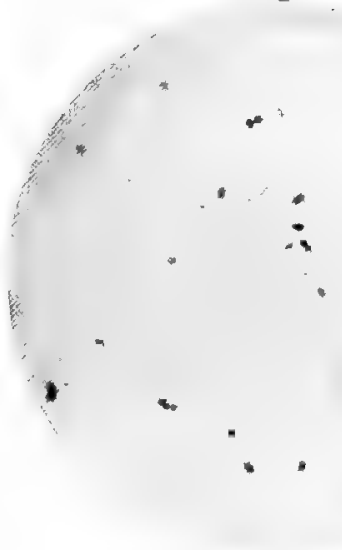

Fig. 166, h.-Streptococcus lacticus from litmus milk. (Strain II.)

Fig. 166, $a-h .-$ Microphotographs of Streptococcus pyogenes and Streptococcus lacticus, showing the tendency to diplococcus formation in litmus milk.

the bacteria of milk are invaders and not indigenous, and it is therefore reasonable to assume that lactic acid bacteria are also derived from outside sources. They can be identified easily with 
well-known types that are widely distributed in nature and especially in the dairy.

The influence of Streptococcus lacticus on milk is desirable from the butter and cheese makers' viewpoints. While predominance of Bacillus aërogenes produces off flavors in dairy products, most strains of Streptococcus lacticus produce desirable flavors. Butter starters, as a rule, are pure cultures of Str. lacticus.

The distribution of the two groups of lactic acid organisms in nature has been investigated to some extent. Barthel found Streptococcus lacticus widely distributed on meadows, plants, and cultivated lands, but scarce and in enfeebled condition on wooded land. In the dairy he found it in cow manure, in the dust of the air, in water, very commonly on the coat of the animal, on hay, straw, in oil cake, bran, malt, and even on flies. The occurrence of Streptococcus lacticus in cow manure explains its constant presence in milk. In fact, the writer was able to produce souring of milk which closely resembled the "normal" souring by inoculating sterile milk with small quantities of cow manure.

Hölling isolated streptococci from the feces of infants, horses, and other domestic animals, and was able to show that sterile milk coagulated typically when inoculated with these organisms.

Bacillus coli has been found by Prescott practically as widely distributed as Streptococcus lacticus. He found it on grains, plants, and cereals, so that its common occurrence in nature has been demonstrated. Whether Bacillus aërogenes shares in this wide distribution is not known. It has been reported that Bacillus aërogenes is more common in cow manure that B. coli, but Rogers states that "the B. coli type is found abundantly in bovine feces, while the B. aërogenes type is very rare." Further investigation of this subject is desirable. However, there is no question about the occurrence of both Bacillus coli and B. aërogenes in cow manure, and, consequently, they are almost universally present in milk.

Rogers found that "through its greater resistance to the unfavorable conditions found in water the Bacillus aërogenes type is able to survive longer than B. coli." It is conceivable that a similar state of affairs obtains in milk, inasmuch as milk may offer more favorable food conditions for Bacillus aërogenes than for B. coli, with the ultimate result that the former type prevails. However, this is hypothetic, and the term "Bacillus coli group" is intended to include both types.

In the "normal" souring of milk both groups, the Bacillus coli and the streptococcus groups, are active agents. It may be assumed that immediately after milking these two groups are 
represented and start growth on equal terms. In exceptionally clean milk they are sometimes very scarce, so that it may require considerable quantities of milk to demonstrate their presence. However, even the cleanest market milk will, as a rule, turn sour on standing and, therefore, the presence of the two groups is evidenced. Media containing dextrose favor the growth of Bacillus coli and streptococci, whose detection is, therefore, facilitated by the use of carbohydrate media.

When milk sours the Bacillus coli group multiplies and forms acids from the milk-sugar. When about 0.4 to 0.5 per cent. acid has been formed the coli-aërogenes group begins to drop out of competition, while the streptococcus group continues to flourish until about 1 per cent. acid has been produced. At this stage the limit of the "normal" souring process has been practically reached. After this there is a gradual return to neutral and then alkaline reaction in the milk (compare page 266).

Temperature is of considerable influence in bringing about the souring process, and according to the temperature the result varies, as has been previously explained. At temperatures above $30^{\circ} \mathrm{C}$. the Bacillus coli group is favored, and the curd is not of the same desirable character as the curd that is produced at lower temperature, when the streptococcus group overgrows the Bacillus coli group more readily.

Bacillus aërogenes belongs to Group 1 of Löhnis' classification, and has the following general characteristics: It is Gram-negative and frequently capsulated; it grows well on ordinary media and coagulates milk promptly; it does not liquefy gelatin and does not dissolve the casein in milk; it produces gas from dextrose, lactose and saccharose, and some other carbohydrates; acid is also produced from carbohydrates; the acid is composed of lactic acid and volatile acids; the bacilli are arranged in irregular groups and colonies are fairly large: they grow preferably under aërobic conditions, which fact accounts for their presence chiefly in surface layers of milk.

Streptococcus lacticus belongs to the second group of Löhnis' classification and has the following characteristics: It is an oval, round, or flat coccus, inclined to anaërobiosis and chain formation; the chains are usually short, the diplococcus form being most prevalent, although in old milk cultures longer chains frequently occur; it grows scantily on ordinary media, better on media containing carbohydrates; on agar slants the surface growth is thin, veil-like, or composed of drops; it is Gram-positive, coagulates milk promptly, the coagulum being smooth and compact, with separation of little or no whey; it does not liquefy gelatin or dissolve casein, as a rule, although rare forms have been reported 
that do liquefy gelatin and digest casein; it forms no gas from carbohydrates, although rare forms also have been reported that form gas; the colonies are small. The tendency to anaërobiosis accounts for the fact that Streptococcus lacticus is most abundant in deep portions of the milk.

The bacteria of the coli-aërogenes group attack both carbohydrates and protein, but as long as carbohydrate is available proteins are protected, so that relatively small amounts are broken down. Deep cleavage products from protein may appear, although usually in small quantity. The lactose in milk is first inverted to dextrose and galactose, and then lactic, acetic, formic, propionic, succinic, and sometimes small amounts of valeric acids are formed. Some strains produce relatively large amounts of lactic acid, others less lactic and more acetic acid. The gases formed are chiefly carbon dioxid, hydrogen, and traces of marshgas. The members of this group not infrequently produce a peculiar taste and odor in milk. At first the taste is aromatic and not unpleasant, but later it becomes sharp, and finally reminds one of stable odor.

The streptococcus group attacks chiefly carbohydrates, while proteins are decomposed to a very small degree. It is probable that proteins are not utilized for food to a considerable extent by streptococci before they have been partially broken down by other bacteria, such as the liquefying micrococci, members of the hay bacillus group, and other peptonizing bacteria. Jensen has shown that streptococci attack chiefly peptones or caseones, the latter being even more suitable than the former. From the lactose in milk they produce nearly pure lactic acid, although the amount produced by different strains varies within rather wide limits. The lowest amount is about 0.3 per cent., while the largest is about 1.3 per cent. Those strains that produce the smaller amounts of acid do not coagulate milk, but the strains which usually coagulate milk in typical fashion produce up to 0.9 per cent.

The quantity of acid produced by lactic acid bacteria depends upon several factors. Since Streptococcus lacticus forms more acid than Bacillus aërogenes, predominance of the former will result in a higher percentage of acid. As stated before, conditions in perfectly fresh milk are not as suitable for growth of Streptococcus lacticus as during later stages when some of the protein has been broken down and rendered more easily assimilable. Marshall has shown by his work on Bacterial Associations in the Souring of Milk that saprophytic bacteria may or may not favor growth of lactic acid bacteria. Marshall states, "the means by which acceleration of lactic acid fermentation is produced is not 
the same in all cases. It appears to be due to products manufactured by the associate micro-organisms, sometimes stable to heat, sometimes unstable; sometimes under alkaline conditions, sometimes under acid conditions; sometimes with apparent digestion, sometimes with no apparent digestion. The period at the beginning of lactic fermentation during which no lactic acid formation can be determined, and during which the number of bacteria is continually increasing, may be greatly shortened by vigorous associate bacteria influencing the lactic micro-organisms. Usually the associate micro-organisms disappear, with the formation of appreciable amounts of lactic acid; yet the associate micro-organisms may continue to persist, causing abinormal lactic fermentation." The work of Marshall shows clearly that the amount of acid formed during lactic fermentation depends to some degree upon the presence of associate bacteria which furnish food for more or less rapid multiplication of the lactic acid bacteria and, since there is no regularity about the number or kind of associate organisms, the souring process must be subject to variations. Koestler also found that the presence of bacteria of the hay bacillus group favors acid formation by using up the oxygen and partially breaking up the proteins, rendering them more available for nutrition of lactic acid bacteria.

It is obvious that the relative number of lactic acid bacteria of one group as related to the number present of another group may influence the result. When the coli-aërogenes group is well represented their products will be produced in larger measure than when present in small numbers. The temperature at which the souring process occurs also influences the result. High temperatures-i.e., above $30^{\circ} \mathrm{C}$-- favors growth of the coli-aërogenes group, while streptococci multiply as readily at lower temperatures. At lower temperature, therefore, lactic acid will be produced in larger quantity than at higher temperature, and gas will be produced more readily at the higher temperature.

Since the conditions that govern the production of acid in milk vary to a marked degree, we cannot expect to find a definite relation between the number of lactic acid bacteria in milk and the amount of acid formed, or the time required to produce complete coagulation. Variety of types, temperature, and, as Marshall has shown, the presence of other bacteria influence the result. The number of lactic acid bacteria increases to a given point, then decreases. At high temperature the maximum is reached in a shorter time than at lower temperature. After the maximum number has been reached the bacteria decrease rapidly, but acid formation continues for some time. This phenomenon is due to the liberation of lactic-acid-forming enzyms from the 
broken-down cells. Sometimes the lactic acid bacteria increase in number, then the number decreases, only to increase again to a second maximum, which may be greater or smaller than the first maximum. Such fluctuations have been referred to in another connection (see page 266). Under the action of different types of bacteria the available food-supply is constantly changing.

The relation of numbers of bacteria to the amount of acid formed is illustrated in the chart (Fig. 167).

The chart shows that in sterile milk inoculated with large numbers of Streptococcus lacticus coagulation is slower and acid formation smaller than in raw milk, other conditions being equal. It is furthermore clear from this chart that coagulation is not directly dependent upon the presence of a certain amount of acid or upon the number of lactic acid bacteria. This absence of a definite relation between coagulation, on the one hand, and acid and number of bacteria, on the other hand, may be due to the kinds of associate bacteria present, the kind of acid formed, and the activity of enzyms produced by bacteria.

The quantity of peptone present in the culture-medium has a pronounced influence on the amount of acid formed by lactic acid bacteria. As stated before, Jensen has shown that the lactic acid bacteria of the Streptococcus lacticus type attack peptones and caseones with greater ease than complex proteins. Koestler obtained similar results, and determined that the amount of acid increased as the percentage of peptone was increased. This author claims that part of the acid is produced from the peptone and not solely from the carbohydrate. Rahn, on the other hand, thinks that the peptone simply favors greater growth of the bacteria, so that more acid is produced. He determined the exact amount of acid produced by a single cell of Streptococcus lacticus, and found a larger amount of acid to be formed when the quantity of peptone was increased, but that each cell produced the same amount no matter what the peptone content was.

Koestler studied the influence of oxygen pressure on the amount of acid formed by Streptococcus lacticus, and found that in deep layers of the medium, when air had but a small relative surface contact, the amount of acid formed was greater than in shallow layers.

An interesting study of the acid formation and the effects resulting from the acid formation in milk under the influence of Bacillus acidi lactici (B. aërogenes) and Bacterium lactis acidi (Streptococcus lacticus) was published by Van Slyke and Bosworth. Milk was inoculated with both these organisms and allowed to ferment for sixty hours, and longer. The authors found that 22 per cent. of the milk-sugar had been decomposed and that 


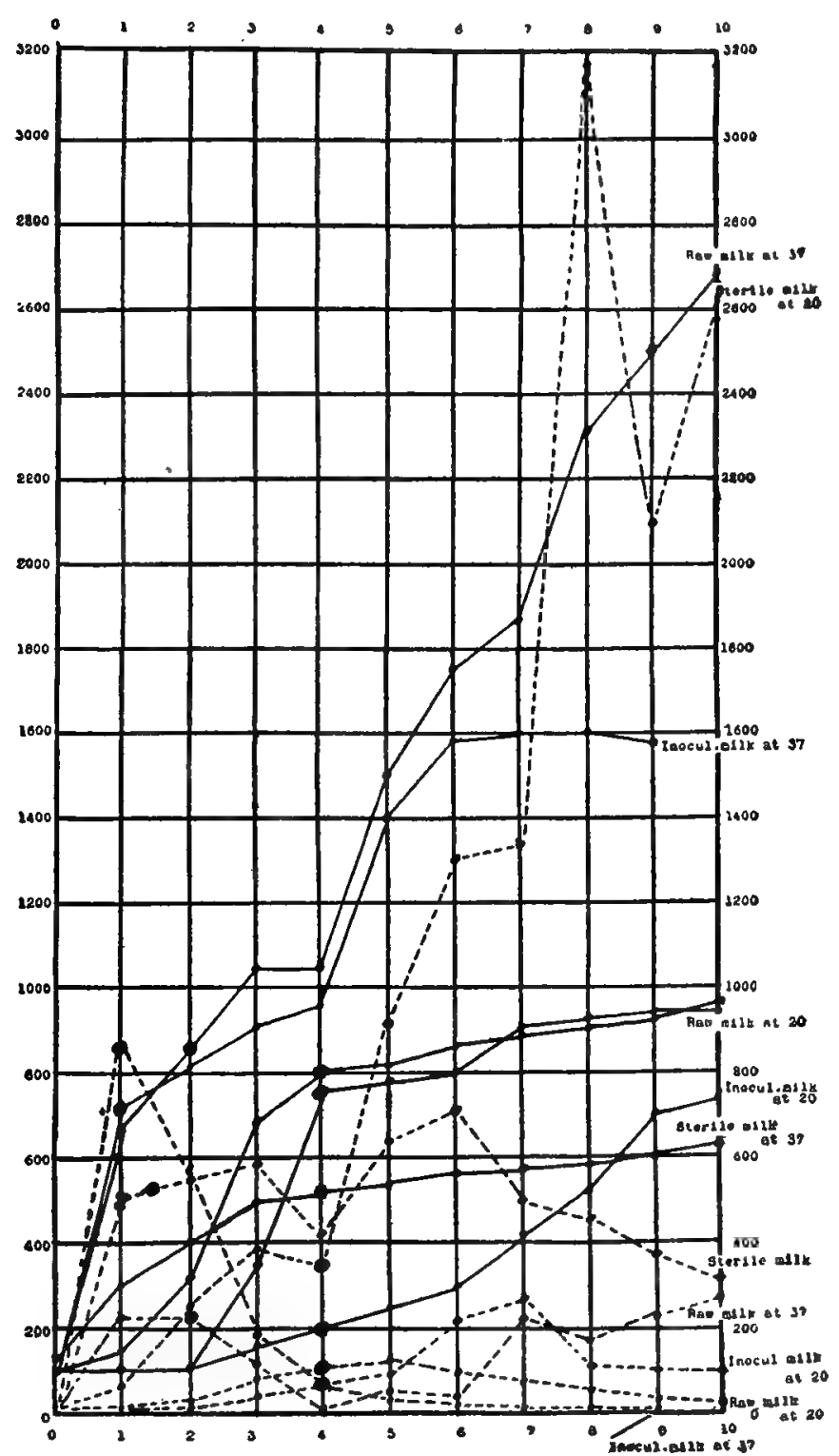

Fig. 167.-Amount of acid formed in milk and number of bacteria present. Acid is represented by the solid line; bacteria, by the dotted (Heinemann).

88.5 per cent. of the lost sugar had been converted into lactic acid. Incidentally they confirmed the findings of Bosworth and 
Prucha that citric acid had disappeared and had been converted into acetic acid and carbon dioxid.

The acid thus formed rendered some insoluble inorganic constituents soluble. In fresh milk the insoluble calcium is in combination with phosphoric acid as $\mathrm{CaHPO}_{4}$ and with casein as $\mathrm{Ca}_{4}$ caseinate. When lactic acid was produced by bacterial activity the dicalcium phosphate was converted into monophosphate $\left(\mathrm{CaH}_{4} \mathrm{P}_{2} \mathrm{O}_{8}\right)$, and the calcium caseinate changed first into a caseinate containing less calcium, and finally the calcium was completely eliminated from its combination with casein and the latter precipitated.

The albumin of milk is also profoundly affected according to Van Slyke and Bosworth. The authors found that more albumin passes through a porous filter from sour milk than from sweet milk. The authors think that this phenomenon is due to the formation of lactic acid which decreases the absorption of albumin by casein, or that it may be due to a combination of a base with the albumin and a gradual separation of the base and protein in much the same manner as happens with casein.

The authors furthermore determined the rate of acid formation, and found that during the first period the acid increased slowly, while much acid was formed from the tenth to the twentyfifth hour. After 0.7 per cent. lactic acid was present, bacterial activity was much reduced. Between the forty-eighth and ninetysixth hours the sugar was changed but slightly. There was, therefore, a rapid increase of acidity during the first twenty-four hours, followed by a much smaller increase. In fresh milk no lactic acid was found, and the acidity of fresh milk must, therefore, be due to acid phosphates. The acidity of the milk serum also increased but little after the lapse of twenty-four hours.

The following table is given by Van Slyke and Bosworth, and shows the results of their work in detail:

TORMATION OF LACTIC ACID IN THE SOURING OF MILK.

\begin{tabular}{|c|c|c|c|c|c|}
\hline $\begin{array}{l}\text { Age of milk when } \\
\text { sampled. } \\
\text { Hours. }\end{array}$ & $\begin{array}{l}\text { Sugar. } \\
\text { Grams. }\end{array}$ & $\begin{array}{l}\text { Amount of } \\
\text { unchanged } \\
\text { sugar in } 100 \\
\text { c.c. of milk. } \\
\text { Grams. }\end{array}$ & $\begin{array}{l}\text { Lactic acid. } \\
\text { Grams. }\end{array}$ & $\begin{array}{l}\text { Milk-sugar } \\
\text { changed. } \\
\text { Per cent. }\end{array}$ & $\begin{array}{l}\text { Fermented } \\
\text { sugar } \\
\text { changed into } \\
\text { lactic acid. } \\
\text { Per cent. }\end{array}$ \\
\hline 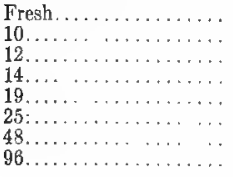 & $\begin{array}{l}5.30 \\
5.07 \\
4.83 \\
4.68 \\
4.58 \\
4.42 \\
4.30 \\
4.26\end{array}$ & $\begin{array}{l}0.00 \\
0.23 \\
0.47 \\
0.62 \\
0.72 \\
0.88 \\
1.00 \\
1.04\end{array}$ & $\begin{array}{l}0.000 \\
0.200 \\
0.330 \\
0.513 \\
0.671 \\
0.665 \\
1.052 \\
1.124\end{array}$ & $\begin{array}{r}0.0 \\
4.3 \\
8.9 \\
11.7 \\
13.6 \\
16.6 \\
18.9 \\
20.0\end{array}$ & $\begin{array}{c}0 \\
87 \\
70 \\
82 \\
93 \\
75.5 \\
0 \\
0\end{array}$ \\
\hline
\end{tabular}

The figures in this table indicate very clearly that the most rapid acid formation occurs during the interval from the tenth to the twenty-fifth hour. At this time 0.665 per cent. lactic acid 
has been produced, and the further accumulation of acid proceeds rather slowly and is probably due to enzym action, while the growth of bacteria has largely ceased. After forty-eight hours the increase of acid is very slight.

As pointed out before, during the so-called incubation period of milk there is very little acid formation. It has been suggested that the acid that is actually formed during this period is largely neutralized by some of the calcium held by the casein so that no free acid appears. After the tenth hour the balance of the calcium held by the casein is rapidly absorbed and free acid accumulated. This accumulation continues up to the point where the acid acts as an inhibitory agent on the further growth of the lactic acid bacteria, while enzyms continue to produce acid to a certain degree.

Lactic acid is known to exist in three modifications according to its action on polarized light, namely: 1, the dextrorotatory; 2 , the levorotatory; and 3 , the racemic or inactive acid. The particular kind of lactic acid produced by different types of lactic acid bacteria has been considered an aid in differentiation of the types, and the subject has, therefore, received considerable attention. Each type produces either one of the two active modifications, or when one of two types produces the dextro-, the other the levorotatory modification, the racemic variety appears. Contrary to earlier opinions, it has been shown, chiefly by Harden, that one type of micro-organism always produces the same modification of lactic acid without regard to changes in condition or environment. Bacteria of the Bacillus coli or B. aërogenes type always produce levorotatory acid, while the streptococcus type always produces dextrorotatory acid. This has been shown by Hölling and independently by the writer. Pyogenic streptococci have also been shown by the same authors to produce d-acid.

The kind of lactic acid found in sour milk, therefore, depends upon the predominance of one of the types of lactic acid bacteria, and this again depends upon several conditions. Since Bacillus aërogenes grows more rapidly than Streptococcus lacticus during the initial period of souring, the milk at this stage contains chiefly l-acid. Later, when streptococci grow more rapidly than Bacillus aërogenes owing to the accumulation of acid, d-acid appears. The consequence is that racemic acid is formed through the combination of the two acids, but one or the other of the two active modifications of lactic acid may predominate.

The kind of lactic acid produced by the different types of lactic acid bacteria has been determined by several investigators, but the results of early work did not seem to agree. Günther and Thierfelder found that "normally" soured milk did not always 
contain the "fermentation lactic acid" (racemic or inactive acid), but that frequently there was a preponderance of d-acid. They furthermore determined that Bacterium lactis acidi (Streptococcus lacticus) in pure culture always produced pure d-acid. Leichmann also found that Bacterium lactis acidi produced only d-acid in pure culture, but when milk soured at high temperature racemic acid was formed. The investigations of Thiele have shown that when milk sours at room temperature mostly d-acid is formed during the first few days, but after seven days there was chiefly r-acid, with a slight excess of d-acid. When this author examined milk that had soured at $37^{\circ} \mathrm{C}$. he also found d-acid at first, but r-acid appeared after thirty-six hours, and finally l-acid was in excess of r-acid. Kozai's work is not entirely in accord with that of Thiele, inasmuch as he found in milk soured at room temperature either pure d-acid or d-acid with a slight amount of r-acid. In milk soured at $37^{\circ} \mathrm{C}$. Kozai found r-acid and l-acid. Utz is of the opinion that in sour milk r-acid or r-acid with some d-acid are present, whether the fermentation occurred at room temperature or at $37^{\circ} \mathrm{C}$. Hölling examined a number of samples of milk and came to the conclusion that milk incubated either at $22^{\circ} \mathrm{C}$. or at $37^{\circ} \mathrm{C}$. contained d-acid. Pure cultures of Streptococcus lacticus and strains of streptococci isolated from infants' stools and from the feces of horses, asses, cows, rabbits, and dogs produced only d-acid in milk, while a culture of a non-motile strain of Bacillus coli produced 1-acid.

On the surface these results do not appear harmonious. However, MacKenzie argued that the disagreement of results obtained by different investigators may in part at least be due to the methods employed. The usual proceeding for determination of the kind of lactic acid present in milk is to prepare the zinc salts of lactic acid and then determine the rotatory power of the zinc lactate, which is the reverse of that of the corresponding acid. Sour, loppered milk is filtered and the clear filtrate evaporated to a syrupy consistency on a water-bath. The residue is strongly acidulated with phosphoric acid, and the liberated lactic acid shaken out with ether. After the ether has been evaporated the golden-yellow fluid is dissolved in water and the solution boiled with zinc carbonate until effervescence ceases. The salt is then crystallized from the solution. Addition of animal charcoal aids in producing a colorless solution of the zinc lactate.

According to MacKenzie, active zinc lactates may remain in solution after the inactive salt has been crystallized, since the active salts are soluble in $\mathbf{1 7 . 5}$ parts of water at $15^{\circ} \mathrm{C}$., while the inactive salt requires at least 53 parts of water for solution. The inactive salt crystallizes, therefore, more readily than the active 
salt, and some of the latter may remain in solution and be overlooked, unless the remaining solution is tested separately.

In a series of studies made by the writer it was found that the kind of acid produced in souring milk depends upon the following factors:

1. The relative number present of Streptococcus lacticus and Bacillus aërogenes. Since Streptococcus lacticus produces d-acid and Bacillus aërogenes l-acid, we will have racemic acid with excess of d-acid when Streptococcus lacticus predominates and with excess of l-acid when Bacillus aërogenes predominates. During the initial period of acid fermentation Bacillus aërogenes is usually present in larger numbers than Streptococcus lacticus, and l-acid is the chief product. Furthermore, during the initial period the proteins, as pointed out before, are not broken up, and food conditions for Streptococcus lacticus are relatively unfavorable. Bacillus aërogenes, therefore, multiplies at a greater rate than Streptococcus lacticus.

2. The temperature at which the fermentation occurs is of influence. Since Bacillus aërogenes grows more rapidly at relatively high temperature $i$. e., $30^{\circ} \mathrm{C}$. and higher - than Streptococcus lacticus, more l-acid is formed at this temperature than at lower temperature.

3. The kind of acid present varies according to the length of time the fermentation has lasted. In initial stages of souring Bacillus aërogenes predominates, and consequently l-acid is found in excess, but later, when the food material is more suitable for Streptococcus lacticus and when the acid has accumulated to a degree to inhibit further growth of Bacillus aërogenes, d-acid is the chief product. The d-acid and l-acid combine to form $r$-acid, and during later stages of fermentation d-acid remains in excess.

The facts are probably not entirely explained by the conditions mentioned. Autotransformation of active acid into racemic acid has been observed by Nef, and, furthermore, lactic anyhdrid is formed, according to Jungfleisch and Godchot, when solutions of lactic acid or of lactates are evaporated to concentration. This lactic anhydrid is levorotatory and its presence may bring misleading results.

In milk obtained under unusual conditions of cleanliness, such as certified milk, for example, the number of bacteria is exceedingly small, and consequently Streptococcus lacticus, being more adapted to growth in milk than most other bacteria, rapidly becomes predominant, and consequently mostly d-acid is formed. It follows that the presence of d-acid in sour milk indicates desirable conditions for dairy products, since members of the coli- 
aërogenes group are present in relatively small numbers and are easily outgrown by Streptococcus lacticus.

Furthermore, it should be remembered that observations have been reported showing that some micro-organisms may assimilate one of the active modifications of lactic acid in preference to the other one, so that the latter remains intact. D-acid seems to be utilized more frequently than l-acid, and this agrees with Nef's theory that $\mathrm{d}$-acid is more readily dissociated than 1-acid. And finally, we know that when bacteria disintegrate, enzyms are liberated, which for a time continue the fermentative process carried out during the life of the cell.

The conditions become still more complicated by virtue of the fact that Bacillus aërogenes and $B$. coli produce acids other than lactic acid in considerable quantity, while Streptococcus lacticus produces practically pure d-acid. It is, therefore, possible to have l-acid in excess of d-acid only when enormous numbers of the coli-aërogenes group are present, and this occurs chiefly when milk contains excessive amounts of filth or when milk has been. kept at temperatures high enough to favor the growth of Bacillus , aërogenes.

The presence of d-acid, I-acid, or r-acid can be readily explained then when we know which one of the two chief types of lactic acid bacteria is predominant. Bacillus aërogenes always produces l-acid, and when it is present in larger numbers than Streptococcus lacticus, or when the temperature is such as to favor its growth, l-acid will be formed. But Streptococcus lacticus produces d-acid at the same time and, therefore, part of the l-acid is neutralized and r-acid appears. In initial stages of souring, therefore, 1-acid will usually be the chief modification, except perhaps in exceptionally clean milk. As the fermentative process proceeds, racemic acid takes the place of inactive acid, and finally d-acid predominates. In loppered milk usually inactive acid is present with d-acid in excess. At high temperature more l-acid is formed and more rapidly than at low temperature, and, therefore, more $r$-acid with less d-acid results.

The character of the coagulum produced in souring milk by different types of lactic acid bacteria is by no means of the same nature. Streptococcus lacticus forms a smooth jelly, with the separation of only a small quantity of whey. Even after several days the amount of whey that becomes visible is small. Bacillus aërogenes, on the other hand, produces a coagulum that contracts and leaves considerable whey, and the coagulated casein is broken up by gas-bubbles. However, Bacillus coli or B. aërogenes in pure culture does not form a coagulum rapidly, so that much gas escapes before the coagulum is solid enough to retain large amounts. 
And furthermore, with the increase in acid the growth of Bacillus coli and B. aërogenes is restrained and gas formation decreases. The amount of gas in a curd is, therefore, not always an indication of the number of the coli-aërogenes group present in the milk.

When, as Hammer has shown, Streptococcus lacticus and either Bacillus coli or B. aërogenes are inoculated into milk at the same time, a curd is formed rapidly by the acid produced by Streptococcus lacticus, and consequently a large amount of gas is retained. This phenomenon is more prominent when growth takes place at $37^{\circ} \mathrm{C}$. than at room temperature.

Different strains of Bacillus coli and B. aërogenes vary considerably in their power to produce gas, and also in other properties. This has been shown by Harrison, who studied 66 varieties isolated from milk, and found many modifications which seemed to link the extremes together. Hammer has made the interesting observation that members of the coli-aërogenes group when freshly isolated from milk produce more gas than when kept for some time (eight months) on laboratory media. After this time they produced about as much gas as strains from sources other than milk. It seems, therefore, that when gassy curds are formed the cause may not always be looked for in large numbers of the coliaërogenes group, but rather in the presence of strains that have acquired the property of producing much gas and have become highly acid resistant because of their growing together with Streptococcus lacticus.

The desirable curd for making cheese is the one produced by Streptococcus lacticus, and when this organism is present it restrains the coli-aërogenes group, as a rule, so that a suitable curd is formed. This is especially true at temperatures below body temperature. However, Doane and Eldredge have stated that cultures of Bacillus bulgaricus are more suitable for suppressing gas formation in Emmenthaler cheese than Streptococcus lacticus.

The Wisconsin curd test, worked out by Babcock, Russell, and Decker, gives the cheese maker a simple method of testing the quality of the milk for this particular purpose, and is performed as follows: The milk to be tested is placed in sterile pint jars and warmed to $90^{\circ} \mathrm{F}$. Then 10 drops of rennet extract are added and the curd cut into pieces with a knife. After the curd has settled the whey is poured off. Then the jars are kept at $100^{\circ}$ to $105^{\circ} \mathrm{F}$. After twelve hours the curd is examined. If it is of solid, firm texture and the odor agreeable, the milk is suitable for cheese making. If the curd is full of gas-bubbles, is of spongy consistency, and has an unpleasant odor, it indicates milk of poor quality for cheese making. By this simple and useful test the cheese maker can easily trace any trouble to the proper source 
(Figs. 168, 169). The coagulum is the result of acid or rennin, or

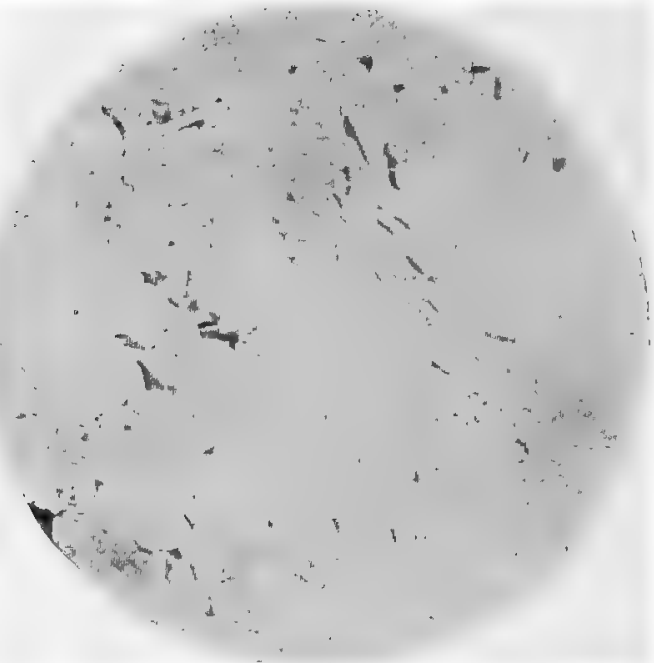

Fig. 168.-Curd test. A good curd obtained from milk cont xining no harmful bacteria but many desirable acid-forming organisms (Russcll and Hastings).

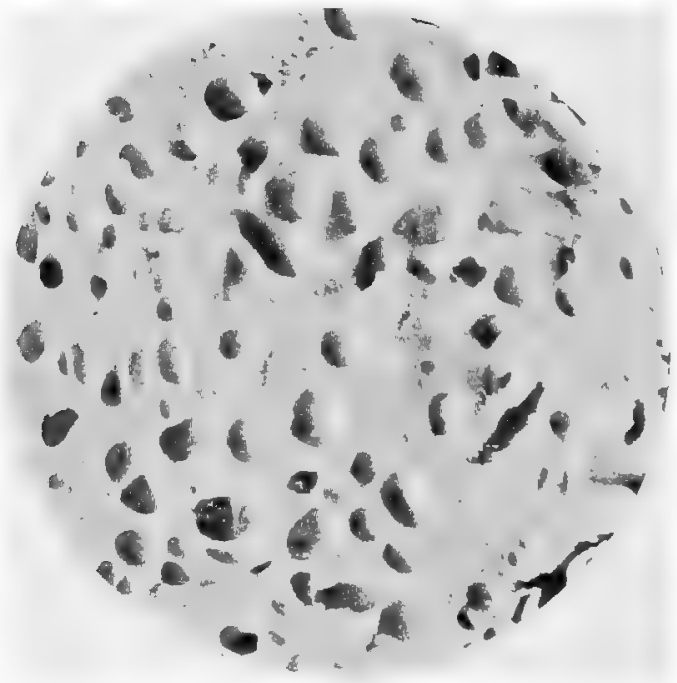

Fig. 169.-Curd test. The curd obtained from milk containing many gas-forming bacteria. The irregular, angular holes are mechanical, due to the imperfect fusion of the pieces of curd (Russell and Hastings).

of the combined action of both factors. It forms more readily at high temperature than at low temperature (Figs. 170, 171). 
The relation of Streptococcus lacticus to Str. pyogenes is a problem of much interest and one that is not easily accounted for. The genus streptococcus, if the term "genus" is permissible in

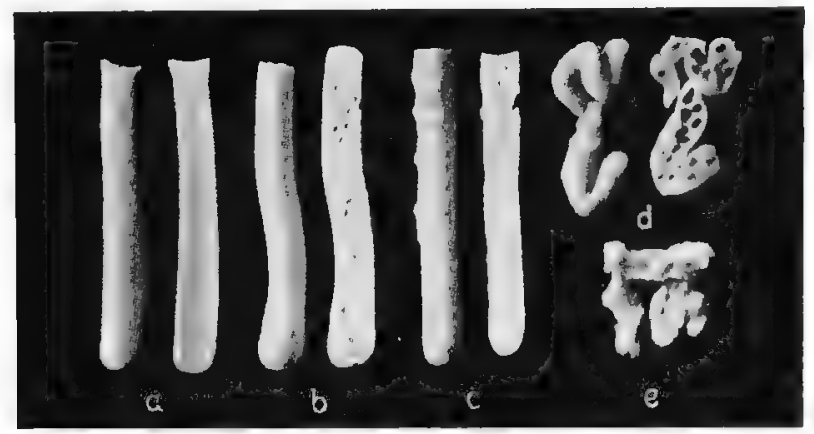

Fig. 170.-Rennet curds: $a$, Smooth curd without holes; $b$, nearly smooth, with many holes; $c$, uneven, with many holes; $d$, spongy; $e$, loose and broken up. (Löhnis.)

connection wlth this group of bacteria, has been the subject of much study and controversy. To discuss this phase of the ques-

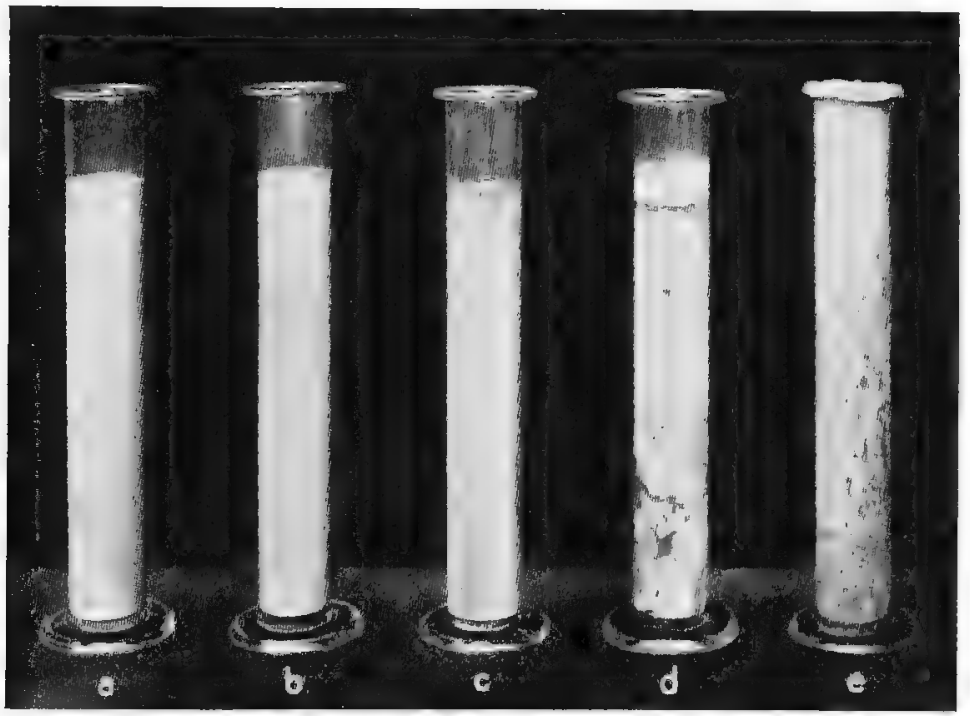

Fig. 171.-Fermentation tests of milk: $a$, Liquid milk; $b$, jelly-like curd; $c$, cheesy curd; $d$, gas formation; $e$, much gas formation. (Löhnis.)

tion is not within the scope of our work, but a few words as to the direct relation of Streptococcus lacticus to the genus streptococcus may find space here. 
Löhnis in his classification of lactic acid bacteria groups Streptococcus lacticus with Str. pyogenes Rosenbach. Kruse, as stated before, was the first author to call attention to the similarity of Bacterium lactis acidi Leichmann to pyogenic streptococci and, therefore, proposed the name Streptococcus lacticus as more suitable than Leichmann's appellation. Hölling states that a sharp differentiation between Streptococcus lacticus, on the one hand, and Str. pneumoniæ and related streptococci, on the other hand, cannot be made. He found among the strains of Str. lacticus which he studied, some which grew as poorly on artificial media as Str. pneumoniæ, and some that produced such small amounts of acid that milk coagulated slowly or not at all. He was able to show that mice are sometimes killed by injection of strains of Str. lacticus, and thinks that a close relationship between the two groups has been demonstrated. The author expresses the belief that later work will show that Str. pyogenes and Str. lacticus belong to the same "species," and that perhaps suitable environmental conditions might render Str. lacticus virulent for animals. The writer has shown that by repeated passage through rabbits a high degree of virulence can be acquired by Str. lacticus, although the opinion, erroneously quoted by some authors, that Str. lacticus and Str. pyogenes are identical was never uttered. A later investigation has shown that strains of Str. lacticus can be rendered virulent so as to produce lesions in rabbits practically identical with those produced by typical Str. pyogenes, and that the fermentation reactions of Str. lacticus can be altered by suitable conditions so as cause a clear approach to other strains, including pathogenic strains as far as ability to produce acid from carbohydrates is concerned. It was possible to show that by animal passage and by cultivation in media containing serum without the presence of a carbohydrate the chain formation of Str. lacticus was favored so as to resemble the so-called pathogenic Str. longus. Even the power to hemolyze human and goat's blood was acquired to a limited extent at least. The power to ferment carbohydrates with acid production was variable and dependent in a measure on the oxygen pressure. The greater the amount of oxygen available, the more readily were carbohydrates fermented.

The morphology of streptococci is very variable, and a distinct classification on this basis cannot stand scrutiny. The cells are known to appear in three distinct forms, namely: 1, the spheric; 2 , the elongated, and 3 , the flattened form. All these forms can be observed in the same strain under varying conditions. The length of the chain is perhaps even more variable than the shape of the individual cell, and, therefore, cannot serve as an important 
means of differentiation. As stated by Rogers, streptococci can be grouped according to certain tests or test substances, but the grouping varies according to the tests selected by the investigator. In the present state of our knowledge we must be contented to assume that Streptococcus lacticus and Str. pyogenes are variations of one parent form, and that characteristics which are acquired may be more or less transient. Buchanan has shown that impressed variations on Str. lacticus do not persist. If, however, acquired characteristics are impressed for very long periods, as may be assumed possible with a strain inhabiting milk for a long time, it is not impossible that these characteristics persist for a considerable length of time. Thus a saprophytic streptococcus may become pathogenic, and a pathogenic one lose its virulence. Str. lacticus should be considered a close relative of Str. pyogenes, but not identical, even though our present means of differentiation do not reveal very marked and permanent differences.

The third group of lactic acid bacilli according to Löhnis' classification is an important one, hardly less so than the two previous groups. The collective name of lactobacilli $i^{1}$ is sometimes used to designate this class of bacteria, and they have attracted considerable attention because they are the chief agents in the production of some fermented milk. The Bulgarian bacillus especially has been advertised broadly as the "bacillus of long life," and has gained much notoriety through the publications of Metchnikoff and some of his associates. Furthermore, this group of bacilli has recently been recognized as playing an important rôle in the final ripening stages of some types of cheese, and pure cultures can be obtained for this purpose.

Many varieties of bacilli belonging to this group have been described in the literature, for example: Bacillus bulgaricus, Streptobacillus lebenis, B. acidophilus, B. acidophil-aërogenes, B. bifidus, Boas-Oppler bacillus, B. panis fermentati, B. casei, Bacterium caucasicum, Körnchen bacillus, Leptothrix buccalis, and others. We have here another illustration of the multiplicity of names assigned to a group of closely related organisms which differ from each other in minor properties and which possibly are but varieties of one type, whose characteristics have been modified by environmental conditions.

An organism closely resembling Bacillus bulgaricus was found by Hefferan and the writer in cornmeal, and was held to be the active agent for the production of lactic acid in salt-rising bread.

${ }^{1}$ The term "lactobacilli" for the group of lactic acid bacteria under discussion seems preferable to terms which are not infrequently encountered, such as "aciduric bacilli," "acidophil bacilli," or "bacilli of the Bacillus bulgaricus group." Such terms are suggestive of some characteristic which may not be applicable to some strains. 
This discovery led to an extensive investigation of the group of lactobacilli, and an attempt was made to co-ordinate the number of bacilli described, to form in one group. The general characteristics of bacilli of this group as given by various investigators are fairly uniform, and the belief is justified that they are derived from one parent form which has assumed slight alterations in properties due to special conditions. The organisms are described as large bacilli occurring singly or in filaments, producing large amounts of acid in milk, sometimes more than 3 per cent. and being Gram-positive. The descriptions are usually meager, owing to the fact that this class of organisms does not grow well on ordinary media. The term "acidophil" is sometimes encountered in relation to these bacteria, a term that is misleading, because this group of bacilli is acid resisting rather than acid loving. Neutral or slightly acid media are, in reality, more suitable for cultivation than media containing much acid.

Bacilli of this group have been isolated by Emmerling from the Armenian fermented milk, "mazun"; by Freudenreich in "kefir"; by Finkelstein in the intestinal canal of both bottle-fed and breast-fed infants; by Moro also in the stools of infants and described under the name of Bacillus acidophilus. Other authors who have given descriptions of similar bacilli are: Beijerinck, who studied kefir and named the organism Bacterium caucasicum; Leichmann called a similar bacillus Bacillus delbrücki; Rodella, Henneberg (B. panis fermentati), Grigoroff (B. bulgaricus from Yoghurt, the Bulgarian milk) are among the investigators of this group of bacilli. Rhist and Khouri found Streptobacillus lebenis in "leben," an Egyptian fermented milk. Grixoni examined the Sardinian milk, "Gioddu," and discovered a similar organism. Weigmann, Gruber and Huss, Düggeli, Piorkowski, and Lürssen and Kühn described members of this group. Sewerin recognized the identity of Bacillus bulgaricus and Streptobacillus lebenis, and called attention to the fact that some strains form a slimy product, while others do not.

The colony formation of lactobacilli has been studied by several authors. Mereschewsky distinguished two strains, one of which formed small colonies, likened to grains of sand, while the other strain formed colonies with woolly edges and of considerable size (Figs. 172 and 173).

Under the name Boas-Oppler bacillus the lactobacilli received attention first from Boas and Oppler. Further studies were published by Strauss, Schlesinger and Kaufmann, Heinemann and Hefferan, Galt and Iles, and Heinemann and Ecker. Kuntze was the first to suggest the identity of the Boas-Oppler bacillus with the lactobacilli, and this suggestion was shown to be true 
by Hefferan and the writer, and by Galt and Iles. Additional proof was brought later by the writer and Ecker and Rahe.

Rodella classed the so-called acidophil bacteria with the lactobacilli, including the Bacillus bifidus of Tissier. Kuntze then showed that there are chiefly two types of bacilli distinguished from each other by their staining properties. While one type, represented by Bacillus bulgaricus, stains solidly with Neisser's stain and alkaline methylene-blue, the other strain shows granules. This latter is the granule bacillus or the "Körnchen" bacillus (Figs. 174-176).

The lactobacilli, as stated before, grow but sparingly on laboratory media, but growth is favored by the presence of dextrose or lactose. Milk, or a medium prepared from milk, such as whey-agar, is the best culture-medium. Rahe, in some studies as to the fermentative power of lactobacilli, used unneutralized meat-peptone sugar-free broth, with addition of carbohydrates. Beerwort agar has also been used with some success. By addition of pieces of marble or calcium carbonate in some other form the acid is neutralized as soon as formed, and growth is much prolonged.

The optimum temperature is usually given as ranging from $40^{\circ}$ to $45^{\circ}$ C. and even higher, but some strains grow fairly well at lower temperature. At least this must be assumed, since in the ripening of some types of

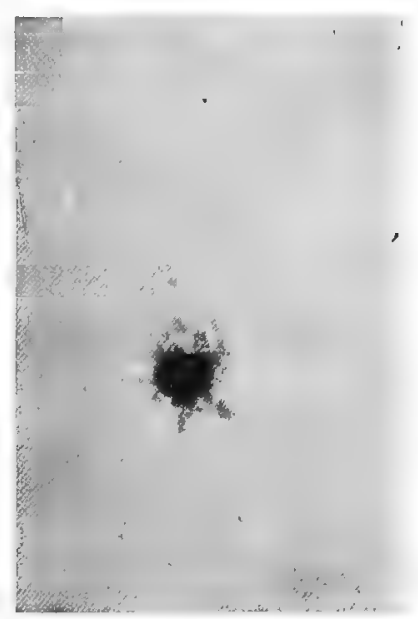

Fig. 172.-Colony of Bacillus bulgaricus. cheese lactobacilli play an important rôle. This has been shown by Eldredge and Rogers and by Evans, Hastings, and Hart.

The lactobacilli retain the stain when treated with Gram's iodin solution when the cultures are young, but in old cultures negative forms prevail. If a Gram stain is made of a culture several days old and a red counterstain applied, filaments that are composed of red and blue cells can be frequently observed. The presence of oxygen is not necessary for growth; in fact, anaërobic conditions are preferred by the lactobacilli.

Owing to the difficulty experienced in attempting cultivation of lactobacilli their wide distribution in nature is a recent discovery. Hefferan and the writer found them in the feces of cows, horses, and in human feces; in soil where manure was present; in human saliva; in the gastric juice; in market milk; in various 


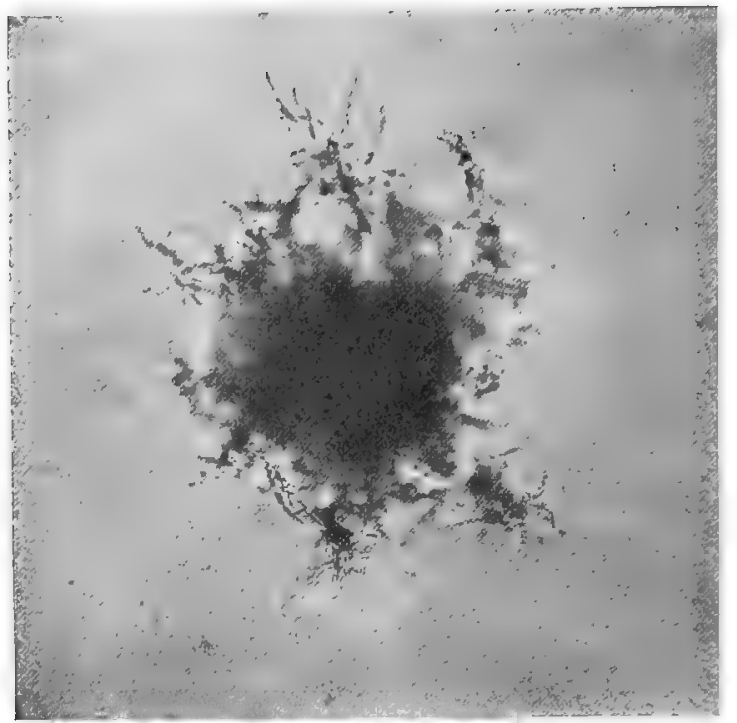

Fig. 173.-Colony of Bacillus bulgaricus highly magnified.

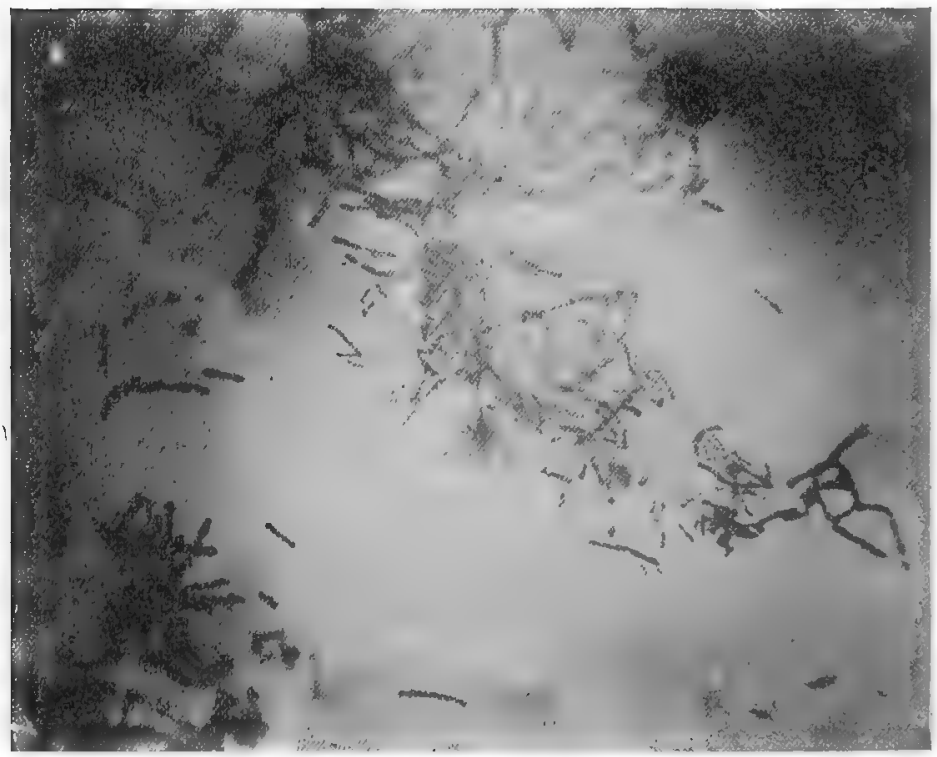

Fig. 174.-Bacillus bulgaricus, young cultures.

kinds of fodder for cattle (bran, silage, dry brewer's grains); in cornmeal, sourkrout, olive juice, dill pickles, and pepper mango. 
Hunter and Bushnell think that the fermentation of silage is dependent upon the activity of lactobacilli. Hastings and Hum-

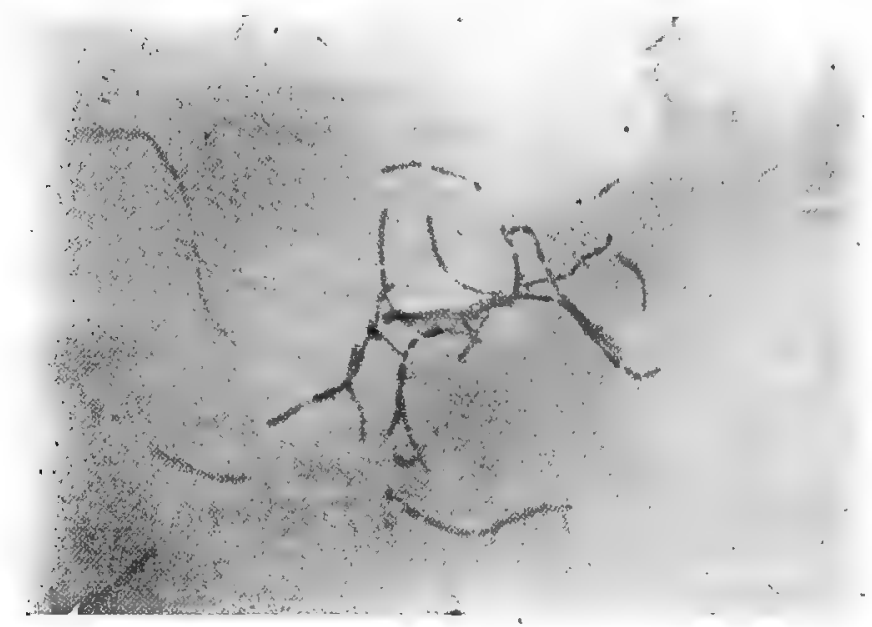

Fig. 175.-Bacillus bulgaricus showing granules.

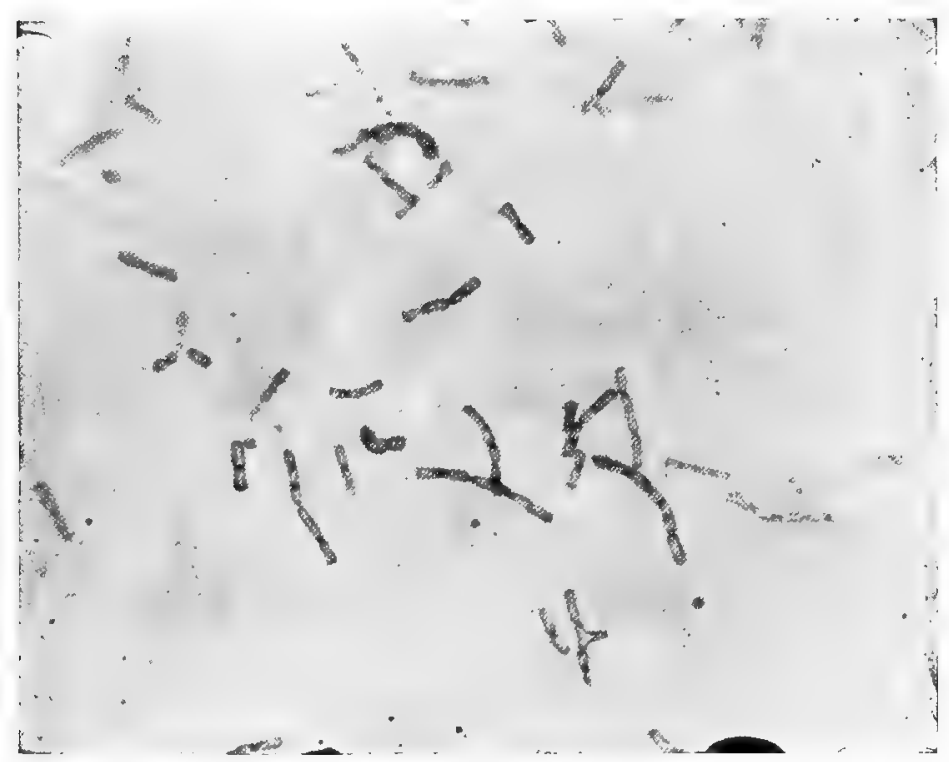

Fig. 176.-Bacillus bulgaricus from cultures several days old.

mer isolated lactobacilli from milk, butter, and cheese. Eldredge and Rogers found them in large numbers in Emmenthaler cheese; Evans, Hastings, and Hart, in Cheddar cheese; Esten and 
Mason, in Camembert and Roquefort cheese; Dotterer and Breed found them in enormous numbers in the raw and pasteurized whey from cheese factories. This last discovery is of special interest, inasmuch as it shows that the thermal death-point of the bacilli must be above pasteurization temperature, since in pasteurized whey they were present almost in pure culture. White and Avery, however, claim that a minimum exposure of fifteen minutes to $60^{\circ} \mathrm{C}$. was necessary to kill all strains.

Pathogenicity to man or animals has never been observed.

Lactobacilli produce chiefly lactic acid. Hefferan and the writer found that 5.8 to 6.1 per cent. of the total acid formed consisted of volatile acid. The nature of the volatile acid was not determined. According to Bertrand and Weisweiller and Bertrand and Duchacek acetic, formic, and succinic acids are formed. White and Avery state that all strains observed by them produced small amounts of volatile acid, the nature of which was not determined. The same authors found small but appreciable amounts of alcohol in the distillates from whey of ten-day-old cultures, but neither acetone nor aldehyd. They state further that the casein and fat are slightly decomposed so that a bitter acrid taste is produced.

The influence of oxygen pressure on acid formation by lactobacilli has been studied by Koestler. Working with Bacillus casei of Freudenreich, the author determined that more acid is formed when the surface of the culture-medium exposed to the air is reduced. The author also found that more acid is produced when the quantity of peptone is increased, and that acid is not produced exclusively from the carbohydrate, but that part of it is derived from the peptone. When all conditions as to composition of the medium, the temperature, and the oxygen pressure were equal, Koestler always found that the same amount of acid was produced.

The lactic acid formed by those lactobacilli which produce large amounts of lactic acid is of the inactive variety according to Heinemann and Hefferan and White and Avery, while according to the latter authors the low acid producers form levorotatory acid. This is in agreement with the findings of Heinemann and Ecker that the Boas-Oppler bacillus, which belongs to the class of low acid formers, produces levorotatory acid. Currie found dextrorotatory acid formed by lactobacilli isolated from human saliva, human feces, malt, kraut, cheddar cheese; he found d-acid with a small admixture of i-acid in strains from cheddar cheese; from another strain from cheddar cheese he found pure l-acid; and in milk soured at $38^{\circ} \mathrm{C}$. he found l- and i-acid mixed.

Currie's results are not entirely in harmony with those of 
other observers. Whether this is due to the fact that he studied a larger number of strains or to some other reason cannot be determined, and the decision must be obtained by future work.

The nature of the coagulum formed by the different strains varies somewhat. Some strains produce a smooth semifluid, sometimes slimy coagulum without separation of whey, while others produce a coagulum that is fairly firm and from which a small amount of whey separates.

Attempts at organizing the lactobacilli into groups have not been wanting. Löhnis distinguishes six types, as follows:

1. Type: Bacillus casei, Freudenreich. Coagulate milk and form gas. Members of this type are: Bacterium casei $\delta$, Freudenreich; Lactobacillus caucasicus, longus and fragilis, Beijerinck; Bacterium pabuli acidi III, E. Weiss.

2. Type: Bacterium casei, Leichmann. No gas formed and milk coagulated. Members of this type are: Bacterium casei I to III, Leichmann and Bazarewski; Bact. pabuli I and II, E. Weiss; Bact. casei $\alpha$, Freudenreich; Bact. lactici aërobans, Conn; Bact. No. XIX, Adametz (Bact. truncatum, Migula); Streptobacillus lebenis, Rist and Khouri; Bact. bulgaricus, Lürssen and Kühn; Bact. lactis acidi, Marpmann; Bact. Eckles, from Harz cheese; Bact. Listeri and Wortmanni, Henneberg.

3. Type: Bacterium caucasicum, Lehmann and Neumann. Form gas, but do not coagulate milk. Members of this type are: Bacillus from kefir, Freudenreich; Lactobacillus fermentum, Beijerinck; Bacterium panis fermentati, Heyducki, Buchneri and brassicæ fermentatæ, Henneberg.

4. Type: Bacterium delbrücki, Leichmann. Does not form gas and does not coagulate milk. Members of this type are: Bact. delbrücki, Leichmann; Bact. acidificans longissimus, Lafar; Long bacilli from sour dough, Holliger; Bact. lebenis, Rist and Khouri; Bact. Leichmanni I-III and Beijerinckii, Henneberg.

5. Type: Slimy type. Members of this type are: Varieties of Bacterium lactis acidi, Leichmann; Lactobacillus caucasicus, Beijerinck; Bacterium casei $o$ and $\varepsilon$; Bact. abderholdi, Henneberg, and a strain from Yoghurt.

6. Type: Forms colonies with branches. Members of this type are: Bacterium lactis acidi, Leichmann; Bact. casei $\delta$ and $\varepsilon$, Freudenreich; Bacilli from mazun described by Düggeli and by Weigmann, Gruber, and Huss; Granule bacillus of Lürssen and Kühn; Bact. yoghurt, Kuntze; Bacillus from kumiss described by Schipin; Bact. sardous, Grixoni; Lactobacillus conglomeratuus, Beijerinck; Bacterium delbrücki $\delta$, Henneberg; different bacilli from lactic acid in stomach.

This classification undoubtedly might be simplified by an ex- 
haustive study, which would show that the multiplicity of names is useless, and that different types have been described where one would answer the purpose.

A simpler, although not as comprehensive, classification has been proposed by White and Avery, namely:

Type A: With Löffler's methylene-blue or with Neisser's stain the protoplasm is homogeneously stained. Acid production amounts to 2.7 to 3.7 per cent. lactic acid in milk. The lactic acid formed is the inactive variety.

Type B: With Löfller's methylene-blue or with Neisser's stain the presence of intensely staining granules may be demonstrated in the protoplasm. Acid production amounts to 1.2 to 1.6 per cent. lactic acid in milk. The lactic acid formed is the levorotatory variety.

Finally, Rahe found that the ability to ferment maltose offered a useful means for classification. Three types are distinguished by this author, as follows:

Type A: Which clots milk, but has no action on maltose.

Type B: Which clots milk and ferments maltose.

Type C: Which ferments maltose, but does not clot milk.

Rahe extended this study, and in a recent publication states that "the aciduric bacilli, including Bacillus bifidus in its aciduric phase, may best be classified in accordance with their ability to ferment certain carbohydrates." The author tested the fermentative ability of his strains with maltose, sucrose, lactose, raffinose, glucose, and mannite.

It must be confessed that these attempts at classification serve a useful purpose temporarily, but that they are still incomplete, and perhaps of not sufficient breadth. An exhaustive study of the members of the group of lactobacilli, therefore, should be made to bring a rational classification to a higher degree of perfection.

The lactobacilli can be isolated by inoculating the material containing them into a broth to which 2 per cent. of dextrose and 0.5 per cent. of acetic acid have been added. The acetic acid inhibits the majority of other organisms present, and after transfers for several days and incubation at a high temperature of about $42^{\circ}$ to $45^{\circ} \mathrm{C}$. the lactobacilli will usually be found in pure culture. Inoculation into milk then will facilitate study. Plates in wheyagar may be prepared so that pure cultures are assured, and the colonies may then be transferred to slanted whey-agar.

The fourth group of lactic acid bacteria, according to Löhnis' classification, consists of micrococci, and these are derived chiefly from the udder. It has been previously stated that the majority of bacteria in milk while still in the udder belongs to the class of micrococci or staphylococci. The type of this class is Staphy- 
lococcus (pyogenes) aureus, Rosenbach, and the micrococci found in milk are either identical with Staphylococcus aureus in cultural and biochemical properties or, at most, environmental modifications. They are Gram-positive, grow well on laboratory media, and frequently produce pigments. The golden-yellow pigment is the common one produced, but lemon-yellow, pink, and reddishbrown pigments are not infrequent. Staphylococcus albus is the variety that produces no pigment. The micrococci grow best at about $35^{\circ}$ to $37^{\circ} \mathrm{C}$., but some varieties have a lower optimum temperature, some as low as $20^{\circ} \mathrm{C}$. They grow also at temperatures near the freezing-point of water.

The staphylococci found in milk produce, as a rule, three enzyms, namely, one which attacks milk-sugar with the production of acid; one which coagulates the casein; and a proteolytic enzym. The micrococci are, therefore, of importance in the ripening of some cheeses, notably Emmenthaler, Limburger, and Camembert cheese. They produce volatile substances which in part are responsible for the aroma in some cheeses. Gorini's acid-coagulating micrococci belong to this group.

As a rule the micrococci found in milk are non-pathogenic, but occasionally they may cause an inflammation in the udder. One type of mastitis is caused by the staphylococci. Miss Evans occasionally found staphylococci that were pathogenic for rabbits in the udder. Pathogenicity for man has not been established.

The staphylococci usually coagulate milk promptly, although they do not produce as much acid as the other groups of lactic acid bacteria. Coagulation is brought about by the combined action of acid and the coagulative enzym.

\section{Spore-Bearing Bacteria in Milk}

Spore-bearing bacteria occur constantly in milk, and are either aërobic or anaërobic. The aërobic spore-bearers are of the proteus and the hay bacillus groups. The presence of these, especially of the latter type, favor the growth of anaërobes in milk, since the pellicle formed at the surface aids in excluding the oxygen of the air.

The bacilli of the hay bacillus or the potato bacillus type are common on hay, fodder, potatoes, and in manure. Their entrance into milk is, therefore, readily explained. As a rule, they produce a coagulative enyzm, and after coagulation break up the proteins. The milk assumes a brownish or reddish-brown hue and becomes translucent. Studies of anaërobes in milk have been published by Grassberger and Schattenfroh and by Brown.

The bacteria of this group have come into prominence through the work of Flügge, who isolated several types from pasteurized 
and boiled milk in which the spores survived. The author came to the conclusion after experiments with animals that toxins are produced by these organisms, and that consequently the digestive tract is injured, especially in infants.

Anaërobic spore-bearing bacteria cause butyric acid and propionic acid fermentations in milk. In addition to these acids, valeric acid is sometimes formed, and the milk always emits a disagreeable odor under the influence of these bacteria. The buty-
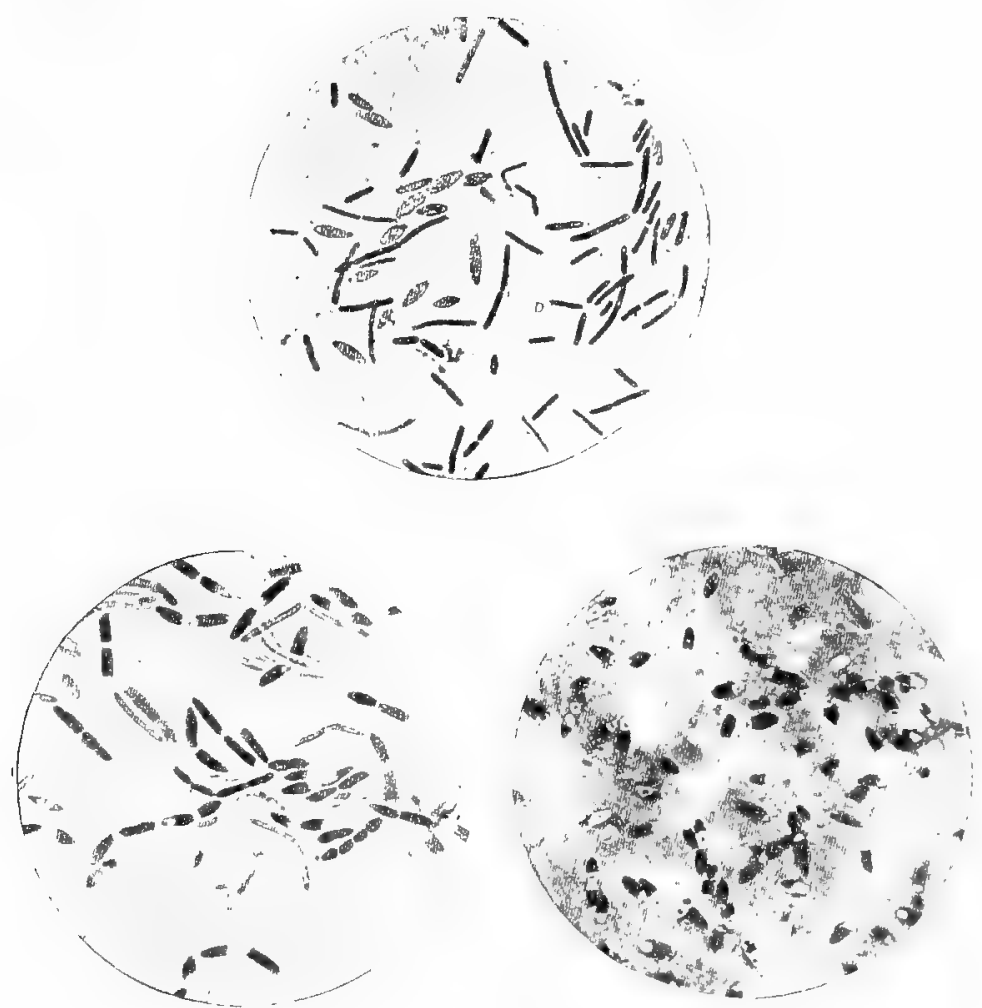

Fig. 177.-Anaërobic spore-bearing bacteria (Weigmann).

ric acid bacteria are widely distributed in cultivated soil, manure, on grain, and some fodder. The spores are terminal and a drumstick or clostridium-shaped large bacillus is seen in stained preparations (Fig. 177).

The butyric acid bacteria are sometimes separated into the motile and the non-motile varieties. The motile butyric acid bacillus, named Granulobacillus saccharobutyricus mobilis or Bacillus saccharobutyricus, is not as common in milk as the 
non-motile type, named Granulobacillus saccharobutyricus immobilis or Bacillus dimorphobutyricus. This latter occurs in cow manure, and hence is common in milk. The spores of the motile bacillus are not as highly resistant to heat as those of the non-motile. The latter are destroyed only by prolonged boiling, while those of the former are killed by three minutes' boiling.

The Bacillus putrificus of Bienstock belongs to this group of anaërobic bacteria, and is frequently found in milk. The spores of this organism are also terminal, and are destroyed by five minutes' boiling, but not after three minutes.

Weigmann's Plectridium fotidum belongs to the spore-bearing bacteria, and was isolated by the author from Limburger cheese. It dissolves milk proteins with evolution of gas and a strong odor of Limburger cheese.

Butyric acid bacteria produce acid from milk-sugar, calcium lactate, and protein. The chief products from carbohydrates are lactic, acetic, and formic acids. Sometimes valeric acid and alcohol also are formed. The gas consists of hydrogen and carbon dioxid, hydrogen being produced in greater quantity than carbon dioxid. From complex carbohydrates glycerin is sometimes produced. The proteins yield chiefly butyric and succinic acids and are broken down into albumoses, peptones, amino-acids, trimethylamin, ammonia, ammonium carbonate, hydrogen sulphid, etc.

Bacillus welchii and B. sporogenes are also common in milk, as might be anticipated, and it is not at all improbable that these organisms can be identified with some of the butyric acid bacilli mentioned above.

The propionic acid bacteria grow with difficulty, and at best slowly on ordinary media. Weigmann recommends the following medium for study of this type of bacteria: In 1000 c.c. of water dissolve 20 grams of peptone, 2 grams of dipotassium phosphate, 5 grams of sodium chlorid, and 20 grams of calcium lactate. They are anaërobes and decompose lactates, with production of carbon dioxid, propionic acid, and some acetic acid. The casein is but slightly broken up. They have been isolated from Limburger and Emmenthaler cheese, and were formerly thought to produce the holes or "eyes" in Emmenthaler cheese by evolution of carbon dioxid. Other anaërobes sometimes occurring in milk which produce capronic acid, butyl- and propyl alcohol have not been sufficiently studied. Detailed descriptions of spore-bearing bacteria in milk are given in a study by Lawrence and Ford.

As a rule, spore-bearing bacteria are not of material sanitary significance in milk, and their chances for growth are relatively poor, since milk is constantly in contact with air and contains appreciable quantities of oxygen in solution. 


\section{Chromogenic Bacteria in Milk}

It happens not infrequently that milk assumes a peculiar color after it has stood for some time. The change in color is due in most instances to the multiplication of pigment-forming bacteria, which, it is true, are almost universally present in milk, but ordinarily do not grow in sufficiently great measure to impart their peculiar pigment to the milk. Thus milk sometimes appears blue, red, yellow, chocolate brown, and other colors.

The bacteria producing these pigments are not related to each other in such manner as to form a distinct group. The chief property in common is their ability to produce pigment; otherwise there is no marked resemblance. The pigments are quite different when produced by bacteria of various groups. For example, a yellow sarcina produces a yellow sediment in milk; Bacillus prodigiosus produces a red pigment; B. cyanogenes, a blue pigment. These pigments are not always in evidence even when the bacteria are present, as certain conditions are required for the formation of pigments. Acid is sometimes inhibitory to pigment formation, as, for example, in the case of the fluorescent pigment of Bacillus fluorescens. The acid which develops in milk soon after milking prevents the formation of the fluorescent pigment, even though the bacilli may be present in fairly large numbers. The blue pigment produced by Bacillus cyanogenes, on the other hand, becomes more intense when acid develops, although in this instance the result is probably due to increased growth rather than to the formation of a pigment of greater intensity. A sort of metabiosis between the lactic acid bacteria and Bacillus cyanogenes is responsible for greater growth of the latter in presence of acid than without the acid.

The presence of free oxygen is necessary for the formation of many pigments, so that these appear near the surface of the milk rather than in deep layers. There are, however, exceptions to this rule. Bacillus erythrogenes, for example, forms pigment in the absence of free oxygen. A stab-culture of this organism develops pigment in absence of free oxygen, but it grows well also under aërobic conditions.

Temperature is an important factor in pigment formation. At $37^{\circ} \mathrm{C}$. many chromogenic bacteria do not produce pigment, while at a lower temperature it may be formed in abundance. Light has an inhibitory effect on pigment formation, but in an opaque fluid like milk light is unable to penetrate to an appreciable depth, and pigment bacteria are not materially influenced.

Finally, it should be remembered that bacteria have a tendency to rise with the cream, so that the cream layer frequently shows 
the presence of pigment when the skimmed milk below has a normal appearance.

Colored milk has never, as far as our knowledge goes, been produced by bacteria that are injurious to health. However, the appearance of colored milk naturally arouses the suspicion of the consumer, and is, therefore, frequently the source of considerable annoyance to the producer and dealer. Colored milk is an annoyance for the additional reason that the milk usually shows no evidence of color when it leaves the producer's or even the dealer's hands. The pigment appears after the milk has been standing for some time, so that pigment-forming bacteria have had opportunity to multiply.

As indicated, the pigment frequently affects only limited portions of the milk. The surface may be uniformly colored; or colored spots appear which gradually expand and coalesce, and finally penetrate to some depth; or the whole volume of the milk is affected; or, finally, the pigment may in rare instances appear in lower portions of the milk only.

There are cases occasionally where milk is colored by agencies other than micro-organisms. The presence of blood is not an infrequent cause of a red tint in milk, and, according to Olson, milk which has been allowed to stand in iron dishes for several hours may assume a bluish-gray color due to solution of some iron. Milk from diseased udders may have a decided yellowish tint. It has furthermore been held that some pasture plants which are eaten by cows influence the milk so as to produce coloration, but observations of this sort are not entirely trustworthy.

\section{BuUe Milk}

Blue color in milk has probably been more frequently observed than any other "color fermentation" of milk. Sometimes the blue pigment appears only after the acidity of the milk is pronounced, and observers agree that the pigment becomes more intense as acidity increases. Probably this phenomenon is not due to a chemical influence as much as to the fact that the milk becomes more suitable for growth of the organism when acidity develops. It is an example of an associative effect of lactic acid bacteria and the pigment-producing types. Hammer has observed that the pigment develops more rapidly in raw milk than in pasteurized milk, and in pasteurized milk more rapidly than in sterilized milk. A blue color develops quite rapidly in pasteurized milk when it curdles promptly. The influence of lactic acid bacteria is quite obvious, since raw milk sours more rapidly than pasteurized milk, and pasteurized milk more rapidly than 
boiled milk. As a matter of fact, boiled milk does not usually sour.

Bacillus cyanogenes or Bacterium syncyaneum is probably the most common cause of blue milk. It has been isolated and described by authors in this country as well as in Europe, and, therefore, may be assumed to be widely distributed. The color is not produced in milk kept at $37^{\circ} \mathrm{C}$., according to Hammer, who has made an exhaustive study of some strains of this organism. The distribution of the color seems to be more uniform throughout the volume of the milk when the milk has been pasteurized than when raw.

Bacillus cyanogenes is an actively motile rod; it is readily discolored by Gram's method of staining; according to some authors (Weigmann, Hammer) the organism does not produce spores, while others (Conn, Esten, and Stocking) claim to have observed spore formation. On agar, pigment does not develop, but in old cultures a brownish color appears near the puncture. Surface colonies are large and appear somewhat bluish. Gelatin is not liquefied, but casein seems to be broken up in a moderate degree. Hammer states that a most intense blue color develops in dextrose broth; a bluish-green in glycerin broth, and a brownish tinge in levulose broth. Broth containing either sucrose, mannit, raffinose, or lactose turns slightly brown, while with maltose, salicin, or inulin a greenish tinge is observed. No pigment develops on potato. Bacillus cyanogenes does not produce gas from carbohydrates and does not grow in the closed arm of a fermentation tube. According to Hammer, acid is produced from dextrose, but not from other carbohydrates.

Blue milk has been observed more frequently in summer than in winter. Weigmann states that feeding of turnips or of clover mixed with horsetail (Equisetum arvense) causes the blue pigment to appear in milk, and that a change of food relieves the trouble. The micro-organisms producing the pigment are said to be disseminated by the foods mentioned, and consequently they are also present in cow feces, and may gain access to the milli from this source.

The pigment of Bacillus cyanogenes as it appears in milk, according to Weigmann, is composed of two pigments, namely, a steel-blue and a fluorescent one. The fluorescent pigment is intensified by presence of magnesium sulphate, while phosphates favor development of the blue pigment.

Bacillus cyaneofluorescens is sometimes mentioned as causing blue milk. This organism is a small, motile bacillus with terminal flagella, and does not form spores. Gelatin is not liquefied and an odor of trimethylamin develops in cultures. Pigment forma- 
tion is favored by the presence of acid. Large blue spots of the size of a dollar are formed on the surface of milk by this organism. Whether this is a type distinct from Bacillus cyanogenes or merely a variation is not known.

Wolff mentions Bacterium indigonaceum as an organism producing bluish-green milk; Bact. cæruleum, producing a sky-blue cream; Bacillus violaceus, which does not color the whole milk, but forms a blue film, and Bacillus membranaceus amethystinus. Descriptions are too meager to classify these organisms.

Weigmann has isolated a species of oildium that produces a blue color in milk. The author made the interesting observation that the pigment is not carried by all cells composing a filament of the mold, but that colored cells occur intermittently within the threads.

\section{RED MiLK}

As a rule, red pigments develop in milk less rapidly than blue pigments. The red color appears generally after a lapse of two to three days, so that the milk is delivered to the consumer in apparently good condition. When milk is colored red from the presence of blood the color naturally appears immediately after milking.

Red milk is probably caused by Bacillus prodigiosus more frequently than by other red pigment-forming micro-organisms. Usually the cream alone appears colored as the bacteria rise with the fat globules. Such milk is, of course, entirely harmless and objectionable only on account of appearance.

Bacillus erythrogenes, first described by Hüppe, sometimes imparts a red color to milk. The red color is then diffused throughout the whole volume of the milk. Other organisms mentioned by Weigmann that occasionally cause red milk are Bacillus lactorubefaciens (Gruber), Sarcina rosea, and Micrococcus cerasinus (Keferstein).

\section{Other Colored Milks}

Bacillus fluorescens is a common inhabitant of water and feces, and consequently of milk. Its fluorescent pigment, however, appears but rarely, since the acid prevents its formation. Yellow milk is very uncommon, although a few accounts may be found in the literature. Sarcina lutea may form a yellow pigment in milk, but the pigment settles and does not impart a yellow color to the whole milk. Bacterium synxanthum produces a pigment that diffuses throughout the milk. This organism is a small, motile bacillus that coagulates milk and dissolves the casein, leaving a lemon-yellow fluid. 


\section{Slimy, Stringy, and Ropy Milk}

Slimy, viscous, stringy, or ropy conditions in milk are among the commonest and most troublesome of all abnormal conditions of milk. The consistency of milk changes so that it can be drawn out into strings or threads, sometimes to a length of several feet (Fig. 178). This condition is particularly obvious when the milk is passed through a sieve, the threads hanging tenaciously from the meshes of the sieve. The nature of such abnormal milk varies considerably; sometimes the strings are fine like silk, sometimes

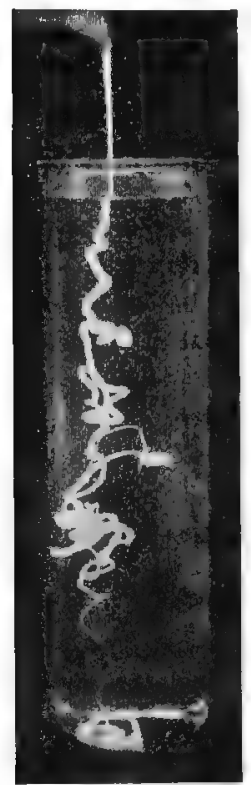

Fig. 178.-Slimy milk. It does not mix with water when poured into it (Russell and Hastings).

thicker; sometimes, again, the tendency is not to form strings of considerable length, but the milk becomes thick and of tenacious consistency. When sliminess develops the chemical change in the milk is slight. It may turn sour in the usual fashion, and there is usually no radical alteration of the casein or breaking down of the milk-sugar, although slime-forming organisms that break down casein to the point of complete liquefaction are rarely encountered. The greatest chemical change occurs when the stringiness is due to a pathologic condition of the udder. This is frequently accompanied by a profound proteolysis.

When the viscosity is caused by microorganisms the taste of the milk is not materially altered; the digestibility is not impaired; acidity develops as usual, but the physical condition somewhat veils the acid taste. In some countries viscous milk is prepared for the table and considered a delicacy. The Norwegian tatté mélk or tätmjölk is an example. The milk is inoculated with butterwort (Pinguicula vulgaris), on which a slimeforming bacterium is known to exist. In conjunction with a yeast which produces an agreeable flavor a fermentation begins, and a thick milk results, which is eaten with a spoon or even with a knife and fork.

Lange wei is a viscous whey that was quite generally used in Holland for making Edam cheese. The whey contains a lactic acid bacterium, Streptococcus hollandicus, that is the cause of the viscous condition and produces acid at the same time. For many years it was thought that the best quality of Edam cheese could be produced only by the use of this lange wei, of which 
1 part was added to 200 parts of the milk to be used. Recent studies, however, have shown that Streptococcus hollandicus is but a variety of Str. lacticus, and that by the use of pure cultures of Str. lacticus an equally good product can be obtained. The consequence is that lange wei is now not in general use. Str. hollandicus forms viscous milk only at moderate temperature of about $20^{\circ} \mathrm{C}$., and when cultivated at higher temperature it causes souring of milk without slime formation.

It has been repeatedly reported that when strains of Streptococcus lacticus are cultivated for successive generations in milk they not infrequently acquire the ability to produce slimy milk. This fact has been particularly annoying when butter starters are propagated. Slimy or ropy milk is difficult to handle for butter and cheese making, and is, therefore, undesirable from this point of view. Furthermore, the slimy or ropy condition sometimes develops slowly, so that the milk is delivered to consumers in apparently good condition, but shows evidence of an objectionable character after standing for some time.

Slimy or ropy milk has been observed in many parts of the world, and it must be taken for granted that the organisms which produce this abnormal condition are widely distributed. Some authors make distinctions between slimy, ropy, and stringy milk. The term "ropy milk" is used to designate milk that can be drawn out into long threads, which is not possible with slimy milk. Stringy milk, according to some authors, applies only to milk from diseased udders. The milk then contains fibrin and large numbers of body cells which cause the stringy condition. The definition of stringy milk implies, therefore, that bacteria are only indirectly responsible for the abnormal condition by being the cause of the pathologic condition, while in ropy or slimy milk bacteria are directly responsible by attacking some of the milk constituents, with production of slimy or ropy substances.

The effect of different organisms, or different temperatures, or of other, at present unknown, conditions is such as to cause a different degree of viscosity. The viscosity can be measured by comparing the length of time required for a definite amount to be discharged from a pipet, or by allowing the milk to flow down an inclined pane of glass. Sometimes, however, the viscosity is so intense that the milk will not flow at all, and a tube containing such milk can be inverted without spilling the contents.

Some organisms producing viscosity in milk grow chiefly at the surface, so that lower portions of the milk are not as intensely slimy as upper portions, while other organisms produce an equal degree of viscosity throughout. Usually slime is formed at a moderate temperature of about $20^{\circ} \mathrm{C}$., while at higher tempera- 
ture the consistency remains normal. This applies chiefly, as stated before, to lactic acid bacteria of the Streptococcus lacticus type. Lactic acid bacteria of the Bacillus aërogenes type may also produce a slimy condition in milk, but in this case the most favorable temperature is higher than when Streptococcus lacticus is the slime-forming organism. There are also lactobacilli that produce a viscous condition in milk, and the best temperature for these organisms is $42^{\circ}$ to $45^{\circ} \mathrm{C}$.

Increase in acidity usually destroys the viscous condition of milk, and it is found, therefore, that the viscosity which appears when cultures are young disappears after several days. Shaking a slimy milk culture usually causes the viscosity to disappear.

Even before bacteriology had become an established science it was assumed by some investigators that slimy milk was the result of bacterial activity, and after the perfection of bacteriologic technic many reports of organisms causing slimy milk were published both in European countries and in the United States. In this country Theobald Smith (1891), Marshall (1896), Conn (1899), Ward (1901), and Buchanan and Hammer (1915) have reported on findings of bacteria in slimy milk, and in Canada Harrison and Barlow (1905-06) encountered a similar phenomenon. The writer had occasion to isolate an organism from slimy milk that was causing trouble in a large suburban dairy of Chicago in 1915.

It is plain that slime-producing organisms are widely distributed. Some of these always produce slime when they gain access to milk and when temperature conditions are suitable; others suddenly acquire the ability to produce viscosity in milk, and may just as suddenly lose this property. The reason for this phenomenon is not understood. Streptococcus lacticus especially is liable to acquire slime-forming ability when transplanted successively in milk, and this happens not infrequently when starters are propagated by frequent transplants. Bacillus aërogenes also acquires the slime-forming capacity sometimes, and retains it even in artificial cultures.

When a starter that has become viscous is examined through a microscope it may be observed that the chains of streptococci are of unusual length and that the cells are frequently surrounded by capsules. Buchanan and Hammer, who have recently made an exhaustive study of slime-forming organisms, state that the chains form a network in the casein and thus cause the viscosity (Figs. 179-181). The sliminess, however, rapidly disappears when the milk is shaken or when it is heated to a temperature above $45^{\circ} \mathrm{C}$.

Viscosity in milk does not inhibit acid formation; on the contrary, Buchanan and Hammer state that it was not unusual to 
find that the cultures that gave evidence of the most intense viscosity contained as much acid as those that had the least viscosity. Sliminess was not reduced by holding cultures at $37^{\circ} \mathrm{C}$.

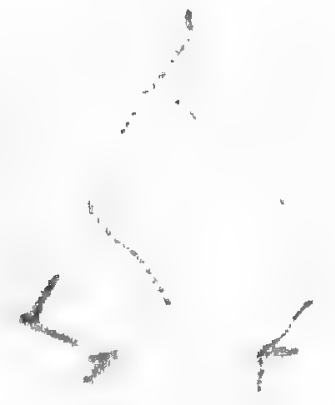

Fig. 179.- Streptococcus lacticus, from first transfer of a commercial starter culture. Capsule stain. It will be noted that some chains of organisms are capsulated, others are not capsulated. (R. F. Buchanan and B. W. Hammer in Research Bull. No. 22, Icwa State College of Agriculture.)

or by transferring them frequently and incubating at the same temperature.

While Streptococcus lacticus and Bacillus aërogenes are frequently the cause of slimy milk, the organism most commonly

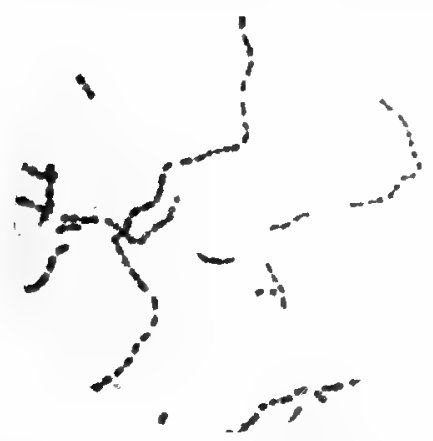

Fig. 180.-Streptococcus lacticus, occurring in long chains in a starter from which sliminess has disappeared.

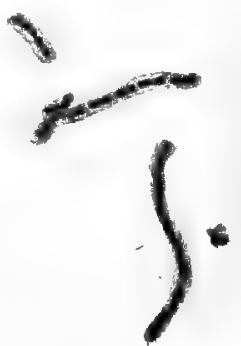

Fig. 181.-Streptococcus lacticus, capsulated chains from a slimy commercial starter culture.

(R. E. Buchanan and B. W. Hammer in Research Bull. No. 22, Iowa State College of Agriculture.)

responsible is.B. (lactis) viscosus, first described by Adametz. This organism grows preferably at low temperature, as low as the temperature of a house refrigerator. Ward was able to recover it from water, ice, and the stable air, and believes, with other investigators, that surface waters are frequently inhabited by this 
organism, and that cows after wading carry it on their coats to the stable. Even ice may, therefore, be the transmitting agent. B. (lactis) viscosus was the cause of the trouble investigated by the writer, and the strain isolated did not grow at all at $37^{\circ} \mathrm{C}$. The sliminess was not evident in the milk when delivered to the consumer, but developed after the milk had been kept in a refrigerator for a few hours.

After the organism has been introduced into a dairy it is not an easy matter to exterminate it. Superficial steaming of the utensils and machinery is not sufficient. Steam must be applied until the metal is thoroughly heated. The utensils or machinery may be filled with milk of lime, and this allowed to remain there for several hours before being washed out.

Buchanan and Hammer found a new type of slime-forming bacterium in a tube of litmus milk which had been autoclaved. This bacillus digests the casein and leaves a viscous residue. The discoverers named it Bacterium peptogenes.

Some strains of Bacillus bulgaricus have a strong tendency to slime formation in milk. The slime is particularly evident in young cultures, but after a few days it usually disappears. No capsules have been demonstrated in cultures of this organism. Other members of the group of lactobacilli occasionally produce a slimy milk, but this faculty is readily lost.

The bacterial products that cause viscosity in milk may be derived either from the carbohydrate or from the protein. When milk-sugar is the mother substance the viscous material is a gum which hydrolyzes either to dextrose or to galactose. The former is known as dextran, the latter as galactan. Galactan is probably more common in milk than dextran.

When the proteins are the mother substances a mucin is formed which contains a carbohydrate and a protein radical. When heated with acids the presence of both a carbohydrate and a protein can be demonstrated (Buchanan and Hammer). These mucins may be produced by bacteria of the hay bacillus group, by butyric acid bacteria, staphylococci, and by Bacillus pyocyaneus.

The gums and mucins produced by these bacteria are precipitable by alcohol, and the precipitate easily redissolves in water. According to Buchanan and Hammer a gum is formed when the cell wall of the bacteria is composed of cellulose, and that a mucin is formed when the cell wall is an ectoplasm.

Slimy milk may be the result of the formation of long chains or, as Buchanan and Hammer ${ }^{1}$ assume, of extraordinarily intense

${ }^{1}$ A list of the slime-producing organisms with descriptions and review of the literature can be found in the publication of Buchanan and Hammer. 
growth. In other cases slime is formed by the associate action of two types either one of which alone would not produce slime.

\section{Other Abnormal Conditions in Milk}

Bitter Milk.-A bitter taste develops sometimes in milk, and is caused in most cases by action of micro-organisms. It was formerly thought that some kinds of fodder, such as turnips, raw potatoes, vetches, moldy hay and straw, were direct causes of bitter substances passing through the mammary glands into the milk. The idea was supported by the fact that a bitter taste is liable to occur when cows are pasturing, since some plants contain bitter principles. It is now believed that foods act merely as carriers of micro-organisms which thus gain access to the milk. This is probably the true explanation, since fresh milk rarely has a bitter taste, although it may develop after the milk has been standing for several hours. The taste may be noticeable after five to six hours and becomes intense after twelve to twenty-four hours.

Perhaps the common cause of a bitter taste in milk is the presence of peptones and albumoses which are formed from the proteins in milk by bacterial action. Liquefying cocci are the most common agents, and in boiled milk the spores of members of the hay bacillus group pass into the vegetative forms and multiply. These digest the casein and produce a bitter taste. Undoubtedly, varieties of the proteus group which are commonly present in milk may digest the casein, with the production of a bitter taste. Some of these peptonizing bacteria grow at relatively low temperature at which lactic acid bacteria grow but slowly, and the latter, therefore, do not inhibit the growth of digesting organisms.

The presence of peptones in milk as a result of bacterial action has been held to be the cause of digestive troubles, especially in the intestinal tract of infants. Flügge in particular has advocated this hypothesis, and went so far as to claim that some of these spore-bearing bacteria produce violent poisons. This argument has been used frequently as an objection to heating milk for infant feeding. The evidence, however, is not entirely conclusive, and it is quite possible that peptones were, in reality, the substances causing the trouble. Flügge argued that heating milk destroyed the vegetative forms of bacteria, including, of course, the lactic acid bacteria, and that the surviving spores then would grow and produce poisons, Flügge's theory found much favor among pediatricians for some time, but as it has not been confirmed, so it has lost ground.

Aside from bacteria that form protein decomposition products 
there are some micro-organisms that seem to be capable of producing peculiar bitter substances. Conn described a Micrococcus lactis amari and Harrison found in bitter milk a torula which was named Torula amara. Members of the coli-aërogenes group may also produce protein decomposition products that impart to milk a bitter taste which is usually accompanied by an odor reminding one of stable air. These abnormal tastes develop when lactic acid bacteria are absent or at least are so scarce that the acid produced is not sufficient to inhibit the growth of other microorganisms.

Sweet Curdling of Milk.-Milk sometimes curdles shortly after milking before a sufficient amount of acid is present to precipitate the casein. This is caused by bacteria forming a rennet enzym, and occurs most frequently in cool wet summers or in winter. When milk curdles without acid formation the curd may be smooth or broken up (cheesy curd). The formation of a curd may be due to the hay bacillus group, in which case the curd is smooth, or to the acid-rennet micrococci, which produce a cheesy curd. Butter is difficult to make from sweet curdled milk.

Soapy Milk.-A soapy taste in milk appears occasionally, and such milk when shaken foams similarly to a soap solution. Bacillus saponaceus is usually the cause of this abnormal condition, but the substance produced is unknown. Weigmann reports another organism that is capable of producing a soapy milk, Bacterium sapolacticum. This is a small non-liquefying bacillus producing a slightly fluorescent pigment. Both types occur on the bedding and food of cows, and are thus transmitted to milk.

Abnormal tastes and odors, pleasant or otherwise, caused by micro-organisms which should be mentioned are:

1. Fruit-like odor, especially strawberry odor, produced by Bacillus coli.

2. The butter flavor produced by Conn's 41 .

3. Marshall and Farrand's Bacterium fulvum, which causes an unpleasant taste and odor.

4. Löhnis' Bacterium kirchneri, which produces a rancid odor.

It is sometimes difficult to dispose of dairy troubles that are caused by unusual numbers of disturbing micro-organisms. The first step is to locate the origin by sampling the milk from the different producers, and thus to determine the source. It is then further necessary to examine the milk from each cow in the herd, so as to find the animal or animals involved. The offending animals must be removed from the herd until the milk is normal. The stables and utensils must be disinfected, and at the collecting station the cans, coolers, bottling machines, etc., must be treated likewise. Pressure steam, if applied long enough to thoroughly 
heat the metal, will usually suffice, but the application of steam as usually practised is not always sufficient. Sometimes even pasteurized milk may suffer from some extraordinary bacterial infection, as some bacteria are more heat resistant than others and may slip through the apparatus. Later they multiply and cause an abnormal appearance or taste in the milk. The pasteurizer and other machinery may be filled with milk of lime, which is allowed to remain for several hours and is then washed out with hot water.

Disinfection of stables may become necessary because of the presence of obnoxious or infectious micro-organisms. The germicidal agent must, of course, penetrate all crevices and openings, and proper preparation of the stable should precede the actual application of the germicide. All food, bedding, manure, and other material must be removed, and the surfaces of walls, ceiling, mangers, stalls, floor, etc., scraped to free them from adhering or caked substances. Dust and cobwebs must be swept away. In places where wood has decayed it should be replaced by sound material, because such places offer special opportunity for germs to lodge. The removed wood should be burned to destroy the infectious material. Water-troughs and mangers require special attention, as they are difficult to clean thoroughly. The barnyard should be cleaned and covered with a layer of dry straw or other inflammable material, which is then burned.

There are several efficient germicides from which to choose for disinfecting stables. Compound solution of cresol (Liquor cresolis compositus, U. S. P.) is a good disinfectant. It is composed of equal parts of cresol and linseed-oil-potash soap and is easily soluble in water. In each gallon of water 4 to 5 ounces of this compound should be dissolved.

Mercuric chlorid is perhaps the most reliable stable disinfectant, but has the disadvantage of being a violent poison, so that great care is necessary in handling it. After it has been used the mangers and water-troughs must be washed with water to remove the poison.

Chlorid of lime may be used in proportion of 6 ounces to 1 gallon of water, but is objectionable because of the odor and the uncertainty of strength of the commercial product. The same may be said about crude carbolic acid.

Formaldehyd gas liberated by addition of potassium permanganate is a powerful disinfectant of great penetrating power, but efficient only when the stable can be sealed nearly air-tight. Under ordinary conditions this is a difficult thing to accomplish.

Cresol is also a good disinfectant, but dissolves in water with considerable difficulty. A 2 per cent. solution of cresol in hot 
water will answer the purpose when the solution is properly prepared.

The germicidal solution must be sprinkled on all surfaces of the stable with considerable force in order to cause it to penetrate all cracks and crevices. For a small stable a spraying pump attached to a pail containing the disinfectant may be used. When a larger stable is to be disinfected a barrel sprayer is convenient.

After application of the disinfectant the walls and ceiling should be covered with lime whitewash or the lime may be mixed with the germicidal solution. Pope gives the following recipe for such a mixture: "Slake $7 \frac{1}{2}$ pounds of lime, using hot water if necessary to start action. Mix to a creamy consistency with water. Stir 15 fluidounces of cresol (commercially known as liquid carbolic acid) at least 95 per cent. pure, and make up to 5 gallons by adding water. In case compound solution of cresol (liquor cresolis compositus) is used, add 30 fluidounces instead of 15 , as in the case of cresol. Stir thoroughly. If to be applied through a spray nozzle, strain through a wire sieve. Stir thoroughly when applying and keep covered when not in use."

Miss Evans describes a streptothrix which she found in 18 out of 21 samples of milk obtained from a herd of cows.

\section{Molds, Yeasts, and Torula in Milk}

Molds, yeasts, and torulæ are present in all milks. Torulæ, as a rule, do not produce marked changes, although there are exceptions to the rule. A special study of lactose-fermenting yeasts has been made by Hastings, who found yeasts capable of producing violent fermentation from lactose widely distributed in milk, whey, rennet, and cheese. Torulæ multiply slowly, and in competition with lactic acid bacteria rarely cause serious trouble.

Among the molds, Oidium lactis is probably the most common one in milk. It forms a felt-like layer on the surface of old milk and digests the casein. Iactose is fermented, with production of carbon dioxid, acids, and a small amount of alcohol. A peculiar odor resembling that of Limburger cheese develops.

Penicillium, mucor, and other molds are also commonly found in milk.

The presence of yeasts in milk is of interest inasmuch as they are active in producing fermentations and aroma in fermented milk beverages. Many such beverages are used and have been used for ages. They vary in character according to the kinds of micro-organisms that change the milk. While lactic acid bacteria produce acidity and texture, yeasts produce characteristic flavoring substances in these fermented milks. In some beverages 
alcohol in appreciable quantity is formed from the lactose by yeasts.

Hunter recently isolated a lactose-fermenting yeast which seems to be the cause of the so-called "foamy cream." Cream is not infrequently fermented, and the foam overflows, involving considerable loss. This yeast grows at relatively high temperature, which explains the fact that "foamy cream" is most prevalent in summer.

\section{BIBLIOGRAPHY}

Adametz: Milchzeitung, 1889, vol. 18, p. 941.

Adametz: Landwirthschaftl. Jahrbuch, 1891, vol. 20, p. 185.

Ayers and Johnson: United States Dept. of Agri., B. A. I., Bull. 126, November, 1910.

Babcock, Russell, and Decker: Quoted from Russell and Hastings, Outlines of Dairy Bacteriology, Tenth Edition, 1914.

Barthel: Révue Générale du Lait, 1906, vol. 5, Nos. 10 et suiv.

Beijerinck: Quoted from White and Avery, Centr. f. Bakt., 1910, vol. 25, p. 161.

Bertrand and Duchacek: Annal. de l'Inst. Pasteur, 1909, vol. 23, p. 402.

Bertrand and Weisweiller: Ibid., 1906, vol. 20, p. 977.

Boas and Oppler: Deutsch. Med. Wchnschr., 1895, vol. 21, p. 73.

Bosworth and Prucha: Jour. Biol. Chem., 1910, vol. 8, p. 479.

Brown: 41st Annual Report of the State Board of Health of Massachusetts, Boston, 1910.

Buchanan and Hammer: Agricultural Experiment Station Iowa State College of Agriculture and Mechanic Arts, Research Bull. 22, July, 1915.

Clauss: Inaugural Dissertation, Wurzburg, 1889.

Conn: Annual Rep. Storrs' Agri. Exper. Sta., 1899.

Conn, Esten, and Stocking: Annual Rep. Storrs' Agri. Exper. Sta., 1906. Classification of Dairy Bacteria, Annual Rep. Storrs' Agri. Exp. Sta., 1906.

Currie: Jour. Biol. Chem., 1911, vol. 10, p. 201.

Doane and Eldredge: United States Dept. of Agri., B. A. I., Bull. 148, March, 1915.

Dotterer and Breed: New York Agri. Exper. Sta., Bull. 412, December, 1915, p. 581 .

Düggeli: Cent. f. Bakt., 1905-6, vol. 15, p. 577.

Eldredge and Rogers: Cent. f. Bakt., Abt. 2, 1914, vol. 40, p. 5.

Emmerling: Cent. f. Bakt., Abt. 2, 1898, vol. 4, p. 418.

Esten: Annual Rep. Storrs' Agri. Exper. Sta., 1896.

Esten and Mason: Storrs' Agri. Exper. Sta., Bull. 83, September, 1915.

Evans: Jour. Inf. Dis., 1918, vol. 23, p. 373. Jour. of Inf. Dis., 1916, vol. 18, p. 437.

Evans, Hastings, and Hart: Jour. of Agri. Research, 1914, vol. 2, p. 167.

Finkelstein: Deutsch. Med. Wchnschr., 1900, vol. 26, p. 263.

Flügge: Zeitsch. f. Hygiene, 1894, vol. 17, p. 288.

Freudenreich: Ann. de l'Inst. Pasteur, 1895, vol. 9; p. 811.

Galt and Iles: Jour. of Path. and Bact., 1914, vol. 19, p. 239.

Gorini: Cent. f. Bakt.; Abt. 2, 1902, vol. 8, p. 139.

Grassberger and Schattenfroh: Arch. f. Hygiene, 1904, vol. 48, p. 1. Arch. f. Hygiene, 1902, vol. 42, p. 219.

Grigoroff: Rev. méd. de la Suisse Rom., Genève, 1905, vol. 25, p. 714.

Grixoni: Cent. f. Bakt., Abt. 2, 1905-6, vol. 15, p. 750 .

Grotenfelt: Migula, System der Bakterien, 1900, vol. 2, p. 544.

Günther and Thierfelder: Arch. f. Hygiene, 1895, vol. 15, p. 164.

Hammer: Agri. Exper. Sta. Iowa State Coll. of Agri. and the Mechanic Arts, Research Bull. 15, February, 1914.

Hammer: Agri. Exper. Sta. Iowa State Coll. of Agri. and the Mechanic Arts, Research Bull. 27, January, 1916. 
Harden: Proc, of the Chem. Soc., 1903, vol. 19, p. 48.

Harding, Rogers, and Smith: New York Agri. E'xper. Sta., Bull. 183, December, 1900 .

Haring: Univ. of Calif. Coll. of Agri., Circular.91.

Harrison: Cent. f. Bakt., Abt. 2, 1905, vol. 14, p. 359. Ibid., Abt. 2, 1905, vol. 14 , p. 472.

Harrison and Barlow: Cent. f. Bakt., Abt. 2, 1905-6, vol. 15, p. 517.

Harrison and Vanderleck: Rev. Générale du Lait, 1909, vol. 7, No. 15.

Hastings: 23d Annual Report of the Wis. Agri. Exper. Sta., Univ. of Wisconsin. Science, 1908 , N. S., vol. 28 , p. 636 .

Hastings and Hammer: Cent. f. Bakt., Abt. 2, 1909, vol. 25, p. 419. Univ. of Wis. Agri. Exper. Sta., 1909, Research Bull. 6.

Heinemann: Jour. of Inf. Dis., 1906, vol. 3, p. 173 . Jour. of Inf. Dis., 1907, vol. 4, p. 87. Jour. of Biol. Chem., 1907, vol. 2, p. 603. Jour. of Inf. Dis., 1915, vol. 16, p. 285. Jour. of Inf. Dis., 1915, vol. 16, p. 221.

Heinemann and Ecker: Jour. of Bacteriology, 1916, vol. 1, p. 435.

Heinemann and Hefferan: Science, N. S., 1909, vol. 29, p. 1011. Jour. of Inf. Dis., 1909, vol. 6, p. 304.

Henneberg: Cent. f. Bakt., Abt. 2, 1903-4, vol. 11, p. 168.

Hölling, Inaugural Dissertation, Bonn, 1904.

Hunter: Jour. of Bacteriology, 1918, vol. 3, p. 293.

Hunter and Bushnell: Science, 1916, N. S., vol. 43, p. 318.

Hüppe: Mitth. a. d. Kaiserl. Gesundh. Amt., 1884, vol. 2, p. 309.

Jensen: Milchwirthsch. Zentr., 1915, vol. 44, p. 136. Centr. f. Bakt., Abt. 2, 1898 , vol. 4, p. 196.

Jungfleisch and Godchot: Compt. rend. de l'Acad. des Sci., 1906, vol. 142, p. 515 .

Kendall: Jour. Med. Res., 1910, vol. 22, p. 153.

Koestler: Inaugural Dissertation, Zürich, 1907.

Kozai: Zeitschr. f. Hygiene, 1899, vol. 31, p. 337.

Kruse: Cent. f. Bakt., Abt. 1, 1903, vol. 34, p. 737.

Kuntze: Cent. f. Bakt., Abt. 2, 1908, vol. 21, p. 737.

Lawrence and Ford: Jour. of Bacteriology, 1916, vol. 1, p. 273.

Leichmann: Cent. f. Bakt., 1894, vol. 16, p. 122. Cent. f. Bakt., 1896, vol. 2, p. 777.

Lister: Quarterly Jour. of Micros. Sci., 1878, vol. 18, p. 177.

Löhnis: Handbuch der Landwirthschaftlichen Bakteriologie.

Lürssen and Kuhn: Cent. f. Bakt., Abt. 2, 1907, vol. 20, p. 234.

MacKenzie: Jour. of the Chem. Soc., 1905, vols. 87 and 88, p. 373.

Marshall: Mich. State Agri. Coll. Exper. Sta., Spec. Bull. 33, June, 1905. Ibid., Spec. Bull. 42, March, 1908. Mich. State Agri. Coll., Exper. Sta., Bull. 140, 1896.

Mereschewsky: Cent. f. Bakt., Abt. 1, 1905, vol. 39, p. 380.

Moro: Wiener Klin. Wochenschr., 1900, vol. 13, p. 114.

Neff: Ann. d. Chem., 1904, vol. 335, pp. 243 and 290.

Olsen: Univ. of Wis. Agri. Exp. Sta., Bull. 162, p. 7.

Pasteur: Ann. de Chim. et Phys., Serie 3, 1858, vol. 52, p. 404. Compt. rend., 1859, vol. 48, p. 337. Ibid., 1864, vol. 58, p. 149.

Piorkowsky: Cent. f. Bakt., 1908, vol. 21, p. 95.

Pope: United States Dept. of Agri., Farmer's Bulletin 480, January, 1912.

Prescott: Science, 1902, N. S., vol. 15, p. 363 . Biological Studies of the Pupils of William Thompson Sedgwick, Boston, 1906.

Rahe: Jour. of Inf. Dis., 1914, vol. 15, p. 141. Jour. of Bact., 1918, vol. 3, p. 407.

Rahn: Mich. State Agri. Coll. Exper. Sta., Technical Bull. 10, June, 1911.

Rhist and Khouri: Ann. de l'Inst. Pasteur, 1902, vol. 16, p. 65.

Rodella: Cent. f. Bakt., Abt. 1, 1901, vol. 29, p. 717.

Rogers: Jour. of Bact., 1918, vol. 3, p. 313.

Rogers and Dahlburg: Jour. of Agri. Research, 1914, vol. 1, p. 491.

Rogers and Davis: United States Dept. of Agri., B. A. I., Bull. 154, September, 1912.

Schardinger: Monatschefte f. Chemie, 1890, vol. 11, p. 544. 
Schattenfroh: Arch. f. Hygiene, 1902, vol. 42, p. 251. Ibid., 1904, vol. 48, p. 77.

Schattenfroh and Grassberger: Cent. f. Bakt., 1899, vol. 5, p. 209. Arch. f. Hygiene, 1900, vol. 37, p. 54 .

Schierbeck: Arch. f. Hygiene, 1901, vol. 38, p. 294.

Schlesinger and Kauffmann: Wien. Klin. Rundschau, 1895, vol. 9, p. 225.

Sewerin: Cent. f. Bakt., Abt. 2, 1908, vol. 22, p. 3.

Smith, Theobald: Cent. f. Bakt., 1891, vol. 10, p. 180.

Strauss: Ztsehr. f. Klin. Med., 1895, vol. 28, p. 578.

Thiele: Zeitschr. f. Hygiene, 1904, vol. 46, p. 394.

Torrey and Rahe: Jour. Inf. Dis., 1915, vol. 17 , p. 437.

Utz: Cent. f. Bakt., Abt. 2, 1903-4, vol. 11, p. 600.

Van Slyke and Bosworth: Jour. Biol. Chem., 1916, vol. 24, p. 191.

Ward: Cornell Univ. Agri. Exper. Sta., Bull. 195, November, 1901.

Weigmann, Gruber, and Huss: Cent. f. Bakt., Abt. 2, 1907, vol. 19, p. 70. Mykologie der Milch, 1911.

White and Avery: Cent. f. Bakt., Abt. 2, 1910, vol. 25, p. 161.

Wolff: Milchwirthsch. Zent., 1913, vol, 42, p. 571. 


\section{FERMENTED MILKS}

IT has been shown in a previous chapter that under the influence of various fermentations, caused by groups of micro-organisms, the normal condition of milk undergoes substantial alteration. Fermented milks that have been used as food for ages are the result of microbial activity and, according to the predominating kinds of micro-organisms, the product varies in character. Fermented milks are used chiefly in Asia, the eastern parts of Europe and in Egypt, but in western Europe and among uncivilized tribes in Africa they are by no means unknown.

The use of fermented milks has received material impetus of late years through the publications of Metchnikoff, who asserted and attempted to prove that auto-intoxication and premature senility are due, in part at least, to poisonous substances produced by putrefactive bacteria in the colon. This condition, Metchnikoff thought, could be combated by habitual consumption of sour milk. the argument being that the acid produced by lactic acid bacteria would prevent growth of putrefactive bacteria by changing the chemical reaction of the digestive fluids in the alimentary canal from alkaline to acid. Metchnikoff recommended a fermented milk produced by a mixed culture, consisting of $\mathrm{Ba}-$ cillus bulgaricus and Streptococcus lacticus, or, as Metchnikoff calls this organism, the paralactic bacillus.

In his book, "The Prolongation of Life," Metchnikoff develops the theory that the cause of auto-intoxication and premature senility lies in the fact that food remnants accumulate in the large intestine and are there decomposed by putrefactive bacteria. The colon was evolved, so the author contends, to enable animals to control defecation, and that this faculty was especially useful when the animal was pursued by some enemy. This accumulated food is subject to bacterial activity, and the cleavage products of protein invade the system from the colon and cause autointoxication and premature senility. Metchnikoff illustrates his hypothesis by the statement that birds have no colon and no bladder, and are, therefore, compelled to defecate frequently. The ostrich is an exception to this rule. It lives on the ground and has more difficulty in escaping from an enemy than birds that are able to fly, and, therefore, has developed a colon. Birds are long lived, while terrestrial animals, as horses, cattle, sheep, etc., are relatively short lived, a circumstance ascribed by Metchnikoff to the fact that food remnants and waste products are held in the 
large intestine for a considerable length of time, sometimes for several days, and are then subject to putrefactive decomposition by bacteria. According to the author's theory, the protein cleavage products enter the circulation and tend to abbreviate the lives of these animals.

Herter also believes that premature senility is due, in part at least, to putrefactive products of anaërobes. Bacillus welchii is considered by this author as one of the chief offenders. He states further that the character of the food influences the intestinal flora both numerically and in kind. In the upper portion of the intestinal canal of infants fed on human milk the Bacillus bifidus of Tissier is prominent, and, as this organism which belongs to the group of lactobacilli produces a relatively large amount of acid, other bacteria are largely suppressed. The intestinal flora of infants fed on cow's milk is decisively different from that of those fed on human milk, as different types of bacteria, including some anaërobes, are present in considerable numbers.

In the stomachs of adults relatively few bacteria exist because of the germicidal effect of the hydrochloric acid in the gastric juice. But farther down in the digestive tract the number of bacteria increases, and in the colon they are present in enormous numbers, the number being so great that, according to some authors, 33 to 45 per cent. of the fecal discharges consist of living and dead bacteria.

The bacterial flora in the intestines of birds is considerably smaller than that of terrestrial animals, and it is to this condition that Metchnikoff ascribes the greater longevity of birds as compared with terrestrial animals. In other words, the bacterial flora in the intestines of terrestrial animals produces powerful decomposition products from the food remaining in the colon. Birds, having no colon, discharge waste products frequently, and consequently have a small bacterial flora. The formation of protein decomposition products in birds is also relatively small because of frequent defecation and consequent lack of food for the bacteria.

Conditions obtaining in the colon are eminently suitable for the growth of putrefactive bacteria, especially anaërobes. The oxygen which reaches the stomach with food is gradually absorbed not only by living organisms but also by food remnants, especially meat. Furthermore, the reaction of the contents of the lower intestine is alkaline and part of the food may not be properly digested, due, in a measure, to imperfect mastication. Therefore food, absence of oxygen, and suitable temperature combine to render the colon a favorable place for the growth of anaërobes.

Protein cleavage products, chiefly oxyacids, indol and phenol 
derivatives, which are of a more or less injurious influence if they penetrate to the circulation, may be formed in the colon by anaërobes and by bacteria of the Bacillus coli type. It is an open question, however, whether these injurious products are formed in sufficient quantity to induce auto-intoxication or other bodily ailments. Although exact scientific investigations in this field are still incomplete, it may be assumed that injurious results occur chiefly when the system has been rendered susceptible by disease or some other cause, so that small quantities of poisonous products have a deleterious effect.

The question naturally presents itself whether the bacterial flora of the intestinal tract can really be changed by sour milk food or by any other means, for that matter, and if so, is the change sufficiently permanent to be of lasting benefit? Work on this subject has been carried on chiefly with milk prepared with cultures of the Bulgarian bacillus. Some authors claim to have established this organism in the intestinal tube and to have shown the presence of these bacilli in the fecal discharges. However, others have determined that they are normally present in the whole digestive tube, and that the mere finding of lactobacilli in the feces does not prove that they have been introduced with the milk.

The sanguine statements of Metchnikoff and others that Bacillus bulgaricus can be implanted in the intestinal tract have not been generally confirmed. Lürssen and Kühn, Herter and Kendall, Rahe, and Hull and Rettger were unable to implant Bulgarian bacilli in the intestines, although Herter and Kendall believe that the bacterial flora can be influenced by a substantial change of food which is accompanied by a reduction of protein and an increase of carbohydrate. Oehler fed mice and monkeys with Bulgarian sour milk for eight days and found Bulgarian bacilli in the intestinal tract during the feeding period, but they disappeared in two or three days. Belonovsky, after feeding mice for one and one-half months with milk cultures of Bulgarian bacilli added to sterilized grain and water, was able to detect the bacilli for fifteen days after the last feeding.

Cohendy, after ingesting cultures of Bacillus bulgaricus, claimed to have observed a material reduction of intestinal putrefaction, and found the organism in the feces for several weeks after discontinuing ingestion. Herter experimented with dogs and was able to note increased putrefaction after feeding Bacillus coli and proteus, while feeding cultures of lactic acid bacteria seemed to reduce putrefaction. Tissier thought he had reduced putrefaction by the use of cultures of Kozai's Bacillus acidi paralactici. 
Herter and Kendall established an acid reaction throughout the intestinal tract of a monkey by feeding an exclusive diet of sour milk prepared with Bacillus bulgaricus, but failed to establish the organism in the ileocecal region, and even in the large intestine the bacilli were found only in small numbers. "Thus in the region characterized by the most active putrefaction the lactic acid bacilli failed to establish themselves in relatively large numbers." Even more conclusive are the experiments of Rahe, who failed utterly in acclimatizing Bulgarian bacilli in the lower human intestine.

Heinemann and Hefferan succeeded in isolating lactobacilli from human feces and in demonstrating their presence throughout the digestive tube, including the mouth, the stomach, and the intestines.

Wegele, after using Metchnikoff's sour milk, came to the conclusion that the production of lactic acid in statu nascendi in the digestive tube was of greater benefit than the ingestion of lactic acid in sour milk, and Wejnert thought he had markedly reduced the number of bacteria in feces by using lactobacilline milk, which contains Bacillus bulgaricus, Streptococcus lacticus, and a yeast.

The difficulty in securing reliable proof of such observations as have been mentioned leaves us in doubt as to the validity of the conclusions arrived at by investigators. It is hardly probable that the introduction of lactic acid bacteria, no matter in what form, in the digestive tube would be accompanied by the formation of a sufficient degree of acidity to really inhibit the growth of anaërobes. If, however, this should occur, there would be also a decided inhibition of digestion, since the digestive fluids of the intestinal tract are of an alkaline reaction and require an alkaline reaction for normal work. The reaction would be changed to an acid reaction by the acid produced by the bacteria.

Metchnikoff states in his very interesting book that during his travels in Bulgaria he found exceedingly large numbers of centenarians, and ascribes their long lives to the extensive use of sour milk. The fermented milk foods of the Bulgarians and neighboring peoples, however, differ somewhat from the milk recommended by Metchnikoff. While the fermented milks of the natives of southeastern Europe contain a small amount of alcohol due to the presence of yeasts, Metchnikoff condemns this method of producing fermented milks and claims superiority of milks prepared by the use of lactic acid bacteria without yeasts. Perhaps the habits of the Bulgarians have some effect on prolonging life, as they are a hardy race, habituated to a simple diet, and they spend much of their time in the open air.

It has been claimed that ingestion of lactic acid bacteria is 
followed by decidedly curative effects. Berthelot thought he had observed an antagonism between Bacillus bulgaricus and the meningococcus; Biernacki obtained good results in the treatment of enteritis, colitis, and constipation with Bulgarian bacilli; Horowitz found a reduction of glucose in the urine of diabetics and putrefaction was restrained.

Admitting the correctness of these observations, although the conclusions drawn are sometimes based on a small number of cases, it should be remembered that similar beneficial effects have resulted from a simple diet in which milk was prominent. Hull and Rettger have shown that a milk diet and even consumption of pure milk-sugar changed the intestinal flora in experimental animals so that lactobacilli became numerous.

Cultures of Bacillus bulgaricus have been used for the treatment of external conditions. Thus North studied 300 cases of pathologic conditions accompanied by pus formation, which were treated with such cultures with apparently beneficial results.

However, in the present state of our knowledge, it would be premature to draw sweeping conclusions for or against the therapeutic effect of Bulgarian bacilli or milk prepared with cultures of this organism. But the use of buttermilk or other fermented milk products should be encouraged, because fermented milks are more easily digested than sweet milk, and the fermentative process preserves the milk in a condition suitable for consumption.

The popular mind is easily attracted by anything that promises to prolong life. Manufacturers have taken advantage of this fact, and have placed on the market a number of preparations for making buttermilk at home. Buttermilk therapy has been widely advertised through these preparations, although the claims made frequently are exaggerated, and some of the preparations do not give the most desirable result. They are in tablet or capsule form; others are liquid or are milk cultures, the milk having coagulated under the influence of the acid produced. Very palatable sour milk beverages can be prepared from some of these products.

It is important to use active cultures in order to obtain a good product. Liquid cultures when fresh are preferable to tablets or capsules, because they can be evenly distributed in the milk, but the viability of bacteria in liquid cultures decreases rapidly, more so than in tablets or capsules. Milk cultures are the most successful, since lactic acid bacteria, especially the group of lactobacilli, grow better and produce more acid in milk than in any other medium.

Although the claims made in favor of the therapeutic value of fermented milks is exaggerated, there are some benefits that can 
be expected to accrue from their consumption. The food value of fermented milks is nearly the same as that of sweet milk. The difference between the food value of sweet milk and fermented milk is a small reduction of lactose which is used by micro-organisms in the formation of acids and gases, and as some fermented milks are made of partially or wholly skimmed milk, the amount of fat is diminished. Fermented milks have some advantages over sweet milk, except that in some cases the acid is irritating to the mucous membranes. One advantage is common to all fermented milks, namely, the condition of the casein which is precipitated and, therefore, partially digested. Furthermore, the presence of carbon dioxid gas in some fermented milks is stimulating and favors digestion. The use of fermented milk as food is, therefore, indicated in many cases of weak digestion. Metchnikoff advises a reduction of protein in the diet when fermented milks are used, and it cannot be denied that the addition of an easily digested food, such as fermented milk, to the diet may be of considerable advantage if the amount of other food is reduced proportionately. But beneficial effects can hardly be expected when the milk is added to the usual diet without modification.

Buttermilk has also been used for infant feeding, and there is ground for the belief that it agrees in some cases when sweet milk cannot be tolerated. The presumption that the acidity in buttermilk is the cause of its digestibility has not been proved, however, but the reduced amount of fat alone would render it beneficial in some cases, and possibly skimmed milk would be as readily digested as buttermilk. Furthermore, as stated before, the casein is in more digestible form in buttermilk than in sweet milk, and this may be an explanation of the success that has sometimes followed the substitution of buttermilk for sweet milk in infant feeding.

There are two classes of fermented milks, namely, those that have undergone acid fermentation only, and those that have been subjected to acid and alcoholic fermentations. In both classes there are other properties that lend a peculiar character to the fermented milk. These differences depend upon the kinds of micro-organisms that are active. Aroma is produced by yeasts; in some fermented milks the protein is partly digested by microbial activity; some fermented milks are viscous; and the amount of alcohol and carbon dioxid developed varies in different milks according to the kinds of yeasts present and the method of preparing the product. 


\section{BUtTERMilK}

Buttermilk is the chief representative of the first class of fermented milks. Originally buttermilk means the sour skimmed milk left in the churn after butter has been removed. Usually cream is allowed to sour and is churned when the acidity has reached about 0.6 per cent. The buttermilk contains a higher percentage of acid than the cream from which it is made, since its volume is reduced by the removal of the fat, while the actual amount of acid remains practically the same and is present, therefore, in greater concentration in the buttermilk than in the sour cream. It is not uncommon to dilute the sour cream before churning, as this facilitates the separation of fat.. The buttermilk, therefore, does not contain the same percentage of plasma solids as the cream. The amount of fat in buttermilk from the churn is about 1 per cent.

Commercial buttermilk is now largely made from skimmed milk after inoculation with a starter, and is sometimes called "ripened milk." Since the introduction of the cream separator a highly concentrated cream can be obtained and the quantity of buttermilk is relatively small. The skimmed milk as it leaves the separator contains about 0.1 per cent. fat or less, and is inoculated with a starter consisting of a culture of Streptococcus lacticus. After loppering, the milk is churned and sold as buttermilk.

Buttermilk is churned sour milk from which the greater part of the fat has been removed. The churn buttermilk is richer in fat than the artificial product, but the latter contains the full amount of protein, milk-sugar, and mineral matter because undiluted, and is, therefore, a more nutritious product than buttermilk made from diluted cream. The amount of acid in commercial buttermilk is from 0.7 to 0.9 per cent. In freshly churned buttermilk the casein is evenly suspended, but as it stands the coagulated flakes gradually settle and the palatability of the buttermilk suffers.

The composition of buttermilk made from sour cream, sweet cream, milk, and separated milk is given on page 74 .

A good substitute for commercial buttermilk can be made by allowing sweet milk to lopper and then beating it until smooth. If whole milk is used the aroma of the product is superior to that of commercial buttermilk because the fat is not removed. After pasteurization milk does not sour as readily as raw milk, and for making buttermilk pasteurized milk should be inoculated with a commercial starter or with a small amount of a previous lot. It is always advisable to use pasteurized milk for preparing butter- 
milk to avoid possible infection, although the high acidity has a pronounced germicidal effect and is, therefore, destructive to pathogenic bacteria.

Sour milk starters can easily be preserved, as shown by the writer, by desiccating a small amount of coagulated milk and preserving this in the dry state. This dry loppered milk keeps its efficiency for several weeks, and as it contains large numbers of Streptococcus lacticus will quickly start an acid fermentation when inoculated into sweet milk. By pasteurization of sweet milk before inoculation with a starter the majority of undesirable bacteria is destroyed, and those that remain are readily overgrown by Streptococcus lacticus. Pasteurization, therefore, serves two purposes: it insures a good aroma of the product and renders it safe from pathogenic bacteria.

Lactic acid, like many other acids, has considerable germicidal power when in sufficient concentration. Statements appear in the literature that lactic acid bacteria destroy pathogenic bacteria in milk, but this undoubtedly refers to the germicidal effect of the acids produced by the lactic acid bacteria. Work published by Barthel, Bassenge, and Behla in regard to the germicidal effect of acid in buttermilk has led to contradictory results, while the work of Northrup has shown definitely that typhoid bacilli are destroyed by 0.33 per cent. lactic acid when this acid is produced by Streptococcus lacticus (Bacterium lactis acidi). When, however, according to this author, the acid is produced by Bacillus bulgaricus the surprising observation was made that it required nearly twice as much acid for the same destructive effect upon typhoid bacilli. Krumwiede and Noble, studying the longevity of typhoid bacilli in sour cream, have reached the conclusion that the bacilli are gradually destroyed in sour cream by the acids produced, and that the rate of destruction is proportionate to the degree of acidity and the number of bacilli present. These authors have stated further that with a moderate contamination the typhoid bacilli are killed in about four days; with heavy contamination or when initial multiplication took place a longer time is required. Attention is also called to the difficulty of determining by present bacteriologic methods whether all typhoid bacilli really are destroyed, because other bacteria grow rapidly in milk and are liable to obscure the presence of typhoid bacilli. From this work it would appear that a cream produced under sanitary conditions and which sours slowly would be more dangerous, if infected with typhoid bacilli, than an ordinary cream which sours rapidly.

In an extensive study of the germicidal action of lactic acid in milk the writer tested its effect by adding definite quantities 
of lactic acid to sterilized milk and then inoculating this milk with pure cultures of various types of bacteria. It was shown that some acid-tolerant cells of Bacillus coli could survive 0.6 per cent. lactic acid, although the great majority of cells were destroyed. Bacillus dysenteriæ, B. typhosus, B. diphtheriæ, B. paratyphosus $\mathrm{B}$, and Spirillum choleræ were destroyed by the presence of 0.45 per cent. lactic acid. However, there may be rare strains of these bacteria that might survive this amount of acid. Since buttermilk contains 0.7 to 0.9 per cent. acid, it is probable that pathogenic bacteria are destroyed, and it may be assumed that buttermilk is usually free from infection, even when prepared from infected sweet milk. Similar results were obtained by Penelope Marsh in 1918.

\section{Tätté MelK, TÄtTemjöLK, OR KJernemelK}

Tätté melk, tättemjölk, or kjernemelk is a milk food prepared in Norway and Sweden. It is a thick, viscous milk of slightly cheesy taste and odor, and is eaten with a spoon. The fermentation is started by adding to milk leaves of Pinguicula vulgaris or a variety of Drosera, plants that grow abundantly in these countries. A small amount of a previously finished product is also used as starter, and sometimes pieces of linen are dipped into the fermented milk which, after drying, will keep their fermentative property for a long time and which are used if the starter is sent by mail. The temperature most suitable for the fermentation is body temperature.

Troili-Peterson described but one organism as the active agent in tättemiölk. This organism is a streptococcus and is named by the authoress Bacterium lactis longi (the bacterium of "long" milk). It resembles Bact. lactis acidi (Streptococcus lacticus), but forms less acid and produces a slimy consistency in milk. Troili-Peterson states that she was unable to produce normal tättemjölk in all trials with leaves from the plants mentioned. Alcoholic fermentation is insignificant because the temperature of ripening is too high.

There are three organisms in this milk that are responsible for the fermentation, according to an investigation made by the writer. A lactic streptococcus that differs from Streptococcus lacticus by coagulating milk slowly and producing a stringy substance is probably the most important organism, and no doubt the same one that Troili-Peterson has described. A yeast of the morphology of Saccharomyces cerevisiæ is present and produces the aroma. In pure culture the yeast ferments lactose and saccharose with violent gas formation, while from levulose gas is 
formed slowly, and from maltose not at all. In beerwort the yeast produced a somewhat slimy consistency. Owing to the high temperature of fermentation the yeast probably grows reluctantly in tätté melk, so that its products are present only in small quantity. Oidium lactis is also found in this fermented milk and probably causes the cheesy taste and odor.

Different types of other micro-organisms are usually found in tätté melk, but these have no bearing on the normal fermentation and are of the kind usually found in milk. A lactobacillus can also be found, but in relatively small numbers. The acidity of the finished product is mild, and this fact shows that lactobacilli grow but slowly, if at all. It is, however, not surprising to find a member of the group of lactobacilli in tätté melk, since they are universally present in cow's milk.

A fermented milk of similar properties is prepared in the Bretagne and is known as "Gros Lait."

\section{Fermented Milks of Pre-eminently Acid Fermentation}

The people inhabiting the Caucasus Mountains, Bulgaria, Turkey, Egypt, Sardinia, Sicily, Armenia, Serbia, and Montenegro consider fermented milk a very important part of the daily diet. Visitors are served with these milks, and some of the inhabitants regard them with the reverence due divine gifts. The milks of different tribes vary somewhat, but have much in common. The fresh milk is boiled usually over a slow fire, sometimes for a short time, sometimes long enough to reduce its volume materially. With the reduction of volume the percentage of solids is proportionately increased, and the taste, therefore, differs materially from that of other fermented milks. After boiling the milk is cooled to $45^{\circ}$ to $50^{\circ} \mathrm{C}$., the temperature being judged by dipping the fingers into the milk. A small amount of a previously prepared milk is added as a starter and the mixture then incubated for several hours. The temperature is maintained by wrapping and covering the vessels with woolen cloths.

Considerable work by eminent investigators has been carried on to determine the active agents in these milks. The results of this work show that there are always three types of organisms present, and these are required to produce the normal product.

The most important organism is a lactobacillus, variously called Bacillus bulgaricus, Streptobacillus lebenis, Bacterium caucasicum, etc. The relatively high temperature of incubation favors the growth of this organism, and the final product has in large measure the appearance, taste, and texture which is characteristic of its activity in milk. All these fermented milks, when ripe, 
are either thickly fluid or of jelly-like consistency, the firmness of which varies with the customs of the different peoples in treating the milk. The acidity is relatively high.

The second organism is Streptococcus lacticus, whose function is the initiating of the souring process. The third organism is a saccharomyces, which produces aroma and a very slight, almost negligible alcoholic fermentation, the high temperature of incubation restraining the growth of yeasts. By inoculating sweet boiled milk with pure cultures of these three micro-organisms the proper fermentation takes place and the product is normal.

In addition, however, other micro-organisms are invariably found in these fermented milks, and their presence has been the cause of some confusion in scientific investigations inasmuch as their functions have been sometimes misunderstood. As a matter of fact, these organisms are contaminations and sometimes perhaps spore-forming bacteria that survive the boiling process. Owing to Metchnikoff's propaganda, yoghurt, the fermented milk of the Bulgarians, has been made very prominent. It does not, however, differ materially from milk foods used by other nations, except in the fact that it is made from milk evaporated to onehalf or one-third the original volume. The universal occurrence of lactobacilli, streptococci, and yeasts in milk has made it possible for different peoples to evolve fermented milks independently, with the result that the products resemble each other in large measure.

The quality of the milk used for preparing fermented beverages and foods of superior quality is considered of great importance by the natives, but it is not likely that the milk is responsible for failures as much as bacterial contamination.

Yoghurt, joghurt, yaoert, yahourt, jaurt, jugurt, and kissélo mélko are names for the fermented milks of the Bulgarians, Greeks, Turks, and inhabitants of the Balkan Mountains. Yoghurt is prepared from buffalo's, goat's, or cow's milk in the following manner: Milk is boiled in clean earthenware vessels over a slow fire until the volume is reduced by one-quarter, one-half, or even more. It is then cooled to between $45^{\circ}$ to $50^{\circ} \mathrm{C}$. and a small amount of a previous lot added. This ferment is called "maya," "podkwassa," or "zakvaska." The ferment is mixed with the milk and the vessel containing the mixture wrapped in skins and cloths to maintain a uniform temperature. After ten to twelve hours. the milk is ready for consumption.

If the fermentation is not disturbed the product is of jelly-like. consistency, has a sweet taste and agreeable odor. The sweetness is intense in proportion to the degree of inspissation, and acidity is about 0.8 to 0.9 per cent. The cooked taste which is 
prominent in boiled milk is barely noticeable, being covered up by the acid.

If the milk is frequently shaken during the ripening period it remains thickly fluid and is used as a beverage.

The Bulgarian milk prepared and sold in this country is somewhat different from the original. The milk is not evaporated, but inoculated, after boiling and cooling to $105^{\circ}$ to $110^{\circ} \mathrm{F}$., with a commercial ferment, of which several are purchasable. The peculiar aroma produced by the Bulgarian bacillus and the smooth consistency of this milk render it particularly palatable.

Yoghurt may contain a small amount of alcohol, and the casein is slightly digested after the yoghurt has been kept for some time. It is customary to keep the ripened product in a cool place if it is not intended for immediate consumption, as low temperature prevents further fermentation.

Similar to yoghurt is the fermented milk leben, leben raïb, or laban of the Egyptians. It is prepared from buffalo's, goat's, or cow's milk. A small amount of the ripe product, "roba," is mixed with boiled milk, and the mixture incubated for six hours at $45^{\circ}$ to $50^{\circ} \mathrm{C}$.

The finished product resembles yoghurt, but is of somewhat coarser texture. There is likewise a weak alcoholic fermentation which is held in check by the high temperature of incubation.

Gorini gives an account of a fermented milk, "skorup," used in Serbia and Montenegro, which is similar to yoghurt and leben, but, instead of whole milk, cream or boiled milk is used. Ripe skorup is of creamy consistency, has an agreeable sour taste and odor, and is frequently eaten after addition of potato or some other food. A small amount of salt is usually added. The author isolated a lactobacillus, Streptococcus lacticus, and a yeast from skorup, and found that the acidity varies from 1.9 to 2.23 per cent.

Very similar in consistency, taste, and method of preparation is "gioddu" or "cieddu," a fermented milk used in Sardinia, and "mazzoradu," used in Sicily. In India "dadhi" is prepared, which also belongs to this class of fermented milks. In the Balkan Mountains a similar milk, "urgoutnik," is prepared from sheep's milk.

In Armenia a milk beverage is prepared that, according to some authors, occupies a place between yoghurt and the fermented milks, in which alcoholic fermentation is more important than acid fermentation. It is prepared from buffalo's, sheep's, goat's, or cow's milk, and is known as "mazun" or "matzoon." Milk is boiled and cooled to body temperature. Some old mazun is mixed with milk or water and added to the boiled milk. The 
vessel containing the mixture is wrapped in cloth to maintain the proper temperature and kept in this condition for twelve to eighteen hours, when the product is ready for use.

Mazun is a solid coagulum of characteristic taste and odor. It is eaten or diluted with water for a beverage. The coagulum may be pressed, and then is known as "tan" or "than"; or it is mixed with flour and dried in the air. The product is "tschoratan," which is prepared for consumption with spinach and rice and flavored with peppermint. A favorite solid food is thus furnished.

Mazun is rich in lactobacilli which were isolated by Düggeli and by Weigmann, Grüber, and Huss. These authors named the lactobacillus Bacterium mazun. A yeast, streptococcus, and oildium were isolated by the last-named authors from mazun. Also a spore-bearing bacillus was present which digests casein, with the production of a cheesy odor.

\section{Fermented Milks with Pre-eminently Alcoholic FERMENTATION}

Distinctly different from the fermented milks described above are "kefir" and "kumiss." Both are the result of a pronounced alcoholic fermentation which is favored by a relatively low temperature of incubation, so that the acid fermentation proceeds but slowly. The organisms necessary for the production of these two beverages are not fully determined, but there is probably a streptococcus active in producing acid and a yeast which is capable of fermenting milk-sugar with alcohol and gas formation.

Rogers suggests that similar beverages can be prepared by inoculating ordinary buttermilk with an alcohol and carbon dioxid, producing yeast, and adding cane-sugar to buttermilk, since lactose-fermenting yeasts are relatively uncommon.

Kefir, keffir, kephir, kifyr, kiafyr, kephor, or kyppe, meaning "best beverage," is a fermented milk prepared by the inhabitants of the Caucasus Mountains from sheep's, goat's, or cow's milk. It contains alcohol, carbon dioxid, and lactic acid as products of decomposition of the milk-sugar, and also small quantities of glycerin and succinic, acetic, and butyric acids. The casein and albumin are slightly peptonized. The fermentation is started by kefir grains which, according to some legends, were gifts of the gods, or, according to others, grew on bushes. These grains form masses of various size, and each mass is composed of grains which vary from the size of a millet seed to that of a hazelnut. The color of the grains is golden to dark yellow. When dry they can be preserved for a long time without losing viability (Fig. 182). 
For the preparation of kefir the grains are soaked in lukewarm milk for two to three hours. The milk is then poured off and the grains covered again with fresh milk, which process is repeated four to five times. When the grains have swollen, sometimes to 100 times the original size, they rise to the surface, are skimmed off, and added to freshly boiled milk. The milk is ripened at a temperature of $14^{\circ}$ to $18^{\circ} \mathrm{C}$. for eight to twelve hours. The product of this fermentation, "sakwaska," is passed through a sieve or cloth, the grains are recovered, dried in the air, and preserved for future use. The milk is placed in bottles for a secondary fermentation at $12^{\circ}$ to $15^{\circ} \mathrm{C}$, and as this second fermentation proceeds the milk becomes rich in alcohol and carbon dioxid, and is usually consumed within three days.

The fermentation is sometimes carried on in large containers made of skin, and these are hung near a door so that passers-by

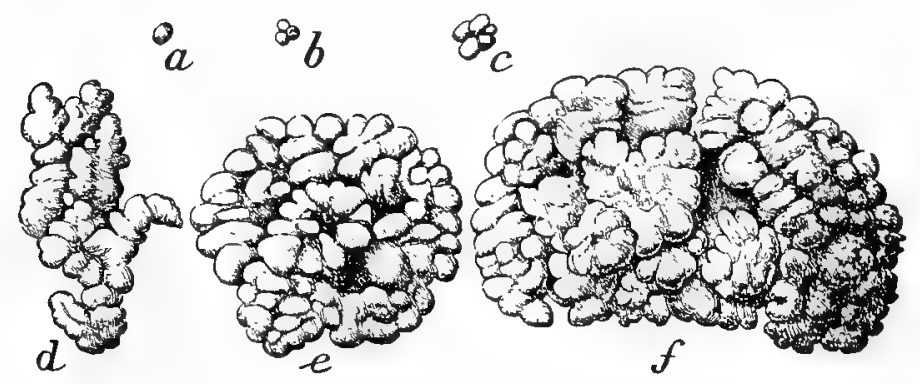

Fig. 182.-Masses of kefir grains: $a, b, c$, Dry grains; $d, e, f$, swollen grains. (Weigmann.)

can agitate them by kicking, or children, by playing with them. At the end of the ripening period a small portion of the skin bottle is tied off with a cord and the bulk emptied out for use. The large part of the bottle is filled again with freshly boiled milk, the portion that was tied off released, and thus the fermentation renewed.

Kefir is also made by adding 1 part of ripe kefir to 3 to 4 parts of milk and allowing the mixture to ferment for forty-eight hours, with occasional shaking.

Kefir is a thickly fluid, creamy, effervescent, alcoholic beverage. On standing, the casein settles, but shaking renders the fluid homogeneous. There is little or no digestion of the casein in fresh kefir, but in old kefir the casein may be partly dissolved.

It is customary to use milk that is not very rich in fat for making kefir, otherwise a rancid taste is liable to develop.

The following analyses of kefir are given in Richmond's Dairy Chemistry: 


\begin{tabular}{|c|c|c|c|}
\hline \multicolumn{4}{|c|}{ COMPOSITION OF KEFIR } \\
\hline & $\begin{array}{l}\text { Konig. } \\
\text { Per cent. }\end{array}$ & $\begin{array}{l}\text { Hammarsten. } \\
\text { Per cent. }\end{array}$ & $\begin{array}{l}\text { Vieth (Old Sample). } \\
\text { Per cent. }\end{array}$ \\
\hline 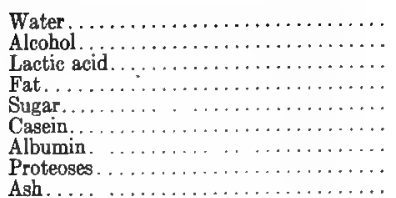 & $\begin{array}{r}91.21 \\
0.75 \\
1.02 \\
1.44 \\
2.41 \\
2.83 \\
0.36 \\
0.30 \\
0.68\end{array}$ & $\begin{array}{r}88.915 \\
0.720 \\
0.727 \\
3.088 \\
2.685 \\
2.904 \\
0.186 \\
0.067 \\
0.708\end{array}$ & $\begin{array}{r}90.09 \\
0.64 \\
0.44 \\
1.82 \\
1.87 \\
2.90 \\
0.07 \\
0.45 \\
\cdots\end{array}$ \\
\hline
\end{tabular}

Rogers gives a method for preparing kefir without kefir grains, as they are difficult to obtain in this country. Buttermilk is prepared in such a manner as to have the curd thoroughly broken up in order to obtain a smooth product. Cane-sugar is dissolved in the buttermilk, the quantity to be used being governed by the extent of the alcoholic fermentation desired. Ordinarily 1 to $1 \frac{1}{2}$ teaspoonfuls to 1 pint of buttermilk are sufficient. The yeast is prepared by adding $\frac{1}{2}$ teaspoonful of sugar to 6 to 8 ounces of boiled and cooled water, and to this solution one yeast cake is added. This yeast culture is allowed to stand over night before using.

One teaspoonful of the yeast culture is added to a quart of buttermilk and the mixture placed in strong bottles such as are used for carbonated beverages, as ginger ale bottles, for example. These bottles are kept at a temperature of $18^{\circ}$ to $21^{\circ} \mathrm{C}$. and are shaken frequently while the fermentation is proceeding. The kefir can be used on the third or fourth day. The finished product should be smooth and creamy, effervesce rapidly when poured from the bottle, and taste of buttermilk with addition of carbon dioxid gas and a small amount of alcohol. This artificial kefir will keep a week or longer if placed on ice.

Kefir contains lactobacilli, streptococci, yeasts, oïdium, and other micro-organisms which have no significance. The lactobacilli are not of importance, since they multiply slowly at the temperature required for alcoholic fermentation. Kefir, therefore, has a relatively low acidity.

Kumiss, koumiss, chumis, chemius, kumys, khoumese, also called "milkwine," originated in the steppes or treeless plains of south Russia and Asia, particularly in Siberia. The nomadic tribes of Kirgiz, the Kalmucks, Tartars, and Scythians consider mare's milk the only suitable kind of milk for making kumiss. They obtain the milk from a hardy race of mares which furnish a large amount of it, but sometimes it is made from the milk of camels or jennets. Kumiss is prepared by adding old kumiss to boiled mare's milk in the proportion of 1 to 10 and then keeping the mixture at a temperature of $20^{\circ}$ to $23^{\circ} \mathrm{C}$. for sixteen to twenty hours. The dry sediment of kumiss or sour milk may also be used 
as starter. The normal product is obtained after several lots have been fermented from the same starter.

If the starter is lost, kumiss can be made in this manner: Beer yeast, wheat flour, honey, and milk are mixed, and this mixture allowed to ferment. The fermenting mass is placed in a bag and this is hung in boiled milk, which is then stirred frequently during the fermentation period.

The natives are said to be able to start kumiss with fermenting or decaying matter, decomposed eggs, a piece of meat or tendon, blood, glue, and similar material. Even old copper covered with verdigris is said to be used for a starter.

From kumiss the Kalmucks distil a brandy-like alcoholic beverage known as "araka," "rack," "racky," or "ojran," which contains 7 to 8 per cent. of alcohol.

Mare's milk is particularly suitable for making kumiss because it has a low protein and high sugar content, and alcoholic fermentation is thereby favored. Richmond in his Dairy Chemistry gives the following analysis of mare's milk:

\begin{tabular}{cccccc}
\multicolumn{7}{c}{ COMPOSITION } & OF MARE'S MILK \\
& Water. & Fat. & Sugar. & Protein. & Ash. \\
Per cent.................. & 90.06 & 1.09 & 6.65 & 1.89 & 0.31
\end{tabular}

Yeasts and streptococci are the chief agents, the former to carry on the alcoholic fermentation, and the latter to form a mild acidity. A beverage similar to kumiss is made in Switzerland from skimmed milk by addition of yeast and cane-sugar.

Kumiss has the highest alcohol content of the known kinds of fermented milks. The following analyses are given in Richmond's Dairy Chemistry:

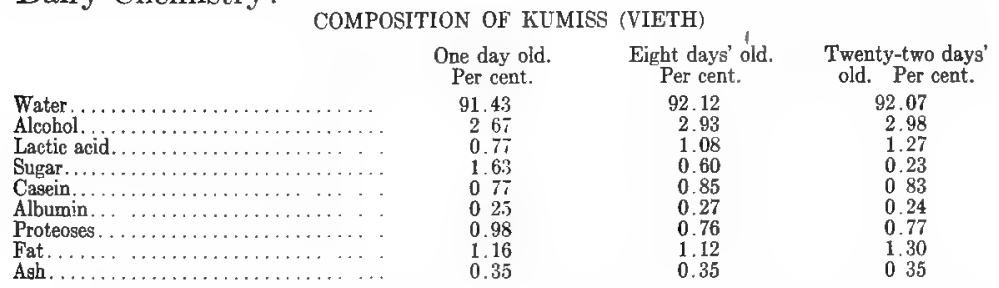

The analyses show that the milk-sugar is largely broken down into alcohol and lactic acid, while carbon dioxid and probably some other by-products are also present. In addition to casein and albumin some proteoses appear, indicating a slight proteolysis.

In this country under the name of kumiss or milk champagne a beverage is offered for sale which is made from cow's milk, is highly effervescent, and has a considerable alcohol content. 
Grotenfelt mentions "omeira," a fermented milk of the Nama Hottentots in South Africa, and "taryk," a milk prepared by shepherds in Tibet, by adding sour milk to boiled milk. Studies of these milks are not available.

While the fermented milks described have been studied and are the best known, there is no question but that many other kinds exist. It is well known that savage tribes consume fermented milks and also use it for preserving meats, since the acid content prevents decomposition. Fermented milk is merely preserved milk, or, in other words, a perishable food converted by the action of micro-organisms into a more stable product which contains practically the same food value as the original sweet milk.

\section{BIBLIOGRAPHY}

Barthel: Die Bakteriologie des Meiereiwesens, Leipzig, 1901.

Bassenge: Deutsch. Med. Wchnschr., 1903, vol. 29, p. 675.

Behle: Lafar Handbuch d. Tech. Mykologie.

Belonovsky: Cent. f. Bakt., Abt. 2, 1908, vol. 21, p. 431.

Berthelot: C. R. Soc. de Biol., 1910, vol. 68, p. 529.

Biernacki: Wien. Klin. Wchnschr., 1908, vol. 21, p. 613.

Cohendy: Compt. Rend. de la Soc. Biol., 1906, vol. 60, p. 364.

Douglas: The Bacillus of Long Life, G. P. Putnam's Sons, New York and London, 1911.

Düggeli: Cent. f. Bakt., Abt. 2, 1905-6, vol. 15, p. 577.

Gorini: Milchwrtsch. Zent., 1913, vol. 42, p. 369.

Grigoroff: Rev, Med. de la Suisse Rom., Genève, 1905, vol. 25, p. 714.

Grixoni: Cent. f. Bakt., Abt. 2, 1905-6, vol. 15, p. 750.

Grotenfelt: Fortschr. d. Med., 1889, vol. 7, p. 121.

Heinemann: Jour. Amer. Med. Assoc., 1909, vol. 52, p. 372. Ibid., 1912, vol. 58, p. 1252 . Jour. Inf. Dis., 1915, vol. 16, p. 479: Science, N. S., 1911, vol. 33 , p. 630 .

Heinemann and Hefferan: Jour. Inf. Dis., 1909, vol. 7, p. 304.

Herter and Kendall: Jour. Biol. Chem., 1908, vol. 5, p. 293.

Horowitz: Medical Record, 1912, vol. 81, p. 468.

Hull and Rettger: Jour. Bacteriology, 1917, vol. 2, p. 47.

Krumwiede and Noble: Am. Jour. Pub. Health, 1914, rol. 4, p. 1006.

Lürssen and Kühn: Cent. f. Bakt., Abt. 2, 1908, vol. 20, p. 234.

Marsh: Amer. Jour. of Public Health, 1918, vol. 8, p. 590.

Metchnikoff: The Prolongation of Life, Optimistic Studies. Translated by P. C. Mitchell, New York, 1908.

North: Medical Record, 1909, vol. 75, p. 505.

Northrup: Mich. Agri. Exper. Sta., Tech. Bull., No. 9, 1911.

Oehler: Cent. f. Bakt., Abt. 2, 1911, vol. 30, p. 149.

Rahe: Jour. Inf. Dis., 1915, vol. 16, p. 210.

Richmond: Dairy Chemistry.

Rist and Khouri: Ann. de l'Inst. Pasteur, 1902, vol. 16, p. 65.

Rogers: United States Dept. of Agri., B. A. I., Circular 171, 1911. United States Dept. of Agri., B. A. I., Bull. 319, 1916.

Tissier: Ann. de l'Inst. Pasteur, 1905, vol. 19, p. 273.

Troili-Peterson: Ztschr. f. Hygiene, 1899, vol. 32, p. 366

Wegele: Deut. Med. Wchnschr., 1908, No. 1.

Weigmann, Grüber, and Huss: Cent, f. Bakt., Abt. 2, 1907, vol. 19, p. 70.

Wejnert: Wien. Med. Wchnschr., 1908, No. 14. 


\section{THE BACTERIOLOGIC EXAMINATION OF MILK}

Physical and chemical examinations of milk give information about its richness and food value and the presence of preservatives or adulterations. The commonest adulterant-water-may leave the milk as wholesome as the natural product unless the water is contaminated with disease germs, but the consumer is paying for more than he is receiving. Chemical and physical tests, therefore, are commercially necessary to protect the consumer, but give no insight into the sanitary condition of the milk. Bacteriologic examination is designed to determine the quality of milk in relation to health.

Bacterial examination is made for two purposes, namely, to estimate the degree of cleanliness surrounding the production and handling of the milk, and to detect the presence of infectious micro-organisms. The degree of cleanliness can be determined within limits by simple enumeration of bacteria. The total count gives valuable information about the conditions at the dairy, the care practised, during milking operations, and the temperature maintained during transportation. The count of bacteria, therefore, is of immense value to the health officer.

The interpretation of bacterial numbers in milk is not as simple a matter as might appear at first glance. The bacteria count should be considered one of several tests, the results of which give information as to the quality of the milk. Knowledge of conditions surrounding the journey of milk from producer to consumer should accompany and influence the final judgment. Milk may have been produced with much care and the initial number of bacteria may be small. But, if the milk is not promptly cooled and kept cool up to the time of delivery to the consumer, bacteria will multiply and the final product will give high counts. Furthermore, the sources of bacterial pollution are numerous, and mere counts give only a limited insight into the exact source of contamination. If large numbers of bacteria enter the milk at the point of production, lack of care or cleanliness at one or several points is indicated. The cows may be dirty; the stable air may be rich in dust; the pails, cans, and other utensils may not have been properly washed and steamed. It is not possible to determine, by merely enumerating bacteria, which part of the production or handling is at fault. The producer may do everything to the best of his knowledge. The only way to find the exact 
cause of trouble is to test the milk at all stages of handling, a timeconsuming and expensive process. It follows that any single test is inadequate to afford proper control of milk-supplies. High numbers of bacteria indicate that something is not as it ought to be, and it is then the duty of the dairy inspector to follow the trail and find the true cause of pollution. After locating the source of the trouble the inspector should inform the producer or dealer and suggest means for improvement. Repeated bacterial tests will then show whether the trouble has been successfully dealt with. Large initial numbers mean that through carelessness or ignorance dirt-chiefly cow manure-has entered the milk, a matter which is not a pleasant consideration, to say the least. If, however, large numbers of bacteria are due to multiplication during transportation the matter stands out in a different light. It is known that lactic acid bacteria, as a rule, multiply in milk with greater rapidity than other bacteria. Consequently, large numbers due to faulty temperature conditions during transportation mean that the milk contains large numbers of harmless lactic acid bacteria and not necessarily dirt. If multiplication of lactic acid bacteria is permitted to continue until several hundred million are present, a product is formed which is distinguished from buttermilk only by the larger amount of fat present. And buttermilk, in spite of many millions of bacteria, is not considered either dirty or harmful. In this case, however, the great majority of bacteria is of a known type, known to be harmless, and not a mixture of many types among which there might be pathogenic bacteria. Therefore a separate enumeration of lactic acid bacteria is of distinct value. However, it should be remembered in this connection that if the temperature during transportation is high pathogenic bacteria may multiply to some extent along with lactic acid bacteria, and the danger is proportionately increased. Pathogenic bacteria are restrained or destroyed only when the acidity is so high that the milk has a decidedly sour taste, and in this condition milk is not marketable. The consumer wants and pays for sweet fresh milk, not for milk that is fermented and that may contain injurious micro-organisms.

More important for a sanitary survey of a milk-supply than cleanliness of the product is the possibility of its carrying infection. At the present stage of our knowledge it is a difficult task to isolate pathogenic bacteria from milk, because some do not multiply in milk, and if it is kept cold practically none do. However, they may remain alive long enough to possibly cause infection, while other bacteria actually multiply.

A further difficulty in finding infectiousness in milk is the fact 
that initial contamination with pathogenic bacteria is, as a rule, relatively small, so that, after the milk has been suitably diluted for making the bacteria count, pathogenic bacteria are so scarce that they are almost universally overlooked. For these reasons attempts to isolate disease germs from milk are rarely made by bacteriologists, although, if a rapid method of isolation were known, it would be of distinct value, as milk-borne epidemics could be more promptly terminated.

It is true that after an epidemic has broken out we have more rapid means than the determination of types of bacteria to find whether a milk-supply is guilty. The evidence obtainable by these means is usually very convincing, and the finding of a specific disease germ rarely adds materially to the evidence. Therefore, at the present state of bacteriologic technic evidence of the infectiousness of milk is circumstantial and depends upon the fact that the epidemic follows in the wake of a certain supply, and that when the incriminated supply is removed from the market the epidemic terminates.

When extraordinarily large numbers of bacteria are present in milk and a great variety represented, it is frequently argued that the same carelessness or ignorance which permits the admission of many micro-organisms may be the cause of the entrance of pathogenic varieties. This is the chief reason for the establishment of bacterial standards; but are standards really of as great value as some sanitarians have assumed? Jordan says, "The numbers of bacteria in milk have little meaning unless the sanitary history of the milk is known." In other words, the keynote of the production of sanitary milk is to be found in inspection of the health of the cows; the health of employees; the cleanliness in the care of the milk in all stages, and a suitable temperature during transportation. It is true that the inspector has no better guide for his work than the bacterial examination which should extend beyond market milk to the product in earlier stages. But it is obvious that milk with large numbers of harmless bacteria has little influence on health, while one with a small number of pathogenic germs is injurious.

However, if the producer is taught to furnish a milk with low bacterial content there is a distinct moral gain. The greater the care and intelligence exercised in milk production, the smaller, probably, are the chances of infectious material entering. This has been abundantly shown by the influence certified milk has exerted on milk production in general.

Some dealers have gained much credit in public opinion by advertising their milk as being of low bacterial content. From an esthetic viewpoint such milk is highly commendable and 
appeals to the consumer because the layman is still under the impression that disease follows the very presence of bacteria and, therefore, is frightened at the mention of large numbers. However, there is little evidence of the injuriousness of the bacteria and their products commonly occurring in milk. The grading of the New York City Board of Health, according to which Grade B milk may contain 1,500,000 bacteria before pasteurization, shows that reliance is placed on pasteurization as a destructive agent. It is also interesting that the belief in the responsibility of bacterial products for high infant mortality is losing ground.

A bacteriologic examination should not be compared with a chemical analysis. The latter is exact; the former not. Results of analyses of the same substance by different chemists are in close agreement, while those of bacterial examinations vary, sometimes within wide limits. It is possible, therefore, to draw more definite conclusions from chemical analysis than from bacterial examination. It is not usually difficult, for example, to detect some definite poison by chemical methods, but no bacteriologist would presume to state that a specific disease germ is absent from milk because he cannot find it.

A great deal has been said and written about the means of reducing the bacterial content of milk, but instructions of such nature have not infrequently been based on theory rather than knowledge. Reference has been made in a previous chapter to the research of Harding and his co-workers, who have shown that the stable air and barn conditions need be of little influence on the bacterial content of milk if due care is exercised in other directions. It seems that demands have been made on the dairyman which were not justified by scientific research and that, therefore, energy and money have sometimes been uselessly expended.

All foods should be sold and served under cleanly and decent conditions; more than that, the food itself should be as free as possible from filth or the results of filthy habits of those producing and handling it. High bacterial counts mean one or more of three things: 1, filthy production; 2 , high temperature during transportation, and 3, old milk. But milk with low bacteria content is not necessarily fresh, nor is milk with large numbers necessarily stale. Still such is the interpretation sometimes given according to established bacterial standards.

To sum up, bacterial examination is of immense importance as a guide to inspectors and as a control of supplies. But it does not justify the recommendation or condemnation of milk without the benefit of inspection. The bacterial count simply shows that 
there is some polluting tributary which can be eliminated by efficient inspection. If high numbers are the result of growth, be this in utensils, or bottles, or during transportation, the types of bacteria that are present are usually of harmless varieties. On the other hand, the presence of a germ carrier may render a milk of small bacterial content suspicious.

Examination of milk for bacteria leads to the discovery that one or more phases in the long journey of milk from producer to consumer is not receiving proper care, but does not locate the exact source of contamination and does not distinguish between harmless and injurious organisms. Furthermore, the results obtained by different workers and by different methods are far from uniform.

There are two methods of counting bacteria in milk, namely, by the colony count and the count by direct microscopic examination. These methods have both advantages and shortcomings. The enumeration of colonies is at present more commonly practised than the direct method of counting. Since it is important for the control of milk-supplies to obtain results in as short a time as possible, it is unfortunate that there is no possibility of obtaining results by the usual plate method before a definite period of incubation has elapsed. Consequently, the milk which is being examined is consumed by the time results are available. It follows that enumeration of bacteria by the plate method cannot serve the purpose of rating a single day's supply. The benefit derived is the control of regular supplies. By making several tests of a milk from a particular source the average quality and the conditions at the dairy can be judged, but it is not sufficient to make occasional tests. It happens not infrequently that a milk suddenly contains more than the usual number of bacteria. Exceptional conditions may be the cause, and it would not be fair to judge the regular supply by these conditions. Tests should be made at regular intervals and at all seasons. Bacterial examination is useful for detecting irregularities in the general supply, but its usefulness for the purpose of estimating the quality of a single bottle or can of milk is limited.

Laboratory methods of preparing plates for the bacterial enumeration in milk vary considerably, and it is largely due to this fact that results are so widely divergent. This divergence is sometimes so great that the same sample of milk would be classified under different grades. The shaking of the milk sample is the first step that may lead to different results. If milk is shaken violently the clumps of bacteria are broken up to a greater extent than if milk is poured from one vessel to another. On the other hand, violent shaking introduces the error of swelling the volume 
of the milk by the formation of air-bubbles which rise slowly

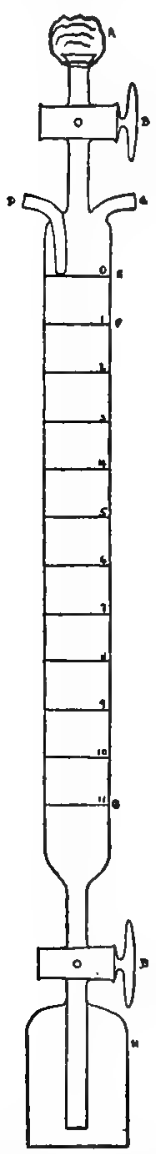

Fig. 183.-Freas' apparatus for accurately filling dilution blanks: $\AA$, Cotton filter; B, stop-cocks; $\mathrm{C}$, connection to suction pump; D, connection to sterile water reservior; $\mathrm{E}$, point of constant level; $\mathrm{F}$, first, 9 c.c. graduation; $\mathrm{G}$, eleventh, 9 c.c. graduation (0-11-99 c.c.); H, shield to prevent dust contamination. (American Journal of Public Health.) meat infusion with 1 per cent. agar and a reaction of 1.5 per cent. acid to phenolphthalein gives appreciably higher counts. dilution this objection, of course, does not hold.

A slight error is involved in the usual method of diluting, which consists of filling flasks or bottles with water and then sterilizing them. Some of the water evaporates during sterilization, and the quantity lost is variable according to the method of sterilization, the surface of the water in the flask, and the width of the mouth of the flask. This error can be avoided by sterilizing a quantity of water in a large container and measuring the exact amount required for each dilution. An apparatus for this purpose can easily be designed by an experienced laboratory worker. Freas has described a practical method for distributing sterile water. The water is sterilized in 2-gallon bottles and is connected with the top of a buret by means of a glass tube. Another glass tube from the upper part is connected with a water suction-pump, and at the top is a cock which breaks up the effect of suction when this is indicated. The opening above this cock is filled with cotton to filter the air that enters. At the lower end of the buret is a glass bell to protect the outflowing water from air contamination (Fig. 183). Check plates should always be made to test the sterility of the water.

The composition and reaction of the culture-medium is usually considered of great importance, although closer investigation of this subject is desirable. Some authorities believe that the kind and reaction of the medium are factors. of considerable influence on the results, while others hold that they are negligible. Slack, for example, thinks that because of the viscosity of milk. After 
than beef extract agar, or a medium with 1.5 per cent. agar. Conn, on the other hand, believes that the difference in composition and reaction of media is not of great importance. Ayers recommends casein agar as the most suitable medium for milk examination, especially when it is desirable to determine the number of liquefiers in milk. The author states that casein agar is not as favorable for lactic acid bacteria as other media, but more so for liquefiers. Ayers' casein agar is prepared as follows:

"To 300 c.c. of water (distilled) add 10 grams of casein (Eimer \& Amend C. P. casein prepared according to Hammarsten) and 7 c.c. normal sodium hydroxid. Dissolve casein by heating to boiling. It is desirable to let this stand for several hours to get a perfect solution. This is not necessary, however. Make up volume to 500 c.c. and bring the reaction of the solution to between +0.1 and +0.2 Fuller's scale. Do not allow solution to become alkaline to phenolphthalein or over +0.2 . If the casein is weighed accurately and the normal solution is accurate the reaction will be about +0.2 .

"The agar solution is prepared by dissolving 10 grams of agar in 500 c.c. of water.

"Both casein and agar solutions should be filtered, then mixed. Tube and sterilize in autoclave under pressure for twenty minutes; then cool the tubes quickly in cold water or ice water. The final reaction of the medium will be about +0.1 , Fuller's scale. If the medium is alkaline the bacterial growth will be restricted. If the medium is more than +0.1 some of the casein may be precipitated during sterilization. The casein agar should be clear and almost colorless when poured into Petri dishes."

The time and period of incubation of the plates has to be considered. Bacteria in milk are chiefly of fecal origin, but there are others which may multiply with difficulty at high temperature. It is hopeless to attempt to account for all types of bacteria in milk by using one kind of medium, one temperature of incubation, and only aërobic cultivation. However, other things being equal, the best method is the one which gives the largest number of colonies and the largest number of varieties in a relatively short time. If the plates are incubated at $37^{\circ} \mathrm{C}$. the fecal bacteria will multiply at a great rate, the colonies will be relatively large, and small colonies of other bacteria may be obscured. At lower temperature fecal bacteria grow quite well, as a rule, but the colonies are not so large, and those of other bacteria have a chance to assert themselves. At room temperature, therefore, we may expect not only a larger count but also a fairer representation of groups or types of bacteria than at $37^{\circ} \mathrm{C}$. Colonies form more slowly at lower temperature than at $37^{\circ} \mathrm{C}$., and this 
is a serious objection, as it delays obtaining results and ties up a great deal of laboratory material. In the interest of accuracy, however, too much weight should not be attached to these objections. A study of the influence of temperature and period of incubation and, incidentally, of the influence of dextrose on the number of colonies developing, made by Glenn and the writer, led to the following conclusions:

"1. Since pathogenic bacteria are difficult, in most cases impossible, to find in milk, a higher temperature of incubation has no advantage over room temperature from this viewpoint.

"2. Incubation at $20^{\circ} \mathrm{C}$. is superior to incubation at $37^{\circ} \mathrm{C}$. because a higher count is obtained and a better differential count.

" 3 . Dextrose is preferable to lactose as an addition to the medium.

"4. Milk is usually consumed before results of bacterial examinations are available. Bacteriologic and chemical examinations should, therefore, have the principal object of improving and controlling the general supply, and accuracy is of greater importance than quick results. The loss of a day in the interest of accuracy is irrelevant."

The chart (Fig. 184) illustrates the results obtained.

Conn found that the five-day count in most cases was slightly higher than the two-day count, although in some cases it was somewhat lower. Slack thinks that the addition of a carbohydrate to the medium is irrelevant, and he has obtained as good results with media containing no carbohydrate.

Much also depends upon the number of colonies developing on a plate. A large number gives too low a count, because some colonies remain small and may be overlooked, while a small number of colonies on a plate may give too high a count, unless undiluted milk is plated. This is a difficult proceeding because the opalescence of the milk renders colonies hard to distinguish. Plates with 40 to 200 colonies are considered the best for a fair estimation. At least two, better three, plates should be made from each dilution, and the average taken as the proper number.

A very important source of difference in results is the assumption that each colony originates from one cell. This is not true, and it is not known what percentage of error is caused by this irregularity. Chains of streptococci and clumps of other bacteria frequently adhere with considerable tenacity, and a colony may have originated from a number of cells rather than from one. This objection to the colony count cannot be wholly overcome with present-day technic.

The apparatus for counting colonies should be of uniform type, since light and other factors may render small colonies discernible 
with difficulty. If litmus is used and a differential count made, some colonies forming but slight amounts of acid may escape proper classification.

There are many devices for counting colonies, some of great simplicity, others more or less complex. The counting apparatus

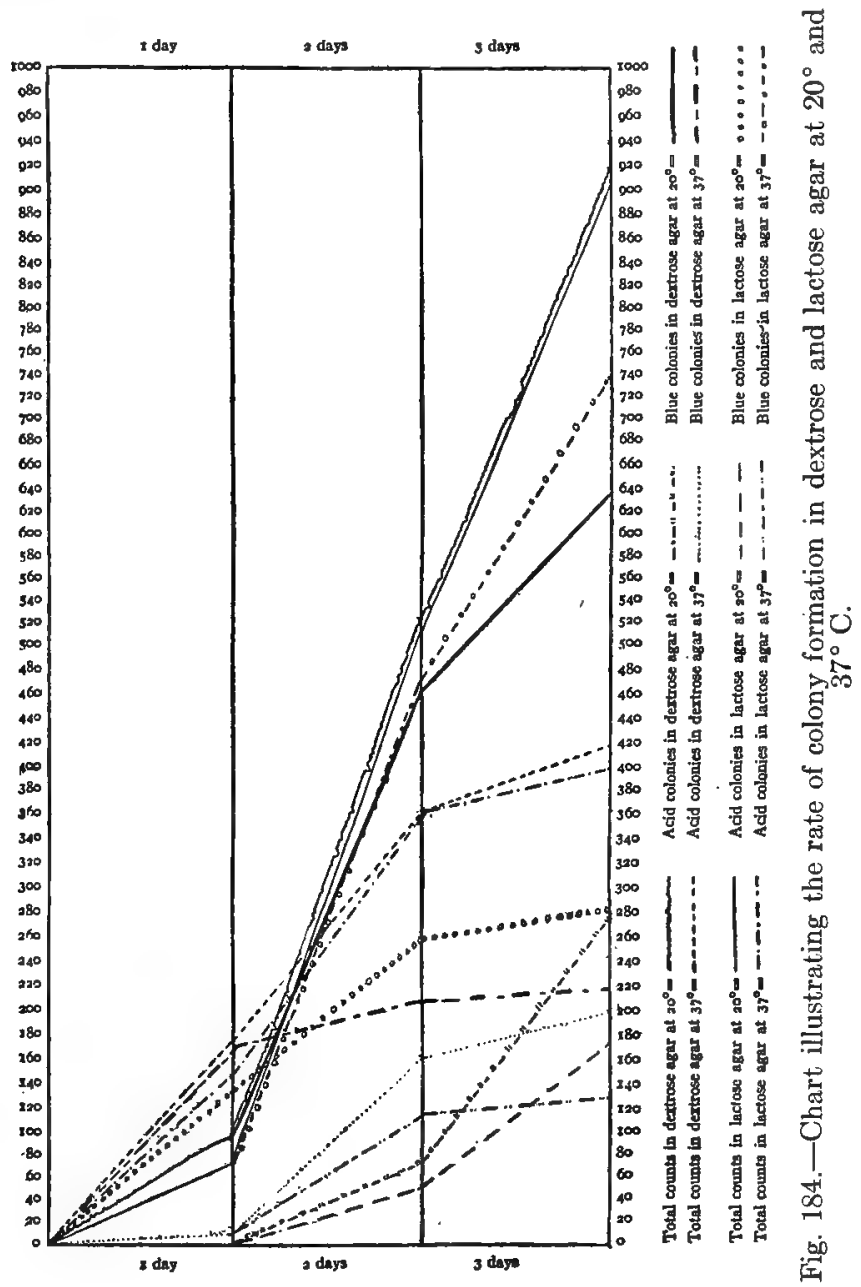

recommended by Slack requires a smali school slate on which a circle $4 \frac{1}{2}$ inches in diameter is cut. The circle is divided into 10 equal segments and the lines filled with red lead. The surface is occasionally rubbed with vaselin. Another apparatus is the one designed by Ayers (Fig. 185). It consists of a wooden box, 7 
inches long and $6 \frac{1}{2}$ high. The top is covered by a piece of ground glass over which is placed a square counting plate. The light enters from the front of the box, which is open. The eyes are protected by a shield of wood, 14 by 7 inches, and which is at-

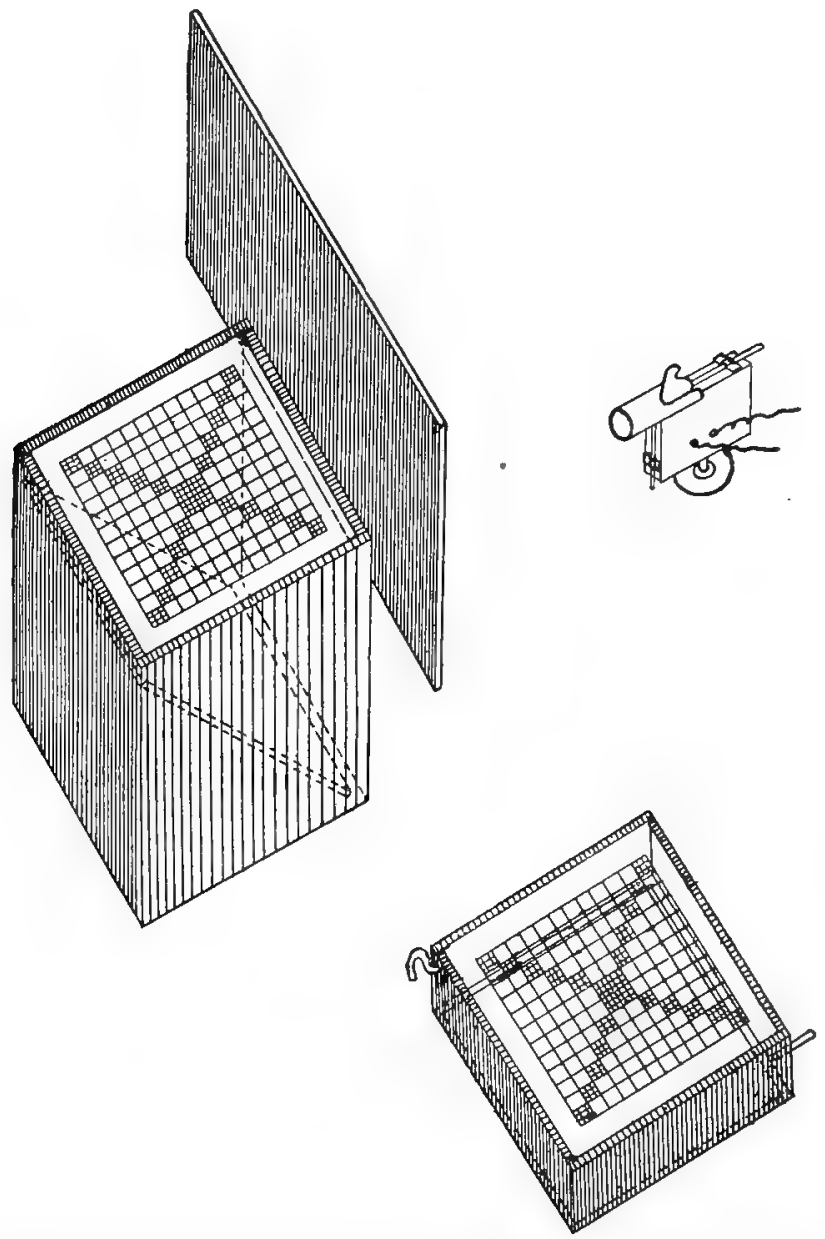

Fig. 185.-A colony counting apparatus with a cold counting plate for use with gelatin plates. (Ayers, in Jour. Amer. Pub. Health Assoc, vol. 1, No. 12, December, 1911.)

tached to the front of the box. The light should be white. By an additional device cold water can be run into a copper box so that gelatin plates remain solid.

The personal equation enters in counting colonies as well 
as in any similar work. As a matter of fact, different workers may record varying numbers of bacteria in the same sample of milk and even counting the same plates. This is due to several factors. One of the most important ones is the uneven distribution of bacteria in milk. Tests made from one part of a sample may show higher or lower counts than those made from another part. It is impossible to overcome this difficulty, but it may be stated that, as a rule, the difference in results is not large enough to cause misinterpretation of the quality of the milk, unless the number of bacteria is very close to the standards. In such borderline cases one worker may condemn a milk because his enumeration is slightly higher than the permissible limit for a certain grade, while another worker may consider the sample passable. These cases, of course, occur rarely.

The difference in counts is well illustrated by the following figures of Slack:

RELATION OF COUNT OF INDIVIDUAL WORKERS TO AVERAGE COUNT

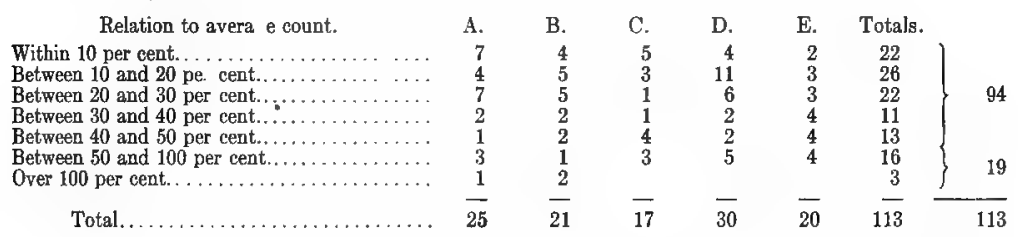

The American Public Health Association has published a booklet entitled "Standard Methods for the Bacterial Examination of Milk." In this publication certain methods and media are described which are to serve as guides for milk examinations throughout the country. The results obtained in different laboratories are comparable only when uniform methods are followed. Although the methods of the Committee of the American Public Health Association are by no means perfect and are not approved by some authorities, for the sake of uniformity they should be universally adopted. In spite of care there are fundamental conditions which render it difficult to obtain consistent results. It should be remembered that the plate method as usually practised does not reveal the presence of either anaërobes, soil bacteria, or pathogenic bacteria. The relative representation of these groups may be different in different milks, so that the proportion actually counted bears no definite relation to the number actually present. Furthermore, the variable possibility of breaking up clumps will always be a factor beyond accurate control.

Recently a comparative study of methods practised in different laboratories in New York City and the results obtained wsre 
made and an account published by Conn, who acted as referee. A few of the most important comments made are these:

"1. The Standard Methods for Bacterial Examination of Milk published by the American Public Health Association need revision, as they lay great emphasis on some of the least important points, while they neglect to lay emphasis on some of the most important points.

"2. Individual analyses under the best conditions are subject to considerable variation.

" 3 . The question of the exact composition of the media to be used is of far less significance than of the methods used in manipulation.

"4. Greater care should be given to the proper dilution selected for counting colonies and method of counting. Magnifying lenses should be of uniform power.

"5. A series of tests has proved that if a sample of milk can be put into iced water, containing floating ice, it may be kept for twenty hours with very little change in bacteria count."

Breed and Stocking, on the other hand, have found that in the hands of careful manipulators, using technic which differs much in detail, the agar plate method has given very consistent results when compared with the rapid work of laboratory assistants using routine methods.

It is obvious that the plate method, or any other method for that matter, requires care, accuracy, and experience if consistent results are to be obtained. The rush of work in commercial laboratories and sometimes the lack of experienced workers may explain in part the divergence of results. This divergence is particularly unfortunate, since it tends to throw discredit on bacterial counts in milk and renders their application for improvement of milk-supplies more or less difficult.

Frost has published a method for preparing "little plates" and counting the colonies by means of the microscope within three or four hours for raw milk and eight to twelve hours for pasteurized or very good milk. The author describes the method as follows:

"One-twentieth c.c. of milk is mixed with standard nutrient agar and spread over a definite area of a sterile glass slide. When the agar is hard, this little plate culture is put in the incubator for about six hours under conditions which prevent evaporation. It is then dried, given a preliminary treatment to prevent the agar from firmly binding the stain, stained, decolorized, and cleared. When this dried and stained plate culture is viewed under the microscope the little colonies are definitely stained and appear highly colored on a colorless or slightly colored background. 
These colonies can be rapidly counted and the number of bacteria per cubic centimeter calculated."

The author has designed a special water-bath, a nivellating apparatus, and an incubating cabinet for executing his method (Figs. 186-188).

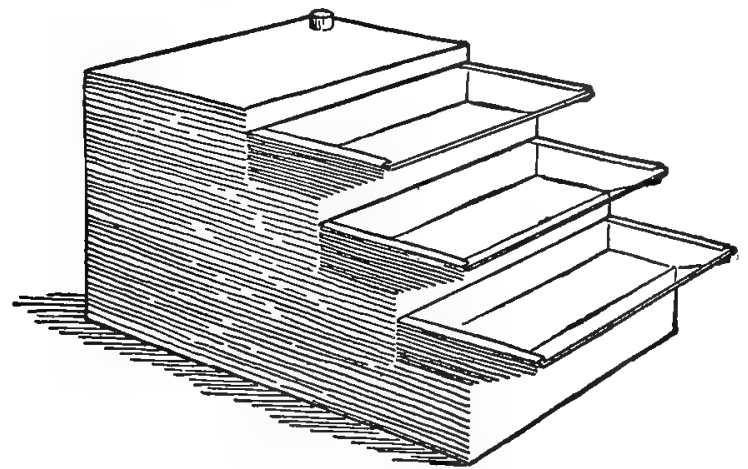

Fig. 186.-Warm box of water-bath, kept at $45^{\circ}$ C., used to keep the little plates warm while the agar is being spread. (Frost, in Jour. Amer. Med. Assoc., vol. 66, 1916.)

Since quick results are under some conditions desirable, attention has recently been given to bacterial enumeration by direct microscopic examination. This is really a revival of the first

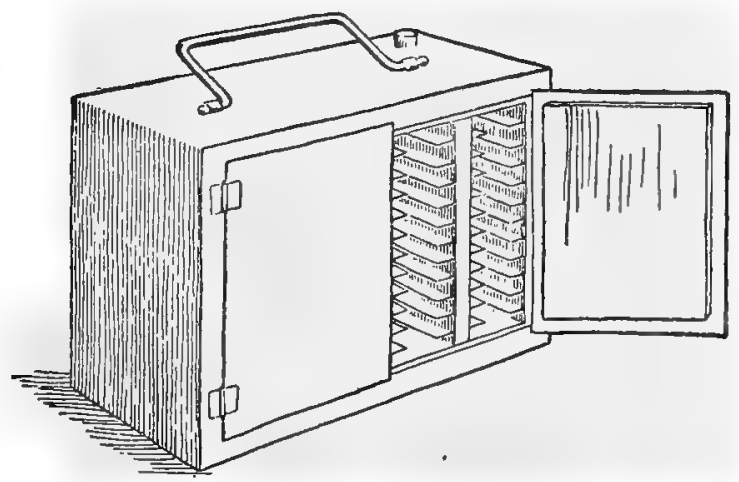

Fig. 187.-Incubating cabinet. Little plates are kept moist during incubation. Cabinet is put in incubator. (Frost, in Jour. Amer. Med. Assoc., vol. 66, 1916.)

attempts made to count bacteria. Before the plate method was evolved numbers were estimated by direct observation. A microscopic method for enumerating bacteria in sewage was devised by Winslow in 1905, while Slack was the first to apply the method 
to counting bacteria in milk. This method consists of collecting the sediment of a definite quantity of milk by centrifugation and smearing the sediment over a surface of about $4 \mathrm{sq} . \mathrm{cm}$. with the aid of a drop or two of sterile water. The sediment is stained with methylene-blue after having been dried with gentle heat. Bacteria can be counted under the microscope, and the method is sufficiently accurate to eliminate samples which are below the standard. When, however, the milk contains more than the permissible number, as determined by the microscopic examination, plate counts should be made to confirm the direct count.

Prescott and Breed worked out a method for enumerating cells in milk by direct microscopic observation, and Breed applied a similar method for enumerating bacteria. This is described by Brew and is carried out as follows: 0.01 c.c. of milk is taken di-

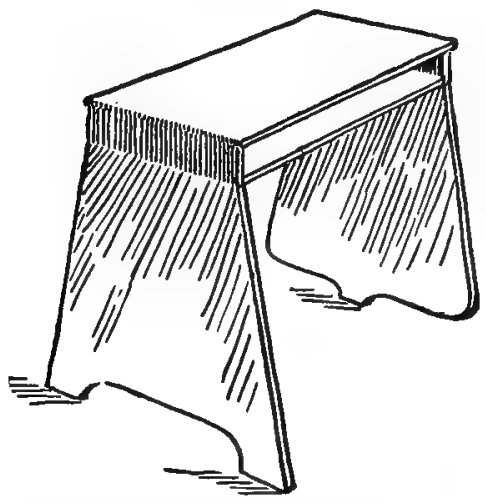

Fig. 188.-Nivellating apparatus for setting agar on little plates in a film of uniform thickness. (Frost, in Jour. Amer. Med. Assoc., vol. 66, 1916.)

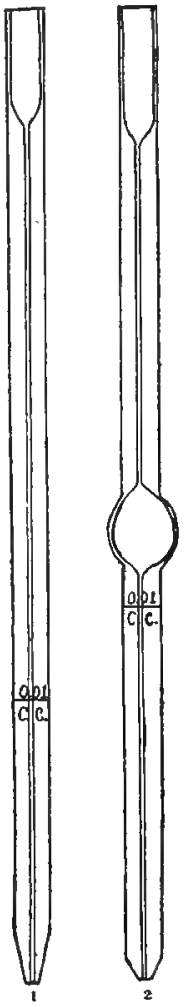

Fig. 189.-Convenient forms of capillary pipets. (Breed and Brew, Tech. Bull. 49, New York Agric. Exp. Sta., 1916.)

rectly from a well-shaken sample by means of a specially graduated pipet (Fig. 189). The drop of milk is deposited on a clean glass slide and spread over an area of $1 \mathrm{sq} . \mathrm{cm}$. with a stiff, straight needle. Duplicate smears of each sample are made on the same slide. The milk is then dried by gentle heat which is obtained over a level wooden surface placed on a steam radiator. The 
smear should not become too hot, as this makes it check, and satisfactory staining is then impossible. As soon as dry, the slides are placed for a short time in a Coplin staining jar containing xylol, which removes the fat. The surplus xylol is then wiped off with filter-paper. The smears are dried and fixed in 95 per cent. alcohol. After fixation they are immediately stained for two to three minutes in Löffler's methylene-blue and then decolorized to a light blue in 95 per cent. alcohol. The counting is done under an oil-immersion lens. The number of fields composing 1 c.c. is figured, and this is the factor for multiplication. It is necessary to count several fields and take the average.

By direct microscopic enumeration clumps of bacteria can be observed. The individual cells in the clumps can be counted, unless, as happens sometimes, they are so thick that single cells cannot be distinguished. This is an obvious advantage over the plate method, but confusing if results are to be compared with those of the plate method. According to Brew, experience has shown that in milk with low bacterial content the direct count is about forty-four times as high as the plate count, if individual cells are counted, and sixteen to seventeen times as great if clumps are counted as single cells. When the number of bacteria approaches $1,000,000$ the direct count is about 5 per cent. higher than the plate count.

In the investigation by Conn referred to above Dr. Breed made counts by his method of the same samples of milk that were plated in the laboratories. Professor Conn states that (1) in making a comparison of the plate count with the direct count clumps should be counted as individuals, and that then the microscopic method gives good results; (2) considerable experience by the person making the count is needed to distinguish between bacteria and dirt particles, particularly when the milk contains minute micrococci; (3) when the microscopic count is made by one who has had sufficient experience, the group count agrees somewhat closely with the plate count, and (4) raw, fresh milk does not contain any appreciable number of dead bacteria which might disclose themselves to the microscope.

The advantages claimed for the direct microscopic method are several. In the first place, it shows the presence of bacteria which do not grow on agar, and in the second place the work consumes but a short time, so that results can be had quickly; and furthermore, the necessary apparatus is simple and less expensive than that required for the plate method. Breed and Brew claim that the microscopic examination of milk is more useful for detecting the causes of a large germ content than the plate method, espe- 
cially since they have been able to detect large numbers of streptococci by the direct method.

Brew and Dotterer realize that the clumps of bacteria affect the accuracy of the microscopic count, and that the counting is rendered difficult when the clumps are large and dense. But they add that the plate count is affected not only by the same conditions, but that the clumps do not break up entirely into individuals, and that thereby the plate count becomes less reliable than the microscopic count. The authors emphasize the usefulness of the microscopic test in rapidly grading milk and distinguishing between milks of small, medium, and large germ content.

However, modern bacterial standards, and, in fact, nearly all published reports of bacterial enumerations in milk, are based on the plate method. If the direct microscopic method were generally introduced, ideas in regard to numbers of bacteria in milk would have to be changed. However, this should not be a valid objection to a new method, if such method is recognized as superior. An improved method that brings us nearer the truth compels us to discard old standards and establish new ones. Therefore, it is desirable that comprehensive tests of the microscopic enumeration of bacteria in milk be made and, if its superiority be proved, it should find its proper place in bacteriologic technic.

As stated before, the discrepancies in results obtained by different workers have been instrumental in casting doubt on the value of the bacterial examination of milk. It is true that the precision possible in a chemical analysis cannot be obtained in a bacterial examination. However, the differences are usually not large enough to undermine the relative accuracy of the bacterial count. It is of no consequence whether a milk is said to contain 5000, 6000, or even 8000 bacteria; such milk is of the best quality as far as the bacterial test goes. Neither is it important to differentiate between a milk containing 1,000,000 and one containing 1,500,000. These differences are irrelevant as long as it is necessary to depend upon bacterial enumeration without distinction of groups or types. When bacteriologic technic shall have evolved means for determining groups and types of bacteria with reasonable certainty, then a closer relationship of numbers may become of value.

\section{Other Bacteriologic Tests}

Milk is frequently examined for streptococci with a view to determining the presence of pathologic strains. Lactic acid streptococci appear chiefly in diplococcus form and sometimes in short 
chains. When long chains of streptococci are observed the assumption is sometimes made that a pathologic condition of the udder is indicated. This important subject will be considered in another connection.

The presumptive Bacillus coli test has been successful in detecting polluted drinking-water, and in the opinion of some sanitarians the presence of B. coli in milk assumes similar importance. The test is carried out in the same manner as the presumptive test for water pollution. It must be confessed, however, that the presence of $\mathrm{B}$. coli in milk and that of $\mathrm{B}$. coli in water receive different interpretations. When B. coli is present in water it is, as a rule, derived from human excreta, although a few cells may enter from another source. The presence of $\mathrm{B}$. coli in 1 c.c. or less of a surface water is the usually accepted standard, and is considered an indication of pollution with human excreta. In such polluted water organisms causing intestinal diseases in man, chiefly typhoid fever, may be present. In milk, however, when B. coli is present - and it is invariably present in raw market milk-it is usually derived from bovine feces. Cows are not susceptible to typhoid fever and do not carry the typhoid bacilli in their digestive tract, hence the presence of colon bacilli in milk does not indicate the probability of infectiousness for man. Since the majority of bacteria in milk are of manurial origin a positive qualitative test for $\mathrm{B}$. coli adds little to our knowledge.

There is considerable evidence to the effect that market milk is never entirely devoid of bacteria of the coli-aërogenes group. Prescott found Bacillus coli in 77 per cent. of 118 samples of certified milk, and stated his conviction that if a sufficiently large volume of certified mill were examined the organism could be detected in all samples. Race substantially agrees with Prescott. Ayers and Clemmens found that commercial milk produced under the best of conditions always contained bacteria of the coli-aërogenes group.

It is necessary to know the origin of coli-aërogenes bacteria in milk if significance is to be attached to their presence. The methods generally practised for their detection do not differentiate the Bacillus coli and B. aërogenes types. In market milk the two types are present in nearly equal proportion, according to Rogers, Clark, and Evans. These authors state that in bovine feces $B$. aërogenes is rare, while B. coli is the predominating type. Ayers and Clemmens found only 4 cultures of $B$. aërogenes in 1160 cultures obtained from samples of cow excreta. It follows that B. aërogenes does not represent fecal pollution in milk, no matter how large the number present, although Ayers and Clemmens found that "as feces dries the proportion of B. aërogenes to 
B. coli may increase slightly." In fresh milk the same authors found that $B$. coli far exceeds $B$. aërogenes in numbers.

Bacillus aërogenes must come from a different source. Rogers, Clark, and Evans studied 166 cultures of the coli-aërogenes group obtained from grain, of which 151 were of the B. aërogenes type. Hunter isolated bacteria of this group from silage, alfalfa, and kafir corn, and classified 79 per cent. as B. aërogenes. Johnson and Levine found "aërogenes-cloacæ" organisms abundant in soil.

It is clear from these findings that the "presumptive Bacillus coli test" when applied to milk does not shed the desired light on conditions.

Ayers and Clemmens made counts of the coli-aërogenes group in milk obtained under conditions ranging in variety from those so cleanly as to equal methods practised in certified milk dairies to those involving conditions of filthiness beneath the meanest dairy. They found fresh milk did not contain more than 2000 coli-aërogenes bacteria per cubic centimeter, with but one exception; and naturally concluded that when a larger number than 2000 per cubic centimeter is present, this is due to growth rather than to initial pollution. Unfortunately, there is no method known by which the descendants can be distinguished from those present in freshly drawn milk.

By carefully eliminating one factor after another, the same authors determined that bacteria of the coli-aërogenes group in milk are chiefly derived from neglected utensils.

Prescott and also Barthel have stated that Bacillus coli grows slowly at $10^{\circ} \mathrm{C}$. Race found no growth at $7.2^{\circ} \mathrm{C}$., and Ayers and Clemmens observed that there is some indication of a slight growth at $10^{\circ} \mathrm{C}$. But as the temperature increases multiplication becomes more rapid. This is shown clearly in the following table:

GROWTH OF ORGANISMS OF COLI-AËROGENES GROUP AT $10^{\circ}$ AND $70^{\circ} \mathrm{C}$.

Colon count.

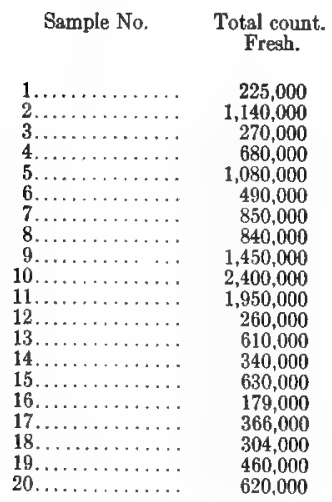

\begin{tabular}{|c|c|c|}
\hline Fresh. & $\begin{array}{c}\text { Held for twenty- } \\
\text { four hours at } \\
10^{\circ} \mathrm{C} \text {. }\end{array}$ & $\begin{array}{c}\text { Held for twenty } \\
\text { four hours at } \\
21.1^{\circ} \mathrm{C} \text {. }\end{array}$ \\
\hline 28,400 & $\begin{array}{r}100 \\
83,000\end{array}$ & $\begin{array}{r}180,000 \\
55,500,000\end{array}$ \\
\hline $\begin{array}{r}20,700 \\
\ldots\end{array}$ & $\begin{array}{r}00,000 \\
200\end{array}$ & $\begin{array}{r}2,600,000 \\
2,600,000\end{array}$ \\
\hline$\ldots$ & $\ldots$ & $2,350,000$ \\
\hline$\cdots$ & $\cdots$ & $3,400,000$ \\
\hline 900 & 1,300 & $\begin{array}{l}5,100,000 \\
8,300,000\end{array}$ \\
\hline$\ldots$ & 200 & $2,700,000$ \\
\hline$\ldots$ & 600 & $2,520,000$ \\
\hline$\ldots$ & $\ldots$ & $12,800,000$ \\
\hline$\ldots$ & $\ldots$ & $22,000,000$ \\
\hline & & $1,250,000$ \\
\hline 2,000 & 600 & $15,300,000$ \\
\hline$\cdots$ & $\ldots$ & 830,000 \\
\hline$\ldots$ & $\ldots$ & $1,170,000$ \\
\hline$\ldots$ & $\ldots$ & $1,180,000$ \\
\hline$\ldots$ & $\ldots$ & $6,400,000$ \\
\hline$\ldots$ & $\ldots$ & 120,000 \\
\hline$\ldots$ & & $1,810,000$ \\
\hline$\ldots$ & 400 & $2,200,000$ \\
\hline
\end{tabular}


It is clear that a test for Bacillus coli in milk requires a thorough knowledge of conditions for proper interpretation. It cannot, at the present stage of our knowledge, serve as a measure of manurial pollution, but does indicate that the milk has probably been kept at a temperature high enough to permit growth. And since it appears that B. coli is really of manurial origin, while B. aërogenes comes chiefly from a different source, such tests must remain of doubtful value as long as a rapid method of distinguishing the two types is not known. And furthermore, while high counts of bacteria of the coli-aërogenes group are due to growth, initial pollution is largely due to poorly cared for vessels in which growth has taken place before the bacteria have entered the milk.

The presumptive colon test has been thought to give proof whether milk has been properly pasteurized, on the assumption that the bacillus is destroyed by pasteurization temperature. This subject has been studied by Ayers and Johnson, who have stated that at $60^{\circ} \mathrm{C}$. $\left(140^{\circ} \mathrm{F}\right.$.) for thirty minutes 54.59 per cent. of the test cultures survived; at $62.8^{\circ} \mathrm{C}$. $\left(145^{\circ} \mathrm{F}\right.$.) 6.89 per cent. survived, and at $65.6 \mathrm{C}$. $\left(150^{\circ} \mathrm{F}\right.$.) one culture survived on the first heating, but in repeated experiments was always destroyed. This work shows that the finding of colon bacilli in pasteurized milk, even in relatively large numbers due to growth, is not a reliable test for efficient pasteurization. Furthermore, in another publication the same authors have shown that some anaërobic bacteria occurring in milk produce gas in the closed arm of the fermentation tube. This might become a serious source of error when gas formation is the only criterion for determining the presence of Bacillus coli.

Anaërobes are constantly present in milk either in the vegetative form or as spores, or in both forms. Recently Weinzirl and Veldee have worked out a method of numerical determination of Bacillus sporogenes in milk. The object of the test is a quantitative estimate of manurial pollution and is made by placing 10 c.c. of the milk in one tube and suitable dilutions in other tubes, covering the milk with melted paraffin and heating to $80^{\circ} \mathrm{C}$. for ten minutes. Only spores will survive this treatment. The tubes are incubated and the presence of Bacillus sporogenes is indicated by gas formation which pushes the paraffin plug up. If proteus is present there will be digestion of the casein, but no gas. The real value of the test must be determined by comprehensive investigations. As a matter of fact, the same argument that holds in the interpretation of total counts and colon bacilli holds in that of anaërobes. It is probably true that strict anaërobes do not multiply in milk under normal conditions, while 
Bacillus coli does. There are, however, other spore-bearing bacteria in milk which grow both aërobically and anaërobically, and if spores of these are present in large numbers the characteristic reaction of Bacillus sporogenes may not appear.

\section{Sampling Milk for Bacteriologic Examination}

A representative sample of milk for bacteriologic examination is of the utmost importance, because many types of bacteria thrive in milk and the flora changes rapidly numerically and in kind. Samples should be taken from well-mixed milk only, and if possible plated immediately, or smears made for the microscopic count. If transportation is necessary, the samples should be kept cool. Conn has stated that if a sample of milk is kept in ice water the bacterial count after twenty hours is but slightly different from the one made of the fresh sample.

Samples can be taken in bottles or test-tubes and can be kept cool in one of the many devices obtainable for the purpose.

Care should be taken that the cream is thoroughly mixed with the milk before sampling. As explained in a previous chapter, cream is liable to become stiff when cold and mixes readily only if warmed. The importance of this is evident considering the fact that bacteria rise with the cream by adhering to the fat globules.

\section{BIBLIOGRAPHY}

American Public Health Association: Standard Methods for the Bacterial Examination of Milk, 1916.

Ayers: Jour. of the Amer. Pub. Health Assoc., 1911, vol. 1, p. 891 . United States Dept. of Agri., B. A. I., 28th Annual Report, 1911.

Ayers and Clemmens: United States Dept. of Agri., Bull. 739, B. A. I., December, 30, 1918.

Ayers and Johnson: United States Dept. of Agri., B. A. I., Bull. 161, March, 1913. Jour. Agri. Research, 1915, vol. 3, p. 401.

Barthel: Révué Gen. du Lait, 1906, vol. 5, Nos. 10, et suiv.

Brecd: Cent. f. Bakt., Abt. 2, 1911, vol. 30, p. 337.

Breed and Brew: New York Agri. Exper. Sta., 1916, Tech. Bull. 49. New York Agri. Exper. Sta., Bull. 443, December, 1917.

Breed and Stocking: Jour. of Dairy Science, 1917, vol. 1, p. 19.

Brew: New York Agri. Exper. Sta., Bull. 373, February, 1914.

Brew and Dotterer: New York Agri. Exper. Sta., Bull. 439, November, 1917.

Conn: United States Public Health Reports, August, 1915, Reprint, 295.

Freas: Amer. Jour. of Pub. Health, 1905, vol. 5, p. 1035.

Frost: Jour. Amer. Med. Assoc., 1916, vol. 66, p. 889. Jour. Infect. Diseases, 1916, vol. 19, p. 273. Proceedings of the Ninth Annual Convention of the International Milk Dealers' Association, held in Springfield, Mass., 1916, pp. 63, 78. Jour. of Bacteriology, 1917, vol. 2, p. 567.

Heinemann and Glenn: Jour. Infect. Diseases, 1908, vol. 5, p. 412.

Hunter: Jour. of Bact., 1917, vol. 2, p. 635.

Johnson and Levine: Jour. of Bact., 1917, vol. 2, p. 379.

Jordan, E. O.: Jour. Amer. Med. Assoc., 1917, vol. 68, p. 1080.

Prescott: Proceedings of the Sixth Annual Convention of the International Milk Dealers' Association, held in Chicago, Ill., 1913, p. 36. 
Prescott: Report of Hearing on Ice Cream before Dr. C. L. Alsberg, Chief of Bureau of Chemistry, United States Dept. of Agri., 1914, p. 88.

Prescott and Breed: Jour. Infect. Diseases, 1910, vol. 7, p. 632.

Rogers, Clark, and Evans: Jour. Inf. Dis., 1914, vol. 15, p. 100. Jour. Inf. Dis., 1915, vol. 17, p. 137. Amer. Jour. of Public Health, 1916, vol. 6, p. 374.

Slack: Jour. Infect. Diseases, Suppl. 2, 1906, p. 214. Technology Quarterly, 1906, vol. 19, p. 37. Amer. Jour. of Pub. Health, 1917, vol. 7, p. 690.

Weinzirl and Veldee: Amer. Jour. of Pub. Health, 1915, vol. 11, p. 862.

Winslow: Jour. Infect. Diseases, 1905, Suppl. 1, p. 209. 


\section{MILK-BORNE INFECTIONS}

Since about the middle of last century, evidence has rapidly accumulated that milk not infrequently is a vehicle for carrying infection. It has been shown that there are many ways in which milk may be contaminated with bacteria, and it is, therefore, not surprising that sometimes pathogenic germs gain access. Milk is a suitable medium for growth of many micro-organisms, including forms of pathogenic bacteria, while water does not favor the growth of this class of germs. Since milk is frequently handled in a careless manner and not cooled sufficiently, pathogenic bacteria that enter it not only live but in many cases multiply at a considerable rate. Therefore, epidemics following the use of infected milk or infected milk products-chiefly ice-cream and butter-have occurred. And when the enormous quantity of milk and milk products consumed is taken into account it is almost surprising that the number of epidemics due to these foods is not greater than it actually is. In 1899, according to the twelfth census of the United States, 740,000,000 gallons of milk were consumed in this country. This amount averages 23 . gallons for each person and does not include milk used for manufacture of butter, cheese, and other dairy products. Since that time the consumption has, of course, increased materially.

Unfortunately the frequency of milk-borne infections in relation to those due to other causes has not been carefully studied. For example, in the literature statements appear that 10 to 25 per cent. of all typhoid epidemics are milk-borne, but accurate statistical evidence to this effect is lacking. The layman is only too frequently impressed with the number of epidemics that have followed in the wake of milk consumption, and it cannot be denied that there is much ground for guarding milk-supplies against contamination with disease germs. This, however, is a difficult undertaking, because, as has been pointed out in an earlier chapter, disease germs are difficult to isolate from milk, chiefly for the following reasons:

1. The relative number of pathogenic bacteria, as a rule, is small in comparison with the number of saprophytes. Consequently, high dilutions of milk are necessary in the preparation of plates in order to bring the number of colonies to a reasonable figure for study. As a consequence, colonies of pathogenic bac- 
teria will be scarce and may be easily overlooked. Negative findings, therefore, do not prove conclusively the absence of disease germs.

2. Pathogenic bacteria do not multiply readily at the temperature of market milk, while many saprophytes do multiply. Under these conditions isolation of disease germs is difficult.

3 . The time required to isolate pathogenic bacteria from milk is so great that the period of an epidemic is unduly lengthened before preventive measures are put in operation.

4. The causal organism of some diseases is still undetermined.

5. Milk may have been intermittently contaminated with the virus of a disease, or only the product of a single day may contain the infectious material. At the time the epidemic is discovered the milk may be free from dangerous organisms, while the milk actually responsible has been consumed before suspicion pointed to the supply.

6. Some pathogenic bacteria cannot be cultivated on artificial media.

However, the menace in milk, great as it is, has probably been somewhat exaggerated, and a beginning at least has been made to cause the pendulum to swing to its normal position. In an interesting article Kelley has shown that the number of cases of disease and deaths due to milk infection is small if compared to that due to other causes. In the author's words, "Whenever the subject is approached in an impartial manner it is rather astonishing to see how little real basis there is on which to form any definite estimates as to the comparative importance of milk infection as compared to other modes of infection, such as water, carriers, or direct contact." The author has stated after considerable study "that in only 0.03 per cent. of cases was the transmission of diphtheria definitely assigned to infected milk, and in only 0.19 per cent. was milk either proved or suspected; 1.6 per cent. of the reported cases of scarlet fever were definitely attributed to milk infection, and 1.8 per cent. proved or suspected; in 79 per cent. of the cases septic sore throat (not reportable in Massachusetts until 1914) milk was assigned as the cause; and in 5 per cent. of the cases of typhoid milk was definitely assigned as the cause, and in 6 per cent. of the cases of typhoid milk was either proved or suspected to be the agent of infection in this disease. Taking all of these diseases in a group, 3.9 per cent. were definitely attributed to milk, and in 4 per cent. of all the cases milk was proved or suspected. Considering mortality, 3 per cent. of typhoid deaths are possibly attributable to milk, 0.08 per cent. of diphtheria deaths, 0.8 per cent. of scarlet fever deaths, and 98 per cent. of septic sore throat deaths; an average 
for the whole group of 2 per cent: of the deaths may be attributed to infected milk."

High infant mortality has been commonly ascribed to contaminated milk, although no specific germ so far has been identified as the cause of cholera infantum. The importance of milk in relation to this disease has also been exaggerated, and Schereschewsky goes so far as to state that "the hypothesis that the ordinary saprophytic germs of milk produce disease and death in infants is singularly lacking in experimental confirmation."

Admitting that the culpability of milk as a carrier of infection has been exaggerated, the fact that the virus of diseases is disseminated through its means cannot be denied, and any study that leads to the decrease of milk-borne morbidity or death should be encouraged.

Milk-borne epidemics have characteristics which usually distinguish them clearly from epidemics due to other causes. The explosive outbreak of a milk-borne epidemic is similar to that of a water-borne epidemic, but differs inasmuch as it is usually confined to patrons of a particular dealer. It is true that not all those who consume milk from the same supply are taken ill. As a matter of fact, among the users of the same supply the number of those taken ill may vary from a small percentage to 80 or 90 per cent. This, of course, is due to certain factors that have to be taken into account, the most important of which are:

1. The quantity of milk consumed: It is obvious that the larger the quantity of milk consumed, the greater is the intoxication, and since it is a well-known fact that while a moderate number of bacteria may not cause disease, a large number is more liable to do so. This is the reason why milk-borne epidemics are more frequent among the well-to-do class than among poorer people, since the latter purchase their supply in moderate quantity for immediate consumption, while the former use milk more liberally. The following figures taken from Swithinbank and Newman's Bacteriology of Milk clearly illustrate the relation of the amount of milk consumed to the number of cases of disease occurring:

RELATION OF AMOUNT OF PARTICULAR MILK CONSUMED TO INCIDENCE OF EPIDEMIC (Wimbleton and Morton 1886-87)

\begin{tabular}{|c|c|c|c|c|c|c|}
\hline $\begin{array}{l}\text { Amount of particular millk } \\
\text { consumed daily per household. }\end{array}$ & $\begin{array}{c}\text { Total } \\
\text { houses. }\end{array}$ & $\begin{array}{l}\text { No. } \\
\text { invaded. }\end{array}$ & $\begin{array}{l}\text { Invaded } \\
\text { per cent. } \\
\text { of total. }\end{array}$ & $\begin{array}{c}\text { Total } \\
\text { persous. }\end{array}$ & $\begin{array}{c}\text { No. } \\
\text { invaded. }\end{array}$ & $\begin{array}{l}\text { Invaded } \\
\text { per cent. } \\
\text { of total }\end{array}$ \\
\hline 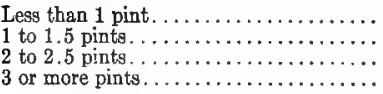 & $\begin{array}{r}81 \\
102 \\
43 \\
48\end{array}$ & $\begin{array}{l}39 \\
62 \\
32 \\
39\end{array}$ & $\begin{array}{l}48.1 \\
61.7 \\
76.7 \\
81.2\end{array}$ & $\begin{array}{l}315 \\
472 \\
207 \\
362\end{array}$ & $\begin{array}{r}68 \\
162 \\
87 \\
169\end{array}$ & $\begin{array}{l}21.6 \\
34.5 \\
42.0 \\
46.6\end{array}$ \\
\hline
\end{tabular}

The fact that women and children are larger consumers of milk than men explains the greater liability of women and children to milk-borne infections. 
Furthermore, the infectious material may not be evenly distributed through the milk, and, as a matter of fact, it has happened that but one out of a number of milk cans was actually infected. Infectious material may gain access to a relatively small number of bottles, thus carrying disease to a limited group of families.

2. Susceptibility to the disease: Individual susceptibility to a disease naturally plays an important rôle in the number of persons coming down with a milk-borne infection. If, for example, a milk-supply is contaminated with typhoid bacilli the percentage of persons taking the infection will be smaller in a community in which typhoid fever has been more or less prevalent than in a community relatively free from the disease. Furthermore, since typhoid fever is a disease chiefly confined to certain age limits, those within these limits are more liable to suffer than others.

3. The manner in which milk is used: If milk is used chiefly on cereals, fruit, etc., it is consumed in relatively small amount, and when taken in hot tea or coffee the incidence may be quite small, since these beverages are taken at a temperature which destroys a large number of bacteria.

4. The virulence of the organism: The well-known variability in virulence of pathogenic bacteria may be the cause of affecting a small or large percentage of milk consumers.

The facts stated show clearly that a milk-supply may be responsible for an epidemic even if only a small number of persons is affected. On the other hand, it may happen that persons who do not regularly use the incriminated supply are affected. These persons may have visited friends or relatives in the stricken district; or may have taken milk at a public eating house where the particular milk was served; or, finally, they may have contracted the disease by contact with those originally affected by the milk.

Pathogenic bacteria may gain access to milk in various ways, namely: 1 , from the personnel employed in handling the milk and from the clothes of employees; 2 , from contaminated bottles and utensils; 3 , from flies; 4 , from dust in the air; 5 , from domestic animals; 6 , from the cows.

1. From the Personnel Employed in Handling the Milk and from their Clothes.-There are several possible ways in which milk may become infected from employees. During the milking process a carrier may be responsible for the entrance of pathogenic germs. Diseases of the respiratory tract are communicated by coughing, sneezing, or from the hands-the germs of intestinal - diseases may adhere to the hands of the milkers and enter the milk. Cleanliness is, unfortunately, not as widely practised as is desirable, and some typhoid fever epidemics have been traced 
to carriers whose lack of personal cleanliness was responsible. Skin diseases may be communicated to milk in a similar manner.

Germ carriers are particularly dangerous, since they are well, and there is no reason for suspecting them of carrying infection. The same applies to those who are in the incubation period of a disease. In typhoid fever, for example, the bacilli are frequently discharged before the patient takes to bed. Furthermore, ambulant cases are by no means scarce and constitute a serious menace

It is almost needless to state that the clothes of those carrying infection may be the source of milk contamination.

There are cases on record showing that nurses may communicate disease germs to milk. When a farmer has to care for a sick person and also attend to the milking, his soiled hands may communicate the virus to the milk. In the milk collecting station a carrier or a person in the incubation period of a disease may cause disaster, and even in the home, nurses may communicate infection to the milk.

The discharges of patients suffering from a communicable disease should be properly disinfected if the milk-supply is to be guarded. There is the frequently cited example of the Springfield, Mass., typhoid fever epidemic which was caused by human feces spread on the field and then carried on the boots of the men to an open well in which the milk was cooled in leaky cans.

Employees may also be responsible for infecting utensils and bottles. Even pasteurization may not be an entirely reliable safeguard against this menace, unless effective precautions are taken. The most modern pasteurization machines provide effcient protection against this mode of infection, inasmuch as it is not necessary for an employee to handle the bottles, or for the milk to be exposed to human infection. The milk is constantly under cover and the bottles are automatically inverted to receive the milk from the cooler.

2. Cans and Bottles.-The cans and bottles may be the sources of infection when contaminated water is used for washing and when the utensils are not thoroughly steamed before use. Sometimes bottles are contaminated with disease germs in the home. In many communities it is now compulsory to retain the bottles as long as there is a communicable disease in the house, and after recovery of the patient they are sterilized with special care.

3. Flies may easily communicate infectious material to milk, since they carry it either on their feet and wings or drop it from the intestinal canal. It is almost impossible to exclude flies entirely from cow stables, and even in the best dairies the pest is quite plentiful during the warm season. It is easily conceivable 
that pathogenic germs are deposited in the milk under these conditions.

A bottle of milk left unprotected outside of the house may furnish flies with the means of communicating disease virus, since frequently a few drops of milk remain on the surface of the bottle cap. A simple box to hold the milk will prevent this menace.

4. Dust.-Although infections through dust are considered relatively scarce, the possibility of its communicating pathogenic germs to milk cannot be entirely excluded. If, for example, there is a case of typhoid fever in the family of a milk producer, and the dejecta are left near a dairy barn or a milk house, the dust may soon carry germs to the milk. It has been shown that typhoid bacilli may live for weeks and even months under such conditions, and in the soil for more than a year. Human dejecta, therefore, should never be used for manuring.

5. Domestic Animals. - The careless habit of leaving bottles of milk outside the house without protection exposes them to visits from cats and dogs. Both animals may carry diphtheria germs and the germs of other diseases, and by licking the caps of milk bottles leave the germs which finally find their way into the milk.

6. The Cow.-Finally, infection may be derived from the cow. Of chief importance is the transmission of bovine tuberculosis through milk. That bovine tubercle bacilli are infectious for man, especially during infancy, is not questioned, and many investigations have shown that a considerable proportion of raw market milk harbors living bovine tubercle bacilli. They reach the milk either from a diseased animal directly when the udder is affected, or through the dust from the dejecta of tuberculous animals.

It is clear that milk and cream are exposed to infection at many points, and the problem of prevention is proportionately difficult. Methods of prevention are studied chiefly by investigators of epidemics by definitely locating the source of infection.

As previously stated, milk-borne epidemics are studied successfully only by epidemiologic methods, while the isolation of a specific disease germ, though desirable, is difficult and not altogether necessary. The epidemiologist will attempt to tabulate all cases of the disease and make inquiries as to the water and milk-supplies of the stricken families, the exact date of the outbreak of the disease, and similar points of interest. Trask gives the following points to be ascertained in the investigation of milkborne epidemics:

"1. The number of cases of the disease existing in the involved territory during the time covered by the epidemic.

"2. The number of houses invaded by the disease. 
"3. The number of invaded houses supplied in whole' or in part, directly or indirectly, by the suspected milk. plied.

"4. The number of cases occurring in invaded houses so sup-

" 5 . The number of houses supplied with the suspected milk.

"6. The relative proportion of houses so supplied to those supplied by other dairies.

"7. The time covered by the epidemic.

"8. The location of the case or cases from which the milk became contaminated.

" 9 . The relation of the original case to the epidemic.

" 10 . The time relation of the original case to the epidemic.

"11. The special incidenec of the disease among milk drinkers.

"12. The elimination of other common carriers of infection.

"13. The effect upon the epidemic of closing the dairy or taking such measures as will eliminate the possibility of milk contamination from the suspected focus.

"14. The finding of the specific organism in the milk."

The cases are marked on a map and a so-called spot-map prepared. A milk-borne can be distinguished from a water-borne epidemic by the fact that in the latter the cases are spread more or less evenly over the whole community, while a milk-borne epidemic is more or less confined to a limited area. This is due to the fact that the water-supply is generally a uniform one throughout a community, while milk is supplied by a number of dealers, and the infection is confined to one dealer or, at most, a small number of dealers.

After the epidemiologist has found evidence which leads him to suspect a particular milk dealer, he will investigate conditions on the dealer's premises and at the producers' farms. Usually the cause can then be attributed to a diseased person or a carrier. The diagnosis is confirmed by a bacteriologic examination of the sputum, dejecta, urine, or other discharges. The finding of the specific organism clinches the evidence. If the epidemic ceases after exclusion of the suspected supply from the market, the evidence of the culpability of the particular milk-supply is considered complete.

The prevention of milk-borne epidemics is one of the most difficult tasks of health administration. The larger the community, the more complex is the problem, since the milk is derived from a great variety of sources. This might seem an argument in favor of supplies being taken over by large corporations or even by city governments, similar to the method now practised of distributing drinking-water. There are surely many reasons why a single milk-supply controlled by a municipal authority 
would be advantageous, but it should not be forgotten that milk requires a great deal of handling by human beings, while water is a product of nature that requires much less care. It seems impossible to employ men for milk production who are surely free from disease and who do not carry disease germs. The task of a medical supervisor would be enormous. Bacteriologic technic is not yet sufficiently developed to infallibly locate all carriers. Furthermore, the larger the milk-supply, the greater is the danger of spreading infectious material, because the contaminated milk is mixed with the balance of the supply. It is true that this process also involves a proportionate dilution of the virus, but how far this is a source of protection is problematic. Efficient dairy inspection, guided by bacteriologic control, which leads to cleanliness in methods; exclusion of flies; thorough cleaning and steaming of all utensils and bottles, and proper sealing of containers to prevent tampering, may aid in the reduction of milk-borne disease. Medical examination of all employees and veterinary inspection of the cows also will help in obtaining the desired result. But these safeguards are limited and uncertain owing to the difficulties involved in their execution. Under modern conditions there is but one remedy-efficient pasteurization.

The diseases which have been known to be disseminated through milk may be divided into two classes, namely: 1 , those which are derived from human beings engaged in handling milk, and 2, those which are derived from diseased cattle. To the first class belong typhoid fever, dysentery, paratyphoid fever, diphtheria, septic sore throat, human tuberculosis, Asiatic cholera, and scarlet fever. To the second class belong bovine tuberculosis, foot-and-mouth disease, mastitis or garget, contagious abortion, anthrax, rabies, actinomycosis, botryomycosis, cowpox, milk sickness, and gastro-intestinal troubles. Malta fever, commonly carried by goat's milk, also belongs to the second class.

\section{Diseases Derived from Human Beings}

Typhoid fever is one of the most important infections carried through milk, and is communicated to milk through human agencies only, since cows are not susceptible to the disease. The bacilli grow well in milk if temperature conditions are favorable, but in properly cooled milk there is little if any growth. The changes caused in milk by Bacillus typhosus are slight and not noticeable to the unaided senses. The amount of acid formed is too small to be recognizable except by the use of chemical indicators, and some strains of typhoid bacilli produce alkali after an initial acid production, with the result that the acid is neutralized. Typhoid 
bacilli may be present in milk in large numbers without materially changing the taste, odor, and appearance of the milk. Like other bacteria, typhoid bacilli rise with the cream, and in this case cream may become highly infectious. If infected cream is used in tea and coffee the danger from typhoid bacilli is lessened, since both are usually consumed hot-say $60^{\circ}$ to $70^{\circ} \mathrm{C}$. However, the menace is by no means entirely eliminated.

Typhoid fever is an intestinal disease and the dejecta and urine of patients or carriers are, therefore, the chief sources of infection. The organisms are abundant in feces and the urine is sometimes so heavily charged that it is turbid. In carriers the discharge is intermittent and the milk is infected at intervals, a circumstance which makes it difficult to detect the true source of infection.

Infection of milk by carriers, ambulant cases, or persons in the incubation period of the disease is due to lack of cleanliness. The utensils, bottles, and caps may be infected by contact. A further menace lies in the use of polluted water for washing utensils, especially in small dairies where steam is not available.

When the dejecta of typhoid patients are used for manuring the soil, typhoid bacilli may live a long time. How an epidemic may be started under such conditions is illustrated in the abovementioned typhoid fever epidemic in Springfield, Mass. Rain may wash typhoid bacilli from the field into wells, and if this water is used for washing utensils infection becomes possible. Jordan and Irons have reported an epidemic of typhoid fever in LaGrange, Ill., which they traced to an infected shallow well.

Milk-borne typhoid fever epidemics have been traced to carriers in many instances. Thus Parker found that in an outbreak in Belleville, Ill., 86.3 per 'cent. of all cases had milk from one dairy, and Jordan and Irons reported that in the Hoopeston, Ill, epidemic, out of a total of 96 cases, 62 were traced to one dairy and 18 to another one. In both epidemics carriers were the causes of the infection of the milk.

Senftner reports an epidemic of typhoid fever due to the milk-supply in Bakersfield, California. This epidemic extended over a period of more than a year. It was caused by a carrier and was intermittent in intensity, owing to the well-known fact that the bacilli appear periodically in the discharges of carriers.

That infected water used for washing utensils may become the cause of milk-borne typhoid fever is shown in an outbreak at Colusa, Califormia, reported by Geiger.

Swithinbank and Newman give the percentages of milk-borne typhoid fever epidemics due to various causes as follows: 
By cases of typhoid at the farm or milk shop $\ldots \ldots \ldots \ldots \ldots \ldots \ldots \ldots \ldots \ldots 70$ per oent.

By cases of typhoid at the farm.

By cases of typhoid at the milk shop.

By using polluted water for dairy purposeg.

By insanitation at the farm or milk shop and miscellaneous ..............,

Detailed histories of typhoid fever epidemics are given by Swithinbank and Newman, the Bacteriology of Milk; in Hygienic Laboratory Bulletin 56, and in Jordan's article, the Case for Pasteurization.

Dysentery and paratyphoid fever may be communicated through milk, although milk-borne epidemics of these diseases are less frequent than those of typhoid fever. The method of transmission is similar to that of typhoid fever, and what has been said in this respect applies to dysentery and paratyphoid fever. An epidemic of paratyphoid fever due to improper handling and bottling has been reported by Levine and Emerson.

Diphtheria.-The transmission of diphtheria through milk is a grave possibility, and a considerable number of epidemics have been definitely traced to milk. The diphtheria bacillus grows well in milk and produces changes which are not ordinarily noticeable. It gains access to milk chiefly from carriers, who emit bacilli through coughing, sneezing, loud talking, or direct contact. The filthy habit of expectorating into the hands before milking in order to lubricate the teats is probably obsolete at present, but undoubtedly has been the cause of transmission of diphtheria and other throat diseases through milk.

Milk bottles from a home in which there is a case of diphtheria are subject to infection and should not be removed before the patient has recovered and before the throat of the patient has been shown to be free from bacilli. Such bottles should be sterilized with special care before using.

Since domestic animals have been known to carry diphtheria bacilli from one house to another, it is clear that milk and cream bottles should be protected from contact with these animals.

Diphtheria may be derived from the cow, although she is not susceptible to the disease in the sense that human beings are. Several investigators, notably Dean and Todd, have observed crusts and ulcers on the teats of udders of cows. These lesions were caused by diphtheria bacilli and were undoubtedly of human origin.

The methods of dissemination of diphtheria through milk is well illustrated in an outbreak at Dorchester, Milton, and Hyde Park in 1907. In Bulletin 56 of the Hygienic Laboratory the chart which is shown on page 440 explains the routes of infection. 


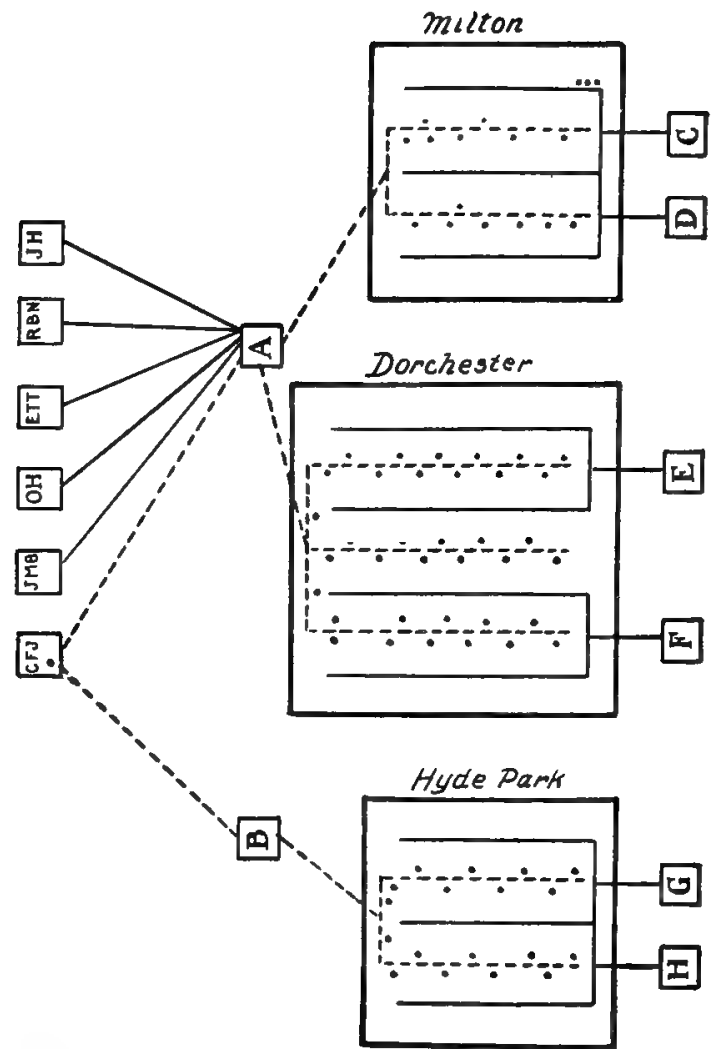

Fig. 190.-Showing relation of milk routes to diphtheria cases during the outbreak at Dorchester, Milton, and Hyde Park, 1907. (Trask, Hygienic Bulletin, No. 56.)

JH, RBN, ETT, OH, JMB, and CFJ are the farmers producing milk.

$A$ is the milk dealer delivering milk in both Milton and Dorchester. $B$ is the milk dealer delivering milk in Hyde Park.

The lines connecting the producing farms and the milk dealers show to which dairy the farmer sold his milk.

The large squares represent Milton, Dorchester, and Hyde Park.

The dash-lines extending from $\mathbf{A}$ to $\mathbf{B}$ into the towns represent the milk routes carrying the supposedly infectious milk. Each dot represents a case of diphtheria and is placed on the milk route from which it was supplied.

C, D, E, F, G, and $H$ represent the other dairies selling milk. The lines extending from them into the towns represent their routes and are inserted to show their freedom from diphtheria cases.

Reports of other milk-borne diphtheria epidemics can be found in Swithinbank and Newman's Bacteriology of Milk and in Hygienic Laboratory Bulletin 56.

Septic sore throat is considered by some authorities the milkborne disease par excellence. Investigations of this disease are 
of very recent date, and in many cases the epidemics have been attributed to milk. Earlier reports, originating chiefly in England, traced sore throat outbreaks to the milk of herds in which mastitis was found to exist. Therefore it was believed that mastitis was the cause of sore throat in man. However, the evidence is not entirely convincing, and the fact that mastitis is wide-spread would lead to the assumption that sore throat is much more common among milk drinkers than it actually is. Furthermore, epidemics of sore throat appear chiefly in winter and early spring, while mastitis occurs at all seasons without distinction. When epidemics of sore throat occur and are traced to milk-supplies, it is not difficult to find some cases of mastitis in suspected herds, since the disease is common; so common, in fact, that some authorities claim there is no herd of cows entirely free from it.

That milk has been the vehicle of the virus of septic sore throat has been clearly shown, although contact infection frequently plays an important rôle. Still the true source of infection has rarely been discovered. Winslow has reported an extensive epidemic in Boston and some neighboring cities, and has traced it definitely to a milk-supply, but in casting about for a source of infection of the milk he failed to find conclusive evidence, and surmised the presence of a human carrier in the dairy. The incriminated supply was one of the best ones in the city; exceptional care was exercised to guard the milk against infection; and constant scientific control of the milk at all stages of production and during handling was exercised. No disease among the cattle could be detected. In an epidemic in Chicago in 1911-12, which was traced to a milk-supply, the cases occurred chiefly in limited districts, and the writer was able to locate a carrier in the dairy who seemed responsible for communicating the infection. It was there stated that "the epidemic may be attributed to a partial infection of the milk-supply rather than to infection of the whole." As a matter of fact, the infection gained access to the milk after pasteurization. The man who handled the bottles was suffering from a severe case of septic sore throat, and by coughing, sneezing, etc., might have infected the bottles intermittently. This explains the occurrence of cases in groups rather than over the whole territory covered by the supply.

Mastitis is usually caused by streptococci, and investigators have concluded that the streptococcus causing septic sore throat in human beings is derived from mastitis. Streptococci may produce a great variety of pathologic conditions in man, and it is conceivable that the same strain which is the cause of mastitis in cows may adapt itself in such manner as to produce sore throat in man. 
However, there is no reliable evidence to support this assumption. Pathogenicity for experimental animals does not presuppose pathogenicity for man. When mastitis milk is injected into guinea-pigs it frequently causes lesions, but not invariably. Puppel injected mastitis milk and a culture of mastitis streptococcus into the stomachs of guinea-pigs, but health, temperature, appetite, and digestion remained undisturbed. Feeding guinea-pigs with milk from a cow whose udder was caked with mastitis produced no untoward effect. Lameris and Harrevelt and Reed and Ward considered mastitis streptococci harmless to guinea-pigs, although the latter authors were able to produce mastitis in cows by injecting mastitis streptococci into the udder.

The studies of Davis and of Smith and Brown on the relation of mastitis streptococci to human sore throat have thrown much light on the question. The latter authors injected guineapigs with milk containing many leukocytes and with one sample of milk containing streptococci. The guinea-pigs showed no disease and increased in weight. The authors also injected rabbits with three hemolytic streptococci without results. They say, "in searching for the particular streptococcus of an epidemic we must search for an individual strain rather than a type." They conclude that "the streptococci of cow mastitis are different from streptococci of human tonsillitis; virulent streptococci of man do not cause any appreciable inflammation of the cow's udder; mastitis streptococei do not cause affections in man; the udder of a cow inoculated with virulent human streptococci may permit certain strains to multiply in the milk ducts." In explanation of the heightened virulence of the streptococci causing outbreaks of septic sore throat the authors say, "if bovine, they must represent a special strain rather uncommon, otherwise we should expect epidemics all the year round. If human, they may also represent some peculiar type or else the product of a temporarily increased virulence due to two co-operating factors, reduced virulence on the part of human beings in the late winter and early spring brought about by a combination of untoward living conditions and better opportunity for rapid passage from throat to throat - a process tending to raise virulence in many microorganisms."

It appears that epidemics of septic sore throat may be disseminated through milk-supplies, but the direct origin of the infection is obscure in most cases. There is little doubt about the fact that contact plays an important rôle in the transmission of the disease. This was shown to be true in the Chicago epidemic, and Winslow and Hubbard have emphasized the importance of contact in their study of an outbreak of septic sore throat in New 
York State. The authors tabulated 905 cases, and came to the conclusion that, "for the most part, the disease was spread by contact and in prosodemic fashion, but a small milk or cream epidemic was superimposed upon the general prosodemic spread of the disease." Krumwiede and Valentine came to similar conclusions.

Pathogenic streptococci have no great resistance to heat and are probably destroyed by pasteurization temperature. Pasteurization of milk is, therefore, the most effective method of prevention of this disease.

Human Tuberculosis.-Dissemination of human tuberculosis through milk is conceivable, although it does not seem to happen frequently. Clear records of this mode of transmitting tuberculosis are not available, and the insidious onset of the disease, together with the uncertain incubation period, render exact observations difficult.

However, a tuberculous employee engaged in milking or handling milk might spread the infection by coughing, sneezing, or direct contact of his hands.

Asiatic cholera is essentially an intestinal disease, and the possibility of the virus entering milk is by no means excluded. However, actual cases of cholera resulting from milk infection are rare, probably because the spirilla die rapidly in milk, and because carriers of the disease are uncommon.

Scarlet Fever.-A number of epidemics of scarlet fever have been traced to milk-supplies, but the method of dissemination is not quite clear owing to our ignorance of the causal organism. It has been believed that the virus might be derived from the cow, but there is no conclusive evidence to this effect.

More probable is infection of bottles or utensils either at the farm, by the middleman, or in the home. Milk probably becomes infected with the virus of scarlet fever by contact with persons in early stages of the disease, or from bottles and utensils handled by them. According to Swithinbank and Newman the infection can be carried by garments, toys, books, bedding, etc. Milk infection from these objects is conceivable. Dust probably does not form a serious source of dissemination.

Investigation of scarlet fever epidemics is carried on in a manner similar to that of other milk-borne epidemics. Pasteurization of milk is an effective preventive measure, as in many other epidemics.

\section{Poisonous Milk}

Poisoning caused by milk and milk products has been reported repeatedly. Real poisoning may be due to the presence of mem- 
bers of the Bacillus enteritidis and paratyphosus group of bacteria. This kind of poisoning resembles meat-poisoning and may be accompanied or followed by infections of the alimentary tract. The poison is sometimes preformed in the milk.

The term "milk-poisoning" is occasionally used when babies are unable to tolerate milk. The milk may be perfectly normal and wholesome, but some infants have an idiosyncrasy in regard to cow's milk which has never been satisfactorily explained. In these cases the term milk-poisoning is misleading, and dairymen have been wrongfully suspected of selling really poisonous milk.

Accounts of milk-borne epidemics of scarlet fever can be found in Swithinbank and Newman, the Bacteriology of Milk, in Hygienic Laboratory Bulletin 56, and in Jordan's article, The Case for Pasteurization.

\section{Diseases Derived from Cows}

Any abnormal physical or nervous condition of the cow is followed by the production of a milk abnormal both in quantity and quality. With acute or chronic diseases the flow may stop abruptly. An observant milker may be of much service in the detection of disease, since a sudden decrease in quantity or a sudden strange appearance of the milk should be noted at once. The cow should be immediately separated from the herd and subjected to examination. Sometimes the quality shows degeneration before there is a decided decrease in quantity. The milk may acquire an off-taste, may coagulate rapidly; the amount of milksugar, ash, protein, and fat may increase or decrease from the normal average, and the reaction may turn alkaline, while the consistency may become thin or stringy. Any one or more of these changes indicate some pathologic condition. The most common and, therefore, the most important disease met with is tuberculosis. Foot-and-mouth disease is of more common occurrence in Europe than in this country, although of late years there have been several severe epidemics of the disease in the United States. Other diseases of less importance derived from cows are mastitis or garget, anthrax, rabies, actinomycosis, botryomycosis, cowpox, milk sickness, contagious abortion, and gastro-intestinal troubles. In goats Malta fever is of some importance.

Tuberculosis.- It is difficult to estimate the amount of tuberculosis among cattle, since it is almost impossible to examine all animals. Tuberculosis is a communicable disease and is caused by the tubercle bacillus, discovered by Koch in 1882 . Following the discovery of this bacillus the belief was prevalent that bovine 
and human tuberculosis were caused by the same organism, but Theobald Smith called attention to distinct differences between the human and bovine bacilli. Koch in 1901 went so far as to intimate that the disease in man and cattle was caused by totally different organisms, and that no precautions were necessary to protect human life against infection with the bovine bacillus. This statement has so effectively stimulated scientific investigation that an enormous amount of work has accumulated to indicate that, although infections of man with the bovine tubercle bacillus are fewer than infections with the human variety, bovine infections and deaths resulting therefrom are frequent enough to seriously engage the attention and activity of sanitarians.

Tuberculosis among cattle has both an economic and a sanitary aspect.

The loss of live stock from tuberculosis is difficult to measure. Cattle suffering from the disease lose in value whether they are beef producers or milkers. A single animal suffering from tuberculosis may infect a whole herd. The loss of live stock from tuberculosis is enormous. Probably at least 10 per cent. of dairy cows are tubercular, and loss among hogs is no less. Moore found that among 421 herds in New York State, 302 contained cattle reacting to tuberculin. The total number of cows was 9633 , and 3432 of these reacted. Russell and Hoffmann, in Wisconsin, found 363 herds infected among 1562, and 263 herds were infected through purchase. The financial loss from tuberculosis among cattle and hogs is difficult to estimate, of course. Not only do some cattle and hogs die, but others lose flesh and the quantity of milk is materially reduced. It is certain that the loss amounts to millions of dollars annually. According to Melvin's estimate, the total loss among farm animals in the United States is at least $\$ 14,000,000$ annually.

The most important methods of dissemination of the disease are these:

1. Contact with infectious material in stables, railway cars, in pastures, etc.

2. Introduction of diseased animals into sound herds, either by purchase or by contact at public exhibitions.

3. Feeding calves on unpasteurized milk, skimmed milk, or whey from infected animals.

1. Tuberculosis is an insidious disease of unknown and probably variable incubation period. Cows may have the appearance of perfect health; they may eat well and show no symptoms of the disease and still be afflicted with it. In such cases the lesions are usually small. Progress of the disease is more or less'rapid, according to the resistance of the animal. Sanitary stables, 
clean animals, good food and water prolong the usefulness of the cow and may retard the progress of the disease. One of the most important means of communicating tuberculosis is through the excretion of large numbers of the bacillus with the feces of tuberculous cattle. It has been estimated that about 40 per cent. of tuberculous cattle which give no outward indication of the disease discharge tubercle bacilli with their excreta. After initial infection there is a period without discharge of tubercle bacilli in the dejecta, and this fact complicates the difficulties of ridding a herd of tuberculosis. Some bacilli are also expelled from the mouth and perhaps from the nose. Since tubercle bacilli are discharged in large numbers with feces, it follows that market milk is frequently contaminated with them.

Examination of raw market milk in large cities in this country and in Europe has shown that tubercle bacilli are frequently present. Earlier observations showed even greater frequency of tubercle bacilli than later ones, but cannot be relied upon, because the specific stain for tubercle bacilli was depended upon for diagnosis. It is now known that there are harmless acidproof bacilli widely disseminated on food and the bedding of cattle and, therefore, found in milk, which give a microscopic picture similar to that of tubercle bacilli in milk. Later investigators have depended for results upon infection of guinea-pigs that have been injected with the milk. To make this test the milk is centrifugalized and the sediment and cream united. Tubercle bacilli rise with the cream and sink with the sediment, so these two parts of the milk contain practically all the bacilli present. The mixture is then injected into guinea-pigs. However, other bacteria in the milk also rise with the cream and sink with the sediment, and are liable to cause infection. Therefore in order to obtain as many infections with tuberculosis as possible, at least three guinea-pigs should be injected with one sample.

Investigators in various cities have given the percentage of market milk containing tubercle bacilli at 5 to 17 , and even higher. A conservative estimate might place the average at 6 to 8 per cent. Milk from the same source will not always contain tubercle bacilli, and the relative numbers when they are present will vary. Therefore it is essential that a series of tests be made from each milk-supply. The usual experience is that tubercle bacilli appear in the milk intermittently, and that sometimes they are so scarce that when several guinea-pigs are inoculated but one of them will contract tuberculosis. Milk-supplies which contain tubercle bacilli at intervals are especially dangerous, since a false sense of security may be created by not finding the bacilli in every sample. It is more important to learn which supplies may occasionally 
contain tubercle bacilli than to determine the actual percentage of milk infected.

Since tubercle bacilli are frequently present in milk, it is selfevident that milk products may also contain them. Bacilli rise with the fat globules; consequently, cream contains more tubercle bacilli than the milk from which the cream was separated. Schroeder and Cotton have found that tubercle bacilli disappear from the skimmed milk and are found in the sediment and cream, whether the cream be gravity or separator cream. Therefore tubercle bacilli may be in higher concentration in butter than in milk. Furthermore, the bacilli retain their virulence in butter for a considerable period. According to the same authors, they are not materially attenuated in ordinary salted butter for forty-nine days and are highly virulent even after three months. Since butterine and oleomargarine contain some butter made from cream or milk, these products are not exempt from the possibility of harboring tubercle bacilli.

Since cream is liable to contain tubercle bacilli, any product prepared from it becomes a menace. Ice-cream, therefore, should be made only of heated cream. In buttermilk the danger is probably not great, because, as stated before, the bacilli rise largely with the fat which is removed as butter. But there remains the possibility that buttermilk may be contaminated with tubercle bacilli, and it is not known whether the acid in buttermilk has sufficient germicidal power to destroy tubercle bacilli.

Milk, cream, and buttermilk are always consumed within a few days, at the most, and living tubercle bacilli may be present. Cheese, however, is usually consumed after a period of ripening, and it has been found that tubercle bacilli die before the end of the ripening period. Harrison, after a series of experiments, decided that there is no danger from tuberculosis in Emmenthal and Cheddar cheese, as they are rarely consumed before they are four months old or more. However, the author found that cream cheese is not entirely free from danger, and it is reasonable to assume that cheeses which are eaten when fresh, as cottage cheese, for example, may contain virulent tubercle bacilli.

In the main, tubercle bacilli enter milk from either excreta or diseased udders. They may be derived from excreta, whether these are dislodged from the coat of the animal during milking or from dust in the air.

In a previous chapter it was shown that there is conclusive evidence that bacteria cannot pass through the healthy mammary gland. Investigators were puzzled for a long time by the presence of tubercle bacilli in milk from cows whose udders showed no tuberculous lesions. There are two factors which account for 
this phenomenon, the first of which is the existence of acid-proof bacilli which, when stained, simulate tubercle bacilli. This difficulty was eliminated when animal inoculation tests were recognized as the only reliable method of determining the presence of tubercle bacilli in milk.

The second fact is the presence of large numbers of tubercle bacilli in the dejecta of tuberculous animals. These dejecta communicate bacilli to the milk through the air or by any other means which permit the entrance of cow manure into milk. Schroeder has made extensive investigations of this subject, and has come to the conclusion that the dejecta are the chief source of contamination, inasmuch as he found that 40 per cent. of tuberculous cows emitted tubercle bacilli with the feces. All investigators do not agree with this opinion, and considerable uncertainty is involved in the results obtained, since some observers base their opinions on microscopic examinations, while others test the virulence on guinea-pigs. Peterson's results, for example, are by no means in agreement with those of Schroeder. Moore has stated that milk is usually infected with tubercle bacilli when it is taken from cows with tuberculous udders. It may, through contamination with feces or uterine discharges, be infected when drawn from cows with open lesions in the respiratory tract or organs of reproduction.

"Tubercle bacteria are not, as a rule, present in milk of cows that react to tuberculin and which, on careful physical examination, exhibit no evidence of disease."

Jordan and Arms found that 26.66 per cent. of feces from cows which were shown to be tuberculous by the tuberculin test and by autopsy contained tubercle bacilli.

Unquestionably, a large percentage of tuberculous animals discharge tubercle bacilli with their feces, and from this source the bacteria easily gain access to milk. The consequence is that milk from perfectly healthy animals may become contaminated with tubercle bacilli.

Diseased udders are surely the most prolific means of infecting milk with tubercle bacilli. Moore states that "the number of tubercle bacteria in market milk would be greatly reduced and possibly entirely (?) eliminated by having frequent and thorough physical examinations of the dairy cows, and the removal from the herd of all individuals showing evidence of disease."

Infection of cows with tuberculosis may occur by inhalation or by ingestion. The latter mode is probably more common than the former and, as a matter of fact, the disease frequently settles on the peritoneum. But opinions on the subject are not entirely in accord. Tubercle bacilli, like other bacteria, are destroyed by 
sunlight and injured by diffuse daylight. Consequently, when they are present in feces they are protected from light and retain their virulence. Briscoe found tubercle bacilli to live in cow manure for seventy-three days when exposed to weather conditions in a pasture in the shade, and for forty-nine days when exposed to sunshine. It is, therefore, desirable to construct stables so as to admit plenty of light and roomy enough to avoid crowding. Railway cars in which cows are shipped may be the means of communicating the infection on account of crowded conditions and the close contact of animals.

2. The plague may find a permanent foothold if diseased animals are ushered into a sound herd or if a tuberculous bull, for pairing, be introduced into the herd. Especially is this true in large herds. New animals are being purchased constantly, and these may be in the initial stages of tuberculosis. This can be avoided only by purchasing from herds known to be free from the scourge, but whether it is possible to know that a herd is entirely free from the scourge is questionable. Therefore all new animals should be tested with tuberculin and retested after about six weeks, since the injection of tuberculin renders them immune for a period up to six weeks, a fact which has led cattle dealers to deceive purchasers. In the intervals between testings the cows should be kept separate from the healthy herd, and it should be made compulsory by legislation that all animals responding to the tuberculin test be branded in some manner.

Herds of valuable cattle have been known to contract the disease at public exhibitions as a result of coming in contact with infected animals or infected discharges. Grazing on the same pasture with infected animals and drinking water from a common trough are dangerous.

3. A most prolific source of infection is through the distribution of whey from cheese factories or of skimmed milk from creameries. In Denmark distribution of these by-products is prohibited by law unless they are pasteurized, as pasteurization destroys tubercle bacilli. It can be readily understood that through the distribution of raw skimmed milk or whey tuberculosis can be spread from one herd of cows to another. These by-products are frequently used for feeding hogs, and as the latter are highly susceptible to tuberculosis there is a tremendous loss annually from the ravages of this disease.

There are two principal methods of diagnosing tuberculosis in living cattle: by physical examination and by testing with tuberculin.

Physical examination has its limitations. As stated before, cows do not show outward signs of tuberculosis for some time 
after infection. This period may cover several years. After the disease has started to develop certain symptoms begin to be apparent. Food does not seem to be well digested, the coat becomes rough, and the skin loses its normal elasticity. These symptoms are followed by a progressive loss of flesh and, later, by loss of appetite, bloating, and diarrhea. If the lungs are affected a cough develops, and when the disease reaches the udder, hard lumps are felt after milking. When postmortem examinations are made, tubercles may be found in any organ. The. tubercles are sometimes as small as millet seeds or peas, or may be several inches thick. Inside of the tubercles is a cheesy mass of yellow color or a dry gritty substance. Tubercles of the size of millet seeds or peas are frequently found attached to the peritoneum. This form of the disease is called "pearl disease" (perlsucht).

The chief limitation of physical examinations is the failure to disclose the disease at an early stage. Cows may have the appearance of perfect health, may give milk of normal composition; furnish an abundant supply of milk; even feed normally, and still harbor tuberculous lesions which, in the course of time, will develop into advanced tuberculosis. During early stages the animal is an unrecognized source of infectious material, endangering healthy members of the herd and causing contamination of the milk.

The tuberculin test is sufficiently delicate to disclose the presence of tuberculosis. Tuberculin was first prepared by Koch in 1890. For production on a large scale the procedure is as follows: A strain of tubercle bacilli is cultivated from sputum or from a tubercle of an animal dead from the disease. The medium for isolation may be agar, potato, blood-serum, or egg medium with 5 to 7 per cent. glycerin added to the medium. After several weeks a surface layer of bacilli will form and a film may cover the surface of the condensation water. From the surface growth or from the film a small amount is floated on the surface of a medium in a large Erlenmeyer flask. This medium is prepared as follows: One pound of chopped beef or veal is covered with 1 liter of water and digested over night. The meat is then pressed out, the volume brought up to 1 liter, and 1 per cent. pepton and 0.25 per cent. sodium chlorid dissolved. The solution is boiled and filtered, the reaction adjusted to 0.75 to 1 per cent. acid to phenolphthalein, and finally filtered again and sterilized. It need not be perfectly clear. It is then filled into Erlenmeyer flasks, each flask to contain 100 to 250 c.c. Tubercle bacilli contain a relatively large amount of phosphorus, and Dorset recommends, therefore, to add $\frac{1}{2}$ per cent. of acid potassium phosphate. 
After inoculation the flasks are incubated at $37^{\circ} \mathrm{C}$. When the surface is covered with a heavy film the fluid is shaken carefully so as to cause the film to sink, leaving enough surface growth to start a new generation. This process is repeated several times. The length of time required for sufficient growth is from four to twelve weeks. When freshly isolated strains are used the incubation period is longer than when strains have been recultivated for some time and have become habituated to the medium. Virulence of the organism is gradually lost, but the products are such as to produce an efficient tuberculin. After the incubation period the flasks are placed in a hot-air oven until the fluid boils. This destroys all living bacilli. The cotton plugs are removed, the fluid filtered, and evaporated over a water-bath. Koch evaporated his tuberculin to one-tenth the original volume. When the desired volume has been attained, 0.5 per cent. carbolic acid is added as a preservative. For use on human beings tuberculin is finally filtered through a Berkefeld filter for complete sterilization. The finished product is kept in sealed bottles in the dark.

Standardization of tuberculin is not very satisfactory, but several methods are in use. The amount of tuberculin necessary to produce a rise of $4^{\circ}$ to $5^{\circ} \mathrm{C}$. in a guinea-pig of 1 pound weight forms one standard; by another the amount of tuberculin necessary to kill a tuberculous guinea-pig is determined. Sometimes the amount of acid produced by the tubercle bacillus serves as a guide. It is assumed that the amount of acid corresponds to the growth that has taken place.

It takes considerable experience to make a test with tuberculin for tuberculosis in cattle. The normal temperature of cattle is not always the same, varying from 1 to 3 degrees, according to such circumstances as warm weather, the use of cold drinkingwater, or to disturbances in health. The temperature in different individuals is not quite uniform. The average for cows is $101^{\circ}$ to $102^{\circ} \mathrm{F}$, probably nearer to $102^{\circ} \mathrm{F}$. in the majority of cases. The best season for the test is when the weather is cool and the animals are kept most of the time in stables. The temperature of the animal to be tested is taken during the day every two or three hours and the tuberculin injected in the evening of the same day. Commencing early the next morning the temperature is taken again at regular intervals. The temperatures of the previous day and of the day following injection are then plotted on a chart and the curves compared. A sample of such a chart is shown in Fig. 190.

If the maximum temperature after injection is $2^{\circ} \mathrm{F}$. or more above the normal temperature, tuberculosis is indicated. A rise of 1.5 degrees is suspicious, and the animal should be retested 
after about six weeks. Injections are usually made subcutaneously in front of the shoulder.

The tuberculin reaction is considered an anaphylactic phenomenon. The "sensitizing" dose is the result of broken-down cells of the tubercle bacillus. Therefore if the animal is diseased the injection of tuberculin is the "intoxicating" dose which brings on the
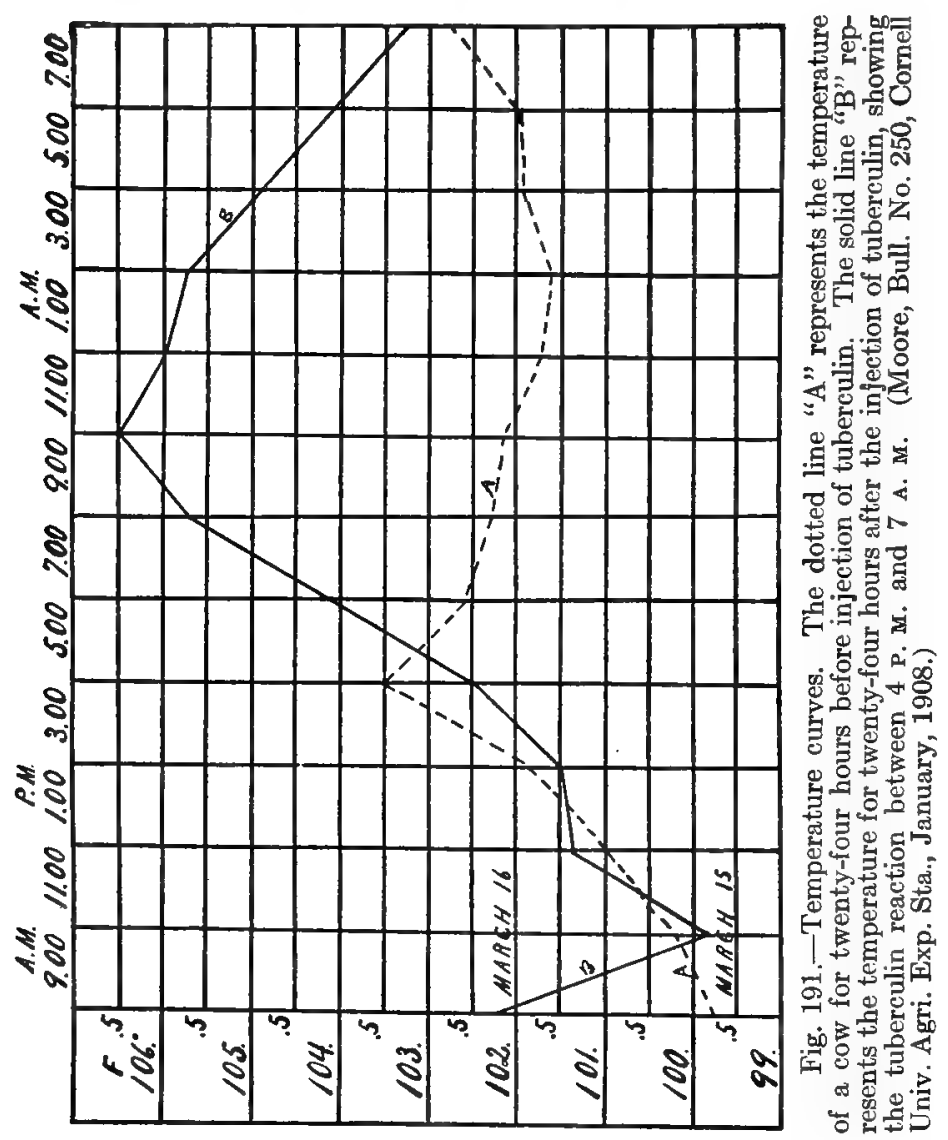

temperature reaction. If the animal is free from tuberculosis there will be no reaction following the injection of tuberculin.

Tuberculin is sometimes injected intradermally instead of subcutaneously. Haring and Bell claim that the intradermal method, which depends upon a local swelling and not on a rise in temperature, is preferable to the subcutaneous method under conditions that may modify the temperature curve, such as hot 
weather, fatigue, use of cold drinking-water, etc. The ocular method is also used occasionally, and has the advantage over

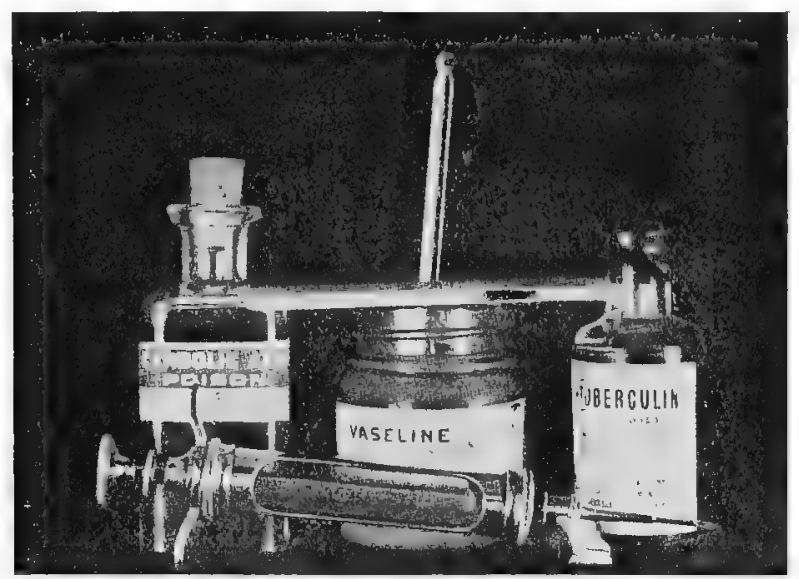

Fig. 192.-A tuberculin test outfit. (Ward and Haring, Bull. No. 199, Univ. of California Agri. Exp. Sta.)

other methods in that the observer can compare the normal, untreated eye with the eye receiving the tuberculin treatment.

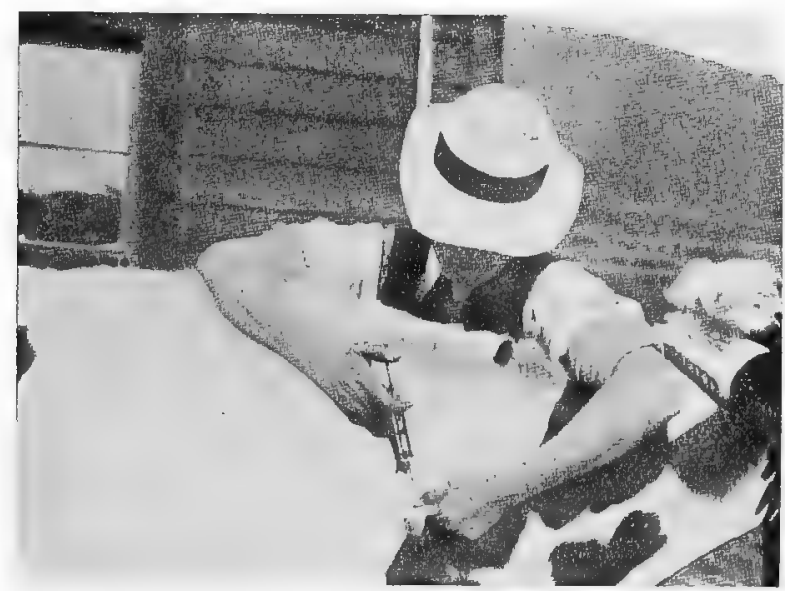

Fig. 193.-Manner of injecting tuberculin. (Ward and Haring, Bull. No. 199, Univ. of California Agri. Exp. Sta.)

The diagnostic value of tuberculin is variously stated to be 95 to 98 per cent. correct. There are several limitations to the test. When the disease has reached the last stages animals may 
not react, but in such cases physical examination is reliable. Sometimes animals but slightly affected do not react, the tubercle not having developed typically (occult tuberculosis); on the other hand, reacting animals sometimes fail to show lesions on postmortem examination. In the hands of experienced and careful veterinarians, however, it rarely happens that lesions are not found in reacting animals. The percentage of failures is really very small and cannot be used successfully as an argument against the efficiency of the tuberculin test.

The use of tuberculin as a diagnostic means for tuberculosis has aroused much antagonism among producers. Among the prejudices existing is the claim that tuberculin has caused diseases and abortions in cows. Careful observation has invariably failed to confirm such claims. Abortion is a common malady among cows and has never been successfully traced to tuberculin injections. The fever produced by tuberculin in reacting animals and other slight derangements disappear, as a rule, in forty-eight hours. Another source of prejudice is the immunity caused by the injection of tuberculin. This immunity may last for six weeks. An animal retested during this period will not react, and producers have used this phenomenon as an argument against the reliability of tuberculin. Unfortunately, this same immunity has been created in cattle by unscrupulous dealers. The purchaser of cattle that are "doped" with tuberculin finds them immune when tested and believes them to be free from the disease. A subsequent test then shows the deception. In any case it is essential that a reliable preparation be used for this test.

The producer often fails to realize that a herd free from tuberculosis is more productive of profit than an infected herd. Although tuberculous cows in the initial stages of the disease may yield normal quantities of milk, their period of usefulness is relatively short, and consequently the profit to the producer not what it might be. The same argument holds good for beef cattle. However, the temporary loss is sometimes enormous, and it is only fair to the cattle owner that the community bear part of the loss caused by slaughtering consumptive cattle. Unless the disease is far advanced the beef value remains. Tuberculous cattle are condemned as food only when they are in advanced stages of the disease. Danger to human health from the use of infected meat is slight, since the bacilli are destroyed by cooking-roasting, for example. When the carcase is a total loss an indemnity should be paid by the state or city. Only by such means is it possible to interest the producer in freeing his herd from tuberculosis. At best, this is a lengthy and expensive process. The antagonism of producers has led in a few cases to 
legislation which forces milk from tuberculous cows upon the consumer.

There are two systems in vogue in different countries for ridding herds of tuberculous cattle and at the same time minimizing the temporary losses. The system practised first in Denmark is known as the Bang system. Under this system all animals are tested with tuberculin. Reactors are separated from non-reactors by being placed in different stables or in divided stables. The two herds never come in contact with each other and occupy separate pastures when out of doors. All animals with advanced tuberculosis are slaughtered. Calves from infected animals are removed immediately after birth and fed upon pasteurized milk or milk from healthy cows. The calves, when old enough, are placed with the herd of non-reactors. This herd is then tested every six months and reacting animals removed. Thus a herd free from tuberculosis is raised and the diseased animals gradually eliminated. In the meantime reacting cows are useful for breeding purposes and for producing milk to be pasteurized for feeding calves.

The Ostertag system originated in Germany. This system is based on clinical examination instead of tuberculin testing. All animals showing lesions on clinical examination are slaughtered. Calves from all other cows are removed immediately after birth, are kept separate, and are fed on pasteurized milk or on milk from healthy animsls. Later they are placed with the other cattle. Clinical examination is repeated frequently.

While the Bang system eliminates all cows suffering from tuberculosis, no matter how insignificant the lesions, the Ostertag system removes only advanced cases, on the theory that infection is spread chiefly by the latter, and that infection from early cases is so slight as to be negligible. That this theory is correct is by no means generally believed. Animals showing no outward signs of tuberculosis have been known to disseminate tubercle bacilli with their excreta. It happens also that infection of the udder is not recognized for some time, with the result that tubercle bacilli are discharged directly into the milk. The Ostertag system, therefore, cannot be as successful as the Bang system.

Both methods entail considerable loss to the herd owner. In Denmark owners are permitted to use milk from reactors with milk from healthy cows, since it is subsequently pasteurized. Only milk for infant feeding is excepted. Also, there are no restrictions on the selling of infected animals. In countries where such restrictions exist producers suffer great hardships.

The International Commission for the Control of Bovine Tuberculosis recommends the following procedures: 
"Group 1.-Where 50 per cent. or more of the animals are infected. 1. Eliminate by slaughter all animals giving evidence of the disease on physical examination.

"2. Build up an entirely new herd from the offspring. The calves should be separated from their dams immediately after birth and raised on pasteurized milk or on that of healthy cows. This new herd must be kept separate from any reacting animals.

"3. The young animals should be tested with tuberculin at about six months old, and when reactors are found at the first or any subsequent test the others should be retested not more than six months later. When there are no more reactors at the six months' test annual tests should thereafter be made. All reacting animals should at once be separated from the new herd and the stables which they have occupied thoroughly disinfected.

" 4 . When the newly developed sound herd has become of sufficient size the tuberculous herd can be eliminated by slaughter under inspection for beef.

"Group \%.-Herds where a small percentage (15 per cent. or less) of the animals are affected. The procedure is as follows:

" 1 . The reacting animals should be separated from non-reacting ones and kept constantly apart from them at pasture, in yard, and stable.

"(a) Pasture: The reactors should be kept in a separate pasture. This pasture should be some distance from the other, or so fenced that it will be impossible for the infected and non-infected animals to get their heads together.

"(b) Water: When possible to provide otherwise, reacting cattle should not be watered at running streams which afterward flow directly through fields occupied by sound cattle. The water from the drinking-trough used by infected animals should not be allowed to flow into stables, fields, or yards occupied by sound animals.

"(c) Stable: Reacting cattle should be kept in barns or stables. entirely separate from the ones occupied by sound animals.

" 2 . Calves of reacting cows should be removed from their dams. immediately after birth. Milk fed these calves must be from healthy cows; otherwise it must be properly pasteurized. These calves should not come in contact in any way with reacting animals.

"3. The non-reacting animals should be tested with tuberculin in six months, and when reactors are found at the first six months' or any subsequent test the others should be retested not more than six months later. When there are no more reactors at the 
six months' test, annual tests should thereafter be made. All reacting animals should at once be separated from the new herd and the stables which they have occupied thoroughly disinfected.

"4. The milk from reacting animals may be pasteurized and used.

"5. Any reacting animal which develops clinical symptoms of tuberculosis should be promptly slaughtered.

"6. An animal that has once reacted to tuberculin should under no circumstances be placed in the sound herd.

"7. As soon as the herd has become well established, infected animals should be slaughtered under proper inspection.

"Group 3.-Herds where a large number (15 to 50 per cent.) of the animals are diseased. The procedure is as follows:

"Herds that come within this group should be dealt with either as in Group 2, where the herd is separated, or as in Group 1, where all of the animals are considered as suspicious and an entirely new herd developed from the offspring."

When a stable has been occupied by tuberculous animals it should be disinfected before a sound herd is admitted. Gaseous disinfectants are not suitable, since it is difficult to seal a barn tightly enough to prevent leakage of the gas. Milk of lime or, better, milk of lime with 1 pound of chlorid of lime for each 3 gallons, crude carbolic acid, and liquor cresolis compositus, U. S. P., are recommended for disinfection. Milk of lime with chlorid of lime is probably the best all-round disinfectant for a stable, as phenol compounds have a strong odor which may be imparted to the milk. Before disinfection the walls, ceiling, floor, and all fixtures should be washed. The disinfectant is then sprinkled on all surfaces. Mangers can be washed with a strong solution of copperas. Bedding and other loose material should be burned. The grass in pastures where tuberculous cattle have grazed should be plowed under or burned.

Immunizing cattle against tuberculosis was first tried out by Koch, while an antitoxin was prepared by Maragliano. Several investigators have followed similar lines of work, with the result that a temporary immunity was established, but none of sufficient duration and intensity to be of practical value. Injection of human bacilli into cattle also produces a limited degree of immunity. Von Behring's "bovovaccine," an attenuated culture of living tubercle bacilli of the human type, has been tested rather extensively. Experiments with bovovaccine have been carried out by Russell and Hoffmann. The authors conclude that in view of the expense connected with the process, and since only young cattle can be treated, the practical usefulness of the treat- 
ment is questionable. Other difficulties present themselves, such as the length of time required to finish vaccination and the necessity of keeping the vaccinated animals separated from each other. Furthermore, in spite of vaccination, some animals become infected with tuberculosis and the immunity is always short-lived, lasting for a period of from one to two years. As a practical method for combating bovine tuberculosis, vaccination has proved a failure up to the present time.

It is clear that from an economic standpoint eradication of bovine tuberculosis is much to be desired. Another aspect of the question is the relation of the disease to human health. Milk is one of the most important articles of diet, especially in infancy. It has been shown that milk is frequently contaminated with living tubercle bacilli of the bovine type. The infectiousness of bovine tubercule bacilli for man is, therefore, a question of utmost importance. Tuberculosis is the commonest disease of man and of cattle alike. It has been stated that Theobald Smith was the first to prove conclusively that there are differences between bacilli of the human and bovine types. Human bacilli gain access to the system through inhalation, although infection of the alimentary tract from contaminated food may play an important rôle. Tubercle bacilli enter chiefly with food, except in the case of accidental, external infections contracted by veterinarians, butchers, and others occupied with slaughtering cattle.

It was formerly believed that inhalation was by far the most common means of infection. For some years this view has lost ground, and proofs are accumulating which lay stress upon infection through the digestive tract. It has been shown that tubercle bacilli can pass through the intestinal mucosa and through the mesenteric glands. Intestinal tuberculosis is relatively rare in adults. In infancy the mesenteric glands are easily affected. Consequently, intestinal tuberculosis is much more common among infants than among adults. Moreover, it has been shown that dust particles do not penetrate the lungs, as a rule, beyond the first branches of the bronchi. Tuberculosis of the lungs commences in the capillaries, and this has been considered proof of the hematogenous origin of the disease.

Transmission of tuberculosis through the air is now considered to be less frequent than it was formerly believed to be. Of course, tubercle bacilli are emitted with sputum of patients, but the sputum is a sticky, gummy substance which is difficult to break up and which settles quickly. By the time sputum is so completely dried and pulverized that it can be carried into the air as dust, the bacilli have been exposed to sunlight and desiccation for a long time. The majority of bacilli are probably de- 
stroyed and the surviving ones attenuated. The danger from inhalation is naturally greater in houses than in the open air, because the effect of sunshine indoors is limited and the dust raised may carry tubercle bacilli that have not been seriously affected by light.

Communication of tuberculosis through sputum is probably not as important as has been generally believed. The bacilli which gain entrance through the intestinal tract are carried there with food. Bovine bacilli introduced with milk or milk products have not been exposed to adverse conditions as have bacilli in sputum. In milk and butter they have been shown to retain virulence for several months, and they can, therefore, reach the intestinal tract in fully virulent condition. The relation of bovine tuberculosis to human health hinges on the question of infectiousness of tubercle bacilli of the bovine type for man.

Koch stated in 1901 that the question whether man is susceptible to bovine tuberculosis has not been definitely settled, but that if such a susceptibility exists it is very rare. He stated that he believed that no special protective measures were necessary. Von Behring takes the opposite view, believing that tuberculosis in man is commonly contracted in childhood through drinking infected milk. Both views may be extreme, but an enormous amount of work has shown that man is susceptible to bovine tuberculosis, and that, especially among children, the percentage of cases due to bovine infection is considerable. It is unnecessary to discuss in detail the work of many European and American investigators whose results are very concordant. Commissions were appointed by the English and German governments to investigate the question and a great deal of work has been done in the government laboratories in Washington, D. C., and in a number of State Experiment Stations. The most comprehensive work on this subject was published in two papers by Park and Krumwiede. These authors investigated 1242 cases sent to them at random from various hospitals. The results show that among adults of sixteen years or over suffering from tuberculosis-1.27 per cent.; among children between five and sixteen years-23.53 per cent.; and among children below five years-23.21 per cent. were infected with bovine tubercle bacilli. The two types were distinguished by cultural characteristics-morphology and virulence for rabbits. The medium used for cultivation was glycerinated egg medium and glycerinated potato. The presence of glycerin favors clear distinction of properties. The chief differences between human and bovine tubercle bacilli may be summarized as follows (Park and Krumwiede.): 
Bovine.

Growth more or less moist, not adhering to the surface of the medium; is diffusible in $\mathrm{NaCl}$ solution or broth; initial growth is always sparse; pigment appears only after long cultivation.

In glycerin broth alkali is produced until original acidity has been neutralized, terminal reaction alkaline.

After isolation bacilli are shorter and plumper than the human type. After cultivation they stain evenly.

Are highly pathogenic for cattle, causing generalized tuberculosis, which usually terminates fatally.

$0.01 \mathrm{mgr}$. of surface growth injected intravenously into rabbits causes progressive generalized tuberculosis, terminating fatally in fortyfive to sixty days.

Guinea-pigs highly susceptible; generalized tuberculosis after injection.

\section{Human.}

Growth is raised, wrinkled, dry; adheres tenaciously to the medium; diffuses with difficulty in $\mathrm{NaCl}$ solution; growth luxuriant; pigment formation marked.

In glycerin broth alkali is produced until acidity is nearly neutralized, then acid increases until original acidity is reached or exceeded.

After isolation bacilli are longer than bovine type, and after cultivation stain unevenly.

Pathogenicity for cattle slight; tuberculosis local and recovery usual.

$0.01 \mathrm{mgr}$. of surface growth injected intravenously into rabbits causes either no lesions or lesions confined locally to organs; never progressive tuberculosis.

Guinea-pigs slightly susceptible; tuberculosis usually localized, or generalized only after several months.

There are many observations on record which seem to show that there are transient forms between the two extreme types. Park and Krumwiede state, after careful study of the evidence: "Each type shows certain differences, the most important for separation being those found culturally and in .virulence. The great majority of cultures group themselves around two extremes, from which there are a few cultures showing variant characteristics. There is no overlapping of characteristics.

"These two types are probably different because of residence in different hosts over long periods of time, and as such are stable. The evidence in favor of rapid change of type is incomplete and inconclusive."

The authors explain reported findings by insufficient control observations. Inoculation of human tubercle bacilli into calves and repeated passage through calves had led some observers to believe that the original human strain was converted into a bovine strain. In these cases either virulence was increased, with no correlation of changed culture characteristics, or when culture characteristics were changed apparently a natural infection of the calves with bovine bacilli had existed so that mixed cultures were obtained. In other cases cultures were studied 
before they were many generations old. As a matter of fact, after a number of generations the culture characteristics of the two strains approach each other and differentiation becomes more difficult. On the other hand, human beings have been infected with bovine tubercle bacilli in slaughter houses, and later pulmonary tuberculosis and tuberculosis of internal organs have developed. It is possible that the original infection with bovine tubercle bacilli was superimposed upon infection from human sources. In all these cases transformation of the two types of tubercle bacilli is not a necessary conclusion.

It is clear that the bovine type of tubercle bacilli is distinct from the human type, and that the human type is more virulent for man than the bovine type. In adults tuberculosis caused by bovine bacilli is rare and might perhaps be called negligible, if it could be safely assumed that Von Behring's theory of infection in childhood is incorrect. In children bovine infections constitute about one-fourth of all cases of tuberculosis, and $6 \frac{1}{3}$ to 10 per cent. of the total fatalities from tuberculosis among children are due to bovine infections. This is surely not a negligible quantity. The necessity of freeing milk-supplies from living tubercle bacilli is obvious. This problem must be attacked, and has been attacked with some success by two procedures: 1, Through eradication of tuberculosis among milk cows, and, since this requires much time for successful completion, 2 , by pasteurization of all milk.

The following figures given by Kiernan show what has been accomplished toward the eradication of tuberculosis among cattle in the District of Cloumbia during the years 1910 to 1917:

THE ERADICATION OF TUBERCULOSIS IN THE DISTRICT OF COLUMBIA BY THE USE OF THE TUBERCULIN TEST

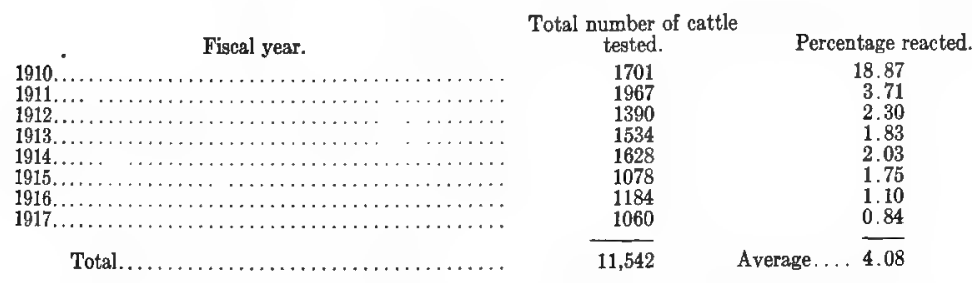

Foot-and-mouth Disease.-This disease is widely disseminated in European countries, and quite a number of sudden epidemics have been experienced in this country. The cause of this disease is an ultramicroscopic organism. It is an affection of the mucous membrane of the mouth and of the skin between the toes and above the hoofs. Vesicles form and later rupture. Sometimes the udder is affected. The milk from diseased cows 
suffers the loss of solid constituents, except the ash, which remains constant or even increases. The disease is highly infectious for cattle. Infection of man takes place by consumption of infected milk or sometimes by contact. In man vesicles form on the mucous membrane of the mouth, sometimes on the hands, ears, breast, and arms. Temperature accompanies the other symptoms. The digestive tract is affected, and vomiting and diarrhea follow. Children are very susceptible to the disease, but the disease is rarely fatal. Efficient pasteurization of the milk destroys the infection.

Mastitis, or garget, is a disease of the udder which is very wide-spread, much more so than is generally assumed. It has been stated by some authorities that there is probably no herd that is entirely free from mastitis. The disease assumes either a chronic or an acute form. Symptoms in the chronic form may be sufficiently insignificant to escape attention for some time. There are intermediate stages between the two forms, so it is not surprising that cases of mastitis are actually found in herds which have been subjected to a painstaking examination and which have been thought to be free from the disease.

When cows suffer from mastitis the milk undergoes material changes in appearance, taste, and composition. These changes are more pronounced as the disease becomes more acute. During chronic attacks or at the commencement of the acute stage of the disease, the changes are slight and sometimes difficult to detect. In well-developed, acute cases parts of the blood pass into the milk and the number of body cells becomes enormously increased. However, there is no definite relation established between the number of body cells and pathologic conditions. If the disease is acute the udder enlarges, the temperature rises, and the milk becomes stringy, bloody, or yellow. During chronic attacks the changes progress slowly. At first the milk seems normal, but later becomes thick, slimy, and may contain red blood-cells. On standing, a yellowish sediment appears. Instead of becoming thick and slimy, the milk may appear thin, as though watered. The taste turns bitter. It is a relatively easy matter for the milker to detect these changes in the milk if he is attentive. Close questioning of milkers by a veterinarian may give much aid in locating affected animals. When the milk becomes thin a laboratory test may give the impression that the milk has been watered. This is an additional argument to show that single tests should not be relied upon to judge the quality of milk.

The following are the most common changes which may arouse suspicion: The fat content may become abnormally high or low; the lactose may diminish; the total solids and plasma solids may 
decrease; heat-coagulable albumin may increase remarkably, while casein decreases. The reaction is decidedly alkaline and alcohol coagulates mastitis milk without the presence of acid. Some enzyms, especially catalase, increase in quantity. Coagulation due to acid or rennet action is usually delayed.

Mastitis may be caused by several kinds of bacteria, but streptococci are by far the most common cause. Other organisms are Bacillus coli and staphylococci, and occasionally members of the paratyphoid group of bacilli.

Streptococcus mastitis is extraordinarily common. Once it has gained a foothold in a herd, it is difficult to eradicate, especially if the pernicious habit of spilling the first few streams of milk on the floor is practised. By this means mastitis streptococci are disseminated through the air and by direct contact. With increasing care and cleanliness dissemination becomes less general.

The intensity of the disease depends upon several factors, the most important of which is perhaps the relative virulence of the organism, which, as is well known, may vary within wide limits. The affected part or parts of the udder, as a rule, degenerate as a consequence of the disease. In many cases the animal never recovers. The individual susceptibility is an important factor, and accidental lesions of the udder may afford opportunity for the streptococci to gain a foothold.

It is of importance to recognize cases of mastitis at an early period of the disease. Clinical examination will frequently fail if the disease is in its initial stage or is of the slowly developing, chronic type. Certain laboratory tests have been devised for the discovery of the disease. Some of the tests are based on the presence of body cells in large numbers accompanied by long chained streptococci; other tests are the catalase test (see page 237) and the alcohol test (see page 208).

Much importance has been attached by some sanitarians in the past to the number of leukocytes in milk. Methods for enumerating leukocytes have been devised by several authors. The commonest one is the smeared sediment test, which consists in smearing the sediment of centrifugalized milk on a slide, fixing and staining with methylene-blue, and counting the cells in a field of the immersion lens. The first method was devised by Stokes and Wegefarth. Ten c.c. of the milk were placed in a centrifuge and whirled for five minutes. After the supernatant fluid was poured off a loopful of the sediment was spread on a slide, the fat dissolved with ether, and the film then stained with methylene-blue. Ten fields of the microscope were counted and the standard fixed at five cells per field. Above this number, pus was supposed to be indicated. From five cells per field the 
standard was raised to ten by Bergey. The method is evidently inaccurate.

Slack's modification of the method is used in many laboratories. The milk is placed in small tubes, each end of which is closed with a rubber stopper. The tubes are then centrifuged, and the sediment and cream-both of which adhere to the rubber stoppers-are spread on a slide, stained, and examined microscopically.

An improved method was proposed by Doane and Buckley. It was modified by Russell and Hoffmann, who found that cellular elements are precipitated with greater ease and that a larger count is obtained from heated milk than from raw milk. The method is carried out as follows: The sample of milk is heated to $85^{\circ} \mathrm{C}$. for one minute. Ten c.c. of the heated sample are then whirled in a centrifuge at a speed of about 2000 revolutions per minute for twenty minutes. The cream is removed with a cotton swab. The supernatant milk is removed with a pipet, leaving 0.5 c.c. of milk. Two drops of a saturated alcoholic solution of methylene-blue are added to the sediment, and then the tube is kept in boiling water for two or three minutes. Enough water is added to bring the volume to 1 c.c. A Thoma-Zeiss blood counter is used for counting the cells. The cells should be counted in several hundred squares to obtain accurate results. The average number of cells counted per square is multiplied by 200,000 to arrive at the number per cubic centimeter of milk.

Trommsdorff proposed a method radically different from the foregoing ones. This method calls for special tubes which are drawn out to capillary points. They are graduated from 0.001 to 0.02 c.c. Ten c.c. of milk are whirled for a few minutes at a speed of 1500 to 2000 revolutions per minute and the amount of sediment read in the graduated capillary tube. If the sediment is yellow or pink, there is reason for suspicion. The sediment may be large on account of dirt in the milk and, consequently, the test is not always reliable.

The latest and most accurate method is the one devised by Prescott and Breed. The sample is well shaken and 0.01 c.c. removed with a specially constructed pipet with a rubber bulb. The amount is spread evenly over $1 \mathrm{sq}$. $\mathrm{cm}$. of an ordinary slide. The smear is dried by gentle heat, the fat dissolved out with xylol, and the slide then immersed in alcohol for a few minutes for fixation. The slide is then dried and overstained with methylene-blue and decolorized with alcohol. The cells show up clearly in a blue field, the background consisting of the dried plasma solids. Smears should be made in duplicate, as it is sometimes difficult to obtain an even spread. The diameter of the field is 
then adjusted by means of the draw-tube to equal $0.16 \mathrm{~mm}$. Each field then represents $0.005 \mathrm{sq}$. $\mathrm{cm}$., and each cell seen is equal to 500,000 per cubic centimeter of the sample. For accurate work a hundred fields should be counted. For routine work a lower power can be used and a smaller number of fields counted.

The method of Prescott and Breed has thrown considerable light on the significance of cellular elements in milk. The authors have shown that by centrifuging milk the number of cells thrown into the sediment may be all the way from one-fortieth to onehalf of the actual number present in milk. The balance rise with the cream, except a relatively small number which remain on the surface of the sediment and just below the lower line of the cream. Consequently, the number of cells in the sediment is so variable that no reliable estimate can be made. By the new method the cells are evenly distributed and enumeration is fairly accurate.

Sanitarians have placed faith in certain maximum numbers permissible. With the evolution of better methods the standards have been raised from time to time. Now Prescott and Breed report finding $10,690,000$ cells per cubic centimeter in a milk of apparently normal condition.

In a later paper Breed amplified on the sanitary significance of cellular elements in milk. It is known that milk under some conditions, aside from mastitis, contains large numbers of cells. Colostrum milk and milk during the last weeks of lactation, as stated before, contain exceedingly large numbers of cells. It is quite natural, therefore, that examination of a herd will show some members present which are in initial or terminal stages of lactation, or individuals that are suffering from actual disease. It is not surprising when a relatively high leukocyte count has been the cause of investigation that some abnormal milk is actually found, since some abnormal milk, in small quantity at least, is produced by almost every herd. Breed has found the number of cells in normal milk to be variable even in the milk from different quadrants of the same udder. The largest number is found in the strippings. The same author found $54,300,000$ cells in the strippings of an apparently normal cow, and stated that no ill consequences followed consumption of this milk. In the milk of 122 cows in apparently normal condition he found 49 per cent. with less than 500,000 cells per cubic centimeter, 29 per cent. with 500,000 to $1,000,000$, and 22 per cent. over $1,000,000$. The author states further that with the data available there is no relation traceable between the high number of cells and streptococcus infections of the udder; other pathologic conditions; colostral milk; milk from the terminal period of lactation, and certain temporary abnormal conditions of the cow. 
The question may be asked with justice, What is the real significance of leukocytes in milk? They are frequently spoken of as "pus cells." That this is a misnomer is evident. The resemblance to pus cells is chiefly due to the fact that they are more or less broken down in milk, which is to be expected in a lifeless fluid. In the light of present knowledge no sanitary significance can be attached to mere numbers of cellular elements. The kinds of cells existing in milk have never been systematically investigated. Hewlett, Villar, and Revis found in full milk from healthy cows chiefly "large uninuclears" and a few other cells, but at the beginning and end of lactation "multinuclears" were more prominent. They state their opinion, derived from the kinds observed, that it is not possible to recognize diseased conditions by means of microscopic examination of the cells present. Woodhead and Jones described finely granular eosinophils, coarse granular eosinophils, large, rounded or oval mononuclear cells, small cells corresponding to lymphocytes of the blood, extruded nuclei, large oval neutrophil cells, basophil cells, small type of basophil cells, large epithelial and fat cells, multi- or mononucleated cells, and red corpuscles. Luckhardt made an attempt at classification of cellular elements in separator slime. He found polymorphonuclear leukocytes of the neutrophil type, large mononuclear leukocytes, and small lymphocytes in all samples examined. Occasionally eosinophils were found and large cells of irregular outline which greatly resembled protoplasm with very pale nuclei. These latter cells were phagocytic and the author believes that they represent desquamated epithelial cells. Some polymorphonuclear leukocytes contained many cocci or short chains of streptococci. Breed thinks that normal milk contains cells derived from the body fluids of the cow, which are of two types: $(a)$ white blood-corpuscles, largely polynuclear and polymorphonuclear, and (b) epithelial cells. It is clear that investigations of the kinds of cells may lead to more intelligent interpretation of their significance, while simple enumeration seems to be of little value. 'The presence of fibrin with many cells has been demonstrated and may have more intimate connection with pathologic conditions of the udder.

There seems to be considerable evidence that when large numbers of leukocytes are found together with long-chained streptococci, mastitis is indicated. It has been shown that streptococci are present in practically all market milk, and that these streptococci are non-pathogenic for man and cows. Mastitis streptococci are pathogenic for cows. The question of differentiating between different varieties of streptococci has been widely discussed, and much experimental work has been done. The chief 
factors that have been studied are morphology, acid formation and coagulation in milk, acid formation from different carbohydrates, agglutination, hemolysis, relation to free oxygen, and virulence. Streptococci have been classified by various authors according to one or more of these properties.

The fundamental question is whether streptococci represent one species or a multiplicity of species. Both views have champions. However, the essential difference between the two views is not as great as might appear. It is difficult to determine accurately the meaning of "bacterial species." It has been shown that some strains of streptococci can adapt themselves with greater or less readiness to environmental conditions, and in doing so alter some properties materially. A brief summary of the present state of our knowledge on this subject follows.

Morphology.-Some streptococci form long chains; others, short chains. Experiments have shown that the character of the culture-medium has some influence on this property. As a rule, absence of carbohydrate in the food is conducive to long chain formation. Liquid media favor long chain formation. Media containing carbohydrate, as milk, for example, tend to shorten chains. There are exceptions, of course. The general tendency only is indicated. Some strains preserve certain properties with greater tenacity than others. The shape of the individual cell is subject to variation. Some strains are represented by strictly spherically shaped cells, others have cells of more or less elongation. The long diameter of elongated cells may be parallel to the axis of the chain or transverse. The chain itself may be continuous or may be so interrupted as to give the appearance of being composed of diplococci. The fundamental causes for these differences in morphology are obscure. Probably the rapidity of cell division has some influence. It has been recorded that cultures which originally were composed of one form, to all appearances, would later show some of the other forms, mixed with the original one. Transition forms are, therefore, common, but under what conditions they appear is not well understood.

Capsule formation has been observed in some strains of streptococci. It is sometimes assumed that passage through animals develops the property of forming capsules. This is unquestionably true with some strains, while others do not form capsules after repeated passage. It has not been conclusively demonstrated that capsule formation is always the result of passage through animals, and that it has a definite relation to virulence.

It is obvious that morphology gives no clue for differentiation of types. The composition of the medium and the particular environment which has surrounded the strain in the past are 
essential factors influencing the shape of the cell, chain formation, and capsule formation.

Acid Formation and Coagulation in Milk.-As a general rule, pathogenic streptococci produce less acid than saphophytic streptococci. Sometimes acid production is so small that milk does not coagulate for days, if at all. If streptococci with small acidproducing power are cultivated persistently on carbohydrate media, preferably dextrose media, the quantity of acid produced may increase materially. This is not always true, some strains responding with greater readiness than others. Vice versa, high acid producers may partially lose this property if cultivated on carbohydrate-free media. The more persistently a strain has become habituated to albuminous food, the less the power to ferment carbohydrates. In this respect strains also differ in susceptibility to changed environment. Therefore acid formation and coagulation are not criterions for differentiation.

Relation of Amount of Acid Formed from Different Carbohydrates.-By cultivation of a large number of strains of streptococci from various sources Gordon and Andrews and Horder have attempted to differentiate strains. They used litmus in the medium as indicator of acid production. Winslow and Palmer studied the amount of acid formed by titration with normal alkali. An extensive literature has accumulated, which, however, has not led to entirely uniform results. Attacking the problem from a different point of view, the writer has shown that by passage through animals, the fermentation properties of two strains of Streptococcus lacticus could be altered. In fact, the two strains, isolated from ice-cream and certified milk, did not have identical fermentation reactions to start out with, one fermenting mannite, the other failing to do so. Otherwise they had the typical reactions of Streptococcus lacticus. Considerable irregularity was noted after the strains had been passed through rabbits and guinea-pigs. Therefore acid formation from carbohydrates cannot be regarded as a permanent basis for differentiation of strains of streptococci, but may be of sufficient constancy to determine the immediate source from which the strain was isolated. That is to say, a strain isolated from a certain source will show definite fermentation reactions until it has been under a different environment for some time. After this, fermentation reactions may be altered.

Agglutination of streptococci has been investigated by a number of workers. The majority agree that agglutination with homologous strains is, as a rule, pronounced, but agglutination with other strains variable and sometimes negative. When polyvalent sera are prepared the reaction is different within wide limits with 
different strains used for immunization. Specificity of agglutination reactions in general is not sufficiently pronounced to serve the purpose of differentiation.

Hemolysis.-Hemolytic properties of streptococci have also been widely investigated. Saprophytic strains, as a rule, do not hemolize; pathogenic strains frequently do. However, the property is not always constant. Some strains retain hemolytic power with considerable tenacity through many generations on artificial media; others fluctuate or lose the property entirely. Passage through animals in many cases increases hemolytic power or may change a non-hemolytic strain into a hemolytic one. Environment seems to play as great a rôle in this reaction as in others. Hemolytic strains of streptococcus have been found in milk by several investigators, and the hemolytic property has been considered of sufficient constancy to warrant differentiation. This has been true especially in connection with studies of the etiology of septic sore throat in man. These studies have led several authors to the conviction that septic sore throat is caused by infection from human beings. Smith and Brown have isolated hemolytic streptococci from human throats; and Krumwiede and Valentine have isolated similar hemolytic streptococci from the udder of a cow. The latter authors assume that the cow was infected with these organisms from human beings. Davis believes that septic sore throat may be caused by streptococci derived from persons handling the milk, who first cause infection of the udder and thus communicate the virus to human beings. Both Davis and Mathers were able to produce intense mastitis in cows by injecting hemolytic streptococci directly into the milk ducts. The latter author states that while hemolytic streptococci injected into the milk ducts produce severe and persistent mastitis, when cultures of streptococcus lacticus are similarly injected they also cause lesions, but of less severity and duration.

Davis found hemolytic streptococci in 23 out of 92 samples of milk, and stated that they are more common in raw than in pasteurized milk. These hemolytic streptococci are, as a rule, not virulent, for animals, and produce reactions in milk which are identical with those produced by Streptococcus lacticus. The author thinks that "there are both hemolytic and non-hemolytic lacticus strains, both of which are non-virulent, active acidifers and coagulators of milk," and are readily distinguished from hemolytic streptococci of human origin.

Virulence of some bacteria for a particular species can be increased by passage through animals of the same species, but virulence for other animals may decrease at the same time. Nonvirulent bacteria may become virulent by passing through ani- 
mals. The writer has repeatedly shown that Streptococcus lacticus by rabbit and guinea-pig passage may become eminently virulent. Rosenow has stated that streptococci from milk resembled morphologically and culturally the streptococcus of rheumatism, and that other strains from milk showed selective preferences for joints, muscles, gall-bladder, and other organs. Virulence is variable and cannot be depended upon for differentiation. Virulence is sometimes expressed by a "virulence number." The virulence number is determined by the phagocytic property of leukocytes. A suspension of leukocytes is mixed with a suspension of the organisms to be tested. The number of leukocytes out of 100 in which no bacteria are found expresses the virulence number. If the number is higher than 60 , strep-

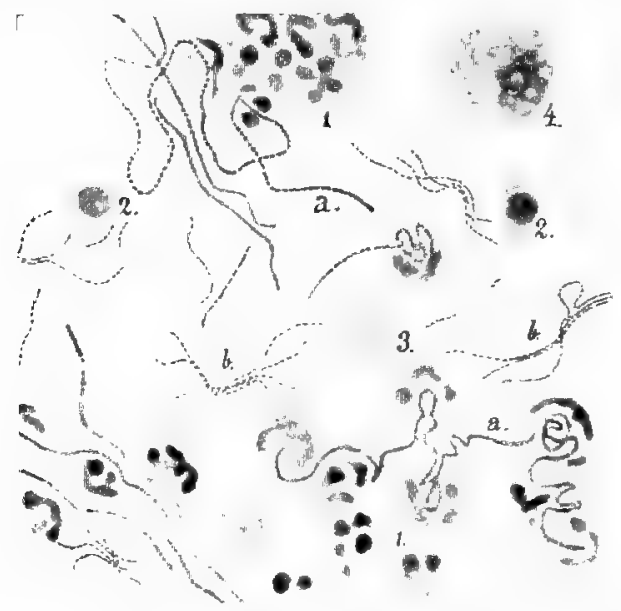

Fig. 194.-Sediment from mastitis milk twenty-four hours old (Ernst) : $a$, Mastitis streptococci; $b$, descendants of streptococei; $1,2,3,4$, cellular elements.

tococci are considered virulent. The result refers naturally only to the species from which the leukocytes were obtained. Therefore the test is only relative and of little practical value.

It is obvious that methods of differentiation between streptococci have yielded unsatisfactory results. The same thing is true of mastitis streptococci. Not only that different strains of mastitis streptococci cannot be separated from each other by their properties but also that it is not always possible to distinguish mastitis streptococci from saprophytic ones, including Streptococcus lacticus, which is nearly always present in milk.

If it is borne in mind that some properties of certain strains of streptococci persist for a reasonable period when conditions are not materially altered, it would seem that mastitis streptococci 
should show some specific characteristics by which they can be recognized. Indeed, this is frequently true. The shape of the

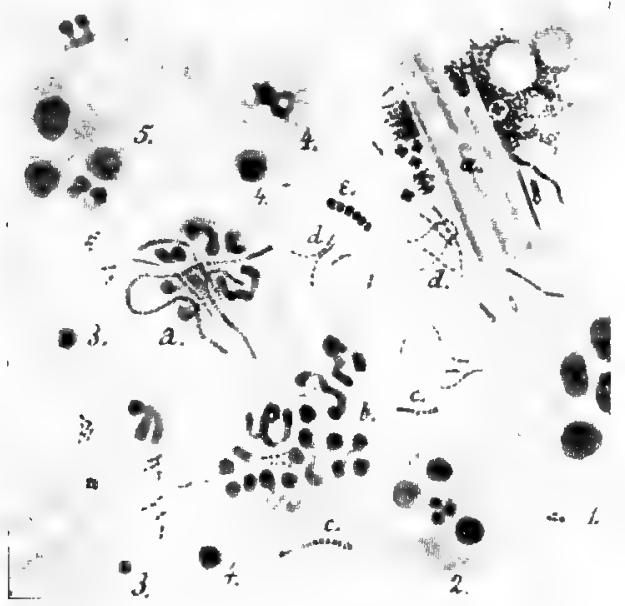

Fig. 195.--Sediment trom market milk (Ernst): $a, b, c$, Mastitis streptorocci; $d, e$, lactic streptococci; $1,2,3,4,5$, cellular elements.

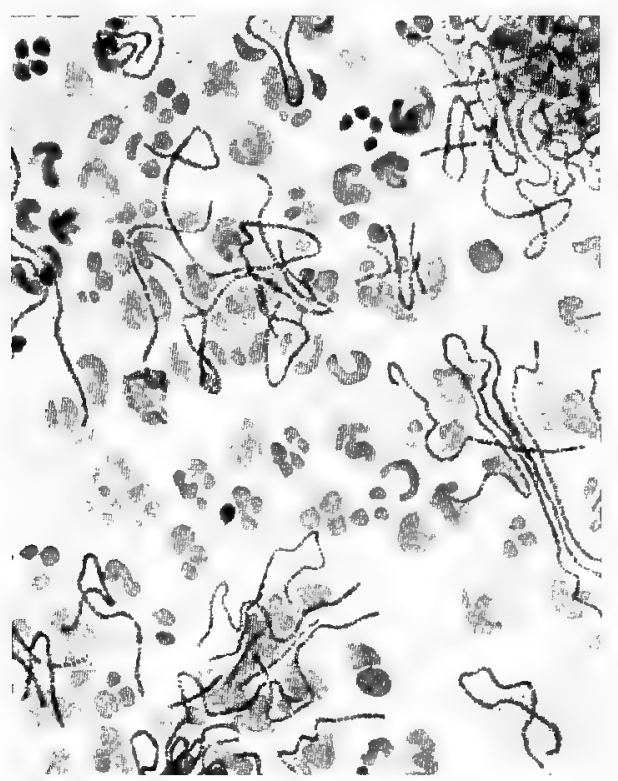

Fig. 196.-Long-chained streptococci from mastitis pus (Ernst).

cell is usually flat, the longer axis being at right angles with the axis of the chain. This "picket-fence" shape is quite common in 
mastitis streptococci. In addition, they usually appear in long chains. There seems also to be some relation between the number of leukocytes in the milk and the length of chains formed by streptococci. When large numbers of leukocytes and longchained streptococci appear the microscopic picture is fairly characteristic. A smear made from centrifugal sediment from mastitis milk forms a reasonably certain guide for further investigation, and in most cases leads to discovery of one or more animals with acute mastitis in the suspected herd. The amount of sediment is naturally large when pus resulting from an udder infection is in the milk. The Trommsdorff method is based on this fact, and is a fairly reliable guide if foreign matter can be excluded from the centrifugal sediment (Figs. 194-196).

Of course, milk which precipitates a sediment of this nature contains different strains of streptococci, though mastitis streptococci are present in abundance if the disease has progressed beyond the initial stages. Isolating streptococci from the sediment may lead to erroneous conclusions. Very careful study of the strains isolated is necessary, and with our limited knowledge of streptococci it is difficult to know which strain is really responsible for the disease in the cow. Pathogenicity for experimental animals is not a safe guide, since pathogenicity for one species furnished no proof of pathogenicity for other species. When mastitis milk is injected into guinea-pigs it frequently causes lesions, but not invariably. In fact, about as many guinea-pigs are affected as remain without untoward results, and among the former, Bacillus coli infection is as frequent as streptococcus infection. This shows that streptococci which are highly virulent for cows have but limited pathogenic powers for guinea-pigs. Milk from severe cases of mastitis has been fed to guinea-pigs without the slightest effect beyond that of furnishing food.

If lactic streptococci can adapt themselves to a protein diet and then become virulent, it is not impossible that the same streptococci which cause common souring of milk may be the cause of mastitis if some accidental lesion in the udder affords them a foothold. Indeed, Mathers has shown that injections of cultures of Streptococcus lacticus into the milk-ducts of a cow did produce a mastitis, although it was of relatively light nature and of short duration. It is evident, then, that innocent streptococci may become virulent. Passing from one cow to another, they may gradually acquire virulence. As a rule lactic streptococci are scarce in the udder, but there are cases on record where they were present in large numbers. When this happens udder diseases are not necessarily the consequence, but an udder lesion caused by accident or ill treatment may give the disease a start. 
Ill effects after consumption of mastitis milk by human beings have been reported in some instances. It is surprising, however, that such instances are not far more numerous than they actually seem to be, since the disease is so wide-spread and is recognized only in relatively few instances. The symptoms reported after consumption of mastitis milk are usually gastro-intestinal disturbances, accompanied by vomiting, diarrhea, and abnormal temperature. A number of epidemics of sore throat traced to infected milk-supplies have been reported in England. They have been frequently connected with milk from herds in which mastitis was found to exist. This subject has been discussed previously.

All efforts to differentiate mastitis streptococci from streptococci of human diseases of the throat have not given entirely satisfactory results as yet. In essential properties they are not distinguishable from lactic streptococci, although some authors consider hemolysis sufficiently constant to constitute a differential feature. While it has not been conclusively proved, Streptococcus lacticus may become pathogenic if it is able to obtain a foothold in some udder lesion. In the present stage of our knowledge it is not justifiable to consider mastitis streptococci and lactic streptococci identical, and milk infected with mastitis streptococci should not be permitted to be sold. It is not possible to determine with absolute certainty whether mastitis milk is present; at least not when the admixture is small or if it is derived from chronic or initial cases. Well-developed mastitis can be located with some certainty by the appearance of many leukocytes associated with long chains of streptococci.

Mastitis caused by staphylococci and by Bacillus coli are relatively scarce, and the milk causing this mastitis should be excluded from the market as far as possible.

Anthrax.-Danger of infection with anthrax through milk is not great. Usually the secretion of milk ceases with the beginning of the disease, although the flow of milk may continue for some time. Anthrax bacilli gain access to the milk during the last stages of the disease only and have occasionally been demonstrated in milk. There is small danger from vegetative forms of anthrax bacilli, since they are destroyed by the digestive juices, but the spores are more resistant. The disease is very common in European countries, causing enormous loss of cattle, and it is astonishing that infections of human beings do not occur frequently. Only one case (Ernst) is reported as far as the writer is aware. Of course, milk from animals suffering from anthrax should be excluded from the general supply.

Rabies is a disease rare among cattle. Milk may contain 
the virus, but it is probably not dangerous, since the virus is not absorbed through uninjured mucous membranes of the mouth or the digestive tract.

Actinomycosis sometimes attacks the udder, and the appearance then resembles, and has been mistaken for, tuberculosis. Spores of actinomyces are widely distributed on grain, hay, straw, soil, manure, etc., and can easily gain access to milk. They are usually not infectious for man unless they locate in some injured part of the system. There is practically no danger from this disease if the milk contains spores. In fact, no case has ever been recorded. However, as a precaution, milk should be condemned if derived from actinomycotic animals.

Botryomycosis.-This disease is very rare in the udder, but may endanger the milk. Therefore such milk should be excluded.

Cowpox is sometimes transferred to the udder from calves, which are used for the preparation of smallpox vaccine. It spreads rapidly through a herd by being carried from cow to cow by the milker's hand. Pustules and ulcers form on the teats. Milk infected with the virus is dangerous, especially for children. An infection of the digestive tract is produced. Dean and Todd have isolated a bacillus from cowpox pustules which seems identical with the diphtheria bacillus. Diphtheria bacilli may be communicated to infected teats from the hands of diphtheria carriers. The milk from cows with pustules or ulcers on the teats should, therefore, be considered suspicious and be excluded from the supply.

Milk-sickness is a disease peculiar to the United States west of the Alleghenies. It is also known as "trembles," "slows," and "staggers." It is believed to have been more common formerly than at present. It is called milk-sickness because it seems to follow ingestion of milk or milk products from infected cattle. The meat of cattle infected with the disease is also infectious for man. Its distribution is confined to limited localities. Cattle infected with the virus become weak, are easily tired, fall on their knees, and tremble violently. The temperature of such cattle is normal or subnormal. The cause of the disease, according to Jordan and Harris, is a spore-bearing bacillus which grows well on artificial media. This organism was named Bacillus lactimorbi. Besides cattle; the disease occurs in horses, sheep, goats, dogs, and perhaps in hogs. Some of the symptoms have been reproduced in calves, dogs, and cats by injection of cultures of Bacillus lactimorbi.

The virus persists in nature for a long time. In soil it may remain for at least fifty to sixty years if the land is left wild. 
When land is cleared, drained, and cultivated the virus disappears. The disease is most common during the months of August, September, October, and November, although occasionally cases have occurred in May and June. The organism has not been found in greater numbers in soil where milk-sickness exists than in other regions. An organism not distinguishable from Bacillus lactimorbi has been isolated from normal cow dung and from some grain and forage plants.

The disease is communicated to man through milk from infected cows or through milk products. It is characterized by vomiting and constipation. The breath of both man and cattle during the disease has the peculiar odor of acetone. The mortality in man is estimated by Jordan and Harris at about 10 per cent. Relapses are frequent and little immunity follows an attack.

Since milk and milk products may carry the infection to man, the exclusion of such infected milk is imperative. Pasteurization does not destroy the spores of Bacillus lactimorbi. ${ }^{1}$

Contagious abortion, also known as infectious abortion and epizoötic abortion, is very common among milk cows, especially in pure-bred herds, and the disease results frequently in "slinking" or "slipping" the calf. It has been estimated that this infection entails an annual loss of over $\$ 20,000,000$ in this country. Hadley estimates the annual loss in Wisconsin at $\$ 3,370,000$. In its wake may follow blood-poisoning, garget, catarrh of the uterus, and other diseases, terminating in sterility of the cow.

Contagious abortion may be regarded as a disease of the fetus rather than of the cow. The latter is seriously affected chiefly when the after-birth is incompletely expelled or when the dead calf is retained.

The disease is caused by Bacillus abortus, which was first isolated by Bang in 1896. Smith and Fabyan have studied the bacillus which is responsible for abortion of cows in the United States, and came to the conclusion that it is identical with Bang's organism. It produces abortion in pregnant cows and other animals, such as mares, sows, and ewes. Guinea-pigs injected with cultures of the bacilli are seriously affected, but usually recover.

${ }^{1}$ In a recent paper (Jour. of Inf. Dis., 1919, vol. 24, p. 231) Sackett states that work published during the past year points "quite conclusively to Euphorbium urticefolium (white snakeroot) as the true cause of trembles." The author was able to extract from fresh green snakeroot and from the dry leaf powder a substance which was poisonous for rabbits, but not for guineapigs. The symptoms produced in rabbits resembled those of milk-sickness. The poison is soluble in 95 per cent. alcohol and is present chiefly in the leaves of the plant. It is not claimed that all cases of milk-sickness are due to intoxication with the poison of white snakeroot, since Jordan and. Harris studied "a disease with similar, if not identical, symptoms" in New Mexico, where white snakeroot has not been found. 
The germs of contagious abortion may live for weeks or months outside of the body of the cow. Hadley states that it was isolated from dead fetuses after five to nine months; from a calf which had been frozen for twenty-four hours; and from uterine discharges left on ice after seven months. It would seem likely from these statements that pastures where infected cows graze might harbor the infection, but the menace from this source is probably small, since freezing and thawing rapidly disintegrate bacteria.

The virulence of Bacillus abortus varies considerably, a consideration which accounts for the fact that some herds do not suffer as seriously as others after the virus has been introduced.

The bacillus is present in large numbers in the discharges from the vagina of an affected cow and in aborted fetuses. Hadley states, "When not pregnant the udder is the only organ in the body where abortion bacilli can live," and "there is proof that the udder acts as a breeding ground for the germs." The abortion bacillus carrier is, therefore, a prolific source of infection, and introduction of a carrier into a sound herd is frequently the means of infection. Such carriers are sometimes difficult to detect, as they may calve normally. The infection is communicated most readily immediately before and after abortion.

Bulls may also become infected and then transmit the disease, but this is probably not as common as is generally believed. According to Hadley, bulls are endowed with a sexual or individual immunity, and are, consequently, less susceptible than cows. The disease is milder in bulls than in cows, and the germs when present in the body of a bull lose vitality in a relatively short time, so that the bull becomes safe for service of non-infected cows.

Contagious abortion may be transmitted through contaminated food and water and food poor in mineral matter, as, for example, wheat rations which may predispose the animal to the disease. Food is a menace chiefly when it is contaminated with vaginal discharges of infected cows. In stables, therefore, where animals are closely stalled the infection may spread rapidly and movements of the cows may aid in disseminating the virus. The common notion that moldy and decomposed grain or roughage may be the cause of abortion is probably not true.

The virus enters the body of the cow through the digestive tract, the genital organs, and through a break in the skin or other wound. The germs reach the uterus from any portal of entry, as they seem to possess a selective attraction for this organ.

Heifers are more susceptible to the disease than calves and cows and are most commonly infected after the first calf is born, while the womb is still open. A calf born from an infected cow is 
always infected. There seems to be no difference in the susceptibility among various breeds.

The Bacillus abortus is widely disseminated among cows. In one instance Cooledge found that 27 per cent. of the cattle examined had udders infected with the organism. It is not uncommon in market milk, as shown by a number of investigators, among whom may be mentioned Schroeder and Cotton, Fabyan, Melvin, Evans, Cooledge, and others. Miss Evans found Bacillus abortus in 23.4 per cent. of the samples examined. The highest number counted was 50,000 per cubic centimeter. The author distinguished three types of the organism, and named the type occurring most frequently Bacillus abortus lipolyticus, because it decomposed butter-fat. The bacillus was found in certified milk by Fleischner and Meyer. Milk containing the germs of abortion should be pasteurized before it is fed to calves.

Cows suffering from contagious abortion develop an immunity, as has been shown by complement-fixation and agglutination tests. Artificial immunity can be produced by vaccination with living cultures, while killed cultures do not appear to have a similar effect. Hadley states that 93.5 per cent. of cattle vaccinated with living cultures acquired immunity which lasted for a variable length of time. When immunized for one gestation period few animals aborted, and when immunized for two periods the immunity seemed to be permanent. But it should be emphasized that the artificial immunity does not necessarily eliminate the germs, and vaccinated animals may remain a menace to those free from disease. Only unbred heifers and open cows at least two months before being bred should be vaccinated.

When a cow shows symptoms of contagious abortion she should be isolated. The symptoms are not difficult to discover. The udder and vulva swell, there is a whitish discharge, the ligaments above the seat of the tail sink, and the milk becomes thick. After abortion the fetus and all discharges should be burned. The external parts, including tail, rump, and thighs, should be bathed in a 3 per cent. solution of liquor cresolis compositus, and the vagina should be douched with a 1 per cent. solution of sodium chlorid.

Hadley recommends the following measures for prevention of contagious abortion: " 1 . Daily douching with the salt solution of all cows that have a vaginal discharge; 2 , provision for a foodsupply that is adequate as to nutritive and mineral content and free from contamination; 3 , complete removal of retained afterbirths, with subsequent cleansing of the womb . . . to prevent an accumulation of pus which is likely to result in sterility; 4, disposal of aborted fetuses and contaminated bedding by burn- 
ing or deep burying, and disinfection of the gutters and floor; 5 , isolation of all cows known to be infected with abortion; 6, when possible, treatment of all heifers and cows about two months before breeding with a vaccine composed of live abortion germs."

Whether Bacillus abortus is infectious for human beings is a matter that has not yet been clearly demonstrated. The evidence available does not justify the assumption of its pathogenicity for man, although some authors (Larsen and Sedgwick) think there is reason for suspicion. Of interest in this connection is a study of Miss Evans, comparing Bacillus abortus with B. melitensis. The author found considerable resemblance between the two organisms both by cultural and immunologic methods. Since the organism is not infrequently contained in milk, such milk should be excluded from the market or be pasteurized.

Gastro-enteritis.-Milk from cows suffering from gastro-intestinal disturbances becomes thin, bluish, and acquires a bitter taste. It may be the cause of similar disturbances in man and should be excluded from public supplies.

Malta Fever.-Although Malta fever is a disease of goats and not of cows, it is of sufficient importance to merit mention. The disease occurs on the island of Malta and other islands of the Mediterranean and along the coast. It is also reported from India, South Africa, the Philippine Islands, the West Indies, and in some parts of this continent. The virus is contained in goat's milk and is communicated through goat's milk to man. The disease runs a slow, long-drawn-out course, and is characterized by headache, rheumatism-like affection of the joints, constipation, and anemia. It is rarely fatal, the fatalities being about 2 or 3 per cent. The causal factor is Bacillus melitensis, also called Micrococcus melitensis. It has been estimated that the milk of 10 per cent. of the goats in Malta contains the organisms, while the blood of 50 per cent. has agglutinative properties.

Cholera infantum is frequently classed as a milk-borne disease, and some authorities still hold that milk is the chief, if not the only, cause of this disease. Cholera infantum occurs most often during warm weather, and is largely responsible for the high death-rate among infants. Cholera infantum is more common among bottle-fed than among breast-fed babies, but modern scientific methods of artificial feeding of infants has tended to gradually reduce the high mortality resulting from summer diarrhea. There are authorities who believe that artificial feeding may be perfected to such a degree that the rate of infant mortality among bottle-fed babies will be very materially decreased.

Since bottle-fed infants are frequently given cow's milk as a substitute for human milk, and since there are more deaths. 
among artificially fed than among breast-fed infants, the facts would seem to justify a serious indictment against milk. Still there are other known causes and perhaps unrecognized ones which may contribute to the high death-rate of bottle-fed babies.

The absence of hydrochloric acid from the stomach of infants permits the passage of bacteria into the digestive tube. The membrane of the alimentary tract of infants is delicate, and it is conceivable that large numbers of bacteria, including varieties usually considered harmless, may cause disturbances. So far no specific organism has been identified as the cause of cholera infantum. Schereschewsky (quoting Pietschel, Leifmann and Lindemann, and others) has stated "that the influence of cow's milk in causing summer infant mortality has been overestimated." However, it is important in our present state of knowledge that a good grade of milk, preferably certified milk, be used for infant feeding, and that relative security from infection be assured by the use of boiled or pasteurized milk. A discussion of the relation of milk to gastro-intestinal troubles of infants will be found in a separate chapter.

There is a distinct relation between infant mortality and the season of the year. During the colder months-from October to March-the infantile death-rate is relatively low, while with the commencement of spring the number of deaths increases rapidly and reaches the highest point in August. The curve of infantile mortality follows closely the curve of temperature, the curve of bacterial content of milk, and the increase in the number of flies.

Schereschewsky, who has studied the relation of infant mortality to the three factors mentioned, has shown that the mortality curve rises within a short time after a period, or even after a single day, of hot weather. He believes that cholera infantum occurs as a seasonal disease rather than in the form of an epidemic, as would be expected were food alone to blame.

Hot weather is weakening to the system and, therefore, causes a predisposition to infection. Abt agrees that debility is caused by heat, and that the influence of heat is emphasized when it is accompanied by excessive moisture in the atmosphere. Flies become more numerous in hot weather and may have some connection with high infant mortality. What this connection may be is not understood, but an observation by Armstrong is suggestive. He selected two districts in New York City which were similarly located; had approximately the same population, with similar living conditions; and had about the same number of infants. One of these districts was supplied with screens for doors and windows and the inhabitants were instructed in methods of excluding flies. The other district was left unprotected. It was 
found that in the unprotected district there were many more deaths of babies and that the average duration of sickness was much greater than in the protected district.

In addition to milk, heat and flies seem to be factors in the causation of cholera infantum. It is important in attempts to reduce infant mortality to realize and combat as many causes as possible. If one cause is overrated, others will not receive the attention they merit. In addition to providing a clean, wholesome food, other conditions must be considered. This subject is discussed in a later chapter by Abt and Levinson.

\section{BIBLIOGRAPHY}

Abt: Trans. of the Society for Study and Prevention of Infant Mortality, 1913, p. 129.

American Veterinary Medical Association: Report of the International Commission on the Control of Bovine Tuberculosis, 1910.

Andrews and Horder: Lancet, 1906, vol. 2, pp. 708, 775, 852.

Armstrong: Jour. Amer. Med. Assoc., 1914, vol. 57, p. 200.

Breed: Verhandlungen des VIII Internationalen Zoölogen Kongresses zu Graz., 1910, p. 419.

Breed: New York Agri. Exper. Sta., Bull. 380, Mareh, 1914. Jour. Inf. Dis., 1914, vol. 14, p. 93.

Breed and Stidger: Jour. Inf. Dis., 1911, vol. 8, p. 361.

Briscoe: Univ. of Ill. Agri. Exper. Sta., Bull. 161, November, 1912.

Campbell: United Stated Dept. of Agri., B. A. I., Bull. 117, October, 1909.

Cooledge: Jour. Med. Res., 1916, vol. 34, p. 459. Ibid., 1917, vol. 37, p. 207.

Davis: Jour. Amer. Med. Assoc., 1912, vol. 58, p. 1852. Amer. Jour. of Publ. Health, 1918, vol. 8, p. 40 . Jour. of Inf. Dis., 1916, vol. 19, p. 236. Ibid., 1918, vol. 23 , p. 559.

Dean and Todd: Jour, of Hygiene, 1902, vol. 2, p. 194.

DeSchweinitz: United States Dept. of Agri., Yearbook for 1898.

Doane: Maryland Agr. Exper. Sta., Bull. 102, May, 1905.

Dorset: United States Dept. of Agri., B. A. I., Cireular 61, 1904.

Ernst: Monatsch. f. Prakt. Tierheilk., vol. 20, Hefte 9-12, and vol. 21, Hefte 1, 2. Milchhygiene f. Tierärzte, Ferd, Enke, Stuttgart, 1913.

Evans: Jour. Inf. Dis., 1916, vol. 18, p. 437. Ibid., 1918, vol. 22, p. 580. Ibid., 1918, vol. 23, p. 354 .

Fabyan: Jour. Med. Res., 1913, vol. 28, p. 85.

Fleischner and Meyer: Amer. Jour. of Dis. of Children, 1917, September, p. 157.

Geiger: Jour. Amer. Med. Assoc., 1917, vol. 68, p. 987.

Gordon: Lancet, 1905, vol. 2, p. 1400.

Hadley: Agricultural Experiment Station of the University of Wisconsin, Bull. 296, September, 1918.

Haring: Univ. of Calif. Coll. of Agri., Circular 92.

Haring and Bell: Univ. of Calif. Coll. of Agri., Bull. 243, March, 1914.

Harris: Jour. Inf. Dis., 1907, Suppl. 3, p. 50.

Harrison: Report from 19th Report of B. A. I., 1902.

Hastings: Univ. of Wis. Agri. Exper. Sta., Bull. 243, October, 1914.

Heinemann: Jour. Inf. Dis., 1907, vol. 4, p. 87. Ibid., 1915, vol. 16, p. 221. Jour. Amer. Med. Assoc., 1912, vol. 59, p. 716.

Heinemann, Luckhardt, and Hicks: Jour Inf. Dis., 1910, vol. 7, p. 57.

Hewlett, Villar, and Revis: Jour. of Hygiene, 1909, vol. 9, p. 271. Ibid, 1910 , vol. 10 , p. 56.

Hygienic Laboratory Bulletin 56.

Jordan, E. O.: Jour. Amer Med. Assoc., 1912, rol. 59, p. 1450.

Jordan, E. O., and Harris: Jour. Inf. Dis., 1909, vol. 6, pp. 401, 505.

Jordan, E. O., and Irons: Jour. Amer. Med. Assoc., 1912, vol. 58, p. 169. 
Jordan, J. O., and Arms: Amer. Jour. of Pub. Hygiene, 1909, vol. 19, May.

Kelley: Jour. Amer. Med. Assoc., 1916, vol. 67, p. 1667.

Kiernan: Sixth Annual Report of the International Association of Dairy and Milk Inspectors, held in Washington, D. C., 1917, p. 215.

Krumwiede and Valentine: New York Dept. of Health, Reprint 36, 1915.

Lameris and Harrevelt: Ztschr. f. Fleisch und Milch Hygiene, 1901, vol. 11, p. 114.

Larson and Sedgwick: Proc. of the 7th Annual Conference of the Amer. Assoc. of Med. Milk Commissions, 1913, p. 199.

Levine and Emerson: Bull. Iowa State Coll. of Agri. and Mech. Arts, 1916, vol. 15, No. 3 .

Mathers: Jour. Inf. Dis., 1916, vol. 19, p. 222.

McFadyean and Stockman: Jour. of Comp. Pathol. and Therapy, 1912, vol. 25, p. 22.

Melvin: United States Dept. of Agri., B. A. I., Circular 198, March, 1912.

Moore: Cornell Univ. Agri. Exper. Sta., Bull. 420, January, 1905. Bovine Tuberculosis and its Control, Carpenter and Co., Ithaca, New York, 1913.

Nowak: Annal. de l'Inst. Pasteur, 1908, vol. 22, p. 541.

Park and Krumwiede: Jour. Med. Res., 1910, vol. 23, p. 205. Ibid., 1910, vol. 25, p. 313 .

Parker: Am. Jour. of Pub. Health, 1913, vol. 3, p. 486.

Peterson: Thesis for the Degree of Ph.D., Cornell Univ., 1910.

Prescott and Breed: Jour. Inf. Dis., 1910, vol. 7, p. 632.

Puppel: Ztschr. f. Hygiene, 1912, vol. 70, p. 449.

Reed and Ward: Jour. of the Boston Soc. of Med. Sci., 1901, vol. 5, p. 387.

Rettger and White: Storrs' Agri. Exper. Sta., Bull. 93, January, 1918.

Rosenow: Jour. Inf. Dis., 1915, vol. 17, p. 69.

Ross: Cornell Univ. Agri. Exper. Sta., Bull. 303, July, 1911.

Russell: Univ. of Wis. Agri. Exper. Sta., Bull. 143, February, 1907.

Russell and Hastings: Univ. of Wis. Agri. Exper. Sta., Bull. 133, February, 1906.

Russell and Hoffmann: Jour. Inf. Dis., 1907, Suppl. 3, p. 63. Univ. of Wis. Agri. Exper. Sta., 24th Annual Report, 1907, p. 231. Am. Jour. of Pub. Health, 1908, vol. 18, p. 285. Univ. of Wis. Agri. Exper. Sta., Bull. 165, November, 1908. Univ. of Wis. Agri. Exper. Sta., Bull. 175, May, 1909.

Schereschewsky: Trans. of the 4th Annual Meeting of the Amer. Soc. for Study and Prevention of Infant Mortality, 1913, p. 113. Trans. of the Society for Study and Prevention of Infant Mortality, 1913, p. 99.

Schroeder: United States Dept. of Agri., B. A. I., Circular 118, December 21, 1907.

Schroeder and Cotton: United States Dept. of Agri., B. A. I., Bull. 99, May, 1907. United States Dept. of Agri., B. A. I., Circular 127, April, 1908. 28th Annual Report of the B. A. I., 1911, p. 139.

Senftner: Jour. Amer. Med. Assoc., 1917, vol. 68, p. 1893.

Slack: Jour. Inf. Dis., 1906, Suppl. 2, p. 214.

Smith: Jour. Exper. Med., 1898, vol. 3, p. 251.

Smith and Brown: Jour. Med. Res., 1915, vol. 31, p. 455.

Smith and Fabyan: Cent. f. Bakt., Abt. 1, 1911-12, vol. 61, p. 549.

Stokes and Wegefarth: Jour. of State Med., 1897 , vol. 5, p. 439. Med. News, 1897 , vol. 71 , p. 45.

Swithinbank and Newman: The Bacteriology of Milk, New York, Dutton and Co., 1903.

Trask: Hygienic Bulletin 56.

Trommsdorff: Münch. Med. Wchschr., vol. 53, p. 541.

Trueman: Storrs' Agri. Exper. Sta., Bull. 53, June, 1908.

Vermont State Board of Health, Bull. 3, 1912, vol. 12, p. 58.

Ward and Haring: Univ. of Calif. Coll. of Agri., Bull. 199, August, 1908.

Winslow: Jour. Inf. Dis., 1912, vol. 10, p. 73.

Winslow and Hubbard: Health News, New York State Dept. of Health, September, 1915.

Winslow and Palmer: Jour. Inf. Dis., 1910, vol. 7, p. 1.

Woodhead and Jones: Jour. of Path. and Bact., 1915, vol. 20, p. 135. 


\section{CERTIFIED MILK}

RECOGNITION of the dangers that may lurk in milk, especially when used as food for infants or invalids, has led health authorities to assume control of public milk-supplies. Sometimes such control is accomplished by suitable legislation either by state or municipal authorities, and sometimes by conferring the necessary authority on boards of health. The large amount of milk consumed and the variety of sources from which it is derived necessarily hinder progress whenever such control is attempted. Therefore in 1891 a movement was inaugurated to supply a limited amount of milk of dependable quality worth the recommendation of physicians. The originator of this movement was Dr. Henry L. Coit, of Newark, N. J., who outlined the production of this kind of milk in the following way: "The legal requirements are stringent and binding. The code includes ample sureties for its fulfilment-necessary forfeiture clauses, a territorial limit for the sale of the product, and provision for the compensation of the experts employed by the commission. It controls the character of the land used for pasturage and the cultivation of fodder; determines the construction, location, ventilation, and drainage of buildings; provides for an abundant and pure water-supply, and prevents the use of water from wells or springs holding surface drainage. It requires in the stable cleanliness and order, and disallows the keeping of live stock, except the cow, within 300 yards of the dairy buildings. It regulates the assortment of the herd with reference to uniform results, as well as the health, the breed, and temperament of the animals. It excludes animals that are tuberculous or are found in a state of health prejudicial to the herd. It provides for proper housing and shelter of the animals, together with their grooming, their treatment, and the prompt removal of their waste from the stable. It regulates the feeding with reference to uniformity in the chemical composition of the product, and restrains the use of all questionable or exhausted materials for food. It governs the collection and handling of milk by insisting upon a proper regard for cleanliness as viewed by the bacteriologist in its relation to the animal, her surroundings, the milkers' hands, the vessels, and the association of persons handling the milk with immediate or remote sources of infection. It controls by minute specified requirements every step in the cooling of the milk and its preparation for shipment, 
and adds to the product every detail of care necessary to promote its keeping qualities or favor its safe transportation.

"The motives of the commission are disinterested and its members forbid to themselves any pecuniary rewards. The experts are employed by the commission and paid by the dairyman. The bi-monthly reports of these officers to the commission are the basis of its approval of the product which, in the form of a certificate, is issued to the dairyman."

The first contract was made between the Medical Milk Commission of Essex County, N. J., and Stephen Francisco of Caldwell, N. J., in 1893. A copy of the contract follows:

COPY OF THE AGREEMENT BETWEEN THE MEDICAL MILK COMMISSION OF ESSEX COUNTY, N. J., AND STEPHEN FRANCISCO, OF CALDWELL, N. J., DATED MAY 19, 1893

The following agreement, made this nineteenth day of May, 1893, between Henry L. Coit, M. D., of Newark, New Jersey; Theron Y. Sutphen, M. D., of Newark, New Jersey; William B. Graves, M. D., of East Orange, New Jersey; L. Eugene Hollister, M. D., of Newark, New Jersey; Joseph W. Stickler, M. D., of Orange, New Jersey, and James S. Brown, M. D., of Montclair, New Jersey, parties of the first part; and Stephen Francisco, of Caldwell, New Jersey, party of the second part: Witnesseth as follows: That the party of the second part doth hereby bind himself to a fulfilment of the provisions of this contract, for and in consideration of the benefits hereinafter named by the parties of the first part.

Furthermore, the following named persons: Frank A. Wilkinson, of Newark, New Jersey; Isaac Lane, of Caldwell, New Jersey, and William Bush, of Caldwell, New Jersey, all acquaintances of the party of the second part, hereby affix their signatures to this agreement, attest to the honor of the party of the second part, and become sureties for the execution of this agreement.

1. The party of the second part doth hereby agree to conduct such parts of his dairy as may be hereinafter named, collect and handle its products in conformity with the following code of requirements, for and in consideration of the promised endorsement of the parties of the first part, as hereinafter indicated. The milk thus produced shall be known as certified milk; shall be designed especially for clinical purposes, and when at any time the demand shall be greater than the supply, and is required by a physician, either for infant feeding or the diet of the sick, it is hereby agreed that such shall be the preferred purchaser.

2. The party of the second part further agrees to pay for chemical and bacteriologic examinations of the aforesaid certified milk, at such times as in the judgment of the parties of the first part is desirable,

3. He also agrees to defray the cost of a bi-monthly inspection of his dairy stock, or oftener, if necessary, by a competent and approved veterinarian, all of which persons, namely, the chemist, the bacteriologist, and the veterinary surgeon, shall be chosen by the parties of the first part, to whom they shall render their reports in writing.

4. It is expressly understood and agreed, that the party of the second part shall not pay more than the sum of five hundred dollars in any one year for the services of chemist, bacteriologist and veterinary surgeon, and the party of the first part shall limit the expense of such service to that amount. It is furthermore agreed that the party of the second part, on receipt of a certified copy of the reports of the experts, shall mail to the persons indicated by the parties of the first part, and not to others, a duplicate printed copy of the aforesaid reports, bearing the signatures of the experts and the 
names of the physicians. The same to be issued at such intervals as in the judgment of the parties of the first part is desirable; also that the necessary expenditures for printing and circulation be met in the same way as herein provided for expert examinations.

\section{Location of Lands}

5. It is hereby understood and agreed, that the lands used by the owners, agents or assigns of the dairy, conducted by the party of the second part, and employed for pasturage, or any lands that may be hereafter acquired for such purposes, or such lands as may be used for the cultivation of hay or fodder, shall be subject to the approval of the parties of the first part.

\section{Buildings}

6. It is also understood and agreed, that the buildings, such as stables, creamery, dairy house and spring house, shall be constructed after the most approved style of architecture, in so far as construction may affect the health of the dairy stock, or the character and conditions of the milk.

7. That the buildings used for the housing of the animals shall be situated on elevated grounds, and capable of being properly drained.

8. Said buildings to be sheltered from cold winds, lighted and ventilated according to approved hygienic methods. The buildings shall be constructed so as" to favor the prompt and easy removal of waste products.

9. The apartments used for the storage of either feed or fodder shall be removed from possible contamination by stable waste or animal odors.

10. All buildings shall, in addition to healthful location, approved construction and proper ventilation, be kept free from animal or vegetable matter in a state or process of decomposition or decay, and always free from accumulations of dust or mould.

\section{The Water-supply}

11. The dairy shall be supplied with an abundance of pure water.

12. No water from shallow wells or springs holding surface drainage shall be used for watering stock, cooling milk, or cleaning vessels. the stable.

13. Nor shall any well or spring be located within three hundred feet of

\section{Surroundings}

14. It is further understood and agreed that the immediate surroundings of the buildings shall be kept in a condition of cleanliness and order. There shall not be allowed to accumulate in the vicinity any loose dirt, rubbish or decayed vegetable or animal matter, or animal waste.

15. Nor shall there be within three hundred yards of any building any constantly wet or marshy ground or stagnant pools of water.

16. Nor shall there be kept within three hundred yards of any building used for dairy purposes any fowl, hogs, horses or other live-stock.

17. It is hereby understood and agreed that the following unhealthful conditions shall be a sufficient reason to exclude any animal from the herd used for any purpose in the aforesaid dairy: Any animal that is judged by a competent observer to suffer from tuberculosis even though the disease be localized or latent.

18. Any animal with fever. Any animal suffering from septic absorption or other disease followed or associated with parturition.

19. Any animal suffering from mammitis or mammary abscess.

20. Any animal with persistent diarrhea or any other abnormal physical condition which could in any way be detrimental to the character of the milk.

21 . It is furthermore agreed that when an animal shall be found by a competent observer to be in a state of ill health, prejudicial either to the other animals in the herd or to human health, the same shall be removed immediately and if necessary shall be killed.

22. It is also understood and agreed that the party of the second part shall exclude from the herd used for producing certified milk, immediately 
after discovery, any animal subject to the following conditions: Any animal that was bred through consanguinity within a period of three generations.

23 . And from this time forth, any animal of those bred by the party of the second part, used for producing certified milk, that was not, as a heifer, kept sterile during its first twenty-seven months.

24. Any phenomenal milker, except that glandular disease or tuberculosis has first been excluded by a competent observer.

25. It is furthermore agreed that if at any time it is desired by the parties of the first part, that a different breed of milch cows should be substituted for the one in use, in order that the standards of quality in the milk may be raised, the party of the second part will endeavor to carry the same into effect.

\section{Housing and Care}

26. It is furthermore agreed, that the dairy stock employed in the production of certified milk shall be properly sheltered from the influences of weather and climate prejudicial to their health; also that the animals shall be kept clean, groomed every day, and treated kindly at all times.

27. The waste products of the stable shall be removed so frequently, and the stable floor so thoroughly cleaned, that the same shall be as free as possible from animal odors.

28. It is also agreed that no milch cow shall be used for dairy purposes while in a state of excitement, either as a result, or during the period of estrux, or which has been made nervous either by beating, whipping, kicking, prodding, or running.

\section{Feeding}

29. It is hereby understood and agreed that the methods of feeding the cows furnishing the certified milk shall be subject to the approval of the parties of the first part. The feed and fodder shall consist only of nutritious and wholesome materials; such as grass, clover and timothy hay, whole grain, or the entire result of the grist. No materials shall be employed which are or may become injurious to the health of the animals. There shall not be fed at any time, or in any quantity, either alone or mixed with other feed or fodder, hulls, screenings, wet or dry brewer's grains, sour ensilage, or any waste by-product in the treatment of grain, low marsh grass, or any of the questionable or exhausted feeds or fodders employed either to increase the milking capacity of the animal, or that will produce an impoverished milk, or that will impart to it unnatural odors or flavors. Nor shall the cows be allowed to eat green or worm-eaten fruit, poisonous weeds, or to drink poisonous or stagnant water.

\section{Collecting and Handling}

30. It is furthermore understood and agreed, that the cows from which is obtained certified milk shall be milked only in a clean building, and not in an ill-ventilated stable containing foul odors and bad air.

31. No animal furnishing certified milk shall be milked until the udder shall first have been cleaned in a manner approved by the parties of the first part.

32. No person shall be allowed to draw the milk who has not within fifteen minutes of the milking first washed his or her hands, using soap and nail brush, and afterward thoroughly rinsing the hands in clean water.

33. The person or persons engaged in milking shall also be dressed in clean overclothes.

34. No person shall be allowed to draw the milk who has been engaged with the care of horses, in the same clothing or without first washing his hands.

35. No milk shall be represented as certified milk that is not received from the udder into vessels, and from these into cooling cans, both of which are perfectly clean and dry, having been cleansed and heated, at a temperature adequate to effect complete sterilization, since the last milking; and have been kept inverted in a clean, dry and odorless atmosphere. 
36. No milk shall be represented as certified milk that has not been passed through a sieve of wire or other cloth, either while milking or immediately thereafter, having not less than one hundred meshes to the linear inch.

37. No milk shall be represented as certified milk that does not consist of the entire contents of the udder at each milking, including the fore-milk, middlings, and strippings.

38. No milk shall be represented as certified milk that has been drawn from the animal at abnormal hours, such as midnight or noon; nor from any animal for a period of nine weeks before calving, or that has not been separated for nine days after parturition.

39. No milk shall be represented as certified milk which has been exposed to the emanation or infection of any form of communicable disease, either in the person or persons handling the milk or by accidental contamination in cleaning milk containers, or by the association of any person engaged in handling the milk, with person or persons sick of contagious disease.

\section{Preparation for Shipment}

40. It is hereby understood and agreed, that all milk represented as certified milk shall receive every known detail of care that will promote its keeping qualities, and favor its safe transportation.

41. That the milk on being drawn from the cow shall be treated by ice, or clean, cold water in motion, and proper aëration, in order, first, to remove its animal heat, and, second, to reduce its temperature to a point not above fifty degrees, nor below forty degrees Fahrenheit; said temperature to be acquired within forty-five minutes after milking, and maintained within the above limits while held for shipment, during its transportation, and until it is delivered to the purchaser.

42. That the cooling of the milk shall not be conducted in the same building in which it is drawn, nor in an atmosphere containing dust or tainted with animal odors.

43. That all the foregoing provisions concerning the cleansing and condition of vessels or utensils shall be complied with in the said cooling process.

44. It is furthermore agreed, that no milk shall be represented as certified milk, that has been changed or reduced in any way, by the addition of water or any solid or liquid substance, in or out of solution, or the subtraction or removal, in any manner, of any part thereof.

45. It is hereby understood and agreed, that all milk to be represented as certified milk, shall be packed in flint glass quart jars immediately after it is cooled.

46. Said jars to be of pattern approved by the parties of the first part.

47. It is furthermore agreed that the bottles or jars, before being used, shall be cleaned by hand, separately, with the aid of hot water, alkaline soaps, rotating brush and steam, and that they shall be rinsed in two separate baths of clean, hot water, and then thoroughly dried and kept inverted until used, without covers, in a clean, dry atmosphere free from odors.

48. It is agreed that the jars shall be filled by a method approved by the parties of the first part.

49. That they shall be sealed after all air has been excluded, by the most approved device for closing them.

50. The bottles after being filled, shall be labeled across the cap, bearing the words "Certified Milk," with the name of the dairyman, together with the date of milking.

51. It is furthermore agreed, that no milk shall be sold as certified milk that is more than three hours old when bottled, nor more than twenty-four hours old when delivered.

\section{Transportation and Delivery}

52. It is hereby understood and agreed, that the transportation and distribution of all milk represented as certified milk, shall be conducted by the party of the second part, either in person or by persons employed by him. 
53. That in transit, the milk shall not be exposed to any of the foregoing prohibitory conditions.

54. That it shall not be subjected to agitation.

55. That it shall not be exposed to the heat of the sun.

56 . That the delivery wagons shall be so constructed that the required temperature of the milk may be maintained during transit.

57. That before the wagons are filled for shipment, the body, the trays, and compartments shall be flushed with boiling water.

58. It is furthermore agreed that the distributing agents shall during the transfer of the milk from the dairy to the purchaser, be subject to the following restrictions, namely: That they shall use no tobacco.

59. That they shall take no intoxicating drinks.

60. That they shall not collect the empty containers, nor receive money or milk checks from houses in which an infectious or contagious disease is known to exist.

61. It is also hereby agreed that the collection of empty bottles from places where infectious or contagious disease is known to exist shall be made by other persons than those employed to deliver the milk.

62. That these collections be made with wagons not employed in the distribution of the milk.

63. That before these empty bottles shall be returned to the dairy, they shall be carried to a separate building and first be subjected to the process of cleaning bottles indicated in a former clause of this contract.

64. It is hereby understood and agreed, that if any further precautions or changes in method, calculated to improve the quality of milk, or guard the same from impurities or dangers, is desired, that the party of the second part will cheerfully be governed by such additional rules and regulations as may be laid down by the parties of the first part.

65. It is understood and agreed by the party of the second part, the same binding the owners, agents or assigns of the aforesaid dairy, that the product known as certified milk shall be under the following restrictions in its sale, namely: That until the amount required within the boundaries of Essex County shall first be supplied, it shall not be sold beyond these limits, except that the parties of the first part shall give their consent.

66. It is furthermore agreed by the party of the second part, the same binding the owners, agents or assigns of the aforesaid dairy, that in the event of a failure to comply with any or all of the requirements of the foregoing contract, the party of the first part shall reserve the right to withdraw from the contract, and publish the fact in such manner as they deem best.

67. Finally: It is understood and agreed, that nothing in this contract shall prevent the abrogation of any of the provisions of the same by the parties of the first part, provided that it shall be done for the purpose of substituting other provisions, designed to promote the objects of their organization.

68. It is further understood and agreed by and between the parties hereto, that the party of the second part shall be at liberty to cancel this agreement by giving two months' notice in writing of his desire to do so, in case of inability for any reason, to comply with the terms of the same.

IN Witness Whereof, the said parties have hereunto set their hands, the day and year first above written.

Stephen Francisco, Party of Second Part.

Frank A. Wilkinson, ISAAC LANE, William Bush,

Sureties.
Henry L. CoIt,

Theron Y. Sutphen,

William B. Graves,

L. Eugene Hollister,

Joseph W. STICKLER,

James S. Brown,

Parties of First Part.

Office of

GuIld \& Lom, Counsellors-at-Law. 
This contract has been the model for other contracts made between medical milk commissions and interested producers.

In return for carrying out all the exacting conditions of the agreement and paying the expenses of experts, the Medical Milk Commission gives the dairyman certificates which are placed on all bottles. The milk then carries the endorsement of the milk commission, but the certificate does not absolutely guarantee the quality and purity of the milk in the bottle to which it is attached. It guarantees efficient supervision of the methods employed in production, shipment, and delivery. It is not surprising, therefore, that certified milk is sold at a price higher than that of ordinary milk, retailing for 15 cents or more per quart.

Since the Essex County Milk Commission commenced certifying milk 81 medical milk commissions have been organized in the United States. Legal protection has seemed desirable to. counteract the influence of the unscrupulous dealer, who has used the word "certified" for inferior milk in order to command the superior price. For instance, the writer found a "certified" milk which, upon inquiry, turned out to be milk "certified" to by the producer to contain at least 3 per cent. butter-fat. New Jersey, Kentucky, New York, Massachusetts, and New Hampshire have passed legislation to protect the term "certified milk." A copy of the New Jersey law follows:

\section{MEDICAL MILK COMMISSION LAW}

The following act was inspired by the Essex County, New Jersey Medical Milk Association, was introduced in the Legislature by Senator Joseph S. Frelinghuysen, received the affirmative vote of every member of the Senate present except one, and the unanimous vote of the House of Assembly, and was approved by Governor J. Franklin Fort, on A pril 21 st, 1909.

An Act providing for the incorporation of medical milk commissions and the certification of milk produced under their supervision. Jersey:

Be IT ENACTED by the Senate and General Assembly of the State of New

\section{Certified Milk Commissions}

1. Any five or more physicians duly authorized to practice medicine under the laws of this State who shall desire to associate themselves together for the purpose of supervising the production of milk intended for sick room purposes, infant feeding and for use in hospitals, may make, record and file a certificate in writing in the manner hereinafter mentioned.

\section{Objects Set Forth: Name, Purposes, Directors, County}

2. Such certificate shall set forth:

(I) The name of such association which shall be as hereinafter designated.

(II) The purposes for which the association shall be formed.

(III) The names and the residences of the medical directors who shall manage the affairs of the association for the first year of its existence.

(IV) The county in this State where such association shall operate. 


\section{Recorded in County Clerk's Office. Filed with Secretary of State}

3. Such certificate shall be proved or acknowledged and recorded as required of deeds of real estate in a book to be kept for the recording of certificates of incorporation in the office of the clerk of the county where the purposes of such association are to be carried out, and after being so recorded, shall be filed in the office of the Secretary of State; said certificate or a copy thereof duly certified by the said clerk or Secretary of State shall be evidence in all courts or places.

\section{A Body Politic. May Sue, etc.}

4. Upon making such certificate and causing the same to be recorded and filed as aforesaid, the said physicians so associating themselves together and their successors shall by virtue of this act be a body politic and corporate in fact and in law by the name stated in such certificate and by that name they and their successors shall have perpetual succession with power to sue and be sued, plead and be impleaded, answer and be answered unto in all courts and places whatsoever and to make and use a common seal at pleasure.

\section{Corporate Name}

5. The name of such association shall be the "The Medical Milk Commission of . .............. (designating name of county) County, of New Jersey," and in case of more than one association shall be organized under this act or otherwise, such subsequent association or associations shall use the name designated herein, but shall indicate in such name its proper sequence in organization or incorporation by adding thereto the words: "Number Two," "Number Three," "Number Four," or as the case may be.

\section{Powers of Directors. Certify to Milk}

6. Such medical directors shall have the power from time to time to make, alter and amend by-laws not inconsistent with the Constitution and Laws of the United States and of this State, fixing or altering the number of its medical directors and providing for the mode of filling vacancies and removing any member from their number and prescribing qualifications for membership in the association and the appointment of such agents and officers as shall in their judgment tend to promote or advance any purpose or purposes of such commission, and to prescribe their respective duties; and for the regulating of the conditions under which milk shall be produced by any dairyman or dairymen under contract with such commission.

Such medical milk commissions shall have power to certify to any milk produced under their supervision which shall meet the requirements hereinafter mentioned.

\section{No Compensation for Directors. Penalty}

7. No medical director of any association organized under this act shall receive, directly or indirectly, from such association or dairyman or dairymen producing milk under agreement with such commission any salary or emolument or any compensation of any kind or character for any services rendered under the provisions of this act, and any medical director who shall receive any salary, emolument, or compensation of any kind or character for such services, shall be liable to a penalty of one hundred dollars $(\$ 100.00)$, to be recovered in an action of debt by the association of which he is a member, and in addition thereto shall be removed from his office as a member of said association and thereafter disqualified from becoming a member of any association incorporated under the provisions of this act.

\section{Agreement with Dairymen. Standard Milk. Terms of Contract}

8. Every such association shall have power to enter into agreement in writing with any dairyman or dairymen for the production of milk under the supervision of such association for the purposes enumerated in section one hereof and to prescribe in such agreement the conditions under which such 
milk shall be produced, which conditions, however, shall not be below the standards of purity and quality for "Certified Milk" as fixed by "The American Association of Medical Milk Commissions," and the standards for milk now fixed or that may hereafter be fixed by the Board of Health of the State of New Jersey. In any contract entered into by any such commission with any dairyman or dairymen, it may be provided that such medical milk commission may designate any analysts, chemists, bacteriologists, veterinarians, medical inspectors or other persons who in its judgment may be necessary for the proper carrying out of the purposes of such commission for employment by such dairyman or dairymen and to prescribe and define their powers and duties, and that such persons so employed by such dairyman or dairymen may be discharged from employment whenever such medical milk commission may request such discharge or removal in writing.

\section{Certificate Attached to Milk Containers}

9. All containers of any kind or character used in the carrying or distribution of milk produced by any dairyman or dairymen under contract with any medical milk commission shall have attached thereto or placed thereon a certificate or seal bearing the name of the Medical Milk Commission with which such dairyman or dairymen producing such milk shall be under contract, which certificate shall have printed, stamped or written thereon the day or date of the production of the milk contained in any such container and the words "Certified Milk" in plain and legible form.

\section{Subject to State Board of Health}

10. The work and methods of any Medical Milk Commission organized under this act and of the dairies on which milk is produced under contract with any such commission, shall at all times be subject to investigation and scrutiny by the Board of Health of the State of New Jersey. The secretary of said State Board of Health shall be an ex-officio member of every milk commission organized under this act,

\section{Milk Not to be Sold as Certified Unless Produced According to Standards. Penalty}

11. No person, firm or corporation shall sell or exchange or offer or expose for sale or exchange as and for certified milk, any milk which is not produced in conformity with the methods and regulations prescribed by and which does not bear the certification of a medical milk commission, incorporated pursuant to the provisions of this act or organized or incorporated in some other State for the purposes specified in Section 1 hereof, and which is not produced in conformity with the methods and regulations for the production of certified milk from time to time adopted by the American Association of Medical Milk Commissions, and which is below the standards of purity and quality for certified milk as fixed by the American Association of Medical Milk Commissions; and any such person, firm or corporation violating any of the provisions of this section shall be guilty of a misdemeanor.

\section{Repealer}

12. All acts and parts of acts inconsistent with this act be and the same are hereby repealed, and this act shall take effect immediately.

Approved April 21, 1909.

Attempts made by other medical milk commissions to have protective legislation enacted have not been successful. Where there is no legal protection for the term "certified milk," physicians and consumers can be warned to buy no milk as certified milk which does not bear the words on the certificate "certified by the Medical Milk Commission." 
The beneficial influence of certified milk has been twofold. In the first place, a milk of the highest quality becomes available. In the second place, the moral and educational influence is considerable. It has been clearly shown that a clean milk with less than 10,000 bacteria per cubic centimeter can be obtained and that the herd can be kept free from tuberculosis and other infections. Menace from pathogenic bacteria has been greatly reduced as a result of periodic medical examination of employees and

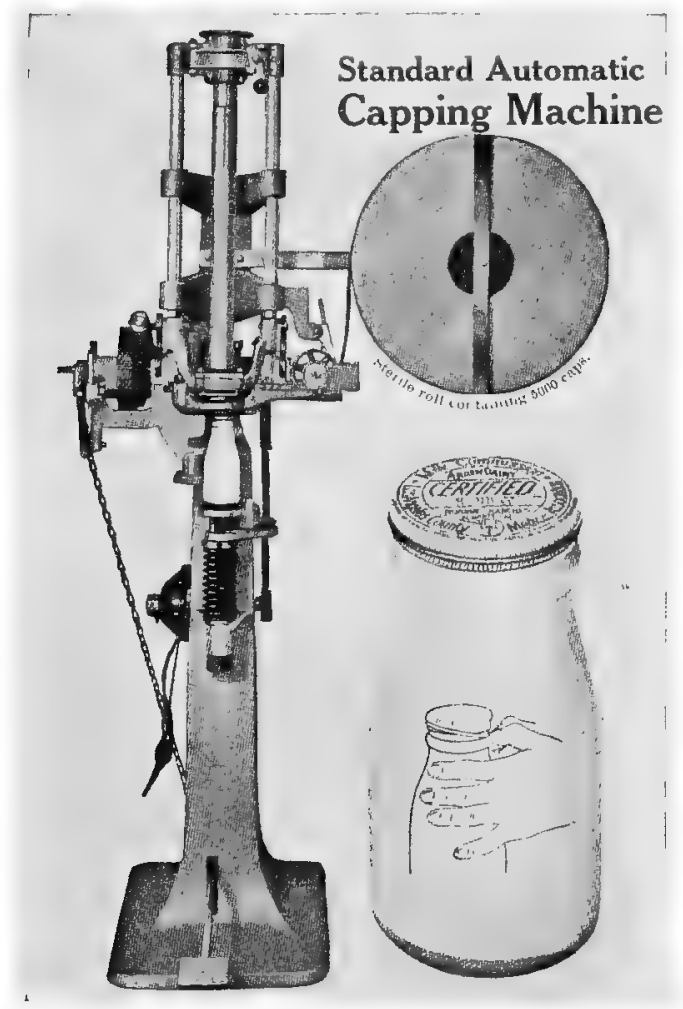

Fig. 197.-Standard automatic capping machine.

veterinary inspection of the animals. Sanitary inspection of certified milk plants has been so successful as to materially reduce the chances of infection. In the 33d Annual Report of the State Board of Health of New Jersey (1909) an account is published which shows how much can be done by a competent, vigilant milk commission to suppress imminent danger of infection. In the dairy in question the medical examiner of the commission found one of the employees with an erythematous rash. This employee 
was immediately isolated. A few days later another employee was found suffering from sore throat. $\mathrm{He}$, too, was isolated, and the following day was found to have scarlet fever. Another suspicious case developed a day later. The commission came to the conclusion that all employees had been exposed and might be carriers. The men were stripped, given a scrubbing with soap and warm water, and were wiped with a 1 per cent. solution of
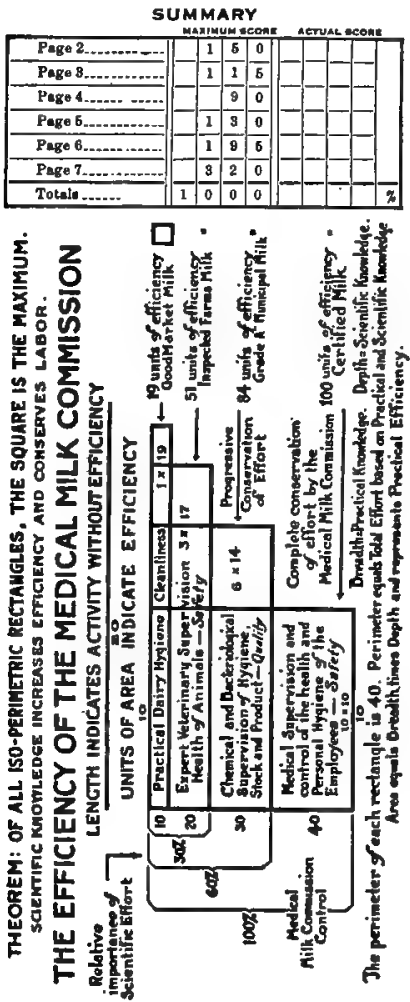

Voored by

Dale
AN EFFICIENCY SCORE CARD

POR THE USE OF

THE MEDICAL MILK COMMISSION

IN DIRECTING

THE PRODUCTION OF

CERTIFIED MILK

ICINICAL MIINO

Based on the code of methods and standards adopted by the American Association of Medical Milk Commissions, and the author's estimate of the relative value of the several factors in the system represented by

Dairy Hygiene, Veterinary Supes: vision of the Animals, Chemical and Bacteriological Investi. gations and Modical Inspection of Employeces.

Promed is is completed form at the Eighth Anmal Mosian

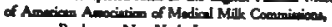
Rocteoser, N- Yod, Juen ipl, 1914

BY

HENRY L. COIT, M. D. NEWARK NEW JERSEY

Fig. 198.

chlorid of lime. All-80 in number-were equipped with new milking suits which had been treated with formalin. In addition, the milk was pasteurized as long as danger from contamination seemed possible. The customers were notified of what had happened and were informed that the milk would be pasteurized for some time.

When such thorough work is done it may be said that ideal 
conditions exist. However, with less vigilance there is a possibility that certified milk may prove untrustworthy. Several epidemics have been traced to milk the production and handling of which was surrounded by the most exacting precaution, but only one has been traced to certified milk. It should be remembered in this connection that at present the amount of certified milk consumed is less than 1 per cent. of the total milk-
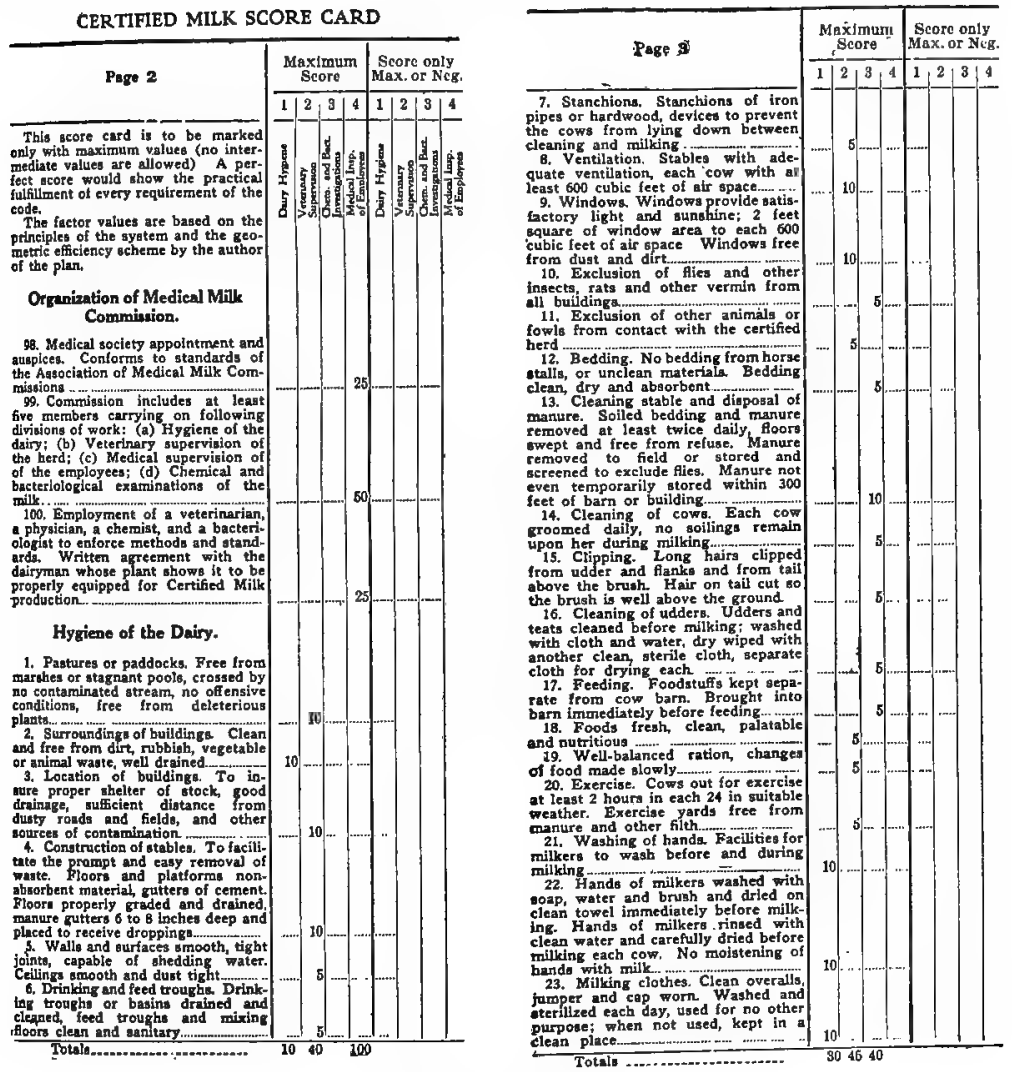

Fig. 198 continued.

supply. Too much faith may be placed in low bacterial counts to the neglect of regular medical examination and veterinary inspection. Germ carriers are often difficult to detect, and unless medical and veterinary examinations are made at sufficiently short intervals and unless they prove thorough and exhaustive, infection may be carried into a dairy farm from visitors or from employees. New employees should not be permitted to handle 
milk before medical examination has shown them to be free from disease germs. It is also essential that dependence can be placed on the owner or superintendent of the dairy to report promptly every case of illness of an employee.

The reliability of certified milk depends largely upon the personnel of the certifying commission and the capability of the experts employed by the commission. Dr. Coit comments on
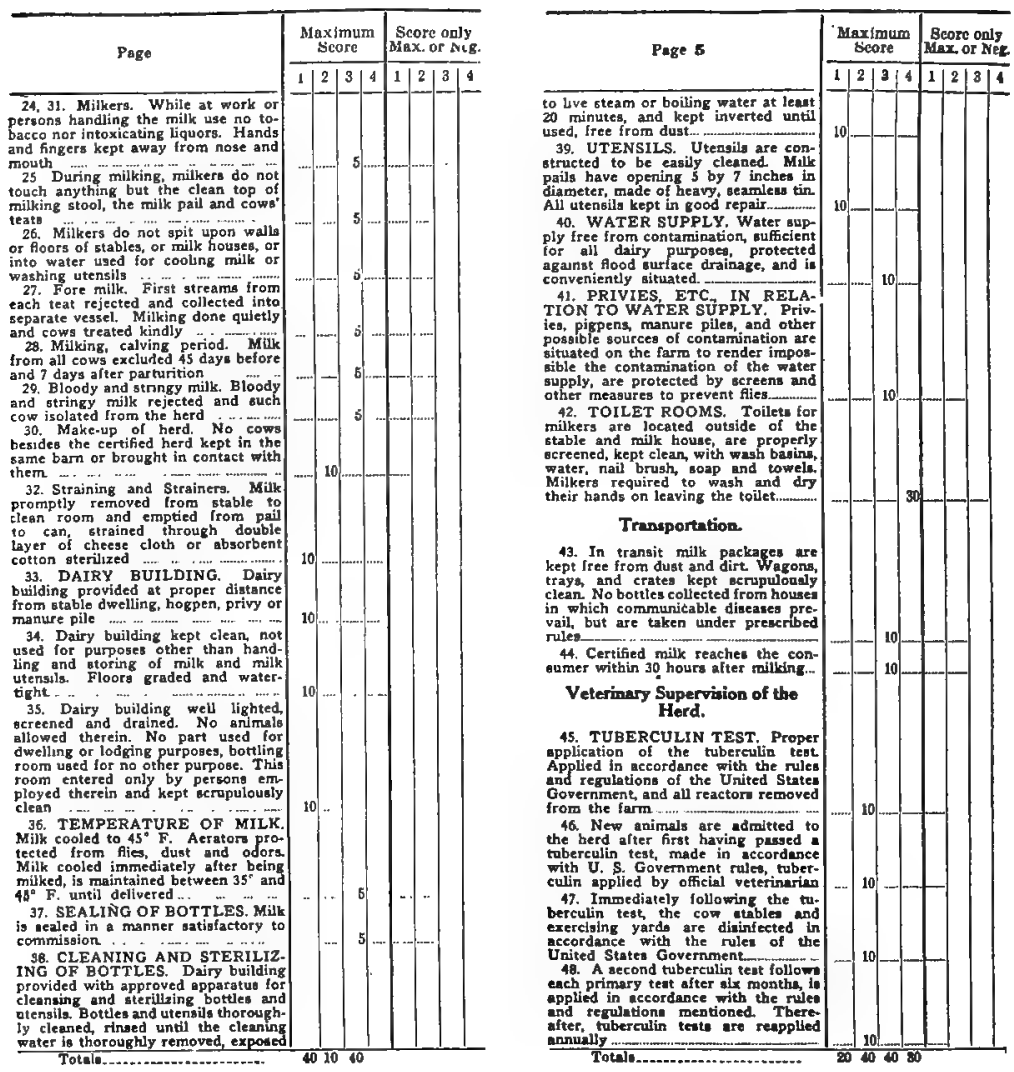

Fig. 198 continued.

this phase of the subject in the following words: "A medical milk commission which fails to carry out any one or more of the essential parts of the system does not represent the system. The product which such commissions permit to be called certified represents a serious menace to the certified milk system. Such certification establishes a false security in the minds of physicians and the public who have learned to trust the system and the 
name. Such certification savors of deception and, as respects the milk itself, is a misbranding and falsification. The work of such a commission is a detriment to the cause of certified milk and reflects upon the reputation and diminishes the influence of the American Association of Medical Milk Commissions. A few such commissions have, unfortunately, gained admission to our Association. No chain is stronger than its weakest link, and
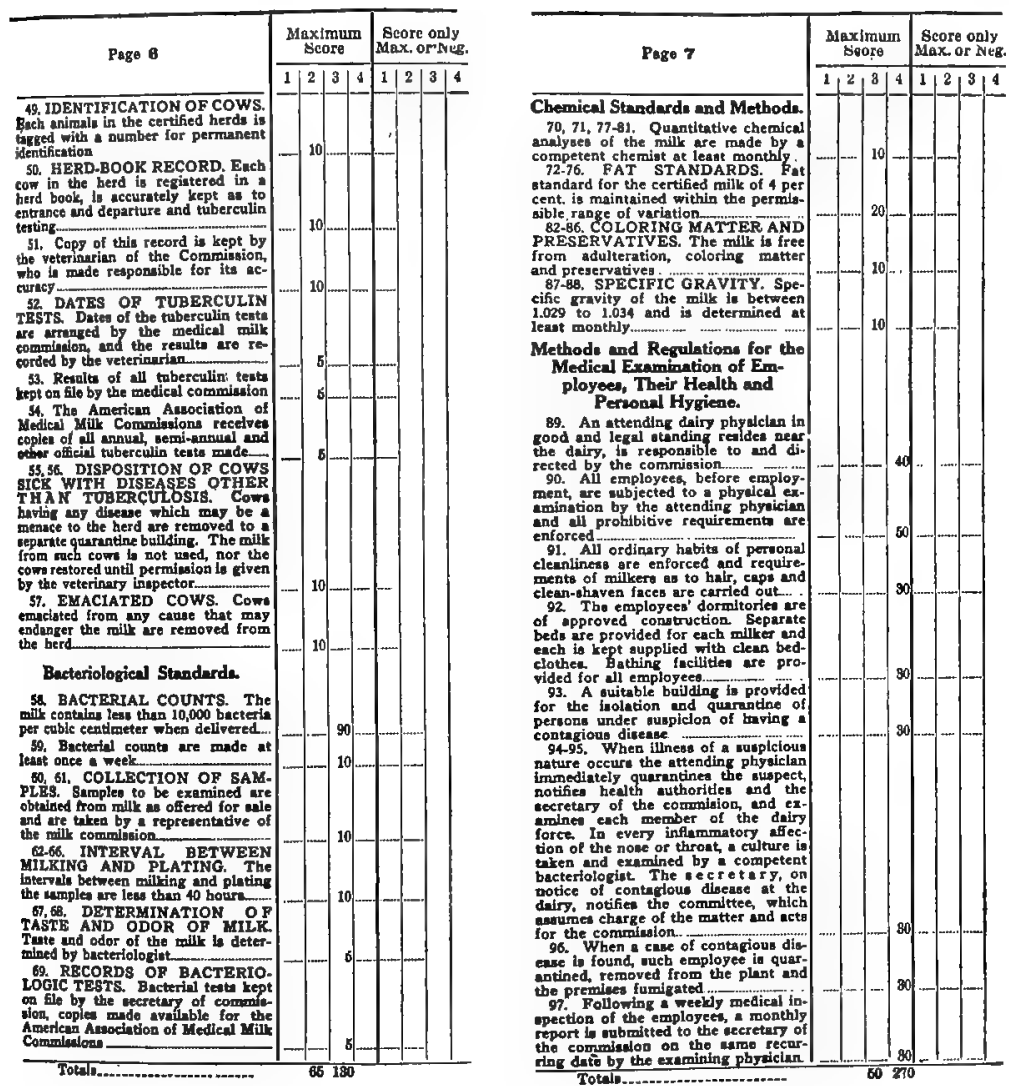

Fig. 198 continued.

any commission which weakens the strength of this national chain should not be tolerated as a factor in the government or legislation of the Association."

A score card has been worked out for the guidance of medical milk commissions by the American Association. A copy of this card is given on pages $492-495$.

The work of medical milk commissions has had a most bene- 
ficial influence on milk production in general. The importance of bacterial counts as a guide for detecting imperfections in milk production has been amply demonstrated. It has been made clear that bacterial pollution in the first stages of production can be controlled in large measure, and that at later stages of handling or during transportation material increase in numbers of bacteria can be avoided. The effect of cleanly production and continued low temperature during transportation has been well illustrated by Mr. H. B. Gurler, who sent milk from DeKalb, Ill., to the Paris exposition in 1900 . The astonishment was great when it was found that after twenty-one days from the time of milking the product was still sweet and wholesome. Similarly, it is a common practice to take bottles of certified milk for infant feeding on ocean trips. The milk will remain sweet for the period of the trip if kept cold.

Supervision of milk production by medical men and veterinarians has shown that the disease germs of man and cattle can be excluded with reasonable certainty. It is important, as has been pointed out, that this kind of supervision be painstaking and the work of competent experts. Careful tests for tuberculosis with tuberculin must be made at intervals of six months, and all reacting cattle promptly removed. Care must be exercised in regard to introduction of new animals. When all these precautions are conscientiously carried out certified milk can be depended upon to be of the highest quality and as free from infectious germs as our present knowledge can make it.

From a commercial point of view there remains much to be done. Owners of some certified milk dairies claim that there is no profit in production. Dairymen, as a rule, are deterred from going into the business because a large capital is needed for equipment and because the overhead expense is large. To insure a safe product the control cannot be relaxed, but medical milk commissions sometimes make extraordinary demands on the producer. Instead of receiving counsel the producer may lose his certificate. Troubles do arise occasionally, and the commission should then investigate and attempt to locate the trouble. Mistakes may have a discouraging effect on producers, especially when they are new to the business. At each inspection some suggestion can be made, and the establishment of the producer can be gradually improved to relative perfection. A friendly attitude will do more good than insistance upon needless or arbitrary rules. Certified milk has filled a great need, and only by intelligent co-operation between producer and the commission can the greatest benefit be conferred upon the public.

It has been demonstrated that milk practically equal to cer- 
tified milk in every respect can be produced at relatively small cost. The investment need not be as large as is usually taken for granted. With the development of this aspect of the question the price of certified milk will gradually come within the reach of the poorer classes. The writer had occasion to visit a dairy in southern Wisconsin where milk was produced under conditions acceptable to a medical milk commission. The bacterial counts of 17 tests made during the summer months averaged 2553 per cubic centimeter. Six of the counts were below 1000 and only one was 14,400 . The counts were made after three days' incubation at room temperature. Higher counts are obtained by this method of incubation than by the accepted two days' incubation at $37^{\circ} \mathrm{C}$. The whole equipment of this dairy, exclusive of land and cattle, cost about $\$ 1630$. This sum does not cover the cost of the original old-fashioned building, but does include the improvements necessary to make the stable acceptable to the demands of the commission. It was a small dairy with a herd of 30 cows and a daily production of 250 quarts of milk. The milk was sold with a fair profit at 6 cents a quart to a distributing dairy, which marketed the milk and paid the expense of certification. Naturally, the larger the herd, the more difficult it is to efficiently supervise all operations of milk production. Medical milk commissions can do much to encourage certified milk production by relieving producers from the necessity of investing capital in superfluous equipment.

The movement has received much support by the foundation in 1907 of the Association of Medical. Milk Commissions. In the following year the Certified Milk Producers' Association was organized. By the concerted efforts of these two organizations the production of certified milk was placed on a sounder basis than before. The American Association of Medical Milk Commissions has published standards for certified milk which every medical milk commission is expected to live up to. Following is a copy of the standards and regulations:

\section{METHODS AND STANDARDŚ FOR THE PRODUCTION AND DIS- TRIBUTION OF CERTIFIED MILK}

(Adopted by the American Association of Medical Milk Commissions May 1, 1912)

Hygiene of THE DAIRY

Under the Supervision and Control of the Veterinarian

1. Pastures or Paddocks.-Pastures or paddocks to which the cows have access shall be free from marshes or stagnant pools, crossed by no stream which might become dangerously contaminated, at sufficient distances from offensive conditions to suffer no bad effects from them, and shall be free from plants which affect the milk deleteriously. 
2. Surroundings of Buildings.-The surroundings of all buildings shall be kept clean and free from accumulations of dirt, rubbish, decayed vegetable or animal matter or animal waste, and the stable yard shall be well drained.

3. Location of Buildings.-Buildings in which certified milk is produced and handled shall be so located as to insure proper shelter and good drainage, and at sufficient distance from other buildings, dusty roads, cultivated and dusty fields, and all other possible sources of contamination; provided, in the case of unavoidable proximity to dusty roads or fields, the exposed side shall be screened with cheesecloth.

4. Construction of Stables. - The stables shall be constructed so as to facilitate the prompt and easy removal of waste products. The floors and platforms shall be made of cement or other non-absorbent material and the gutters of cement only. The floors shall be properly graded and drained, and the manure gutters shall be from 6 to 8 inches deep and so placed in relation to the platform that all manure will drop into them.

5. The inside surface of the walls and all interior construction shall be smooth, with tight joints, and shall be capable of shedding water. The ceiling shall be of smooth material and dust-tight. All horizontal and slanting surfaces which might harbor dust shall be avoided.

6. Drinking and Feed Troughs.-Drinking troughs or basins shall be drained and cleaned each day, and feed troughs and mixing floors shall be kept in a clean and sanitary condition.

7. Stanchions.-Stanchions, when used, shall be constructed of iron pipes or hard wood, and throat latches shall be provided to prevent the cows from lying down between the time of cleaning and the time of milking.

8. Ventilation.-The cow stables shall be provided with adequate ventilation either by means of some approved artificial device, or by the substitution of cheesecloth for glass in the windows, each cow to be provided with a minimum of 600 cubic feet of air space.

9. Windows.-A sufficient number of windows shall be installed and so distributed as to provide satisfactory light and a maximum of sunshine, 2 feet square of window area to each 600 cubic feet of air space to represent the minimum. The coverings of such windows shall be kept free from dust and dirt.

10. Exclusion of Flies, etc.-All necessary measures should be taken to prevent the entrance of flies and other insects and rats and other vermin into all the buildings.

11. Exclusion of Animals from the Herd.-No horses, hogs, dogs, or other animals or fowls shall be allowed to come in contact with the certified herd, either in the stables or elsewhere.

12. Bedding.-No dusty or moldy hay or straw, bedding from horse stalls, or other unclean materials shall be used for bedding the cows. Only bedding which is clean, dry, and absorbent may be used, preferably shavings or straw.

13. Cleaning Stable and Disposal of Manure.--Soiled bedding and manure shall be removed at least twice daily, and the floors shall be swept and kept free from refuse. Such cleaning shall be done at least one hour before the milking time. Manure, when removed, shall be drawn to the field or temporarily stored in containers so screened as to exclude flies. Manure shall not be even temporarily stored within 300 feet of the barn or dairy building.

14. Cleaning of Cows.-Each cow in the herd shall be groomed daily, and no manure, mud, or filth shall be allowed to remain upon her during milking; for cleaning, a vacuum apparatus is recommended.

15. Clipping.--Long hairs shall be clipped from the udder and flanks of the cow and from the tail above the brush. The hair on the tail shall be cut so that the brush may be well above the ground.

16. Cleaning of Udders. - The udders and teats of the cow shall be cleaned before milking; they shall be washed with a cloth and water, and dry wiped with another clean sterilized cloth-a separate cloth for drying each cow.

17. Feeding.-All food-stuffs shall be kept in an apartment separate from and not directly communicating with the cow barn. They shall be brought 
into the barn only immediately before the feeding hour, which shall follow the milking.

18. Only those foods shall be used which consist of fresh, palatable, or nutritious materials, such as will not injure the health of the cows or unfavorably affect the taste or character of the milk. Any dirty or moldy food or food in a state of decomposition or putrefaction shall not be given.

19. A well-balanced ration shall be used, and all changes of food shall be made slowly. The first feedings of grass, alfalfa, ensilage, green corn, or other green feeds shall be given in small rations and increased gradually to full ration.

20. Exercise.-All dairy cows shall be turned out for exercise at least two hours in each twenty-four in suitable weather. Exercise yards shall be kept free from manure and other filth.

21. Washing of Hands.-Conveniently located facilities shall be provided for the milkers to wash in before and during milking.

22. The hands of the milkers shall be thoroughly washed with soap, water, and brush and carefully dried on a clean towel immediately before milking. The hands of the milkers shall be rinsed with clean water and carefully dried before milking each cow. The practice of moistening the hands with milk is forbidden.

23. Milking Clothes.-Clean overalls, jumper, and cap shall be worn during milking. They shall be washed or sterilized each day and used for no other purpose, and when not in use they shall be kept in a clean place, protected from dust and dirt.

24. Things to be Avoided by Milkers.-While engaged about the dairy or in handling the milk employees shall not use tobacco nor intoxicating liquors. They shall keep their fingers away from their nose and mouth, and no milker shall permit his hands, fingers, lips, or tongue to come in contact with milk intended for sale.

25. During milking the milkers shall be careful not to touch anything but the clean top of the milking stool, the milk pail, and the cow's teats.

26. Milkers are forbidden to spit upon the walls or floors of stables, or upon the walls or floors of milk houses, or into the water used for cooling the milk or washing the utensils.

27. Fore-milk.-The first streams from each teat shall be rejected, as this fore-milk contains large numbers of bacteria. Such milk shall be collected into a separate vessel and not milked on to the floors or into the gutters. The milking shall be done rapidly and quietly, and the cows shall be treated kindly.

28. Milk and Calving Period.-Milk from all cows shall be excluded for a period of forty-five days before and seven days after parturition.

29. Bloody and Stringy Milk. - If milk from any cow is bloody and stringy or of unnatural appearance, the milk from that cow shall be rejected and the cow isolated from the herd until the cause of such abnormal appearance has been determined and removed, special attention being given in the meantime to the feeding or to possible injuries. If dirt gets into the pail, the milk shall be discarded and the pail washed before it is used.

30. Make-up of Herd.-No cows except those receiving the same supervision and care as the certified herd shall be kept in the same barn or brought in contact with them.

31. Employees Other than Milkers.-The requirements for milkers, relative to garments and cleaning of hands, shall apply to all other persons handling the milk, and children unattended by adults shall not be allowed in the dairy nor in the stable during milking.

32. Straining and Strainers.-Promptly after the milk is drawn it shall be removed from the stable to a clean room and then emptied from the milk pail to the can, being strained through strainers made of a double layer of finely meshed cheesecloth or absorbent cotton thoroughly sterilized. Several strainers shall be provided for each milking in order that they may be frequently changed.

33. Dairy Building.-A dairy building shall be provided which shall be located at a distance from the stable and dwelling preseribed by the local commission, and there shall be no hogpen, privy, or manure pile at a higher level or within 300 feet of it. 
34. The dairy building shall be kept elean and shall not be used for purposes other than the handling and storing of milk and milk utensils. It shall be provided with light and ventilation, and the floors shall be graded and water-tight.

35. The dairy building shall be well lighted and sereened and drained through well-trapped pipes. No animals shall be allowed therein. No part of the dairy building shall be used for dwelling or lodging purposes, and the bottling room shall be used for no other purpose than to provide a place for clean milk utensils and for handling the milk. During bottling this room shall be entered only by persons employed therein. The bottling room shall be kept scrupulously clean and free from odors.

36. Temperature of Milk.-Proper cooling to reduce the temperature to $45^{\circ} \mathrm{F}$. shall be used, and aërators shall be so situated that they can be protected from flies, dust, and odors. The milk shall be cooled immediately after being milked, and maintained at a temperature between $35^{\circ}$ and $45^{\circ} \mathrm{F}$. until delivered to the consumer.

37. Sealing of Bottles.-Milk, after being cooled and bottled, shall be immediately sealed in a manner satisfactory to the commission, but such seal shall include a sterile hood which completely covers the lip of the bottle.

38. Cleaning and Sterilizing of Bottles. - The dairy building shall be provided with approved apparatus for the cleansing and sterilizing of all bottles and utensils used in milk production. All bottles and utensils shall be thoroughly cleaned by hot water and sal soda, or equally pure agent, rinsed until the cleaning water is thoroughly removed, then exposed to live steam or boiling water at least twenty minutes, and then kept inverted until used, in a place free from dust and other contaminating materials.

39. Utensits. - All utensils shall be so constructed as to be easily cleaned. The milk pail should preferably have an elliptical opening 5 by 7 inches in diameter. The cover of this pail should be so convex as to make the entire interior of the pail visible and accessible for cleaning. The pail shall be made of heavy seamless tin, and with seams which are flushed and made smooth by solder. Wooden pails, galvanized-iron pails, or pails made of rough, porous materials are forbidden. All utensils used in milking shall be kept in good repair.

40. Water-supply. - The entire water-supply shall be absolutely free from contamination, and shall be sufficient for all dairy purposes. . It shall be protected against flood or surface drainage, and shall be conveniently situated in relation to the milk house.

41. Privies, etc., in Relation to Water-supply.-Privies, pigpens, manure piles, and all other possible sources of contamination shall be so situated on the farm as to render impossible the contanination of the water-supply, and shall be so protected by use of screens and other measures as to prevent their becoming breeding grounds for flies.

42. Toilet Rooms. - Toilet facilities for the milkers shall be provided and located outside of the stable or milk house. These toilets shall be properly screened, shall be kept clean, and shall be accessible to wash basins, water, nail-brush, soap and towels, and the milkers shall be required to wash and dry their hands immediately after leaving the toilet room.

\section{TRANSPORTATION}

43. In transit the milk packages shall be kept free from dust and dirt. The wagon, trays, and crates shall be kept scrupulously clean. No bottles shall be collected from houses in which communicable diseases prevail, unless a separate wagon is used and under conditions prescribed by the department of health and the medical milk commission. milking.

44. All certified milk shall reach the consumer within thirty hours after

\section{Veterinary SUPERVision of the Herd}

45. Tuberculin Test.-The herd shall be free from tuberculosis, as shown by the proper applieation of the tuberculin test. The test shall be applied 
in accordance with the rules and regulations of the United States Government, and all reactors shall be removed immediately from the farm. ${ }^{1}$

46. No new animals shall be admitted to the herd without first having passed a satisfactory tuberculin test, made in accordance with the rules and regulations mentioned; the tuberculin to be obtained and applied only by the official veterinarian of the commission.

47. Immediately following the application of the tuberculin test to a herd for the purpose of eliminating tuberculous cattle, the cow stable and exercising yards shall be disinfected by the veterinary inspector in accordance with the rules and regulations of the United States Government.

48. A second tuberculin test shall follow each primary test after an interval of six months, and shall be applied in accordance with the rules and regulations mentioned. Thereafter, tuberculin tests shall be reapplied annually, but it is recommended that the retests be applied semi-annually.

49. Identification of Cows. - Each dairy cow in each of the certified herds shall be labeled or tagged with a number or mark which will permanently identify her.

50. Herd-book Record.-Each cow in the herd shall be registered in a herd book, which register shall be accurately kept so that her entrance and departure from the herd and her tuberculin testing can be identified.

51. A copy of this herd-book record shall be kept in the hands of the veterinarian of the medical milk commission under which the dairy farm is operating, and the veterinarian shall be made responsible for the accuracy of this record.

52. Dates of Tuberculin Tests.-The dates of the annual tuberculin tests shall be definitely arranged by the medical milk commission, and all of the results of such tests shall be recorded by the veterinarian and regularly reported to the secretary of the medical milk commission issuing the certificate.

53. The results of all tuberculin tests shall be kept on file by each medical milk commission, and a copy of all such tests shall be made available to the American Association of Medical Milk Commissions for statistical purposes.

54. The proper designated officers of the American Assoriation of Medical Milk Commissions should receive copies of reports of all of the annual, semiannual, and other official tuberculin tests which are made and keep copies of the same on file and compile them annually for the use of the association.

55. Disposition of Cows Sick with Diseases Other than Tuberculosis.Cows having rheumatism, leukorrhea, inflammation of the uterus, severe diarrhea, or disease of the udder, or cows that from any other cause may be a menace to the herd shall be removed from the herd and placed in a building separate from that which may be used for the isolation of cows with tuberculosis, unless such building has been properly disinfected since it was last used for this purpose. The milk from such cows shall not be used nor shall the cows be restored to the herd until permission has been given by the veterinary inspector after a careful physical examination.

56. Notification of Veterinary Inspector.- In the event of the occurrence of any of the diseases just described between the visits of the veterinary inspector, or if at any time a number of cows become sick at one time in such a way as to suggest the outbreak of a contagious disease or poisoning, it shall be the duty of the dairyman to withdraw such sickened cattle from the herd, to destroy their milk, and to notify the veterinary inspector by telegraph or telephone immediately.

57. Emaciated Cows.-Cows that are emaciated from chronic diseases or from any cause that in the opinion of the veterinary inspector may endanger the quality of the milk, shall be removed from the herd.

\section{Bacteriologic Standards}

58. Bacterial Counts.-Certified milk shall contain less than 10,000 bacteria per cubic centimeter when delivered. In case a count exceeding 10,000

${ }^{1}$ See Circular of Instructions issued by the Bureau of Animal Industry for making tuberculin tests and for disinfection of premises. 
bacteria per cubic centimeter is found, daily counts shall be made, and if normal counts are not restored within ten days the certificate shall be suspended.

59. Bacterial counts shall be made at least once a week.

60. Collection of Samples. - The samples to be examined shall be obtained from milk as offered for sale and shall be taken by a representative of the milk commission. The samples shall be received in the original packages, in properly iced containers, and they shall be so kept until examined, so as to limit as far as possible changes in their bacterial content.

61. For the purpose of ascertaining the temperature, a separate original package shall be used, and the temperature taken at the time of collecting the sample, using for the purpose a standardized thermometer graduated in the centigrade scale.

62. Interval Between Milking and Plating.-The examinations shall be made as soon after collection of the samples as possible, and in no case shall the interval between milking and plating the samples belonger than forty hours.

63. Plating. - The packages shall be opened with aseptic precautions after the milk has been thoroughly mixed by vigorously reversing and shaking the container twenty-five times.

64. Two plates at least shall be made for each sample of milk, and there shall also be made a control of each lot of medium and apparatus used at each testing. The plates shall be grown at $37^{\circ} \mathrm{C}$. for forty-eight hours.

65. In making the plates there shall be used agar-agar media containing 1.5 per cent. agar and giving a reaction of 1.0 to phenolphthalein.

The following is the method recommended by a committee of the American Public Health Association ${ }^{1}$ for the making of the media, modified, however, as to the agar content and reaction to conform to the requirements specified in Section 65:

1. Boil $\mathbf{1 5}$ grams of thread agar in $\mathbf{5 0 0}$ c.c. of water for half an hour and make up weight to 500 grams, or digest for ten minutes in the autoclave at $110^{\circ} \mathrm{C}$. Let this cool to about $60^{\circ} \mathrm{C}$.

2. Infuse 500 grams finely chopped lean beef for twenty-four hours with its own weight of distilled water in the refrigerator.

3. Make up any loss by evaporation.

4. Strain infusion through cotton flannel, using pressure.

5. Weigh filtered infusion.

6. Add Witte's peptone, 2 per cent.

7. Warm on water-bath, stirring until peptone is dissolved and not allowing temperature to rise abnve $60^{\circ} \mathrm{C}$.

8. To the 500 grams of meat infusion (with peptone) add 500 grams of the 2 por cent. agar, keeping the temperature below $60^{\circ} \mathrm{C}$.

9. Heat over boiling water (or steam) bath thirty minutes.

10. Restore weight lost by evaporation.

11. Titrate after boiling one minute to expel carbonic acid.

12. Adjust reaction to final point desired +1 by adding normal sodium hydrate.

13. Boil two minutes over free flame, constantly stirring.

14. Restore weight lost by evaporation.

15. Filter through absorbent cotton or coarse filter paper, passing the filtrate through the filter repeatedly until clear.

16. Titrate and record the final reaction..

17. Tube (10 c.c. to a tube) and sterilize in autoclave one hour at 15 pounds pressure or in the streaming steam for twenty minutes on three successive days.

${ }^{1}$ In a provisional report of the Committee on Standard Methods of Bacteriological Milk Analysis, published in the American Journal of Public Health, 1916, vol. 6, p. 1315, a change is proposed in the composition of standard agar which, according to Sears and Case (Jour. of Bact., 1916, vol. 3, p. 351), gives low and irregular counts. 
66. Samples of milk for plating shall be diluted in the proportion of 1 part of milk to 99 parts of sterile water; shake twenty-five times and plate 1 c.c. of the dilution.

The committee on bacterial milk analyses of the American Public Health Association in Part IV of its report presented details with respect to plating apparatus and technic in part as follows:

Plating Apparatus.-For plating it is best to have a water-bath in which to melt the media and a water-jacketed water-bath for keeping it at the required temperature; a wire rack which should fit both the water-baths for holding the media tubes; a thermometer for recording the temperature of the water in the water-jacketed bath, sterile 1 c.c. pipets, sterile Petri dishes, and sterile dilution water in measured quantities.

Dilutions.-Ordinary potable water, sterilized, may be used for dilutions. Occasionally spore forms are found in such water which resist ordinary autoclave sterilization; in such cases distilled water may be used or the autoclave pressure increased. With dilution water in 8-ounce bottles calibrated for 99 c.c. . . . all the necessary dilutions may be made.

Short, wide-mouthed "blakes" or wide-mouthed French square bottles are more easily handled and more economical of space than other forms of bottles or flasks.

Eight-ounce bottles are the best, as the required amount of dilution water only about half fills them, leaving room for shaking. Long-fiber non-absorbent cotton should be used for plugs. It is well to use care in selecting cotton for this purpose, to avoid short-fiber or dusty cotton, which gives a cloud of lint-like particles on shaking. Bottles ... should be filled a little over the 99 c.c. . . . to allow for loss during sterilization.

Pipets.-Straight sides 1 c.c. pipets are more easily handled than those with bulbs; they may be made from ordinary $\frac{3}{18}$-inch glass tubing and should be about 10 inches in length.

Plating Technic.-The agar after melting should be kept in the waterjacketed water-bath between $40^{\circ}$ and $45^{\circ} \mathrm{C}$. for at least fifteen minutes before using to make sure that the agar itself has reached the temperature of the surrounding water. If used too warm the heat may destroy some of the bacteria or retard their growth.

Shake the milk sample twenty-five times, then with a sterile pipet transfer 1 c.c. to the first dilution water and rinse the pipet by drawing dilution water to the mark and expelling; this gives a dilution 1 to 100 .

... Then with a sterile pipet transfer 1 c.c. to the Petri dish, using care to raise the cover only as far as necessary to insert the end of the pipet.

Take the tube of agar from the water-bath, wipe the water from outside the tube with a piece of cloth, remove the plug, pass the mouth of the tube through a flame, and pour the agar into the plate, using the same care as before to avoid exposure of the plate contents to the air.

Carefully and thoroughly mix the agar and diluted milk in the Petri dish by a rotary motion, avoiding the formation of air bubbles or slopping the agar, and after allowing the agar to harden for at least fifteen minutes at room temperature, place the dish bottom down in the incubator.

Plating should always be done in a place free from dust or currents of air.

In order that colonies may have sufficient food for proper development 10 c.c. of agar shall be used for each plate.

67. Determination of Taste and Odor of Milk.-After the plates have been prepared and placed in the incubator, the taste and odor of the milk shall be determined after warming the milk to $100^{\circ} \mathrm{F} .1$

68. Counts. - The total number of colonies on each plate should be counted, and the results expressed in multiples of the dilution factor. Colonies

${ }^{1}$ Should it be deemed desirable and necessary to conduct tests for sediment, the presence of special bacteria, or the number of leukocytes, the methods adopted by the committee of the American Public Health Association should be followed. 
too small to be seen with the naked eye or with slight magnification shall not be considered in the count.

69. Records of Bacteriologic Tests.-The results of all bacterial tests shall be kept on file by the secretary of each commission, copies of which should be made available annually for the use of the American Association of Medical Milk Commissions.

\section{Chemical Standards and Methods}

The methods that must be followed in carrying out the chemical investigations essential to the protection of certified milk are so complicated that in order to keep the fees of the chemist at a reasonable figure, there must be eliminated from the examination those procedures which, while they might be helpful and interesting, are in no sense necessary.

For this reason the determination of the water, the total solids, and the milk-sugar is not required as a part of the routine examination.

70. The chemical analyses shall be made by a competent chemist designated by the medical milk commission.

71. Method of Obtaining Samples.-The samples to be examined by the chemist shall have been examined previously by the bacteriologist designated by the medical milk commission as to temperature, odor, taste, and bacterial content.

72. Fat Standards.-The fat standard for certified milk shall be 4 per cent., with a permissible range of variation of from 3.5 to 4.5 per cent.

73. The fat standard for certified cream shall be not less than 18 per cent.

74. If it is desired to sell higher fat-percentage milks or creams as certified milks or creams, the range of variation for such milks shall be 0.5 per cent. on either side of the advertised percentage and the range of variations for such creams shall be 2 per cent. on either side of the advertised percentage.

75. The fat content of certified milks and creams shall be determined at least once each month.

76. The methods recommended for this purpose are the Babcock (a), the Leffmann-Beam (b), and the Gerber $(c)$.

(a) Babcock Test.-The Babcock test is based on the fact that strong sulphuric acid will dissolve the non-fatty solid constituents of milk, and thus enable the fat to separate on standing. It can be conducted by any of the Babcock outfits which are purchasable in the market.

"The test is made by placing in the special test bottle 18 grams ( 17.6 c.c.) of milk. To this is added, from a pipet, buret, or measuring bottle, 17.5 c.c. commercial sulphuric acid of a specific gravity of 1.82 to 1.83 . The contents of the bottle are carefully and thoroughly mixed by a rotary motion. The mixture becomes brown and heat is generated. The test bottle is now placed in a properly balanced centrifuge and whirled for five minutes at a speed of from 800 to 1200 revolutions per minute. Hot water is then added to fill the bottle to the lower part of the neck, after which it is again whirled for two minutes. Now, enough hot water is added to float the column of fat into the graduated portion of the neck of the bottle, and the whirling is repeated for a minute. The amount of fat is read while the neck of the bottle is still hot. The reading is from the upper limits of the meniscus. A pair of calipers is of assistance in measuring the column of fat." (Jensen's Milk Hygiene, Leonard Pearson's translation.)

(b) Leffmann-Beam Test.-The distinctive feature is the use of fusel oil, the effect of which is to produce a greater difference in surface tension between the fat and the liquid in which it is suspended, and thus promote its readier separation. This effect has been found to be heightened by the presence of a small amount of hydrochloric acid.

The test bottles have a capacity of about 30 c.c. and are provided with a graduated neck, each division of which represents 9.1 per cent. by weight of butter-fat.

Fifteen centimeters of the milk are measured into the bottle, 3 c.c. of a mixture of equal parts of amyl alcohol and strong hydrochloric acid 
added and mixed. Then 9 c.c. of concentrated sulphuric acid is added in portions of about 1 c.c.; after each addition the liquids are mixed by giving the bottle a gyratory motion. If the fluid has not lost all of its milky color by this treatment, a little more concentrated acid must be added. The neck of the bottle is now immediately filled at about the zero point with 1 part sulphuric acid and 2 parts water, well mixed just before using. Both the liquid in the bottle and the diluted acid must be hot. The bottle is then placed at once in the centrifugal machine; after rotation from one to two minutes, the fat will collect in the neck of the bottle and the percentage may be read off.

(c) Gerber's Test.-This test is applied as follows: The test bottles are put into the stand with the mouths uppermost; then, with the pipet designed for the purpose, or with an automatic measurer, 10 c.c. of sulphuric acid are filled into the test bottle, care being taken not to allow any to come in contact with the neck. The few drops remaining in the tip of the pipet should not be blown out. Then 11 c.c. of milk are measured with the proper pipet and allowed to flow slowly on to the acid, so that the two liquids mix as little as possible. Finally, the amyl alcohol is added. (It is important to use the reagents in the proper order, which is-sulphuric acid, milk, amyl alcohol. If the sulphuric acid is followed by amyl alcohol and the milk last, then the result is sometimes incorrect.) A rubber stopper, which must not be damaged, is then fitted into the mouth of the test bottle, and the contents are well shaken, the thumb being kept on the stopper to prevent it coming out. As a considerable amount of heat is generated by the action of the sulphuric acid on the milk, the test bottle should be wrapped in a cloth.

The shaking of the sample must be done thoroughly and quickly, and the test bottle inverted several times, so that the liquid in the neck becomes thoroughly mixed. By pressing in the rubber stopper the height of the liquid can be brought to about the zero point on the scale.

If only a few samples have to be analyzed and the room is warm, the test bottles can be put into the centrifuge without any preliminary heating, otherwise the test bottles must be warmed for a few minutes (not longer) in the water-bath at a temperature of $60^{\circ}$ to $65^{\circ} \mathrm{C}$. When the temperature rises higher than this, say above $70^{\circ} \mathrm{C}$., the rubber stopper is liable to be blown out of the test bottle. After the test bottles have been heated they are arranged symmetrically in the centrifuge and whirled for three to four minutes at a speed of about 1000 revolutions per minute. When the centrifuge has a heating arrangement attached to it, the preliminary warming is not, of course, necessary. When the test bottles are taken out of the centrifuge, they are again placed in the water-bath at a temperature of $60^{\circ}$ to $65^{\circ} \mathrm{C}$., and left there for several minutes before being read; where the centrifuge is heated, the tubes can be read off as taken from the centrifuge.

By carefully screwing in the rubber stopper, or even by pressing it, the lower limit of the fat column is brought on to one of the main divisions of the scale, and then, by holding the test bottle against the light, the height of the column of fat can be accurately ascertained. The lowest point of the meniscus is taken as the level when reading the upper surface of the fat in a sample of whole milk, and the middle of the meniscus for separated milk.

If the column of fat is not clear and sharply defined, the sample must be again whirled in the centrifuge.

Each division on the scale is equivalent to 0.1 per cent., so it is very easy to read to 0.05 per cent. or, with a lens, to 0.025 per cent. If the number which is read off is multiplied by 0.1 , then the percentage quantity of fat in the milk is obtained, e. g.. if the number on the scale was 36.5 , then the percentage of fat is 3.65. (Milk and Dairy Products, Earthel; translated by Goodwin, p. 71.)

77. Before condemning samples of milk which have fallen outside the limits allowed, the chemist shall have determined, by control ether extractions, that his apparatus and his technic are reliable.

78. Protein Standard.-The protein standard for certified milk shall be 3.50 per cent., with a permissible range of variation of from 3 to 4 per cent. 
79. The protein standard for certified cream shall correspond to the protein standard for certified milk.

80. The protein content shall be determined only when any special consideration seems to the medical milk commission to make it desirable.

81. It shall be determined by the Kjeldahl method, using the Gunning or some other reliable modification, and employing the factor 6.25 in reckoning the protein from the nitrogen.

Kjeldahl Method.-Five cubic centimeters of milk are measured carefully into a flat-bottom 800 c.c. Jena flask, 20 c.c. of concentrated sulphuric acid (C. P.; sp. gr., 1.84) are added, and 0.7 gram of mercuric oxid (or its equivalent in metallic mercury); the mixture is then heated over direct flame until it is straw-colored or perfectly 'white; a few crystals of potassium permanganate are now added till the color of the liquid remains green. All the nitrogen in the milk has then been converted into the form of ammonium sulphate. After cooling, 200 c.c. of ammonia-free distilled water are added, 20 c.c. of a solution of potassium sulphid (containing 40 grams sulphid per liter), and a fraction of a gram of powdered zinc. A quantity of seminormal $\mathrm{HCl}$ solution more than sufficient to neutralize the ammonia obtained in the oxidation of the milk is now carefully measured out from a delicate buret (divided into $\frac{1}{20}$ c.c.) into an Erlenmeyer flask and the flask connected with a distillation apparatus. At the other end the Jena flask containing the watery solution of the ammonium sulphate is connected, after adding 50 c.c. of a concentrated soda solution ( 1 pound "pure potash" dissolved in 500 c.c. of distilled water and allowed to settle); the contents of the Jena flask are now heated to boiling, and the distillation is continued for forty minutes to an hour, until all ammonia has been distilled over.

The exness of acid in the Erlenmeyer receiving flask is then accurately titrated back by means of a tenth-normal standard ammonia solution, using a cochineal solution as an indicator. From the amount of acid used the per cent. of nitrogen is obtained; and from it the per cent. of casein and albumen in the milk by multiplying by 6.25 . The amount of nitrogen contained in the chemicals used is determined by blank experiments and deducted from the nitrogen obtained as described. (Farrington and Woll, Testing Milk and Its Products, p. 221.)

82. Coloring-matter and Preservatives.-All certified milks and creams shall be free from adulteration, and coloring-matter and preservatives shall not be added thereto.

83. Tests for the detection of added coloring-matter shall be applied whenever the color of the milk or cream is such as to arouse suspicion.

Test for Coloring-matter.-The presence of foreign coloring-matter in milk is easily shown by shaking 10 c.c. of the milk with an equal quantity of ether; on standing, a clear ether solution will rise to the surface; if artificial coloring-matter has been added to the milk, the solution will be yellow colored, the intensity of the color indicating the quantity added; natural fresh milk will give a colorless ether solution. (Testing Milk and Its Products, Farrington and Woll, p. 244.)

84. Tests for the detection of formaldehyd, borax and boric acid shall be applied at least once each month. Occasionally application of tests for the detection of salicylic acid, benzoic acid, and the benzoates is also recommended.

Test for the Detection of Formaldehyd.-Five cubic centimeters of milk is measured into a white porcelain dish, and a similar quantity of water added; 10 c.c. of $\mathrm{HCl}$, containing a trace of $\mathrm{Fe}_{2} \mathrm{Cl}_{6}$, is added, and the mixture is heated very slowly. If formaldehyd is present, a violet color will be formed. (Testing Milk and Its Products, Farrington and Woll, p. 249.)

Test for Boric Acid (Borax, Borates, Preservaline, etc.).-One hundred cubic centimeters of milk are made alkaline with a soda or potash solution, and then evaporated to dryness and incinerated. The ash is dissolved in water, to which a little hydrochloric acid has been added, and the solution 
filtered. A strip of turmeric paper moistened with the filtrate will be colored reddish brown when dried at $100^{\circ} \mathrm{C}$. on a watch-glass, if boric acid is present.

If a little alcohol is poured over the ash to which concentrated sulphuric acid has been added, and fire is set to the alcohol, after a little while this will burn with a yellowish-green tint, especially noticeable if the ash is stirred with a glass rod and when the flame is about to go out. (Testing Milk and Its Products, Farrington and Woll, p. 247.)

Test for Salicylic Acid (Salicylates, etc.).-Twenty cubic centimeters of milk are acidulated with sulphuric acid and shaken with ether; the ether solution is evaporated, and the residue treated with alcohol and a little ironchlorid solution; a deep violet color will be obtained in the presence of salicylic acid. (Testing Milk and Its Products, Farrington and Woll, p. 248.)

Test for Benzoic Acid.- Two hundred and fifty to five hundred cubic centimeters of milk are made alkaline with a few drops of lime or baryta water, and then evaporated to about a quarter of the bulk. Powdered gypsum is stirred into the remaining liquid until a paste is formed, which is then dried on the water-bath. The gypsum only serves to hasten the drying, and powdered pumice stone or sand can be used equally well. When the mass is dry, it is finely powdered and moistened with dilute sulphuric acid and shaken out three or four times with about twice the volume of 50 per cent. alcohol, in which benzoic acid is easily soluble in the cold, the fat only being dissolved to a very slight extent or not at all. The acid alcoholic liquid from the various extractions, which contains milk-sugar and inorganic salts in addition to the benzoic acid, is neutralized with baryta water and evaporated to a small bulk. Dilute sulphuric acid is again added, and the liquid shaken out with small quantities of ether. On evaporation of the ether, the benzoic acid is left behind in almost pure state, the only impurities being small quantities of fat or ash.

The benzoic acid which is obtained is dissolved in a small quantity of warm water, a drop of sodium acetate and neutral ferric chlorid added, and the red precipitate of benzoate of iron indicates the presence of the acid. (Milk and Dairy Products, Barthel; translated by Goodwin, p. 121).

85. Detection of Heated Milk.-Certified milk or cream shall not be subjected to heat unless specially directed by the commission to meet emergencies.

86. Tests to determine whether such milks and creams have been subjected to heat shall be applied at least once each month.

Detection of Heated Milk-Storch's Method.-Five cubic centimeters of milk are poured into a test-tube; a drop of weak solution of hydrogen dioxid (about 0.2 per cent.) which contains about 0.1 per cent. sulphuric acid, is added, and 2 drops of a 2 per cent. solution of paraphenylendiamin (solution should be renewed quite often), then the fluid is shaken. If the milk or the cream becomes at once indigo blue, or the whey violet or reddish brown, then this has not been heated or, at all events, it has not been heated higher than $78^{\circ} \mathrm{C}$. $\left(172.5^{\circ} \mathrm{F}.\right)$; if the milk becomes a light bluish gray immediately or in the course of half a minute, then it has been heated to $79^{\circ}$ to $80^{\circ} \mathrm{C}$. $\left(174.2^{\circ}\right.$ to $176^{\circ} \mathrm{F}$.). If the color remains white, the milk has been heated at least to $80^{\circ} \mathrm{C}$. $\left(176^{\circ} \mathrm{F}\right.$.). In the examination of sour milk or sour buttermilk, limewater must be added, as the color reaction is not shown in acid solution.

Arnold's Guaiac Method.-A little milk is poured into a test-tube and a little tincture of guaiac is added, drop by drop. If the milk has not been heated to $80^{\circ} \mathrm{C}$. $\left(176^{\circ} \mathrm{F}\right.$.) a blue zone is formed between the two fluids; heated milk gives no reaction, but remains white. The guaiac tincture should not be used perfectly fresh, but should have stood a few days and its potency have been determined. Thereafter it can be used indefinitely. These tests for heated milk are only active in the case of milks which have been heated to $176^{\circ} \mathrm{F}$. or $80^{\circ} \mathrm{C}$. (Jensen's Milk Hygiene, Pearson's translation, p. 192.)

Microscopic Test for Heated (Pasteurized) Milk-Frost and Ravenel.About 15 c.c. of milk are centrifuged for five minutes, or long enough to throw down the leukocytes. The cream layer is then completely removed with 
absorbent cotton and the milk drawn off with a pipet, or a fine-pointed tube attached to a Chapman air pump. Only about $2 \mathrm{~mm}$. of milk are left above the sediment which is in the bottom of the sedimentation tube.

The stain, which is an aqueous solution of safranin 0 , soluble in water, is then added very slowly from an opsonizing pipet. The important thing is to mix stain and milk so slowly that clotting does not take place. The stain is added until a deep opaque rose color is obtained. After standing three minutes, by means of the opsonizing pipet, which has been washed out in hot water, the stained sediment is then transferred to slides. A small drop. is placed at the end of each of several slides and spread by means of a glass. spreader, as in Wright's method for opsonic index determinations.

In an unheated milk the polymorphonuclear leukocytes have their protoplasm slightly tinged or are unstained.

In heated milk the polymorphonuclear leukocytes have their nuclei stained. In milk heated to $63^{\circ} \mathrm{C}$. or above, practically all of the leukocytes. have their nuclei definitely stained. When milk is heated at a lower temperature the nuclei are not all stained above $60^{\circ} \mathrm{C}$. The majority, however, are stained.

87. Specific Gravity.-The specific gravity of certified milk shall rangefrom 1.029 to 1.034 .

88. The specific gravity shall be determined at least each month.

The Quevenne lactodensimeter is recommended for the determination of the specific gravity. It is made like an ordinary aërometer and divided into degrees which correspond to a specific gravity from 1.014 to 1.040 , or only 1.022 to 1.038 , since by the latter division a greater space is gained between the different degrees without unduly lengthening the instrument. From such a lactodensimeter one can easily read off four decimal places.

The milk the specific gravity of which is to be determined is well shaken and poured into a high glass cylinder of suitable diameter; the aërometer is dropped in slowly, in order to prevent its bobbing up and down. (The bulb should be free from adhering air bubbles.) The figures on the stem are the second and third decimals of the numbers of the specific gravity, so that 34 is to be read 1.034. For this examination, the temperature of the milk must be $15^{\circ} \mathrm{C} .\left(60^{\circ} \mathrm{F}\right.$.) ; if it is not, the specific gravity of the milk at $15^{\circ} \mathrm{C}$. must be calculated from the specific gravity found and from the temperature, for in milk inspection and analysis this is the standard.

\section{Methods and Regulations for the Medical Examination of Employees, Their Health and Personal Hygiene}

89. A medical officer, known as the attending dairy physician, shall be selected by the commission, who should reside near the dairy producing certified milk. He shall be a physician in good standing and anthorized by law to practice medicine; he shall be responsible to the commission and subject to its direction. In case more than one dairy is under the control of the commission and they are in different localities, a separate physician should be designated for employment for the supervision of each dairy.

90. Before any person shall come on the premises to live and remain as an employee, such person, before being engaged in milking or the handling of milk, shall be subjected to a complete physical examination by the attending physician. No person shall be employed who has not been vaccinated recently or who upon examination is found to have a sore throat, or to be suffering from any form of tubereulosis, venereal disease, conjunctivitis, diarrhea, dysentery, or who has recently had typhoid fever or is proved to be a typhoid carrier, or who has any inflammatory disease of the respiratory tract, or any suppurative process or infectious skin eruption, or any disease of an infectious or contagious nature, or who has recently been associated with children sick with rontagious disease.

91. In addition to ordinary habits of personal cleanliness all milkers shall have well-trimmed hair, wear close-fitting caps, and have clean-shaven faces. 
92. When the milkers live upon the premises their dormitories shall be constructed and operated according to plans approved by the commission. A separate bed shall be provided for each milker and each bed shall be kept supplied with clean bedclothes. Proper bathing facilities shall be provided for all employees on the dairy premises, preferably a shower-bath, and frequent bathing shall be enjoined.

93. In case the employees live on the dairy premises a suitable building shall be provided to be used for the isolation and quarantine of persons under suspicion of having a contagious disease.

The following plan of construction is recommended:

The quarantine building and hospital should be one story high and contain at least two rooms, each with a capacity of about 6000 cubic feet and containing not more than three beds each, the rooms to be separated by a closed partition. The doors opening into the rooms should be on opposite sides of the building and provided with locks. The, windows should be barred and the sash should be at least 5 feet from the ground and constructed for proper ventilation. The walls should be of a material which will allow proper disinfection. The floor should be of painted or washable wood, preferably of concrete, and so constructed that the floor may be flushed and properly disinfected. Proper heating, lighting, and ventilating facilities should be provided.

94. In the event of any illness of a suspicious nature the attending physician shall immediately quarantine the suspect, notify the health authorities and the secretary of the commission, and examine each member of the dairy force, and in every inflammatory affection of the nose or throat occurring among the employees of the dairy, in addition to carrying out the abovementioned program, the attending physician shall take a culture and have it examined at once by a competent bacteriologist approved by the commission. Pending such examination, the affected employee or employees shall be quarantined.

95 . It shall be the duty of the secretary, on receiving notice of any suspicious or contagious disease at the dairy, at once to notify the committee having in charge the medical supervision of employees of the dairy farm upon which such disease has developed. On receipt of the notice this committee shall assume charge of the matter, and shall have power to act for the commission as its judgment dictates. As soon as possible thereafter, the committee shall notify the commission, through its secretary, that a special meeting may be called for ultimate consideration and action.

96. When a case of contagious disease is found among the employees of a dairy producing certified milk under the control of a medical milk commission, such employee shall be at once quarantined and as soon as possible removed from the plant, and the premises fumigated.

When a case of contagion is found on a certified dairy it is advised that a printed notice of the facts shall be sent to every householder using the milk, giving in detail the precautions taken by the dairyman under the direction of the commission, and it is further advised that all milk produced at such dairy shall be heated at $145^{\circ} \mathrm{F}$. for forty minutes, or $155^{\circ} \mathrm{F}$. for thirty minutes, or $167^{\circ} \mathrm{F}$. for twenty minutes, and immediately cooled to $50^{\circ} \mathrm{F}$. These facts should also be part of the notice, and such heating of the milk should be continued during the accepted period of incubation for such contagious disease.

The following method of fumigation is recommended:

After all windows and doors are closed and the cracks sealed by strips of paper applied with flour paste, and the various articles in the room so hung or placed as to be exposed on all sides, preparations should be made to generate formaldehyd gas by the use of 20 ounces of formaldehyd and 10 ounces of permanganate of potash for every 1000 cubic feet of space to be disinfected.

For mixing the formaldehyd and potassium permanganate a large galvanized-iron pail or cylinder holding at least 20 quarts and having a flared 
top should be used for mixing therein 20 ounces of formaldehyd and 10 ounces of permanganate. A cylinder at least 5 feet high is suggested. The containers should be placed about in the rooms and the necessary quantity of permanganate weighed and placed in them. The formaldehyd solution for each pail should then be measured into a wide-mouthed cup and placed by the pail in which it is to be used.

Although the reaction takes place quickly, by making preparations as advised all of the pails can be "set off" promptly by one person, since there is nothing to do but pour the formaldehyd solution over the permanganate. The rooms should be kept closed for four hours. As there is a slight danger of fire, the reaction should be watched through a window or the pails placed on a non-inflammable surface.

97. Following a weekly medical inspection of the employees, a monthly report shall be submitted to the secretary of the medical milk commission, on the same recurring date by the examining visiting physician.

The following schedule, filled out in writing and signed by himself, is recommended as a suitable form for the attending physician's report:

This is to certify that, on the dates below indicated, official visits were made to the —— dairy, owned and conducted by — of — (indicating town and State), where careful inspections of the dairy employees were made.

(a) Number and dates of visits since last report.

(b) Number of men employed on the plant. - -

(c) Has a recent epidemic of contagion occurred near the dairy, and what was its nature and extent?

(d) Have any cases of contagious or infectious disease occurred among the men since the last report?

(e) Disposition of such cases.

(f) What individual sickness has occurred among the men since the last report?

(g) Disposition of such cases.

(h) Number of employees now quarantined for sickness.

(i) Describe the personal hygiene of the men employed for milking when prepared for and during the process of milking.

(j) What facilities are provided for sickness in employees?

(k) General hygienic condition of the dormitories or houses of the employees.

(l) Suggestions for improvement.

$(m)$ What is the hygienic condition of the employees and their surroundings?

(n) How many employees were examined at each of the foregoing visits?

Date,

Attending Physician.

\section{BIBLIOGRAPHY}

Coit: Kentucky State Medical Journal, May, 1908. Archives of Pediatrics, 1912 , vol. 29, No. 8 .

Essex County Medical Milk Commission: 22d Report, May, 1911.

Heinemann: Hoard's Dairyman, 1910, vol. 41, p. 1223.

Kelley: Bulletin of the United States Dept. of Agriculture, No. 1, September 17, 1913.

Lane: United States Dept. of Agriculture, B. A. I., Bull. 104, May, 1908.

Proceedings of the American Association of Medical Milk Commissions: Sixth, Seventh, and Eighth Annual Conferences, 1912, 1913, 1914. 


\section{PASTEURIZATION OF MILK AND OTHER METHODS OF REDUCING THE GERM CONTENT}

The problem of conserving perishable foods has engaged the attention of man from the remotest period of his existence to the present day. The real cause of food decomposition or food "spoiling" was not understood before the era of bacteriology, the science which taught that minute organisms were nearly omnipresent, and that through their activity food was rendered valueless for man. However, several efficient methods of food conservation were evolved even among savage tribes. The production of butter, cheese, and fermented milks was the natural consequence of such attempts. Conservation has also been effected by the application of heat and cold; by desiccation; by the use of harmless preservatives, such as sugar and acid, and by the use of chemical preservatives. Heat, with its destructive, and cold, with its restraining, effect upon micro-organisms are probably the most successful and most commonly applied assets of food conservation. Both are extensively applied to the preservation of milk.

When it was discovered that micro-organisms caused milk "spoiling," it seemed feasable to apply heat to prolong the period during which milk could be kept sweet. Soxhlet in 1866 had special bottles made which were filled with milk, then closed tightly, and immersed in boiling water. The milk was exposed for a short time to a temperature near the boiling-point of water. Soxhlet erroneously thought that milk treated in this manner was sterilized. However, good results were obtained by feeding this milk to babies, and in 1889 Jacobi first recommended the Soxhlet method for the preparation of milk in this country.

Milk heated to the temperature of boiling water undergoes profound physical and chemical changes. Taste and appearance are altered, and in a measure the nutritive value is affected. These alterations have been dealt with previously (see page 131). In order to avoid these changes a method similar to the one first used by Pasteur for the preservation of beer and wine has been devised for milk and has found considerable favor. "Pasteurization" was originally designed for preservation of milk, but the term has been used rather loosely. At the present time the advantage of preserving milk has been more or less lost sight of in view of the success attained by efficient pasteurization in destroying disease 
germs in milk. This must be considered the ultimate object of modern methods of pasteurization.

The thermal death-point of those pathogenic organisms which have been known to infect milk-supplies serves as a basis for calculating pasteurization temperatures. These bacteria are the bacilli of tuberculosis, typhoid fever, dysentery, diphtheria, Malta fever, the spirillum of Asiatic cholera, and the unknown organisms of scarlet fever and foot-and-mouth disease. Except Bacillus tuberculosis, all these micro-organisms are destroyed by exposure to $60^{\circ} \mathrm{C}$. for ten minutes. In fact, the great majority of cells are killed before $60^{\circ} \mathrm{C}$. is actually reached.

The thermal death-point of the tubercle bacillus has led to contradictory results. According to some reports the bacilli were not killed by one or even two boilings, while others indicated that they were destroyed at much lower temperatures. Some conclusions were based on applying the specific stain for tubercle bacilli to the milk after heating. This method may lead to erroneous results, since staining does not distinguish tubercle from acid-proof bacilli commonly found in milk, and does not distinguish between living and dead bacilli. The criterion adopted by later investigators is the production of tuberculous lesions in guinea-pigs. Even this method, as pointed out by Rosenau, leads to reliable results only if doubtful lesions are transferred to another guinea-pig, since dead tubercle bacilli sometimes form lesions closely resembling those produced by living bacilli. Theobald Smith has called attention to another source of error. When milk is heated a membrane forms on the surface, which in contact with the air cools rapidly and protects bacteria from destruction. Smith found that when this source of error is eliminated tubercle bacilli are destroyed by twenty minutes' exposure to $60^{\circ} \mathrm{C}$., if infection of guinea-pigs is taken as the index. His work has been confirmed by Russell and Hastings, Rosenau, and others. Tubercle bacilli are evidently somewhat more resistant to heat than other non-sporing bacilli, and for that reason their thermal death-point should be taken as a basis for milk pasteurization. As a general rule it may be stated that the higher the temperature, the shorter the time necessary for destruction of bacteria.

The effect of pasteurization on mold spores in milk has been investigated by Thom and Ayers, who state that in milk heated to $145^{\circ} \mathrm{F}$. $\left(62.8^{\circ} \mathrm{C}\right.$.) for thirty minutes the conidia of every species investigated were killed except those of Aspergillus repens, A. flavus, and $\mathrm{A}$. fumigatus. The molds which survived are rarely found in milk. In milk heated to $165^{\circ} \mathrm{F}$. $\left(73.9^{\circ} \mathrm{C}\right.$.) for thirty seconds the spores of all molds tested were destroyed, except many spores of one form and occasional spores of three forms. In 
milk heated to $175^{\circ} \mathrm{F}$. $\left(79.5^{\circ} \mathrm{C}\right.$.) only occasional spores of two forms developed.

It is a common practice to pass the milk through a clarifier before pasteurization. The object is to remove odors and insoluble foreign substances. From one point of view this is an advantage, but it also serves to conceal dirty milk, since the dirt is left in the clarifier slime. As pointed out in a previous chapter, the colony count of clarified milk is usually greater than that of

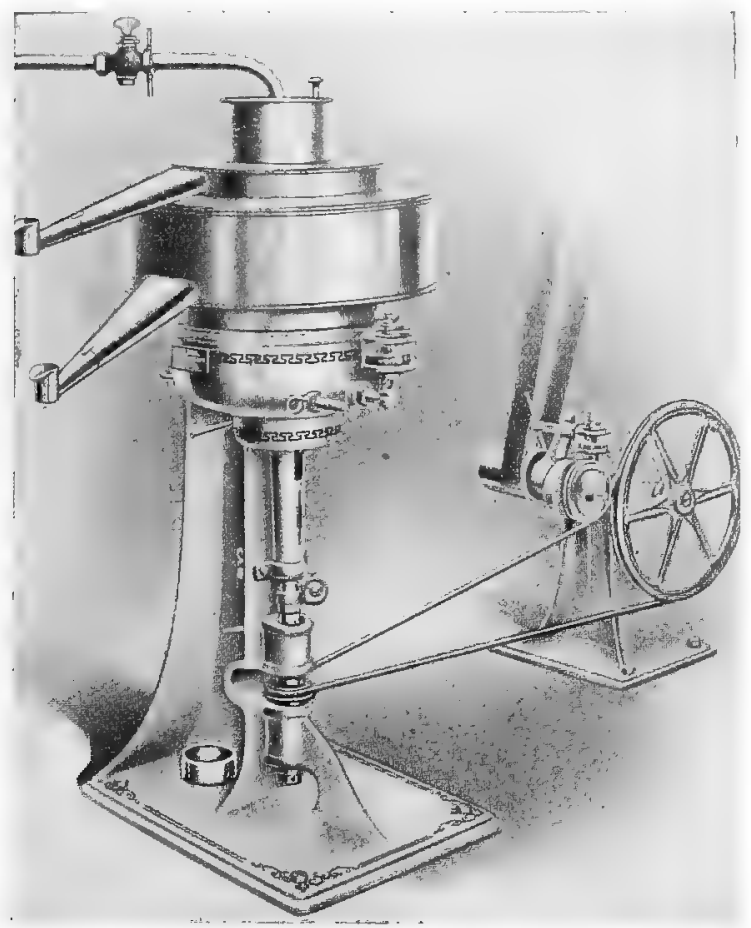

Fig. 199.-Belt drive DeLaval all-disk clarifier.

the unclarified milk, and the bacterial content of clarified milk may be very high, even though the insoluble dirt is removed.

The clarifier is similar to the cream separator, inasmuch as it is operated by centrifugal force. The cream, however, is not separated, and only particles heavier than milk are thrown out. A type of clarifier is shown in Fig. 199.

At present there are three distinct systems of milk pasteurization in vogue: 1 , the flash process; 2 , the holding process, and 3 , pasteurization in the final package.

1. In the flash or continuous process of pasteurization milk 
is heated to a relatively high temperature for a short period. This method is practised in Denmark, where milk is heated to $85^{\circ} \mathrm{C}$. for about half a minute. At this temperature there is a great reduction in the number of bacteria. The system has been successful in Denmark, especially as an aid in controlling bovine tuberculosis. Skimmed milk from creameries and whey from cheese factories are pasteurized by this method, and Bang states that a temperature of $85^{\circ} \mathrm{C}$. always destroys tubercle bacilli.

In some types of pasteurizers the milk is either forced up or flows by gravity over or between heated surfaces. These types are illustrated in Figs. 200-206.

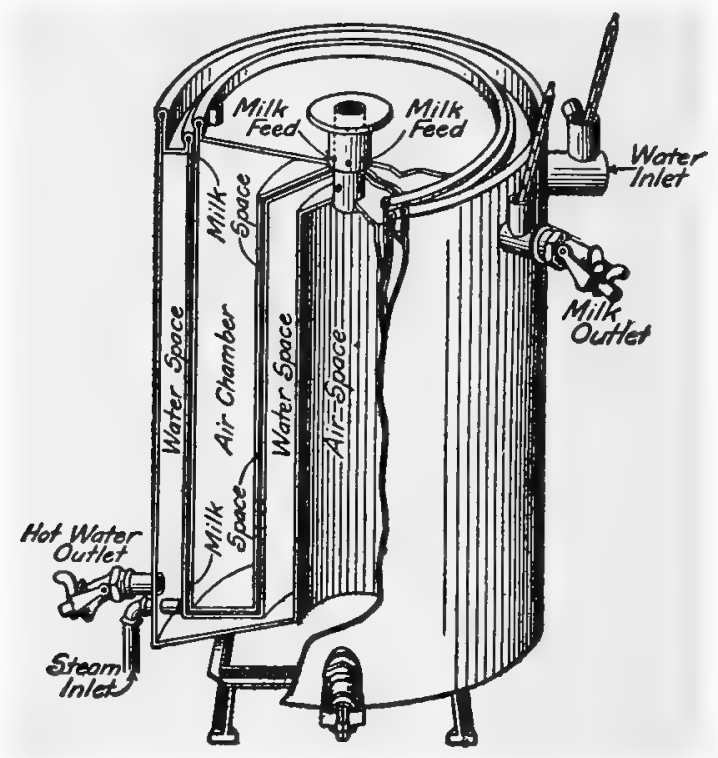

Fig. 200.-A simple pasteurizer through which milk flows by gravity. (S. H. Ayers in Cireular 184, Bureau of Animal Industry, U. S. Dept. of Agriculture.)

The tubular type of continuous pasteurizers consists of a series of pipes through which the milk flows. These pipes are contained in larger pipes filled with hot water. This type is shown in Fig. 204. The same system is used for cooling the milk when the larger pipes contain the cooling mixture.

Regenerative pasteurizers are those in which the water is preheated, by being used for cooling the hot milk. This principle is designed to save heat units (Figs. 205 and 206).

Harding and Rogers, after studying at different temperatures the efficiency of a continuous pasteurizer of the Danish type, 
came to the following conclusions: "At $70^{\circ} \mathrm{C}$. $\left(158^{\circ} \mathrm{F}\right.$.) the efficiency of the continuous pasteurizer varies greatly from day to day. Tests upon fourteen different days gave an average of 15,288 living germs per cubic centimeter left in the pasteurized milk, with a maximum of 62,790 and a minimum of 120 germs. At $80^{\circ} \mathrm{C}$. $\left(176^{\circ} \mathrm{F}\right.$.) the reduction in germ content is both very uniform and very great. Tests upon twenty-five different days gave an average of only 177 living germs per cubic centimeter in the

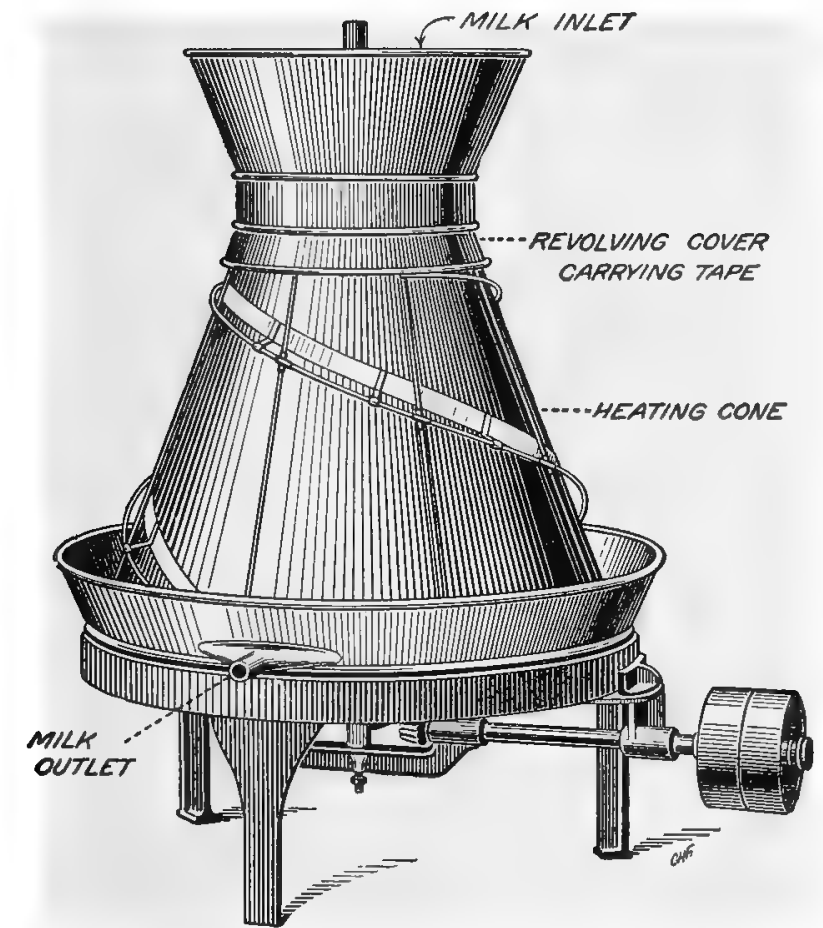

Fig. 201.-Conical type of simple pasteurizer. (S. H. Ayers in Circular 184, Bureau of Animal Industry, U. S. Dept. of Agriculture.)

pasteurized milk, with a maximum of 297 and a minimum of 20 germs. At $85^{\circ} \mathrm{C}$. $\left(185^{\circ} \mathrm{F}\right.$.) the average reduction is not more marked than at $80^{\circ} \mathrm{C}$, but the range of variation is less. This temperature has the added advantage, according to Dr. Bang, of removing the danger from germs of tuberculosis in the milk. Even when the whole milk was heated to $85^{\circ} \mathrm{C}$. the butter did not have a permanent cooked flavor."

It has been found that heating milk to $85^{\circ} \mathrm{C}$. has serious disadvantages, the most important of which is the reduction of the 
cream column and partial obliteration of the cream line. This is known to be due to the breaking up of clumps of fat globules,

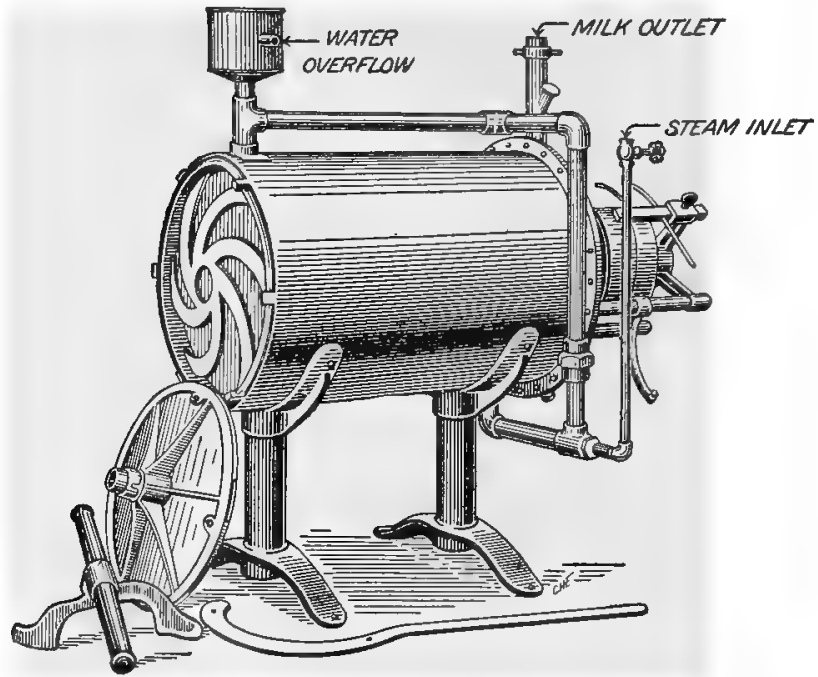

Fig. 202.-Another simple pasteurizer, showing cover removed. (S. H. Ayers in Circular 184. Bureau of Animal Industry, U. S. Dept. of Agriculture.)

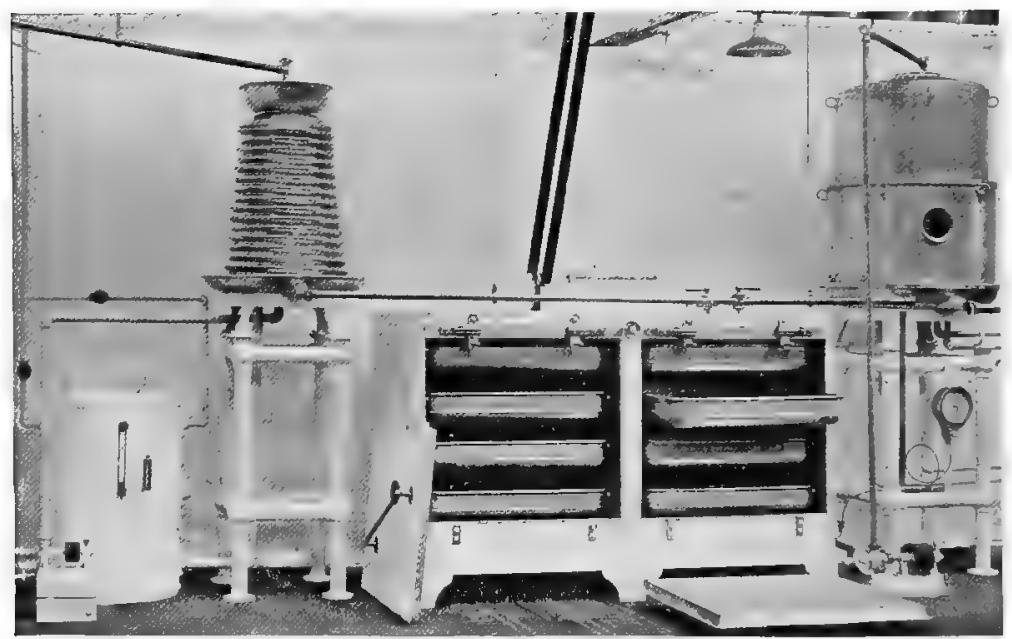

Fig. 203.-Skidd's positive pasteurizing system, showing cover removed from heater and doors removed from holder.

with the result that they do not rise as readily and as completely as in raw milk. Milk dealers found this disadrantageous, since 


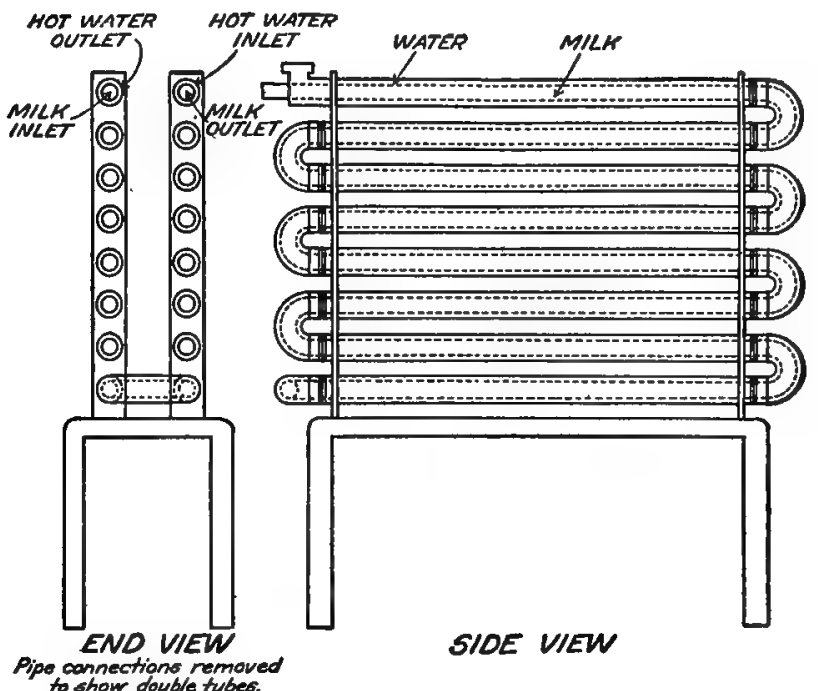

Fig. 204.-A double-tube milk heater. (S. H. Ayers in Circular 184, Bureau of Animal Industry, U. S. Dept. of Agriculture.)

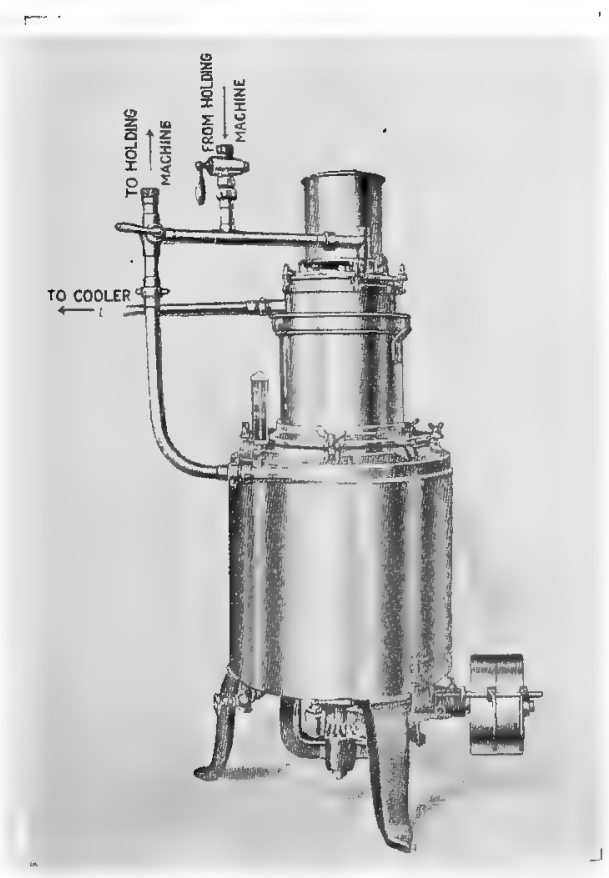

Fig. 205.-Willmann regenerative pasteurizer. 
customers believed the milk had been skimmed. It is natural, therefore, that the temperature for flash pasteurization was gradually reduced, until at present the average temperature practised in this country is $71.1^{\circ} \mathrm{C}$. $\left(160^{\circ} \mathrm{F}\right.$.). This temperature cannot be depended upon to destroy all pathogenic bacteria, although it results in a material reduction of bacteria. There are, then, two objections to flash pasteurization at $160^{\circ} \mathrm{F} .: 1$, apparent reduction of the quantity of cream, and 2 , uncertainty as to the destruction of pathogenic bacteria.

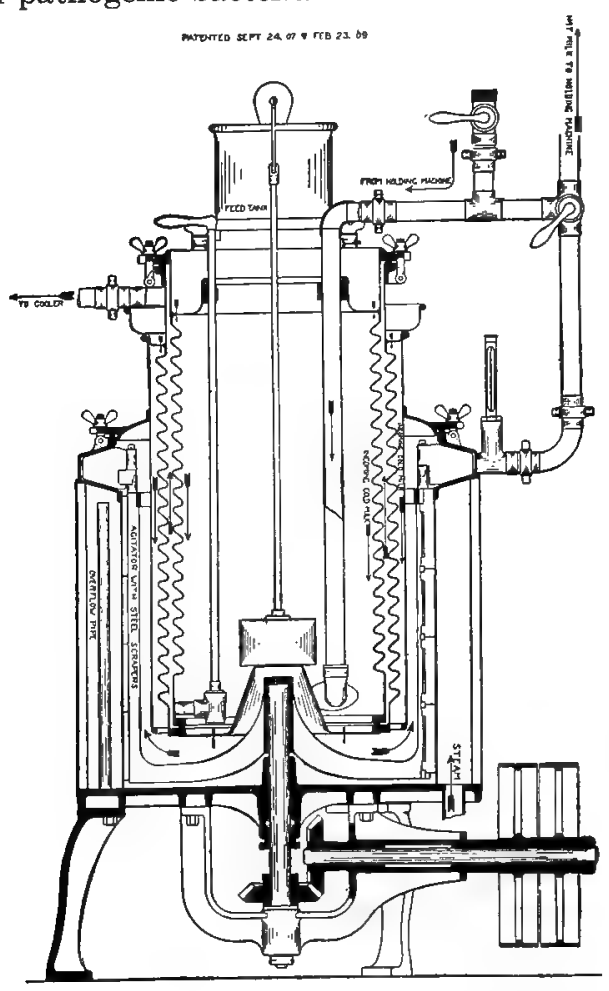

Fig. 206.-A regenerative pasteurizer for use with holding tank. (S. H. Ayers in Circular 184, Bureau of Animal Industry, U.S. Dept. of Agriculture.)

2. The holding process overcomes these difficulties in large measure. The holding or held process, as originally designed, means that the milk is heated to $60^{\circ} \mathrm{C}$. $\left(140^{\circ} \mathrm{F}\right.$.), held at this temperature for twenty minutes, and finally cooled. The cream line is not appreciably affected, and the temperature and period of exposure are sufficient to destroy pathogenic bacteria.

In laboratory experiments the holding process has proved to be efficient when the milk is heated to $140^{\circ} \mathrm{F}$. for twenty minutes, 
but under commercial conditions there are some difficulties which have to be taken into account. When large quantities of milk are handled the temperature is not always consistent throughout the tank, running lower in some parts and higher than is desired in others. Even on the assumption that all parts of the milk have at some time reached the desired temperature, there may be some parts which have not been held at the right temperature for the right length of time. Shorer and Rosenau have investigated temperature conditions in connection with a large pasteurizer in Boston, and have concluded that in order to have a margin of safety the temperature should be $145^{\circ} \mathrm{F} .\left(62.8^{\circ} \mathrm{C}\right.$.), and that the milk should be held at this temperature for thirty minutes.

A second difficulty in operating a holding pasteurizer is the formation of foam on the milk. A stirring device is usually installed in the holding tank to insure reasonable distribution of heat, and consequently more or less foam will form according to the kind and intensity of the stirring. This foam loses some of the heat, and therefore has a protective influence on bacteria, similar to that of the membrane which forms on heated milk. It is desirable, therefore, to have a stirring device which moves the mass of milk quietly, with as little foam formation as possible.

There are chiefly two kinds of pasteurizing machines in which the milk is held for a definite period at relatively low temperatures. The one type is the absolute holder, the other the continuous flow system. The difference between the two lies in the fact that in the absolute type the milk is held in an insulated tank after the proper temperature has been attained, while in the continuous-flow type the milk flows through the system. After having been heated milk enters the pasteurizer and flows at a rate which insures its being held at the proper temperature for the requisite length of time.

In the absolute-holder type there is an arrangement by which the milk is automatically discharged into the cooling system after the period of pasteurization has elapsed. The tanks must be insulated and the milk gently agitated in order that all parts of it may be held at the right temperature for the right length of time. Leaky valves which admit or discharge the milk too early defeat the purpose of pasteurization. The stirring device should excite as little foam as possible.

Another type of holder consists of a tank in which there is a coil of pipe (Figs. 207, 208), This coil contains the hot water or steam and revolves, with the result that the milk is kept in motion. Usually several tanks are used in a single plant in order that there may be a continuous flow of heated milk through the cooling system. 
According to Kilbourne, pasteurization can be carried on in the vacuum pans which are used for condensing milk. These pans have a coil at the bottom through which live steam is passed for the condensation of milk. For pasteurization, water of suit-

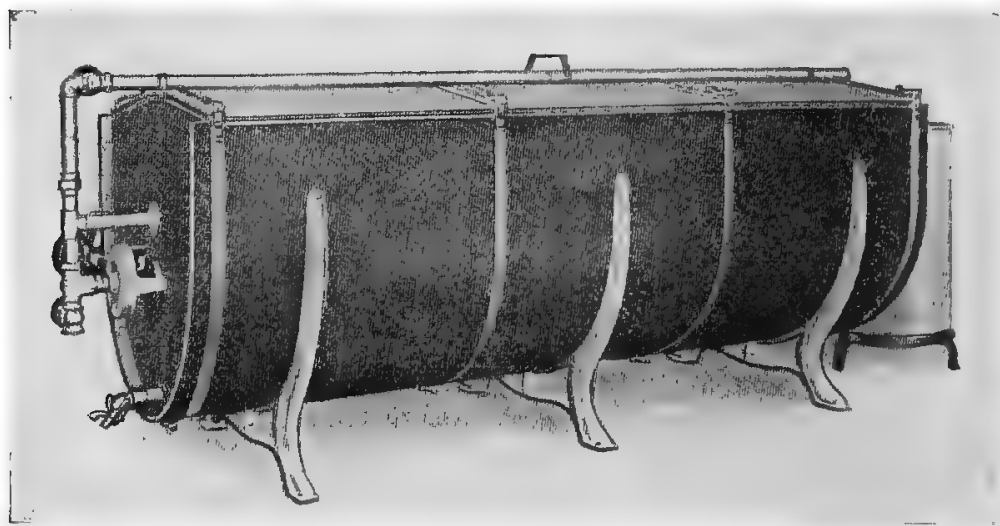

Fig. 207. -A large capacity Reid positive pasteurizer with wood body.

able temperature should be used in place of live steam. After the milk has reached the proper temperature it can be held for a suitable length of time in these pans.

One kind of continuous holder, also known as a retarder (Fig. 209), consists of a series of tanks, one lower than the pre-

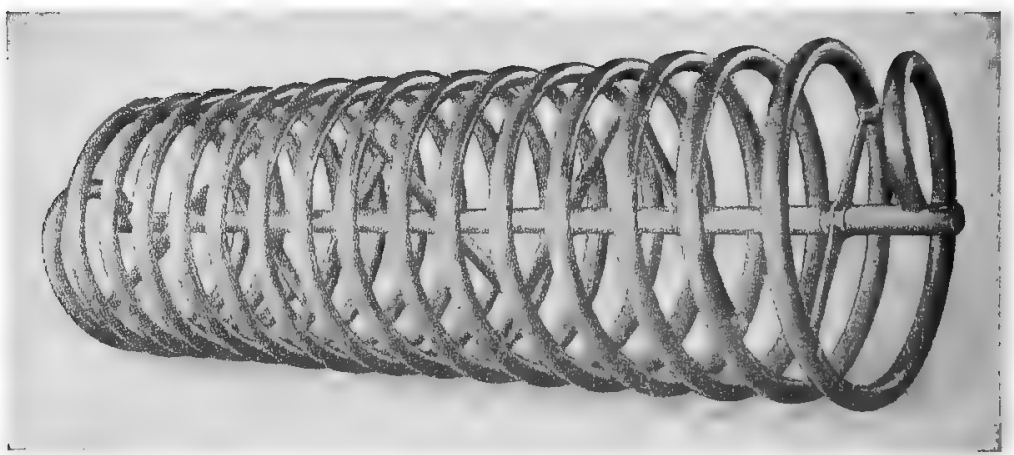

Fig. 208. - The one-piece all brazed coil. The braces are wrapped well around the coil tubing and are pinned fast to the center shaft.

vious one, which allows the milk to flow slowly through the system. Another sort consists of large tubes which are made continuous by being connected at both ends. The heated milk enters from the top and is discharged through a pipe which connects with the lowest tube, and rises above the highest one. By 


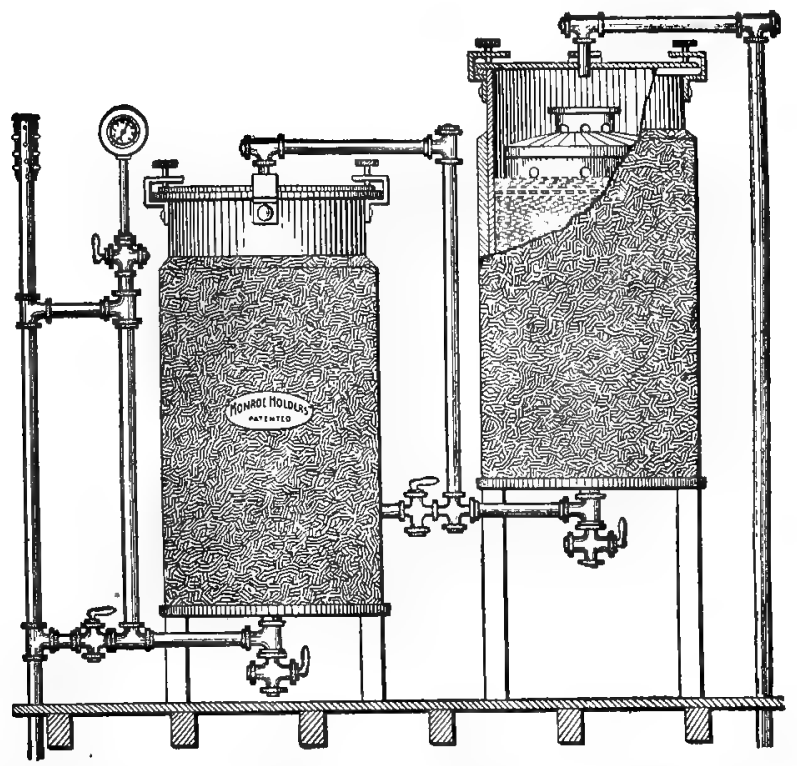

Fig. 209.-The Monroe retarders or holders.

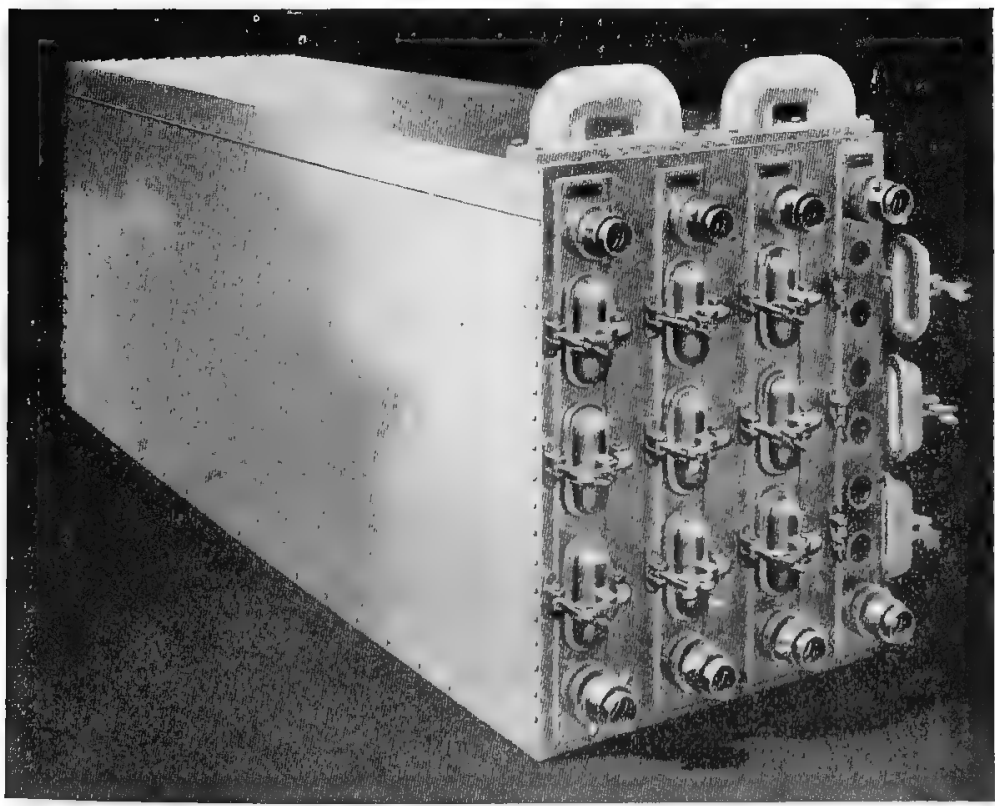

Fig. 210.-Continuous holder pasteurizer, Davis Milk Machinery Company, Chicago, Ill. 
this means the milk cannot leave the machine without having passed through the entire system (Fig. 210).

Several tank types of holding machinery are manufactured. The tank may be divided into a series of compartments (Fig. 211) in order that the milk may flow freely from one compartment to the next.

As has been stated earlier, experience has taught that the more frequently milk is handled, the greater is the probability of bacterial contamination. This applies to milk after pasteurization quite as well as to the production of raw milk. After milk has been pasteurized by either process it is collected in a large tank and then piped to a bottling machine. This exposes it to

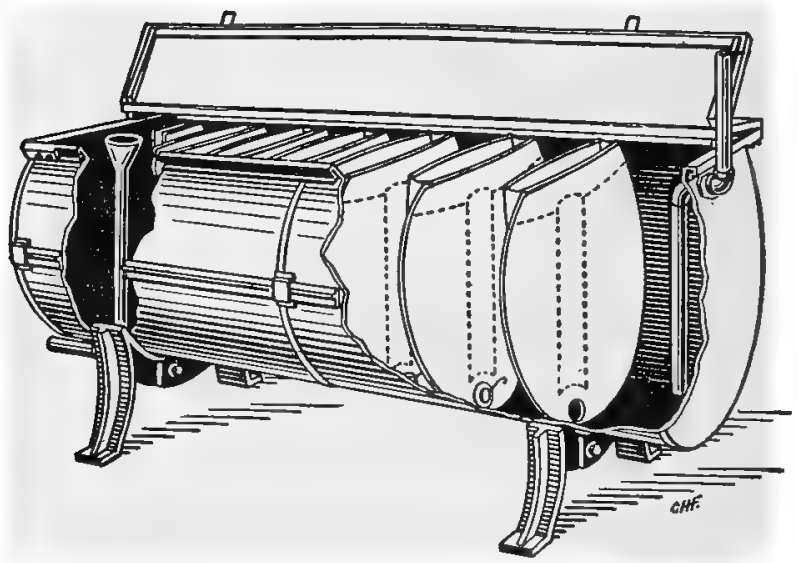

Fig. 211.-Tank retarder with compartments. (S. H. Ayers in Circular 184, Bureau of Animal Industry, U. S. Dept. of Agriculture.)

contamination in the pipes, the bottling machine, and the bottles. In well-managed plants the chances of reinfection are greatly reduced by the use of suitable machinery and efficient supervision of the same. To avoid this menace of reinfection another process has been proposed and is carried out in some dairies in this country. This process is pasteurization in the final package.

3. Pasteurization in the final package means that the milk is bottled and then pasteurized. The bottles are immersed in water which is gradually warmed to the desired temperature. After the milk has reached the proper temperature it is held for thirty minutes and then cooled. The cooling may be effected by chilling the surrounding water, or the bottles may be sprayed first 
with hot and then with cold water. By another process water of increasing temperature is sprayed on the bottles. The feasability of pasteurizing in bottles has been demonstrated by brewers, who have applied a similar process to beer for years. The writer called attention to the possibility of applying the principles of beer pasteurization to milk in 1908. Two types of bottle pasteurizers are shown in Figs. 212-214.

There are three objections to pasteurization in the final package, but these can be overcome in time. The first objection arises from the fact that odors are retained in the milk thus pasteurized. Since most milk contains an appreciable amount of manurial

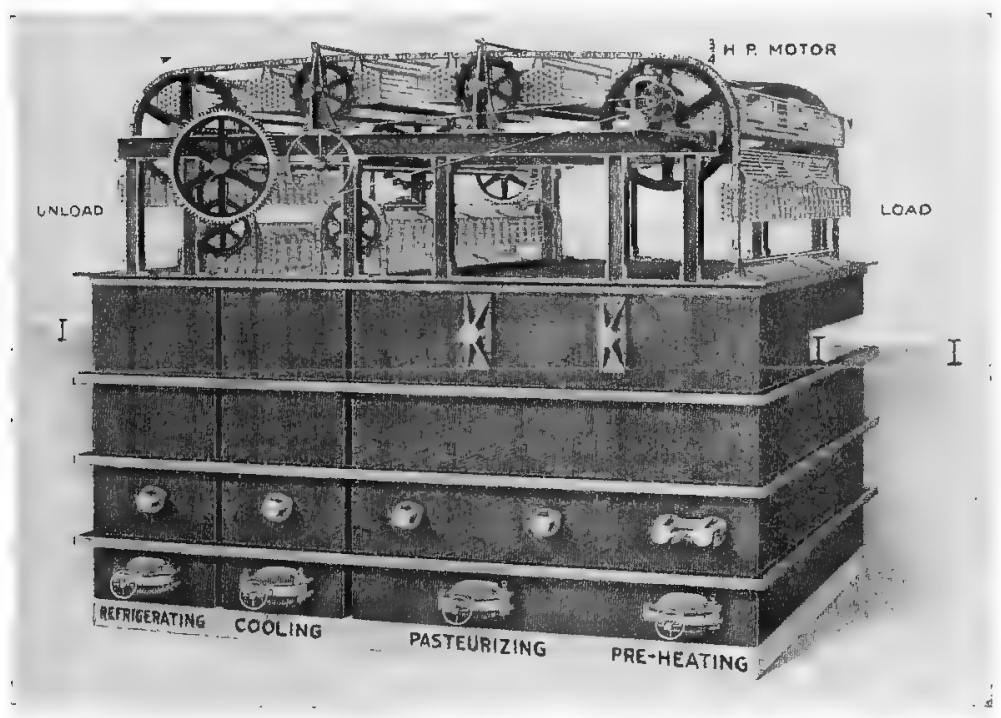

Fig. 212.-The Barry-Wehmiller national milk pasteurizer.

pollution which imparts a "cowy" odor, the gases producing this odor have no outlet for escape if sealed in bottles. Milk pasteurized by the flash or holding process is freed from disagreeable odors, as they can escape during the operation. For pasteurization in the final package, therefore, a relatively clean milk must be available. The second objection, one that can also be overcome, comes from the necessity of discarding the present costly machinery and replacing it with new and equally expensive machinery. Finally, air- and water-tight caps are considerably more expensive than pulp caps, and unless air-tight caps are used there is danger that the water used for cooling the bottles may leak through the caps, and as this water is not guaranteed to be germ- 
proof, contamination of the milk may follow. By a new device the tops of bottles may be protected from the water so that the ordinary pulp caps can be used.

Ayers and Johnson have devised a method combining the holder process with that of pasteurization in the final package. After the milk is pasteurized by the holding process it is filled

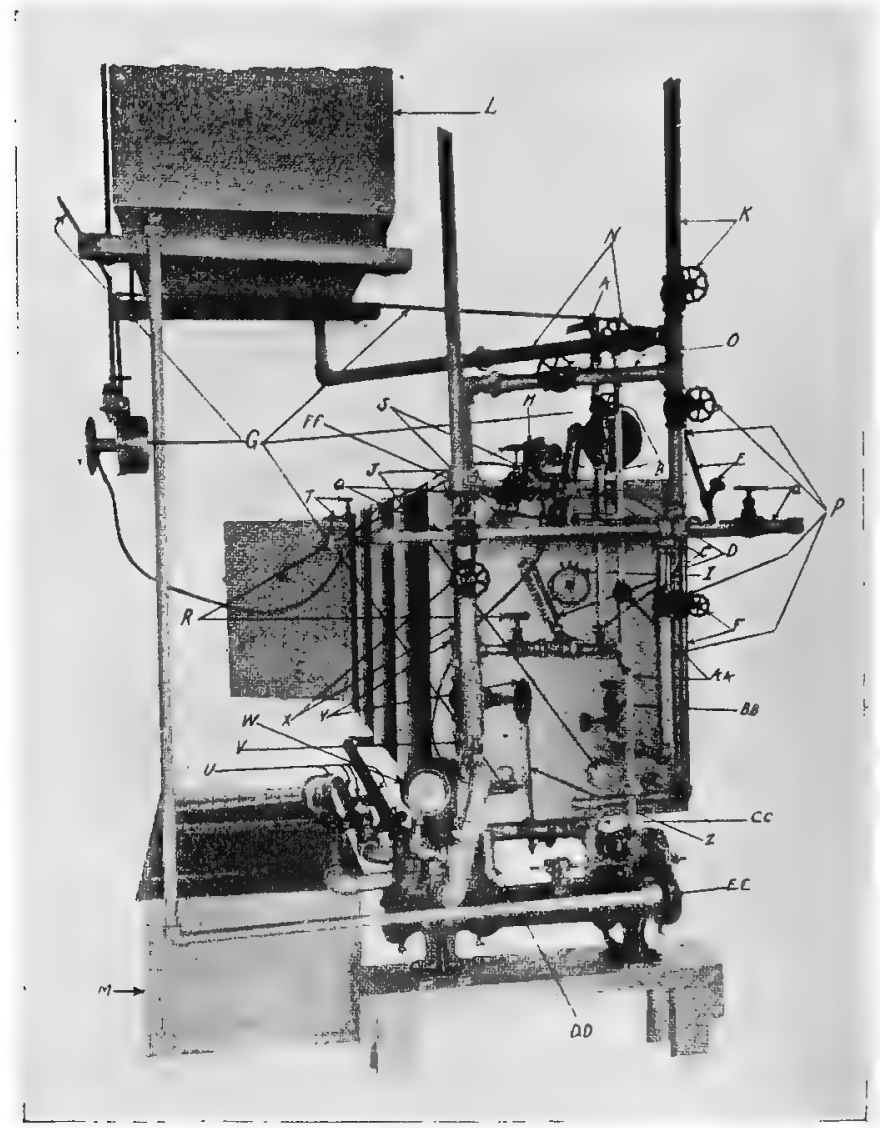

Fig. 213.-Cauffman's pasteurizer properly installed.

into hot steamed bottles and then cooled by a cold-air blast. The use of hot steamed bottles prevents contamination of the milk from the bottles.

These authors have estimated the efficiency of the process of bottling hot milk pasteurized in bulk as compared with that of pasteurizing milk in bottles. When pasteurizing milk in bottles 
it is necessary, in addition to providing water-tight caps on perfect bottles, to allow for the expansion of heated milk. The authors found the amount of expansion to be about 0.62 ounce for 1 quart of milk. Therefore bottles for this purpose should be made somewhat larger than modern bottles, permitting the air space to care for the increased volume during heating.

It was also found that the temperature in a bottle was not uniform. When the temperature at the top was $145^{\circ} \mathrm{F}$., it took ten and four-fifths minutes longer for the temperature at the

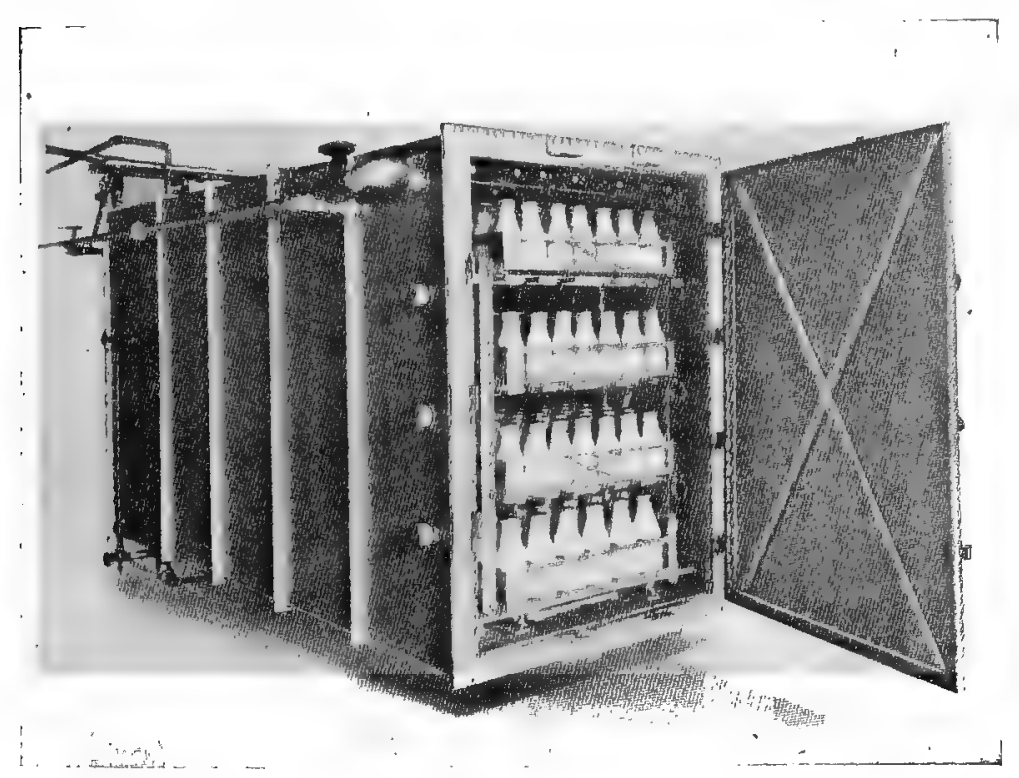

Fig. 214,--Front view of 48-case (576-quart) Cauffman pasteurizer.

bottom to reach $140^{\circ} \mathrm{F}$. Therefore, a period of exposure should be calculated from the time the temperature at the bottom of the bottles reaches the desired degree.

In a series of 34 tests made by Ayers and Johnson the bacterial efficiency of milk pasteurized in bottles averaged 90.86 per cent., varying from 17.67 to 99.98 per cent.

Comparing the bacterial efficiency of pasteurizing in bulk and filling in hot steamed bottles with that of pasteurizing in bottles, the authors obtained the following average results: 
COMPARISON OF BACTERIAL REDUCTION OF PASTEURIZATION IN BOTTLES AND BOT. TLING HOT PASTEURIZED MILK

\begin{tabular}{|c|c|c|c|c|}
\hline \multirow{3}{*}{ Raw milk. } & \multicolumn{4}{|c|}{ Milk pasteurized at $145^{\circ} \mathrm{F}$. for thirty minutes. } \\
\hline & \multicolumn{2}{|c|}{$\begin{array}{l}\text { Hot pasteurized milk in hot } \\
\text { steamed bottles. }\end{array}$} & \multicolumn{2}{|c|}{ Milk pasteurized in bottles. } \\
\hline & $\begin{array}{c}\text { Bacteria per } \\
\text { cubic centimeter. } \\
.\end{array}$ & $\begin{array}{l}\text { Percentage } \\
\text { reduction. }\end{array}$ & $\begin{array}{c}\text { Bacteria per } \\
\text { cubie centimeter. }\end{array}$ & $\begin{array}{l}\text { Percentage } \\
\text { reduct on. }\end{array}$ \\
\hline $\begin{array}{r}2,115,268 \\
571,766\end{array}$ & $\begin{array}{l}3467 \\
5965\end{array}$ & $\begin{array}{l}96.50 \\
97.46\end{array}$ & $\begin{array}{r}9,083 \\
11,295\end{array}$ & $\begin{array}{l}88.341 \\
95.48^{2}\end{array}$ \\
\hline
\end{tabular}

The authors claim for the process of bottling hot, pasteurized milk that the cream line is not affected to a greater extent than by ordinary methods of pasteurization.

The apparatus for the process designed by Ayers and Johnson is shown in Fig. 215.

The same authors state that it is a mistake to judge bacterial efficiency of pasteurization by percentages. A standard should be adopted as has been done in judging the efficiency of water purification plants. Pasteurization of milk with low bacterial content will naturally show a smaller percentage of efficiency than pasteurization of milk with large numbers of bacteria. The pasteurized product of the former will still contain fewer bacteria than the product of the latter. Therefore it is difficult to establish fair standards at present. The commission on standards of the New York Milk Committee has considered 50,000 bacteria for milk and 100,000 for cream a fair standard. In a measure such standards involve the same difficulty as do standards for raw milk, since they do not show whether the pasteurizer or subsequent handling are at fault. ${ }^{3}$

Hammer and Hauser made a series of experiments with pasteurization in the final package by immersing the filled bottles in water of a temperature ranging from $140^{\circ}$ to $170^{\circ} \mathrm{F}$. The best results were obtained by immersion at $145^{\circ} \mathrm{F}$. for fifty minutes. Milk pasteurized by this method soured much as does raw milk of good quality. The cream line suffered slightly, in some instances more than in others, but on the average not sufficiently to be objectionable. A heated flavor developed, but this also was so slight as to pass unnoticed by the majority of consumers.

${ }^{1}$ Bottles were washed clean in hot water before they were filled with raw milk.

${ }^{2}$ Bottles were steamed two minutes and cooled before they were filled with raw milk.

${ }^{3}$ The principal kinds of pasteurization apparatus, cooling devices, and bottling machines are described by Ayers in Circular 184, United States Dept. of Agri., B. A. I., 1912. 
Undesirable flavors were never decreased, and in some instances intensified, but the reduction in the numbers of bacteria was satisfactory. The average percentage of reduction was 99.56 and was always above 99 .

In a later paper Hammer and Hauser draw attention to the fact that in pasteurizing milk in bottles the heating may not be uniform. As a result the bacterial content and the creaming ability of the milk in different bottles when pasteurized by this process may vary widely. This was found to be true when a certain type

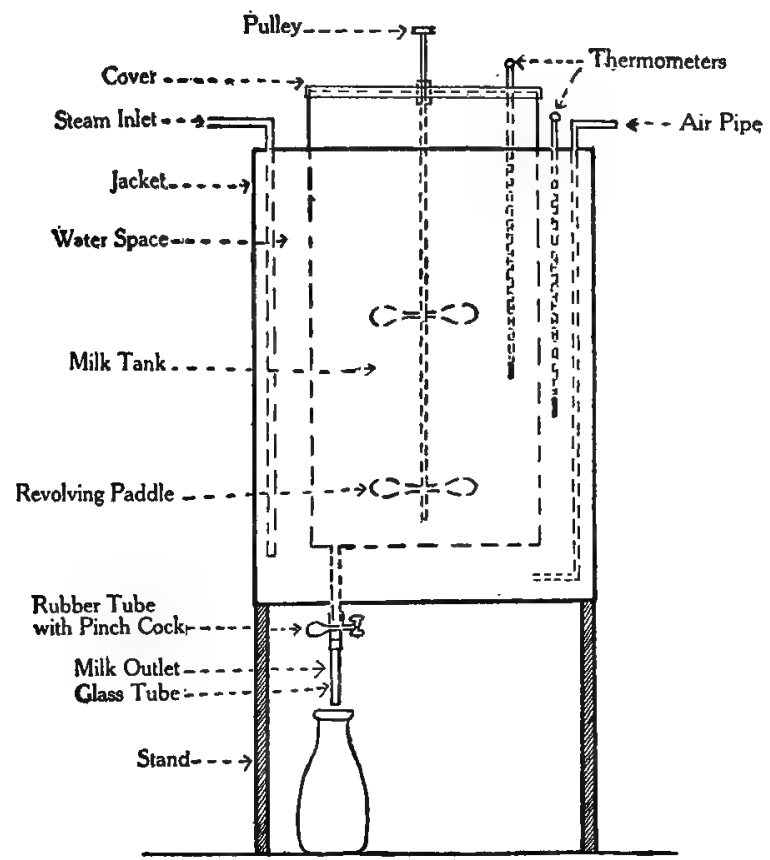

Fig. 215.-Apparatus for pasteurizing milk in bulk. (S. H. Ayers and W. T. Johnson, Jr., from Dairy Division, U. S. Dept. of Agriculture, Washington, D. C., Jour. of Inf. Dis.,1914, vol. 14, p. 224.)

of pasteurizer was used, while in another type the differences were slight, although, as a rule, the bottles from the top tier of cases had the lowest and the bottles from the bottom tier the highest bacterial counts. The authors noted a distinct, though not precise, relation between the bacterial count and the creaming ability. The more the creaming ability suffered, the smaller was the bacterial content. The test for creaming ability, according to Hammer and Hauser, "affords a simpler and quicker method of detecting the uniformity or lack of uniformity in heating with the 
final package method than does the determination of the bacterial counts."

Pasteurization in bottles has then two advantages: 1, It minimizes the danger of reinfection after pasteurization; and 2, loss of milk caused by evaporation and by adhesion to machinery is avoided. Its disadvantages are the possible breakage due to immersion of hot bottles in cold water and the expense of watertight caps. The last disadvantage does not obtain in Ayers and Johnson's modification.

It is usually stated that after pasteurization milk should be cooled rapidly, because it is thought that there is considerable bacterial multiplication during the period of cooling and that rapid cooling aids in the destruction of bacteria. Ayers and Johnson have shown that there is no greater increase in the number of bacteria if the process of cooling occupies as much as five hours than if it is done in a shorter time. They explain this on the basis of the influence of pasteurization temperature on bacteria. Those which survive are temporarily weakened and require some time to recover their natural vitality, but rapid cooling does not increase the destructive effect of pasteurization.

The most important advantage of pasteurization lies in the destruction of pathogenic bacteria. In order to accomplish this object pasteurization must be efficient. To make it universally so, pasteurization plants should be under supervision of health officers, who should provide for the following points:

1. No milk should be used for pasteurization if it is derived from a filthy dairy. Pasteurization cannot do away with dairy inspection. As a tentative standard for admission of milk to pasteurization it might be required that the dairy whose milk is to be pasteurized should score at least 55 on the government score card.

2. Milk should be kept cool during transportation to prevent excessive multiplication of bacteria. Health officers should test the temperature of the milk upon its arrival at the pasteurization plant.

3. The holding process should take the place of the flash process. The flash process as usually practised, by heating milk to $160^{\circ} \mathrm{F}$. for a fraction of a minute, is not to be depended upon to render the milk safe. It is essential that dealers as well as consumers should understand that pasteurized milk means milk heated at sufficiently high temperature to surely destroy pathogenic bacteria. A clear definition of the term "pasteurization" should be decided upon by boards of health. It is safe to define pasteurization as the process of heating milk to $145^{\circ} \mathrm{F}$. and holding it at this temperature for thirty minutes, or heating to $160^{\circ} \mathrm{F}$. for five minutes. 
4. After pasteurization the milk should be cooled to $50^{\circ} \mathrm{F}$. or below, and kept cool until delivered.

5. Automatic devices for recording the exact temperature of the milk during pasteurization should be installed with each machine. These devices should be kept locked and remain inaccessible to any one but the deputy of the health department. Both the temperature and the period of holding should be recorded, and it is advantageous to have a temperature recorder both before the milk enters and after it leaves the holding system.

6 . The efficiency of pasteurization should be controlled by bacterial enumeration. As previously stated, definite percentage standards are of little value, since in a milk of high bacterial content a higher percentage is destroyed than in one containing few bacteria. Comparative counts of bacteria before and after pasteurization will, however, aid in proper control of the process.

7. After pasteurization milk should receive as much care as raw milk.

8. Consumers are entitled to know they are receiving pasteurized milk and the day when it was pasteurized. The fact that the milk has been pasteurized and the date of pasteurization should be indicated on the bottles.

Evidence that pasteurized milk is beneficial to public health is difficult to gather. Introduction of pasteurization is a slow and gradual process and one that is not easily controlled, because milk is assembled from many sources. However, a few indications of benefits derived are available. Thus Jordan states that typhoid fever is more prevalent in cities of the United States than in European cities, even when American cities have good watersupplies. He ascribes this to the common custom in Europe of heating milk before its consumption. Rosenau, Lumsden, and Kastle, after investigating the causes of typhoid fever in Washington, D. C., found that the lowest percentage of cases was among customers of the only dealer who pasteurized the milk and sterilized the bottles. Straus states that before distribution of pasteurized milk for infant feeding in New York City, the death-rate among children below five years was 96.2 per 1000 per annum and 136.4 per 1000 in June, July, and August. After distribution of pasteurized milk the death-rate fell to 55 per 1000 per annum and 62.7 during the summer. It is probable, however, that the good results were not wholly due to pasteurization. Important accessory factors here were the limited quantity given each baby and the instructions tendered the mothers as to the care of the baby.

Pasteurization of milk is of immense importance in the handling of skimmed milk from creameries and whey from cheese factories. These by-products frequently contain tubercle bacilli and 
the organisms of other cattle diseases, and may serve to spread these diseases. Furthermore, dairy products are frequently injured or may have to be rejected on account of the activity of micro-organisms which cause abnormal fermentation. These organisms are also spread frequently through skimmed milk and whey.

Skimmed milk and whey should always be pasteurized before they are delivered to patrons of creameries or cheese factories. Dotterer and Breed and Farrington and Hastings recommend flash pasteurization at $176^{\circ} \mathrm{F}$. for these products. In Denmark and several states of this country legislation has made pasteurization of skimmed milk and whey compulsory.

Tests.-Hastings recommends two tests for the proper pasteurization of skimmed milk and whey, namely, the Storch test and the potassium-iodid-starch test. According to this author the tests are carried out as follows: Storch's test: Two solutions are prepared: 1. Dilute 1 part commercial hydrogen peroxid with 14 parts water. This solution keeps for about six weeks. 2. One part paraphenylendiamin is dissolved in 50 parts water and the solution filtered. To 20 c.c. of the milk in a teacup are added 3 to 5 drops of Solution 1, and after mixing, 1 to 2 drops of Solution 2. A grayish-blue color develops at once in raw milk, while in milk heated to $176^{\circ} \mathrm{F}$. or above no color appears immediately. Some color may appear in two minutes or after a longer interval. One per cent. raw milk in heated milk can be detected by this test.

The potassium-iodid-starch test is preferred to the Storch test by Hastings, because the material can be readily purchased. Two solutions are necessary for this test, namely: 1 , The potassium-iodid-starch solution, and 2, diluted hydrogen peroxid. The first solution is prepared as follows: Mix 2 to 3 parts of wheat starch with a little cold water and then pour 100 parts boiling water on it. Stir well. Then add 2 to 3 parts potassium iodid, previously dissolved in a little water. For the test, place 20 to 30 c.c. of the milk in a teacup and mix with it 15 to 20 drops of Solution 1. Then add 6 to 8 drops of Solution 2. In raw milk a blue color appears immediately around the hydrogen peroxid, or sometimes the color is greenish when an insufficient quantity of potassium-iodid-starch solution is present. Any color developing later may be disregarded.

The critical temperature of both tests is $176^{\circ} \mathrm{F}$. If the milk has been heated to this temperature or higher, no color develops, but if heated to a temperature between $160^{\circ}$ and $174^{\circ} \mathrm{F}$., the color appears more slowly than in raw milk.

There have been a number of objections raised to pasteuriza- 
tion of milk. The most commonly advanced one is the supposed destruction of lactic acid bacteria and the survival of spores of peptonizing bacteria which are said to produce poisonous substances. This objection is based largely on the much discussed work of Flügge, who isolated spore-bearing bacteria from heated milk, and after cultivation injected them into rabbits. Intoxication followed in some cases. It is usually assumed that lactic acid bacteria are "beneficent" or "nature's danger signal," etc. It is true that the acid produced by this group of bacteria restrains many other varieties, and even may destroy them when a sufficient amount of acid has accumulated to coagulate the casein and impart a decidedly sour taste to the milk. On the other hand, it has never been conclusively proved that peptonizing bacteria actually produce poison. Flügge's work shows that large numbers may produce intoxication in rabbits, an observation which cannot be applied to human beings without further evidence. But if peptonizing bacteria do produce poisons they will do so in raw as well as in pasteurized milk, and most bacterial poisons are destroyed at $60^{\circ} \mathrm{C}$.

What changes in the bacterial flora of milk actually take place during pasteurization was a matter of speculation before Ayers and Johnson made their exhaustive study. The results of this study are of great importance, and some space can profitably be devoted to them. The work of Ayers and Johnson is peculiarly exhaustive, and has been confirmed by many observations since it was published. Study of individual types of bacteria in milk is difficult, time consuming, and sometimes misleading. The authors therefore classified milk bacteria into the following five groups: 1, Acid-coagulating; 2, acid, not coagulating; 3, inert; 4, alkali forming; 5, peptonizing. Grouping was based on the study of the reactions in litmus milk. Each colony on suitable plates prepared from milk was transferred to a tube of litmus milk, incubated at $30^{\circ} \mathrm{C}$, and kept under observation for fourteen days. Plates were prepared from raw milk and from the same milk after heating for thirty minutes at the desired temperature. The accompanying charts (Figs. 216, 217) graphically show the results.

The following important facts are demonstrated by this work: In raw milk the inert group is the largest. After pasteurization at $62.8^{\circ} \mathrm{C}$. $\left(145^{\circ} \mathrm{F}\right.$. $)$ for thirty minutes the relative number of acid-forming bacteria has greatly increased, while the relative number of alkali-forming and peptonizing bacteria has decreased. At $71.1^{\circ} \mathrm{C}$. $\left(160^{\circ} \mathrm{F}\right.$.) the percentage of acid-forming bacteria is still the largest, but they have been affected by the heat so that the majority coagulate milk slowly. Alkali-forming and peptonizing bacteria represent the smallest groups. After pas- 
teurization at $76.7^{\circ} \mathrm{C} .\left(170^{\circ} \mathrm{F}\right.$. $)$ there is little change in the relation of the acid group, but the peptonizing group begins to increase. This increase is continued as the pasteurization temperature is raised. When milk is pasteurized at $82.2^{\circ} \mathrm{C}$. $\left(180^{\circ} \mathrm{F}\right.$.) peptonizing bacteria are predominant and continue to predominate at still higher temperatures.

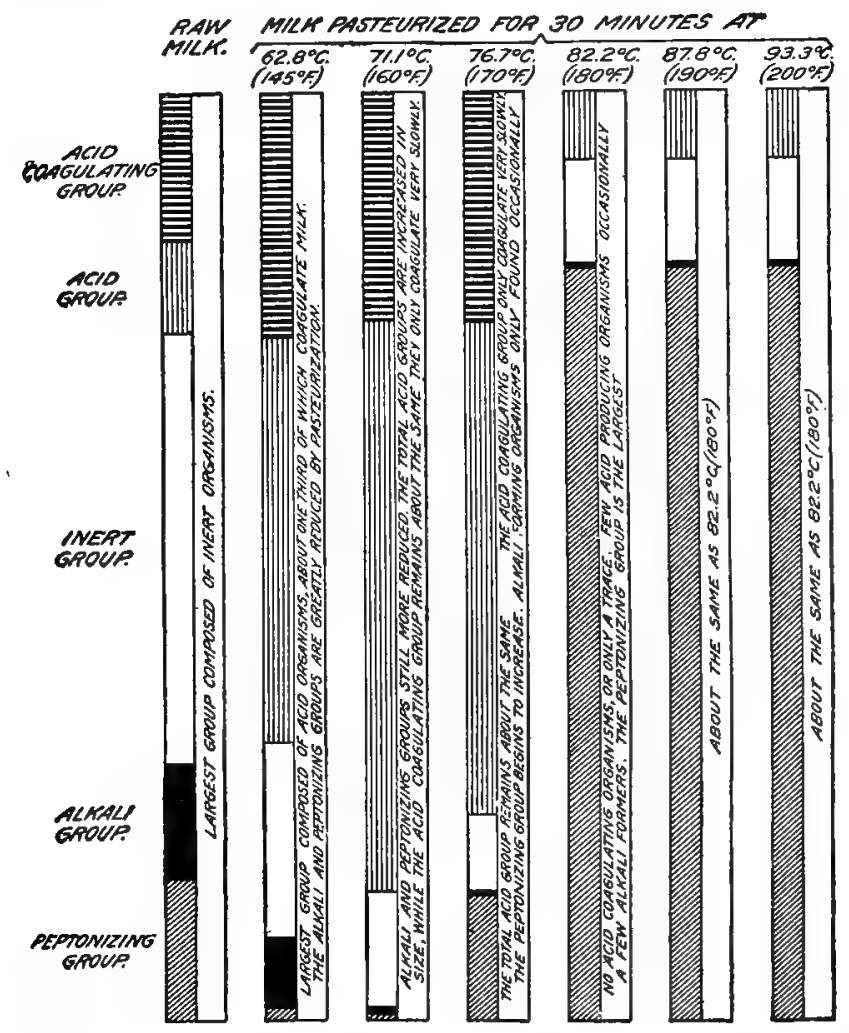

Fig. 216.-The hypothetic relations of the bacterial groups in raw and pasteurized milk. (Ayers and Johnson, Bull. 161, Bureau of Animal Industry, U.S. Dept. of Agriculture.)

As long as the pasteurization temperature is not higher than $76.7^{\circ} \mathrm{C}$. $\left(170^{\circ} \mathrm{F}\right.$.) acid-producing organisms predominate. When higher temperatures are applied the acid group is largely destroyed and peptonizing bacteria predominate. The percentage of lactic acid bacteria surviving pasteurization in different kinds of milk varies from 1.27 to 4.55 per cent.

When milk is pasteurized at $62.8^{\circ} \mathrm{C}$. $\left(145^{\circ} \mathrm{F}\right.$.) for thirty minutes and then kept at room temperature the changes pro- 
duced by bacteria vary according to the quality of the milk. If it has a low bacterial content, peptonizing bacteria may multiply at a great rate, and will prevent lactic acid bacteria from substantial proliferation. The milk peptonizes. In a milk of me-

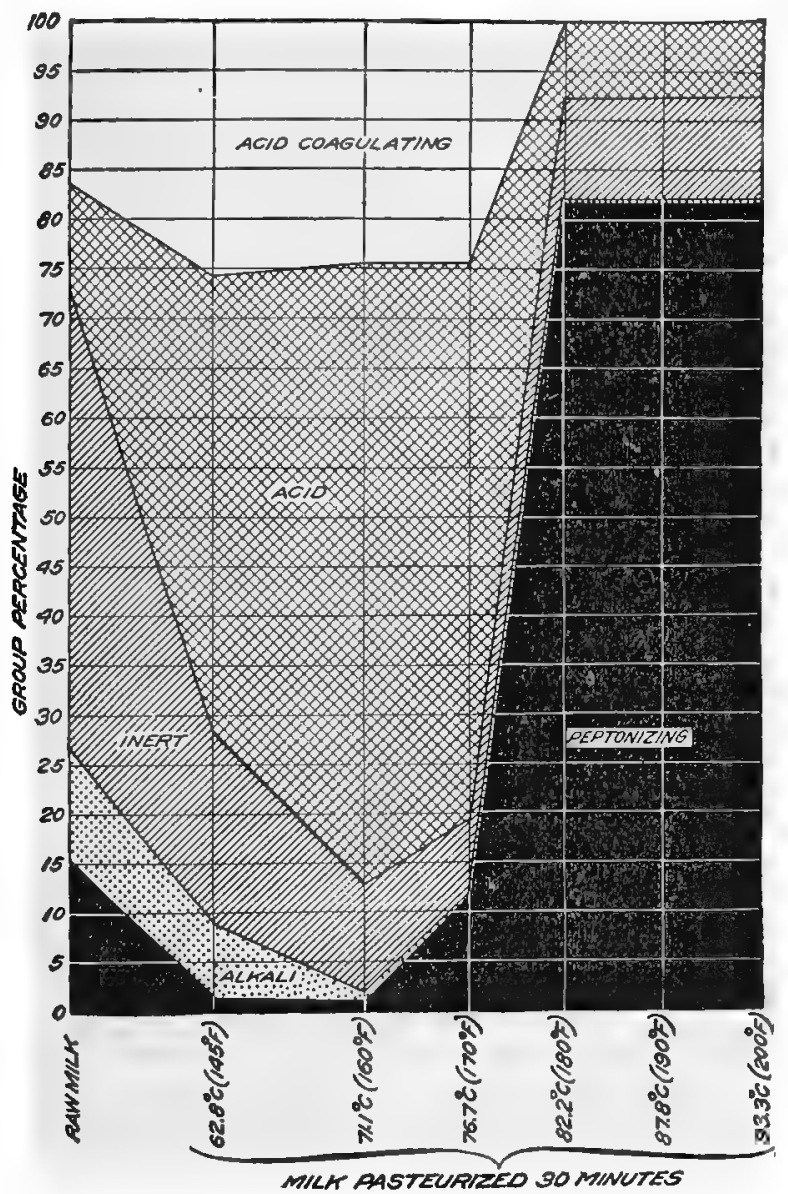

Fig. 217.-The hypothetic relation of the bacterial groups in raw and pasteurized milk. (Ayers and Johnson, Bull. 161, Bureau of Animal Industry, U.S. Dept. of Agriculture.)

dium quality lactic acid bacteria multiply from the beginning, checking all other groups by the amount of acid formed, and the milk sours normally. In a poor grade of milk both peptonizing and lactic acid bacteria multiply at the beginning, but the acid group gradually takes the lead. If milk pasteurized at $62.8^{\circ} \mathrm{C}$. 
$\left(145^{\circ} \mathrm{F}\right.$.) for thirty minutes is kept in an ice-chest at $10^{\circ} \mathrm{C}$. $\left(50^{\circ} \mathrm{F}\right.$.) the changes produced by bacteria are different. Peptonizing bacteria multiply slowly, if at all; the relative number of lactic acid bacteria remains the same for some time and alkaliforming bacteria may increase after five days. Ultimately the acid group predominates.

The authors determined the thermal death-points of 64 acidforming bacteria. One culture in broth required a temperature of $79.4^{\circ} \mathrm{C} .\left(175^{\circ} \mathrm{F}\right.$.) for thirty minutes for its complete destruction. In milk it was necessary to expose a certain strain of Streptococcus lacticus to a temperature of $75.6^{\circ} \mathrm{C}$. (168 ${ }^{\circ} \mathrm{F}$.) for thirty minutes to accomplish destruction.

Ayers thinks there are two classes of streptococci which survive pasteurization, namely: 1, Streptococci which have a low majority thermal death-point and among which there are a few individuals that survive pasteurization temperature, and 2, streptococci which have a high majority thermal death-point and survive because this point is above the temperature of pasteurization.

Prolonged heating at $54.4^{\circ} \mathrm{C} .\left(130^{\circ} \mathrm{F}\right.$.) increases the relative destruction of bacteria. However, in mill pasteurized at $62.8^{\circ} \mathrm{C}$. $\left(145^{\circ} \mathrm{F}\right.$.) application of heat for six hours does not produce greater destruction of bacteria than heating for thirty minutes.

This work of Ayers and Johnson has thrown the first light on the changes which take place in the bacterial flora during pasteurization. It shows clearly that some lactic acid bacteria survive, with the result that pasteurized milk usually sours normally. In exceptional cases efficiently pasteurized milk does not turn sour, but is peptonized. This same phenomenon happens in very clean raw milk.

The comprehensive investigations of Ayers and Johnson were made under laboratory conditions. Therefore only tentative conclusions can be drawn as to the effect of commercial pasteurization upon bacteria. However, the results are so clear cut that it seems reasonable to assume that they apply, in a measure at least, to efficient pasteurization.

In a more recent paper the same authors have published further investigations on the ability of streptococci to survive pasteurization. Strains, 139 in number, were isolated from cow feces, from the udder and mouth of the cow, and from milk and cream. At $60^{\circ}$ C. $\left(140^{\circ}\right.$ F.) 64.03 per cent. survived; at $62.8^{\circ} \mathrm{C}$. $\left(145^{\circ}\right.$ F.) 33.07 per cent. survived, and at $71.1^{\circ}$ C. $\left(160^{\circ} \mathrm{F}\right.$.) 2.58 per cent. survived. All were destroyed at $73.9^{\circ} \mathrm{C}$. $\left(165^{\circ} \mathrm{F}\right.$.). The strains from milk and cream were more resistant than strains from other sources. Of the milk and cream strains, 100 per cent. 
survived at $60^{\circ} \mathrm{C}$, 94.44 per cent. at $62.9^{\circ} \mathrm{C}$., and 50 per cent. at $68.3^{\circ} \mathrm{C}$. At $73.9^{\circ} \mathrm{C}$. all streptococci from milk and cream were destroyed. Long-chained streptococci, which are considered by some authors to be pathogenic, were less resistant to heat than short-chained ones. These tests were made under laboratory conditions similar to commercial pasteurization and have, therefore, practical significance.

It is interesting and important to note that Ayers and Johnson, in an experimental study of the thermal death-points of pathogenic streptococci, found that none survived heating in milk to $60^{\circ} \mathrm{C}$. $\left(140^{\circ} \mathrm{F}\right.$.) for thirty minutes.

In another connection it has been mentioned that some strains of Bacillus coli are able to survive pasteurization at $62.8^{\circ} \mathrm{C}$. $\left(145^{\circ} \mathrm{F}\right.$.). Since lactic acid bacteria of both the B. coli and streptococcus group survive, pasteurized milk will sour much as does raw milk. The chief difference lies in the fact that in pasteurized milk streptococci are more likely to gain ascendency over the Bacillus coli group than in raw milk. Therefore sour pasteurized milk will show the effect of Streptococcus lacticus more plainly than raw milk. That is to say, the curd will be uniform, there will be very little gas, and the taste will be that of lactic acid. The souring process will be delayed, of course, on account of the destruction of many lactic acid bacteria. The so-called beneficent bacteria exist in pasteurized milk, and "nature's danger signal" is in operation in pasteurized as well as in raw milk. Peptonizing bacteria survive, too, but the proportion of these is smaller than in raw milk, so that the digestion of milk proteins rarely occurs. There is less danger from peptonizing bacteria in pasteurized milk than in raw milk, and a valid objection to pasteurization on this score is not tenable.

A common objection to pasteurization is the alleged alteration that heat produces in milk. Appearance, taste, odor, and digestibility are said to be affected. It is true that boiling does change the appearance, and that a cooked taste and odor are acquired. In milk pasteurized at $145^{\circ} \mathrm{C}$. for thirty minutes these alterations, if there are any, are so slight as to be unnoticeable. This subject has been discussed in detail on page 131. As to digestibility, it has been said that pasteurized milk is the cause of scurvy and rickets. Milk is more commonly boiled in Holland, France, and Germany than in this country, and still scurvy and rickets are no more frequent in these countries than here in the United States. In reality, these disorders are scarce everywhere and yield readily to simple treatment. Freeman has analyzed 356 cases of scurvy investigated by the American Pediatric Society, with the following results: 60 per cent. were due to 
proprietary foods, 19 per cent. to sterilized milk, 10 per cent. to condensed milk, 3.5 per cent. to breast milk, and 4.5 per cent. to pasteurized milk. These figures speak for themselves.

It is said that pasteurization encourages filthy production, and that the day is deferred when clean, raw milk-termed by Nathan Straus an "elusive ideal"-will be the common market milk. It is said by some that the producer will consider care and cleanly habits superfluous if he knows his milk is to be pasteurized anyhow. Perhaps this objection would not be wholly without foundation if it were proposed to pasteurize any kind of milk. Attention has been called to the necessity of dairy inspection which should eliminate milk from producers whose score is less than 55 on the government score card. If efficient inspection is carried out in conjunction with pasteurization this objection cannot hold.

"Life" in milk is destroyed, according to some objectors. "Life" in milk is obviously a loose term, and usually refers to the presence of enzyms in milk, whether these are native enzyms or of bacterial origin. Whether milk enzyms are of use in aiding digestion of milk has never been determined, but admitting the possibility, enzyms in cow's milk were not intended by nature for babies. If it can be shown that they are of benefit for calves, no proof is implied that they are of benefit to human beings. Besides, heating milk to $60^{\circ} \mathrm{C}$. for thirty minutes does not destroy enzyms; most of them are not affected and only a few are weakened. These are reductases and catalases and have no concern in digestive processes.

The effect of the temperature and holding period of pasteurization on enzyms and some of the most important pathogenic bacteria has been graphically illustrated by North in the chart (Fig. 218).

The statement is sometimes made that vitamins are destroyed by pasteurization. Vitamins seem to be essential for reproduction and development, but scientists are still ignorant of their nature. They are widely distributed, especially in some foods, such as milk and eggs, and also in the leaves of plants. Two types of vitamins are recognized. One of these types is fatsoluble and is present in some fats, notably butter-fat and the fat from the yolks of eggs. It is contained also in other substances, as in alfalfa leaves for example. The other type is water-soluble. According to Hart and Steenbock, the water-soluble vitamin is present in milk, eggs, grain, the leafy portions of plants, and in a very limited degree in polished rice. It can be obtained by extracting these substances with water. Both vitamins are necessary for normal growth, but experiments made by Hart and 
Steenbock have proved that they are not destroyed by pasteurization.

Cow's milk was never intended by nature for human consumption. If man decides to use an alien milk which is drawn and handled under conditions of his own making, he cannot expect it to be in the same condition as when it is consumed in nature's fashion directly from the udder. Man must use means of self-protection under the circumstances. Pasteurization may not be the ideal remedy, but ideal raw milk is so far removed from

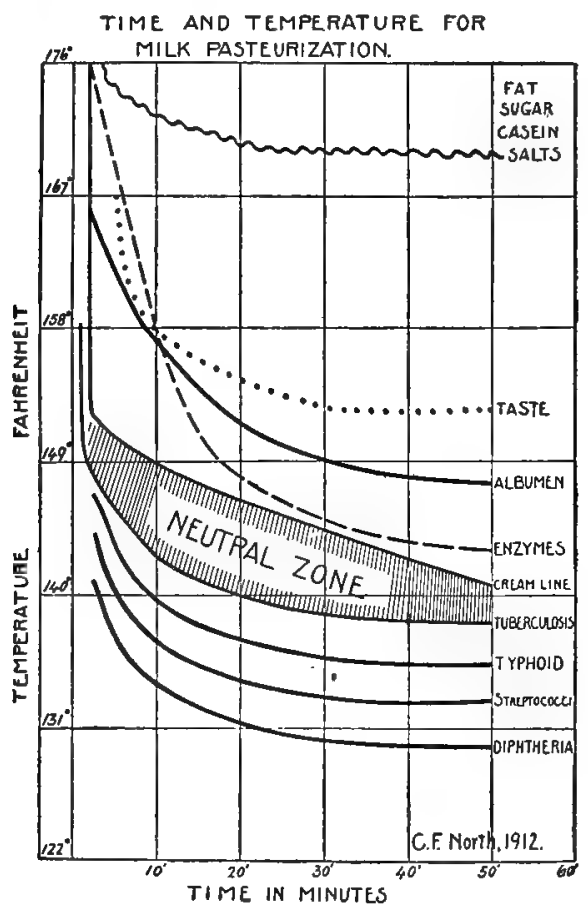

Fig. 218.-Showing the effect of the temperature and holding period of pasteurization on enzyms and some of the important pathogenic bacteria.

realization under present conditions that a remedy like pasteurization is not only advisable, but becomes a necessity. If some of those whose duty it is to control the process in the interest of public safety do not fulfil their duty properly there will be less harm done than if a similar class of inspectors of raw milk production has to be depended upon.

Dealers have sometimes objected to the increased cost of production occasioned by pasteurizing their product. Bowen, who has thoroughly investigated this point, has stated that it 
costs 0.313 cent per gallon to pasteurize milk. Safety from disease is surely worth this additional cost.

In certain quarters the cry is raised that pasteurization is not always carried out conscientiously. This may be true, but cannot be used as an argument against the efficiency of the process. The dishonesty or ignorance of some individuals does not vitiate the principle of pasteurization. In the large cities of this country pasteurization is commonly practised, as shown by the following figures given by Ayers:

EXTENT OF PASTEURIZATION OF MILK IN CITIES IN THE UNITED STATES

\begin{tabular}{|c|c|c|c|c|c|}
\hline Population of cities. & $\begin{array}{l}\text { Number of } \\
\text { cities } \\
\text { answering } \\
\text { question. }\end{array}$ & $\begin{array}{c}\text { More than } \\
50 \text { per cent. } \\
\text { pasteur- } \\
\text { ized. }\end{array}$ & $\begin{array}{c}11 \text { to } 50 \\
\text { per cent. } \\
\text { pasteur- } \\
\text { ized. }\end{array}$ & $\begin{array}{c}0 \text { to } 10 \\
\text { per cent. } \\
\text { pasteur- } \\
\text { ized. }\end{array}$ & $\begin{array}{c}\text { None } \\
\text { pasteur- } \\
\text { ized. }\end{array}$ \\
\hline $\begin{array}{l}\text { More than } 500,000 \ldots \ldots \ldots \\
100,001 \text { to } 500,000 \ldots \ldots \ldots \\
75,001 \text { to } 100,000 \ldots \ldots \ldots \\
50,001 \text { to } 75,000 \ldots \ldots \ldots \\
25,001 \text { to } 50,000 \ldots \ldots \ldots \ldots \\
10,001 \text { to } 25,000 \ldots \ldots \ldots \ldots\end{array}$ & $\begin{array}{r}9 \\
40 \\
19 \\
30 \\
78 \\
168\end{array}$ & $\begin{array}{r}7 \\
12 \\
5 \\
4 \\
13 \\
10\end{array}$ & $\begin{array}{r}2 \\
20 \\
8 \\
15 \\
31 \\
40\end{array}$ & $\begin{array}{r}0 \\
6 \\
4 \\
6 \\
12 \\
18\end{array}$ & $\begin{array}{r}0 \\
2 \\
2 \\
5 \\
22 \\
100\end{array}$ \\
\hline Total. & 344 & 51 & 116 & 46 & 131 \\
\hline
\end{tabular}

PROPORTION OF TOTAL MILK-SUPPLY PASTEURIZED IN CERTAIN CITIES 1

\begin{tabular}{|c|c|c|c|}
\hline City. & $\begin{array}{l}\text { Percentage } \\
\text { pasteurized. }\end{array}$ & City. & $\begin{array}{l}\text { Percentage } \\
\text { pasteurized. }\end{array}$ \\
\hline $\begin{array}{l}\text { Boston, Mass. } \ldots \ldots \ldots \ldots \ldots \ldots \ldots \\
\text { Chicago, Ill... } \ldots \ldots \ldots \ldots \ldots \ldots \ldots \\
\text { Detroit, Mich. } \ldots \ldots \ldots \ldots \ldots \ldots \ldots \\
\text { New York, } N . \text { Y } \ldots \ldots \ldots \ldots \ldots \ldots\end{array}$ & $\begin{array}{l}80 \\
80 \\
57 \\
88\end{array}$ & 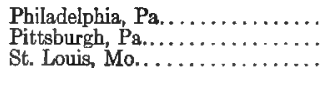 & $\begin{array}{l}85 \\
95 \\
70\end{array}$ \\
\hline
\end{tabular}

The same author states that in 1912, of 231 milk plants examined, 99 per cent. of those using the holder process, pasteurized at the proper temperature, while among those using the flash process 57 per cent. employed temperatures high enough to give satisfactory results. The holder process is constantly gaining favor, and at the present time milk is probably more efficiently pasteurized than the above figures indicate. Every new process must have time for development and attainment of perfection.

Instruction of the public as to the meaning of pasteurization should receive more attention than heretofore. The consumer must not be allowed to believe that pasteurized milk needs less care than raw milk, and he should know that pasteurized milk means milk heated to a degree which destroys infectious material. Otherwise a feeling of false security may be created. This principle also applies to certified milk, as has been pointed out.

Whether milk should be pasteurized in the home is a question which presents itself. In European countries milk is commonly boiled, but this is a different matter from pasteurization. It is easy to know when milk is boiling, but to know when it has reached a certain temperature means the intelligent use of a good thermometer. This thermometer should always be inserted into

${ }^{1}$ In the small cities the percentage of milk pasteurized is much lower. 
one of the milk bottles. Experience has shown that home treatment of water or milk is not always successful. For the greater part of the population, milk pasteurized on a large scale is probably the safer milk.

Directions for home pasteurization of milk are given by Rogers as follows: A small pail with a perforated false bottom is used. An inverted pie tin with a few holes punched in it answers the purpose. The bottles of milk are placed on this false bottom and

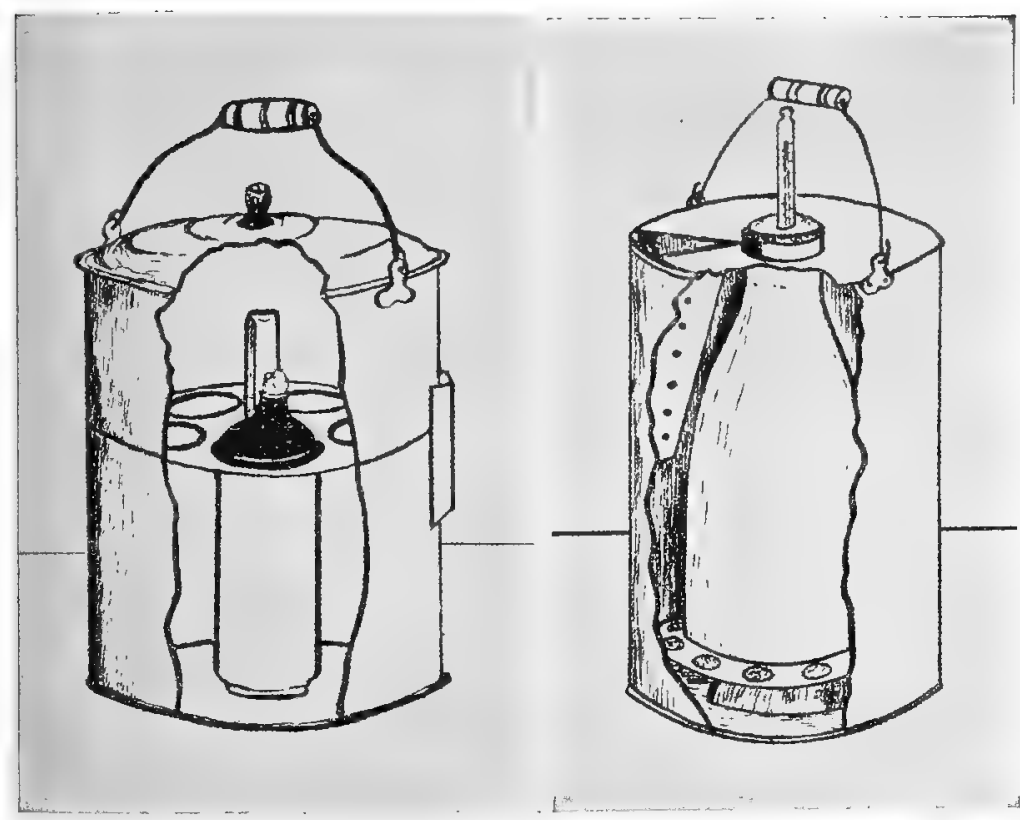

Fig. 219.-Desirable arrangement for pasteurizing milk for infants' use.
Fig. 220.-An especially constructed pail devised in dairy laboratory for efficient pasteurizing and cooling of milk. Can be made by any tinner.

(Frandsen in Bull. No. 39, Univ. of Neb. Agri. Exp. Sta.)

a good thermometer inserted into one of the bottles. The pail is filled with water nearly to the surface of the milk, and heated until the thermometer shows a temperature of not less than $145^{\circ} \mathrm{F}$. nor more than $150^{\circ} \mathrm{F}$. (Figs. 219,220 ). The bottles are then removed and covered with a towel to hold the temperature for twenty to thirty minutes. The milk is cooled by placing the bottles first in warm water-to avoid breakage-and then in cold water. Lastly they are placed on ice. A wire basket can be used to hold the bottles, as shown in Fig. 221. In this case the bottles 
are removed after the thermometer shows the desired temperature of $145^{\circ}$ to $150^{\circ} \mathrm{F}$, and the water is then cooled to the same temperature by addition of cold water. The bottles in the basket are placed into the pail again and held for twenty to thirty

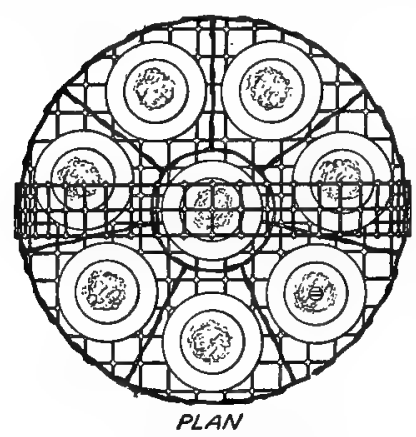
minutes. Then cold water is run into the pail until the bottles have cooled.

Frost has described a test for determining whether milk has actually been heated to $60^{\circ} \mathrm{C}$. The basis of the test depends on staining leukocytes broken down by heating and susceptible to staining. The test is made as follows: The stain is prepared by adding about 7 grams of Grübler's dry methylene-blue to 100 c.c. distilled water.

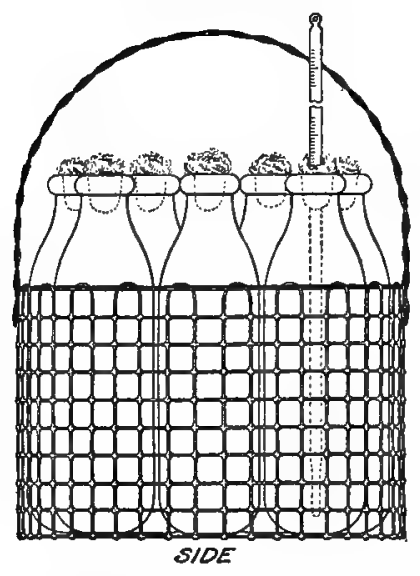

Fig. 221.-Wire basket holding bottles for pasteurization of milk. (Rogers in Circular 197, Bureau of Animal Industry, U. S. Dept. of Agriculture.)

leukocytes appear in the blue background. The fat globules are smaller than the leukocytes. Under high power the leukocytes are practically colorless. Mononuclear cells are well stained and are not considered, the test depending on the lack of stain of polymorphonuclear cells. In heated milk the background is not as deeply stained as in raw milk. Leukocytes are always more deeply stained than the background, and can be seen under low powers as dark blue areas in a lighter blue field. Under the oilimmersion lens leukocytes are less irregular in outline than those 
in raw milk and are rounded and shrunken. Nuclei are distinctly stained. The author of this method of staining claims that with little practice the difference between heated and raw milk becomes easily apparent.

Attempts have been made to prolong the keeping quality of milk and to render milk safe by means other than heat. Budde in 1903 introduced a process known as "buddeizing." This consists in adding 12 c.c. of hydrogen peroxid to 1 quart of milk and keeping the mixture at $52^{\circ} \mathrm{C}$. for several hours. 'The majority of bacteria are destroyed, but a small excess of hydrogen peroxid imparts a disagreeable bitter taste to the milk. This can be overcome by adding a catalase. "Hepin" is a catalase prepared from the liver of a rabbit and has been used for this purpose. However, the method is too complicated to be of practical value and the rapid separation of cream after buddeizing is a decided disadvantage. The process has never been popular and is uncertain in results because of the variable potency of commercial preparations of hydrogen peroxid. Some of these contain poisonous substances, such as mineral acids, acetanilid, arsenic or barium salts, and at best are unstable products.

Von Behring's recommendation to add formaldehyd to milk has been given some attention. No detrimental results could be - observed when animals were fed with milk containing formaldehyd in the proportion of $1: 1250$ parts of milk. Formaldehyd in the proportion of $1: 10,000$ cannot be detected by means of the senses and bacterial growth is inhibited for a number of days. The amount recommended by $\mathrm{v}$. Behring is $1: 40,000$. This amount is not germicidal, but has a restraining effect on bacterial growth. The benefit derived from its use is therefore doubtful, and constant ingestion of even small quantities of formaldehyd is probably harmful to infants.

Destruction of bacteria by ultraviolet rays has been proposed as a means of reducing the bacterial content of milk. Ayers and Johnson have made a comprehensive investigation of the value of this method. The rays are generated by powerful lamps and the milk must be exposed to this light in thin layers. Under the most favorable conditions 99.9 per cent of the organisms are destroyed. However, ultra-violet rays have not the same selective action on pathogenic bacteria that heat has and the process can hardly take the place of pasteurization. The factors involved are more nurnerous than in pasteurization processes, and are consequently more difficult to control under commercial conditions. Vegetable cells succumb more easily than spores, and the process is less suitable for cream than for milk, probably because the viscosity causes it to flow' in thicker layers. When 
milk is exposed to ultraviolet rays for a time sufficiently long to destroy bacteria, a disagreeable flavor is produced which renders the milk valueless Milk bottles are not sterilized by ultraviolet rays as efficiently as by steam.

Biorization of milk is a process by which milk is heated rapidly to $75^{\circ} \mathrm{C}$. and cooled as rapidly. This is accomplished by dispersing the milk into fine droplets in a room at $75^{\circ} \mathrm{C}$. and then cooling in a Liebig condenser. Schmitz claims that all pathogenic bacteria are absolutely destroyed by this process and that the milk retains raw milk properties.

Electricity and ozonization have been recommended for the destruction of germ life in milk. Up to the present none of these methods has been successfully applied. Wiener believes he has demonstrated that the process of ozonizing milk is superior to any method applied at the present time; that ozonized milk is free from pathogenic microbes without having suffered alteration in taste. Milk has been frozen for exportation, as the low temperature prevents bacterial multiplication. The milk, when frozen, does not decompose to an appreciable extent, but, as stated earlier, undergoes serious physical changes. The thawed product is never the same as the original milk. This process of preservation has been used extensively in Denmark.

\section{BIBLIOGRAPHY}

Ayers: United States Dept. of Agri., B. A. I., Circular 184, April, 1912. United States Dept. of Agri., B. A. I., Bull. 342, January, 1916.

Ayers and Johnson: United States Dept. of Agri., B. A. I., Bull. 126, November, 1910. United States Dept. of Agri., B. A. I., Bull. 161, March, 1913. Jour. of Inf. Dis., 1914, vol. 14, p. 217. Cent. f. Bakt., Abt. 2, 1914, vol. 40, p. 109. Jour. Agri. Res., 1914, vol. 2, p. 321. United States Dept. of Agri., Professional Paper, Bull. 240, July, 1915. Jour. Agri. Res., 1915, vol. 3, p. 401. Jour. of Inf. Dis., 1918, vol. 23, p. 290

Ayers, Bowen, and Johnson: United States Dept. of Agri., B. A. I., Bull. 420, October, 1916.

Bowen: United States Dept. of Agri., Bull. 85, 1914.

Budde: Milchzeitung, 1903, vol. 44, p. 690.

Farrington and Hastings: Univ. of Wis. Agri. Exper. Sta., Bull. 148, April, 1907.

Frandsen: Univ. of Nebraska Agri. Exper. Sta., Press Bull. 39, February, 1913.

Freeman: Jour. Amer. Med. Assoc., 1910, vol. 54, p. 372.

Frost: Jour. Amer. Med. Assoc., 1915, vol. 64, p. 821.

Hammer and Hauser: Agri. Exper. Sta. Iowa State Coll. of Agri. and Mechanic Arts, Bull. 154, November, 1914. Jour. of Dairy Science, 1918, vol. 1, p. 462 .

Harding and Rogers: New York Agri. Exper. Sta., Bull. 172, December, 1899.

Hart and Steenbock: Agri. Exper. Sta. of Univ, of Wisconsin, Bull. 291, June, 1918.

Heinemann: Archives of Pediatrics, June, 1908.

Jordan, E. O.: Jour. Amer. Med. Assoc., 1912, vol. 59, p. 1450.

Kilbourne: The Pasteurization of Milk, John Wiley and Son, New York, 1916.

Koehler and Tonney: Jour. Amer. Med. Assoc., 1911, vol. 56, p. 713. 
Rogers: United States Dept. of Agri., B. A. I., Circular 197, April, 1912. United States Dept. of Agri., B. A. 1., Bull. 73, 1905.

Rosenau: Hygienic Lab., Bull. 42, 1908. Hygienic Lab., Bull. 56, p. 684.

Rosenau, Lumsden, and Kastle: Hygienic Lab., Bull. 44, 1908.

Russell and Hastings: 17th Annual Report Wis. Agri, Exper. Sta., Madison, Wis.

Schmitz: Milchwscht. Zentr., 1915, vol. 44, p. 241.

Shorer and Rosenau: Jour. Med. Res., 1912, vol. 21, p. 127.

Smith, Th.: Jour. Exper. Med., 1899, vol. 4, p. 217.

Thom and Ayers: Jour. Agri. Res., 1916, vol. 6, p. 153.

Wiener: Ann. D'Hygiène Publique et De Médicine Légale, August, 1910. 


\section{THE CONTROL OF MILK-SUPPLIES}

Aттемpтs at regulating public milk-supplies were made long before modern sanitary science became established. In 1599 the Senate of Vienna forbade the sale of milk, butter, and cheese for a time on account of an epidemic which was believed to originate from dairy products. In an encyclopedia in 1739 the first intimation of eleanly proceedings appeared. "Milk from old cows or cows raised for beef is not good; good milk is either white or yellow, not green or blue; cows must be properly fed and the straw must be clean; milk maids must keep themselves clean; utensils must be kept clean and after milking the milk should be filtered through a cloth; uncleanly milk turns sour." In Paris in 1743 a milk ordinance was passed which regulated the feeding of cows, goats, and asses. An attempt at hygienic milk production was made by John Peter Frank near the end of the 18th century, as is indicated by the following extract: "Milk should not be handled in vessels of zinc, lead, copper, or brass. In Paris, where milk is handled in copper vessels, whole families have perished from poisoning with verdigris." The same author calls attention to sanitary conditions in cow stables, and quotes a case where a cow was bitten by a mad dog as a result of which a farmer and his family contracted rabies. The lactometer was introduced by Cadez de Waux. Another sign of progress came in the passing of a milk ordinance in Hamburg in 1818. In 1842 a book was published by Hartley, who lost a child and ascribed its death to impure milk. It was published in New York and is entitled "An Historical, Scientific, and Practical Essay on Milk, as an Article of Human Sustenance; with consideration of the effects consequent upon the present unnatural methods of producing it for the supply of large cities." Recently a great impetus was given dairy development in this country by Dr. Coit's plan for certified milk.

Meat and food inspection was commenced earlier than milk inspection and is more efficient at the present time. It is true that milk control involves unique difficulties, as milk is usually consumed twenty-four to forty-eight hours after production, while meat and other foods are held for considerable periods. When meat and other foods are found unfit for consumption there is time enough to eliminate the offending lots, but milk has been consumed by the time its quality has been determined. Therefore milk control must cover a large field of inquiry, and can be 
effective only in reference to general supplies, not to individual cases. Inspection of milk-supplies assumes special importance when it is considered that the bulk of the population cannot afford certified milk. Babies of the poor must be fed with a cheaper milk, and there should be available a low-priced milk of reliable quality. Some dealers are now carrying different qualities of milk, namely, certified, inspected, and pasteurized milks. Inspected milk is obtained from herds free from tuberculosis as determined by the tuberculin test. It is produced under conditions of cleanliness which guarantee a maximum bacterial count of 100,000 per cubic centimeter during the summer months and 50,000 to 60,000 in the winter months. This milk is sold at an advance of about 2 cents per quart over the price of pasteurized milk. Inspected milk is sold to those who prefer raw milk to pasteurized milk. However, it offers no safeguard against the germs of typhoid fever, dysentery, diphtheria, scarlet fever, etc., other than additional cleanliness and the protective influence of limited inspection.

To give consumers a choice of different grades of milk is a policy which aids in showing the public that milk may differ in quality. This has been amply demonstrated in New York, where the different grades of milk have been sharply defined by the Board of Health. The regulations in force in New York City are concise and in many respects worthy of imitation. A copy of them is given here:

\section{REGULATIONS OF THE DEPARTMENT OF HEALTH OF THE CITY OF NEW YORK RELATIVE TO THE GRADING OF MILK AND CREAM}

Section 156. Milk and Cream; Grades and Designations.-All milk or cream held, kept, offered for sale, sold, or delivered in the City of New York shall be so held, kept, offered for sale, sold or delivered in accordance with the Regulations of the Board of Health and under any of the following grades or designations and not otherwise:

"Grade A: For Infants and Children."

1. Milk or cream (raw).

2. Milk or cream (pasteurized).

"Grade B: For Adults."

1. Milk or cream (pasteurized).

"Grade C: For Cooking and Manufacturing Purposes Only."

1. Milk or cream not conforming to the requirements of any of the subdivisions of Grade A or Grade B, and which has been pasteurized according to the Regulations of the Board of Health or boiled for at least two (2) minutes.

2. Condensed skimmed milk.

The provisions of this section shall apply to milk or cream used for the purpose of producing or used in preparation of sour milk, buttermilk, homogenized milk, milk curds, sour cream, Smeteny, Kumyss, Matzoon, Zoölak, and other similar products or preparations, provided that any such product or preparation be held, kept, offered for sale, sold, or delivered in the City of New York. 
Regulations Governing the Sale of Grade "A" Milk or Cream (Raw)

Definition.-Grade "A" milk or cream (raw) is milk or cream produced and handled in accordance with the Regulations as herein set forth:

Regulation 11\%. Tuberculin Test and Physical Condition.-Only such animals shall be admitted to the herd as are in good physical condition, as shown by a thorough physical examination accompanied by a test with the diagnostic injection of tuberculin, within a period of one month previous to such admission. The test is to be carried out as prescribed in the Regulations of the Department of Health governing the tuberculin testing of cattle. A chart recording the result of the official test must be in the possession of the Department of Health before the admission of any animal to the herd.

Regulation 114. Bacterial Contents.-Grade " $\mathrm{A}$ " milk (raw) shall not contain more than 60,000 bacteria per c.c. and cream more than 300,000 bacteria per c.c. when delivered to the consumer or at any time prior to such delivery.

Regulation 115. Scoring of Dairies.-All dairies producing mailk of this designation shall score at least 25 points on equipment and 50 points on methods, or a total score of 75 points on an official dairy score card approved by the Department of Health.

Regulation 116. Time of Delivery.-Milk of this designation shall be delivered to the consuiner within thirty-six hours after production.

Regulation 11\%. Bottling.-Milk or cream of this designation shall be delivered to the consumer only in bottles, unless otherwise specified in the permit.

Regulation 118. Labeling.-The caps of all bottles containing Grade "A" milk or cream (raw) shall be white, with the grade and designation "Grade A (raw)," the name and address of the dealer, and the word "Certified" when authorized by the state law, clearly, legibly, and conspicuously displayed on the outer side thereof. No other word, statement, design, mark, or device shall appear on that part of the outer cap containing the grade and the designation unless authorized and permitted by the Department of Health. A proof print or sketch of such cap, showing the size and arrangement of the lettering thereon, shall be submitted to and approved by the said Department before being attached to any bottle containing milk or cream of the said grade and designation.

\section{Additional Regulations Governing the Sale of Grade "A" Milk or Cream (Pastedrized)}

Definition.-Grade "A" milk or cream (pasteurized) is milk or cream handled and sold by dealers holding permits therefor from the Board of Health, and produced and handled in accordance with the Regulations as herein set forth:

Regulation 119. Physical Examination of Cows.-All cows producing milk or cream of this designation must be healthy, as determined by a phys ical examination made annually by a duly licensed veterinarian.

Regulation 120. Bacterial Content.-Milk of this designation shall not contain more than 30,000 bacteria per c.c. and cream more than 150,000 bacteria per c.c. when delivered to the consumer or at any time after pasteurization and prior to such delivery. No millk-supply averaging more than 200,000 bacteria per c.c. shall be pasteurized to be sold under this designation.

Regulation 121. Scoring of Dairies. - All dairies producing millk or cream of this designation shall score at least 25 points on equipment and 43 points on methods, or a total score of 68 points on an official score card approved by the Department of Health.

Regulation 122. Times of Delivery.-Milk or cream of this designation shall be delivered within (thirty-six hours after pasteurization.

Regulation 193. Bottling.- Milk or cream of this designation shall be delivered to the consumer only in bottles unless otherwise specified.

Regulation 124. Bottles Only.-The caps of all bottles containing Grade "A" milk or cream (pasteurized) shall be white with the grade and designa- 
tion "Grade A (pasteurized)," the name and address of the dealer, the date and hours between which pasteurization was completed, and the place where pasteurization was performed, clearly, legibly, and conspicuously displayed on the outer side thereof. No other word, statement, design, mark, or device shall appear on that part of the outer cap containing the grade and designation, unless authorized and permitted by the Department of Health. A proof print or sketch of such cap, showing the size and arrangement of the lettering thereon, shall be submitted to and approved by the said Department before being attached to the bottles containing milk of the said grade and designation. No other words, statement, design, or device shall appear upon the outer cap unless approved by the Department of Health. The size and arrangement of lettering on such cap must be approved by the Department of Health.

Regulation 125. Pasteurization.-Only such milk or cream shall be regarded as pasteurized as has been subjected to a temperature of from $142^{\circ}$ to $145^{\circ} \mathrm{F}$. for not less than thirty minutes.

\section{Additional Regulations Governing the Sale of Grade "B" Milk or Cream (Pasteurized)}

Definition.-Grade " $\mathrm{B}$ " milk or cream (pasteurized) is milk or cream produced and handled in accordance with the minimum requirements of the Regulations herein set forth and which has been pasteurized in accordance with the Regulations of the Department of Health for pasteurization.

Regulation 128. Physical Examination of Cows,-All cows producing milk or cream of this designation must be healthy as determined by a physical examination made and approved by a duly licensed veterinarian.

Regulation 129. Bacterial Contents.-No milk under this designation shall contain more than 100,000 bacteria per e.c. and no cream shall contain more than 500,000 bacteria per c.c. when delivered to the consumer, or at any time after pasteurization and prior to such delivery. No milk-supply averaging more than $1,500,000$ bacteria per c.c. shall be pasteurized in this city under this designation. No milk-supply averaging more than 300,000 bacteria per c.c. shall be pasteurized outside the City of New York to be sold in said city under this designation.

Regulation 130. Scoring of Dairies.-Dairies producing milk or cream of this designation shall score at least 20 points on equipment and 35 points on methods, or a total score of 55 points on an official score card approved by the Department of Health.

Regulation 131. Time of Delivery.-Milk of this designation shall be delivered within thirty-six hours. Cream shall be delivered within seventytwo (72) hours after pasteurization. Cream intended for manufacturing purposes may be stored in cold storage and held thereat in bulk at a temperature not higher than $32^{\circ} \mathrm{F}$. for a period conforming with the laws of the state of New York. Such cream shall be delivered in containers, other than bottles, within twenty-four (24) hours after removal from cold storage and shall be used only in the manufacture of products in which cooking is required.

Regulation 132. Bottling.- Milk of this designation may be delivered in cans or bottles.

Regulation 193. Labeling.-The caps of all bottles containing Grade " $B$ " milk (pasteurized) and the tags attached to all cans containing Grade "B" milk or cream (pasteurized) shall be white with the grade and designation "Grade B (pasteurized)," the name and address of the dealer, and the date when and place where pasteurization was performed, clearly, legibly, and conspicuously displayed on the outer side thereof. The caps of all bottles containing Grade "B" cream (pasteurized) shall be white with the grade and designation "Grade B Cream (pasteurized)" the name and address of the dealer, and the date when and the place where bottled, clearly, legibly, and conspicuously displayed on the outer side thereof. No other word, statement, design, mark, or device shall appear on that part of the outer cap or tag containing the grade and designation unless authorized and permitted by the Department of Health. A proof print or sketch of such cap or tag, 
showing the size and arrangement of the lettering thereon shall be submitted to and approved by the said Department before being attached to any receptacle containing milk or cream of the said grade and designation.

Regulation 134. Pasteurization.-Only such milk or cream shall be regarded as pasteurized as has been subjected to a temperature of from $142^{\circ}$ to $145^{\circ} \mathrm{F}$. for not less than thirty minutes.

Additional Regulations Governing the Salm of Grade "C" Milk or Cream (Pasteurized) (for Cooking and Manufacturing Purposes ONLY)

Definition.-Grade " $\mathrm{C}$ " milk or cream is milk or cream not conforming to the requirements of any of the subdivisions of Grade " $A$ " or Grade " $B$ " and which has been pasteurized according to the Regulations of the Board of Health or boiled for at least two minutes.

Regulation 186. Physical Examination of Cows.-All cows producing milk or cream of this designation must be healthy, as determined by a physical examination made by a duly licensed veterinarian.

Regulation 19\%. Bacterial Content.-No milk of this designation shall contain more than 300,000 bacteria per c.c. and no cream of this grade shall contain more than $1,500,000$ bacteria per c.c. after pasteurization.

Regulation 138. Scoring of Dairies.-Dairies producing milk or cream of this designation must score at least 40 points on an official score card approved by the Department of Health.

Regulation 139. Time of Delivery.-Milk or cream of this designation shall be delivered within forty-eight hours after pasteurization.

Regulation 140. Bottling.- - Milk or cream of this designation shall be delivered in cans only.

Regulation 141. Labeling.-The tags attached to all cans containing Grade "C" milk (for cooking) shall be white with the grade and designation "Grade C milk (for cooking)," the name and address of the dealer, and the date when and place where pasteurization was performed, clearly, legibly, and conspicuously displayed thereon. No other word, statement, design, mark, or device shall appear on that part of the tag containing the grade and designation, unless authorized and permitted by the Department of Health. A proof print or sketch of such tag, showing the size and arrangement of the lettering thereon shall be submitted to and approved by the said Department before being attached to the cans containing milk of the said grade and designation. The cans shall have properly sealed metal covers painted red.

Regulation 140. Pasteurization.--Only such milk or cream shall be regarded as pasteurized as has been subjected to a temperature of $145^{\circ} \mathrm{F}$. for not less than thirty minutes.

\section{Additional Regulations Governing the Sale of Condensed Skimmed MiLK}

Definition.-Condensed skimmed milk is condensed milk in which the butter-fat is less than twenty-five (25) per cent, of the total milk solids.

Regulation 145. Cans to be Painted Blue.-The cans containing condensed skimmed milk shall be colored a bright blue and shall bear the words "Condensed Skimmed Milk" in block letters at least 2 inches high and 2 inches wide, with a space of at least $\frac{1}{2}$ inch between any two letters. The milk shall be delivered to the person to whom sold, in can or cans, as required in this regulation, excepting when sold in hermetically sealed cans.

Additional Regulations Governing the Labeling of Milk or Cream Brought into, Delivered, Offered for Sale, and Sold in New YORK CITY

Regulation 146. Labeling of Milk or Cream.-Each container or receptacle used for bringing milk or cream into or delivering it in the City of New York shall bear a tag or label stating, if shipped from a creamery or dairy, 
the location of the said creamery or dairy, the date of shipment, the name of the dealer, and the grade of the product contained therein, except as elsewhere provided for delivery of cream in bottles.

Regulation 14\%. Labeling of Milk or Cream to be Pasteurized.-All milk or cream brought into the City of New York to be pasteurized shall have a tag affixed to each and every can or other receptacle indicating the place of shipment, date of shipment, and the words "to be pasteurized at (stating location of pasteurizing plants)."

Regulation 148. Mislabeling of Milk or Cream.-Milk or cream of one grade or designation shall not be held, kept, offered for sale, sold, or labeled as milk or cream of a higher grade or designation.

Regulation 149. Word, Statement, Design, Mark, or Device on Label.No word, statement, design, mark, or device regarding the milk or cream shall appear on any cap or tag attached to any bottle, can, or other receptacles containing milk or cream which words, statement, design, mark, or device is false or misleading in any particular.

Regulation 150. Tags to be Saved.-As soon as the contents of such container or receptacle are sold, or before the said container is returned or otherwise disposed of, or leaves the possession of the dealer, the tag thereon shall be removed and kept on file in the store, where such milk or cream has been sold, for a period of two months thereafter, for inspection by the Department of Health.

Regulation 151. Record of Milk or Cream Delivered.-Every wholesale dealer in the city of New York shall keep a record in his main office in the said city, which shall show from which place or places milk or cream, delivered by him daily to retail stores in the city of New York, has been received and to whom delivered, and the said record shall be kept for a period of two months, for inspection by the Department of Health, and shall be readily accessible to the inspectors of the said Department at all times.

Marketing different qualities of milk is as reasonable a procedure as marketing different qualities of other foods. In the majority of instances when milk spoils it undergoes a simple souring process which does not render it injurious. In fact, sour milk of different kinds is known to be consumed as a delicacy by many people. Other food substances usually undergo putrefactive processes which render them unpalatable. When eggs or meat spoil, the odor and taste become offensive. As long as part of the population has to be satisfied with inferior food there is no reason why milk should not be offered in different qualities at different prices. But every known method of eliminating infection should be applied.

Milk products, chiefly butter and cheese, have suffered from lack of control. These products are not consumed as soon as milk is, and, therefore, might be more effectively controlled if they were not so generally classified with milk as milk products.

The enormous quantity of milk consumed and the great number of producers back of this consumption render control difficult and expensive because a host of officers is required to effect it. As health departments frequently lack funds, they find it extremely difficult to exert proper control.

Furthermore, it must be admitted that scientific methods of determining the quality of milk are not only insufficient, but are 
frequently carried out by inexperienced persons who are unable to interpret results. The significance of Bacillus coli, of streptococci, and of cellular elements can be reasonably interpreted only by experts. A variety of problems confront the worker. Is the presence of large numbers of bacteria due to early pollution or to multiplication during transportation? Are large numbers of Bacillus coli in pasteurized milk the result of inefficient pasteurization, or are they due to the multiplication of a few heat-resisting individuals? Does the presence of streptococci mean pus or multiplication of harmless varieties? What is the real significance of cellular elements in milk? Is a relatively low fat content due to manipulation, or is it a case of dealing with milk from cows whose milk naturally yields small amounts of fat?

Questions of this nature must confront the laboratory worker, and to decide the quality of a milk after a single test may result in doing an injustice. As many tests as possible should be made, and the results correlated, if a real history of the milk is to be obtained. If laboratory tests give rise to suspicion that there is something wrong with the milk-supply, the inspector's business is to go up-stream, watch the tributaries, and by the use of appropriate tests trace the trouble.

Inspection is an important factor in milk hygiene. It commences in the barn, where the veterinary inspector examines the animals for disease. The sanitary inspector looks after cleanliness in methods of milk production, care for the well-being and comfort of the cow; he sees to it that the food of the cow is wholesome; that the utensils in use are of good quality and kept clean; that the milk is promptly cooled; that the bottling machine is kept in good condition and that the bottles are clean; that manure and other waste are promptly disposed of, and that proper drainage takes care of liquid waste. Supervision of equipment and methods of production, of conditions during transportation and delivery are of as much importance as bacteriologic and chemical examination. Laboratory examinations serve as the final control and as reliable indicators when one or more links in the chain are defective. They are a guide to efficient inspection.

Milk inspection is all important for milk control. Unfortunately, there are undesirable inspectors. An inspector should have some knowledge of chemistry, bacteriology, animal husbandry, diseases of cattle, farm sanitation, and all the practical elements that enter into the producing and handling of milk. This is not all. He should be a man of personality, who is able to impress the producer with his knowledge, and still one to approach the dairyman as a kindly and interested instructor rather than as a police officer. With the use of tact on the in- 
structor's part the producer-whose sins against sanitary requirements are mostly the result of ignorance-can be interested in his work, and in time will experience a certain pride in his product.

Sometimes too much is expected of inspectors. Inspection goes far toward preventing the entrance of filth and infectious matter into milk, but it cannot give positive assurance that the milk is both clean and safe. Right at this point bacterial examination comes in. If, in spite of care on the part of the inspector, the bacterial count is not satisfactory, then a close search is to be made for the cause of the trouble. As has been pointed out before, pathogenic bacteria are difficult to find in milk, and therefore pasteurization of the product becomes necessary, even when inspection is all that can be desired. This does not render inspection less important, for pasteurization does not guarantee to remove filth; it does not guarantee to restore partially decomposed milk to its normal condition; it can in no manner atone for slovenly dairy habits. These must be corrected by efficient inspection. The work of the inspector should be suitably organized so as to enable him to visit as many dairies as possible without slighting the character of inspection. A map of the district, showing the location of dairies, wagon roads, railways, and electric roads will facilitate the planning of his day's work.

Milking operations are the most fruitful source of bacterial pollution. The inspector should calculate his visits in order to be present at a dairy during milking hours. This cannot be done in all cases. The two daily milking periods are about twelve hours apart, and it is not possible to be present at them on all tours of inspection. It would mean that only two dairies could be inspected in a day and would involve a long day, since farms to be visited may be far apart. The inspector should contrive to be present during milking time once in several visits, and the plan of visits should be changed periodically in order that the dairyman may have no way of knowing when the inspector is to be expected.

To supply large communities milk may have to be shipped for many miles. Means of transportation are, therefore, of great importance. There can be no objection to shipping milk for long distances if railway facilities are such as to keep the milk cool. Some roads have built cars especially for transporting milk. These cars have refrigerator walls, refrigerator doors, and only four doors, so as to avoid constant passing to and fro of train employees. In summer, heat and dust will not be readily admitted, and in winter there is small danger of the milk freezing. Many of the cars in use at present for milk shipments have thin walls, more doors than are desirable, and in some cases offices are located in them. In the latter instance heat is supplied and 
train officials pass through at their pleasure. The temperature in these cars fluctuates and more or less dust and dirt is admitted. As properly constructed refrigerator cars become more common, milk will keep well during transportation over long distances. Not only is refrigeration insufficient at the present time, but, in addition, milk trains are usually run on slow schedule, and improvement in this respect is desirable. Ice can be furnished in milk cars at small cost, not to exceed $\frac{1}{32}$ cent per quart of milk. To correct the evils of milk transportation cars should be inspected and the service controlled by proper legislation.

The reports of inspectors should be submitted to an inspectorin-chief, whose knowledge and experience in the work should enable him to eliminate the personal equation, and who, by comparing the data with earlier records, can judge of improvements in the inspected dairies. An improved product is the best evidence of efficient dairy inspection, not the number of prosecutions scored.

As a guide for dairy inspectors the score card is coming much in favor. Several types of cards have been designed, since the idea of scoring by means of a card was introduced by Dr. Woodward. The card was subsequently modified by Pearson, and in 1908 a committee of the Official Dairy Instructors' Association presented a card which is the one most commonly used at present. It is desirable that the same card be used universally to render results comparable.

The Association score card is divided into two parts-equipment and methods. A perfect equipment counts 40 points and perfect methods 60 points, making a total of 100 points for a perfect dairy. Other cards have 200 , some 500 , points for perfect scores. The following is a copy of the Association card:

[United States Department of Agriculture, Bureau of Animal Industry, Dairy Division.]

SANITARY INSPECTION OF DAIRIES

Dairy Score CARD

Adopted by the Official Dairy Instructors' Association

Owner or lessee of farm

P. O. address.

Total number of cows.

State.

Gallons of milk produced daily.

Product is retailed by producer in.

Sold at wholesale to

For milk-supply of

Permit No.

Date of inspection.

191

Remarks

(Signed)

The form here given is that revised in February, 1910. 
[Back of card.]

DETAILED SCORE

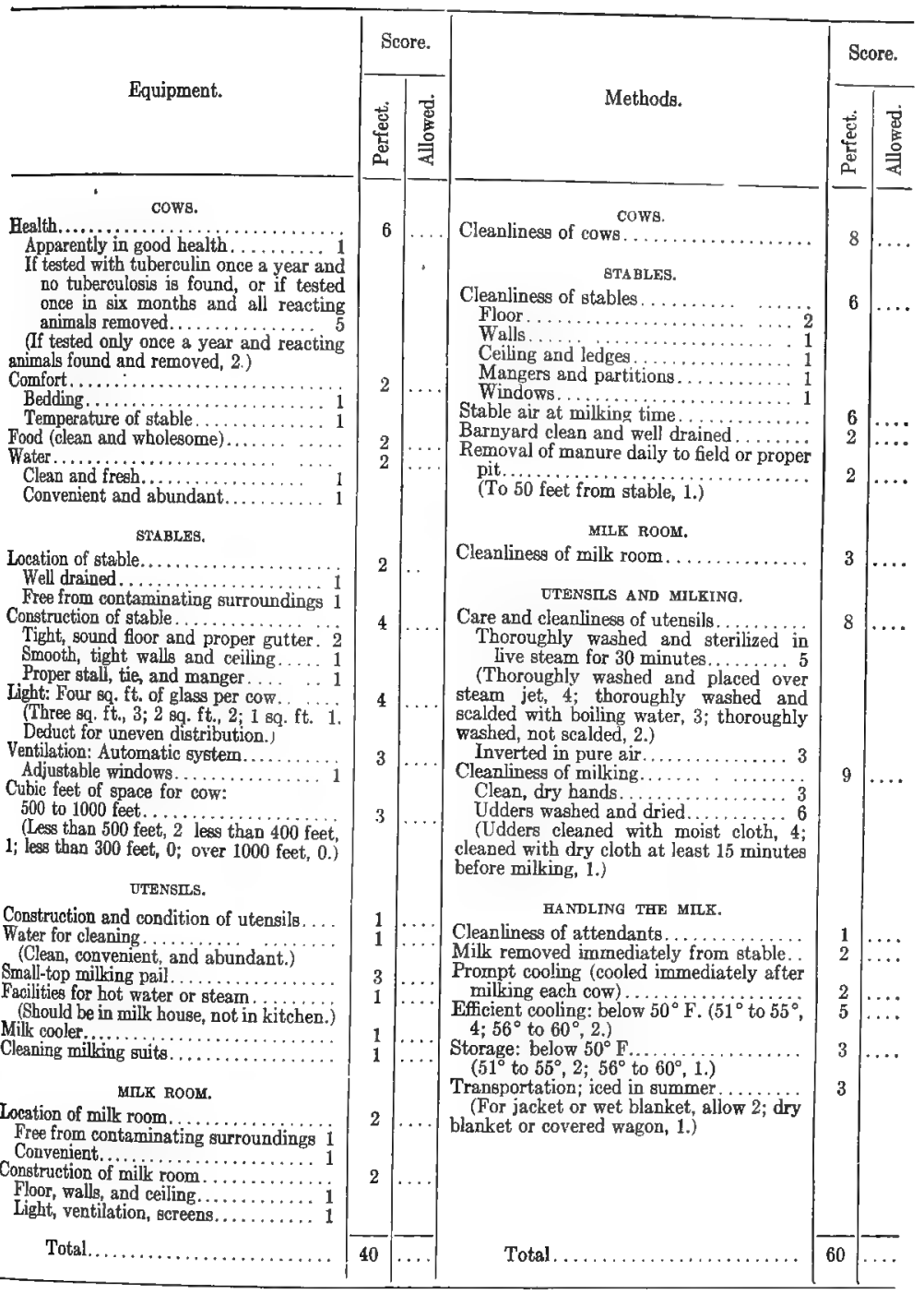

Equipment.

+ methods.

final score.

NOTE 1.-If any filthy condition is found, particularly dirty utensils, the total score shall be limited to 49 .

Note 2.-If the water is exposed to dangerous contamination or there is evidence of the presence of a dangerous disease in animals or attendarts, the score shall be 0 .

Dairy score cards are of relatively recent origin and, therefore, are imperfect. As a rule, they do not emphasize methods 
sufficiently. Excellent milk can be produced by good methods with relatively poor equipment, but good milk cannot be produced by poor methods in spite of fine equipment. Therefore, though a good equipment must receive due credit on a score card, methods should be emphasized more than they have been in the past.

There has been some discussion as to the relation the score of a dairy bears to the bacterial count of the product. It is obvious that there must be some relation, because milk from a filthy dairy with a low score for both equipment and methods naturally would contain more bacteria than milk from a dairy with a high score. On the other hand, it cannot be expected that there be a close relation. Brew, in an investigation of the relation of score and bacterial counts in milk, has found that milk with relatively few bacteria was produced with poor equipment, and with good equipment milk rich in bacterial content was sometimes produced. This implies a criticism of modern score cards which has been mentioned before, namely, that methods are not receiving the recognition they merit, while equipment is somewhat overrated. Perhaps, if methods occupied a relatively large space on the score card, a relation between filthy dairies and bacterial counts would become plainer. However, when a large number of bacterial counts and the corresponding scores are tabulated, some sort of relation becomes evident. Lane, Harding, and Gamble have shown this by a comparison of 1392 counts of bacteria from 484 dairies supplying a city of 100,000 population. The data are as follows:

No. of dairies
47
46
334
711
254

Seore.
Over 80
71 to 80
61 to 70
50 to 60
Below 50

Average count.
25,000
98,000
352,000
470,000
566,000

A similar view is taken by Kelley, who has expressed his experience in the following words: "It is true that they (the score card and the bacterial count) do not always jibe; furthermore, I am not sure that it is desirable to do so. We often find a man who, because of an exceptional personality, will, with poor equipment, still keep the bacterial count of his product at a low figure. . . Unquestionably, there are instances where a high score may obtain with a high bacterial count, and vice versa, but observation of many farms throughout the country has demonstrated that, as a rule, good conditions on a farm will make for a low bacterial count, and average bad conditions for a high bacterial count." 
Score cards have become of special value in preserving records of previous inspections. Comparisons show plainly whether a dairy has progressed. What was considered clean a short time ago is below the present standard, since one of the objects of inspection is the raising of standards. Furthermore, the chief supervisor can check up the work of inspectors by means of the score card.

The inspector is told by the score card what to expect; he can neglect no important points if the card is before him while he is at work; and it gives him ample opportunity to consult with the dairyman and win his interest in the work. The producer learns from the score card what to do, and receives tacit assurance that favoritism is not likely to occur. The score card has proved valuable by creating a rivalry among producers, each one working for a higher score than his neighbor has attained. Poor dairies and those producers who are unwilling to improve are weeded out, with the result that progress is encouraged.

Some large dairies have profited greatly by the introduction of the score card system. They are able to select the best dairies for their supply and improve their output. By offering financial advantage for high scores much has been accomplished in inducing the producer to furnish a cleaner product than heretofore.

In large cities milk is now sold in bottles, except for wholesale trade with large institutions. There is, however, a considerable quantity of milk sold from cans, especially in small places. Grocery stores frequently sell milk in bulk in any desired quantities. This is a boon for poor people who are limited to a few cents of milk at a time, as the price of bulk milk is somewhat lower than that of bottle milk. However, there are serious disadvantages to milk sold in bulk. The first customers may get richer milk than the last ones, if the milk is dipped from the top of the can; or if the can has a faucet at the bottom, the last customers may get the best milk. Danger of odor absorption is coupled with store selling of bulk milk and the chances of infection are naturally multiplied. Therefore store bulk milk requires supervision. The score card for rating stores as published by the Department of Agriculture is shown on page 556 .

The score card system has proved so successful in rating dairies and stores that supervision of milk depots, creameries, and pasteurization plants has been undertaken. The forms in use by the Health Department of the City of Chicago are shown in Figs. 222-229.

At present all these cards are in a stage of evolution; that is to say, they are not perfect. They will be perfected in time as 
[United States Department of Agriculture, Bureau of Animal Industry, Dairy Division.]

\section{SANITARY INSPECTION OF STORES HANDLING BULK MILK}

Operator:—_. Address:_—_. Gallons sold daily:——. Permit No._. Date:-— Remarks:-

Back of card.

Inspector.

DETAILED SCORE

\begin{tabular}{|c|c|c|c|c|c|}
\hline \multirow[b]{2}{*}{ Equipment. } & \multicolumn{2}{|c|}{ Score. } & \multirow[b]{2}{*}{ Methods. } & \multicolumn{2}{|c|}{ Score. } \\
\hline & 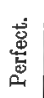 & 要 & & $\frac{\stackrel{s}{8}}{\stackrel{\Xi}{5}}$ & 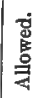 \\
\hline 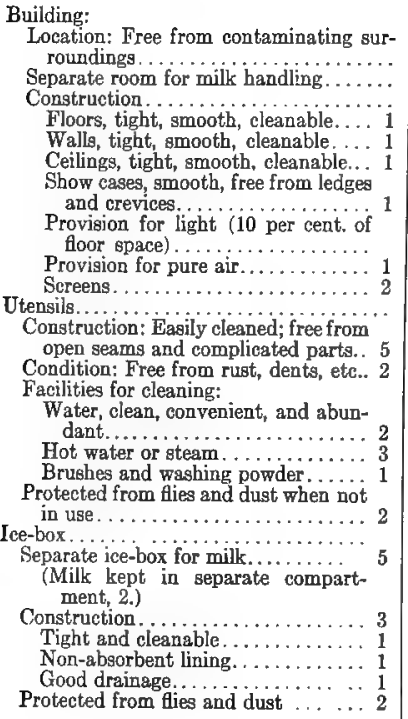 & $\begin{array}{l}2 \\
5 \\
8\end{array}$ & & 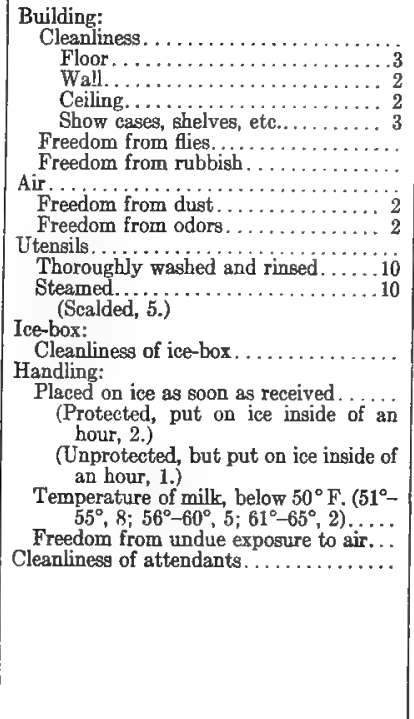 & $\begin{array}{l}3 \\
2 \\
4\end{array}$ & $\begin{array}{c}\cdots \\
\cdots \\
\cdots \\
\cdots \\
\cdots \\
\end{array}$ \\
\hline Total ............... & 40 & $\ldots$ & Total... & 60 & $\ldots$ \\
\hline
\end{tabular}

Equipment.

+ Methods

$=$ Tota

NOTE. - If the conditions in any particular are so exceptionally bad as to be inadequately expressed by a score of " 0 ," the inspector can make a deduction from the total score.

\section{experience accumulates and as inspection is entrusted to expert} hands.

Milk-supplies may be controlled by federal, state, or municipal authorities. Federal control affects only interstate shipments, but the research of federal laboratories has contributed to our knowledge. Federal officials have given substantial aid by their collaboration with state and municipal authorities. Inspection of dairies is carried out chiefly by state and municipal authorities. Theoretically, state inspection is to be preferred to municipal 


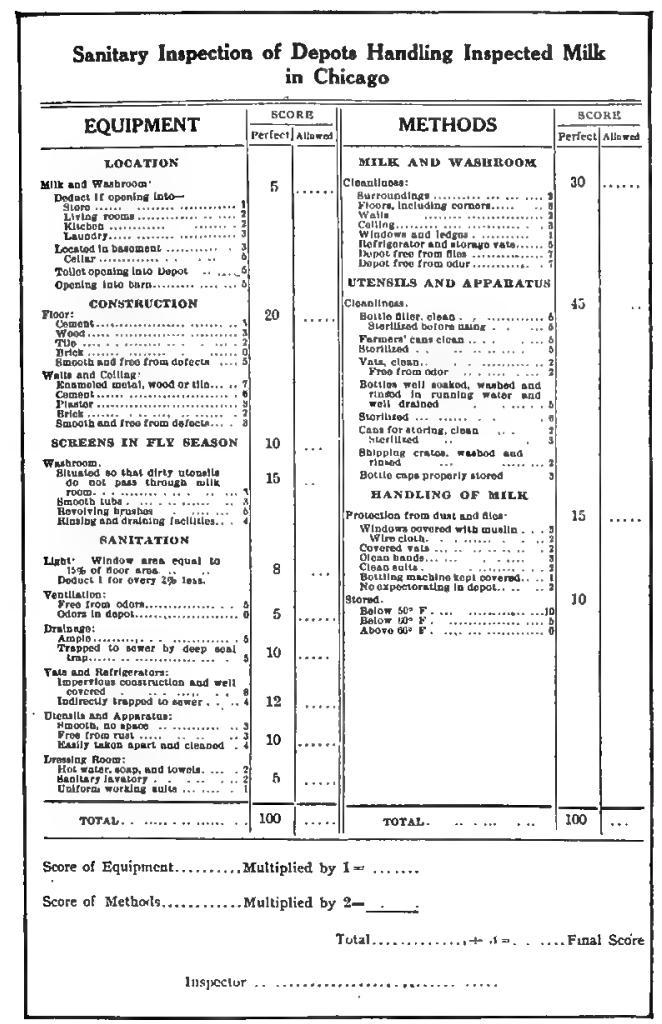

Fig. 222.

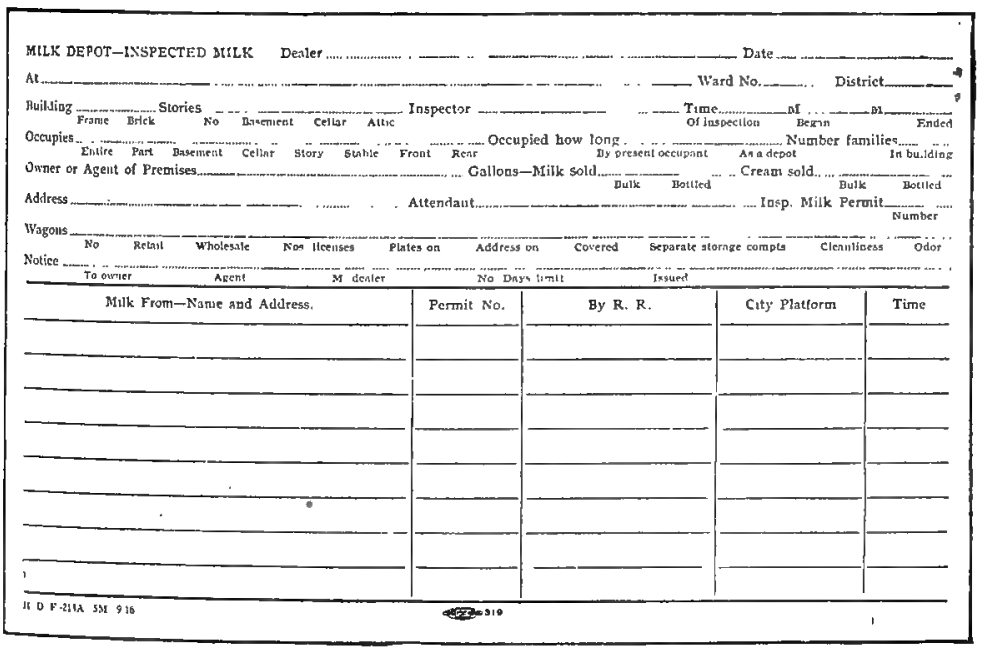

Fig. 222A. 


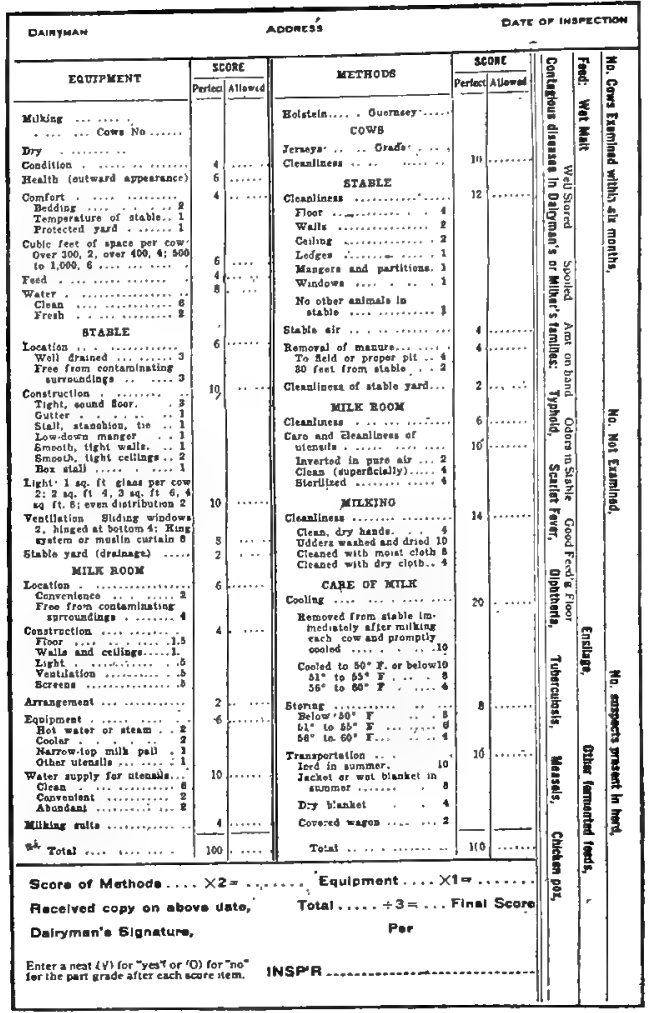

Fig. 223.

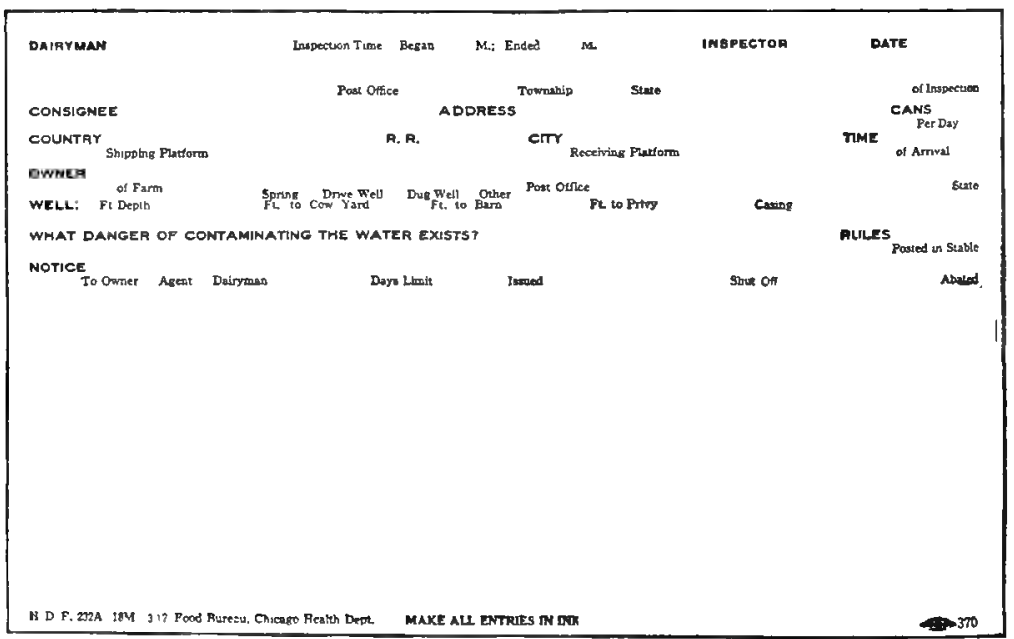

Fig. 223A. 
inspection. State control imposes the same conditions on all the producers in the state. If municipalities determine the conditions of milk-supplies it sometimes becomes awkward for a producer who furnishes milk to different cities. Requirements may vary, and while his milk may be satisfactory in one place, it may fail to comply with the ordinances of another. Besides, the same producer may be subjected to the visits of two or more

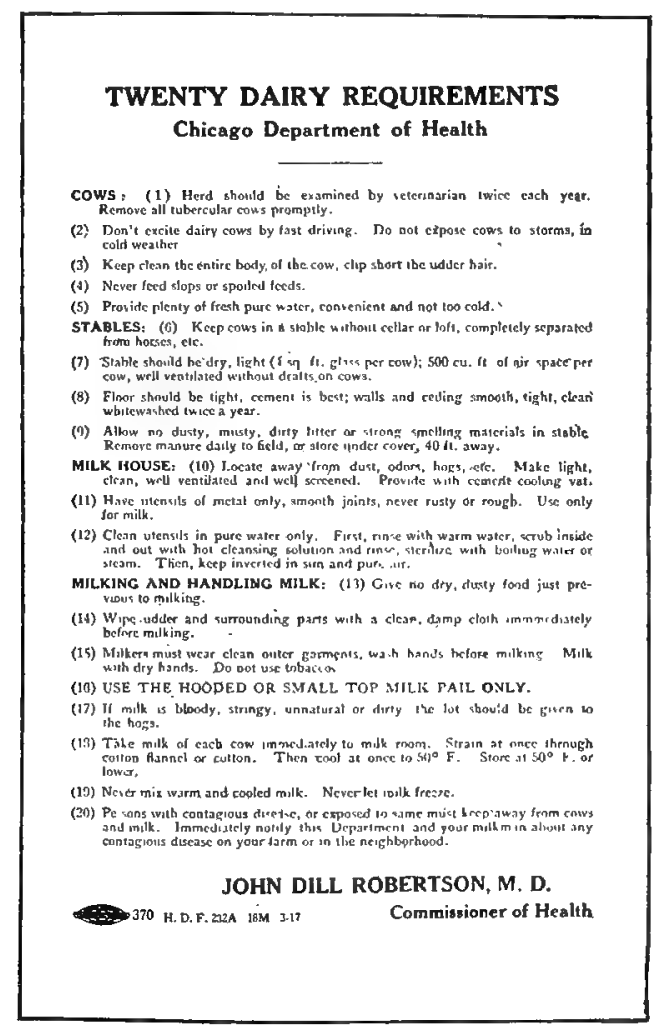

Fig. 224.

inspectors, a circumstance leading to further confusion. Such conditions are exemplified in a statement made by Brown, namely, that in a section of New York State the producer is subject to inspection and regulation from New York City, Newark, Montclair, and Orange, while the New York milk-shed overlaps that of Syracuse, Albany, Boston, Newark, and Jersey City. Milk producers are certainly discouraged when pursued by such diversified "control" and cannot be blamed for protesting against it. If a 


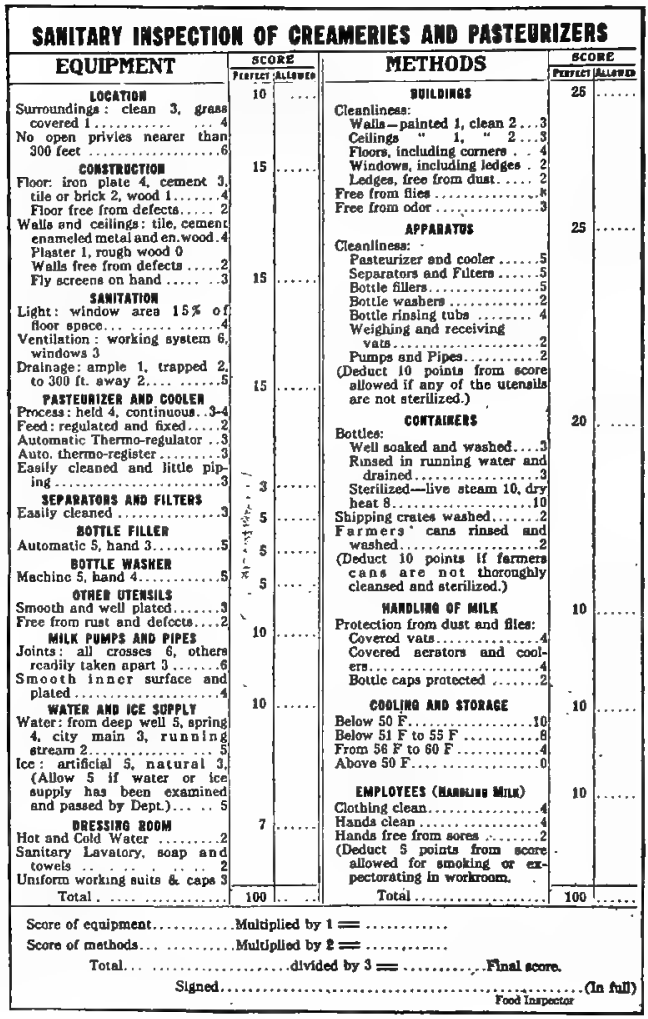

Fig. 225.

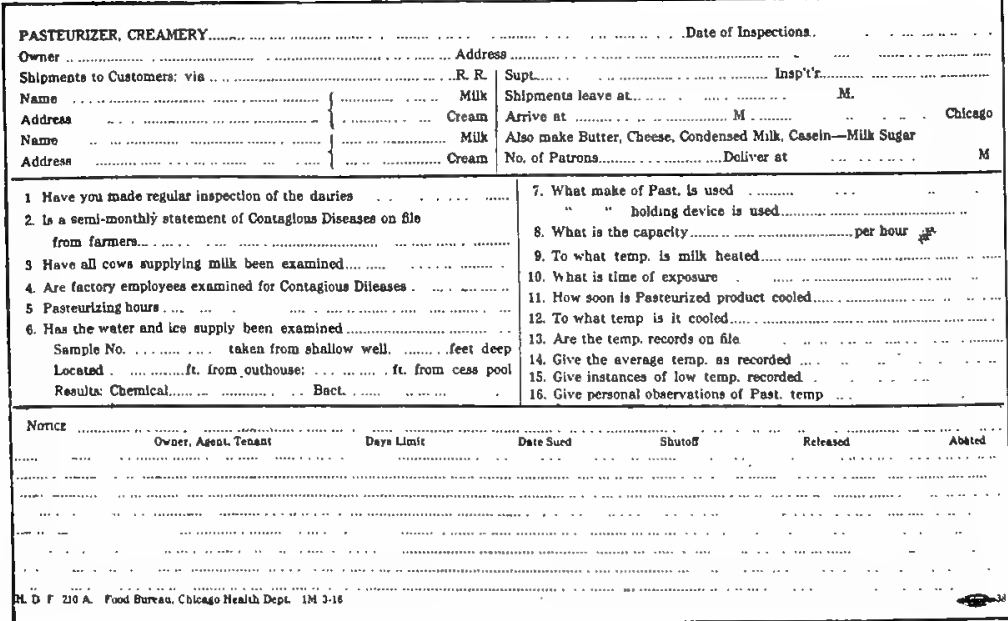

Fig. $225 \mathrm{~A}$. 


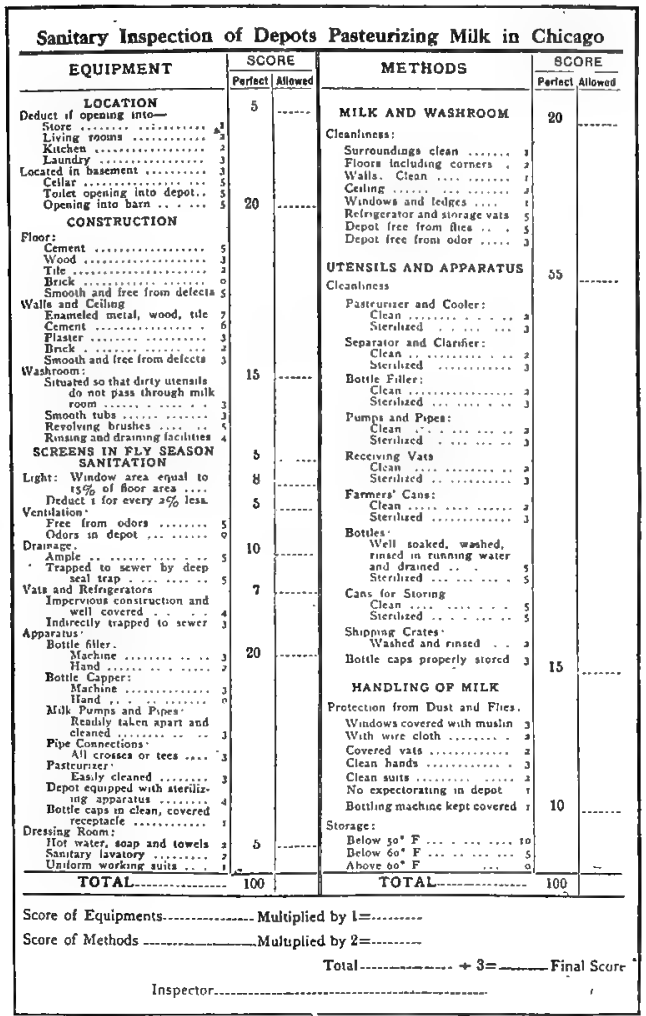

Fig. 226

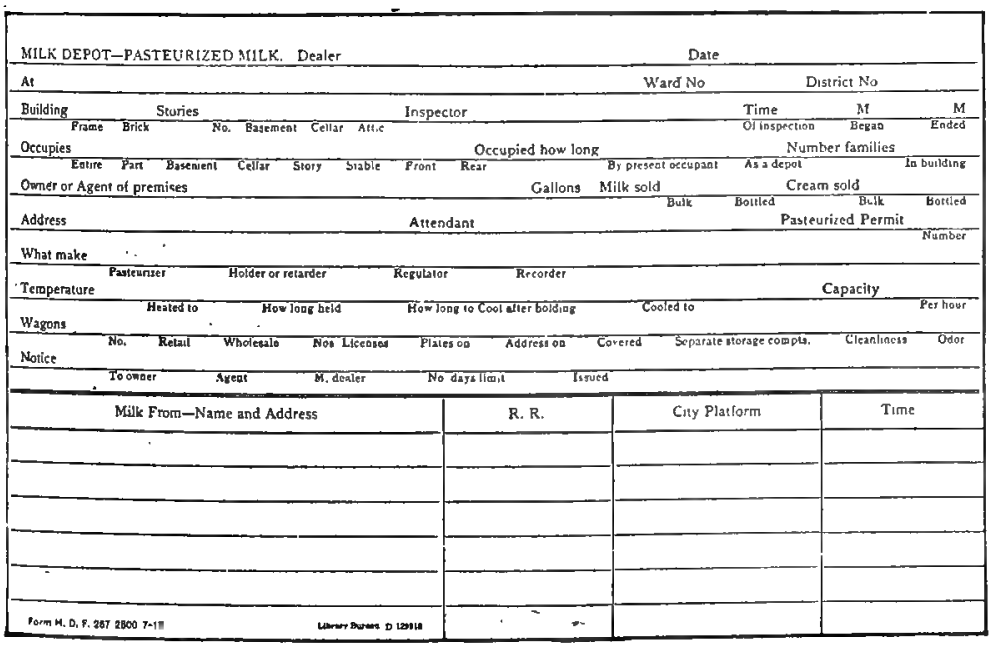


dealer does business in several places, he may have to procure several licenses.

\begin{tabular}{|c|c|c|}
\hline EQUIPMENT & & METHODS \\
\hline 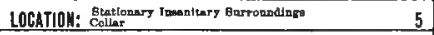 & & 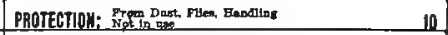 \\
\hline CONSTRUCTIOH: Dofocelime & & 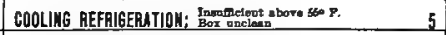 \\
\hline LIGHT: Inagrfflost & & 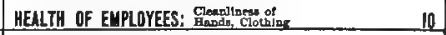 \\
\hline YEHTILATION: Jasamelont & & ATTENTION TO SIGNS: \\
\hline PLUMBIHG Lenky, Ineapstory, Luromelent & & 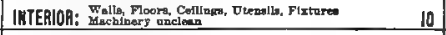 \\
\hline DRESSIMG ROOMS OR TOJLETS: Ventingog & & GARBAGE REFUSE OFFAL: Dispoend neqlacted \\
\hline LAVATOAMES: Noter, No Torols, No Boap & & 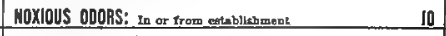 \\
\hline PROTECTIOH: Nove from Dust, Fhea, Fendilng & & 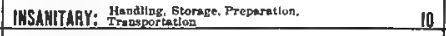 \\
\hline 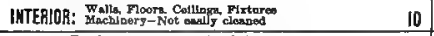 & & 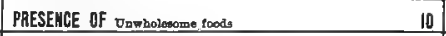 \\
\hline 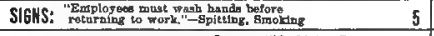 & & 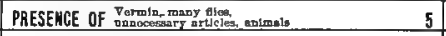 \\
\hline 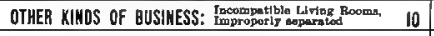 & & USE OF Improra mater, loo \\
\hline MECESSARY EQUUPMEKT ABSENT & & 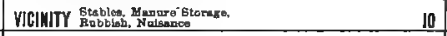 \\
\hline EXTRAS & & EXTRAS \\
\hline & & \\
\hline & & \\
\hline Total & & Total \\
\hline MULTIPLY EQUIPMENT TOTAL BY I. METHOD TOTALS EY 2. ADD & AND & DIVIDE BY 2. THEN SUBTRACT FROM IOO. TOTKL GCORE \\
\hline
\end{tabular}

Fig. 227.

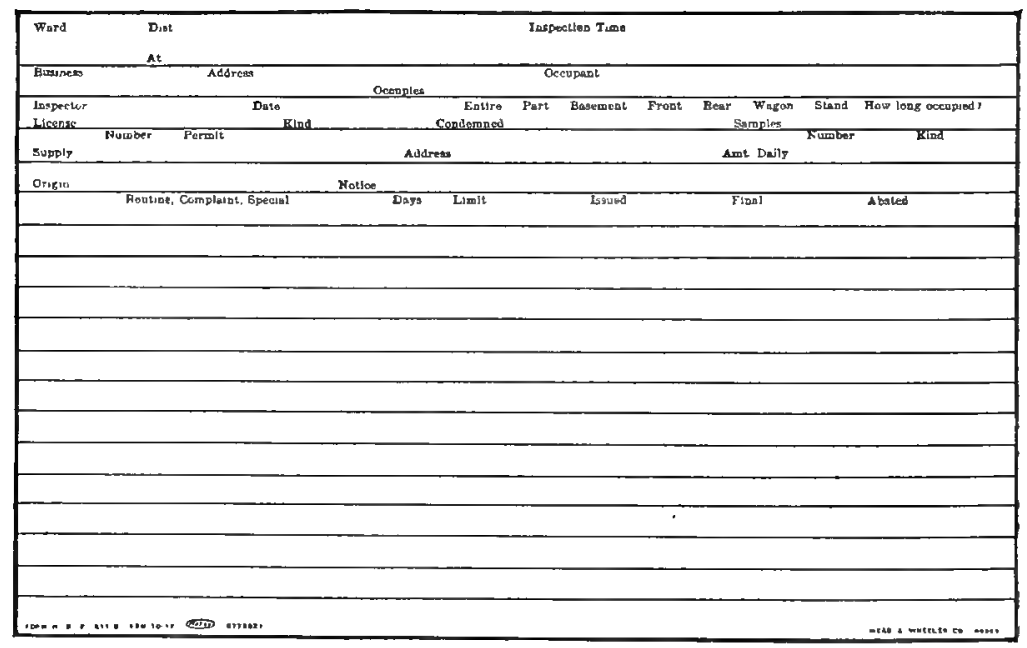

Fig. 227A.

On the other hand, it has happened that state legislation has interfered with municipal control in favor of the producer. The result has been an invalidation of city ordinances, with direful results. In Chicago an ordinance existed permitting the sale of 
raw milk obtained from herds free from tuberculosis as shown by the tuberculin test. All other milk was to be pasteurized. A

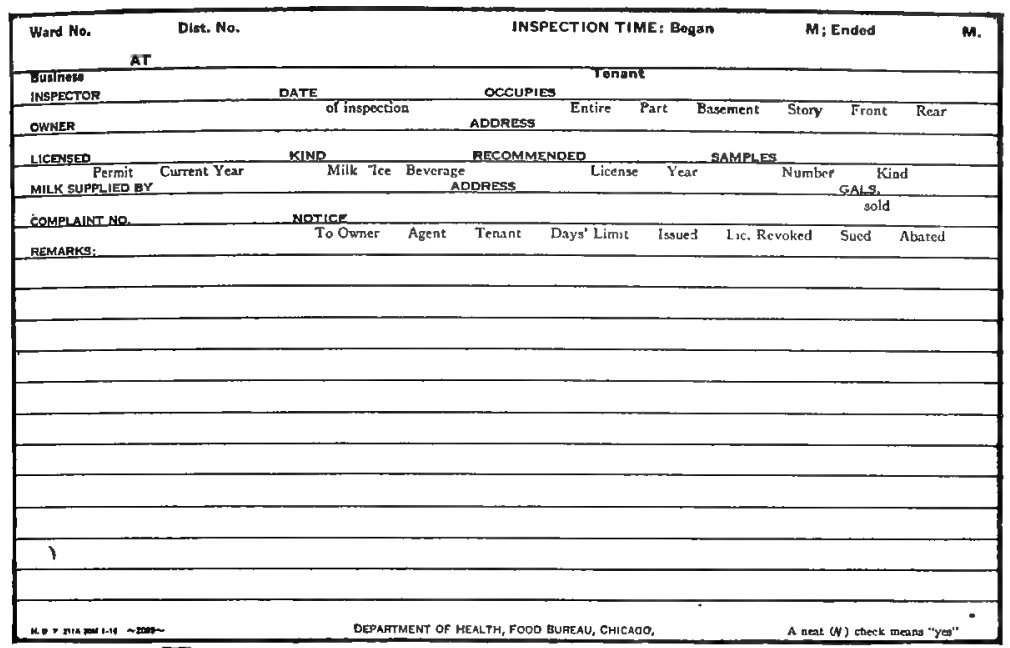

Fig. 228.

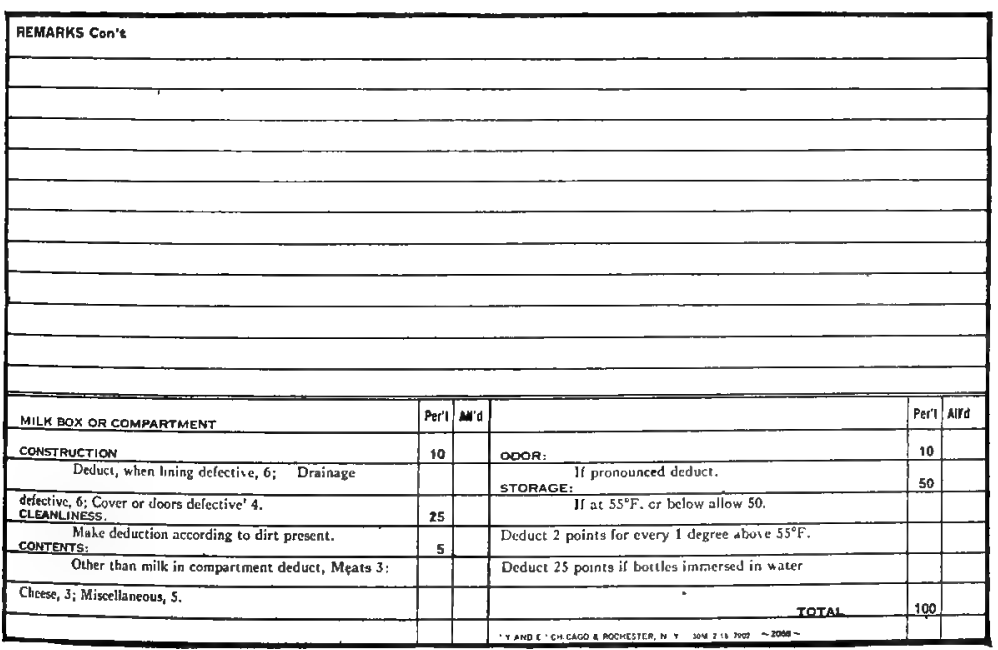

Fig. 228A.

state law was enacted which forbade the enforcement of tuberculin testing, and the only resource the city had was to substitute a general pasteurization ordinance. Such complications are un- 
fortunate and bound to retard the movement for safe and clean milk-supplies.

As a general rule, legislation should be conservative and should not impose undue hardships upon producers by attempting too much at a single step. A milk famine may result, and opposition is bound to follow radical legislation. The most progressive dairies are usually in advance of regulations which have for their purpose the controlling of supplies furnished by dealers whose object is evasion of the law rather than the production of a sanitary milk.

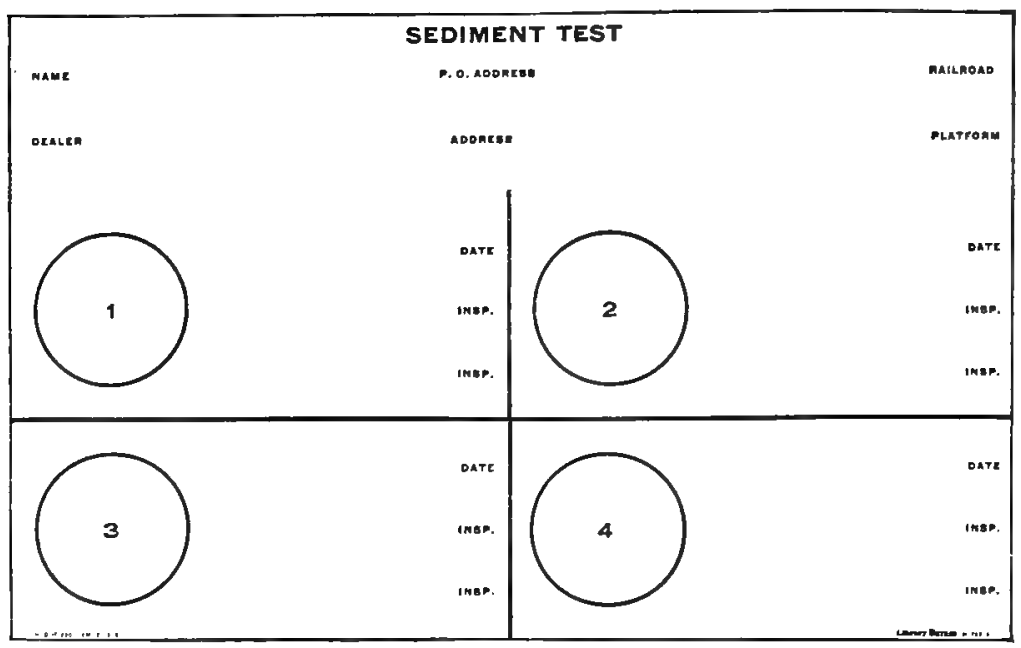

Fig. 229.

It is unfortunate that the various states and municipalities have enacted legislations which clash. It is true that conditions are unlike in different places, and that legislation must take cognizance of this fact. It is for this reason that Federal control of milk-supplies is not favored by some who have studied the problem. Harding, for example, states that "because of the extent and diversity of our country and because of the limitation of our knowledge of the factors involved Federal regulations uniformly applicable are difficult if not impossible."

Brown has made an extensive study of municipal milk regulations, and found that a surprising diversity of demands existed. Among the ordinances studied, he found the following curious facts: 


included in
analysis.

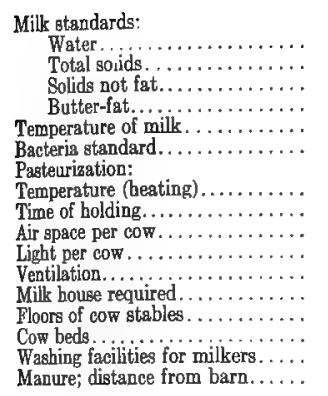
Per cent. agree. analysis. answering. Presum. ably no requirements.

$$
\begin{array}{r}
27 \\
27 \\
57 \\
20 \\
42 \\
20 \\
75 \\
40 \\
24 \\
7 \\
25 \\
100 \\
41 \\
1 \\
100 \\
36
\end{array}
$$

$\begin{array}{rr}9 & 8 \\ 9 & 8 \\ 8 & 9 \\ 14 & 3 \\ 14 & 3 \\ 12 & 5 \\ & 5 \\ 8 & 9 \\ 8 & 9 \\ 7 & 10 \\ 8 & 9 \\ 8 & 9 \\ 9 & 8 \\ 9 & 8 \\ 4 & 13 \\ 7 & 10 \\ 6 & 11\end{array}$

Jordan also reports discrepancies in milk regulations of different municipalities, and draws attention to the crude wording of some of them. The author states as his opinion that "the problems of sanitary administration in a large city are of quite a different nature from those in small towns or thinly populated districts, and it is certain that general state regulations applying to the latter group will often not fit the needs of the former."

Melvin and Alsberg have recognized the necessity of uniform legislation, and have worked out a model ordinance in such elastic shape that it may serve as a guide for the enactment of local legislation. This is an important contribution, and a copy of this model ordinance follows: This ordinance, according to the authors, covers (1) Fraud, (2) disease, (3) cleanliness in the production and handling of milk. It is reasonable and does not work hardship on the dairy industry, as such a law would never be successful.

\section{FORM OF ORDINANCE. AN ORDINANCE TO REGULATE THE PRODUCTION AND SALE OF MILK AND CREAM, AND FOR OTHER PURPOSES}

Be it ordained by the of the city of - That for the purpose and within the meaning of this ordinance, (a) "milk" is the lacteal secretion obtained from the complete milking of cows; (b) "skimmed milk" is milk from which substantially all the milk-fat has been removed; $(c)$ "certified milk" is milk produced and handled in conformity with the "Methods and Standards for the Production and Distribution of Certified Milk," adopted by the American Association of Medical Milk Commissions May 1, 1912, and amendments thereto, in effect at the time of production, and certified to by a milk commission constituted in compliance therewith; $(d)$ "grade A milk" is milk produced from healthy cows, as determined by the tuberculin test and physical examination within not exceeding one year previously by a qualified veterinarian, from dairies that score not less than on the dairy-farm score card in current use at the time by the United States Department of Agriculture, which milk shall not, at any time, contain more than —_ bacteria per cubic centimeter; $(e)$ "grade B milk" is milk produced from healthy cows, as determined by physical examination within not exceeding one year 
previously by a qualified veterinarian, from dairies that score not less than on the dairy-farm score card in current use at the time by the United States Department of Agriculture, which milk shall not, at any time, contain more than - bacteria per cubic centimeter; $(f)$ "pasteurized milk" is milk which has been heated to, and for at least 30 minutes held at, a temperature of approximately $145^{\circ}$, never less than $142^{\circ} \mathrm{F}$; $(g)$ "cream" is that portion of the milk, rich in milk-fat, which rises to the surface of the milk on standing, or is separated from it by centrifugal force, and containing not less than - per cent. of milk-fat; $(h)$ "homogenized" or "emulsified" milk or cream is milk or cream which has been subjected to the mechanical process of homogenization or of emulsification, as the case may be; (i) "unsterilized containers" are containers which either have not been subjected to moist heat at a temperature as high as $205^{\circ} \mathrm{F}$. for two minutes or longer, or do not comply with such alternative requirements, to be prescribed by the regulations made pursuant to this ordinance, as may be necessary to effect sterilization thereof; and ( $j)$ "person" imports both the plural and the singular, as the case demands, and includes corporations, partnerships, societies, and associations.

When construing and enforcing the provisions of this ordinance, the act, omission, or failure of any officer, agent, or other person acting for or employed by any individual or by any corporation, partnership, society, or association, within the scope of his employment or office, shall in every case be also deemed to be the act, omission, or failure of such individual, corporation, partnership, society, or association, as well as that of such officer, agent, or other person.

SEC. 2. That no person shall sell or deliver for consumption as milk or cream or have in his possession with intent to sell or deliver for consumption as milk or cream either-

(a) Milk or cream to which water or any foreign substance has been added; or

(b) Milk containing less than —_- per cent. of milk-fat or less than - _ per cent. of solids not fat, or cream containing less than cent. of milk-fat, unless such milk or cream is plainly and conspicuously labeled "Subnormal," together with a statement showing the actual per cent. of milk-fat contained therein; or

(c) Skimmed milk which has not been pasteurized, or made from pasteurized milk, or which is not labeled "Skimmed Milk"; or

(d) Milk or cream containing, or which has been exposed to, any disease-producing bacteria; or

(e) Milk or cream the container of which is labeled or branded so as to mislead or deceive the purchaser; or

(f) Milk or cream produced from diseased cows, or from cows during the period of fifteen days preceding parturition or within such time thereafter as the milk is abnormal, or from cows which have been fed unwholesome food or have had access to contaminated water; or

(g) Milk or cream which falls below the requirements of Grade B, as defined herein, or milk or cream which has been produced, stored, handled, or transported in any unclean or insanitary manner: or

(h) Milk or cream the retail, or the final, container of which does not bear a plain and conspicuous statement showing the kind and grade as herein defined; or

(i) Milk or cream in unsterilized containers; or

(j) Milk or cream which such person has kept at a temperature higher than $50^{\circ} \mathrm{F}$; ; or

(k) Grade B milk which has not been pasteurized; or

(l) Homogenized milk or cream, or emulsified milk or cream, unless it is plainly and conspicuously labeled "Homogenized" or "Emulsified," as the case may be; or

$(m)$ Milk which has had the cream line increased by any artificial means.

SEC. 3. That nothing in this ordinance shall be construed to prohibit the sale, when labeled so as to show its true character, of either $(a)$ sour milk or sour cream; or $(b)$ buttermilk, or any similar product made from pasteur- 
ized milk or cream; or (c) modified milk if made from milk or cream equal at least to Grade B.

Sec. 4. That no person shall sell or deliver, or have in his possession with intent to sell or deliver, for consumption as milk or cream, any milk or cream without a permit from the board of health of

SEC. 5. That the board of health of - - is authorized to make such regulations, from time to time, as are necessary for the efficient execution of the provisions of this ordinance, and to issue permits to sell and deliver milk or cream in - The board of heilth, after affording the permittee an opportunity for a hearing, may suspend or revoke any permit issued by it under this ordinance whenever it shall determine that the permittce has violated any of the provisions of this ordinance or of the regulations made hereunder, and, without affording such opportunity, may suspend such a permit temporarily whenever it deems necessary.

SEC. 6. That the board of health of - its members, officers, and agents, shall, at all reasonable times, have access to any dairy or any other place where milk or cream is produced for sale; to any wagon, truck, train, car, warehouse, or station in which milk or cream for sale is being transported or is being held for transportation or delivery; and to all establishments, plants, depots, or stores where milk or cream is kept or stored for sale. Any person who hinders or prevents such access shall be guilty of a violation of this ordinance.

SEc. 7. That any producer, handler, or seller of milk, or cream, whether principal, agent, or employee, who, on demand, refuses to sell or deliver a sample, not to exceed one pint, of milk or cream in his possession to any official designated by the board of health to collect samples, shall be guilty of a violation of this ordinance.

SEC. 8. That any person violating any of the provisions of this ordinance shall, on conviction by any court of competent jurisdiction, be punished by a fine of not more than _- dollars, or by imprisonment of not more than - or by both such fine and imprisonment, in the discretion of the court; and for each subsequent offense, and conviction thereof, shall be punished by a fine of not more than - dollars, or by imprisonment of not more than - or by both such fine and imprisonment, in the discretion of the court.

A system of licensing milk dealers has been in vogue in many cities, and may be regarded as the first attempt to control milksupplies as well as many other lines of business. It is proper that the sale of an important food product should be subject to license, but the license fee need not be large. The object is to enable health departments to catalog dealers and reach them with a view to controlling their supply. All dealers should be licensed, no matter how insignificant their business. The scord care is of considerable usefulness in passing judgment on the merits of an applicant for license. Under a license system it is possible to keep track of each individual milk dealer, of the quality of the milk he furnishes, of the condition of the herds from which the milk is drawn, and, finally, a list of customers can be obtained to refer to in case an epidemic breaks out. Licenses should be renewed annually.

\section{BIBLIOGRAPHY}

Brew: New York Agri. Exper. Sta., Bull. 398, March, 1915.

Brown, L. P.: Ninth Annual Report of the Convention of the International Milk Dealers' Association, Springfield, Mass., 1916, p. 45. 
Harding: The Creamery and Milk Plant Monthly, 1916, vol. 4, p. 19.

Jordan, E. O.: Jour. Amer. Med. Assoc., 1913, vol. 61, p. 2286.

Kelly: Proceedings of the Sixth Annual Conference of the American Association of Medical Milk Commissions, 1912, p. 84. United States Dept. of Agri., B. A. I., Circular 217, 1913.

Lane and Whitaker: United States Dept. of Agri., B. A. I., Circular 139, April, 1909. Lane, Harding, and Gamble: The Creamery and Milk Plant Monthly, 1915,
vol. 4, p. 15.

Melvin and Alsberg: United States Dept. of Agri., Bull. 585, October, 1917. 


\section{THE ECONOMIC ASPECT OF MILK PRODUCTION}

THE cost of cleanly milk production is necessarily greater than that of indifferent production. A larger investment is required to build sanitary stables than to build ordinary barns; good utensils are more or less expensive and intelligent help require good wages. It takes time to clean stables, to curry the cows daily, to remove manure frequently, to promptly cool and bottle milk, and the time required for these activities calls for additional labor and recompense for the same. The milk producer is a hard-working man who milks the cows twice daily, including Sundays and holidays, and he expects a fair profit for his work. The extra expense involved in clean milk production can be offset, in part at least, if consumer, producer, and middleman will do their share. There are at least four ways in which to meet this problem: 1, By increasing the price paid for milk; 2 , by increasing the productivity of herds; 3 , by the sale of by-products; 4 , by economy in distribution of milk in cities.

1. The public should be willing to pay a higher price for a better product. It is a strange anomaly that increase in the price of other food articles meets with little antagonism, while agitation against a higher price for milk is usually intense. And this is in spite of the fact that milk is by far the cheapest kind of food. This attitude of the public and of the newspapers is to be deplored, since it discourages improvement in milk-supplies and encourages the sale of poor milk. When health departments demand a cleaner milk the producer must either become a philanthropist or go out of business. This condition is one of the greatest obstacles to rapid improvement in the quality of milk. The consumer places the blame on the producer, and the producer blames the consumer. Success is assured only with their combined efforts.

It is not sufficient for health departments and legislators to enact legislation, but education of the public must be undertaken. It is relatively easy for the layman to distinguish between spoiled and good meat, between old and fresh vegetables; in short, to judge the quality of most foods. But it is impossible for the untrained observer to distinguish good milk from milk of inferior quality. If the consumer demands a clean and safe product and is willing to pay a fair price for it, he can have it. The apathy of the public is well illustrated by the relatively small number of requests made upon public health laboratories for examination 
of milk samples. James O. Jordan says: " . . While laws and regulations may insure sanitary surroundings for all milk produced, they unfortunately do not guarantee that any milk will be raised at all. It would be as sensible to attempt to legislate that gold should be sold at the price of scrap iron, as to assume that legislation will give us clean milk while we are purchasing that commodity upon a dirty milk basis."

An increase in price, sufficient to insure fair profit, is an effective means of stimulating production of good milk. Harding and Brew have studied this subject, and have come to the conclusion that at present the wholesale price of milk is not high enough to yield a satisfactory profit to the producer, and that, consequently, the cheapest milk acceptable to the market is supplied. If the wholesale price were raised to a figure which would make good milk more profitable than poor, the production of good milk would be encouraged. Harding and Brew state that in the city in which they collected data the wholesale price of milk was increased $\frac{1}{2}$ cent per quart as the product advanced from a medium to a good grade, or from a good grade to an excellent one. Tabulation gave the following results:

September, 1907-good milk, 5 per cent.; medium, 57.5 per cent.; poor, 37,5 per cent.

March, 1911-excellent milk, 12.8 per cent.; good, 87.2 per cent.

January, 1913-good milk, 18 per cent,; medium, 82 per cent.

Under the influence of the financial stimulus, the extraordinary improvement from September, 1907, to March, 1911, took place. During the next two years there was a falling off in quality, which the authors ascribe to a change in inspectors. The new inspectors were not competent, and the scores remained constant in spite of the fact that the producers became negligent. There had been no change in the city ordinance, but the new inspectors failed to stimulate the producers to keep up the quality of their product, so the general supply suffered. The retailers were bound by contract to pay a certain price based on the official score card rating, and, although they recognized the deterioration in quality, they had no legal recourse.

The authors studied the problem for five years, and believe that farmers will produce any grade of milk that is desired if the production is rendered profitable. "Under present conditions there is a demand for milk for three distinct purposes: for the feeding of infants, for use by adults at the table, and for cooking. The simplification of the municipal milk problem lies along the line of defining and establishing commercial grades of milk which shall correspond to the market demands." An ordinance in New 
York City has actually provided for grades of milk on a similar basis.

The profit of the middleman should also receive due consideration. The quantity of milk sold fluctuates from day to day and from season to season, and since milk is a perishable product, any surplus must be used for some other purpose or it will go to waste, and this after the expense of bottling, icing, carrying, etc., has been incurred. The profit made on butter churned from surplus milk is consequently small.

But the middleman can also effect a saving of milk by using proper methods, especially when milk is sold from cans. The careless manner employed in dipping milk causes some of it to drop on the floor or the outside of the can, and this is a total loss, of course. Lane estimates that when one-half of the milk is sold by dippage, 10 per cent. of the amount handled is lost.

The consumer can aid the producer in properly caring for empty bottles. The bottles should be cleaned first with cold water and then with hot soapsuds. They should be returned in good condition and never used for purposes other than holding milk. The average life of a bottle is variously stated to be from eight to fifteen deliveries. With due care on the part of the consumer its period of usefulness can be lengthened considerably. Williams states that the loss due to lost or broken milk bottles in Rochester, N. Y., is at least $\$ 10,000$ a year. Every dairy has a pile of broken milk bottles which represent considerable loss, whether the breakage be due to accident or abuse of the bottle. The shape and wide. mouth of the milk bottle appeal to the householder so strongly that it is not surprising to find it in use at canning time, or for holding paint and varnish in housecleaning time. As many of the purposes to which the handy milk bottle are put render it unfit for further milk distribution, it may represent an almost total loss. The solution of the problem will possibly be found in the use of pulp bottles. These are used but once for milk distribution and are cheaper than glass bottles; they do away with the expense of cleaning, they weigh less than glass bottles, thus facilitating transportation; and they do away with the possibility of disseminating disease through returnable glass bottles.

2. With reference to what the producer can do to increase his profit, a large field, but one poorly understood by the majority of farmers, presents itself. Marshall says: "If one were to make a close investigation with the idea of determining how many farmers are capable of producing milk profitably and in a pure form, I am certain it would be found that less than 1 per cent. could fulfil the requirements. A man capable of producing milk 
that will answer the requirements of the sanitarian is an unusual agricultural man and fit for success in almost any profession. $\mathrm{He}$ must be a thoroughly capable man, and, being a capable man, of course demands a fitting remuneration. His profession and himself are too little appreciated by society and scientific men." The farmer must know how to treat cows; how to breed sufficiently; must feed them properly and economically; must see that the pasturage is free from plants which may impart undesirable flavors to milk. Abnormal conditions of animals and many other things must be thoroughly understood by him to make dairying a success. When he has learned to produce sanitary milk and is obtaining a fair price for it, some other producer may enter the field of competition and offer a cheaper and poorer grade of milk. Thus the difficulties of the milk producer multiply.

Formation of a profitable dairy herd is essential and requires study and circumspection. Cows have different characteristics; some produce large quantities of milk, others less; some produce milk rich in fat, others produce milk poor in fat; some can forage on poorer pastures than others. If the milk is intended for direct consumption, a herd composed of cows producing milk with high fat content is not as advantageous as one containing some large producers. For creamery purposes milk rich in fat is more suitable than milk poor in fat. The farmer must choose in which line he is chiefly interested before beginning to raise a herd.

Lane mentions the following breeds of cows as most desirable for dairy purposes:

Ayrshires.-They are able to obtain sufficient food on rough and poor soil and are hardy enough to stand all kinds of weather. Still they yield large amounts of milk. Lane quotes an example of a herd of Ayrshires which averaged 6407 pounds of milk per cow annually for a period of nineteen years. The average percentage of butter-fat is 3.8 per cent., varying from 3.5 to 4 per cent. The fat globules are small, even in size, and do not separate easily. Ayrshire milk is, therefore, better adapted for milk trade than for making butter.

Guernseys. - The home of this breed is on the island of Guernsey. They produce a large amount of butter of rich, goldenyellow color, and a rich appearing cream and milk. The Guernsey milk is, therefore, highly prized by consumers. A Guernsey cow produces 5000 to 6000 pounds of milk annually.

Holstein-Friesians.-This race originates in North Holland and Friesland. They are large animals, black and white, have large udders, and produce large amounts of milk. Herds may average 8000 or even 10,000 pounds of milk a year from each animal. The fat content is low and the globules are small. 
Jerseys.-The home of this breed is the island of Jersey. They are small, delicate, gentle, but nervous animals. They produce a milk rich in butter-fat, the average being about 5 per cent., although some individuals produce milk still richer in fat. The color of the milk is rich and the globules are large. They are, therefore, good butter producers.

Brown Swiss.-This is a favorite breed in Switzerland, but is scarce in this country. They are strong, muscular animals, able to produce 6000 pounds of milk with 3.5 to 4 per cent. butterfat.

Devons.-These cows come from Devonshire in southwestern England. They are a hardy race, thriving on poor pastures and able to live in hilly and mountainous countries. They yield about 4000 pounds of milk of moderately rich quality.

Dutch Belted.-This race is also at home in Holland. The animals are hardy and vigorous. One herd, according to Lane, averaged 5840 pounds per cow in a year.

Shorthorns.-Originally this is a breed of beef producers, but the cows are also used for milk production. The best herds average 6000 to 7000 pounds of milk with 3.75 per cent. fat. The globules are of medium size and very uniform. The cream separates readily.

Polled Durhams.-These cows are similar to Shorthorns, but are hornless.

Red Polls.-They are hornless, of medium size, and produce a fair amount of milk of moderate richness. The fat percentage is 3.75. Select herds yield 6000 to 7000 pounds of milk.

A dairy herd may be formed by breeding or by purchasing animals. When formed by purchase there is constant danger of introducing disease into a healthy herd. This is a serious disadvantage. There is the added disadvantage that, as a rule, poor bulls will be coupled with cows of such herds, and as a result calves with only meat value instead of good milk producers will be borne.

Breeding as a means of building up a herd requires much attention, but is usually considered the safer and more profitable method. The herd is started with a few select animals and a good bull chosen. "The bull is half the herd" is a common expression, and it is no doubt true that the productivity of the herd depends largely upon the kind of bull used. Breeding a good bull with recognized breeds of milk cows results in building up a productive herd, and the calves from such herds have more than mere meat value." As Winkjer says: "If the best bulls were used to their full capacity in pure-bred herds, and if only good bulls were used in the ordinary herds, the income from the dairy business could be vastly increased." And further: "The influence of 
the bull in the herd will be noticeable for many generations." The same author states that in one herd " 14 out of 16 daughters excelled their dams, the average increase being 30 per cent."

In most herds as they exist at present there are cows that produce larger amounts of milk than others. The importance of eliminating poor producers and replacing them with better animals is not widely recognized by herd owners. The correct method of separating cows according to their relative milk producing ability is to weigh the amount of milk produced and to make butter-fat tests at regular intervals. The common method of guessing at the quantity and quality of milk is entirely unreliable and misleading. Fraser has published results of a comprehensive study on this subject. He speaks of "Uncle Sam's Three Herds of Dairy Cattle." The poorest of the three herds produced 3654 pounds of milk and 134 pounds of fat annually, each cow lacking $\$ 7.25$ of paying for her board. The middle herd averaged 5000 pounds of milk and 198 pounds of butter-fat. The annual profit of the middle herd was $\$ 7.85$. The best herd averaged 6765 pounds and 278 pounds of fat, with a profit of $\$ 26.82$. Extending this classification over the United States it may be assumed that each of these three herds contains $7,000,000$ cows. If the average number of cows for each herd in the country is placed at 30 , this would represent more than 230,000 herds. It requires 230 ,000 farms, buildings, and equipment to care for these herds. While the poorest herds lose $\$ 50,000,000$ annually, the best herds make a profit of $\$ 177,000,000$. Thus there is a great amount of labor lost. If a cow does not produce 4000 pounds of milk and 160 pounds of fat annually the owner loses money. Fraser quotes examples of 6 herds which received no special attention as to grading of cows and 6 herds in the same locality which were raised by breeding with a pure bred sire. The former group of herds yielded 175 pounds of fat each year, while the latter yielded 265 pounds. The profit of the first group was $\$ 3.40$ per cow annually, and of the latter group $\$ 24.80$. Of the better kind of cows, 25 would make as much profit as 1021 of the poorer kind. The saving in equipment, buildings, and labor necessary for 25 cows over 1021 cows is obvious. A herd of 25 cows can be kept on a small farm in a small stable, while a herd of 1021 cows requires larger stable facilities, more pasture land, and a greater foodproducing area. While the capital invested in and the labor required for 25 good cows is much smaller than for 1021 poor cows, the profit in both cases is the same. An average cow of the best herd is worth as much as 24 cows of the poorest. Fraser has graphically illustrated the results of his study in two charts (Figs. 230 and 231). 
By weighing the milk of each cow in the herd and determining the fat content, the poor ones can be located and eliminated. Good cows can be substituted, and then the total product can be raised with no additional expense except that required for labor to handle the product. Fraser quotes an example where in two years the product of a herd was brought from 5800 pounds of milk and 224 pounds of butter-fat per year to 8057 pounds of milk and 307 pounds of fat.

Selling calves can be made a source of profit to the owner of a good herd. He can keep enough calves to fill up his own herd and sell the others. It is generally believed that heifers raised from good cows and a good sire ultimately yield a better profit

\section{COW PATHS THAT LEAD FAR APART}

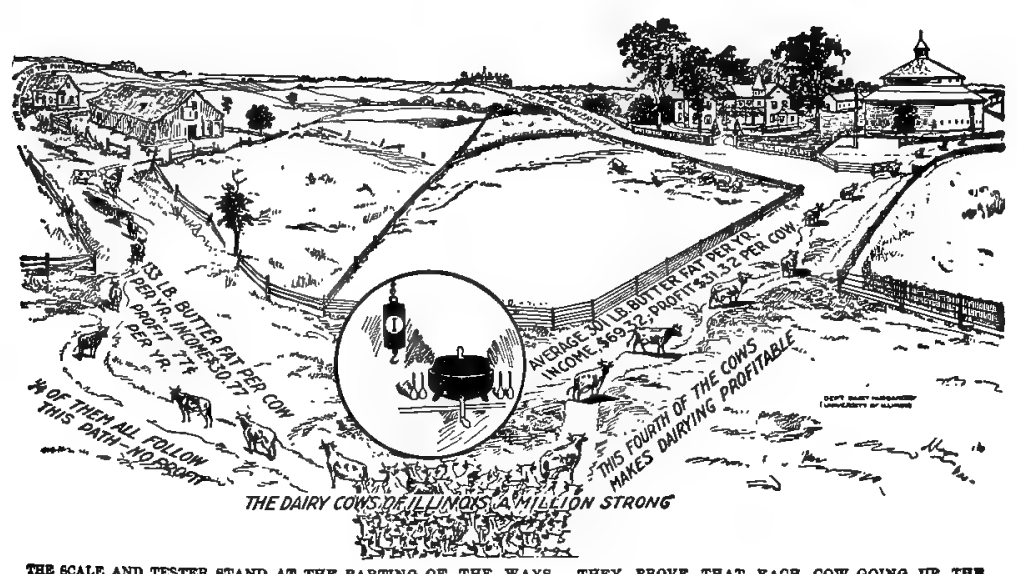

THE gCALE AND TESTER BTAND AT THE PARTING OF THE WAYS. THEY PROVE THAT EAOB COW GOING UP THE BIGHT-BAND PATH IS WORTh AS HUCH TO THE DARYMAN AS 41 COWB ON THE LETT-HAND PATH.

Fig. 230.-(Fraser, Univ. of Illinois Agri. Exp. Sta., Circular 118.)

than purchased animals. Good cows are not easily obtained in the market and are expensive. The cost of raising calves is not great. At the Illinois Experiment Station calves were raised on milk that would have been sold for $\$ 2.70$ in the open market. Calves can be raised for $\$ 20$ to $\$ 40$ and bring prices from $\$ 50$ to $\$ 60$. By judicious breeding milk producers can realize a good revenue both from the sale of milk and from that of calves.

To raise a profitable herd it is necessary for the owner to get well acquainted with each individual cow. He must know how much milk and butter she produces and the amount of food she consumes. Systematic bookkeeping, which must include overhead expenses, such as buildings, labor, bedding, etc., does not consume much time, and in the end will contribute to a more 


\section{WHEN THE COWS COME HOME}

Twenty - five cows, each producing 301 ib. butter fat per year, return a profit of $\$ 783$.

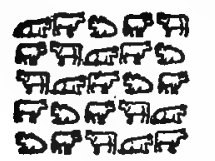

The picture below shows exactly how many cows of the poor kind, $(1,02 x)$ it takes to return identically the same profit $\left(\$ 78_{3}\right)$ as the above 25 good cows.
This is the average production of 139 cows comprising the best fourth of 554 cows in $3^{6}$ Illinois dairy herds.

The lowest fourth (139 cows) of the same $3^{6}$ herds averaged 133? tb. butter fat per year.

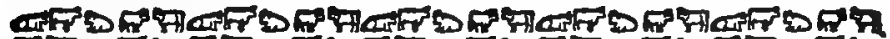

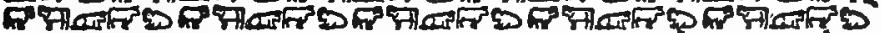
औी

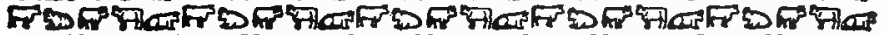

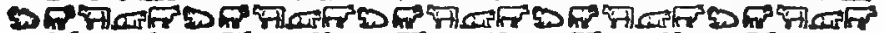

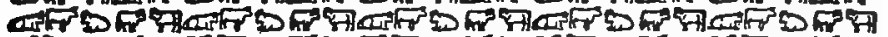

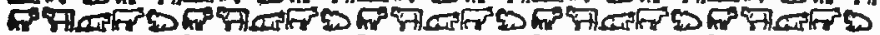

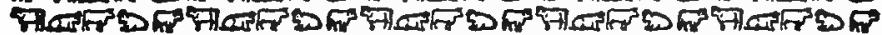
FP DS Fै

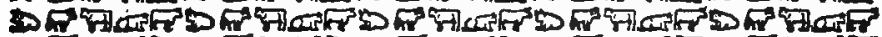

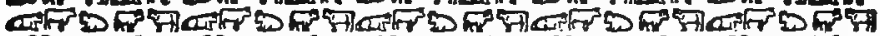

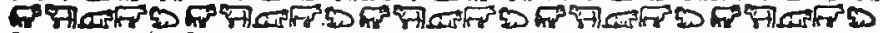

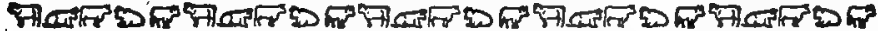

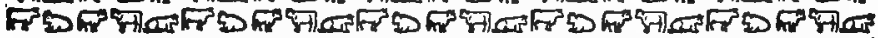
की मP

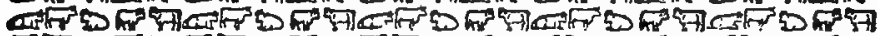
CP

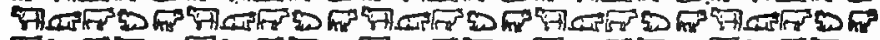

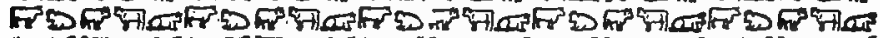

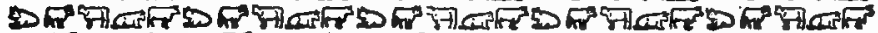

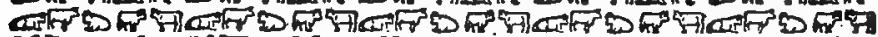

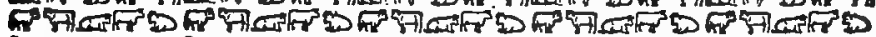

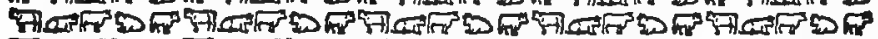
FP है मि DाP

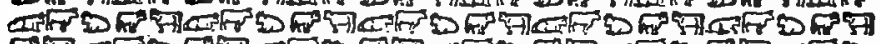

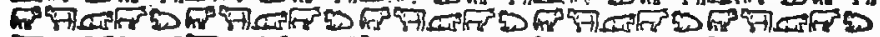

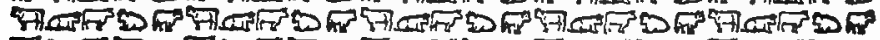
Fr' 2 hi

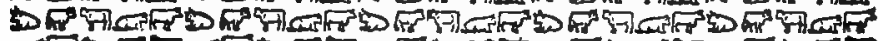

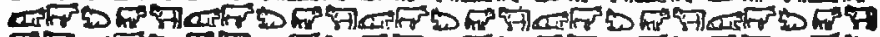

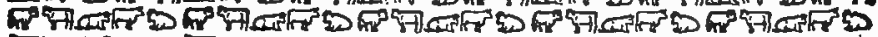

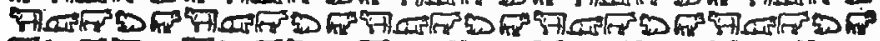

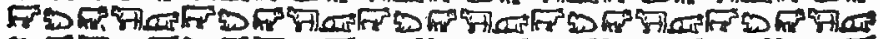

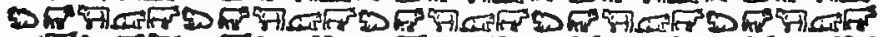

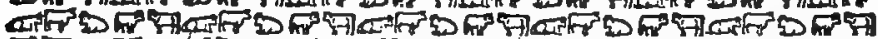

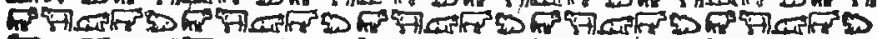

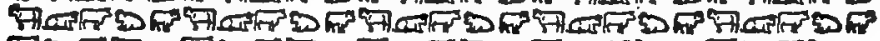

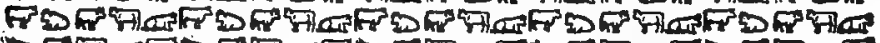

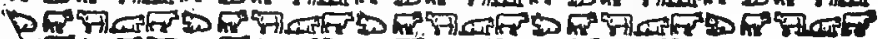

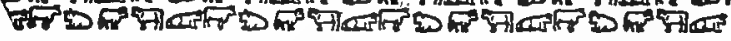

Fig. 231.-(Fraser, Univ. of Illinois Agri. Exp. Sta., Circular 118.) 
profitable herd. Stationery for the purpose of keeping records of cows can be purchased.

Fraser summarizes an investigation of dairy conditions on 317 farms in the following manner: "It is encouraging to know that the labor involved in making the profit of $\$ 5000$ per year in dairying is practically no greater than that expended when $\$ 1500$ is lost, and . . that there is no question as to the possibility of making money by dairy farming." The following table illustrates conditions:

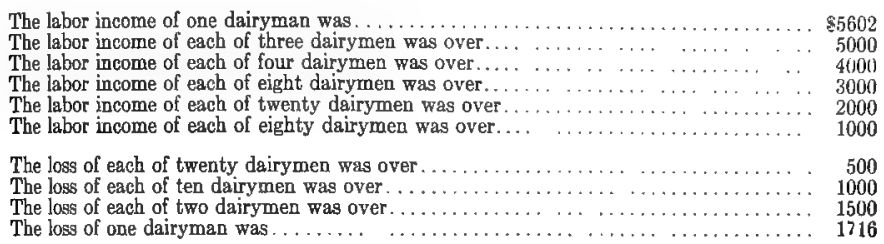

"Any man who speaks lightly of the great difference in the final results of keeping good and poor cows, and raising good and poor crops, shows only his ignorance of the height or depth to which these factors can take a dairyman and his family."

Lane gives an example of a dairyman who profited greatly by introducing the Babcock test. Out of his 64 cows, 21 failed to come up to the standard of 200 pounds of butter per year, and these were disposed of. The second year the dairyman raised his standard to 210 pounds of butter-fat, and disposed of $15 \mathrm{ciws}$ which did not reach this amount. The third year the standard was set at 225 pounds, and 6 cows were sold. The fourth year his mature cows produced 300 pounds of butter.

In another case related by Lane, the average amount of butter produced by the cows was raised from 125 to 151 pounds. After the lapse of eleven years more, the amount of butter was 343 pounds. In dollars and cents this example shows how the sales can proceed from an actual loss to a profit of $\$ 60.28$ per cow.

Co-operation and organization have done much for milk producers in many parts of the country. "Cow-testing associations" were first organized in Denmark in 1892. The first associatıon in this country was organized by Rabild in Fremont, Mich., in 1905. The object of this association was "to promote the dairy interests of its members, and particularly to provide means and methods for testing the milk of the cows of the members periodically." Since that time many similar associations have been established.

The object of cow-testing associations is carried out in the following manner: The cow tester, who is especially trained for this kind of work, gives one day of every month to each member 
of the association. He weighs the food of each cow, weighs and tests the milk, and enters the results in a book specially designed for his purpose. He carries an outfit with him, consisting of a Babcock tester with the necessary glassware and chemicals, sample bottles, a spring balance, a milk sampler, thermometer, and dividers. He also carries a "shot-gun can" which is 8 inches in

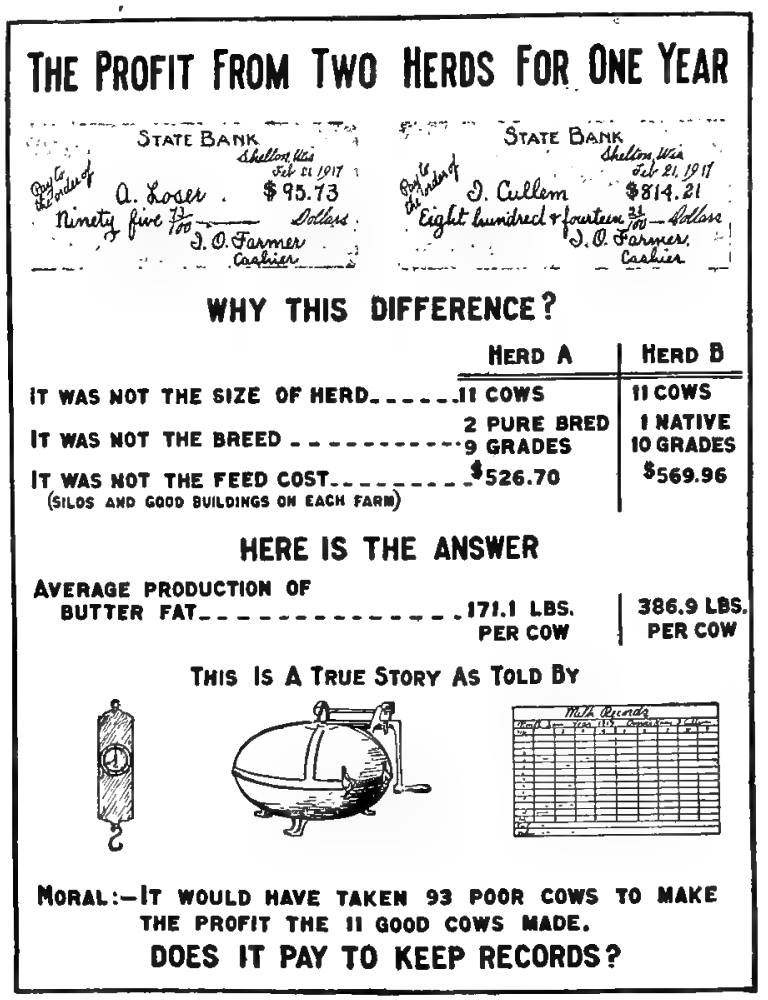

Fig. 232.- - What are your herd profits? The yearly reports of these herds in adjoining counties illustrate how many dairymen are wasting time and money on low producing cows. Why not get rid of your visitors? (Negley and Harris, Circular 67, February, 1917, Extension Service of the College of Agriculture, Univ. of Wisconsin.)

diameter and 20 inches high. The can holds 35 pounds of milk and, since the sides are straight, a correct sample can be obtained with a sampler.

The tester does all his work on the farm, a matter of some importance, inasmuch as it interests the farmer and teaches him many things about his herd and the product, which would otherwise escape his attention. The influence of this work is psycho- 
logic and improvement of the product is the consequence. The tester figures the amount of milk drawn per year, the amount of butter-fat produced and the cost of food consumed by each cow, and the herd owner is thereby placed in possession of the facts which will enable him to weed out unprofitable animals and increase the productivity of his herd.

The expense to members of cow-testing associations is small. The general rule is that each member pays $\$ 1.00$ a year for each cow he owns, and this money constitutes the salary of the tester. In addition, the members pay 25 cents a year dues, which goes toward paying for chemicals, etc. The tester gets his board and lodging free at the place where the tests are made.

The benefits of cow testing are graphically illustrated by Negley and Harris in the chart (Fig. 232).

McDowell has recently gathered some valuable statistics showing the value of cow-testing associations. While the average production of dairy cows in the United States is 160 pounds of butter-fat, the average production of the cows of forty associa'tions was 247 pounds. The income increase resulting from greater butter-fat production is shown by the author in the following table:

RELATION OF BUTTER-FAT PRODUCTION TO INCOME OVER COST OF FEED. AVERAGE RESULTS FROM 5587 YEARLY RECORDS OF FORTY COW-TESTING ASSOCIATIONS

\begin{tabular}{|c|c|c|}
\hline \multicolumn{2}{|c|}{$\begin{array}{l}\text { Average production } \\
\text { of butter-fat. }\end{array}$} & $\begin{array}{l}\text { Average income over } \\
\text { cost of feed. }\end{array}$ \\
\hline 100 poun & per year. & $\ldots \$ \quad 5.00$ \\
\hline & & $\ldots 21.00$ \\
\hline & $" 1 "$ & $\ldots \quad 34.00$ \\
\hline & “" “ & $\ldots \quad 50.00$ \\
\hline 300 & “" $"$ & $\ldots \ldots, 63.00$ \\
\hline & " " & $\ldots \ldots \ldots 74.00$ \\
\hline $400 "$ & $"$ " & ... 87.00 \\
\hline 450 & $" 1$ & $\ldots \ldots \ldots 100.00$ \\
\hline $500 "$ & “" “ & $\ldots \ldots .118 .00$ \\
\hline
\end{tabular}

The same author states that some associations make it possible for their members to own a share in a good bull. If each member instead of purchasing a scrub bull would contribute the price toward the purchase of a pure-bred bull the latter could be purchased for the use of all members of the association, and the offspring would be proportionately valuable. In one association of 17 daughters of selected bulls 16 excelled their dams.

Some of these associations do not limit their activities to cow testing, but place the products on the market more advantageously than a single producer could, and arrange for the disposal of surplus milk for butter making or other purposes. Other associations care for the purchase of fodder, and by co-operation supplies are bought on a large scale so that the outlay is smaller than it would be for individual purchases.

Recently co-operative bull associations have been organized for 
the purpose of improving dairy herds. The first one was started by the Michigan Agricultural College in 1908, and on July 1, 1917 , there were 36 active associations in 17 states, with a membership of 1158 owning 189 pure-bred bulls (Winkjer). A cooperative bull association is formed by a number of producers whose territory is divided into five or more blocks. A high-grade bull is purchased for each block, and after the bulls have served for two years they are moved to the next block to prevent interbreeding. By this scheme the bulls are useful for ten years or more. The quality of the herds is improved, while without a co-operative bull association each farmer has to own a separate bull. While a scrub bull may cost about $\$ 75$, the actual investment in a high-grade bull belonging to an association is one-third to one-quarter this amount. Other advantages of co-operative bull associations are less expense for feed, since several farmers own one pure-bred bull instead of each producer owning one scrub; the chance of raising a herd of one breed; the encouragement of community breeding; and the importance of bringing producers together, a factor of educational value. Furthermore, a producer who has invested in a pure-bred bull may not get appreciable results for three years or more, and may become impatient and sell his bull. Belonging to an association would prevent such a mistake.

Milk producers have been rather slow in recognizing the advantages of co-operation, but many co-operative creameries and cheese factories have demonstrated the expediency of organization. The advantages of united efforts are chiefly: 1 , The reduction of expense in handling the product; 2 , the ready disposal of the product and reduction of waste; 3 , the improvement of the quality of the product economically as well as from a sanitary viewpoint, and 4 , the economic use of by-products, such as whey and skimmed milk.

3. Some by-products on dairy farms have proved of value when properly cared for. The manure can be utilized profitably for fertilizing purposes. Skimmed milk is a useful food in the home. This is not recognized by the public, and consequently the demand for it is small. The dairyman must dispose of his skimmed milk in some other way. It may be used for feeding calves and swine or sold for the manufacture of casein, which is used for a number of purposes (see page 83). Buttermilk from creameries is also used largely for feeding hogs. Both skimmed milk and buttermilk from creameries should be pasteurized before they are utilized for food.

Buttermilk and skimmed milk can be used for the manufacture of casein, which has been previously shown to have a ready 
market. In large creameries where 10,000 or more pounds of buttermilk are available the production of a pound of casein costs 3 cents or less, and the yield from 100 pounds of undiluted buttermilk is 2.8 to 3.1 pounds (Dahlberg). The casein is usually precipitated by heating the buttermilk to $130^{\circ} \mathrm{F}$. or by adding 1 pint of sulphuric acid, diluted with 1 gallon of water, to each 1000 pounds of skimmed milk. The whey is drawn off from the bottom of the vat and the casein gathered on a cloth-lined drain rack. The casein is washed at least twice with water, pressed, ground, and spread on trays. These are introduced into a tunnel and exposed to hot air of a temperature of $130^{\circ} \mathrm{F}$. for seven hours. Details of the process and description of the apparatus necessary can be found in Bulletin 661 of the U. S. Department of Agriculture, published April 9, 1918.

4. The present system of milk distribution involves considerable waste of energy, labor, and capital. Williams made a careful and interesting study of the methods of milk distribution in Rochester, N. Y. In one section of Rochester 57 distributors supplied 363 homes. The milk wagon had to cover 30 miles, while, if one distributor had delivered the milk, but $1_{1}^{\frac{7}{1}}$ mile would have been covered. In another section 353 homes were supplied by 61 dealers, traveling 36 miles, while one distributor traveling 3 miles could have accomplished the same results.

Williams found that the $\mathbf{1 7 0}$ small milk dealers used 295 horses and 255 wagons for milk delivery. These horses and wagons represent a value of $\$ 82,400$. The author estimates that one firm with 40 horses, 16 trucks, and 2 motor trucks, costing $\$ 29,000$, could have done the same work. An experiment in milk distribution was made to demonstrate the enormous saving possible. One driver and two assistants with a horse truck carrying 1000 quarts of milk distributed 400 to 500 quarts per hour, while actually the average milk dealer delivered but 175 quarts daily.

The work is summarized by the author in a table giving the figures under the present system and those under a model system. His charts and figures are so instructive that they are worthy of reproduction here (see Figs. 233, 234).

Perhaps it is not unreasonable to state that with proper economy the cost of producing and handling milk can be reduced enough to offset the increased cost of sanitary milk. The producer can save by business-like management of the dairy and the herd. The production of the herd can be increased materially with small additional expense. By economy in construction of buildings the investment need not be excessive and by-products can be profitably utilized. The producer can learn by attending 
milk and cream contests where he can see what his neighbor is doing. Furthermore, he can learn about methods of production by attending instructive and educational meetings held in connection with dairy exhibits.

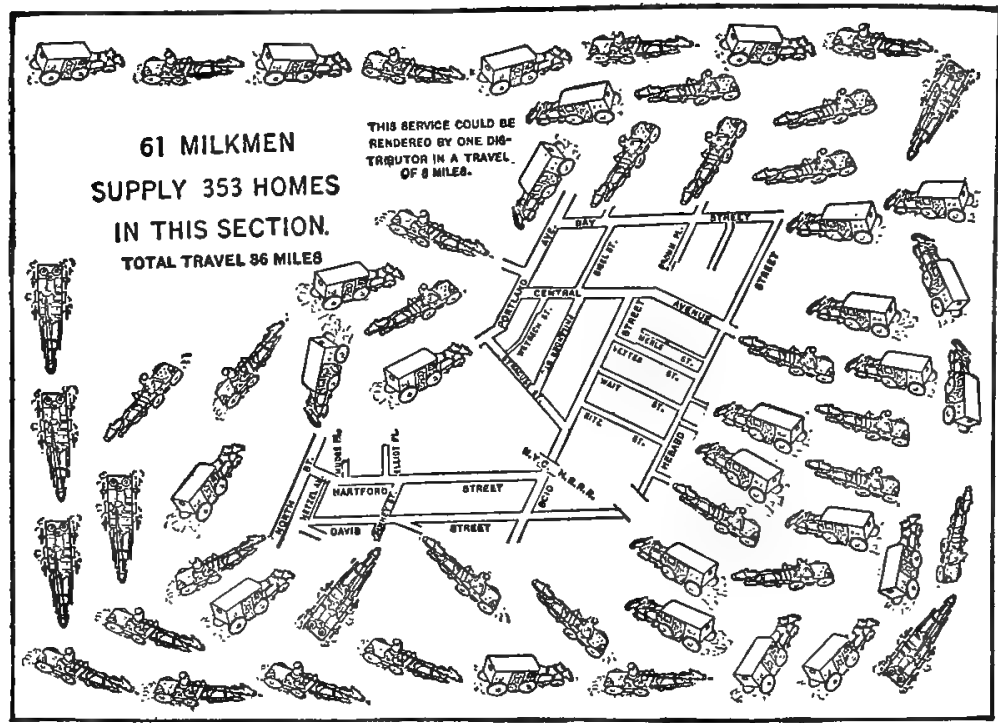

Fig. 233.-Wasted effort in distributing milk in a populous city district. (Williams, The World's Work, February, 1913.)

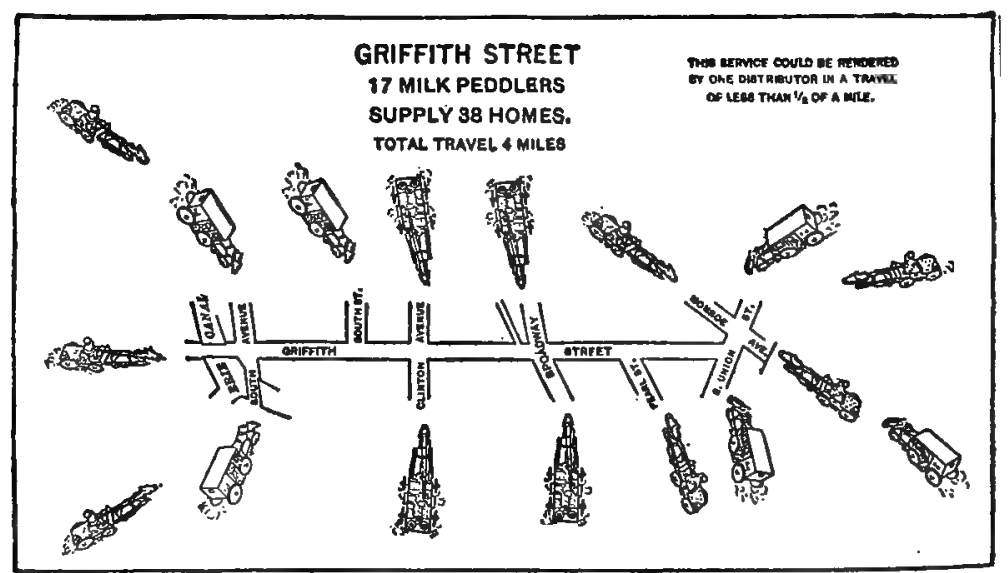

Fig. 234.-An economic waste in the distribution of milk in Rochester, N. Y. (Williams, The World's Work, February, 1913.) 


\section{The Cost of Distributing Milk in Rochester}

Under the Present System

356 men and in many cases their families.

380 horses.

305 wagons.

2509 miles of travel.

$\$ 76,600$ invested in milk room equipment.

$\$ 108,000$ invested in horses and wagons.

$\$ 2000$ present daily cost of distribution.

$\$ 720,000$ yearly cost of distribution.

\section{Under a Model System}

90 men.

80 horses.

25 horse-drawn trucks.

300 miles of travel.

$\$ 40,000$ equipment for one sanitary plant.

$\$ 30,750$ equipment of horses and trucks.

$\$ 600$ estimated daily cost of distribution.

$\$ 220,000$ estimated yearly cost of distribution.

The middleman can save by organizing means of distribution on a sound economic basis, and the consuming public can help by caring for the milk at home, by promptly returning milk bottles in good condition, and by learning to appreciate the true food value of milk, skimmed milk, buttermilk, and other milk products.

\section{BIBLIOGRAPHY}

Alvord: United States Dept. of Agri., Farmer's Bull. 55, 1904. Dahlberg: United States Dept. of Agri., Bull. 661, April, 1918.

Fraser: Univ. of Illinois Agri. Exper. Sta., Circular 118, April, 1908.

Harding and Brew: New York Agri. Exper. Sta., Bull. 363, April, 1913.

Hopper: Univ. of Illinois Agri. Exper. Sta., Circular 76, May, 1904.

Jordan, James O.: Amer. Jour. of Pub. Hygiene, 1907, vol. 17, p. 1.

Kelly: United States Dept. of Agri., B. A. I., Circular 205, October, 1912.

Lane: The Business of Dairying, New York, Orange Judd Co., 1914.

Larson: Milk Production Cost Accounts, New York, Columbia University Press, 1916.

Marshall: Mich. State Agri. Coll. Exper. Sta., Bull. 228, June, 1905.

McDowell: Separate from the Yearbook of the Dept. of Agri., 1917, No. 743.

Mortensen: Iowa State Coll. of Agri. and Mechanical Arts, Bull. 121, February, 1911.

Negley and Harris: Circular 67, February, 1917. Extension Service of the Coll. of Agri., the University of Wisconsin, the Wisconsin Dairymen's Association, and United States Dept. of Agri. Co-operators.

Rabild: United States Dept. of Agri., B. A. I., Circular 179, October, 1911.

Thompson: United States Dept. of Agri., B. A. I., Circular 188, 1910.

Williams: Proceedings of the Sixth Annual Conference of the Amer. Assoc. of Med. Milk Commissions, 1912, p. 94. The World's Work, February, 1913, p. 443.

Winkjer: United States Dept. of Agri., Farmer's Bulletin 993, July, 1918. 


\title{
MILK IN ITS RELATION TO INFANT FEEDING
}

\author{
Isaac A. Abt, M. D., and A. Levinson, M. D., Chicago
}

Introduction.--Although milk has been universally recognized as the food for infants since the beginning of the human race, a knowledge of the scientific relation of milk to infant feeding is of comparatively recent origin. Not only did the ancients know little about the composition of milk, but until recently even modern chemists have had only a meager knowledge of the chemistry of milk, either human or bovine. Though there is still much to be learned, great progress is being made in the study of milk as it affects infant feeding through the valuable researches of biochemists and bacteriologists and through the tireless efforts of pediatricians all over the world.

Milk is the food of most animal species, nature having provided each mother with milk for her infant. Particularly did nature intend that the human infant should be supplied with human milk-the milk of its mother. Yet it frequently happens that the infant is deprived of mother's milk either entirely or in great measure. It then becomes necessary to have recourse to the milk of other animals. Thus it is that infants have been fed on the milk of cows, sheep, goats, asses, camels, etc. The milk most commonly employed, however, as a substitute for mother's milk is the milk of the cow.

Mother's Milk and Cow's Milk.-A Study of Their Comparative Values.-Human and cow's milk differ materially both quantitatively and qualitatively. The quantitative differences are illustrated in the following table:

\begin{tabular}{|c|c|c|}
\hline 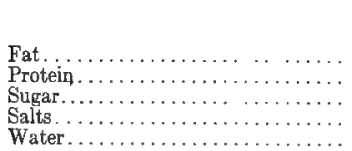 & $\begin{array}{c}\text { Mother's milk, } \\
\text { per cent. } \\
4.0 \\
1.5 \\
7.0 \\
0.2 \\
87.30\end{array}$ & $\begin{array}{c}\text { Cow's milk, } \\
\text { per cent. } \\
3.5 \\
4.5 \\
4.5 \\
0.5 \\
87.25\end{array}$ \\
\hline
\end{tabular}

Qualitatively the two kinds of milk differ in the character of their salt and protein content. The salts of mother's milk consist principally of alkaline bases, while those of cow's milk are chiefly of the alkaline earths, such as caloium and magnesium. The protein of mother's milk contains a larger quantity of lactalbumin and a smaller amount of casein than does that of cow's milk. Many make the greater predominance of casein in cow's milk responsible for the large, heavy curds given off by cow's milk when it is acted on by the rennin of the stomach. It is 
very likely, however, that the difference in the size of the curds given by the two types of milk is due to the difference in the quality and quantity of their salts and probably also the difference in their reaction, cow's milk being slightly more acid than human milk.

In still other ways do human and cow's milk show marked differences. Human milk contains a diastatic ferment which has the power of splitting starch into maltose and dextrose, and a fat-splitting ferment, lipase, which is more active than in cow's milk. Human milk also has more antibodies than cow's milka factor thought to be responsible for the immunity of breast-fed children to many infectious diseases during their nursing period.

Whatever the differences between human and cow's milk, one fact is indisputable, and that is that human milk is far better for the human infant than cow's milk. It therefore behooves every mother to nurse her child unless special conditions make it impossible or inadvisable to do so. Artificial feeding has to be resorted to when the mother is suffering from an exhaustive disease, such as advanced tuberculosis, carcinoma, or chronic nephritis, with a constant loss of protein in the urine, the strain of another pregnancy, or the drying up of the breast milk. In cases of this kind the child must be fed on cow's milk. The vital question then arises as to the best modification of cow's milk that will make it approach as nearly as possible the composition of mother's milk.

Milk Modification.-There have been many ways suggested for modifying cow's milk so that it approximates mother's milk. The plan most commonly employed for many years has been the dilution of cow's milk and the addition of sugar and cream to the mixture. In the main, two methods have been followed in the modification of milk. One is based on the percentage principle and the other on the principle of the caloric value of the two kinds of milk.

The modification of cow's milk on a strict percentage basis has been standardized by the late Dr. Rotch, of Boston, who elaborated the methods of Biedert and Meigs. The principle of the percentage system is to modify cow's milk in such a way as to make the protein, fat, and sugar equal the amount present in human milk. To accomplish this it is first of all necessary to dilute the milk so that the protein content is not more than 1.5 to 2 per cent. Enough fat in the form of cream is added to make up for the amount of fat lost through dilution. Enough sugar is then added to the mixture to bring the sugar content to $6 \frac{1}{2}$ or 7 per cent. of the total, the exact percentage depending upon the needs of the infant. An illustration will make this clearer: 
If, for instance, one wishes to feed an infant 20 ounces of milk that contains 1.5 per cent. of fat, 5 of sugar, and 0.75 per cent. protein, he will have to prescribe a milk dilution somewhat on the following order: Cream 2 ounces, milk 2 ounces, water 15 ounces, and sugar $\frac{4}{5}$ ounce.

If one wishes to make up a mixture of 20 ounces that contains 3 per cent. of fat, 5 per cent. of sugar, and 1 per cent. of protein, he should prescribe a milk dilution composed of the following: Cream 4 ounces, milk $1 \frac{1}{2}$ ounces, water $13 \frac{1}{2}$ ounces, and sugar $\frac{4}{5}$ ounce. This is on the basis of 4 per cent. of fat in milk and 12 per cent. of fat in cream. In all of the older formulas lime-water was added to the milk mixture to reduce the acidity of the cow's milk, but at present lime-water is not used very extensively. To make the dilution more simple some authors advise the use of top-milk in the place of cream.

The second system of infant feeding - the caloric-is based on metabolic experiments done on children by Heubner and Rubner. Rubner found that an infant under six months of age needed 100 calories per kilogram of weight, or 40 to 50 calories per pound of weight. Knowing the caloric value of milk, Heubner suggested three mixtures, one consisting of one-third milk and 8 per cent. of lactose, the second of half milk and 10 per cent. of lactose, and the third of two-thirds milk and 12 per cent. of lactose.

Although both the percentage and caloric systems of milk modification are extensively followed, they are not entirely satisfactory. The percentage method of milk modification is valuable in that it aims at an accurate adjustment between cow's milk and human milk. However, even after the most careful adjustment, cow's milk is found to differ materially from human milk in the quality of its protein, its salt, and its other constituents. The objection most commonly raised to the caloric formula of Heubner is that the solutions he advises call for too high a percentage of sugar, which has a tendency to disturb the digestive balance in delicate infants.

The question as to the kind of sugar best adapted for use in artificial feeding is one that has been answered differently by different authorities. There are some that favor the use of lactose, others that advocate the use of a sugar which combines dextrin and malt, and still others that prefer ordinary cane-sugar. Most normal children do well on any kind of sugar, but experience with a large number of feeding cases has shown that dextrimaltose is more applicable to feeding than either cane-sugar or lactose. Both cane-sugar and lactose are generally too laxative in their effects. Lactose has the added disadvantage of being hard to sterilize. It might be of interest in this connection to note what 
Prof. Mathews has to say in favor of the use of lactose in infant feeding. The following paragraph is taken from Prof. Mathews text-book on physiologic chemistry:

"The greater proportion of lactose in human milk may be correlated with the very much greater brain development of human beings. There is a very rapid myelinization of the fibers of the brain occurring shortly after birth in the first six weeks of life. In myelin there is a large amount of galactolipins of the nature of phrenosin or cerebrosids of various kinds. Galactose is one of the constituents of this material. It may be that the larger amount of lactose in human milk is to supply this need. No other place of formation of galactose in the body is known than the mammary glands, and these are, of course, very rudimentary in the infant. The replacement of lactose by cane-sugar in milk or in milk substitutes would seem open to serious criticism on this account."

The diluent for milk may consist of boiled water or the various gruels. Gruel as a diluen $t$ for milk was innovated by the French. A. Jacobi in this country advocated the use of barley gruel in cases of diarrhea and oatmeal gruel in cases of constipation. In a study made of oatmeal gruel in infant feeding Levinson corroborates the findings of Jacobi regarding the efficacy of oatmeal gruel in relieving constipation. He also recommends its use in infant feeding because of its caloric value and its high iron content. Rice-water is frequently used by mothers in cases of diarrhea. The different gruels, although they may often be indicated, are not indispensable, and plain boiled water may be used in their stead as a diluent for milk.

The question of raw or boiled milk is one that has not yet been settled. Pasteurized milk was for years considered the ideal food for infants. Now, however, boiled milk is held to be not only as good as pasteurized milk, but even better. Only very small curds are formed in the stomach after the intake of boiled milk, and hardly any curds are found in the stool after its ingestion. Boiling of milk has another advantage - it destroys the bacteria that may contaminate the milk. As for the objection so frequently raised against the use of boiled milk, that it gives rise to scurvy, the early use of fruit juices acts as a very efficient preventive. The only state in which raw milk should be given to an infant is when the milk is certified., $i . e$., when it bears a seal showing that it has been prepared under extraordinary aseptic conditions under the supervision of medical men. However, even with such precautions one often runs a greater risk than in using boiled milk.

Whatever the state of the milk given to the infant, it should 
be produced under the best conditions possible. Utmost cleanliness in every particular cannot be emphasized too strongly. The cows should be kept clean and well fed; the milk receptacles should be chemically clean and bacteriologically sterile, and the milk should not be allowed to stand too long before it is delivered to the consumer. It is best to give a baby milk which is a mixture of several breeds of cows, as it has been found that different breeds produce milk of a different composition. Holstein cows, for instance, produce milk that has a smaller percentage of fat than that given off by Jersey or Guernsey cows.

It is absolutely necessary that the cows from which milk for baby' is taken be free from tuberculosis. The routine tuberculin. tests made on cows in this country and abroad have done a great deal to diminish intestinal tuberculosis in infancy, although one of the greatest factors in the decrease of intestinal tuberculosis in infants has been the use of boiled milk in infant feeding.

There are various rules for the quantity of milk to be given the child, both the quantity to be given at each feeding and the entire amount to be given in twenty-four hours. The rule of giving a child at one feeding 2 ounces more than his age in months is a good and simple one. For instance, a child two months of age should receive 4 ounces of the proper mixture at each feeding; a child of five months, 7 ounces; a child of six months, 8 ounces; 8 ounces of a milk mixture at one feeding should be the maximum. If more calories are needed the child should receive additional carbohydrate or other forms of food to make up the necessary caloric requirement. Budin's rule of giving milk to the amount of one-tenth of the body weight works out quite well. According to Budin an infant that weighs 10 pounds should receive the equivalent of 1 pound a day, or 1 pint of milk, properly diluted in twenty-four hours. Interpreted a little differently, an infant may receive daily $1 \frac{1}{4}$ to $1 \frac{1}{2}$ ounces of milk for every pound of body weight. This rule of giving $1 \frac{1}{2}$ ounces of milk per pound of weight has also been found to be of great assistance.

The length of time that a baby should be at the breast is a matter that calls for consideration. Some babies nurse for a few minutes, fall asleep, and then nurse again in half an hour or so. Other babies nurse for thirty to forty minutes at a time and then vomit. Of course, neither of the two extremes should be permitted. Fifteen to twenty minutes at the breast should suffice to supply the baby with the amount of nourishment it requires.

The intervals elapsing between feedings form an important factor in the feeding of an infant. Many mothers are inclined to nurse their babies entirely too often. Experience has shown that an interval of three to four hours between feedings is much 
better for the infant than a shorter interval, thus making from five to seven feedings in twenty-four hours. Under no circumstances should a normal baby receive more than seven feedings in a day. The work done by Carlson, Ginsburg, and Taylor on hunger contractions of the infant's stomach brings out some interesting facts in connection with the frequency of nursing intervals in infancy. Taylor found that in full-term infants under two weeks of age the hunger contractions come on an average of two hours and fifteen minutes after feeding, with a minimum of two hours and a maximum of four hours. In infants of two weeks to four months of age three hours and forty minutes is the average, with a minimum of three hours and twelve minutes and a maximum of four hours and thirty-five minutes. An interpretation of these figures would lead one to the conclusion that children under two weeks of age should be fed every two and a half to three hours, and children over two weeks, every four hours.

Premature infants form an exception to the rule of three- or four-hour feeding intervals. Premature infants need more calories per kilo of their body weight than do full-term infants. In addition to their relatively high caloric requirement the premature infants are usually unable to take as large quantities of milk at one feeding as full-term babies. It is therefore wise in the case of prematures to do away with the four- or even the three-hour feeding regulation and feed the infant at more frequent intervals and in smaller quantities. When the premature infant is too weak to nurse from the breast, as frequently happens, the milk should be pumped up and fed to the child by spoon or by Breck's feeder. Important as breast milk is for the normal infant, it is doubly so in the case of the premature.

An example will help to illustrate how the various rules formulated for infant feeding may be utilized. If, for instance, one wishes to feed artificially a normal child of two months whose weight is 9 pounds, the following should be the procedure:

According to the rule of giving a child 2 ounces more of the mixture than its age in months, a child of two months should receive 4 ounces per feeding. Six feedings of 4 ounces each gives us a total of 24 ounces for twenty-four hours. Applying the rule of giving $1 \frac{1}{2}$ ounces of milk per pound of body weight, a child weighing 9 pounds should receive $13 \frac{1}{2}$ ounces of milk for twentyfour hours. This will make 13 ounces of the milk and $10 \frac{1}{2}$ ounces water. As each ounce of milk has a food value of 21 calories, an infant receiving $13 \frac{1}{2}$ ounces of milk will receive 284 calories per day. However, since each pound of body weight requires 45 calories, an infant weighing 9 pounds will need 405 calories. To make up the deficiency of 121 calories the baby should receive in 
addition to the milk and diluent an ounce of dextrimaltose, which has a caloric value of 120 calories.

After the child has reached the age of five or six months one feeding of breast or artificial milk should be replaced by a cereal. Any cereal will answer the purpose, but it is possibly best to start out with farina or cream of wheat. As the child grows older it may gradually receive more substantial forms of food to replace most of the milk feedings. Thus, a child of seven months should receive one cereal, one vegetable broth, and three nursings if it is breast fed, and one cereal, one vegetable broth, and three bottles, each containing 6 or 7 ounces of milk, if it is artificially fed. It has been the custom of many pediatricians to keep a child on diluted milk until it reaches the age of a year. We have found repeatedly, however, that a child of eight months can take whole milk very well.

A breast-fed baby should be weaned from the breast at ten or eleven months of age. A child that is nursed too long becomes pale and anemic looking because of the lack of iron in mother's milk. Prolonged nursing has also been made responsible for rickets.

It is advisable to give all infants two or three months of age or over some fruit juice in addition to the milk they are getting. This is especially important when babies are fed on boiled milk to counteract the possible development of scurvy. Orange juice is most valuable for this purpose, as it is the best antiscorbutic we have. It should, however, be given at least half an hour before or after feeding to prevent the curdling of the milk in the infant's stomach. When no orange juice is obtainable, prune juice or carrot juice may be given instead. These juices also possess antiscorbutic properties, although not in so marked a degree as the orange juice. Potato water (water in which potatoes have been boiled) has also been found useful as an antiscorbutic.

\section{Alimentary Disturbances}

The gastro-intestinal disturbances of infancy have engaged the attention of pediatrists for a great many years. What is the cause of these disturbances, and what is the process that takes place in the diarrheas accompanying them are questions that pediatricians have sought to answer. Many theories have been offered in explanation. The earlier pediatricians considered the various gastro-intestinal disturbances of infancy as pathologic entities, but postmortem examinations performed on infants that died of diarrhea proved this impression to be an erroneous one. There were some that attributed the alimentary disturbances of childhood to bacterial infections and who classified the diarrheas produced according to the organisms causing them. This theory, 
however, did not prove fruitful either, for investigation of most cases of gastro-intestinal disturbance has not shown the presence of any distinct bacteria in the gastro-intestinal tract. Still another opinion was advanced that the diarrheas of infancy were neither bacteriologic nor pathologic entities, but metabolic processes. Pediatric literature for many years has been made the battlefield for controversies regarding the nature of the metabolic process and the character of the food element responsible for the alimentary disturbance. At oae time the protein in the milk was thought to be the predisposing factor, but Czerny and Keller found that animals fed on protein alone showed no intestinal derangement. They therefore suggested fat as the disturbing element. Shortly after Finkelstein and Meyer found that children fed on the coagulum of mother's milk which had been added to the whey of cow's milk showed intestinal disturbances, whereas children fed on the opposite combination, the coagulum of cow's milk mixed with the whey of mother's milk, showed no intestinal disturbances. From this experiment Finkelstein and Meyer arrived at the conclusion that it was the whey in cow's milk that was responsible for the rise of the alimentary disturbance. As for the nature of the metabolic process involved in severe nutritional disturbances, the explanation of Czerny, that it is an acidosis, is the one most generally accepted at present. The entire question is still far from settled, but as we must have some basis on which to work we shall adopt the classification of Finkelstein, which is the one in most general use, for the study of alimentary disturbances:

I. Nutritional disturbances due to quantity of food:

A. Overfeeding.

B. Underfeeding.

II. Nutritional disturbances due to quality of food or intolerance of food:

A. Light form:

1. Disturbances of weight balance or failure to gain.

2. Dyspepsia.

B. Graver forms:

1. Intoxication.

2. Decomposition.

III. Nutritional disturbances due to-

A. Primary intolerance followed by infection.

B. Heat.

C. Infectious diarrhea.

D. Congenital defects.

We shall discuss these points separately in the order of their presentation. 
Overfeeding.-That overfeeding is responsible for many of the nutritional ills of childhood there exists no shadow of a doubt. A great many infants are overfed either through getting too much food at one feeding or through receiving food at too frequent intervals. This may be equally true of both the baby that is breast fed and the one that is artificially fed, although it occurs more frequently in the case of breast-fed babies. It is not always easy to gauge the exact amount of milk received at a breast feeding. A much greater evil, however, lies in the tendency of many mothers to allow their babies to nurse at their breasts continuously. When overfeeding is stretched over a long period of time vomiting sets in, and if the condition continues the child soon becomes unable to retain even the amount of food required for its age and weight. Later on a diarrhea may set in and persist for a considerable length of time.

The treatment of overfeeding is essentially one of prophylaxis. Mothers should be taught to nurse their babies at regular intervals. When vomiting and diarrhea do occur, rest of the stomach should be enforced by withholding food from the child for a period of from twelve to twenty-four hours, depending upon the severity of the case. If vomiting still persists, lavage and small doses of sodium bicarbonate are recommended.

Underfeeding.- This condition may be present in breast-fed as well as in artificially fed children, although it presents itself more often in the artificially fed, being due in most cases to the prolonged use of a greatly diluted milk. The most frequent symptoms of underfeeding are loss in weight, irritability, and vomiting. The weight curve goes down instead of going up; the muscles become flabby, the skin loses its elasticity, and the abdomen sinks in. The child acts restless and cries most of the time. Many children also vomit. The condition is frequently accompanied either by constipation or diarrhea.

The treatment of underfeeding, like that of overfeeding, is essentially one of prophylaxis. It consists primarily in giving the child food sufficient in quantity and in caloric value. The determination of underfeeding in breast-fed babies is most easily and most efficiently effected by weighing the child a number of times before and after nursing to see how much or how little the baby receives at one feeding. Chemical examination of mother's milk is worth very little. If the child gets a sufficient amount of breast milk it is safe to assume that the milk is of good quality. If it is found that the child does not get enough nourishment from the mother, a supplemental feeding should be instituted. The child should be put to the breast for ten to fifteen minutes, and 
immediately afterward should be given a mixture of cow's milk to make up the required amount of feeding.

If underfeeding occurs in the case of an artificially fed child both the quantity and the quality of the milk the child has been getting should be scrutinized and means taken to improve both. Increases in the amount of the food should be made very gradually, however. When a child has reached the stage where it shows marked effects of underfeeding it is best to procure some breast milk for it. If that is not possible, the child should be started on small doses of cow's milk given at short intervals, the quantity to be increased by degrees until the child is able to take the amount required for its age and weight.

Disturbance of Balance.-The second group of alimentary disturbances has to do with qualitative errors in the food given, one or more of the food elements being at fault.

The disturbance in weight balance constitutes the lightest form of qualitative alimentary disturbance. It manifests itself principally in a stationary weight curve, or in a fluctuation of the weight curve in contrast to the continuously ascending weight curve of the normal infant. If the weight curve continues to be stationary for any length of time the child becomes restless and less resistant to infection than a healthy infant. The stool may be normal or it may be lighter and drier than usual. Occasionally also the stool may present the type known as fat-soap stool, socalled because it contains more earth-alkali soaps and less free fatty acids.

Disturbances in weight balance may be due either to an excess of fat or to an insufficiency or even a complete lack of carbohydrates in the food. The element of food directly responsible for this nutritional disturbance both Czerny and Finkelstein believe to be the fat. The trouble lies in the superabundance of fat and the deficiency of carbohydrates. The treatment consists in the reduction of the amount of milk and in the addition of carbohydrates to the food. The latter may be given in the form of dextrimaltose, flour, or malt soup. The additions should be made very gradually, however, to avoid upsetting the child's digestive power, thereby producing a severe alimentary disturbance.

Dyspepsia is a more advanced form of alimentary derangement than disturbance of balance. It is characterized by loss of appetite, distention of the abdomen, vomiting, and numerous stools. The stools of a child suffering from dyspepsia are usually of thin consistency, mucous in content, and greenish in color. The weight curve varies in different cases; it may go down, it may remain normal, or it may even go up for a few days, only to 
fall suddenly. As a rule there is no or very slight elevation in temperature.

Dyspepsia may set in after a disturbance in the weight balance or it may occur in the case of a child previously healthy. The food element primarily responsible for this form of alimentary disturbance is apparently the carbohydrate, fat playing a secondary rôle.

The treatment varies with the manifestations the child presents. If the dyspepsia is acute, the infant should be deprived of food for from six to twelve hours and given only water or weak tea and saccharin. After that it is best to put the infant on breast milk if possible. If no breast milk is available the artificial feeding should be resumed gradually. It should be less in amount and strength than that usually required for the age of the infant, and both the fat and the whey in the milk should be reduced for several days. If the vomiting persists, buttermilk or albumen milk should be given, and if it is very severe, lavage should be done. The question of catharsis in dyspepsia has been a widely discussed subject for a long time. Many pediatricians practice catharsis in all cases of dyspepsia; others claim that catharsis by calomel is contraindicated and catharsis by castor oil unnecessary. We have found that in most cases of dyspepsia no catharsis is required.

Intoxication.-A state of intoxication may follow a severe dyspepsia or it may come on during the stage of decomposition. A baby that gives a history of vomiting with several watery, green stools a day may get into. a toxic state and present symptoms of drowsiness and coma. In such a state the temperature is high and the respiration is labored, like that of an animal intoxicated with a large amount of acids. The stools continue to be numerous and watery. The urine shows abnormalities, usually being highly concentrated and exhibiting the presence of sugar, and often also of albumin and acetone. The blood shows a leukocytosis. If the child does not improve, or if it does not recover from its toxic state, death usually follows in a few days or even in a few hours.

Some pediatrists, notably Czerny, consider this condition an acidosis. They base their claim on the character of the respiration-its similarity to the labored breathing of a rabbit made toxic with acids. Finkelstein and Meyer, however, explain the condition as an intolerance to carbohydrates and salts.

The treatment consists in the detoxication of the infant. Starvation for from several to twenty-four hours is necessary to give the gastro-intestinal tract a complete rest. All food should be withheld from the patient and he should be put on a mixture 
of water and saccharin. After the starvation period is over feeding may again be resumed, but very gradually. The best food to begin with is breast milk in small quantities, given at short intervals, say 1 ounce every two hours. If the child vomits the breast milk, it should be given in diluted form. If no breast milk is available, "Eiweiss" milk of Finkelstein should be given. Eiweiss milk is prepared in the following manner:

To a quart of whole milk heated to $98^{\circ}$ or $100^{\circ} \mathrm{F}$. 2 level tablespoonfuls of chymogen (pepsin) powder is added. This is brought to a temperature of $107^{\circ} \mathrm{F}$, at which it is kept for fifteen to twenty minutes until the milk has all been coagulated. The mixture is then put into a muslin bag which is suspended from a hook to drain off the fluid portion of the milk. The curd remaining is rubbed through a copper hair strainer three times or it is churned through a meat-grinder three times. To this is added a pint of buttermilk and enough flour to make up the required percentage of carbohydrates. The entire mixture is then boiled for ten minutes, being rubbed constantly, but not stirred.

Some, carbohydrate should be given with the albumen milk from the beginning to supply the necessary carbohydrate requirement. As a rule, a 2 per cent. flour ball is a good proportion with which to start. After the state of intoxication is over the amount of carbohydrate should be gradually increased. After the diarrhea has been checked and the stool becomes clay colored the albumen milk should be discontinued and the patient put on a plain milk formula.

Decomposition, which the older physicians termed "marasmus" or "atrophy," constitutes a condition of emaciation in which all the body functions of the child are below par. Decomposition, which is rarely primary, usually comes on as the result of repeated dyspepsia that wastes the body of the infant.

Decomposition presents a picture that is unmistakable-an emaciated condition of the body, a flabbiness of the skin, which looks ashen gray in color, and a subnormal temperature. The child in a state of decomposition is restless and refuses to take food. The character of the stool is not uniform, generally being hard. Often, however, there is an interchanging diarrhea with the constipation. The fat in the stool is often greatly increased, a condition known as "fat diarrhea." A differential diagnosis must always be made between chronic wasting due to other constitutional conditions and that due to alimentary decomposition.

The treatment of decomposition consists in increasing the child's tolerance for food. No child with decomposition should be starved for any considerable length of time. If it has been artificially fed it should be put on breast milk given in small doses 
at short intervals. If breast milk is not obtainable, the child should be put on a milk poor in fat, skimmed milk being the best substitute. As the child's tolerance for food is increased it should be given diluted milk in the proper proportions.

Infectious Diarrhea.-A certain number of diarrheas are due to direct bacterial infections, such as the Bacillus dysenteriæ or similar bacteria. The onset in cases of infectious diarrhea is usually sudden, high temperature, vomiting, and loose stools accompanying the condition. The stools usually show the presence of mucus and blood. The diagnosis of infectious diarrhea can generally be established through direct bacteriologic examination of the stool and by cultures.

The most effective way to treat infectious diarrhea is to starve the patient for a while, and then put it on a food antagonistic to the bacteria. If, for instance, the offending organism has been the Bacillus dysenteriæ, cereal should be given and also Eiweiss. The administration of Bacillus bulgaricus has often been found of value in combating diarrhea due to Bacillus dysenteriæ.

\section{Milk in Its Relation to Infant Welfare}

When we compare infant mortality of today with that of several years ago we find a marked reduction in the mortality rate of every country. The marked saving in human life is attributable to many factors, chief among them being our constantly increasing knowledge of milk in general and of its relation to infant welfare in particular.

An examination of the infant death-rate in various countries shows the following figures:

Between 1884 and 1893 the death-rate per 100 infants under one year of age in the various countries of Europe was as follows:

\begin{tabular}{|c|c|c|c|}
\hline & Per cent. & & Per cent. \\
\hline Norway..... & 9.5 & France... & 16.7 \\
\hline Ireland . . . . . . . & 9.6 & 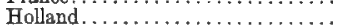 & 17.5 \\
\hline Scotland....... & 12.2 & 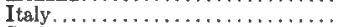 & 19.0 \\
\hline Denmark . . . . . . . . . . . . . . & 13.4 & 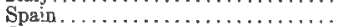 & 19.2 \\
\hline England $\ldots \ldots \ldots \ldots \ldots$ & 14.6 & Germany.$\ldots \ldots \ldots \ldots \ldots \ldots$ & 22.0 \\
\hline 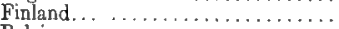 & 14.9 & Austria...... & 24.9 \\
\hline Belgium . . . . . . . . . . . . . . & 16.3 & Russia. . $\ldots \ldots \ldots \ldots \ldots \ldots \ldots$ & 26.8 \\
\hline 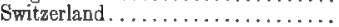 & 16.4 & & \\
\hline
\end{tabular}

When we compare these figures of 1884 with the infant mortality rate of the years 1900 to 1914 we find the following figures per 100 infants under one year of age:

\begin{tabular}{|c|c|c|c|}
\hline & Per cent. & & Per cent. \\
\hline . & 7.0 & Italy..... & 14.7 \\
\hline , Wales and Scotland..... & 10.9 & Germany. & 17.0 \\
\hline 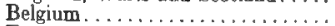 & 14.1 & Austria. & 19.7 \\
\hline France........... & 11.0 & Russ.a..... & 24.6 \\
\hline
\end{tabular}


What are the reasons for the lowered infant mortality in some countries compared to that of others, and what steps should be taken to reduce infant mortality to a minimum? A survey of the various statistics brings out some of the most important forces operating in both the cause and prevention of infant mortality.

1. Climate.-There is no doubt that the climatic conditions of various countries affect in a great degree the mortality rate of the infant population. The very low infant mortality of New Zealand may, we believe, be attributed primarily to its excellent climate and only secondarily to its efficient system of infant welfare.

2. Nationality.-It has been found that nationality plays a rôle in infant mortality. In the report of the Health Department of the city of New York a statistical survey is given of the mortality of the children of different races under five years of age. The report shows that the lowest rate occurs among children of Russian, Austro-Hungarian, and Swedish parents. On the other hand, a high mortality prevails among the children of English, German, Irish, and Italian parents. The highest death-rates from congenital diseases are found among American, Irish, and German infants. The rate for respiratory diseases among Italian children is double and triple that of the children of all other nationalities. Emphasis is laid on the fact that in many respects native stock seems less sturdy than foreign stock of recent acquisition. The children of native parents, for instance, furnish the highest mortality rate due to malformations (47 per 10,000 ), to marasmus (222 per 10,000), and to tuberculosis (21 per 10,000).

That race exerts an influence on infant mortality there is no question. It is a well-known fact that mortality among colored children is three times that of white children.

3. Study of Infant Feeding.-One of the greatest factors in the reduction of infant mortality has been our growing knowledge of the principles and methods of infant feeding. The medical world now universally recognizes breast milk as the ideal food for infants. Every physician is aware of the fact that to reduce infant mortality it is necessary that as many mothers as possible be urged to nurse their babies. In many hospitals a system of wet nurses has been instituted where mothers who have a superabundance of milk are employed by the hospital for the purpose of supplying breast milk to very sick babies. By this means many babies have been saved who could not otherwise have been saved. Not only in regard to breast feeding but in regard to artificial feeding also has the medical world learned a great deal within the last few years. Many so-called "truths" of infant feeding have 
been abandoned of late. We have learned that milk if not boiled should at least be pasteurized. We have learned that to get good milk for babies the cows must be kept in good condition, in hygienic surroundings, and must be free of disease, especially of tuberculosis.

4. Infant Welfare.-One of the means of educating the public to the importance of clean milk and the necessity of a regular nursing period has been the Infant Welfare Movement. This movement was started by Budin in France about 1892 and was soon followed in different countries. At present there is hardly a country that has no infant welfare societies in operation. In this country the National Association for the Study and Prevention of Infant Mortality was organized in 1909, and the Federal Children's Bureau was organized in 1912. These two organizations are doing a great deal for the promotion of infant welfare in this country. Besides these central organizations there are infant welfare societies in every state in the Union. The purpose of the Infant Welfare Society is to instruct the mother in the care of her infant, in the choice and regulation of its food, and even in the matter of the clothing. The infant welfare societies are doing particularly good work among the poorer classes who live in unhygienic surroundings and who cannot afford to pay private physicians for advice about the welfare of their infants.

\section{BIBLIOGRAPHY}

Budin, P.: The Nursling, The Feeding and Hygiene of Premature and Fullterm Infants (translated by W. J. Maloney), London, 1907.

Carlson, A. J., and Ginsburg, H.: The Gastric Hunger Contractions of the Newborn, Amer. Jour. of Physiol., 1915, vol. 37, p. 29.

Czerny, A., and Keller, A.: Des Kindes Ernährung, Ernährungstör ungen und Ernährungstherapie, Leipzig and Wien, 1901.

Finkelstein, H.: Säuglingskrankheiten.

Finkelstein and Meyer: Die Krankheiten der Verdauungsorgane, Feer's Lehrbuch der Kinderheilkundie, Jena, 1914.

Heubner: Lehrbuch der Kinderheilkunde, Leipzig, 1911.

Levinson, A.: Oatmeal Gruel in Infant Feeding, Archives of Pediatrics, 1917, vol. 34, p. 707 .

Mathews: Text-book of Physiological Chemistry, New York, 1916.

Rotch: Infant Feeding, Keating's Cyclopedia of the Diseases of Children, 1889.

Rubner and Heubner: Natürliche Ernährung eines Säuglings, Zeitschrift für Biologie, vol. 36 , p. 43. Die künstliche Ernährung eines normalen Säuglings, Zeitschrift für Biologie, vol. 36 , p. 315 . .

Taylor, R.: Hunger and Appetite Secretion of Gastric Juice in Infants' Stomachs, Amer. Jour. of Diseases of Children, 1917, vol. 14, p. 258. 


\section{BUTTER}

BUTTER is milk-fat from which the greater part of the milk plasma has been removed by a process of agitation known as churning. The clumps of fat globules in butter retain their general physical condition, although this is true only of butter of normal quality. The texture of butter may vary, but is especially dependent upon the temperature at which churning is carried on. If a high temperature is employed the fat softens or even melts, and a greasy product is churned. On the other hand, if a low temperature is used a butter of firm consistency is churned. Milk-fat containing relatively large amounts of olein produces a soft butter. It is believed that the food a cow consumes greatly influences the consistency of butter-fat. While food rich in vegetable oils produces a milk-fat rich in olein, dry fodder and that containing much starch produces a hard fat. The size of the fat globules is also said to influence the condition of butter, inasmuch as large globules are supposed to furnish a butter of soft texture, while small globules have the opposite effect.

While a high temperature facilitates the separation of butter from cream, due largely to the reduced viscosity, a good butter maker always keeps the temperature of churning below the melting-point of butter-fat. As this point is not the same in all butterfats, the most suitable temperature for churning varies somewhat. It is usually stated that it should not be below $50^{\circ} \mathrm{F}$. nor above $65^{\circ} \mathrm{F}$.

The rapidity and completeness of separation of butter-fat from the cream depends upon several factors. Temperature is of importance in this respect, as a high temperature permits easier and more complete separation of fat than does a low one. The cause of this difference is probably ascribable to the effect of , temperature on the viscosity. A second factor of importance is the size of the fat globules. The larger they are, the more readily can they be separated. Jersey milk, with its large globules, churns easier than does Holstein milk; milk derived from a cow in the early stages of lactation is more churnable than that from later stages; homogenized milk is always difficult to churn and the fat is removed incompletely.

Rich cream churns more easily than lean cream because in the former the fat globules are close together. In sour cream the viscosity is greatly reduced, and consequently the fat separates more easily than from sweet cream, and the yield is greater. 
Chemical analyses of butter have given the following composition:

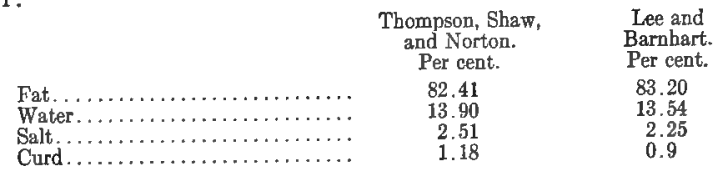

Of course, these figures are average ones. There is considerable variation in the composition of market butter, especially in the moisture content. Butter makers aim to incorporate as much water as the law permits-16 per cent.-but must exercise judgment, since the moisture is not evenly distributed and may exceed the legal limit in some places. Soft butter retains water in greater measure than hard butter. Raw cream butter usually contains more water than butter made from pasteurized cream; large churnings and those at high temperature have a similar effect. During storage some of the moisture is lost, more from salted butter than from sweet butter.

The mineral content of butter varies considerably, depending largely upon the amount of salt worked into it. The object of adding salt to butter is chiefly to render it more resistant to decomposition, and incidentally the salt covers up off-flavors to a limited extent. The presence of salt, furthermore, adds to the palatability of the butter. The amount of salt added varies up to 5 per cent.

Although it is possible to make butter from milk, by far the largest amount is made from cream. Cream churns more easily than milk; in fact, the richer the cream, the more readily does it churn.

Cream is separated from milk in one of two ways: either by gravity-this is gravity cream-or by means of a centrifugal separator.

Gravity cream is obtained either by the "shallow pan system" or by the "deep-setting system." In the former case the milk is placed in pans 2 to 4 inches deep and kept at $60^{\circ} \mathrm{F}$. in pure air to avoid bacterial contamination as far as possible. The cream is finally skimmed off, leaving a skimmed milk containing from 0.5 to 1 per cent. fat. Better results are obtained by the deep-setting system. Four-gallon shotgun cans, or specially constructed cans with a piece of glass to observe the cream line, are filled with milk and kept at $55^{\circ} \mathrm{F}$. or lower. The cream separates in about twenty-four hours and is then skimmed off, or the skimmed milk is removed if the can is provided with a faucet at the bottom. This skimmed milk may contain as little as 0.2 per cent. fat. 
Creaming is facilitated if the milk is cooled rapidly after drawing, and also by diluting it with about an equal volume of water, by which means the viscosity is reduced and the rising of the fat hastened. Dilution with water, however, usually leaves more fat in the skimmed milk than is left by undiluted milk, and, furthermore, the skimmed milk is so highly diluted that it is not suitable for further use. Diluting the milk for creaming is, therefore, not a common practice.

Cream is now more generally separated from milk by means of centrifugal separators. The advantages of the separator method over that of gravity are so great that the original outlay for a separator is soon compensated for. Centrifugal force separates the cream more completely than does gravity, so that the separated milk frequently contains less than 0.1 per cent. fat, often as little as 0.05 per cent. This is one important gain, and another is the fact that a concentrated cream containing 60 or more per cent. butter-fat can be obtained, while gravity cream rarely contains more than 20 per cent. butter-fat. However, it is not desirable to use a cream of more than 45 per cent. fat for butter making, as otherwise the viscosity becomes so great that a part of the cream adheres to the sides of the churn, making proper agitation impossible and causing the yield of butter to suffer.

A further advantage of separator cream is derived from the fact that it is separated while perfectly fresh, still warm with animal heat. Bacterial decomposition has no time to take place and the ripening process can be more efficiently controlled. As a matter of fact, a large number of micro-organisms are thrown out by the centrifugal force.

When milk is subjected to centrifugal force it separates into three parts, namely: 1 , the cream-being the lightest part-moves toward the center; 2 , the separator milk, and 3 , the heaviest parts of the milk-consisting of insoluble salts, dirt, casein, cellular elements, and micro-organisms - are thrown on the wall of the bowl. These last constituents form a thick, slimy mass, known as the separator slime or bowl sediment.

The richness of the cream is controlled by a screw with a hole through which the cream-in some machines-or the skimmed milk-in others-flows. The nearer the hole in the screw is to the center, the richer is the cream, or if the screw controls the skimmed milk, the nearer the hole is to the periphery, the richer is the cream. The rate at which the milk flows into the separator also influences the richness of the cream. A low rate of speed in the machine produces a leaner cream than a high rate, and finally a high temperature causes a rapid flow of cream of low fat content. The temperature, however, should not be so low as to in- 
crease the viscosity of the milk materially, to prevent clogging of the machine.

Although the temperature range for best results is greater for centrifugal separation of cream than for gravity, it should receive proper attention. The milk, if it is not separated immediately after milking, which is impossible except on the farm, should be warmed slowly and without much agitation. The temperature most suitable for separating is about $90^{\circ} \mathrm{F}$., and if the milk is heated rapidly the fat is not liable to become soft enough for efficient separation. However, McKay and Larsen found that milk could be heated rapidly to a temperature of $170^{\circ} \mathrm{F}$., and that, contrary to earlier beliefs, the butter did not suffer from this heating.

It is very important that the milk be perfectly sweet for centrifugal separation. Sour milk quickly clogs the machine and, at best, separation is imperfect.

A separator should run smoothly and at a uniform speed if the best results are desired.

As stated before, butter is most commonly made from sour or "ripened" cream. The ripening process is a very important one, since it not only increases the yield of butter, but conditions the flavor and aroma. Ripening of cream is a process carried on by bacteria. Whether but one type is concerned in it or several is still a matter of controversy, but it is established that a clean cream produces good butter only when the ripening process proceeds normally. Good butter cannot be produced from dirty milk, as this teems with types of micro-organisms that produce taints.

The ripening of cream is desirable because (1) the fat separates more readily in sour than in sweet cream, and churning is, therefore, facilitated and the yield increased; (2) sour cream butter keeps its aroma and texture for a longer time than does sweet cream butter, and (3) sour cream butter has a richer aroma than sweet cream butter. The best temperature for cream ripening is $60^{\circ}$ to $70^{\circ} \mathrm{F}$. It is true that the lactic acid bacteria grow somewhat better at a higher temperature, but undesirable organisms are also favored. At a moderate temperature the lactic acid bacteria overcome competition of undesirable organisms more readily than at higher temperature.

During the winter months, when cattle are kept closely in stables, undesirable bacteria are more common in cream than in summer, when cattle are outdoors most of the time. Ripening, therefore, proceeds more satisfactorily in summer than in winter.

It is a well-known fact that in certain localities a high-grade butter is produced, while in others the quality is inferior. This 
is probably due to the presence of bacteria which are common in these localities and which produce results in accordance with their nature.

There are two methods of cream ripening - the natural and the artificial. The natural ripening of cream means merely allowing it to sour spontaneously. It is obvious that by this method the result is more or less haphazard. If the souring process is carried on by bacteria which produce an agreeable aroma the resultant butter will be of fine quality, but if carried on by the type of bacteria producing an unpleasant aroma, an inferior butter will result. The only control possible when cream is allowed to ripen spontaneously is care in the production of a clean milk and protection during the souring process.

The souring of cream is the result of the activity of types of Streptococcus lacticus. This organism is so universally present in cream that it rarely fails to ripen it. But the aroma varies with different types of Str. lacticus. While some produce an agreeable aroma, others produce an indifferent or even unpleasant aroma. It is held by some investigators that butter aroma is due solely to the action of this organism, while others believe that associated bacteria materially affect it. In any case, it is generally conceded that the aroma is the result of a slight decomposition of butter-fat caused by microbial action.

Artificial cream ripening is carried on by the use of starters; that is to say, the cream is inoculated either with a batch of sour cream from the last ripe cream or with pure cultures which are purchasable. The batch of sour cream used for inoculation is known as a natural starter, while pure cultures are known as artificial starters.

It is a common practice to save a small amount of ripened cream and mix this with a new lot. Sour cream, when of good quality, contains Streptococcus lacticus in almost pure culture and in enormous numbers. The number present is variously stated to be from $500,000,000$ to $3,000,000,000$ per cubic centimeter. The new cream, therefore, is seeded with large numbers of desirable bacteria. If a butter maker finds his cream does not ripen in a satisfactory manner, he obtains a natural starter from a neighbor who is obtaining better results. The starter should not be too old, as the high acid content destroys many bacteria and renders the starter inefficient. By keeping a starter on ice it can be used after several days without there being a material deterioration.

Artificial starters are gradually superseding natural starters because they enable the butter maker to control his product with a certain degree of perfection. Artificial starters are made from 
laboratory cultures of Str. lacticus, and these cultures are purchasable for a small price. Butter makers have fresh cultures mailed to them at regular intervals, since it is difficult to preserve a pure culture indefinitely under commercial conditions. Most commercial starters are really pure cultures, while some contain contaminating organisms. They are sold either in liquid or tablet form. While liquid starters are more active when fresh than dry starters, the dry ones preserve their viability for a longer period than do the liquid starters.

To prepare a starter from a commercial culture requires care and judgment. Other bacteria must be kept out, otherwise the result will be a failure. The first step is the preparation of the "mother starter." A quart milk bottle is cleaned and filled.about two-thirds full with a good quality of milk or skimmed milk. A cotton swab attached to a piece of heavy copper wire (Bushnell and Wright) or a silver-plated teaspoon with a piece of wire soldered to the handle (Hastings) is inserted and the bottle then closed with a cotton plug or an inverted tumbler, or both. The milk is then sterilized in steam for thirty or forty minutes. One sterilization does not destroy all bacteria, of course, so some prefer to apply steam for three successive days, although this is not necessary. After the milk is cooled the culture is added, mixed with the milk, and then incubated at $65^{\circ}$ to $85^{\circ} \mathrm{F}$. After eighteen to twenty-four hours the mother starter is ready. The curd should be smooth, without gas holes, and practically free from whey. The starter should be examined for abnormal appearance, taste, and odor. The acid present should be calculated by the use of Farrington's alkali tablets. In order to observe the physical condition it is advisable to use a glass vessel.

The incubation temperature can be maintained, according to Hastings, by placing the bottle or bottles in an insulated box, such as a fireless cooker, and keeping the temperature constant by means of a pail filled with water at $80^{\circ}$ to $90^{\circ} \mathrm{F}$.

The largest number of lactic acid bacteria are present when the milk curdles at $70^{\circ} \mathrm{F}$. and has an acidity of 0.6 to 0.7 per cent. If the amount of acid is less, there are fewer bacteria, and if it is greater, the number also decreases, owing to the destructive effect of the acid.

Fresh cultures frequently do not produce the desired effect, and a fresh bottle of milk should then be inoculated from the first one. This may have to be repeated several times before the starter has gained proper vigor.

If the mother starter is not intended for immediate use, it should be placed on ice to prevent the souring process from going too far. 
The starter proper is prepared by mixing 1 quart of the mother starter with about 40 quarts of milk which has been pasteurized and then cooled to $65^{\circ}$ to $85^{\circ} \mathrm{F}$.. This is then incubated for twenty-four hours, after which it is ready to be used with the cream in the proportion of from 5 to 20 per cent.

The acidity of properly ripened cream is usually given as 0.5 to 0.7 per cent. In rich cream the acidity should be lower than in lean cream, because the acid is contained in the plasma, not in the fat, but in measuring acidity the whole volume of cream is considered. The larger the fat content of cream, the smaller is the amount of plasma.

A considerable quantity of butter is made from pasteurized cream, and the advantages of using such cream are becoming more apparent to butter makers. One advantage is the destruction of pathogenic bacteria; another is the fact that by using pasteurized cream the ripening process can be absolutely controlled. Pasteurization destroys the majority of bacteria, and by inoculating pasteurized milk with a pure culture starter, ripening proceeds uniformly. The product is always of the same high quality, and has, therefore, commercial advantages over butter made from raw cream. Furthermore, the stability and aroma of the butter are improved.

The flash process of pasteurization is generally used for cream to be used for butter making. According to Rogers, Berg, and Davis, the temperature for continuous pasteurization should not be below $74^{\circ} \mathrm{C}$. $\left(165^{\circ} \mathrm{F}\right.$.) nor above $80^{\circ} \mathrm{C}$. $\left(175^{\circ} \mathrm{F}\right.$.). If pasteurized below $74^{\circ} \mathrm{C}$. the stability of the butter suffers; if above $80^{\circ} \mathrm{C}$., the flavor is affected.

The churning process is stopped when the fat appears in small granules. The buttermilk is strained off and the butter remains on the sieve. It is then mixed with clean, pure water, churned, and strained again. This process is repeated until the buttermilk has all been practically removed. The temperature of the water used for washing is gauged according to the consistency of the butter-fat. If it is soft, the water should be cold; if hard, the water should be warm. Salt-up to 5 per cent.-is then sifted on the butter and worked in.

The working of the butter is an important process. By working the salt is incorporated, water or buttermilk is removed, and the texture becomes firm unless the working is overdone, in which case the texture becomes greasy. Too much manipulation may have a detrimental effect on the aroma of the butter. This, as stated previously, is largely the result of bacterial activity on the fat. The aromatic split-products are absorbed partly by the fat and partly by the remains of buttermilk. Consequently, if the 
butter is worked too much, some of the water-soluble aromatic substances are lost and the taste of the butter becomes flat.

Finished butter has a relatively small bacterial content owing to the unfavorable conditions for bacterial life and multiplication. Oleomargarine and butterine usually contain fewer bacteria than natural butter. The droplets of buttermilk or water remaining enmeshed after churning and washing dissolve the salt which is worked into the butter, and this salt solution is unfavorable for bacterial growth. The fat itself offers food for a few types only. The latter, however, are undesirable, since they decompose fat and produce fatty acids and glycerin. They are the cause of rancidity in butter.

After churning there is an increase in bacterial content, followed by a decrease. Löhnis gives the following numeric relation of bacteria in butter according to age. The numbers are to bè multiplied by $1,000,000$ :

\begin{tabular}{|c|c|c|}
\hline & \multicolumn{2}{|c|}{ Sweet cream butter. } \\
\hline & Outside. & Inside. \\
\hline Fresh butter................. & $\begin{array}{r}1 \\
30\end{array}$ & $\begin{array}{r}1 \\
10\end{array}$ \\
\hline Two months old $\ldots \ldots \ldots \ldots \ldots \ldots \ldots$ & 2 & 0.6 \\
\hline
\end{tabular}

\begin{tabular}{|c|c|}
\hline \multicolumn{2}{|c|}{ Sour cream butter. } \\
\hline $\begin{array}{c}\text { Outside. } \\
10 \\
8 \\
2\end{array}$ & $\begin{array}{c}\text { Inside. } \\
10 \\
3 \\
0.1\end{array}$ \\
\hline
\end{tabular}

According to this table sweet cream butter contains fewer bacteria right after churning than sour cream butter, but after one week, the relation is reversed. After two months both kinds of butter contain less bacteria than after one week.

The number of micro-organisms in butter depends to some extent upon the thoroughness with which it is washed. If washed insufficiently buttermilk remains and offers food for bacteria. After repeated washing the buttermilk is replaced by water and bacteria find little food. The fat is of food value only to a few types of micro-organisms which, as stated before, decompose the fat, with production of a rancid taste and odor. The commonest ones of these are Oïdium lactis, Chladosporium butyrii, Bacillus fluorescens, and more rarely B. prodigiosus. Decomposition by these organisms commences from the outside, since they are aërobic.

Abnormal conditions of butter may be due to one or more of the following causes:

1. Poor control of conditions in butter making.

2. Abnormal ripening of the cream.

3. Poor milk.

Poor control frequently shows itself in the texture of the butter. If cows are permitted to feed on marshy vegetables, or if a wet spring has caused watery plants, the fat in milk is soft. The fat is hard when straw, potatoes, or beet tops are fed in 
abundance. As pointed out before, insufficient cooling of the cream, especially after pasteurization, leaves the fat in a soft condition. If this is not corrected by proper cooling the quality of the butter suffers.

If the butter is worked too much a physical change occurs in the fat, which imparts to the butter an oily consistency. On the other hand, insufficient manipulation makes the butter streaky and the salt is not well distributed. Streaky butter may also result from mixing different lots of ripened cream before churning. The churning temperature should not be too high, otherwise the fat becomes soft. About $55^{\circ} \mathrm{F}$. is a good churning temperature.

If the ripening process goes too far the casein precipitate is hard and particles of casein become enmeshed in the fat. This also occurs when hot water is added to sour cream to raise the temperature. A cheesy taste is then imparted to the butter. After churning at high temperature the butter may contain very small drops of water in abundance and fat globules are then broken up. The normally clear appearance of the butter is disturbed and a cloudiness takes its place. In good butter the water is present in relatively large drops.

High temperature of ripening may produce abnormal flavors by favoring the multiplication of Bacillus coli, B. subtilis, and other bacteria which impart a bitter taste. A turnip taste is ascribed by some to strains of B. coli. Lactose-fermenting yeasts may also produce a bitter taste. If $\mathrm{B}$. fluorescens remains in the butter, either from unclean cream or water, the butter may soon become rancid. This organism multiplies at relatively low temperature.

The influence of light in presence of oxygen produces rancidity and decolorization of butter. It should, therefore, be protected both from light and air by suitable packing. The keeping quality of butter is then enhanced. Sufficient working to remove the buttermillk and preservation in cold storage are important factors for keeping butter in good condition. If it were possible to eliminate all bacteria except lactic acid bacteria, butter would keep well for indefinite periods in the dark and at low temperature. As it is impossible under commercial conditions to prevent some contamination, decomposition may be expected. However, Rogers, Berg, Potteiger, and Davis have found that at $0^{\circ} \mathrm{F}$. there is no increase in soluble nitrogen for a long period. There was probably no bacterial multiplication at this temperature, but the authors found some evidence of proteolysis caused by bacterial enzyms. They further found that butter from sweet pasteurized milk keeps much better than butter made from raw sweet cream. Rahn, Brown, and Smith found an increase of 
amido-nitrogen in butter, and studied bacteria which were able to multiply slowly at $-6^{\circ} \mathrm{C}$. in salted butter. The authors are in doubt, however, whether these bacteria cause deterioration. Thom and Shaw found that molds attack unsalted or slightly salted butter, but rarely affect fully salted butter. Guthrie, after a careful study, declares that chemical changes in butter were slight when biologic agencies were checked. Exposing butter and butter-fat to high temperature, light, and air caused no rancidity and no important change in the iodin number. In fact, according to this work, the rancidity of butter ordinarily spoken of, is rare and a strong flavor is frequently mistaken for rancidity.

In some cheese factories butter is made from the whey, and this is called whey butter. The whey may contain as much as 1 per cent. of fat. Two-thirds of the fat can be saved by allowing the whey to stand for twenty-four hours and then skimming the fat off. A better yield is obtained by boiling the whey and skimming the "cream" off the surface. This "cream" contains about 10 per cent. fat, while only 0.05 per cent. remains in the whey. This by-product can be utilized to still better advantage if the whey, when it leaves the cheese kettle, is passed through a cream separator. The separated "cream" is then churned and the product is equal to a good quality of market butter. A good price is realized from this butter, while the whey butter obtained by the first two methods is sold at the price of lard. Doane states that 2 to 5 pounds of whey butter can be obtained from 1000 pounds of milk.

Butter is scored by experts according to flavor, body, color, salt, and style of packing. Michels has defined good butter as follows:

"Flavor should be rich, pleasing, creamy, and suggest nothing objectionable to either the taste or smell.

"Body should be firm and waxy.

"Color should be even, showing a luster and an oat straw shade, unless the particular market wants a different color.

"Salt well dissolved, and just enough to bring out the highest flavor of the butter.

"Package clean and neat in appearance."

Off-flavors may be curdy, too acid, rancid, oily or greasy, fishy, stable-taste and odor, bitter, weedy (when cows have been fed on strong-smelling plants), or unclean from ill-kept utensils or poor water.

The fishy flavor of butter similar to the oily flavor of mackerel or salmon is not uncommon, and has been studied by Rogers. The author says that fishy flavor is caused by a "substance produced by the oxidation of one of the combinations of the acid 
developed in the ripening process of cream. The substance oxidized may be the result of a hydrolysis of one of the constituents of butter by the acid." Fishy flavor is more common in hot weather than in cold, and occurs when cream overripens or when it is overworked. But high-acid cream does not always produce a fishy butter. The flavor is not apparent in fresh butter, but develops during storage. Rogers found no bacteria or molds responsible for the fishy flavor. By making butter from pasteurized cream the occurrence of the fishy flavor is prevented.

For bacteriologic examinations of butter a sample of 200 to 300 grams is drawn with a sterile butter trier. The sample is melted at a low temperature $\left(35^{\circ} \mathrm{C}\right.$. $)$ in a sterile glass jar. When melted a portion is poured into an Erlenmeyer flask and kept at about $35^{\circ} \mathrm{C}$. in a water-bath. All dilution flasks and pipets must be kept at the same temperature to prevent hardening of the butter. From the liquid butter, dilutions can be prepared and plates made in the usual manner. One gram of butter equals about 1.15 c.c.

\section{Chemical Analysis of Butter}

Samples are taken with butter samplers. The whole sample is melted in a closed vessel at low temperature. The melted butter is shaken until homogeneous and until sufficiently solid to prevent separation of water and fat.

Determination of Moisture.-Evaporate 1.5 to 2.5 grams to dryness on a water-bath and desiccate over calcium chlorid.

Determination of Fat.-Dissolve with absolute ether or petroleum ether the dry butter obtained in the determination of moisture. Transfer to a Gooch crucible with the aid of a wash bottle filled with the solvent, and wash until free from fat. Dry'the crucible and contents on a water-bath and calculate the fat.

Determination of Casein, Ash, and Chlorin.-Cover the crucible containing the residue from the fat determination and heat gently at first, raising the temperature to just below redness. Remove the cover and heat until white. The loss in weight is casein; the residue, mineral matter. To determine the chlorin, dissolve the mineral matter in water slightly acidulated with nitric acid. To this solution add a known volume of normal onetenth silver nitrate 'solution until an excess is' present. Stir well, filter, and wash the silver chlorid precipitate thoroughly. To the filtrate and washings add 5 c.c. ferric indicator (a saturated solution of iron alum) and a few cubic centimeters of nitric acid. Titrate the excess of silver with one-tenth normal ammonium or potassium thiocyanate solution until a permanent light brown color appears. Calculate the amount of silver nitrate solu- 
tion used and from this the amount of chlorin (Volhard's method of chlorin determination).

Determination of Salt.-Take 1 gram of butter from different parts of the sample, mix, and place 5 to 10 grams in a beaker. Add 20 c.c. of hot water, and after the butter has melted transfer to a separatory funnel. Shake, and after all fat has collected on the surface draw off the water without allowing any fat to pass through. Repeat the extraction ten to fifteen times, using 10 to 20 c.c. of hot water each time. Determine the amount of sodium chlorid in an aliquot portion of the solution with silver nitrate solution and potassium chromate as indicator.

\section{BIBLIOGRAPHY}

Beach: Storrs' Agri. Exper. Sta., Bull. 40, April, 1906.

Bushnell and Wright: Mich. Agri. Coll. Exper. Sta., Bull. 246.

Conn: Storrs' Agri. Exper. Sta., Bull, 12, February, 1894.

Doane: United States Dept. of Agri., B. A. I., Circular 161, June, 1910.

Esten and Mason: Storrs' Agri. Exper. Sta., Bull. 83, September, 1915.

Farrington: Univ. of Wis. Agri. Exper. Sta., Bull. 132, December, 1905.

Guthrie: Jour. of Dairy Science, 1917, vol. 1, p. 218.

Hammer: Agri. Exper. Sta. Iowa State Coll. of Agri. and Mech. Arts, Bull. 156, December, 1914.

Hastings: Univ. of Wis. Agri. Exper. Sta., Bull. 181, September, 1909.

Lee: Univ. of Ill. Agri. Exper. Sta., Bull. 138, September, 1909.

Lee and Barnhart: Univ. of Ill. Agri. Exper. Sta., Bull. 139, October, 1909.

Lee, Hepburn, and Barnhart: Univ. of Ill. Agri. Exper. Sta., Bull. 137, September, 1909 .

Löhnis: Vorlesungen über Landwirthschaftliche Bakteriologie, 1913, Berlin, Borntraeger.

McKay and Larsen: Principles and Practice of Butter Making, 1911, New York, John Wiley and Sons.

Michels: Univ. of Wis. Agri. Exper. Sta., Bull. 182.

Mortensen: Agri. Exper. Stta. Iowa State Coll. of Agri. and Mech. Arts, Bull. 156, December, 1914.

Rahn, Brown, C. W., and Smith, L. M. : Mich. Agri. Coll., Tech. Bull. 1, June, 1908. Mich. Agri. Coll., Tech. Bull. 2, September, 1909.

Rogers: United States Dept. of Agri., B. A. I., Circular 146, April, 1909.

Rogers, Berg, and Davis, B. J.: United States Dept. of Agri., B. A. I., Circular $189,1912$.

Rogers, Berg, Potteiger, and Davis, B. J.: United States Dept. of Agri., B. A. I., Bull. 162, April, 1913.

Sayer, Rahn, and Farrand: Mich. State Agri. Coll. Exper. Sta., Tech. Bull. 1, June, 1908.

Thom and Shaw: Jour. Agri. Res., 1915, vol. 3, p. 301.

Thompson, Shaw, and Norten: United States Dept. of Agri., B. A. I., Bull. 149, September, 1912. 


\section{CHEESE}

Chresse is a ripened product made from milk. The ripening process is carried on by different groups of micro-organisms which cause a series of chemical changes. Some groups produce proteolysis of the casein and decomposition of the fat and milksugar. Flavor in cheese is also the result of these activities. The collective work of these groups of micro-organisms is very complex, and the results of their combined action are different from the sum of the individual group activities. Green cheese contains casein, fat, water, and the salts of milk, and for a short period milk-sugar is present.

The chemical changes in cheese are more complex than those in butter. In butter there is acid and aroma formation which determines the quality of butter, but there is not the essential variation in butter that there is in types of cheese. The microflora in butter is simple when compared with that of cheese. The aroma of butter is due to the activity of certain bacteria, and, similarly, the type of cheese is determined by the kinds of microorganisms which are concerned in the ripening process. It was formerly believed that the different types of cheese were merely the result of differences in manipulation, as some were pressed more vigorously than others, causing a variation in the amount of water, and as the ripening temperature varied with the different kinds of cheese. Of course the influence of varying manipulations was learned by experience, but it is now known that they have bearing on microbial life. Conditions of ripening are made suitable for the particular type of cheese.

Cheeses may be divided into two groups, namely, sour milk and rennet cheeses. Sour milk cheeses are made from sour milk by precipitating the curd from the milk in a cheese kettle over gentle heat. They are always soft and the fresh precipitate consists chiefly of casein. When rennet is used for precipitating the curd, less acid is required than for the preparation of sour milk cheese. Rennet cheeses may be soft or hard, and their coagulum consists chiefly of paracasein. The consistency of the curd is determined by the amount of whey that remains, the type of cheese varying from a consistency so hard that the cheese is difficult to cut to one very soft or even semifluid. In hard cheese the ripening process proceeds more or less uniformly throughout the mass, while in soft cheese ripening commences from the outside. The surface of soft cheese is covered with micro-organisms which produce characteristic changes in the curd, and enzyms secreted by these micro-organ- 
isms gradually penetrate to the center of the curd and effect changes similar to those produced by the micro-organisms themselves. It follows that the interior of the cheese ripens more slowly than the outside, and while the outer layer soon assumes a smooth, transparent appearance, the inside remains white and granular for some time. The size of a hard cheese is not an important matter, since microbial activity is uniform throughout the mass, but soft cheese must be ripened in relatively small pieces, so as to offer a large outside surface for the action of microorganisms which need oxygen. In hard cheeses air is not only unnecessary, but in some respects disadvantageous.

There are more than 400 varieties of cheese manufactured, but only a small number are of commercial interest. However, the consumption of cheese is on the increase, and new varieties appear on the market from time to time. Doane and Lawson have described 245 varieties of cheese, and have stated that during the years 1900 to 1905 the value of imported cheese rose from $\$ 1,946$,033 to $\$ 3,875,161$. Most of the imported cheese comes from Italy, Switzerland, France, and Holland. The most popular varieties imported from Italy are the Parmesan and Gorgonzola; from Switzerland, the Emmenthaler; from France, the Roquefort, Camembert, and Brie; from Holland, the Edam. Several types are manufactured in this country, chiefly hard cheeses, and some imported cheeses have been imitated with considerable success. Among the latter are Emmenthaler, or Swiss cheese, Limburger, Camembert, Brie, Isigny, Roquefort, Stilton, and others.

Since cheese contains fat and protein in an easily digestible condition and in relatively large proportion, it is a valuable article of food. The true food value has not been fully appreciated by the public, although the increase of importation shows that cheese as a food is becoming more popular. The proteins in cheese are easy to digest, especially those in soft cheese. But hard cheese-although frequently assumed to be indigestibleis not difficult to digest if it is thoroughly masticated. The fat in cheese is more easily assimilated than that of meat and vegetables. Furthermore, cheese contains abundant mineral matter. Only carbohydrates are absent, except in fresh cheese, such as cottage cheese. But even in cottage cheese the sugar is present in small quantity. Cheese is a successful rival of meat as food for human consumption, as it contains the necessary food elements and is cheaper than meat. Langworthy and Hunt have published in Farmers' Bulletin 487 of the United States Department of Agriculture a popular description of the most favored cheese, and a large number of home recipes for utilizing cheese for food. In this useful bulletin the food value of cheese is discussed and its 
composition compared with that of other food articles. Explicit directions are given for the preparation of cheese dishes which may serve as meat substitutes; for the concoction of cheese soups; for combining cheese with vegetables, etc. Its use is recommended for making cheese salads, cheese sandwiches, cheese pastry, cheese sweets, and similar dishes. A total of more than 80 recipes is given.

Cheese contains chiefly water, protein and protein decomposition products, fat, and mineral matter. By averaging the analyses given by Doane and Lawson the following approximate values of a few representative cheeses were obtained:

\begin{tabular}{|c|c|c|c|c|}
\hline Kind of cheese. & Water & Fat. & Protein, etc. & Total ash. \\
\hline Brie....... & 50.14 & 24.27 & 18.12 & 428 \\
\hline Camembert & 50.30 & 22.79 & 19.24 & 4.06 \\
\hline American Cheddar . . . . . . . . . . . & 34.78 & 31.77 & 28.11 & 3.70 \\
\hline Emmenthaler................ & 34.87 & 28.18 & 30.88 & 5.38 \\
\hline Edam . . . . . . . . . . & 36.93 & 26.19 & 27.45 & 5.68 \\
\hline American Edam. . . . . . . . . . . & 46.87 & 24.08 & 22.65 & 3. 10 \\
\hline 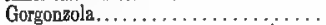 & 36.75 & 31.76 & 26.29 & 4.37 \\
\hline Parmesan $\ldots \ldots \ldots \ldots \ldots \ldots \ldots$ & 31.22 & 20.09 & 40.77 & 6.02 \\
\hline Roquefort............... & 31.25 & 44.09 & 27.23 & 6.53 \\
\hline Stilton, .................... & 27.02 & 38.61 & 27.15 & 3.47 \\
\hline
\end{tabular}

Thom has tabulated analyses made by different analysts of twelve samples of Camembert cheese in the American market. Following are the average figures:

$\begin{array}{lccc}\text { Water. } & \text { Fat. } & \text { Protein. } & \begin{array}{c}\text { Proportion of fat } \\ \text { to protein. } \\ 47.91\end{array} \\ 27.33 & 19.66 & 1: 0.71\end{array}$

These figures clearly show the great value of cheese as a food, and this fact is being gradually recognized, so that cheese is constantly winning popularity as an article of diet.

The relation of micro-organisms to cheese ripening was first recognized by Cohn in 1872. Since that time an extensive literature on chemical and bacteriologic investigations of cheese has accumulated. A great deal has been learned, but the problem is one of such complexity that much is still obscure. However, present knowledge of the biologic processes of cheese ripening has placed the manufacture of many cheeses on a more rational basis than heretofore, and has made a more stable and delightful product possible.

Clean milk is a fundamental necessity for producing good cheese, and a good quality of milk assures a better cheese than an indifferent quality. Any off-taste in milk is intensified in the cheese made from it. Hence cleanliness in production is as important when the milk is intended for cheese manufacture as when it is used for any other purpose. Milk held in dirty or rusty utensils infallibly produces a poor quality of cheese.

Since most of the milk-fat is precipitated with the curd, the fat content of cheese depends upon the richness of the milk used. It is important, therefore, that the cheese maker should know the 
quality of the milk he purchases. The sediment test for dirty milk, the Babcock test for fat, and the Hart test for casein are easily made, and furnish the cheese maker with the necessary information about the quality of the milk to be used for cheese making. The Babcock and Hart tests also furnish an equitable basis for valuation of the milk.

It is claimed that exceptionally pure milk is not suitable for cheese making because it is so poor in bacteria that cultures of micro-organisms must be used to produce results. On the other hand, some bacteria commonly present in unclean milk may cause abnormal flavors or objectionable gas formation. Pasteurized milk has the advantage of containing but few bacteria, and when it is used, pure cultures of cheese-forming bacteria can be inoculated into the milk. However, there are some drawbacks to the use of pasteurized milk which as yet have been only partially overcome. The first objection to be raised is the retardation of rennet action upon the casein. This is due to the precipitation of calcium salts by heat, and can be rectified by addition of calcium chlorid or some other soluble calcium salt. The second objection is the softness of the curd produced with the use of pasteurized milk. No universal remedy for this trouble has been found and, therefore, pasteurized milk is not as suitable for the making of hard cheeses as for the manufacture of soft ones. However, Sammis and Bruhn have succeeded in making a satisfactory Cheddar cheese from pasteurized milk. Instead of using sour milk they added hydrochloric acid to produce coagulation. The product scored better than cheese made from the same milksupply in the usual manner, and the yield was nearly 5 per cent. greater. It is confidently expected that some means will be discovered which will correct the consistency of the curd from pasteurized milk so that pasteurized milk can become the basis of all kinds of cheese. When this can be done the cheese maker's work will be facilitated, since under present conditions his milksupply varies from day to day in bacterial content, coming, as it does, from a number of producers, and therefore constituting a mixed product. Pasteurization would make the quality of the milk fairly constant and the results would be uniform with the use of cultures of micro-organisms. There would be established a regular routine of work which is unheard of under present conditions.

Milk for cheese making has been sterilized by the use of hydrogen peroxid and then inoculated with cheese-ripening cultures in order to avoid the detrimental influence of the many bacteria usually present in milk. However, the process is confined to special kinds of cheese and has been only partially successful.

It is true that the use of pure cultures for cheese making is 
still limited, owing to our fragmentary knowledge of the biologic reactions involved. In a few cases, however, cultures have proved very successful. The Institut Pasteur is placing cultures on the market for ripening Camembert cheese. Camembert cheese made in this country is also ripened by the aid of cultures. Cultures of lactic streptococci are used in Holland for making Edam cheese; in Switzerland cultures of lactobacilli are used for making Emmenthaler cheese. It is not unreasonable to assume that in the course of time a variety of cheeses will be made under one roof, where the manufacture will be controlled by the use of special cultures. It has happened, however, in places where more than one type of cheese is prepared that so-called "bastards" have resulted by accidental contamination of one kind of cheese with cultures intended for another.

Bacteria of cheese originate from the milk, rennet, water, air, and utensils. Bacteria from the milk are obviously the most important. As to the bacteria from rennet, the number and kinds depend upon the kind of rennet used. In European rennet there are millions of bacteria, and among them lactobacilli. This rennet is prepared by making an extract of calves' stomachs with sour whey. Lactobacilli are numerous in the digestive tract of calves and in sour whey. They are, therefore, present in the rennet extract. Rennet used in this country is prepared by extraction of the fourth stomach of a calf with salt solution and contains a negligible number of bacteria. Rennet extract contains a pepsinlike enzym which digests casein when acid is present. This enzym is activated by the lactic acid contained in the curd.

Bacteria from water, air, and utensils do not assume importance if proper cleanliness is exercised. If such cleanliness is neglected these bacteria may cause the cheese to be of inferior quality.

The distribution of bacteria in cheese is fairly uniform in initial stages of ripening, but later on they are more concentrated in some places than in others, so that ripening does not proceed uniformly throughout the cheese. Streptococci and lactobacilli are most prominent in inner portions, while micrococci are common on the outside. In ripe Cheddar cheese there are chiefly lactobacilli, while in fresh Cheddar cheese streptococci are predominant. When the curd is prepared 70 to 80 per cent. of the bacteria in the milk are enclosed in the cheese. When the curd is pressed, however, some of these bacteria are expelled with the whey. Löhnis states that in young Emmenthaler cheese 500,000,000,000 bacteria are present in 1 gram of the slimy outer layer, and that this layer consists almost entirely of bacteria. Lactic streptococci are by far the largest group of organisms present in "green cheese." They act on the milk-sugar which remains dissolved in 
the moisture of the curd and gradually decompose it. After a few days there is usually no milk-sugar left.

The fat is also enclosed in the curd, while the whey rarely contains more than 1 per cent. of fat, usually less.

As to the number of bacteria in cheese, the following figures are instructive:

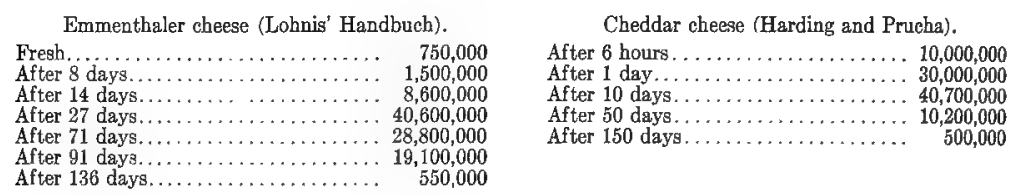

The ripening temperature influences the number of bacteria, as the following table illustrates (Harrison and Connel):

\begin{tabular}{|c|c|c|c|c|}
\hline Days. & $60^{\circ}-67^{\circ} \mathrm{F}$. & $37^{\circ}-40.5^{\circ} \mathrm{F}$ & $64^{\circ}-67^{\circ} \mathrm{F}$ & $38^{\circ}-40.5^{\circ} \mathrm{F}$ \\
\hline 1. & $528,000,000$ & $523,000,000$ & $635,000,000$ & $635,000,000$ \\
\hline ... & $263,000,000$ & & $273,000,000$ & $520,000,000$ \\
\hline 15. & $145,000,000$ & $489,000,000$ & $264,000,000$ & $475,000,000$ \\
\hline$\cdots$ & $97,000,000$ & $475,000,000$ & $175,000,000$ & $494,000,000$ \\
\hline$\cdots$ & $12,000,000$ & $471,000,000$ & & $, 000,000$ \\
\hline$\ldots \ldots \ldots \ldots \ldots$ & $4,100,000$ & $473,000,000$ & $32,000,000$ & $255,000,000$ \\
\hline
\end{tabular}

According to these figures, there is an initial period, during which the number of bacteria increases materially. This period is followed by a decline in bacterial population, so that in fully ripened cheese the number of bacteria is relatively small. Recent work on the bacteria in cheese seems to indicate that these conditions do not always obtain. Eldredge and Rogers, for example, give the following figures:

BACTERIA IN CHEESE AT DIFFERENT AGES

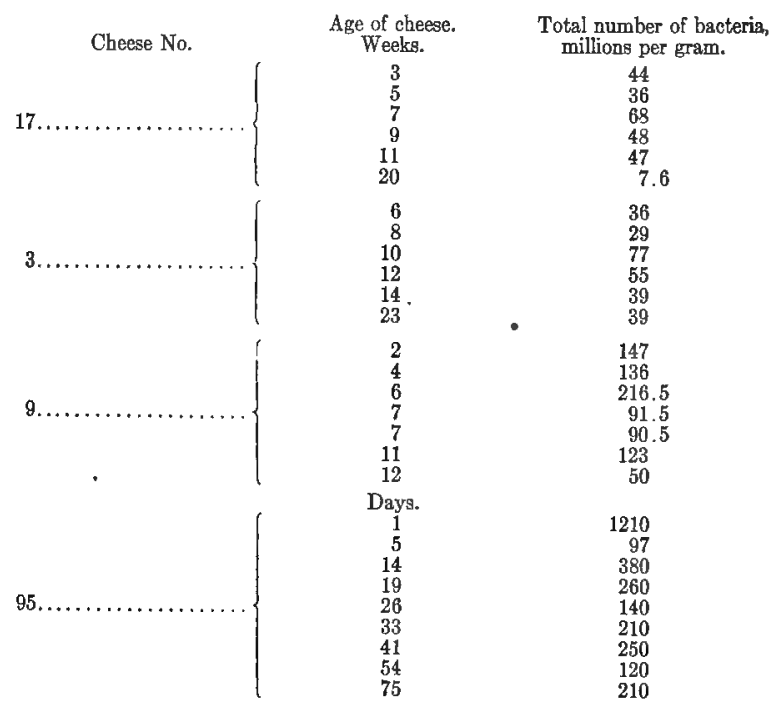


The culture-medium used for determining the number of bacteria is of importance, and may materially influence the result. Eldredge and Rogers found that lactobacilli increase in number during the ripening period of Emmenthaler cheese, and these would be overlooked if ordinary media were used. Special media are necessary to demonstrate the presence of lactobacilli. It is probable, therefore, that our notions concerning the number of bacteria present in cheese at different periods of the ripening process will have to be revised. Esten and Mason found lactobacilli in Camembert, Roquefort, Neufchatel, and Gorgonzola cheese, and Evans, Hastings, and Hart found Bacterium casei in Cheddar cheese. Bacteria of the group of lactobacilli have been frequently overlooked in dairy products because of the difficulty in cultivating them. Therefore it may be expected that they will be found, perhaps in large numbers, in many cheeses besides those mentioned.

Frequently the curd is heated to about $55^{\circ} \mathrm{C}$. This heating has an influence on the texture of the cheese. If not heated the curd is liable to be soft, and if heated to high temperatures it becomes hard. Heating has the additional advantage of destroying many bacteria and eliminating abnormal fermentations. For example, members of the Bacillus coli group suffer by heating to $55^{\circ} \mathrm{C}$., so that gassy fermentation is not likely to occur. The lactic streptococci which survive produce acid in the curd by decomposing the milk-sugar.

The chief decomposition products of milk-sugar in cheese are lactic acid and some volatile acids. The amount of acid in hard cheese is 1 to 1.5 per cent.; in soft cheese, 2 to 4 per cent. These figures represent the sum of free acid, acid phosphates, and casein, which is a weak acid. If lactic streptococci are not present in sufficient numbers to produce a relatively large amount of acid, gas is liable to be formed by the members of the Bacillus coli group. Gassy cheese is undesirable because large holes are formed and a disagreeable, bitter taste is developed. The cheese swells, and is known as being "swelled" or "buffed." In the middle portion of hard cheese conditions are anaërobic, so that streptococci and lactobacilli find favorable conditions for their growth, while in soft cheese a small amount of oxygen remains in the central portion. After all milk-sugar has been converted into acid, conditions are ripe for the growth of molds, yeasts, and liquefying cocci, which gradually neutralize the acid until in some cheeses the reaction becomes alkaline.

Digestion of casein commences in green cheese, if not earlier in the milk. The acidity prevents peptonizing bacteria of the Bacillus subtilis group from acting, but liquefying, acid-producing 
micrococci begin to peptonize the casein. The pepsin ferment contained in rennet is activated by the acid, and other enzymsgalactase, for example-produce proteolytic decomposition. In hard cheese the casein is decomposed in lesser degree than in soft cheese. The latter ultimately may become semiliquid. The degree of decomposition is measured chemically by determining the relative quantities of soluble nitrogen, amino-acids, and ammonia. The amount of acid present is an important factor influencing protein decomposition in cheese. As soft cheese contains much whey, there is a large quantity of acid in the central portion, and ripening is slower here than at the outside. When the outer portion has become transparent through proteolysis, the inner part is still opaque and white for some time. Decomposition of cheese is carried on by liquefying aërobic micrococci, lactobacilli, and molds. It was thought formerly that anaërobic and aërobic spore-forming bacteria were active, but these have been found to be of little or no consequence. The digestion of protein in cheese frequently leads to the formation of amino-acids. In Emmenthaler cheese a large number of amino-acids have actually been demonstrated, and the cheese owes its sweetish taste to their presence.

Dox found the following substances in Camembert cheese: Caseoglutin, protocaseoses, deuterocaseoses, peptones, histidin, arginin, lysin, glutaminic acid, tyrosin, and leucin. He did not find paranuclein, tryptophan, indol, skatol, mercaptan, hydrogen sulphid, and phenols. There is, therefore, no putrefaction in Camembert cheese unless ripening is allowed to go too far. The author concludes that the digestion is an ereptic one, and that the enzym isolated from Camembert mold is a vegetable ereptase.

The fat is but slightly broken up in some cheeses, while in others decomposition is pronounced. Volatile acids are formed, and these are responsible for flavor. The decomposition of fat may go so far as to impart a rancid taste and odor to the cheese. Fat decomposition is carried on by aërobic bacteria or molds. It commences, therefore, on the outside. If a mild cheese is desired, cheese is ripened in large bulk, so as to offer a relatively small surface to the air. The rind is sometimes specially protected against the air by a coat of paraffin. In Edam cheese the same object is sought by drying the ripe cheese in the sun, rubbing it with linseed oil, and coloring with Berlin red or annatto. If a strong taste is desired cheese is ripened in small pieces and thus a large surface exposed to the air. Among the products of fat decomposition are: alcohols, esters, acetic, butyric, propionic, caprionic, valeric, formic, and acetic acids. Volatile acids impart the characteristic cheese odor. Currie decided that the peppery 
taste of Roquefort cheese is caused by the formation of hydrolyzable salts of caproic, caprylic, and capric acids. Penicillium roquefortii produces a water-soluble lipase which decomposes the fat, with the formation of the acids mentioned.

The initial stage of cheese ripening is more or less alike in all cheeses. There is always acid present and peptonization commences early. There are some differences even in early stages. For example, in Emmenthaler cheese a large quantity of acid is not desirable, although the use of cultures of lactic acid bacteria is quite general, while in Cheddar cheese the presence of much acid is of importance. After the first stage of ripening, processes begin to differ materially in the many types of cheese. All manipulations are calculated to favor the development of the kind of micro-organism which produces the particular type of cheese. Cheddar cheese is ripened at low temperature; for Emmenthaler cheese the curd is heated; salt is worked in with the curd in Cheddar cheese; in Emmenthaler no salt is added at first, but is placed on the outside from time to time. That these and other methods of treating cheeses are important for microbial life is a matter of recent understanding, but one long experienced. However, since it has been understood that micro-organisms are the chief agencies in cheese ripening the reasons for different manipulations have become apparent. With the aid of the results of scientific investigations conditions can be regulated with more precision that heretofore.

Emmenthaler cheese is not perfect without holes, commonly called "eyes." The formation of these holes occurs at relatively high temperature. After a period of ripening at low temperature the cheese is placed in a room with a higher temperature to favor hole formation. In Cheddar cheese holes should not form, and, therefore, it is ripened at low temperature to the end of the process.

In the presence of much acid, peptonization proceeds rather slowly, but during later stages of ripening, when the acid is neutralized in whole or in part by the activity of molds and bacteria, peptonization is more rapid. When the fresh curd contains but a small amount of acid there is usually a secondary acid fermentation later.

Cottage cheese and buttermilk cheese are simple to prepare and require little if any ripening. Cottage cheese is usually made from skimmed milk and is a nourishing, palatable food, especially when sweet or sour cream is mixed with it. One gallon of skimmed milk furnishes about $1 \frac{1}{2}$ pounds of cottage cheese. According to Matheson and Cammack, cottage cheese can be prepared as follows: Sweet skimmed milk is set aside at a temperature of about $75^{\circ} \mathrm{F}$, and after it has coagulated, which process takes about 
thirty hours, it is cut into 2-inch squares and stirred with a spoon. The vessel containing the clabber is placed in hot water and kept at $100^{\circ} \mathrm{F}$. for thirty minutes, with an occasional stirring applied. The curd and whey are then poured into a cheesecloth bag and hung so that the whey is strained off. The curd is worked toward the center of the bag with a spoon. The cheese is finally removed, a teaspoonful of salt per pound added, and cream mixed with it to suit the taste. Cottage cheese can also be made by using sweet skimmed milk with addition of rennet. Rennet cheese has a finer texture than sour milk cheese, is made in a shorter time, and less curd is lost in the process. Dahlberg recommends the use of pasteurized milk for making cottage cheese.

Buttermilk cheese is made by coagulating buttermilk with heat. Sammis states that buttermilk cheese is superior in texture and flavor to cottage cheese, and can be sold with profit for half the price. Its food value is equal to that of lean beefsteak.

Cottage and buttermilk cheese are not ripened cheeses in the commonly accepted sense. The bacteria and molds which are active in producing fully ripened cheeses have been studied exhaustively in a few instances, and cultures are now used for the manufacture of several types of cheese. Camembert cheese has been studied more thoroughly than any other type and the microbiology of several others is fairly well understood, as Emmenthaler, Cheddar, and Roquefort cheeses, for example.

Emmenthaler cheese has been studied by several European and American investigators. The chief groups of micro-organisms are the common lactic acid bacteria, liquefying micrococci, and lactobacilli. The holes or eyes in this cheese are of particular interest and the number and size of the holes serve as a guide for judging its quality. A "blind" cheese, that is to say, one without holes, is of small value in the market. Formerly it was believed that these holes were caused by gas formed from milksugar by bacteria of the Bacillus coli group. This theory is not tenable, since milk-sugar disappears within a few days after ripening commences, while holes appear at later stages of ripening. The theory now held by some is that propionic acid bacteria decompose calcium lactate, with formation of gas, and that this gas forms the holes. The calcium lactate is formed by lactic acid combining with the calcium of casein. According to Clark, the gas consists of carbon dioxid and nitrogen. The nitrogen gas is derived from air originally contained in the curd and is not produced by bacterial action. Eldredge and Rogers could not find propionic acid bacteria in three samples of Emmenthaler cheese made in Wisconsin. They did find them by the same bacteriologic methods in a special 
cheese with which they worked. In regard to the bacterial flora in Emmenthaler cheese the authors stated that the cultures isolated could not be grouped by fermentation tests, but were sharply differentiated by morphologic characters into cocci, long rods, and short rods. The rods included typical cultures of Bacillus bulgaricus and also all gradations between typical cultures and those producing no acid in milk. In young cheese short rods were present almost exclusively. They decreased slowly in number as ripening progressed, while the long rods increased. After six to eight weeks both groups were present in about equal numbers. At the end of the ripening period the long rods were predominant. These long rods produce a small amount of proteolysis.

Extensive studies of American Cheddar cheese were made by Evans, Hastings, and Hart. The authors believe that the factors involved in ripening of Cheddar cheese are: 1 , pepsin contained in the rennet; 2 , lactic acid formed by lactic acid bacteria from milk-sugar, the acid activating the pepsin; 3 , the enzym galactase, and 4, certain biologic agents other than those simply concerned in the first lactic acid fermentation. In Cheddar cheese, as in Emmenthaler, three groups of organisms are active, namely: 1, lactic acid bacteria of the streptococcus group; 2, lactobacilli, and 3, micrococci. By studying different groups after inoculation into 300 c.c. of sterile milk and after incubation for four months the authors found the following substances: formic, acetic, caproic, propionic, butyric, citric, and lactic acids. The lactobacilli produced large quantities of lactic acid, both active and racemic. This group is also held responsible for the pungent taste which develops during the later ripening period of Cheddar cheese.

Among the soft cheeses, Camembert has received the greatest amount of attention. The Institut Pasteur prepares the sets of cultures for making this cheese, namely: 1, lactic acid bacteria; 2, yeasts, Oidium lactis and Penicillium camemberti, and 3, peptonizing micrococci which produce a reddish pigment. The procedure with these cultures is as follows: The milk, which should be pasteurized, is inoculated with the culture of lactic acid bacteria and ripened at $18^{\circ}$ to $20^{\circ} \mathrm{C}$. When ripe, Culture 2 is mixed with the milk and the casein precipitated with rennet at $26^{\circ} \mathrm{C}$. Salt is then added and the curd placed in a dry room at $13^{\circ}$ to $15^{\circ} \mathrm{C}$. The cheeses are turned frequently until covered with a layer of mold. They are then placed in ripening cellars at $7^{\circ}$ to $8^{\circ}$ or $10^{\circ}$ to $12^{\circ} \mathrm{C}$. At the lower temperature the process is slower than at the higher one, but the product is of better quality. The red peptonizing bacteria (Culture 3 ) are cultivated in milk, and the rush mats which are placed under the cheese are soaked 
in the culture. Before soaking the mats should be boiled and dried at high temperature $\left(70^{\circ}\right.$ to $80^{\circ} \mathrm{C}$.). After soaking in the milk culture for half an hour the mats are placed in the ripening cellar and the surface smeared with moldy cheese. The red cocci multiply rapidly and soon break through the layer of cheese. The curd which now contains lactic acid bacteria, yeasts, molds, and Oidium lactis is placed on the mats and the ripening process progresses rapidly. The balance of the milk culture of micrococci is sprinkled on the walls of the cellar.

In this country Thom has given much time to the study of Camembert cheese. He describes the stages of ripening as follows: First two weeks: Cheeses enter the ripening room on the third day after making. They usually become sticky, with evidence of Oiddium lactis, and often with the smell of yeast, within three or four days. In five or six days threads of Camembert mold appear. In nine to twelve days the colonies of Camembert mold show traces of colored spores. The colonies of the Camembert mold appear as patches on the side or edges or as a light covering well distributed, but they should not form a heavy felt all over. Uncovered areas should show a marked slimy, reddish covering. If the room is too wet, oildium, yeast, bacteria, and mucor may displace the Camembert mold. Soon in normal ripening the slime-forming organisms are covered by the mycelium of the Camembert mold. This mold extracts water from the surface and the rind becomes too dry for the slime-forming bacteria. At the end of two weeks' ripening the rind of the cheese should be well established and the first traces of softening appear. If the rooms are kept cold every stage of ripening may require double the amount of time needed at $52^{\circ}$ to $56^{\circ}$ or $58^{\circ} \mathrm{C}$. Cheeses low in water content require more time than those with high percentages of water.

Third week: During the first two weeks little or no change in the sour curd is noticeable. A piece of litmus paper pressed against the cut cheese will show an acid reaction, although surface layers for perhaps $\frac{1}{8}$ inch may test alkaline. Ripening proceeds more rapidly during the third week, and the curd just below the rind softens. The line between the sour and ripened curd is a fairly sharp one, as shown by the softening of the texture. Ripe cheese is usually neutral or alkaline to litmus, although occasionally it may be acid.

When this softening becomes noticeable at the edges of the cheeses they must be removed from the matting, otherwise the rind may peel off and adhere to the matting. They are then placed on ripening boards and turned once a day to secure uniformity of ripening. The time required depends largely upon the 
temperature at which the cheese is ripened. At about $60^{\circ} \mathrm{F}$. cheese ripens almost completely in twenty-one to twenty-four days, while at $50^{\circ}$ to $54^{\circ} \mathrm{F}$. it may take twice as long. Cheeses ripened rapidly decay rapidly. Cheese which has ripened for a long period retains its condition for a long time. Usually after three weeks of ripening the cheeses are wrapped in parchment paper or tinfoil and placed in boxes. Tinfoil wrapping prevents evaporation, hastens ripening, produces a more liquid cheese, and leads to strong odors and flavors. Fully ripe cheese is of the consistency of moderately soft butter or may be soft enough to run. The cheeses are sent to the market when ripening has progressed to a stage where softening extends about $\frac{1}{4}$ inch from the surface. Ripening is finished in cellars of dealers or those of hotels or cafés.

The ripening agents, according to Thom, are Penicillium camemberti, or its white form P. camemberti var. rogeri, Oïdium lactis, and species of bacteria which, with Oïdium lactis, take up the reddish slime. The properties of Camembert cheese are due to complex chemical changes of the casein, while the fat is little affected. The Camembert mold causes the changes in texture, while Oidium lactis and the red slime-forming bacteria produce the flavor. Therefore the presence of red slime on a cheese is a criterion of a good quality.

A bluish-green layer on Camembert cheese indicates either contamination with a green penicillium or an overproduction of spores of the Camembert mold. In both cases the cheese is of poor quality.

Roquefort cheese is harder than Camembert cheese, but not as hard as Emmenthaler or Cheddar cheese. Ripening of Roquefort cheese is due to the action of lactic acid bacteria and a green penicillium which has been thought to be identical with $\mathrm{P}$. glaucum, the common green mold. It seems, however, that the Roquefort cheese mold is a variety closely related to $\mathrm{P}$. glaucum. The acid curd is placed in caves which have been used for ripening the cheese, and many fine holes are punched into the curd by means of a special instrument. The Roquefort mold spores enter these holes and ripening begins. The holes also serve the purpose of admitting air which is needed for growth of the mold. The curd may be mixed with moldy bread which has been dried and pulverized. Ripening is very uniform throughout the cheese. The texture is soft and crumbly and the taste peculiarly sharp. Roquefort cheese is most commonly prepared from sheep's or goat's milk, but cow's milk is also used. The characteristic green marble-like appearance of the cheese is due to colonies of the mold. Gorgonzola, Stilton, and Brinsen cheeses are similar to 
Roquefort cheese, and are ripened by lactic acid bacteria and a green mold.

Brie and Isigny are cheeses similar to Camembert cheese. The curd is prepared much as is the Camembert curd, but the micro-organisms concerned in the ripening process are different. These cheeses have not been studied to a great extent and the microflora has not been precisely determined. The French Brie cheese is ripened by groups of micro-organisms similar to those producing Camembert, but the American product is quite different.

Cheese made from goat's milk has a darker color than most other cheeses, and has a strong odor and taste which appeal to the tastes of some people.

\section{Abnormal Cheese}

One of the most frequent abnormal forms of cheese is gassy cheese. Gas formation militates against good taste and appearance. Gassy cheese may have either too many small holes or a few very large ones. Manurial pollution of milk or old rennet are responsible for gassy cheese in most instances. Gas formation is caused by lactose fermentation caused by members of the Bacillus coli group of bacteria or closely related bacteria, as, for example, the organism described by Moore and Ward, which not only produced a gassy cheese but also a taint. Bacteria of this group are rarely present in the udder, but can be found in nearly all milk after it has been drawn. If present in large numbers, as in dirty milk, they may gain ascendency over lactic acid bacteria unless these are scarce. Heating of the curd, pasteurization of the milk, and salting of the curd are preventive measures. Sammis has found that in the presence of lactic acid bacteria the gas produced by the Bacillus coli group is retained in the curd, while in the absence of lactic acid bacteria most of the gas formed escapes. Doane and Eldredge came to the conclusion that gas formation is prevented by the presence of Bacillus bulgaricus, but not that of the common lactic acid bacteria.

The Wisconsin curd test (see page 210) is especially designed to aid the cheese maker in determining the quality of milk as regards possible gas formation. The curd may appear chiefly in five types, as follows:

1. The curd remains fluid with a sweetish or slightly bitter taste, or but slightly sour with a bitter taste. This happens when exceptionally clean milk is used and results from interaction of Streptococcus lacticus, Bacillus coli or B. aërogenes, and various micrococci.

2. The curd is gelatinous and may show streaks of gas. A smooth gelatinous curd is due to action of Streptococcus lacticus. 
If Bacillus coli or B. aërogenes is present enough gas is formed to cut small holes in the curd. The B. subtilis group may also produce a smooth coagulum, but this is redissolved later.

3. The curd may be granular, with whey enclosed and fissures. This shows the presence of Bacillus coli, Streptococcus lacticus, and liquefying cocci.

4. The curd adheres to the walls of the vessel and the whey is greenish white and has a sharp, sour taste. The Bacillus coli group and micrococci are well represented.

5. The curd is heavily charged with gas-bubbles and rises to the surface (floater or floating curd). Large numbers of the Bacillus coli group are present.

Of course these are only types, many variations being possible.

The catalase test (page 237) is of use to the cheese maker in discovering abnormal conditions in milk. This test shows the presence of colostrum milk, old milk, milk derived from cows near the end of lactation, or milk from diseased cows. Milk from cows suffering from udder disease or gastro-intestinal disturbances gives a positive catalase test.

In some cheese factories a small amount of potassium nitrate is added to the milk to prevent gassy fermentation. The amount necessary is from 0.04 to 0.1 per cent. Potassium nitrate protects the milk-sugar against attack by Bacillus coli or B. aërogenes, as they derive their oxygen supply from the nitrate instead of the milk-sugar.

A not uncommon trouble with cheese is the appearance of small yellowish-red spots or patches, the so-called "rusty spot." As a matter of fact, these spots are more common than is generally supposed, but frequently the color of the spots is so light that they are covered by the coloring-matter often added to the cheese. The "rusty spots" are colonies of bacteria, variously named Bacterium casei fusci, Micrococcus chromoflavus, and Bacillus rudensis. B. rudensis is probably more frequently the cause of rusty spots than the others.

Yellow color and white spots in Cheddar cheese are due to the action of Bacillus coli and torulæ.

Bitter cheese is caused by several bacteria and torulæ. Freudenreich's Micrococcus casei amari and Harrison's torula amara have been isolated from bitter cheese. -Harding, Rogers, and Smith found a short bacillus as the cause of a bitter taste in Neufchatel cheese.

The same authors ascribe the sweet or fruity flavor, which causes an annual loss of at least $\$ 10,000$ worth of Cheddar cheese, to the presence of yeasts, although yeasts are rarely found in normal Cheddar cheese. 
Blue cheese occurs sometimes as a result of bacterial action or from a chemical process. If the whole surface is covered, it is due to a chemical process resulting from the use of iron vessels. The lactic acid takes up some of the iron, which is then precipitated as a dark blue substance, with the evolution of some hydrogen sulphid. Copper from copper vessels also may dissolve and cause coloration of the cheese. Blue spots are sometimes caused by Bacillus cyanofuscus, which occurs in surface waters. Iron bacteria also may cause the formation of bluish-black spots.

As a carrier of disease germs cheese is not very important. As a rule, cheese is consumed after a long period of ripening, and pathogenic bacteria do not survive exposure to adverse conditions such as are found in cheese making. The acid and the competition of enormous numbers of saprophytic micro-organisms act unfavorably on disease germs. Mohler, however, has stated that tubercle bacilli were found in Cheddar cheese when four months old. There is some menace to health in cheese which is consumed fresh, such as cottage cheese, for example. Pasteurization of the milk used for this class of cheeses is, therefore, advisable.

Schroeder and Brett express their opinion of the possible infectiousness of cheese in the following words:

" 1 . We may safely say, and we say it with great satisfaction, that cheese of the kind which requires some time to ripen rarely if ever contains true living, pathogenic bacteria when it is marketed, and it does not seem likely that such cheese is apt to contain dangerous products of bacterial origin.

" 2 . Cream cheese, which is an elegant, palatable, nutritious article, recommended by many physicians as excellent food for children and invalids, until quite recently was heavily contaminated with tubercle bacilli of the bovine type, or tubercle bacilli of the kind which have their origin in the bodies of tuberculous cattle."

Poisoning after the consumption of cheese has been reported. The symptoms are nausea, vomiting, and diarrhea, followed by general weakness. There are different theories as to the cause of such sickness. In a few cases a poison has been found in the cheese, and this was called tyrotoxin (Vaughan and Perkins). In other cases the origin of the poison was ascribed to strains of Bacillus coli which were held responsible for diarrhea in cows and which gained access to the milk. Again, it has been believed that formation of ptomains, such as putrescin and cadaverin, or formation of hydrogen sulphid and indol have been responsible for poisoning. These substances are not supposed to be intensely poisonous and are probably the cause of untoward symptoms only when real putrefaction has taken place, so that they are present in rela- 
tively large quantity. Perhaps even small amounts may affect people with weak digestive organs. The causes of cheese poisoning are still obscure, and precise observations are desirable. Possibly the presence of bacteria of the Bacillus enteritidis group may be responsible for some cases of cheese poisoning.

Bacteriologic examination of cheese is accompanied by some difficulties, the most important of which is the proper selection of culture-media. It is obvious that the use of ordinary laboratory media may lead to erroneous results, since some bacteria do not grow on them. Lactobacilli, for example, grow but poorly, some strains not at all, on ordinary media. Eldredge and Rogers, in their studies of Emmenthaler cheese, used a medium prepared in the following manner:

"(a) Heat skimmed milk to the boiling-point and add 20 c.c. of 10 per cent. lactic acid per liter of milk.

" $(b)$ Filter, and add to the filtrate: pepton, 1 per cent.; beef extract, 5 per cent.; agar, 1.2 per cent.

"(c) Heat to the boiling-point until the agar is melted.

"(d) Correct the reaction to -1.2 per cent., using phenolphthalein.

"(e) Cool to $45^{\circ} \mathrm{C}$. and add the white of one egg to each liter.

" $(f)$ Heat to $100^{\circ} \mathrm{C}$. for forty-five minutes and filter through cotton.

" $(g)$ Correct reaction if necessary, tube, and sterilize three successive days in the Arnold."

The authors state that cultures of the Bacillus bulgaricus type form good-sized colonies on this medium in four to five days at $30^{\circ} \mathrm{C}$.

A suitable medium for growth of bacilli of the Bacillus bulgaricus type was used by the writer and Hefferan. This is prepared in the following manner:

Certified milk is skimmed and heated. When near the boiling-point a few drops of acetic acid are added to coagulate the casein. The serum is filtered off and enough sodium hydrate solution added to make the reaction 1 per cent. acid to phenolphthalein. Then 1 per cent. pepton and 2 per cent. dextrose are dissolved. In this solution 1.5 per cent. agar is dissolved by heating, and the medium clarified with the whites of eggs. Then it is tubed and sterilized in the autoclave. At temperatures from $37^{\circ}$ to $45^{\circ} \mathrm{C}$. bacilli of the Bacillus bulgaricus type develop large colonies in about two days.

For isolation of the majority of bacteria in milk or milk products Ayer's casein agar is an excellent medium. The preparation of this medium has been given on page 415 .

Samples of cheese for bacteriologic examination should be 
taken with sterile cheese samplers or cheese triers. For composite samples each portion of the cheese should be represented. Before making plates the sample is emulsified in sterile physiologic salt solution.

For chemical examination of cheese a wedge-shaped piece is cut from the outside to the center. This is passed three times through a sausage-grinding machine. When the cheese cannot be cut, samples are taken with a cheese trier. Several plugs are taken and mixed.

Determination of Moisture--Mix 2 to 5 grams of the mixed sample with some porous material and heat in a water oven for ten hours.

Determination of Ash.-Determine the same way as in butter.

Determination of Nitrogen Compounds.-Follow the procedure used for milk.

Determination of Fat.-The fat can be conveniently determined by the Babcock method. Weigh 6 grams of the sample in a tared dish and add 10 c.c. boiling water, with a few drops of ammonia. Stir the mixture until a perfect emulsion has been formed. Add one-half of the usual amount of sulphuric acid and transfer to a Babcock bottle. The other half of the sulphuric acid is used for washing out the beaker. Then proceed as with milk. Multiply the reading by 18 and divide by the weight of the sample to obtain the percentage of fat.

\section{BIBLIOGRAPHY}

Ayers: United States Dept. of Agri., B. A. I., 1911, 28th Annual Report, p. 225.

Babcock, Farrington, and Hart: Univ. of Wis. Agri. Exper. Sta., Bull. 197, July, 1910.

Clark: United States Dept. of Agri., B. A. I., Bull. 151, September, 1912.

Cohn: Beiträge zur Biologie der Pflanzen, 1872, Band 1, Heft 2, p. 127.

Conn, Thom, Bosworth, Stocking, and Issajeff: Storrs' Agri. Exper. Sta., Bull. 35, April, 1905, and United States Dept. of Agri., B. A. I., Bull. 71,1905 .

Currie: Jour, Agri. Res., 1914, vol. 2 , No. 1.

Dahlberg: United States Dept. of Agri., B. A. I., Bull. 576, September, 1917.

Doane and Eldredge: United States Dept. of Agri., B. A. I., Bull. 148, March, 1915 .

Doane and Lawson: United States Dept. of Agri., B. A. I., Bull. 146, December, 1911.

Dox: United States Dept. of Agri., B. A. I., Bull. 109, Norember, 1908.

Eldredge and Rogers: Cent. f. Bakt., Abt. 2, 1914, rol. 40, p. 5 .

Esten and Mason: Storrs' Agri. Exper. Sta., Bull. 83, September, 1915.

Evans, Hastings, and Hart: Jour. Agri. Res., 1914, vol. 2, p. 167.

Hammer: Agri. Exper. Sta. Iowa State Coll. of Agri. and Mech. Arts, Research Bull. 27, January, 1916.

Harding and Prucha: New York Agri. Exper. Sta., Tech. Bull. 8, p. 121.

Harding, Rogers, and Smith: New York Agri. Exper. Sta., Bull. 183, December, 1900 .

Harrison and Connel: Cent. f. Bakt., 1903-4, Abt. 2, vol. 11, p. 640.

Hart, Hastings, Flint, and Evans: Jour. Agri. Res., 1914, vol. 2, p. 193. 
Heinemann and Hefferan: Jour. Inf. Dis., 1909, vol. 6, p. 304.

Issajeff: Storrs' Agri. Exper. Sta., Bull. 46, February, 1907.

Langworthy and Hunt: United States Dept. of Agri., Farmer's Bull. 487, February, 1912.

Löhnis: Handbuch der Landwirthschaftlichen Bakteriologie, 1910, Berlin, Borntraeger.

Löhnis: Vorlesungen über Landwirthschaftliche Bakteriologie, 1913, Berlin, Borntraeger.

Matheson and Cammack: United States Dept. of Agri., B. A. I., Farmer's Bull. 850, August, 1917.

Moore and Ward: Cornell Univ. Agri. Exper. Sta., Bull. 158, January, 1899.

Olson: Univ. of Wis. Agri. Exper. Sta., Bull. 162, April, 1908.

Sammis: Univ. of Wis. Agri. Exper. Sta., Bull. 239, June, 1914. Suzuki and Laabs, Univ. of Wis. Agri. Exper. Sta., Research Bull. 7, February, 1910.

Sammis and Bruhn: United States Dept. of Agri., B. A. I., Bull. 165, June, 1913.

Schroeder and Brett: Sixth Annual Report of the Association of Dairy and Milk Inspectors, held in Washington, D. C., 1917, p. 190.

Thom: Storrs' Agri. Exper. Sta., Bull. 58, June, 1909. 'United States Dept. of Agri., B. A. I., Bull. 82, 1906. United States Dept. of Agri., B. A. I., Circular 145, January, 1909. United States Dept. of Agri., B. A. I., Bull. 115, October, 1909. United States Dept. of Agri., B. A. I., Bull.' 118, February, 1910.

Vaughan and Perkins: Archiv. f. Hygiene, 1896, vol. 27, p. 308. 


\section{ICE-CREAM AND ICES}

ICE-CREAM is a term applied to a variety of frozen products, but commonly means a frozen mixture of cream, milk, sugar, eggs, condensed milk, and flavoring substances. Ice-cream is usually eaten as a delicacy and not as a food, although it contains a large amount of valuable nutritive material. The French say "crême glacé" or "glace à la crême," which means cream-ice, a term which preceded that of ice-cream, the latter being of relatively modern origin. The French recognized two kinds of frozen desserts, namely, frozen water with fruits and ices with cream. Until it was introduced into England ice-cream was never made from cream alone; then frozen flavored and sweetened cream was prepared for the first time. The mixture was not agitated when freezing, but that part of the mixture which had congealed on the sides of the vessel was removed. The modern ice-cream freezer is an American invention and was introduced about seventy years ago. Since that time the consumption of ice-cream has increased enormously.

Modern frozen dainties are the result of evolution, probably occurring simultaneously in different parts of the world. The brief recital of the development of modern ice-cream which is given here is an abstract of an article by Washburn, published in Bulletin No. 155 of the Vermont Agricultural Experiment Station.

Cool beverages are used chiefly during the warm season and in hot climates. During biblical times the Jews, Greeks, and Romans cooled wines and other beverages by adding snow, and this practice still prevails in parts of Spain and Turkey. The snow is obtained from snow-capped mountains, and in localities where snow is not available the beverages are placed in porous jars and urns, then exposed to cool breezes, or air currents are created by swinging the jars.

History relates that Alexander the Great used iced beverages, and that Henry the Third of France had snow and ice served at his table. The Italians introduced a solution of saltpeter in the snow and ice, and later dropped that salt directly into the snow and ice in which the vessel containing the beverage was revolved. The saltpeter materially reduced the temperature of the freezing mixture so that the beverage became partly solid.

Water-ices were first used in Italy, and were introduced into France about 1550 by Catherine de Medici. Whether the use of 
cream for frozen dainties is of later date than that of water-ices is not known. It is reported that a book which contained a recipe similar to that for ice-cream was published in Rome by Quintus Maximus Gurges.

Water-ices and milk-ices were introduced into Europe from Asia by Marco Polo, and "cream ice" was served at the court of Charles the First of England. The chef of Louis the Fourteenth of France at an entertainment served a cold, solid sweetmeat in the shape and color of an Easter egg.

In 1776 a French cook, Clermont, published in London a book in which directions for making sweet ices were contained. English cream-ices at that time were made of milk, sugar, eggs, arrowroot or flour, and flavoring extracts. Fancy molded creams were probably first made in Germany.

In the United States ice-cream was first prepared in New York by Mr. Hall. Ice-cream was served at a dinner in Washington, of which dinner President Washington partook. In 1786 an advertisement appeared in the "Post Boy," a New York publication, stating that "Ladies and Gentlemen may be supplied with ice-cream every day at the City Tavern by their humble servant, Joseph Crowe."

The first wholesale ice-cream business was launched in 1851 by Jacob Frussell, of Baltimore. He was in the milk business, and utilized surplus cream for making ice-cream; this he sold at 60 cents a quart. This side-line soon proved more profitable than the original milk business, which was then discarded.

Ice-cream made in this country is in great demand in other countries and, consequently, steamers loading in New York take on this commodity for such distant countries as India, China, Japan, and Australia.

"Fried ice-cream" was introduced at the World's Fair in Chicago in 1893. This is prepared by dipping a cube of hard icecream into a thin fritter batter and then plunging it into hot fat. The pastry hardens quickly and the cream is not softened.

Today such a large variety of ice-creams and water-ices are made that every preference can be satisfied. The total annual output is estimated at $100,000,000$ gallons per year or 1 gallon per capita, representing a money value of $\$ 140,000,000$, figured at a retail price of $\$ 1.40$ a gallon. Instead of using ice, factories now generally run refrigerating machines for freezing their product.

At present a great variety of ices and ice-creams are served in hotels and restaurants. The so-called French ice-cream is frozen without agitation, and is solid and heavy. American ice-cream is light and soft, due to the violent agitation in the freezer. A large volume of air is mixed with the ice-cream during the freezing proc- 
ess, so that the finished product occupies a larger space than the original mixture. This increase in volume, known as "swell" or "overrun," may be as great as 80 per cent. While 1 gallon of French cream is made from 1 gallon of mixture, nearly 2 gallons of American ice-cream are made from 1 gallon of mixture.

Manufacturers use different formulæ for ice-cream mixtures. The chief ingredients in American ice-cream are cream, unsweetened condensed milk, milk, sugar, and flavors. In French icecream eggs are also used and the mixture is cooked before freezing. This, in reality, is a frozen custard. The total solids in ice-cream are about 35 per cent. After the ingredients are mixed the fluid is kept in a cold room at about $35^{\circ} \mathrm{F}$. and is then placed in a freezer. Here it is agitated and frozen to a semisolid consistency. When this stage has been reached the cream is filled into cans and placed in a refrigerator room at about zero $F$. for a period of twelve to twenty-four hours. The ice-cream ripens here, becomes hard, and the flavors blend. It is then ready for the market.

The flavor of ice-cream is conditioned by the flavoring extracts added and the fat content. The higher the fat content, the richer the flavor, but beyond a certain limit the fat renders the icecream greasy and less palatable. Cream of 22 to 25 per cent. fat is most suitable. Below this amount the taste is lean, and above it the consistency is unfavorably affected.

The quality of the cream and milk used in making ice-cream is of the utmost importance. The cowy taste of dirty milk or cream is quickly recognized in ice-cream. The acidity of the milk or cream used should never be above 0.25 per cent., expressed in lactic acid.

Separator cream gives as good results as gravity cream. Homogenized cream is now used in many ice-creams. Homogenized cream is cream which has been passed through a homogenizer at a pressure of 3000 to 5000 pounds. The fat globules are dispersed so that they are very small and are difficult to separate even with a separator. A peculiar richness is imparted to the cream by this process, with the result that cream of 16 to 17 per cent. fat content can be used and a product obtained which practically equals one made with the usual 22 to 25 per cent. cream. Experience has shown, however, that the addition of 10 to 20 per cent. natural cream gives better results than the exclusive use of homogenized cream.

Some manufacturers add a small amount of salt to the mixture, say, $\frac{1}{2}$ teaspoonful to the gallon, as this seems to appeal to the palates of many customers.

Milk and cream used in the manufacture of ice-cream are now frequently pasteurized in order to prevent the possible spread of 
infection. Pasteurized cream is held in a cool place for at least twelve hours, or longer, before it is used. During this period the viscosity, which is largely destroyed by pasteurization, reappears. Viscosity is a vital quality of cream for ice-cream making, as without it the overrun is difficult to obtain.

Ice-cream manufacturers give considerable attention to obtaining a product which has the right "body" and "texture." These terms are frequently confused and are defined by Washburn as follows: "The words 'body' and 'texture' are used in ice-cream making to mean two quite different things. Body is synonymous with structure or substance. It refers to the entire mass as a unit. Texture, on the other hand, has to do with the finer make-up of the article. The structure of table linen, for instance, consists of a smooth fibrous piece of cloth. Its texture, on the other hand, indicates a lot of closely woven threads. The one has to do with the mass characteristics, the other with the arrangement of the particles."

The body of ice-cream is conditioned chiefly by the milk solids. It is, therefore, the practice of many manufacturers to add evaporated milk to the mixture, by which process the smoothness and food value of ice-cream are incidentally and materially increased. Sometimes wheat flour, rice flour, or cornstarch are added, especially when the cream is poor in fat. When rich cream is used such additions offer no advantage.

Gelatin is also very generally used to improve the body of ice-cream.

The aim of ice-cream manufacturers is to sell a product which is firm and mellow.

The texture of ice-cream should be smooth and there should be no ice crystals present. The manner of freezing is important in this respect, as rapid freezing produces crystals, while slow freezing with violent agitation causes the product to be smooth and free from crystals. The agitation or "whipping" incorporates a large amount of air with the mixture, frequently as much as 33 to 40 per cent. The addition of gelatin or such substances as gum tragacanth, eggs, etc., insures the stability of the texture and prevents the formation of crystals when the ice-cream stands. These substances are known as "stabilizers," "binders," "fillers," and "colloids."

For ordinary creams gelatin is probably used more than any other substance as a filler. A very small amount is needed. If a good quality of gelatin is used, 4 ounces is a sufficient addition to 10 gallons of ice-cream mixture. The product is rendered smooth and does not become sandy or have a crystalline texture. Large quantities of gelatin are to be avoided, since they make the 
ice-cream stiff, sticky and spongy, and influence the taste unfavorably. Poor qualities of gelatin should never be used, because they both impair the taste of the product and usually contribute enormous quantities of micro-organisms. The gelatin is dissolved in hot water or, better, in hot skimmed milk before it is added to the mixture.

Eggs are efficient stabilizers, and are used chiefly in French and Neapolitan ice-creams. They should be well cooked before they are used.

Rennet coagulates milk and consequently produces a firm body and smooth texture. Gum tragacanth is also not infrequently used as a stabilizer. A stock solution is made by soaking 1 ounce of gum in 1 quart of hot water, and then- dissolving 3 pounds of sugar in the same. The sugar acts as a preservative, making it possible for the solution to remain usable for several weeks. One quart of gum tragacanth and sugar solution suffice for 10 gallons of ice-cream, according to Washburn.

So-called "ice-cream powders" for producing a rich and smooth ice-cream are purchasable in the market. They consist of gelatin or gum tragacanth, or a combination of both. They are triturated with six to ten times their weight of sugar, and are then dusted on the mixture before freezing. Some ice-cream powders contain starchy substances as well, such as flour or cornstarch. Some even have powdered rennet mixed with other stabilizers. When wheat flour, rice flour, or cornstarch are to be used they should be well cooked before they are added to the mixture. Otherwise a granular texture may result."

Sugar is always added to ice-cream mixtures, chiefly to increase the palatibility of the ice-cream. The quantity of sugar used amounts to about 14 per cent. of the finished product.

The swell or overrun of ice cream is due chiefly to the air which is incorporated during the freezing process by the violent agitation. The expansion of the cream also adds somewhat to the overrun. The cream should be viscid in order to retain the air. The swell adds to the palatability of ice-cream and frequently increases the volume of the product 80 per cent. Slow freezing with continued whipping increases the swell.

Washburn states that the swell commences to form at $34^{\circ} \mathrm{F}$., and ceases to form at $27^{\circ} \mathrm{F}$. The maximum is reached at $28.5^{\circ} \mathrm{F}$, but the cream should not be removed before the temperature has reached $28^{\circ} \mathrm{F}$., otherwise some of the swell is lost by the loss of air. When the swell exceeds 80 per cent. of the mixture the body of the ice-cream deteriorates. In the chart (Fig. 235) Washburn illustrates the relation of temperature to swell.

A relative test for the quantitative determination of the 
overrun was devised by Benkendorf, and is carried out as follows (Bull. 241, July, 1914, Agri. Exper. Sta. of Univ. of Wisconsin):

"The apparatus used in making the test consists of an icecream sampler, a 250 c.c. Florence flask, a 200 c.c. Florence flask, a funnel or a 250 c.c. beaker, a buret, and a 1 c.c. pipet. All of these, except the ice-cream sampler, can be readily obtained from any supply house.

"The ice-cream sampler is a cylinder, about $1 \frac{5}{16}$ inches in diameter (inside measurements) and about $2 \frac{1}{4}$ inches long, preferably made of thin brass tubing. The sampler when filled

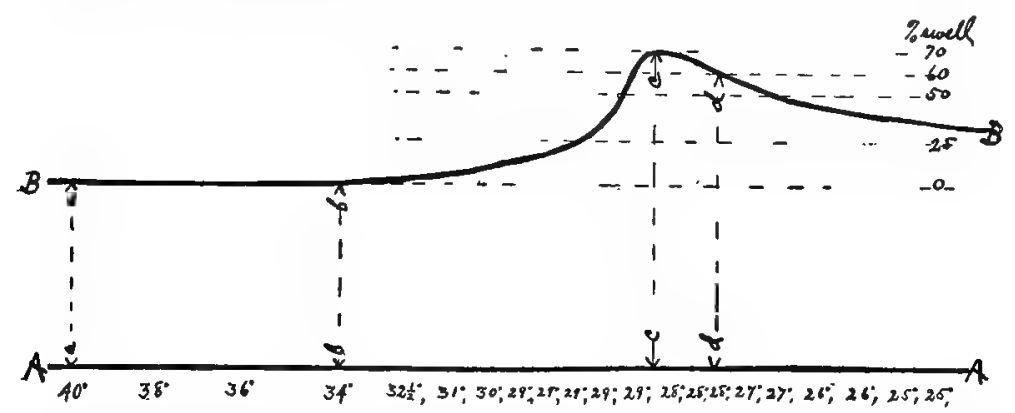

TEMPERATURE-SWELT CFIART

represent the between the lower straight line $\mathbf{A A}$ and the upper curved line $\mathrm{Bi}$ represent the space occupied by the mix before, during and after freezing. Let the figures below the lower straight line represent the temperatures of the mix taken at minute intervals during the freezing process. Now, assume that the dasher is being turned at a uniform rate of speed. Then, distance $a a$ will be the volume of the mix at the temperature $40^{\circ}$ and $b b$ its volume at $34^{\circ}$, at about which point the swell commences. It will be noted that the increase in volume continues but slowly at first, but very abruptly after the mass has been beaten at the temperature $29^{\circ}$ for about flve minutes, reaching its maxlmum volume, ( $70 \%$ swell) at about the temperature $28 \%^{\circ}$ or at the point represented by the distance $c c$ This crest is reached at about the point of thorough freezing. As the temperature falls to $28^{\circ}$ the mass begins to become brittle and "beat down" to a polnt represented by distance $d d$ with $60 \%$ swell If the beating and hardening processes are continued, the mass will gradually beat down as lndicated by the downward curve of the line. This figure is essentially a diagram of averages.

Fig. 235.-(Bull. 155, Vermont Agri. Exp. Sta., September, 1910.)

should contain exactly 50 c.c. of ice-cream. For testing icecream that has been packed and has fully hardened the sampler should be provided with a handle. This type of sampler is also preferred where the ice-cream container has a small diameter. These samplers are open at both ends. The sampler for use with the continuous type of ice-cream freezer or for determining the swell of soft ice-cream is closed at the lower end.

"Making the Overrun Test.-A sample of 50 c.c. of the icecream is obtained by pressing the sampler down into the hardened ice-cream until it is entirely below the surface. Allow the sampler to remain there for a moment to get cold and withdraw the sampler and the ice-cream which it contains. By means of a case knife 
or a piece of tin the protruding ice-cream can be removed from both ends of the tube. Where a continuous freezer is used, the sampler may be held under the spout of the freezer and filled with little difficulty. The sample is transferred from the sampler to the funnel, the stem of which is inserted in the neck of the 250 c.c. flask. In order to readily hold the 50 c.c. of ice-cream the opening of the funnel should be 3 inches in diameter.

"To transfer the ice-cream from the funnel to the 250 c.c. flask it is melted by pouring over it exactly 200 c.c. of hot water.

"In case a funnel is not available, equally good results can be obtained by transferring the sample of ice-cream to a 250 or 300 c.c. beaker. By using the hot water from the 200 c.c. flask it can be melted and then transferred to the 250 c.c. flask.

"To Reduce the Foam.-All melted ice-cream contains more or less foam which appears in the neck of the flask and must be destroyed before it is filled to the 250 c.c. mark. The foam can be eliminated by introducing a measured amount of ether directly into it. Usually 1 c.c. of ether will suffice. As soon as the foam has disappeared the flask can be filled with water to the 250 c.c. mark. This is best done by means of a buret.

"How Calculations are Made.-The number of cubic centimeters of water and ether used to bring the volume up to the 250 c.c. mark represents the shrinkage which the 50 c.c. of icecream have undergone when melted. Subtracting this shrinkage from 50 gives the original volume of the mix before freezing. It is then an easy matter to determine the percentage of overrun simply by dividing the number of cubic centimeters of shrinkage by the number of cubic centimeters there were in the original mixture. This can be illustrated as follows:

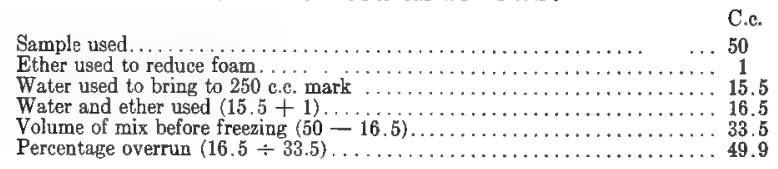

"Comparison of Results. - The following data, obtained by A. C. Baer, in charge of the ice-cream work at the University of Wisconsin, show comparisons of the results obtained with this method and methods commonly employed:

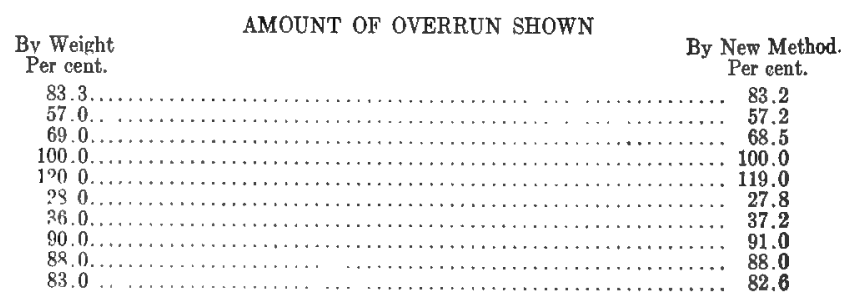


"Advantage of the New Method.-As previously stated, it is a matter of considerable importance for a manufacturer to know the amount of overrun which his ice-cream maker obtains, not
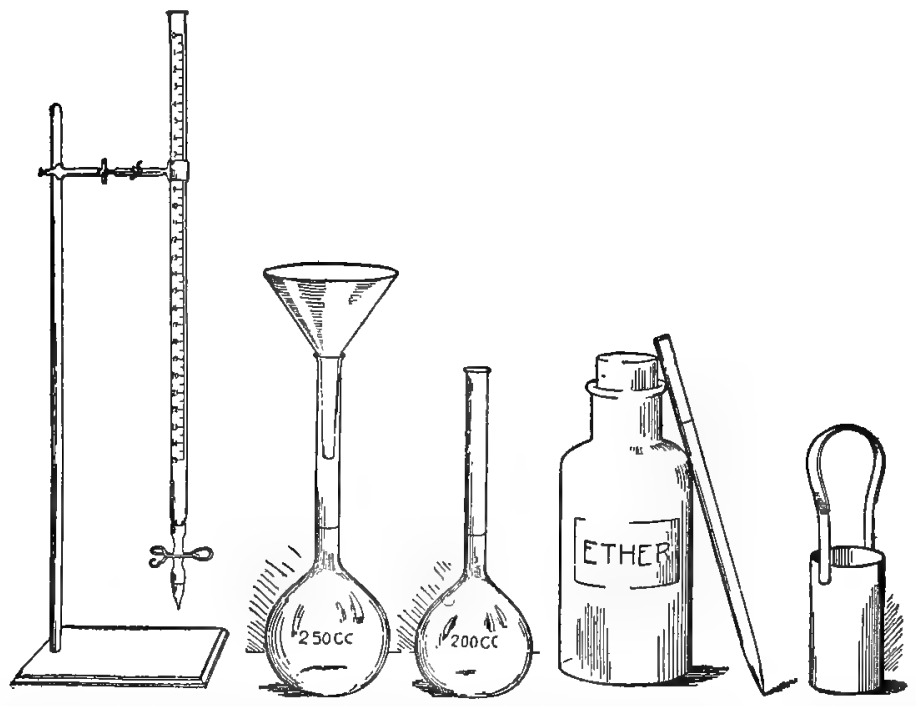

Fig. 236.-Apparatus for testing ice-cream overrun. As both the yield and quality of the finished product varies with the amount of overrun, its accurate determination is desirable. (Benkendorf, Univ. of Wis. Agri. Exp. Sta., Bull. 241, July, 1914.)

only from a financial standpoint, but from the standpoint of the quality of ice-cream produced. By this method the manufacturer is able, at any time, to determine the amount of overrun obtained by his ice-cream maker and to check up his work better from day to day, the importance of which is readily appreciated. The apparatus is simple, the expense is small, and but little time is required to make the test.

"A Few Precautions. - The glassware and the sampler should be correctly calibrated; any icecream adhering to the outside of the sampler should be carefully wiped off by means of a dry cloth

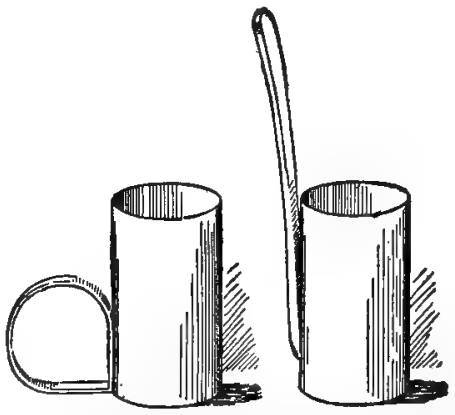

Fig. 237.-Ice-cream samplers. The kind for use with containers having a large diameter. (Benkendorf.)

or it might accidentally be transferred to the 250 c.c. flask. All of the hot water should be removed from the 200 c.c. flask to the 250-c.c. flask." 
The freezer should be stopped at $27^{\circ}$ to $28^{\circ} \mathrm{F}$., when the cream mixture has a consistency of condensed milk. The fat has no influence on the freezing-point, as it solidifies at a much higher temperature, but when a cream rich in fat is used the product is firmer than one made of lean cream. Flour and starches also do not affect the freezing-point, while eggs and gelatin depress the freezing, although so slightly that the effect is of no practical significance. Sugar, on the other hand, depresses the freezingpoint materially.

If ice-cream were frozen without agitation, the different constituents, having different freezing-points, would separate. This separation is prevented by the whipping, although there is a belief among some ice-cream manufacturers that fat is "lost" during the freezing process. Figures published by Wyman seem to bear out this belief, since he found differences varying from 8 to 28 per cent. fat in samples taken from the freezer at different periods, while the original mixture contained 18 per cent. fat. In an investigation made by Gordon and the writer the differences were so slight as to range within experimental error. It is true that in a preliminary series of tests some differences in fat content were found, but this was due to imperfect technic. During the ripening process it appeared that there was a slight movement of fat toward the center and top of the can, as shown by the following figures:

AVERAGES OF PERCENTAGE OF FAT FROM EIGHT CANS OF ICE-CREAM

\begin{tabular}{|c|c|c|c|}
\hline Kind of sample. & $\begin{array}{l}1-3 . \\
\text { Per cent. fat. }\end{array}$ & $\begin{array}{l}\text { 4-8. } 8 \text {. } \\
\text { Per cent. fat. }\end{array}$ & $\begin{array}{l}1-8 . \\
\text { Per cent. fat. }\end{array}$ \\
\hline Bottom at edge. . . . . . . . . . . . . & 8.27 & 7.98 & 8.09 \\
\hline 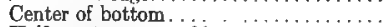 & 8.23 & 8.60 & 8.46 \\
\hline Half way to center of bottom. . . . . . . . & 8.40 & 8.98 & 8.76 \\
\hline Edge at top $\ldots \ldots \ldots \ldots \ldots$ & 8.73 & 9.00 & 8.80 \\
\hline Half way to center at top. . . . . . . . . . . & 8.80 & 9.20 & 9.05 \\
\hline 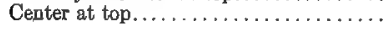 & 8.43 & 9.42 & 9.05 \\
\hline Average $\ldots \ldots \ldots \ldots \ldots \ldots \ldots \ldots$ & 8.48 & 8.86 & 8.70 \\
\hline
\end{tabular}

Washburn could find no difference in fat content between the portions taken at the top, middle, and bottom of the can which was held solidly frozen for a week, but he did find considerable differences in cream which had softened, as the following figures show:

FAT CONTENT OF DIFFERENT PORTIONS OF SOFTENED ICE-CREAM (WASHBURN)

\begin{tabular}{|c|c|c|c|c|}
\hline \multirow[b]{2}{*}{ Sample from } & & & Jo. & \\
\hline & 1 & 2 & 3 & 4 \\
\hline …........ & 28 & 22 & 10 & 12 \\
\hline ……..... & $\begin{array}{r}10 \\
5.5\end{array}$ & $\begin{array}{r}14 \\
8\end{array}$ & 8 & 4 \\
\hline
\end{tabular}

These figures show a very material movement of the fat, and while the fat rises, the heavier substances-such as fruit, syrups, 
etc.-go to the bottom. It follows that if ice-cream has softened it should not be refrozen unless it is first thoroughly agitated in the freezer.

Refreezing, as a rule, should be discouraged, because the icecream has been exposed to influences which may make it unsafe. Softening usually occurs in retail stores where the can is frequently opened and chance given for the entrance of infectious material. Furthermore, poisonous products due to microbial decomposition may form in softened ice-cream.

The test for fat in ice-cream is usually made by a modified Babcock method. The original Babcock method is not suitable because the sulphuric acid attacks the sugar and possibly some other substances, with the result that a clear fat column is not obtained. Washburn gives the following method:

"Carefully weigh 18 grams of a well melted (but not overheated) and mixed sample of ice-cream into a 30 per cent. cream bottle. To this add 4 or 5 c.c. of lukewarm water. Now add ordinary sulphuric acid, a little at a time, thoroughly mixing the fluids with each addition. Little more than half and seldom as much as two-thirds the usual amount of acid is required; and not more than one-half of this amount should be used at the outset, and some little time should be allowed for it to act. If the color is not yet that of strong coffee, add a little more acid, shake, and pause for a time. If still the color is too light, add yet more acid. In this way the color is built up to the desired point. When the contents of the bottle have assumed almost the desired amber color, add 4 or 5 c.c. of cool water to check the further action of the acid. The test is thereafter conducted as would be an ordinary cream test, care being taken that the machine does not become too hot during whirling. If this scheme is carefully followed, particularly in the matter of the slow and gradual addition of the acid, the fat should appear in the neck of the test bottle of a clear, light brown color and distinct from the solution below. When this distinct, clean-cut condition has been obtained, the tester may feel sure, provided the work has been in other respects carried out in accord with the well understood details of the Babcock method, that the results will be reasonably accurate."

The Illinois Food Commission advises the following modification of the Babcock method:

"Weigh 9 grams of the melted and thoroughly mixed sample into a 10 per cent. Babcock milk bottle. Add 10 c.c. of glacial acetic acid, washing down the neck of the bottle with the acid. Heat this mixture by putting the body of the bottle in hot water until the contents appear smooth, uniform, and free from lumps. Then, while still hot, add ordinary Babcock sulphuric acid about 
1 to 2 c.c. at a time, mixing contents after each addition, until the color of the mixture becomes dark chocolate brown.

"Whirl in a Babcock machine for five minutes, fill with boiling water to bottom of neck, and whirl one minute.

"Read the fat column and multiply the reading by $2 . "$

Notes on Above Method.- "A uniform mixture before weighing out samples is, of course, essential to accurate and uniform results.

"Too long heating or overheating of the mixture of acetic acid and ice-cream has practically no effect on the results. Heating for five to ten minutes in water slightly below boiling temperature is usually sufficient. The hotter the mixture is, the less sulphuric acid will be required to produce the proper color.

"The fat column should be perfectly clear and free from any curd or char. In case the fat column contains curd or char, duplicate the test, adding sulphuric acid to a darker color in the case of interfering curd, or to a lighter color in the case of interfering char.

"With very little practice in judging this color, perfect fat columns may be obtained in every test."

Good results are also obtained by using 20 c.c. of a mixture of equal parts of hydrochloric and glacial acetic acids in place of sulphuric acid, called for in the original Babcock method. This mixture of acids does not produce heat as sulphuric acid does, and, therefore, the bottles containing the ice-cream acid mixtures should be warmed to the proper temperature by immersion in a water-bath. Otherwise the test is carried out as the Babcock test is executed,

Instead of the mixture of acetic acid and hydrochloric acid, the following mixture may be used: 25 c.c. each of hydrochloric acid and fusel oil are mixed and shaken occasionally for three hours. To this are added 450 c.c. of glacial acetic acid and the mixture allowed to stand for twenty-four hours. For a 9-gram sample of ice-cream 5 c.c. of the mixture are used.

Another method, according to Benkendorf, is the following: 88 parts of commercial sulphuric acid are poured into 12 parts of concentrated nitric acid. Weigh 18 grams of ice-cream into a dry beaker, add 4 to 5 c.c. of the acid mixture, and mix by a rotary motion. If the contents do not assume a dark brown color, add 2 to 3 c.c. more of the acid. Then transfer to a 30 per cent. cream bottle, rinse the beaker with hot water, and add this to the contents of the bottle. Then proceed in the usual manner.

The Illinois State Food Commission gives the following method for calculating the percentage of milk-fat in ice-cream, according to the contents of a gallon can: 
"The percentage of milk-fat in the finished ice-cream may be calculated from the total weight of materials and weight of fat entering the batch, or it may be obtained by the analysis of the finished product.

"In determining the percentage of fat by calculation it is necessary to know the weight of each material entering the batch. The weights of cream may be calculated from the following table:

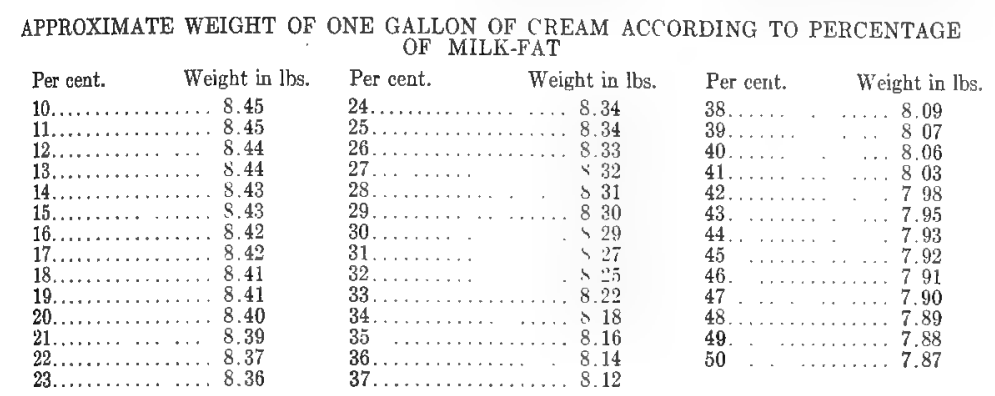

"For the purposes of calculation the following weights per gallon may be used:

"Milk 8.6 lbs., skimmed milk 8.7 lbs., 8 per cent. superheated bulk condensed 9.2 lbs., 12 per cent. condensed 9.15 lbs., 14 per cent. condensed 9.45 lbs.

"Calculation.-(a) Multiply the weight in pounds of each material containing milk-fat used in the batch by the percentage of milk-fat that it contains.

"(b) Add together the weights of materials entering the batch. This sum is the total weight of the batch.

"(c) Now add together the figures obtained in paragraph (a) above, and divide this sum by the total weight of the batch. The result is the percentage of milk-fat that the ice-cream will contain providing that the batch has been uniformly mixed.

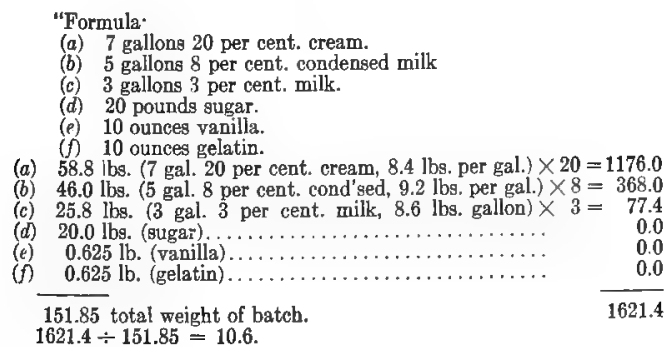
fat."

"Therefore the ice-cream will contain 10.6 per cent. of milk-

The preparation of a sample of ice-cream for the fat test should 
be made with special care. In the first place a representative sample must be obtained. Similar amounts should be removed from different parts of the can, so that the top, the center, the bottom, and the intermediate parts between the center and the periphery are represented. Butter samplers are very suitable for this purpose. Equal parts of each portion should be mixed and the ice-cream then allowed to melt. The viscosity of the cream retains air-bubbles tenaciously and, therefore, samples must be weighed and not measured. Food inspectors should always be careful to take representative samples. Samples of cartons of ice-cream or from small portions of a can may be misleading.

Selling ice-cream in stores at retail has sometimes been compared to skimming milk. Since under ordinary store conditions the ice-cream is liable to become soft, there is a movement of the fat to the top, and early customers obtain a cream richer in fat, but poorer in heavy solids, than do late customers.

The bacterial content of ice-cream has been frequently found to be very high. Stiles and Pennington found the following numbers of bacteria in ice-cream in Washington: In 1906 and 1907 263 samples gave an average of $26,612,371$ bacteria per cubic centimeter. The maximum count was $365,000,000$ and the minimum count 137,500. Ayers and Johnson give the following table:

\begin{tabular}{|c|c|c|c|c|c|}
\hline \multirow{2}{*}{\multicolumn{2}{|c|}{ Bacteria per cubic centimeter. }} & \multicolumn{2}{|c|}{ _unmer____ } & \multicolumn{2}{|c|}{-Winter._____ } \\
\hline & & No. of samples. & Per cent. & No. of samples. & Per cent. \\
\hline 0 to & $50,000 \ldots \ldots$ & & - & 5 & 5.49 \\
\hline 50,000 to & 100,000 & & & 8 & 8.79 \\
\hline 100,001 to & $500,000 \ldots \ldots \ldots$ & 9 & 9.57 & 23 & 25.27 \\
\hline 500,001 to & $1,000,000 \ldots \ldots \ldots$ & 9 & 9.57 & 2 & 2.20 \\
\hline $1,000,001$ to & $5,000,000 \quad \ldots \ldots \ldots$ & 16 & 17.03 & 21 & 23.08 \\
\hline $5,000,001$ to & $10,000,000$ & 12 & 12.77 & 5 & 5.49 \\
\hline $10,000,001$ to & $20,000,000 \ldots \ldots \ldots$ & 13 & 13.83 & 11 & 12.09 \\
\hline $20,000,001$ to & $30,000,020 \ldots \ldots \ldots$ & 10 & 10.64 & 5 & 5.49 \\
\hline $30,000,001$ to & $50,000,000 \ldots \ldots \ldots$ & 8 & 8.51 & $\mathbf{3}$ & 3.30 \\
\hline $50,000,001$ to 1 & $100,000,000 \ldots \ldots \ldots$ & 9 & 9.57 & 4 & 4.40 \\
\hline Over $100,000,0$ & $100 \ldots \ldots \ldots \ldots$ & 8 & 8.51 & 4 & 4.40 \\
\hline
\end{tabular}

Hammer gives the following results of investigations of icecream:

\begin{tabular}{|c|c|c|c|c|c|}
\hline \multirow{5}{*}{$\begin{array}{l}\text { Source. } \\
\text { Philadelphia . . . . . . . . . . . . . . . . . . . } \\
\text { Boston } \\
\text { Washington . . }\end{array}$} & \multirow{3}{*}{$\begin{array}{l}\text { Year. } \\
1905-6\end{array}$} & \multirow{3}{*}{$\begin{array}{c}\text { No. of samples. } \\
49\end{array}$} & \multicolumn{3}{|c|}{-Bacteria per cubic centimeter. } \\
\hline & & & Average. & Highest. & Lowest. \\
\hline & & & $17,833,031$ & $79,800,000$ & 70,000 \\
\hline & $1906-7$ & 35 & $23,000,000$ & $150,000,000$ & $1,000,000$ \\
\hline & $1906-7$ & 263 & $26,612,371$ & $365,000,000$ & 137,500 \\
\hline Chicago. & 1909 & 89 & $16,662,134$ & $125,000,000$ & 20,000 \\
\hline Git.... & 1910 & 306 & $15,401,000$ & $100,000,000$ & 20,000 \\
\hline Milwaukee. $\ldots \ldots \ldots \ldots \ldots$ & 1911 & 26 & & $8,000,000,000$ & 200,000 \\
\hline Des Moines & 1911 & 10 & $19,920,000$ & $39,000,000$ & $4,200,000$ \\
\hline ate College.... . . . & 1911 & 12 & $19,775,000$ & $72,000,000$ & 500,000 \\
\hline
\end{tabular}

Ayers and Johnson have also studied the groups of bacteria in ice-cream, with the following results:

Arid-coagulating.

Acid-forming.

Inert

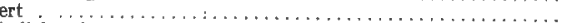

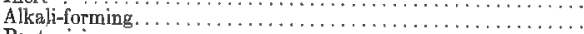

Peptonizing.

Summer
Per cent
49.82
20.72
13.98
1.86
13.62

Winter.

Per cent.

30.84

38.03

4.81

5.42
20.90 
In summer, as a rule, the bacterial count of ice-cream is higher than in winter. The acid-forming organisms are approximately the same in both seasons, but peptonizing bacteria are relatively numerous at all times. Ayers and Johnson found gas-forming bacteria in $\frac{1}{10}$ c.c. in 88.83 per cent. of the samples.

In Chicago in 1913 the writer found, in examinations of 60 samples of ice-cream, figures ranging from 150,000 to $60,000,000$ bacteria per c.c. As a rule, the higher the number of colonies, the greater was the proportion of acid formers. Similar figures have been reported from a number of cities in this country.

The bacteria in ice-cream are derived from the different substances which enter its composition. Cream and milk are naturally the most important sources of these bacteria. Cream and milk are held at refrigerator temperature from the time they are delivered at the ice-cream factory until they are used. This is a relatively short period and the number of bacteria will, therefore, not increase materially. The sugar contains but a negligible number of micro-organisms, but molds are usually prevalent. Gelatin may contain several thousand to several million bacteria per gram. However, the gelatin is dissolved in water or milk at boiling temperature, so that the majority of bacteria are destroyed. Some bacteria are contained in flavoring substances.

Enumeration of bacteria in finished ice-cream has shown that there are many more bacteria present than in the materials from which the ice-cream has been prepared. This can be explained by the breaking up of clumps of bacteria by the violent agitation to which the mixture is exposed during the freezing process. As a matter of fact, the number of bacteria according to the colony count increases somewhat as the freezing process proceeds. This is shown in the following table (Heinemann and Gordon):

GERM CONTENT OF ICE-CREAM IN THE FREEZER

\begin{tabular}{|c|c|c|c|c|c|c|c|c|c|c|}
\hline Time of freering. & 1 & 2 & 3 & 4 & 5 & 6 & 7 & 8 & 9 & Average. \\
\hline 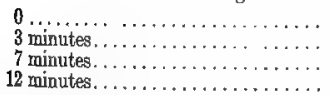 & $\begin{array}{l}37 \\
37 \\
61 \\
47\end{array}$ & $\begin{array}{l}188 \\
229 \\
213 \\
310\end{array}$ & $\begin{array}{l}279 \\
160 \\
116 \\
154\end{array}$ & $\begin{array}{l}237 \\
317 \\
324 \\
408\end{array}$ & $\begin{array}{r}964 \\
895 \\
1003 \\
1137\end{array}$ & $\begin{array}{r}818 \\
958 \\
1063 \\
1092\end{array}$ & $\begin{array}{l}710 \\
630 \\
540 \\
590\end{array}$ & $\begin{array}{l}1010 \\
10 \subseteq 0 \\
1330 \\
1800\end{array}$ & $\begin{array}{l}2050 \\
2270 \\
2410 \\
2420\end{array}$ & $\begin{array}{l}699 \\
732 \\
785 \\
884\end{array}$ \\
\hline Average. ............... & 45 & 235 & 177 & 321 & 1006 & 983 & 617 & 1307 & 2287 & 775 \\
\hline
\end{tabular}

The distribution of bacteria in a can of ice-cream has, as far as the writer is aware, not been thoroughly studied. It would appear that the whipping in the freezer would effect a very even distribution, although, as previously stated, the number constantly increases during the freezing process if the colony count is the index. In a series of counts made by Gordon and the writer there was no evidence of an uneven distribution of bacteria 
as long as the cream remained solidly frozen. It is probable, however, that in softened ice-cream bacteria move with the fat, and that in such cream a larger number are at the surface than at the bottom.

The change of bacterial content during refrigeration has not been studied exhaustively. It has been stated that for several days there is a decrease in the number of bacteria, but what happens after that is not definitely known. Miss Pennington states that usually there is a decrease at refrigerator temperature which may last for several days, and that this decrease is followed by a decided rise.

Miss Pennington has also determined the presence of streptococci in the samples of ice-cream examined. In one series they were found in 82.5 per cent. of all samples. In other series they were also numerous. In all probability these were lactic acid streptococci, so that their presence in the majority of samples is not surprising.

Bacterial tests, like fat determinations, are made when the ice-cream has become fluid. The longer the melted cream stands, the more complete is the loss of air, but at the same time there is bacterial multiplication. The usual method of making bacterial enumerations is to take a cubic centimeter of cream as soon as a sufficient quantity has melted. Ten minutes at room temperature will easily accomplish this. Some air remains, with the result that the volume of 1 c.c. really does not represent a cubic centimeter of ice-cream. Weighing 1 gram is also accompanied with difficulties, as the handling may cause contamination from the air. Bacterial counts vary considerably under the most perfect conditions known to technic, and it is to be expected that with ice-cream variations are especially great. Comparable results can be obtained only if all laboratories will consent to use exactly the same method. Standard methods should be adopted, therefore, before bacterial examinations of ice-cream can be of comparative value.

When ice-cream is made from raw milk or cream it becomes a possible carrier of infection. As a matter of fact, a number of epidemics have been definitely traced to ice-cream. Mitchel found that typhoid bacilli were able to live in ice-cream for twelve to thirty-nine days. Several outbreaks of typhoid fever due to the consumption of infected ice-cream have been reported in England.

Lumsden definitely incriminated ice-cream in two typhoid fever epidemics, one in Birmingham, Ala., and the other in Chattanooga, Tenn. The author in his report emphasizes the importance of observing cleanliness in the collection and preparation of all 
ingredients entering into ice-cream mixtures, and urges that these ingredients be properly pasteurized. Furthermore, the author demands that ice-cream be manufactured under rigid and adequate official supervision.

Of course, it is conceivable that any of the infections which are known to be transmitted occasionally through milk may also be disseminated through ice-cream. It is probable that pathogenic bacteria gradually die in ice-crean, although there are no reliable data on the subject available. However, ice-cream is usually consumed within a few days after manufacture, so the disease germs have a chance to survive long enough to cause infection.

Poisoning from ice-cream has been sometimes reported. In most cases the actual cause has not been determined conclusively. It is sometimes assumed that poisons in the cream are formed by bacterial decomposition. More likely seems the supposition that bacteria of the Bacillus enteritidis group are the real offenders. In some cases bacteria which have proved infectious and fatal to guinea-pigs have been isolated from suspected ice-cream. Such evidence is not final, and it is desirable that thorough investigations of so-called ice-cream poisoning be made.

Governmental supervision of ice-cream is important and as necessary as control of other food articles, chiefly because icecream is consumed in the raw state, and legal definition of what constitutes ice-cream is desirable.

The United States pure food law recognizes three classes of ice-cream, as follows:

"1. Ice-cream is a frozen product made from cream and sugar, with or without a natural flavoring, and contains not less than 14 per cent. of milk-fat.

"2. Fruit ice-cream is a frozen product made from cream, sugar, and sound, clean, mature fruits, and contains not less than 12 per cent. of milk-fat.

"3. Nut ice-cream is a frozen product made from cream, sugar, and sound, non-rancid nuts, and contains not less than 12 per cent. milk-fat."

The demands of governmental regulations suffer from a lack of uniformity in the same sense that those of milk regulations suffer. For example, the Illinois State Food Standard Commission defines ice-cream as follows: "Ice-cream is a frozen substance, made from cream, or milk and cream, and sugar, with or without the addition of such other wholesome substances as have customarily ${ }^{1}$

${ }^{1}$ The following other substances have customarily been used in making ice-cream: eggs, flours, starches, butter, gelatin, flavoring, harmless colors, nuts, fruits, pastries, and condensed milk. 
been used in making ice-cream, and contains not less than 8 per cent. of milk-fat, and manufactured, stored, distributed, and dispensed in a sanitary manner."

The Illinois Commission also recognizes "certified ice-cream," which means ice-cream "manufactured from certified dairy products, and under conditions approved by a milk commission."

In the public mind at present every frozen dessert is called either ice or ice-cream, no distinction between these two terms being recognized. Ices should mean frozen water with fruit or some other substance used as flavor. Ice-cream is generally understood to mean any frozen product containing either milk or cream, or some custard, both being flavored with a variety of substances. The word "cream" in ice-cream seems to carry not only the meaning of cream derived from milk, but also cream in the sense of "creamed gravy" or "creamed potatoes, creamed onions," etc., in which dishes cream from milk is not a necessary ingredient. Therefore a suitable legal definition is necessary when governmental control is established.

For the purpose, of rating ice-cream several score cards have been devised, notably by Washburn, Mortensen, and at the University of Nebraska (Frandsen and Markham). The cards give percentage figures as to flavor, texture, body, richness, appearance, color, permanency, and package. Defects in one or more of these points are subtracted from the perfect score given in the card according to the judgment of the examiner. Flavor may be wanting when sour or tainted cream is used; when flavoring substances do not blend; when poor or too much gelatin is used; when excess of sugar is present; when a poor quality of fruit is used, etc. The body is determined by experienced persons by finger pressure; the texture is lacking when poor or an insufficient quantity of gelatin is used, or when the ice-cream is improperly packed. The coloringmatter may be unnatural. Permanency refers to the quality of the ice-cream, which allows it to retain its firm consistency for a reasonable length of time on the dish on which it is served. It should not melt away too quickly before being eaten.

In order to prevent contamination with disease germs as far as possible, ice-cream factories should be subjected to periodic inspections. Sanitary construction of the buildings and the equipment; cleanliness and control of the health of employees should be obligatory. Some modern ice-cream factories are built of concrete, coated with enamel paint. Everything is arranged to facilitate cleaning and drainage. Cream and milk should be pasteurized, and all other ingredients heated to a temperature high enough to destroy pathogenic bacteria. All machinery which comes in direct contact with the ice-cream and all containers 
should be sterilized with live steam, and attention should be given to the excluding of flies from these establishments.

\section{BIBLIOGRAPHY}

Ayers and Johnson: United States Dept. of Agri., B. A. I., Bull, 303, October, 1915.

Benkendorf: Agri. Exp. Sta. of the Univ. of Wis., Bull. 241, July, 1914. The Creamery and Milk Plant Monthly, 1917, vol. 5, p. 48.

Frandsen and Markham: The Manufacture of Ice-creams and Ices, New York, Orange Judd Company, 1915.

Hammer: Iowa State Coll. of Agri. and Mech. Arts, Bull. 134, July, 1912.

Heinemann and Gordon: The Creamery and Milk Plant Monthly, vol. 5, August, 1917.

Illinois State Food Commission: Bull. 28, 1914.

Lumsden: Amer. Jour. of Pub. Health, 1917, vol. 7, p. 1005.

Mitchell: Jour. Amer. Med. Assoc., 1915, vol. 65, p. 1795.

Pennington: Hygienic Laboratory Bull. 56, p. 266.

Stiles and Pennington: Hygienic Laboratory Bull. 56, p. 255.

Washburn: Vermont Agri. Exper. Sta., Bull. 155, September, 1910.

Wyman: Proceedings of the Ninth Convention of the National Association of Ice-cream Manufacturers, held at Cincinnati, Ohio, December, 1909. 


\section{CONDENSED AND DESICCATED MILKS}

Condensed and evaporated milks, along with milk powder or flour, have been placed on the market chiefly to meet the demand for a milk that will keep indefinitely and one whose bulk is sufficiently reduced to make shipment easier. While fresh milk contains about 87 to 88 per cent. of water, sweetened condensed milk contains about 25 per cent.; unsweetened condensed milk (evaporated) contains about 63 per cent., and milk powder about 5 per cent. water. The bulk of these products is, therefore, smaller than that of fresh milk, and transportation charges are correspondingly less. Condensed or evaporated milk keeps sweet for a long time, and milk powder almost indefinitely. Consequently, concentrated milks are in great demand in countries where fresh milk is scarce or in hot climates where milk remains sweet for a short time only.

Richmond gives the following analyses of sweetened condensed milk, of unsweetened condensed milk, and of milk powders:

COMPOSITION OF SWEETENED CONDENSED MILK

\begin{tabular}{|c|c|c|c|c|c|c|c|}
\hline Authority. & Water. & Fat. & Lactose. & $\begin{array}{l}\text { Cane- } \\
\text { sugar. }\end{array}$ & $\begin{array}{l}\text { Pro- } \\
\text { tein. }\end{array}$ & Ash. & Total. \\
\hline Richmond ........ & 24.06 & 11.28 & 13.97 & 38.31 & 9.36 & 2.13 & 99.11 \\
\hline Pearmain and Moor. . & 26.10 & 10.84 & 14.68 & 36.93 & 9.55 & 1.90 & 100.00 \\
\hline Fleischmann... & 25.69 & 10.98 & 16.29 & 32.37 & 12.33 & 2.34 & 100.00 \\
\hline Pearmain and Moor. . & 29.87 & 1.17 & 14,68 & 41.54 & 10.74 & 2.00 & 100.00 \\
\hline Richm ond.......... & 29.05 & 1.28 & 14.91 & 40.07 & 10.63 & 2.33 & 98.2 \\
\hline Richmond.... ......... & 29.23 & 0.64 & 15.50 & 40.19 & 10.73 & 2.63 & \\
\hline Richmond........... & 28.43 & 0.36 & 16.88 & 39.27 & 11.73 & 2.58 & \\
\hline
\end{tabular}

COMPOSITION OF UNSWEETENED CONDENSED MILK

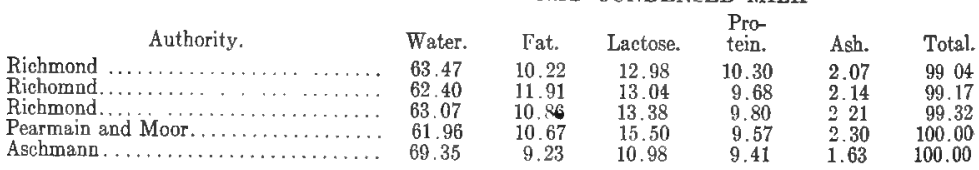

\section{COMPOSITION OF MILK POWDERS}

\begin{tabular}{|c|c|c|c|c|c|c|c|}
\hline & 1 & 2 & 3 & 4 & 5 & 6 & 7 \\
\hline Moisture. & 6.39 & 4.92 & 3.30 & 3.55 & 4.74 & 5.15 & 6.00 \\
\hline$\cdots$ & 27.35 & 27.98 & 23.97 & 2.55 & 29.16 & 19.90 & 25.60 \\
\hline Milk-sugar . . . . . . . . . & 31.42 & 34.16 & 37.32 & 45.60 & $32 \quad 24$ & 34.96 & 32.83 \\
\hline le-sugar. . . . . . . . . . & & 1. 25 & 1.53 & 2.80 & & & 200 \\
\hline rotein . . . . . . . . . . . . & $\begin{array}{r}27.48 \\
6.00\end{array}$ & 2459 & 26.38 & 35.45 & 26.66 & 31.10 & 23.84 \\
\hline & 6. 00 & 6.24 & 6.19 & 7.89 & & 7.11 & 6.44 \\
\hline
\end{tabular}

The term "condensed milk" usually means concentrated milk to which cane-sugar has been added. "Plain condensed milk" is concentrated milk and is sold in bulk to ice-cream manufacturers and confectioners. This bulk condensed milk is not sterilized 
and must be kept cool to prevent decomposition. "Evaporated milk" is concentrated milk filled in cans and sterilizerl after the cans are sealed.

Sweetened condensed milk should contain at least 28 per cent. of milk solids and 8 per cent. of fat. Condensed evaporated skimmed milk should have at least 20 per cent. of milk solids.

Gail Borden introduced condensed milk on a commercial scale in 1856. Since that time the industry has developed to such an extent that in 1909-according to Wells, who gives a detailed account of the industry - there were more than 300 milk condensing plants in the United States, representing an investment of $\$ 15,000,000$. The value of the total output in 1909 was $\$ 33,563,129$. Recently the use and export of concentrated milk has increased enormously. It takes the place of fresh milk in soldiers' camps, since fresh milk is difficult to obtain, and is growing in favor with the housewife, who, although she may have access to fresh milk, likes to keep it along with other staple goods.

Condensed or evaporated milk may be made from skimmed milk or from whole milk. Skimmed milk is condensed to onefourth its volume and whole milk to one-third. The product sold in bulk is usually made from skimmed milk, while canned milk is made from whole milk. Only clean milk should be used for condensing, as abnormal flavors become more concentrated during the condensing process. The acidity of the milk must be low, as otherwise the condensed product will coagulate. Manufacturers are very careful in the selection of the raw milk they intend for condensing purposes, and employ experts to detect off-flavors.

Milk is condensed principally by two methods: either by the use of a vacuum pan in which the milk is evaporated under reduced pressure so that the boiling-point lies at $130^{\circ}$ to $135^{\circ} \mathrm{F}$.; or by the use of hot air. In the second case the milk is heated to $140^{\circ} \mathrm{F}$. and hot air then blown into it. The hot air takes up the water from the milk, and by this means the desired consistency is obtained. Before condensing, the milk is passed through a cream separator, and if whole condensed milk is to be prepared the cream is mixed with the condensed skimmed milk.

After canning there is some change in the physical condition similar to that in milk when it stands quietly. The fat rises, while the heavier constituents sink. To prevent the rising of the fat the milk is sometimes homogenized before condensing takes place.

Evaporated (unsweetened milk) is normally free from bacteria, since it is sterilized after canning. Sweet condensed milk is not sterilized, and usually contains bacteria, although they rarely multiply in view of the high concentration and sugar content of the product. However, some investigators have found large numbers 
of bacteria in condensed milk. Miss Bengtson counted as high as 1,000,000 per cubic centimeter. Micrococci seem to be the predominating types in condensed milk.

Hammer found a bacillus related to the proteus group, which he named Bacillus ichthyosmius, and in the condensed milk where this organism flourished a fishy odor developed. The author was able to produce the same fishy odor in milk, cream, and evaporated milk by inoculating pure cultures, but butter was not similarly affected.

The same author isolated a bacillus-Bacillus coagulansfrom cans of condensed milk which had acquired a sweetish, cheesy odor, and found it to be motile and spore forming.

Desiccated milk, milk powder, or milk flour is used by confectioners and ice-cream manufacturers, although its usefulness might be extended to households to take the place of fresh milk. Wells states that in 1911 there were 10 desiccated milk factories in the United States and that 8,500,000 pounds of milk were used for the purpose of desiccation. The use of milk powder is on the increase, especially since it is now possible to desiccate whole milk and even cream containing 18 per cent. fat. Jordan (J. O.) states that eminent authorities believe that such products have all the nutritional qualities of fluid milk and that consequently the consumer is benefited by having a milk which keeps indefinitely and which is available at any time and in any quantity. The producer is benefited by being able to dispose of all his milk during the most favorable season of production and by suffering no loss from surplus milk. As milk powder can be shipped to any part of the world, people in warm climates can have sound sweet milk at their disposal.

The powder is dissolved in water before it is used, and the resulting milk is almost equal to fresh sweet milk. This is especially true when milk powder is made by the "atomizing process." Investigations have shown that when this powder is dissolved in water the casein assumes its natural colloidal condition and the fat forms an emulsion.

Whole milk is reduced to one-eighth its volume and skimmed milk to one-eleventh by desiccation.

The yield from 100 pounds of raw milk is about 9 pounds of desiccated milk and 3 to 4 pounds of butter, according to the richness of the milk. Desiccated milk has the appearance of flour and, therefore, is called milk flour. It is hygroscopic and should be kept in tightly sealed containers. Whole milk powder contains about 27 per cent. fat.

There are several methods of desiccating milk, a brief description of which, as given by Wells, follows: 
1. The Ekenberg System.-The milk is clarified by filtering through cotton and passing through a separator after having been warmed in a continuous flow of $90^{\circ} \mathrm{F}$. The cream is pasteurized, cooled to a low temperature, and preserved for mixing with separated milk for the better grades of milk powder. The separated milk is pasteurized, cooled, and stored in an insulated tank from which it is drawn to the exsiccators. The exsiccator is a large vacuum chamber in which a revolving cylinder is hung. Another vacuum chamber-the products chamber-is separated from the first one by a series of gates. A constant vacuum is thus maintained when the products chamber is opened.

A milk chamber, also under vacuum, is attached to the vacuum chamber, and into this chamber the milk is drawn. A specially constructed condenser, to which a suction pipe is attached, is provided with a stream of water, which passes through the condenser and carries off the vapors.

A pump forces the milk through a spray pipe on to the revolving cylinder, which is heated slightly by exhaust steam. The milk dries quickly under the influence of heat and vacuum and is removed from the cylinder by silver knives. The temperature of the milk is never above $120^{\circ} \mathrm{F}$. and rarely above $110^{\circ} \mathrm{F}$.

The dried milk is completely desiccated by being placed in a chamber of $90^{\circ} \mathrm{F}$. for twenty minutes to an hour. The crisp, dry chips and ribbons of milk are then ground to a fine powder.

2. Atomizing and Hot-air System.-Milk is atomized and sprayed into currents of heated air. The dry powder is retained by a screen while the moist air passes through. This process was invented by Robert Stauf, of Posen, Germany, and is successfully used in this country.

3. The Just System.-Two polished metal cylinders are side by side and slightly separated. They revolve inversely at the rate of about 6 revolutions per minute. They are heated by superheated steam, so that the outer surface of the cylinders reaches considerably above $212^{\circ} \mathrm{F}$. The milk flows from a pipe between the rollers and forms a very thin layer on the rollers. The water is quickly evaporated and a knife cuts the milk from the cylinders in continuous sheets, which are caught in receptacles, where they break up. The dry milk is then ground to a fine powder.

4. The Campbell System.-The milk is heated by sterilized air blasts and agitated in a large round copper vessel, and then drawn into rectangular concentrating vessels. These vessels contain coils and are surrounded by hot water. Sterilized air is also introduced into the milk below the surface. This air is under pressure and escapes when the milk enters the tanks, and by this means the water vapor is driven off. As the milk becomes concentrated the 
temperature is lowered. On a floor below large roller drums with cone-shaped ends are located, and into these the concentrated milk is discharged. Air blasts enter the head of the drum, which revolves so that the concentrated milk is carried up on the side and then dropped through the dry air. The milk soon becomes too thick to be carried up in the drum, falls into the cone-shaped end, and here it is ground into small particles. These particles are completely desiccated in specially constructed drums and then ground.

5. The Passburg System.--The milk is placed in a large steamheated iron drum which revolves in a vacuum chamber. It is scraped off with a steel knife when perfectly dry.

Stocking gives the composition of milk powder made by the Ekenberg process, as follows:

\begin{tabular}{|c|c|c|}
\hline & $\begin{array}{c}\text { Skimmed milk. } \\
\text { Per cent }\end{array}$ & $\begin{array}{l}\text { Whole milk } \\
\text { Per cent. }\end{array}$ \\
\hline 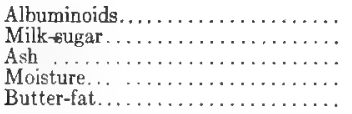 & $\begin{array}{l}34-35 \\
51 \\
7.5-8 \\
4 \\
\cdots\end{array}$ & $\begin{array}{c}25.0 \\
40.0 \\
5.3 \\
3.0 \\
25-27\end{array}$ \\
\hline
\end{tabular}

The composition of milk and cream powders made by the Merrell-Soule (atomizing) process is given by the same author in the following table:

\begin{tabular}{|c|c|c|c|c|c|c|}
\hline & $\begin{array}{c}\text { Butter- } \\
\text { fat. }\end{array}$ & Casein. & $\begin{array}{c}\text { Al- } \\
\text { bumin. }\end{array}$ & $\begin{array}{l}\text { Milk- } \\
\text { sugar. }\end{array}$ & Ash. & $\begin{array}{l}\text { Moist- } \\
\text { ure. }\end{array}$ \\
\hline Skimmed milk. & 1.35 & 29.79 & 7.91 & 49.94 & 8.21 & 2.40 \\
\hline Half skimmed. & 14.20 & 25.56 & 6.70 & 44.41 & 7.01 & 2.12 \\
\hline $\begin{array}{l}\text { Whole milk } \ldots \ldots \ldots \ldots \ldots \ldots \ldots \ldots \\
15 \text { per cent. eream. }\end{array}$ & 28.20 & 21.22 & 545 & 47.88 & 5.75 & 1.50 \\
\hline $\begin{array}{l}15 \text { per cent. eream. } \\
18 \text { per cent. cream. }\end{array}$ & 65.15 & 10.60 & 2.82 & 17.86 & 2.91 & .66 \\
\hline & 70.47 & 9.08 & 2.42 & 15.01 & 2.46 & .56 \\
\hline
\end{tabular}

Even milk modified for the feeding of infants has been desiccated, and the following table (Stocking) shows the results compared with the composition of human milk:

\begin{tabular}{|c|c|c|c|}
\hline \multirow{7}{*}{ 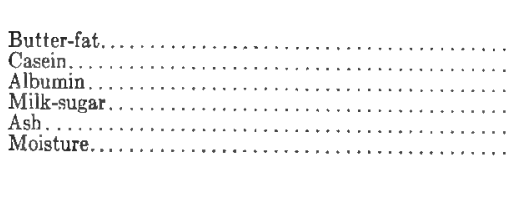 } & D y. & Restored. & Huinan. \\
\hline & 19.20 & 2.28 & 3.3 \\
\hline & 8.51 & 1.06 & 10 \\
\hline & & 0.93 & 0.5 \\
\hline & 57.37 & 7.17 & 6.8 \\
\hline & $\begin{array}{l}.20 \\
1.21\end{array}$ & 87.65 & $\begin{array}{r}0.2 \\
88.2\end{array}$ \\
\hline & & 100.00 & 100.00 \\
\hline
\end{tabular}

The fat in concentrated milk can be estimated by the use of the Babcock method, but Hunziker worked out a modification which he considered satisfactory. The method is as follows: After mixing the milk, 4.5 grams are weighed into a 10 per cent. Babcock bottle and 17.6 c.c. of water added from a Babcock pipet. The usual amount of sulphuric acid is added, the contents of the bottle mixed until complete solution results, and then centrifuged for five minutes. Equal parts of water and sulphuric acid are mixed in a beaker, and this mixture, while hot, filled into the bottle to the 
zero mark. The bottle is centrifuged for two minutes, hot water added to the 8 per cent. mark, the bottle whirled for one minute, and the fat read. The fat is read from the top of the upper meniscus to the bottom of the lower one, and the reading multiplied by 4 .

For bacteriologic examinations a weighed quantity of concentrated milk should be dissolved in a measured amount of sterilized water and then plated in the usual manner.

\section{BIBLIOGRAPHY}

Bengtson: Jour. of Home Economics, 1916, vol. 8, p. 29.

Hammer: Agri. Exper. Sta. Iowa State Coll. of Agri. and Mech. Arts, Research Bull. 19, January, 1915. Agri. Exper. Sta. Iowa State Coll. of Agri. and Mech. Arts, Research Bull. 38, January, 1917.

Hunziker: Condensed Milk and Milk Powder. Published by the author. La Grange, I1l., 1918.

Jordan, J. O.: The Creamery and Milk Plant Monthly, 1919, vol. 8, p. 26.

Richmond: Dairy Chemistry, London, Charles Griffin \& Company Limited, 1914.

Stocking: Manual of Milk Products, New York, The MacMillan Company, 1917.

Wells: United States Dept. of Agri., B. A. I., Yearbook of 1912, Separate 595. 


\section{MILK FROM MAMMALS OTHER THAN THE COW}

Human Milk.-In previous chapters frequent reference has: been made to human milk, and little more need be added. As a rule, human milk is more yellowish than cow's milk and has a sweeter taste, owing to a larger content of milk-sugar. The fat globules are larger than those of the milk of most cows, but. fewer in number. The size of the fat globules varies from 0.9' to 32 microns. The fat rises within a few hours after drawing and separates more completely than the fat in cow's milk. Therefore, human skimmed milk is more transparent than cow's milk. Human cream is decidedly yellow in color.

Coagulation of the casein is produced with some difficulty. By adding dilute acetic acid to diluted skimmed milk at $40^{\circ} \mathrm{C}$. a fine flaky precipitate is formed which does not settle, but rises to the surface. Rennet coagulation is not apparent to the naked eye unless acid is added. By rennet coagulation human casein is split into paracasein and a soluble albumin, similar to the splitting of cow casein by rennet. Pure human casein is soluble in weak alkalies, but the solution has a yellowish in place of the bluish tint of cow casein.

Bosworth and Giblin found that the valency of human casein is 8 and its molecular weight 8888 . The valency of human paracasein is 4 and its molecular weight 4114 . The same authors state that human casein resembles bovine and goat casein in several respects. These caseins have the same nitrogen, phosphorus, and sulphur content; they have the same valency and form the same salts with bases; they have the same molecular weight; they are acted upon by rennet in the same manner; and the paracasein resulting from action upon human casein is similar to that of cow's milk.

Fresh human milk is slightly acid to phenolphthalein and alkaline to litmus. It sours and coagulates spontaneously. Hammarsten gives the freezing-point of human milk at $0.589^{\circ} \mathrm{C}$. The specific gravity of the fat is 0.966 at $15^{\circ} \mathrm{C}$. It melts at $34^{\circ} \mathrm{C}$. and solidifies at $20.2^{\circ} \mathrm{C}$.

The same author states that human milk is coagulated by gastric juice, but subsequently dissolves in it readily. Human milk is richer in lecithin than cow's milk, but the latter contains more phosphorus than human milk because of its higher casein content.

The ash of human milk varies between 0.19 and 0.34 per cent., which is considerably less than that of cow's milk. Trunz 
gives the following tabulation of the composition of ash in human milk:

COMPOSITION OF ASH OF HUMAN MLK

\begin{tabular}{|c|c|c|c|c|}
\hline & \multirow[b]{2}{*}{ Söldner. } & & \multicolumn{2}{|c|}{ Backhaus and Cronheim. } \\
\hline & & de Lange. & 1 & \\
\hline 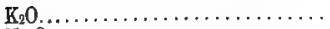 & 31.4 & 19.9 & 33.74 & 27.33 \\
\hline $\mathrm{Na} \mathrm{O}_{\ldots \ldots \ldots \ldots \ldots \ldots \ldots \ldots \ldots \ldots \ldots \ldots \ldots \ldots}$ & 11.9 & 29.6 & 1191 & 15.88 \\
\hline $\mathrm{CaO} \ldots \ldots \ldots \ldots \ldots \ldots \ldots \ldots$ & 16.4 & 12.6 & 17.36 & 15,52 \\
\hline 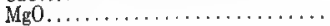 & 2.6 & 2.9 & 317 & 2.13 \\
\hline $\mathrm{F}_{2} \mathrm{O}_{8} \ldots \ldots \ldots \ldots \ldots \ldots \ldots \ldots$ & 0.16 & 0.25 & 0.63 & 1.75 \\
\hline $\mathrm{P}_{2} \mathrm{O}_{6} \ldots \ldots \ldots \ldots \ldots \ldots \ldots$ & 13.5 & 17.9 & 14.79 & 11.75 \\
\hline $\mathrm{cl} \ldots \ldots \ldots \ldots \ldots \ldots \ldots \ldots$ & 20.0 & 21.3 & 15.47 & 23.93 \\
\hline $\mathrm{SO}_{3} \ldots \ldots \ldots \ldots \ldots \ldots$ & $\ldots$ & $\ldots$ & 5.01 & 5.21 \\
\hline $\mathrm{CO}_{2} \ldots \ldots \ldots \ldots \ldots \ldots \ldots$ & $\cdots$ & . . . & $\ldots$ & 1.50 \\
\hline
\end{tabular}

Goat's Milk.-The goat is sometimes called the poor man's cow, because she produces about, twice as much milk in proportion to her body weight as the cow does. A goat may yield ten to twelve times her body weight in milk per year, while a cow yields but five to six times her body weight. In some countries goat's milk is used to a considerable extent, as in Switzerland, Germany, and some tropical and subtropical countries, such as the Island of Cuba, for instance. Goats eat much more than cows do in proportion to their size, but are satisfied with cheaper food. They are hardy animals, and many breeds of goats are suitable mill producers in all climates. The goat is a good foster mother, successfully raising infants, calves, lambs, colts, and pigs. In some countries babies obtain their food-supply by being placed directly to the teats of goats.

In France and Switzerland some sanitariums advertise as a special feature that goat's milk is used, and special beneficial results are claimed for those who use it. Goat's milk is sometimes. preferred to cow's milk for infant feeding. However, there is no positive evidence of its superiority. Goat's milk may be used in place of cow's cream in coffee, tea, and cakes. It is said to give a rich flavor.

The fat globules in goat's milk are relatively small and of fairly uniform size. They rise slowly and in most cases no cream layer is formed; only rarely does a very small amount of cream collect at the surface. The cream cannot be separated by centrifuging. Goat's milk is said not to keep as well as cow's milk. This may be due to lack of cleanliness in production. There is a peculiar "goaty" taste in goat's milk due to manurial pollution, and this is also imparted to cheese made from goat's milk.

Goat's milk has a higher degree of viscosity than cow's milk. With rennet the casein coagulates, forming a more compact mass than bovine casein. For this reason goat's milk is considered less digestible than cow's milk.

Bosworth and Van Slyke have made a chemical study of the composition of goat's milk. The following points were determined 
by these authors: "The soluble compounds can be separated from the suspended or colloidal compounds by filtration through a Pasteur-Chamberland filter. The serum from fresh goat's milk is nearly transparent and has a faint greenish-yellow tinge, with slight opalescence. In true solution are sugar, the salts of potassium, sodium, and chlorin. Partly in solution or in colloidal solution are albumin, inorganic phosphates, calcium and magnesium compounds, and citrates. Entirely in suspension or in colloidal solution are fat and casein. The insoluble portion of goat's milk when freshly prepared and moist is grayish to greenish white, glistening, and gelatinous. Shaken with water this insoluble part is suspended and the mixture assumes the appearance of milk. This suspension is neutral to phenolphthalein. The insoluble portion consists of calcium caseinate, di- and tricalcium phosphate, and magnesium phosphate."

According to the same authors, goat's milk differs from cow's milk "( 1 ) in containing tricalcium phosphate, di- and trimagnesium phosphate, and monopotassium phosphate, and (2) in containing no monomagnesium or dipotassium phosphates. Human milk differs from goat's (and cow's) milk in containing no insoluble phosphates. Goat's and cow's milk contains more phosphates than human milk. Chlorids are present in goat's milk in larger quantity than in either human or cow's milk. In human and cow's milk chlorin is present as calcium chlorid, and in goat's milk potassium and sodium chlorids are also present."

The authors give the following table, showing the composition of cow's, goat's, and human milk:

A COMPARISON OF THE COMPOSITION OF COW'S, GOAT'S, AND HUMAN MILK

\begin{tabular}{|c|c|c|c|}
\hline Compounds. & Cow's milk. & Goat's milk. & Human milk. \\
\hline Fat... & 3.90 & 3.80 & 3.30 \\
\hline Milk-sugar , . $\ldots \ldots \ldots \ldots \ldots$ & 4.90 & 4.50 & 6.50 \\
\hline Protein combined with calcium . . . . . . . & 3.20 & 3.10 & 1.50 \\
\hline Salts. . . . . . . . . . . . . . & 0.910 & 0.939 & 0.313 \\
\hline Dicalcium phosphate $\ldots \ldots \ldots \ldots \ldots \ldots$ & 0.175 & 0.092 & 0.000 \\
\hline Tricaleium phosphate. ............. & 0.000 & 0.062 & 0.000 \\
\hline Monomagnesium phosphate. . . . . . . . . . & 0.103 & 0.000 & 0.027 \\
\hline Dimagnesium phosphate............... & 0.000 & 0.068 & 0.000 \\
\hline Trimagnesium phosphate . . . . . . . . . . . & 0.000 & 0.024 & 0.000 \\
\hline Monopotassium phosphate............ & 0.000 & 0073 & 0.069 \\
\hline 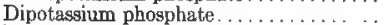 & 0.230 & 0.000 & 0.000 \\
\hline Potassium citrate. . . . . . . . . . . & 0.052 & 0.250 & 0.103 \\
\hline Sodium eitrate................. & 0.222 & 0.000 & 0.055 \\
\hline Potassium chlorid. . . . . . . . . . . . . & 0.000 & 0.160 & 0.000 \\
\hline Sodium chlorid ................. & 0.000 & 0.095 & 0.000 \\
\hline Calcium chlorid................... & 0.119 & 0.115 & 0.059 \\
\hline
\end{tabular}

The molecular weight of goat casein was determined by Bosworth and Van Slyke to be 8888, and the valency of the protein molecule in basic casein to be 8 . The elementary composition of moisture and ash-free casein from goat's and cow's milk was determined as follows: 


\begin{tabular}{|c|c|c|}
\hline & From goat's milk. & From cow's milk. \\
\hline . & 036 & 0.06 \\
\hline$\ldots \ldots \ldots \ldots$ & 52.50 & 53.50 \\
\hline $\mathbf{H}, \ldots \ldots \ldots \ldots \ldots \ldots \ldots \ldots \ldots$ & 716 & 7.13 \\
\hline $\mathbf{N}, \ldots \ldots \ldots \ldots \ldots \ldots \ldots \ldots$ & 15.67 & 15.80 \\
\hline . $\cdots$ & 0.71 & 0.71 \\
\hline$\ldots \ldots \ldots$ & 071 & 072 \\
\hline O (by difference). . & 23.25 & 22.08 \\
\hline
\end{tabular}

It has been claimed that goats are not as susceptible to tuberculosis as cows, and that for this reason alone the use of goat's milk would be advantageous. In Cologne, of 1600 goats examined, only 0.6 per cent. were found to be tuberculous, and in Prussia, of 47,705 goats examined, only 0.41 per cent. were tuberculous. This seems to prove, however, that goats are susceptible to tuberculosis, and the disease might be more prevalent among goats if they were kept in herds and in stables under unsanitary conditions such as cows are frequently subjected to.

Sheep's milk contains more fat, casein, and sugar than cow's milk. The total solids are 16 per cent. or more. Sheep's milk is yellowish and the fat globules are large. Sheep's milk is used in some countries for preparation of fermented milks, and the original Roquefort cheese is made from sheep's milk.

Buffalo's milk is also rich in solids, which amount to 17 per cent. and over. It is particularly rich in fat. Buffalo's milk is white and has a peculiar taste and odor, reminding one of musk. It is used in Egypt for preparing the fermented milk, leben railb.

Ass's milk was used in former ages for medicine, so Aristotle has stated. It is white with a bluish tint, and has a disagreeable odor which increases as the lactation period progresses. Ass's milk is poor in solids (10 per cent.) due chiefly to low fat content. It is alkaline to litmus and slightly acid to phenolphthalein. Ass's milk coagulates spontaneously with difficulty, and the coagulum consists of small flakes. It is coagulated completely by boiling, owing to the relatively large amount of albumin which carries the casein with it. Rennet produces a coagulum similar to that of human milk. The fat globules are very small.

Ass's milk is used in Italy, Spain, and southern France, where it is considered the most suitable substitute for human milk. It is easy to digest, and asses are not considered susceptible to tuberculosis. The nutritive value is impaired by the small fat content.

Mare's milk has a similar composition to ass's milk. It is poor in solids (10 per cent.) and has a low fat content. Mare's milk is white with a bluish tint, and has an aromatic, sweet, but rather sharp taste. The original koumiss is made from mare's milk.

Camel's Milk.-The composition of camel's milk is very variable, owing to a great variation in food, but, on the whole, it 
is similar to cow's milk. Camel's milk is richer in sugar than cow's milk and has a pleasant, sweet taste. It is of a pure white color. The proteins react similarly to those of human milk, and camel's milk is frequently used for infant feeding.

\section{BIBLIOGRAPHY}

Bosworth and Giblin: Jour. of Biol. Chem., 1918, vol. 35, p. 115.

Bosworth and Van Slyke: Jour. Biol. Chem., 1916, vol. 24, p. 173.

Hammarsten: Textbook of Physiological Chemistry.

Sommerfeld: Handbuch der Milchkunde.

Trunz: Zeitschr. f. Physiologische Chemie, 1903-4, vol. 40, p. 263. 


\section{INDEX OF NAMES}

Авт, 479

Adametz, 383

Alexander, 309

Allen, 83

Alsberg and Melvin, 565

Alvord, 49, 262

Anderson, J. F., 259

Anderson, L., 49

Andrews and Horder, 468

Appel and Backhaus, 271

Arms and Jordan, J. O., 448

Armstrong, 479

Aschmann, 648

Avery and White, 370,372

Ayers, 415, 417, 514-518, 522, 526, 534,538

Ayers and Clemmens, 425, 426

Ayers and Johnson, W. T., 208, 209, $250,343,427,524,525-528,531-$ $534,541,642,643$

Ayers and Taylor, 321

Ayers and Thom, 512

Ayers, Cook, and Clemmens, 281, 336

\section{BABCOCK, 72}

Babcock and Farrington, 203

Babcock and Russell, 65, 231, 232, 233

Babcock, Russell, and Decker, 361

Babcock, Russell, and Vivian, 233

Babcock, Russell, Vivian, and Hastings, 233

Backhaus, 284, 296

Backhaus and Appel, 271

Backhaus and Cronheim, 259, 655

Baer, 636

Bang, 455, 475, 514, 515

Barlow and Harrison, 382

Barnes and Eckles, 259

Barnhart and Lee, 600

Barthel, 268, 278, 350, 399, 426, 505, 507

Basch, 75, 76

Basch and Weleminsky, 268

Basenau, 250, 268

Bassenge, 399

Batchelder and Sedgwick, W. T., 262

Bauer, 244, 245

Bauer and Sassenhagen, 247

Beach, 124, 175, 309

Béchamp, 61
Behla, 399

von Behring, 224, 250, 459, 541

Beijerinck, 366

Bell and Haring, 452

Belloni and Biscaro, 99

Belonovsky, 394

Bengtson, 650

Benkendorf, 635, 637, 640

Berg, Rogers, and Davis, 605

Berg, Rogers, Potteiger, and Davis, 607

Bergey, 268, 275, 464

Berthelot, 396

Bertrand and Duchacek, 370

Bertrand and Weisweiller, 370

Bieder and Meigs, 585

Biernacki, 396

Biscaro and Belloni, 99

Bischoff, 331

Bitting, 56

Boas and Oppler, 366

Boekhout and DeVries, 268

Bolaffio and Lambroso, 39

Bolley and Hall, 268

Bosworth and Giblin, 654

Bosworth and Prucha, 355

Bosworth and Van Slyke, 85, 86, 88, $186,190,354,356,655,656$

Bowen, 64, 65, 66, 68, 537

Breed, 422, 465, 466

Breed and Brew, 422, 423

Breed and Dotterer, 370, 530

Breed and Prescott, 422, 464, 465

Breed and Stocking, 420

Brett and Schroeder, 626

Brew, 422, 423, 554

Brew and Breed, 422, 423

Brew and Dotterer, 424

Brew and Harding, 570

Brieger and Ehrlich, 250

Briscoe, 449

Brown, C. W., Rahn, and Smith, L. M., 607

Brown, H. R., 373

Brown, J. H., and Smith, Th., 442, 469

Brown, L. P., 559, 564

Brown, T. R., and Chester, 223

Brudny, 251

Bruhn and Sammis, 614

Buchanan, 365

Buchanan and Hammer, 382, 383, 384 
Buchner, 230

Buckley and Doane, 464

Budde, 225, 541

Budin, 588, 598

Burr, 275

Bushnell and Hunter, 369

Bushnell and Wright, 604

Cammack and Matheson, 619

Carlson and Ginsburg, 589

Carlyle, 127

Carter and Richmond, 100

Case and Sears, 502

Caspari, 125

Chester and Brown, 223

Clark, 620

Clark, Rogers, and Evans, 425, 426

Class and Heineman, 260

Clauss, 347

Clemmens and Ayers, 425, 426

Clemmens, Ayers, and Cook, 281, 336

Cohendy, 394

Cohn, 613

Coit, 482, 494, 544

Commanduci, 216

Conn, 275, 328, 347, 382, 386, 415, $416,420,423,428$

Conn and Esten, 331, 340, 378

Conn, Esten, and Stocking. 340, 378

Connel and Harrison, 616

Cook, Ayers, and Clemmens, 281, 336

Cooledge, 477

Cope and Evans, 251, 267

Coplans, 251

Cotton and Schroeder, 447, 477

Courant, 86

Courtney, Holt, and Fales, 84

Creasy, 33

Cristadoro, 30

Cronheim and Backhaus, 259, 655

Csonka and Edelstein, 102

Currie, 370, 618

Czerny, 36, 591, 593, 594

Czerny and Keller, 591

Daflberg, 581,620

Davis, B. J., and Rogers, 344

Davis, B. J., Rogers, and Berg, 605

Davis, B. J., Rogers, Berg, and Potteiger, 607

Davis, D. J., 442, 469

Dean and Todd, 439, 474

Decker, 138

Decker, Babcock, and Russell, 361

deVries and Boekhout, 268

Doane, 608

Doane and Buckley, 464

Doane and Eldredge, 361, 624

Doane and Lawson, 612,613

Dorset, 450
Dotterer and Breed, 370, 530

Dotterer and Brew, 424

Dox, 618

Duchacek and Bertrand, 370

Duclaux, 231

Düggeli, 366

ECKer and Heineman, 366, 367, 370

Eckles and Barnes, 259

Eckles and Palmer, 63, 123

Eckles and Reed, 110

Eckles and Shaw, 80, 107, 108, 111$121,126,142,143,145,176,179$

Edelstein and Csonka, 102

Ehrlich, 241, 243, 244

Ehrlich and Brieger, 250

Eldredge and Doane, 361, 624

Eldredge and Rogers, 367, 369, 616, $617,620,627$

Emerson and Levine, 439

Emmerling, 366

Engel, 76

Ernst, 35, 47, 48, 57-59, 69, 470, 471, 473

Esten, 347

Esten and Conn, 331, 340, 378

Esten and Mason, 276, 279, 282, 291, $293,295,369,617$

Esten, Conn, and Stocking, 340, 378

Evans, 275, 373, 388, 477, 478

Evans and Cope, 251, 267

Evans and Hastings, 208

Evans, Hastings, and Hart, 367, 369, 617,621

Evans, Rogers, and Clark, 425, 426

FABYAN, 477

Fabyan and Smith, Th., 475

Fales, Holt, and Courtney, 84

Fárrand and Marshall, 386

Farrington and Babcock, 168, 203

Farrington and Hastings, 530

Farrington and Woll, 163, 167, 172, $198,199,506,507$

Finkelstein, 366, 591, 593, 595

Finkelstein and Meyer, 591, 594

Fischer and Hooker, 62

Fleischmann, $43,68,72,78,95,179$, 648

Fleischner and Meyer, 477

Fliegel, 203

Flower and Lydekker, 41

Flügge, $373,385,531$

Fokker, 249

Foord and Wing, 124

Ford, 277

Ford and Lawrence, 375

Frandsen, 539

Frandsen and Markham, 646

Fraser, 124, 279, 283, 286, 330, 574577 


\section{Freas, 414}

Freemen, 298, 535

von Freudenreich, 272, 275-277, 366, 625

von Freudenreich and Thöni, 274

Frost, 420, 540

Frost and Ray̧enel, 507

\section{GAINES, 34, 37-43}

Galt and Iles, 366

Gamble, Lane, and Harding, 554

Geiger, 438

Gerber, 203

Giblin and Bosworth, 654

Ginsburg and Carlson, 589

Glenn and Heineman, 251, 252, 416

Godchot and Jungfleisch, 359

Goodwin, 505, 507

Gordon, 468

Gordon and Heineman, 638, 643

Gorini, 373, 403

Grassberger and Schattenfroh, 373

Grigoroff, 366

Grixoni, 366

Grotenfelt, 347, 408

Gruber and Huss, 366

Gruber, Weigmann, and Huss, 404

Günther and Thierfelder, 347, 357

Guthrie, 608

Gutzeit, 80

\section{HADLEY, 475-477}

Haecker and Little, 308

Hall and Bolley, 268

Halliburton, 82

Hammarsten, 75, 88, 94, 654

Hammer, 334, 361, 377, 378, 642, 650

Hammer and Buchanan, 382-384

Hammer and Hastings, 369

Hammer and Hauser, 526, 527 .

Hammer and Johnson, A. R, 68

Hammer, Ravenel, and Hastings, 331

Hammond, 43

Harden, 357

Harding, 328, 412, 564

Harding and Brew, 570

Harding and Prucha, 616

Harding and Rogers, 514

Harding and Smith, 309, 311

Harding and Van Slyke, 232

Harding and Wilson, 269, 270, 272, 274,276

Harding, Lane, and Gamble, 554

Harding, Prucha, and Weeter, 321

Harding, Rogers, and Smith, 625

Harding, Ruehle, Wilson, and Smith, 285-287, 297, 322, 324

Harding, Wilson, and Smith, 298, 303, $304,309,312-314$

Haring and Bell, 452
Haring and Ward, 453

Harrevelt and Lameris, 275, 442

Harris, N. MacL., and Jordan, E. O., 474,475

Harris, R. T., and Negley, 578, 579

Harrison, 284, 307, 318, 361, 386, 447, 625

Harrison and Barlow, 382

Harrison and Connel, 616

Hart, 108, 186-188

Hart and Steenbock, 536

Hart and Van Slyke, 90, 93

Hart, Evans, and Hastings, 367, 369, 617,621

Hastings, 100, 129, 388, 530, 604

Hastings and Evans, 208

Hastings and Farrington, 530

Hastings and Hammer, 369

Hastings and Hoffmann, 269, 276, 307, 308

Hastings and Ravenel and Hammer, 331

Hastings and Russell, 51, 54, 259, 277. $285,362,380,512$

Hastings and Sherman, 275

Hastings, Babcock, Russell, and Vivain, 233

Hastings, Evans, and Hart, 367, 369, 617,621

Hauser and Hammer, 526, 527

Hayden, 49

Hefferan and Heineman, 365, 366, 370 , 395,627

Hehner and Richmond, 179

Heineman, 263, 268, 281, 344, 347, $350,355,357,359,364,382,399$, $400,441,468,470,523,643$

Heineman and Class, 260

Heineman and Ecker, 366, 367, 370

Heineman and Glenn, 251, 252, 416

Heineman and Gordon, 638, 643

Heineman and Hefferan, 365, 366, $367,370,395,627$

Heineman and Jordan, E. O., 262, 329

Heineman, Luckhardt, and Hicks, $260,305,335$

Henneberg, 366

Herter, 393-395

Herter and Kendall, 394, 395

Herz, 215

Hesse, 250

Heubner, 586

Heubner and Rubner, 586

Hewlett, Villar, and Revis, 466

Hicks, Heineman, and Luckhardt, $260,305,335$

Hildebrand, 75

Hill, 84

Hippius, 250

Hirth, 33

Hoffman and Hastings, 269, 276, 307, 308 
Hoffmann and Russell, 445, 457, 464 Hölling, 347, 350, 357, 358, 364

Holt, Courtney, and Fales, 84

Hooker and Fischer, 62

Horder and Andrews, 468

Horowitz, 396

Hubbard and Winslow, 442

Hull and Rettger, 394, 396

Humphrey and Woll, 126, 309

Hunt and Langworthy, 612

Hunter, 389, 426

Hunter and Bushnell, 369

Hunziker, 114, 250, 328, 652

Hunziker and Mills, 172

Hüppe,'267, 344-347, 379

Huss and Gruber, 366

Huss, Weigmann, and Gruber, 404

ILes and Galt, 366

Illinois Food Commission, 639, 645

Irons and Jordan, E. O., 438

JACOBI, 511,587

Jensen, 344, 352, 354, 504, bu7

Jenter and Jordan, W. H., 77, 78

Johnson, A. R., and Hammer, 68

Johnson, A. R., and Levine, 426

Johnson, W. T., and Ayers, 208, 209, $250,343,427,524,525-528,531-$ $534,541,642, \cdot 643$

Jones and Woodhead, 466

Jordan, E. O., 411, 439, 444, 529, 565

Jordan, E. O., and Harris, 474, 475

Jordan, J. O., $330,570,650$

Jordan, J. O., and Arms, 448

Jordan, E. O., and Heineman, 262, 329

Jordan, E. O., and Irons, 438

Jordan, W. H., and Jenter, 77, 78

Judkins and White, 109, 113, 126

Jungfleisch and Godchot, 359

KASTLE, 71

Kastle and Porch, 235

Kastle, Rosenau, and Lumsaen, 529

Kaufmann and Schlesinger, 366

Keller and Czerny, 591

Kelley, 431, 554

Kendall and Herter, 394, 395

Khouri and Rhist, 366

Kiernan, 461

Kilbourne, 520

Klimmer, 250

Klusemann, 80

Koch, 444, 445, 457, 459

Koestler, 353, 354, 370

Kolle, 250

König, 406

Koning, 233, 237, 250, 253

Kozai, 347, 358
Krumwiede and Noble, 399

Krumwiede and Park, 459, 460

Krumwiede and Valentine, 443,469

Kruse, 344, 347, 364

Kühn and Lürssen, 366, 371, 394

Kulp and Ruehle, 293, 294

Kuntze, 317, 366, 367

Kuntze and Löhnis, 317

LAMBroso and Bolaffio, 39

Lameris and Harrevelt, 275, 442

Lamson, 260

Lane, 298, 306, 309, 571-573, 577

Lane and Stocking, 310

Lane, Harding, and Gamble, 554

Lane-Claypon and Starling, 39

deLange, 655

Langworthy and Hunt, 612

Laqueur, 93

Larson and McKay, 602

Larson and Sedgwick, 478

Lawrence and Ford, 375

Lawson and Doane, 612, 613

Leach, 73, 105, 112, 147, 148, 150, $174,193,194,195,217-219,221$, $222,226,227$

Lee and Barnhart, 600

Leeuwenhoeck, 60

Leichmann, 100, 347, 366

Lemus, 80

Levine and Emerson, 439

Levine and Johnson, 426

Levinson, 587

Lewis and Wright, 329

Lister, 267, 346

Little and Haecker, 308

Lloyd, 52

Loevenhart, 93

Löhnis, 284, 345, 363-365, 371, 386, $606,615,616$

Löhnis and Kuntze, 317

Long, 196

Luckhardt, 249, 466

' Luckhardt, Heineman, and Hicks, $260,305,335$

Lumsden, 644

Lumsden, Rosenau, and Kastle, 529

Lürssen and Kühn, 366, 371, 394

Lux, 271, 273, 274

Lydekker and Flower, 41

Lythgoe, 127

MaCKenzIE, 358

Mai, 129

Maragliano, 457

Markham and Frandsen, 646

Marsh, 400

Marshall, 102, 103, 250, 352, 353, 382, 571

Marsha!l and Farrand, 386 
Martiny, 17, 18, 20, 22-24, 28-30, 306 Pennington and St. John, 250

Mason and Esten, 276, 279, 282, 291, Pennington and Stiles, 642 $293,295,369,617$

Mason and Stocking, 307-309

Matheson and Cammack, 619

Mathers, 469, 472

Mathews, 61, 97, 587

McCandlish, 123

McCoy and Rosenau, 249, 251, 252

McDowell, 579

McKay and Larsen, 602

Meek, 308

Meigs and Bieder, 585

Melvin, 445, 477

Melvin and Alsberg, 565

Mereschewsky, 366

Metchnikoff, 365, 392-395, 397

Meyer and Finkelstein, 591, 594

Meyer and Fleischner, 477

Michels, 608

Mills and Hunziker, 172

Mitchell, 644

Mitchell and Woodhead, 243

Mohler, 626

Moor and Pearmain, 648

Moore, 267, 268, 445, 448, 452

Moore and Ward, 45, 46, 624

Moro, 366

Morres, 209

Mortensen, 646

Much and Römer, 242

Perkins and Vaughan, 626

Peterson, 448

Pfaundler, 32, 38, 44, 76

Piorkowsky, 366

Porch and Kastle, 235

Pope, 388

Potteiger, Rogers, Berg, and Davis, 607

Prescott, 350, 425, 426

Prescott and Breed, 422, 464, 465

Price, 309

Prucha and Bosworth, 355

Prucha and Harding, 616

Prucha, Harding, and Weeter, 321

Publow and Van Slyke, 91, 93, 96, 107, $109,117,118,126,190$

Puppel, 442

\section{RABILD, 577}

Race, 425,426

Rahe, 367, 372, 394, 395

Rahn, 354

Rahn, Brown, and Smith, 607

Rauber, 40

Raudnitz, 87-89, 96, 99, 104, 131

Ravenel and Frost, 507

Ravenel, Hastings, and Hammer, 331

Reed and Eckles, 110

Reed and Ward, 275, 442

Reischauer, 207

NeF, 359, 360

Negley and Harris, 578, 579

Newman and Swithinbank, 106, 259, $267,432,438,439,440,443,444$

Niederstadt, 259

Noble and Krumwiede, 399

North, 396, 537

Northrup, 399

Norton, Thompson, and Shaw, 600

Norton, Turner, Shaw, and Wright, 126

\section{Oehler, 394}

Oliver, 72

Olsen, $95,96,377$

Oppler and Boas, 366

Ottolenghi, 36

Reiss and Sommerfeld, 201

Renk, 202

Rettger and Hull, 394, 396

Revis, Hewlett, and Villar, 466

Rhist and Khouri, 366

Ribbert, 39

Richmond, 62, 66, 67, 72-74, 79, 81, $84,87,88,100,112,120,130,179$, $182,220,405,407,648$

Richmond and Carter, 100

Richmond and Hehner, 179

Roberts, 267

Rodella, 366, 367

Rogers, 234, 350, 365, 404, 406, 539, $540,608,609$

Rogers and Davis, 344

Rogers and EIdredge, 367, 369, 616, $617,620,627$

Rogers and Harding, 514

Rogers, Berg, and Davis, 605

Patmer and Eckles, 63, 123

Palmer and Winslow, 468

Park; 250, 262

Park and Krumwiede, 459, 460

Parker, 438

Pasteur, 346, 511

Pearmain and Moor, 648

Pearson, 504, 507, 552

Pennington, 331,644

Rogers, Berg, Potteiger, and Davis, 607

Rogers, Clark, and Evans, 425, 426

Rogers, Harding, and Smith, 625

Rolet, 259

Römer and Much, 242

Rosenau, 262, 512

Rosenau and McCoy, 249, 251, 252

Rosenau and Shorer, 519 
Rosenau, Lumsden, and Kastle, 529

Rosenheim and Tunnicliff, 225

Rosenow, 470

Rotch, 585

Rubner and Heubner, 586

Ruehle and Kulp, 293, 294

Ruehle, Harding, Wilson, and Smith, 285-287, 297, 322, 324

Rullman, 331

Rullman and Trommsdorff, 249, 253

Rupp, 95, 97, 132

Russell, 270, 275, 284, 295, 317

Russell and Babcock, 65, 231-233

Russell and Hastings, 51, 54, 259, 277, $285,362,380,512$

Russell and Hoffmann, 445, 457, 464

Russell, Babcock, and Decker, 361

Russell, Babcock, and Vivian, 233

Russell, Babcock, Vivian, and Hastings, 233

\section{SACKeTT, 475}

Sammis, $164,620,624$

Sammis and Bruhn, 614

Sassenhagen and Bauer, 247

Savage, 275

Schardinger, 236, 239, 347

Schattenfroh and Grassberger, 373

Schein, 40

Schereschewsky, 432, 479

Schern, 248

Scheurler, 259

Schierbeck, 347

Schlesinger and Kaufmann, 366

Schmitz, 542

Schroeder, 447, 448, 477

Schroeder and Brett, 626

Schroeder and Cotton, 447, 477

Schulz, 267, 270, 271, 284

Sears and Case, 502

Sebelein, 97, 98

Sedgwick, J. P., and Larsen, 478

Sedgwick, W. T., and Batchelder, 262

Seljgmann, 235, 236

Senftner, 438

Severin, 260

Sewerin, 366

Shaw, 172,228

Shaw and Eckles, 80, 107, 108, 111$121,126,142,143,145,176,179$

Shaw and Thom, 608

Shaw, Thompson, and Norton, 600

Shaw, Turner, Norton, and Wright, 126

Sherman, 334

Sherman and Hastings, 275

Shorer and Rosenau, 519

Simon, 268

Slack, 414, 416, 417, 419, 421, 464

Smetham, 74

Smith, G. A., and Harding, 309, 311
Smith, G. A., Harding, and Rogers, 625

Smith, G. A., Harding, and Wilson, 298, 303, 304, 309, 312-314

Smith, G. A., Harding, Ruehle, and Wilson, 285-287, 297, 322, 324

Smith, L. M., Rahn, and Brown, 607

Smith, Th., 100, 382, 445, 458, 512

Smith, Th., and Brown, J. H., 442, 469

Smith, Th., and Fabyan, 475

Söldner, 101, 133, 655

Sommerfeld, 133, 214

Sommerfeld and Reiss, 201

Soxhlet, 511

Spolverini, 233

Starling and Lane-Claypon, 39

St. John and Pennington, 250

Steenbock and Hart, 536

Stiles and Pennington, 642

Stocking, 251, 272-274, 284, 290, 295, $300,302-305,652$

Stocking and Breed, 420

Stocking and Lane, 310

Stocking and Mason, 307-309

Stocking, Conn, and Esten, 340, 378

Stokes and Wegefarth, 463

Storch, 61

Straus, 529, 536

Strauss, 366

Stutzer, 202

Swithinbank and Newman, 106, 259, $267,432,438-440,443,444$,

TANGLE, 87

Taylor, 589

Taylor and Ayers, 321

Thiele, 358

Thierfelder and Günther, 347,357

Thom, 613, 622, 623

Thom and Ayers, 512

Thom and Shaw, 608

Thompson, Shaw, and Norton, 600

Thöni and von Freudenreich, 274

Tieman, 98

Tissier, 394

Todd and Dean, 439, 474

Tonney, 205

Trask, $435,439,440,444$

Troili-Peterson, 400

Trommsdorff, 267, 464, 472

Trommsdorff and Rullmann, 249, 253

Trueman, 290

Trunz, 101, 121, 122, 127, 654

Tunicliff and Rosenheim, 225

Turner, Shaw, Norton, and Wright, 126

UFFELMANN, 250

Uhl, 281

Utz, 347,358 
VALENTINE and Krumwiede, 443, 469 |Wells, 649, 650

Van Slyke, 72, 79, 95, 96, 108, 112, Wheeler, 124

$214,215,237$

Van Slyke and Bosworth, 85, 86, 88 , $186,190,354,356,655,656$

Van Slyke and Harding, 232

Van Slyke and Hart, 90, 93

Van Slyke and Publow, 91, 93, 96, $107,109,117,118,126,190$

Vaughan and Perkins, 626

Veldee and Weinzirl, 427

Vieth, 74, 130

Villar, Hewlett, and Revis, 466

Vivian, Babcock, and Russell, 233

Vivian, Babcock, Russell, and Hastings, 233

deVries and Boekhout, 268

WARD, 268, 382, 383

Ward and Haring, 453

Ward and Moore, 45, 46, 624

Ward and Reed, 275, 442

Washburn, 630, 633, 634, 638, 639, 646

Webster, 172, 282, 283, 323

Weeter, Prucha, and Harding, 321

Wegefarth and Stokes, 463

Wegele, 395

Weigmann, 366, 374, 375, 378, 379, 386,405

Weigmann, Gruber, and Huss, 404

Weinzirl and Veldee, 427

Weisweiller and Bertrand, 370

Wejnert, 395

Weleminsky and Baseh, 268

White and Avery, 370, 372

White and Judkins, 109, 113, 126

Wiener, 542

Wiley, 193

Wilkens, 259, 261

Williams, 571,581

Willoughby, 72

Wilson and Harding, 269, 270, 272, 274,276

Wilson, Harding, and Smith, 298, 303, $304,309,312-314$

Wilson, Harding, Ruehle, and Smith, $285-287,297,322,324$

Wing and Foord, 124

Winkjer, 573,580

Winslow, 421,441

Winslow and Hubbard, 442

Winslow and Palmer, 468

Wolff, 379

Woll, 124

Woll and Farrington, 163, 167, 172, $198,199,506,507$

Woll and Humphrey, 126, 309

Woodhead and Jones, 466

Woodhead and Mitchell, 243

Woods, 125

Woodward, 552

Wright and Bushnell, 604

Wright and Lewis, 329

Wright, Turner, Shaw, and Norton, 126

Wyman, 638 



\section{INDEX OF SUBJECTS}

ABNoRMal butter, 606

cheese, 624

taste and odor of milk, 386

Abrin, 241

Absolute holders, 519

Acid-coagulating bacteria, 343, 531 micrococci, 373

Acidity, degree, 199

tests, 196-200

Farrington's, 198

Manns', 197

Marshall's, 198

Publow's, 198

Spillman's, 199

Van Norman's, 197

Acid-non-coagulating bacteria, 343, 531

Acidophil bacteria, 365-367

Acid-proof bacilli, 446, 448, 512

Acid-rennet micrococci, 386

Acids, amino-, 70

glycerids of non-volatile, 71,79 , 80

of volatile, $71,79,80$

influence of, on rennet action, 93 mono-amino-, 90

Aciduric bacteria, 365, 372

Actinomycosis, 474

Adams' fat determination, 147

Adulteration of milk, 213

Aëration of milk, 102, 335

Agglutinins in milk, 243, 251

Air, stable, bacteria in, 290

Albumen milk, 594, 595

Albumin, determination of, 183

Albuminophore, 59

Albumose in milk, 98

Alcohol, fat-saturated, 156, 173 test, 207

Aldehyd catalase, 236

Alimentary disturbances of infants, 590

Alizarol test, 209

Alkali forming bacteria, 343,531

influence of, on rennet action, 93

Amboceptor, 244

American Association of Medical Milk Commissions, 497

ice-cream, 631

Amido-compounds, determination of, 184
Amino-acids, 70

Ammonia in milk, 70 determination of, 184

Amylase, 233

Anaërobes in milk, 374,427 test for 427

Analysis of butter, 609 of casein, 87

Anaphylactic test, 246

Anilin dyes in milk, 221 detection of, 221

orange, 222 detection of, 222

Annatto, 221

detection of, 221

Anthrax, 473

Antibodies in colostrum, 242

in milk, 70, 240, 585

Antirennin, 96

Antiseorbutics, 590

Antitoxin for tuberculosis, 457

globulin, 242

in milk, 240

Araka, 407

Arginin, 618

Arnold's reaction, 238, 507

Aroma of butter, 603, 605

Artificial ripening of cream, 603 starters, 603

Aseptine, 223

Ash of cow's milk, 101, 102, 121

determination of, $179-181$

of human milk, 654

Ash-free casein, 85 paracasein, 86

Asiatic cholera, 443

Aspergillus flavus, 512 fumigatus, 512

repens, 512

Ass's milk, 70, 105, 657 casein, 87

Association score card, 552

Atomizing system of milk desiccation, 651

Atrophy in infants, 595

Auto-intoxication, 392, 394

Ayers' casein agar, 415 counting apparatus, 417

Ayrshires, 572

Azo-dyes, 221

in milk, 221 
BABCOCK centrifuge, 162, 163

fat determination, 155-164, 504

formula, 176

pipet, 158,162

test bottles, 156, 159, 160, 167

bottle-washer, 164

for fat in buttermilk and whey, 173-175

in cheese, 628

in cream, 167

in ice-cream, 639

in skimmed milk, 173-175

Bacilli, acidophil, 365,366

acid-proof, 446, 448, 512

aciduric, 365,372

Bacillus abortus, 275, 276, 475-478

lipolyticus, 477

acidi lactici, $341,344,346$

acidophil-aërogenes, 365

acidophilus, 365 , 366

aërogenes, 265, 341, 344, 346, 350, $357,382,425$

bifidus, 365,393

botulinus, 241

bulgaricus, $341,342,365-367,384$, $394,399,401,596,621$

casei, 365,371

coagulans, 650

coli, $265,276,344,350,351,425$, $427,463,473$

cyanofluorescens, 378

cyanofuscus, 626

cyanogenes, 376,378

delbrücki, 100, 366

dimorphobutyricus, 375

diphtheriæ, 439

dysenteriæ, 596

enteritidis, 444, 627

ery throgenes, 376,379

fluorescens, $376,379,606$

ichthyosmius, 650

lactimorbi, 474,475

lactorubefaciens, 379

lebenis, 341

melitensis, 478

membranaceus amethystinus, 379

morbificans, 268

of Boas-Oppler, 341, 365, 366, 370

of botulism, 241

of long life, 365

panis fermentati, 365

paratyphosus, 444

prodigiosus, $268,277,376,379,606$

putrificus, 375

pyocyancus, 384

radiciformis, 276

rudensis, 625

saccharobutyricus, 374

saponaceous, 386

sporogenes, 375,427

subtilis, 276

tuberculosis, 460
Bacillus typhosus, 437

violaceus, 379

viscosus, 383,384

welchii, 375, 393

Bacteria, acid-coagulating, 343, 531

acid-non-coagulating, 343,531

acidophil, 365-367

acid-rennet, 386

aciduric, 365,372

alkali forming, 343,531

butyric acid, 374,375

chromogenic, 376

in butter, 606

in butterine, 606

in buttermilk, 263, 399

in Cheddar cheese, 621

in cheese, 615

in colostrum, 269

in cream, 259,329

in curry powder, 282

in Emmenthaler cheese, 620

in evaporated millk, 649

in fodder, 291, 292

in foremilk, $270-272$

in gravity cream, 259

in ice-cream, 642

in market milk, 261, 262

in middle milk, $270-272$

in milk, 259, 261, 262, 328, 329, 340

in oleomargarine, 606

in pasteurized milk, 531-535

in separator cream, 259

in stable air, 290

in strippings, 270-272

in udder, 267-278

inert, 343, 531

iron, 626

lactic acid, $265,266,275,343,531$, $533,534,604$

classification of, 344,345

distribution of, 350

in starters, 604

on cow hair, 285

on flies, 293

on hands, 295

pathogenic, in butter, 605

in buttermilk, 399

in cheese, 626

in cream, 399

in ice-cream, 644

in milk, 410, 430

peptonizing, $266,343,531,535$

propionic acid, 375,620

proteolytic, 265,266

rennet-forming, 266, 386 .

soil, 343

surviving pasteurization, 531

Bacterial examination of butter, 609

of certified milk, 501-503

of cheese, 627

of concentrated milk, 653

of milk, 409, 501 
Bactericidal substances in milk, 243, 249,250

Bacterium cæruleum, 379

casei fusci, 625

caucasicum, 365, 366, 401

fulvum, 386

güntheri, 341

indigonaceum, 379

kirchneri, 386

lactis, 346

acidi, $275,276,291,292,341,347$, 349,364

longi, 400

mazun, 404

of lactic acid, 347

of long milk, 400

of sour milk, 347

peptogenes, 384

sapolyticum, 386

syncyaneum, 378

synxanthum, 379

Bang system, 455

Barrel churn, 22

Bedding for cows, 293

Benzidin test, 238

Benzoic acid in milk, 225 detection of, 228,507

Beta-naphthol, 235

Binders in ice-cream, 633

Biorization of milk, 542

Bitch's milk, 70

Bitter butter, 607

cheese, 625

milk, 385

Blue cheese, 626 milk, 377

Boas-Oppler bacillus, 341, 365, 366, 370

Body of ice-cream, 633

Bohemian pyopagus twins, 39

Boiled milk for infant feeding, 587

Borax in milk, 224 detection of, 227,506

Boric acid in milk, 224 detection of, 227,506

Botryomyeusis, 474

Bottle cappers, $319,320,491$ fillers, 319

washers, 325,326

Bottling hot pasteurized milk, 524

Botulism, 241

Bovine casein, 86, 657

tubercle bacilli, $435,445,458$

tuberculosis, 444-461

Bovovaccine, 457

Bowl sediment, 601

Box churn, 22

Bread, salt-rising, 365

Breed's counting method, 422-424

Breeds of dairy cows, 572,573

Brie cheese, 612,624

Brinsen cheese, 623
Brown Swiss, 573

Buddeized milk, 225, 541

Buffalo's milk, 70, 657

Bull associations, co-operative, 579, 580

Burrell-Lawrence-Kennedy milking machine, 312, 313

Butter, 599

abnormal, 606

analysis of, 609

aroma of, 603, 605

bacteria in, 606

bacterial examination of, 609

bitter taste in, 607

cheesy taste in, 607

chemical analysis of, 600

churning, 605

composition of, 600

decolorization of, 607

derivation of word, 19

fat-splitting ferment in, 234

fishy flavor in, 608

flavor in milk, 386

influence of light on, 607

mineral content of, 600

off-flavor in, 608

origin of, 18

rancidity in, 606-608

scoring of, 608

streaky, 607

texture of, 599,605

tubercle bacilli in, 447

water in, 600

whey-, 608

working of, 605

Butter-fat, chemistry of, 78-81

melting-point of, $80,108,112,120$, 121,125

separation of, 599

solubility of, 80

Butterine, bacteria in, 606

tubercle bacilli in, 447

Buttermilk, 74, 397, 398

Babcock test for fat in, 173-175

bacteria in, 263, 399

cheese, 619,620

composition of, 74,75

therapy, 396

tubercle bacilli in, 447

typhoid bacilli in, 399

Butterwort, 380

Butyric acid bacteria, 374, 375

Butyrometer, 165

Butyrorefractometer, 148, 149

By-products of cheese factories, 323 of creameries, 323

Cadaverin in cheese, 626

Calculation of fat in ice-cream, 641

Caloric system of milk modification, 586 
Camel's milk, 70, 657

Camembert cheese, 612, 621-623 micro-organisms in, 621 mold, 622,623

Campbell's system of milk desiccation, 651

Can rinser, 320, 321

Cane-sugar for infant feeding, 586 in milk, detection of, 219

Capping machines, 319, 320, 491

Caramel in milk, 221 detection of, 222

Carbohydrate-splitting ferment, 233

Care of milk in home, 333 on wagons, 332

Carotin, 63, 221

Casease, 231

Casein, 71, 82

agar, 415

analysis of, 87

ash-free, 85,86

ass's milk, 87

bovine, 86,657

chemistry of, 82-8:

coagulation of, 89

commercial uses of, 83

composition of, 87

formula of, 87

goat, $87,656,657$

composition of, 656

molecular weight of, 656

human, 87,654

hydrolysis of, 89

manufacture of, 580

molecular weight of bovine, 88 of goat, 656 of human, 654

origin of, 75

precipitation of bovine, $82,83,88$, 90

of human, 654

preparation of, $83-86$

properties of, 86-90

solubility of, 88,90

source of, 75

specific gravity of, 88

tests for, 188-191

tryptic digestion of, 89

Caseinogen, 82

Caseoglutin, 618

Caseone, 89

Caseoses, determination of, 184

Catalase, 234, 235, 463

aldehyd, 236

tests, 237,625

Cellular elements in colostrum, 465 in milk, $57,63,463-466$

Centrifugation of milk, 56, 132

Centrifuge, Babcock, 162, 163

Cephalin, 99

Cerebrosid, 587

Certified ice-cream, 646
Certified milk, 482

bacterial examination of, 502, 503:

chemical examination of, 504-510

definition of, 482

producer's association, 497

production of, 483-487, 497-510

score card for, 492-495

Changes in composition of milk, 128$134,264-266$

Cheddar cheese, 233, 614, 616, 621

bacteria in, 621

tubercle bacilli in, 447

Cheese, 611

abnormal, 624

bacteria in, $615-617$

bacterial examination of, 627

bitter, 625

blue, 626

Brie, 612, 624

Brinsen, 623

buttermilk, 619,620

cadaverin in, 626

Camembert, 612, 621-623 micro-organisms in, 621

Cheddar, 233, 614, 616, 621

bacteria in, 621

tubercle bacilli in, 447

chemical examination of, 628

composition of, 613

cottage, $233, \cdot 612,619,620$

tubercle bacilli in, 447

cream, tubercle bacilli in, 447

dishes, 613

distribution of bacteria in, 615

Edam, 380, 612

Emmenthaler, 375, 447, 612, 616 $619,620,621$

bacteria in, 620,621

eyes in, $375,619,620$

tubercle bacilli in, 447

factory by-products, 323

food value of, 612

from pasteurized milk, 614

fruity flavor in, 625

gassy, 617,624

goat's milk, 624

green, 20

Gorgonzola, 612, 623

hard, 611

hydrogen sulphid in, 626

indol in, 626

Isigny, 612,624

lactobacilli in, 369,617

Limburger, 375,612

micro-organisms in. 613

Neufchatel, 617, 625

number of bacteria in, 616

Parmesan, 612

pathogenic bacteria in, 626

poisoning, 626

ptomains in, 626

putrescin in, 626 
Cheese, rennet, 611

ripening of, 611 cultures for, 615

Roquefort, $612,619,623$

rusty spots in, 625

salt-soluble substance in, 90

soft, 611,619

sour millk, 611

Stilton, 612, 623

sweet, 625

Swiss, 612

texture of, 617

tubercle bacilli in, 447, 626

varieties of, 612

white spots in, 625

yellow, 625

Cheesy taste in butter, 607

Chemah, 19

Chemical analysis of butter, 609

examination of certified milk, 504510

of cheese, 628

of milk, 136, 504

Chemistry of butter-fat, 78-81

of casein, 82-86

of milk, 70

Chemius, 406

Chladosporium butyrii, 606

Chocolate-brown color in milk, 376

Cholera infantum, 432, 478-480

Cholesterin, 70

Chromogenic bacteria, 376

Chumis, 406

Churn, 18-28

Churning, 605, 607

Chymogen, 595

Chymosin, 91

Cieddu, 403

Cistern in udder, 47

Citric acid in milk, 70

Clarifiers, 280, 281, 334, 513

Classes of ice-cream, 645

Classification of lactic acid bacteria, 344,345

of lactobacilli, 371,372

Coagulating enzym, 91,373

Coagulation of casein, 89 of rennet, 90-97

Coagulum formed by lactic acid bacteria, 360,361

Co-efficient of expansion, 66

Cohesion of milk, 64

Colloids in ice-cream, 633

Colony counting apparatus, 417,418

Color of milk, 63,64

Colored milk, 376-379

Coloring matter in milk, 221, 222, 506

Colostrum, $36,55,62,72,73$

antibodies in, 242

bacteria in, 269

cells in, 465

composition of. 72,73
Colostrum corpuscles, $36,57,73$

fat, 76,77

specific gravity of, 62,63

test for, 246

Commercial starters, 604 uses of casein, 83

Complement fixation, 245

in milk, 244

Composite samples, 140, 141, 171

Composition of ass's milk, 105

of butter, 600

of buttermilk, 74,75

of casein, 87

of cheese, 613

of colostrum, 72, 73

of condensed milk, 648

of cow's milk, 70, 72, 105, 656

of cream, 73, 74

of desiccated milk, 648,652

of evaporated milk, 648

of ewe's milk, 70

of foremilk, 112

of goat's milk, 105, 655, 656

of human milk, $105,584,656$

of mare's milk, 105

of middle milk, 112

of milk, changes in, 128-134

from different mammals, 70, 654

powder, 648

of skimmed milk, 74

of stripplings, 112

of whey, 74

Compounds, amido-, in milk, 70, 184

Condensed milk, 648

bacterial examination of, 653

composition of, 648

fat determination of, 652

fishy odor in, 650

plain, 648

Condensation of milk, 649

Conditions of rennet action, 93-97

Construction of stable, 286-288

Contagious abortion, 475-478

immunization against, 477

vaccination against, 477

Continuous flow pasteurization, 519 process pasteurization, 513

Control of milk supplies, 544, 546

Cooling milk, 328-332

Co-operative bull associations, 579 , 580

cheese factories, 580

cow-testing associations, $\mathbf{5 7 7}$

creameries, 580

Corpuscles of Nissen, $35,52,60$

Cost of pasteurizing milk, 537

Cottage cheese, $233,612,619,620$

Counting apparatus for colonies, 417 , 418

Cow feces, tubercle bacilli in, 448

Cowpox, 474

Cow-testing associations, 577 
Cream, bacteria in, 259, 329

composition of, 73,74

foamy, 389

gravity, 52, 54, 73, 259, 600

homogenized, 632

ice-, 630

layer, 52

powder, 650

ripened, 602

ripening, 602

sampling, 139, 171

separktion from milk, 600,601

separator, 334,601

test bottles, 159,167

tubercle bacilli in, 447

typhoid bacilli in, 399

Creamery by-products, 323 score card, 560

Creaming, 52, 53, 601

Creatin and creatinin, 99

Crotin, 241

Cryoflora, 342

Cultures for cheese ripening, 615

Curd tests, 210, 361, 624

Cystin, 90

DADHI, 403

Dairy by-products, 580

cows, 572

herd, 572

formation of, 573

productiveness of, 574

inspection, 550

requirements, 559

score card, 552,553

troubles, eradication of, 386

Danish type of pasteurizer, 514

Decker's sampling pipet, 138

Decolorization of butter, 607

Decomposition in infants, 595 of milk-fat, 81

of products in cheese, 617,618

of Bacillus coli, 352

of micro-organisms in milk, 264 of Streptococcus lacticus, 352

D-dextrose, 99

Deep-setting system, 55, 600

Definition of certified milk, 482 of ice-cream, 645

D-galactose, 99

Degrees of acidity, 199

Derivation of word butter, 19

Desiccated milk, 648, 650 composition of, 648,652

modified milk, 652

Desiccation of milk, 651

Detection of anilin-dyes, 221 orange, 222

of annatto, 221

of azo-dyes, 221

of benzoic acid, 228,507
Detection of borax, 227, 506

of boric acid, 227,506

of cane-sugar, 219

of caramel, 222

of catalase, 237

of coloring matter, 221, 506

of colostrum milk, 246

of foreign fat, 220

of formaldehyd, 225-227, 506

of gelatin, 220

of heated milk, 237, 238, 507

of mastitis milk, 246

of nitrates, 219

of salicylic acid, 229, 507

of skimmed milk, 214

of sodium bicarbonate, 229

carbonate, 229

of thickening agents, 219

of watered milk, 214

Determination of acidity, 196-200

of albumin, 183

of amido-compounds, 184

of ammonia, 184

of ash, 179-181

of casein, 183

of caseoses, 184

of fat, $147-175$

in butter, 609

in buttermilk, 173

in cheese, 628

in concentrated milk, 652

in ice-cream, 639

in skimmed milk and whey, 173

of formaldehyd in milk, 227

of ice-cream overrun, $635-637$

of lactalbumin, 183

of lactose, 191-196

of milk-sugar, 191-196

of pepton, 184

of plasma solids, 176

of protein, 181-191, 506

of solids-not-fat, 176

of specific gravity, 141-147

of total nitrogen, 181

solids, 175

Deutro-caseose, 618

Development of mammary gland, 34

Devons, 573

Dextran, 384

Dextrimaltose, 586, 593

Dextro-rotatory lactic acid, $357-360$

Dextrose, 71, 100

Diagnosis of tuberculosis, 449

Dialysis of milk, 133

Diastatic ferment in human milk, 585

Difference in composition of milk due to breed, 106

due to individuality, 110

from the same individual, 111

Differentiation of streptococci, 467473

Dilution of milk, 133 
Diphtheria, 439, 440 carriers, 439

Direct enumeration of bacteria, 421424

Dirt in milk, 278-282

Diseases, milk-borne, 263, 437

Disinfection of stable, 387,457

Dissemination of tuberculosis, 445 , 448,449

Distribution of Bacillus coli, 350

of bacteria in cheese, 615

in cream, 259

in ice-cream, 643

in milk, 258

in udder, 273

of lactic acid bacteria, 350

of lactobacilli, 567

of milk, 581

of Streptococcus lacticus, 350

Dolphin's milk, 70

Drosera, 400

Dry milking, 296

Duration of lactation period, 43

Dust in stable air, 286

Dutch Belted, 573

Dysentery, 439

Dyspepsia of infants, 593

Economic aspect of milk production, 569

Edam cheese, 380,612

Effect of thunderstorms on milk, 133

Eggs in ice-cream, 633

Egyptian buffalo, 100

Ehrlich's hypothesis, 243

Eiweiss milk, 595

Ekenberg system of milk desiccatıon, 651

Eldredge and Rogers' medium, 627

Electric conductivity, 67

Elementary analysis of casein, 87

Elephant's milk, 70

Emmenthaler cheese, 375, 447, 612 $616,619,620,621$

bacteria in, 620,621

eyes in, $375,619,620$

tubercle bacilli in, 447

Emulsion, 51, 61, 62, 71

Endo-enzyms, 230

Enterokinase, 234

Enumeration of bacteria in milk, 413 , 421

Enzyms, carbohydrate-splitting, 233 coagulating, 91,373

diastatic, 585

endo-, 230

exo-, 230

extracellular, 230

tat-splitting, in butter, 234

in cow's milk, 234

in human milk, 585
Enzyms in milk, 70, 230, 231, 536, 585 inherent, 230,236

intracellular, 230

proteolytic, 91,231

Epidemics, icemcream-borne, 644 milli-borne, 263, 411, 430, 432

Epidemiology of milk epidemies, $435-$ : 437

Epithelial colls, 59

Epizoötic abortion, 475-478

Iiquisetum arvense, 378

Equity milk sampler, 139

Eradication of dairy troubles, 386

of tuberculosis, 455-457

Erepsin, 89

Ereptase, 618

Lssential oils in milk, 240

Euphorbium urticæfolium, 475

Evaporated milk, 648, 649

bacteria in, 649

composition of, 648

Ene's milk, 105

Examination of milk, bacterıal, 409, 502

chemical, 136, 504

physical, 136

Exercise and nervous influences, 127

Exo-enzyms, 230

Expansion of milk, 66

Extent of milk pasteurization, 538

Extracellular enzyms, 230

Extract, rennet, 90

Extractives, 70, 99

Eyes in Emmenthaler cheese, 375, 619, 620

FARrington's alkali tablets, 198

Fat determination, Adams', 147

Babcock's, 155-164, 504

ether extraction, 147

Gerber's, 165, 505

Leffman-Beam's, 504

refractometer method, 148

Russian, 164

Werner-Schmidt's, 148

Wollny's refractometer method, 148

diarrhea, 595

globules, $51-53,55,56,60-62,80$, $108,113,119,120,132,599$

in goat's milk, 655

in human milk, 654

nature of, $60-62$

in buttermilk and whey, Babcock's

test for, $173-175$

in cheese, 613

Babcock's test for, 628

in concentrated milk, 652

in cream, Babcock's test for, 167

in foremilk, 112

in human milk, 654 
Fat in ice-cream, Babcock's test for, Fruity flavor in cheese, 625 639

in middle milk, 112

in skimmed milk, Babcock's test for, $173-175$

in strippings, 112

melting-point of, 108, 112, 120, 121, 125

Fat-saturated alcohol, 156, 173

Fat-soap stool, 593

Fat-splitting ferment in butter, 234 in cow's milk, 234

in human milk, 585

Feeding fat into milk, 125

Fermentation lactic acid, 358

of silage, 369

tests, 210

Fermented milks, 392

Ferments in cow's milk, 230

in human milk, 585

organized, 230

unorganized, 230

Feser's lactoscope, 217

Fibrin ferment, 230

Fillers in ice-cream, 633

Filtration of milk, 334

Final package pasteurization, 522-528

Fishmouth milking pail, 301

Fishy flavor in butter, 608 odor in condensed milk, 650

Flash process of pasteurization, 513

Flavor of butter, 80

of ice-cream, 632

of milk, 80

Fleischmann's formula, 179

Fliegel's sediment test, 203

Floating curd, 211, 625

Fluorids in milk, 223, 225

Foamy cream, 389

Food balance in infant feeding, 593 influence on milk, 123 value of cheese, 612

Foot-and-mouth disease, 461

Foreign fat in milk, 220

Foremilk, bacteria in, 270-272 composition of, 112 fat in, 112

Formaldehyd in milk, 223 detection of, 225-227, 506

Formation of dairy herd, 573 of secretion, 34

Formula of casein, 87

Freezine, 223

Freezing ice-cream, 632 of milk, 128

Freezing-point of cow's milk, 67, 128 of human milk, 654

French ice-cream, 631

Fried ice-cream, 631

Frost's counting method, 420

Frozen custard, 632 milk, 542 odor in milk, 386

Galactan, 384

Galactase, 231-233

Galactolipins, 587

Galactose, 99, 587

Galactozyme, 98

Gamoose, 100

Garget, 462-473

Gases in milk, 70, 71, 102-104

Gassy cheese, 617, 624

curd, 211

Gastro-enteritis, 478

Gelatin, detection of, 220 in ice-cream, 633

Gerber's butyrometer, 165

fat determination, 165,505

fermentation test, 211

sediment test, 203

Germ carriers, 434

Germicidal property of milk, 249

Gioddu, 366, 403

Girba, 17

Girbe, 17

Glace à la crême, 630

Gland ducts, 37

lobules, 47

Globe milking machine, 312

Globulin in milk, 71 source of, 75

Glutaminic acid, 618

Glycerids of non-volatile acids, 71,79 , 80

of volatile acids, $71,79,80$

Glycocoll, 90

Glymol, 173

Goat casein, 87, 656, 657 composition of, 656

milk, 70, 105, 655-657

cheese, 624

composition of, 105,655

fat globules in, 655

tubercle bacilli in, 657

Gorgonzola cheese, 612,623

Grading milk, 545

Granulobacillus saccharobutyricus immohilis, 375

mobilis, 374

Gravity cream, 52, 54, 73, 259, 600

Green cheese, 20

Gros lait, 401

Growth of bacteria in udder, 273

Guaiacum, 235

Guernseys, 572

Gum tragacanth in ice-cream, 634

HaPTOGEN membrane, 88

Hard cheese, 611

Hart's casein tests, 186-188 
Heat, influence on milk, 131, 132

Heated milk, detection of, 237, 238, 507,540

Hehner's formaldehyd test, 225 number, 81

Hehner and Richmond's formula, 179

Held pasteurization, 518-522

Hemi-casein-albumin, 93

Hemolysins in milk, 243

Hepin, 541

Herz's formula for skimmed milk, 215 for watered milk, 215 and skimmed milk, 216

Histidin, 618

Historical, 17

History of ice-cream, 530

Holding process of pasteurization, $518-522$

Home pasteurization, 538

Homogenized cream, 62, 632

Hormones, 38-40

Horsetail, 378

Human milk, 70, 584, 654

ash in, 654

casein, 87, 654

molecular weight of, 654

precipitation of, 654

composition of, $105,584,656$

diastatic ferment in, 585

fat in, 654

globules in, 654

fat-splitting ferment in, 585

freezing-point of, 654

paracasein, molecular weight ot, 654

properties of, 654

reaction of, 654

rennet coagulation, 654

specific gravity of, 654

tuberculosis, 443,445

type of tubercle bacilli, 458,460

Hydrogen peroxid, 223, 225, 234, 235 sulphid in checse, 618,626 in milk, 70, 132

Hydrogenase, 236

Hydrolysis of casein, 89

Hypersensitiveness, 243

Hypoxanthin, 78, 99

\section{ICE-CREAM, 630}

American, 631

bacteria in, 642

binders in, 633

body of, 633

certified, 646

classes of, 645

colloids in, 633

definition of, 645

distribution of bacteria in, 643

eggs in, 633

epidemics, 644
Ice-cream, fat test for, 639

filler's in, 633

flavors of, 632

French, 631

fried, 631

gelatin in, 633

growth of bacteria in, 644

gum tragacanth in, 634

neapolitan, 634

overrun, 632

test for, $635-637$

pathogenic bacteria in, 644, 645

poisoning, 645

powder, 634

refreczing, 639

regulations, 646

rennet in, 634

ripening of, 632

sampling of, 635

scoring of, 646

solids in, 632

source of bacteria in, 643

stabilizers in, 633

streptococci in, 644

swell of, 632

texture of, 633

tragacanth in, 634

tubercle bacilli in, 447

Iceline, 223

Ices, 630

Immersion refractometer, 217

Immune bodies in milk, 240, 241

Immunization against contagious abortion, 477

tuberculosis, 457

Inactive lactic acid, 357

Incubation period of milk, 264

Index of oxidation, 216

Indigo, 236

Indol in cheese, 618,626

Incrt bacteria, 343,531

Infant, alimentary disturbances in, 590

atrophy in, 595

decomposition in, 595

dyspepsia in, 593

feeding, $584,586,588$

boiled milk for, 587

cane-sugar for, 586

milk-sugar for, 586

oatmeal gruel for, 587

pasteurized milk for, 587

quantity of milk for, 588

rice-water for, 587

infectious diarrhea of, 596

intoxication, 594

mortality, 432, 596, 597

overfeeding of, 592

underfeeding of, 592

welfare, 596,597

societies, 598

Infectious abortion, 475-478 
Infectious diarrhea of infants, 596

Influence on composition of milk due to skill of milker, 127

of acids on rennet action, 93

of alkali on rennet action, 93

of dilution of milk on rennet action, 96

of electricity on milk, 133

of food on milk, 123

of heat on milk, 131, 132

of light on butter, 607

of quality of milk on rennet action, 96

of saits on rennet action, 94, 95

of temperature on rennet action, 95

of thunderstorms on milk, 133

of weather and temperature on milk, 126,127

Inherent milk enzyms, 230

Inspected milk, 545

Inspection of dairies, 550

Intoxication, auto-, 392, 394 infantile, 594

Intracellular enzyms, 230

Intradermal tuberculin test, 452

Iodin number, $76,108,113,114,120$, $121,122,125$

Iodized fat, 125

Iodo-albumin, 125

Iodo-casein, 125

Iron bacteria, 626

Isigny cheese, 612,624

Isocasein, 89

Isolation of pathogenic bacteria from milk, 430

JACKETS, milk shipping, 329

Jaurt, 402

Jerseys, 573

Joghurt, 402

Jugurt, 402

Just system of milk desiccation, 651

KIAFYR, 404

Keffir, 404

Kefir, 366, 404-406

grains, 404, 405

Kephir, 404

Kephor, 404

Khoumese, 406

Kifyr, 404

Kinds of bacteria in udder, 274 of lactic acid produced by bacteria, 357,370

of micro-organisms in milk, 340

Kirba, 17

Kirne, 17

Kirnu, 17

Kissélo mélko, 402

Kjeldahl-Gunning protein determination, 506
Kjernemelk, 400

Koettstorfer number, 108, 114, 120, 121

Koning's catalase test, 237

Körnchen bacillus, 365, 367

Koumiss, 406

Kumiss, 19, 404, 406

Kumys, 406

Kyppe, 404

LABAN, 403

Lac coactum, 20

compressum, 20

concretum, 20

Lactalbumin, 71,97

determination of, 183

source of, 75

Lactation, 37

period, 43

physiology of, 32

theories of, 37

Lactic acid bacteria, $100,265,266,275$, $343,531,533,534,604$

classification of, 344,345

distribution of, 350

thermal deathpoint of, 534

dextro-rotatory, 357-360

fermentation, 358

kinds of, produced by bacteria, $357-360,370$

levo-rotatory, 357

modifications of, 357

racemic, 357

rotation of, 357

streptococci, 472

Lactobacilli, 100, 266, 365-372, 384

distribution of, 367

in cheese, 369

in whey, 370

Lactobacilline milk, 395

Lactochrome, 63

Lactodensimeter, 508

Lactoglobulin, 98

source of, 75

Lactometer, 25, 142

New York Board of He alth, 142, 143

Quevenne, 142, 143

Shaw and Eckles, 142, 143

Spence's New York Board of Health, 143

Lactomucin, 70, 98

Lactoprotein, 98

Lactoscope, 216

Lactose, 71, 99

determination of, 191-196

in infant feeding, 586

Lactose-fermenting yeasts, 100

Lactosen, 70

Lacto-serum, 243, 246

Lacto-serum-protein, 93

Lactothermometer, 143 
Lange wei, 65,380

Leach's formaldehyd test, 226

Leben, 366, 403

raïb, 403 .

Lecithin, 70, 99, 256

Leffman-Beam's casein and albumin determination, 183

fat determination, 504

Legislation, milk, 564

Leptothrix buccalis, 365

Leucin in cheese, 618

Leukocytes in colostrum, 63,465

in milk, 36, 59, 463-466

Levo-rotatory lactic acid, 357

Levure lactique, 346

Limburger cheese, 612

Llama's milk, 70

Location of mammary glands, 33

Lorenz sediment tester, 203

Lymphocytes in colostrum, 63 in milk, 59

Lysin, 618

\section{Malta fever, 478}

Mammary glands, 32-34, 37, 38

Manns' acidity test, 197

Manufacture of casein, 580

Marasmus, 595

Mare's milk, 70, 105, 407, 657

Market milk, bacteria in, 261-263 streptococci in, $275,276,424$ tubercle bacilli in, 263, 446, 447

Marsh gas, 70

Marshall's acidity test, 198

rennet test, 208

Mastitis, 441, 462-473. milk, 442 test for, 246 streptococci, 441

Matzoon, 403

Mazun, 366, 403, 404

Mazzoradu, 403

Maya, 402

McKay sampler, 137

Medical milk commissions, 483

Melting-point of milk-fat, $80,108,112$, $120,121,125$

Membranes of fat globules, 61

Mercaptan in cheese, 618

Mesoflora, 342

Methods of milk condensation, 649 pasteurization, 513

Methylene-blue test for bacteria, 237

Micrococci, 346, 372

acid-coagulating, 373

acid-rennet, 386

in udder, 275

Micrococcus casei amari, 625

cerasinus, 379

chromoflavus, 625

lactis acidi, 276
Micrococcus lactis albidus, 276

amari, 386

aureus, 276

varians, 276

melitensis, 478

Micro-organisms in bowl sediment, 259

in Camembert cheese, 621

in milk, 258, 340

in separator cream, 259

milk, 259

slime, 259

in udder, $258,267-278$

Microscopic test for heated milk, 507, 540

Middle milk, bacteria in, 270-272 composition of, 112

fat in, 112

Milk, abnormal taste and odor of, 386

adulteration of, 213

aëration of, 102, 335

agglutinins in, 243,251

albumose in, 98

armmonia in, 70

determination of, 184

anaërobes in, 374,427

anilin dyes in, 221

antibodies in, $70,240,585$

antitoxins in, 240

ash of, 101, 102, 121

determination of, 179-181

ass's, 70, 105, 657

bacteria, 340

bacteria in, 261, 262, 328, 329, 410

bactericidal substances in, 243,249 , 250

benzoic acid in, 225, 228, 507

biorization of, 542

bitch's, 70 .

bitter, 385

blue, 377

borax and boracic acid in, 224, 227, 506

epidemiology of, $435-437$

bottles, $327,335,571$

buddeized, 225,541

buffalo's, 70, 657

camel's, 70, 657

can jackets, 329

cans, 315,316

caramel in, 221

care of, in home, 333

on wagon, 332

centrifugation of, 56,132

certified, 482

champagne, 407

chemical examination of, 136, 504

chemistry of, 70

chocolate-brown, 376

clarifiers, $280,281,334,513$

colored, 376-379

coloring matter in, $221,222,506$ 
Milk commission, 483

composition of, $70,72,105,656$

concentrated, 648

condensed, 648

coolers, 317,318

dealers' license, 567

depots, 557

desiccation of, 651

dialysis of, 133

dilution of, 133

distribution of, 581

dolphin's, 70

eiweiss, 595

elephant's, 70

enumeration of bacteria in, 413,421

enzyms, $70,230,231,536,585$

essential oils in, 240

evaporated, 648

expansion of, 66

fat-splitting ferment in, 234,585

fermented, 392

ferments in, 230

filter, 280

filtration of, 334

flavor of, 80

fluorids in, 223, 225

formaldehyd in, 223, 225-227, 506

freezing-point of, $67,128,654$

from different mammals, 70,654

fruity odor in, 386

gases in, 70, 71, 102-104

germicidal property of, 249

goat's, 70, 105, 655-657

grading of, 545

human, $70,584,654$

composition of, $105,584,656$

properties of, 654

hydrogen peroxid in, 223,225

immune bodies in, 240,241

incubation period of, 264

in relation to infant feeding, 584

inspected, 545

legislation, 564

leukocytes in, 36, 59, 463-466

line, 37

llama's, 70

mare's, 70, 105, 407, 657

micro-organisms in, 258,340

mineral content of, 78, 101

modification of, 585

molds in, 265, 388

normal, 63

souring of, 264-266, 340, 343, 350, 351

opsonins in, 243

ordinance, 565

oxidases in, 234

ozonization of, 542

pails, 297-305

pasteurization of, 131, 263, 511

pathogenic bacteria in, 410, 430

phagocytes in. 59,249
Milk, physical examination of, 136

plasma, 51, 71

poisoning, 444

poisonous, 443

potassium bichromate in, 223,225

powder, 650

precipitins in, 243

preservatives in, 223

price of, 569,570

rabbit's, 70

rancid odor in, 386

reaction of, 104

red, 379

reductases in, 234,236

regulations, 545

reindeer's, 70

ripened, 398

ropy, $380-385$

salicylic acid in, 223, 225, 229, 507

samplers, 136-139

sampling, 136-140, 428

scale, Richmond's, 179

secretion, 34,40

formation of, 34

serum, 71

sheep's, 657

shipping jackets, 329

sickness, 474

slimy, 380-385

soapy, 386

sodium carbonate and bicarbonate in, 229

souring of, $264-266,340,343,350$, 351

sow's, 70

specific gravity of, $52,65-67,121$, 141-147

spontaneous souring of, 264

strainers, 304, 316, 317

strawberry odor in, 386

streptococci in, $275,276,424$

streptothrix in, 388

stringy, 380-385

superoxidases in, 234

supplies, control of, 544, 546

test bottles, 159

thickening agents in, 219

thief, 139

torulæ in, 388

toxins in, 240

transportation of, $327,329,551$

typhoid bacilli in, 433

viscous, 384

watered, 214

yeasts in, 265, 276, 388, 402

yellow, 379

Milk-borne epidemics, 263, 411, 430

infections, $263,411,430,432$

Milk-fat, 51, 71, 81

decomposition of, 81

melting-point of, 80

rancidity of, 81 
Milk-fat, solubility of, 80

source of, 76

specific gravity of, 52

Milk-flour, 650

Milk-ice, 631

Milk-sugar, 37, 71, 78, 89, 99 determination of, 191, 196 source of, 78

Milk-wine, 406

Milking, 296

bag, Nutricia, 284

machines, 42, 305-314

Butrell-Lawrence-Kennedy，312, 313

Globe, 312

Thistle, 307

stools, 327

Mineral content of butter, 600 of milk, 78, 101 source of, 78

Modification of Babcock test, 164-167 of lactic acid, 357

of milk, 585

Mold spores in milk, 512

Molds in milk, 265, 388

in udder, 276

Molecular weight of bovine casein, 88 paracasein, 88

of goat casein, 656 paracasein, 656

of human casein, 654

paracasein, 654

Mono-amino acids, 90

Monrad's rennet test, 207

Morphology of streptococci, 364

Mortality, infantile, 432, 596, 597

Mother starters, 604

Mucin, 71

Mucoid protein, 61,98

Myristicin, 80

NARROW-TOP pails, 299-305

Natural cream ripening, 603 starters, 603

Nature of fat globules, 60

Neapolitan ice-cream, 634

Neufchatel cheese, 617,627

New York Board of Health lactometer, 142, 143

milk regulations, 545

Nissen corpuscles, $35,52,60$

Nitrates in milk, detection of, 219

Nitrogen-containing extractives, 70, 99

Non-volatile acids, $71,79,80$

Normal milk, 63

souring of milk, 264-266, 340, 343, 350,351

Nucleic acid, 75

Nucleoglycoprotein, 75

Nucleoprotein, 87

Number of bacteria in butter, 606
Number of bacteria in cheese, 616 . in ice-cream, 642

in market milk, 261

in udder, 274

Nutricia milking bag, 284

Nutritive ratio, 124

OATMEaL gruel for infant feeding, 587

Objections to pasteurization, $530-538$

Occult tuberculosis, 454

Ocular tuberculin test, 453

Odor in milk, 64, 71, 80 abnormal, 386

Off-flavors in butter, 608

Official Dairy Instructors Association, 552

Oïdium lactis, 388, 401, 606, 622, 623

Ojran, 407

Olein, 80

Oleomargarine, bacteria in, 606 tubercle bacilli in, 447

Omeira, 408

Opalisin, 98

Opsonins in milk, 243

Ordinance for milk supplies, 565

Organized ferments, 230

Origin of butter, 18

of casein, 75

of globulin, 75

of lactalbumin, 75

of lactoglobulin, 75

of lactose, 78

of milk constituents, 75

of milk-fat, 76

of milk-sugar, 78

of mineral constituents, 78

Orotic acid, 70, 99

Ostertag system, 455

Overfeeding of infants, 592

Overrun of ice-cream, 632

Oxidases in milk, 234

Ozonization of milk, 542

PAILS, narrow-top, 300-305 small-top, 300-305

Palmitin, 80

Paracasein, 82, 86, 92

ash-free, 86

lactate, 90

molecular weight of, $88,654,656$

Paralactic bacillus, 392

Paranuclein, 618

Paraphenylindiamin, 235

Paratyphoid fever, 439

Parmesan cheese, 612

Passburg system of milk desiccation, 652

Pasteurization, continuous, 513

flow, 519

cooling after, 528 
Pasteurization, cost of, 537 extent of, 538

flash, 513

held process of, 518-522

holder process of, $518-522$

home, 538

in final package, $522-528$

objections to, $530-538$

of milk, 131, 263, 511

of skimmed milk and whey, 529

plants, 561

systems of, 513

Pasteurized cream for butter, 605

for cheese, 614

milk and public health, 529

bacteria in, 531-535

for infant feeding, 587

microscopic test for, 540

tests for, 530

Pasteurizers, absolute holders, 519

continuous flash, 513

holders, 519

Danish type, 514

flash, 513

regenerative, 514

retarder type, 520

tubular type, 514

Pathogenic bacteria in butter, 605

in buttermilk, 399

in cheese, 626

in cream, 399

in ice-cream, 644

in milk, 410,430

isolation of, 430

streptococci, thermal deathpoint of, 535

Pavy-Long's lactose determination, 196

Pearl disease, 450

Penicillium camemberti, 621, 623

glaucum, 623

roquefortii, 619

Pepsin, 91

Pepton, 618 determination of, 184

Peptonizing bacteria, 266, 343, 531, 535

Percentage system of milk modification, 585

Perlsucht, 450

Perhydrol, 237

Peroxidases in milk, 234-236

Phagocytes in milk, 59, 249

Phases of milk-souring, 264-266, 340

Phenol, 235

Phenolphthalein, 235

Phosphoprotein, 75, 87

Phrenosin, 587

Physical examination of milk, $130^{\circ}$ properties of milk, 51

Physiologic origin of milk constituents, 75
Physiology of lactation, 32

Pigments in milk, 63, 70

Pinguicula vulgaris, 380,400

Pituitrin, 41

Plasma, milk, 51, 71

solids, 73

determination of, 176

specific gravity of, 65

Platelets in milk, 57

Plectridium fotidum, 375

Podkwassa, 402

Poisoning from cheese, 626

from ice-cream, 645

from milk, 444

Poisonous milk, 443

Polariscope, 192

Polenske's number, 81

Polled Durhams, 573

Pope's whitewash, 388

Potassium bichromate in milk, 223, 225

Potassium-iodid-starch test, 530

Powdered cream, 650

Precipitation of bovine casein, 82,83 , 88,90

of human casein, 654

Precipitin reaction, 244

Precipitins in milk, 243

Premature infants, 589 senility, 392

Preparation of casein, 83-86

of tuberculin, 450

Preservaline, 223, 506

Preservatives in milk, 223

Presumptive Bacillus coli test, 425

Price of milk, 569,570

Primitive methods of milking, 18

Production of certified milk, $483-487$, 497-510

Productiveness of dairy herds, 574

Properties of bovine casein, 86 of human milk, 654

of normal milk, 63

Propionic acid bacteria, 377, 620

Proteins, determination of, 181-191, 506

Proteolytic bacteria, 265, 266 enzyms, 91,231

Proteus in milk, 427

in udder, 276

Protocaseose, 618

Ptomains in cheese, 626

Pseudoglobulin, 242

Publow's acidity test, 198

Pulp bottles for milk, 571

Putrescin in cheese, 626

Pycnometer, 142, 145

QUANTTTY of milk for infant feeding, 588

produced by cows, 49 
Quantity of milk produced during lactation period, 44

Quarg, 20

Quevenne lactometer, 142, 143

RABBIT's milk, 70

Rabies, 473

Racemic lactic acid, 357

Rack, 407

Racky, 407

Rancid odor in milk, 386

Rancidity of butter, $606-608$ of milk-fat, 81

Reaction, Arnold's, 238, 507

of cow's milk, 104

of human milk, 104

precipitin, 244

Rothenfusser, 238

Recknagel phenomenon, 67, 142

Red milk, 379 polls, 573

Reductases in milk, 234, 236

Refractive index, 67

Refractivity, 67

Refractometer, 148, 196, 217

Refreezing ice-cream, 639

Refrigerator cars, 551

Regenerative pasteurizers, 514

Regulations for ice-cream manufacture, 646

for milk supplies, 545

Reichert-Meissl number, $81,108,112$, $113,114,120,121,122$

Reimann's plummet, 146

Reindeer's milk, 70

Relation of dirt to germ content, 281

Renk's sediment test, 202

Rennet, 90

action, 90

influence of acids on, 93 of alkalies on, 93

cheese, 611

coagulation, 90-97

extract, 90

in ice-cream, 634

tests of milk, 207

Rennet-forming bacteria, 266,386

Rennin, 91, 92, 230

inhibition, 248

temperature resistance of, 96

Requirements for dairies, 559

Retarder type pasteurizer, 520

Rice-water for infant feeding, 587

Richmond's formula, 179

sliding rule, 179

Ricin, 241

Rickets, 535

Ripened cream, 602 milk, 398

Ripening of cheese, $611,610 ̈$

of cream, 602,603
Ritthausen nitrogen determination, 182

IRoba, 403

Ropy milk, 380-385

Roquefort cherence, 612, 623 mold, 623

Rotation of lactic acid, 357

Rothenfusser reaction, 238

Russian fat test, 164

Rusty spots in cheese, 625

Saccharomyces cerevisiæ, 400

Siakwaska, 405

Salicylic acid in milk, 223,225 detection of, 229,507

rialolase, 234

sult-rising bread, 365

Fitlt-soluble substance in cheese, 90

Nimplers, milk, 136-140

Sampling cheese, 628

cream, 139, 171

ice-cream, 635

milk, 136-140, 428

pipet, 138

Sarcina lutea, 379

rosea, 379

Sarcinæe in udder, 276

incarlet fever, 443

Nchardinger's reductase, 236 test, 239

Score card for certified milk, 492-495 for creameries, 560

for dairies, 552,553

for milk depots, 557

for pasteurization plants, 561

for stores, 556,562

Scoring butter, 608

ice-cream, 646

Sicovell's sampling tube, 137

Sicurvy, 535, 590

Secretion of milk, 34,40 formation of, 34

Sediment test, 200-207, 281

Separation of butter-fat, 599 of cream from milk, 600,601

Separator cream, 259, 600

milk, 259

slime, 601

Septic sore throat, $440-443$

Serum, milk, 71

Shallow pan system of cream separation, 600

Shaw and Eckles' lactometer, 142,143

Sheep's milk, 70, 657

Shipping jackets, 329

Shorthorns, 573

Silage fermentation, 369

Sinus lactiferua, 47

Size of fat globules, $52,55,60,108$, 113

Skatol in cheese, 618 
Skimmed milk, 52 composition of, 74 detection of, 214 fat test, 173-175 pasteurization of, 529 test bottles, 173

Skorup, 403

Slack's counting apparatus, 417 method of counting bacteria, 422

Sliding rule, Richmond's, 179

Slimy milk, 380-385

Slows, 474

Small-top pails, 279-305

Snake venom, 241

Snakeroot, 475

Soapy milk, 386

Sodium carbonate and bicarbonate in milk, 225 detection of, 229

Soft cheese, 611,619

Soil bacteria, 343

Solids in ice-cream, 632

Solids-not-fat, 73 determination of, 176 specific gravity of, 65

Solubility of casein, 88,90 of milk-fat, 80

Sore throat, 440

Sour milk cheese, 611 starter, 399

Source of bactcria in cheese, 615 in ice-cream, 643 in milk, 258 in udder, 268,269

of casein, 75

of globulin, 75

of lactalbumin, 75

of lactoglobulin, 75

of lactosic', 79

of milk-fat, 76

of milli-sugar, 78

of mineral constituents, 78

Souring of milk, 264-266, 340, 313, 350,351

Sow's milk, 70

Soxhlet ether extractor, $111 \mathrm{~S}$

Specific gravity, detcrmination of , 141147

of rasein, $\mathrm{x}$

of certificed milk, $50 \mathrm{~s}$

of colostrum, 62,63

of human milk, 6.54

of milk, 52, 65-67, 121, 141-147 solids, 65

of milk-fat, 52

of plasma solids, 65

of solids-not-fat, 65

of total solids, 65

heat, 68

Spence's New York Board of IIcalth lactometer, $14: 3$

Spider venom, 241
Spillman's acidity test, 199

Spirillum choler 2,250

Split-products of tryptic digestion, 89

Spontaneous changes in milk, 128 souring of milk, 264

Spore-bearing bacteria in milk, 276, 373

Stabilizers in ice-cream, 633

Stable air, bacteria in, 290 construction of, 286-288 disinfection of, 387,457 windows, 292

Staggers, 474

Stanchions, 288

Standardization of tuberculin, 451

itaphylococci, 346,372

Staphylococcus aureus, 373 mastitis, 463,473

Starter, artificial, 603 mother, 604 natural, 603

Steam sterilizer for cans, 322

itearin, 80

Sterilizers for bottles, 321 for cans, 322

Sterilizing ovens, 324

Stilton cheese, 612,623

Sttools, milking, 327

Storch's test, 238, 507, 530

Strainer pail, 297

Strawberry odor in milk, 386

Streaky butter, 607

Streptobacillus lebenis, $365,366,371$, 401

Streptococci, differentiation of, $467-$ 473

in icc-cream, 644

in market milk, 275, 276, 424

morphology of, 364

thermal deathpoint of, 534

itreptococcus hollandicus, 341, 380, 381

lasticus, $265,275,276,291,341,347-$ $350,354,357,364,381,3 \aleph^{\circ}$, $398,399,400,402,472,534$, $535,603,604$

decomposition products of, 352

distribution of, 350

lactic acid produced by, 357

longus, 364

mastitis, $441,462-473$

pneumoniæ, 364

pyogenes, 276,364

Stringy milk, 380-385

Strippings, 43,55

bacteria in, $270-272$

colls in, 465

composition of, 112

fat in, 112

Stutzer's sediment test. 202

Subcutaneous tuberculin test, 452

Sucrate of lime, 220 
Sugar of milk, 37, 71, 78, 89, 99

Sugars for infant feeding, 586

Superoxidases in milk, 234

Sweet cheese, 625

curdling of milk, 266, 386

Swell of ice-cream, 632

Swiss cheese, 612

Systems of cream separation, 600

of milk condensation, 649

desiccation, 651

modification, 585

pasteurization, 513

TAN, 404

Taryk, 408

Taste of milk, 64, 131 abnormal, 386

Tatté mélk, 65, 380, 400

Tättmjölk, 380, 400

Teat, 46 duct, 47

Temperature of churning, 607 resistance of rennin, 96

Test, albumin, 210

alcohol, 207

alizarol, 209

anaphylactic, 246

Arnold's, 238, 507

Babcock, 155-164, 504

benzidin, 238

complement fixation, 245

fermentation, 210

for acidity, 196-200

Farrington's, 198

Marshall's, 198

Manns', 197

Publow's, 198

Spillman's, 199

van Norman's, 197

for anaërobes, 427

for anilin dyes, 221

for annatto, 221

for azo-dyes, 221

for benzoic acid, 228, 507

for borax and boric acid, 227, 506

for caramel, 222

for catalase, 237,625

for coloring matter, 221

for colostrum, 246

for formaldehyd, 225-227, 506

for heated milk, 237, 238, 507, 540

for ice-cream overrun, 635-637

for mastitis mill, 246

for nitrates, 219

for pasteurized milk, 530, 540

for reductase, 239

for rennin inhibition, 248

for salicylic acid, 229

for sediment, $200-207$

for sodium carbonate and bicarbonate, 229
Test for viscosity, 207

rennet, 207

Sichardinger's, 239

Storch's, 238, 507, 580

to distinguish buman from cow's milk, 210

Wisconsin curd, 210, 361, 624

Tetanus antitoxin, 242

Tewficose, 100

Texture of butter, 599, 605

of chersec, 617

of ice-cream, 633

Than, 404

Theories of lactation, 37

Thermal deathpoint of lactic acid bacteria, 534

of mold spores, 512

of streptococci, 534

of tubercle bacilii, 512

Thermoflora, 342

Thickening agents, 219

Thistle millking machine, 307

Thunderstorms, influence on milk, 133

Tin cow, 293

milk sampler, 139

Tonney's sediment test, 205

Torula amara, 386,625

Torula in milk, 388

Total nitrogen determination, 181

solids, determination of, 175 of ice-cream, 632

specific gravity of, 65

Toxins in milk, 240

Tragacanth in ice-cream, 634

Transmission of tuberculosis, 458

Transportation of milk, 327, 329, 551

Trembles, 474

Tributyrin, 79

Triglycerids, 78

Trikresol, 235

Trowbridge cálibrator, 160

Trypsin, 89

Tryptic digestion of cascin, 89

Tryptophan in cheese, 618

Techoretan, 404

Tubercle bacilli, bovine, $435,445,448$, $449,458,459,460,512$

human, $443,445,458,460$

in butter, 447

in butterine, 447

in buttermilk, 447

in cheese, 447,626

in cow feces, 448

in cream, 447

in ice-cream, 447

in market milk, 263, 446, 447

in oleomargarine, 447

thermal deathpoint of, 512

Tuberculin, 449-454

test, 450,454

intradermal, 452

ocular, 453 
Tuberculin test, subcutaneous, 452

Tuberculosis, 444

antitoxin, 457

bovine, 444-461

diagnosis of, 449

eradication of, 455-457

human, 143,445

immunization against, 457

in goats, 657

oceult, 454

transmission of, 458

vaccination against, 457

Tubular type of pasteurizer, 514

Turnip taste in butter, 607

Tvarog, 20

Typhoid agglutination, 243

bacilli in buttermilk, 399

in cream, 399,438

in ice-cream, 644

in milk, 433,437

carriers, 438

fever, 437

Tyrosin, 90,618

Tyrothrix tenuis, 231

Tyrotoxin, 626

\section{UDDER, 45}

Bacillus coli in, 276

bacteria in, 267-278

growth of bacteria in, 273

kinds of bacteria in, 274

micrococci in, 275

micro-organisms in, 258, 267-278

molds in, 276

number of bacteria in, 274

source of bacteria in, 268, $2: 69$

spore-forming bacteria in, 276

yeasts in, 276

Ultimate follicle, 47,48

Ultra-violet rays, $\mathbf{5 4 1}$

Uncle Sam's three dairy herds, 574

Underfeeding infants, 592

Unorganized ferments, 230

Urea, 78, 99

Urgoutnik, 403

Uric acid, 99

VACCINATION against abortion, 477 against tuberculosis, 457

Vacuum cleaners for cows, 285

Van Norman's acidity test, 197

Van Slyke's formula for casein, 108 for skimmed milk, 214

for watered milk, 215

Van Slyke and Bosworth's cascin determination, 190
Variability of composition of milk, 105 during lactation period, 114

Varicties of cheese, 512

Virgin lactation, 38

Virulence number, 470

Viscogen, 65

Viscosity of milk, 64

Viscous milk, 380-385

Vitamins, 536

Volatile acids, $71,79,80$

Volumetric casein determination, 185

WATER in butter, 600

Watered milk, detection of, 21.4 formula for, 215

Water-ice, 630

Werner-Schmidt's fat determination, 148

Westphal balance, 142,146

Wet milking, 296

Whey, $71,370,529$

albumin, 93

butter, 608

composition of, 74

determination of fat in, $\mathbf{1 7 3}$

lactobacilli in, 370

media for lactobacilli, 627

pasteurization of, 529

White snakeroot, 475

spots in cheese, 625

Whole milk, 52

Wisconsin curd test, $210,361,624$

Witch's milk, 34, 38

Wollny's refractometer test for fat, 148 for lactose, 196

Working butter, 605

Xanthin bases in milk, 99

Xanthophyll, 63, 221

YAHODRT, 402

Yaourt, 402

Yeasts, lactose-fermenting, 100

in milk, 265, 276, 388, 402

in udder, 276

Yellow cheese, 625

milk, 379

Yoghurt, 366, 402, 403

ZAKVASKA, 402

Zeiss butyrorefractometer, 149 immersion refractometer, 217

Zinc lactate, 358

Zwarg, 20 




\section{Nervous and Mental Diseases, Children, Hygiene, and Medical Jurisprudence}

\section{W. B. SAUNDERS COMPANY WEST WASHINGTON SQUARE PHILADELPHIA 9. HENRIETTA STREET COVENT GARDEN, LONDON}

\section{Dercum's Mental Diseases}

Clinical Manual of Mental Diseases. By Francis X. Dercum, PH. D., M. D., Professor of Nervous and Mental Diseases at Jefferson Medical College, Philadelphia. Octavo of 479 pages. Cloth, $\$ 3.50$ net.

\section{SECOND EDITION-Published November, 1917}

This is a book really useful to the family physician-a book that tells you definitely how to diagnose, how to treat-either at home or in an institution-all classes of mental diseases. First, Dr. Dercum takes up the various primary forms of mental disease, giving emphasis to those you meet in your daily practice as general practitioner-delirium, confusion, stupor. Then melancholia, mania, the insanities of early life, paranoia, the neurasthenic-neuropathic disorders, and the dementias follow. The mental disturbances of the infections (syphilis, tuberculosis, malaria, pellagra, rheumatic fever, etc.), the various forms of intoxicational insanities, those due to metabolic disorders, visceral disease, diseases of the nervous system are all given you-and from your viewpoint. An important section is that devoted to the insanities of pregnancy. An entire part is devoted to the psychologic interpretations of symptoms as evolved by Freud and his disciples. You get a full discussion of the rôle of dreams.

\section{The Medical World}

"This book gives just the information necessary, and gives it in a style studiously adapted to the needs of the general physician."

Our books are revised frequently, so that the editions you find here may not be the latest. Write us about any books which interest you 


\section{Church and Peterson's} Nervous and Mental Diseases

Nervous and Mental Diseases. By Archibald Church, M. D., Professor of Nervous and Mental Diseases and Medical Jurisprudence, Northwestern University Medical School, Chicago; and FREDERICK Peterson, M. D., formerly Professor of Psychiatry at the College of Physicians and Surgeons, N. Y. Handsome octavo, 944 pages; 350 illustrations. Cloth, $\$ 5.00$ net.

October, 1914

\section{EIGHTH EDITION}

For this new ( $8 t \pi)$ edition this standard work has undergone a thorough revision. Vertigo and its labyrinthine relations, as developed by Bárány, has received careful consideration; much new matter has been added to the section on Infantile Paralysis; syphilis of the nervous system has been brought into accord with recent epoch-making discoveries. Throughout, references to the new investigations of the spinal fluid, and the relation of spinal fluid changes to the various organic diseases of the brain and cord have been introduced. The bearing of internal secretion upon nervous disorders has been brought right down to date. Tetany has been given its place among nervous diseases associated with glandular disorder. Altogether over 300 interpolations and alterations have been made. It is more than ever the stixdard.

\section{American Journal of the Medical Sciences}

" This edition has been revised, new illustrations added, and some new matter, and really is two books. . . The descriptions of disease are clear, directions as to treatment definite, and disputed matters and theories are omitted. Altogether it is a most useful text-book."

\section{Kaplan's Serology of Nervous and Mental Diseases}

Serology of Nervous and Mental Diseases. By D. M. Kaplan, M. D., Director of Clinical and Research Laboratories, Neurological Institute, New York City. Octavo of 346 pages, illustrated. Cloth, $\$ 3.50$ net.

Published June, 1914

This is an entirely new work, giving you the indications, contra-indications, preparation of patients, terhnic, after-phenomena, after-care, and disposal of the fluids obtained by lumbar puncture. You get a full discussion of the serology of all nervous and mental diseases of non-luetic etiology (including disorders of internal secretion), and of every type of luetic nervous and mental disease, giving the Wassermann reaction in detait, the use of salvarsan and neosaivarsan, etc. 


\section{Herrick's Neurology}

Introduction to Neurology. By C. Judson Herrick, Ph. D., Professor of Neurology in the University of Chicago. I 2 mo of 360 pages, illustrated.

Second Edition-Publısbed August. 1918

\section{A KEY TO NEUROZOGY}

Professor Herrick's new work will aid the student to organize his knowledge and appreciate the significance of the nervous system as a mechanism right at the beginning of his study. It is sufficiently elementary to be used by students of elementary psychology in colleges and normal schools, by students of general zoölogy and comparative anatomy in college classes, and by medical students as a guide and key to the interpretation of the larger works on neurology.

\section{Herrick and Crosby's Laboratory Neurology}

A Laboratory Outline of Neurology. By C. Judson Herrick, Ph. D., Professor of Neurology, University of Chicago; and Elizabeth C. Crosby, Ph. D., Principal of the High School, Petersburg, Mich. I 2 mo of I 20 pages, illustrated. Cloth, \$I.5O net. Published January 1917

\section{Brill's Psychanalysis}

Second Edition published May, 1914

Psychanalysis: Its Theories and Practical Application. By A. A. Brill, Ph. B., M. D., Clinical Assistant in Neurology at Columbia University Medical School. Octavo of 392 pages. Cloth, $\$ 3.25$ net.

To the general practitioner, who first sees these "borderline" cases (the neuroses and the psychoses), as well as to those specially interested in neurologic work, Dr. Brill's work will prove most valuable. Dr. Brill has had wide clinical experience, both in America and in Europe. The results of this experience you get in this book. Here you get the practical application of all Freud's theoriesand from the pen of a man thoroughly competent to write.

\section{Hunt's Diagnostic Symptoms of Nervous Diseases}

Diagnostic Symptoms of Nervous Diseases. By EDWARD L. HunT, M. D., formerly Instructor in Neurology and Assistant Chief of Clinic, College of Physicians and Surgeons, New York. I $2 \mathrm{mo}$ of 292 pages, illustrated. Cloth, $\$ 2.00$ net.

Second Edition published June, 1917

\section{Stiles on the Nervous System}

The Nervous System and its Conservation. By Percy G. Stiles, Instructor in Physiology at Harvard University. I 2 mo of 240 pages, illustrated. Cloth, \$.I 50 net. 


\section{American Illustrated Dictionary}

\section{New (9th) Edition-2000 New Words}

The American Illustrated Medical Dictionary. A new and complete dictionary of the terms used in Medicine, Surgery, Dentistry, Pharmacy, Chemistry, Veterinary Science, Nursing, and kindred branches; with over I00 new and elaborate tables and many handsome illustrations. By W. A. Newman Dorland, M. D. Large octavo, I 179 pages, bound in full flexible leather, $\$ 5.00$ net; with thumb index, $\$ 5.50$ net.

Published October, 1917

The American Illustrated Medical Dictionary defines hundreds of terms not defined in any other dictionary-bar none. It gives the capitalization and pronunciation of all words. It makes a feature of the derivation or etymology of the words. Every word has a separate paragraph, thus making it easy to find a word quickly. The tables of arteries, muscles, nerves, veins, etc., are of the greatest help in assembling anatomic facts. Every word is given its definition-a definition that defines in the fewest possible words.

Howard A. Kelly, M. D., Johns Hopkins University, Baltimore.

"The American Illustrated Dictionary is admirable. It is so well gotten up and of such convenient size. No errors have been found in my use of it."

\section{Owen's $\mathbf{T}_{\text {reatment of }} \mathbf{E}_{\text {mergencies }}$}

The Treatment of Emergencies. By Hubley R. Owen, M. D., Surgeon to the Philadelphia General Hospital. I 2 mo of 350 pages, with 249 illustrations. Cloth, $\$ 2.00$ net.

Published June, 1917

Dr. Owen's book is a complete treatment of emergencies. It gives you not only the actual technic of the procedures, but, what is equally important, the underlying principles of the treatments, and the reason why a particular method is advised. You get treatments of fractures, of contusions, of wounds. Particularly strong is the chapter on gun-shot wounds, which gives the new treatments that the great European War has developed. You get the principles of hemorrhage, together with its constitutional and local treatments. You get chapters on sprains, strains, dislocations, burns, sunburn, chilblain, asphyxiation, convulsions, hysteria, apoplexy, exhaustion, opium poisoning, uremia, electric shock, bandages, and a complete discussion of artificial respiration, including mechanical devices. 


\section{Kerley's Pediatrics}

Practice of Pediatrics. By Charles Gilmore Kerliy, M. D., Professor of Diseases of Children, New York Polyclinic Medical School and Hospital. Octavo of $9 \mathrm{r} 3$ pages, illustrated. Cloth, $\$ 6.50$ net.

Published January, 1918

\section{SECOND EDITION}

This work is not a cut-and-dried treatise-but the practice of pediatrics, giving fullest attention to diagnosis and treatment. The chapters on the newborn and its diseases, the feeding and growth of the baby, the care of the mother's breasts, artificial feeding, milk modification and sterilization, diet for older children-from a monograph of 125 pages. Then are discussed in detail every disease of childhood, telling just what measures should be instituted, what drugs given, 60 valuable prescriptions being included. The chapter on vaccine therapy is right down to the minute, including every new method of proved value-with the exact technic. There is an excellent chapter on Gymnastic Therapeutics. Another feature consists of the 165 illustrative cases-case teaching of the most practical sort.

Dr. A. D. Blackader, McGill University, Montreal

"Dr. Kerley is a pediatrician of large experience who thinks for himself and is never content to accept, without testing, the experiences or statements of previous writers. His book hes a very definite value."

\section{Bandler's The Expectant Mother}

Published August, 1916

This is decidedly a book for the woman preparing for childbirth. It has chapters on menstruation, nourishment of mother during pregnancy, nausea, care of breasts, examination of urine, preparations for labor, care of mother and child after delivery, twilight sleep, and dozens of other matters of great interest to the expectant mother.

I2mo of 213 pages, illustrated. By S. WyLlis Bandler, M. D., Professor of Diseases of Women, New York Post-Graduate Medical School and Hospital. Cloth, \$1.25 net.

\section{Winslow's Prevention of Disease}

Published November, 1916

This book is a practical guide for the layman, giving him briefly the means to avoid the various diseases described. The chapters on diet, exercise, tea, coffee, and alcohol are of special interest, as is that on the prevention of cancer. There are chapters on the prevention of malaria, colds, constipation, obesity, nervous disorders, tuberculosis, etc. The work is a record of twenty-five years' active practice.

I2mo of 348 pages, illustrated. By KENEIM WINsLow, M. D., formerly Assistant Professor of Comparative Therapeutics, Harvard University. Cloth, \$1.75 net.

\section{Kerr's Diagnostics of Children's Diseases}

Dr. Kerr's work is written absolutely for the general practitioner-to aid him in diagnosing disease in his child patients. He approaches his subject as the child is approached in the sick-room. It is strictly a clinical work-a first aid in the diagnosis of disease in children.

Published February, 1907

Octavo of 542 pages, illustrated. By LE Grand KeRR, M. D., Professor of Diseases of Children in the Brooklyn Postgraduate Medical School. Brooklyn. $\quad$ Cloth, $\$ 5.00$ net. 


\section{Hill and Gerstley's Infant Feeding}

Clinical Lectures in Infant Feeding. By Lewis WezB Hill, M. D., Alumni Assistant in Pediatrics, Harvard Medical School, and Jesse R. Gerstley, M. D., Instructor in Pediatrics, Northwestern University Medical School. I 2 mo of 377 pages, illustrated. Cloth, $\$ 2.75$ net.

Published October, 1917

In these clinics you are given the full details of the Boston method of infant feeding as developed by Dr. Rotch, and of the Chicago method. You are given the theory, use in both normal and abnormal cases, exact quantities and percentages, and concrete clinical examples. The book is equivalent to a postgraduate course in infant feeding. It brings these two systems right to your door.

\section{Abt's Preparation of Infants' Foods}

The Preparation of Infants' Foods. By Isaac A. Abt, M.D., Professor of Diseases of Children, Northwestern University Medical School. I2mo of 143 pages. Cloth, \$I.25 net. Published July, 1917

This is a practical guide for infant feeding, giving to young mothers, nurses, and caretakers minute directions on the preparation of food for infants and young children. You get weights and measures; the mineral constituents and caloric values of foods. You get such practical material as diet-lists for constipation in older children, an outline of a plan for feeding babies, care of nipples and bottles, etc., and a great host of recipes for beverages of all kinds, milk preparations, soups and broths, puddings and cereal preparations, custards, eggs, vegetables, fruits, meats, sea foods, and breads.

\section{Aikens' Home Nurse's Hand-Book}

Second Edition Published March, 1917

Home Nurse's Hand-Book. By Charlotte A. Aikens. I 2 mo of $3 \circ 3$ pages, illustrated.

Cloth, \$I.50 net.

The point about this work is this: It tells you and showes you just how to do those little but important things often omitted from other nursing books. "Home Treatments" and "Points to be Remembered" - terse, crisp reminders-stand out as particularly practical. Just the book for those who have the home-care of the sick.

\section{Galbraith's Personal Hygiene for Women}

Personal Hygiene and Physical Training for Women. By AnNa M. Galbraith, M. D. I 2 mo of 393 pages, with original illustrations. Cloth, $\$ 2.25$ net.

Published January, 1917

"It contains just the sort of information which is very greatly needed by the weaker sex. Its illustrations are excellent."-Dietetic and Hygienic Gazette.

\section{Galbraith's Four Epochs of Woman's Life}

The Four Erochs of Woman's Life. By Anna M. Galbraith, M. D. With an Introductory Note by Jorn H. Musser, M. D., University of Pennsylvania. I 2 mo of 296 pages. Cloth, \$I.50 net.

"We do not as a rule care for medical books written for the instruction of the public; but we must admit that the advice in Dr. Galbraith's work is, in the main, wise and wholesome."-Birmixgham Medical Review.

Published March, 1917 


\section{Griffith's Care of the Baby}

The Care of the Baby. . By J. P. Crozer Griffith, M. D., Professor of Pediatrics in the University of Pennsyivania. I 2 mo of 455 pages, illustrated. Cloth, $\$ 1.50$ net.

\section{SIXTH EDTTION-published June, 1915}

The. author has endeavored to furnish a reliable guide for mothers. He has made his statements plain and easily understood, so that the volume will be of service to mothers and nurses.

\section{New York Medical Journal}

"We are confident if this ltttle work could find its way into the hands of every trained nurse and of every mother, infant mortality would be lessened by at least fifty per cent."

\section{Grulee's Infant Feeding}

Infant Feeding. By Clifford G. Grulee, M. D., Assistant Professor of Pediatrics at Rush Medical College. Octavo ot 326 pages, illustrated, including 8 in colors. Cloth, \$3.25 net.

\section{THIRD EDITION-Published September, 1917}

Dr. Grulee tells you how to feed the infant. He tells you-and shows by clear illustrations-the technic of giving the child the breast. Then artificial feeding is thoughtfully presented, including a number of simple formulas. The colored illustrations showing the actual shapes and appearances of stools are extremely valuable.

\section{Ruhräh's Diseases of Children}

A Manual of Diseases of Children. By JOHN RUHRÄH, M. D., Professor of Diseases of Children, College of Physicians and Surgeons, Baltimore. I 2 mo of 552 pages, fully illustrated. Flexible leather, $\$ 2.75$ net.

FOURTH EDITION-published September, 1914

In revising this work for the fourth edition Dr. Ruhräh has carefully incorporated all the latest knowledge on the subject. All the important facts are given concisely and explicitly, the therapeutics of infancy and childhood being outlined very carefully and clearly. There are also directions for dosage and prescribing, and many useful prescriptions are included.

\section{American Journal of the Medical Sciences}

"Treatment has been satisfactorily covered, being quite in accord with the best teaching, yet withal broadly general and free from stock prescriptions." 


\section{Keefer's Military Hygiene}

Military Hygiene and Sanitation. By Frank R. KEefER, Colonel, Medical Corps, United States Army. I 2 mo of 340 pages, illustrated. Cloth, \$r.75 net.

This is a concise, though complete text-book on this subject, containing chapters on the care of troops, recruits and recruiting, personal hygiene, physical training, preventable diseases, clothing, equipment, water-supply, foods and their preparation, hygiene and sanitation of posts and barracks, the troopship, hygiene and sanitation of marches, camps, and battlefields, disposal of wastes, tropical and arctic service, venereal diseases, alcohol and other narcotics, and a glossary.

\section{Bergey's Hygiene}

The Principles of Hygiene: A Practical Manual for Students, Physicians, and Health Officers. By D. H. Bergey, A. M., M. D., Assistant Professor of Bacteriology in the University of Pennsylvania. Octavo volume of 543 pages, illustrated. Cloth, \$3.50 net.

SIXTH EDITION-Published February, 1918

This book is intended to meet the needs of students of medicine in the acquirement of a knowledge of those principles upon which modern hygienic practises are based, and to aid physicians and health officers in familiarizing themselves with the advances made in hygiene and sanitation in recent years. This fifth edition has been very carefully revised, and much new matter added, so as to include the most recent advancements.

\section{Buffalo Medical Journal}

"It will be found of value to the practitioner of medicine and the practical sanitarian; and students of architecture, who need to consider problems of beating, lighting, ventilation, water supply, and sewage disposal, may consult it with profit."

\section{Pyle's Personal Hygiene}

New (7th) Edition-August, 1917

A Manual of Personal Hrgiene: Proper Living upon a Physiologic Basis. By Eminent Specialists. Edited by Walter L. Pyle, A. M., M, D., Assistant Surgeon to Wills Eye Hospital, Philadelphia. Octavo volume of 555 pages, fully illustrated.

Cloth, \$I.75 net.

The book has been thoroughly revised for this new edition, and a new chapter on Food Adulteration by DR. HARVEY W. WILEY added. There are important chapters on Domestic Hygiene and Home Gymnastics, Hydrotherapy, Mechanotherapy, and First Aid Measures.

"The work has been excellently done, there is no undue repetition, and the writers have succeeded unustually well in presenting facts of practical significance based on sound knowledge."-Boston Medical and Surgical Journal. 


\section{Bohm and Painter's Massage}

Massage. By MAx Böhm, M. D., of Berlin, Germany. Edited, with an Introduction, by Charles F. PAINTER, M, D., Professor of Orthopedic Surgery at Tufts College Medical School, Boston. Octavo of 91 pages, with 97 practical illustrations. Published June, 1913

Cloth, \$1.75 net.

\section{Golebiewski and Bailey's Accident Diseases}

Atlas and Epitome of Diseases Caused by Accidents. By Dr. ED. Golebiewski, of Berlin. Edited, with additions, by Pearce Bailey, M. D., Consulting Neurologist to St. Luke's Hospital, New York. With 7 I colored illustrations on 40 plates, 143 text illustrations, and 549 pages of text. Cloth, \$4.00 net. In Saunders' Hand-Atlas Series.

Published 1901

\section{Hofmann and Peterson's Legal Medicine}

In Saunders'

Atlas of Legal Medicine. By DR. E. VON Hofmann, of Vienna. Edited by Frederick Peterson, M. D., Professor of Psychiatry in the College of Physicians and Surgeons, New York. With I 20 colored figures and 193 half-tone illustrations. Cloth, $\$ 3.50$ net.

Published April, 1898

\section{Jakob and Fisher's Nervous System}

Saunders'

Atlases

Atlas and Epitome of the Nervous System and its Diseases. By Professor Dr. Chr. JAKob, of Erlangen. Edited, with additions, by EDWARD D. Fisher, M. D., University and Bellevue Hospital Medical College. With 83 plates and copious text. Cloth, $\$ 3.50$ net.

Published 1901

\section{Spear's Nervous Diseases}

A Manual of Nervous Diseases. By Irving J. Spear, M. D, . Professor of Neurology at the University of Maryland, Baltimore. I 2 mo of 660 pages, illustrated.

Cloth, $\$ 3.00$ net.

This is a comprehensive digest, supplying the means to a clear understanding of neurology, and robbing that subject of much of its difficulty. You are given, first, a brief description of the practical anatomy and physiology, with those facts and theories that bear on the mechanism of organic nervous diseases. Then pathology is given, the simpler diseases being considered first, gradually preparing the reader to grasp the more difficult ones. The descriptions are clear and brief, differential diagnoses and treatments being brought out very definitely. Only the most recent accepted facts have been considered. For the treatments recommended, no special apparatus is required beyond a galvanic and faradic battery; they demand no special training, and they are easily remembered. 


\section{American Pocket Dictionary}

New (10th) Edition

American Pocket Medical Dictionary. Edited by W. A NewMan Dorland, M. D., Editor "American Illustrated Medical Dictionary." Containing the pronunciation and definition of the principal words used in medicine and kindred sciences, with 75 extensive tables. With 707 pages. Flexible leather, with gold edges, $\$ 1.25$ net; with patent thumb index, \$I.50 net.

Published October, 1917

"I can recommend it to our students without reserve."-J. H. Holland, M. D., Dean of the Jefferson Medical College, Philadelphia.

\section{Morrow's Immediate Care of Injured}

Third Edition

Immediate Care of the Injured. By Albert S. Morrow, M. D., Clinical Professor of Surgery at the New York Polyclinic. Octavo of 356 pages, with 242 illustrations. Cloth, \$2.75 net. Published November, 1917

Dr. Morrow's book on emergency procedures is written in a definite and decisive style, the reader being told just what to do in every emergency. It is a practical book for every day use, and the large number of excellent illustrations can not but make the treatment to be pursued in any case clear and intelligible. Physicians and nurses will find it indispensible.

\section{Shaw on Nervous Diseases and Insanity}

Fifth Edition

Essentials of Nervous Diseases and Insanity: Their Symptoms and Treatment. A Manual for Students and Practitioners. By the late John C. Shaw, M. D., Clinical Professor of Diseases of the Mind and Nervous System, Long Island College Hospital, New York. I 2 mo of 204 pages, illustrated. Cloth, \$1.25 net. In Saunders' Question-Compend Series.

Published October, 1913

" Clearly and intelligently written; we have noted few inaccuracies and several sug. gestive points. Some affections unmentioned in many of the large text-books are noted.' -Boston Medical and Surgical Journal.

\section{Brady's Personal Health}

Published September, 1916

Personal Health: A Doctor Book for Discriminating People. By William Brady, M.D., Elmira, N. Y. I 2 mo of 406 pages. Cloth, \$I. 50 net.

\section{Hecker, Trumpp, and Abt on Children}

Atlas and Epitome of Diseases of Children. By Dr. R. Hecker and Dr. J. TRUMPP, of Munich. Edited, with additions, by IsaAc A. Aвт, M. D., Assistant Professor of Discases of Children, Rush Medical College, Chicago. With 48 colored plates, 144 text-cuts, and 453 pages of text. Cloth, $\$ 5.00$ net.

Published April, 1907

The many excellent lithographic plates represent cases seen in the authors' clinics, and have been selected with great care, keeping constantly in mind the practical needs of the general practitioner. These beautiful pictures are so true to nature that their study is equivalent to actual clinical observation. The editor, Dr. Isaac A. Abt, has added all new methods of treatment. 







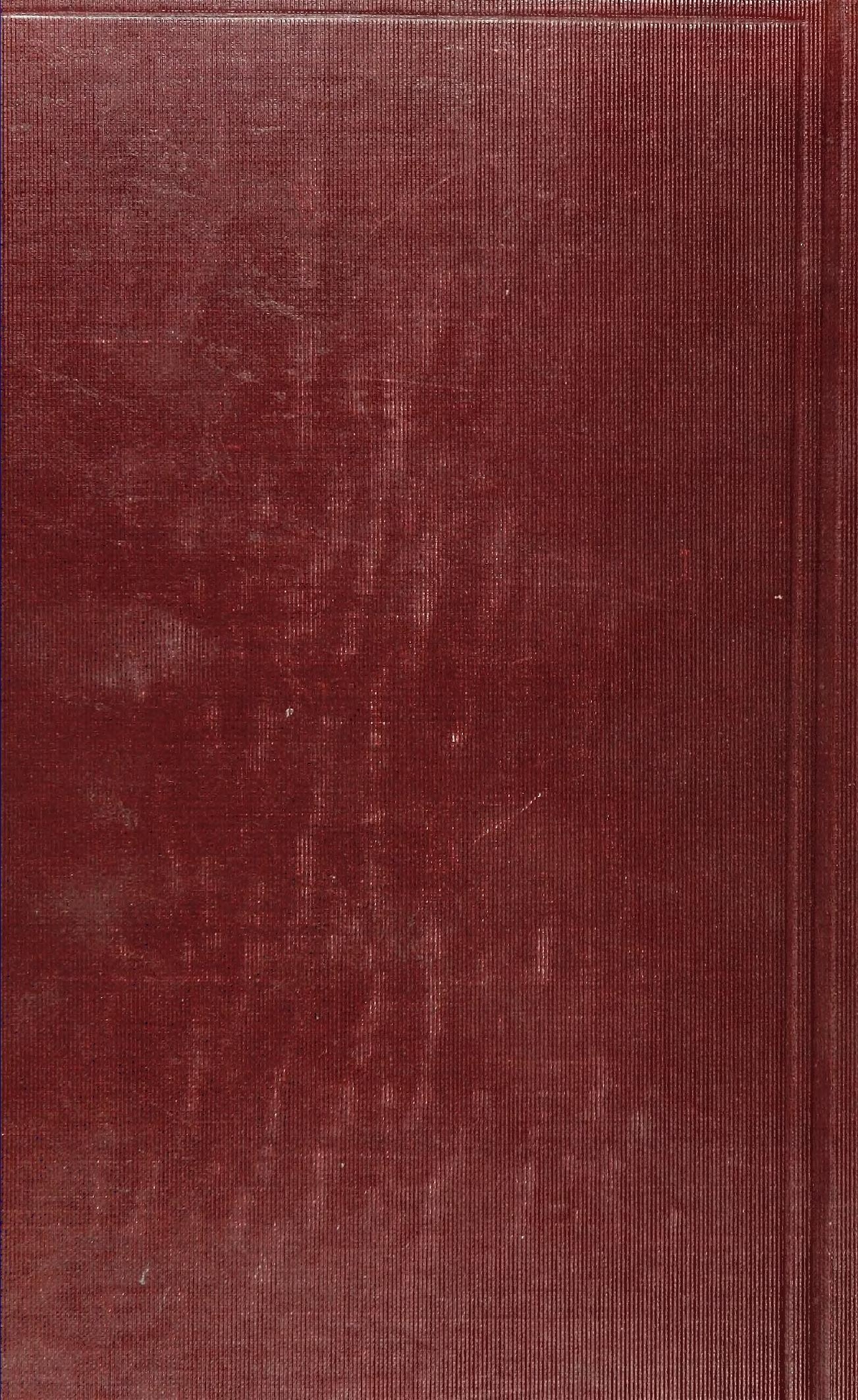

